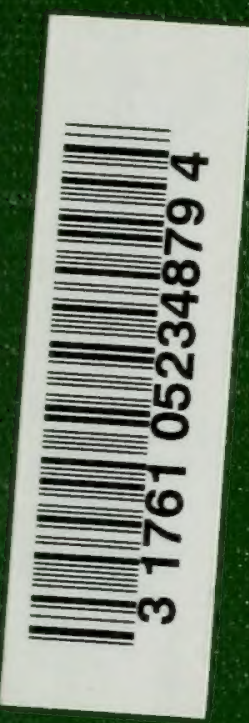







41

384 


\title{
Die
}

\section{Vegetation der Erde}

\author{
Sammlung
}

Pflanzengeographischer Monographien

herausgegeben von

\section{A. Engler}

ord. Professor der Botanik und Direktor

des botan. Gartens in Berlin und

O. Drude

ord. Professor der Botanik und Direktor des botan. Gartens in Dresden.

IX.

\section{Die Pflanzenwelt Afrikas}

insbesondere seiner tropischen Gebiete.

\section{Grundzüge}

der Pflanzenverbreitung in Afrika

und die Charakterpflanzen Afrikas

von

\section{A. Engler}

II. Band

Leipzig

Verlag von Wilhelm Engelmann 


\section{Die}

\section{Pflanzenwe1t Afrikas}

insbesondere seiner tropischen Gebiete

Grundzüge

der Pflanzenverbreitung in Afrika und die Charakterpflanzen Afrikas

von

A. Engler

II. Band

Charakterpflanzen Afrikas

(insbesondere des tropischen).

Die Familien der afrikanischen Pflanzenwelt und ihre Bedeutung in derselben.

I. Die Pteridophyten, Gymnospermen und monokotyledonen Angiospermen.

Mit 16 Vollbildern und 316 Textfiguren

Herausgegeben mit Unterstïtzung des Deutschen Reichskolonialamts

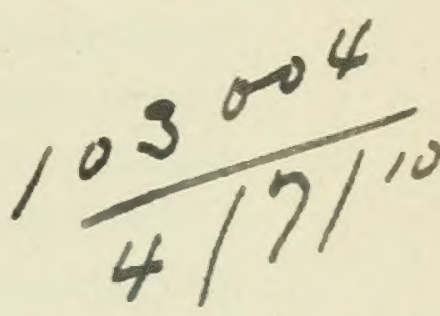

Leipzig

Verlag von Wilhelm Engelmann 1908 
Alle Rechte, insbesondere das der Übersetzung und den Schutz der Abbildungen betreffend, vorbehalten.

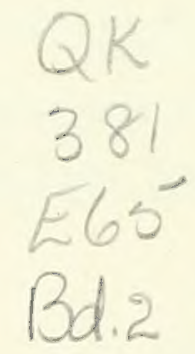




\section{Vorrede.}

Noch vor 50 Jahren war die T'egetation Afrikas, desjenigen Erdteils, der jetzt in der Interessenpolitik der meisten europäischen Großstaaten eine ganz hervorragende Rolle spielt, nur sehr ungeniigend bekannt. Zwar hatte sich schon lange der Forschungstrieb zahlreicher Botaniker dem mediterranen Nordafrika mit Ïgypten sorvic auch Nubien und Abyssinien zugewendet, auch hatte man das fast unvergleichlich reiche Florengebiet des Kaplandes viclfach durchstreift und mit zahlreichen Pflanzenarten desselben die Gewächshäuscr Europas gefüllt: aber von der Vegetation des tropischen Afrika wußte man nur sehr wenig. Wohl war die Flora Senegambiens erforscht worden, wohl waren Sammlungen von Sierra Leone, aus den Mündungsgebicten des Niger und Kongo und von Angola nach Europa gelangt; aber alle diese Sammlungen gaben nur ein höchst unvollständiges Bild von der Vegetation des Lrdteiles, der von Europa aus so leicht zu erreichen war und aus welchem so wenige, welche es gewagt hatten, in ihn cinzudringen, wieder lebend herausliamen. Aber auch dann, als einzelne Afrikareisende mehr Erfolge in geographischer Beziehung aufzuweisen hatten, als ein wcißer Fleck nach dem andern auf den Karten Afrikas rerschwand, auch da war noch recht wenig iiber die Bestandteile der Flora und über dic Zusammensetzung der Vegetationsformationen bekannt. Lange dauerte cs, ehe die großen Sammlungen unseres wissenschaftlichsten Afrikaforschers, I)r. ScmWeineurti, die des hochverdienten Werwitscir, die des um dic Kenntnis der Flora Ostafrikas verdicnten Sir

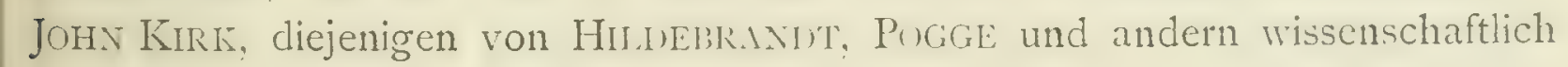
bearbeitet wurden.

Wesentlich änderte sich dicser für den Ausbau des Pflanzensystems und für die Aufgaben der Pflanzengeographie unerquickliche Zustand, als vor etwa einem Vierteljahrhundert dic europäischen Staaten mit größerer Lnergie danach trachteten, sich im tropischen Afrika dauernd festzusetzen und auch Deutschland vier große Gebicte Afrikas für seine kolonialen Bestrebungen in Besitz nahm. 
Hatte es sich darum gehandelt, einige Teile Afrikas ausfindig zu machen, in denen wissenschaftliche Forschungsstationen cinzurichten wären, so hïtte kaum cine glücklichere ITahl getroffen werden künnen, als Gurch dic Besitzcrgreifung von Togo, Kamerun, Deutsch-Ostafrika und des mit Unrecht so mißachteten Südwestafrika. Nit Togo erhielten wir ein bishcr noch gänzlich merforschtes Gebiet, das den L̈bergang zu den teilwcise erforschten Gebieten ron sierra Leone und der Nigermuindungen bildet und im Inneren interessante Formationen der Gebirgsländer aufweist. In Kamerun waren schon frïher durch G. MLNN fur einen nicht unwesentlichen Teil, das Kamerungebirge, die Grundzüge der Pflanzenverbreitung festgestellt worden; aber die nach der Besitzergreifung dieses Landes ron dort eingehenden Sammlungen zeigten bald, welch unerschöpflicher Reichtum von P'llanzenformen hier und in dem benachbarten nummchr auch grindlicher durchforschten Gabun anzutreffen sci und wie viele interessante pflanzengeographische Fragen sich gerade hicr an neuentdeckte Arten knipften. IVir lernten immer mehr Formen kennen, deren Verwandte uns nur aus dem tropischen Amerika bekannt waren, und anderseits solche, welche stark an Arten erinnerten, die im tropischen Asien heimisch sind - und von vielen Typen, die uns bisher in nur einer Art oder in wenigen bekannt waren, wurden uns jetzt ganze Scharen neuer Arten zugeführt. - Deutsch-Südwestafrika, das sich zwischen dem von WELwiTsCH schon ziemlich gut erforschten Benguela und dem auch schon leidlich bekimuten Britisch-Namacululand üher is Breitungrade hinweg erstrecht. War botanisch fast gänzlich terra incognita, bevor es deutsche Kolonie wurde; gleich in den ersten Jahren der deutschen Verwaltung wurden aus diesem Sroßen Gebiet cine Nenge Pflanzenformen bekannt. dic nicht blol3 für unsere Anschaumgen von der Verbreitung tropisch-afrikanischer und sudafrikanischer lypen ron Irichtigkeit waren, sondern auch durch weitgehende Anpassung an extreme Trockenheit der Luft und des Bodens unser Interesse erregten.

Aus Deutsch-Ostafrika war zwar durch verschiedene deutsche und englische Expeditionen allerlei hekannt geworden: aber dies war guringfügig im Verhaitnis zu clem außerorelentlichen Pflanzenreichtum. durch den diescs an verschiedenen Pflanzenformationen so reiche Land ausgezcichnet ist.

Eifrige Sammeltätigkeit einzelner Forscher, welche an großen Expeditionen teilnahmen oder solche allein ausfuihrten. und längere Durchforschung einzelner Gchicte ron seiten ciniger Stationsbeamten rerschafite uns eine gute Kenntnis der Pflanzenformationen und mohrere pflanzengeographische Ergebnisse von allgemeiner Wichtigkeit.

So sind die deutschen Kolonialbestrebungen für die Wissenschaft recht niitzlich gerorden und es ist zu erwarten, daß auch weiterhin Hand in Hand mit der Entwicklung der Kolonien in Afrika, nicht bloß der deutschen. sondern auch derjenigen anderer Vationen die selbstrerstandlich noch immer recht 
großen Lücken in der Kenntnis der Pflanzenwelt Afrikas allmählich ausgefuilit werden. Von allen, welche der afrikanischen Vegetation Beachtung schenkten, oder schenken wollten, wurde wiederholt das Verlangen nach Handbüchern ausgesprochen, und zwar wollte man am liebsten Handbücher mit Abbildungen haben, und dann sollten sie auch wieder nicht zu umfangreich und nicht zu kostspielig sein, man sollte aber auch jede afrikanische Pflanze in dem Buch finden können. Der Fachmann weiß zur Genüge, daß derartige Wünsche nicht zu erfüllen sind. Das für den Fachmann unentbehrliche, von J. D. OLIVIR begonnene und von Sir William Drer mit Hilfe der Beamten von Kew und anderer Botaniker fortgesetzte Wrork. welches jetzt schon mehrere Bände umfaßt, ist noch nicht abgeschlossen und die crsten Bände des Werkes würden, wemn sie auf den Stand unserer heutigen Kenntnis der afrikanischen Flora gebracht werden sollten, den doppelten Umfang crhalten. Ebenso würde das Werk, welches in Berlin für die Pflanzenwelt Ostafrilias im Jahre I 895 herausgegeben wurde und von vornherein nur dazu hestimmt war, cine knappe l̈bersicht uiber die damals bekannte Flora Ostafrikas zu geben, bei ähnlicher Be.. handlung der gegenwärtig aus Ostafrika bekannten Pflanzen um die Hälfte stärker wcrden. Man wünscht aber auch ein Handbuch für Togo, eines für Kamerun, eines für Deutsch-Südwestafrika. Hätten wir 30 geschulte Botanilicr und cine Million Mark zur Verfiigung, so wüirde eben jetzt doch nicht geliefert werden können, was auch nur für 20 Jahre cinen Anspruch auf Vollständiglicit machen könnte. Es hilft nichts - man muß sich in den afrikanischen Kolonien bescheiden und bedenken, daß weder die rothandene Flora ron Brasilien, deren Anschaffung Tausende ron MLark erfordert, noch die Flora ron Niederländisch-Indien trotz der auf dieselben verwendeten Forschungsarbeit Anspruch auf Vollständigkcit machen können. Es ist eben unbestreitbar, dả eine griindliche wissenschaftliche Durcharbeitung der tropischen afrikanischen Flora und ebenso die Bestimmung von Arten aus formenreichen Gattungen nur an den großen botanischen Muscen Europas durchgefuhrt werden kann; im tropischen Afrika selbst wird man sich noch lange mit der Bestimmung der häufiger auftretenden und leichter zu erkennenden Arten begnügen müssen.

Dagegen reichen unsere Kenntnisse jetzt wohl aus, um die Vegetationsformationen des tropischen Afrika und deren wichtigste Charakterpflanzen zu schildern und um auf die allgemeinen Verbreitungserscheinungen sowie auf die Sonderung der Florenprovinzen und Bezirke aufmerksam zu machen. Dic meisten Botaniker und Geographen, welche sich für Pflanzengeographie interessieren, wollen in der Regel auch nicht mehr, ja manchem wäre cs am liebsten: wenn die Schilderung einer Pflanzenformation durch Anführung von zwei bis drei oder höchstens einem halben Dutzend Charakterpflanzen zu erledigen wärc. Dass ist nun aber nicht möglich und am allerwenigsten bei der Mehrzahl der tropischen Formationen. Werden nun aber ähnlich, wie bei der Schilderung 
einer europäischen Formation, dic wichtigsten Arten, welche eine tropische Vegetationsformation zusammensetzen, aufgefuhrt, dann ist sehr oft der nicht speziell mit dem behandelten Florengebiet vertraute Leser nicht in der Lage, mit den angefihrten Pflanzennamen irgendwelche Vorstellung zu verbinden. Es ist der Vorschlag gemacht worden, bei pflanzengeographischen Schilderungen bei der Angabe weniger bekannter Gattungen den Namen der Familie in Klammern beizufügen. Ner tropische Familien kennt, weiß aber, wic wenig damit dem Botaniker und erst gar dem Nicht-Systematiker geholfen ist. Iier liönnen eben nu Beschreibungen oder Abbildungen helfen. Vor allem sind letzicre geeignet, schnell zum Erliennen der Formen zu verhelfen, und zwar nicht die Photographien ganzer Bäume und Sträucher, sondern nach Zeichnungen angefertigte, welche cin genaucres Studium ermöglichen. Die Photographien sind vortrefflich für dic Darstellung charakteristischer WVuchsverhältnisse und die Darstellung der Physiognomie einer Formation; aber sie genügen nur ausnahmsWeise, cbenda, wo eigenartige Wuchsverhältnisse und große Blattformen wiedergegeben werden, zur Erkennung von Gattungen. Da es mein Wunsch ist, sowohl das schon Erforschte ihersichtlich zusammenzustellen, als auch ror allem zu weiterer Erforschung der Vegetation Afrikas anzuregen, so habe ich mich entschlossen, mit der Schilderung der Pflanzenwelt Afrilias eine etwas ausfühlichere Einfuhrung in die Kenntnis der wichtigeren afrikanischen l'flanzenformen, der sogenannten Charakterpflanzen, zu rerbinden. Eine solche, mit Abbildungen ausgestattete Einfihhrung ist zwar an sich nicht dazu bestimmt, cine Flora wie die in Kew herausgegebene zu crsetzen: sic kann aher in mancher Bezichung mehr bieten. Eine gut durchgearbeitete Flora ist eine Registratur, dic, wenn nicht jedes Jahr Nachträge hinzugefuigst werden, immer mehr veraltet. Dagegen ist jutzt schon so viel üher die Flora Afrikas fustgestellt, daß cin mit dem Naterial vertrater Botaniker maturlich nur ein solcher) die allgemeinen Resultate, welche sich aus dem registrierten Naterial ergeben, herausfinden liann, und derartiger Resultate gibt es jetzt schon vicle, die cinen bleibenden Wert haben, wenn auch in 30-40 Jahren die Artenzahl mancher Gattungen sich rielleicht noch cinmai verdoppelt haben mag. wie dies gegenwärtig schon für mehrere der in den ersten Bänden der Flora of tropical Africa behandelten Familien zutrifft.

Eine auf Autopsic reichen I Ierbarmaterials gegriindete Durcharbeitung der cinzelnen Familien, welche nicht gerade jede cinzelne Art derselben behandelt, sondern vichehr die Verteihng charaliteristischer Gruppen derselben nach Formationen und geographisch besonders hervortretenden Gebicten im Auge behält, ist cbenso vortcilhaft für die natiirliche Begrenzung dieser Gebiete, wie für die Vorstellung ron der Entwicklung der behandelten Pflanzengruppen. Einige Teile Nordafrikas, Algiers, Tunis und cinen kleinen Tcil Ägyptens, Britisch-Ostafrikas, 1) cutsch-Ostafrilias von der Kiuste bis zum Kilimandscharo, 
Südrhodesia, Transvaal, Natal und das Kapland konnte ich selbst bereisen. Das ist nicht viel von dem großen Gebiet, welches ich behandeln will: abur dic zum Teil erst in vorgerücktem Alter unternommenen Reisen haben mir nebst vieler Belehrung auch dic Beruhigung gegeben, daß die Vorstellungen, welche ich mir durch die seit langer Zeit betriebenen Studicn ron den einzelnen Formationen gemacht hatte, ziemlich zutreffend waren. So hoffe ich denn nach IBenutzung der reichen mir zur Verfigung stehenden Sammlungen und der cinschlägigen Literatur mit der I Icrausgabe dieses Werkes nicht zu viel gewagt zu haben.

In dem vorliegenden Band sind die Gräser (S. I I4-I92) von Herrn Dr. R. PIIGER bearbeitet worden. Beziiglich der Nomenclatur der Pteridophyten verdanke ich Herrn Prof. Dr. HirRoNints wertrolle Auskunft. Später werde ich auch bei cinigen anderen Fanilien Mitarbeiter heranzuziehen suchen, sofern dieselben geneigt sind, den von mir besonders betonten pflanzengeographischen und ökologischen Verhïlnissen eingehendere Beachtung zu schenken.

Trotz der zahlreichen neuen kostspieligen Ahbildungen hat die Verlagsbuchhandlung einen schı mäßigen P'reis für diesen Band angesetzt, um cine möglichst weite Verbreitung im Interesse weiterer Forschungsarbeiten und in dem unserer Kolonien zu ermöglichen. Bei allem guten Willen des Herrn Verlegers und des Verfassers wäre aber cin höherer l'reis nicht zu vermeiden gewesen, wenn nicht das Reichskolonialamt cine Unterstiitzung zur Deckung der Kosten für die Abbildungen bewilligt hätte.

Es ist mir daher cine angenchme P'flicht, hicrfuir dem Reichskolnnialamt meinen ergebensten Dank auszusprechen.

Ebenso danke ich denjenigen I Iurren, welche mich mit photographischen Aufnahmen zur Herstellung der Vollbilder unterstitzt habcn, Sr. Excellenz Hern Geheimrat P'rof. Dr. Ronkk Kum, Herm Prof. Dr. Filimanx, Herrn Prof. Dr. Uhlig und Herrn Prof. Dr. Vossler.

Den Plan des gesamten Werkes wolle man aus der Übersicht auf folgenden Seiten ersehen.

Dahlem, im Juli I 908.

A. Engler. 


\title{
Inhalts-Übersicht.
}

\author{
I. BAND.
}

Alscomeiner Iberblick iiber die Pflanzenwelt Afrikas und ihre Existenzbedingungen.

VORREDE.

EINLEITUNG: Allgemeiner Überblick iiber die Pflanzenwelt des gesamten Afrika.

ERSTER TEIL. Allgemeine geographische Verhältnisse.

I. Kapite1. Lage und Aufbau des Kontinents.

2. Kapitel. Klima. Wärme Niederschläge.

3. Kapitel. Bodenverhältnisse. ZWEITER TEIL. Regionen.

DRITTER TEIL. Kurze Übersicht der Formationen.

VIERTER TEIL. Florenbestandteile und allgemeine Grundziige der Gliederung der Flora.
I. Kapitel. Die Elemente der Flora.

a) Das palaeotropische Element.

b) Das afrikanische Tropenelement.

c) Das afrikanisch-asiatische Tropenelement.

d) Das afrikanisch-malagassische Tropenelement.

e) Das afrikanisch - amerikanische Tropenelement.

f) Das makaronesische Element.

g) Das mediterrane Element.

h) Das boreale Element.

i) Das austral-afrikanischeElement.

2. Kapitel. Allgemeine Gliederung der afrikanischen Flora.

II.-IV. Band. Charaliterpflanzen Afrikas (insbesondere des tropischen). Die Familien der afrikanischen Pfanzenwelt und ihre Bedeutung in derselben. Übersicht iiber die Gattungen und ihre Verbreitung. Hervorhebung der wichtigeren. Arten und Besprechung ihres Anteils an der Zusammensetzung der Formationen.) Mit zahlreichen Abbildungen.

II. BAND.

1. Die P'teridophyten. Gymnospermen und monokotyledonen

Angiospermen.

III. BAND.

2. Die archichlamydeen dikotyledonen Angiospermen.

IV. BAND.

3. Die sympetalen dikotyledonen Angiospermen. - 4. Die niederen 


\section{BAND.}

Spezielle Darstellung der Vegetationsformationen und Florenprovinzen des tropischen Afrika.

ERSTER TEIL. Vegetationsformen. ZWEITER TEIL. Vegetationsformationen.

DRITTER TEIL. DieFlorenprovinzen des tropischen Afrika.

Bei jeder derselben wird gegeben:

I. Kapitel. Geschichte der botanischen Erforschung.
2. Kapitel. Wichtigste botanische Literatur.

3. Kapitel. Schilderung der Vegetation.

VIERTER TEIL. Floristische Beziehungen zu anderen Gebieten.

FÚNFTER TEIL. Die Entwickelungsgeschichte der Flora Afrikas.

Für Zusendung von guten Photographien, besonders charakteristischer, noch nicht gut abgebildeter afrikanischer Pflanzentypen oder Pflanzengemeinschaften, begleitet von den zur wissenschaftlichen Bestimmung nötigen Pflanzenteilen und für die Erlaubnis, solche Photo. graphien in diesem Werke publizieren zu dirfen, werde ich sehr dankbar sein.

Dahlem-Steglitz bei Berlin, im Februar 1908.

A. Engler. 



\section{Asiphonogame Embryophyten.}

\section{Unterabt. Pteridophyta. \\ Klasse Filicales (Farnartige Pflanzen). \\ Reihe Filicales leptosporangiatae. \\ Fam. Hymenophyllaceae (Hautfarne).}

Bekanntlich sind die Arten dieser durch charakteristischen Bau der Sori sowie der Sporangien ausgezeichneten Farne großenteils mit Blattflächen versehen, welche nur aus einer Zelllage bestehen und der Spaltöffnungen entbehren; an den sehr diunnen Stämmchen stehen die Blätter meist in zwei Zeilen, durch längere Internodien voneinander getrennt, weniger häufig sind die Blätter zusammengedrängt und radiär angeordnet. Wie in vielen anderen artenreichen Farngattungen sehen wir auch bei den durch röhren-oder krugförmiges Indusium ausgezeichneten Trichomanes und bei den mit zweiklappigem Indusium versehenen Hymemophyllum eine große Mannigfaltigkeit der Blattgestalt von der cinfachen ungeteilten Fläche bis zur gelappten und einfach-oder doppeltoder dreifach fiederteiligen. Eine Beziehung der Blattgestalt zum Standort ist nur insofern vorhanden, als die mit einfachen oder wenig geteilten Blattfächen versehenen Arten immer Felsen oder Baumstämme beklciden, während am Boden frei wachsend nur Arten mit mehrfach fiederteiligen Blättern angetroffen werden, doch kommen viele Arten mit solchen Blättern auch in mehr oder weniger dichten Massen an Felsen und Baumstämmen for. Bekanntlich sind die $H$. wegen ihrer zarten Blätter auf andauernde Lufteuchtigkeit angewiesen und selbst die am weitesten nach Norden vordringenden oder in Gebirgen aufsteigenden Arten können nur kurze Zeit eine Erniedrigung der Temperatur unter den Gefrierpunkt ertragen. Die $H$. verlangen nicht sehr hohe Temperatur, sondern begniigen sich mit niedriger Warme. Wenn nur Luftfeuchtigkeit rorhanden ist; demzufolge sehen wir bei ihnen, was auch bei vielen anderen tropischen Waldpflanzen wahrzunehmen ist, daß sie oft eine ausgedehnte rertikale Verbreitung besitzen: denn in den unteren Regionen gedeihen sie nur in Schluchten und an ganz schattigen Plätzen, in welchen oft eine ähnliche Mitteltemperatur herrscht, wie in bedeutenderer Höhe über dem Meere. Vielen Arten kommt auch eine weite horizontale Verbreitung zu. und so treffen wir nicht wenige im tropischen Westafrika wachsende Arten in den Bergwäldern Usambaras wieder, dort aber häufig nur in größerer IIöhe ü. d. M., als in Westafrika, wo sie, geschuitzt vor Steppenwinden, auch in geringer Engler, Charakterpflanzen Afrikas. I. 


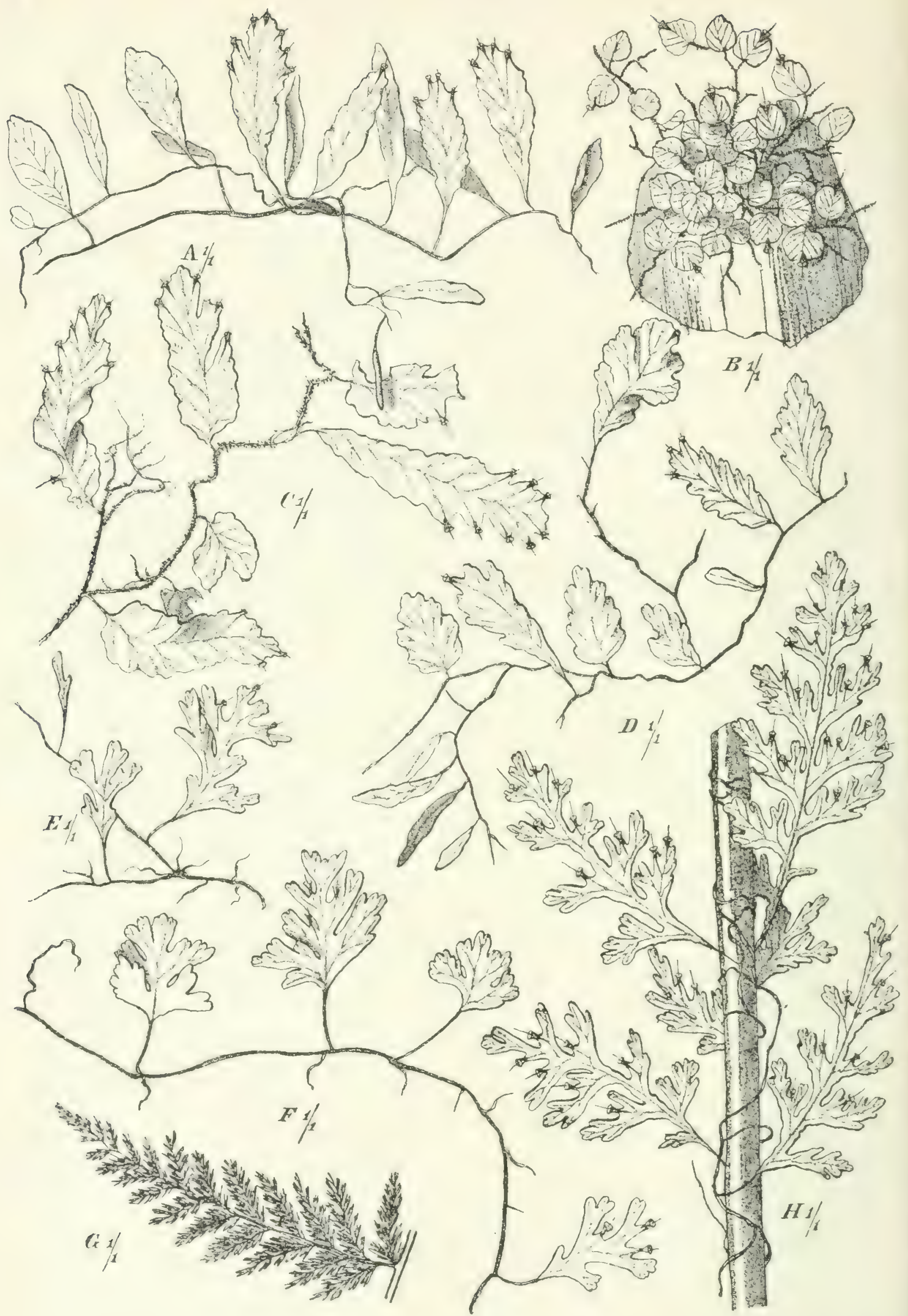

Fig. I. A Trichomanes cuspidatum Willd., Ostusambara; $B$ T. Motleyi v. d. Bosch, Kamerun; $C$ T. Hookeri Presl, Ostusambara; $D$ T. erosum Willd., Kamerun; $E$ T. subsessile Miett., Kamerun: $F$ T. Mannii Hook., Usambara; $G$ T. rigidum Sw. var. pectinatum Mett., Ostusambara; H T. melanotrichum Schlecht, Ostusambara. 
Hohe ü. d. M. gedeihen. Soweit man jetzt überblicken kann, sind in der Nähe von Afrika die $H$. am reichsten auf den östlich vom Kontinent gelegenen Inseln, auf den Comoren und den malegassischen Inseln rertreten; fermer sind, soweit man nach den bis jetzt bekannt gewordenen Funden urteilen kann, mehrere Arten nur den Hochgebirgen Ostafrikas rom Kilimandscharo bis Natal und den genannten Inseln gemein. Dic Abbildungen gehen cine Vorstellung von den wichtigeren Typen der kontinentalen afrikanischen $H$.

Trichomanes Sm. Indusium röhren- oder krugförmig. Das durch schildförmige, mehrschichtige, seidigglänzende Blätter von der Große eines Markstiickes ausgezeichnete $T$. Hildchandtii Kuhn, bis jetzt nur von den Comoren aus einer Höhe von 600-800 m bekannt, ist nicht abgebildet. Dagegen zeigt Fig. I die kleinblättrigsten Arten, welche oft in dichten Massen wic Lebermoose Stämme und feuchte Felsen uberziehen. Ton diesen ist das zierliche T. Motlej'i v. d. Bosch (Fig. I li) nur aus den unteren Väldern Kameruns beliannt, ebenso T. crosum Willd. (Fig. I $D$ ), welches aber vielleicht nur eine Varietät des in den Tropen verbreiteten $T$. muscoides Sw. ist. Dem letzteren dürfte auch T. bimarginatum $\mathrm{v}$. d. Bosch zuzurechnen scin, welches auf den Comoren um I $200 \mathrm{~m}$ gefunden wurde und auch etwas an $T$. Wotley erinnert. Im tropischen Afrika verbreitetere Arten sind die jetzt schon aus Kamerun und Usambara bekannt gewordenen T. cuspidatum Willd. und T. Hookeri Presl (Fig. I C), welche besonders gern in den dunklen Bachschluchten, an feuchten Felsen und am Grunde der Baumstämme wachsen; das erstere, welches auf Réunion um $200 \mathrm{~m}$ Höhe gefunden wurde, ist in Usambara von $800-2000 \mathrm{~m}$ ü. d. $N$. ziemlich häufig. Inwieweit das durch ticf ficderspaltige Blätter ausgezeichnete T. Lenomandii v. d. Bosch (auf der Comoreninsel Johanna) von crosum und muscoidis zu sondern ist, lasse ich dahingestellt. Dem tropischen IVestafrika (Kamerun und Gabun) scheint cigentümlich T. subsessile Mett. (Fig. I I:), welches überführt zu den durch mehr handförmig geteilte Blätter ausgezeichneten T. parmlum Poir. und T. Mamiii Hook. (Fig. I F, in Kamerun bei I $500 \mathrm{~m}$, in Lsambara um Ioco m: Unter den Arten mit einfach fiederspaltigen Blättern fällt durch seine Behaarung auf das in Kamerun bei Lolodorf aufgefundene, aber auch im tropischen Amerika rorkommende T. urispm L. Von den Arten init doppelt fiederspaltigen und kahlen Blättern seien genannt T. bifunctatum Poir. an feuchten Felsen der Comoren und Maskarenen, bei $1000 \mathrm{~m}$, auch auf Madagaskar und im tropischen Asien), T. dilutertum (v. d. Bosch Kuhn (in Kamerun und auf Fernando Po), T. py.rilifinm L., verbreitet in den Tropen, typisch in Kamerun von der unteren Waldregion bis in die obere, nicht selten an Felswänden zusammen mit Moosen und Silagivella, ein wenig abweichend (T. Goitui Hieronym.) in Uluguru ron $1200-\mathrm{I} 800 \mathrm{~m}$, an Baumstämmen.

Dds auch häufig an Baumästen vorkommende T. milanotriihum Schlecht. (Fig. I $H$ ) schließt sich mehr an T. bipunctatum Poir. an und ist vom südwestlichen Kapland bis Usambara (goo-1600 m), zum Ruwenzori und Kamerun (I $100 \mathrm{~m}$ ) verbreitet. Im ganzen tropischen Afrika und auf den benachbarten 


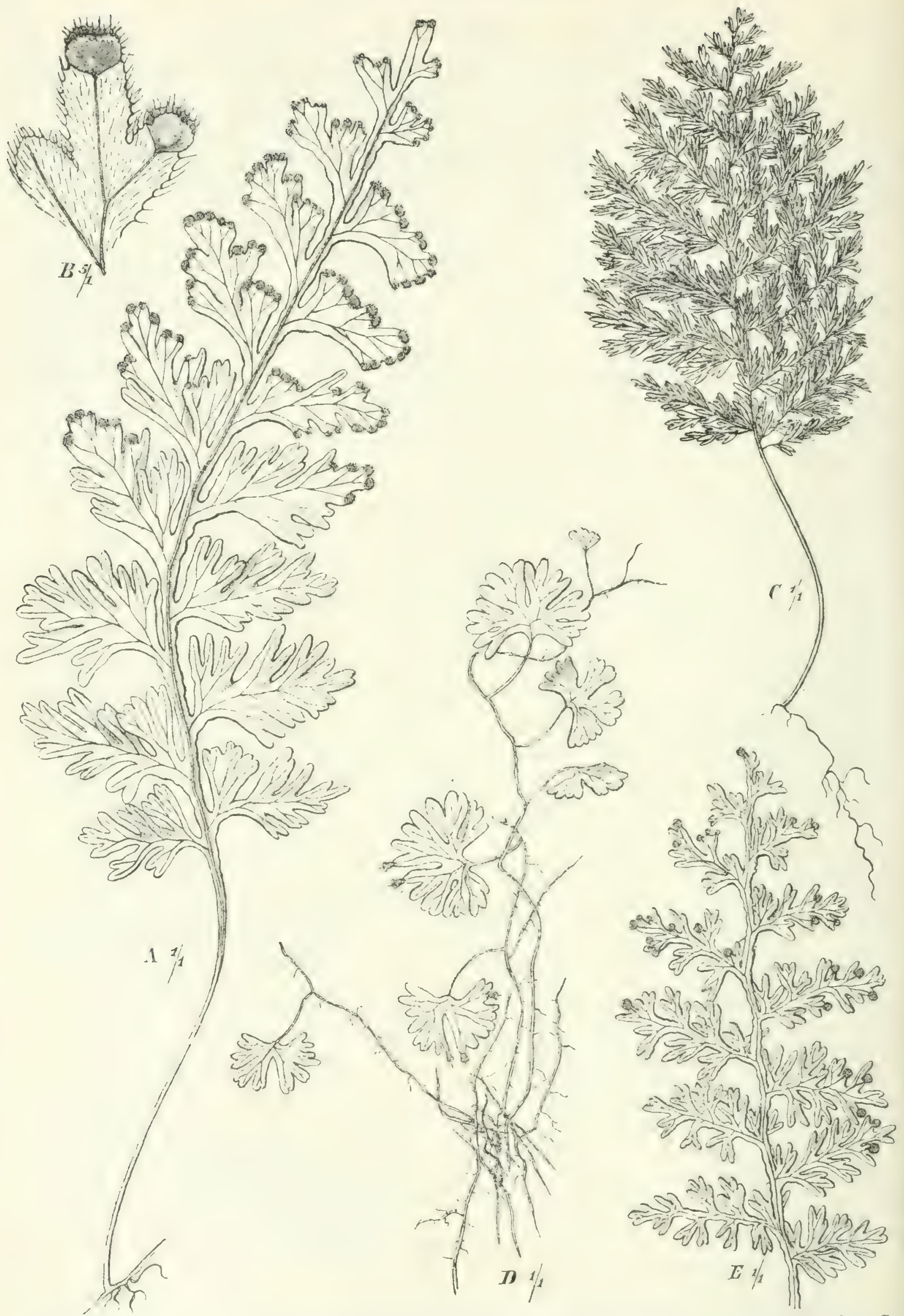

Fig.2. $A, B$ Hymenophyllum ciliatum Sw., San Thomé, I500-2000 m; C H. polyanthos Sw. San Thomé, rooo- $1950 \mathrm{~m} ; D \mathrm{H}$. sibthorpioides (Bory) Mett., Comoren, am Boden, $1570 \mathrm{~m}$; E H. Meyeri Kuhn, Westusambara, 1600-2000 m. 
Inseln, im subtropischen Afrika siidwärts bis Pondoland, nordwestwärts bis zu den Kanaren und Madeira, iiber Afrika hinaus bis Westirland ist das fast allen feuchtwarmen Gebieten der Erde gemeinsame T. radicans Sw. anzutreffen. Im Gegensatz zu den genannten Arten steht durch radiär beblättertes Rhizom und dreifach gefiederte Blätter das stattliche am Boden wachsende T. rigicilum Sw. Fig. I G), welches mit großem Formenreichtum in den meisten tropischen Ländern verbreitet ist, und sowohl im kontinentalen Afrika wic auf den benachbarten Inseln in tief schattigen Regenwäldern nicht selten gesellig angetroffen wird, so auch unmittelbar bei der biologischen Station Amani in Usambara.

Hymenophyllum L. Indusium zweiklappig. Die Arten von Hymenophlllnm sind habituell nicht so verschieden wie die ron Trichonancs und sie bilden meist dichte entweder allein oder zusammen mit Noosen Baumstämme und Äste bekleidende Polster. Bei den meisten Arten sind die einfach oder doppclt fiederteiligen Blätter ganzrandig und kahl. Hierher gehört das in den Tropen verbreitete, sowohl in West- wie Ostafrika bis zu $2000 \mathrm{~m}$ aufsteigende $H$. polyanthos Sw. Fig. $2 \mathrm{C}$. In dessen Verwandtschaft gehören H. incequale Poir. Desv. H. gracile Bory, auf den Comoren und Maskarenen!: H. fumarioides Willd. (auf den Maskarenen, in Natal und Kapland, auch auf dem Tafelberg;, H. tcncllum (Jacq.) Kuhn ( $=$ H. cmorsum Bak, auf Réunion'. Auch sind diesen Arten verwandt H. sphaterocarpum v. d. Bosch (untere Wälder in Kamerun', H. . Heyeri Kuhn (obere Regenwälder in Usambara und am Kilimandscharo, bi.s zu $2300 \mathrm{~m}$ ii. MI., Fig. 2 E) und das mit fast handförmig geteilten Blättern versehene $H$. sibthorpiniles IBory. Mett. (Fig. $2 D$, auf Madagaskar, den Maskarenen, Comoren, sowie in den ostafrikanischen Hochgebirgen, nicht bloß auf Baumstämmen der oberen Regenwälder, sondern auch am Boden wachsend; in der Johannesschlucht am Kilimandscharo fand VuLkixs noch bei $3200 \mathrm{~m}$ Höhe Steine dicht üherzogen von einer hierher gehörigen Pflanze. mit größeren Blattabschnitten. Durch Behaarung der ganzrandigen Blätter sind ausgezeichnct H. hygrometricum (Poir.) Desv. (auf den Maskarenen) und $H$. ciliatum Sw. Fig. 2 $A, B$, eine in den tropischen und subtropischen Ländern weit verbreitete Art, in Kamerun und Cluguru bis zu I $800 \mathrm{~m}$ Höhe beobachtet. H. capillare Desv. ist eine der Arten, welche die obere Waldregion des Kilimandscharo (I 900 bis $2440 \mathrm{~m})$ mit der der Comoren (1200-1600 m) und Maskarenen gemein hat. Endlich sind ron den mit gezähntem Blattrande versehenen Arten auch drei in Afrika anzutreffen, das bekannte H. tunlirilgense L.) Sm. im Kapland auch am Tafelberg) und Natal, H. piltatum Poir.) Desr. ebenda und auf Réunion, II. triangrular Bak. (II. Mermmicmum Mett.) in der mittleren Gebirgswaldregion von Kamerun.

\section{Fam. Cyatheaceae (Baumfarne).}

Wie in anderen tropischen und subtropischen Ländern sind auch im tropischen und subtropischen Afrika zu den Cyatheaceen gehörige Baumfarne verbreitet. Sie wachsen meistens an Bächen, besonders der Hochgebirge, mit 


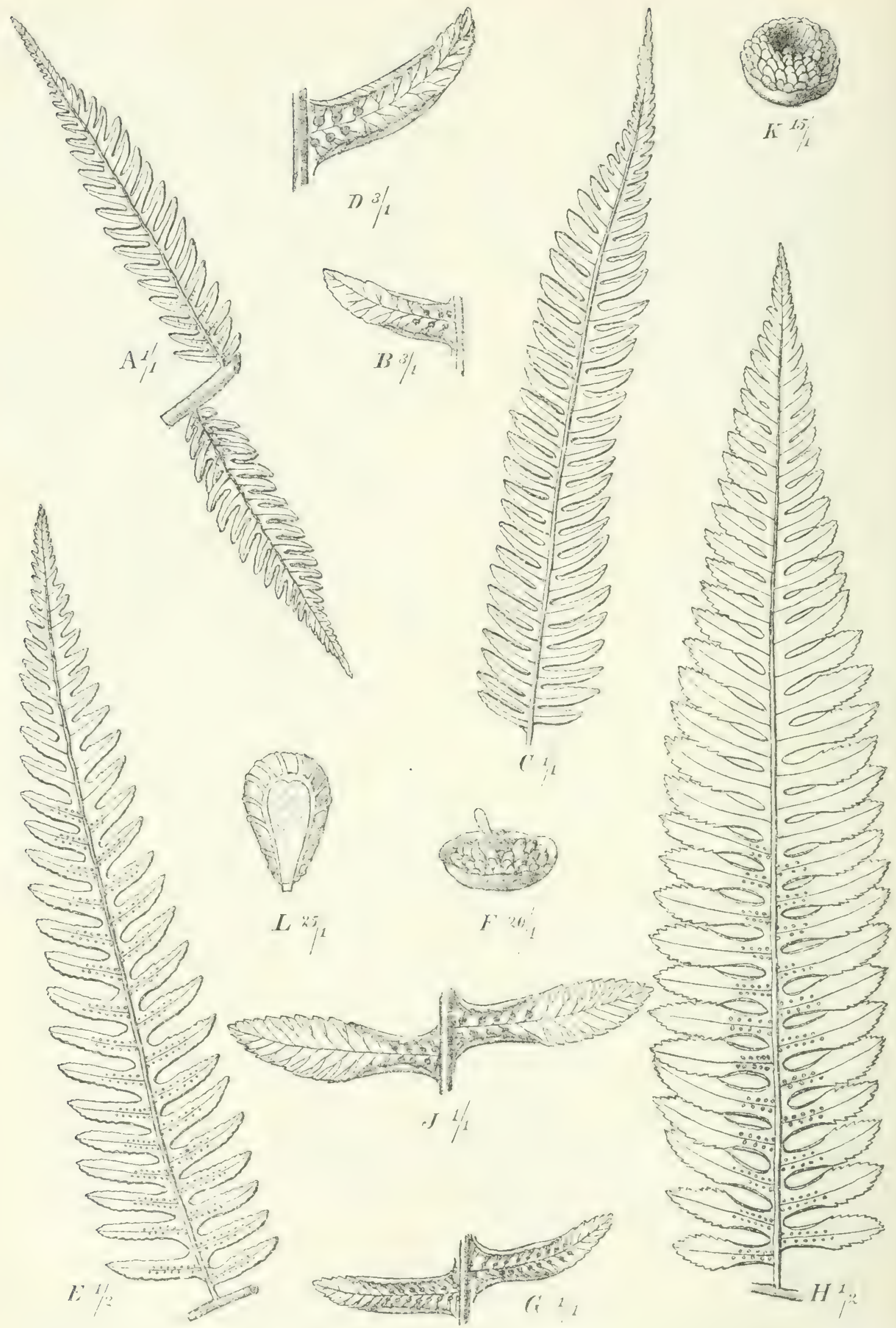

Fig. 3. $A, B$ Cyathea Deckenii Kuhn; $E$ C. camerooniana Hook. f.; $C, F, G$ C. usambarensis Hieron.; $H, \mathcal{F}, K, L$ Alsophila aethiopica Welw. 

Taf. I, zus. 7

Enoler (Pfianzenwelt Afrikas. II) Charakterpflanzen Afrikas. I.

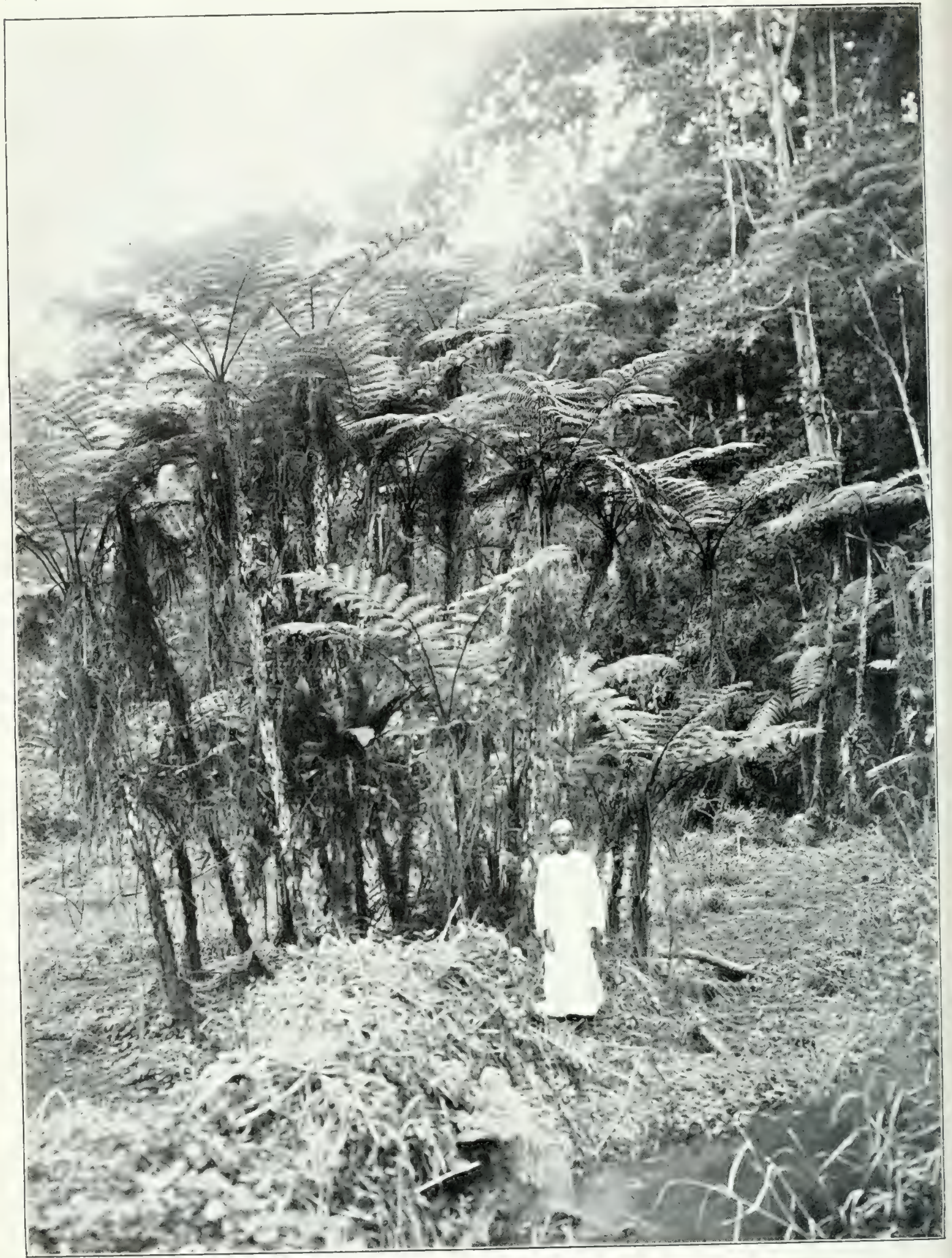

Cyathea usambarensis Hieron.

Amani in Ost-Usambara, $950 \mathrm{~m}$ ü. d. M.

Nach einer Photographie von Prof. Dr. Vossler (I905) 



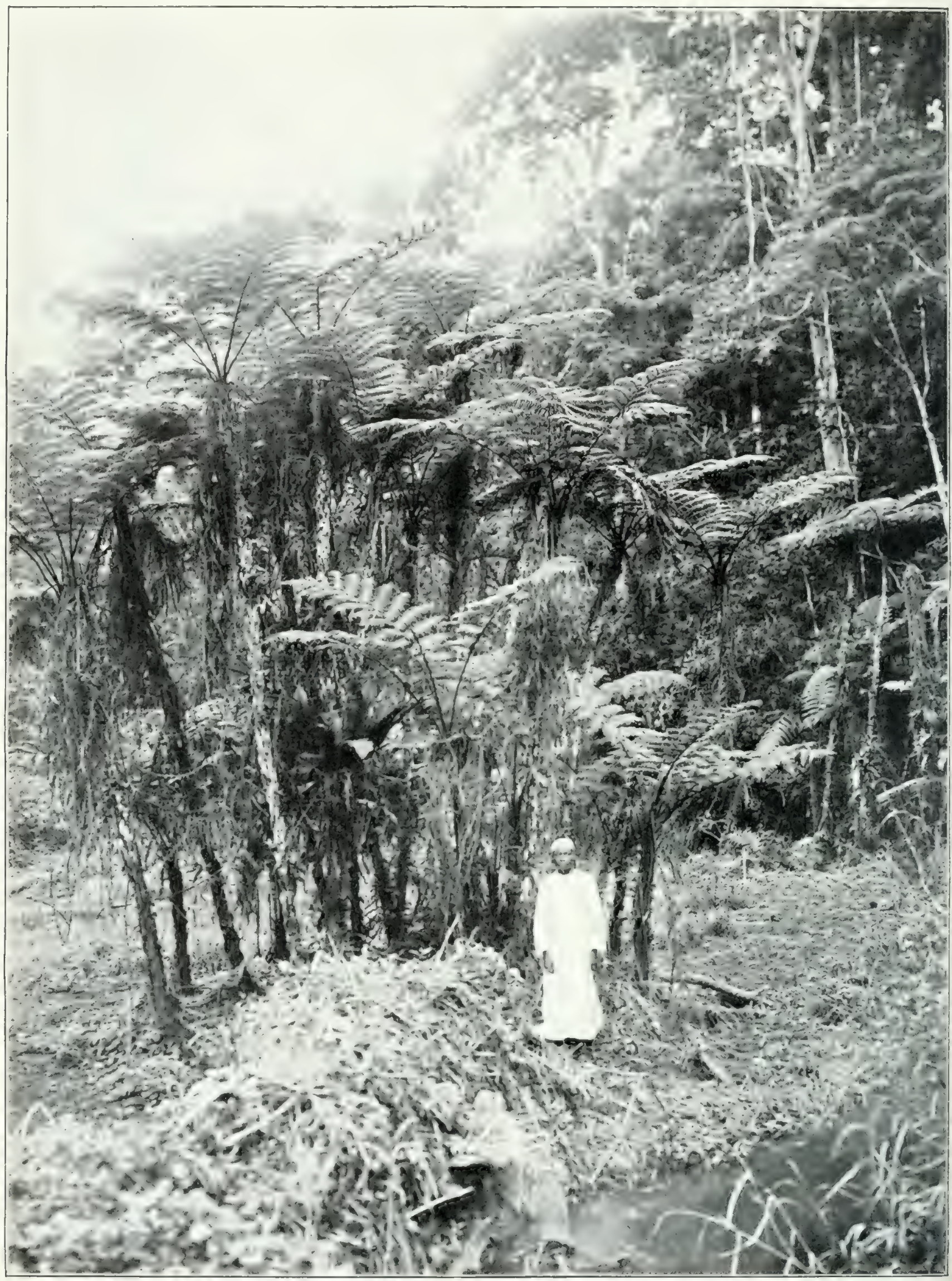

Cyathea usambarensis Hieron.

Amani in Ost-Usambara, $950 \mathrm{~m}$ ii. d. M.

Nach einer Photographie von Prof. Dr. Vossler (I905) 



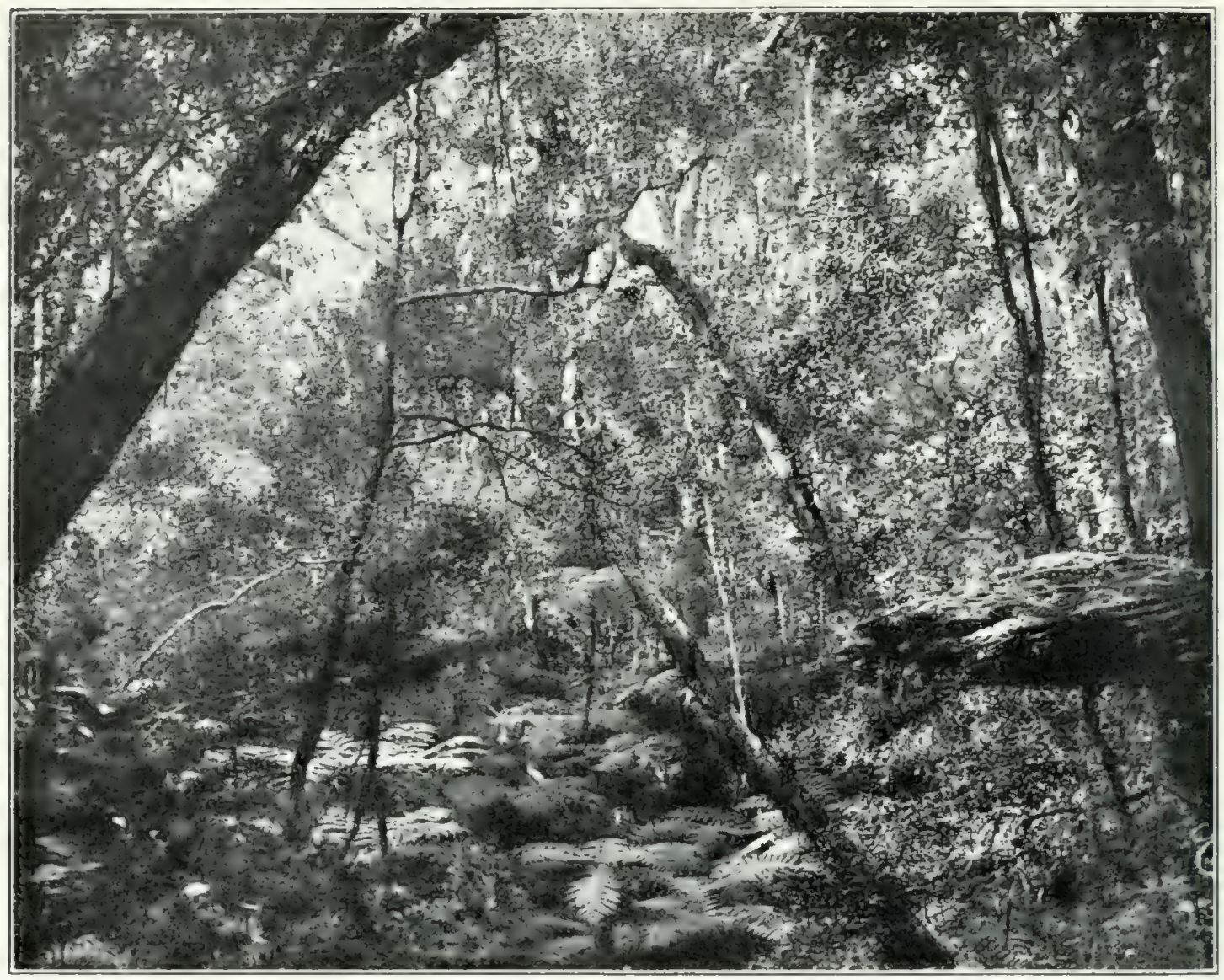

A. Gruppe von jungen Cyathea,

im Kegenwald zwischen Amani und Kiwamkoro, DOA., um Soo-900 m ï. d. M.

Nach einer Photographie von Prof. Dr. Uhlig (1905)

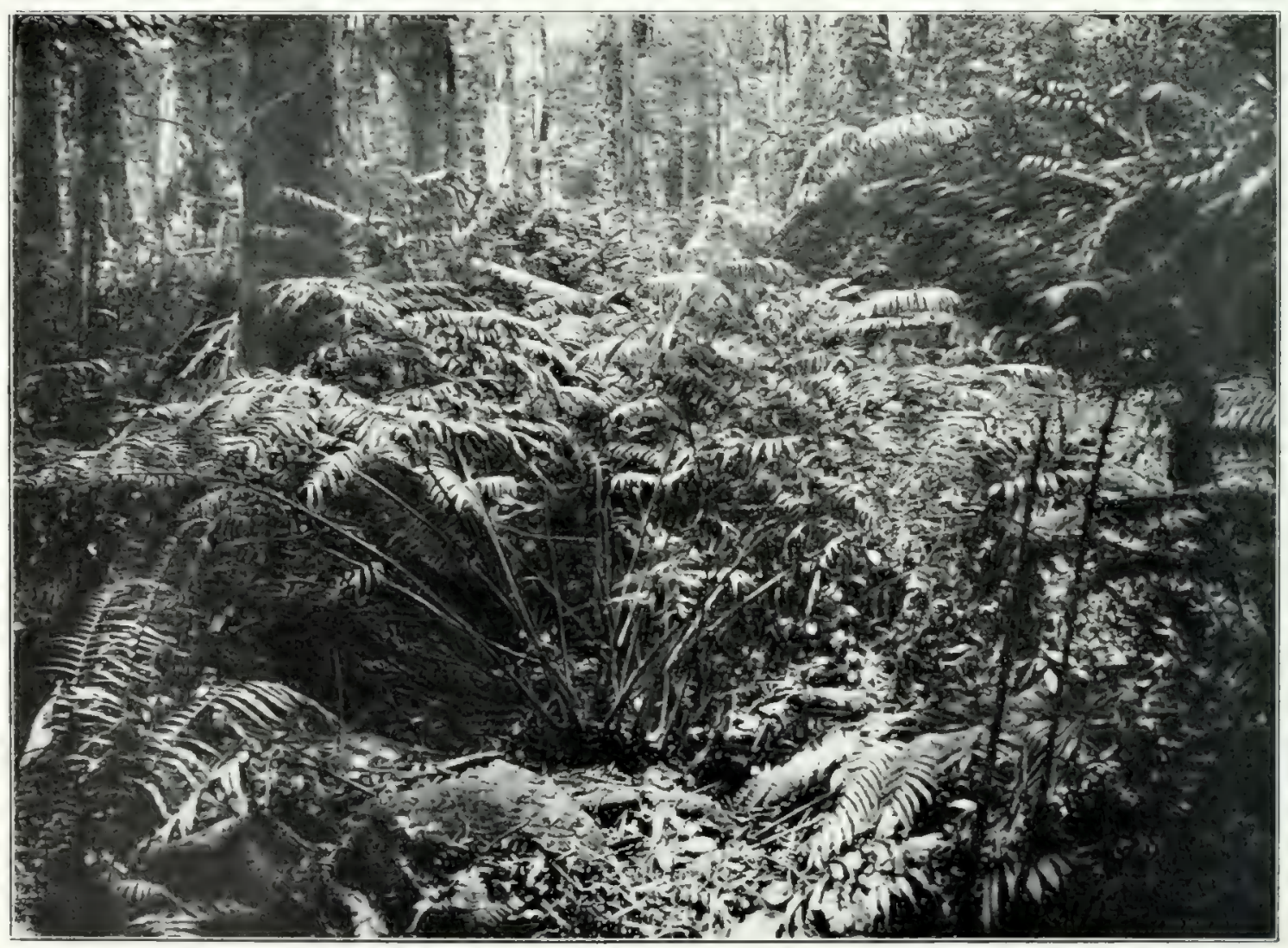

B. Marattia fraxinea Smith.

Im Schluchtenwald bei Amani in Ost-Usambara, um $900 \mathrm{~m}$ it. d. M. Nach einer Photographie von Dr. Braun (1907). 
besonderer Vorliebe an quelligen Stellen felsiger Bachläufe. nicht bloß im Schatten größerer IValdbäume. sondern häufig auch in Wraldichtungen und an Waldrändern.

Die drei auch in Afrika vertretenen Gattungen dieser Familic unterscheiden sich folgendermaßen:

A. Sorus mit häutigem, schüsselförmigem, glattrandigem oder anfangs geschlossenem, später unregelmäßig zerreißendem Indusium

Cyathea.

B. Sorus mit häutigem, unvollständigem, schuppenförmigem Indusium Hemitelia.

C. Sorus ohne Indusium Alsophila.

Diese Gattungen sind keineswegs so scharf abgegrenzt, wie es nach dem Schliissel der Fall zu sein scheint: die sterilen Blätter sind oft bei allen drei nur künstlich aufrecht zu erhaltenden Gattungen gleich ausgebildet.

Cyathea Sm. Eine der verbreitetsten Arten ist C. Dregci Kze., I-2 m hoch mit schenkeldickem Stamm und bis $1.25 \mathrm{~m}$ langen Wedeln; sie findet sich schon im Egosawalde des Pondolandes ron $200-500 \mathrm{~m}$ ii. MI., in Kaffrarien bis zu I $300 \mathrm{~m}$, sodann in Natal an felsigen Flußufern, in östlichen Transvaal zwischen Niddelburg und dem Krokodilfuß, in der Nähe ron Lỵdenhurg, im Moramballadistrikt des Sambesilandes, im nürdlichen Nyassalande bei Umalila um $2300 \mathrm{~m}$. Viel stattlicher ist C. usambarcnsis Hieron. (Fig. $3 C, F, G$ ), häufig mit $7 \mathrm{~m}$ hohem Stamm, im Shagajuralde ron Westusambara. in Ostusambara und Uluguru. Sie ist offenbar nahe verwandt mit C. Mamiana Hook. f. welche in Kamerun (Johann-Alhrechtshöhe und Fernando Po wächst. $\mathrm{Zu}$ letzterer wird als Varietät gerechnet $C$. Deckenii Kuhn (Fig. $3 A, B$ ), mit $7 \mathrm{~m}$ hohem Stamme und $1,5 \mathrm{~m}$ langen Wedeln: sie findet sich im zentralen Uluguru bis zur Waldgrenze bei $2300 \mathrm{~m}$ am Lukwanguleplateau: in Ostusambara aber sah ich sie bei Amani schon in einer Höhe von $860 \mathrm{~m}$ und von da weiter aufwärts bis ı100 m, am Kilimandscharo kommt sie oherhalb Moschi um $2300 \mathrm{~m}$ und ganz hesonders in Schluchten oherhalh Kiboscho zwischen 2200 und $2500 \mathrm{~m}$ an Wasserläufen vor. Auch bei Bukoba scheint dieselbe Art zu wachsen. Es ist mir kaum zweifelhaft, daß man alle diese. Arten einmal als C. Mamiana Hook. f. zusammenfassen wird. C. zambesiaca Bak. aus dem Shire Hochland mit sehr kurzen stumpfen Fiederchen weicht etwas mehr ab. Demselben Typus gehören auch die auf den Comoren, Seychellen und Maskarenen vorkommenden Arten an. Sodann haben wir einige Arten mit doppelt so großen Fiedern letzter Ordnung, als bei C. ALmmiana angetroffen werden, vor allem die auch in Kamerun vorkommende C. comeremianc Hook. f. (Fig. $3 E$ ); sie entwickelt einen höchstens $3 \mathrm{~m}$ hohen Stamm und $1,5 \mathrm{~m}$ lange Blätter. Ihr ähnlich ist die C. Miliitsichii Hook. von San Thomé: aber auch C. mussambicinsis Bak. vom Makuagebiet hat ebenso große, bis $2,5 \mathrm{~cm}$ lange Endfiederchen. Arten ron ebensolcher Laubentwicklung finden wir auch auf Madagaskar und den Maskarenen (C. borbonica Desv.).

Hemitelia R. Br. Sicher kennen wir nur eine Art auf dem afrikanischen Kontinente, H. capensis (L.) R. Br., von der ich selbst, unter Führung des Hern Dr. Makioth, schöne Exemplare in den Schluchten am 
Ostabhange des Tafellberges bei Kapstadt gesehen habe. Der Stamm ist I,5 bis $2 \mathrm{~m}$ hoch, erreicht aber auch $5 \mathrm{~m}$ und bis $15 \mathrm{~cm}$ Durchmesser. Die fertilen Blätter tragen hier auf jedem Segmente nur einen großen Sorus am Grunde der untersten Seitenader. Ferner sind am Grunde der Blattstiele fast immer schr zarte Adventivfiedern oder "Aphlebien " entwickelt, welche den Vegetationspunkt umhiillen (Fig. 4). Diese interessante Art ist von dem an-

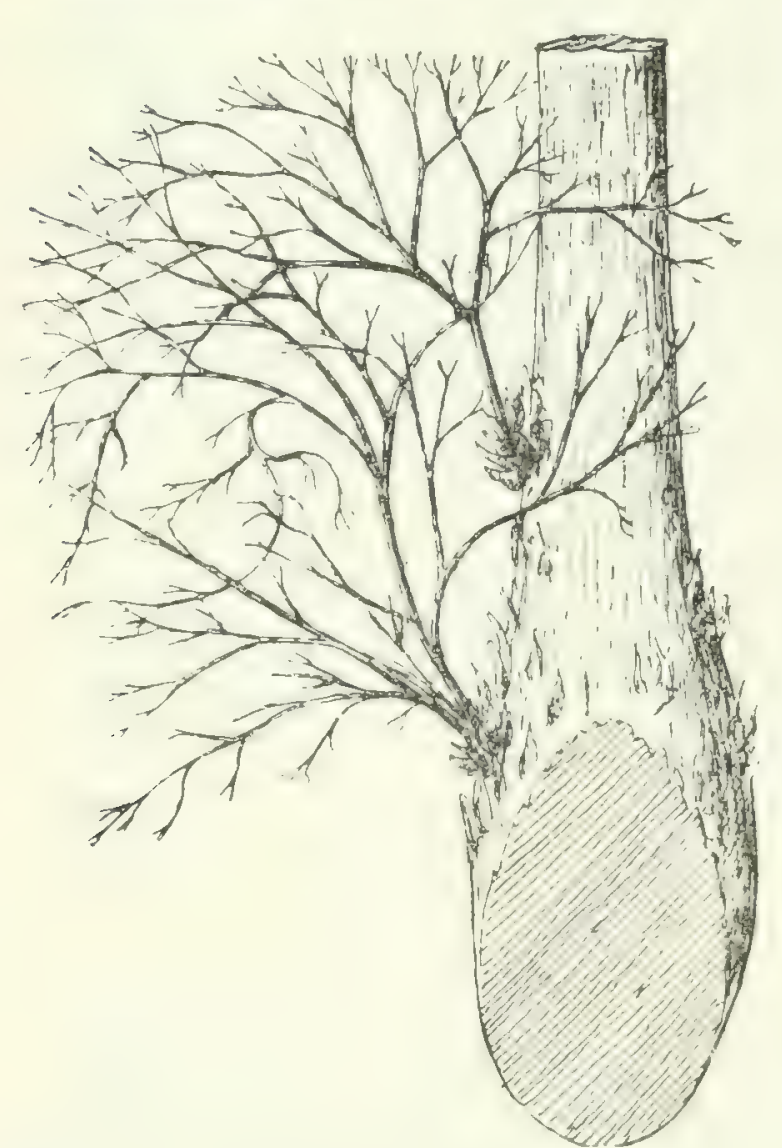

Fig. 4. Basis des. Wedelstieles von Hemitelia capensis (L.) R. Bro mit Adventivfiedern. gegebenen Fundort weiter nordostwärts bis Natal an Wasserfällen und Bächen mehrfach anzutreffen. Die zwei von Madagaskar bekannten Arten der Gattung sind nicht mit den genannten verwandt, sondern nähern sich mehr einer Art von Java und Sumatra.

Alsophila R. Br. Von dieser im tropischen Amerika und Asien ungemein formenreichen Gattung kennen wir nur wenig afrikanische, die selten über $2 \mathrm{~m}$ Höhe hinausgehen und nur einfach gefiederte Blätter mit tief gespaltenen Fiedern tragen. A. obtusiloba Hook. in den Gebirgen Gabuns hat ganzrandige Segmente; A. Zenkcri Hieron. mit glänzend dunkelroter Rachis und A. canemunensis Diels mit gelblicher, rotbraunhaariger Rachis kommen in den Regenwäldern von Kamerun vor. A. aethiopica Welw. (Fig. $3 H-L$ ) wächst in Angola von $300-750 \mathrm{~m}$. Es ist aber auch eine Art, A. Holstii Hieron. im Regenwald von Ostusambara bei $1000 \mathrm{~m}$ ii. M. anzutreffen. Die malegassischen Arten, darunter die auch auf den Comoren wachsende Art A. Boivini Mett. haben doppelt bis dreifach gefiederte Blätter.

Balantium Kaulf. mit kurzem unterirdischem Stamm und mit an der Spitze der Adern stehenđen Soris, fehlt in Afrika, ist aber im makaronesischen Übergangsgebiet durch $B$. culcita (l'Hér.) Kaulfovertreten. Nächste Verwandte in Südamerika.

\section{Fam. Polypodiaceae.}

Von dieser in der nördlich gemäßigten Zone ebenso wie in den Tropen reich entwickelten Familie finden sich im tropischen Afrika Hunderte von Arten, zum Teil rein tropischen (attungen angchörig, zum Teil aber auch solche, welche mit den in der gemäßigten Zone vorkommenden nahe verwandt sind, in den oberen Regionen der Hochgehirge endlich auch solche, welche mit borealen Formen identisch sind oder von ihnen nur unbedcutend abweichen. Es gehören in diese Familic zahlreiche Arten, welche so wie die meisten der 
gemäßigten Zone ein Rhizom mit gestauchten Internodicn besitzen; aber auch viele mit unterirdischem oder oberirdischem kriechendem Rhizom, an welchem die Blätter voneinander entfernt stehen. Ferner finden wir hei vielen der an feuchten, tiefschattigen Standorten wachsenden Arten Adrentivknospen, insbesondere am Ende der IVedel und bei nicht wenigen die Erscheinung der Heterophyllie. Die meisten sind schattenliebend und beanspruchen Luffeuchtigkeit; aber es gibt auch mehrere, welche sonnige Standorte nicht blor nicht scheuen, sondern bevorzugen und endlich auch ausgesprochen xerophile.

Wir halten uns an die in den Natiulichen Pflanzenfamilien "und auch in anderen Werken ziemlich allgemein angenommene Einteilung.

\section{Einteilung der Familie.}

Sori terminal oder dorsal. Receptaculum oft mit eigenen Tracheiden. Indusium unterständig, allseits oder extrors sich öffnend, zuweilen verkümmernd. Blattrand zuweilen modifiziert, Sporen bilateral. - B. ungegliedert oder gegliedert dem Rhizome angefügt I. Woodsieae.

Sori terminal oder dorsal. Receptaculum meist mit eigenen Tracheiden. Indusium oberständig, allseits oder extrors sich öffnend, oft fehlend. Blattrand nicht modifiziert. Sporen bilateral. B. ungegliedert dem Rhizome angefügt . . . . . . . . . II Aspidieae. Sori dorsal an der Ader, meist nahe ihrem unteren Ende. Receptaculum meist mit eigenen Tracheiden. Indusium nierenförmig, extrors sich öffnend. Sporen länglich-nierenförmig. B. gegliedert dem Rhizome angefügt. Spreite ungeteilt. Adern eng parallel, nahe am Rande anastomosierend . . . . . . . . . . . . . III Oleandreae.

Sori meist terminal, oft randständig. Receptaculum mit oder whe eigene Tracheiden. Indusium extrors, sehr selten fehlend. Blattrand häıfig umgeschlagen und modifiziert, oft mit dem Indusium verwachsen. - B. gegliedert oder ungegliedert dem Rhizome angefitgt, meist ein- oder mehrfach gefiedert. Segmente meist \pm akroskop gefördert . . . . IV. Davallieae.

Nanche Davalliae unterscheiden sich von Polypodium wesentlich nur durch das (zureilen untypische) Indusium.

Sori meist seitlich von der fertilen Ader, meist länglich. Receptaculum meist ohne eigene Tracheiden. Indusium intrors (in bezug auf die Rippe einigermaßen selbständiger Segmente), zuweilen daneben auch extrors, selten fehlend. Blattrand zuweilen umgeschlagen. - B. ungegliedert dem Rhizome angefiigt. Segmente oft akroskop gefördert . . 'V. Asplenieae.

Sori terminal oder längs an der fertilen Ader, länglich bis lineal. Receptaculum stets ohne eigene Tracheidenzweige. Indusium meist fehlend. Blattrand oft umgeschlagen, die Sori überdachend, oft modifiziert. Sporen meist tetraedrisch. - B. ungegliedert dem Rhizome angefügt, sehr selten ungeteilt, meist zusammengesetzt. Spikularzellen fehlen. . . . . VI. Pterideae. Sori auf den Adern \pm parallel zur Mittelrippe, länglich bis lincal. Indusium untypisch, oft fehlend. - B. ungegliedert dem Rhizome angefügt, meist ungeteilt. Spreite \pm ganzrandig.

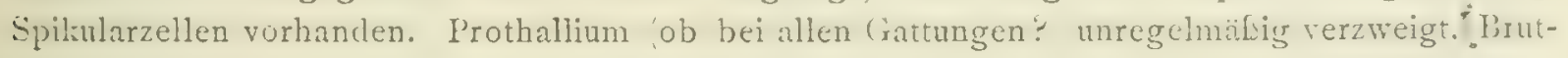
knospen bildend, mit mehreren Archegoniengruppen . . . . . . . VII. Vittaricae.

Sori dorsal oder terminal an der Ader. Receptaculum ohne eigene Tracheidenzweige. Indusium fehlend. - B. gegliedert dem Rhizome angefügt. Segmente \pm gleichzeitig entwickelt.

VIII. Polypodieae.

Sporangien wenigstens einen Teil der Blattunterseite völlig (auch das Parenchym) einnehmend. Indusium daber fehlend. - B. gegliedert oder ungegliedert dem khizone angefügt. B. oft mit dichotomer Aderung.

IX. Acrosticheae.

I. Woodsicac. Kleine Farne, deren Blattstiele dem Khizom ungegliedert eingefügt oder über der Insertion gegliedert sind. - Hygrophyten.

Von dieser Gruppe findet sich nur die fast kosmopolitische Cystopteris fragilis Sw. im tropischen und subtropischen Afrika und zwar oberhalb der 
Waldregion, in Abgriinden '2500-3500 m), am Kilimandscharo (f000 m), in Natal und dem Kapland.

II. Ispidicac. Die Blattsticle sind dem Rhizom ungegliedert angefügt, und das Indusium ist uber dem Sorus entwickelt, aber auch oft fehlend.

Meist Hygrophyten, einzelne Hydrophyten und Mesophyten, einige fast xerophytisch.

Übersicht der in Afrika vertretenen Gattungen.

A. Fertile Blätter und Blattsegmente nicht oder wenig zusammengezogen; Sporangien sämtlich aderbürtig.

a) Indusium meist herznierenförmig, oft fehlend. Blätter ein- bis mehrfach gefiedert, meist weichkrantig .

Nephrodium.

b Inchsium länglich-nierenförmig oder länglich-schildfürmig; die basiskope Hälfte der Segmente stark reduziert.

Didymochlaena.

c) Indusinm meist schildförmig oder fehlend. Blätter weichkrautig . . . Aspidium.

d) Indusium schildförmig, zuweilen fehlend. Blätter fest, lederig. Blattrand oft grannig gezähnt.

Polystichum.

B. Fertile Blätter und Blattsegmente stark zusammengezogen. Sori die ganze Unterseite des IBlattes bedecliend.

Gymnopteris.

Nephrodium Rich. ist die artenreichste Gattung dieser Gruppe. Alle afrikanischen Arten besitzen einfach oder doppelt oder dreifach gefiederte Blïtter. Zunächst kömnen wir cine Art ausschejden, welche in ITasserlachen gedeiht, im Grunde derselben ein cinige Neter langes Rhizom entwickelt, an diesem 6- $8 \mathrm{dm}$ lange einfach gefiederte Wedel trägt und oft geschlossene Bestände bildet. Es ist dies $N$. propinqunm R. Br. (Fig. 5) von den Autoren meist als $N$. unitum bezeichnet, vom Kap bis Usambara und bis zum Kilimandscharo hier noch von $x 800-2500 \mathrm{~m}$, bis zum Gazellenfluß und Togo verbreitet. So wie diese Art finden wir außerhalb der Wälder auch $N$. thelyfteris L. Strempel rom Kapland bis Benguela und Usambara, an Rändern von Tümpeln und in feuchten Gebiischen. In Buschgehölzen der unteren Region auf tonig-sandigem Boden der Comoren und Maskarenen findet sich das mit $N$. propinqunm verwandte $N$. cucullatum (Bl.) Bak. In Uferwäldern oder Galleriewäldern der Steppengebiete, sowic in Lichtungen der Steppengehölze finden wir bald auf alten Baumstämmen, bald auf Felsen das mit langem Rhizom versehene $N$. pectinatum (Forsk.) Hieron. (= Arthropteris albopuntatid (Bory) J. Smith, nicht hloß in Ost-, Zentral- und Westafrika, sondern auch in Arabien. Von den Arten der unteren Regenwälder VIestafrikas truffen wir in Kamerun . I. punctulatmm Bak. mit langem Rhizom und einfach gefiederten Blättern, ron Liberia bis Kamerun und auch auf Fernando Po $\lambda^{T}$. fretcmmm (Mett.) Hieron. mit doppelt gefiederten Blättern, mehrere damit verwandte Arten auf den Seychellen, Maskarenen und Madagaskar, ferner $N$. venulosm Hook. von Togo bis Gabun, in Ostafrika aber auch im Bergwald. Mehrere Arten wachsen in den Regenwäldern vorzugsweise in Bachschluchten; eine ziemlich auffallende Art mit langen, zwischen den Steinen der Bäche hinkriechenden Rhizomen ist . T. sullominquefulum (P. Beauv.) Hook., (=N. protcnsum (Afzel.) Bak., Fig. 6) verbreitet von Senegambien bis 
Sierra Leone. Viel größer als diese Art, aber mit verkirztem Rhizom und I-2 m langen, bis dreifach gefiederten Blättern ist das in Kamerun vorkommende $N$. variabile Hook. Mehrere andere an Wasserläufen der Wälder vorkommende Arten haben einfach gefiederte Blätter. Von solchen sind auf die Comoren und Maskarenen beschränkt die nur $3-5 \mathrm{dm}$

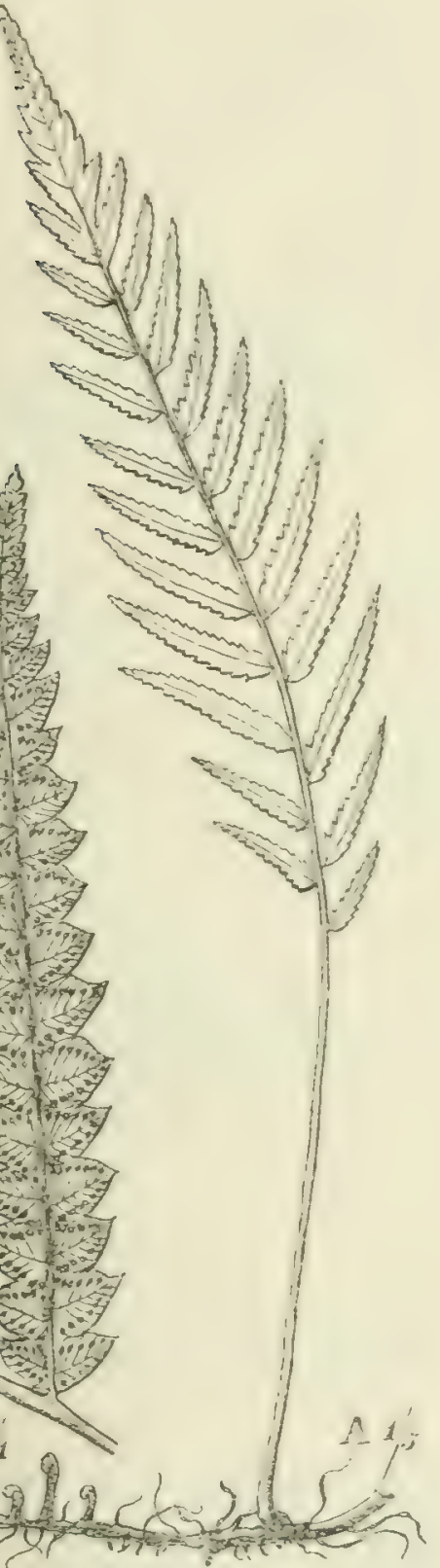

Fig. 5. Nephrodium propinquum R. Br., Kamerun.

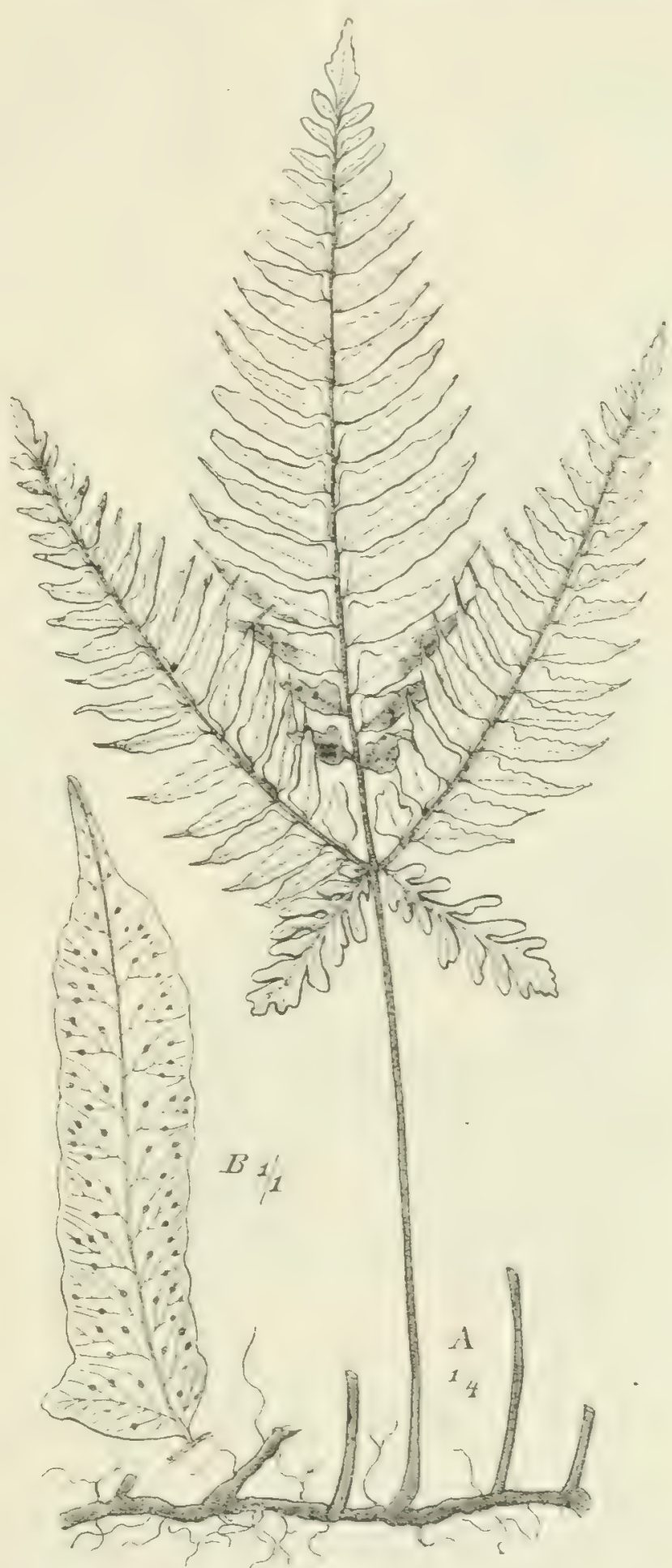

Fig. 6. Tephrodium subquinquefidum(P. Beauv.) Hook, var. tripinnatum Hook, Kamerun.

Höhe erreichenden .1: tumentosum Thouars Desv. und .1. strigesum (VVilld. Desv, auf Transvaal und Madagaskar I. Birgicmum Schlecht. Bak. Einige andere finden sich in West- und Ostafrika. Stattlich sind das von Kamerun, Mombassa und Usambara bekannte $2 \mathrm{~m}$ hohe . I. irrhosum Schum.j Bak. und 
das auf den Comoren sowic in Uganda rorkommende 1. Spckci Bak. Ziemlich verhreitet vom Kapland bis I3enguela und bis zum Ruwenzori, auch in den l'ergwäldern bis zu $2300 \mathrm{~m}$ aufsteigend ist $N$. Gueinzianum (Mett.) Hieron. mit I m langen Blättern. Wie bei $N$. cirrhosum sind die Fiedern bis über die Mitte eingeschnitten auch bei $N$. tottc (Willd.) Diels (Fig. 7), das im ganzen paläotropischen Reiche gemein, auch in Afrika vom Kapland bis zum Kilimandscharo $(2000-3000 \mathrm{~m})$, übrigens auch auf Madeira vorkommt. Eine stattliche Art mit I m langen, dreifach

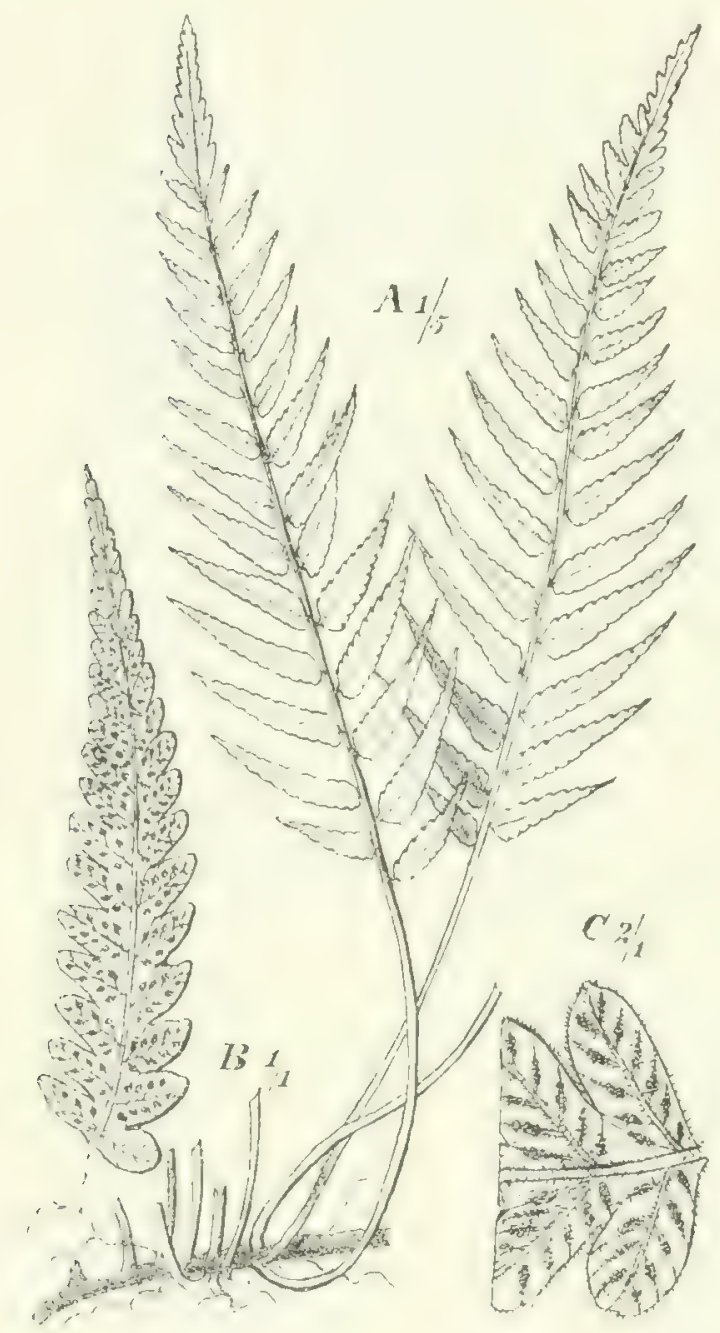

Fig. 7. Nephrodium totta (Willd.) Diels, Kilimandscharo. gefiederten, kahlen Blättern ist das auf den ostafrikanischen Inseln und vom Kap bis Usambara (900-I I 00 m)

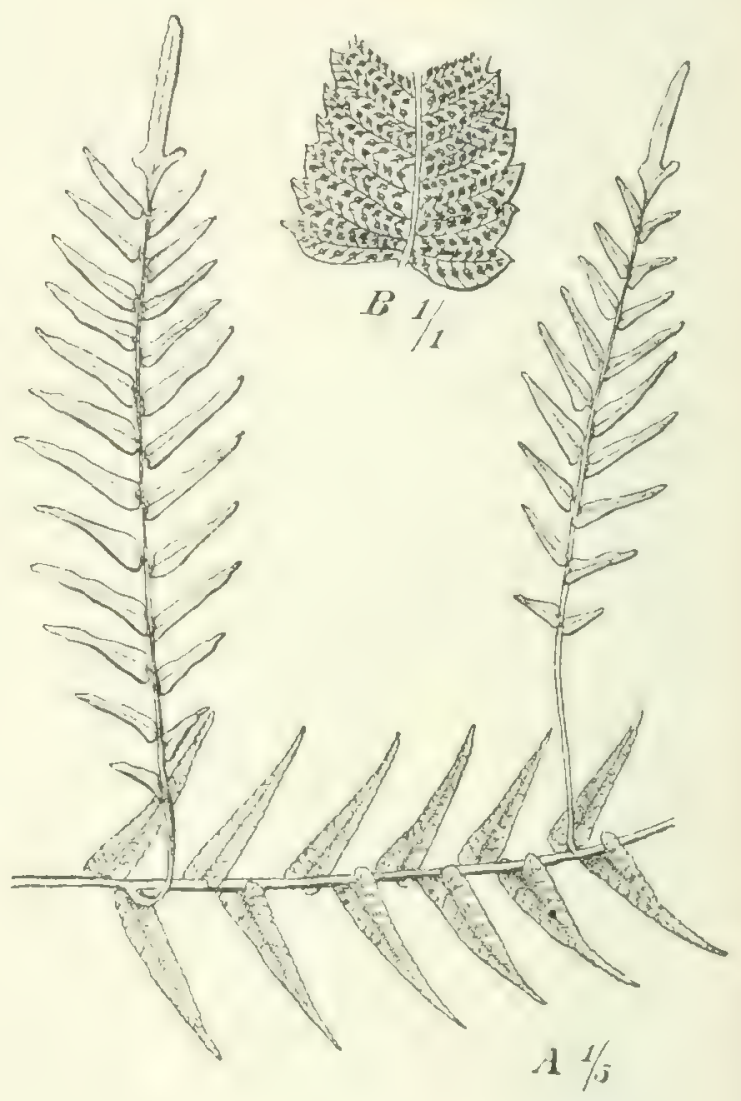

Fig. 8. Nephrodium proliferum (Retz) Keys., Natal.

verbreitete $N$. catoptcron (Kze.) Hook., dem auch noch ein paar auf Réunion beschränkte Arten (A. aquilinoides Desv. und N. Helliamm (Fée Hieron. syn. V. subglindulosum (Mett.) Bak. nahestehen. Besonders kräftig entwickelt sich $N$. venulosum Hook, welches an einem kurzen Stamm bis $2 \mathrm{~m}$ lange, einfach gefiederte Blïtter trägt; es ist in Westafrika von Togo bis Gabun verbreitet und findet sich auch in den üppigen Bergwäldern Ostusambaras. Io $\mathrm{cm}$ hohe Stämmchen besitzt auch das der Sektion Goniopleris (charakterisiert durch Verbindung der untersten Seitenadern zweier Segmentmedianen zu ciner (reieckigen Nasche) angehörige N. arhuscula (Wil'd.) Desv., 
das aus dem tropischen Asien über die Maskarenen bis Usambara vorgedrungen ist. In die Sektion Goniopteris gehört auch N.prolifernm (Retz) Keys. Fig. 8), welches in Natal vorkommt und sich dadurch auszeichnet, daß aus den Achseln der Fiedern niederliegender Blätter neue Blätter senkrecht aufsteigen.

Außer den genannten Liphordinn-Arten gibt es auch noch einige andere in den Gebirgsregenwäldern, welche weniger an dic Wasserläufe gebunden sind, in höheren Regionen vorkommen und auch in den Gubirgsbusch oder in

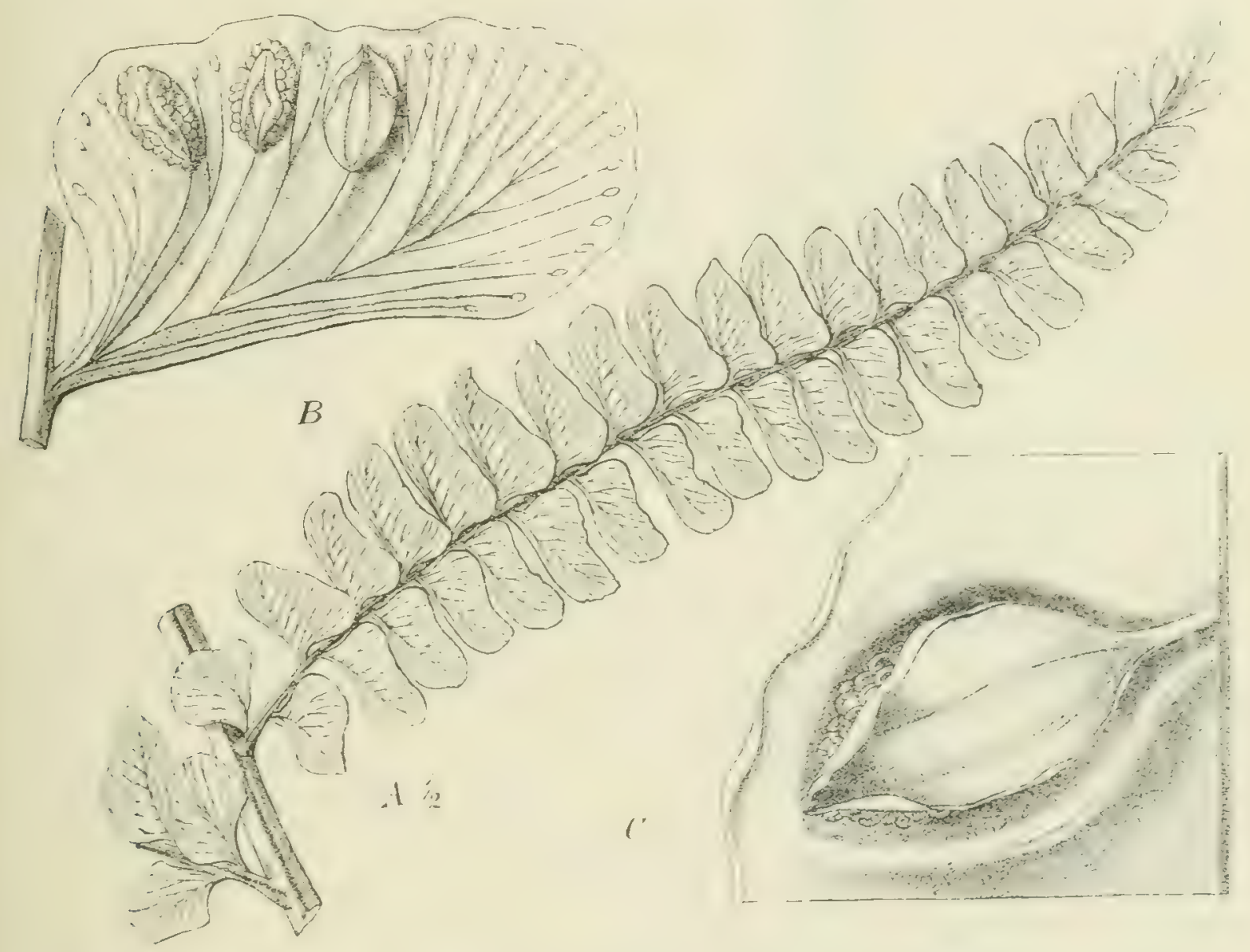

Fig. 9. Didymochlaena lunulata Desv. $A$ Fieder $I$. aus der oberen Region eines B.; $B$ Fieder II. Aderung und Sorus; $C$ Sorns mit Indusium.

den Höhenwald übergehen, so das dem $N$. Gucinzimum verwandte $N$. ehtusilobum (Desv.) ( $=N$. maranguchisc Hicron.), von Natal bis zum Kilimandscharo (2100 $\mathrm{m}$ ) und in Kamerun, ferner das in Afrika nicht bloß von Abyssinien und Sccotra bis Kapland verbreitete, sondern auch auf den Comoren, Naskiarenen, Kapverden, Kanaren und in Algerien rorkommende 1 . molle (Jacq.) R. Br. aus der Sektion Gonioptcris. Doppelt oder dreifach gefiederte Blätter finden wir bei dem $\mathrm{I} \mathrm{m}$ hohen $N$. nigritanum Bak. in Kamerun, bei dem in Natal bis zum Viktoria Njansa verbreiteten 1. athumanticum Hook. bei dem am Kilimandscharo von $\mathrm{I} 300-3000 \mathrm{~m}$ vorkommenden, nur 30 bis $50 \mathrm{~cm}$ hohen $N$. kilemense Kuhn. Einige Arten mit gleicher Teilung der Blitter zeichnen sich auch noch durch starle Beklcidung ihrer 13lattsticle mit 
Spreuschuppen aus; dieselben sind borstenahnlich bei 1 . sqummisctum Hook., das auf Réunion, in Natal und am Kilimandscharo um 2700 $m$ gefunden wurde. dagegen breit und lang an den I $m$ langen Blättern des $N$. Schimperianum Hochst., welches in der Woina Dega Abyssiniens und in der Erica-Zone des Kilimandscharo fast bis zu $4000 \mathrm{~m}$ vorkommt, ebenso auch bei $N$. increquale (Schlecht.) Hook., das von Uitenhage durch Natal und Transvaal bis zum Kilimandscharo bis $2800 \mathrm{~m}$ ! in lichten Gebiischen gedeiht. Indlich ist als fast xerophile Art $N$. odoratum (Bory) Bak. zu bezeichnen, wie voriges von der Tracht des $N$. spimulosm und auffallend durch $2 \mathrm{~cm}$ lange breite Spreuschuppen, an felsigen Ilïtzen im abyssinischen Hochland, auf Socotra und in Transvaal.

Didymochlaena Desv. mit aufrechtem Stämmchen, das mehrere bis $2 \mathrm{~m}$ lange doppelt gefiederte Blätter trägt, deren Sori ron einem länglichen, in der Mitte angewachsenen Indusium bedeckt sind. - Nur eine in den Tropen verbreitete Art, D. lumulata Desv. (Fig. 9) findet sich in Bachwäldern von Natal, Usambara und Kamerun, auch auf San Thomé.

Aspidium Sw. Diese durch schildformige Indusien charakteristische Gattung steht Nefhrofimm sehr nahe; daher wurden auch häufig beide Gattungen miteinander vereinigt; in der jetzigen Umgrenzung ist $A$. bei weitem ärmer an Arten als Nephodium. - In den unteren Regenwäldern des Westens finden sich einige, bis jetzt im Osten nicht beobachtete Arten: A. Barteri J. Sm. und A. sparsiflorum (Hook.), mit fast I $m$ langen, länglich-dreieckigen Blättern und großen lanzettlichen Fiedern, A. varians (Moore) C. Chr. mit doppelt gefiederten Blïttern, an Bächen 4 . Imchhol ii Kuhn: während dies alles sehr stattliche Pflanzen sind, -ist A. gabooncnso Kuhn in Gabun nur etwa $3 \mathrm{dm}$ hoch. Eine der auffallendsten und schönsten Arten dieser Gattung ist A. cicutarim (L.) Sw., mit fast I m langen, doppelt gefiederten Spreiten an $0.5 \mathrm{~m}$ langen Stielen, in allen feuchteren Gebieten der Tropen auf lockerem Waldboden verbreitet und so auch in den Regenwäldern des tropischen Afrika, stellenweise bis zu $2600 \mathrm{~m}$ aufsteigend; diese Art findet sich auch noch im suidlichen Nyassaland und auf den Comoren.

Polystichum Roth, mit schildformigem Indusium, bisweilen ohne solches, ist an den ziemlich starren, fast lederigen, oft grannig gezähnten und stark mit Spreuschuppen besetzten Blättern leicht zu erkennen. Die in Afrika rorkommenden Arten finden sich meist in den oberen Regionen des Gebirgsbusches und der Hohenwälder oder auch in der obersten Strauchregion. Leicht kenntlich ist das mit einfach yefiederten Blättern versehene $I$ '. falcatum L. fil. Diels, rom Kapland bis L'sambara, in letzterem in ciner Hohe ron etra I200-I500 $\mathrm{m}$ vorkommend. Das fast kosmopolitische $P$. aculcatum (L.) Schott fehlt auch nicht im tropischen Afrika, in den Hochgebirgen Abyssiniens, auf den Comoren, am Kilimandscharo (2800-3000 m) und dem Kamerunpik, auf welchem in $3000 \mathrm{~m}$ iber der Strauchregion noch eine kleinblätrige Varietät (onlcanicm Hieron.) angetroffen wird. Nahe verwandt mit vorigem sind $P$. luchosum (Kze.) Moore vom Kaffernland bis Natal, P. pungens (Kaulf.) Presl 
sich aber durch die fiederige Aderung an die anderen Aspidicae anschließen. Alle Arten sind Erdfarne der unteren Regenwälder; sie sind daher vorzugsweise im westlichen Afrika anzutreffen. Die meisten sind leicht kenntlich; so besitzt (i. phanerodictyon (Bak.) langherzförmige Spreiten, G. gahnnensis (Hook.) J. Sm. (Fig. Io), welche an Bachufern häufig ist, lanzcttliche, bis $5 \mathrm{dm}$ lange Blätter. G. Boivini (Mett.) Kuhn (= Acrostichum Laurcntii Christ), von Kamerun bis zum Kongo verbreitet, und G. fluviatilis (Hook.) sowie die zwischen dieser und G. gabunensis in der Mitte stehende G. Prenssii Hieron. be-

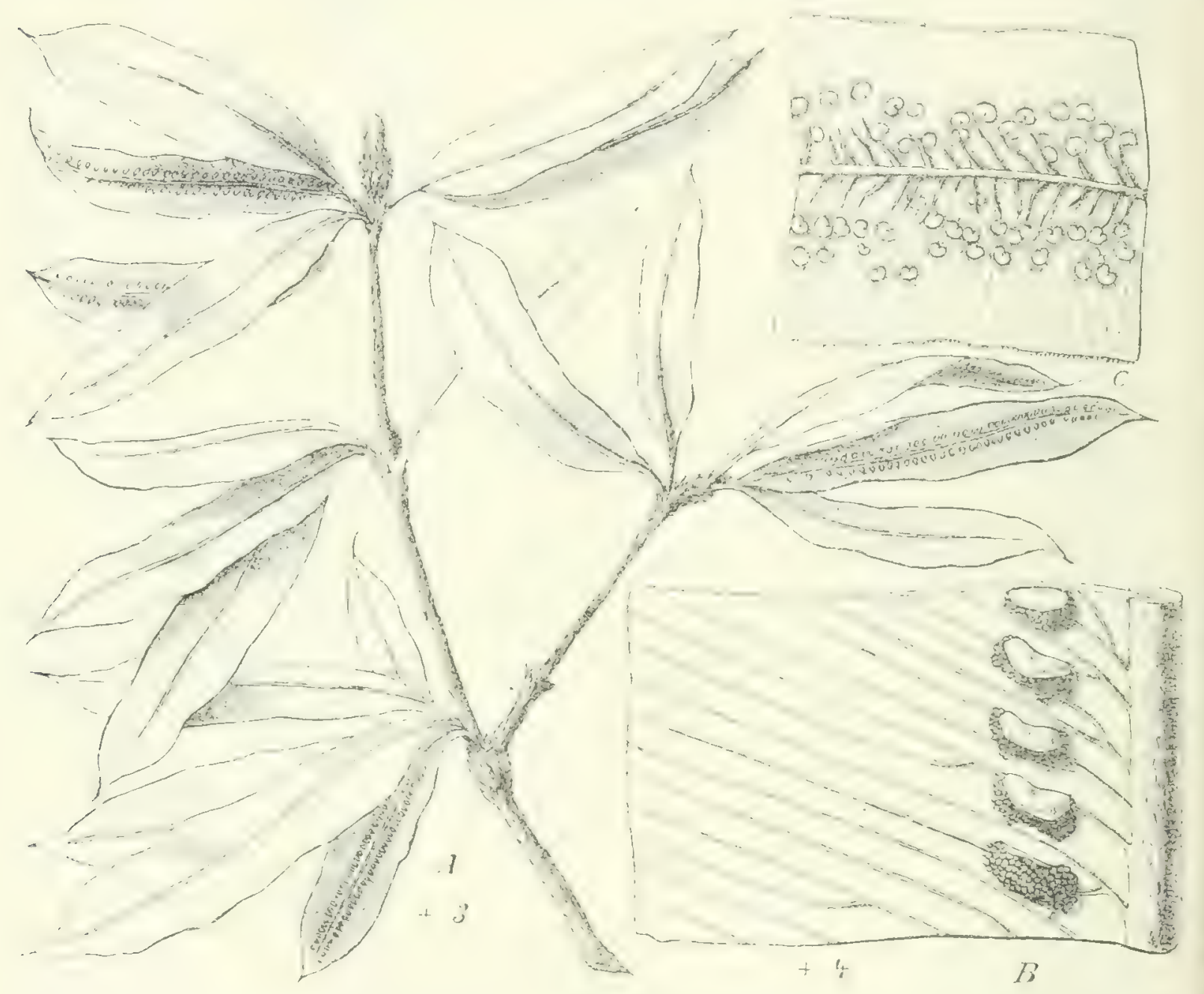

Fig. 12. $A, B$ Oleandra neriiformis (Sw.) Pr., $A$ Habitus, ${ }^{1} / 3$ nat. Gr., $B$ Teil eines Blattes, vergr.; C O. Whitmeei Bak. nicht aus Afrika, sondern von Celebes.

sitzen einige Seitenfiedern unterhalb des langen lanzettlichen Endabschnittes. Mehrere Fiedern haben die bis $0,75 \mathrm{~m}$ langen Blätter der nicht bloß von Kamerun bis zum Kongo verbreiteten, sondern auch in den Regenwäldern Usambaras vorkommenden G. auriculata (Fig. I I), ferner dic von Senegambien und Togo, sowie aus dem Lande der Niamniam belannte G. acrostichoides Afz.) und die an Bachufern wachsende G. Hcudelotii Bory (von der vorigen durch noch schmalere Fiedern verschieden ${ }^{\mathrm{T}}$ ).

I) Nenerdings werden auch die Arten dieser Gattung als Leftochilus Kanlf, bezeichnet, da Gymnopteris Bernh. für Nezrogramme Link vorgezogen werden soll. 
b) Indusium an drei Seiten angewachsen.

๙ ) Blätter gegliedert dem Rhizom ansitzend. Spreuschuppen . . . . Davallia.

ß) Blätter ungegliedert dem Rhizom ansitzend. Spreuhaare. . . . . Microlepia. B. Sori oft zusammenfließend, die gleich gestalteten Indusien daher langgestreckt zusammenhängend.

Schizoloma.

Arthropteris J. Sm. An dem kletternden Rhizom sind die Blätter gegliedert eingefiigt, cbenso die Fiedern der Blattspindel; die punktförmigen

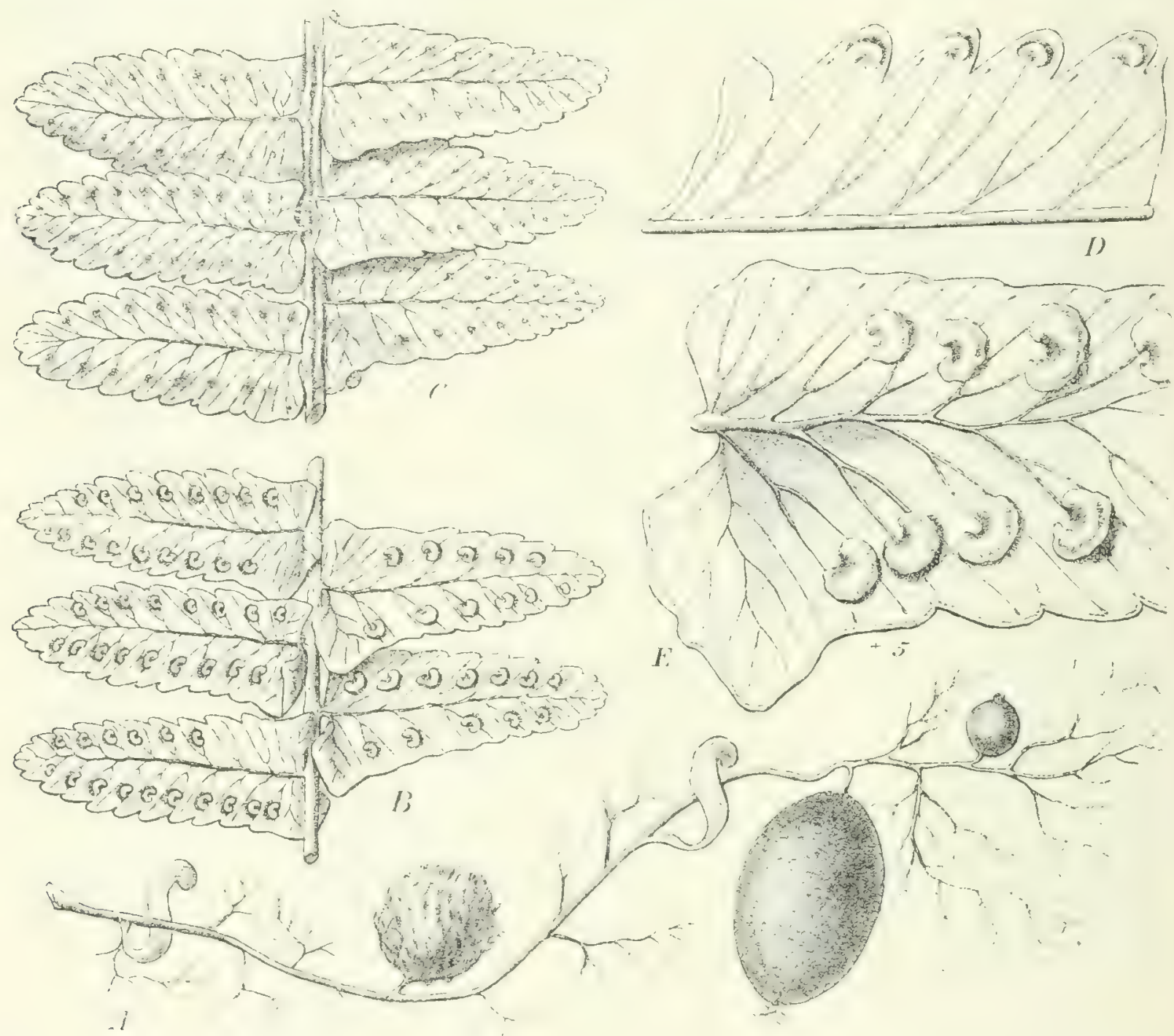

Fig. 14. $A-C, E$ Nephrolepis cordifolia (L.) Presl. A Auslüufer mit Knollen; $B, \mathrm{C}$ Teile eines Blattes (umgekehrt); $B$ Unterseite; $C$ Oberseite; $E$ Teil einer Fieder mit Aderung und Soris; $D$ N. davallioides (Sw.) Kze, aus Malesien.

Sori stehen terminal an Tertiäradern. Nur eine Art, A. obliterata $(\mathrm{R} . \mathrm{Br}$.) J. Sm. (= A. ramosa (Beauv.) Mett.) (Fig. 13), welche auf San Thomé und in Kamerun bis zu $800 \mathrm{~m}$, sowie auf den Comoren mit ihren dünen Rhizomen oft ganze Stämme umspinnt.

Nephrolepis Schott ist von voriger Gattung im wesentlichen durch ungegliedert cingefügte Blattfiedern verschieden, deren Adern an der Stelle, wo unterseits die Sori ansitzen, oberseits Kalk ausscheiden. Hierher gehört die in feuchtwarmen Ländern sehr verbreitete. $\mathrm{r}$. cortifolia (L.) Presl (= N. tulic- 
rosa (Bory) Presli, deren Rhizom Ausläufer besitzt, welche oft schuppige Knollen tragen; sie ist in allen Regenwäldern des tropischen Afrika anzutreffen, auch epiphytisch und auf Felsen, bisweilen auch an Mauerwerk; bemerkenswert ist ferner, daß sie von der Meereskiiste bis zur höchsten Spitze
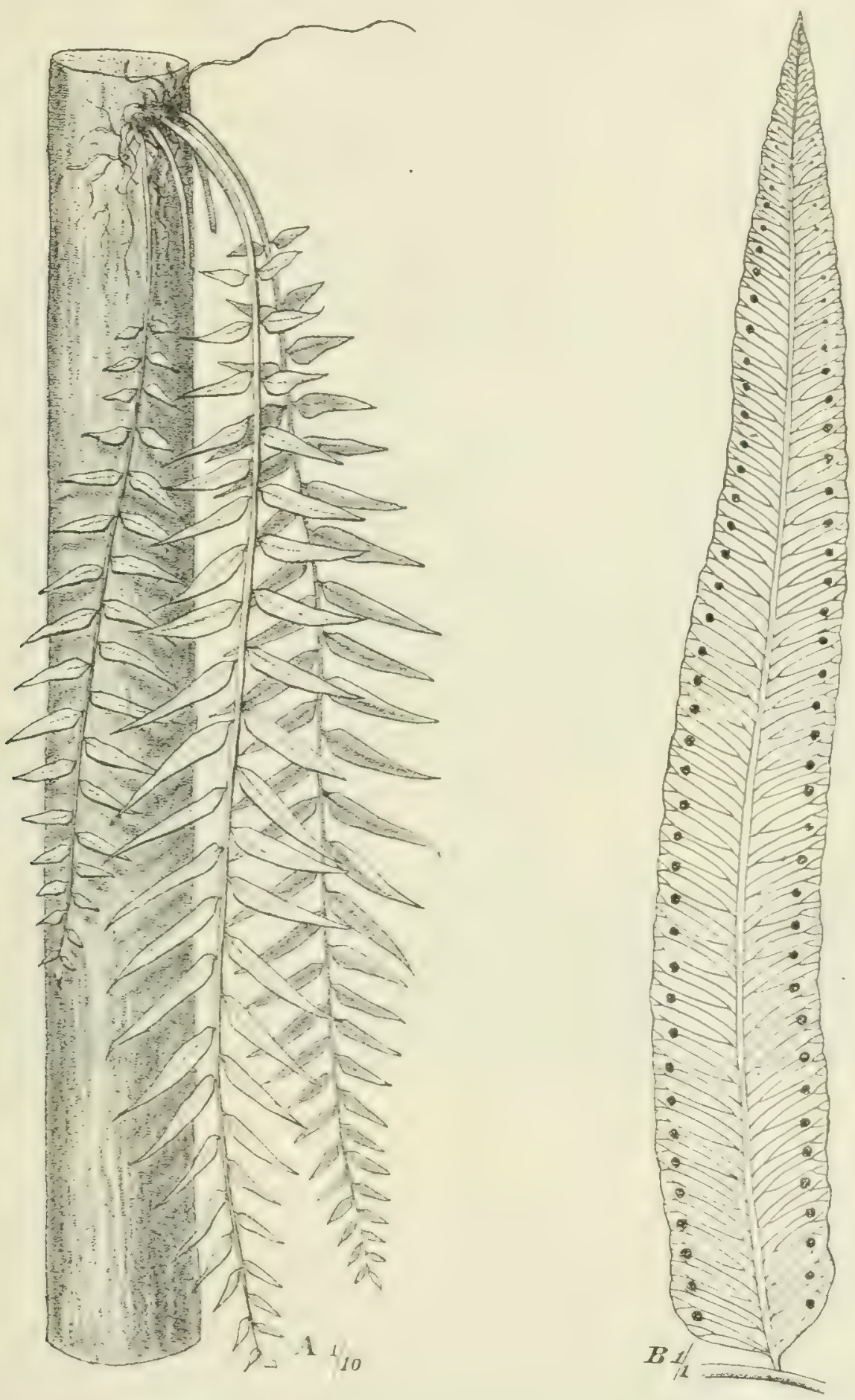

Fig. 15. Nephrolepis biserrata (Sw.) Schott (= acuta (Schk.) Presl.), häufig an Stämmen der Ölpalme, Usambara.

des Kamerunpik angetroffen wird. Die der vorigen Art ähnliche, aber kräftigere 1 . exaltata (Sw.) Schott ist seltener; sie ist nachgewiesen im suidlichen Ostafrika, in Ober-Guinea und Angola; aber gewiß noch weiter verbreitet.

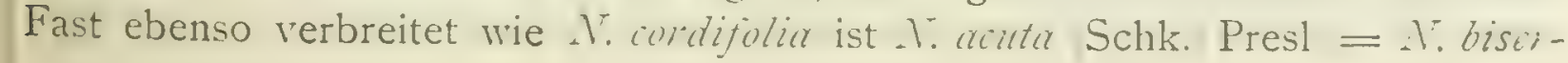


rata (Sw.) Schott (Fig. I5); sie wächst sowohl im Wald am Boden, namentlich an Bachufern und in Bambusbeständen, wie epiphytisch; besonders häufig sieht man in Westafrika die Büschel ihrer $2 \mathrm{~m}$ langen Blätter von den Stämmen der Ölpalmen herabhängen.

Humata Cav. ist nicht von großer Bedeutung im Vegetationsbild von Afrika. Es sind Farne mit Rhizom, dem die gefiederten Blitter gegliedert angefiigt sind; die Fiedern des Blattes sind ron der Spindel nicht abgegliedert und die von dem breit angewachsencn Indusium bedeckten Sori stehen inner-

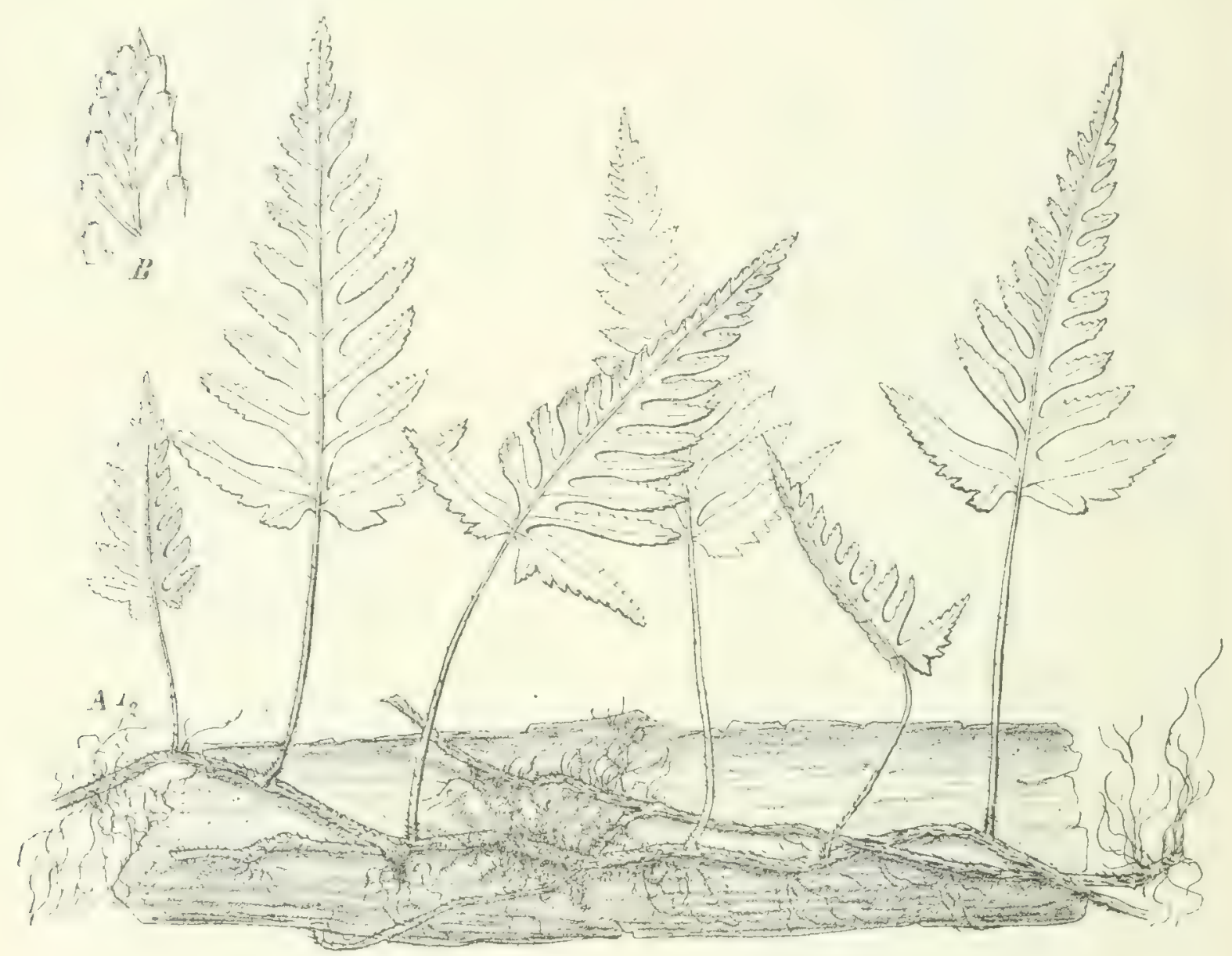

Fig. I6. Humata repens (L. fil.) Diels, Kamerun.

halb des Randes. Die hier abgebildete (Fig. 16) H. repens (L.) Diels wächst auf alten Baumstïmmen in Kamerun sorvic auf den Scychellen, Comoren und Maskarenen.

Davallia Sm. ist leicht kenntlich an dem Indusium, welches an drei Seiten angerachsen ist. Das dicht beschuppte Rhizom klettert oft hoch an Bäumen in die Höhe und läßt die meist mehrfach und zierlich gefiederten Blätter herabhängen.

Schon in Portugal, z. B. auf den Korkeichen bei Cintra, sehen wir die schöne $D$. comminusis (L.) Sm., welche auch im Küstengebiet von Narokko und auf den makilronesischen Inseln sowohl an Folsen, wie auch epiphytisch angetroffen wird. Ihr ähnlich, aber durch große, bis I $m$ lange Blätter aus- 
gezeichnet ist $D$. dinticulatio (Burm.) Nett., welche in unteren Regenwäldern des kontinentalen Afrika und der Comoren nicht selten ist (Fig. I 7 i; sie wächst stets epiphytisch.

Microlepia Presl umfaßt Ërdfarne mit kriechendem Rhizom. Die einzige in den Regenwäldern des tropischen Afrika vorkommende und auch sonst in

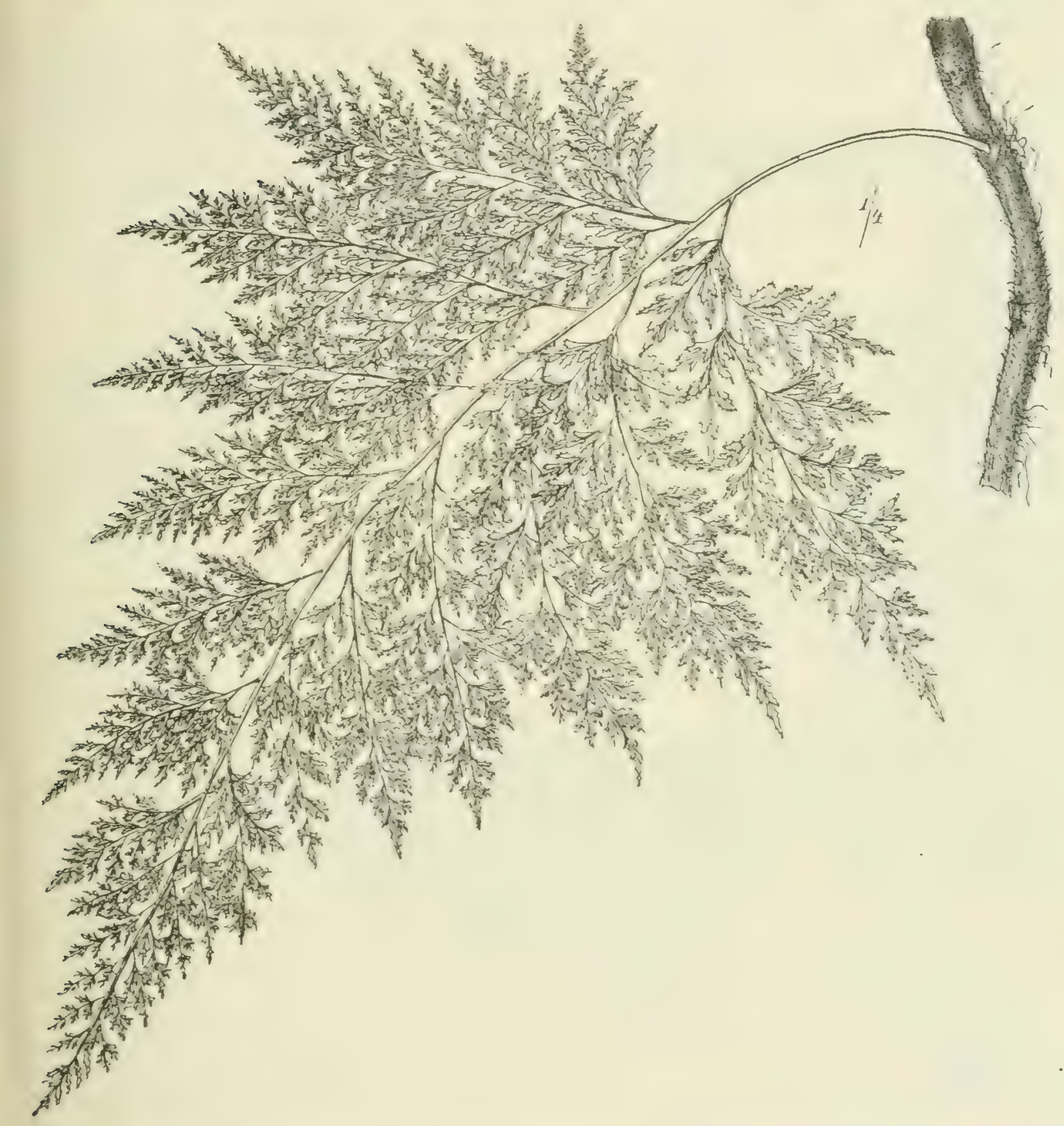

Fig. 17. Davallia denticulata (Burm.) Mett. var. intermedia Mett., Kamerun.

den Tropen verbreitete Art .1\% spiluncac (L.) Moore (Fig. I8) fällt besonders durch ihre I $\mathrm{m}$ langen, bis vierfach fiederspaltigen weichen Blätter auf.

Schizoloma Gaud. mit ungeteilten oder einfach gefiederten Blättern, ist ausgezeichnet durch innerhalb des Blattrandes stehende Sori, welche zusammenfließen und von den zusammenhängenden Indusien bedeckt sind. Nur eine Art, Sch. insifolium (Sw:, J. Sm., welche ganz den Habitus von I'teris creticu hat (Fig. In), erreicht von ihrem Verbreitungsgebiete im tropischen Asien auch Natal. 
V. Asplenieac. Die Blätter sind dem Rhizom mit ungegliedertem Blattstiel eingefiigt und tragen Sori mit flachem Receptaculum, welche seitlich an den Adern entspringen, bedeckt von Indusien, welche meist der Rippe des Abschnittes zugewendet sind.

Meist Hygrophyten und Mesophyten, einige Asplenim und Ceterach xerophytisch.

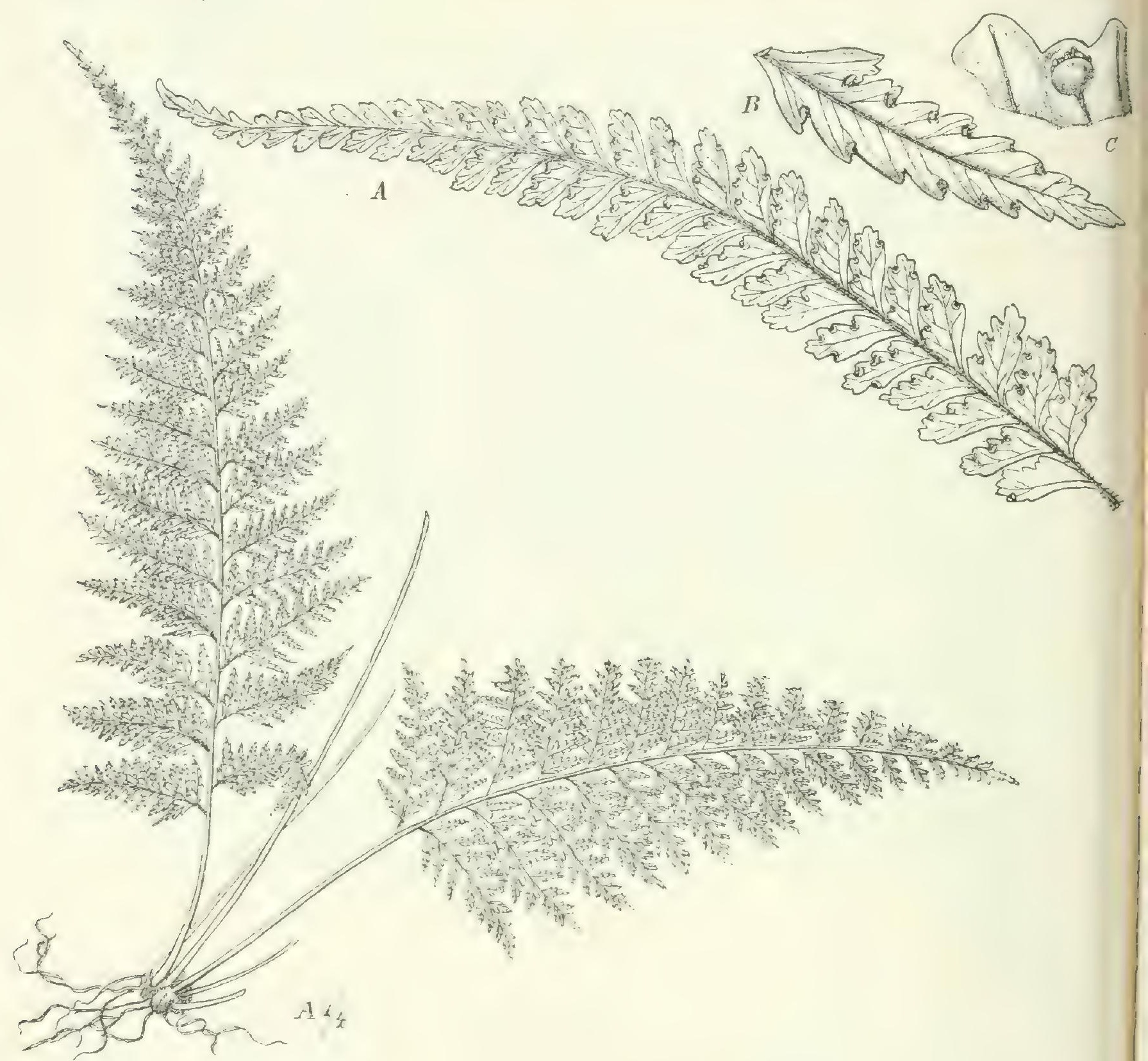

Fig. I8. Microlepia speluncae (L.) Moore, Kamerun. A ganze Pflanze I/4 nat. Gr. und eine Fieder I.; $B$ Fieder II.; $C$ Sorus.

Übersicht der in Afrika vorkommenden Gattungen.

A. Sori parallel den Seitenadern befestigt . . . . . . . . . . . . . Aspleniinae.

a) Spreuschuppen zartzellig. Leitbündel (auf dem Querschnitt des Blattstiels) zwei, getrennt oder nach oben in ein peripherisches, halbzylindrisches verschmelzend. Indusium einerseits frei.

a) Sori meist je eins an einer Ader, kurz. Indusium oft hakenförmig oder über die fertile Ader ibergreifend. . . . . . . . . . . . . . . . Athyrium. 
B) Sori meist je zwei an einer Ader. Indusium sich entgegengesetzt öffnend Diplazium.

b) Spreuschuppen starkzellig. Leitbündel ein oder zwei, welche oben in ein zentrales, drei- bis vierschenkliges verschmelzen. Sori eins an einer Seitenader.

a) Indusien benachbarter Sori paarweise sich gegeneinander öffnend. . Scolopendrium.

B) Indusien alle intrors, sich seitlich öffnend.

I. Blätter ungeteilt oder gefiedert, selten dichotom. Indusiun vorhanden Asplenium.

II. Blätter fiederspaltig. Indusiun zur Verkümmerung neigend . . . . Ceterach.

B. Sori auf einer Ader-Anastomose parallel zur Rippe befestigt. . . . . Blechninae.

a) Sterile Blätter mit freien Adern, fertile mit zwei Maschenreihen zwischen Rippe und Rand. Sori zusammenhängend. Indusium vorhanden . . . . . . . . . Blechnum.

b Sterile und fertile Blätter mit zwei Maschenreihen zwischen Rippe und Rand, aber die Maschen nächst der Rippe sehr schmal. Segmente der fertilen Blätter stark zusammengezogen. Kein Indusium . . . . . . . . . . . Stenochlaena.

c. Sterile und fertile Blätter mit zwei Maschenreihen. Sori getrennt. Indusium vorhanden.

( ) Sori eingesenkt, in einer Reihe . . . . . . . . . Woodwardia.

ß) Sori oberfächlich, in einer bis mehreren Reihen . . . . . . . . Doodia.

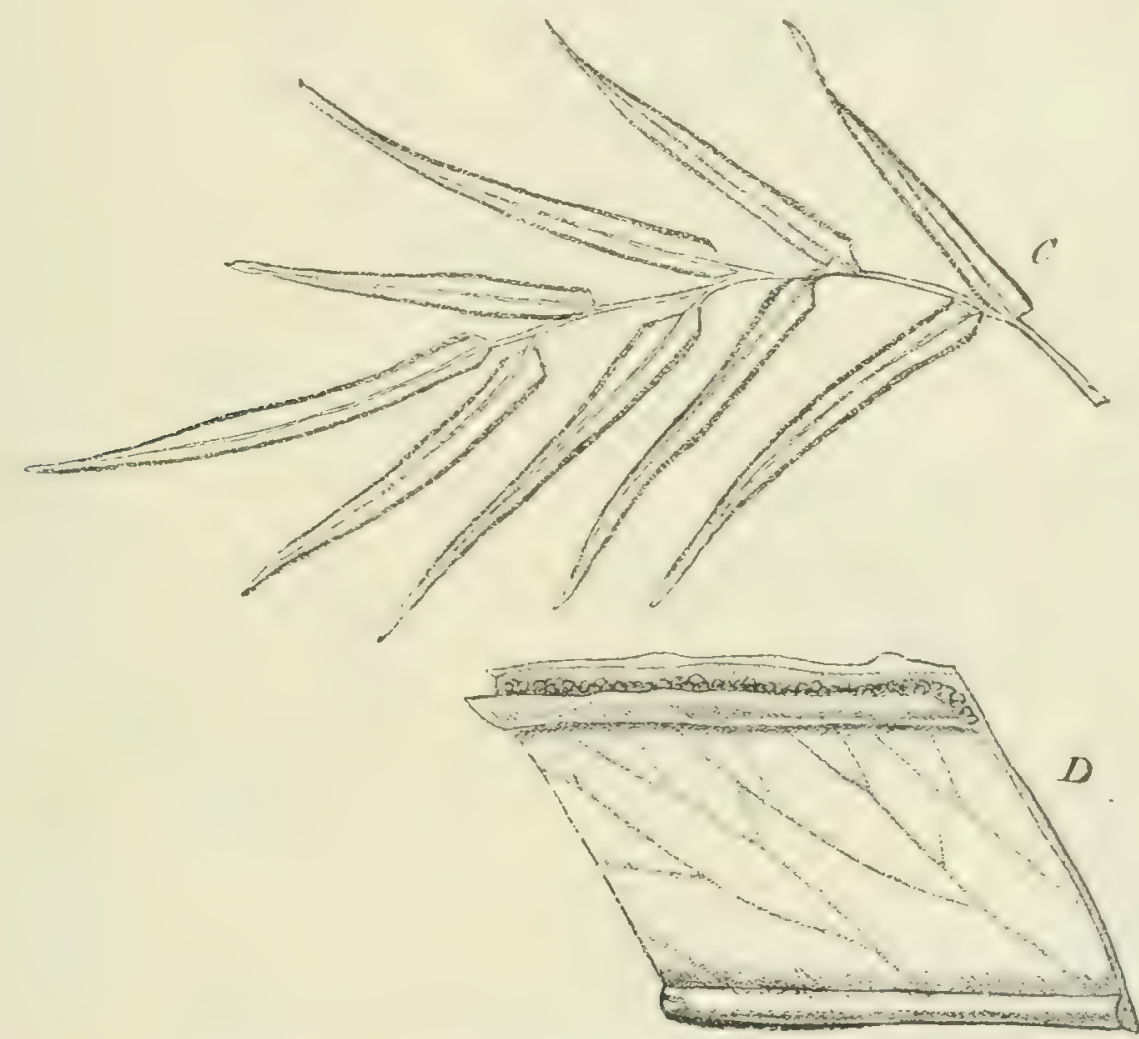

Fig. 19. Schizoloma ensifolium (Sw.) J. Sm.

\section{a) Aspleniinae.}

Von Athyrium Roth, das in der ganzen nördlich gemäßigten Zone durch das häufige A. filix fomina (L. Roth repräsentiert ist, finden wir das wohl nur als Subspezies des letzteren anzusehende 4 . Schimpcri Mougeot in Schluchten der Woina Dega Abyssiniens von 2100-3000 m ii. M. Ebenfalls nur wenig verschieden ist das durch reicher gegliederte Blätter ausgezeichnete 4 . siandicinum (IVilld.) Presl, welches in den Tropen verbreitet ist, in Afrika im Kamerungebiet und von Nyassaland bis Kapland vorkommt.

Diplazium Sw. ist auch in Afrika mit einigen Arten vertreten, welche an der Charakteristik der Waldflora stark beteiligt sind. So findet sich auch in 
Kamerun das in den meisten Tropengebieten wachsende $D$. silvaticum Presl mit cinfach gefiederten Blättern an kriechendem Rhizom (Fig. 20 $A-C$ ) recht häufig, stellenweise den Boden ganz bedeckend, während in Uluguru das auch auf Mauritius vorkommende $D$. pseudoporrectum Hicron. gefunden wird. Noch kräftiger ist $D$. Bommeri Christ (Asplen. crenato-serratum Bommer), mit I m langen Blättern und $2 \mathrm{dm}$ langen Fiedern, das von Kamerun bis zum Kongo

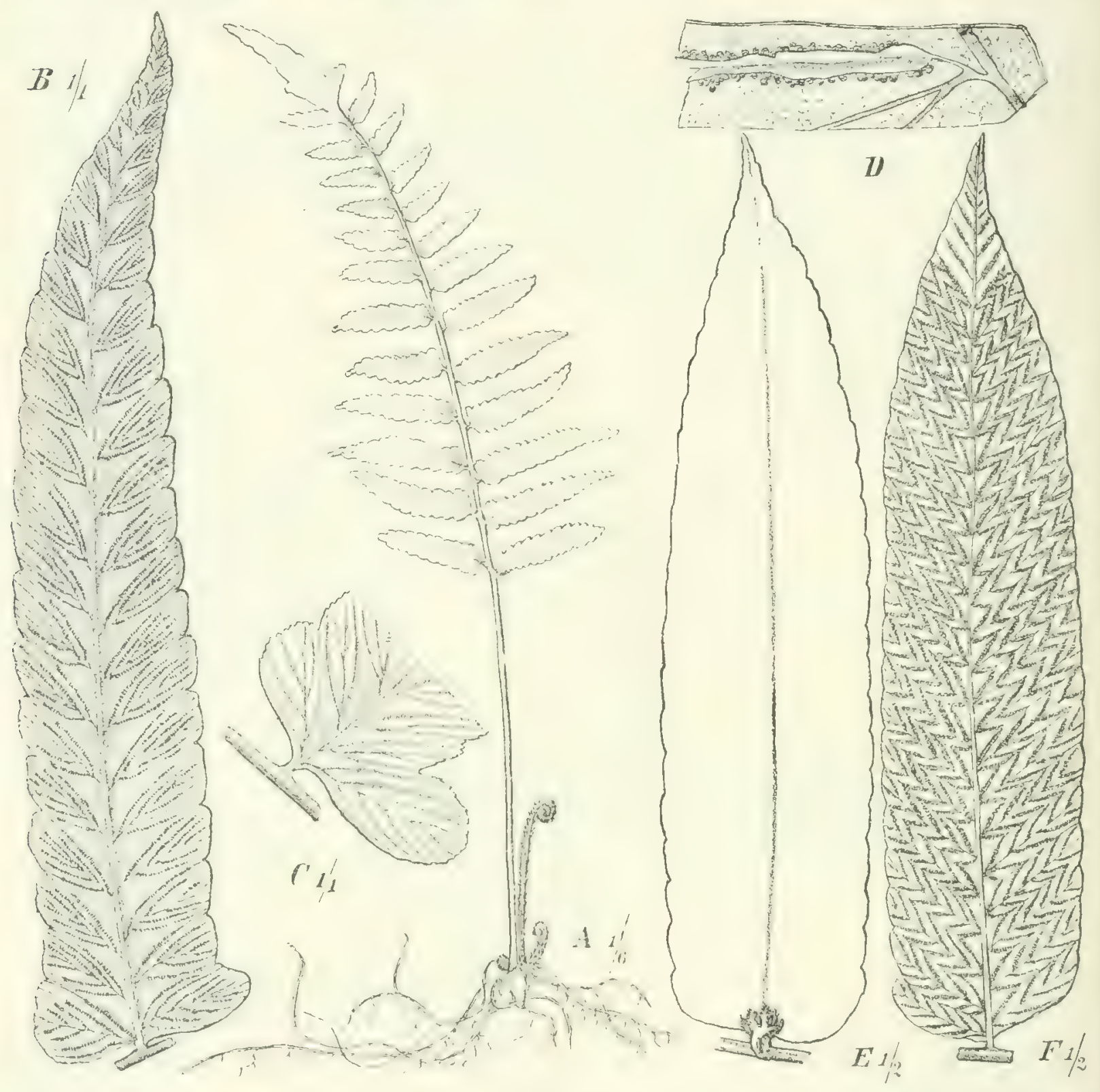

Fig. 20. A-C Diplazium silvaticum (Bory) Sw., Kamerun; $D-F$ D. proliferum (Lam.) Thou,, Kamerun.

und bis in das Ghasalquellengebiet angetroffen wird. D. prolifertm (Lam.) Thou. [ = D. dicussatum (Sw.) Christ] gehört der Sektion Callipteris an, bei welcher die Aderngruppen durch Anastomose der benachbarten Seitenadern verbunden sind; es trägt an kriechendem Rhizom bis über I m lange Blätter, welche oft Adrentivknospen bilden (Fig. $20 \mathrm{D}-\mathrm{F}$ ) und ist in den Regenwäldern des tropischen Westafrika von Oberguinea bis Kamerun verbreitet, findet sich aber auch in Ostusambara. 
Scolopendrium L. Das belannte boreale Si. anlgrum Sm. reicht nur bis Makaronesien.

Asplenium L. In dem hier behandelten Gebiet kommen etwa 75 Arten mit zahlreichen Varietäten vor. Viele sind wichtige Charakterpflanzen, auf die kurz hingewiesen sei.

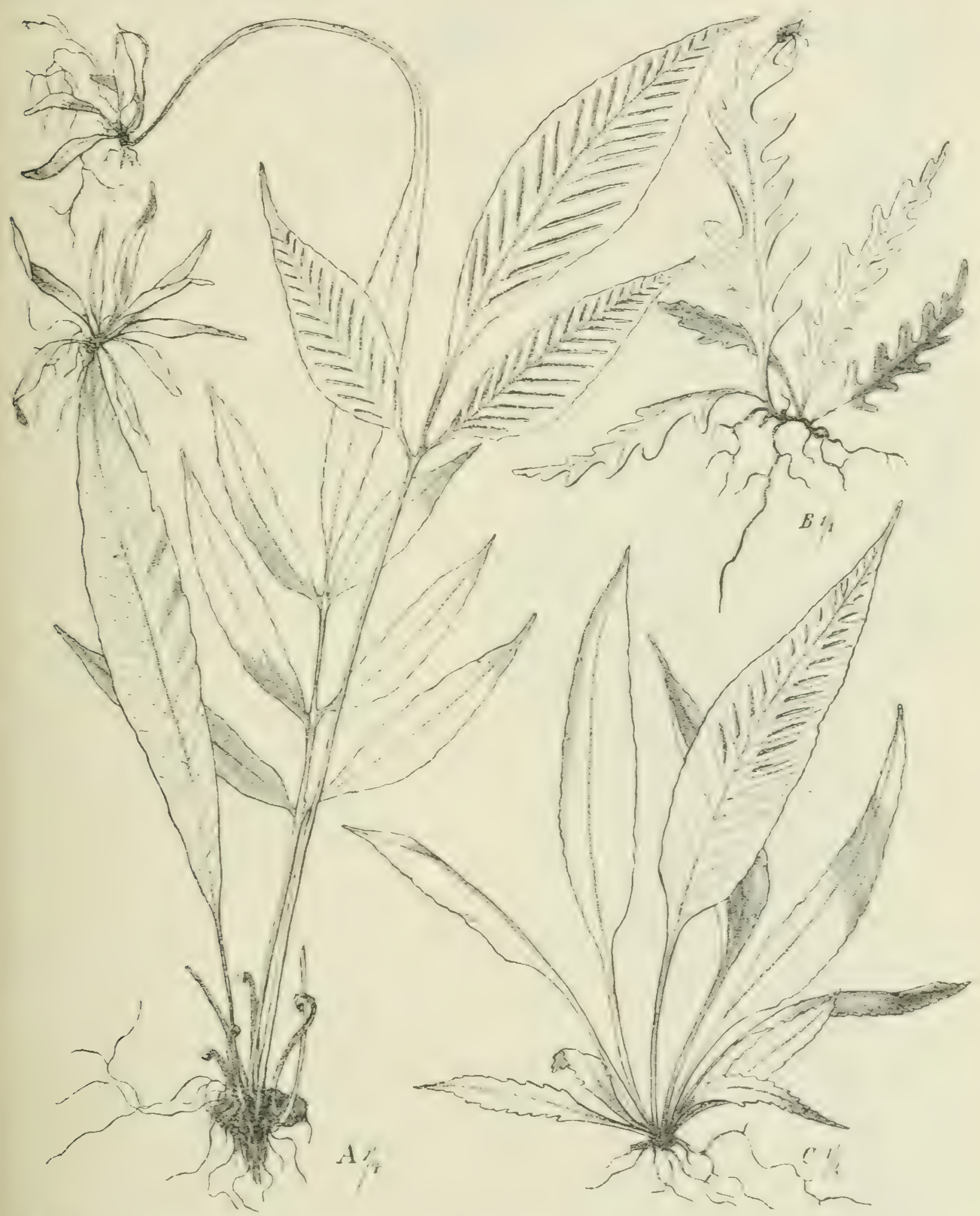

Fig.21. A Asplenium longicauda Hook., Kamerun; B, C A variabile Hook, Kamerun.

Sekt. I. Veottopteris (J. Sm.) mit ungeteilten, länglichen Blättern. - - Das in den Regenwäldern des tropischen Asiens verbreitete, an Baumstämmen, bis- 


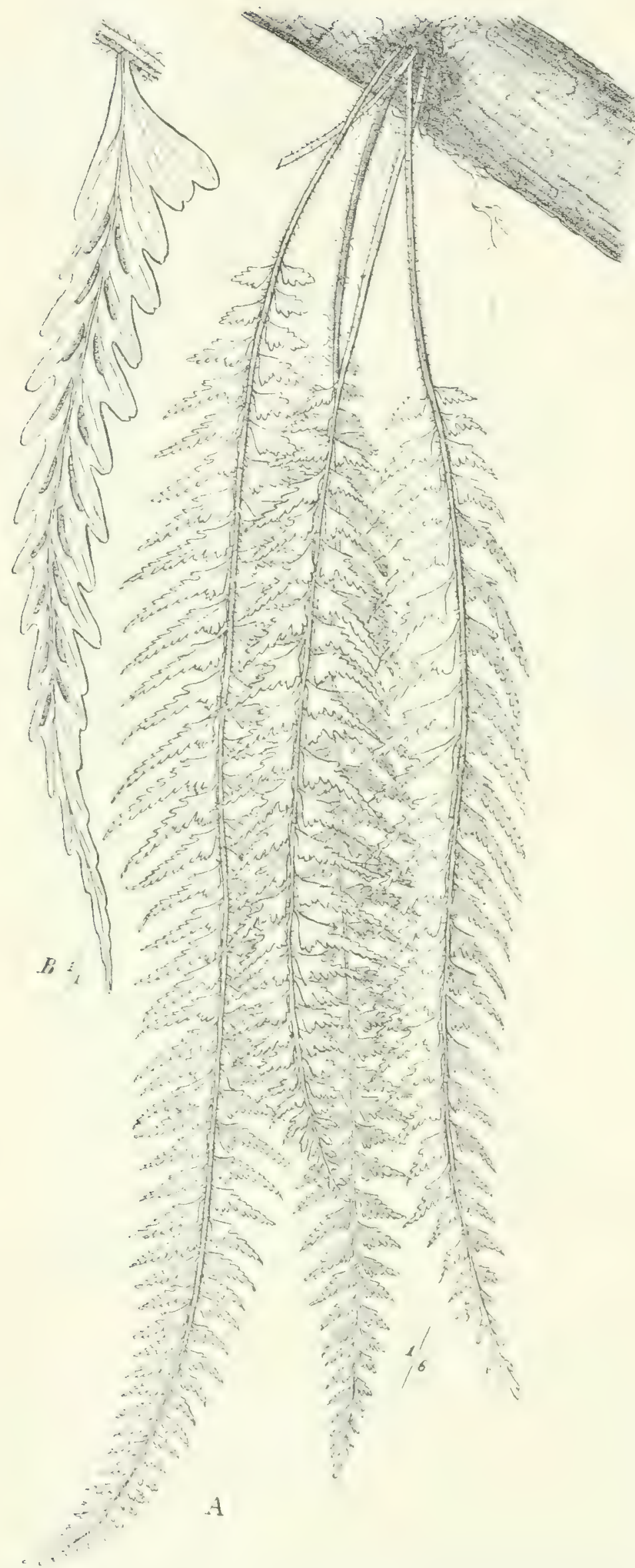

Fig. 22. $A, B$ Asplenium protensum Schrad., Usambara. weilen auch an Felsen wachsende A. nidus L. mit dicken, oft I $\mathrm{m}$ langen und bis $20 \mathrm{~cm}$ breiten Blättern ist für jedermann leicht kenntlich; es ist häufig in Usambara, Uluguru, auf den Comoren und Maskarenen, fehlt aber in Westafrika. Dort kommt im Gebiet des unteren Kongo das weniger kräftige und im tropischen Amerika verbreitete $A$. serratum L. vor, welches am Ende gesägte Blätter besitzt. Viel kleiner, aber von ähnlichem Wuchs ist $A$. simatum P. Beauv., das mir aus Westafrika, Usambara und Uluguru vorliegt. Eine recht interessante Pflanze ist das im Kamerungebiet nicht seltene, vielfach auch an Felswänden wachsende A. variabile Hook. mit fiederspaltigen Jugendblättern und lanzettlichen älteren Blättern (Fig. 2 I $B, C$ ).

Sekt.2. Euasplenium, mit einfach bis mehrfach gefiederten Blättern.

a) Blätter einfach gefiedert. - $A$. vagans Bak. auf dem Pik von San Thomé erinnert an das in den Hochgebirgen Europas verbreitete A. viride Huds. A. Kraussii Moore von Natal und das sowohl im Westen wie im Osten, bis Natal reichende, auch auf Madagaskar, den Comoren und Maskarencn in Nebelwäldern wachsende A.Sandersonii Hook. zeichnen sich durch Adventivknospenbildung an der Spitze ihrer Blätter aus. Interessant 
ist, daß das boreale A. trichomanes L. in Natal und Transvaal sich in ganz gleicher Form wiederfindet wie in Algier. Das nahestehende 4 . manthis L. können wir durch die Maldgebicte Ostafrilias rom Kapland bis Abyssinicn verfolgen, auch findet es sich auf Fernando Po. Mehrere Arten besitzen größere krautige Blätter mit länglichen oder lanzettlichen Fiedern, so 4 . linsricmle Hook. (Fig. 2 I A) vom Kamerungebirgc und das auch in Ostafrika vorkommende - I. marginatum P. Beaur, welche beide kräftige Adrentirsprosse am Ende ihrer Blattabschnitte bilden.

Ein anderer Typus zeichnet sich dadurch aus, daß die Fiedern auf der der Blattspitze zugewendeten Seite am Grunde breiter sind. Hierher gehört das ungemein formenreiche, in allen tropischen Waldgebieten verbreitete $A$. lumulatum Sw. welchem sich auch das vivipare A. Barteri Hook. von Kamerun anschließt. Auch das auf Socotra vorkommende $A$. Schueinfurthii Bak. ist hiermit verwandt, aber von lederiger, sehr xerophytischer Textur des Blattes. Durch viel größere Blätter und Fiedern zeichnet sich $A$. prionites Kze. aus, das vom Kapland bis Natal verbreitet ist. Eine recht charakteristische Art dieser Gruppe ist das häufig vivipare $A$. anisophyllum $\mathrm{Kze}$., welches mit dem tropischen Afrika als Zentrum sich westlich bis Südamerika, südlich

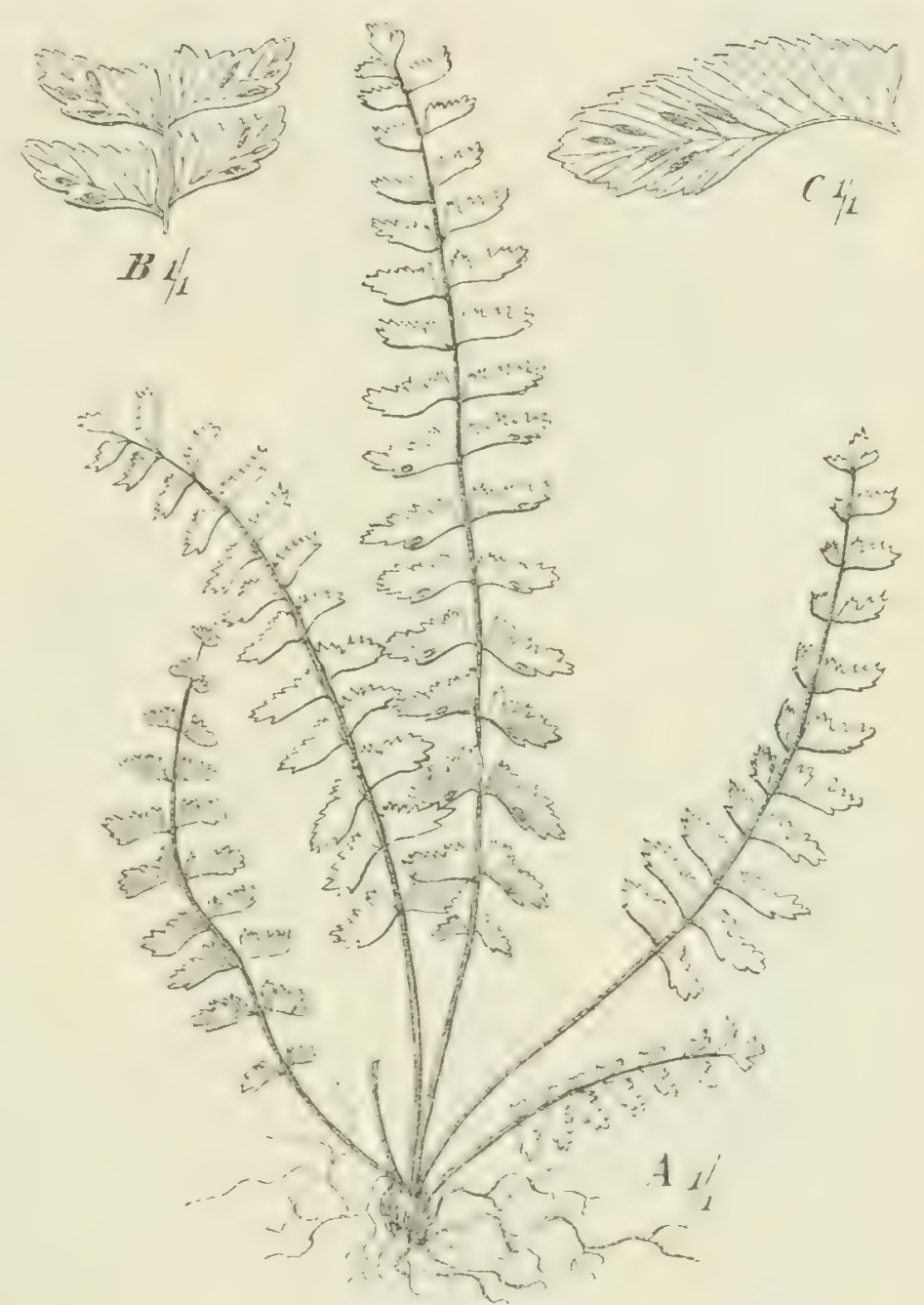

Fig. 23. A Asplenium formosum Willd, Togo;

$B$ A. pulchellum Raddi, Kamerun; $C A$. resectum J. Sm., Usambara. bis Natal, östlich bis nach den Iaskarenen hin verbreitet hat. Fast in allen Väldern Afrikas ron Abyssinien bis zum Kapland, sowie auch im Mesten tritt . frotensum Schrad. (Fïg. 22) auf, ausgezeichnet durch tief oder auch doppelt gezahnte Fiedern dur bisweilen I $m$ Länge erreichenden Blättur. - Einige Arten zeichnen sich dadurch aus, daß die Fiedern an ihrer basisliopen Seite oft his zur Hälfte reduziert sind, so die weit verbreiteten, im tropischen Afrika abcr nur im ITesten häufigen. sonst mehr beschränkten zierlichen Arten .1. pulikilmm Raddi, 1. formusm Willd. und A. resectum J. Sm. (Fig. 23).

Eine recht stattliche PHanze dieser Gruppe ist 1. Gimmifirm Schrad.. 


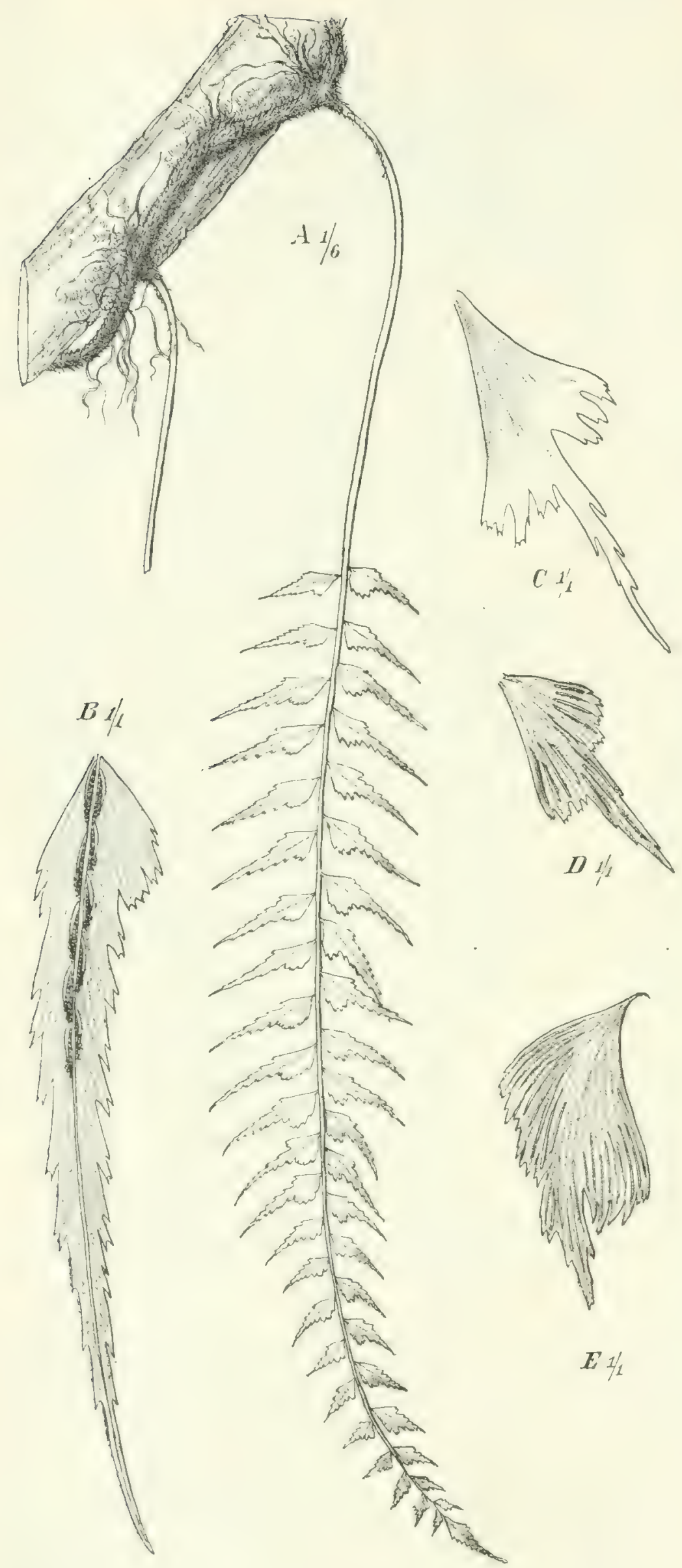

Fig. 24. $A, B$ Asplenium caudatum Forsto, Usambara; $C-E$ A. dimidiatum $\mathrm{Sw}_{\text {. }} E$ typicum vel genninum, Kamerun; $D$ var. Zenkeri Hieron., Kamerun; $C$ var, longicaudatum Hieron., Usambara. das vom deutschen Ostafrika bis zum Kapland verbreitet ist und wie so viele der ostafrikanischen Arten auch in den Bergwäldern der Comoren wiederkehrt, viviparierend und auch mit doppelt fiederteiligen Blättern vorkommt. Eine seltene, aber durch ihre Verbreitung interessante Art ist das nur etwa $2 \mathrm{dm}$ hohe, einfach und doppelt gefiederte Blätter aufweisende $A$. bipartitum Bory aus den Regenwäldern Usambaras, der Comoren, Maskarenen und Madagaskars. Am Grunde ungleichseitige etwas starre Fiedern haben $A$. serra Langsd. et Fisch. von Kamerun, A. nitens. Sw, von den Comoren und Maskarenen, A.macrophyllum Sw., ebenda vorkommend. Ihnen steht sehr nahe A. folcatum Lam. mit tief gelappten und scharf gezähnten Fiedern, in Amerika, auf San Thomé, dem Kamerungebirge und den Comoren; hierzu duirfte auch das am Kilimandscharo sowie auf den Comoren wachsende, durch tiefer eingeschnittene Blätter ausgezeichnete A. contigumm Kaulf. als Varietät zu rechnen sein, desgl. das durch lang zugespitzte Fiedern auffallende, in Usambara und 
Nordmadagaskar häufige A. combutum Forst. Fig. 2. . I, I); die herabhängenden Blätter dieser epiphytischen Pflanze erreichen oft I m Länge. Durch am Grunde breit keilförmige Blattficlern ist das im tropischen Amerika und Afrika verbreitete $A$. dimidiatum Sw. (Fig. $24 C-E$ ) leicht kenntlich. Einc der auffallendsten Arten ist 4 . Lamrintii Bommer mit abgestutzten breit kcilförmigen Fiedern, vom Kongo bis Kamerun (Fig. 25).

b) Blätter doppelt bis vielfach fiederspaltig. - Zahlreiche Arten dieser Gruppe zeichnen sich durch fächerige Aderung aus. Hierher gehört das in Europa und Asien weitverbreitete $A$. adiantum nigrum L., welches seinen Weg auch auf den Kamerunpik, sowie über Abyssinien und den Kilimandscharo nach Südafrika gefunden hat; ihm steht das auf Abyssinien beschränkte $A$. pumilum Sw. ziemlich nahe, desgleichen $A$. solidum Kze, von Natal. Leicht kenntlich ist das weitverbreitete, aber im tropischen Afrika nur zerstreut auf alten Baumstämmen vorkommende $A$. cuneatum Lam. mit sehr stark hervortretenden Adern der keilförmigen Fiederchen; das mehr in Südafrika, von Transvaal und Natal bis zum Kap vorkommende A. splerdens Kze. dürfte dazu zu rechnen sein. Eine durch längere Rhizome ausgezeichnete Art ist $A$. Goetzci Hieron. von den Ulugurubergen, aus dem Höhenwald um $2400 \mathrm{~m}$. Endlich gehört noch in diesen Verwandtschaftskreis das pantropische auch

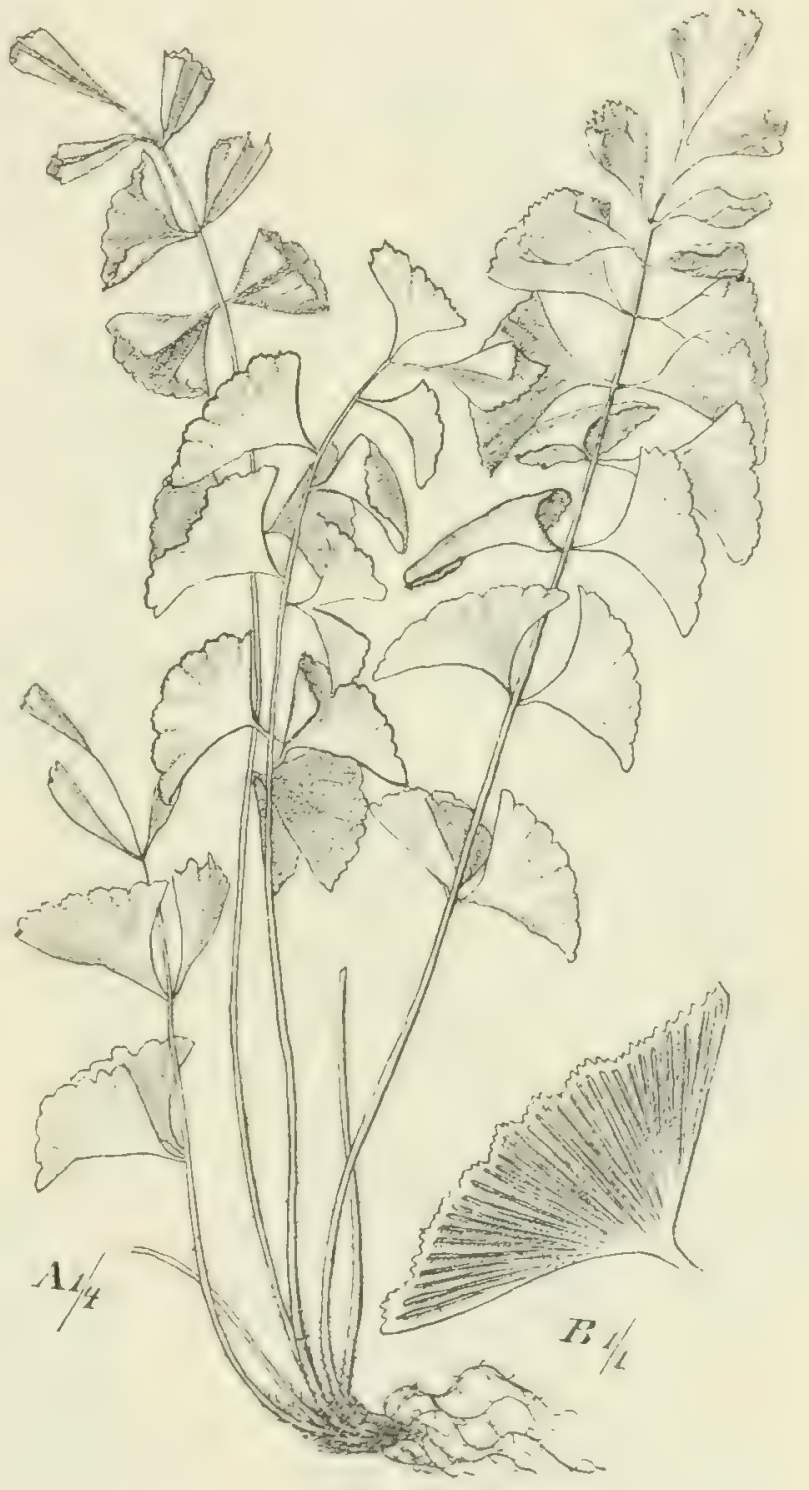

Fig. 25. Asplenium Laurentii Bomm., Kamerun. noch bis nach den Kanaren und Madera, sowie nach Abyssinien und dem südwestlichen Kapland gelanste A. promorsum Sw. (Fig. 26 B, F), welches im Gegensatz zu den vorigen mit kahlen Blattstielen versehenen Arten einen wolligen Blattstiel besitzt; es ist ebenso an Baumstämmen wie an Felsen, häufiğ zwischen Moospolstern sitzend anzutreffen. Eine im zentralafrikanischen Seengelsiet vorkommende Pflanze, welche kriechendes Rhizom und breite dreicckig eiförmige tief 3-5 lappige Fiedern besitzt, ist als 1 . Stuhlmamnii Hicron. unterschieden worden. Zwei gut unterschiedene Arten dieses Formenkreises sind dic im Bestand der livica arborea am Kilimandscharo vorkommenden 1 . Volkensii 
Hieron. (Fig. 26 C) und A. Linckii Kuhn (Fig. 26 A); letzteres findet sich auch in Vestusambara und im Gürtelwald des Kilimandscharo. - Ficderig geaderte, lanzettliche Abschnitte besitzt das im westlichen Nittelmeergebiet, dem atlantischen Europa und auch in Makaronesien vorkommende 1. luncoulatum Huds. - Ebenfalls fiederige Aderung kommt dem A. cicutarium (L.) Sw. zu, dessen Fiedern zweiter Ordnung gestielt und fast bis zur Spindel eingeschnitten sind;

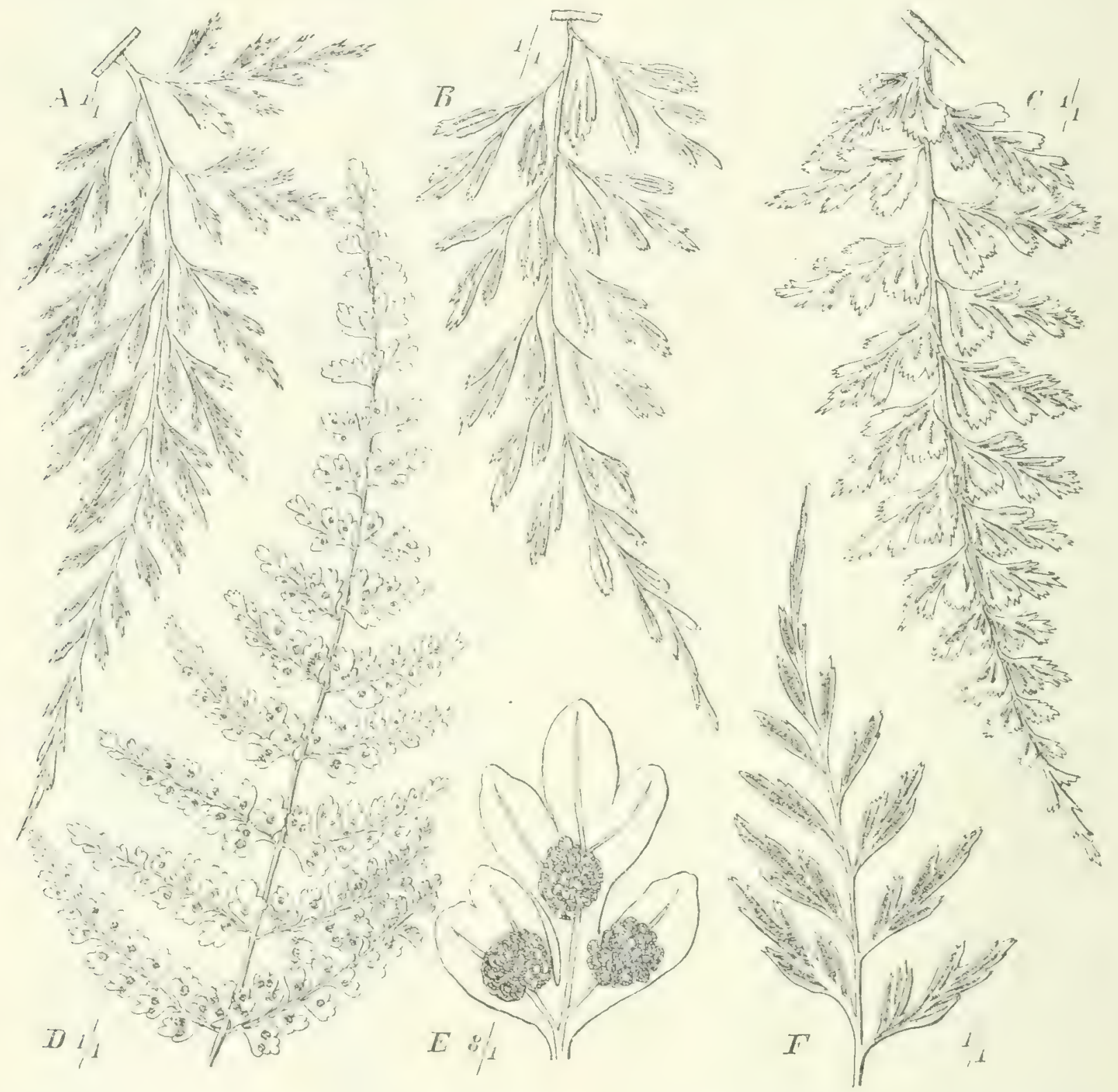

Fig. 26. A Asplenim Linkii Ǩ̉hn, Kilimandscharo; $B$ A. praemorsum Sw. var. tripinnatum Bak., Usambara; $C$ A. Volkensii Hieron., Kilimandscharo; $D, E$ A. abyssinicum Fée, Abyssinien; F A. praemorsum Sw., Usambara.

diese Pflanze ist ebenso im tropischen Amerika, wie im tropischen Afrika verbreitet. in Ostafrika rom Kilimandscharo und Usambara bis zu den Magalisbergen. Zwei schr schöne Hochgebirgsarten dieser Gruppe sind 1. Kuhnianum C. (hr. in der oberen Waldregion von Uluguru bis zum Kenia) und . al absini(unll Fíe (Fig. 26 I), F; ron Abyssinien über den Kirunga-Vulkan zu verfolgen bis zum Kamerungebirge). 
Sekt. 3. Darea Juss. Die Teilung des Blattes ist hier am weitesten vorgeschritten und die Segmente letzter Ordnung sind schmal linealisch, die Sori randständig. Hier sei zuerst erwähnt A. mtifolium (Berg.) Kze. (Fig. 27 A, B), von Usambara und dem Kilimandscharo suidwärts bis zur Kaphalbinsel, auf den Comoren. Maskarenen und Madagaskar. Zartere Blätter besitzt -1. D)rescemm Kze. (inkl. A. brachiftorm Kze.), eine zierliche Art, welche im schattigen Regenwald der Gebirge von r 200 - I $900 \mathrm{~m}$ an Bäumen und auf Felsen dichte Büschel bildet; sie ist von San 'Thomé und dem Kamerungebirge, von Angola, von Bukoba, dem Nyassaland und Madagaskar bekannt und läßt sich suidwärts bis Natal verfolgen. Eine etwas kräftigere Pflanze ist das viviparierende A. amriculatum (Thunb.) Kuhn (=A. Thunbergii Kze.) (Fig. 27 E, F), mit ziemlich demselben Areal wie vorige, aber auch in Liberia; eine vicl schwächere Pflanze dagegen ist . 1. ITammii Hook. f. von Fernando Po und dem Kamerumpik. Längere und rigidere Blätter als - amiculentm besitzt das in Ostafrika in Uluguru, Usambara und am Kilimandscharo vorkommende A. sertularioides Bak. Durch viel größere, bisweilen I $m$ lange Blätter fällt das am Boden wachsende $A$. loxoscaphoides Bak. (Fig. 27 C, D) auf, welches am Kilimandscharo im Wald von I $200-3000 \mathrm{~m}$, ferner auf dem Ruwenzori, in Kikuju, Uluguru und auf der Insel Bourbon angetroffen wird, eines der vielen Beispiele fuir die Verbreitung ostafrikanischer Hochgebirgspflanzen nach den Maskarenen und Comoren. Die weitestgchende Teilung der Blattspreite vierfach fiederteilig) zeigt 1 . hipomelas Kuhn (Davallia nigrescens Hook., Loxoscaphe n. Moore), ein prächtiger, namentlich auch an Farnböumen wachsender Epiphyt mit I m langen Blättern, in den Regenwäldern Kameruns, des Kilimandscharo, Usambaras und Ulugurus.

Sekt. 4. Loxoscaphe Moore. In den letzten Segmenten der fein zerteilten Blätter sind die Adern gegabelt. - A. concimm (Schrad.) Kuhn ( $=$ A. thecifermm (H. B. Kunth) Mett. var.) (Fig. 27 G), epiphytisch, oft hoch in den Kronen der Biume zwischen Moos sitzend, ron Abysinien und Kamerun bis zum Kapland verbreitet.

Ceterach Willd. steht der vorigen Gattung sehr nahe und ist von derselben nur durch das schwach entwickelte, nicht selten rerkiimmerte Indusium unterschieden, habituell leicht kenntlich an den cinfach fiederlappigen bis fiederspaltigen Blättern.

C. Dalhousine (Hk.) C. Chr., mit deutlichem Indusium, ist dem im Mittelmeergebiet und IVcstcuropa häufigen C. officinrmm DC. ähnlich und findet sich in Bergwaldern Abysiniens um $2100 \mathrm{~m}$, lommt auch sowic die mediterrane Art im Himalaya vor. C. auremm (Cav.) L. v. Buch ist eine prächtige, ziemlich großblattrige Art in den Lorbeerwäldern der Kanarischen Inseln. C. cordatum (Thunb.) Desv. ist eine xerophytische, an Felsen wachsende Art mit kleinen, nur 2-5 cm langen Blättern, welche von Angola und Transraal his zum Kapland und auf Réunion vorkommt.

b) Blechninae.

Blechnum L. zählt etwa I2 Arten in Afrika, mit einfach fiederteiligen Blättern. 


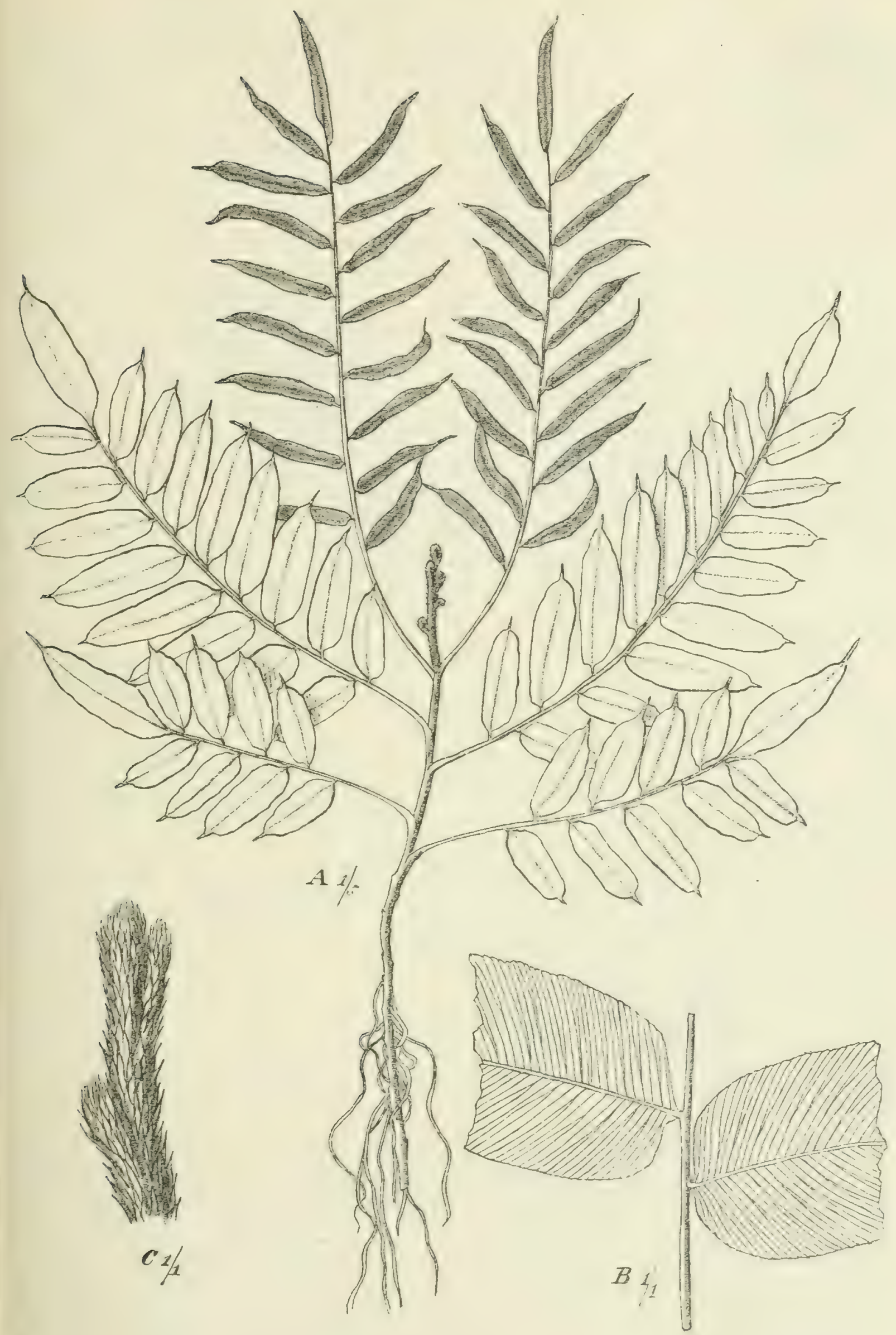

Fig. 28. Stenochlaena guineensis (Kuhn) Underwood. A ganze Pflanze; $B$ Stïck des sterilen Blattes; $C$ Ende des kletternden Sprosses. 
Sekt. I. Eublechmm Diels umfaßt Arten, bei denen die sterilen und fertilen Blïtter nahczu gleich sind. Hicrher gehört nur das rom Kapland bis Damaraland, und Transvaal, auf Madagaskar und den Maskarenen vorkommende $B$. australe L.

Sekt. 2. Lomaria (Willd.) zeichnet sich durch schmalere Fiedern der fertilen Blätter aus. Hier ist zuerst zu nennen B. attematum (Sw.) Mett., welches sich von den iibrigen Arten dadurch unterscheidet, dal3 sich die sterilen Fiedern der 0,4 - I m langen Blätter am Grunde berïhren, es ist auf der südlichen IIemisphäre weit verbreitet, rom Kapland bis Kamerun und zum Kilimandscharo, auch auf den Maskarenen. Bei den folgenden Arten sind dic Fiedern am Grunde getrennt, wie bei den von Europa bis nach Makaronesien reichenden B. spicant (L.) Wither. B. punctulatum Sw. ist eine nur auf die östlich von Kapstadt vorkommenden Wälder beschränkte mittelgroße Art. Dagegen ist B. capense (L.) Schlecht. (auch bekannt als Lomaria procera Spreng.) eine stattliche Art mit kräftigem Stamm und oft über I $m$ langen Blättern; in der südlichen Hemisphäre weit verbreitet, erstreckt sie sich vom Kapland bis Natal. Einen noch kräftigeren Stamm besitzt das auf Amerika, das südliche Afrika und Madagaskar beschrinkte T). tahulare Thunb., Kuhn, wclches wir vom Kapland bis Uluguru verfolgen können; es liebt etwas sumpfige Stellen im Walde.

Stenochlaena J. Sm. umfaßt Arten mit oft einige Meter hoch kletterndem Rhizom. St. gnimeensis (Kuhn) Underw. (Fig. 28) hat einfach gefiederte fertile Blätter, welche nur halb so groß als die sterilen sind; sie wächst in allen tropischen Valdgebicten, in Afrika von Kamerun bis Usambara. Dieser Art entspricht im südüstichen Afrika (an sumpfigen Stellen des Küstenwaldes im Pondoland und Natal, Usaramo und auf den Comoren) St. temifoliu (Desv.) Moore mit doppelt gefiederten fertilen Blättern.

Woodwardia Sm. Die bekannte, mehr subtropische, auf der nördlichen Hemisphäre weit verbreitete $W$. radicans (L.) Sm. findet sich häufig in der Nebelwaldregion der Kanarischen Inseln. wo sie oft Felswände und lehmige Abhänge bekleidet.

VI. Pterideac. Längliche Sori der Sporangien längs der Adern, an deren Enden oder einer ()ueranastomose, meist ohne Indusium, aber häufig vom umgeschlagenen Blattrand bedeckt. Blätter vom Rhizom ungegliedert abgehend.

Meist Hygrophyten; aber auch Xerophyten und Mesophyten.

Diese Gruppe enthält viele Gattungen, die nur wenig Arten umfassen neben einigen artenreicheren, deren Arten schwerer zu erkennen sind.

\section{Übersicht über die in Afrika vertretenen Gattungen.}

A. Sori die gesamten Adern einnehmend

Gymnogramminae.

a) Aderung der Segmente fächerig oder wenigstens mehrmals dichotom. Adern frei. Spreuhaare.

r) Blätter kahl

Adenogramme.

; Plätter \pm behart

Gymnogramme. 
b) Aderung der Segmente fiederig (selten fächerigł. Sprevihare oder Spreuschuppen.

(e) Blätter kahl.

Coniogramme.

ß) Blätter behaart

Ceropteris.

B. Sori den Vorderteil der Adern einnehmend, von dort zuweilen zusammenfließend oder sich rïckwärts ausbreitend. Blattstiel oft schwarz poliert . . . . . . Cheilanthinae. a) Alle Blätter gleichgestaltet.

(e) Adern am Ende kaum verdickt.

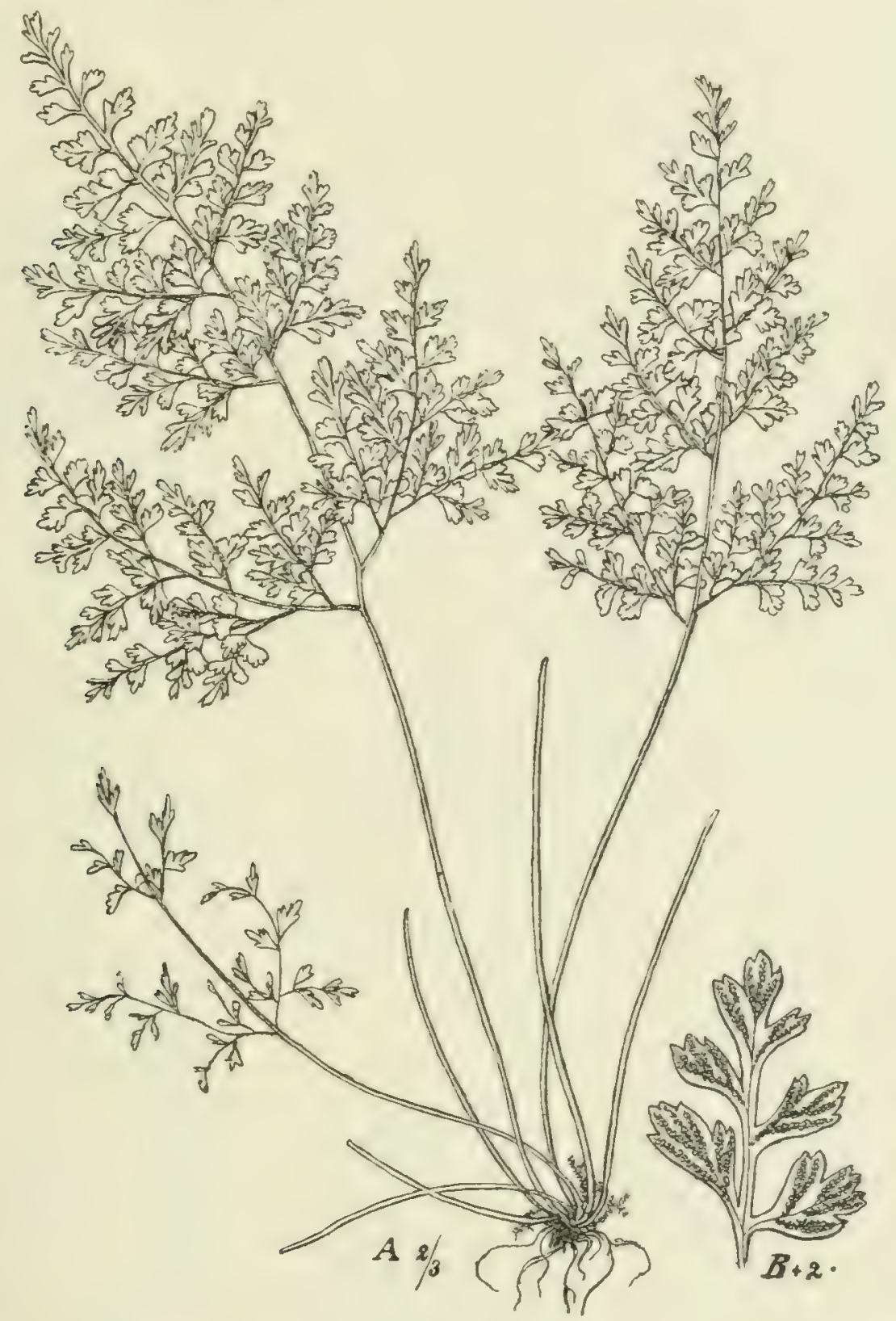

Fig. 29. Gymnogramme argentea (Bory) Mett. var, aurea (Bory) Mett.

I. Blattrand umgeschlagen, oft modifiziert, Fiedern fast gleichseitig.

I. Fiedern gegliedert-gestielt . . . . . . . . . . . Pellaea.

2. Fiedern nicht gegliedert-gestielt. . . . . . . . Doryopteris.

II. Blattrand kaum umgeschlagen. Spreuschuppen . . . . . Nothochlaena.

B) Adern am Ende verdickt.

I. Blattrand überall \pm umgeschlagen. . . . . . . . . Cheilanthes.

II. Blattrand nur über dem buchtenständigen Sorus als Decklappen umgeschlagen.

b) Blätter dimorph

Hypolepis.

Cryptogramme. 
C. Sori das Ende der Adern innerhalb der umgeschlagenen Randlappen einnehmend, zuweilen auf das Parenchym übergreifend. Blattstiel schwarz poliert. Fiedern meist akroskop gefördert.

Adiantinae. Adiantum.

D. Sori auf intramarginalem Verbindungsstrang der Adernenden. Blattstiel selten schwarz poliert. Blattsegmente selten akroskop gefördert

Pteridinae. a) Extrorses Indusium fehlend.

r) Blätter mehrfach dichotom verzweigt

Actiniopteris.

3) Blätter nicht mehrfach dichotom, meist gefiedert.

I. Sinus der Blatteinschnitte steril.

I. Sporen kugelig tetraedrisch .

Pteris.

2. Sporen bilateral.

Histiopteris.

II. Sinus der Blatteinschnitte fertil

Lonchitis.

b Extrorse: Indusium rorhanden .

Pteridium.

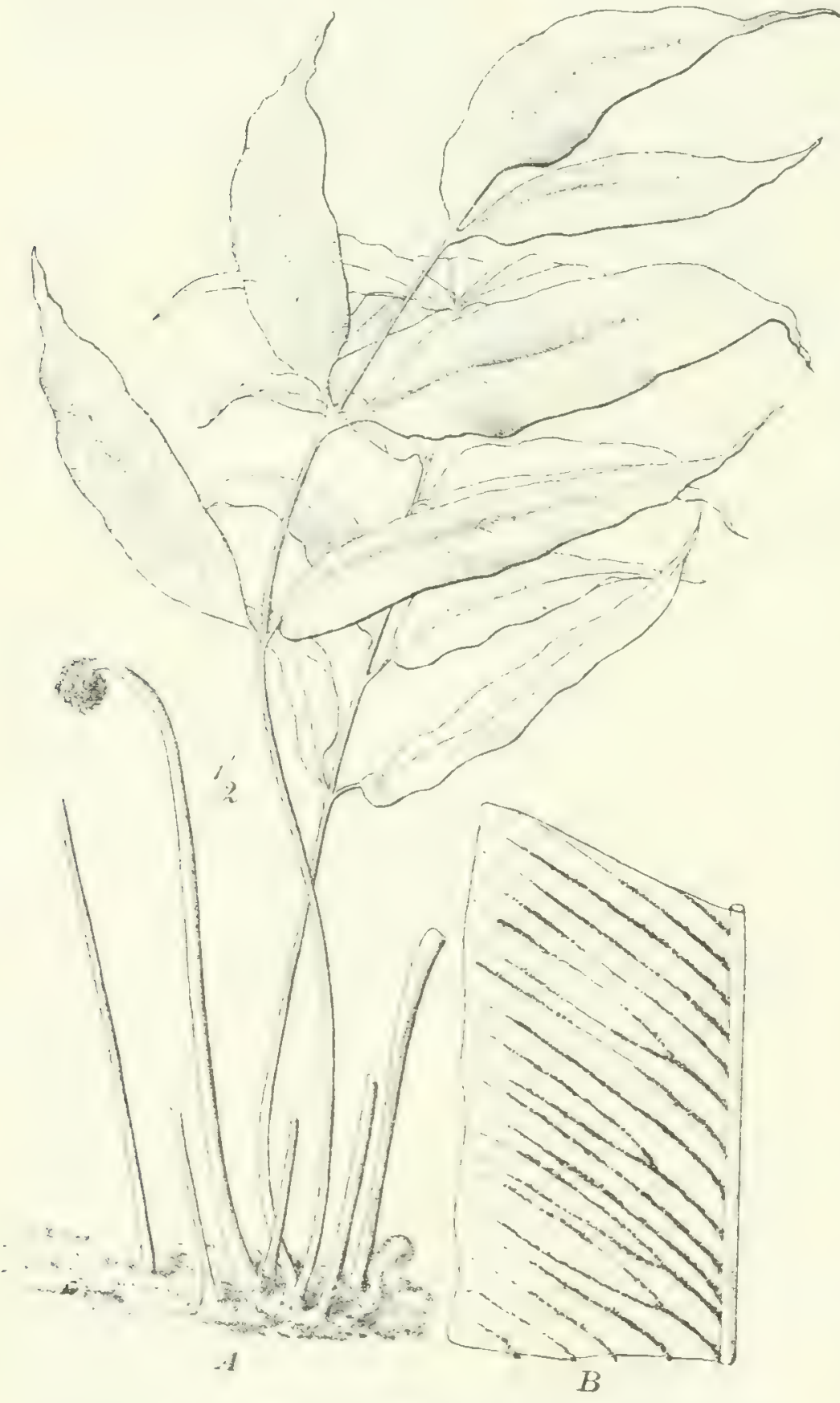

Fig. 30. Coniogramme fraxinea (Don) Diels, Kamerun.

A Habitus; f' 'leil der Hälfte einer Fieder mit Aderung und jungen Soris. a) Gymnogramminae. Meist Hygrophyten, auch Mesophyten.

Adenogramme Link. Die im Mittelmeergebiet und imatlantischen Europa verbreitete $A$. leptophylla (L.) Link findet sich auch an feuchten schattigen Plätzen in Makaronesien und Abyssinien (2 I00 bis $3500 \mathrm{~m}$ ), ferner im Kamerungebirge, am Kilimandscharo und in Kapstadt. Wir sehen bei dieser Art auch, wie in manchen anderen Fällen, daß die afrikanischen Hochgebirge Zwischenstationen für die Pflanzenwanderung vom

Mediterrangebiet nach dem südlichsten Afrika bilden.

Gymnogramme Desv. Nur eine sehr zierliche und auffällige Art, $G$. argentea (Bory) Mett., mit unterseits von mehlartigem Wachsüberzug, weiß, hellrosenrot oder gelb gefärbten, dreifach fiederspaltigen Blättern, an feuchten schattigen 
Plätzen von Natal und Transvaal zum Nyassaland, Angola und Kamerun (Fig. 29).

Coniogramme Fée. Nur eine Art, C. fraxince (Don) Diels mit schr großen bis $2 \mathrm{~m}$ langen, einfach gefiederten Blättern mit lanzettlichen Fieclern, verbreitet im tropischen Asien und Polynesien, in Afrika nur in den Regenund Nebelwäldern Kameruns von I000-3050 m (Fig. 30).
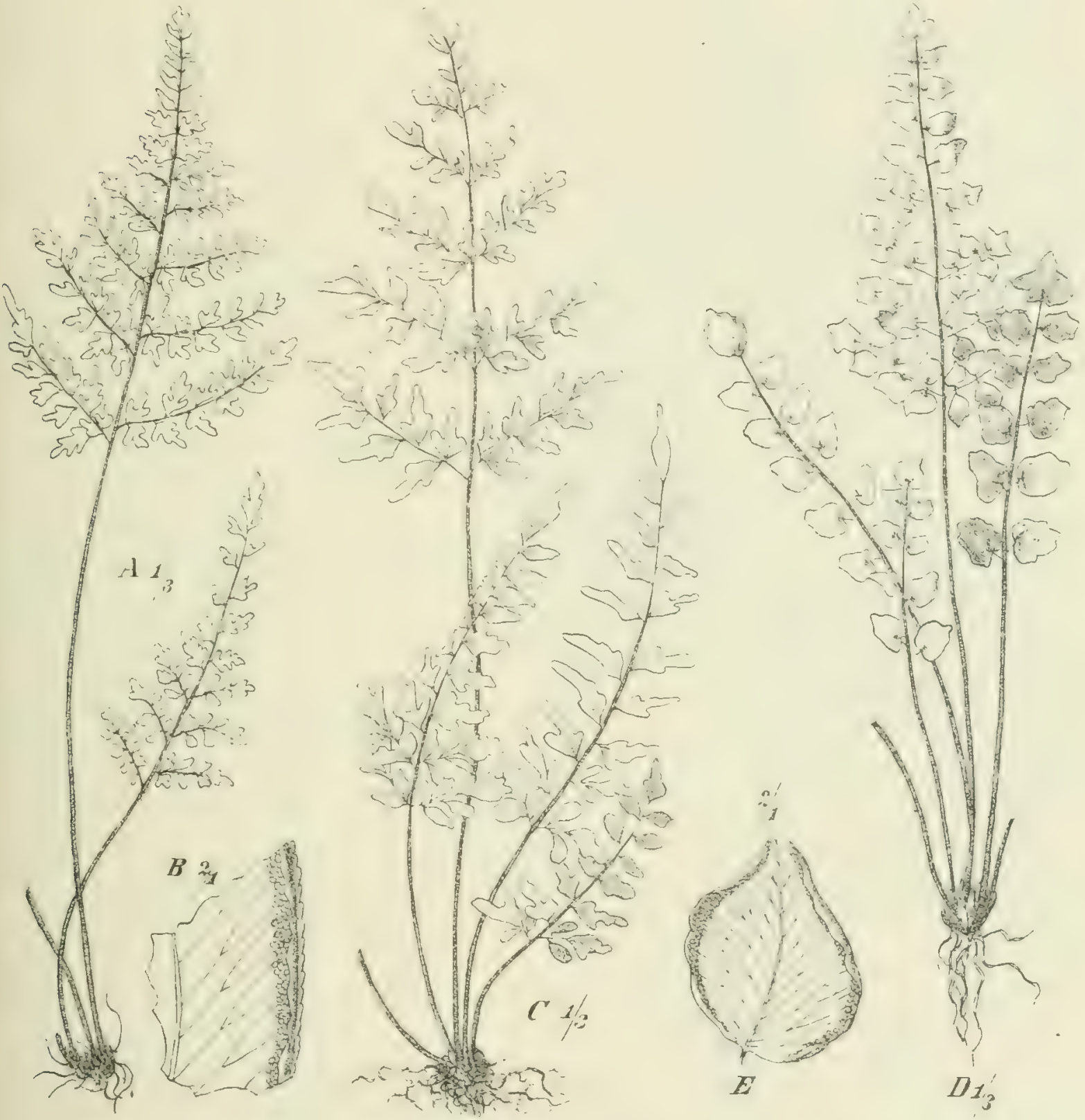

Fig. 3I. $A, B$ Pellaea adiantoides (Desv.) Prantl, Damaraland, Okahandja und Kunene, bei Katumba, $\mathbf{1} 350 \mathrm{~m} . C$, P. viridis (Forsk.) Prantl, Usambara, Nguelo; D, E. P. hastata (Thunb.) Prantl, Okahandja, Felsen $1450 \mathrm{~m}$.

Ceropteris Link. Die im tropischen Amerika verbreitete C. calomilanes (L.) Underw., welche längliche, einfach gefiederte Blätter mit auf der Unterseite reichlich vorhandenen Wachs ausscheidenden Driisenharen besitzt, ist auch nach den westafrikanischen Inseln gelangt. 
b) Cheilanthinae. Meist Xerophyten, seltener Hygrophyten.

Pellaea Link. In Afrika finden sich nur Arten der auch auf den Inseln des indischen Ozeans und in Vorderindien vertretenen Sekt. P'terildlla sowie der auch nach Brasilien übergreifenden Sekt. Pteridellastrum; fast alle sind

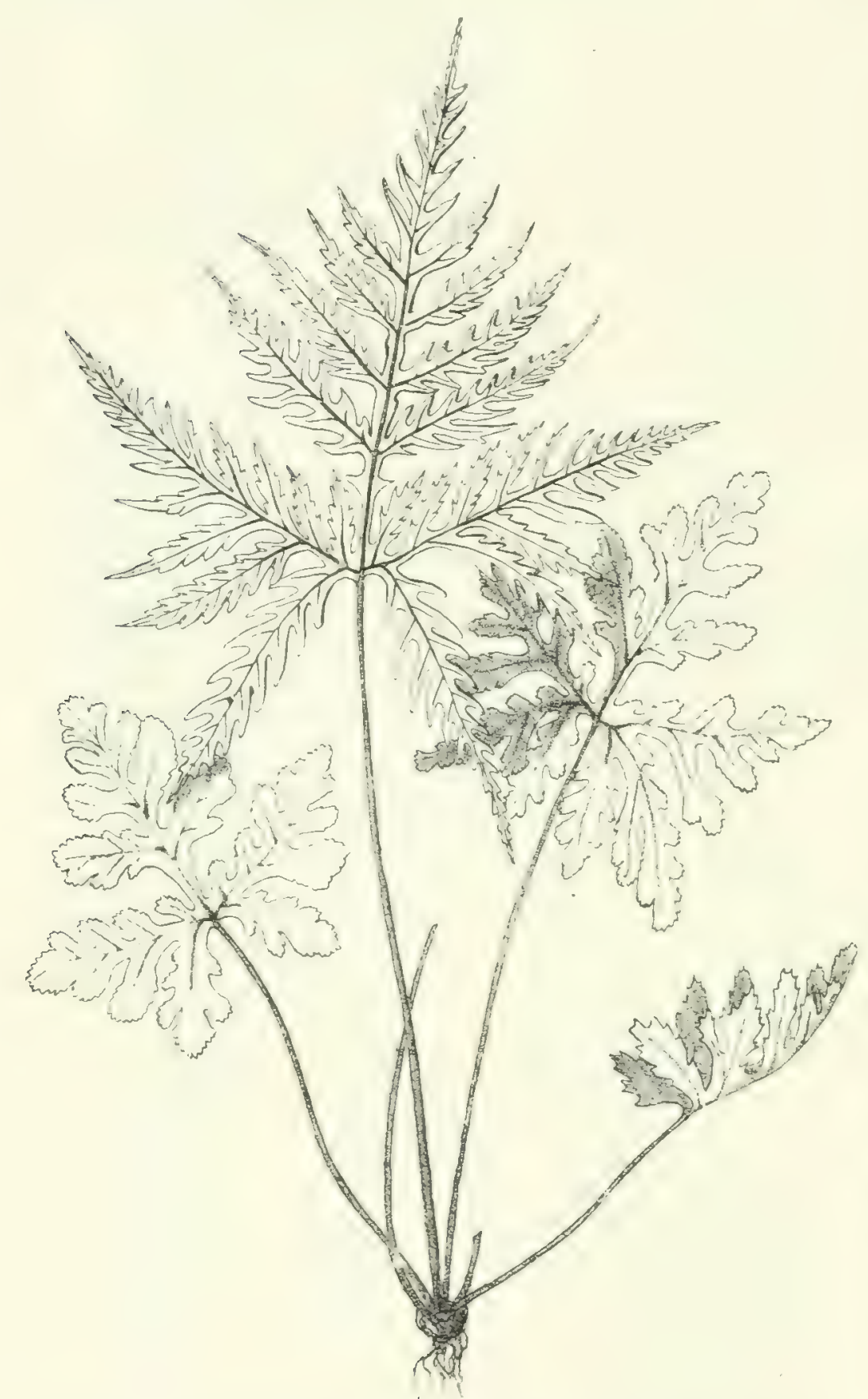

Fig. 32. Doryopteris concolor (Langsd. et Fisch.) Kuhn, Usambara.
Felsenbewohner, sehr viele xerophytisch.

Sekt. I. Pteridella Kuhn. P. Doniana (J. Sm.) Hook. mit einfach gefiederter Spreite, ist verbreitet von Abyssinien bis Togo, Kamerun und zum Sofala-GazaLand, auch auf den Seychellen; ihr nahe steht $P$. Schueinfurthii Hieron., mit behaarten Blättern und Maschen bildenden Adern, an sonnigen Felsen des zentralafrikanischen Seengebietes, Usambaras und Ulugurus. Ihr entspricht im südlichen Nyassaland (Mount Zomba), auf den Comoren und Maskarenen $P$. dura (Willd.) Bak. Gedreite untere Fiedern besitzt die in der

Gebirgsbuschsteppe

West-Usambaras vorkommende $P$. Holstii Hieron. Alle diese Arten haben diarche Leitbündel im Blattstiel, die folgenden dagegen triarche: P. Goudotii(Kze.) C. Chr., mit einfach gefiederten Blättern und schmalzungenförmigen Fiedern ist leicht kenntlich und rom Tanganyika-See und dem Matengo-Hochland suidwärts his Natal an schattigen Felsen zerstreut, auch auf den Comoren. P. hastata (Thunb.) Prantl (P. calonelanos (Sw.) Link, Fig. i I ), I: mit doppelt his dreifach gefiederten lederigen und blaugrinen likitern und breitun, dreicckigen oder herzfömigen Fiedern ist aus- 
gesprochener Xerophyt, an trockenen Felsen ran Abyssinien his zum Kapland. P. adiantoides (Desv.) Prantl (Fig. 3 I $A, B$ ), nähert sich der vorigen und findet sich von Usambara bis Transvaal, in Benguela und Damaraland.

Sekt. 2. Pteridellastmum Prantl. Hierher gehört $P$. auriculata (Thunb.) Fée, besitzt dünne, einfach oder doppelt gefiederte, in der Trockenzeit absterbende Blätter mit ununterbrochenem Deckrand, ziemlich häufig im südwestlichen Kapland. Daselbst kommt auch die stattliche $P$. ptcroides (L.) Prantl mit drei- bis vierfach gefiederten, langgestielten, bis $7 \mathrm{dm}$ langen Blättern vor. Ferner ist im Kapland auch $P$. viridis (Forsk.) Prantl (Fig. 30 C) anzutreffen, eine ebenfalls schr kräftige, bisweilen fast $\mathrm{I} \mathrm{m}$ hohe Pflanze mit einfach oder doppelt gefiederten. Blättern und Paraphysen zwischen den Sporangien; sie ist vom Kap verbreitet durch ganz Ostafrika bis Abyssinien, findet sich auch im Kamerungebirge um $2000 \mathrm{~m}$ und auf den Kapverden. Endlich ist P. quadripimnata (Forsk.) Prantl mit drei- bis vierfach gefiederten Blättern zu erwähnen, welche der vorigen Art sehr nahe steht und von der Knysna über Transvaal und das südliche Nyassaland durch Usambara nach Abyssinien verbreitet ist; sie wächst in der Knysna in Waldlichtungen in Ostafrika, an trockenen Gebirgsabhängen.

Doryopteris J. Sm. ist in

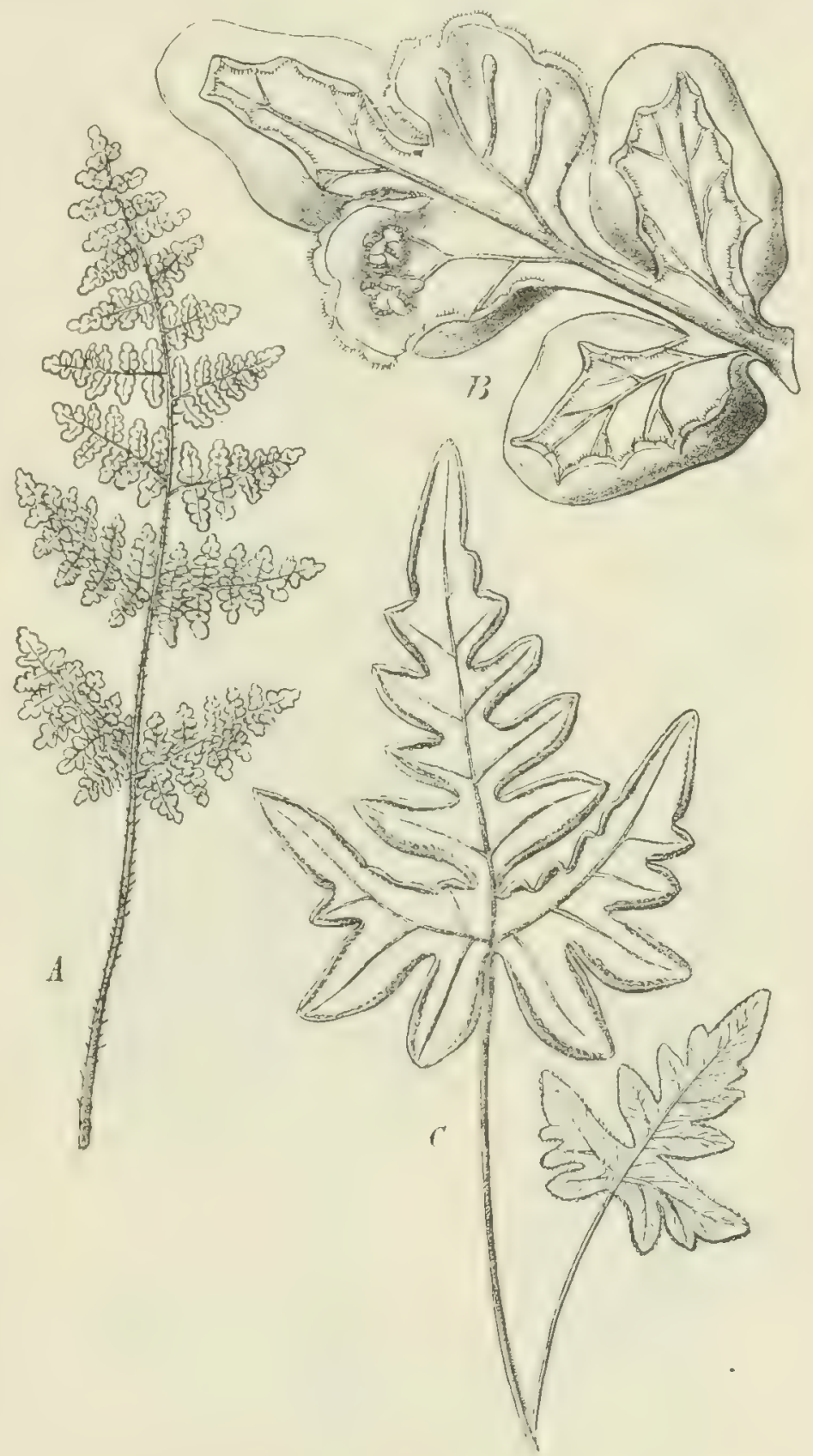

Fig. 33. $A, B$ Cheilanthes fragrans (L.) Webb., Makaronesien. $C$ Ch. farinosa (Forsk.) Kaulf., Ostafrika.

Afrika nur durch die in den tropischen und einigen subtropischen Ländern weit verbreitete $D$. concolor 'Langsd. et Fisch.' Kuhn (Fig. 321 vertreten, deren im Umriß dreieckige, dreifach-fiederspaltige Blätter mit denen eines Geranium verglichen werden können; sie wächst auf feuchten Felsen in Regenwäldern und auch an trockenen Standorten von Abyssinien bis Uitenhage, im Westen von Kamerun bis zum Damaraland. 
Nothochlaona R. Br. Von den in Afrika vorkommenden Arten ist die eine die auch aus Südeuropa bekannte $N$. marantae (L.) R. Br., welche auch auf den Kanarischen Inseln und in Abysinien von $2100-3200 \mathrm{~m}$ vorkommt. Nur als Varietät dieser Art möchte ich N. Eckloniana Kze. ansehen, bei welcher die untersten Fiedern r. Ordnung länger und hasiskop gefördert sind; sie ist rom Kapland bis zum Livingstone-Gebirge (2100 mi und bis Benguela verbreitet, namentlich auch im Hereroland; möglicherweise ist sie die Stamm-

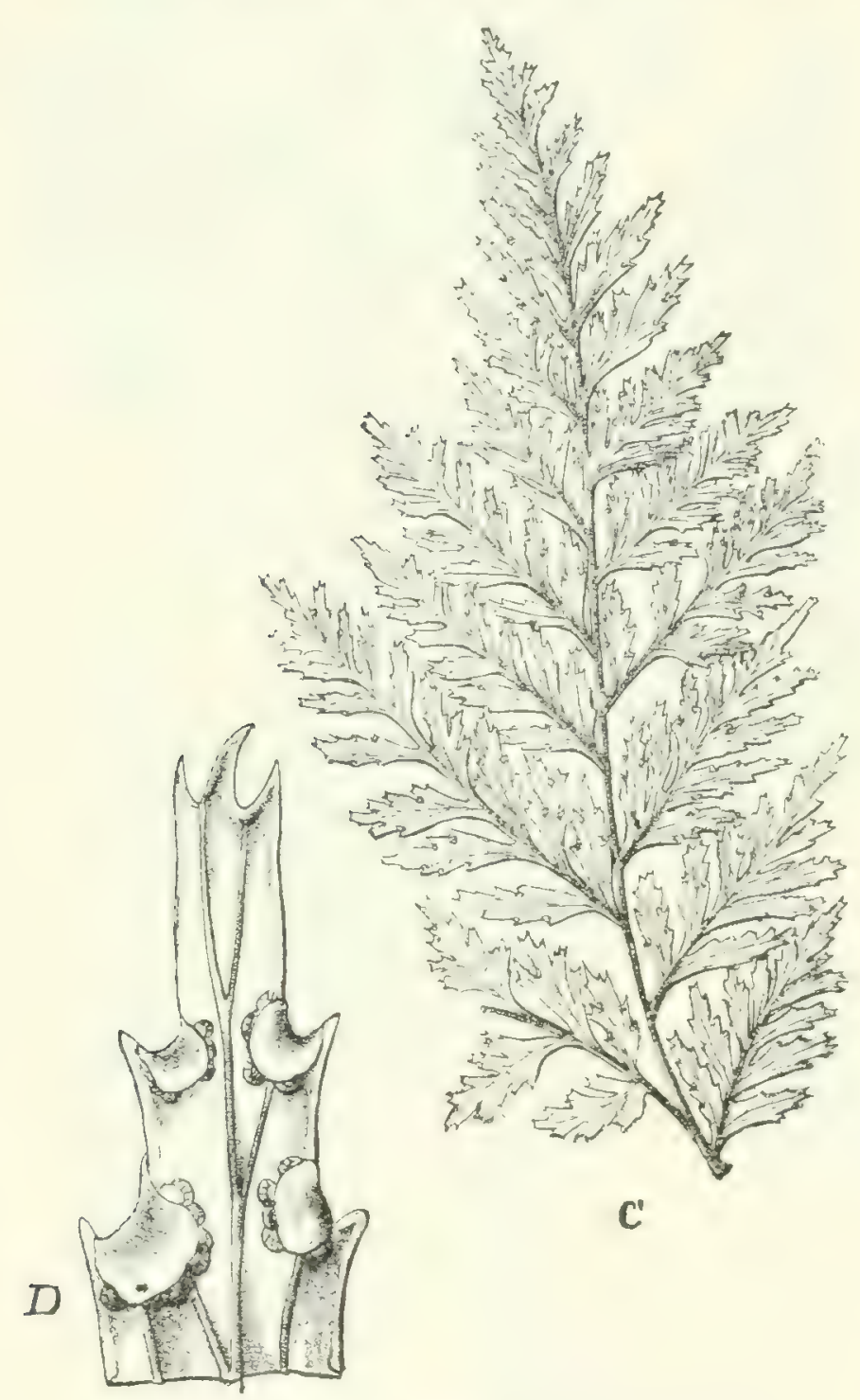

Fig. 34. Hypolepis Schimperi (Kze.) Hook. $C$ untere Fieder; $D$ Teil eines Segmentes. pflanze der $N$. marantac. Eine Schwesterart ist auch $N$. incequalis Kze,, bei welcher die Blätter beiderseits dicht behaart, nicht beschuppt sind; sie ist von Angola bis in das südöstliche Kapland zerstreut an trockenen Felsen. Ziemlich auffallend erscheint durch sehr kurze. Fiedern I. Ordnung N. Razesoni Pappe, welche im Hereroland bei Aus vorkommt. An diese Arten schließt sich auch N. lanuginosa (Desf.) Desv. an, die in Makaronesien vorkommt und fast sitzende ovale Blätter besitzt. Am meisten weicht von allen genannten ab $N$. Buchananii Bak. durch langgestielte, breit dreieckige Blätter; sie liebt etwas feuchte Felsen in Natal und dem Pondoland.

Cheilanthes Sw. ist eine in Afrika reich entwickelte Gattung, deren Arten einander auch recht nahe stehen und ähnliche Beziehungen aufweisen wie die von Nothochlaena.

Sekt. I. Eucheilanthes Hook. Deckrand der Fiedern meist unterbrochen, letzte Segmente nicht rund und konvex. a Arten mit länglichen, beiderseits verschmälerten Blättern. Ch. fragrans L. Mehb et Berth., Fig. 33 -1, B') erstreckt sich rom Mediterrangebiet ostwärts bis Kashmir, westwärts nach Makaronesien. Ihr entspricht in Suidafrika von Angola bis zum Kapland Ch. hirte Sw, deren Blitter bisweilen o, 5 m lang werden; sie wächst an etwas feuchteren und trockenen, felsigen Standorten und variiert sehr in der Teilung der Spreite, so zeigen einen besonders großen Gegensatz die Formen Natals und Litenhages gegenuiber denen der Karroo und der Kapländischen Gebirge. 
Durch unterseits wachsgelben Überzug der bis o; $m$ langen Blätter zeichnet sich die in den Gebirgen von Benguela zwischen 1000 und $2000 \mathrm{~m}$ verbreitete Ch. Triaritschii Hook. aus. - b) Arten mit schmal dreicckigen Blättern: Ch. pulchella Bory auf den Kanarischen Inseln entspricht der licineren von Südarabien durch das Somalihochland bis Abyssinien vorkommenden $C h$. coriacea Decne. $\quad(=C h$. arabica Decne.). Ch. multifida Sw. mit drei- bis vierfach fiederspaltiger Spreite ist häufig an Felsen vom sw. Kapland bis Usambara und Angola. - Von diesen fast kahlblätterigen Arten unterscheidet sich durch unterseits mit weißem Wachsuiberzug versehene Blätter $\mathrm{Cl}$. farinosa (Forsk.) Kaulf. (Fig 33 C), von Abyssinien über den Kilimandscharo und Usambara bis zu den ViktoriaFällen des Sambesi und Angola, auch auf Socotra, den Comoren und Maskarenen; sie ist eine hygrophile Art, welche aus etwas feuchteren Plätzen der Gebirgsbuschregion bis in die Nebelregion der Hochgebirge. (3000 m) aufsteigt.

Sekt. 2. Physapteris Presl. Deckrand über den Soris einen geschlossenen Ring bildend; die letzten Segmente sehr klein, rund und konvex. Hierher gehören nur zwei kapländische

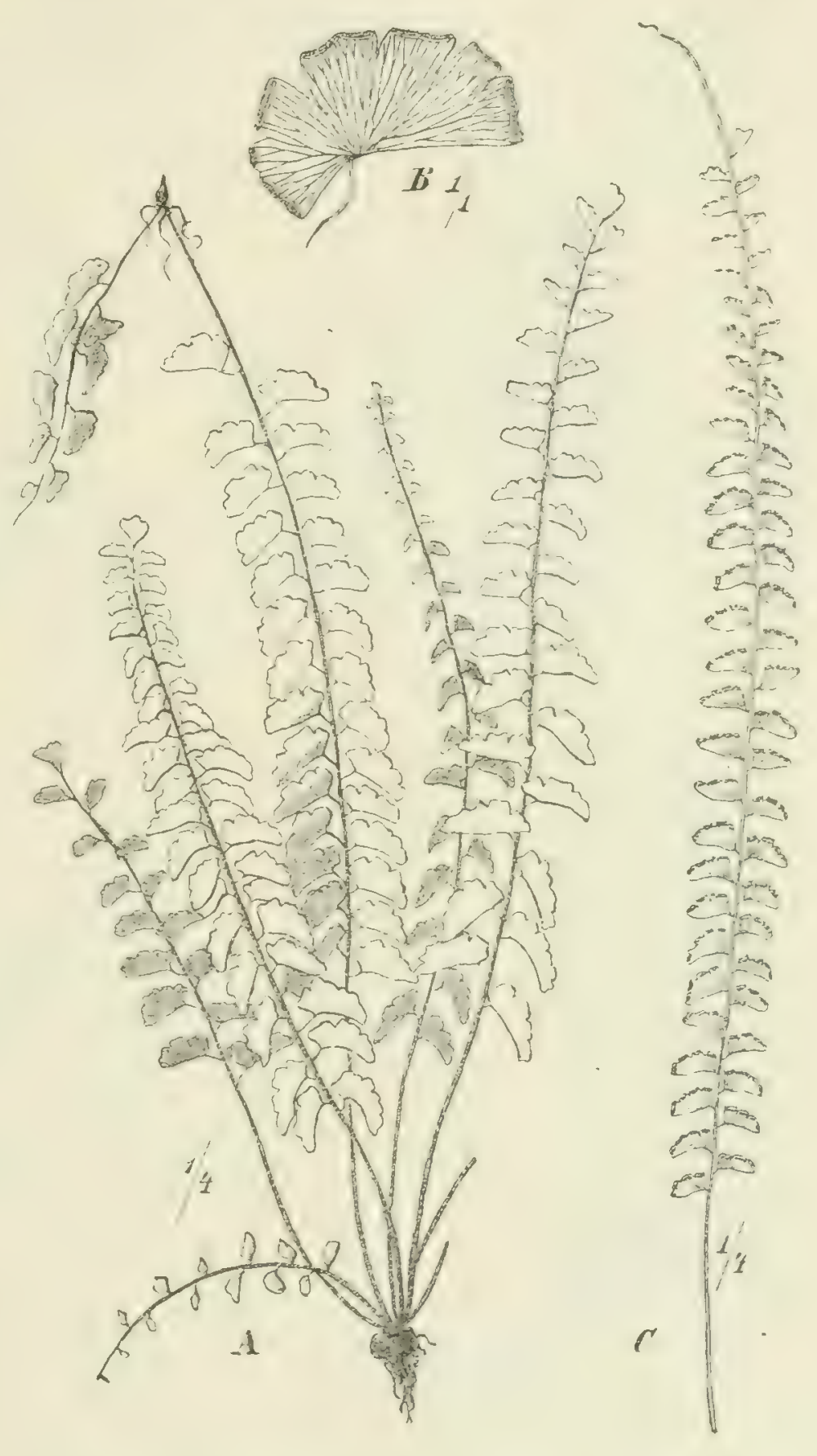

Fig. 35. Adiantum lunulatum Burm., Kamerun. Arten, Ch. indutc Kze. im nordwestlichen Kapland und Ch. Folusiz Bak. im westlichen Kapland.

Hypolepis Bernh. Nur wenige Arten kommen in Afrika vor, zunächst H. Burgiana (Schlecht.) Hook. mit nicht kriechendem Rhizom und bis über I $\mathrm{m}$ langen vierfach fiederspaltigen Blïttern, in feuchten Wäldern vom Kapland durch Natal bis zum Sambesi und Usambara. Dagegen haben die beiden fol- 
genden Arten kriechende Rhizome: H. Schimpari (Kze.) Ilook. (Fig. 34) mit höchstens $0,4 \mathrm{~m}$ langen, rotgestielten Blättern, gern unter Felsen wachsend, vom nördlichen Abyssinien bis zum Nyassaland. H. anthriscifolia Presl, eine riesige Art mit oft über $3 \mathrm{~m}$ langen und $\mathrm{I}, 5 \mathrm{~m}$ breiten Blättern, in Regenwäldern von Fernando Po, Natal und den Maskarenen.

Cryptogramme R. Br. C. melanolepis (Dec.) Prantl ist nur in Abyssinien (Abhänge am Tacaze bei Djeladjeranne, im Ssoturba-Gebirge und auf Socotra

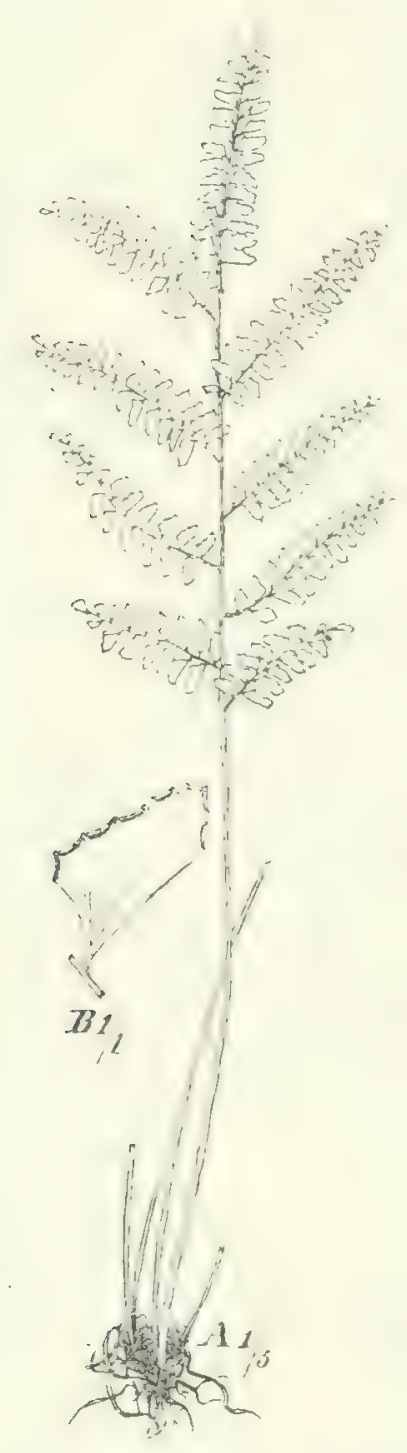

Fig. 36. Adiantum tetraphyllum Humb. Bonpl.; Willd., Kamerun.

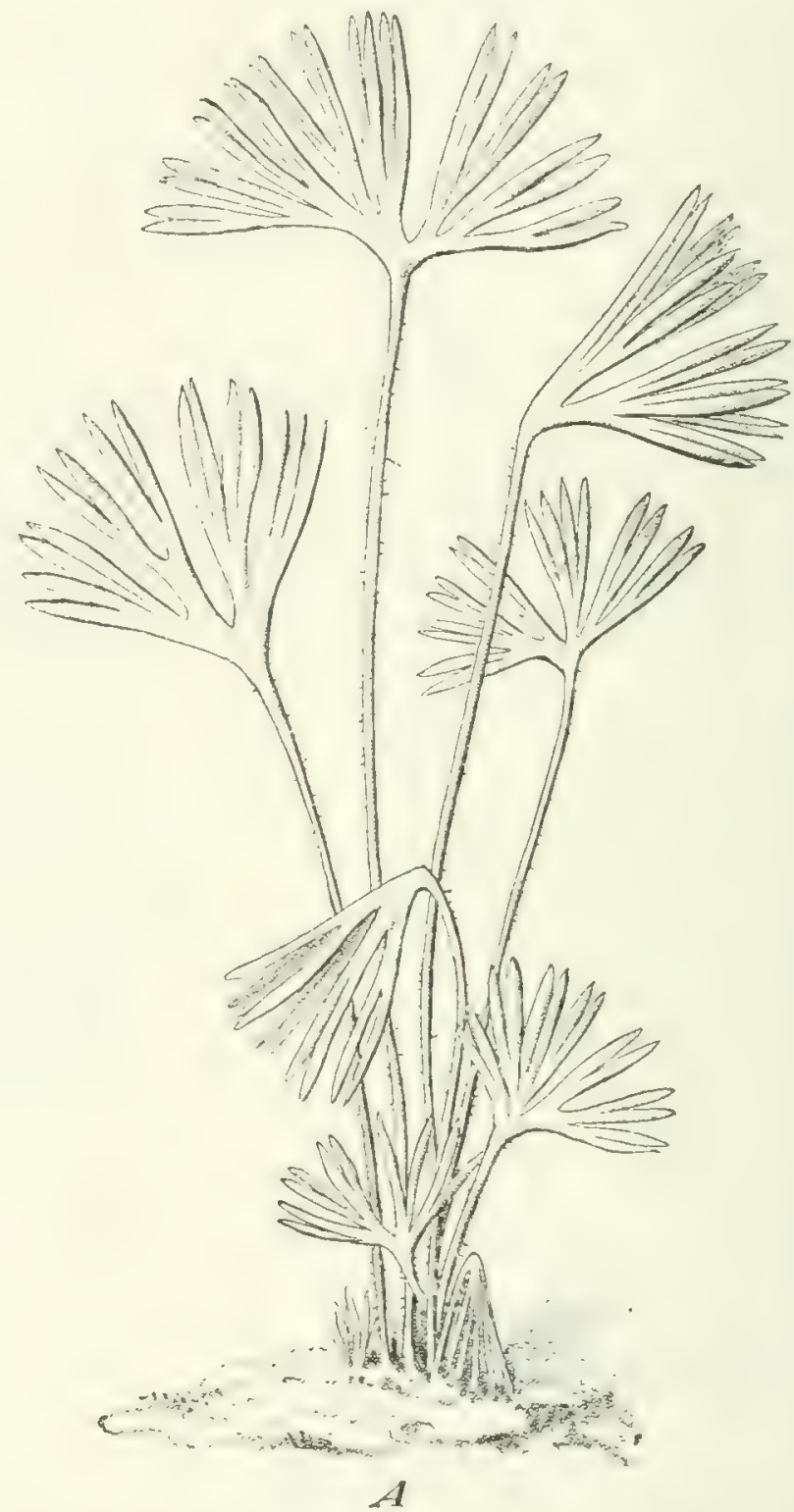

Fig. 37. Actiniopteris radiata (Koenig) Link.

in schattigen Felsspalten anzutreffen; sie ist dann noch weiter im südlichen Persien und Arabien verbreitet.

c Adiantinae. Meist Hygrophyten, aber auch einzelne Xerophyten.

Adiantum L. Diese durch Zierpflanzen ziemlich weit bekannt gewordene Gattung hat in Afrika nur einige Vertreter.

Sekt. I. Euadiantum Kuhn. Sporangien nur auf den Adern. Hierher gehört zunächst das durch ungeteilte rundlich-nierenförmige Blattspreiten aus- 
gezeichnete $A$. roniforme L., welches an feuchten Felsen Makaronesiens und der Kapverden verbreitet ist und als "Yerba tostanera "bekannt ist. Sehr ähnlich und nur durch schmalere Buchten zwischen den Blattlappen unterschieden ist A. asarifolium Willd, von den Maskarenen und den Drakensbergen.

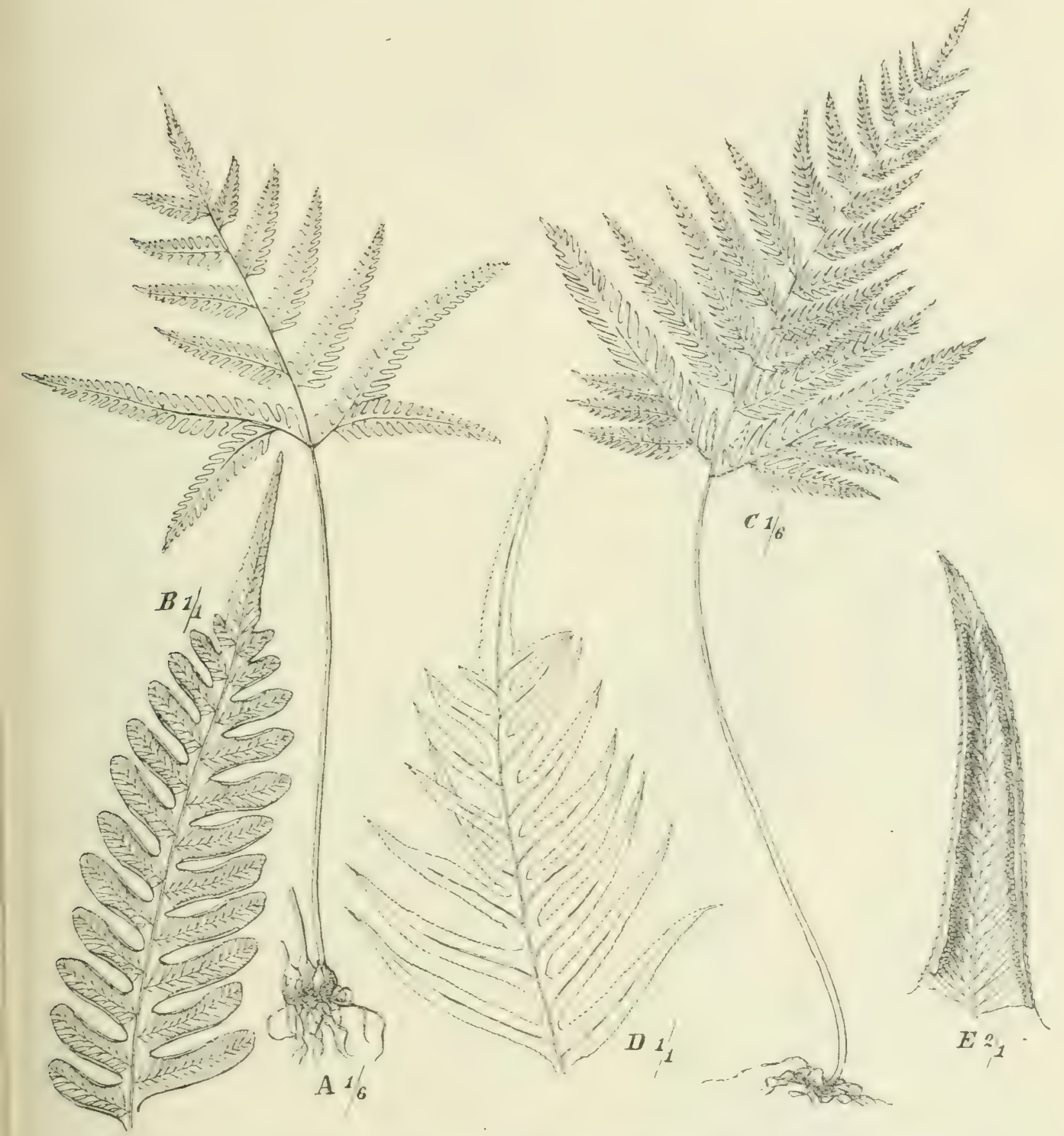

Fig. 38. $A, B$ Pteris quadriaurita Retz, vom Kilimandscharo. $C-E$ Pt, arguta Ait. var. flabellata (Thunb.) Mett., Kilimandscharo.

- Einfach gefiederte, selten teilweise doppelt gefiederte Blätter haben folgende Arten: A. lunulatum, A. rhizophomm, A. coudatum, A. Schweinfurthii, A. Balfourii, die ersten beiden mit gestielten Fiedern, die anderen mit sitzenden. Das in allen Tropenländern weit verbreitete, kahlblätterige A. Iumulatum Burm. (Fig. 35) finden wir von Abyssinien und den Kapverden bis Sambesi- 
land und Angola an feuchten schattigen Plätzen der Regenwälder. So wie bei dieser Art, wurzeln auch die an der Spindel behaarten Blätter von A. rhizofhorum Sw. an ihren dünnen Enden; diese Pflanze findet sich auf Madagaskar, den Maskarenen und Seychellen. Behaart sind die Blätter auch bei dem in

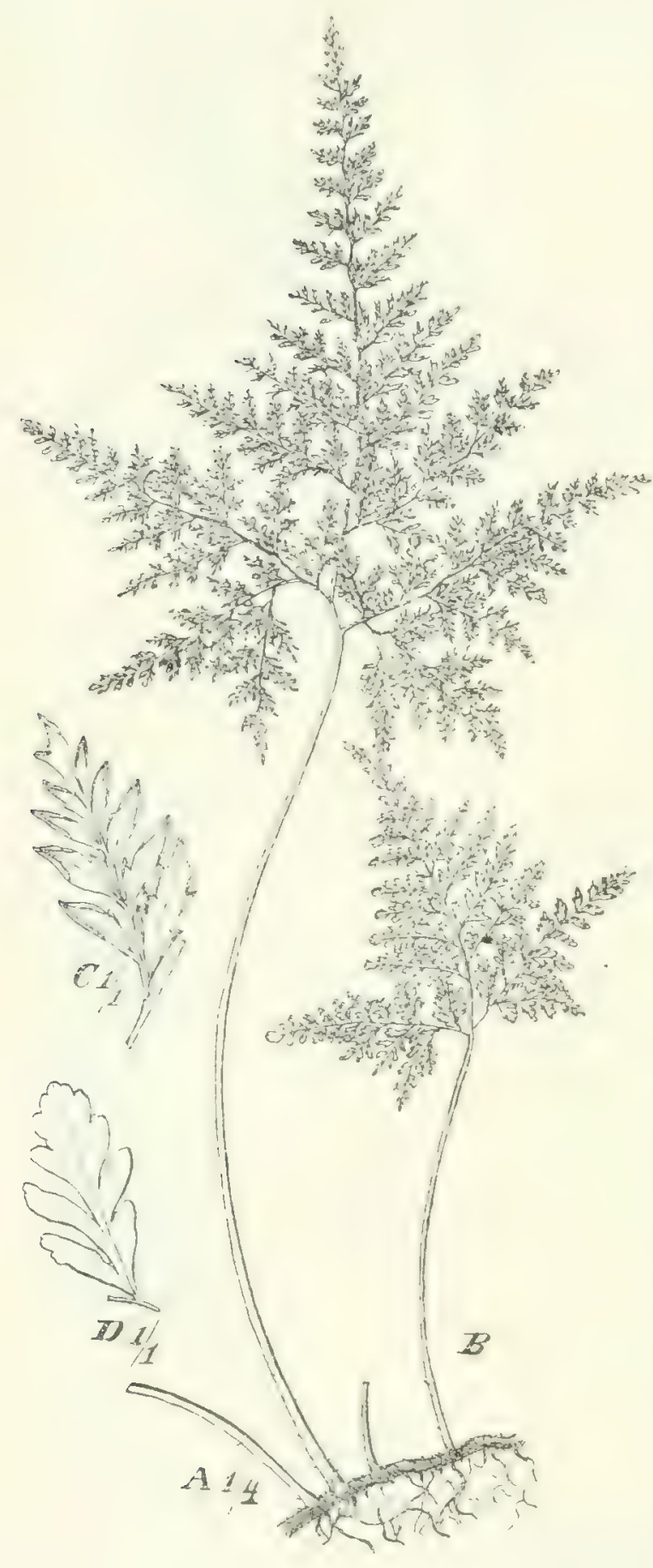

Fig. 39. Pteris nitida Mett., Kamerun, Barombi. den Tropen der alten Welt weit verbreiteten, in Afrika von Abyssinien bis Angola und auf den Comoren vorkommenden $A$. caudatunn $\mathrm{L}$; ; es wächst häufig am Boden der Waldungen und bedeckt mit seinen bis I in langen, an der Spitze wurzelnden Blättern oft große Flecken des Bodens, kommt aber auch an Felsen mit viel kleineren Blättern vor. Das nahestehende A. Schweinfurthii Kuhn im Lande der Niamniam hat ganz kahle Blätter. A. Balfourii Bak. auf Socotra ist sehr auffallend durch fast kreisrunde Fiedern. - Doppeltgefiederte Blätter von oft mehr als I m Länge und mehr als $0,5 \mathrm{~m}$ Breite besitzt A. tctraphyllum Willd. (Fig. 36); es ist von den Regenwäldern des tropischen Westafrika bis zum Ghasalquellengebiet verbreitet, häufig auch im tropischen Amerika, fehlt aber in Ostafrika. Drei- bis vierfach gefiedert sind die Blätter bei dem allgemein bekannten und durch Afrika an etwas feuchten Orten verbreiteten $A$. capillus Veneris L.; auch in den. Oasen der libyschen Wüste findet es sich stellenweise.

Sekt. 2. Adiantellum. Sporangien auf den Adern und dem dazwischen gelegenen Parenchym. - A. aethiopicum. L. und A. crenatum Poir. (nicht Willd.) sind zwei einander sehr nahestehende Arten. Das erstere findet sich zerstreut im Kapland, das letztere, dadurch ausgezeichnet, daß die sterilen Adern der Blattfiederchen zwischen den Blattzähnen, nicht in diesen auslaufen, ist von Abyssinien durch das tropische Afrika bis zum Kapland verbreitet und steigt his zur oberen Grenze der Regenwälder auf, findet sich auch auf den Comoren und Madagaskar. 
d) Pteridinae. Hygrophyten, Mesophyten, Xerophyten.

Actiniopteris Link-A. australis (L. fil.) Link hat sich ganz den Steppen Indiens und Afrikas angepaßt und findet sich ron der Erythrea bis zum Damaraland und der Kalahari, auch in Arabien, auf Socotra und Nadagaskar, in Ostafrika auch in den Felsensteppen.

\section{Pteris L.}

Sekt. I. Eupteris Diels, mit freien, nur bisweilen nahe der Rippe zusammenstoßenden Seitenadern. - Einfach gefiedert sind die Bliitter bei der schon im suidlichen Mittelmeergebiet rorkommenden und zerstreut his Trans-

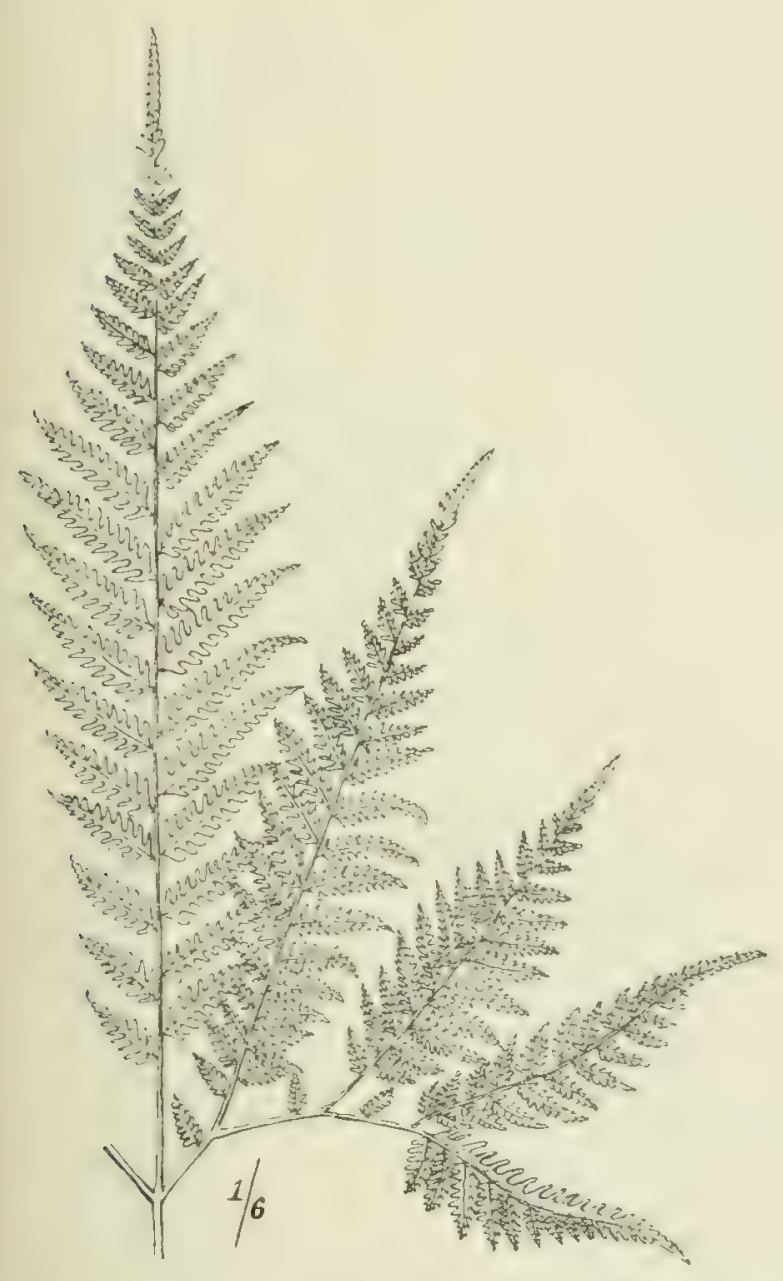

Fig. 40. Pteris tripartita Sw., Gabun (Buchholz).

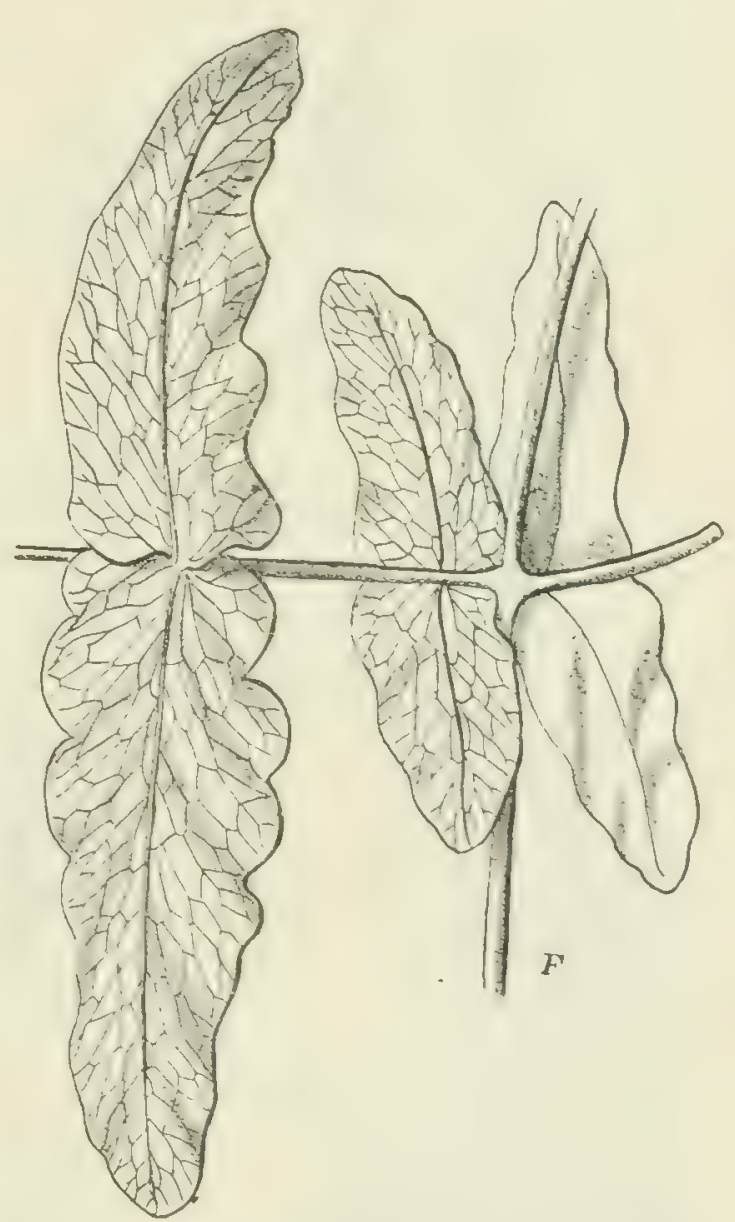

Fig. 41. Histiopteris incisa (Thunb.) J. Sm. unterer Teil zweier Fiedern.

vaal und Angola auftretenden $P$. longifolia L.; im unteren Teil zur Doppe1fiederung neigen die Blätter bei der am FuB der insubrischen Alpen noch zu findenden, durch das ganze östliche Afrika zerstreuten und auch in Benguela nachgeriesenen P. cretica L. - Doppelt bis mehrfach gefiederte Blätter hat I'. quadriaurito Retz (Fig. 38. - B, 3), mit bisweilen über I m langen Blättern, deren Fiedern stumpf und ganzrandig sind, während sie bei $I$. arguk spitz und (die sterilen) oft spitz und gesägt oder gezähnt sind. Dicse Art ist in den Regenwäldern von Abyssinicn und Sierra Leone bis Natal und Angola verbreitet, am Kilimandscharo bis $2100 \mathrm{~m}$, auch auf den Comoren. Maskarenen 
und Serchellen. Eine nahestehende Art ist die mit breiteren Fiedern letzter Ordnung verschene und rom äquatorialen Afrika nur bis Angola reichende $P$. atrovirens Willd. $P$. arguta Ait., welche wir schon in den Nebelwäldern Makaronesiens antreffen, ist im kontinentalen Afrika von Abyssinien bis zum Kapland durch die Varietät flabellata (Thunb.) (Fig. $38 C-E$ ) vertreten; auch sie findet sich auf allen Afrika benachbarten Inseln. - Dreifach gefiedert im

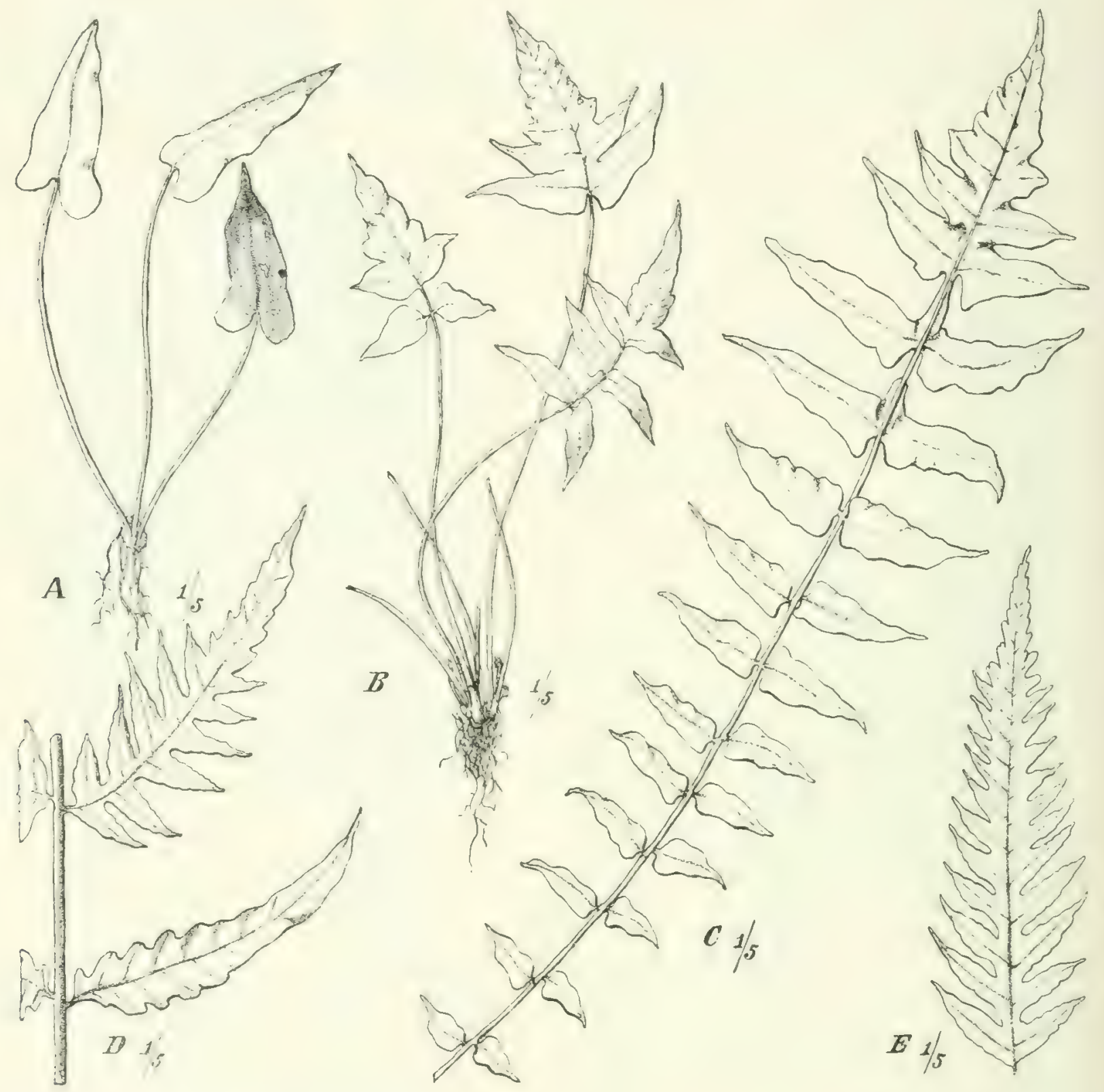

Fig. 42. Lonchitis Currori (Hook.) Mett., Kamerun. $A, B$ junge Stadien, $C-E$ Teile älterer Blätter.

unteren Teil sind die Blätter bei $P$. breizsora Bak., welche nur im Gebirgsregenwald von Fernando Po und Kamerun gefunden wurde. Vierfach gefiedert im unteren Teil sind die im Umriß dreieckigen, beiderseits glänzenden, an kriechendem Rhizon (Fig. 39) stehenden Blätter der I'. niticla Mett., welche in Kamerun und Gabun in der unteren Waldregion, namentlich auch an lichten Stellen alter Farmen häufig ist, eine sehr schöne, auffallende Art.

Sekt. 2. Litobrachia (Presl) zeichnet sich durch vielfältig anastomosierende 
Seitenadern aus. Hierher gehört L'. Camerooniana. Kuhn, welche habituell einer großen $L^{\prime}$. cretica ähnlich sieht, im Regenwald von Fernando Po und Kamerun. Durch starke cymöse Verzweigung des unteren Blattteils /drei- bis vierfach gefiedert) zcichnet sich aus die in Kamerun sehr häufige, aber auch in Natal, auf den Comoren und Seychellen vorkommende P. tripartiti Sw. (I'. Marginata Bory, Fig. 40).

Histiopteris Agardh enthält nur eine Art, H. incisa (Thunb.) J. Sm., welche biologisch dadurch interessant ist, daß die blau bereiften, bis ro $\mathrm{m}$ langen und $2 \mathrm{~m}$ breiten, aber auch viel kleineren, entfernt stehenden Blätter oft schlingen; sie ist von Usambara und Uluguru ( $1300-2000 \mathrm{~m})$ und dem Kamerungebirge südwärts bis zum Kapland verbreitet, findet sich auch auf den Maskarenen, Seychellen, Madagaskar und Ascension (Fig. 4I).

Lonchitis L. Alle Arten sind sehr stattliche Erdfarne mit großen zwei- bis dreifach fiederspaltigen Blättern und stumpfen Abschnitten. L.occidentalis Bak, mit schwacher Maschenbildung der Adern und L. Currori (Hook.) Mett. (Fig. 42) mit starker Maschenbildung sind beide im westafrikanischen Waldgebiet verbreitet, letztere bisweilen mit $3 \mathrm{~m}$ langen Blättern. Während die Sori bei diesen Arten meist nur die Achseln der oberen Randbuchten besetzen, finden sie sich auch in denen der unteren bei $L$. pubescens Willd., welche hauptsächlich in den Gebirgswäldern des tropischen Afrika von 1900 bis $2600 \mathrm{~m}$ verbreitet ist.

Pteridium Gled. Der allbekannte Adlerfarn, Pt. aquilinum (L.) Kuhn ist in ganz Afrika anzutreffen, mit Ausnahme ganz trockener Distrikte. Wie in Europa und Makaronesien tritt er auch in Afrika formationsbildend auf, besonders in den Regionen des Gebirgsbusches und Höhenwaldes, namentlich aber in den Gebirgen an der Stelle von verlassenem Kulturland. Er findet sich auch auf den Comoren, Maskarenen und Madagaskar.

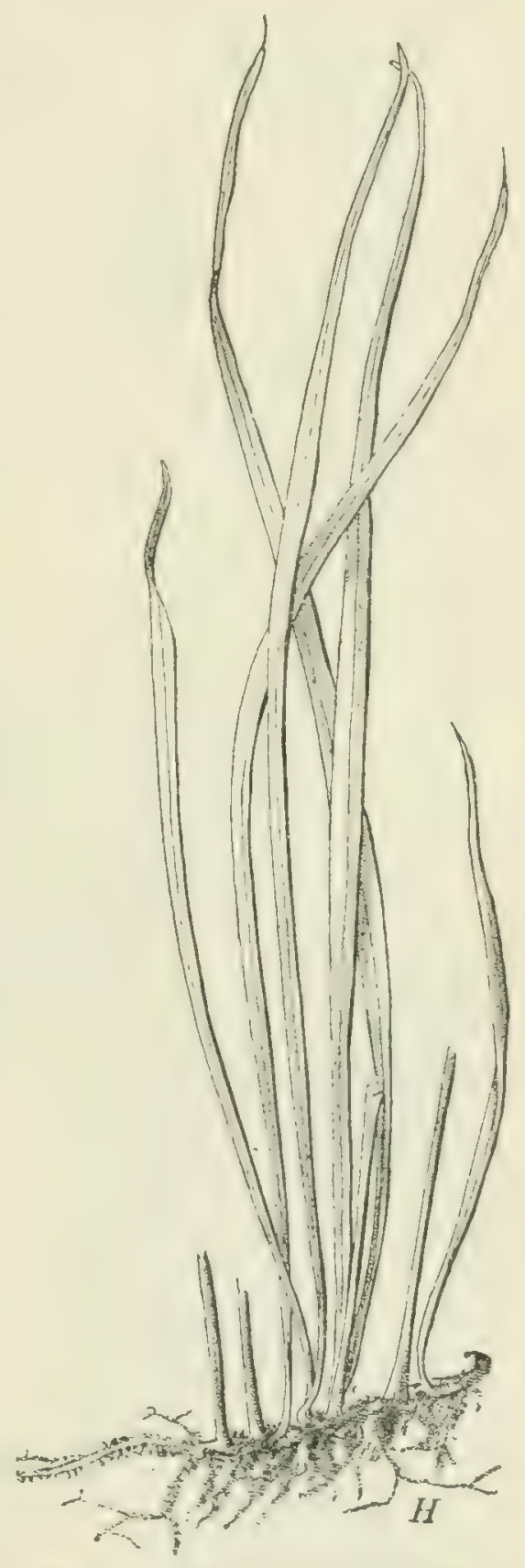

Fig. 43. Vittaria elongata Sw.

VII. Vittarieae. Sori lang gezogen, randständig oder auf Adern parallel zur Mittelrippe. Blätter meist mit ungeteilter Spreite, dem Rhizom ohne Gliederung eingefuigt. - Folgende beiden Untergruppen sind leicht kenntlich.

Hygrophyten.

a) Vittariinae. Sori in einer einzigen kontinuierlichen der Mittelrippe parallelen Linie. - Alle Epiphyten. -- Die durch an der Mittelrippe stehende 
Sori ausgezeichnete Gattung Mtonogramme ist zwar durch $N I$. graminea (Poir.) Schk, auf den Maskarenen vertreten, fehlt aber dem Kontinent.

Vittaria $\mathrm{Sm}$. Die Sori liegen auf einem intramarginalen Verbindungsstrang der Adernenden.

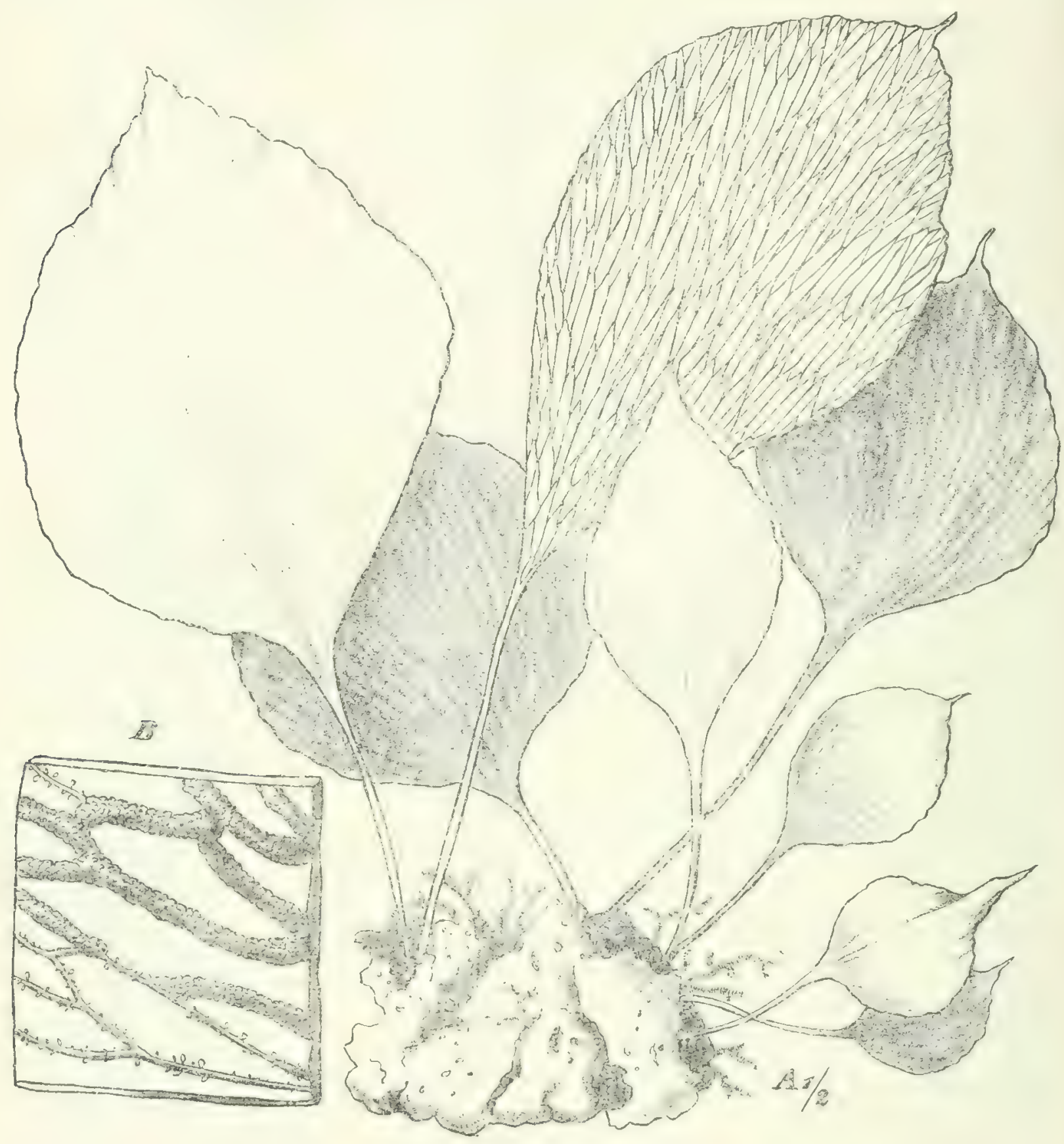

Fig. 44. Antrophyum Mannianum Hook., zwischen Moos und Flechten sitzend.

Sekt. 1. Euvittaria Hook. Indusium dem Deckrande genau gleichwertig und mit ihm eine zweilippige Furche bildend. $V$. elongata Sw. (inkl. $V$. guineensis Desv. und $V$. plantaginea Bory, Fig. 43) mit fast $0,5 \mathrm{~m}$ langen, nicht einmal $\mathrm{I} \mathrm{cm}$ breiten Blättern, in allen Tropenländern der alten Welt verbreitet, findet sich in den Regenwäldern des tropischen Westafrika, in Usambara und am Kilimandscharo, auch bei Quilimane. 
Sekt. 2. Taeniopsis J. Sm. Indusium reduziert - $V$. scolopendrina (Bory) Thwait. mit 0,5 m langen Blättern kommt nur auf den Maskarencn ror und erstreckt sich von hier weit ostwärts. $V$. isoetifolia Bory mit sehr schmalen linealischen Blättern findet sich von Usambara bis zum Kapland und auf den Maskarenen.

b) Antrophyinae. Sori auf den Seitenadern längs verlaufend, mehrere unterbrochene Linien bildend.

Antrophy'un Kaulf. A. immersum (Bory) Mett. mit fleischigen Blättern und eingesenkten Sori, in Usambara, auf den Comoren, Maskarenen und im tropischen Asien. - A. Mannianmm Hook. f., große Art mit breiten verkehrt-eiförmigen, langgestielten Blättern, vom tropischen Westafrika (bis zu I $400 \mathrm{~m}$ ) bis zum südlichen Nyassaland, meist epiphytisch; aber auch an Felsen (Fig. 44).

VIII. Polypodieae. Sori ohne tracheidenfuihrendes Receptaculum, ohne Indusium. Sie sind hauptsächlich noch daran kenntlich, daß die Blätter dem Rhizom ungegliedert eingefügt sind.

Übersicht über die in Afrika vorkommenden Gattungen.

1. Sori lineal an einem auf besonderer Adernanastomose entwickelten Receptaculum. Aderung fiederig.

Taenitidinae. Einzige Gattung . . . . . . Hymenolepis.

B. Sori rund bis länglich, ohne auf besonderer Anastomose entwickeltes Receptaculum. Fertile Blatteile zuweilen zusammengezogen. Aderung meist fiederig Polypodiinae. a) Ohne Nischenblätter.

(e) Blätter mit haarförmigen oder lanzettlichen Schuppen. Sori oberflächlich oder in schüsselförmige Gruben rersenkt. . . . . . . . Polypodium.

i) Blätter mit schildförmigen Spreuschuppen

Lepicystis.

y) Blätter mit Sternhaaren . . . . Niphobolus.

b) Besondere Nischenblätter vorhanden . . Drynaria.

a) Taonitidinae. Hygrophyten.

Von dieser im tropischen Amerika und Asien reichlicher entwickelten Gruppe findet sich nur
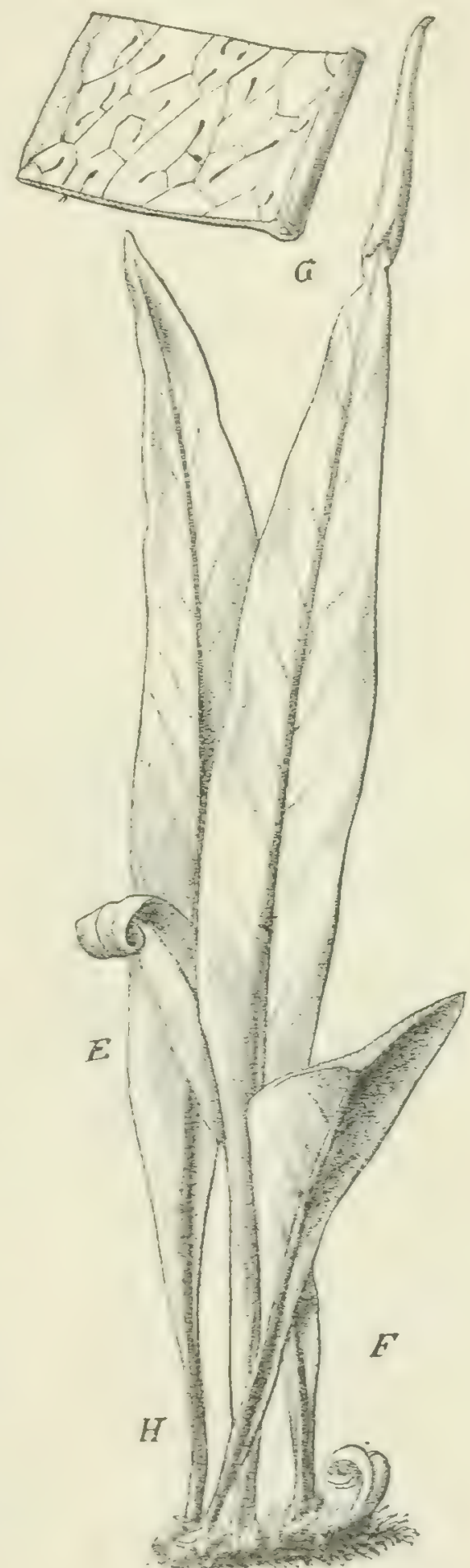

Fig. 45. Hymenolepis spicata (L. f.) Presl. $F$ ganze Pflanze; $G$ Teil der Hälfte eines sterilen Blattes; $H$ Teil der fertilen Blattspitze.

Hymenolepis spicata (L.f.) Presl (Fig. 45), welche von Polynesien durch das tropische Asien bis zu den Naskarenen und Comoren verbreitet ist, auch in den Regenwäldern Usambaras. Dieser Epiphyt ist sofort kenntlich an den lederartigen, lanzettlichen Blättern, deren 
oberes am Rande eingerolltes Ende unterseits von Soris und Schuppen dicht besetzt ist.

b) Polypodiinae. Meist Epiphyten oder Felsenpflanzen, einige wenige der letzteren Xerophyten.

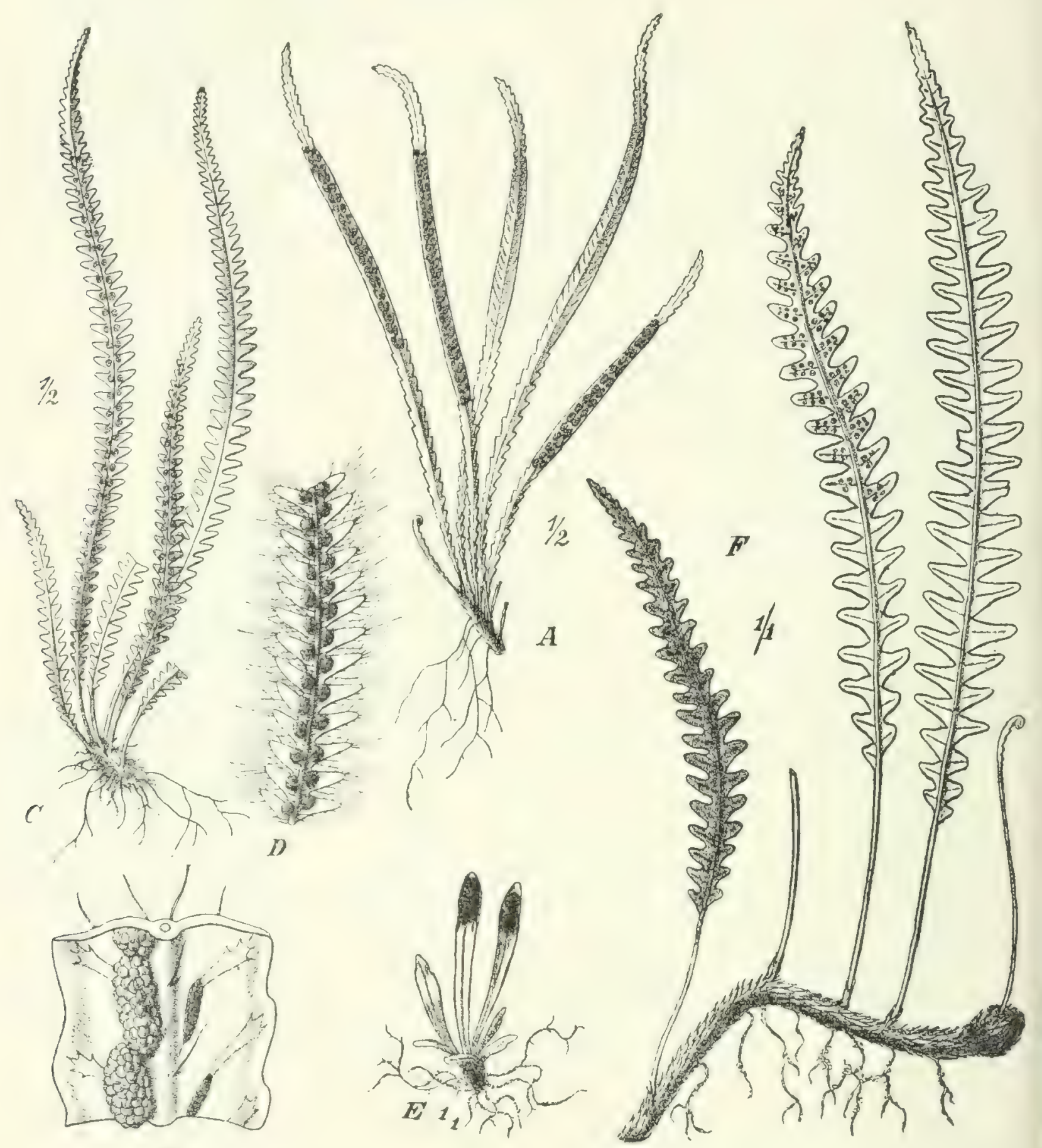

$B$

Fig. 46. $A, B$ Polypodium serrulatum (Sw.) Mett., Kamerun; $C, D$ P. trichomanoides Sw.; E, P. Molleri Bak., San Thomé; F P. rigescens Bory, Kilimandscharo.

Polypodium L. Bei der Arthestimmung hat man zunächst auf die Aderung $z u$ achten, sodann die Teilung der Blattspreite zu berücksichtigen.

Sekt. I. Isupolypodium Diels. Adern alle frei, selten durch einen submarginalen Verhindungsstrang kommunizierend. - Hierher gehört zunächst 
die kleinste Art der Gattung, das mit nur $3-4 \mathrm{~cm}$ langen, lineallanzettlichen Blättern versehene $P$. australc (R. Br.) Mett., welches zwischen Moos an Bäumen und Felsen in den kühleren Gebieten der südlichen Hemisphäre, namentlich in den subantarktischen vorkommt, aber auch bis Nauritius vorgedrungen ist. Ebenso klein ist das mit stumpferen Blättern versehene $P$. Molluri Bak. (Fig. $46 E$ ), welches auf San Thomé um $1900 \mathrm{~m}$ im Regenwald gefunden wurde. Höchstens o, I m lange, sehr schmale, kammförmig gelappte, dichte Polster bildende Blätter besitzt das in den Tropen zerstreute $P$. scmulatum (Sw.) Mett. (Fig. $46 A, B$ ), welches in Afrika bis jetzt in Kamerun als Epiphyt und Felsenpflanze nachgewiesen wurde. In Westusambara kommt von 1600 bis $2000 \mathrm{~m}$ eine ähnliche Pflanze mit etwas breiteren Blättern vor, die mit dem P. myosuroides Sw. von den Antillen und Brasilien ibereinstimmt. Fiederige gelappte Blätter mit länglichen Lappen haben einige Arten, zunächst das nur 5-6 cm hohe $P$. oosorum Bak. aus dem Gebirgsregenwald von San Thomé und dem Kamerungebirge, ferner das viel größere, kahlblätterige $P$ ?. Lcuiosom Boj. von den Maskarenen und Seychellen, sowie das behaarte P. rillosissimum Hook. von Sierra Lcone und Fernando Po. - Vollkommen einfach gefiederte Blätter haben zahlreiche Arten. Unter diesen ist das außerhalb Afrikas weitverbreitete, in Afrika nur nachgewiesene, höchstens $0,15 \mathrm{~m}$ lange $P$. trichmanoidcs Sw. (Fig. 46C, D) dadurch ausgezeichnet, da 3 jede Ficder nur einen Sorus trägt. Zahlreiche Arten aber hahen mehr als einen Sorus auf jeder Fieder und gruppieren sich zunächst in solche mit nicht gegabelten Seitenadern I. Ordnung und anderseits solche mit gegahelten Seitenadern. Zu der ersten Gruppe gehört zunächst das ebenfalls nur kleine, auf den Maskarenen und Comoren vorkommende I'. fariulum Bory, auch das in allen Teilen größere $P$. comorense Bak. und das großblätterige und weichhaarige, im tropischen Amerika, auf Fernando Po und Mauritius wachsende P. cultratum Willd. Erwähnung verdient auch das mit längeren Rhizomen verśchene $P$. rigescens Bory (Fig. $46 \mathrm{~F}$ ), welches, zuerst von den Maskarenen bekannt, auch auf dem Ruwenzori (2900-3100 m und auf dem Kilimandscharo $128 \mathrm{co}$ bis $3200 \mathrm{~m}$ ) aufgefunden wurde. Auch eine dem P. blechnoides (Grev.) Hook. ähnliche, aber mit $P$. rigescens Bory näher verwandte Art mit kürzer gestielten Blättern findet sich bei Yaunde in Kamerun und in Westusambara. In die zweite Gruppe gehört das in der nördlich gemäßigten Zone verbreitete, aber auch nach Makaronesien, Natal und dem Kapland vorgedrungene P'. 'nulgare L., desgleichen auch das unterseits weißmehlig bestäubte $I^{\prime}$. argrratum Bory von den Maskarenen.

Sekt 2. Goniophlabium Bl. Die Seitenadern sind verbunden und bilden längs der Rippe geschlossene Maschen, in deren jeder cin Äderchen frei endet. - Ungeteilte bis $2,5 \mathrm{dm}$ lange Blätter besitzt I. Iringii Kuhn von Oberguinea. - Gefiederte Blätter mit breit angewachsenen Fiedern besitzt das auf Bäumen kriechende $P$. cnsiforme Thunb., welches vom südwestlichen Kapland bis Natal verbreitet ist.

Sekt. 3. Campyloneuron Presl. Seitenadern I. Ordnung durch zahlreiche 
parallele Adern 2. Ordnung verbunden. - In Afrika findet sich nur eine Art mit ungeteilten lanzettlichen Blättern, welche im tropischen Amerika weit verbreitet ist, $P$. phyllitidis L.; sie ist aber bis jetzt nur auf San Thomé gefunden worden.

Sekt. 4. Pleopeltis Humb. et Bonpl. Seitenadern 1. und 2. reich verzweigt, ein dichtes Maschennetz bildend. Aus dieser Gruppe kennen wir Arten mit

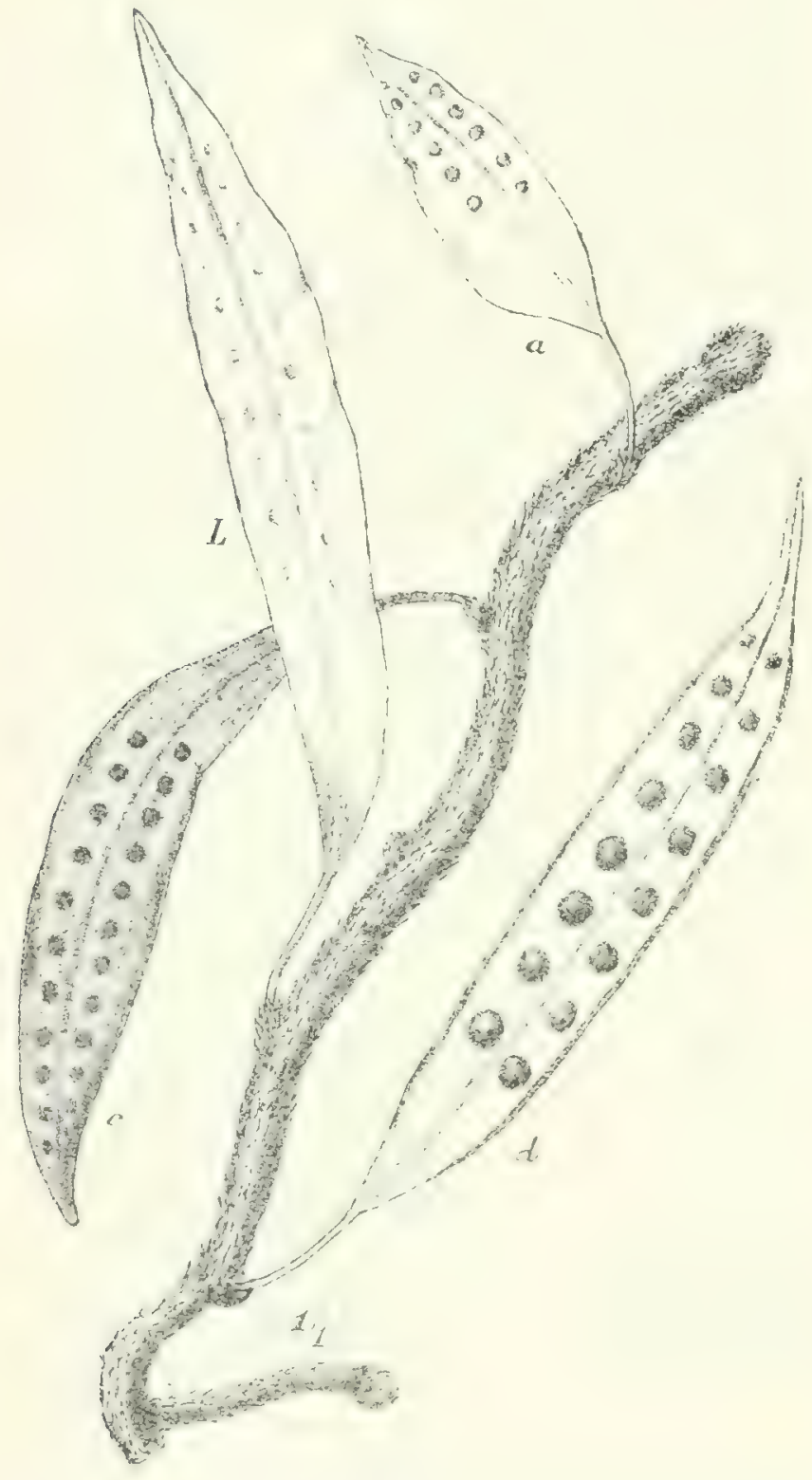

Fig. 47. Polypodium excavatum Bory (= P. simplex Sw.), Uluguru.

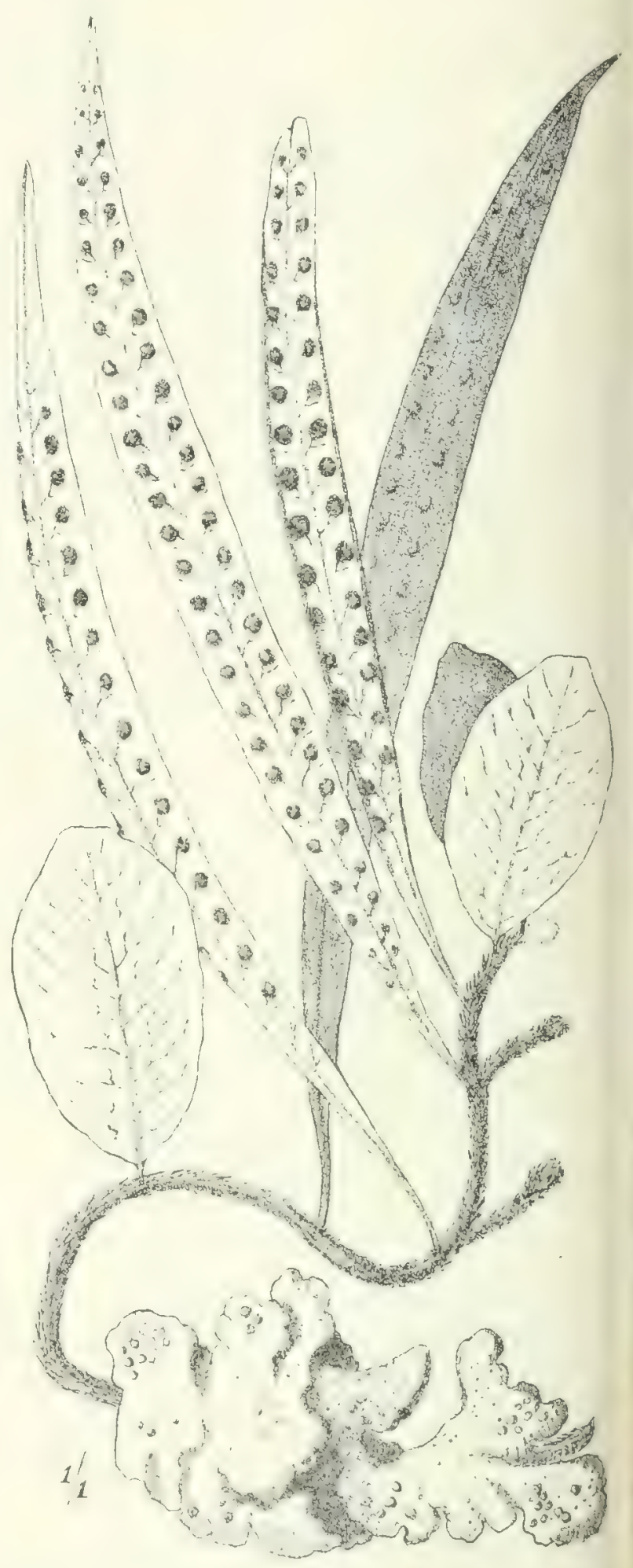

Fig. 48. Polypodium lycopodioides L., zwischen Flechten wachsend.

ungeteilten Blättern, bei denen die Sori regelmäßig in einer Reihe parallel zur Rippe stehen. Hierher gehört die größte der in Afrika vorkommenden Arten, $P$. pmatatnm (L.) Sw. ( $P$. irioides Poir.), welches an kurzem 
Rhizom oft zahlreiche, bis $1,5 \mathrm{~m}$ lange, fleischige, hellgrine Blätter trägt: es wächst in den Regenwäldern oft hoch in der Krone der Bäume, aber auch

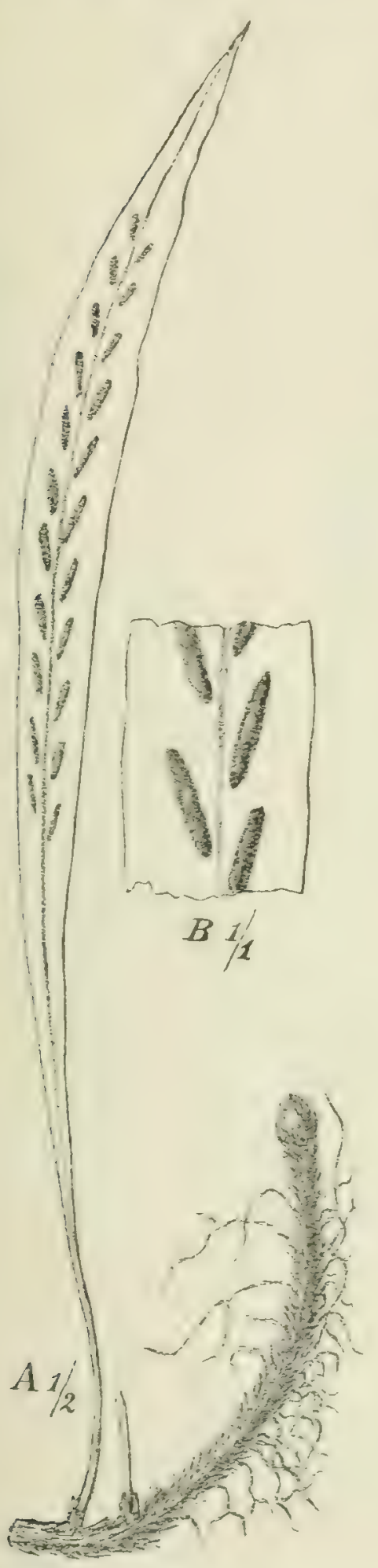

Fig. 49. Polypodium loxogramme Mett. am Grunde der Stämme und auf Felsblöcken, vom zentralafrikanischen Seengebiet und Oberguinea bis Natal und Angola, meist nicht über $1000 \mathrm{~m}$. Auch eine ziemlich stattliche Art mit 3-6 dm langen und $2-5 \mathrm{~cm}$ breiten lanzettlichen Blättern ist P. Pappei Mett., verbreitet im Monsungebiet und im tropischen Himalaya; aber auch in Natal. Nur halb so große Blätter an kriechendem Rhizom besitzt $P$. lineare Thunb., welches in allen paläotropischen Waldgebieten bis an die äußersten Grenzen, so in Afrika bis Abyssinien und Kapland, auch in den Hochgebirgen bis $2700 \mathrm{~m}$ vorkommt. Sehr ähnlich,
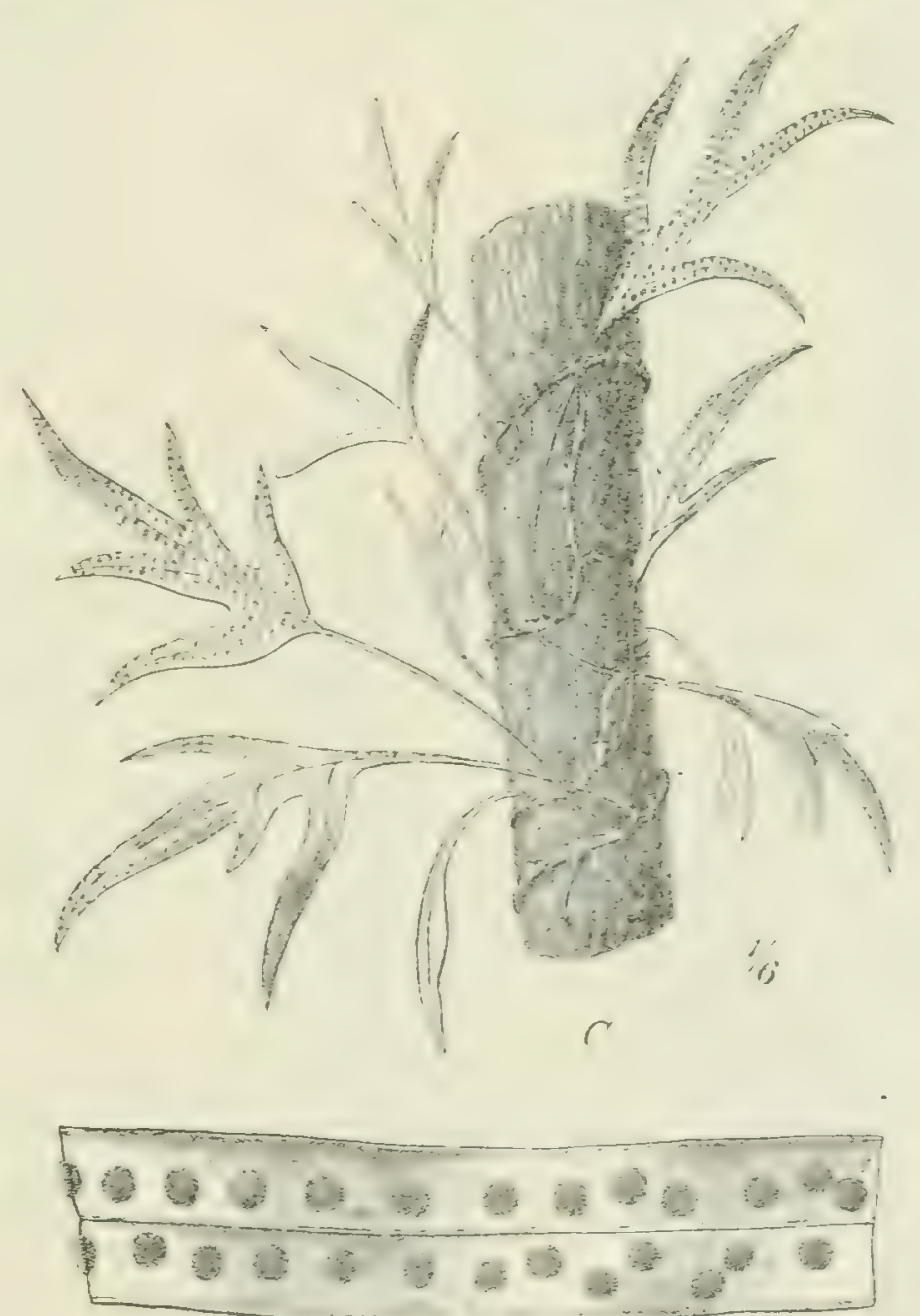

()

Fig. 50. Polypodium phymatodes L.

nur mit etwas breiteren Blätern versehen ist $P$. cratatum Bory $(P$. simplex Sw. (Fig. 47) von ähnlicher Verbreitung in Afrika. - Ilehr länglich bis elliptisch und fast sitzend sind die Blätter an den weithin kricchenden, schuppigen Rhi- 
zomen bei I. Ijeopodioilcs L. (Fig. 48), das von Oberguinea und dem zentralafrikanischen Scengebiet an his Natal verbreitet ist, es steigt von der Küste bis Ig00 $\mathrm{m}$ auf und zeigt oft starke Heterophyllie der sterilen und fertilen Blätter. Endlich hat auch noch einfache lanzettliche kurzgestielte Blätter,

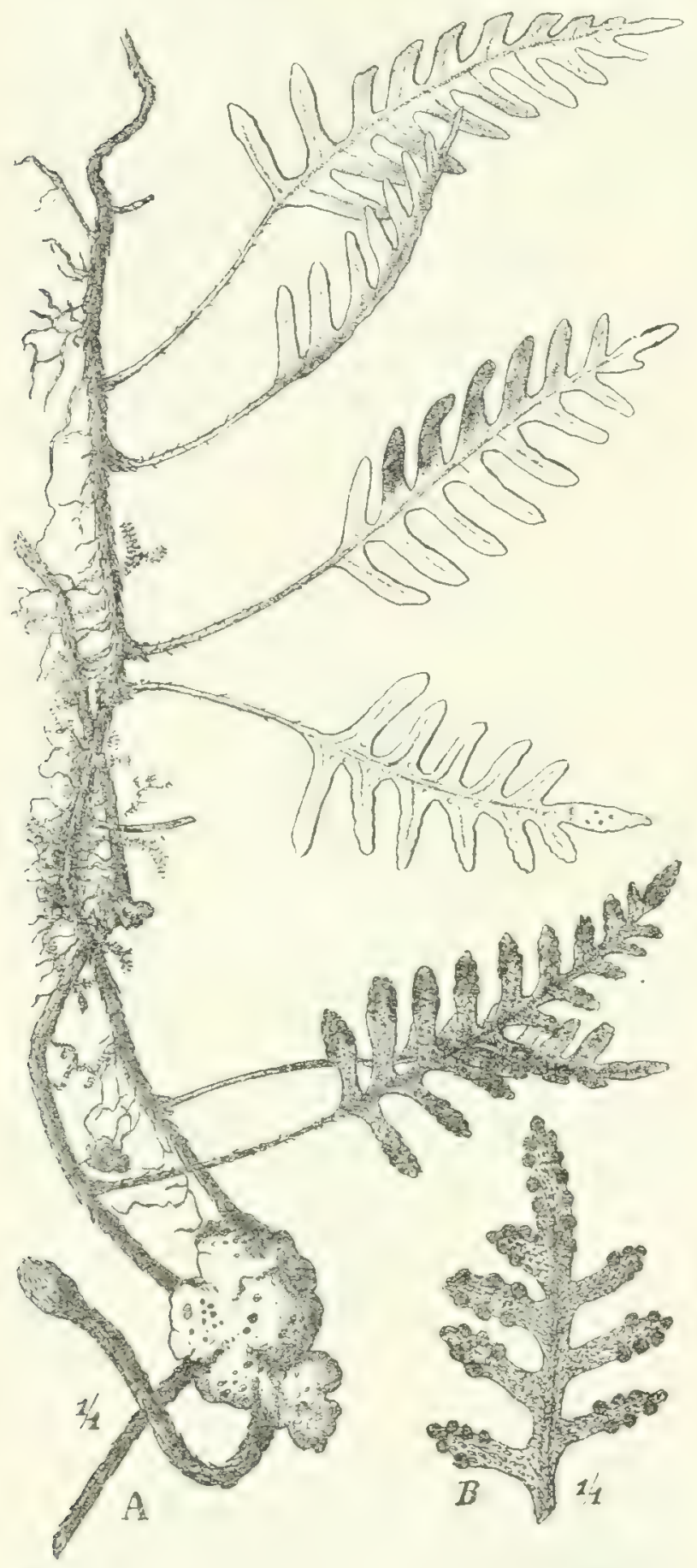

Fig. 51. Lepicystis polypodioides (L.) Hitchc. var. Ecklonii (Kze.), Sambesia. Rhizom mit Flechten und Moosen.

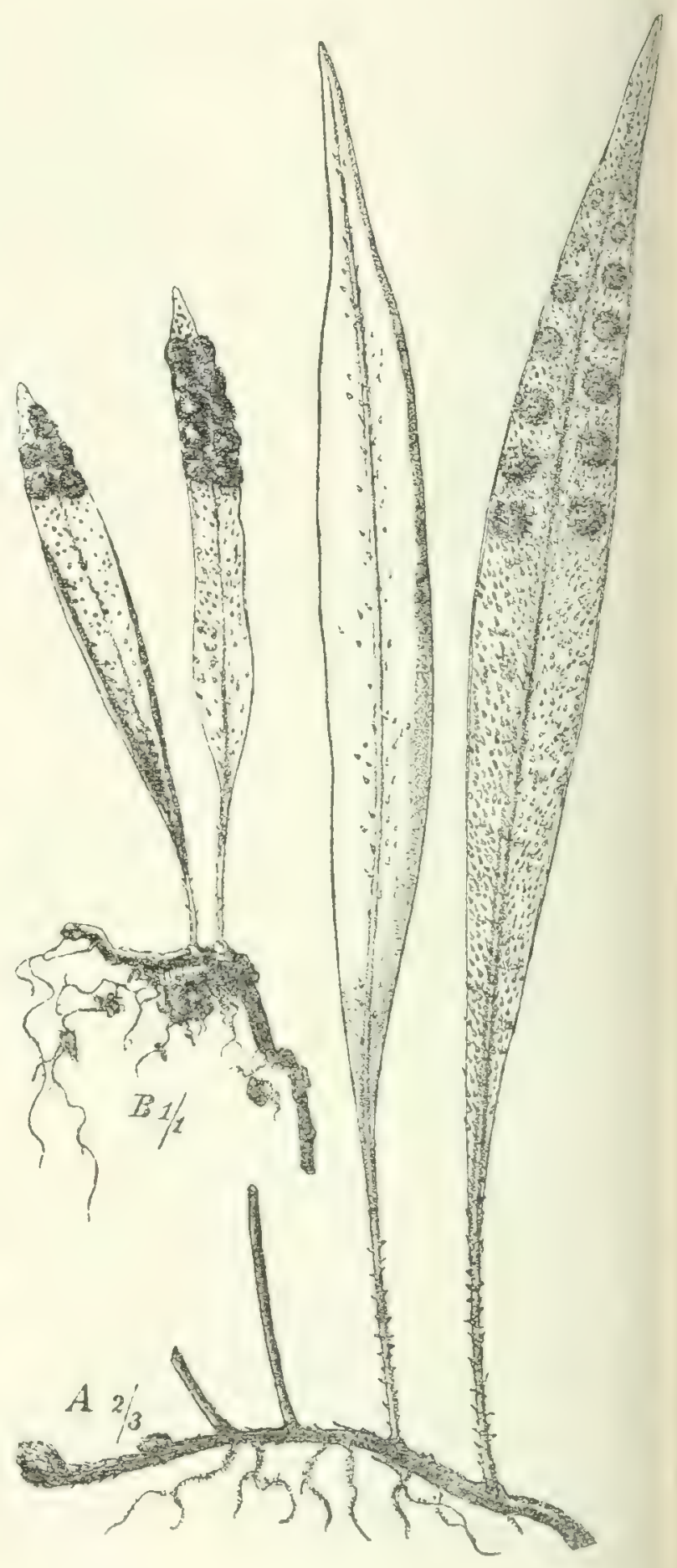

Fig. 52. Lepicystis lanceolata (L.) Diels.

aber mit \pm zusammenfließenden Soris in schiefen Reihen das in allen Tropenländern der alten Welt, in Afrika von Abyssinien bis Natal und Angola verbreitete, in Gebirgen bis $2500 \mathrm{~m}$ aufsteigende P. loxogramme Mett. (Fig. 49! Fiederspaltige Blätter mit sehr wechselnder Fiederzahl und bis I $m$ langer 
Spreite trägt an weithin kricchendem oder kletterndem Rhizom I'. phymatodes L. (Fig. 50); weitverbreitet in den Tropen der alten ITelt, nimmt es in Afrika etwa dasselbe Areal ein, wie das oben erwähnte $P$. punctatum, geht aber südwärts bis Pondoland und steigt in den Gebirgen bis zu $1500 \mathrm{~m}$ ii. M. auf, es wächst sowohl am Boden, wie epiphytisch.

Lepicystis J. Sm. ist eine Polypodium sehr nahe stehende Gattung, welche sich nur dadurch unterscheidet, daß die Blätter mit schildartig befestigten, lanzettlichen Spreuschuppen versehen sind. Die Gattung ist vorzugsweise amerikanisch; aber an die in Amerika von Virginien bis Argentinien und Chile sehr verbreitete fiederblätterige L. polypodioides (L.) Hitchc. $=L$. incana (Sw.) J. Sm.) schließt sich die nur wenig abweichende Varietät Ecklonii (Kze.) an, welche von Kapstadt bis Transvaal und Sambesia verbreitet ist (Fig. 51). Ungeteilte ganzrandige Blätter besitzt L. lanceolate (L.) Diels, eine fast pantropische und auch in Afrika häufige Art (Fig. 52).

Niphobolus Kaulf. (Cyclophorus Desv.). Die Blätter sind mit reich verzweigten Seitenadern versehen und von Spreuhaaren filzig: Alle Arten sind Epiphyten oder Felsenpflanzen; zwei Arten haben eine Reihe Sori, und von diesen besitzt $N$. spissus .(Bory) Desv. gleichgestaltete sterile und fertile, dicht filzige Blätter, die am Rande bisweilen etwas fiederspaltig sind; eine Form dieser Art reicht von Brit. Indien bis Bourbon, eine andere var. continentalis Hieron., welche sich durch länger gewimperte Spreuschuppen auszeichnet, kommt in den Regenwäldern von Usambara, Uluguru und Kamerun vor (Fig. 53). - Zwei bis mehrere Reihen von Soris zeigen die Blätter des $N$. africams (Mett.) Giesenh., welchen wir von Sambesia bis Natal antreffen. Nahe stehende Arten sind N. Schimperianus (Mett.) Giesenh. von Abyssinien, $N$. Mechowii Brause et Hieron. epiphytisch in

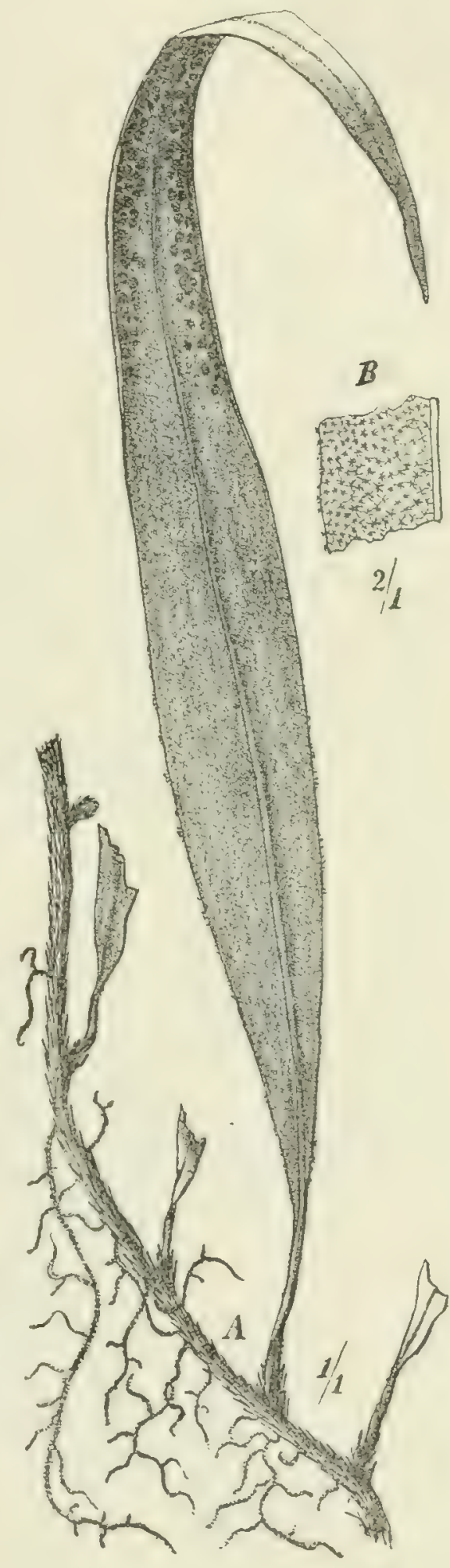

Fig. 53. Niphobolus spissus (Bory) Desv. var. continentalis Hieron. Kamerun und Angola, sowie N. Stoltwii Hieron. (mit lang gestielten Blättern) vom Kondeland aus einer Höhe von $1450 \mathrm{~m}$ ii. M.

Drynaria Bory umfaßt jedermann auffallende epiphytische Farne, welche 
sich an die Sektion Plcopeltis von I'olyodinm anschließen, mit starkem, dicht beschuppten Rhizon an Bäumen hoch hinaufklettern und an ihren Sprossen crst aufrecht sitzende, breit ovale, honkave, chlorophyllarme und stark geaderte, bald nur noch das Adernetz aufweisende Nischenblätter entwickeln, hinter

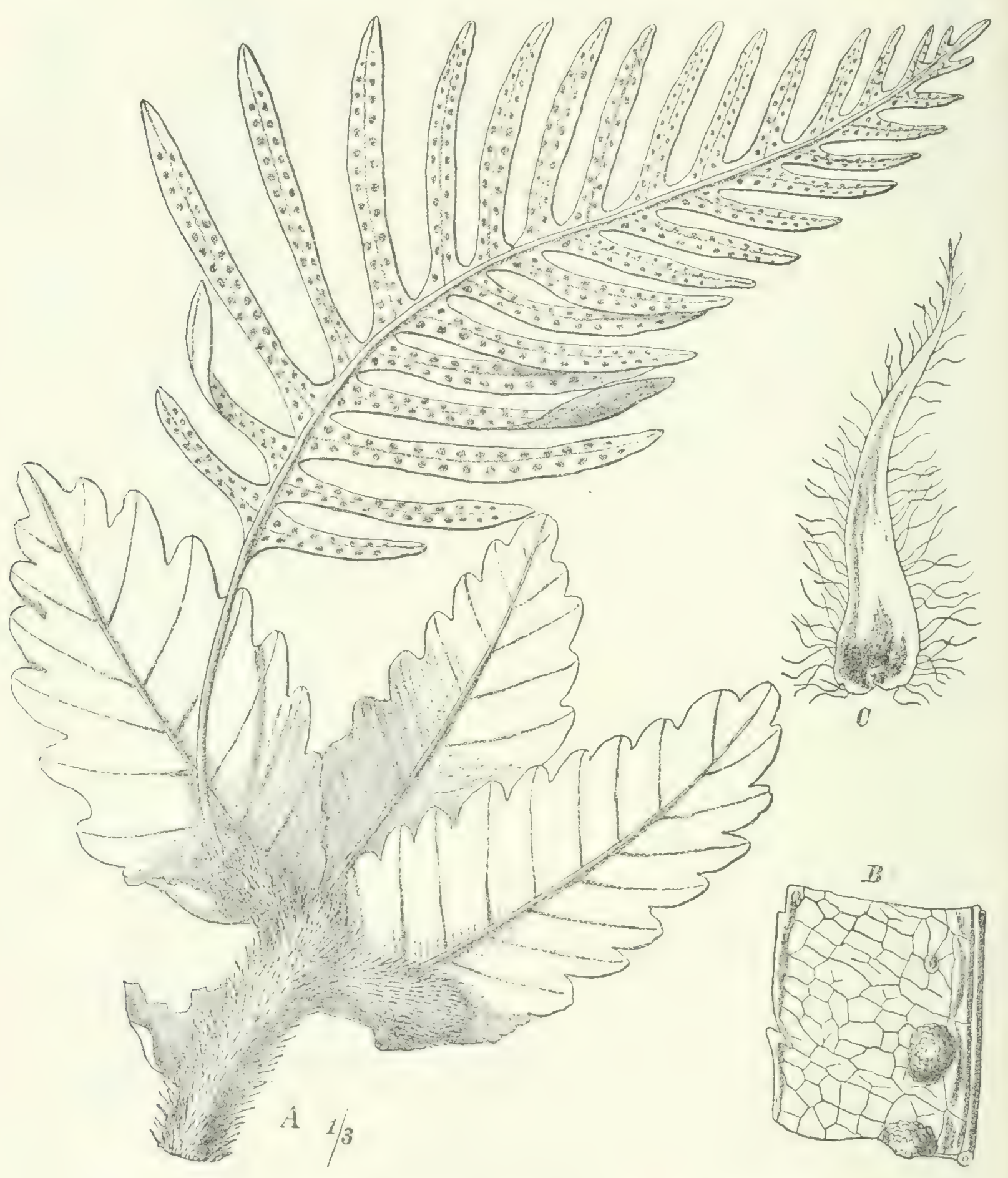

Fig. 54. Drynaria Laurentii (Christ) Hieron., von Usambara.

welchen sich reichlich Humus ansammelt, dann die abstehenden, tief fiederteiligen, assimilierenden und fruktifizierenden Blätter. - D. propinqua (Wall.) J. Sm.. mit oft 5-9 dm langen Fiederblaittern und nicht eingesenkten Soris, ist von Jata und dem Himalaya bis nach den Comoren (var. comorensis Hieron.) 
verbreitet. Im äquatorialen kontinentalen Afrika und auf Fernando Po tritt an ihre Stelle die habituell ibereinstimmende, aber mit gewimperten Spreuschuppen versehene D. I.aurntii (Christ) Hieron. IFig. 51; ; sic ist auch ganz besonders häufig in Usambara, wo sie oft die mächtigen Baumstämme des immergrünen Regenwaldes dicht bedeckt; sie steigt in Ruanda im Regenwald bis $2500 \mathrm{~m}$ auf. Die von letzterem Standort und auch einigen anderen hochgelegenen Punkten herstammenden Pflanzen können als D. Volkensii Hieron. abge-

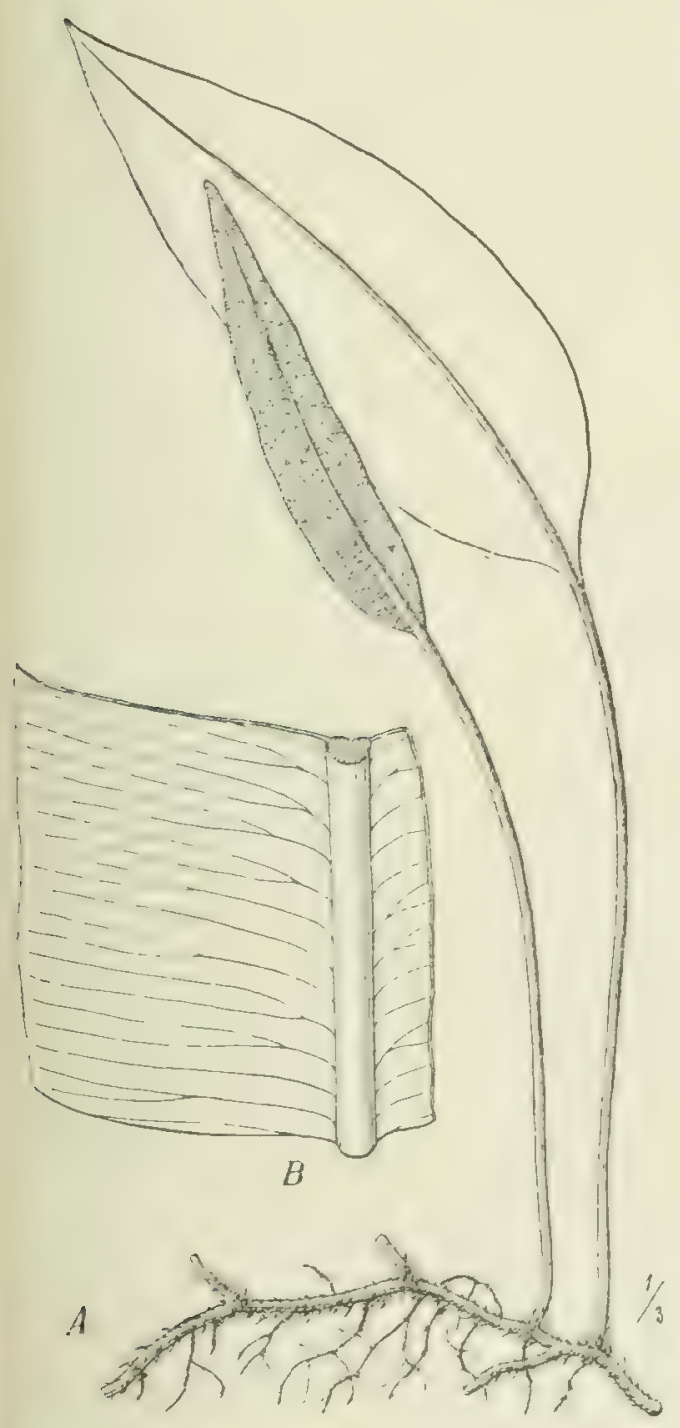

Fig. 55. Elaphoglossum conforme (Sw.) Schott.

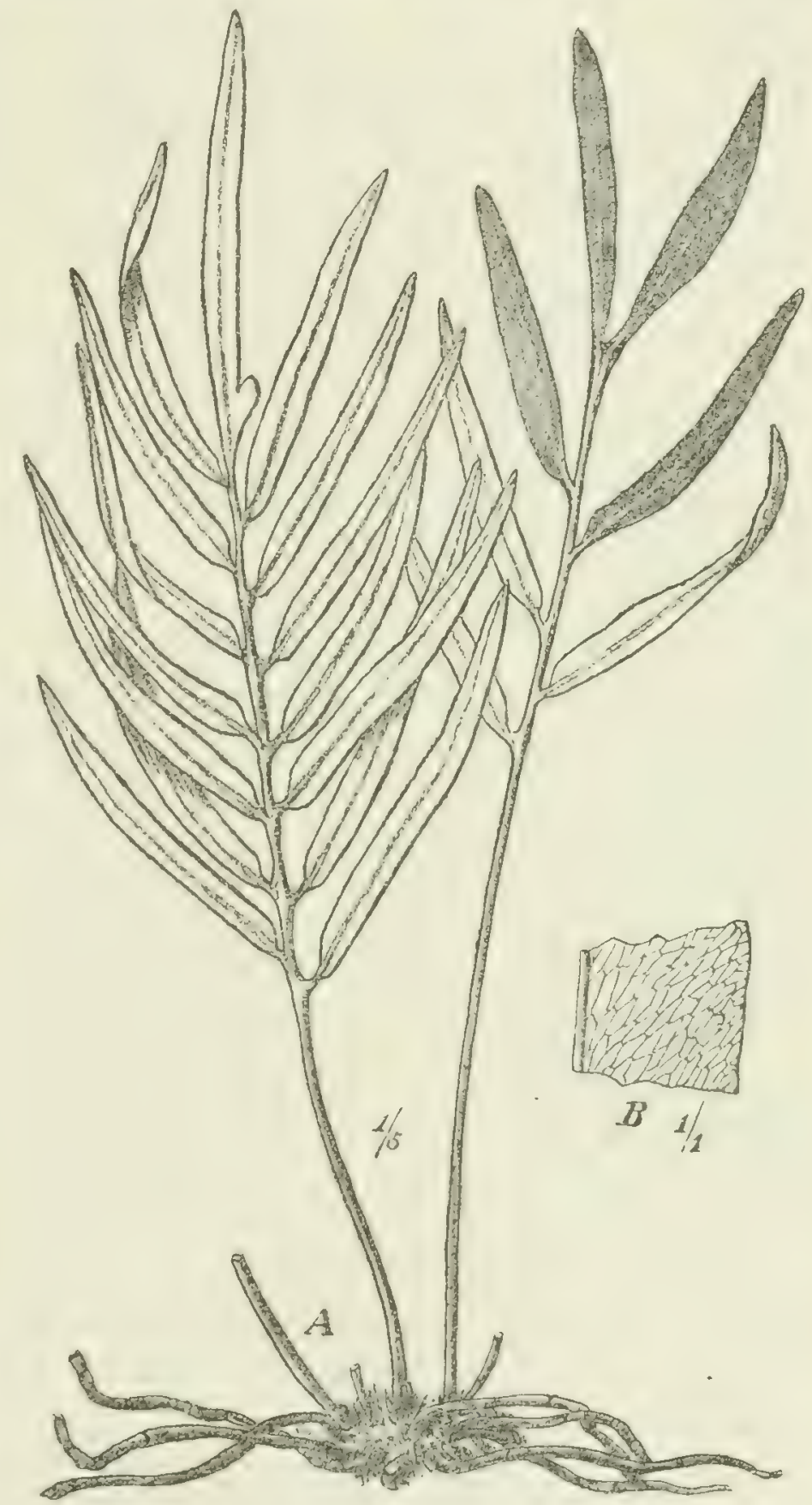

Fig. 56. Acrostichum aureum L.

schieden werden, wenn man darauf Wert legt, daß hicr die Spreuschuppen aus breiter Basis plötzlich in eine lange schmale Spitze zusammengezogen sind. Jedenfalls empfiehlt es sich, daß die in Afrika sammelnden Botanilicr darauf achten, inwiewcit sich das Verhalten der Spreuschuppen konstant crweist. D. Irilldenowii Bory) Woore mit eingesenkten Soris findet sich nur auf Mauritius und Madagaskar. 
IX. Aerosticheae, charakterisiert dadurch, daß die Sporangien einen Teil der Blattunterseite völlig bedecken.

Hygrophyten, Halophyten und Mesophyten.

a) Acrostichinae. Die Sporangien bedecken dic ganze Unterseite der fertilen Blätter. Die Adern der Blätter bilden keine Maschen. - Von den beiden hierher gehörigen Gattungen besitzt Elaphoglossum ungeteilte Spreiten, Acrostichum gefiederte.

Elaphoglossum Schott. a) Völlig kahle Blätter besitzt das hier abgebildete E. conforme (Sw.) Schott (Fig. 55), welches in den Tropenländern weitverbreitet, in Afrika von Usambara und dem Kilimandscharo bis zum suidwestlichen Kapland vorkommt und in clen Gebirgswaldungen sich noch bis $2300 \mathrm{~m}$ findet.

b) Einige Arten sind am Rande der sterilen Spreite mit Haaren oder schmalen, borstenartigen Spreuschuppen versehen, so das ein sehr kurzes Rhizom besitzende E. hybrilum (Bory) Noore, mit größerer steriler und klcinerer fertiler Spreitc, verbreitet rom tropischen Amerika durch die feuchten Waldgebiete Afrikas bis zu den Maskarenen, ferner das mit aufrechtem oder kurz kriechendem Rhizom versehene I: Aubcrtii (Desv.) Moore mit gleicher Verbreitung. Dichtere Schuppenbeklcidung besitzt E. spathulatum (Bory) Moore (E. piloselloides Presl), das in Afrika nur von Natal bekannt ist, sonst noch auf den Maskarenen, Tristan d'Acunha, Ceylon und den Anden vorkommt. Von ihm ist durch horizontal kriechendes Rhizom das auf das Kamerungebiet und Fernando P'o beschränkte E. cimnamonucum (Bak.) Diels verschieden. c) Mit gewöhnlichen breiten Spreuschuppen dicht besetzt sind die Blätter hei E. hirtum (Sw.) C. Chr. (=E. squamosum (Sw.) J. Sm.), welches in den Tropen der alten und neuen Welt weitverbreitet, in Afrika bis jetzt nur auf dem Kamerungehirge um $1900 \mathrm{~m}$ gefunden wurde, aber auch auf den Maskarenen und in Makaronesien sich findet.

Acrostichum L. I lierzu gehört das für die Mangrovensümpfe und die Ufer ron Iilußniederungen der alten und neuen Welt höchst charakteristische, also halophytische, oft massenhaft auftretende -1. aurum L. (Fig. 56) mit holzigem Rhizom und bisweilen $2 \mathrm{~m}$ langen, hart lederigen Fiederblättern, denen anfangs ungeteilte Bliitter vorangehen; es reicht nordwärts bis Sansibar und Liberia, südwärts bis Pondoland.

b) Platyceriinae. Die Sporangien bedecken entweder die ganze Blattunterseite oder einen Teil derselhen. Die Adern bilden ein enges Maschennetz.

Platycerium Desv. Die hierzu gehörigen großen epiphytischen Farne tragen an kurzem Rhizom herznierenförmige, oben konkave, den Baumstämmen sich anpressende, anfangs wasserreiche, dann vertrocknende und bis auf die Adern verwesende Mantelblätter, aus deren zerstörten Substanzen den von ihnen becleckten Adventivwurzeln humöse Nahrung zugeführt wird und meist geweihartig zerteilte Blätter, welche der Assimilation und Fortpflanzung dienen. - Ungeteilte, keilförmige, am Saume gekerbte und rosenfarben behaarte Blätter besitzt $I$. angolcnse Welw. (P. clephantotis Schweinf.), im inneren Afrika im Ghasalquellengebiet, im Livingstonegebirge und im tropischen 


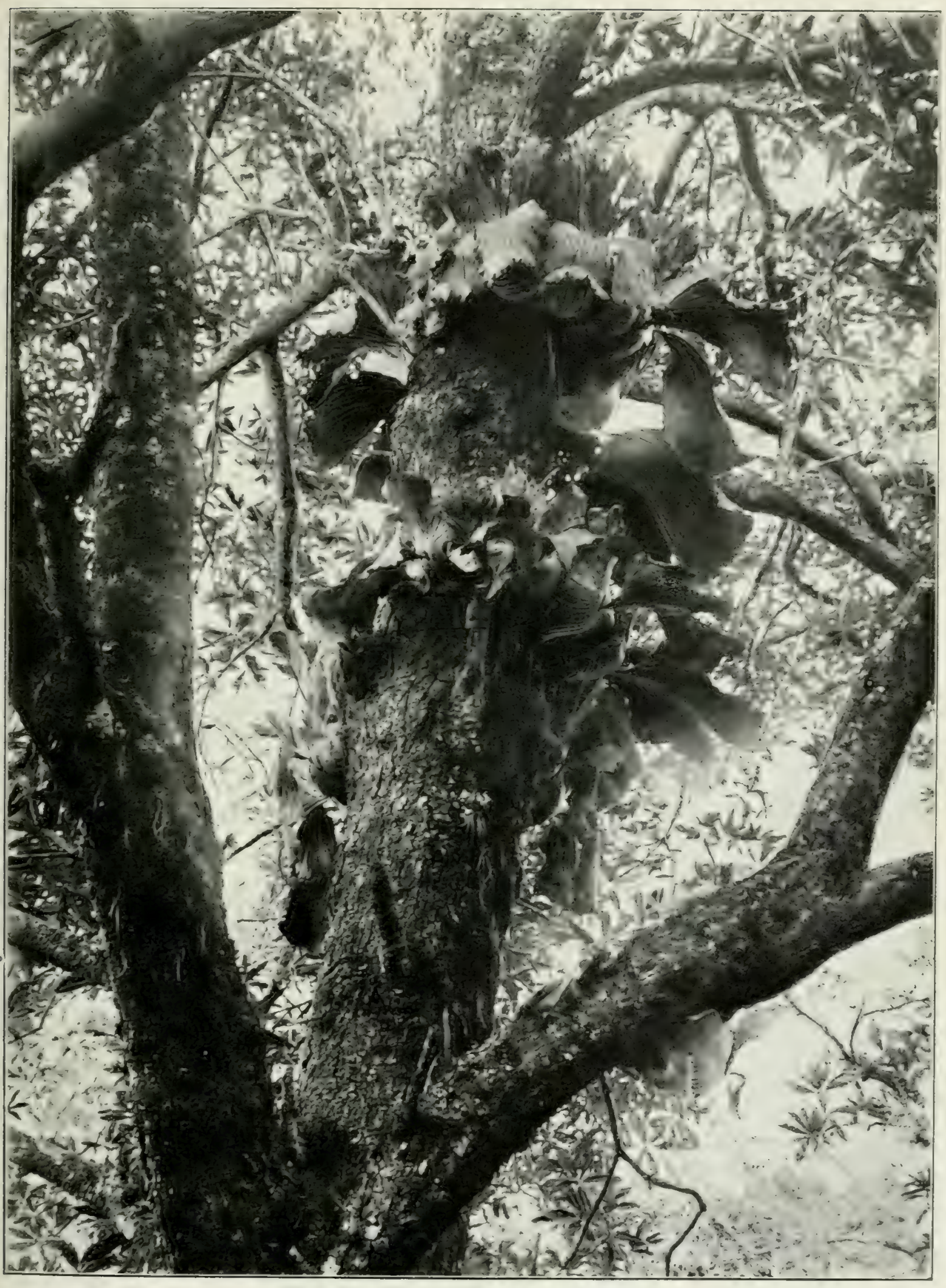

Platycerium angolense, Welw.

Auf Baumstämmen in Schluchten am westlichen Abfall des Livingstonegebirges, um $600 \mathrm{~m}$ ü. d. MI. Nach einer Photographie von Walter Goetze (IS99!. 

Angola. Die übrigen Arten haben dichotom geteilte Blätter, nämlich: $I$. stemmaria (Beauv.) Desv. (Fig. 57), dessen Mantelblätter konkav und am Rande umgeschlagen sind, im tropischen Westafrika von Senegambien bis zum Kongo und bis zum zentralafrikanischen Seengebiet; P. lifurcutum (Cav.) C. Chr.

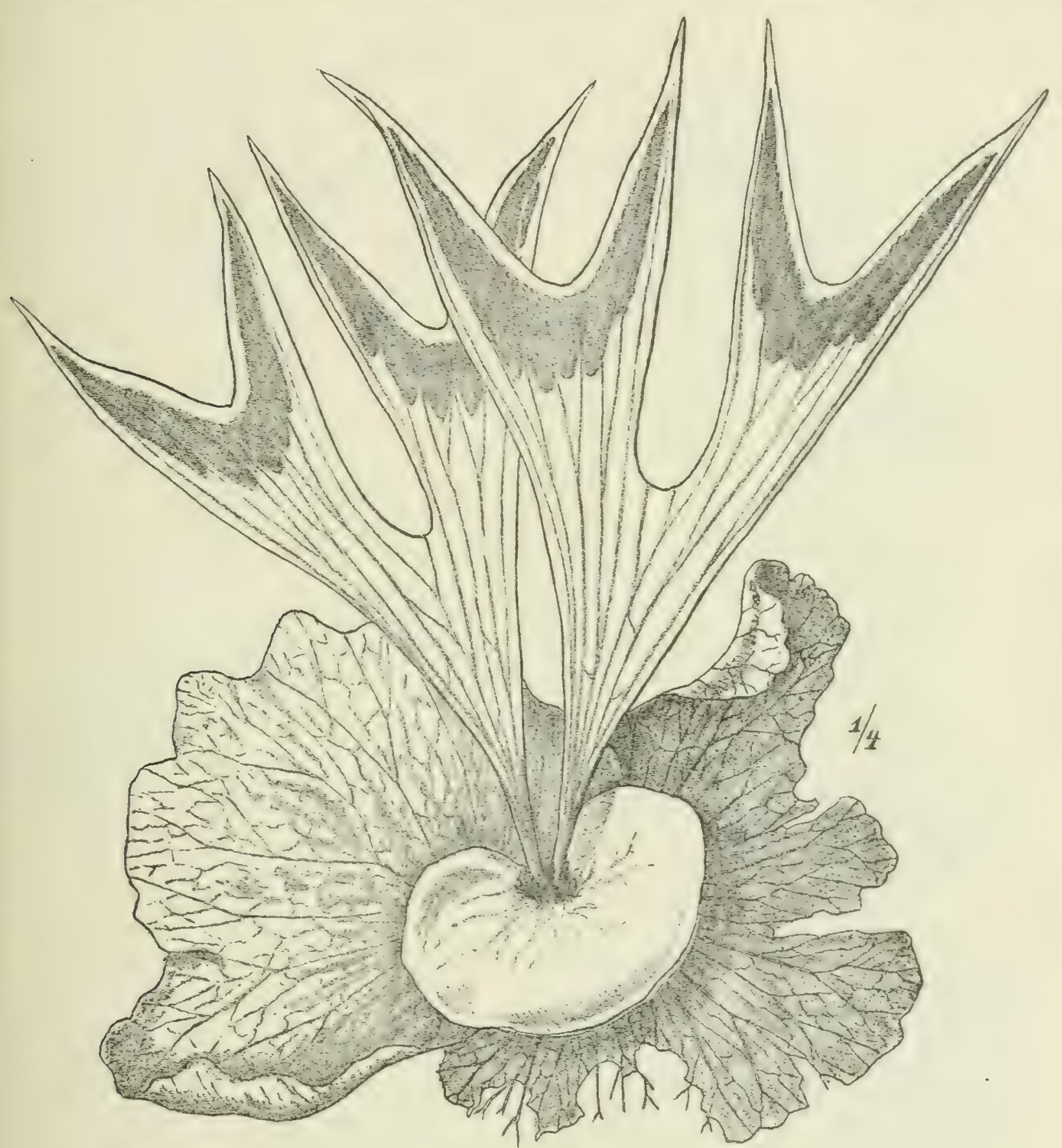

Fig. 57. Platycerium stemmaria (Beauv.) Desv.

(= P. alcicome Desv.', mit gelappten Mantelblättern, bei Mombassa, auf den Maskarenen, Comoren und Madagaskar; auch in Ostaustralien.

\section{Fam. Parkeriaceae.}

Eine monotypische Familie mit einem in Schlamm wurzelnden, auch schwimmenden Wasserfarn mit weitgehender Verschiedengestaltigkeit dor aufo 
einanderfolgenden Blätter: die letzten sind mehrmals gefiedert mit schmal linealischen Abschnitten, auf denen die Sporangien zerstreut stehen. An den Wasserblättern bilden sich in den $\Lambda$ chseln der Blattabschnitte Adventivknospen.

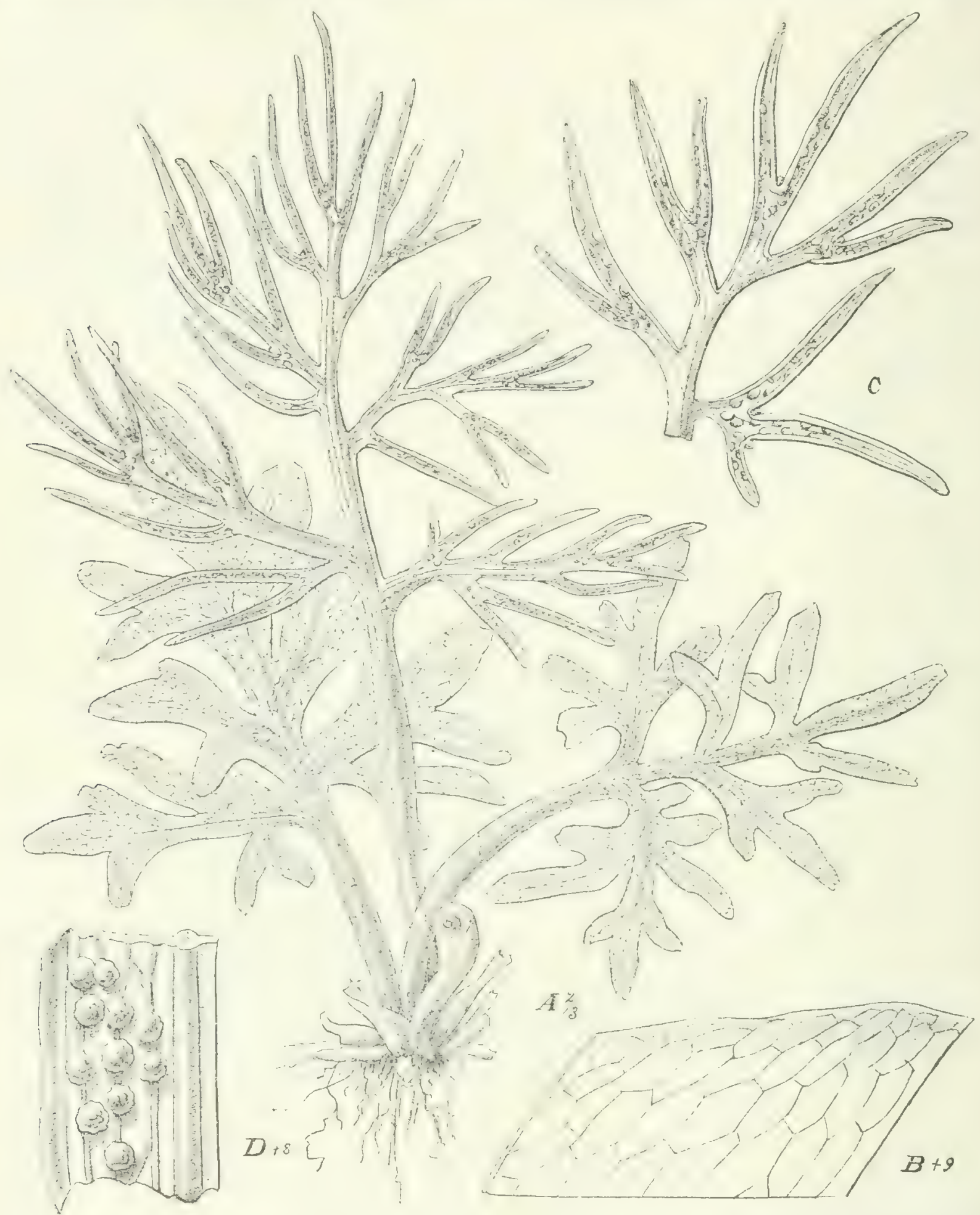

Fig. 58. Ceratopteris thalictroides (L.) Brongn. $A$ Habitus; $B$ Teil eines sterilen Blattsegmentes mit Aderung; $C$ fertile Fieder; $D$ Teil davon.

Hydrophyten.

Ceratopteris thalictroides (L.) Brongn., durch alle Tropenländer verbreitet, findet sich im tropischen Afrika ron Senegambien bis Angola und im Ghasalquellengebiet, auch auf Socotra, ist aber noch nicht aus Ostafrika nachgewiesen. 


\section{Fam. Gleicheniaceae.}

Erdfarne mit meist kriechendem Rhizom, mit ausgesprochicn dichotomischer Verzweigung der ersten Glieder und fiederiger der letzten Ordnung. Sori klein, aus wenigen Sporangien zusammengesetzt, welche mit einem querverlaufenden Ring versehen sind.

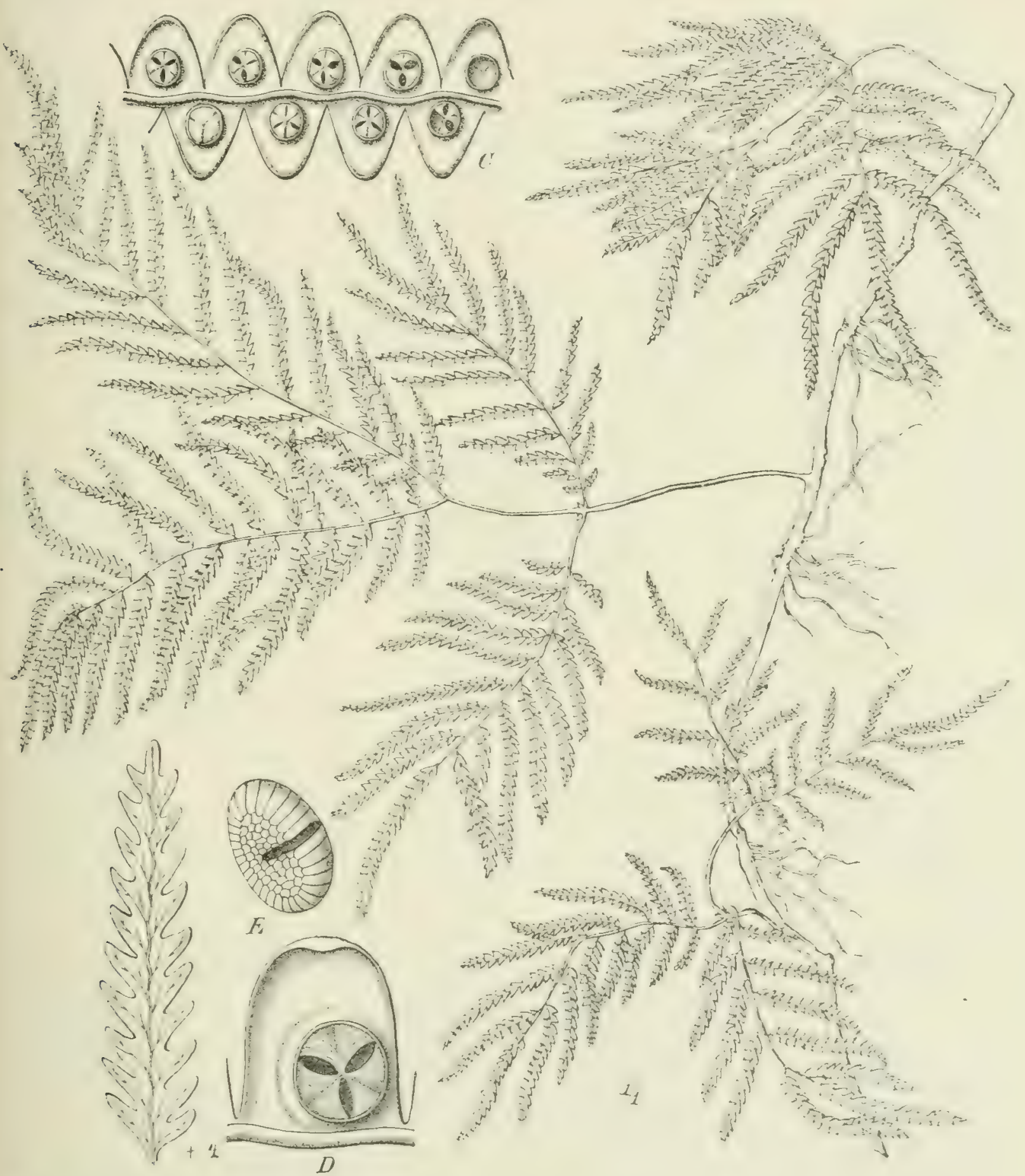

Fig. 59. Gleichenia polypodioides (L.) Sm. von Natal. $A$ Habitus; $B$ steriles Segment; $C$ fertiles; $D$ Stück desselben vergr.; $E$ Sporangium.

Gleichenia Sm. ist in Afrika nur mit wenig Arten vertreten.

Untergatt. Mertensiu (Willd, mit meist länglichen oder linealischen Blattsegmenten. G. umbraculifora (Kze.) Moore zeigt an allen Blattspindeln oberhalb 
der ersten Gabelung lineale Fiedern, sie findet sich in Natal, Transvaal und bei King Williamstown, auch am Mukenge unter $6^{\circ} \mathrm{s} . \mathrm{B},-G$. linearis (Burm.) Clarke (G. dichotoma (Thunb.) Hook.) besitzt wiederholt gegabelte Blätter, bei denen die Spindel nur an den Auszweigungen letzter Ordnung mit Fiedern besetzt ist, außerdem an den Gabelungsstellen zwei gegenständige, etwas kürzere oder reduzierte Fiedern trägt; sie ist in den tropischen und subtropischen Ländern verbreitet und bildet Formationen wie Pteridizm; sie findet sich von Usambara bis Transvaal und von Sierra Leone bis Angola. Im Ulugurugebirge bedeckt sie in feuchten Talschluchten oft weite Flächen und in Kamerun steigt sie an Flußufern zwischen Bäumen und Sträuchern oft bis $10 \mathrm{~m}$ hoch, undurchdringliche Mauern bildend, ebenso auf den Comoren. In den tropischen Gebirgen ist sie bis zu einer Höhe von $2300 \mathrm{~m}$ anzutreffen, ist aber dann niedriger.

Untergatt. 2. Englcichcnia Diels, mit unterseits bläulichweißen Blättern und kleinen, rundlichen Fiedern 2. Ordnung. Hierher G. polypodioides (L.) Sm., von Transvaal und Angola bis zum Kapland (Fig. 59).

\section{Fam. Schizaeaceae.}

Die habitucll sehr verschiedenen und leicht kenntlichen Gattungen dieser Familie haben stets einzeln stchende Sporangien, bei denen der am Scheitel stchende Ring transversal verläuft. Alle Gattungen sind in Afrika vertreten, jedoch nur sparsam.

Hydrophyten, Hygrophyten und Mesophyten.

A. Stammleitbiindel axil.

$$
\text { Übersicht. }
$$

a) Blätter vielzeilig. Spindel aufrecht. Sporen bilateral

Schizaeeae.

b) Blätter einzeilig. Spindel windend. Sporen kngelig-tetraedrisch . Lygodieae. B. Stammleitbündel eine netzige Röhre bildend. Sporen kugelig-tetraedrisch

Aneimieae.

Schizaceac. -- Schizaea Sm. trägt am Rhizom die Blätter in mehreren Reihen, die langgesticlten Blïtter sind ungeteilt oder dichotomisch verzweigt und tragen am Ende der Segmente die gefiederten fertilen Abschnitte. - Nur zwci einander nahestehende Arten in Natal und dem Kapland, Sch. pectinati L.) Sw., von den sandigen Flats um Kapstadt bis auf den Gipfel des Tafelberges, auch an Abhängen, wo das Gras abgebrannt ist; und Sict tenella Kaulf, in Sümpfen wachsend.

Lygodicae. - Lygodium Sw. Dem mit zentralem Leitbündel verschenen kriechenden Stamm entspringen oft schr lange, windende, unbegrenzt wachsende, mehrfach gefiederte Blätter, deren fertile Ảbschnitte die Sporangien einzeln an den fiederigen Adern tragen, dieselben bedeckt von einer darüber gewölbten Hülle. Es kommen nur drei Arten in Afrika vor.

Sekt. I. Tolulilic Prantl. Fiedern 3. Ordnung ohne geförderte Basallappen. - Hierher L. scandens (L.) Sw., mit gestielten Fiedern I., in Usambara und im tropischen Westafrika von Senegambien bis Angola, überall häufig 


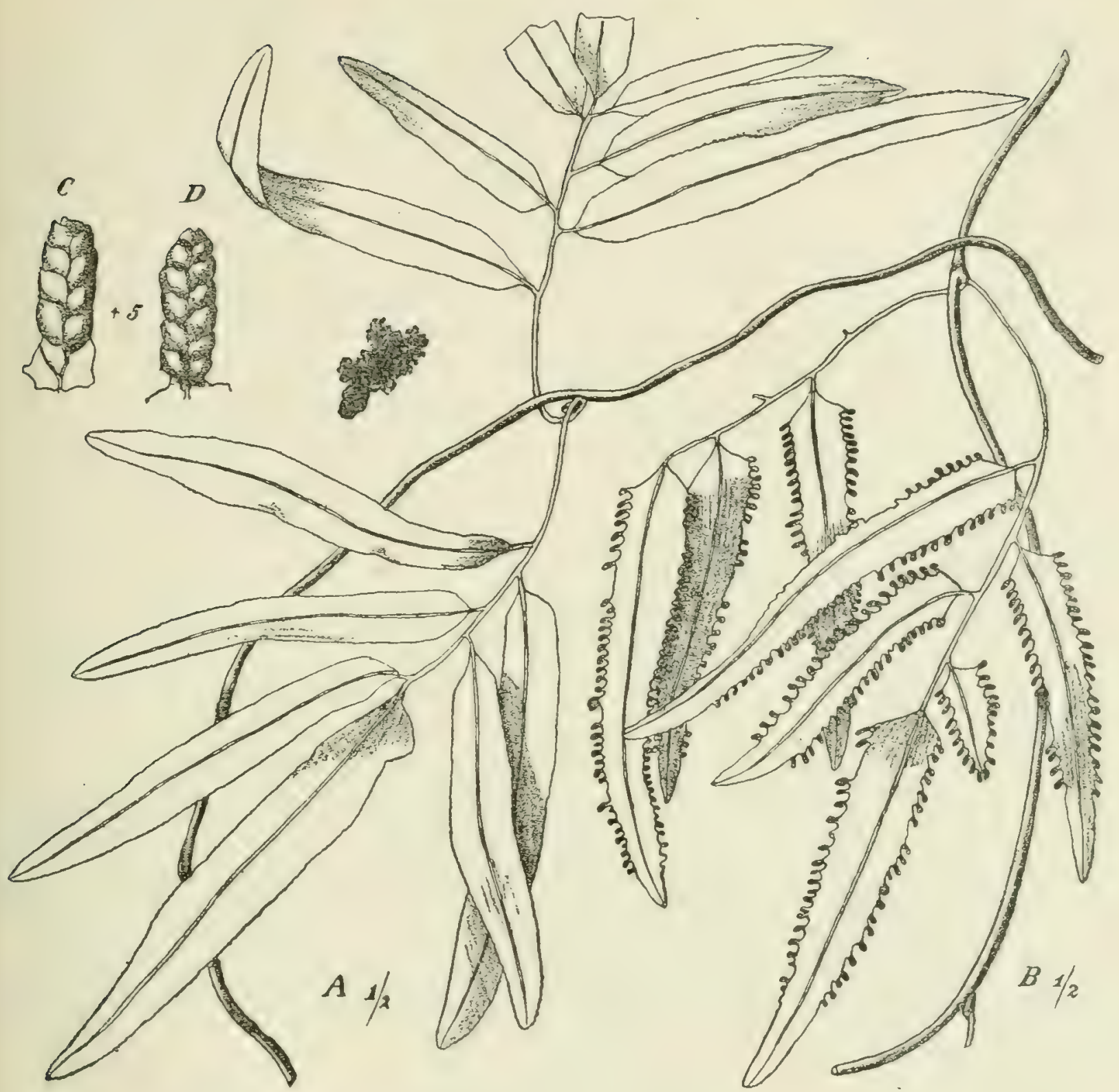

Fig. 6o. Lygodium Smithianum Presl, Kamerm. $A$ steriler Blattteil; $B$ fertiler Blattteil; $C, D$ fertile Enden der Abschnitte mit den dichtstehenden von Hüllen bedeckten Sporangien.

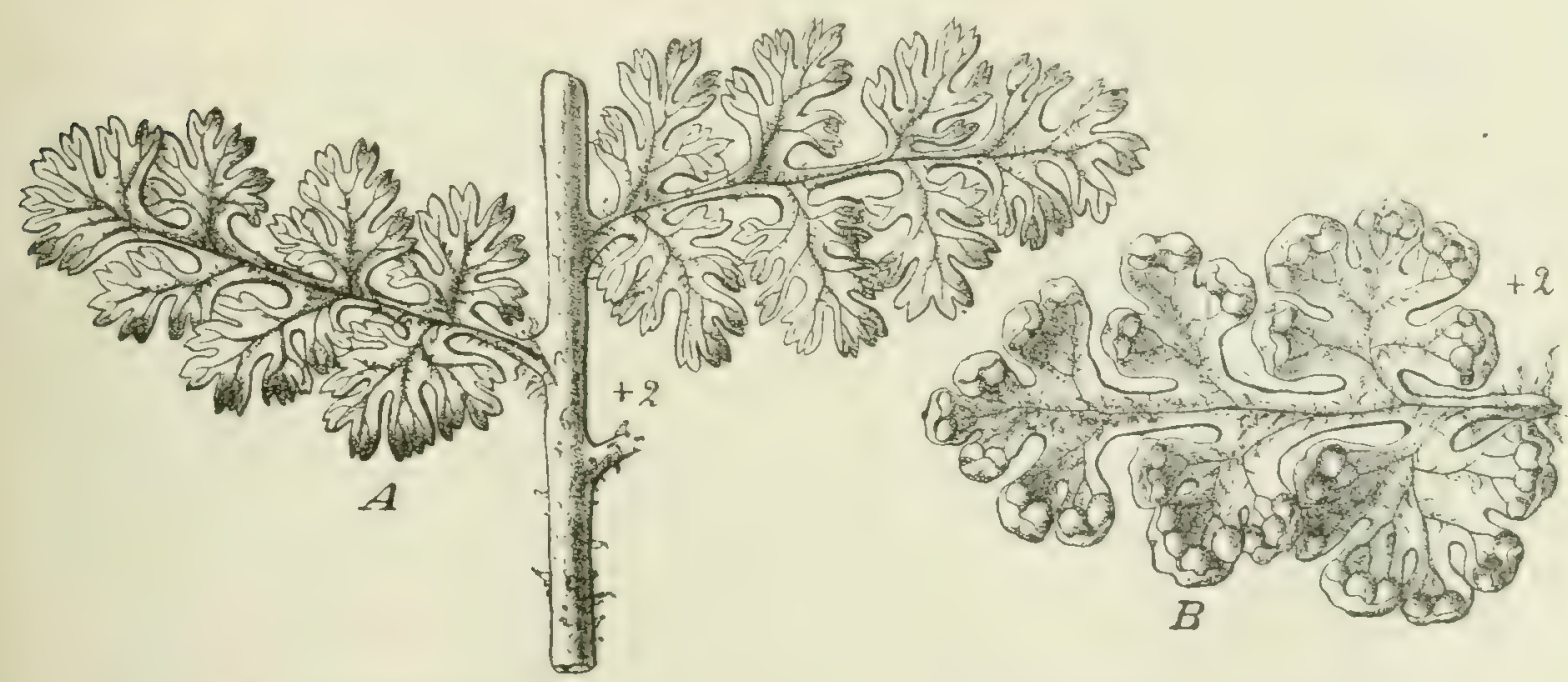

Fig. 61. Mohria caffrorum (L.) Desv. $A$ Teil des sterilen Blattes; $B$ fertile Fieder. 
an Flußufern, bis $5 \mathrm{~m}$ hoch. - L. Smithianm Presl (Fig. 60), bisweilen mit $\therefore \mathrm{dm}$ langen Fiedern letzter Ordnung, nur vom Nigergebiet bis zum südichen Angola, gern in Lichtungen der Regenwälder, selten über $300 \mathrm{~m}$ ü. M.

Sekt 2. Flexuosa Prantl. Fiedern 3. Ordnung mit geförderten Basallappen. - L. Kerstenii Kuhn (=L. subalatum Boj. msc. nach Kuhn), bei Mombassa, auf den Comoren und Nadagaskar; nur in den Niederungen an feuchten Talwänden.

Aneimieae. Die Blätter sind meist fiederig verzweigt.

Mohria Sw, besitzt einzeln stehende Sporangien am Ende der Adern. Wir unterscheiden nur eine Art, . I. cuffromm, L.; Desv. Fig. 6I), mit höchstens $5 \mathrm{dm}$ langen dreifach gefiederten Blättern, welche von Spreuschuppen und klebrigen stark duftenden Drüsen bedeckt sind; die von anderen nach der Behaarung unterschiedenen Arten betrachtet man besser als Varietäten. Die Pflanze ist von Usambara und dem Kilimandscharo bis Natal und von Angola bis Kapland verbreitet. Sie findet sich in Ostafrika besonders in der Region des Gehirgsbusches, an Felsen und zwischen Geroll, aufsteigend bis zu $2300 \mathrm{~m}$, in Südafrika in geringerer Höhe. Die ausgezeichnetste Varietiit ist rar. lepigera Bak. mit lichter Schuppenbekleidung, im südlichen Nyassaland.

Aneimia Sw. Die Gattung fällt besonders dadurch auf, daß an den fertilen Blättern das unterste Fiedernpaar über dic sterilen Fiedern bedeutend verlängert, stark verzweigt ist und längs der Mediane der fertilen Abschnitte dicht in zwei Zeilen stehende Sporangien trïgt. Die Gattung ist in Afrika nur schwach rertreten. in Abyssinien, bei Langenhurg und in Benguella durch 1. Schimpirima Presl mit doppeltyefiederten Fiedern r.) und in den Küstenwäldern von Natal und Pondoland durch . Tregena Kze. (mit einfach gefiederten Fiedern I).

\section{Fam. Osmundaceae.}

Diese entwickeln meist einen sehr kräftigen Grundstock mit dicht gedrängten, großen Blätten, welche kurzgestielte fast kugelige Sporangien ohne Ring tragen. - Hydrophyten.

Todea Willd. entwickelt einen mächtigen, bisweilen I $m$ dicken und hohen, von Adventivwurzeln dicht besetzten Stamm, der I- I, $8 \mathrm{~m}$ lange, doppelt gefiederte, saftreiche Blaster trägt, deren fertile Fiedern nicht zusammengezogen sind. Die einzige Art. T. Kmbtura, L.) Noore. wichst gern an Bächen und ist bisweilen schr häufig: sic ist cine der wenigen Pflanzen, welche ohne weitere Verbreitung zu besitzen, Australien, Neusceland und dem Kapland cigentumlich sind; in letzterem ist sie namentlich an den Bächen des Tafelberges häufig und kommt bis Natal dort auch in den Drakensbergen; ror.

Osmunda L. Die bekannte und von den borealen Ländern bis nach der südlichen Hemisphäre weit verbreitete 0 . regalis $\mathrm{L}$. findet sich in Afrika zerstreut von L'sambara bis zum Kapland; sie wächst gern unter Gebüsch an Bachufern, variert sehr in der Länge und Breite der Fiedern. 


\section{Fam. Marsiliaceae.}

Diese sehr eigenartige, aber durch die in der Knospenlage spiralig eingerollten Blätter und die Entwicklung ihrer Sporangien an die Eufilicineen erinnernde Familie der Unterreihe Hydropteridineen fällt hesonders auf durch die sogenannten Sporocarpe, welche Sori mit Maliro- und Mikrosporangien einschließen, auf deren in allen Handbüchern geschilderten Bau hier nicht cingegangen werden soll. Die durch spreitenlose Blätter und kugelige Sporocarpien ausgezeichnete Gattung I Ilularic L. geht nicht über das Mittelmeergebiet hinaus nach Afrika, dagegen ist die mit vierteiligen Blättern versehene Marsilia in unserem Erdteil ziemlich artenreich. Die Arten wachsen auf zeitweise bewässertem Boden oder in Sümpfen und an Waldbächen; einzelne steigen bis zu $2300 \mathrm{~m}$ ü. $\mathrm{M}$. auf. Die meisten Arten sind wissenschaftlich nur nach den Früchten zu bestimmen; es soll hier ganz kurz auf die wichtigsten hingewiesen werden. Eine Art, $M$. subterranea Leprieur, welche in Senegambien vorkommt, ist dadurch charakterisiert, da $\beta$ die zusammengedrückten, am Grunde des Blattstieles einzeln stehenden und sich nach unten wendendenSporocarpien mit Seitennerven versehen

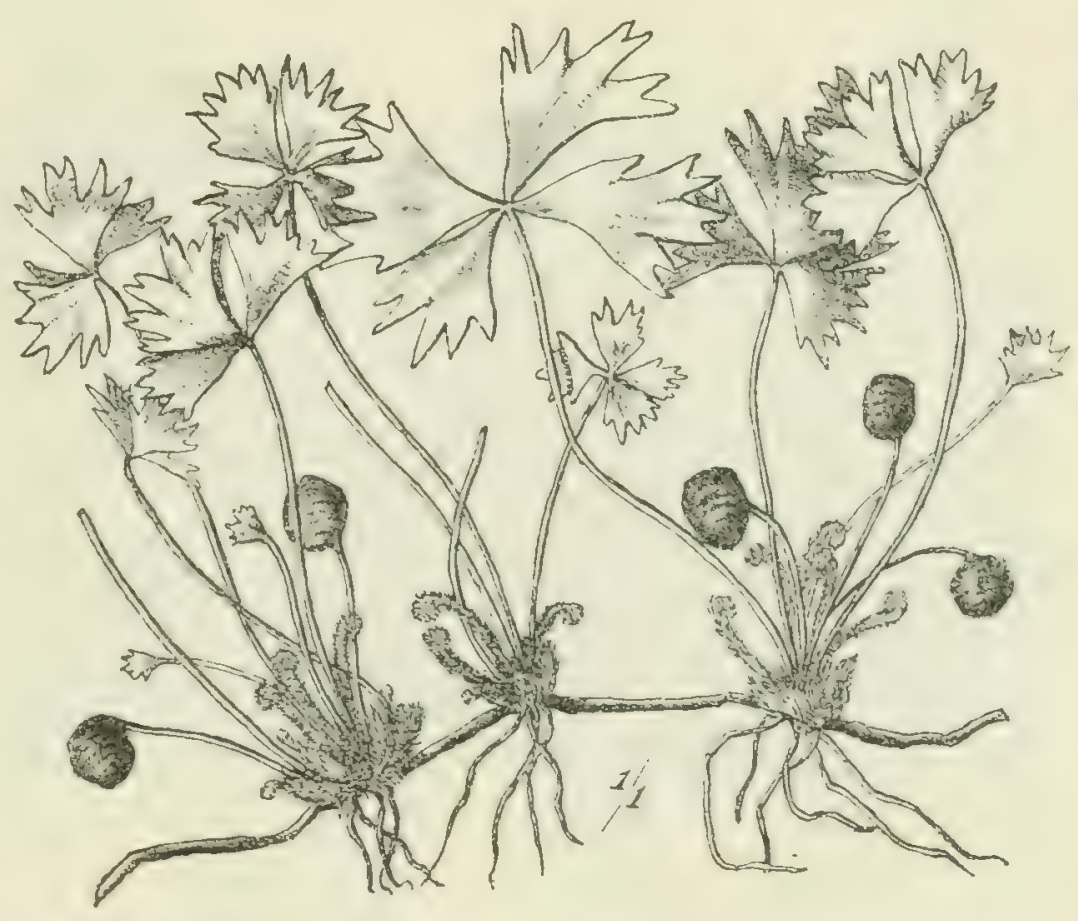

Fig. 62. Marsilia Fischeri Hieron.

sind, welche nahe an der Gabelung anastomosieren. -- Bei allen anderen Arten bleiben die Seitennerven bis zur Bauchnaht des Sporocarps getrennt. Unter diesen besitzen MI. diffusa Lepr. und II. crinulata Desv. mehrere Sporocarpien an demselben Blattstiel, erstere meist 3-4, letztere meist 2. MI. diffuso Lepr. können wir von Algier und den Kanaren nach Senegambien, im Osten nach U'saramo und den Comoren verfolgen, wo sie besonders in Küstensümpfen gedeiht, auch bis Nadagaskar. M. crcmulate Desv. mit gekerbten Blattsegmenten findet sich in Scnegambien und auf Mauritius. - Bei den folgenden Arten ist in der Regel nur ein Sporocarp am Grunde des Blattstiels vorhanden. Hier ist zunächst eine im Kapland, Ägypten und Zentralafrika vertretene Artengruppe durch einen deutlichen Zahn am oberen Ende des Sporocarps ausgezeichnet: II. biloba Willd. und HI. macrocarpa Presl sind die am längsten bekannten Arten dieser Gruppe. . I. macrocarpa Presl vom Kapland besitzt längliche Frïchte, 
und die ihr nahestehende, in Sümpfen Benguellas um $1500 \mathrm{~m}$ mit Ottelia, Xyris und Funcus zusammen wachsende $M$. rotundata $\mathrm{A}$. Br. hat kürzere
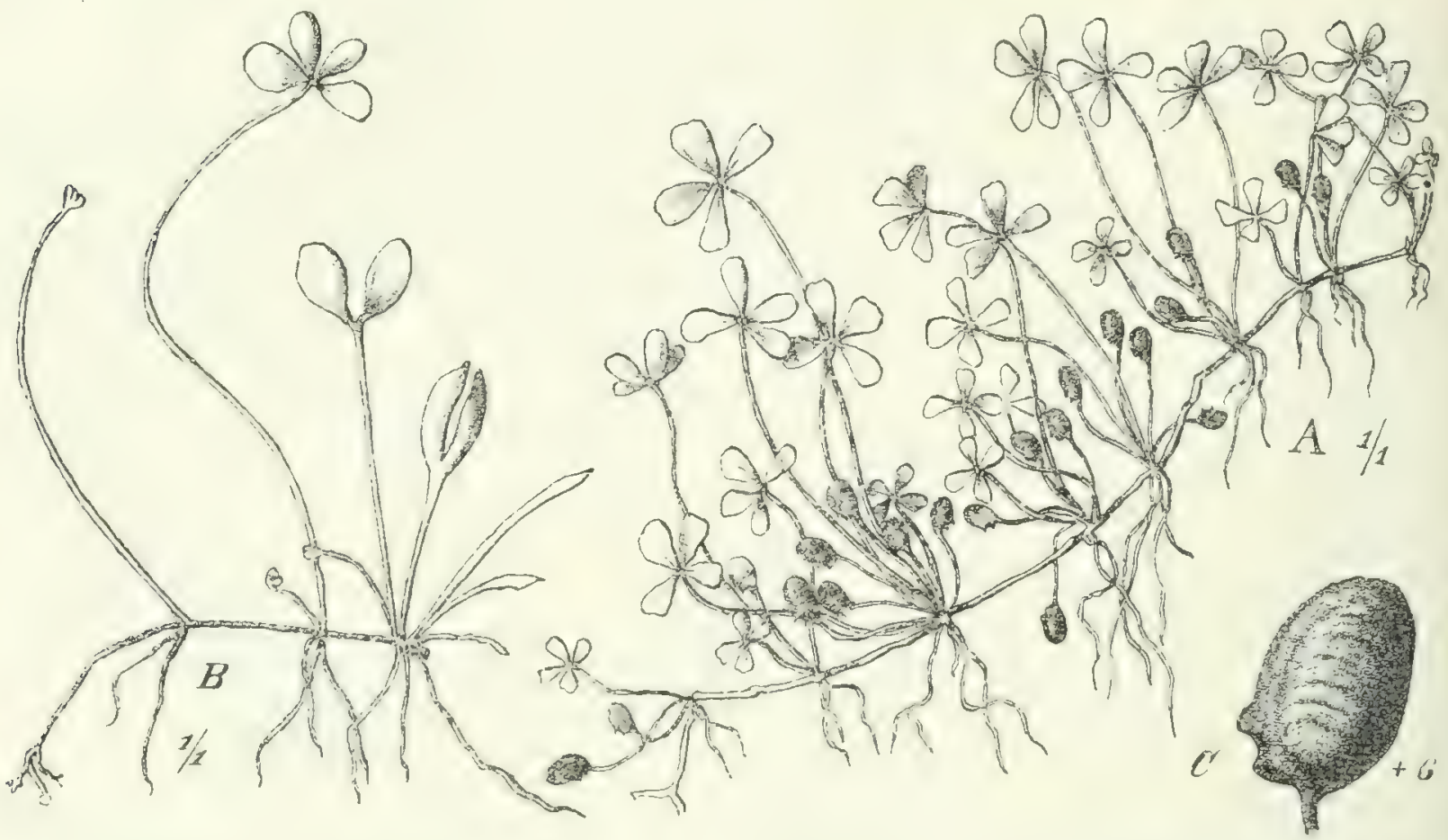

Fig. 63. Marsilia trichopoda Lepr. $A$ ausgewachsene Pflanze; $B$ junge Pflanze; $C$ Sporocarp.

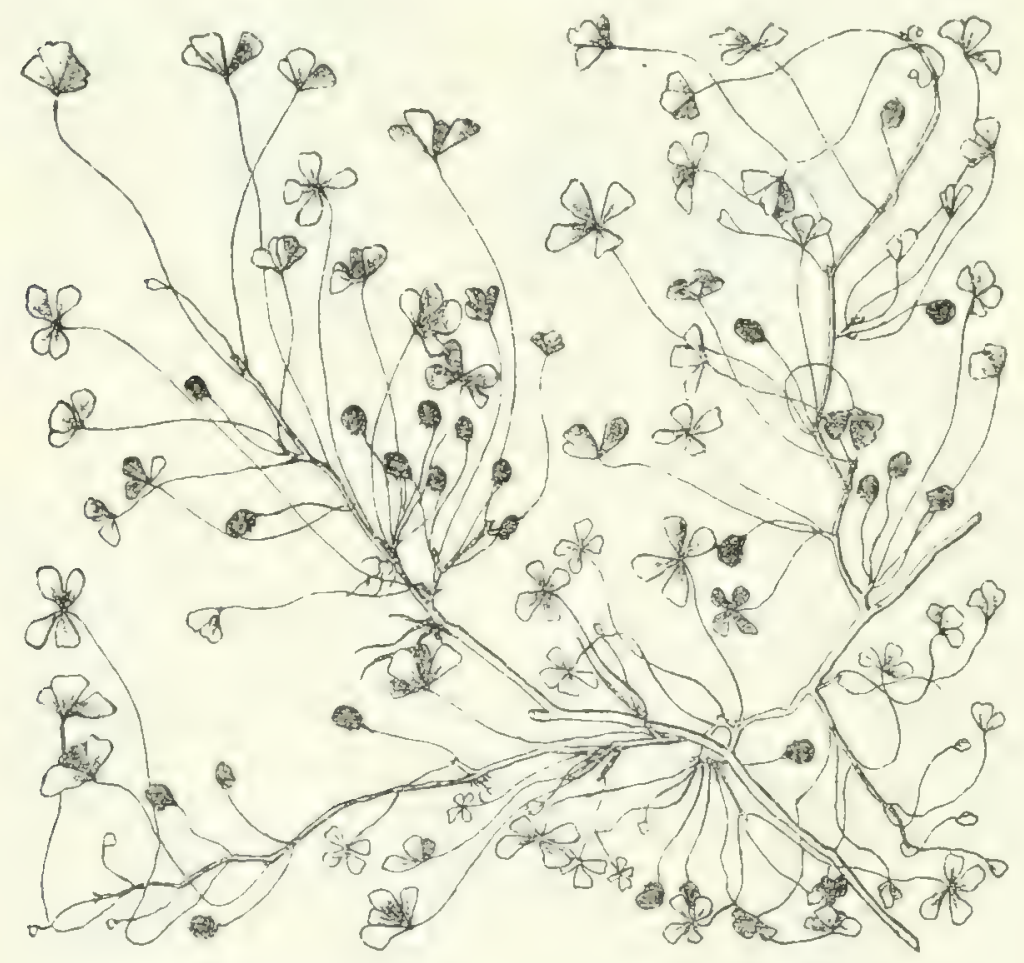

Fruichte; beide Arten haben einen stumpfen Fruchtzahn. Stachelspitz ist derselbe bei M. biloba Willd., welche auch durch zwei- bis vierlappige Blättchen auffällt; sie ist vom westlichen Kapland bis nach dem südlichen Benguella zerstreut anzutreffen. Kürzer ist der Fruchtzahn bei der oft sehr kleinen $M$. capensis A. Br. Mehr abgestutzte Sporocarpien finden sich bei der nordafrikanischen $M$. aegyptiaca Willd. und der im Ghasalquellengebiet vor-

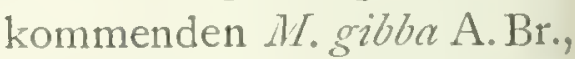
desgl. bei der im Massailand gefundenen $M$. Fischeri

Hieron. Fig. 62, welche durch ihre eingeschnitten gelappten Blattabschnitte auffällt. - Zwei deutliche Zähne zeigen an der sehr lang gestielten Frucht M. trichopoda Lepr. (Fig. 63) und M. muscoides Lepr. (Fig. 64) in Sene- 
gambien. Einige andere Arten besitzen keinen Zahn am Sporocarp, nämlich

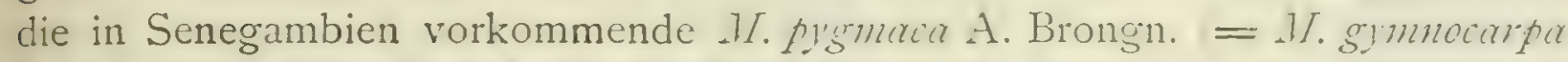
Lepr.; sowie .I. mulica A. Br. in Kordofan, alles kleine, an ausgetrockneten Tümpeln wachsende Arten.

\section{Fam. Salviniaceae.}

Von dieser Familie der Unterreihe Hydropteridine kommen beide hierzu gerechnete Gattungen in Afrika vor.

Hydrophyten.

Salvinia L. Nur eine der in der nördlich gemäßigten Zone weitverbreiteten S. matrms nahestehende Art, welche durch schwarze Punkte auf der Oberseite der Schwimmblätter ausgezeichnet ist. findet sich im Nigergebict, S. nigropunctate $\mathrm{A} . \mathrm{Br}$.

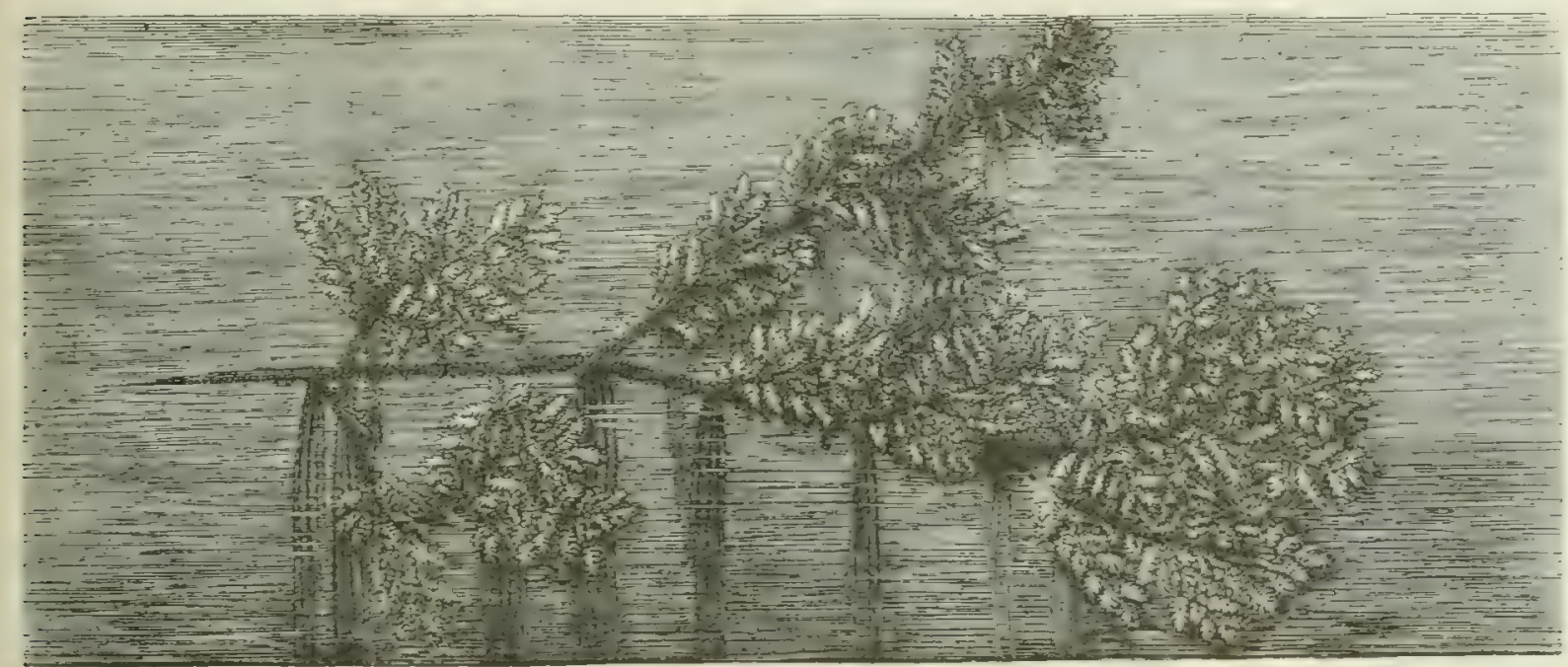

Fig. 63. Azolla nilotica Decne.

Azolla Lam. Es ist hier nicht der Platz, die komplizierten morphologischen Verhältnisse dieser Gattung zu erläutern; der Habitus ergibt sich aus der Abbildung. Es finden sich zwei Arten im tropischen Afrika, bei denen die Makrospore mit neun Schwimmkürpern versehen ist, während die in Amerika und Australien vorkommenden Arten nur drei Schwimmkörper besitzen.

A. pinnata R. Br., welche am Grunde der Zweige keine Seitenknospen produziert und einzeln stehende ITurzeln trägt, ist ron U'sambara bis zum Kapland verbreitet: A. Milotica Decne. (Fig. 65), welche am ganzen Sprosse Seitenknospen bildet und Büschel von Wurzeln trägt, findet sich vom weilßen Nil bis zum Rovuma, Rukwa-See und Lualaba, auch in Tümpeln der Steppe, nicht bloß auf dem Wasser schwimmend, sondern auch sich aufrichtende Zweige bildend; sie kommt am Meru in dem großen Waldsumpf über Eugonjo Engare noch bei i joo $\mathrm{m}$ ü. M. vor (Prof. UHLiG). 


\section{Reihe Marattiales.}

\section{Fam. Marattiaceae.}

Große farnartige Gewächse, alle afrikanischen mit kurzem, oft knolligem und viel Stärke enthaltendem Stamme, mit sehr großen, einfach oder mehrfach gefiederten Blättern, welche in der Jugend von großen Nebenblättern bedeckt

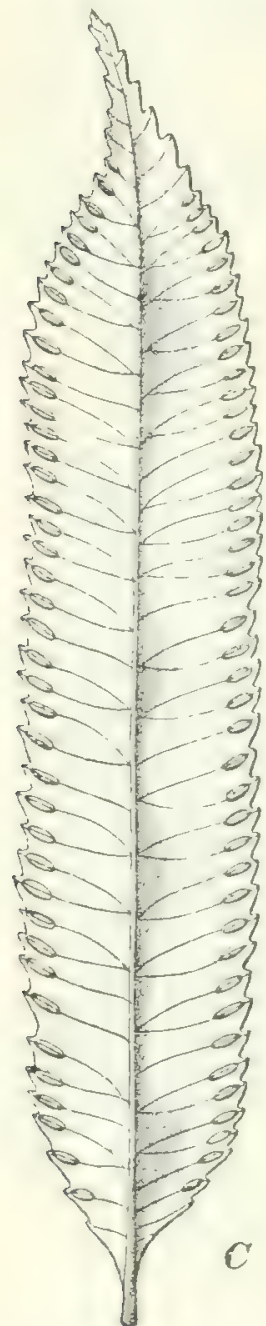

Fig. 66. Marattia fraxinea Sm. $C$ Fiederblättchen; E Synangium; $F$ Querschnitt durch dasselbe.

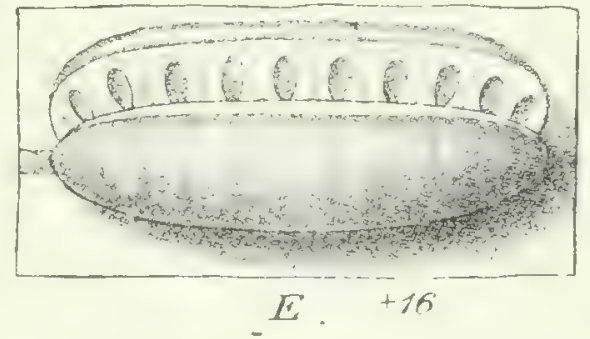
sind und an den Blattstielen, bisweilen auch am Grunde der Fiedern mit Gelenkpolstern versehen sind. Die Sori bestehen entweder aus mehreren in zweỉ Reihen geordneten, freien Sporangien oder stellen ein gefächertes Synangium dar; in jedem Falle werden die Sporangien aus mehreren Zellschichten gebildet. Sie sind ausgesprochene Hygrophyten, die oft in größerer Zahl in den Regenwäldern auftreten.

Marattia Sm., mit Synangien, ist die einzige in Afrika vorkommende Gattung der Familie. MI. fraxinea Sm., bisweilen mit $3,5 \mathrm{~m}$ langen und iiber $2 \mathrm{~m}$ breiten Blättern ist der charakteristische Erdfarn für die immer feuchten, tief schattigen Schluchtenwälder von Usambara bis zum Nyassaland und von Kamerun bis Angola, auch verbreitet auf den Comoren, Maskarenen, Madagaskar, im Monsungebiet und Polynesien. Bisweilen wächst sie auch an den Hängen der Bachufer, zusammen mit Baumfarnen. M. salicifolia Schrad., mit tiefer gesägten Fiedern und kürzeren Synangien, ist vom Nyassaland bis Kapstadt verbreitet.

\section{Reihe Ophioglossales.}

\section{Fam. Ophioglossaceae.}

Von dieser bekannten Familie ist die Gattung Ophioglossum sehr formenreich in Afrika, Botrychinm dagegen nur durch eine Art vertreten. Keine kann als Charakterpflanze bezeichnet werden.

Mesophyten.

Ophioglossum L. Alle afrikanischen Arten sind Bodenbewohner, mit einfacher steriler Spreite.

Subsekt. I. Paraneura Prantl. Seitliche Adern der sterilen Spreite meist ebenso stark wie die mittlere. O. Bergiamm Schlecht. (Fig. $67 \mathrm{~A}$ ) ist ein 
ganz lileines Pflänzchen mit sticlloser, schmal linealer Spreite, welcher am Grunde der Stiel des kurzen Sporangiophors entspringt, sehr selten bei Kapstadt: 0 . granineun Willd. (Fig. 6; $B$ mit gemeinsamem Blattstiele und
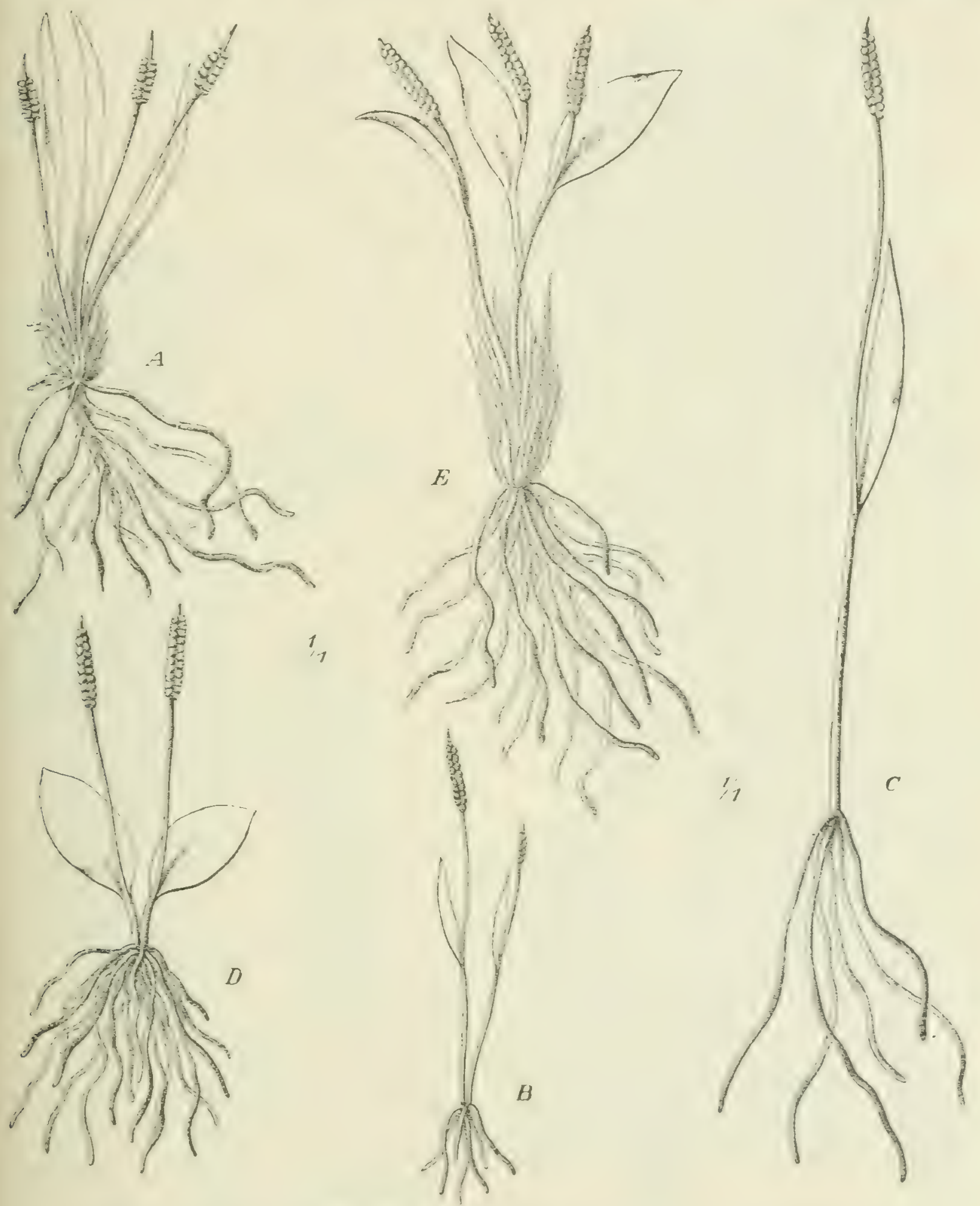

Fig. 67. A Ophioglossum Bergianum Schlechtdl.; $B$ O. graminetm IVilld.;

$C$ O. lusoafricanum Welw.; $D$ O. Gomezianum Welw.; $E$ O. capense Sw. emend.

linealcr bis lineal-lanzettlicher, steriler Spreite, und das größere C. lusufricanum Welw. (Fig. $6 ; C$ ) in Angola (Pungo Andongo: C. lusitanizum L. erstrecht sich von Westeuropa und dem Nittelmeergebiete bis zu den Kanaren: eine 
dimnere Spreite als dieses besitzt O. Lrmmnii Prantl auf den Kap Verden. Von diesen Arten weichen einige andere durch sehr fein zerteiltes Adernetz der sterilen Spreite ab; das winzige, nur $4 \mathrm{~cm}$ über die Erde hinwegragende O. Gomeraicmum Welw. (Fig. 67 D) und das größere O.capcnse Sw. emend. (Fig. 66 F, ausgezcichnet durch eine der lineal-länglichen bis breit-eiförmigen Spreite aufgesctzte Spitze, ron Abyssinien und den Kalp Verden über Nubien bis Natal und zum Kapland zerstreut vorkommend. In diese Gruppe gehört auch das in der nördlich gemäßigten Zone verbreitete $O$. vnlgatum $\mathrm{L}$, welches sich auch auf Madeira und in der var. kilimandscharicum Hieron. auf dem Kifinikavulkan des Kilimandscharo findet.

Subsekt.2. Ptiloneura Prantl, ausgezeichnet durch starke Verzweigung des mittleren Leitbündels. - ( ). mbllum Welw, mit fast kreisförmiger Sprcite von rötlicher Färbung, kommt mit O.graminezun und 0 . Gomezianum zusammen in Angola vor. Hier findet sich auch das durch bleichen Mittelstreifen der sterilen Spreite ausgezeichnete ('. fibrosum Schum., welches auch in Oberguinea und Senegambien, im Ghasalquellengebiet und Transvaal gefunden wurde. Ausgezeichnet durch herzförmige Spreite und dreimal längeren Stiel des Sporophors ist das im tropischen Amerika weitverbreitete, von den Kap Verden durch das tropische West- und Zentralafrika bis nach den Maskarenen gelangte O. reticulatum L., welches in Kamerun bis zu $2900 \mathrm{~m}$ ü. M. vorkommt. Fast alle bewohnen kurzgrasige Wiesen.

Botrychium Sw. ist erst vor kurzem im tropischen Afrika nachgewiesen worden, indem Prof. Dr. PREUss das neue B. chamaeconim Bitter et Hieron. an steilen Felswänden einer um $2200 \mathrm{~m}$ in der Grasregion des Kamerunberges gelegenen Schlucht auffand; es kommt an nächsten dem in Ostindien und Ceylon wachsenden B. lamuginosum Wall.

\section{Reihe Equisetales. \\ Fam. Equisetaceae.}

Equisetum L. Von dieser allgemein bekannten Gattung ist das fast in ganz Europa und Asien, sowie auch in Amerika weit verbreitete E. ramosissimum Desf. auch in Afrika häufig, ganz besonders in Nordafrika bis Abyssinien und im Kaplande, sowie im Kunencgebict; es findet sich auch in Ostafrika von Usambara bis Natal an Bachufern, wurde jedoch bis jetzt noch nicht im tropischen Westafrika nachgewiesen. - Die Kanarischen Inseln erweisen sich als Übergangsgebiet zwischen Europa und Afrilia auch darin, daß sie noch $E$. arvense L. und E. maximum Lam. beherbergen.

\section{Reihe Lycopodiales.}

\section{Fam. Lycopodiaceae.}

Lycopodium L. Diesc Gattung, deren Habitus als bekannt vorausgesetzt werden darf, zeigt in Afrika eine ziemlich große Mannigfaltigkeit der Wuchsverhältnisse; die in Europa vertrctenen Sektionen fehlen auch in Afrika nicht, 
außer diesen schen wir aber noch einzelne andere terrestrische Arten und mehrere epiphytische, von denen einige I m lang von den İsten cer Bäume herabhängen.

Hygrophyten und Mesophyten.

Untergatt. I. Urostachya. Verzweigung deutlich dichotomisch. Wurzeln nur am Grunde.

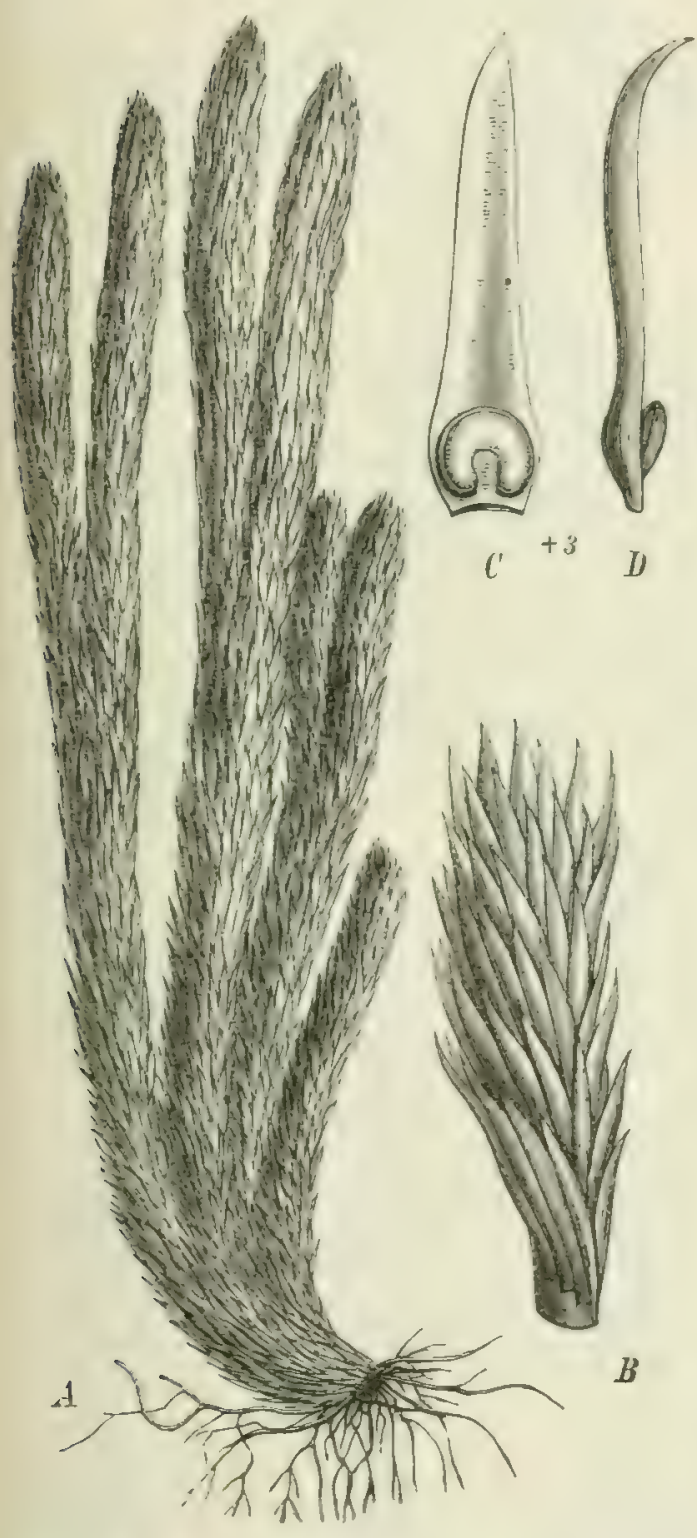

Fig. 6S. Lycopodium saururus Lam. $A$ Habitusbild $\left({ }^{\mathrm{I}} / 3\right) ; B$ Zweigstïck in nat. Gr.; $C$ Sporophyll von oben (innen); $D$ Sporophyll von der Seite.

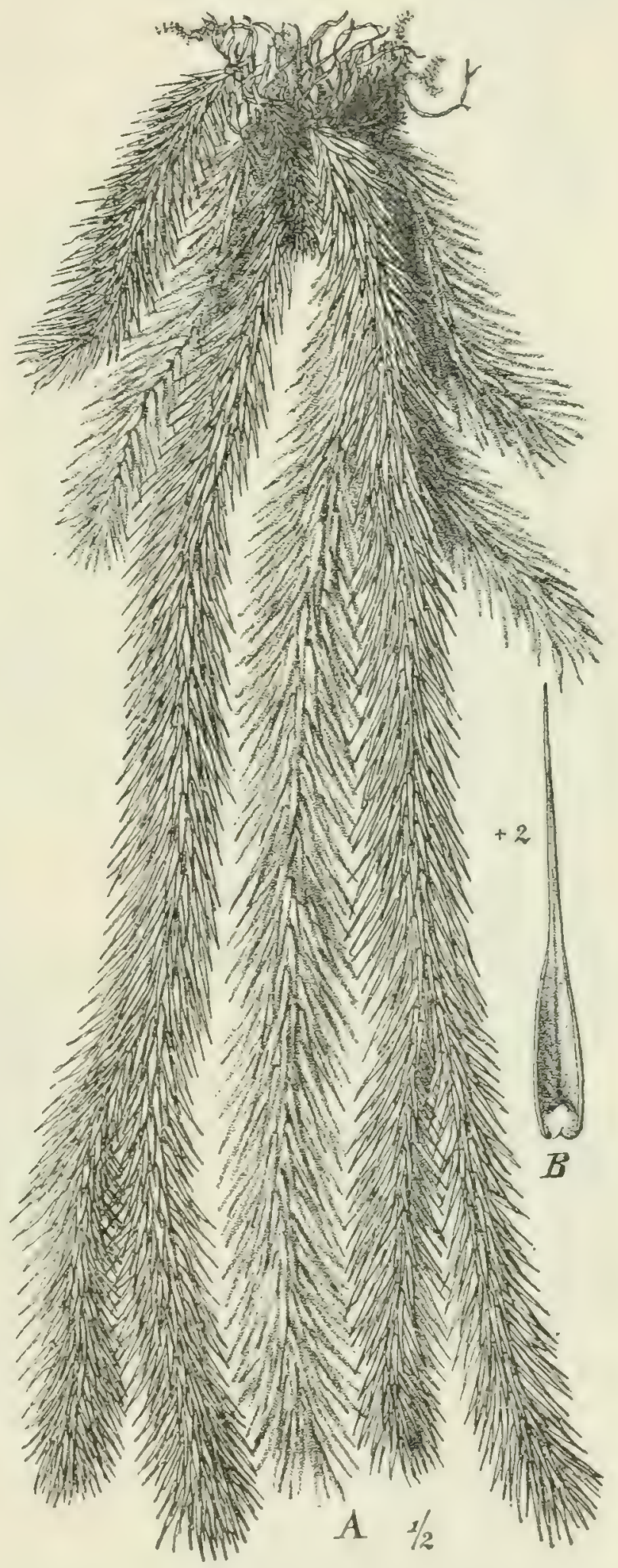

Fig. 69. Lycopodium Holstii Hieron.

Sekt. I. Sclago Dillen. Fertile und sterile Blätter meist nicht verschieden, jedenfalls die letzteren in die ersteren allmählich übergehend. - Das in der nördlich gemäßigten Zone verbreitete L. selago L. findet sich noch auf Madeira; 


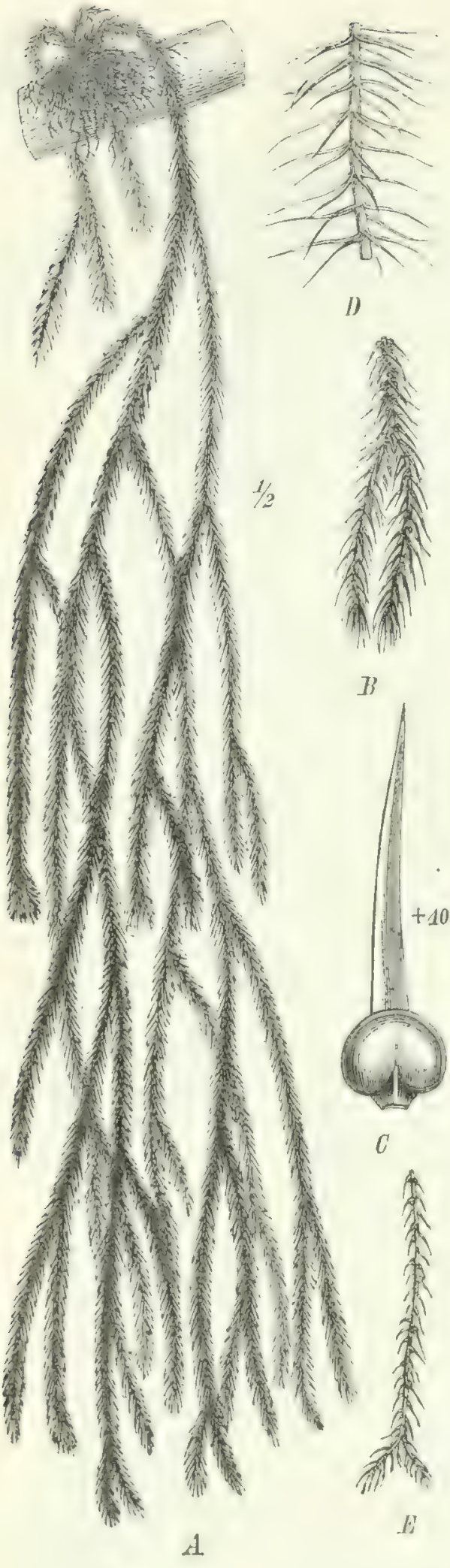

Fig. 70. Lycopodium verticillatum $\mathrm{L}$. fil. $A$ Habitusbild der ganzen Pflanze (forma typica) $1 / 2 ; B$ Zweigende (forma typica), in nat. Größe; $C$ Sporophyll der forma typica, von oben (innen), Io mal vergr.; $D$ Stengelstück der langbärtigen ostasiatischen Form, in nat. Gr.; $E$ Stengelstück der var. filiforme Sw. in nat. Gr. auf dem afrikanischen Kontinent und den Maskarenen tritt an seine Stelle L. saumurus Lam. (Fig. 68), welches von den Gebirgen des Kaplandes bis Natal und Nyassaland zerstreut wächst, auch auf dem Kilimandscharo, Ruwenzori und Kamerungebirge vorkommt, auf letzterem noch auf den Lavafeldern von $3000-3300 \mathrm{~m}$ ii. M. Aus der Verbreitung dieser Art in der südlichen Hemisphäre und auf den Anden möchte man schließen, daß sie eine der südlichen Hemisphäre angehörige Parallelart zu L. selago darstellt.

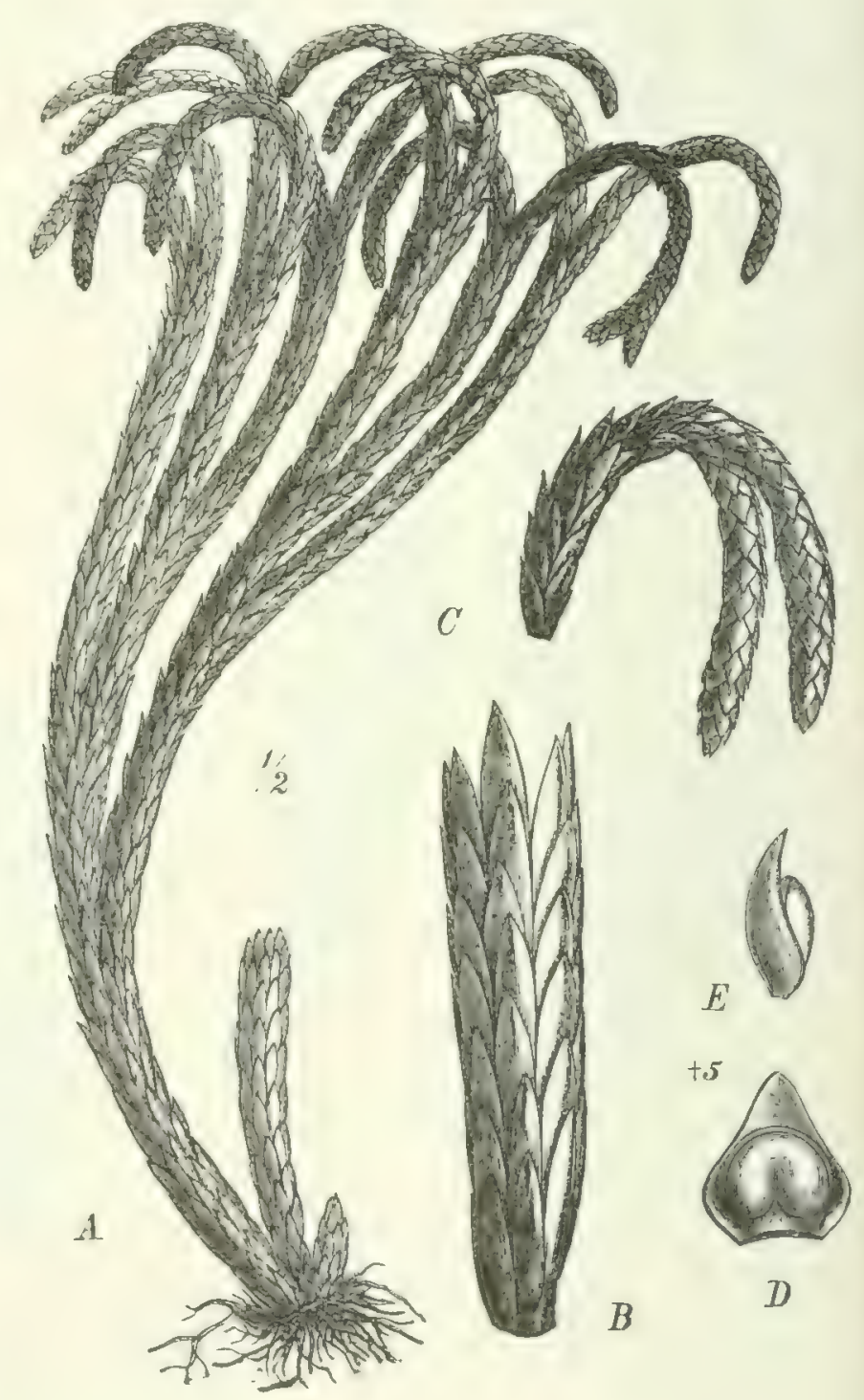

Fig. 71. Lycopodium strictum Bak. A Habitusbild der ganzen Pflanze $(x / 2) ; B$ Stengelstück in nat. Gr.; $C$ Sporophyllstände, in nat. Gr.; $D$ Sporophyll von oben (innen); $E$ Sporophyll von der Seite. 
Während bei diesen Arten die lineal-lanzettlichen Blätter aufrecht stehen, sind sie lineal-pfriemlich, etwa I,5 cm lang bei L. Holstii Hieron., einem Epiphyten der Regenwälder Lsambaras (Fig. 69). Dünne herabhängende Stengel besitzt der in Fig. 70 dargestellte Epiphyt L. verticillatum L. f., verbreitet in allen Tropenländern, in den Gebirgsregenwäldern vom Kapland bis zum Nyassa-

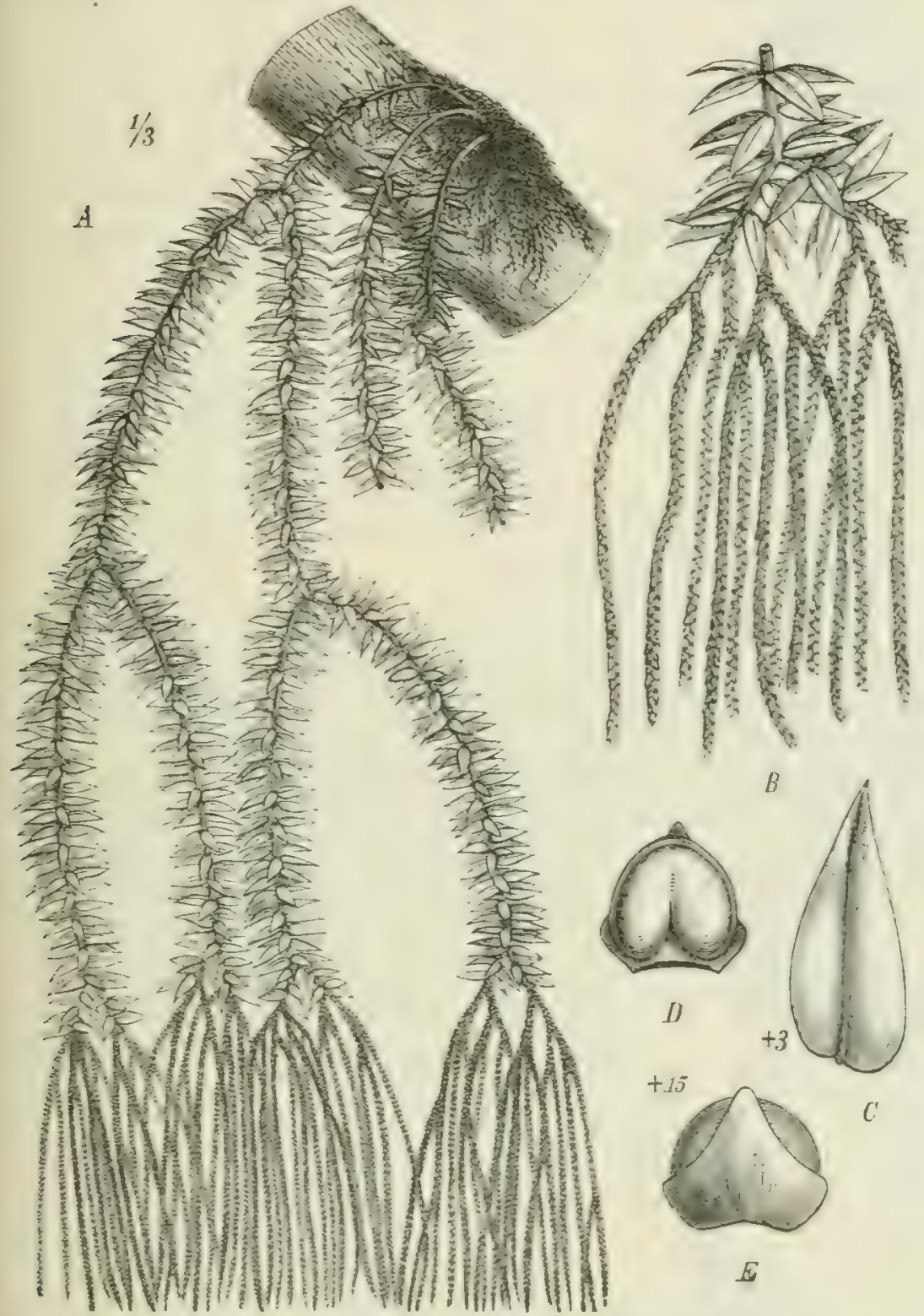

Fig. 72. Lycopodium phlegmaria L. A Habitusbild der ganzen Pflanze $\left({ }^{I} / 3\right) ; B$ Zweigende in nat. Gr.; $C$ steriles Blatt, etwas vergr.; $D$ Sporophyll von außen (unten) vergr.; $E$ Sporophyll von innen (oben), vergr.

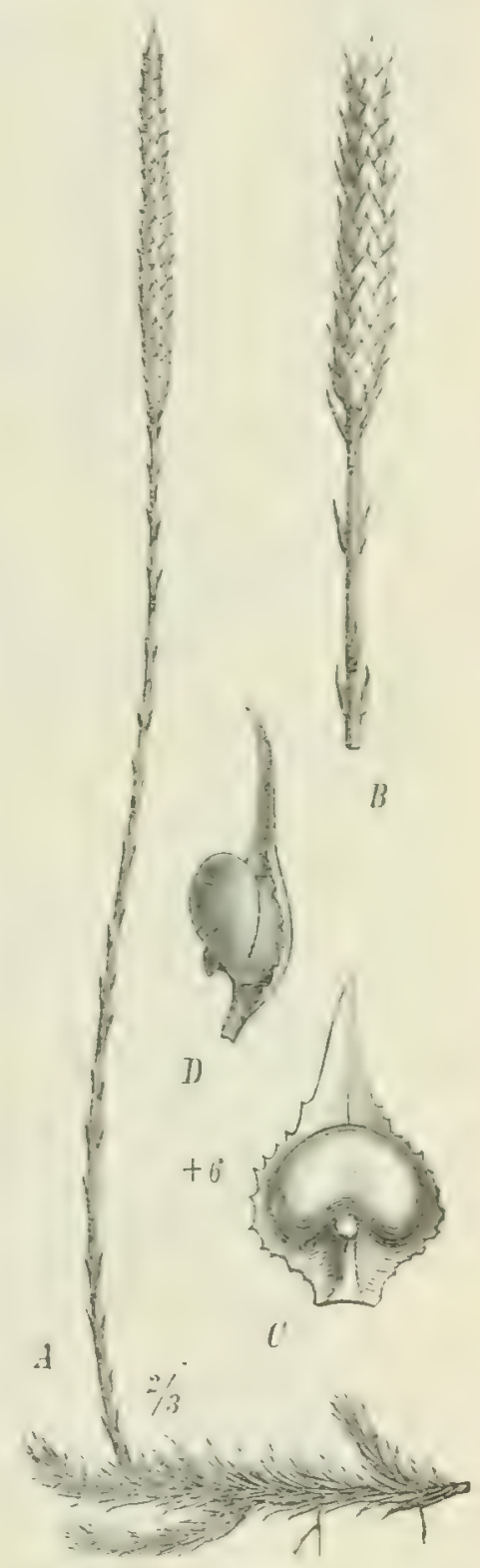

Fig. 73. Lycopodium carolinianum L. A Habitusbild, etwa ${ }^{2} / 3 ; B$ Sporophyllstand (Bluite), nat. Gr.; $C$ Sporophyll von innen (oben), $6 \mathrm{mal}$ vergr.; $D$ desgl. von der Seite, $6 \mathrm{mal}$ vergr.

land, sowie im Kamerungebirge. - Etwas weiter vorgeschritten sind L. ghiciioides L. und L. strictum Bak. (Fig. 71), bei welchen die Sporophylle am Ende der Sprosse zusammengedrängt, kleiner als die sterilen Blätter sind. L. grizilivide's L. f. wächst in den Gebirgen des Kaplandes und Natals, der Maskarenen, Comoren und Madagaskars, an Bächen und vom Wasser bespuilten Felsen, L. strictum Bak. findet sich im Pondoland (30-500 $\mathrm{m}$ ü. M. .) und auf Mladagaskar. Wahrend 


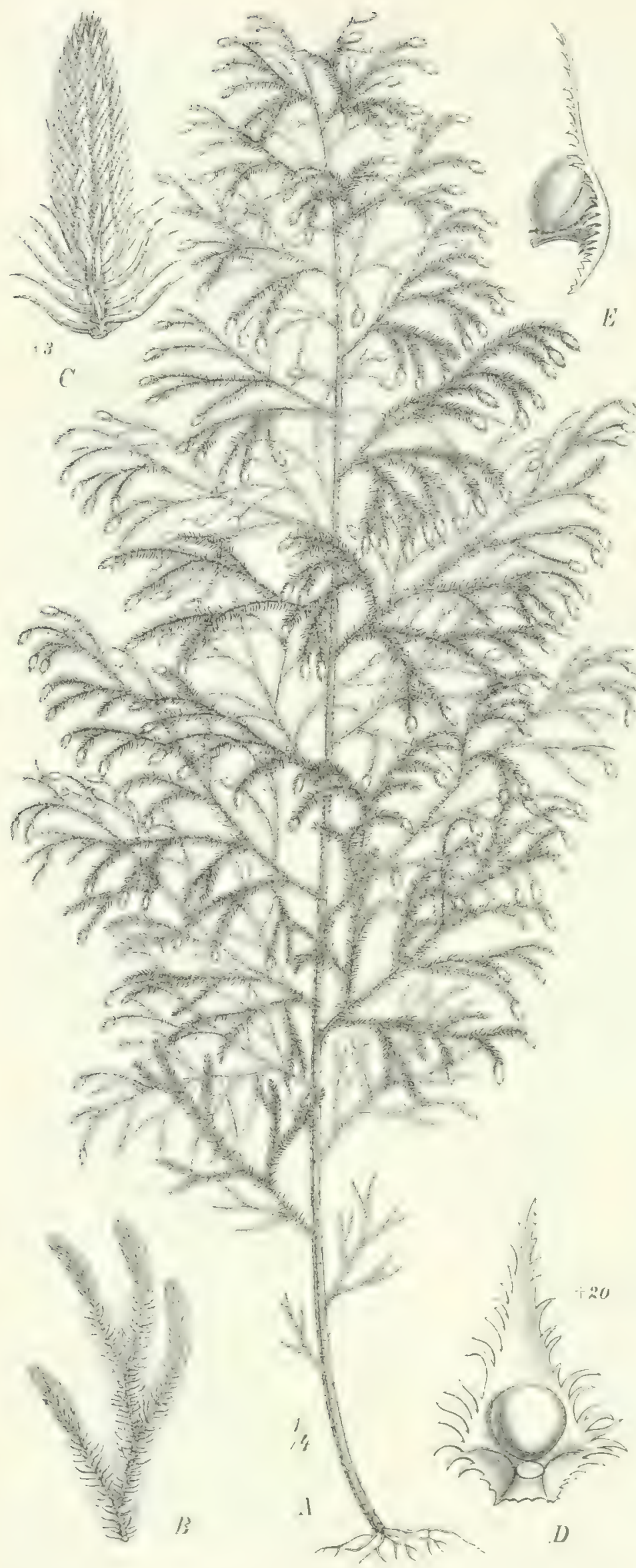

Fig. 74. Lycopodium cernuum L. var. Eichleri Glaz. $A$ Habitusbild $(\mathrm{T} / 4) ; B$ Zweigende in nat. Gr.; $C$ Sporophyllähre, 3 mal vergr.; $D$ Sporophyll von oben, $20 \mathrm{mal}$ vergrößert; $E$ Sporophyll von der Seite, 20 mal vergr. bei diesen Arten die Blätter stumpf sind, sind sie spitz bei dem epiphytisch und hängend wachsenden $L$. dacrydioides Bak., das für die immergrünen Gebirgsregenwälder von Usambara bis Natal und im Kamerungebirge charakteristisch ist.

Sekt. 2. Phlegmaria Bak. Die Sporophylle sind bedeutend kleiner als die sterilen Blätter und setzen scharf hervortretende Blüten zusammen, welche häufig gegabelt sind. Hierher gehört das im ganzen paläotropischen Gebiet verbreitete L. phlegmaria L. (Fig. 72), das in Usambara, am Kilimandscharo und im Kamerungebirge bis $\mathrm{zu} 2800 \mathrm{~m}$ ii. M. als häufiger hängender Epiphyt auftritt. Das nahestehende, auf Fernando Po (2000 $\mathrm{m}$ ) und dem Kamerungebirge sowie auf den Comoren und Maskarenen vorkommende L. ophioglossoides Lam. ist durch schmal elliptische, auch nach unten verschmälerte Blätter verschieden.

Untergatt. 2. Rhopalostachya. Auf dem Boden wachsende Arten mit einer monopodial erscheinenden, aber auch als dichotomisches Gebilde aufzufassenden Grundachse, von welcher die gabelig verzweigten Seitenzweige abgehen.

Sekt. 3. Inmudata Bak. Hierher gehört L. caroliniamam L. (Fig. 73), zerstreut von Oberguinea bis zum Kapland 
und von diesem bis zum Nyassaland, im Süden gern auf feuchten Sandstcinhalden. L. tuberosum A. Br. et Welw. an feuchten Plätzen in Angola, ausgezeichnct durch knöllchenförmige Anschwellungen am Ende der WVurzelträger, ist wohl nur Varietät des vorigen. L. sarcocaulon A. Br. et Welw., von Kapstadt bis zum Kilimandscharo und Kamerungebirge an nassen Abhängen wachsend, zeichnet sich aus durch auffallend große, flache Blätter und schwammige, schneeweiße Wurzelträger; es kommt in Benguella um I $300-1800 \mathrm{~m}$ zusammen mit Drosera, einigen Utricularia und hygrophilen Gentianaceen vor.

Sekt. 4. Cermuc Bak. Aufrechte oder kletternde, meist bäumchenartig verzweigte Arten. - Eine sehr veränderliche Art ist das rom zentralafrikanischen Seengebiet und Senegambien bis zum Kapland verbreitete L. ccmmm L. (Fig: T t).

Sekt. 5. Claìata Bak. Weithin kriechende Arten, mit aufrechten Scitènästen. - Das in der nördlich gemäßigten Zone und auch in den Gebirgen des tropischen Asiens verbreitcte L. clavintum L. ist im tropischen Afrika nicht selten in den Hochgebirgen von Usambara bis zum Kapland, auch auf dem Kamerungebirge, von 2100-2700 m; das ähnlich verbreitcte L. complernatum L. kennen wir auch vom Kapland.

\section{Fam. Psilotaceae.}

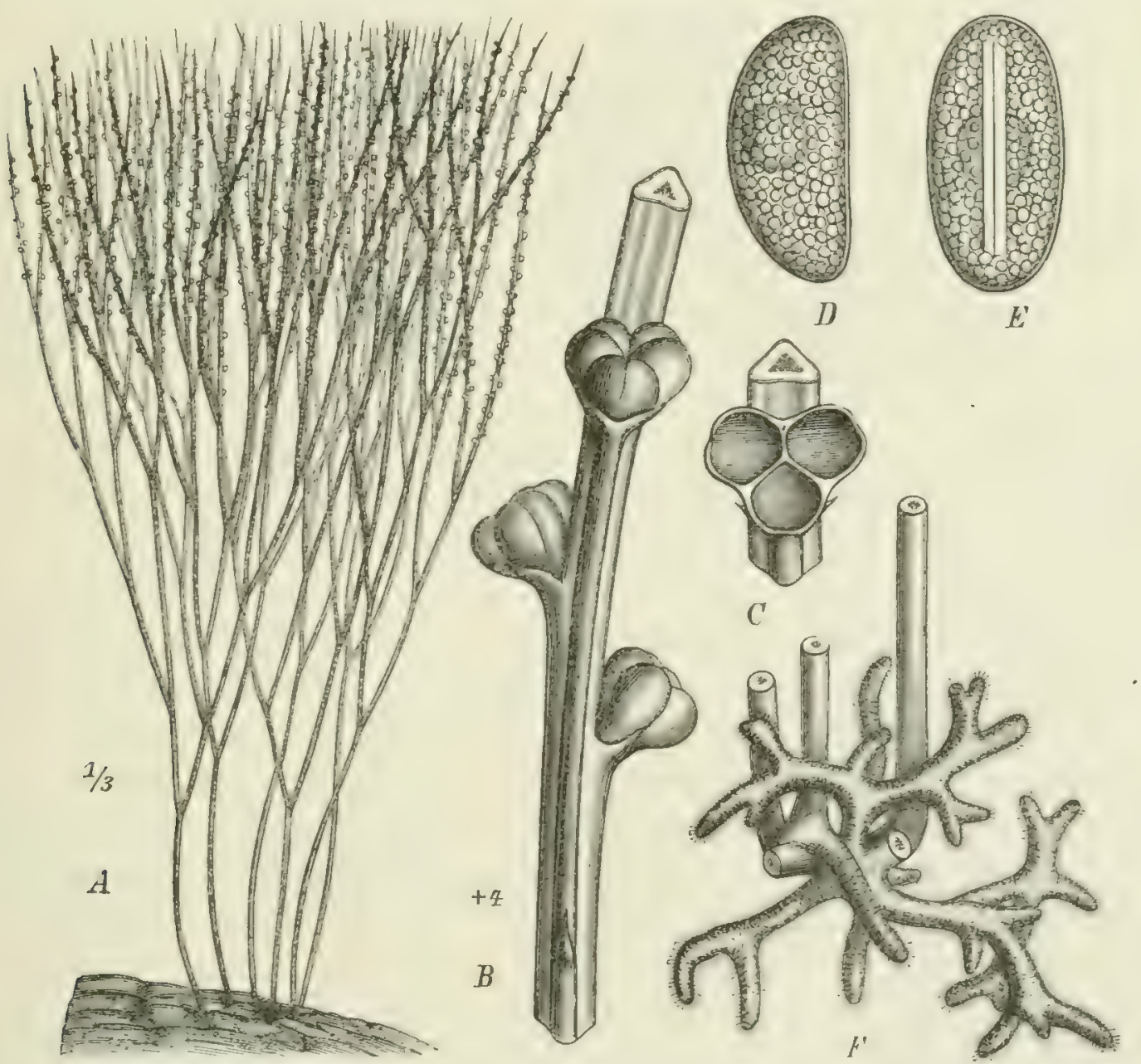

Fig. 75. Psilotum nudum (L.) Griseb. $A$ Habitus; $B$ Sproßstück aus der fertilen Region mit einem sterilen Blatte und drei Sporophyllen; C aufgesprungenes Sporangium; $D$, E Sporen Vergr. 60o, 
Die einzige im tropischen Afrika vertretene sehr eigenartige Gattung dieser Familic wird der Nichtbotaniker anfangs nicht als Verwandte der vorigen Familie, wohl aber an und für sich leicht erkennen. Die immer auf reich humösem Substrat oder epiphytisch im dunkeln Valdesschatten lebenden Vertreter dieser Gattung sind Pflanzen mit gabelig verzweigtem Rhizom ohne Wurzeln und mit reichlich gegabulten Sprossen, an denen sehr kleine angedriickte schuppenartige Blattgebilde entfernt stchen. Dreifacherige, sechsfurchige Sporangien stehen auf zweispaltigen Sporophyllen. die an den Endzweigen zerstreut sind.

Psilotum L.! Einzige afrikanische Art Ps. mudun (L.) Griseb. $(=P$. triquetrum Sw., in Usambara, Natal, an den Viktoriafällen des Sambesi und in Senegambien, besonders an alten Baumstämmen der Regenwälder.

\section{Fam. Selaginellaceae.}

Die Vertreter dieser heterosporen Lycopodiales spielen im tropischen Afrika, wie auch in anderen Tropenländern wegen ihres in der Regel geselligen Auftretens eine nicht unwichtige Rolle in einzelnen Formationen. Oft bedecken sie in schattigen Wäldern den Boden, kommen aber auch an lichten oder halbschattigen Waldrändern vor. Dic große IIehrzahl sind Hygrophyten; aber einzelne sind auch ausgesprochene Xerophyten und bilden sogar charakteristische Formationen auf sonnigem, steinigem Boden.

Untergatt. I. Homoeophy'llum Spring. Blätter überall gleichartig, radiär gestellt.

Sekt. I. Tetragonostachyae Hieron. Sporophylle in vier Reihen, gekreuzt. a) untere Laubbliitter oft gegenständig: S. pumila (Schlccht.) Spring, cin kleines $15 \mathrm{~cm}$. hohes Kraut mit lanzettlichen Blättern an schattigen Plätzen im Kapland und Natal; S. broulus Kaulf. Hicron. nit eiförmigen Blättern, in Südafrika. - b) alle Laubblätter spiralig. S. Dregei. (Presl) Hieron. ist der Typus einer in Afrika clurch wenige Arten vertrctenen Gruppe, mit am Rücken gefurchten, am Kande gewimperten und am Eincle borstigen Blättern; sic wächst gern an trocknen Felsen und trägt wagerecht stehende Blüten, die nur an der Schattenscite Sporophylle entwickeln, an der Lichtscite gewöhnliche Blättcr; sic findet sich an geeigncten Standorten zerstreut von dem Sansibarkiistengebiet bis in die Karroo, häufig auch in Benguella. Die übrigen Arten dicser Gruppe haben aufrechte Blüten, so S. capensis (A. Br.) Hieron. mit $3 \mathrm{~cm}$ langen Blüten, im Kapland und Transvanl, S. cuffremem IIilde' I Tieron., mit nur $0,5 \mathrm{~cm}$ langen Blüten, von Westusambara (z. B. Mlolo) bis Transvaal und Benguella, S. njemnjemensis Hicron. mit kaum + mm langen I3liten in Gallahochland und Ghasalquellengebiet, S. Builunser Hicron nit nur wenigen Blattrandwimpern, an Felsen des Atlas.

Untergatt. 2. Heterophyllum Spring. Blätter verschiedengestaltig und in schiefer Kreuzstellung.

Sekt. I. Pleionacrosporangiatae Hieron. Bliten fast stets mit mehreren oder vielen Makrosporangien, ohne sterile Hülle an der Basis. Alle afrikani- 
schen Arten besitzon Stengel mit cinem zentralen I_eitbiindel. - a' Zu Gruppe der S. mongolia mit niederliegenden Sprossen unc gleichartigen Blättern an der Basis des Hauptstengels gehört dic rerophytiche S. yominsis Sw. Spring im suidlichen Arabien. Abyssinien und dem Somalilande Fig. - c . - b Zur

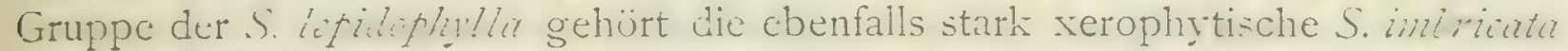
Forsl. Spring, in Arabien, Abyssinien und auf trocknen Basaltfelsen bei cen Viktoriafällen des Sambesi, dort eine Formation bildend Fig. i . - c Zur Gruppe der auf Madagastar und den Maskarenen heimischen S. Fłailli Spring. welche durch ein in der Erde kriechendes ron Niederblättern hesetztes Rhizom

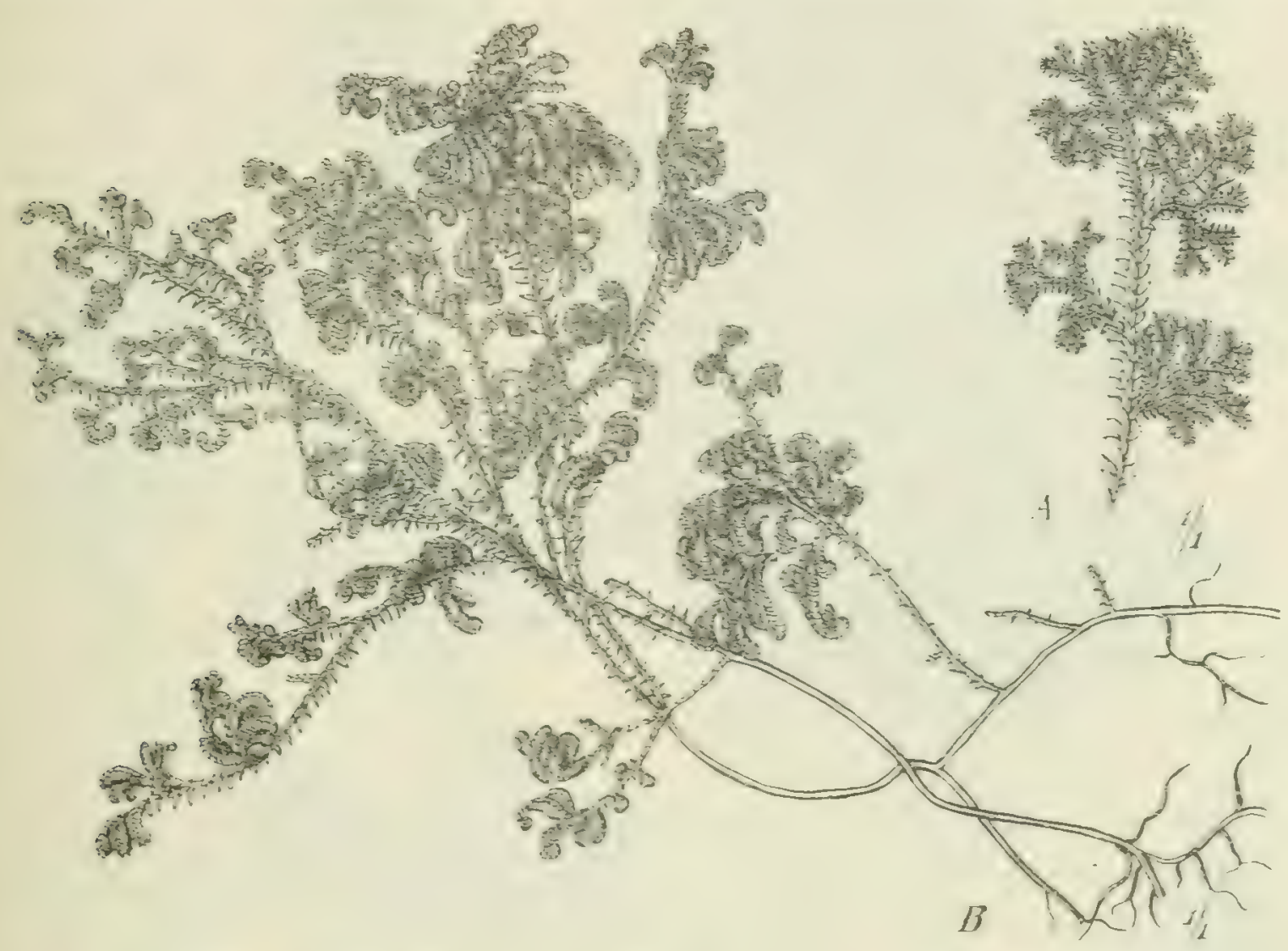

Fig. 76. Selaginella yemensis (Sw.) Spring, aus dem Somaliland. A Zneig in feuchter Luft; $B$ Pflanze in der Trochenzeit.

charakterisiert ist. gehören einige hrgrophile Arten, S. cullifhris A. Br. mit bis $0,5 \mathrm{~m}$ hohen oberirdischen Sprossen, an der Sansibarkiste in Usaramo. S. The tii Spring, größer als rorige. in Kamerun und Gabun, an sehr schattigen Walcplätzen mit lockerem Boden, um $800 \mathrm{~m}$ ii. .I., interessant dadurch, daß die Endzweige in lange Peitschentriebe auswachsen. welche bei Ierihrung mit feuchtem Boden sich direht in Rhizome umbilien ocier an Ger Spitze berurzeln und neue Rhizome bilden. - d Zu der sehr fomenteichen Gruppe ċer S. chilisions, welche durch aufstcigende, oben wiederholt fiedurig rerzweigte. am Grunde mit Ausläufern versehene Sprol3systeme autsgezeichnet ist, gehört von afrikanischen Arten nur S. niţns Bah. in Kamerun. - ci Zu der größtenteils im tropischen Amerika entwicheiten Gruppe der S. raikata Aubl.ı A. Br., deren wedelartige, wiederholt fiederig verzweigte, dorsiventrale, nur I.5 dm 
hohe Sprosse aus kriechender Basis schief aufsteigen, gehört S. i'ersicolor Spring mit schief-eiförmigen Seitenblättern und verkehrt-eiförmigen Mittel-

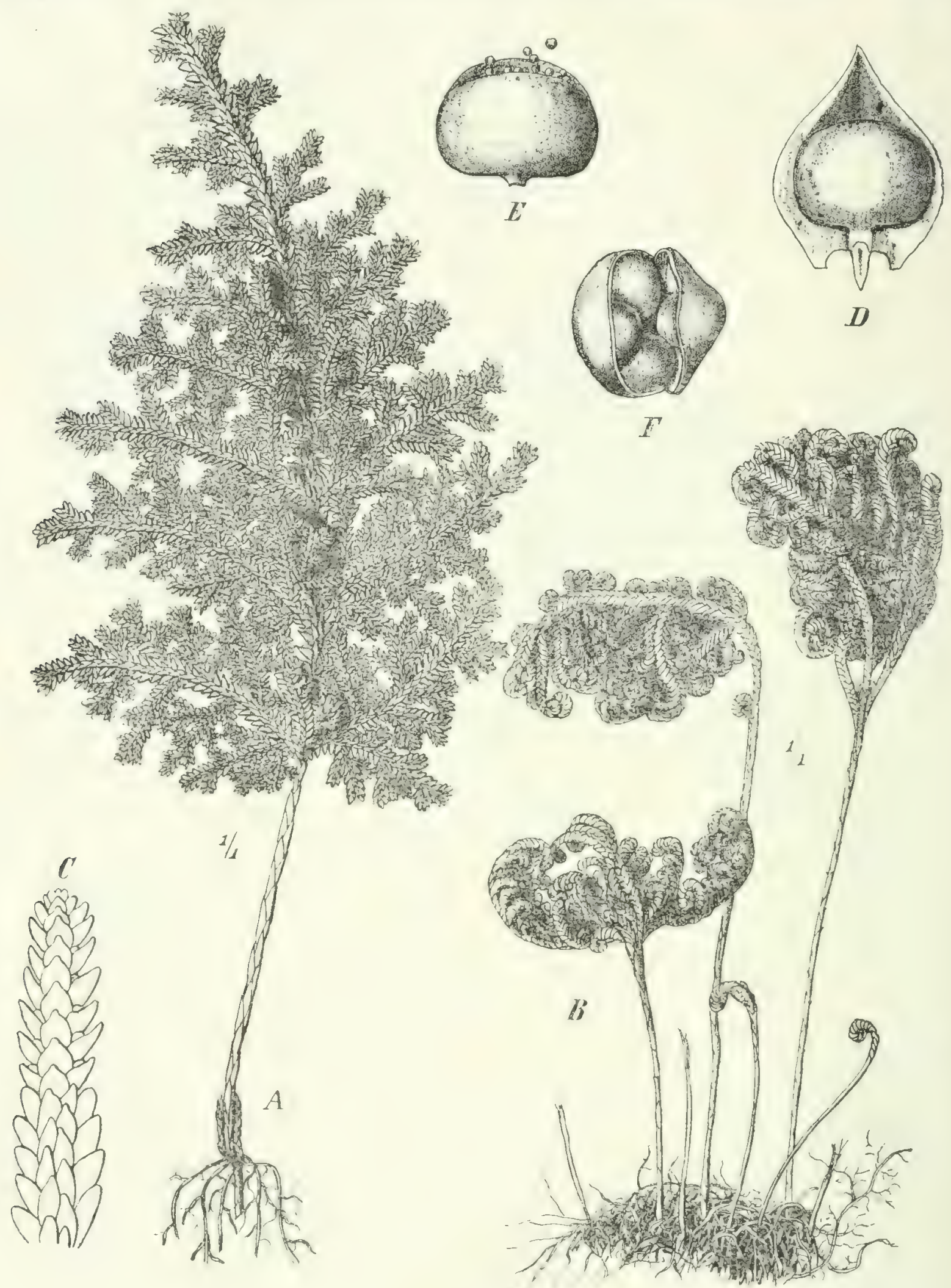

Fig. 77. Selaginella umbricata (Forsk.) Spring. $A$ Pflanze in feuchter Luft; $B$ dieselbe zur Trockenzeit.

bliittern, in den $0,5 \mathrm{~cm}$ langen Bliiten mit chlorophyllarmen ventralen Sporophyllen, von Senegambien bis Angola häufig an feuchten Waldplätzen. - 
Lycopodiales. - Selaginellaceae.
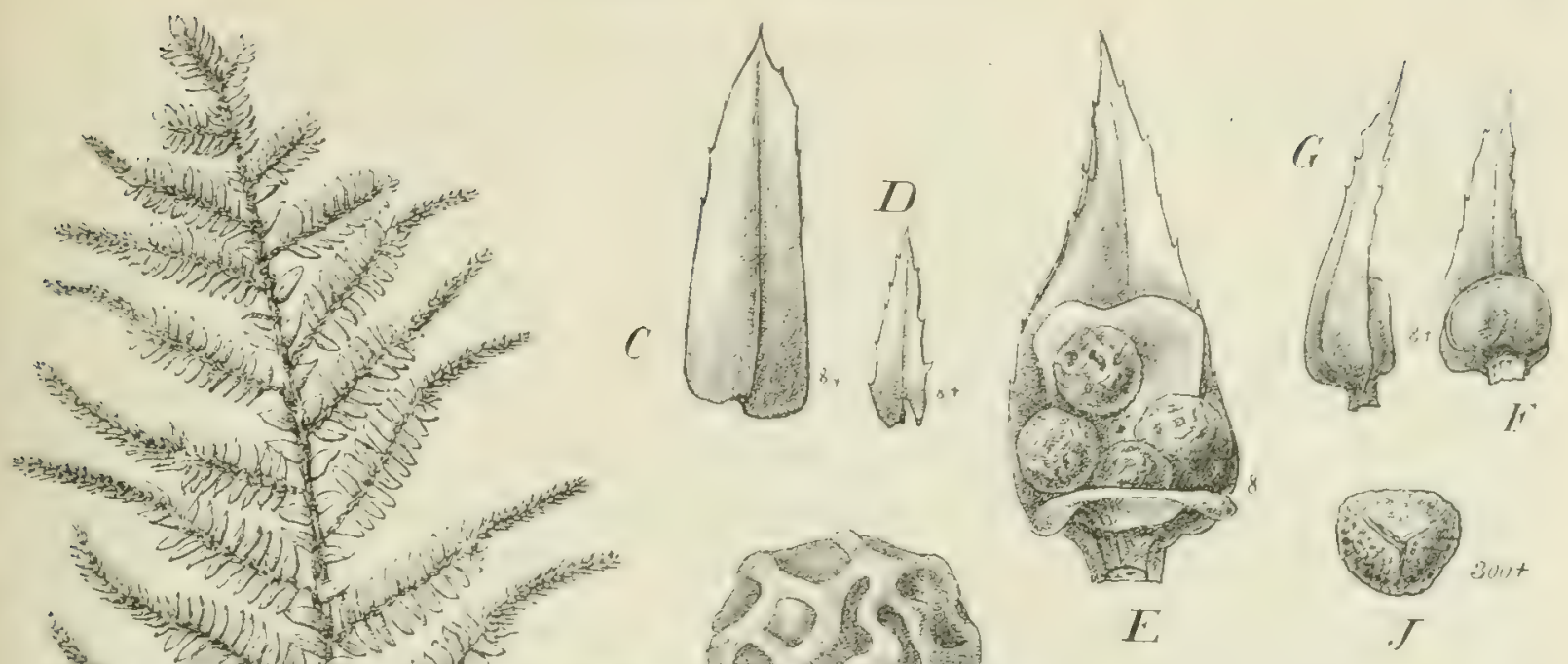

$2=3(1)+y^{2}$

andine

y
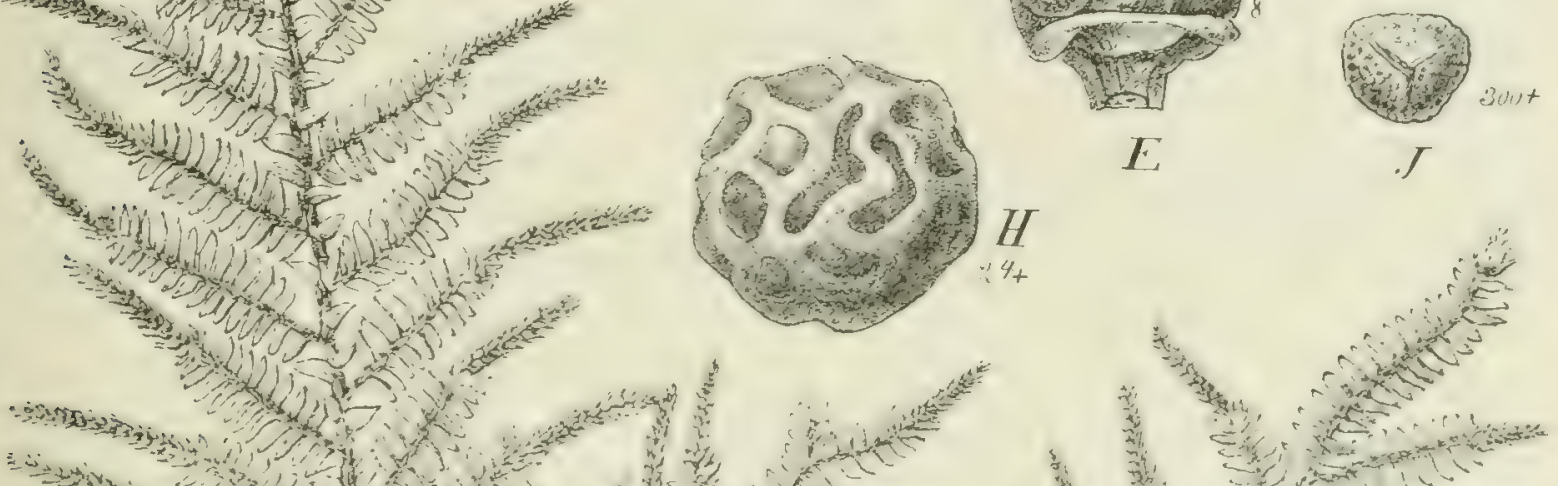

$H$

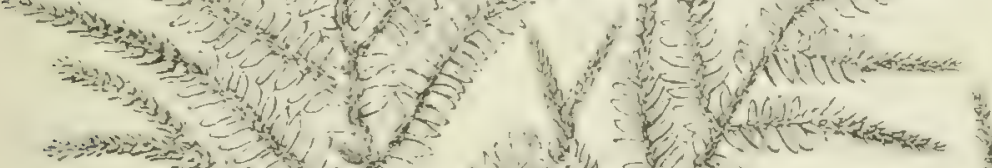

How

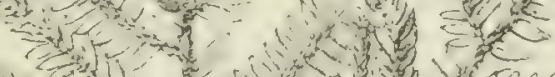

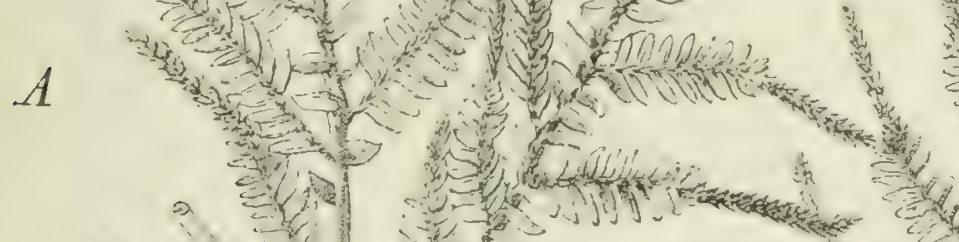

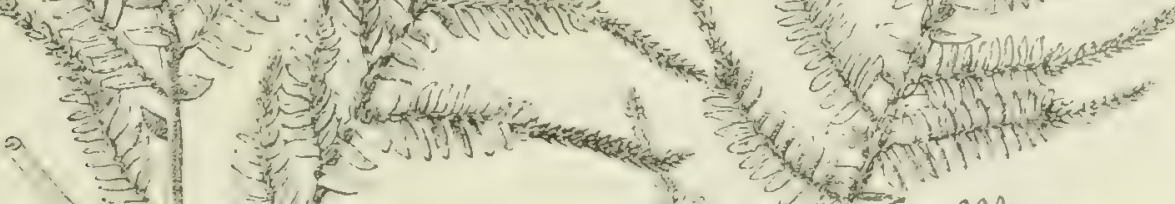

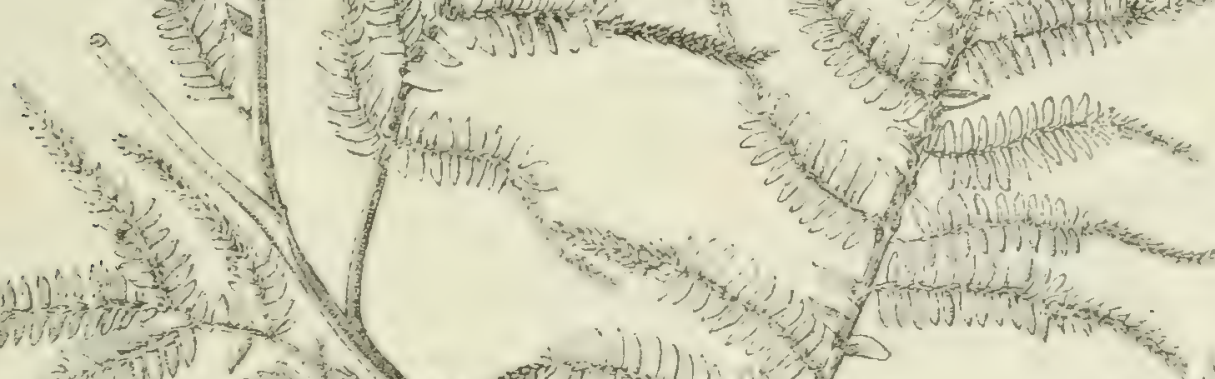

astont

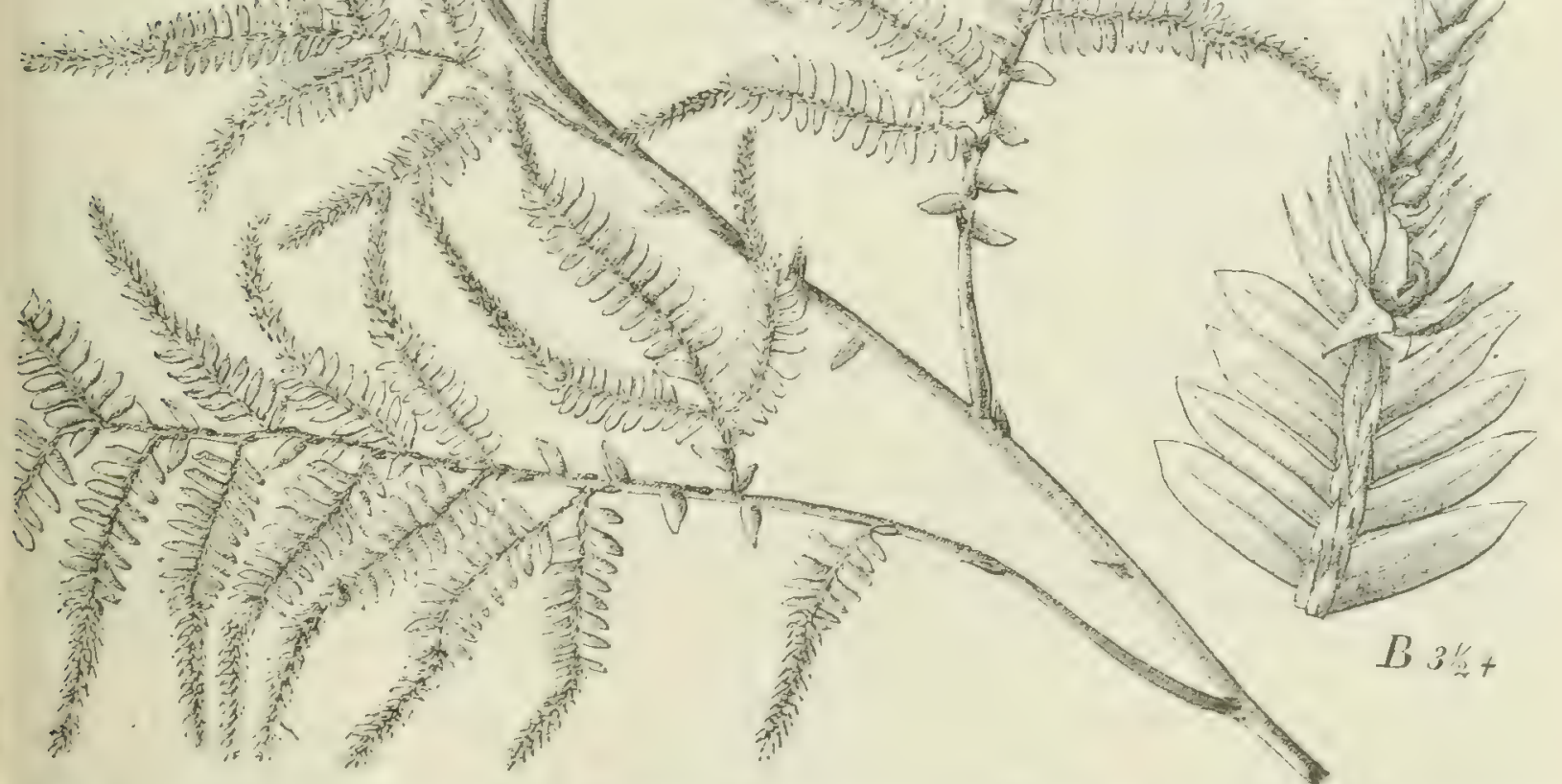

Fig. 78. Selaginella scandens (P. B.) Spring. $A$ Zweigstück; $B$ Blüte mit Sprofsstïck; ('Seitenblatt; $D$. Mittelblatt; E Sporophyll mit geöffnetem reifem Makrosporangium: $F$; $G$ Sporophyll mit Mikrosporangium von der Seite und von oben gesehen; $H$ Makrospore; $\mathcal{F}$ Mikrospore, Scheitelansicht. 
f Ähnlich wie vorige; aber mit Ausläufern an der Basis der kleinen Kräuter und mit flachen Blüten. Zwei Arten mit langer Grannenspitze der Mittelblätter: S. abyssinica Spring in Abyssinien, dem Ghasalquellengebiet, in Westusambara und auf Fernando Po, in steinigen Schluchten die Felsen überkleidend; S. Goctsci Hieron. im Ukinga-Gebirge; eine Art nit kurzer Grannenspitze der Mittelblätter, S. Preussii Hieron., in Kamerun. - g) Zur Gruppe der S. jungemamnioides (Gaud.) Spring, welche niederliegende, uiberall wurzelnde, deutlich gabelig verzweigte Arten umfaßt, gehören außer der im Mittelmeergebiet und auf den Kanaren vorkommenden S. denticulata (L.) Link die im Oranjefreistaat und Natal sowie in Westusambara (Mibalu’ an felsigen Abhängen gegen die Steppe, auch am Kilimandscharo wachsende S. Coopori Bak. und die ihr nahestehende S. depressa (Sw.) A. Br., zerstreut von Usambara und Kamerun bis Kapland. - h) Zur paläotropischen Gruppe der S. proniflora Lam., Bak., welche kleine, kriechende Arten mit dorsiventralen Sprossen und flachen Blïten umfaßt, gehört S. Buchholzii Hieron., ein nur $5 \mathrm{~cm}$ großes Pflänzchen am Quaqua im Kamerungebiet und in Togo. - i) Mehrere aus kurzliegender oder aufsteigender Basis aufrechte Arten, ohne Ausläufer und mit flachen Blüten gehören zur Gruppe der S. suberosa Spring. - I. mit mennigroten Mikrosporen: S. tenerrima A. Br. (Angola), S. Molleri Hieron. (S. Thomé), S. leoneensis Hieron. (Liberia, Sierra Leone), S. Hildebrandtii A. Br. (Comoren, Johanna), S. Mamii Bak. (S. Thomé), S. molliceps Spring inkl. mbricanlis A. Br. verbreitet vom tropischen Westafrika bis zum Nyassaland und Kilimandscharo', S. porpusilla Bak. 'am Kongo), S. Zechii Hieron. Togo), S. Il/ypti Hieron. nördliches Nyassaland, S. subcordater A. Br. (Sierra Leone) und cinige Arten Madagaskars. - II. mit bräunlichweißen Mikrosporen: S. Soyauxii Hieron. (Gabun).

Sekt. 2. Oligonacrosporangiatae. Blüten stets radiär, vierreihig; die untersten Sporophylle steril und cine Art Hiille um das größte unterste fertile Sporophyll bildend. - A) mit ungegliedertem Hauptstengel. Hierher gehören die niedrigen kriechenden Arten S. fissidentoides (Hook. et Grev.) Spring von Oberguinea und den Comoren, und S. sermulata (Desv.) Spring von Usambara und den Comoren sowie auch die spreizklimmende S. scandens (P. Beauv. Spring, mit kriechenden oder kletternden Sprossen (Fig. 78 und oft $4 \mathrm{~cm}$ langen Bliten weitverbreitet im tropischen Westafrika von Liberia bis Gabun. - B) mit gegliedertem Hauptstengel. Neben zahlreichen. amerikanischen Arten in diese Gruppe gehört hierher S. Kraussiana A. Br., welche in den Regenwäldern der ostafrikanischen Gebirge und Kameruns an schattigen feuchten Stellen, oft den lioden völlig bedeckend, bis zu $=600$ m ui. M., auch in Natal und dem siidwestlichen Kapland vorkommt.

\section{Fam. Isoetaceae.}

Von dieser Familie sind außer den im mediterranen Nordafrika vorkommenden landbewohnenden Isoctcs nur einige amphibische Arten bekannt geworden, welche an zeitweise überschwemmten oder bewässerten Plätzen wachsen. Eine 
sehr große kräftige Art mit dreilappigem Stamm und 25-36 cm langen Blättern ist I. Scheveinfurthii A. Br. vom Lande der Djur, weniger kräftig I. natalensis Bak, in Natal. Während diese beiden Arten Sporangien ohne Indusien haben, findet sich ein solches vor bei den drei anderen Arten: I. nigritiana A. Br. im Nigergebiet, I. aequinoctialis Welw. in Angola und I. Melacitschii A. Br. in Benguella. Von diesen wachsen die heiden ersten in Niederungen, die dritte, nur 5- Io $\mathrm{cm}$ hohe, sehr schmalblïttrige Art in Benguella in einer Höhe ron $1800 \mathrm{~m}$ auf den höchsten Punkten der Hochebene Empalanca zwischen Morro de Lopollo und Humpata auf sandigem Boden, der von Scytonemataceen bedeckt ist, welche auch noch nach der Regenzeit durch Aufnahme des Taues den Boden feucht erhalten, und neben diesen Isoetes

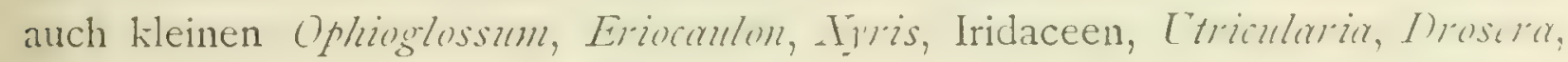
Gentianaceen die Existenz ermöglichen. 


\section{Siphonogame Embryophyten.}

Unterabt. Gymnospermae. (Nacktsamige oder Astigmateae, Narbenlose.)

\section{Klasse Cycadales. \\ Fam. Cycadaceae.}

Xerophyten.

Obwohl von dieser interessanten Familie eine größere Anzahl afrikanischer Arten in botanischen Gärten kultiviert werden und beschrieben worden sind, ist doch verhältnismäßig wenig iiber ihr natürliches Vorkommen bekannt.

Übersicht der afrikanischen Gattungen.

A. Blattfiedern nur mit einem Mittelnerv. Stamm die $O$ Bliite durchwachsend . . . Cycas.

B. Blattfiedern fiedernervig .

Stangeria.

C. Blattfiedern längsnervig ... . . . . . . Encephalartos.

Cycas. Dic im Monsungebiet verbreitete Gattung der Familie berühtt mit ihrem Areal nur die Inseln im Osten von Afrika; der im ganzen südlichen Asien häufige Cycas circinalis L. erscheint auf Madagaskar, den Comoren und auf Sansibar in der subspec. Thonarsii R. Br. Dieselbe trägt am Ende des $4 \mathrm{~m}$ hohen dicken Stammes große dornige Fiederblätter und die weiblichen Stöcke haben Fruchtblätter mit 3-5 Paar taubeneigroßen, roten Samen. Die jetzt schon recht seltene Pflanze findet sich auch am Strande der Sansibarkuiste und Mossambikküste; auch gibt BLEy sie von Ussungula am Kingani an.

Stangeria Th. Moore nimmt in der Familie eine Sonderstellung ein durch die fiedernervigen Fiedern der einfach gefiederten Blätter, welche an einem kurzen bis zu $3 \mathrm{dm}$ hohen Stamm stehen. Seit langer Zeit ist nur St. parodoxa Th. Moore von Natal bekannt.

Encephalartos Lehm. ist bei weitem reicher an Arten, welche zumeist in Siidafrika vorkommen, während eine geringere Zahl in tropischen Afrika nachgewiesen wurde. Alle sind Bewohner trockner Standorte in Buschgehölzen oder auch felsiger Abhänge. Im östlichen Kapland bilden sie bisweilen Dickichte; in der Provinz Albany finden sich 3 hochstämmige Arten, IE. Altenstcinii Lehm., von welchem man in unseren Gewächshäusern bisweilen $3 \mathrm{~m}$ hohe Exemplare mit $3 \mathrm{~m}$ langen Blättern und $50 \mathrm{~cm}$ langen Bliiten sieht, der aber in Albany bis zu $5 \mathrm{~m}$ hoch werden soll. Er wächst namentlich in dem Tembooko genannten Gebiet auf trocknen Hügeln zwischen Succulenten und strauchigen Leguminosen. Dasclbst findet sich auch E. cocolifolins Jacq.) I.chm. mit linealischen Fiedern der I m langen Blätter. 
Auch E. longifolius (Jacq.) Lehm., bei welchem die unteren Fiedern oft mit I- 3 Zähnen versehen sind, kommt in Albany vor und zwar bei Grahamstown. - Einen niedrigen Stamm entwickelt der im Kaffernland schon 1 576 entdeckte E. caffer (Thunb.) Miq., welcher einen dicken Stamm mit i m langen

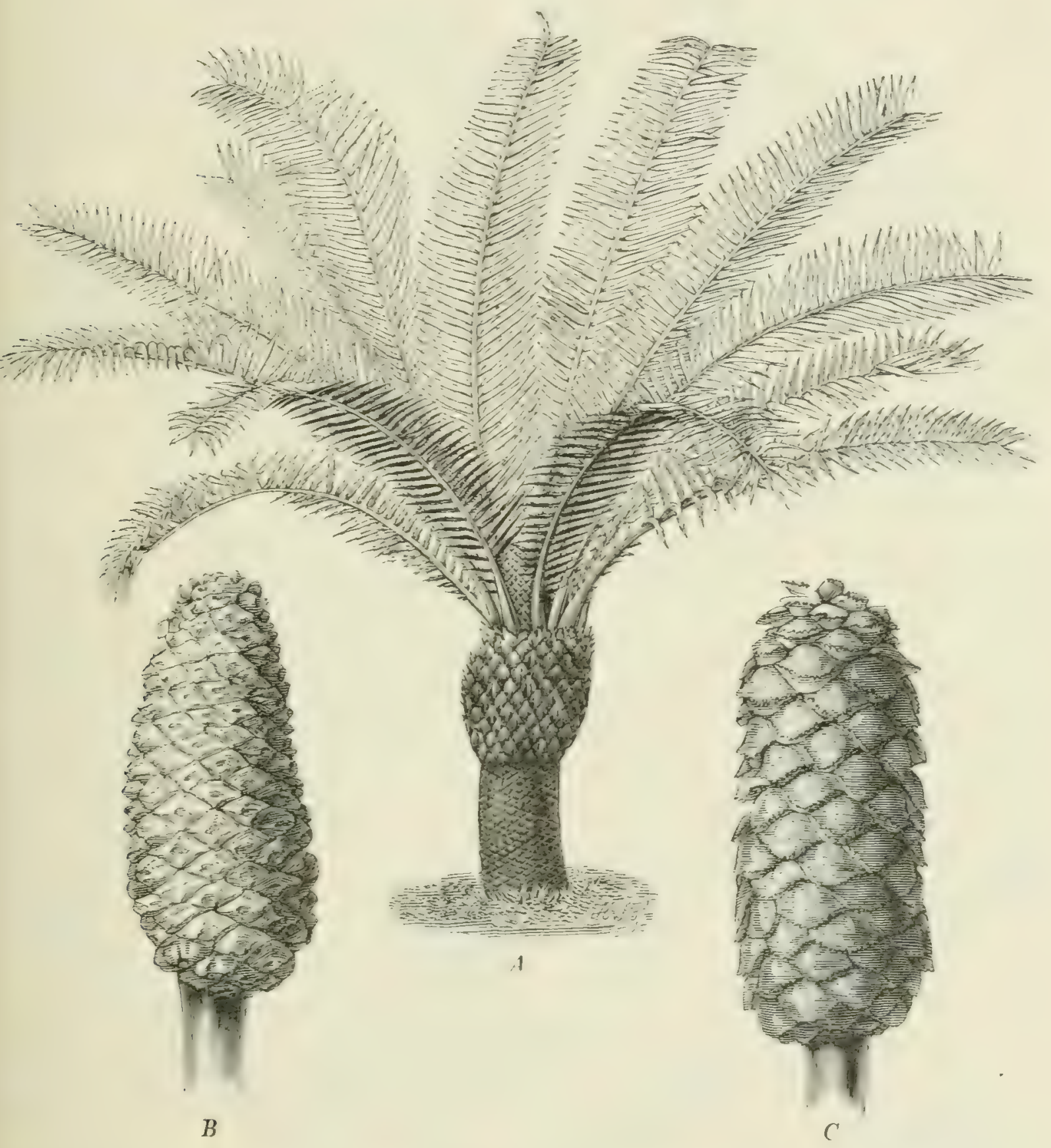

Fig. 79. A Encephalartos Hildebrandtii A. Br. et Bonché, bluihende weibliche Pfanze; $B$ Blüte derselben; $C$ weibliche Blüte von $\mathrm{E}$. villosus Lem.

Blättern besitzt. Durch graugriine Blätter an kurzem, fast ciförmigem Stamm fällt der ebenfalls im Kaffernlande heimische I: Lchmomnimus (Eckl. et Zeyh. auf. Auch in der Karroo kommt eine Art vor, E. horridus Lehm., mit kurzem Stamm, graugrünen Blättern und großgezähnten Ficdern. Weiter nördlich finden wir in Natal E. villosus Lem., zu welchem der oft mit $2 \mathrm{~m}$ hohem 
Stamm versehene E. Hildobrandtii Al. Br. et Bouché als Varictät Hildebrandtii Al. Br. ct Bouché, P. Henn. zu ziehen ist, da bisweilen in demselben Blütenstand neben den als für L. Hildibranltii charakteristisch angesehenen Fruchtblättern auch solche vorkommen, welche I: aillosus kenntlich machen sollen.

Letztere Varietät kommt im Sansibarkuistengehiet in kurzgrasiger Akaziensteppe vor, unweit der Küiste bei Dar-es-Salam, Bagamoyo, Mombas, in Bondei und am Fuß der Gebirge L'samharas. Nördlich des Äquators wächst im NiamNiamland in Troclienwäldern am rechten Tondjufer, auf dem Granithügel Gumango und im Osten rom oberen Huüh E. septentrionulis Schwfth., stets mit kugeligem Stamm bis zu $3 \mathrm{dm}$ Durchmesser und mit $1,5 \mathrm{~m}$ langen Blättern. Aus den xerophytischen Gebieten des Westens kennen wir E. Poggei Aschers., von Porige auf der Hochehene zwischen dem Luisa und Cascrigi im Baschilangegebict entdeckt und daselbst durch die Häufigkeit seines Vorkommens geradezu charakteristisch: auch diese Art besitzt cinen fast kugelrunden Stamm, der sich wenig über die Erde erhebt. Ähnlich ist E. Lemarinelianus de Wildem. et Th. Dur. vom rechten Ufer des Lubi, einige Tagereisen von Lusambo, sowie aus der Gegend zwischen Kanda-Kanda und Luluaburg. Dagegen ist der ebenfalls aus dem Kongostaat stammende L. Lanrentiamus de Vildem. die höchste Art Afrikas; der Stamm erreicht eine Höhe von ro $m$ und eine Dicke von 60 bis $70 \mathrm{~cm}$, und die Blätter werden $6-7 \mathrm{~m}$ lang, mit $35-40 \mathrm{~cm}$ langen Fiedern. Weniger auffallend sind die karminroten männlichen Blüten, welche $17-25 \mathrm{~cm}$ ling worden. Diese Prachtpflanze malele der Eingeborenen), welche auch im Kolonialgarten zu Lacken kultiviert wird, findet sich in Trupps von mehreren Hundert Exemplaren an den steilen Ufern des Quango bei Kasongo, auch auf ganz sonniger Steppe. Endlich erwähne ich noch I: Bertcri Carruth. aus dem unteren Nigergebiet als zweite nördilich rom Äquator vorkommende Art; ihr Stamm ist hïchstens $3 \mathrm{dm}$ lang und trägt $\mathrm{I}, 5 \mathrm{~m}$ lange Blätter, aber etwa $3 \mathrm{dm}$ lange Bliiten. Diese Pflanze wächst in einem heißen Felsental südlich von Zeba auf dem Yombaufer $\left(9^{\circ} 6^{\prime} \mathrm{n}\right.$. Br.), etwa $100 \mathrm{~m}$ ïber dem Fluß und $260 \mathrm{~m}$ ii. M.

\section{Klasse Coniferae.}

\section{Fam. Taxaceae.}

Die artenreichste tropische Gattung dieser Familie, deren Vertreter auch der Nichtbotaniker ebenso wie die der folgenden Pinaceat leicht als "Nadelhölzer erkennt, ist

Podocarpus l'Hérit. Außer den zur folgenden Familie gehörigen Cupressinca gibt es keine Nadelhölzer im tropischen und südlichen Afrika und zwar wachsen alle in den Gebirgen, besonders in den höheren, teils zusammen mit Laubhölzern, teils Bestände bildend. Die in Afrika vorkommenden Arten haben stet.s - linealische oder lineal-lanzettliche Blätter. Die achselständigen männlichen Bluiten sind am Grunde mit kleinen trockenhäutigen sterilen Schuppenblättern rersehen und tragen zahlreiche dichtstehende Staubblätter mit je zwei Staubbeuteln. Dic weiblichen Bliiten besitzen einige Blattgebilde, die am Grunde 


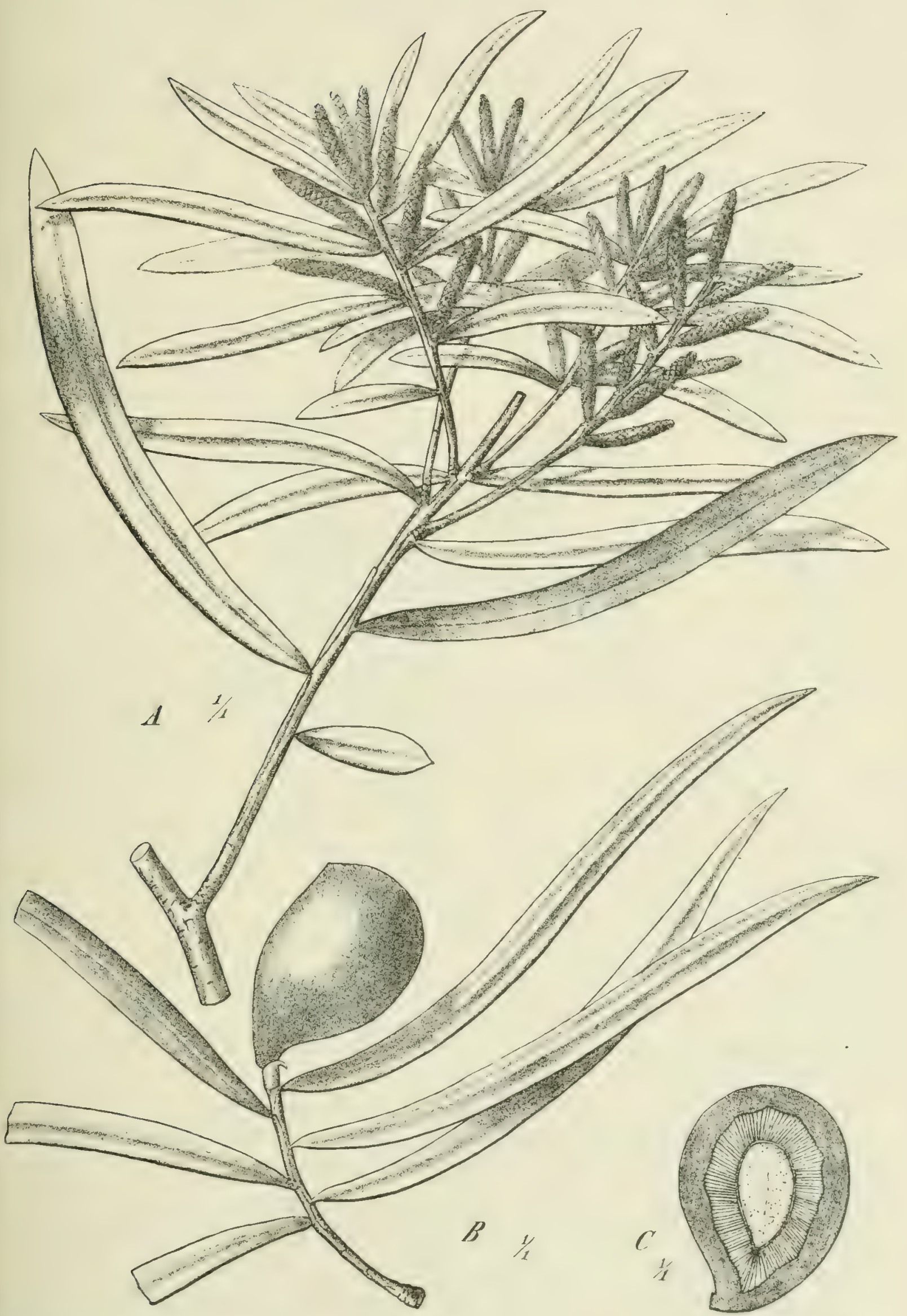

Fig. 8o. Podocarpus Mannii Hook. f. $A$ Zweig mit männlichen Blüten; $B$ Fruchtzweig; $C$ Längsschnitt durch den Samen. 
verwachsend bei den Arten der. Selition Iuforturems ein sogenanntes Receptaculum bilden; in der Regel trägt nur eines dieser Fruchtblätter eine Samenanlage, welche sich zu einem steinfruchtartigen Samen entwickelt, uher dessen Verhreitung noch Beobachtungen anzustellen sind. Jedenfalls war die Gattung in der Tertiärperiode noch weiter verbreitet, namentlich auch in Europa. Von den fïnf Sektionen der Gattung finden sich nur zwei in Afriki, zu deren sicherer Erkennung weibliche Blüten notwendig sind.

Sckt. I. Stachycarpus Endl. Mehrere ơ Bliiten bilden Ähren; die weiblichen Bliiten tragen einige entferntstehende oder wie bei den afrikanischen Arten nur ein bis zwei sehr kleine Fruchtblätter mit oft groß3er Samenanlage. Von den vier afrikanischen Arten dieser Selition entwickeln zwei große Samen mit einer 4-7 mm dicken Sklerenchymschicht. Die eine Art ist der hier abgebildete P. Mannii Hook. f. (Fig. 80), ein 10-I5 $\mathrm{m}$ hoher Baum, welcher auf der Insel São Thomé von I 450 bis zu

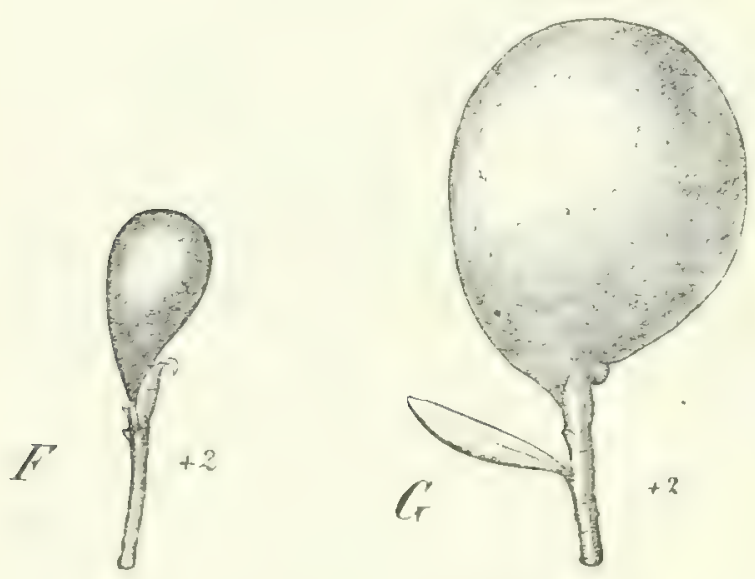

Fig. 81. Podocarpus gracilior Pilger. F weibliche Bliite; $G$ Frucht. $2142 \mathrm{~m}$ häufig angetroffen wird, die andere der durch kleinere Blätter und kugelige oder kugelig-ellipsoidische Samen ausgezeichnete $P$. usambarensis Pilger (muze oder mse), einer der wichtigsten Waldbäume West-Usambaras, von welchem ich selbst mehrfach bis $40 \mathrm{~m}$ hohe Exemplare gesehen habe; er tritt schon in den Bachuferwäldern unterhalb Kwai bei $1500 \mathrm{~m}$ auf und steigt über die Hochweide bis in den Höhenwald des Magamba (bis zu $1900 \mathrm{~m}$ ), allmählich kleiner werdend. Der forstmäßige Anbau dieser Art in den Gebirgen Ostafrikas ist dringend zu empfchlen. - Dic beiden anderen Arten dieser Sektion haben in ihren Samen eine nur I- I,5 mm dicke holzige Schicht; sie düften beide von P. usambarensis abstammen. P. gracilior Pilger (Fig. 8I) rertritt diese Art in den ostafrikanischen Gebirgen des Massaihochlandes, des Gallahochlandes und Abyssiniens, hier in Tigre bis $2600 \mathrm{~m}$ aufsteigend. $P$. folcertus (Thunh.) R. Br. ist siidafrikanisch und kommt zerstreut von den Drakensbergen Natals durch das Pondoland bis Uitcnhage vor; aber nicht im suidwestlichen Kapland.

Sekt. 2. Eupodocarpus Endl. Die Fruchtblätter bilden ein Receptaculum. Hierher gehören drei einander nahestchende Arten Suid- und Ostafrikas. I. clons stus (Ait.) l'Hér. dic am längsten bekannte afrikanische Art mit schmal lineal-lanzettlichen Blättern, kommt als kleiner und bis $25 \mathrm{~m}$ hoher Baum in Schluchten des suidwestafrikanischen Gebirges von Paarl his Clanwilliam vor. Die beiden anderen Arten haben breitere Blätter: I'. Latifolims Thunb.! R. Br. Fig. 's $2 B$ sah ich selbst schon am ()stabhang des Tafelberges in der OrangeKloof, auch auf den Vogelgartbergen kommt er bei $250 \mathrm{~m}$ u. M. vor, dann bildet er Wälder in der Knysna und bei Grahamstown, ist beteiligt an der 
Bildung des Egosawaldes im Pondoland von $200-500 \mathrm{~m}$, findet sich auf den Drakensbergen und im nördlichen Kingagebirge, noch $2500 \mathrm{~m}$ ii. M. Er liefert ein vorzuigliches Nutzholz, aus dem namentlich allgemein Eisenbahnschwellen im Kapland hergestellt werden. - I'. milanjianus Rendle (Fig. 82 C, von dem vorigen durch schmalere lineal-lanzettliche Blätter unterschieden, auch

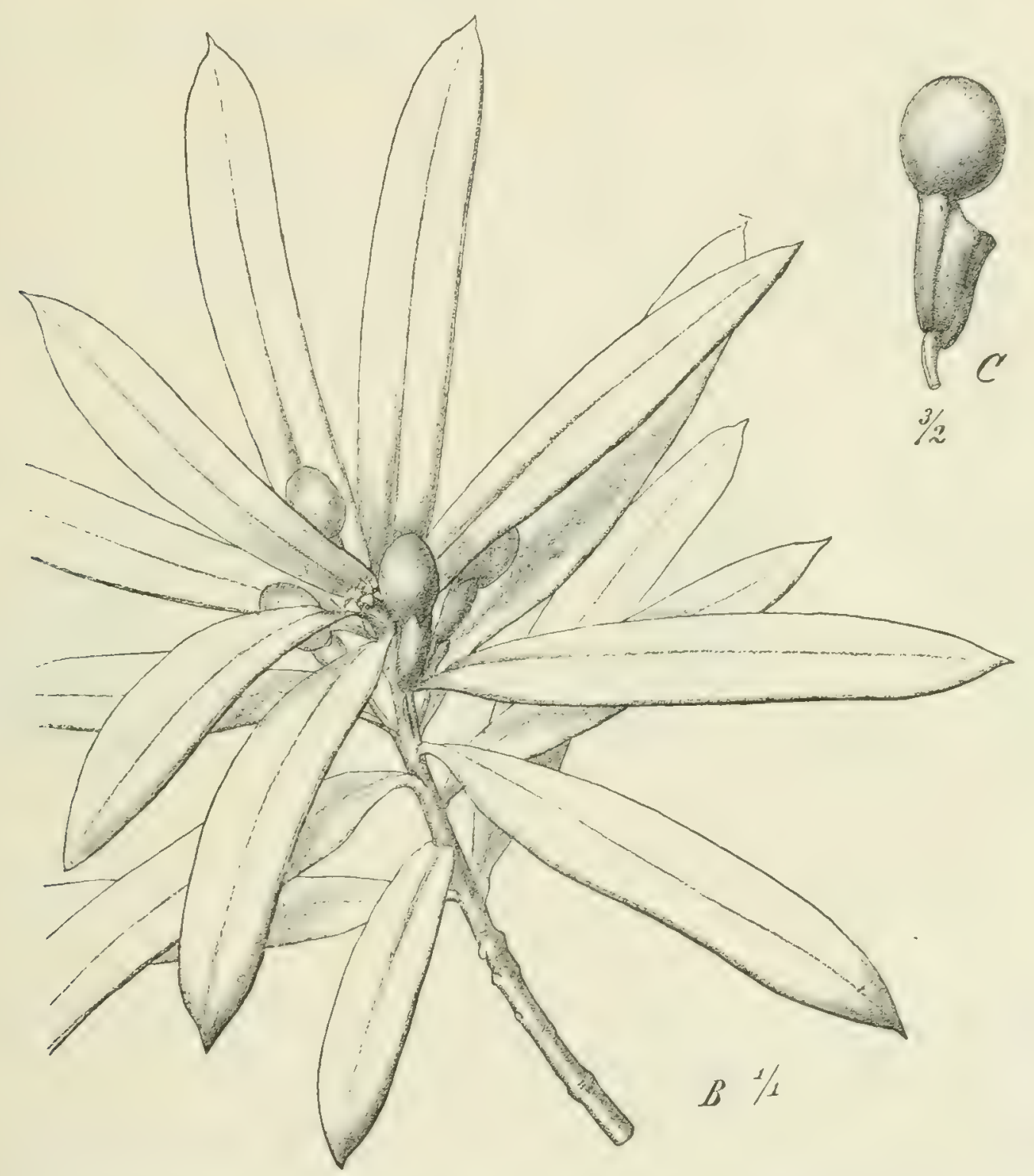

Fig. 82. $B$ Podocarpus latifolius (Thunb.) R. Br., Zweig mit weiblichen Blitten; $C$ P. milanjianus Rendle, Frucht.

ein bis zu $30 \mathrm{~m}$ hoher Baum, ist verbreitet auf den Hochgebirgen Ostafrikas und kommt bisweilen mit I. usamliarensis zusammen vor. Von den Milanjibergen im S. des Nyassa-Sees können wir das Auftreten des Baumes verfolgen über Uhehe (Utschungueberge) Uluguru (2200-25c0 m), Westusambara i 600 bis $2700 \mathrm{~m})$, Kilimandscharo (2000-2900 m;, Massaihochland, Leikipia $2000 \mathrm{~m}$; zum Runssoro $(2600 \mathrm{~m})$ : es ist ein Charakterbaum der Höhenwälder, dessen Verbreitung wohl nur durch Vögel erfolgt sein kann, welche den fleischigen Samcn nachstellten und nach Verzehrung der saftigen Samenhülle dic harte, 
den Keimling mit dem Endosperm einschließende Samenhille wieder von sich gaben. Tatsächliches ist hicriiber nicht bekannt; es seien aber diejenigen, welche Gelegenheit zur Beobachtung der afrikanischen Gebirgsvögel haben, darauf hingerviesen, dals nach der angedeuteten Richtung hin noch viel zu ermitteln ist.

\section{Fam. Pinaceae.}

Von der Familie der Pinaceae sind nur die Cupressinece im tropischen Afrika vertreten, während nördich der Sahara im Atlas noch Abies und Colmis anzutreffen sind.

Callitris Vent. In der unteren Region des Atlas finden wir vom siidlichen und westlichen Narokko an bis in dic Nähe der Stadt Algier die Stammpflanze des Sandarakharzes, Callitris quadriarlitis Vent., als 5- ro m hohen Baum, welche neuerdings auch im südlichen Spanien aufgefunden wurde und auch in der fossilen tertiär- mittel- und siideuropäischen C. Frongmiartii (Renault) Endl. cinc
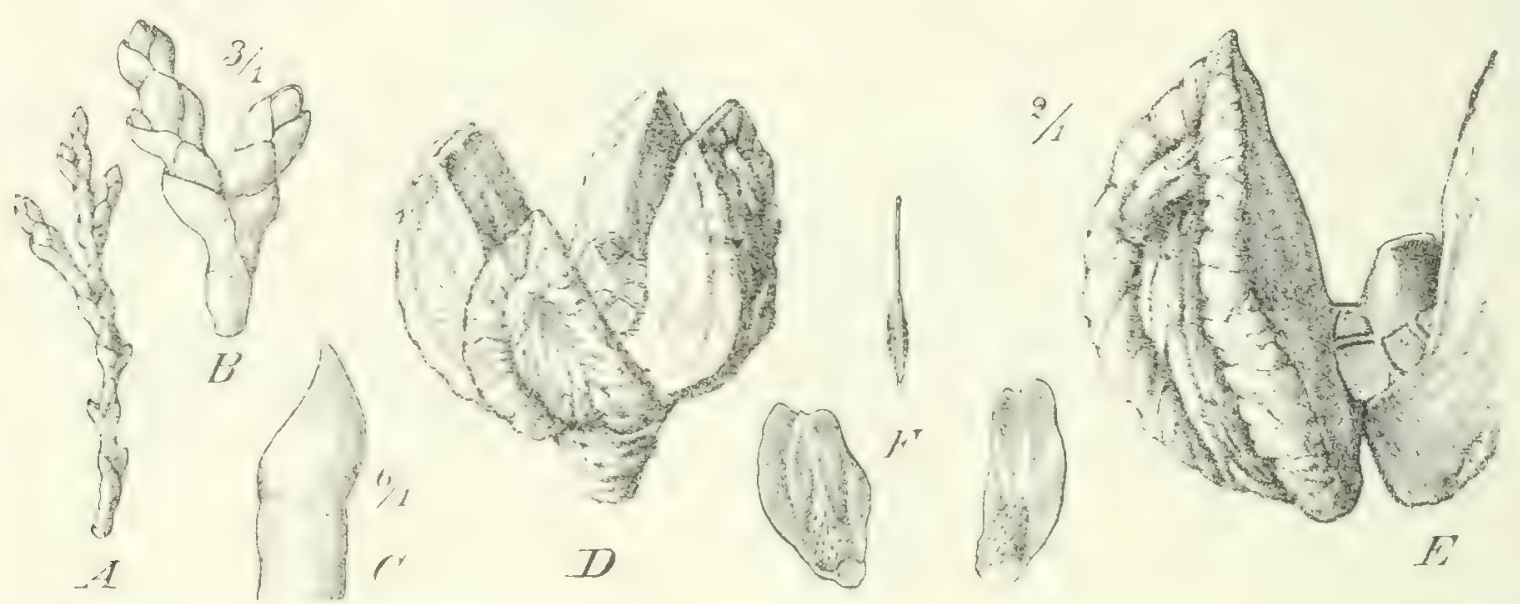

Fig. 83. Callitris Schwarzii Marloth. A Zweigstück; $B$ ein solches, dreimal vergr.; $C$ ein Internodium mit Blatt; $D$ Zapfen; $E$ Fruchtblatt desselben, vergr.; $F$ Same von der Fläche und von der Kante gesehen.

Verwandte besitzt. Einer anderen der vorigen Art sehr nahestehenden Selition, wclche durch dickere Fruchtblätter (Zapfenschuppen) ausgezeichnet ist, I'acliylepis Brongn. = Mïlbingtonie Endl.) gehören einige südafrikanische Arten an, welche daselbst friiher stärker verbreitet waren als gegenwärtig, nämlich: C. juniperoides (L.) Eichl., der bis $12 \mathrm{~m}$ hohe Cederboom von den Cederbergen des siidwestlichen Kaplandes, welcher bei Clanwilliam seine Nordgrenze findet, die ziemlich ahnliche. aber durch kleinere Zapfen Fig. 83) ausgezeichnete, bis $23 \mathrm{~m}$ hohe Callitris Schwarzii Marloth von den Kongabergen $(800$ bis $1200 \mathrm{~m})$, die nur $3-4 \mathrm{~m}$ hohe, als Baumstrauch vom Tafelberg bis Grahamstown, auch in den Drakensbergen rorkommende C. cupressoincs L.j Schrad., endlich die in den Katbergen des Zululandes ron I 300 - I600 m rorkommende ( $:$ equisetiformis Mast., welche durch dreiolicdrige Quirle der Laub- und Fruchtblätter ausgezeichnet ist. Fast spiralige Anordnung der Blätter, welche in vierzeilige ubergeht, zeigen zwei Arten des tropischen Afrika, C. Malioni Mast.', ein bis $10 \mathrm{~m}$ hoher Baum der Melsetter- und Chimaninaberge im südöstlichen 


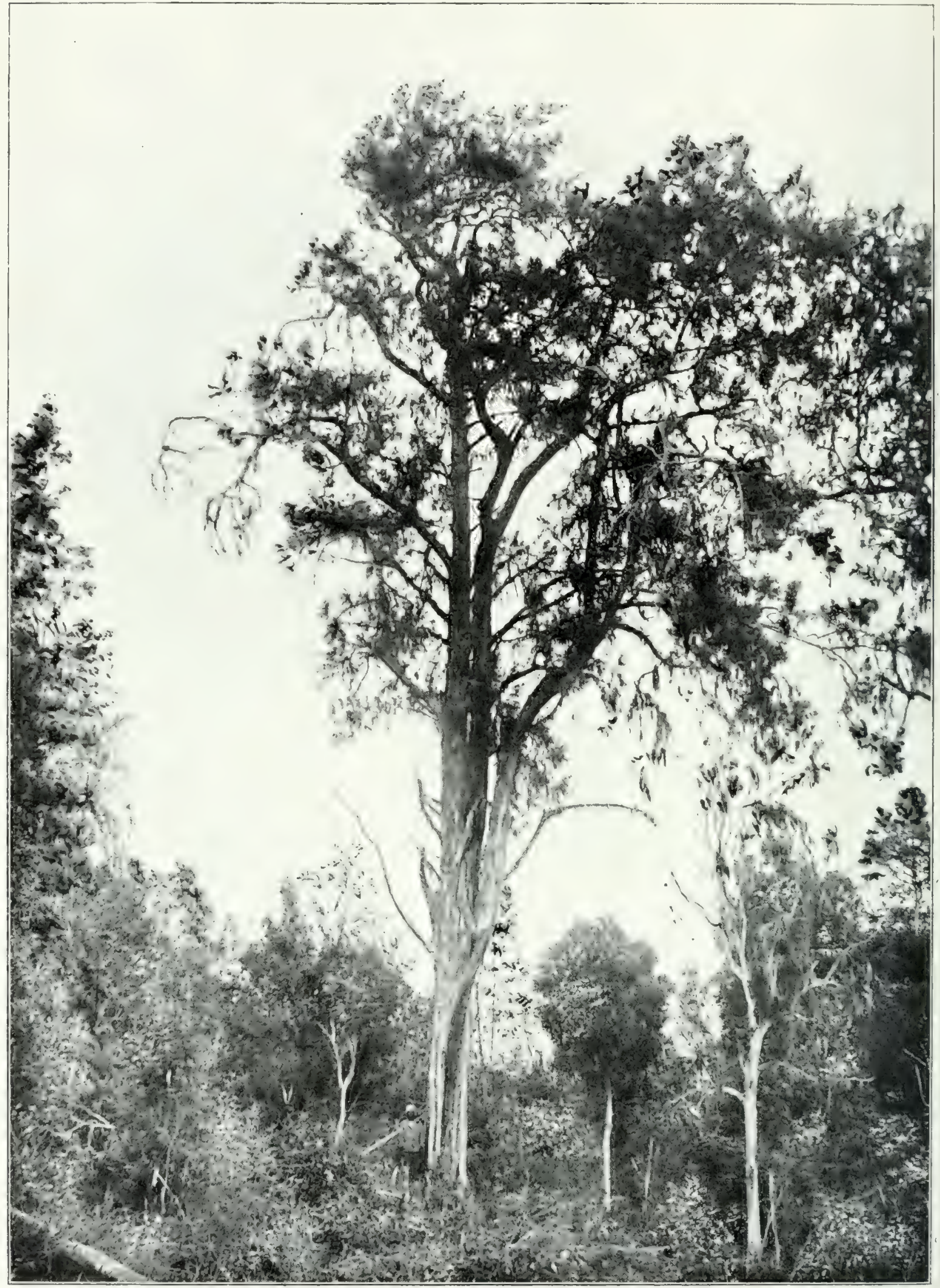

Juniperus procera Hochst.

Im I Iintergrund Bambus (Arundinaria alpina). Aus dem Höhenwald des Pikurugwerückens im Kingagebirge, um $2500 \mathrm{~m}$ ii. d. M.

Nach einer Photographie von Walter Goetze (IS99). 
Rhodesia an der portugiesischen Grenze aus ciner Höhe von $1500-2300 \mathrm{~m}$. Während dieser Baum auch in der Jugend dunkelgrime Bliitter trägt, crscheint die in den Milanjibergen im Siiden des Nyassasees um 2000-jo00 111 vorkommende C. Whyttei (Rendle) Engl. in der Jugend bläulich-grün, besitzt dann auch bis $2,5 \mathrm{~cm}$ lange, abstehende Nadelblätter, während im höheren Alter kleine angedrückte Blätter entwickelt werden. Der Baum erreicht nach WHyte bis $45 \mathrm{~m}$ Höhe mit einem geraden Stamm von bisweilen $30 \mathrm{~m}$ Länge und I,7 $\mathrm{m}$ Dicke in $2 \mathrm{~m}$ Höhe über dem Boden. Das blaßrötliche, leicht zu bearbeitende Holz ist sehr wertroll. Leider sind die Haupthestände auch dirses Baumes, sowie diejenigen der C. juniperoilies im Kapland durch Waldbrände schon sehr reduziert und es finden sich größere Wälder nur noch in den tiefen Schluchten des Lutshenyatales, einzelne Exemplare in den oberen Teilen der Täler. Da ich aber ron diesem Baum sowohl in der Nühe von Johannesburg (Frankenwald), wie bei Kwai in IVest-Usambara um $1600 \mathrm{~m}$ sehr schöne Exemplare sah, welche nur einige Jahre alt waren, so ist zu hoffen, dal man bei Aufforstungen in den afrikanischen Gebirgen diesen Baum ebenso beachten wird wie den folgenden.

Juniperus L. Während die Callitris von Suiden her bis nahe an das Südende des Nyassasees reichen, crstreckt sich Gumipinus proiera Hochst., ciner der wichtigsten Valdbäume der Hochgebirge des tropischen Afrika, von Abyssinien bis nahe an das Nordende des Nyassasees. Der Baum wird 25-40 m hoch und besitzt meist einen geraden Stamm, der am Grunde oft ïber I m dick ist und ziemlich dichtstehende quirlige Äste trägt. Er zeigt dieselbe Heterophyllie wie andere Funipcrus und trägt schwarze Becren, welche denen des gewöhnlichen Wachholders an Größe ziemlich gleichen. Er bildet im abyssinischen Hochland Bestände zwischen 2300 und 3300 m ii. M., das" nördlichste Vorkommen diurfte bei Bayla sein, ostwärts wird er noch im Gebirge des nördlichen Somalilandes bei Meid in geringerer Höhe ii. M. (I600-I.800 m) angetroffen. Vom südlichen Abyssinien (Schoa) südwärts treffen wir den Baum allenthalben in den Schluchten und auf den Gipfeln des Gallahochlandes von 2000-3000 m ii. M., z. B. am Abunas und Abuelkasim, auch im Hochland Sidamo. Weiter können wir den Baum verfolgen durch das Massaihochland vom Mau-Plateau östlich vom Victoria-Njansa $(2300-3000 \mathrm{~m})$ entlang der Ugandabahn bis Kikuju, am Fuß der Aberdarakette ron I930-2100 m; wir finden ihn auch am Westabhang des Kenia. Dann bildet der Baum große Hochwälder in Westusambara, namentlich den sogenannten Schummewald oberhalb Kwai, in welchem einzelne Exemplare bis to $\mathrm{m}$ hoch werden. Am Kilimandscharo treten Bestände am Nordabhang zwischen 2000 und $2800 \mathrm{~m}$ ü. M. auf und am Nordostabhang des Meru geht er bis zu I60o $\mathrm{m}$ an den Rand der Gebirgsbuschsteppe herab, wie auch in Westusambara. Endlich wurde der Baum ziemlich häufig von GrET7E im Kingagebirge gefunden, so am Nordabhang des Kipengcrerïckens. Im allgemeinen kann man sagen, daß der Bạm an den den Seewinden exponierten Abhängen nicht angetroffen wird. Seine nächsten Verwandten finden sich in den trockneren Teilen des Medi- 
terrangebietes, $\dddot{7}$. cxelser M. Bieb. in der Krim, an den Südabhängen des Kaukasus, in Kleinasien, Syrien, Persien, Afghanistan, Beludschistan und Südostarabien, F. thurifera L. in Algier, Südspanien und Portugal.

\section{Klasse Gnetales, \\ Fam. Gnetaceae.}

Diese am weitesten vorgeschrittene Familie der jetzt lebenden Gymnospermen ist in Afrika durch je einen Vertreter ihrer voneinander ziemlich stark abweichenden Unterfamilien repräsentiert.

Gnetum L., im tropischen, zumal dem äquatorialen Amerika, sowie im Monsungebict mit mehreren Arten entwickelt, ist im tropischen Afrika nur durch zwei Arten vertreten, von denen G. africamm Welw. (Fig. $84 A$-F) von Kamerun bis Angola (Golungo Alto, daselbst n-coco genannt) in den unteren Regenwäldern zerstreut, aber nicht selten vorkommt. Es ist eine nicht sehr kräftige, bis $6 \mathrm{~m}$ hoch aufsteigende I.iane mit kurzgestielten, länglichen, in eine stumpfe lange Spitze ausgehenden Blättern, welche gekocht ais Nahrung dienen. In Kamerun wird die Liane nkok genannt. Daselbst wächst auch noch G. Buchholizimum Engl., mit breiteren Blättern und dickeren männlichen Blütenständen (vergl. Fig. $84 G-K)$.

Ephedra L., verbreitet in xerophytischen Teilen des Mediterrangebietes und Zentralasiens, des westlichen Nordamerika und in einem großen Teil ron Siidamerika, beruhrt das tropische Afrika nur im nördlichen Somaliland mit E. alte C. A. Mey., welche bei Berbera und im Ahlgebirge um $1500 \mathrm{~m}$ ii. M. vorkommt. Dieser nur mit ganz kleinen Schuppenblättern versehene, mit seinen aufrechten, grünen, reich rerzwcigten Ïsten assimilicrende, bisweilen im Gesträuche kletternde Strauch findet sich auch an der gegeniiberliegenden Küste Suidarabiens, ron Cyrenaica durch L'nterägypten bis zum Sinai, in Syrien, entlang des persischen Neerbusens bis zum Indus, an diesem nordwärts und $\mathrm{im}$ S. des Kaspischen Meeres. - In Nordafrika kommt die bis zu 8 m Höhe kletternde E. altissima Desf. von Marokko bis Tunis und in der montanen Region des Atlas vor, whihrend die in ihrem Wachstum auch sehr verschiedene E. fragilis Poir. von den Kanarischen Inseln und Madeira sich durch das südliche mediterrane Küstengebiet, inshesondere durch Algier bis Kleinasien erstreckt; sie reicht bis an den Nordrand der Sahara.

Tumboa Welw. (Welwitschic Hook. f., n'tumbo der Eingeborenen von Mossamedes). Diese wegen ihrer höchst eigenartigen Entwicklung auch in weiteren Kreisen bekannt gewordene Gattung ist monotypisch und enthält nur T. Rerincsii Inok. f. (= IT'chitschiar mirabilis Hook. f.), welche auf einer großen Ebene I $10 \mathrm{~m}$ ii. M. zwischen Rio Coroca und Praia da Amelia, auf der steinigen und sandigen Ebene zwischen Caho Negro und Mossamedes, desgl. auf den wüsten Flächen der Namib zwischen Hoanib und Uniab, sowie suidlich und nördlich vom Swakop in der Nähe der jetzigen Bahnstation »Welwitsch« vorkommt. Hier sei kurz darauf hingewiesen, dal3 die Pflanze bei Iossamedes auf Kalktuff, welcher mit 
Sandsteinkieseln bedeckt ist, ferner auf Sandstein selbst häufig ist; selbst klcine Exemplare mit IVurzeln von der Dicke einer Mohrribib können nicht ohne weiteres aus dem völlig trocknen und sterilen Boden herausgezogen werden. Nach BAUMI $^{1}$ ) sind in den trockensten Monaten des Jahres, Juni bis August, dic Pflanzen

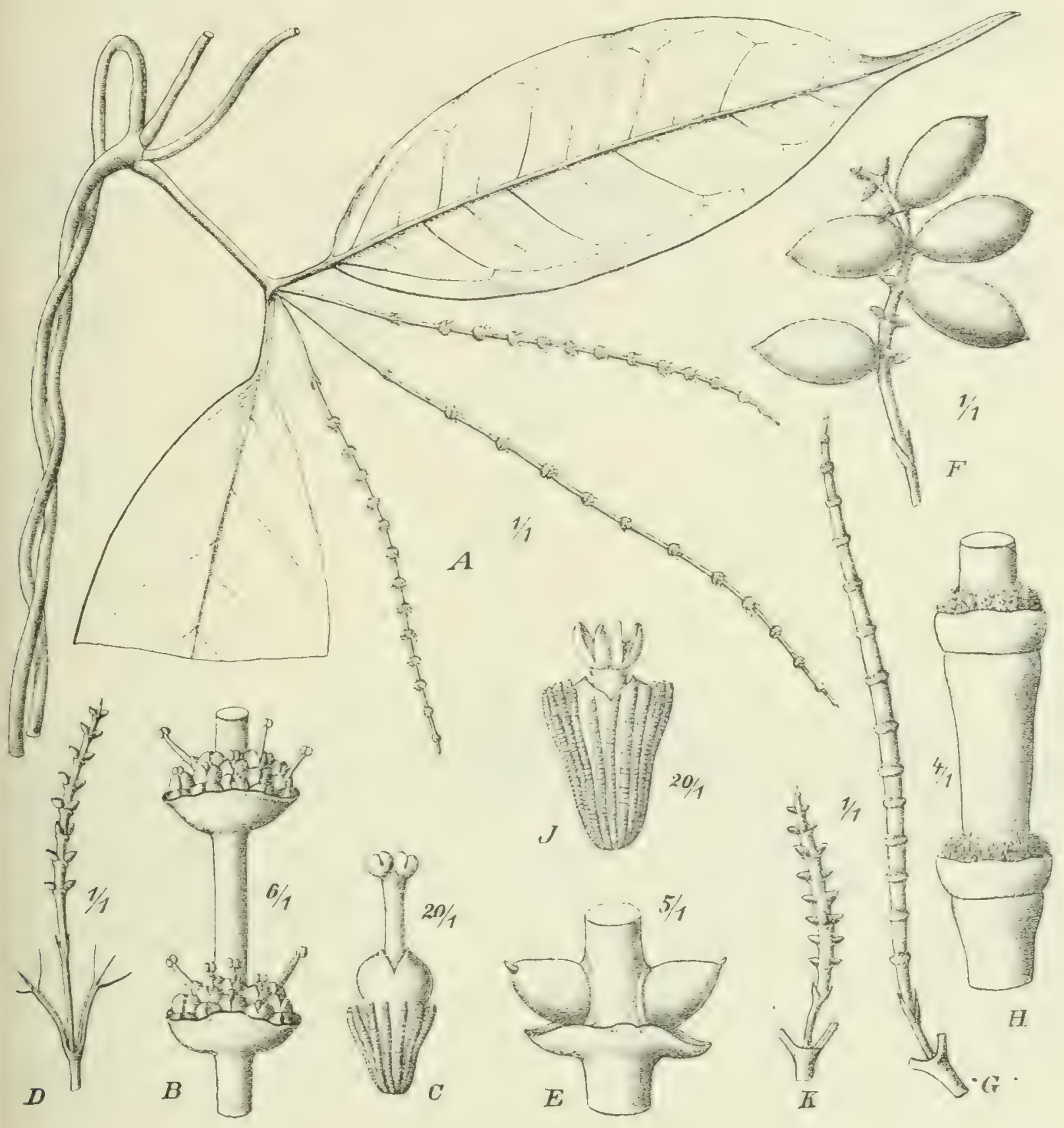

Fig. 84. $A-F$ Gnetum africanum Welw. A Zweig mit männlichen Blitten; $B$ Stück eines männlichen Blütenzweiges; $C$ eine männliche Bliite; $D$ Blütenstand mit weiblichen Bliten; $E$ zwei weibliche Blüten; $F$ Früchte. $G-K$ Gnetum Buchholzianum Engl. $G$ männlicher Blütenstand; $H$ Stück desselben vergr.; 7 männliche Blüte.

durch starke, oft I+ Tage andauernde Nebel vor dem . tustrocknen durch die Sonne geschützt. Diese Nebel werden in den kühlen Nächten zu so starkem Tau niedergeschlagen, daß am Morgen die wenigen Pflanzen, welche in dieser

1) BAUM, Kunene-Sambesi-Expedition, S. 3 . 
IVüste vegetieren, wie im Wasser gebadet erscheinen. Dieser Tau ist wohl oftmals die einzige Feuchtigkeit, welche die Tumboen in regenlosen Jahren benetzt. Diese geringe Feuchtigkeitsmenge ist anscheinend gerade die Bedingung für das Gedeihen diescr Pflanze; denn dort, wo in den Vorbergen des Shellagebirges die Strauchvegetation, bestehend aus niedrigen schirmartigen Akazien, beginnt, verschwindet die Tumboa nach und nach. " Für den Nichtbotaniker sei hier noch erwähnt, daß die heiden Keimblätter der Pflanze abfallen, wenn

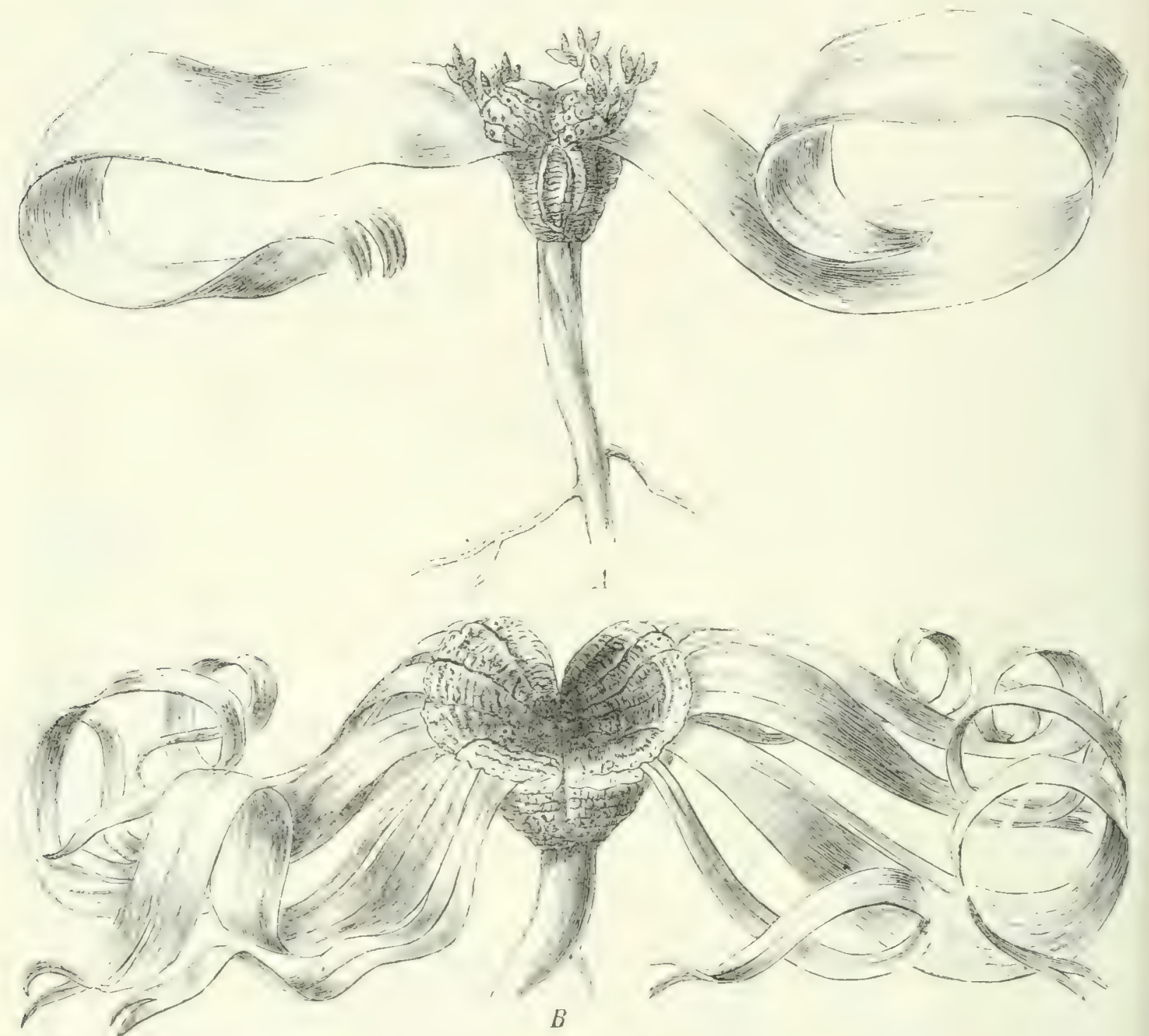

Fig. 85. Tumboa Bainesii Hook. in $1 / \mathrm{ro}$ der nat. Gr. $A$ jüngere, blïhende Pflanze; $B$ ältere Pflanze mit zweilappigem Stamm.

sich die beicen Laubblätter weiter entwickeln. Diese erreichen an dem kreiselförmigen, kaum I dm ïber den Boden tretenden und bisweilen $+\mathrm{m}$ Umfang haltenden Stamm eine Länge von $2 \mathrm{~m}$, sowie eine Breite von $\mathrm{I}, 40 \mathrm{~m}$ und zerreißen später vielfach der Länge nach. „Das freie absterbende Ende der Blätter wird vielfach vom Flugsand verschiittet und dauernd fest an den Boden sedrickt: da das Blatt jahrzehntelang von der Ansatzstelle aus nachwachst, so hauschen sich die Blätter bogenförmig: (L. S(nultaze). Dies zeigt namentlich Fig. $B$ unserer Abbildung. Häufig werden die Tumboen von den durch die 
W'üste wandernden Eingeborenen der Blätter beraubt, welche ihnen als Brennmaterial dienen. Trotzdem entwickeln die entblätterten Stänme ihre ährigen in Rispen angeordneten Blïtenstände. BAUII stellte fest, daß auf den von ihm besuchten Fundorten die männlichen Exemplare ctwa ${ }^{3}{ }_{4}$ der Gesamtahl, die weiblichen $I / 4$ ausmachten.

Unterabt. Angiosperma Bedecktsamige oder Stigmateae:

mit Narben versehene Pflanzen).

\section{Klasse Monocotyledoneae (Einkeimblätrige).}

\section{Reihe Pandanales.}

Fam. Typhaceae (Lieschkolben).

Sämtlich Hydrophyten.

Von diesen dem Bewohner der nördlich gemäßigten Zone bekannten Sumpfgewächsen kommen in Afrika sechs Arten ror, von denen nur drei diesem Erdteil eigentïmlich sind; sie wachsen auch hier an Flußufurn und Teichrändern, scheinen aber in den extrem feuchten Gebieten zu fehlen; meist werden sie aber von den Sammlern tropischer Pflanzen als nicht interessant angesehen und vernachlässigt.

Von den 3 auch in Europa verbreiteten Arten erstreckt sich die bis $3 \mathrm{~m}$ hohe schmalblättrige Typha angustate Bory et Chaub. aus Nordafrika durch Nubien, Cordofan und Sennar bis nach der Erythrea und dem mittleren Abyssinien; die ebenfalls schmalblättrige $T$. ang ustifolia $L$. findet sich vereinzelt in Nubien; die breitblättrige und von den vorigen Arten durch das Fehlen der Bracteen unterhalb der weiblichen Bliten ausgezeichnete T. latifolic L. kommt nur in Abyssinien vor. Mit letzterer Art stimmt hinsichtlich der Bracteen die T. capensis Rohrb. überein, zeichnet sich aber durch einzelligen l'ollen aus; sie ist vom östlichen Kapland bis Dar-es-Salam und im Westen bis Loango zerstreut, auch im Namaqualand anzutreffen. Eine andere auch im Kapland vorkommende und ebenfalls einzelligen Pollen besitzende Art ist T. anstralis Schum. et Thonn; sie steht der T. angustifolia L. ziemlich nahe und findet sich im südlichen Nyassaland, bei Mombas, in der Erythrea, im Hererolande und QberGuinea. Die stattlichste Art ist T. elephantina Roxb., welche 3-4 $\mathrm{m}$ hoch wird; im nordwestlichen Indien verbreitet hat sie das suidliche Abyssinien erreicht, wo sie von ElLexbeck an den Ufern des Akaki in der Provinz Schoa um $2200 \mathrm{~m}$ ü. MI. gefunden wurde; etwas abweichend ist die auch in Abyssinien aufgefundene var. Schimperi (Rohrb.) Graebn.

\section{Fam. Pandanaceae (Schraubenbäume).}

Pandanus L. ist die einzige auch im tropischen Afrika vertretene Gattung dieser auf dic Tropenländer der alten Welt beschränkten Familie. Die teils strauch-, teils baumartig (so immer in Afrika) entwickelten Arten dieser Gattung 
sind für jeden, der sie einnal gesehen, leicht kenntlich an den ringsum am unteren Teil des sich oben gabehnden Stammes, manchmal auch in größerer Höhe an den Verzweigungsstellen entspringenden Stützwurzeln und an den linealischen, am Rande und unterseits an der Mittelrippe dornig gezähnten Blättern; auch fallen sie auf durch die schraubenförmige Drehung der deutlich hervortretenden Gradzeilen der Blätter. Die Blïten sind immer nackt; die männlichen stehen dichtgedrängt in Kolben, welche in der Jugend von einem großen Hochblatt bedeckt sind und zu mehreren oft einen i m langen Blïtenstand bilden. Die weiblichen Blüten bestehen aus einem oder mehreren mit einer Samenanlage versehenen Carpellen und sind zu einem eiförmigen oder länglichen Kolben vereinigt, dessen Frïchte cine große Sammelfrucht bilden. Die afrikanischen Arten von Pandams finden sich großenteils an der Küste und an den Flußufern unweit der Küste; aber einige sind doch auch im Inneren in größerer Höhe ü. M. an Gebirgsbächen gefunden worden, so der bis Io $\mathrm{m}$ hohe P. Engleri Warb. von mir in West-Usambara unterhalb Sakare um etwa $800 \mathrm{~m}, P$. Goetzei Warb. am Lofio-Flurs in thehe um $600 \mathrm{~m}$. Auch die nördlichste Art in Ostafrika I'. rabuicusis Rendle wurde im Inneren, im Gebiet der Rabai-Hills, westlich von Mombassa gefunden. Von der Sansibarküste sind einige Arten ${ }^{\mathrm{T}}$ ) nach dürftigem Material beschrieben worden, so daß es keinen Wert hat, hier ihre Namen aufzuführen. Als die suidlichste Art Ostafrikas ist I'. Lizingstoniamus Rendle zu nennen, welcher im Miindungsgebiet des Sambesi am Luebe vorkommt.

In Westafrika treffen wir auf den ersten Pandanus in Senegambien; es ist dies P. Houdclotianus Balf. f. Am längsten bekannt ist $P$. candelabrum Beauv. von den Ufern des Rio Formosa im Nigergebiet und von. Kamerun, hier hesonders häufig auf den Inseln der Kamerunmündung. Dann begegnen uns noch einige Arten im Kamerungebiet, P. thomensis Henriquez auf São Thomé, bis $16 \mathrm{~m}$ hoch und bis $500 \mathrm{~m}$ ü. M. aufsteigend. Ziemlich vollständig bekannt sind auch P. kamemenensis Warb. von Kamerun und P. Welwitschii Rendle von den Ufern des Cuanza im Bezirk Pungo Andongo. Aus Zentralafrika und dem Ghasalquellengebiet sind uns keine Arten bekannt geworden.

\section{Reihe Helobiae (Fluviales).}

\section{Fam. Potamogetonaceae.}

Sämtlich Hydrophyten.

Von dieser Familie finden sich in Afrika vorzugsweise auch in den benachbarten Erdteilen vorkommende Arten. Viele der Suißwasserpflanzen finden sich auch in Europa, und die im Meere wachsenden Arten sind zum Teil mit denen der indischen Küstengebiete identisch.

Die wissenschaftliche Kenntnis der afrikanischen Pandanus ist noch sebr unvollkommen, und es ist sehr zu wünschen, daß diejenigen, welche Gelegenheit haben, einzelne Exemplare dauernd zu beobachten, von denselben Photographien, Blätter, männliche und weibliche Blütenstände in Alkohol oder letztere getrocknet, aber dann von einem dichten Fadennetz umsponnen, an das Botanische Museum in Dahlem zur weiteren Untersuchung einsenden. 


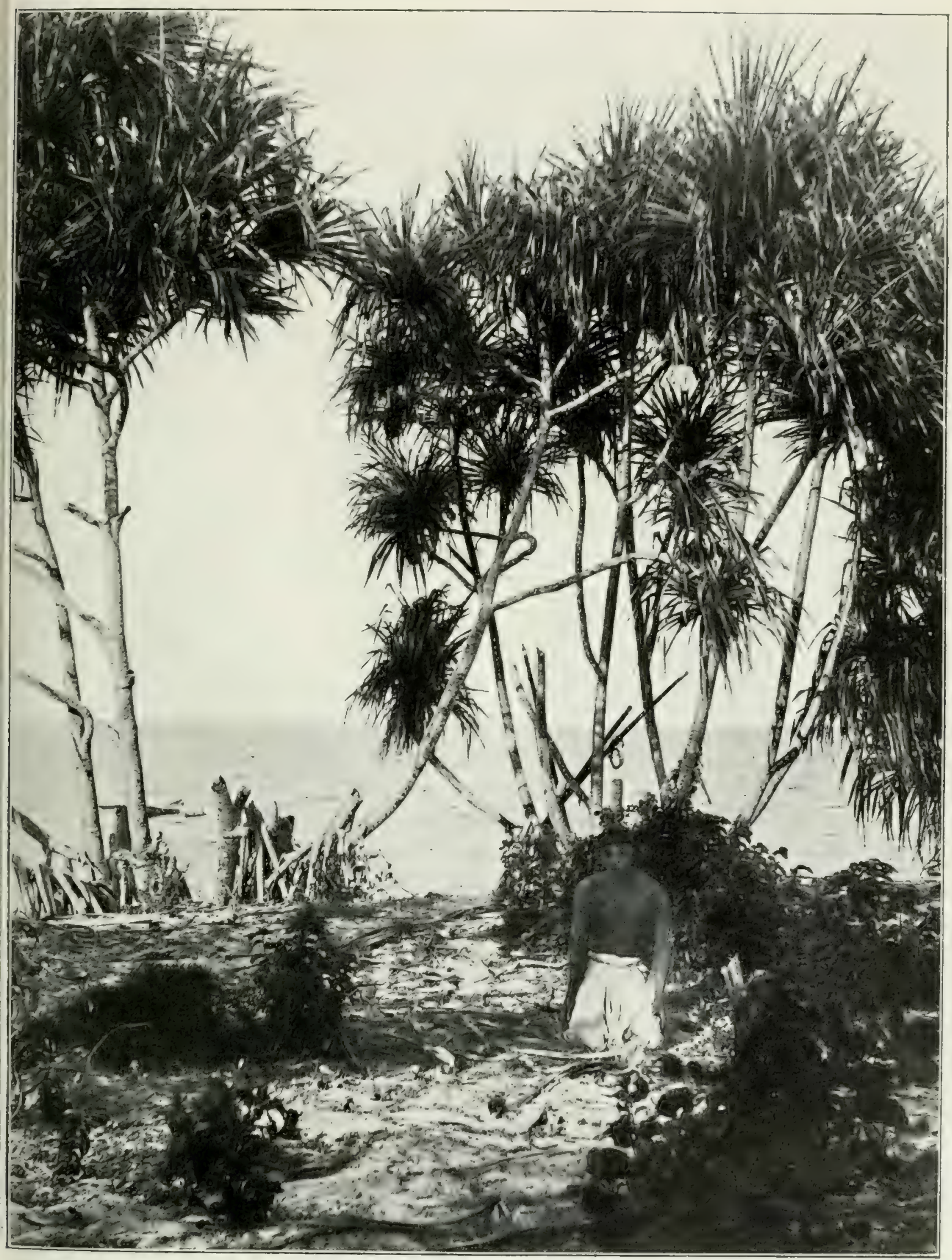

Pandanus spec.

am Mkulumusi bei Tanga, DOA. 

Übersicht ïber die in Afrika vertretenen Gattungen.

A. Bliuten in Äbren.

a) Blüten zwitterig.

r) Blüten mit vier Staubblättern。 Carpelle sitzend......... Potamogeton.

ß) Blüten mit zwei Staubblättern. Carpelle bei der Reife gestielt . . . . Ruppia.

b) Blüten eingeschlechtlich auf flacher dorsiventraler Ähre. Meerespflanzen . . Zostera.

B. Blüten einzeln oder in Trugdolden, eingeschlechtlich.

a) Blütenhülle fehlend. Griffel kürzer als die langen fadenförmigen Narben. Meerespflanzen mit Fadenpollen.

(e) Zwei Antheren in gleicher Höhe ............. Cymodocea.

B) Die eine Anthere höher stehend als die andere......... Diplanthera.

b. Blitenhüllte in den $\subseteq \underset{B}{B l i i t e n}$ rorhanden. Süßwasserpflanzen mit kugeligem Pollen. Zannichellia.

Potamogeton L. Einige kosmopolitische Arten, P. crispus L., lucens L., pusilhus L., fictiratus L., finden sich in Abyssinien und auch im zentralafrikanischen Seengebiet, zum Teil sind sic auch nach Benguclla und dem Kapland gelangt, wie dies auch bei $P$. fluitrns Roth geschehen ist. Der weitverbreitete $P$. filifomis Pers. wurde am Ruwenzori gefunden; es ist wahrscheinlich, daß auch noch die in Sidafrika vorkommenden und sonst weitrerbreiteten $P$. natans L., P. Fricsii Rupr. und $P$. alfimus Balb. im tropischen Afrika nachgewiesen werden. Eine verbreitete paläotropische Art, $P$. javanicus Hassk., ist vom tropischen Zentralafrika bis Suidafrika zerstreut. Von den endemischen Arten steht der in der Erythrea und Abyssinien vorkommende P'. Richarli Solms-Laub. dem $P$. natans L. nahe; $P$. Schweinfurthii A. Benn. aus dem Ghasalquellengebiet und Abyssinien, auch mit Schwimmblättern, ist durch scharf dreikielige Fruichte gut charakterisiert. I'. I'russii A. Benn. von der Lrythrea, Abyssinien und Kamerun, gehört in die Verwandtschaft ron I'. pusillus L. Am eigenartigsten ist 1'. Li-ingstonci A. Benn. rom Nyassasee mit sehr starren, linealischen Blättern, die am Grunde des Stengels dicht zusammengedrängt sind. Auf diese Pflanze dürfte weiter zu achten sein.

Ruppia L. ist mit der weitverbreiteten $R$. maritima L. auch im tropischen Afrika vertreten; sie findet sich in Ägypten, Senegambien subspec. spiralis L. Dumortier), im unteren Nigergebiet und Angola isubspec. rostrate Mcrt. et Koch).

Zannichellia L. Z. palustris L. ist von Nitteleuropa durch das Mittelmeergebiet und auch das mediterrane Afrika verbreitet und tritt dann wieder. von Deutsch-Südwestafrika bis Südafrika auf.

Außer diesen $P$. des süßen Wassers kommen an den afrikanischen Küsten auch einige zu dieser Familie gehörige Seegräser vor, zu deren Erforschung noch viel beigetragen werden kann.

Zostera L. Das Vorkommen der bekannten, weitrerbreiteten \%. marina L. ist für Afrika zweifelhaft, und Z. nanc L. findet sich an den afrikanischen Küsten nürdlich des Wendekreises sowie um das ganze Kapland herum auch an der Ostkuiste und der Küste von Madagaskar.

Cymodocea Koenig ist besonders formenreich an den Kuisten des Roten Meeres. Die mediterrane mit flachen siebennervigen Blättern verschene $C$. nohis 


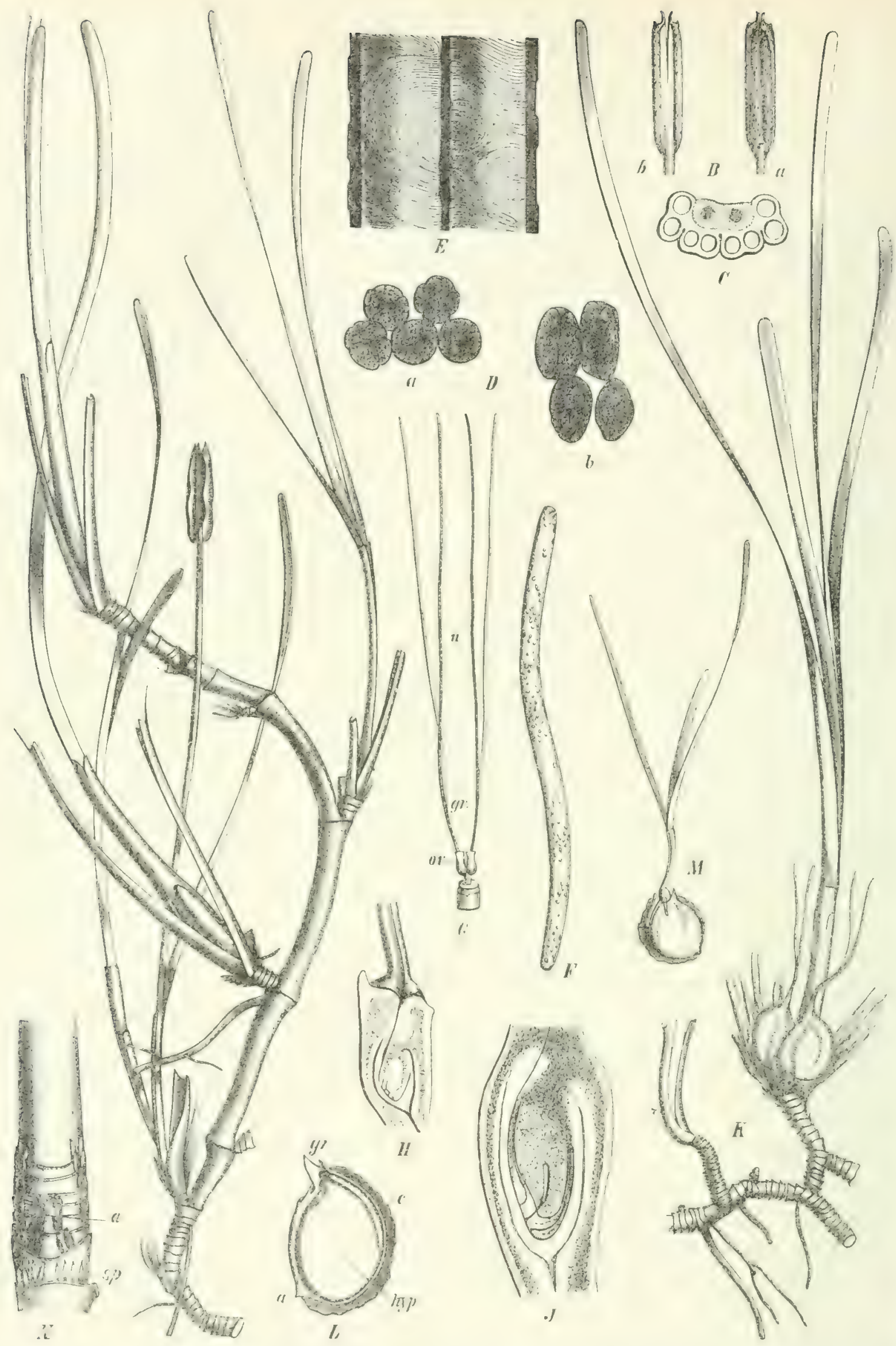

Fig. 86. Cymodocea nodosa (Ucria) Aschers. (nach Bornet). $A$ Pf. mit ô Bl. (nat. Gr.); $B$ ô Bl., a Yun der Yorder-, b von der Rücliseite nat. (ir.): ( dieselbe (jung) im Querschnitt $(60 / 1)$; $D$ die durch Teilung einer Mutteryelle entstehenden Pollenzellen, a ginz jung, b etwas älter (250 1,; E gerifnete Antherenhälfte. die fadenfömigen Pollenzellen zeigend $5 / 1$ ): F cine noch nicht ausgewachsene Pollerzelle 250 I'; $G$ C IBl... Frkn.. (iriffel, $n$ Xarbe (nat. Gr.); $H$ junges Carpell

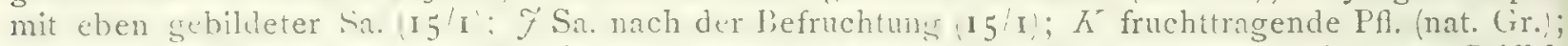
$l$ geciftuctes Irichtchen, den E. zeigend, a Anheftumgstelle des Früchtchens. C Keimb., sr Griffel, hvp hypokotyles Glicd (2/1); $M$ Keimpf. (nat. Gr.); $N$ Teil der Grundachse, a Stiel einer 우 Bl., sp Achselschïppchen (2/I). 
(Ucria Aschers. Fig. \&6) fuhlt im Roten Meer, erstreckt sich aber bis zu den Kanarischen Inseln und an den Küsten Nordwestafrikas bis Senegambien. Von dem Nordende des Roten Mieeres können wir bis an die Münlung des LuahoRirer an der Mossambikkuiste und bis an die Küisten der malegassischen Inseln C. ciliata (Koenig) Ehrenb. (Fig. 8-) verfolgen, welche sichelfürmige I3lätter

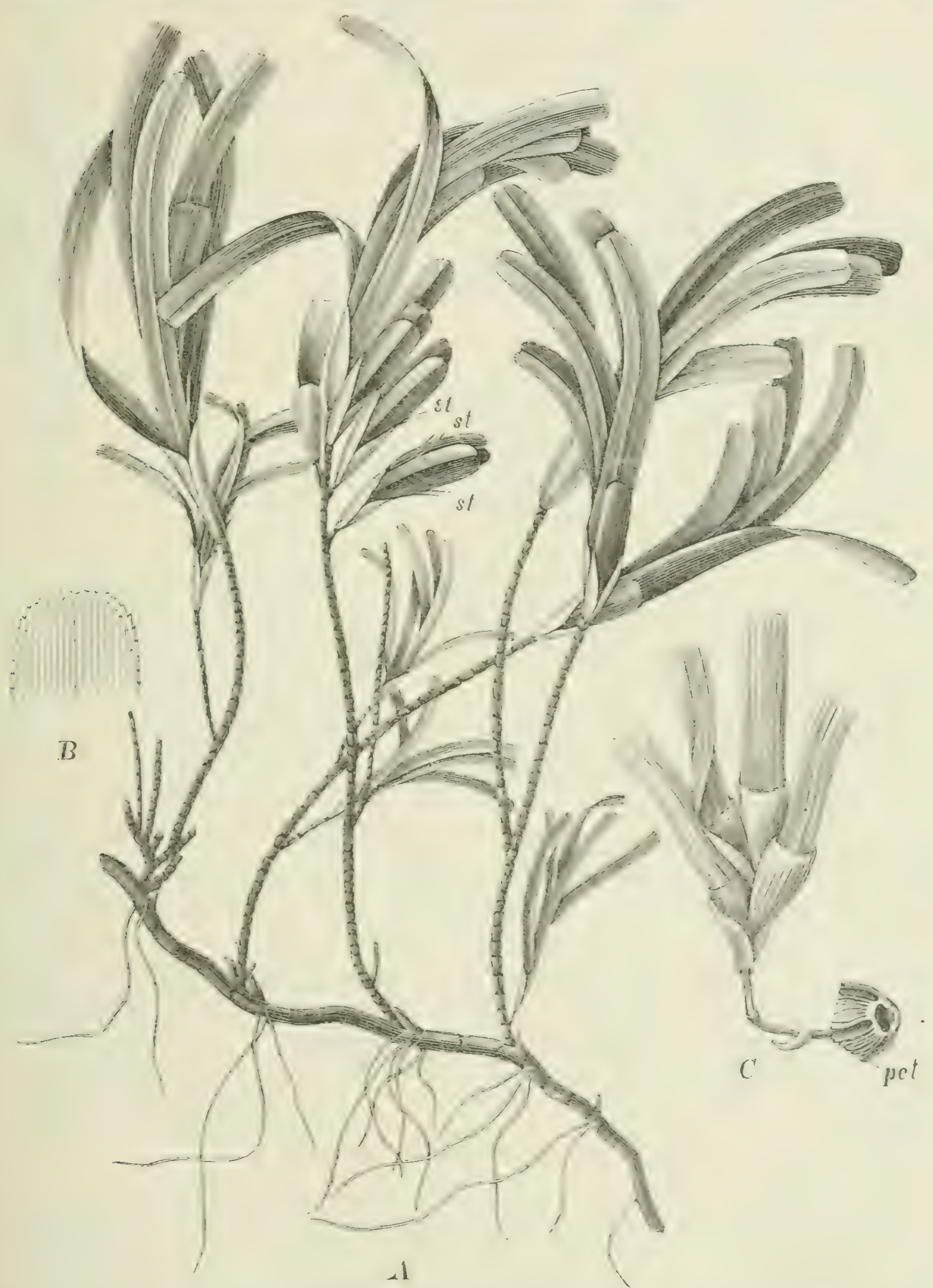

Fig. 87. Cymodocea ciliata (Koenig) Ehrenb. A ganze Pf., verkleinert, st hervorragende N. der 오의 B B Spitze eines Laubb. in nat. Gr. (nach Hemprich und Ehrexberg, Symbolae physicae, Botanica I, tab. VI, C Natiir. Steckling o ron Cymodocen antarctica Endi. fit Kammblatt. nat. Gr. 
besitzt; die durch stielrunde Blätter ausgezeichnete C. isoctifolia Aschers. reicht bis Lamu und findet sich auch an den Küisten des nördichen Madagasliar. Dagegen ist C. sirmlater Spreng.) Aschers. et Magnus im Roten Meer nur von der asiatischen Seite bekannt, an den Kiisten der Seychellen und Madagasliars anzutreffen; auch reichen diese drei Arten ostwärts bis in den Stillen Ozean. C. rotundate Aschers. endlich, mit 9-I3-nervigen geraden Blättern, kommt im Roten Meer und an den Küsten Madagaskars vor.

Diplanthera Thou. (Halodule Endl.), von der vorigen Gattung hauptsächlich noch durch cinnarbige Pistille rerschicden, enthalt zwei Arten, von denen D. uninervis (Forsk.) Aschers. schon von FORSKiL im Roten Meer entdeckt wurde und auch im Indischen Ozean verbreitet ist. Dic andere Art, D. Wrightii Aschers., ist an den Küusten M'estindiens und Angolas ron Ambriz bis Loanda verbreitet. Wir haben also bei diesen Seegrüisurn, ähnlich wie bei den Pflanzen der Mangrove eine scharf hervortretende Sonderung zwischen den Arten der indischen und atlantischen Küste.

\section{Fam. Najadaceae.}

Eine zwar an und für sich sehr interessante Familie; aber ohne Bedeutung fur die in das Auge fallenden Formationen, da alle Arten der einzigen Gattung

Najas L. unter Wasser leben. Da die Gattung in den Tropen viel artenreicher ist als in Europa und die in der nördlich gemäßigten Zone vorkommenden Arten auch in Afrika anzutreffen sind, so ist vielleicht hier oder im Nediterrangebiet ihre ursprimgliche Heimat zu suchen. Die meisten afrikanischen Arten (7) sind monöcisch und gehören zu der Untergattung. Caulinia (Willd.) Aschers.; die mediterran-boreale $N$. minor All. (OT Bliiten von einer Scheide eingeschlossen) wurde auch in Teichen des äquatorialen zentralafrikanischen Seengebietes gefunden; in ihre nähere Verwandtschaft gehören $N$. horrida A. Br., welche von Sentegambien und dem Ghasalquellengebiet bis Mossambik zerstreut vorkommt, und dic seltenere. V. intorufter K. Schum. Drei tropische afrikanische Arten haben die ${ }^{j}$ und die S Bliten von einer Scheide umschlossen, sie wurden alle bis jetzt erst an je einem Standort gefunclen. Die Scheide fehlt um die $\sigma^{T}$ und die $Q$ Bliten bei $N$. graminea Delile, welche vom Mediterrangebiet aus durch die wärmeren Teile der alten Welt verbreitet in Afrika bis zum Ghasalquellengebiet reicht. I'on der diöcischen die L'ntergattung Finnajers Aschers. ausmachenden Art $N$. marina L. kommt eine var. muricata A. Br. et K. Schum. im Albert Njansa vor.

\section{Fam. Aponogetonaceae.}

Hydrophyten.

Mehr als in cinem anderen Erdteil haben dic -1. in Afrika und Madagaskar sich ausgehreitet und an Formengestaltung seronnen. Die hicr beigegebenen

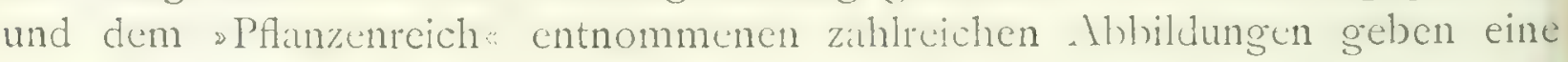
Vorstellung von diesen Pflänzen, so daß auf Beschreibung verzichtet werden kann. Nur das sei zum Verstïndnis bemerkt, dak die Blattgebilde, welche am 
Grunde der Blüten in Fig. $88 E-\mathcal{F}$, Fig. 9 I $G$ hervortreten, nicht wie man zuerst meinen könnte, Bracteen sind, sondern Perigonblätter. Bei dem im Kap-

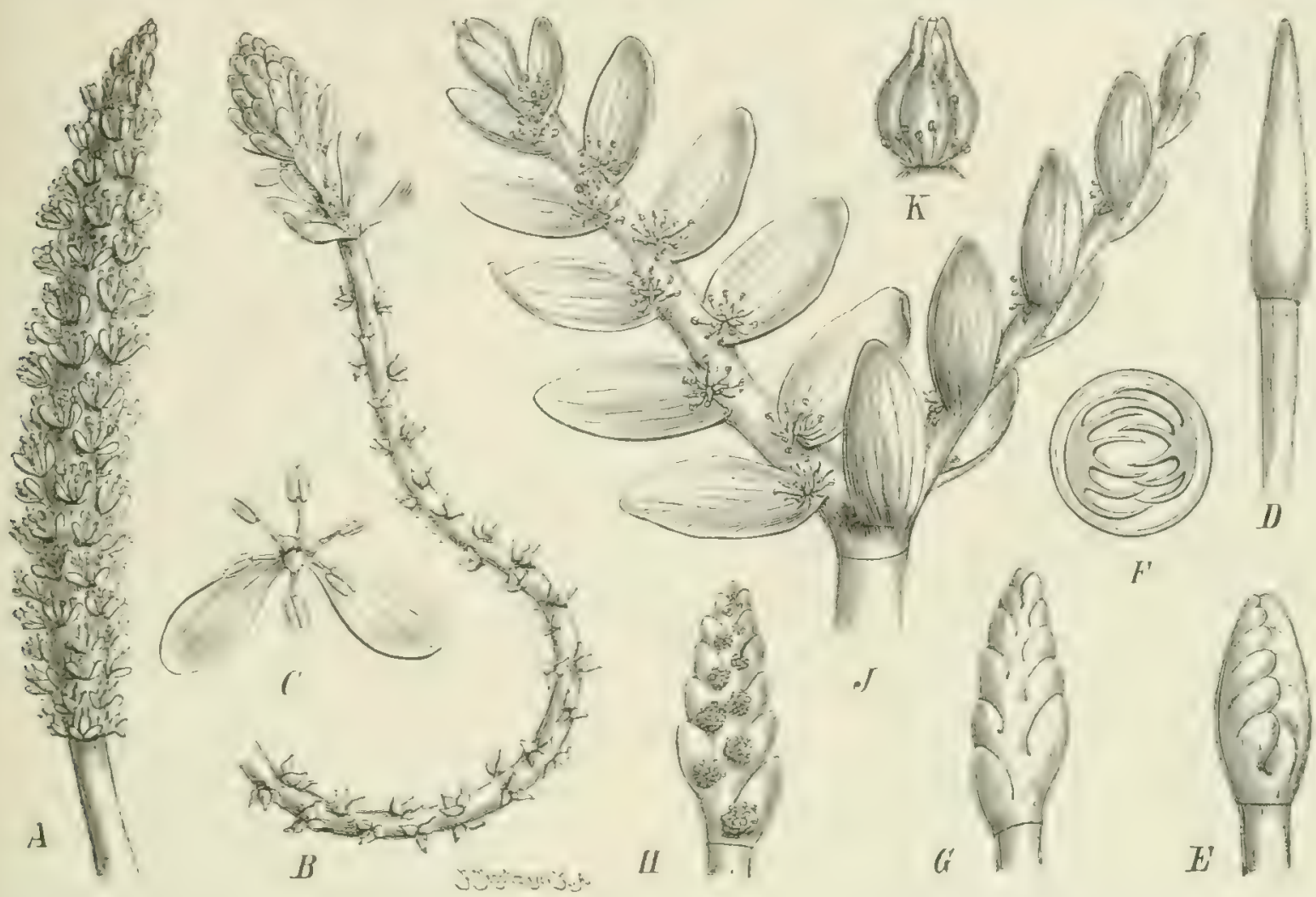

Fig. 88. A Aponogeton natans (L.) Engl. et Krause. (Vorderindien bis Australien.) B A. crispus Thunb. (Ceylon), ein Blïtenstand, von dessen unteren Bl. die Blbbl. abgefallen sind; $C$ einzelne Bl. derselben Art (nach EdgeworTH). $D-K$ A. distachyus L. f. (S.-W. Kapland). $D$ Blütenstand von dem Scheidenb. umbüllt; $E$ derselbe nach Entfernung des Scheidenb.; $F$ Querschnitt durch den von dem Scheidenb. umhüllten Bliitenstand, zeigt die Deckung der zu den einzelnen Bl. gehörigen Blumenb.; $G$ Schenkel des Blittenstandes von der Rückseite; $H$ derselbe von der Vorderseite; $\mathcal{F}$ der ganze Blütenstand geöffnet, mit den abstehenden Blumenb.; $K$ Bl nach Entfernung der Blb. Nach Exgler, Pflfam. II. I. 220.

land vorkommenden $A$. listwhyus L. f. und anderen Arten ist nur ein einziges Perigonblatt in ungewöhnlicher Größe entwickclt, während bei einigen anderen Arten zivei, bisweilen sogar drei Perigonblätter vorkommen.

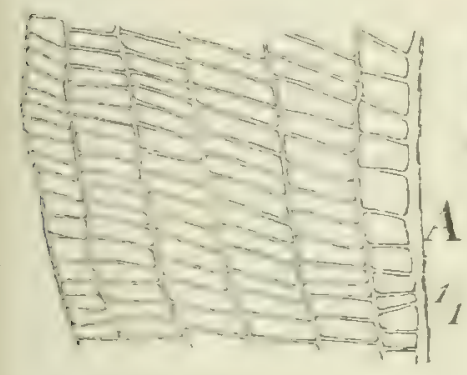

Fig. 89. A. fenestralis (Poir.) Hook. f. von Madagaskar.
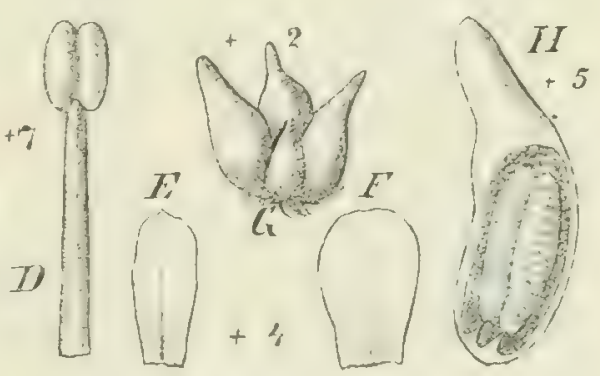

Bliitenteile.

Alle Aponugcton wachsen seltener an Flußufern, häufiger in seichten Teichen und Tümpeln mit sandigem oder kiesigem lioden, die kleineren Arten vielfach auch in Wasserlachen, welche sich zur Regenzeit in den Höhlungen von Granit- 
felsen gebildet haben, im feinen Granitgrus wurzelnd. Wie bei Potamogeton gibt es auch dponogiton mit schwimmenden Blattspreiten und solche mit ganz untergetauchten Blättern. Letztere sind sehr zart und ohne Cuticula, bei dem auf Madagaskar wachsenden A. Bernierianus (Dcsne.) Hook. f. zwischen den Adern teilweise und bei dem ehenda vorkommenden A. fonestrulis Poir.) Hook. f. (Ouvirandra, Gitterpflanze) ganz durchbrochen.

Die Aponogeton sind in ihrem Vorkommen auf Afrika, Madagaskar, das tropische Asien und Nordaustralien beschränkt. Sic finden sich in Afrika sehr

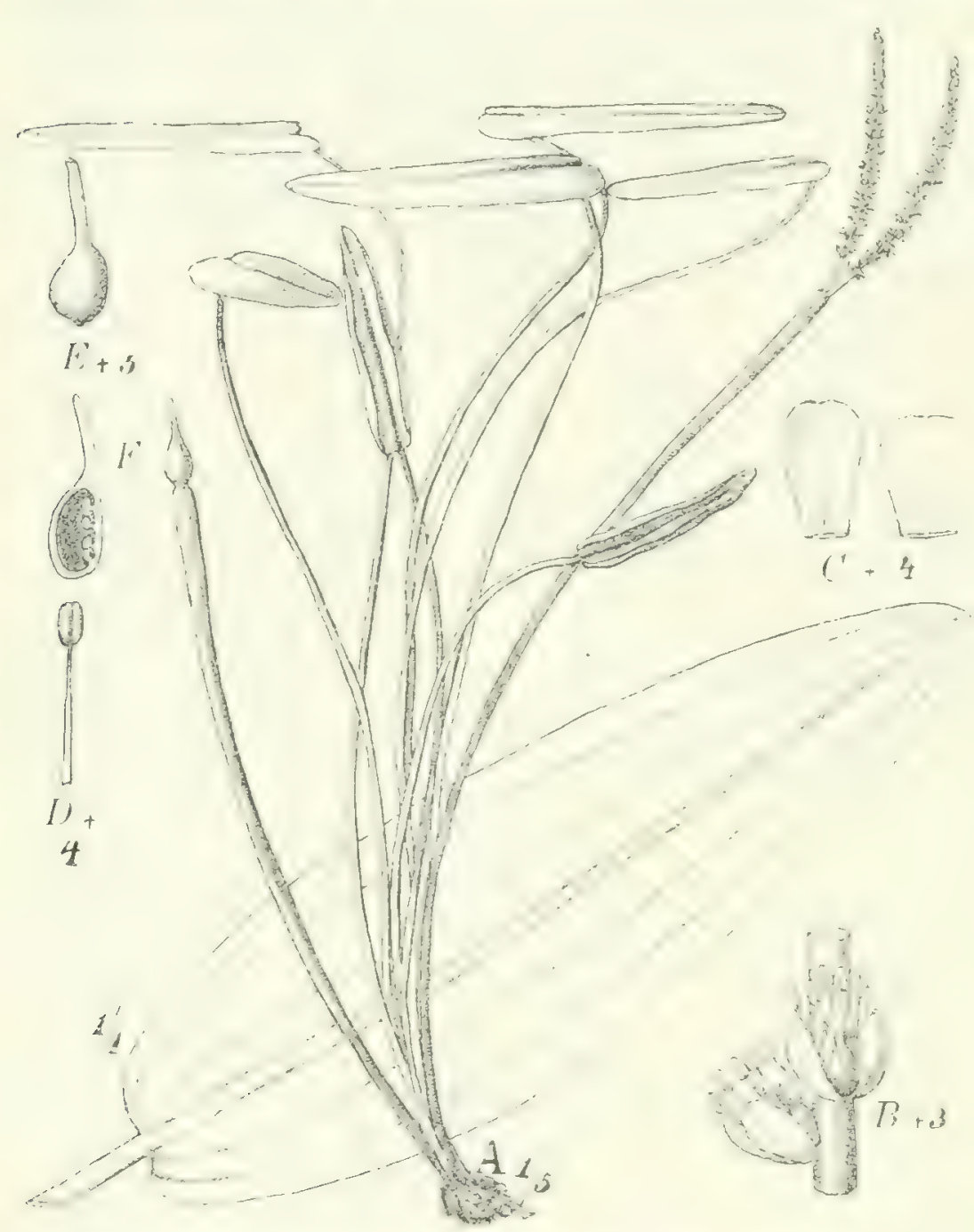

lig. 9o. Aponogeton llinteri Engrl. et Krause. weitverbreitet, von Senegambien und Abyssinien im Norden durch das ganze tropische Zentralafrika bis hinab zumKapland. Eine reiche Entwickelung haben sie ferner in Madagaskar, von wo wir allein vier endemische Arten kennen.

Beachtenswert ist, da $\beta$ wir in dem Areal der Gattung drei ziemlich scharf getrennteGruppen unterscheiden können, erstens die afrikanischen Arten, bei denen man wieder die tropisch-afrikanischen von den kapensischen absondern muß, dann die madagassischen und drittens die Vorderindiens und des Monsungebietes. Die geographische Trennung dieser drei Gruppen ist so scharf, daß wir keine einzige Art kennen, welche etwa gleichzeitig in Afrika und Madagaskar oder gar Indien rorküme, eine Erscheinung, die wenigstens zum Teil mit den geringen Verbreitungsmittein der an das Süß 3 asser gebundenen l'flanzen sowie mit ihrem Ursprung zusammenhängen dürfte. Interessant ist es auch, daß mit dicser scharfen geographischen Trennung die systematische Glicderung schr wohl uib reinstinnt. Wir haben in Afrika grüßstentcils Arten, welche einen zweiahrigen Bliitenstand hesitzen; das gleiche gilt auch fuir die madagassischen Arten, während andererseits die indisch-australischen niemals gespaltene Bliitenstande hahen, sondern stets nur eine einfache crlindrische Blitenähre tragen. Schwimmonde dorsiventrale Blitenstande haben auch nur afrikanische Arten. 
Im nördlichen Deutsch-Ostafrilia, in Usinga, enteckte STUhLinn den 1. Stuhlmannii Engl. (Fig. 9 I $N$-C , wclcher sich den indischen whnlich verhält.

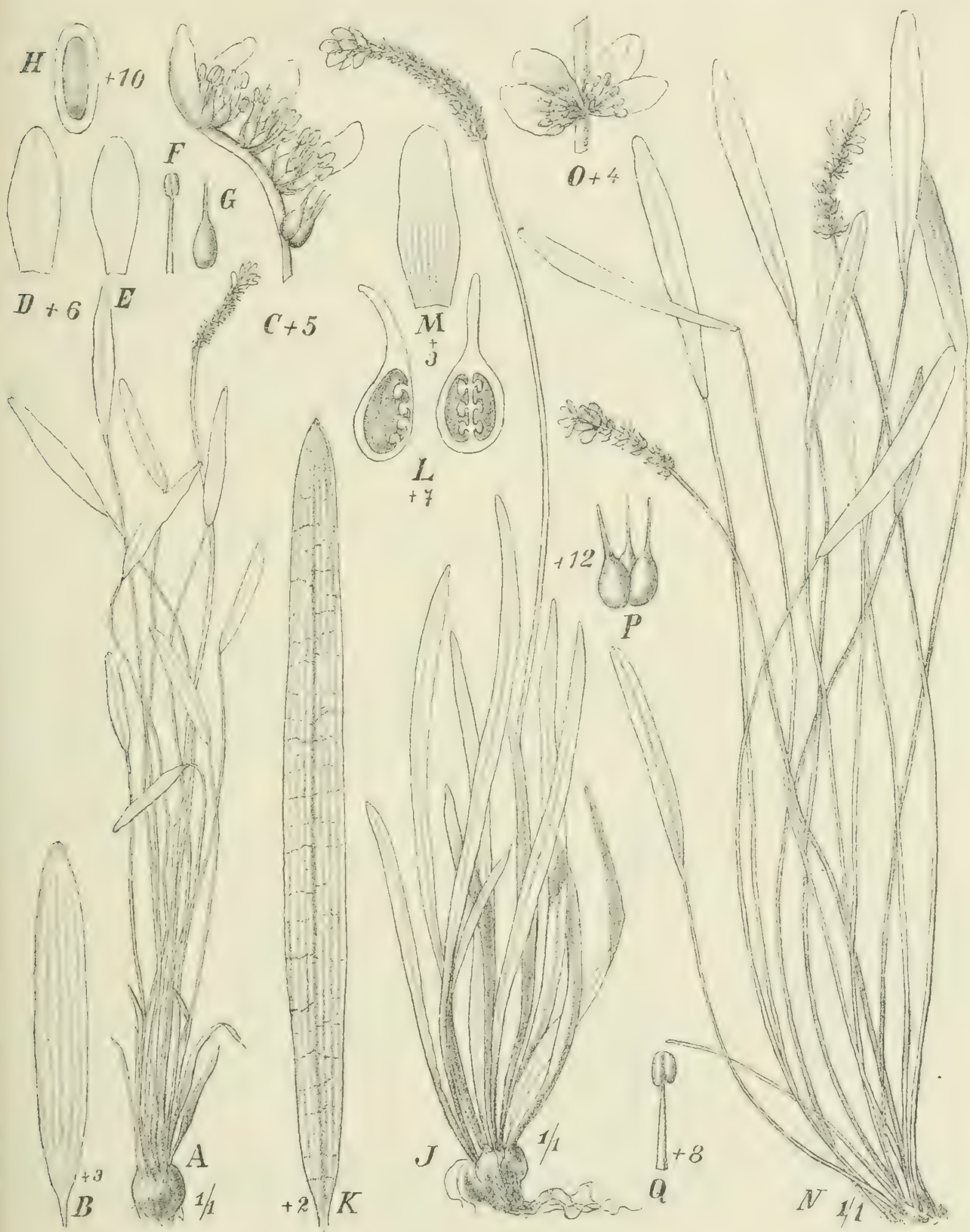

Fig. 9I. $A-H$ Aponogeton gracilis Schinz. $H$ Same. $7-M$ A. vallisnerioides Bak. $N-Q$ A. Stuhlmannii Engl.

Bliitenstände mit zwei- bis mehrcylindrischen Ähren haben t. leptostachyzs E. Mey. Nordostafrika, Erythrea bis Gallaland, Transvaal bis Kaplandi, A. Matcrlinsis Oliv. (Natal), A. Tiochmii Engl. (Unjamwesi), A. Dinteri Engl. et Krause 


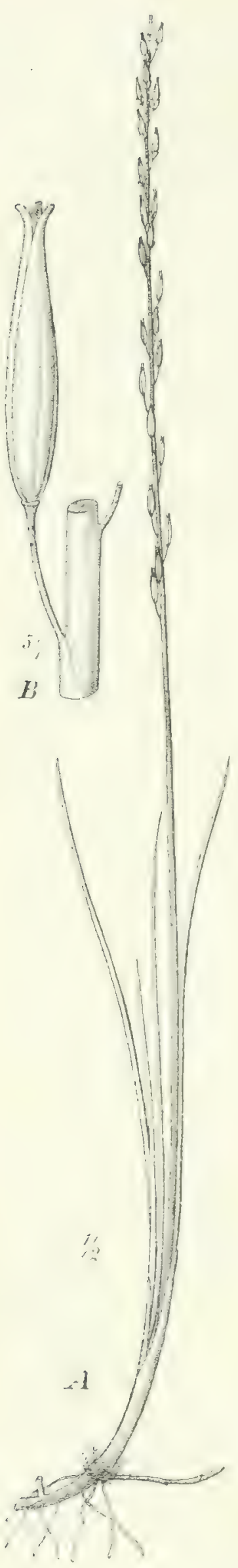

Fig. 92. Triglochin elongata Buchenau. (bei Otjimbingue in Deutsch-Südwestafrika, Fig. 90), $A$. Hcudclotii Engl. (in Senegambien), A. Rehmannii Oliv., mit diöcischen Blüten (in Transvaal und dem Hereroland), sodann die vier madagassischen Arten. Einfache dorsiventrale Ähren haben die beiden in Fig. 9 I abgebildeten Arten A. vallisnerioides Bak. (Ghasalquellengebiet, im Lande der Djur und Bongo) und A. gracilis Schinz (Transvaal). Endlich besitzen zwei dorsiventrale, dem Wasser horizontal aufliegende Ähren A. spathacens E. Mey. (von Mossambik und Angola bis Uitenhage), A. Holubii Oliv. (Betschuanaland), A. angustifolius Ait. und A. distachyus L. f. (Kapland). Letztere ist um Kapstadt in den Teichen der Flats sehr verbreitet, und ihre stärkereichen Knollen dienen so wie die anderer Arten auch als Nahrungsmittel, während die jungen Blütenstände wie Spargel als feines Gemüse genossen werden.

\section{Fam. Scheuchzeriaceae.}

Diese Familie spielt eine sehr unbedeutende Rolle in Afrika.

Triglochin L. T. bulbosa L., im Mediterrangebiet weitverbreitet, aber nicht in Ägypten, hat ihren Weg nach Benguela und Natal gefunden, wo sie auf moorigen Triften vorkommt. T. striata Ruiz et Pav., mit Stolonen und $5 \mathrm{dm}$ hohem Stengel, ist auf der südlichen Hemisphäre weitverbreitet, so auch in Brackwassersümpfen Benguelas. T. elongata Buchenau ist eine ähnliche Art des Kaplandes und Pondolandes'(Fig. 92).

\section{Fam. Alismataceae.}

Von diesen Sumpfgewächsen sind zwei der in Europa verbreiteten Arten auch afrikanisch, mehrere aber auch an den Sumpfrändern Afrikas endemisch.

Alisma plantago L., der gewöhnliche sogenannte Froschlöffel ist über Kordofan, die Erythrea und Abyssinien (daselbst bis $2800 \mathrm{~m}$ ) bis nach dem Leikipia-Plateau im Massaihochland zu verfolgen.

Caldesia Parl. Die in Mittel - und Südeuropa zerstreute C. parnassifolia (Bassi) Parl. ist über Ägypten bis nach dem Ghasalquellengebiet gelangt, wie auch nach Madagaskar.

Limnophyton Miq., von den beiden vorigen Gattungen durch polygamische Blüten unterschieden; aber 
auch wie diese mit kleiner Bliitenachse, ist auf Afrika, Nadagaskar, Vorderindien und Ceylon beschränkt. L. obtusifolium (L., Miq. mit langgestielten, pfeilförmigen Blättern und rispigen, aus Quirlen zusammengesetzten Blïtenquirlen (Fig. 93) ist als Sumpfpflanze schr verhrcitet von Senegambien und Kordofan

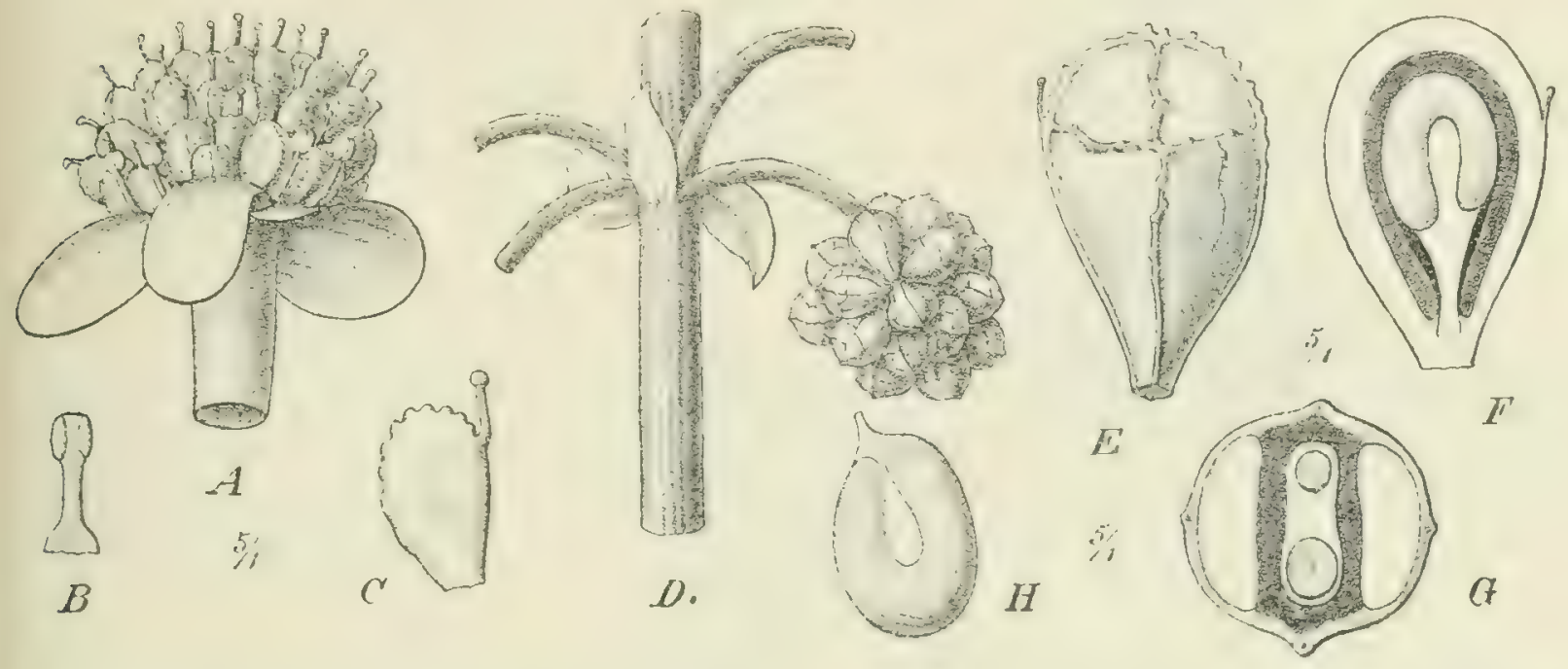

Fig. 93. Limnophyton obtusifolium (L.) Miq. $A$ Blüte; $B$ Staubblatt; $C$ Carpel1; $D$ Frucht; $E-G$ Einzelfrucht; $H$ Same.

bis zum unteren Sambesi; im Wasser wachsende Exemplare entwickeln bisweilen langgestielte Blätter mit kleinen eiförmigen Blattspreiten. L. angolense Buchenau in Angola und Benguela weicht von den vorigen durch dünne, lange Zweige des Bliitenstandes mit wenig Quirlen ab. L. fuituns Graebn. mit

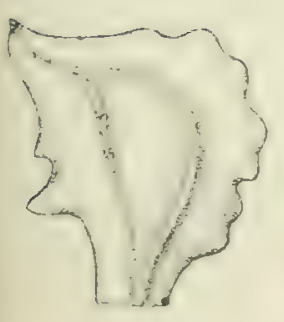

A

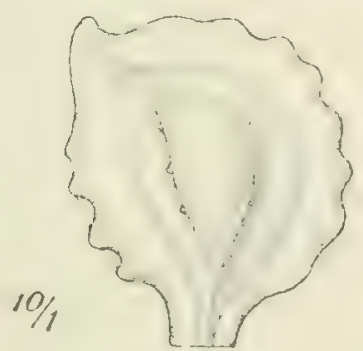

$B$
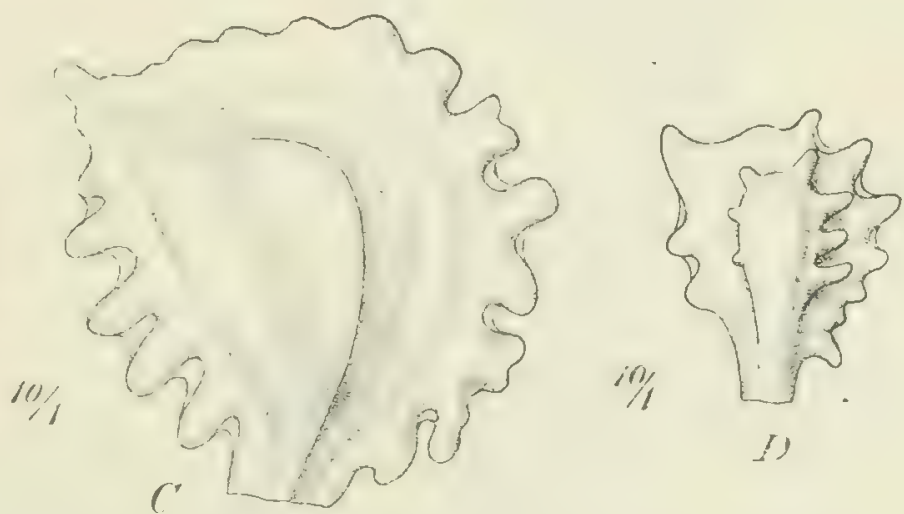

Fig. 94. Lophotocarpus guyanensis (H. B. Kunth) Smith. A gewöhnliche Form; $B$ var. madagascariensis Buchenau; $C$ var. lappula Buchenau (Kordofan); $D$ var. echinocarpus Buchenau.

schmal lanzettlichen flutenden Blättern ist eine ausgezeichnete Art, welche von Dr. Hur. WiNki.Ek in Bächen zwischen dem Njong-Übergang und dem Dorf Kukue bei Victoria in Kamerun entdeckt wurde.

Folgende Gattungen besitzen im Gegensatz zu den vorigen eine konvexe Blïtenachse. 


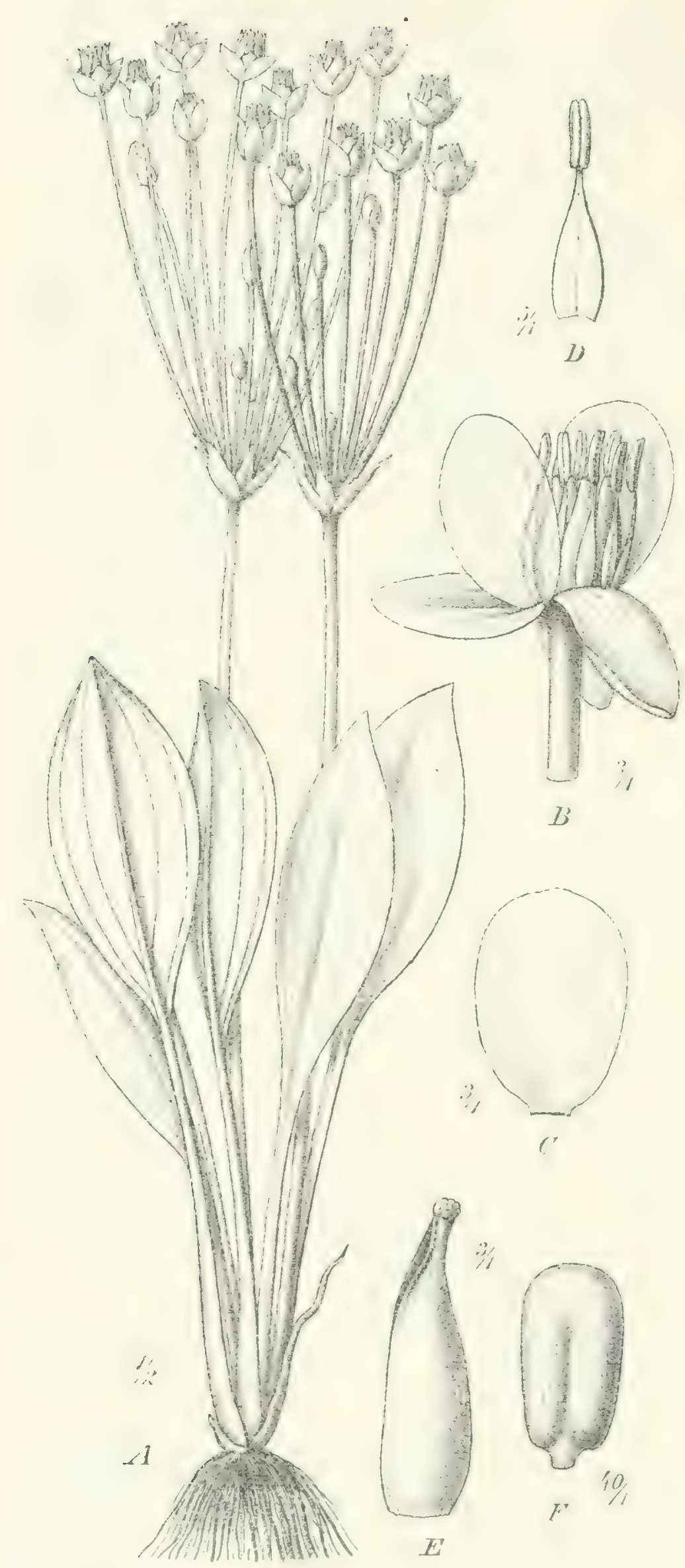

Fig. 95. Tenagocharis latifolia (D. Don) Buchenau von Arasch Col in Kordofan.
Echinodorus humilis (Kunth) Buchenau ist eine kleine einjährige, nur 3 bis $6 \mathrm{~cm}$ hohe Pflanze mit lanzettlichen oder elliptischen Blättern und einzelnen gestielten achselständigen Blüten, sie findet sich von Senegambien bis zu den Ufern des weißen Nil.

Lophotocarpus guyenensis (H. B. Kunth) Smith (Fig. 94), mehrjährig, besitzt flutende, langgestielte eiförmigeBlätter und einen aus zwei bis drei Quirlen bestehenden Bliitenstand mit eingeschlechtlichen Bliiten. Die Pflanze ist im tropischen Amerika und Asien weitverbreitet, auch auf Madagaskar, in Kordofan und Senegambien.

Rautanenia Schinzii Buchenau, eine knollige Wasserpflanze mit $3 \mathrm{dm}$ langen und $5 \mathrm{~mm}$ breiten, linealischen Blättern, endet in eine Rispe mit eingeschlechtlichen diöcischen, nach kölnischem Wasser duftenden Bliuten, in welchen die Blumenblätter kleiner als die Kelchblätter sind; sie ist aus dem Amboland in DeutschSiidwestafrika bekannt.

Burnatia enneandra Micheli, mit knolligem Rhizom, langgestielten, lanzettlichen Blättern und bis $50 \mathrm{~cm}$ hohem, rispigem 
Bliitenstand, diöcisch, mit langgestielten männlichen und kurzgestielten weiblichen Bliiten, ist von Kordofan bis; zum Matabelcland sehr zerstrcut angetrofien worden.

Wiesneria Schucinfurthii Hook. f. ist eine Wasserpflanze mit flutenden langgestielten, lineal-spatelformigen blittern und einem ährenformigen, aus Quirlen cingeschlechtlicher monucischer Bliiten zusammengesutzten IBlitcnstand. bisher im Ghasalquellengebiet gefunden.

Sicher werden weitere Forschungen unsere Kenntnis der afrikanischen Arten dieser Familie sowie ihrer Verbreitung noch erheblich erweitern.

\section{Fam. Butomaceae.}

Tenagocharis letifolic :D. Donj Buchenau ist dic cinzige im tropischen Afrika vorkommende Pflanze dieser Familie, welche durch zahlreiche Samenanlagen auf den Wandungen der sechs Carpelle ausgezeichnet ist (Fig. 95 : sic findet sich in Sümpfen ron Senergambien und dem Nigergebict bis zum weißen Nil, ostwärts hat sie sich nach dem nördlichen Indien verbreitet.

\section{Fam. Hydrocharitaceae.}

An der Zusammensetzung der Vegetation stehender Gewässer sind die Arten dieser Familie ziemlich stark beteiligt. Fuir unsere Zwecke empfichlt es sich, die Uhersicht so zu gestalten, daß die das Süßwasser bewohnenden Gruppen von denen des Meeres gesondert werden.

A. Süßwasserpflanzen.

a) Fruchtknoten aus drei, selten zwei, vier oder fünf Fruchtblättern gebildet. Placenten in das Innere wenig vorspringend . . . . . . . . . . . Vallisnerioideae.

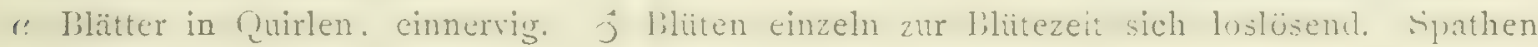
ein- bis dreiblitig. . . . . . . . . . . . . . . . . Hydrilla.

3) Blätter spiralig (selten fast quirlig oder zweizeilig).

I. Bliiten zwitterig oder eingeschlechtlich. Spathen langgestreckt, bis zehnblittig, Samen-

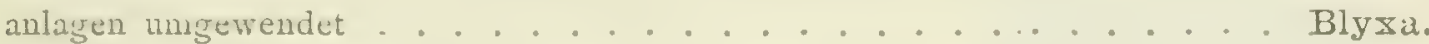

II. Blüten eingeschlechtlich. ô Spathen bis zehnblitig, die ô Blüten sich loslösend. Samenanlagen geradläufig.

I. Stengel verlängert, mit ziemlich gleichlangen Internodien, und Laubblätter einnervig. of Blïten mit drei fruchtbaren Staubblättern und zwei bis vier Stami-

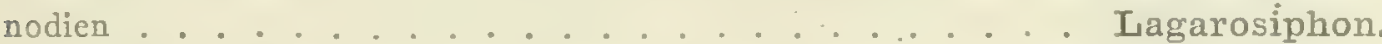

2. Stengel verkürzt mit gedrängten langen Laubblättern. ô Blüten mit zwei fruchtbaren Staubblättern und einem Staminodimm ......... Vallisneria.

b) Fruchtknoten aus 6-I5 Fruchtblättern gebildet. Placenten in das Innere weit vorspringend. Laubblätter spiralig in Rosetten. Samenanlagen auf der ganzen Fläche der Placenten.

Stratiotoideae.

(๕) Blüten zwitterig. Spathen eimblïtig, oft mit zwei bis sechs geflügelten Rippen. Ottelia.

ß) Blüten zweihåusig. Spathen meist ungeflügelt, die ô mehrblïtig . . . . Boottia.

B. Meerespflanzen.

a) Laubblätter gestielt. Fruchtknoten wie bei den Vallisnerioidene. Blütenboden fehlend. Narben die Kelchblätter vịelfach uiberragend.

Halophiloideae. Halophila. 
b) Laubblätter zweizeilig, breit-linealisch. Fruchtknoten wie bei den Stratiotoideac. Blüten zweihäusig . . . . . . . . . . . . Thalassioideae.

(c) Ot Blïten mit drei Staubblättern, zur Befruchtungszeit sich loslösend. O Spathen auf langem, nach der Befruchtung spiralig gewundenem Stiel ....... Enalus.

ßj) ô Blüten mit sechs Staubblättern. Spathen beiderlei Geschlechts mit mäBigem, nicht gewundenem Stiel . . . . . . . . . . . . Thalassia.

\section{Vallisnerioideae.}

Hydrilla L. C. Rich. Nur H. verticillata (L.f.) Royle (Fig. 96), die von Osteuropa bis Australien zerstreut ist; in \frika westlich vom Victoria-Njansa in Bukoba und in der Nähe der Nilquellen $\left(2^{\circ}\right.$ n. B. $)$ findet sich die sehr aus-

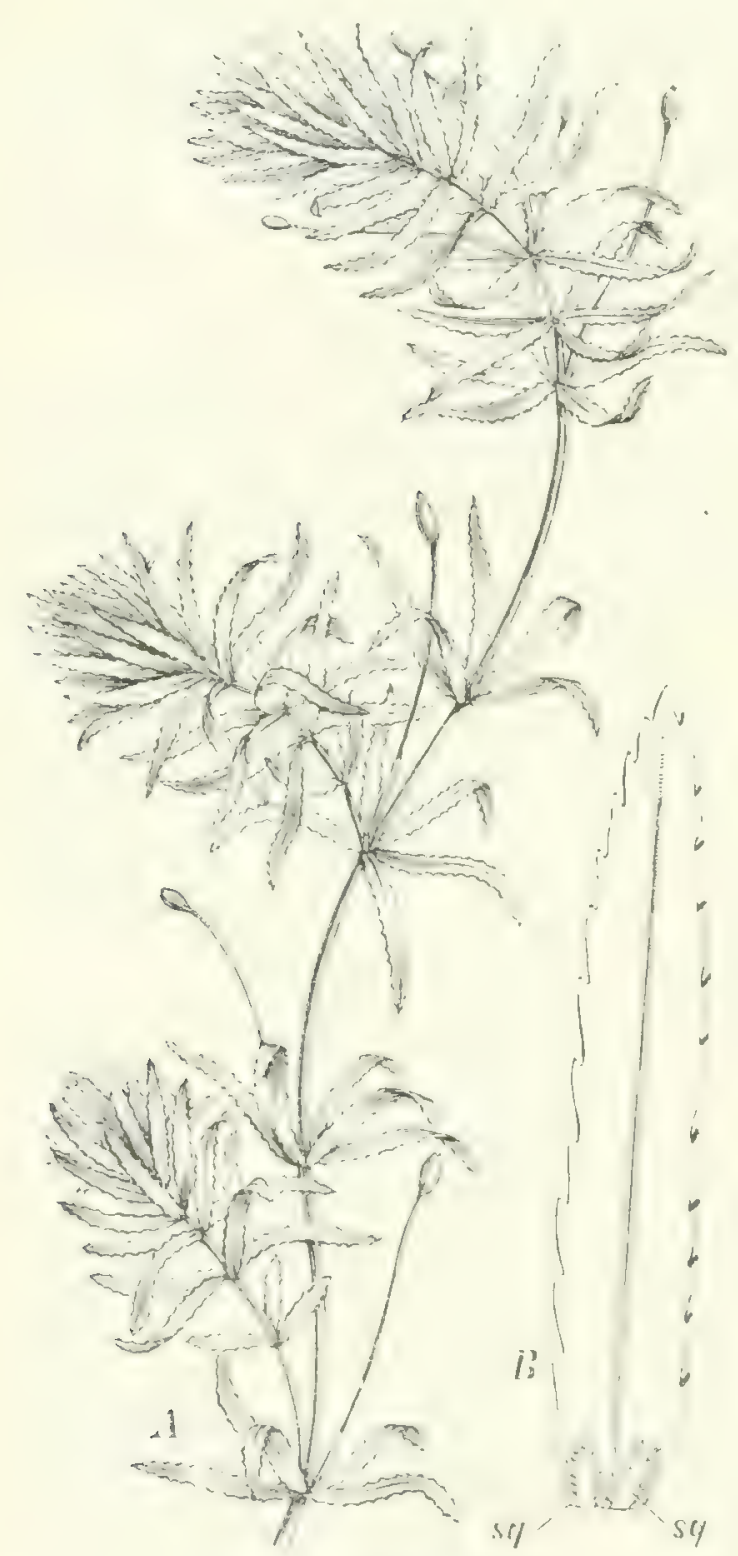

Fig. 96. Hydrilla verticillata (L. f.) Royle. $A$ oberer Teil einer weiblichen Pflanze; $B$ ein Blatt vergr. mit zwei Achselschüppchen. gezeichnete Var. brevifolia Casp. mit eiförmigen oder länglich-eiförmigen Blättern. Auch in Natal und an den Victoria-Fällen des Sambesi wurde $H y$ drilla gefunden, ist aber jedenfalls noch viel weiter verbreitet.

Isagarosiphon Harv. Es sind dies Pflanzen, welche Hydrilla habituell ziemlich ähnlich sind, aber meist abwechselnd stehende Blätter tragen, nur bei $L$. hydrilloides Rendle des Massaihochlandes stehen die Biätter in Quirlen. Sieben Arten sind außerdem noch aus Ostafrika von Abyssinien (L. Stcudneri Casp.) bis Nyassaland bekannt geworden, zwei von Benguela. L. Schweinfurthii Casp. kommt nicht bloß im Lande der Djur und Bongo, sondern auch in Suidwestafrika in Obukonda vor. L. muscoides Harv. läßt sich von Angola und Benguela durch Transvaal nach dem Kapland verfolgen (Fig. 97).

Diese Pflanzen treten in Bächen und Fliissen oft in großen Massen auf, ähnlich wie bei uns Elodea; ihre Stengel werden bis $1,5 \mathrm{~m}$ lang. Da fast jede Art nur von einem Fundort belkannt ist, so bleibt sicher fur die Begrenzung und Feststellung der Verbreitung der einzelnen Arten noch viel zu tun übrig.

Vallisneria L. mit der biologisch interessanten und schon in den oberitalienischen Seen auftretenden $V$. spiralis L. findet sich mehrfach in Ost- und Westafrika vom weißen Nil bis zu den Victoria-Fällen des Sambesi und von Lagos bis zum Stanley-Pool. 
T: acthichica Fenzl ron Sennaar und dem weißen Xil int vielleicht nur eine Zwergform der $V$. spiralis (Fig. 98).

Blyxa Noronha. Von dieser in Vorderindien und Burma rerbrciteten Gattung ist B. radicans Ridley mit kriechendem Rhizom und schmallincalischen, bis $6 \mathrm{dm}$

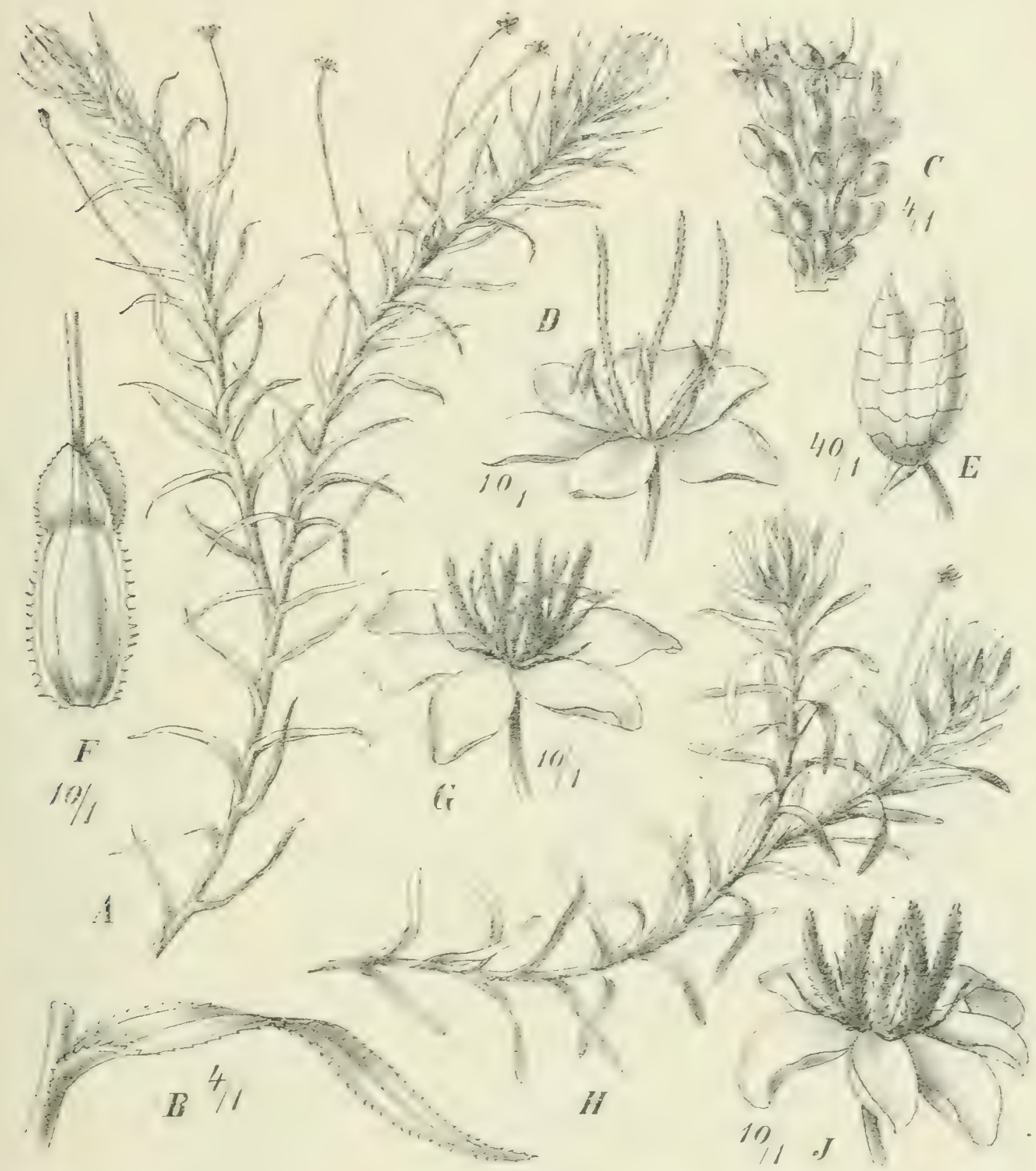

Fig. 97. Lagarosiphon. $A-G \mathrm{~L}$. muscoides Harv. $A \subseteq$ Pflanze; $B$ Blatt; $C$ ô Blütenstand ohne Spatha; $D$ ô Bliite; $E$ Staubblatt; $F$ Spatha des 0 Blitenstandes. $I, \mathcal{F}$ L. Steudneri Casp. $H$ ㅇ Pflanze; $\mathcal{F}$ 으 Blüte. Nach GürkE.

langen Blättern, i $2 \mathrm{~cm}$ langen weihlichen und etwa $\delta \mathrm{cm}$ langen männlichen Bliten bis jetzt nur ron den Wasserfällen des Loprollo in Benguela und ron kleinen Tümpeln am Longa, cinem Zufuß des Kuito beliannt. Die hier abgebildete $B$. octandra (Roxb.) Planch. findet sich in Angola (Fig. 99).

Stratiotoideac. Nur die Gruppe der Cittica: mit den beiden Gatlungen Boottia und Ottclier tritt im tropischen Afrika auf. Es sind dies sehr interessante 
Iffanzen, welche oft herdenweise in stchenden Gewässern mit Ajmplaacon und anderen Wasserpflanzen vorkommen. Die krautigen Blätter dieser Pflanzen dienen als Gemüse.

Ottelia Pers. Wie bei der folgenden Gattung stehen wir erst am Anfang einer genaueren Kenntnis der Arten, da nur wenig Sammler diesen Wasser1,flanzen genigende Beachtung schenken. Dic im Monsungebiet verbreitete O. alismoides (L.) Pers. (Fig. Ioo) wird in Th. Dyer, Flora von Afrika, von Kordofan und dem Nyassa-See zitiert. O. Inncifolia A. Rich., eine durch elliptisch-lanzettliche Blätter, zwcispaltige Spatha und stielrunden Schaft ausgezeichncte
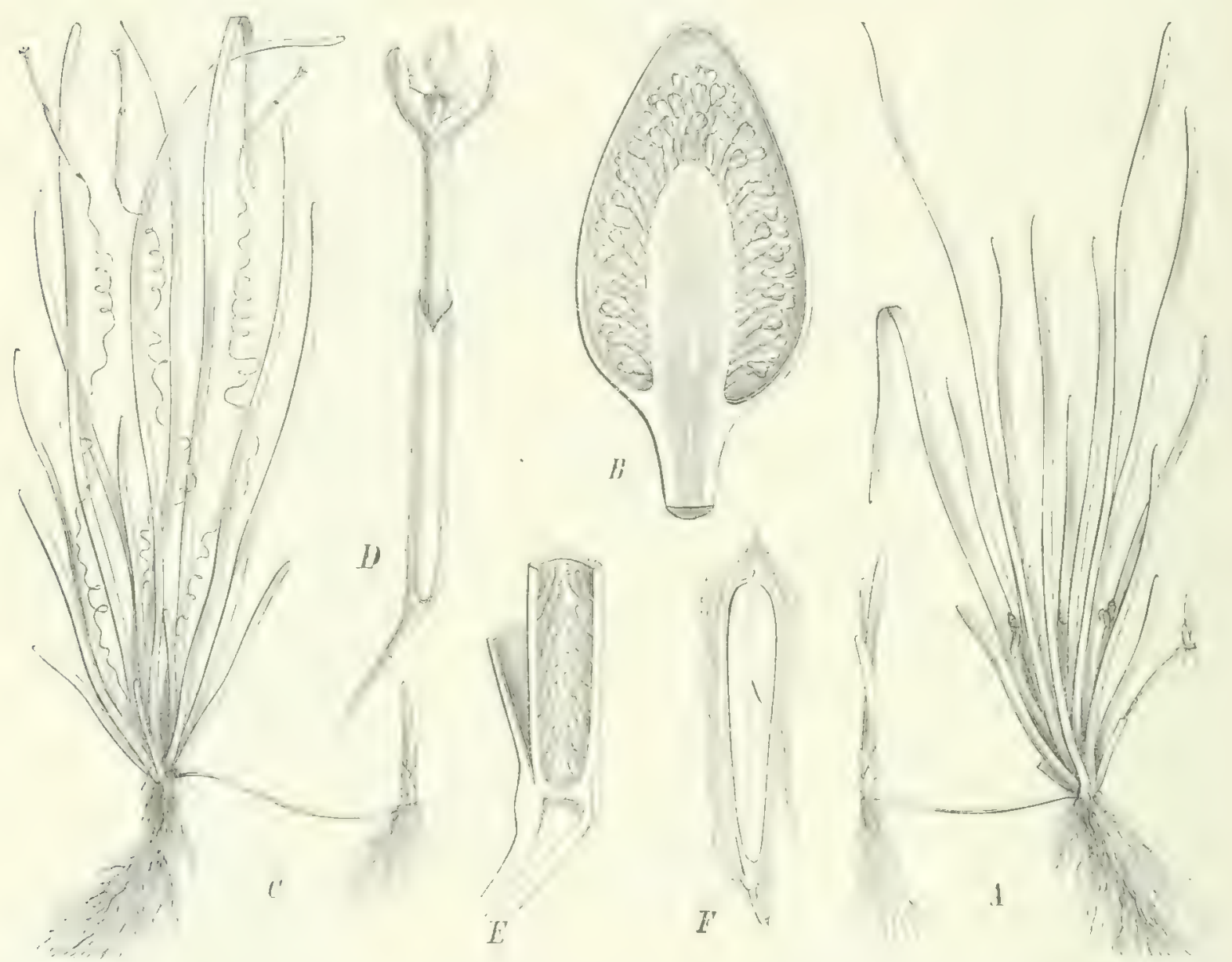

Fig. 98. Vallisneria spiralis L. $A$ männliche Pfanze; $B$ Spatha mit den männlichen Bliten; $C$ weibliche Pflanze; $D$ Spatha mit weiblicher Blïte; $E$ Längsschnitt durch den unteren Teil des Fruchtknotens; $F$ Längsschnitt durch den Samen.

Art, kennen wir von Abyssinien; hier kommt auch im Zana-See O. abyssinica (Ridley) Gürke vor. O. Schucinfurthii Gürke mit 2 dm langen lanzettlichen Blïttern und weißen Bliiten scheint ziemlich verbreitet im Nonbuttuland zu scin. die gelbblihhende 0 . Rolwbaclizana Aschers. et Gürke mit $6-7 \mathrm{dm}$ langen Blïttern in Timpeln am Giazellenfuß. Großse schmallanzettliche und an den Nerven mit kleinen Stachelchen besetzte Blätter besitzt (?. Torlickii Gürke rom Nocroc in Katanga. Im obcren Kongogebict knmmt auch I). hulog gine de Wildem. et Th. Dur. vor. Sehr auffallend ist die in Benguela wachsende O. crassifolia Welw. mit fleischigen, bis fast I $\mathrm{m}$ langen und $5-7,5 \mathrm{~cm}$ breiten, am Rande 
krausen Blätern. Einge andere in Angola und liengucla vorkmmende Arten sind kleiner; hier scheint O. Baunii Gürke besonders verbreitet zu sein.

Boottia Wall, ist eine sehr interessante Gattung, von welcher noch viele newe Arten gefunden wcrien clurften. Sie sind habituell ziemlich vorschicden,

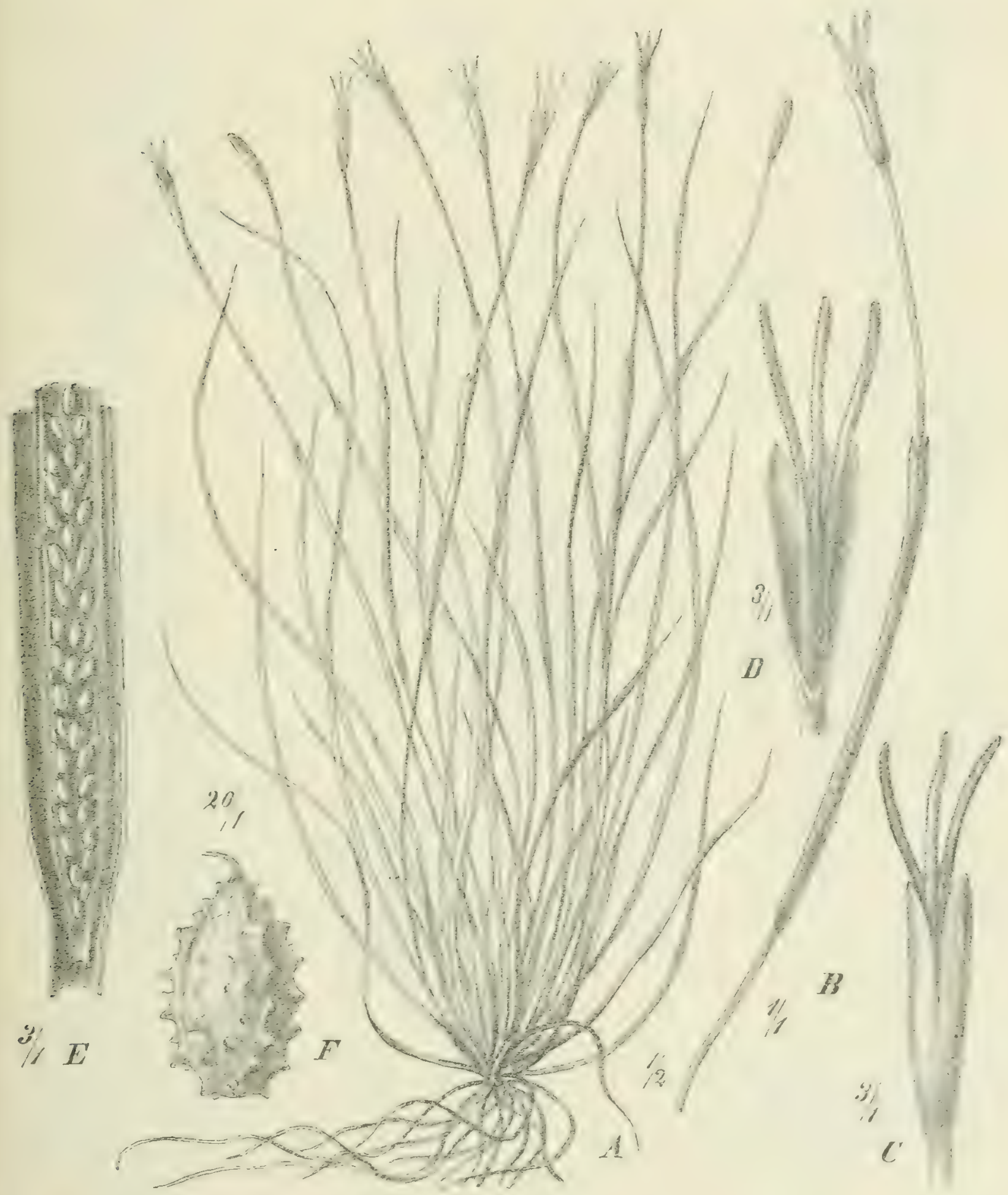

Fig. 99. Blyxa octandra (Roxb.) Planch. A weibliche Pfanze; $B$ Spatha mit weiblicher Blute; $C$ letztere ohne die abgefallenen Blumenblätter, vergr.; $D$ Griffel und Narbenschenliel; $E$ Fruchtknoten im Längsschnitt; F Same stark vergr. Nach GüRKE.

je nachdem die I3lätter sich ganz unter. Wasser hefinden, wher dasselle hinwegragen oder mit ihrer Spreite auf demselben schwimmen. Durch drei- 
kantige längs der Kanten gezähnte Blätter ausgezeichnet ist R. Ascherseniana Guirke, welche von BAUM in der Kuitoniederung um $1200 \mathrm{~m}$ ü. M. gefunden wurde (Fig. IOI).

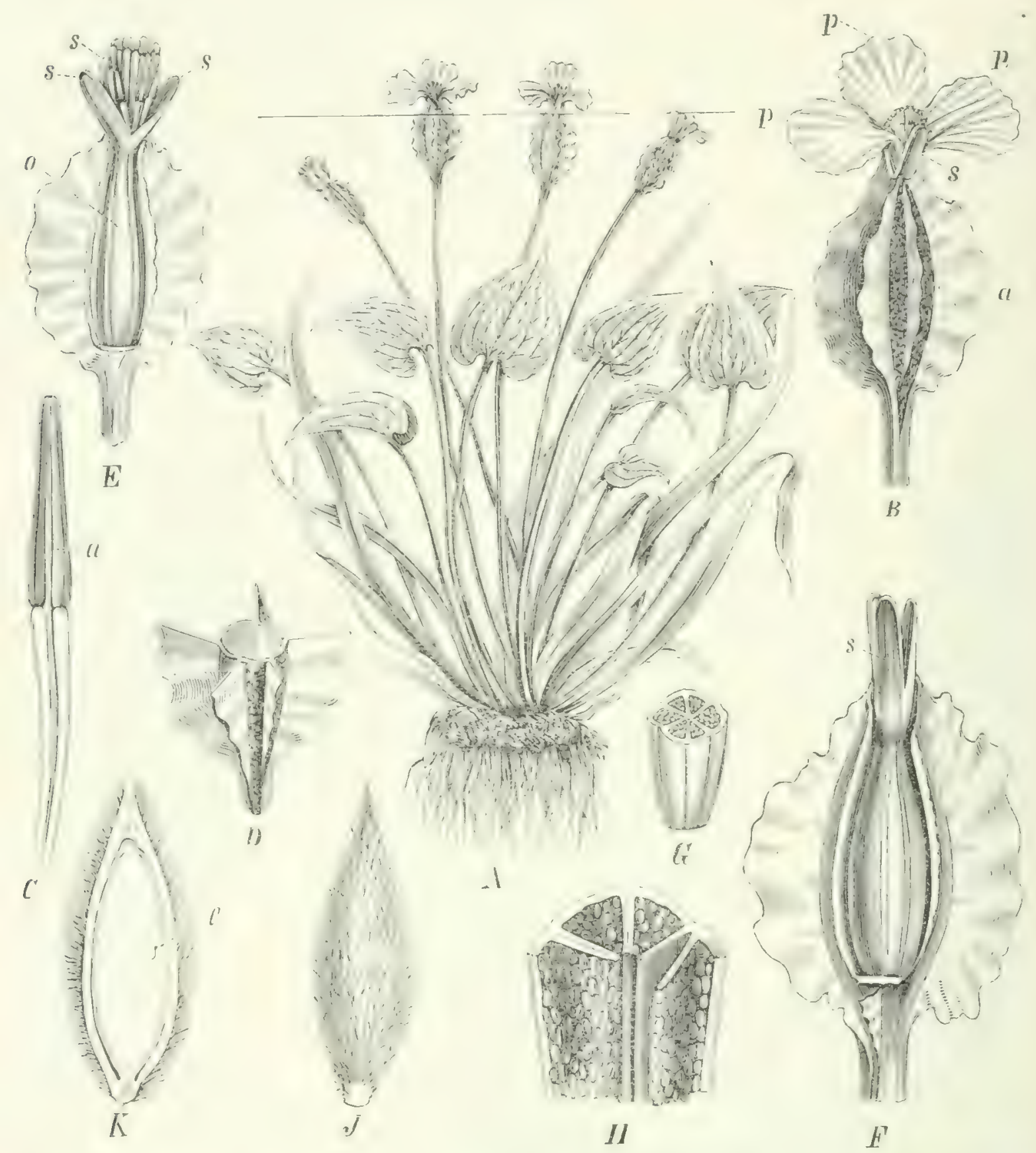

Fig. roo. Ottelia alismoides (L.) Pers. $A$ ganze Pflanze, bis zu den Blumenblättern unter Wasser; $B$ Blïte, $a$ Spatha, $s$ Kelchblätter, $p$ Blumenblätter; $C$ Staubblatt; $D$ Spatha durchschnitten; $E$ Spatha rorn geöffnet, $O$ Fruchtknoten, $s$ Kelchblatt; F Frucht innerhalb der geöffneten Spatha, $s$ Kelchblatt: $G$ Fruchtlinoten quer durchschnitten; H Frucht im Längs- und Querschnitt; 7 Same; $K$ derselbe längs durchschnitten, bei $c$ Plumula. $B-K$ nach Ricriard.

Ganz unter Wasser befindliche, aber breite spatelförmige Blätter besitzen B. brachyphylla Gürke im Djurland und B. scabra (Bak.) Benth. et Hook. f. im Ghasalyuellengehiet, Ir. pariflora Gürke ebendaher. Schmale lineal-lanzettliche untergetauchte Blätter besitzt B. kuncnensis Gürke am Kunene zwischen Kiteve und Humbe in von Wald umgrenzten Pfannen. 
Dagegen ragen die breiten Spreiten wie bei Alisma plantago über die Wasserfläche empor bei der sehr kräftigen B. Fischeri Gürke, welche von FISCHER zwischen Usula und Usika im zentralafrikanischen Seengebiet zuerst

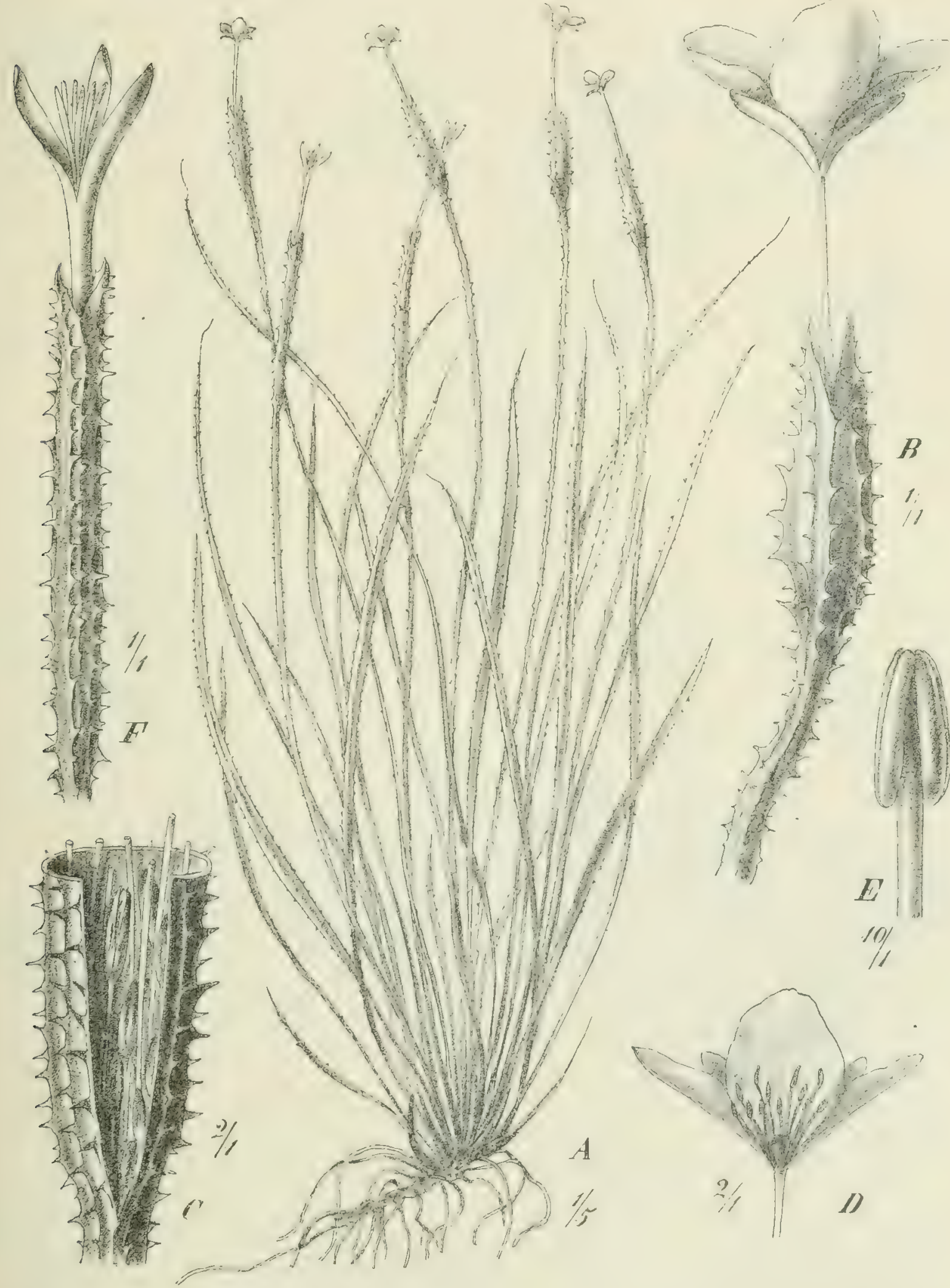

Fig. 1or. Boottia Aschersoniana Gürke. $A$ Habitus der männlichen Pfanze; $B$ männliche Blüte in der Spatha, $C$ Spatha geöffnet, mehrere Knospen und Blittenstiele zeigend; $D$ männliche Blüte geöfnet; $E$ Anthere; $F$ Spatha mit einer weiblichen Blüte. Nach GürkE im Pfanzenreich. 
aufgefunden, dann auch von GoETzE in Sümpfen von Ussangu im nördlichen Nyassaland gesammelt wurde. - Schwimmblätter, ähnlich denen von Potannogetori natans besitzen B. exserta Ridley am Shire und in Quelimane in Portu-

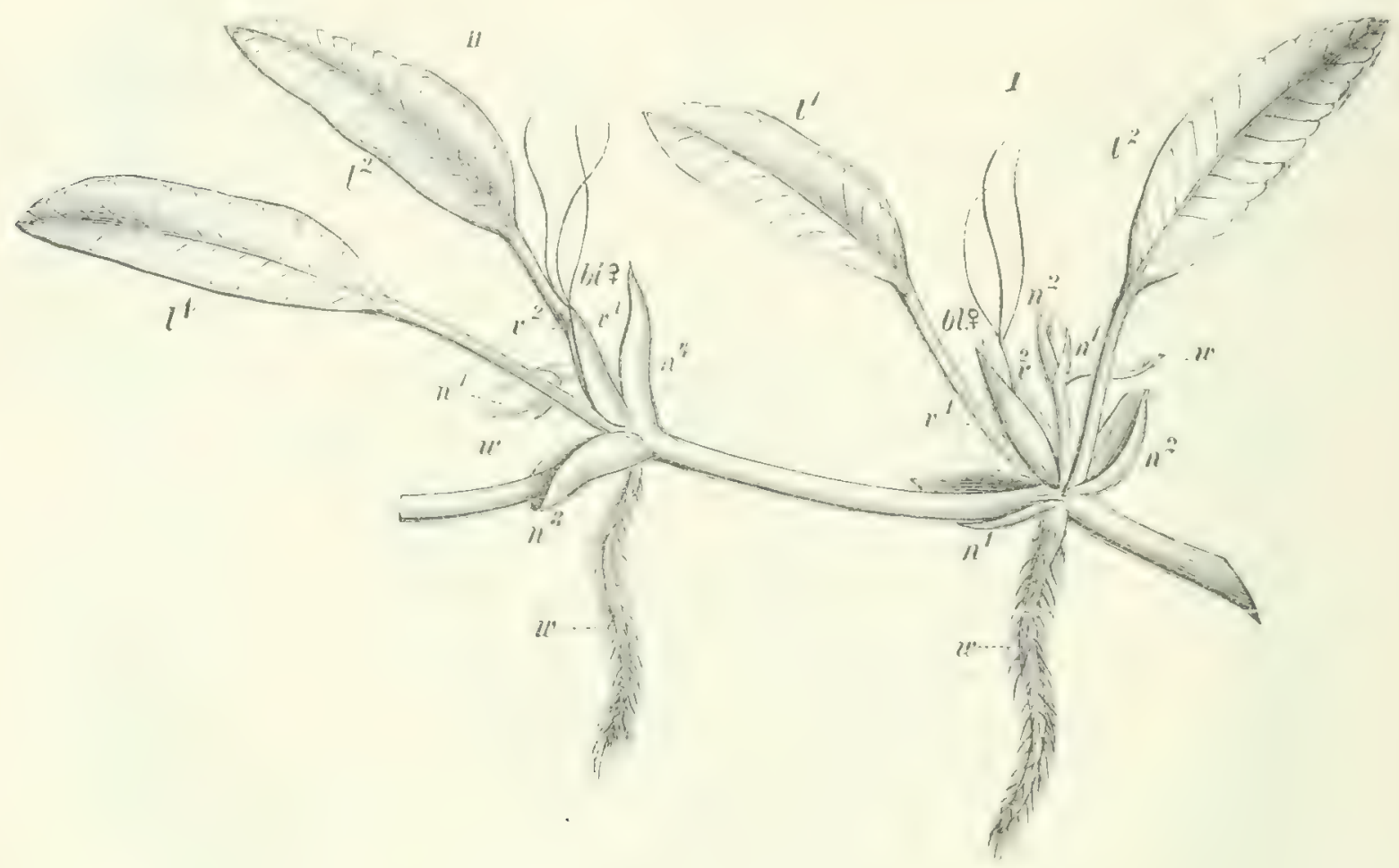

Fig. 102. Halophila ovalis (R. Br.) J. D. Hook. $n$ Niederblätter; in den Achseln von $n^{2}$ der Seitensproß $I$ mit den Laubblättern $l^{1}$ und $l^{2}$ und den Niederblättern $n^{1}$ und $n^{2}$, in der Achsel von 11 die Blüte mit ihren Spathablättern $\sigma^{1}$ und $v^{2}$, ebenso bei dem Sproß $I 1$.

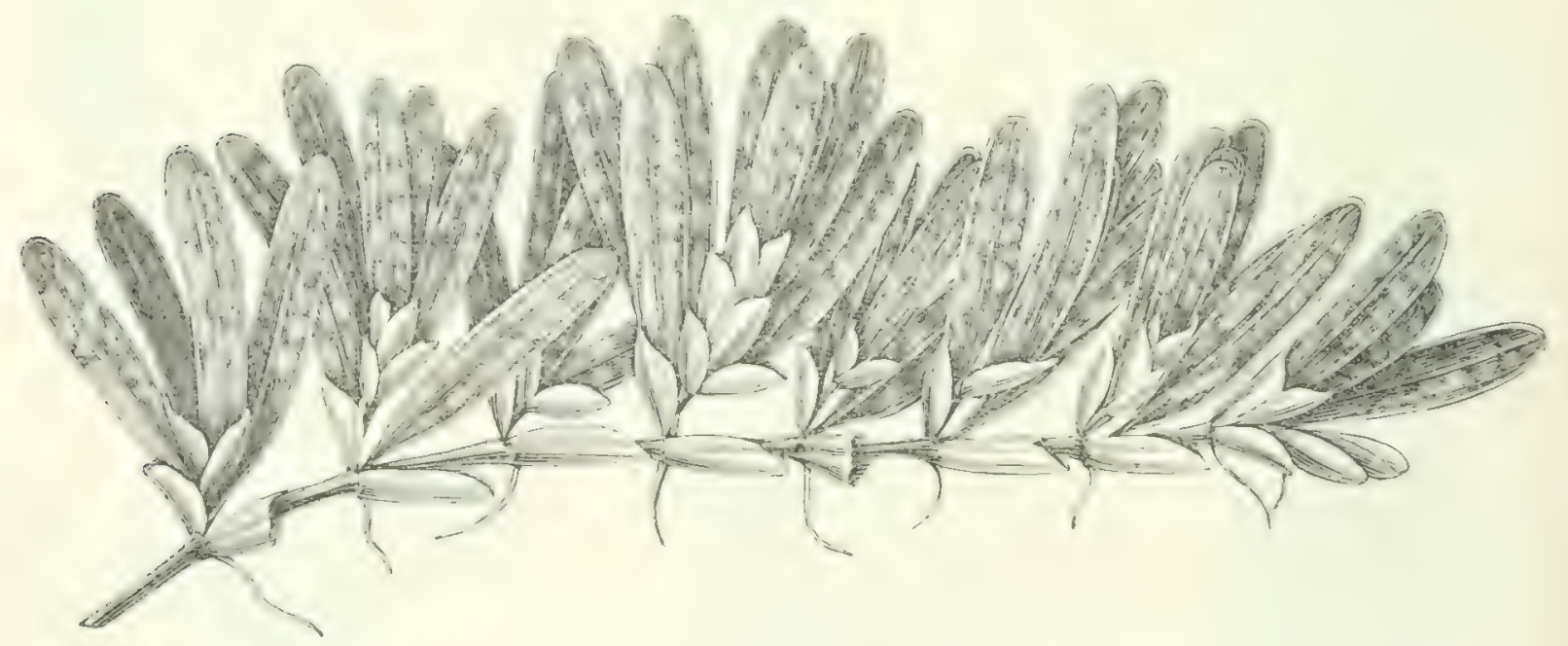

Fig. 103. Halophila stipulacea (Forsk.) Aschers. Nach Henprich und EhreNberg.

giesisch-Ostafrika, B. Rautancnii Gürke im Amboland und B. Schinziana Aschers. et Gürke, in Tümpeln von Benguela und Olukonda in Südwestafrika. Die meisten dieser Arten finden sich iiber rooo $\mathrm{m}$ ii. M.

Halophila Du Pet. Thouars. H. oz'alis (R. Br.) J. D. Hook, nach der hier gegebenen Abhildung IFig: 102, leicht kenntlich, an den Kïsten des indischen 
Ozeans und auch an den pazifischen Küsten des Honsungebietes verbreitet, ist vom Roten Meer bis Natal an der ostafrikanischen Küste anzutreffen.

Auch eine zweite Art, H. stipulacia (Forsk.) Aschers, mit zweihäusigen Blüten (Fig. 103) findet sich vom Roten Neer bis Lamu, sowie auch an den Küsten der Maskarenen und Nord-Madagaskars.

Enalus L. C. Rich. mit der einzigen Art E. acoroides (L. fil.) Steud. ist verbreitet an den nördlichen und westlichen Küsten des Indischen Ozeans, sowie im Roten Meer; weiter suidlich ist sie an der afrikanischen Küiste bis jetzt nicht beobachtet worden. An dem kräftigen Rhizom stehen linealische Blätter

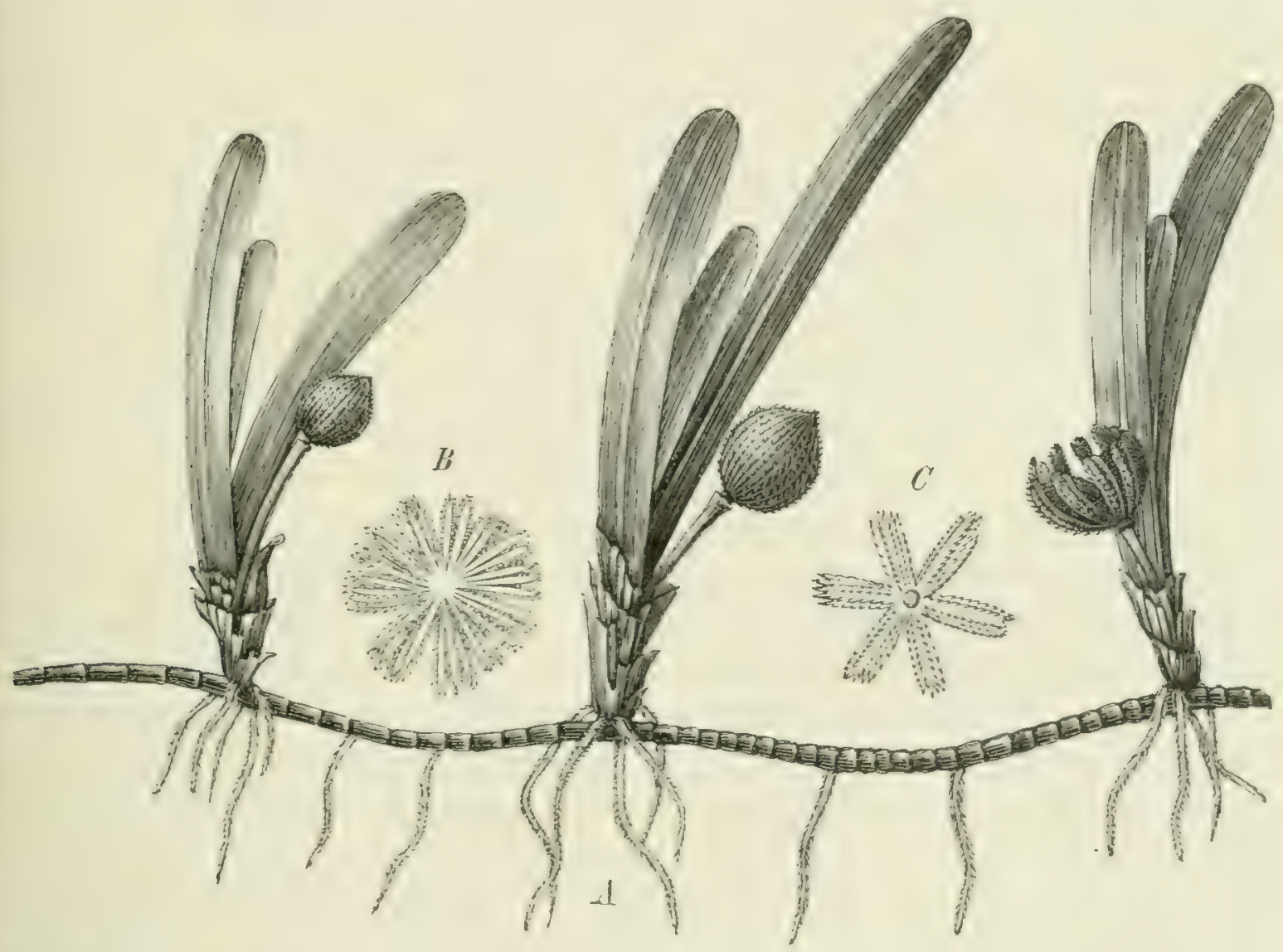

Fig. 104. Thalassia Hemprichii (Ehrenb.) Aschers. $A$ eine fruchttragende Pflanze; $B$ und $C$ aufgesprungene, abgefallene Früchte.

mit verdicktem Rand, welche nach ihrer Zerstörung zwei starke, schwarze glänzende Fäden, die Bastbündel der Randnerven zuriicklassen. Die kleinen männlichen Blüten sind zu mehreren von kurz gestielten Spathen umschlossen und lösen sich zur Befruchtungszeit los, um an die Oberfläche zu treten, wie die or Bliiten von Tallismuria; die reiblichen Bliiten stehen ron ihrer Spatha umschlossen auf langem Stiel, der nach der Befruchtung spiralig gewunden ist und eine wallnußgroße eiformige Frucht trïgt, deren Samen auch genossen werden.

Thalassia Sol. mit der einzigen Art Th. Hemprichii (Ehrenb. Aschers. (Fig. 104) besitzt einzelnstehende männliche Blïten ohne Blumenblätter. welche ebenso wie die weiblichen auf kurzem Stiel stehen; sie ist wie die vorige Art verbreitet und kommt nur an ganz seichten Stellen der Küiste zur Bliite. 


\section{Fam. Gramineae}

bearbeitet von Dr. Pilger.

Wenige ramilien spielen in der Zusammensetzung der Pflanzenformationen Afrikas eine so hervorragende Rolle wie die Gräser. In dieser Beziehung hat Afrika mehr mit Amerika gemein als mit dem tropischen Asien, in welchem die Grasfluren viel mehr zurïcktreten. Da für die weitere Erforschung der Vegetationsrcrhältnisse Afrikas eine eingehendere Beachtung der ron den Sammlern bisher meist sehr vernachlässigten Gräser dringend zu wünschen ist. die Kenntnis der Gattungen ohne Beschreibungen und Abbildungen aber nicht so leicht zu erwerben ist, habe ich Herm Dr. Pilger, der am botanischen Nuseum die Gräser der meisten neueren afrikanischen Sammlungen bestimmt hat, ersucht, diese Familie etwas ausführlich zu behandeln, und auch eine grölsere Anzahl Gräser abbilden lassen. Da die Gräser sich meistens sehr stark auf einzelne Formationen beschränken, so kann man viele Arten auch nach ihrem Vorkommen erkennen und es erfolgt daher die Besprechung der Species zweckmäßig im Anschluß an die Formationen A. E.).

Die Merkmale der Familie seien hier wegen mehrerer technischer Ausdrïcke, welche bei der Charakteristik der Gattungen zur Verwendung kommen, kurz angeführt:

Blüten $\delta$, selten $\sigma^{x} \mathrm{O}$, nackt. Staubblätter meist 3, selten $1,2,6-\infty$; Fruchthnoten mit einer schwach kampylotropen, die Mikropyle nach unten kehrenden Samenanlage: Narben 2; 3 oder I. Caryopsis mit reichlichem Nährgewebe, dessen Vorderseite und Basis der nur rom Pericarp bedeckte Embryo außen anliegt, selten Nuß oder Becre. Embryo mit schildförmiger Erweiterung des Kotyledons scutellum, in dessen vorderer Höhlung das Knospchen und das ron einem Hüllgewebe Coleorrhiza umgebene Würzelchen liegen. Meist Kräuter, selten baumartig mit knotig gegliederten Stengeln (Halmen) und abwechselnden scheidigen Blättern mit Ligula. Die kleinen Blüten in der Achsel von Hochblättern (Deckspelzen, mit einem der Decksp. gegenüberstehenden meist zweikieligen Vorblatt, meist auch noch mit einem über dem Deckblatt stehenden, meist bis zum Grunde zweispaltigen, sehr kleinen saftreichen zweiten Vorblatt /vordere Schiuppchen, Lodiculae, selten auch noch mit einem über dem zweikieligen Vorblatt stehenden dritten ungeteilten Vorblatt (hinteres Schüppchen; oder mit mehr Vorblättern. Die Ährchen oder Einzelblüten meist am Grunde mit leeren spelzenartigen Hüllblättern, in rispen- oder ährenförmigen Blütenständen.

Einteilung der Familie:

A. Ährchen im ganzen, mit den Hüllsp. sich rom Sticle abgliedernd, allermeist cinblütig, häufig eingeschlechtlich; Hüllsp. meist mehr als zwei; Decksp. meist derber als die Hüllsp., unbegrannt oder begrannt.

a) Hüllsp. 2-3; Hilum punktförmig.

a) Decksp. und Vorsp. stets zarter als die Hüllsp. 
I. Achse der ährenförmigen Blütenstände bei der Reife in Glieder zerfallend (ausgenommen die Kulturform vom Mais und von Sorghum); untere Hüllsp. am größten, die folgenden Sp, umfassend.

I. Ährchen eingeschlechtlich, auf getrennten Blütenständen, oder die Bliitenstände im unteren Teil $Q$, im oberen $\sigma^{\top}$; Hüllsp. hart. Nicht wildwachsend in Afrika ........ Maydeae.

2. Ährchen meist paarweis gestellt, das untere $Q$ oder $\$$, sitzend, das obere $\sigma^{T}$ (selten $\$$ oder abortierend); das sitzende Ährchen meist aus der vierten Sp. begrannt; die beiden äußeren Sp. erhärtend .

I. Andropogoneae.

II. Achse des rispen- oder ährenförmigen Blütenstandes ungegliedert, die Ährchen einzeln oder in Gruppen abfallend; Huillsp. derb, Decksp. zart und schmal . . . . . . . III. Zoysieae.

pi) Decksp. und Vorsp. derber als die krautigen Hüllsp. Ährchen unbegrannt, mit drei Hüllsp. und dann einblutig, oder mit unterer $\sigma^{7}$ Blüte in der Achsel der dritten Sp. und oberer $\$$ Blüte; erste Hüllsp. meist kiirzer als die folgenden.

II. Paniceae.

b) Hüllsp. vier oder das untere Paar \pm abortierend; Hilum linealisch. Ährchen einblütig, selten begrannt; Hüllsp. immer kürzer und schmaier als die häutige oder verhärtende Decksp.; Staubblätter häufig sechs.

IV. Oryzeac.

B. Hüllsp. allermeist nur 2 , bei der Reife am Ährchenstiel stehen bleibend, das Ährchen zwischen ihnen und der Decksp. gegliedert; Ährchen ein- bis vielbliitig, die einblütigen häufig mit Achsenfortsatz über der Blüte, die mehrblütigen mit deutlichen Internodien zwischen den Blüten.

a) Ährchen ein- bis mehrblütig, meist an der Spindel von Ähren oder Trauben, die häufig cinen gefingerten Blütenstand zusammensetzen, in zwei einander genäherten Reihen einseitswendig: meist alle Sp. krautig, Decksp. meist begrannt . . . . . . . . X. Chlorideac.

b) Ährchen ein- bis vielblütig, in Trauben oder Rispen, oder wenn ungestielt in gegenüberstehende Reihen in Ähren angeordnet.

a) Halme krautig, jährig.

I. Ährchen gestielt, in Trauben oder Rispen.

I. Ährchen mit einer \& Blüte.

+ Hüllsp. vier, die oberen bisweilen mit männlichen Bliiten in den Achseln, Decksp. verhärtend . . . V. Phalarideae.

++ Hülsp. zwei.

$\odot$ Ährchen einblütig, häufig mit Achsenfortsatz über die Bliite hinaus; Huillsp. krautig, Decksp. krautig oder verhärtend; Vorsp. zweinervig, selten fehlend oder sehr schwach entwickelt. . . . . VI. Agrostideae.

$\odot \odot$ Ährchen zweiblütig oder selten durch Abort der unteren Blüte einblütig (dann mit drei Hüllsp.); untere Decksp. unbegrannt, mit or Blüte, obere Decksp. zweispitzig, 
zwischen den Spitzen begrannt, mehr oder weniger erhårtend, mit \$ Blüte. . . . VII. Arundinelleae.

2. Ährchen zwei- bis vielblütig.

+ Decksp. meist kürzer als die Hüllsp., meist mit am Rücken entspringender gedrehter Granne, selten unbegrannt, dann das Ährchen zweiblütig ohne Achsenfortsatz . . VIII. Aveneae.

++ Decksp. meist länger als Hüllsp., unbegrannt oder aus der Spitze begrannt.

- Ährchen zwei- bis vielbluitig, mit langen Seidenhaaren, die vom Callus der Decksp. oder auch von deren Rücken entspringen; alle Sp. häutig, häufig glänzend, Decksp. umbegrannt, langgespitzt oder in Granne ausgehend; Bliiten häufig $\sigma^{\top} O$, auch kommt Diöcie vor . IX. Arundineae.

-) Ahrchen zwei- bis vielblitig, in mehr oder weniger zusammengesetzten Rispen; Decksp. drei- bis vielnervig, unbegrannt oder aus der Spitze begrannt oder die Granne zwischen zwei Spitzen der Decksp. entspringend, nicht rückenständig, nicht gedreht; Achse des Ährchens über die oberste Blüte hinaus meist fortgesetzt oder die obersten Decksp, unvollkommen ...... . XI. Festuceae. II. Ährchen sitzend, in Ähren angeordnet. Ährchen ein- bis mehrblitig, einzeln oder zu mehreren an den Ährenknoten sitzend oder mehr oder weniger in die Spindel eingesenkt . .XII. Hordeeae. p) Halme meist hochwiichsig, ausdauernd und verholzend; Ährchen cinbis vielblutig, meist große Rispen zusammensetzend; Hüllsp. zwei bis mehrere, im letzteren Falle die oberen in die Form der Decksp. übergehend; Vorsp. scharf zweikielig oder selten von der Form der Decksp.; Bliiten $\$$, seltener $\sigma^{\top} q$, Staubblätter $3-6-\infty$, Narben zwei bis drei. XIII. Bambuseae.

1. Andropogoncare. Meist stattliche Graser, besonders Xerophyten, selten Hydrophyten Sacchamm spontancum, Vossia cuspidata, vgl. S. I50), immer herdenweise und vielfach formationsbildend auftretend.

A. Ährchen homogam, d. h. das gestielte Ährchen dem sitzenden in Form, Geschlecht und Begrannung gleichend; Ährchen in Rispen.

a) Rispe ährenförmig zusammengezogen, Spindel der Scheinähren ungegliedert . Imperata.

b) Rispe ausgebreitet, Spindel der Scheinähren zerfallend, Ährchen lang behaart.

(c) Ährchen unbegrannt. Nur kultiviert ............. Saccharum.

B) Ährchen begrannt .................. Erianthus.

c) Rispe aus gefingerten Scheinähren zusammengesetzt ........ Pollinia.

B. Ährchen heterogam, das sitzende $\subseteq$, das gestielte $\vec{O}$ : seltener das gestielte Ährchen abortierend. (Ausnahme Ischaemum mit häufig \& gestielten Ährchen).

a) Decksp. der Ährchen unbegrannt, Ährchen in einzelne oder \pm zusammengesetzte Scheinähren gestellt; Spindel des Blütenstandes zerbrechlich, die Glieder ausgehöhlt und die sitzenden Ährchen mehr oder weniger umfassend, mit ihnen abfallend.

ce) Erste Sp. begrannt oder lang gespitzt.

I. Erste Sp. beider Ährchen geschwänzt gespitzt, Scheinähren gefingert . . Vossia. 
II. Erste Sp. des sitzenden Ährchens begrannt, Scheinähren einfach oder zusammengesetzt . . . . . . . . . . . . . . . . Urelytrum.

III. Erste Sp. des sitzenden Ährchens mit ein bis zwei kurzen Grannen, erste Sp. des gestielten Ährchens häufig begrannt, letzteres meist steril; Blütenstand eine Scheinähre oder eine aus solchen zusammengesetzte Rispe.......... Rhytachne.

及) Erste Sp. unbegrannt.

1. Erste Sp. flach oder konvex ................ Rottboellia.

2. Erste Sp. liugelig. . . . . . . . . . . . . . . Manisuris.

b) Decksp. wenigstens des sitzenden Ährchens begrannt, (bei Trachypogon des gestielten Äbrchens; Ährchen unbegrannt bei Elionurus).

( ) Sitzendes Ährchen zweiblütig; Ährchen in einfachen oder zusammengesetzten Scheinähren.

I. Gestieltes Ährchen mit $\&$ oder ơ Blüte ............. Ischaemum.

II. Gestieltes Ährchen steril; Scheinähren gefingert, eine Sp. warzig. . Thelepogon.

ß) Sitzendes Ährchen einblütig; Blütenstände mehr oder weniger reich zusammengesetzt, Spindel der Scheinähren meist brïchig.

I. Alle Äbrchen gestielt, das länger gestielte $\$ ;$ Spindel zäh . . . . Trachypogon.

II. $\Varangle$ Ährchen sitzend, Spindel zerbrechlich (ausgenommen Kulturformen von Sorghum.)

I. Ährchen unbegrannt, eine Spelze mit Warzen oder Balsamstreifen, Scheinähren einzeln .................. Elionurus,

2. Ährchen begrannt, erste Spelze ohne Balsamstreifen.

+ Das gestielte Ährchen steril, reduziert oder gänzlich abortiert.

$\odot$ Das gestielte Ährchen steril, reduziert; sitzendes Ährchen mit vom Rücken begrannter erster Sp.; Blätter am Grunde herzförmig, Scheinåhren zusammengesetzt . . . . . . . . . . . Arthraxon.

$\odot \odot$ Abrchen einzeln, gestielt, das zweite Ährchen röllig abortiert . Cleistachne.

++ Das gestielte Ährchen meist $̋$; vierte Sp. des sitzenden Ährchens aus der Spitze oder zwischen zwei Spitzen begrannt....... Andropogon.

+++ Das fertile Ährchen von vier sterilen Ährchen wirtelartig umgeben, die Gruppe in einem scheidenartigen Hochblatt ............ Themeda.

Imperata Cyr. Eine Art von Ägypten bis Sudafrika, I. cylindrica (L.) Beauv. (I. armaninacea Cyr.), in den Tropen weitverbreitet, durch ihre kriechenden Rhizome weite Strecken bedeckend (Alang-Alang-Formation, vgl. S. Is9, Fig. I 33).

Erianthus Michx. Stattliche rohrähnliche Gräser der wärmeren Länder, mehrere Arten (E. capensis Nees) in Südafrika an sandigen Flußufern usw, eine tropisch afrikanisch.

Pollinia Trin. Niedrigere, häufig niederliegende, kriechende Gräser; Südafrika, eine, $P$. villosa Spr., im tropischen Ostafrika.

Vossia Wall. et Griff. Eine Art in Indien und im tropischen Ostafriki, T. cuspilata (Roxb.) K. Schum., kräftiges wasserbewohnendes Gras mit im unteren Teil flutenden oder untergetauchten Halmen (vgl. S. I 50).

Urelytrum Hack. Perennierende, kräftige Gräser, vier Arten im südlichen und tropischen Afrika, U. agropyroides Hack. (vgl. S. I66).

Rhytachne Desv. Fünf Arten im tropischen Westafrilia, südlich bis Angola, eine in Zentralafrika, von verschiedenem Habitus, eine hochwiichsige Art der westlichen Kampinen $R$. congoensis Hack. 
Rottboellia L.f. Ungefähr zehn Arten im tropischen und südlichen Afrika; die Gattung ist in den wärmeren Ländern beider Hemisphären verbreitet, besonders mit der Art R. craltate L. f., die in Afrika auf Lichtungen, gerodetem Land usw. auftritt.

Manisuris Sw. Die einzige Art, M. gramularis L. f. (vgl. S. I92, Fig. I 35), ist ein reichverzweigtes, cinjähriges, niedriges Gras, das als Unkraut tropisch kosmopolitisch ist.

Ischaemum L. Die formenreiche Gattung ist besonders in den Tropen der alten 1 elt verbreitet; die meist ziemlich niedrigen, häufig viel verzweigten und niederliegenden Arten lieben feuchtere Standorte, sind öfters charakteristische Strandpflanzen; fünf Arten im tropischen Afrika, eine auch im östlichen Siidafrika.

Thelepogon Roth. Eine Art, Th. clegans Roth, in Indien und Ostafrika, auch in Togo, subxerophyl, einjährig mit kräftigen Halmen (vgl. S. i6r).

Trachypogon Nees. Die Arten der Gattung wurden von HACKEL in eino formenreiche Art, T. polymorplus Hack. zusammengefaßt; es sind rasenbildende Gräser mit einzelnen oder gefingerten Scheinähren, die besonders für Steppen und steinige Gegenden Südamerikas charakteristisch sind. Mehrere Varietäten treten in Südafrika, vereinzelt auch im tropischen Afrika auf.

Elionurus Humb. und Bonpl. Im tropischen und siddichen Afrika ca. zehn Arten; die meist niedrigen Halme der rasig wachsenden, perennierenden Arten tragen einfache, durch weißseidige Behaarung auffallende Scheinähren: sie sind xerophil und wachsen in Steppen, an trocknen Hügeln usw.

Arthraxon Beauv. Die Gattung ist tropisch asiatisch und tritt noch im nordöstlichen Afrika mit drei bis vier Arten auf: diese sind niedrige zierliche Formen, die durch den breiten, herzförmigen Blattgrund auffallen.

Cleistachne Benth. Eine hochwiichsige Art, C. sorghoides Benth., mit vielblütiger Rispe, die an grasigen Abhängen des tropischen Ostafrika auftritt.

Andropogon L. (inkl. Schizachyrim, Sorghmm, Cymbopogon und Heteropog(m)! Die artenreiche Gattung, die einen der wichtigsten Komponenten der Gramineenflora in den Tropen bildet, ist auch in Afrika in großer Formenfulle entwickelt und besitzt ungefähr 120 Arten in fast allen Formationen, vorzugsweise jedoch in den trockneren, besonders subxerophilen Formationen: diu Gattung ist nicht nur wegen des Artenreichtums von Wichtigkeit, sondern auch wegen des geselligen Auftretens vieler Formen, die dadurch das Bild der Vegetation beeinflussen. In der ostafrikanischen Steppe (rgl. S. I 5 Iff.) sind neben Themald Andropogon-Arten besonders aus der (imbopogen-Gruppe mit dichter Rasenbildung und ausgebreiteter Rispe von Bedeutung, ebenso in der Kampine und Steppe Westafrikas (A. cymbarius, A. schoenanthus, A. nardus, A. mfus). Thnen schließen sich Arten aus der Artholopliz-Gruppe igl. z. B. A. Gayjemus S. 163 Fig. I 20 , und aus der Schizachymm-Gruppe (A. simibrhis S. I $6+$ Fig. I 2 I) an. Zu letzterer gehört auch der tropisch-kosmopolitische. 1. bräifolius Sw., der mit seinen zierlichen reichverzweigten Halmen in Grasfluren filzartige L̈berziige bildet vgl. S. 168, Fig. I22). Der Vertreter der thitiropogon-Gruppe, 
1. contortus, der mit vielen Formen durch alle wärmeren Länder verbreitet ist, tritt in mehrerlei trocknen Formationen auf (vgl. Fig. I 6 h. Androposon Sorghum subsp. satians, die Durrha, ist das wichtigste einheimische. in vielen Varietäten kultivierte Getreide.

Themeda Forsk. In Afrika eine, in den Tropen der alten W'elt verbreitete, variable Art, Th. Forskalii Hack, dichtrasig mit dünnen, ziemlich hohen Halmen mit reichverzweigter Rispe, das wichtigste Steppengras Ostafrikas /rgl. S. I I I. Fig. I 14 ).

II. Paniceac. Diese vorzugsweise tropische Gramineengruppe ist auch fuir Afrika von vorherrschender Wichtigkeit und in allen Formationen vertreten.

A. Ähren 8 .

a) Decksp. verhärtend; Hüllsp. und Decksp. ganzrandig, unbegrannt (vgl. jedoch Chloridion) oder in eine grannenartige Spitze ausgehend.

๘. Ährchen ohne besondere von borsten- oder schuppenförmigen, sterilen Zweiglein gebildete Hülle.

I. Ährchen mit zwei Hüllsp.

I. Ährchen mit einer $§$ Blïte.

+ Ährchen einem wulstartigen Callus, der über der Gliederung des Stieles steht, aufsitzend; Ähren oder Trauben wiederum traubig gestellt .. Eriochloa.

++ Ährchen ohne solchen Callus; Ährchen in einseitswendigen Trauben oder Ähren . . . . . . . . . . Paspalum.

2. Ährchen mit zwei \& Blüten; Decksp. zwei, verhärtend, sonst in Tracht und Blütenhau der Gattung Panicum gleichend . . . . . . . Isachne.

II. Ährchen mit drei Hüllsp., mit einer $\subseteq$ Blïte oder mit 3 Blitte in der Achsel der dritten Sp.

I. Erste Hüllsp. am kiirzesten, Hüllsp. selten grannenartig verlängert, Tracht mannigfach ................... Panicum.

2. Erste Hiillsp. o, zweite klein, dritte begrannt; Decksp. kuirzer, stumpf; Blütenstand wie bei Panicum $\S$ Digitaria. Eine Art Britisch Zentralafrika .. Chloridion.

3. Untere Hüllsp. begrannt, Ährchen schmal; Rispenzweige an der Spindel zerstrèut, Ährchen biischelig genähert............ Oplismenus.

4. Erste Hüllsp. sehr klein, zweite und dritte mit langer. spiralig gedrehter Granne; Decksp. wenig verhärtet . . . . . . . Acritochaete.

B) Ährchen von sterilen, borsten- oder schuppenförmigen Zweigen umigeben.

I. Ährchen mit einem Involucrum von starren, meist schuppenartigen, an der Basis vereinten Borsten . . . . . . . . . . . Cenchrus.

II. Ährchen von dünneren Borsten oder Borstenzweiglein umgeben.

I. Ährchen von stehenbleibenden Borstenzweiglein umgeben, im Bau wie bei Panicum

Setaria.

2. Äbrchen von einem Involucrum umgeben, das meist aus zahlreichen kurzen, nackten oder behaarten Borsten besteht und mit dem Ährchen zusammen abfällt; selten Borsten wenige bis eine ........... Pennisetum.

b) Decksp. wenig verbärtend; Hüllsp. und Decksp. zweilappig oder ansgerandet. meist begranmt

Melinis

B. Ährchen of $Q$, monöcisch.

a) Decksp. der $\odot$ Äbrchen \pm konvex, stark verhärtend . . . . . . . Olyra.

b! Decksp. des $S$ Ährchens kugelig aufgeblasen, schwach rerhärtend . . . Leptaspis. An die Paniceae anzuschließen: Stenotaphrom und Phyllorrhachis.

Paspalum L. Die Gattung ist vorzugsweise im tropischen Amcrika reich entwickelt, in Afrika nur mit wenigen Arten vertreten. 
Isachne R. Br. Drei bis vier Arten im tropischen Afrika, hygrophil, besonders im Urwald und an Lichtungen, mit schwachen, niederliegenden Halmen und verhältnismäßig großer, ausgebreiteter Rispe ähnlich wie bei vielen Panicum-Arten (vgl. S. 137).

Panicum L. (inkl. Digitaria Rich. und Leucophrys Rendle). Die artenreichste Gattung der tropischen Gramineen, auch in Afrika in allen Formationen (mit Ausnahme der Hochgebirge), durch Artenzahl und Menge des Vorkommens von besonderer Wichtigkeit; ungefähr 250 Arten, die in Tracht und Form des Bliutenstandes sehr mannigfaltig sind; Rispe meist reichblütig.

Die Sektion Digituria ist durch meist gefingerte oder genäherte Scheinähren ausgezeichnet; hierher gehört $P$. horizontalc Mey., eines der verbreitetsten Gräser an kultivierten Geländen oder Waldlichtungen usw., mit schwachen niederliegenden, häufig bewurzelten Halmen, und eine Reihe ähnlicher Arten (vgl. S. I 44 und I 9o). Zur Sektion Echinochloc, die durch mehr oder weniger entwickelte Grannen spitzen der zweiten und dritten Sp. ausgezeichnet ist, gehören mehrere kosmopolitische Unkraut- und Futtergräser ( $P$. crus gralli L. usw.), sowie auch stark hydrophile Formen (I'. stagnimm Retz und Verwandte (vgl. S. I 50). Die Sektion Ptychophyllum vermittelt den Übergang zur Gattung Setaria, da bei ihr die Enden der Zweiglein borstenförmig verlängert sind; hierher gehört das prächtige hohe IValdgras I'. sulcatum Aubl. (vgl. S. I 37). Am formenreichsten ist die Eupanicum-Gruppe, in der die Formen mit durchgehend gestielten, in meist reichblütige Rispen gestellten $\ddot{A}$ hrchen vereinigt sind; hierher z. B. das hochwiichsige, durch runzelige Decksp. ausgezeichnete $P$. maximm Jacq., ein wichtiges Futtergras fruchtbareren Bodens.

Oplismenus Beauv. Wenige Arten, einzelne wie O. Burmannii P. Beauv. von weiter Verbreitung in den Tropen, in der Tracht den Isachne-Arten ähnlich und mit ihnen zusammen vorkommend.

Acritochaete Pilger. Eine Art, A. Tolkcnsii Pilger, ein niederliegendes, W'aldgras mit aus wenigen Trauben zusammengesetzter Rispe, am Kilimandscharo.

Cenchrus L. Sieben bis acht Arten, niedrige Formen mit ährenförmigem Bliutenstand, als Unkräuter häufig lästig. Mit $C$. ist vielleicht zu vereinigen Odontclytrum Hack.; die einzige Art ist ein flutendes Wassergras Abyssiniens (vgl. S. I 5 I).

Setaria Beaur. Die Gattung ist durch den dichten zylindrischen Blütenstand und durch die querrunzeligen Decksp. ausgezeichnet; in Afrika kommen ungefähr 25 Arten vor, die vorzugsweise trockne Formationen bewohnen, teilweise dichte Rasen entwickelnd (S. aurea Hochst., S. glauca (L.) Beauv.).

Pennisetum Rich. (inkl. Gymnothrix Beauv., Beckeropsis Fig. et de Not). Gegen 50 Arten in Afrika, mit ährenförmiger oder ausgebreiteter Rispe, besonders in trocknen Formationen, zusammen mit Arten der vorigen Gattung; I. purpurcum Schum. et Thonn., das riesige Elephantengras, besonders in Westafrika auf Wiesen, Lichtungen usw. (vgl. S. 145, Fig. I 2); I'. americamun (L.) K. Schum. (I'micillaria spicata W.), Negerhirse, mit kolbigem Fruchtstand, ist ein wichtiges formenreiches Getreidegras. 
Melinis P. Beauv. Sekt. Ennelinis, Ährchen meist kahl, dritte Sp. leer. Sechs Arten im tropischen Afrika, eine im Osten bis Natal; .I. mimitiflora Beauv. (vgl. Fig. I 32, S. I 85) ist ein sandbewohnendes Gras mit reichverzweigten, niederliegenden, klebrigen Halmen, das auch im tropischen Amerika vorkommt. Sekt. Tricholacna (ink1. Rhynchelytmun), Ährchen seidig behaart, dritte Sp. mit Vorsp. und häufig mit ơ Blüte. Ungefähr is Arten im tropischen und südlichen Afrika.

Olyra L. Hochwuichsige, öfters klimmende VValdgräser von bambuscenähnlichem Habitus, mit breiten Blättern und rispigem Blitenstand, dessen untere Zweige $O$ Ährchen tragen, während die oberen kleincre männliche Ährchen tragen; zwei Arten im tropischen Ost- und Westafria, O. latifolia L. irgl. S. I37, Fig. I09).

Leptaspis R. Br. Tropische Gattung der alten IV'lt, Waldgräser mit breiten Blättern, Blütenstand wie bei voriger; im tropischen Afrika L. conchifera Hack. (vgl. S. I 35).

Stenotaphrum Trin. Blütenstand ährenförmig, mit verbreiterter Rhachis, die zuletzt mehr oder weniger zerfällt; Ährchen einzeln oder zu 2 bis 4, mehr oder weniger eingesenkt; St. ancricamm Schrank, ein reichverzweigtes, kriechendes Strandgras Westafrikas, ebenso im tropischen und subtropischen Amerika.

Phyllorrhachis Trim. Blütenstand ährenförmig, mit blattartig verbreiterter Rhachis; Ährchen meist zu drei, das unterste fertil: eine Art, Ih. sagittater Trim., mit einzelnen aufrechten Halmen mit pfeilförmig eingeschnittenen Blättern, in Angola und im östlichen Kapland.

\section{Zoysicae.}

A. Ährenförmiger Blütenstand aus Gruppen von Ährchen zusammengesetzt.

a) Die unteren Hüllsp. der vier die Gruppe zusammensetzenden Ährchen hart, ein scheinbares Involucrum bildend; ein bis zwei Ährchen in der Gruppe fertil . : Anthephora.

b) Die oberen Hüllsp. der drei bis vier die Gruppe zusammensetzenden Ïhrchen gröfer.

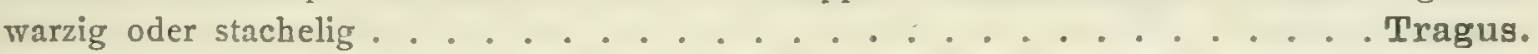

c) Erste Hüllsp. o, zweite rauhnervig, begrannt; Ihrchen vier bis fünf in der Gruppe, nur eines fertil. Eine von HACrel beschriebene Art in Südwestafrika . . . Monelytrum.

B. Ährenförmiger Bliitenstand aus einzelnen $\ddot{A}$ hrchen zusammengesetzt (seltener $\mathrm{A} h r c h e n$ zu zweit .

a) Ährchen klein, in lockerer Scheinähre, mit abgeflacht verbreitertem Stiel; untere Sp. der Ährchen konkav, warzig stachelig .......... Latipes.

b) Ährchen klein, schmal, in dichter Scheinähre, einzeln abfallend; Hüllsp. gleich, lang begrannt

Perotis.

c) Ährchen in Paaren, diese im ganzen abfallend, von vier starren, pfriemlichen Hüllsp. (? involucrumähnlich umgeben; Decksp. mit Grannenspitze. Eine von CHroveNDA bescbriebene Art, ein niedriges Gras in Erythrea

Tetrachaete.

Anthephora Schreb. A. clegans Schreb., dem tropischen Amerika und Westafrika gemeinsam, ist ein niederliegendes Gras der Kulturen, sandiger Wiesen usw. (vgl. S. I 78 ); A. pubscons Nees in Süwestafrika und A. Hoclistittri Nees in Ostafrilia sind dagegen stark xerophil ausgebildet, mit dichtem Rasen und schmalen Blättern (vgl. L c.). 
Tragus L. T. racemosus (vgl. S. I 79) ist ein Unkraut in allen wärmeren Ländern, einjährig mit niederliegenden Halmen, besonders auf Sandboden: eine verwandte Art in Südafrika.

Latipes Kth. Eine niedrig wachsende Art, L. senegalensis Kth., im tropischen Ost- und Westafrika auf Sandboden usw.

Perotis Ait. Zwei Arten, P. indica (L.) K., Schum. im tropischen. Ostafrika und östlichen Südafrika weitverbreitet, auch im tropischen Asien, vgl. S. I 32, Fig. I06, B).

\section{Oryzeae.}

A. Hiillsp. zwei, klein; Decksp. und Vorsp. punktiert, gekielt, Staubblätter sechs

Oryza:

B. Hüllsp. O, Staubblätter eins bis sechs :

Leersia,

C. Hiillsp. klein oder o, Decksp. begrannt

Beckera.

Oryza L. O. sativa L., Reis, in verschiedenen Varietäten in Kultur, doch auch in mehreren Formen im tropischen Afrika wildwachsend, hydrophil (vgl. S. 15 I).

Leersia Sw. Zwei bis drei Arten, darunter die tropisch kosmopolitische L. hexandra, hydrophil, in der Tracht der vorigen ähnlich.

Beckera Fres. Die Scheinähren sind in reichbliitige Rispen vereinigt; vier Arten in Abyssinien, B. polystachya Fresen.

\section{Phalarideae.}

A. Dritte und vierte Sp. (obere Hüllsp.) so groß oder größer als Deck- und Vorsp., mehr oder weniger verhärtend, begrannt oder unbegrannt; Staubblätter sechs oder drei . . Ehrharta.

B. Dritte und vierte Sp. klein, unbegrannt, in den unteren Sp. verborgen; Blïtenstand dicht ährenförmig; Stanbblätter drei

Phalaris.

C. Dritte und vierte Sp. kleiner als die unteren, begrannt; Staubblätter zwei. Anthoxanthum.

Ehrharta Thunb. Die Gattung ist mit ungefähr 30 Arten in Süd- und Südwestafrika verbreitet, die in verschiedenen Formationen auftreten, meist niedrige, häufig xerophile Formen; nur eine Art. I: abyssinia Hochst., kommt im Höhenwald Ostafrikas vor (vgl. S. 139).

Phalaris L. Die besonders in Südeuropa verbreitete Gattung hat in Abyssinien und Südafrika zwei Arten.

Anthoxanthum L. Eine Gattung borealer Verbreitung; 1. mialc K. Schum. (vgl. S. I73, Fig. I 25) ist eine alpine Art Ostafrikas mit breiten Blättern und ausläuferartigen Trieben.

\section{Agrostideac.}

Die Gruppe ist vorzugsweise in gemäßigten Klimaten entwickelt, wo dic Arten als Viesengräser von Bedeutung sind, ferner in Gebirgsgegenden wärmerer Länder; für die Tropen kommen besonders Stipa, Aristida und Sporobolus und zwar fuir trocknere Formationen in Betracht.

A. Die schmale, begrannte Decksp. verhärtet und umschließt eng den Fruchtknoten und die Frucht; der Blütenstand ist rispig.

a) Decksp. mit dreiteiliger Granne

Aristida.

b) Decksp. mit einfacher Granne. 
I. Decksp. schmal, mit spitzem Callus :

Stipa.

II. Decksp. breit, mit mehr oder weniger exzentrischer, zuletzt abfallender Granne

Oryzopsis.

B. Die Decksp. und Vorsp. verhärtet nicht, sie mmschließt die Frucht locker, oder die Frucht fällt heraus; Decksp. begrannt oder unbegrannt; Blutenstand verschieden.

a) Frucht vom Pericarp locker umgeben, Samen häufig frei; Decksp. unbegrannt, länger als die Hüllsp.; Ährchen klein, in schmaler oder ausgebreiteter Rispe . . . . Sporobolus.

b) Frucht vom Pericarp fest umschlossen; Decksp. meist begrannt und häufig lïirzer als die Hïllsp.

(i) Hiillsp. aus der stumpfen Spitze begrannt; Ährchen mit den Huillsp. abfallend

Polypogon.

3) Hiullsp. unbegrannt.

I. Hüllsp. nicht blasig; Decksp. kiirzer als die Vorsp., gestutzt, meist mit rückenständiger zarter Granne, manchmal mit. kleinen Seitengrannen.

Agrostis.

II. Hüllsp. am Grunde blasig aufgetrieben, Decksp. mehrmals küirzer; Achsenfortsatz, Rispe dicht

Gastridium.

Aristida L. Ungefähr 75 Arten im tropischen und suidlichen Afrika. Die drei für die Gattung charakteristischen Grannenspitzen der Decksp. sind entweder rauh oder federig behaart. Letztere Arten, die die Sektion Stipagrostis bilden, sind fuir xerophile Formationen ron Wichtigkeit; sie bilden starre, dichte Büschel und bewohnen Sandflächen und wüstenähnliche Strecken besonders im südwestlichen und nördlichen Afrika (vgl. S. I 77, Fig. I 26, Aristide olutusa). Hochwüchsigere Arten der Sektion Arthrathumm, bei der die langen, rauhen Grannen sich abgliedern, sind besonders in trocknen Grasfluren des westlichen Afrika verbreitet (vgl. S. I6 I, Fig. I 8, 1. Kirstingii). Zur Sektion (huctaria, bei der die rauhen Grannen kürzer sind und nicht abfallen, gehört die in mancherlei trocknen Formationen verbreitete, formenreiche einjährige Art 4 . adscinsionis L. (A. comblescus Desf.), die durch dichten Bliitenstand und reiche Terzweigung ausgezeichnet ist.

Stipa L. Diese für das tropische und subtropische Amerika wichtige Gattung, zu der verbreitete Steppengräser gehören, ist in Afrika nur mit wenigen Arten vertreten; das gleiche gilt von (Oryopsis, von der eine Art in Abyssinien vorkommt.

Sporobolus R. Br. Die wichtige Gattung ist in Afrika mit ungefähn 50 Arten verbreitet und kommt in vielen Formationen vor; am Neeresstrand in Ostafrika tritt der kosmopolitische Sp. aivginius Kth. mit kriechenden Sprossen auf (vgl. S. I30, Fig. I05; ebenso ist Sp. indicus (L.) R. Br. kosmopolitisch aut Kulturboden usw. (vgl. S. I 89, Fig. I06 C); mehrere niedrige Arten mit geschlossenem Rasen sind Steppengräser (vgl. S. I58, Fig. I17. Sp. fistiz'us Hochst..': einjährige niedrige Arten bewohnen trockne Sandflächen.

Agrostis L. Von dieser vorzugsweise borealen Gattung kommen in Ostafrika zehn bis zwölf Arten meist in den Gebirgen vor, die durch schwache, häufig niederliegende Halme ausgezcichnet sind (vgl. S. 1;o ff.); in Südafrika mehrere endemische Arten; mehrere Arten sind unter Trisitaria beschrieben worden, welche Gattung zu den Aveneen gehört. 
Polypogon Desf. Ein bis zwei in wärmeren Ländern weitverbreitete, häufig cingesch!eppte Arten auch hier und da im tropischen Afrika, I'. monspeliensis (L.) Desf.

Gastridium Beauv. Eine einjährige Art, S. lendigerm (L.) Gaud., in Abyssinien.

A. Äbrchen einzeln dentlich gestiel

VII. Arundinelleae.

B. Ährchen in Gruppen zu dreien auf gemeinsamem Stiel

Trichopteryx.

Trichopteryx Nees. Decksp. der obcren, \& Blüte zweizähnig oder zweilappig, mit häufig starker, geknieter Granne; 20 Arten, die meisten im westlichen Afrika, in trocknen Formationen, vicle hochwüchsig mit kräftigen Halmen (vgl. S. I62, I66): eine Art, T. flammila (Trin.) Bth. ist Brasilien und dem westlichen Afrika gemeinsam; T. iammunnsis Stapf ist eine schwächere Art der Bergweiden des Kamerungebirges (vgl. S. I 73).

Tristachya Nees. Ährchen wie bei der vorigen Gattung, mit der $T$. auch im Habitus und Vorkommen ibereinstimmt; die beiden Gattungen sind schwach getrennt. Gegen io Arten im südlichen und tropischen Afrika.

\section{Aveneac.}

Dic Gruppe ist wesentlich auf Länder gemäßigten Klimas beschränkt; in den Tropen bewohnen die Arten meist die Gebirge.

A. Ährchen zweiblütig ohne Achsenfortsatz; Decksp. am Ruicken begrannt . . . . . Aira.

B. Ährchen mehrblütig oder, wenn zweiblittig, die Decksp. 2wischen zwei Zähnen begrannt.

a) Decksp. vom Rücken begrannt

Trisetum.

b) Decksp. eingeschnitten, Granne zwischen den oft grannenähnlich verlängerten Spitzen entspringend.

Danthonia.

Aira L. Die weitrerbreitete zicrliche A. caryopluylled L. kommt in Abyssinien und auf dem Kamerungebirge vor (vgl. S. I 73).

Trisetum Pers. Von dieser borealen Gattung kommen wie auch sonst in den wärmeren Ländern in Ostafrika einige Arten nur in den Gebirgen vor.

Danthonia DC. Von der Gruppe der echten Danthonien mit drei- bis mehrblütigen Ährchen existieren in Suidafrika gegen 30 Arten von recht verschiedener Tracht, doch meist rasenbildend mit lockerer Rispe; im tropischen Afrika finden sich ro Arten in den Gebirgen des Ostens und im Kamerungebirge, im Wuchse typisch alpin (rgl. Fig. I24). Die Sektion I'cntaschistis Nees wurde von STAPF, zum Teil ihrer geschlossenen Verbreitung wegen, als eigene Gattung abgetrennt; sie ist in Süd- und Südwestafrika reich entwickelt; die Arten sind meist zierlich, rasenbildend, mit lockerer Rispe und stets zweiblitigen Ährchen. Einige Arten gehen auf die Gebirge Ostafrikas über, so ist D. bornssica K. Schum. (vgl. S. I7 I, Fig. I 24 A) eine charakteristische Art der Bergwiesen am Kilimandscharo.

\section{Arundineac.}

Phragmites Trin. I'. a'ulgaris (Lam.) Crép., das Schilfrohr, eine kosmopolitische Art, bildet auch in Afrika an Ufern von Flüssen und Seen Bestände (vgl. S. I 49). 


\section{Chlorideae.}

Die Gruppe der Chlorideen ist mit zahlreichen Gattungen vorzugsweise in wärmeren Ländern entwickelt; viele Arten haben eine weite Verbreitung. Die typischen Gattungen sind durch den eigentümlichen Blïtenstand leicht als zur Gruppe gehörig kenntlich, doch ist die Grenze gegen die Festuceen schwer zu ziehen, da manche Gattungen mit rispigem Blitenstand einen Übergang zu letzteren vermitteln.

A. Ährchen zweireihig in einseitswendigen Ähren.

a) Ährchen einblütig, unbegrannt oder begrannt.

re) Decksp. kürzer als die Hüllsp.

I. Decksp. unbegrannt.

I. Ährchen in einzelner, terminaler Ähre

. Microchloa.

2. Äbren zahlreich an der Blütenstandsachse. Decksp. viel kürzer als die Hüllsp.

Craspedorrhachis.

II. Decksp. begrannt .

Schoenefeldia.

3. Decksp. fast so lang als die Hüllsp., kurz begrannt: drei Arten in Südwestafrika.

y) Decksp. länger als die Hüllsp.

Willkommia.

b) Ährchen mit einer \&̊ Blïte, darïber mit ơ Blüte oder mit sterilen Sp.

c) Ährchen mit zwei leeren Spelzen unterhalb der \$ Blüte

Cynodon.

3) Ährchen ohne solche Spelzen.

I. Ähren einzeln, selten zu zweit.

I, Decksp. unbegrannt

Harpechloa.

2. Decksp. begrannt

Enteropogon.

II. Ähren wenige gefingert oder zahlreich an der Achse genähert

Chloris.

III. Ähren viele, kurz und dicht, voneinander entfernt

Melanocenchris.

c) Ährchen mit mehreren \& Blüten

(t) Ähren einzeln oder seltener zu zweien bis dreien, aufrecht.

I. Decksp. mit längerer, mittlerer und zwei kürzeren seitlichen Grannen . Tripogon.

II. Decksp. zwischen zwei Lappen oder unterhalb der Spitze begrannt. . Tetrapogon.

3) Ähren zahlreich, zerstreut, kurz und spreizend. . . . . . . . Dinebra.

y). Ähren fingerförmig gestellt.

I. Ähren mit Endährchen

Eleusine.

II. Ähren mit einer sterilen Spitze abschließend

Dactyloctenium.

B. Ährchen in Rispen, mehr oder weniger lang gestielt.

a) Ährchen in dichten, vielblütigen Rispen, klein.

\%. Ahrchen meist dentlich gest:elt: Decksp. zart begrannt, Seitennerven in Grannen aus-

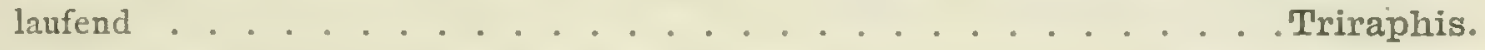

ß) Ährchen fast sitzend; Decksp. lang zart begrannt . . . . . . . Leptocarydium.

b) Ährchen in lockerblütigen Rispen.

(e) Decksp. sehr kurz begrannt .............. Crossotropis.

ß) Decksp. unbegrannt.

I. Decksp. dreizähnig . . . . . . . . . . . Diplachne.

II. Decksp. ungeteilt.

I. Rispe mit zahlreichen kurzen, spiralig angeordneten Ästen . Pogonarthria.

2. Rispe verlängert, schwach zusammengesetzt ........ Leptochloa.

Microchloa R. Br. Eine Art, $M$. setaicl R. Br., ein zierliches, einjähriges Gras, tropisch kosmopolitisch, an sandigen Ufern usw, eine Art in IVestafrika.

Craspedorrhachis Benth. Endemische Gattung in Ostafrika mit zwei Arten, C. africand Benth. (vgl. S. I 85). 
Schoenefeldia Kth. Der Blütenstand besteht aus ein bis vier Ïhren; die Decksp. ist zwischen zwei Spitzen lang zierlich begrannt. Eine Art, S. gracilis Kth., im nördlichen tropischen Afrika.

Cynodon Pers. Ähren drei bis sechs gefingert, Ährchen klein, unbegrannt. C. dactylon I.) Pers., ein tropisch und subtropisch kosmopolitisches Gras mit kriechenden Sprossen, besonders auf Sandboden (vgl. S. I3 I. I57; eine zweite Art, C. plectostachum (K. Schum.) Pilger, in den Stcppen Ostafrikas.

Ctenium Panz. Ähren meist einzeln; Decksp. begrannt. Eine Art, Ct. comimmum Nees, im östlichen Südafrika, drei bis vier im tropischen Afrika.

Harpechloa Kth. Ährchen mit ein bis drei or Bliten über der $\underline{\text { a }}$. Zwei Arten im südlichen und östlichen Südafrika und Nyassaland.

Enteropogon Nees. Thrchen mit zweiter $\vec{\jmath}$ Bliite oder steriler Sp. über der $\$$ Blite: Decksp. der letzteren unbegrannt. Eine Art, E. monostachums (Vahl, K. Schum. im Küstenbuschland Ostafrikas (vgl. S. 1 32 ), mit ansteigenden, verzweigten Halmen.

Chloris Sw. Thrchen klein, Decksp. der ș Bliten meist breit, kurz begrannt, sterile Spelzen über den Blïten zwei bis mehrere zusammengedrängt. Ungefähr 20 Arten im tropischen und südlichen Afrika, mehrere von weiter Verbreitung. Besonders ist die tropisch kosmopolitische C C. arrorta Sw, cine einjährige Art mit vielen Halmen und zusammengedrängten Ähren, auch in Afrika auf Kulturland, Sandboden usw. häufig vgl. S. I80, Fig. I 28; für die Steppen Ostafrikas ist Ch. myriostachl'a Hochst., eine rasenbildende Art mit kräftigen Halmen und dichter Rispe ron Bedeutung (vgl. S. I 56 , ferner Fig. I I $3 C$, S. I 6 , ebenso die durch braune gefingerte Ähren ausgezeichnete Ch. fetraca Thunb.

Melanocenchris Nees. Hüllsp. reich behaart; Dechsp. mit drei Grannen; mehrere sterile begrannte Spelzen. Eine Art im nordöstlichen Afrika.

Tripogon Roth. Ährchen zweireihig sitzend; drei Arten, zwei in Abyssinien, eine in Kamerun, im Habitus Lolium-Arten nicht unähnlich.

Tetrapogon Desf. linkl. I-fidopironia Rich.. Ihren dicht seidig behaart; Hüllsp. ungleich, obere länger, konkav, so lang als das Ährchen. Drei niedrig wachsende Arten im nördlichen Ostafrika.

Dinebra Jacq. Eine einjährige Art, D. retroffix Vahl, Panz., mit aufsteigenden Halmen, durch die Form des Blütenstandes charakterisiert, auf Kulturland, Sandboden usw., von weiter Verbreitung (vgl. S. I 92).

Eleusine Gärtn. Hüllsp. stumpf oder spitzlich; die cinjährige E. indica (L.) Gärtn. gehört zu den verbreitetsten Lnkrautgräsern der wärmeren Länder; die verwandte $F$ : imacan (L.) Gärtn., Dagussa, wird als Getreide angebaut, ferner drei bis vier Arten in Ostafrika.

Dactyloctenium Willd. Mit voriger Gattung nahe verwandt; obere Hüllsp. stachelspitzig. D. aigyptiamm L.) Willd., einjährig; ist als Unkraut auf Kulturboden usw. durch alle wärmeren Länder verbreitet (vgl. S. I92, Fig. I 36).

Triraphis R. Br. Mehrere Arten in Australien und sieben in Süd- und Südwestafrika, ron xerophilem Gepräge, teils niedrig halbstrauchig entwichelt 
(vgl. S. I 6, T. ramosissima Hack.), teils zartere einjährige Formen (vg1. S. I 80, T. Fleckii Hack.).

Leptocarydium Hochst. Drei Arten im östlichen Suidafrika und im tropischen Ostafrika, weitverbreitet L. vulpiastmun (De Not.) Stapf.

Crossotropis Stapf. Eine einjährige Art mit sparrig ausgebreiteten Rispenästen, C. grandiglumis (Nees Rendle in Süd- und Südwestafrika (vgl. S. I85, Fig. I 30).

Diplachne Beauv. Drei bis vier Arten im tropischen Afrika. Ahrchen klein, in Rispen mit verlängerten Zweigen.

Pogonarthria Stapf. Ährchen dicht gestellt, zwei- bis achtblitig, mit derbhäutiger, zugespitzter Decksp. Eine Art, I'. falcatı (Hack.) Rendle in Suid- und Ostafrika (vgl. S. I85, Fig. I31).

Leptochloa Beaur. Hüllsp. meist kïrzer als Decksp. Ungefähr fünf Arten im tropischen Afrika, L. mififore Hochst. in Ostafrika.

\section{Festucear.}

A. Decksp. mit drei bis vielen Grannen, vielnervig.

a) Ährchen in dichter ährenförmiger Rispe, wenigblütig; Decksp. mit vielen Grannen.

Pappophorum.

b) Ährchen in lockerer Rispe; Decksp. in vier Zipfel geteilt, zwischen diesen mit fünf Grannen.

B. Decksp. unbegrannt oder mit einer Granne.

Schmidtia.

a) Ährchen in kopfigen oder dicht walzigen Blütenständen.

x) Ährchen in dichter, unterbrochener oder aus einzelnen Köpfchen zusammengesetzter Rispe, klein; ein Staubblatt . . . . . . . . . . . . Elytrophorus.

3) Thrchen in dichtem zylindrischen Blitenstand, im ganzen abfallend; eine Blüte im Ährchen fertil; Spelzen gespitzt oder begrannt . . . . . . . Fingerhuthia.

b) Ährchen in mehr oder weniger lockeren oder dichten Rispen, selten Blütenstand ährenförmig (Brachypodizm).

«) Decksp. dreinervig, unbegrannt; Spindel des Ährchens meist nicht zerfallend, Vorsp. an ihr stehenbleibend oder wenigstens nicht mit der Decksp. zusammen abfallend.

Eragrostis.

3) Decksp. fuinf- bis mehrnervig, unbegrannt oder begrannt; Deck- und Vorsp. zusammen abfallend.

I. Blätter groß, breit, mit kurzen, vorspringenden transversalen Nerven.

1. Ährchen in langer, einseitswendiger Ähre; Griffel lang, fadenförmig, spiralig gedreht und durcheinander gewirrt. . . . . . . . . . Streptogyne.

2. Ährchen in Rispen; Decksp. häufig bestachelt. . . . . . . . Centotheca.

II. Blätter durchschnittlich schmal. ohne Transversalnerven.

I. Blütenstand rispig.

+ Ährchen in dichten kurzen Ähren oder Knäueln, die an der Spindel zerstreut sind; Decksp. breit, stachelspitzig. . . . . . . . . . . Aeluropus.

++ Abren in ununterbrochenen Rispen.

$\odot$ Fruchtknoten kahl.

X Ährchen einblütig mit Achsenfortsatz; Pflanzen vom Habitus der Festuca gigantea ................... Pseudobromus.

XX Ährchen mebr- bis vielblütig.

I Rispe zusammengezogen, håufig fast ährenförmig; Decksp. drei- bis fünfnervig, mebr oder weniger trockenhäutig, gespitzt oder kurz begrannt . . . . . . . . . . . . . . . . Koeleria. 
II Rispe meist locker; Ährchenspindel meist mit gekräuselten Haaren bekleidet; Decksp. unbegrannt, die Nerven meist nach oben zusammenlaufend ................. Poa.

III Blütenstand verschieden; Decksp. zugespitzt oder kurz begrannt, am Rücken gerundet............... Festuca.

○) Fruchtknoten an der Spitze behaart; Ährchen mehr- bis vielblitig, meist ansehnlich in lockeren Rispen; Decksp. meist begrannt.

Bromus.

2. Ährchen wenige in einfacher Ähre, fast sitzend, vielblütig; Decksp. gespitzt oder begrannt

Brachypodium.

Pappophorum Schreb. Ungefähr zehn Arten, besonders in Sïd- und Südwestafrika, meist niedrigere Halme, häufig mit klebriger Behaarung (vgl. S. I 79, Fig. I 29, P. cenchroides Licht.).

Schmidtia Steud. Zwei bis drei Arten in südlichen und suidwestlichen Afrika, Sch. quinqueseta Benth., einjährig mit mehr oder weniger niederliegenden Halmen (vgl. S. 180, Fig. 127), Sch. bulbosa, perennierend mit knollig angeschwollenen Halmbasen.

Elytrophorus P. Beaus: Eine einjährige niedrige Art in den Tropen der alten Welt verbreitet, eine zweite in Südafrika (vgl. S. 184).

Fingerhuthia Nees. Zwei Arten, xerophil, in Siid- und Siidwestafrika.

Eragrostis Beauv. Eine der wichtigsten, formenreichsten Gattungen, in allen Formationen mit ungefähr I50 Arten durch Afrika verbreitet. Bei der Sektion Cataclastos ist dic .thrchenspindel zerbrechlich; hierher gehören z. B. L. cilaris (L.) Lk. (vgl. S. 192, Fig. 106.t, eine einjährige, ibberall in den Tropen verbreitete Art, und E. asperc (Jacq.) Nees, eine lockerrispige Art mit zierlichen Halmen, die in verschiedenen trocknen Formationen weit verbreitet ist. Aus der Sektion I'latystaily'a mit großen flachen Ährchen ist die schöne F. superber Wawra et Peyrich, mit kräftigen Rhizomen und hohen Halmen, ein verbreitetes Steppengras igl. S. I58, ferner Fig. I 3 B, S. I 76 ); verwandte Arten schließen sich an. Die größere Anzahl mittelhoher und kleiner Arten gehört zur Sektion P'troessa mit zerbrechlicher Ährchenspindel, von einjährigen z. B. die verbreitete $E$. major Host. Stark xerophil ausgebildete Typen in der Gattung sind z. B. E.cypcroides (Thunb.) P. Beauv. und E. spinosa (L. f.) Trin., zwei Arten der Dünen und Sandflächen des Inlandes (vg1. S. 133 und 175). Eine alpine . Irt ist I: oliarcia K. Schum, mit dichten geschlossenen Büscheln (vgl. S. $170^{\prime}$.

Streptogyne Beauv. Eine Art, ein hohes Waldgras, S. crinita Lk., in den Tropen verbreitet (vgl. S. I35, Fig. $108 E-I$ ).

Centotheca Desv. (. lappacir Desv. hygrophiles Waldgras, im Habitus der vorigen ähnlich (vgl. S. I37, Fig. I08 $A-D$ ), eine zweite Art, C. mucronata (Beauv.) Benth. in Ostafrika.

Aeluropus Trin. Zwei Arten in Nordostafrika, kriechende Strand- und Wüstengräser mit harten Blättern, A. repens (Desf.) Parl.

Kooleria Pers. Eine Art, der $K$. cristata nahestehend, mit mehreren Formen in Ostafrika und Kamerun alpin (vgl. S. I 7 I). 
Poa L. Von dieser besonders für die nördliche extratropische Halbkugel wichtigen Gattung finden sich im östlichen tropischen Afrika einige vorzugsweise gebirgsbewohnende Arten.

Festuca L. Die Gattung ist gleichfalls besonders in der nördlichen extratropischen Zone entwickelt; in Ostafrika finden sich sieben bis acht meist gebirgsbewohnende Arten, in Südafrika fünf endemische Arten.

Pseudobromus K. Schum. Die Gattung ist trotz der einbliitigen Ährchen hierher zu stellen, da sie sich offenbar von Fistuca ableitet. Eine Art, F. silwaticus K. Schum., in Gebirgswäldern Ostafrikas (vgl. S. I +o!, mit über meterhohem Halm, eine zweite in Transvaal.

Bromus L. IVenige Arten in Ostafrika, eine in Kamerun, gebirgsbewohnend, B. mussorensis K. Schum.

Brachypodium Beauv. Für Afrika wie vorige Gattung wenig wichtig, zwei Arten in Ostafrika, B. Quartinianmm (Rich.) Hack., zwei in Südafrika.

\section{Hordeeae.}

Die Gruppe, zu der die wichtigsten Cerealien der gemäßigten Zonen gehören, ist für die tropischen Länder von seringer Bedeutung; bei den hier zu erwähnenden Gattungen stehen die Ährchen an den Knoten der Ährenspindel einzeln.

A. Ährchen vielblütig, zusammengedrïckt, mit dem Rücken der Spelzen nach der Spindel gerichtet. Wenige Arten in Abyssinien und Siidafrika. . . . . . . . . Lolium.

B. Ährchen ein- bis dreiblütig; untere Hüllsp. klein oder o, obere länger als die dreinervigen Decksp. Eine Art, ein kleines Pfänzchen im westl. Kapland und in Deutsch-Südwestafrika

Oropetium.

C. Ährchen wenigblütig, zusammengedrückt; Decksp. fünf- bis neunnervig, begrannt oder unbegrannt. Weizen, in Abyssinien gebaut

Triticum.

A. Staubblätter drei.

\section{Bambuseae.}

a) Ährchen mehrblitig in Rispen, Bliiten gleich, Hüllsp, zwei . . . . . Arundinaria.

b) Ährchen zweiblütig, die untere Blite $3 \hat{s}$, die obere $\not{s}$...... Microcalamus.

B. Staubblätter sechs.

a) Staubblätter frei.

re) Vorsp. der obersten Blite im Ährchen gekielt.

I. Hochwüchsig, mit holzigen Halmen . . . . . . . Oreobambos.

II. Niedrig, krautig . . . . . . . . . . . Guaduella.

3) Vorsp. der obersten Blüte im Ährchen der Decksp. gleichend, einnervig; Griffel zur Frnchtzeit sehr verbreitert, der Frncht mützenartig aufsitzend. Zweifelhafte Gattung, eine niedrige Art in Westafrika ............... Atractocarpa.

b) Staubfäden in eine Röhre verwachsen.

(c) Hochwïchsig, mit holzigen Halmen . . . . . . . . Oxytenanthera.

3) Niedrig, krautig. . . . . . . . . . . . . . . Puelia.

Arundinaria Mich. Eine Art, A. alfina K. Schum., hochwiichsig, verbreitet in höheren Lagen in Ostafrika (vgl. S. I 40, Fig. I IO).

Microcalamus Franch. Eine niedrige, krautige Art, M. barbinolis Franch.. in Westafrika (vgl. S. I34 und 143).

Engler, Charakterpfanzen Afrikas. I. 
Oreobambos K. Schum. Ährchen zweiblitig; in dichten Knäueln, die von zwei Bracteen umhüllt sind; eine Art, 0 . Buhwaldii $\mathrm{K}$. Schum., in L'sambara.

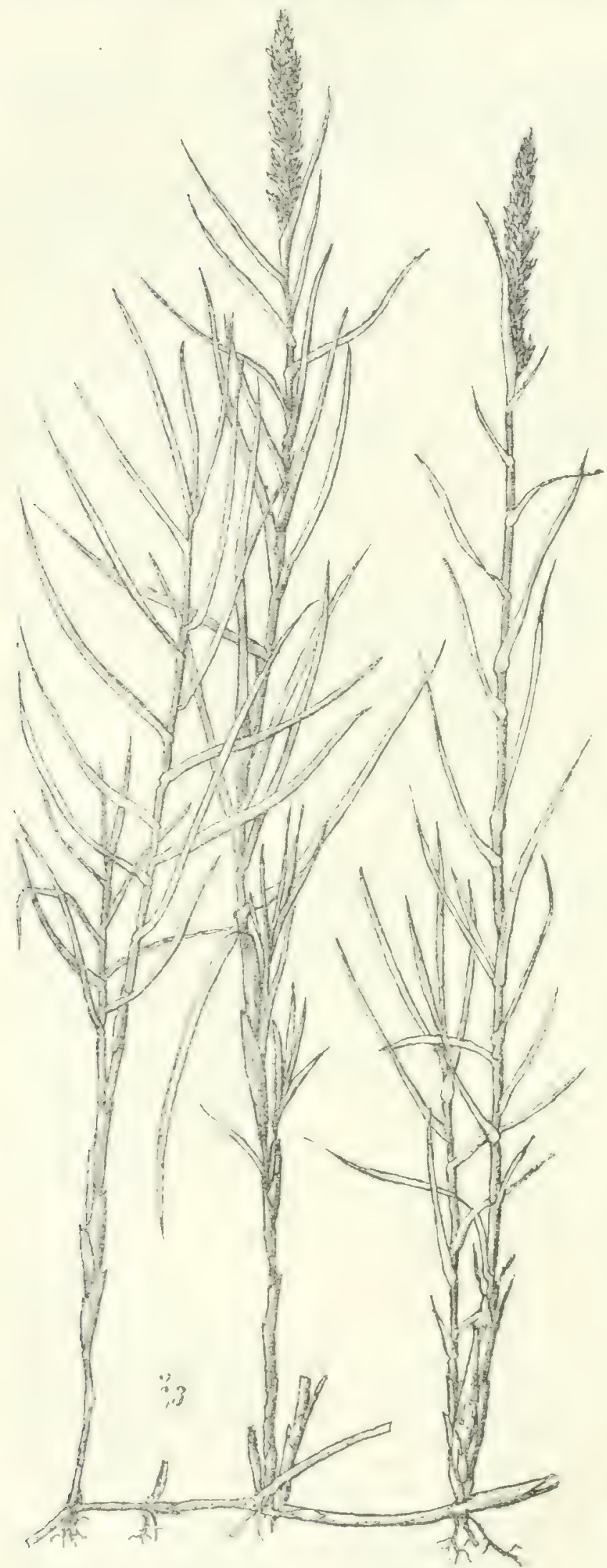

Fig. I0弓. Sporobolus virginicus $K$ th.

Guaduella Franch. Ährchen mehrblütig, in Trauben; drei niedrige, breitblättrige Arten in Westafrika, $G$. marantifolic Franch. (vgl. S. I 33 und 143).

Oxytenanthera Munro. Ährchen in Rispen, die aus köpfchenförmigen Büscheln zusammengesetzt sind, mit einer fertilen Endblüte, deren Vorsp. der Decksp. gleicht; darunter mehrere leere Sp. oder Sp. mit Vorsp. und or Blüte. Eine Art, O. aby'ssinica (A. Rich.) Benth. im tropischen Afrika weit verbreitet, zwei weitere Arten in Ostafrika (vgl. S. I40, Fig. I I I).

Puelia Franch. Ährchen von ähnlichem Bau wie bei voriger Gattung; drei bis vier niedrige, krautige Arten in Westafrika, P. ciliata Franch. (vgl. S. 134 und 143, Fig. 107, P. Schumanniana Pilger).

\section{A. Litoralgråser.}

a) In Ostafrika.

In Ostafrika ist auf den offenen Flächen der sandigen Küste die verbreitetste Art Sporobolus virginicus Kth. (vgl. Fig. I05), der auf die Küstenzone beschränkt ist; das Gras bedeckt ganze Flächen des Strandes, häufig noch an Stellen, die von der Flut erreicht werden. Sporobolus virginicus, der auch an den süd- und westafrikanischen Küsten vorkommt, ist kosmopolitisch über alle wärmeren Länder verbreitet; an den Gestaden des Nittelmeeres und des Roten Meeres, wo er ebenfalls auftritt, sind mehrere einander nahe verwandte Arten von Acluropus von gleicher Bedeutung; das Gras perenniert mit kriechenden Rhizomen und bildet mehr oder weniger langgestreckte Ausläufer, die in einzelne oder büschelig 
verzweigte Halme ausgehen: die Blattspreiten, die wegen der verkürzten Internodien einander sehr genähert sind, sind derb und kurz, stechend und meist stark eingerollt; die dichte kurze Rispe ist ährenförmig.

Etwas weiter von der Grenze der Flut zurück tritt am Sandstrande besonders häufig auf Cinuolon dactylon (L.) Pers., mit dem I'aspalum distichum
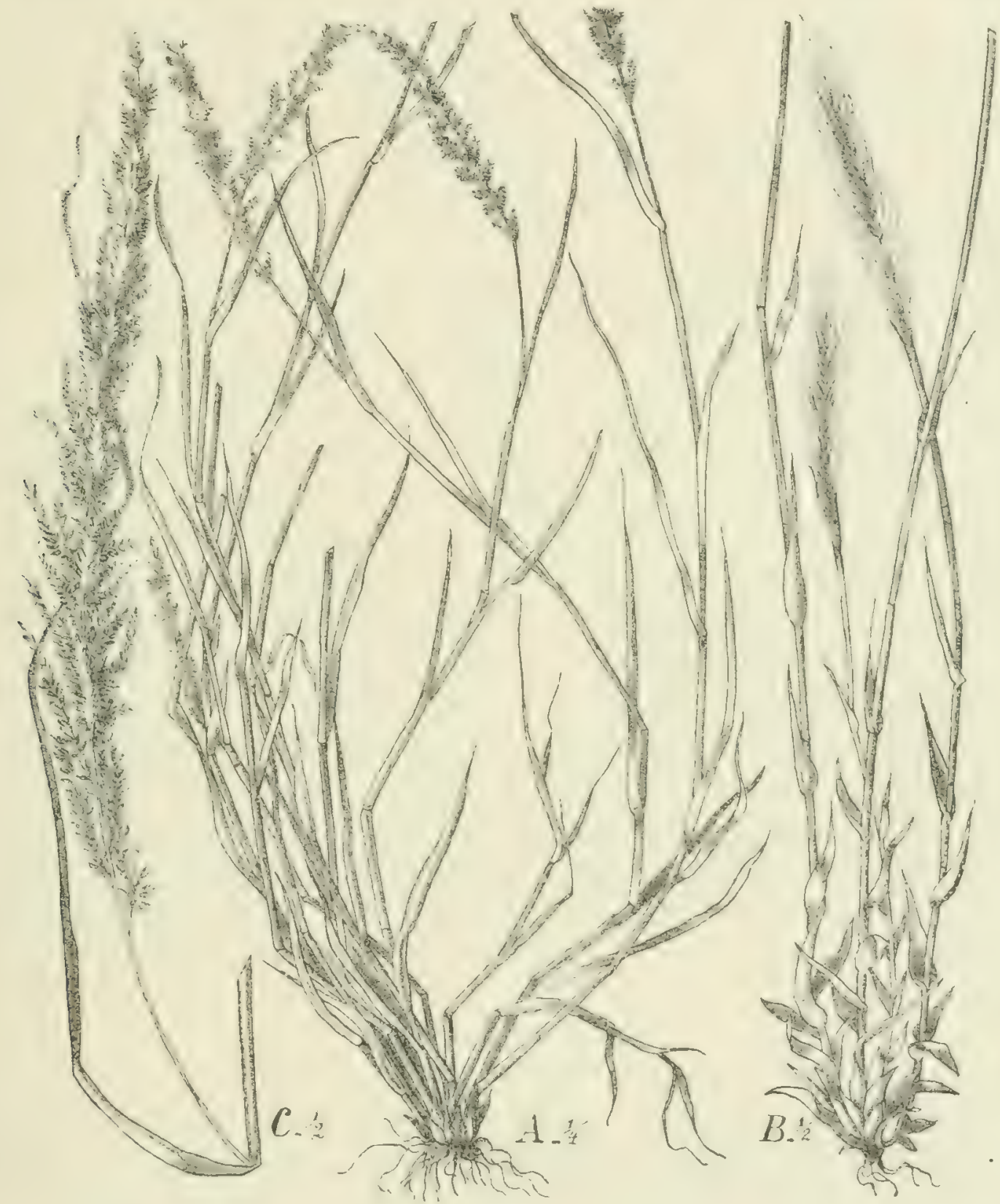

Fig. 106. A Eragrostis ciliaris (L.) Lk.; $B$ Perotis indica (L.) K. Schum.; C Sporobolus indicus (L.) R. Br. Verbreitete Ruderalgräser des Küstenlandes von Ostafrika.

Burm., eine in den Tropen der alten Welt weitverbreitete Art und das ostafrikanische Fonicum argyrotrichum Anderss. vergesellschaftet sind. Cymoton ist nicht auf die Küstenzone beschränlst, sondern auch im Inlande auf mancherlei Formationen anzutreffen; es ist cin recht vielgestaltiges Gras, das nicht nur in der Länge und Breite der Blätter stark variiert, sondern auch in der Ausgestaltung der Ausläufer und der niederliegenden Halme; die ausläuferartigen Sprosse sind dicht mit kurzen Schuppen bekleidet und gehen nach 
kürzerer oder längerer Zeit in aufsteigende, blïhende Halme über; oder aber die niederliegenden Sprosse haben längere Internodien, die mit normalen Scheiden bekieidet sind und Blätter tragen, die allmählich vergehen, so dal3 die Internodien frei werden; an den Knoten sind diese Sprosse häufig bewurzelt und treiben aufsteigende, bliiheride Äste, die mit der fingerförmig geteilten Rispe abschließen.

In dem sich an den Strand anschließenden Grasland der Creeks treten neben diesen Gräsern Arten auf, die auch sonst in Grasfluren des Inlandes verbreitet sind, wie Pirotis indica (L.) K. Schum. (vgl. Fig. ro6 B), Cenchrus cchinatus L., Eragrostis namaquensis Nees, Chloris myriostachy'a Hochst. Diese Formen werden später noch bei der Besprechung anderer Formationen zu bchandeln sein.

Für den Küstenbusch des Creellandes sind neben Tragus raccmosus (L.) All., einer kosmopolitischen Art, die ebenfalls in anderen Formationen wiederkehrt. zwei Formen besonders erwähnenswert, Interopogon monostachy'ss (Vahl) K. Schum. und Eragrostis Chapelieri (Kth.) Nees. Das erstere Gras ist in Ostafrika von Abyssinien, wo die Art in Bergen bis $1300 \mathrm{~m}$ ansteigt, bis Usambara verbreitet und kommt außerdem in Ostindien vor: die Halme sind verhältnismäßig schwach und lehnen sich hochsteigend an Sträucher an, ihre Internodien sind ziemlich gleichmäßig lang; häufig sind sie aus mehreren Knoten verzweigt und schließen mit einem ährenförmigen Bliitenstand $a b$; die offenen Blattspreiten sind schmal, dünn, biegsam, rauh, lang, nach der Spitze zu verschmälert; am Grunde der Halme finden sich nur wenige, meist extravaginale, aber aufrechte Neusprosse. Eragrostis Chapelicri ist in Ostafriki von Sansibar und Usambara bis Natal verbreitet; es ist cin kräftiges Gras mit $60-75 \mathrm{~cm}$ hohen Halmen, die nur I - 2 Knoten haben und mit schmal zusammengezogener Rispe abschließen; den Grund der Halme umgibt ein Rasen von intravaginalen Neusprossen mit sehr schmalen, unregelmäßig zusammengerollten und gedrehten Blättern: die Art entspricht also dem gewöhnlichen Typus von Steppengräsern.

b) In Westafrika.

An den sandigen Küsten Westafrikas tritt an die Stelle von Sporobolus zirginicus häufig Stenotaphram ancricanum Schrank; die Art ist an den Küsten Sülafrikas, sowie des tropischen Amerika weit verbreitet; sie hat ansteigende oder niederliegende, oft weithin kriechende Halme, die an den Knoten bewurzelt sind und aufrechte Äste erzeugen, die am Grunde von dicht gedrängten, fächerförmig gestellten Blättern umgeben sind: die kurzen Spreiten sind linealisch, stumpf, derb, meist längs der Mittellinie scharf gefaltet; die Ährchen sind in die breite Rhachis eines kurzen ährenförmigen Blütenstandes eingesenkt. In Kamerun und Togo ist am offenen Strande Sporobolus robustus Kth. häufig; der in Ostafrika ron Kordofan bis zum Kilinandscharogebiet nur im Inlande auf Steppenformationen anzutreffen ist. Der hohe kräftige Halm liegt am Grunde einc lange Strecke horizontal nieder; scine Internodien sind hier gleichmäßig kurz und die Scheiden werden von aufrechten Trieben durchbrochen; daneben 
kommen stolonenartige, kräftige, von starken Schuppen belleidete Neusprosse ror; der aufgerichtete Halm ist ganz von starken Scheiden bedeckt, die Blattspreiten sind lang, schmal linealisch, lang verschmälert, derb, offen, am Rande sehr rauh.

Für die Sanddünen der Küste des südwestlichen Afrika sind drei Arten charakteristisch: Aristicla sabulicala Pilger, Eragrostis spinose L. f., Trin. und F. cyperoides (Thunb.) P. Ieauv. Es muß bemerkt werden, daß alle drei Gräser nicht auf die Küstenzone beschränlt sind, sondern der Natur des Landes gemäß im Inneren Sanddünen finden, die dieselben V'egetationsbedingungen bieten. Aristida sabulicola kommt nur in Deutsch-Südwestafrika vor; die Art bildet niederliegende Halme mit teilweis nackten Internodien, deren umhïllende Scheiden gänzlich verschwunden sind; an den Kinoten brechen Büschel von kurzen, mit Blütenständen abschließenden Zweigen hervor, die von der Scheide umhiillt waren, die nun allmählich obliteriert und die Zweige frei werden läßt; daneben werden höhere Halme gebildet, die fest ron Scheiden umhüllt sind; die oberen Blätter überragen immer die Blïtenstände, ihre langen Spreiten sind starr, aufrecht, fast drehrund: der Blïtenstand und die ẗhrchen lassen zuerst nicht die Gattung vermuten; die Rispe ist schmal ährenförmig, bis $30 \mathrm{~cm}$ lang; besonders auffallend ist die Granne, die bis zur Verzweigungsstelle kaum I $\mathrm{mm}$ lang ist und deren Äste nur $7-9 \mathrm{~mm}$ an Länge erreichen.

Eragrostis cyperoides ist vom suidlichen Kapland bis Damaraland verbreitet, I: spinosa bis Klein-Namaland. Beides sind starke Sandgräser mit kriechenden Rhizomen und derben, zusammengerollten, stechenden Blättern; Li. spinosa ist durch die knotenlosen blühenden Halme und den eigentümlichen Blitenstand in der Gattung sehr ausgezeichnet; die Rispe endet nämlich ebenso wie die abspreizenden, starren Seitenäste in eine kräftige Stachelspitze; die Ährchen sind an den Zweigen einzeln zerstreut; das starre, stachelige Geriist des Blütenstandes bleibt nach dem Abfall der Ährchen bestehen und läßt seine morphologische Bedeutung nicht mehr vermuten.

\section{B. Gräser der hygrophilen Formationen (Hygrophyten).}

1. In unteren und oberen immergrünen Regenwald.

a) In Westafrika.

In der schattenreichen Formation des immergrinen Regenwaldes ist naturgemäß die Grasvegetation nur spärlich entwickelt und ron besonderem Typus; die meisten Arten berorzugen auch hier die Lichtungen oder etwas schwächer beschatteten Stellen. Von ganz besonderem Interesse sind für Westafrika einige Zwergbambuseen, die sonst nirgends wieder im tropischen Afrika auftreten und auch keinen näheren Anschluß an Arten anderer Formationen zeigen. Sie grehören zu den endemischen Gattungen Iuclia, Guaduclla und Häroralannus. Alle Arten haben perennierende Rhizome und krautige Halne, die bis $70 \mathrm{~cm}$, oft nur bis $30-40 \mathrm{~cm}$ hoch sind; die Blätter sind breit und offen, ihre parallelen Nerven werden, wie so oft bei Schattengräsern, durch sehr kurze Transversalvenen gestiitzt ( folia tesselata $\%$. Ton Ciucduclli sind dru 


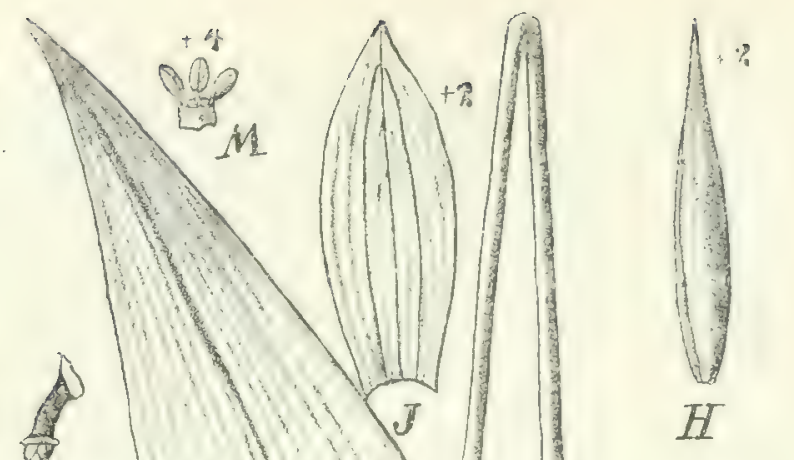

Arten bekannt, die von Kamerun bis zum unteren Kongo reichen; $G$. densiflora Pilger wächst in Kamerun nicht selten auf feuchtem tiefschattigen Waldboden bei Batanga, G. Zenkeri Pilger im Urwald bei Bipindi. Der Halm von $G$. marantifolia Franch. entwickelt meist nur ein großes Blatt, den unteren Teil umgeben mehrere blattlose Scheiden; bei G. Zenkeri trägt der bis $50 \mathrm{~cm}$ hohe Halm mehrere oval-lanzettliche bis $20 \mathrm{~cm}$ lange, kurz gestielte Blätter; der Blütenstand ist traubig, kurz und armblütig. $G$. densiflora zeigt die Eigentümlichkeit, daß sterile und fertile Halme getrennt sind; der fertile Halm ist von blattlosen Scheiden bedeckt und endigt in einen kurzen, dicht-traubigenBlütenstand.

Von Puelia kommen drei bis vier Arten von ähnlichem Habitus in Gabun und Kamerun vor; bei $P$. Schmmaniana Pilger (vgl. Fig. 107), die im Unterholz des Urwaldes bei Bipindi gefunden wurde, sind wiederum fertile und sterile Halme getrennt; $P$. subsessilis Pilger bevorzugt lichtere Stellen im dortigen Urwalde. Microcalamus barbinodis Franch. kommt am unteren Kongo vor, anscheinend dieselbe Art auch

im Unterholz des Urwaldes

Fig. roy. Puelia Schumanniana Pilger. A fertiler Halm; $B$ steriler Halm; $C$ Deck- und Vorspelze aus dem unteren Teil des Ahrchens mit männlicher Blüte; $D, E$ Vorspelze dieser Blite von außen und von innen; $F$ Staubblattröhre vor der definitiven Verlängerung; $G$ Anthere; $H$ Spitze des Ährchens mit zusammengerollter Deckspelze und Vorspelze der weiblichen Blüte; 7 Deckspelze; $K$ Vorspelze der weiblichen Endblite; $L$ Griffel mit 3 Narben; $M$ die 3 Staminodien der weibl. Blite. 
bei Bipindi; die niedrigen krautigen Halme tragen am Grunde mehrere Schuppen, dann gewöhnlich nur ein großes, schmal ovales, nach der Basis und Spitze lang verschmälertes dünnes Laubblatt; der Halm endigt in einen schmalen, langgestreckten Bliitenstand.

Verwandtschaftlich schließt sich von diesen bisher nur aus so beschränktem Verbreitungsgebiet bekannten Gattungen Puelic im Bliitenbau an Orytencmthore an. Wie bei dieser Gattung sind die Staubblätter in eine Röhre verwachsen und nur die oberste Bliite ist fruchtbar; von Ostafrika, wo für Oxytenanthera der Anschluß an das indische Verbreitungsgebiet liegt, ist aber bisher keine I'uclic bekannt geworden. Guaduclla zeigt entferntere Verwandtschaft zu Bambusa, da sechs freie Staubblätter vorhanden sind, Aficrocalamus zu Arundinaria (?), doch ist hier kaum an bestimmte genetische Beziehungen zu denken.

Als Urwaldgras tritt ferner in Westafrika die charakteristische Streptogym crinito Link auf (vgl. Fig. I08 I; ; bei der die ausgefallenen Fruchtspelzen durch die spiraligen, langen, verflochtenen Griffel und Narben zusammenhalten. Sie ist von Sierra Leone bis in das obere Kongogebiet (Nukenge) verbreitet. Sonst kommt sie in Vorderindicn und Ceylon, sowie im tropischen Amerika vor. Sie bevorzugt wohl etwas lichtere Stellen, Wege im Urwalde usw. Habituell gleicht sie in vielen Beziehungen den oben erwähnten Bambuseen. Am Grunde der Halme brechen Ausläufer hervor, die dïn und dicht mit schuppenartigen, blattlosen Scheiden besetzt sind; diese kriimmen sich dann aufwärts und geben einem neuen beblätterten Halme den Ursprung; am Grunde der Halme und an den Ausläufern finden sich derbe, wenig verzweigte IVurzeln; die langen Blätter sind lanzettlich, lang verschmälert, von derber Konsistenz, mit kurzen Quernerven; der Blütenstand ist schmal ährenförmig.

Weiter sind als hochwüchsige Urwaldgräser in Westafrika bemerkenswert I'anicum sulcatum Aubl., Lepterspis conchifora Hack., Olyra latifolia L. (Fig. 109) und Centotheca lappacea Desv. (Fig. Io8 A-D). Olyra latifolia L., die im tropischen Afrika weit verbreitet ist und in Ostafrika bis Zululand reicht, hat alle ihre Verwandten im tropischen Amcrika, wo ungefähr 20 Arten vorkommen. Die Art scheint recht verschiedenen Bedingungen des Standortes in bezug auf Belichtung und Feuchtigkeit zu genügen, was sich besonders in ihrem Auftreten in Ostafrika zeigt. Im Schatten feuchteren Lrwaldes klimmen die Halme zwischen Bäumen und Sträuchern und können so bis 5-6 m Länge erreichen, an weniger schattigen Stellen, an lichten Rändern des Waldes sind die Halme ungefähr meterhoch, straff aufrecht. Olyra gehört zu den Paniccae als atypische Gattung, hat aber vollständig Bambuseenhabitus; die Blätter sind breit und groß, an der Basis abgerundet, kurz gestielt, dün, biegsam, mit zahlreichen Längsnerven.

Im Gegensatz zu Olyre ist I.tptaspis von rein paläotropischer Verbreitung; drei Arten gehen von Vorderindien durch das tropische Asien bis Australien; in Afrika tritt nur I. conchifere Hack. auf, die in Westafrika in feuchten Regenwäldern von Sierra Lcone bis zum oberen Kongogebiet reicht, in Ostafrika bisher nur im Seengebiet aufgefunden wurde. Leptaspis conchifira besitzt schr 


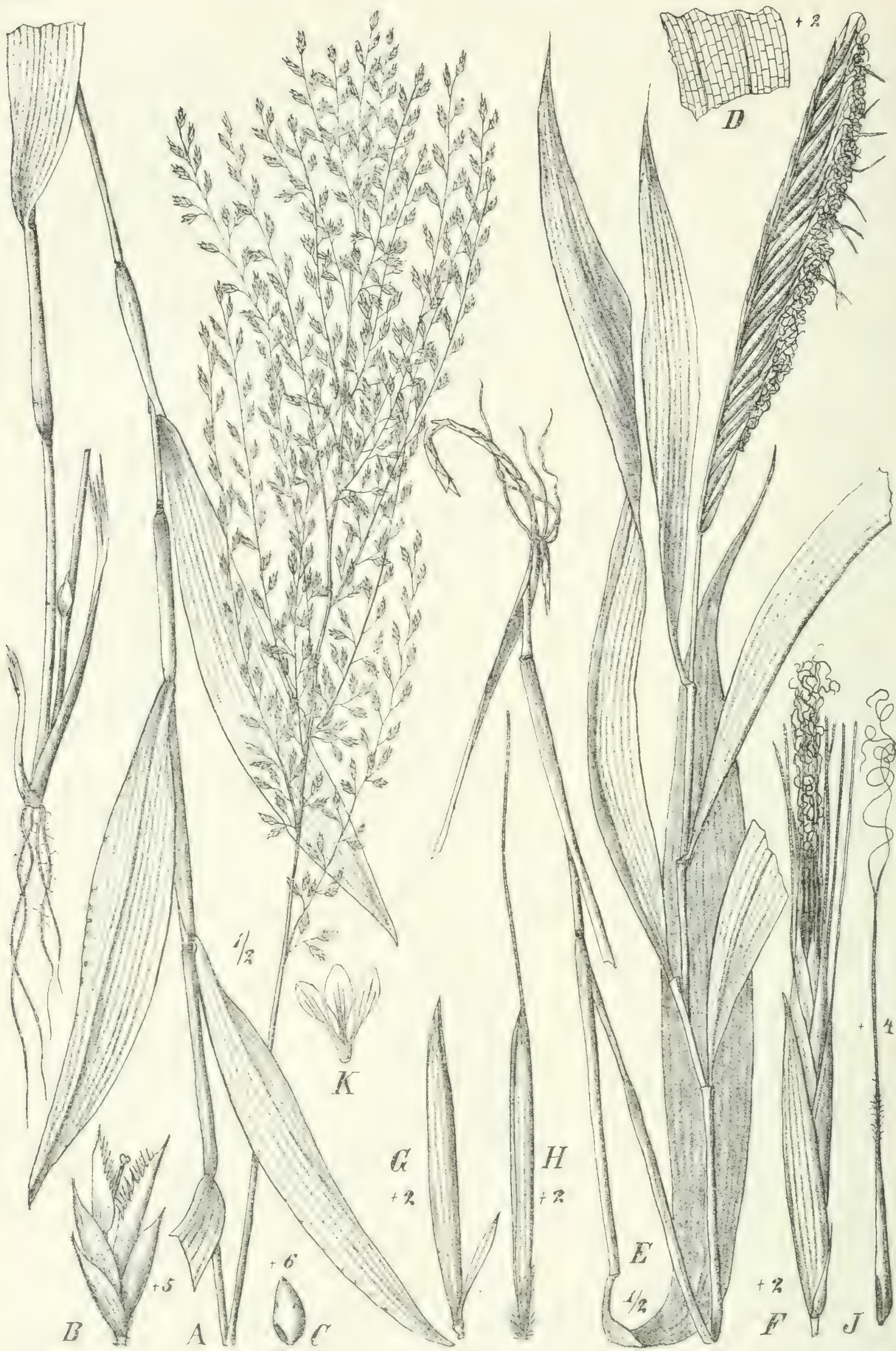

Fig. 108. $A-D$ Centotheca lappacea Desv. $A$ Habitus; $B$ Ährchen; $C$ Frucht; $D$ Teil des Blattes; $E-\mathcal{F}$ Streptogyne crinita Link; $E$ Habitus; $F$ Ährchen; $G$ die beiden Hüllspelzen; $H$ Deckspelze; f Frucht und Griffel. 
breite Blätter mit Quernerven; die Ährchen der großen, sparrig verzweigten Rispen sind wie bei Olyra eingeschlechtlich, im unteren Teil der Rispe männlich, im oberen weiblich.

Lichtere Stellen des unteren Urwaldes, besonders Wegränder und weniger feuchte Stellen bevorzugt Centotheca lappacea Desv. (vgl. Fig. $108 A-D)$, die von Sierra Leone bis zum unteren Kongo auftritt; sonst ist die Art im tropischen Asien weit verbreitet, ist aber bisher aus Ostafrika noch nicht bekannt. Die aus dem Wurzelstock zu mehreren hervorkommenden Halme sind $60-80 \mathrm{~cm}$ hoch, mit ziemlich gleichmäßigen, kurzen Internodien; die Blattspreiten sind oval, lang zugespitzt, nach dem Grunde $\mathrm{zu}$ wenig verschmälert, abgerundet und mehr oder weniger stengelumfassend; die hervortretenden Parallelnerven sind durch kurze Quernerven verbunden.

An ähnlichen Plätzen wie die vorige tritt häufig Panicum sulcatum Aubl. auf, das aber auch in dichten Urwäldern gefunden wird, ein prachtvolles Gras, dessen Halme bis $3 \mathrm{~m}$ Höhe erreichen. Es ist im tropischen Ost- und Westafrika weitverbreitet und bewohnt verschiedene Formationen; aus Südafrika ist es von Natal und Pondoland bekannt, sonst aus dem tropischen Amerika.

Von niedriger wachsenden, zarteren Gräsern des Urwaldes kommen für Westafrika besonders Isachne Biittneri Hack., Oplismenus hivtellus (L.) $\mathrm{R}$. et Sch. subsp. loliacens (P. Beauv.) und Oplismenus Burmannii P. Beauv. in Betracht. Sie gedeihen vorzugsweise in etwas höheren Lagen des Urwaldes an nicht $z u$ feuchten und schattigen Stellen und gehen auch auf offene Lichtungen über. Isachne Buittneri ist nur aus dem Kamerun- und Gabun-

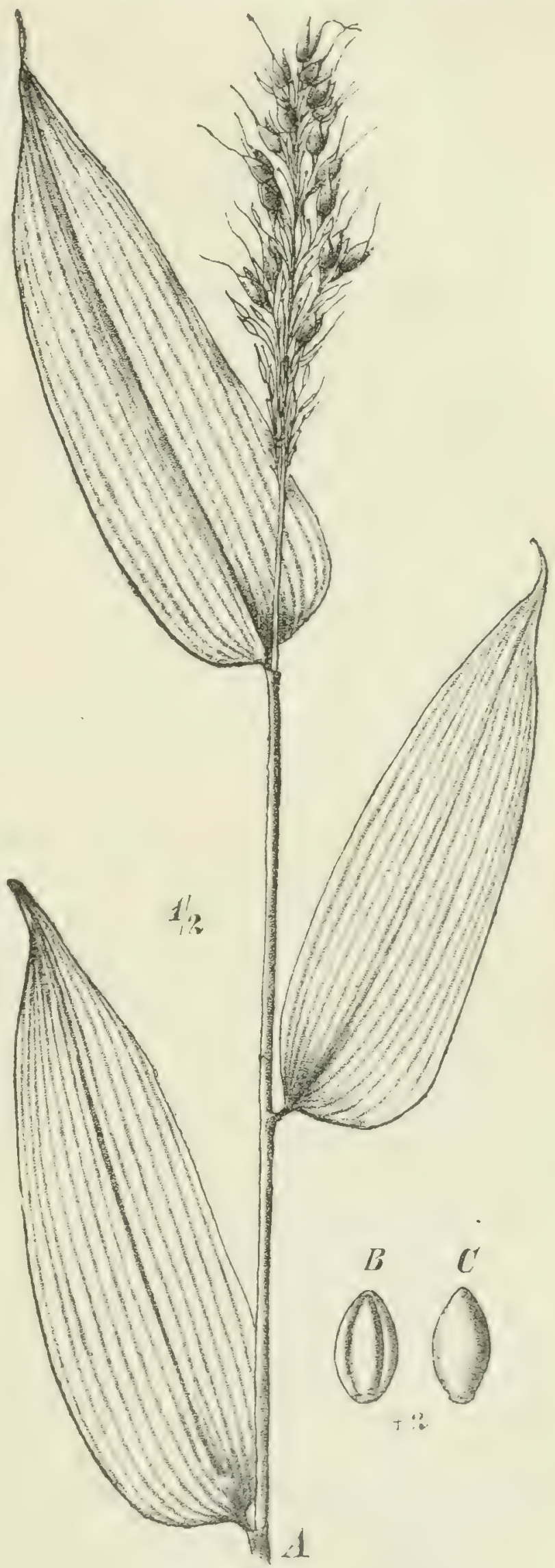

Fig. Io9. Olyra latifolia L. A Habitus; $B, C$ Verhärtete Deck- und Vorspelze. 
gebiet bekannt, ist aber mit der weitverbreiteten Isache albens Trin. nahe rerwandt. Der zarte Halm ist im unteren Teil niederliegend und kriechend, mit zicmlich kurzen Internodien. deren untere von Scheiden gänzlich entblößt sind; auch die Internodien im oberen aufgerichteten Teil des Halmes sind von ziemlich gleichmäßiger Länge; die Kispe ist verhälenismäßig groß mit zarten weitausspreizenden. İsten und kicinen, kugeligen Ihrchen: die Blattspreiten, bis $\mathrm{I}^{\mathrm{I}} / 2 \mathrm{~cm}$ breit, sind offen, diunn, fest und biegsam, mit gleichmäßig hervortretenden zarten Nerven: die unteren Spreiten hleiben im rertrockneten Zustand fest am Halme sitzen. In viclen dieser charakteristischen Merkmale gleichen die beiden urwähnten Oplismmus-Arten der Isuche Buthur, besonders auch in der Blattform. Die dünnen Halme sind niederliegend, die Internodien im unteren Teil frei oder mit vertrockncten Scheiden umgeben, aus den Knoten mehr oder weniger verzweigt und bewurzelt. Die Wurzeln treten aber nicht in Büscheln hervor, sondern einzeln, bis zu $20 \mathrm{~cm}$ lang, mit sehr spärlichen kurzen Seitenwurzeln. O. hirtellus ist die kräftigere Art, O. Burmanini ist noch schlaffer, mit vielgeknieten Halmen.

0 . hirtellus ist in den Tropen der alten und neuen Weit weit verbreitet, desgleichen im siidlichen und östlichen Kapland; die Art wächst in Kamerun im Urwaldschatten, besonders aber an lichteren Stellen bei foo-90o m Höhe; an solchen Standorten kann sie ganze Flächen ausschließlich bedecken, was durch die reiche Verzweigung und Neubildung von Halmen aus den niederliegenden Halmen leicht ermöglicht wird.

\section{b) In Ostafrika.}

Im unteren feuchten Gebirgsregenwald Ostafrikas, wie er z. B. in prachtvoller Ausbildung in L'sambara gedeiht. ist die Gramineenvegetation ziemlich arm; besonders wird erwähnt Cplisminms compositus $\mathrm{P}$. Beaur. var. silications $\mathrm{R}$. et Sch., der im Urwaldschatten und an Bachuforn wächst, aber doch auch die Lichtungen bevorzugt, wo er ausgedehnte Flächen bedeckt. Die Varietät gleicht dem (T. hirttlls im Habitus und hommt sonst noch auf Madagashar, Mauritius und den Comoren vor.

Etwas mehr entwickelt ist dann die Grasflora in oberen Lagen des Regenwalles. IHer sind fuir L'sambara folgende Arten bemerkenswert: (). hirtillu, L. R. et Sch. subsp. Loliacens P. Beauv., Isachne albens Trin., Panicum sulcatum Aubl., Olyra latifolia L., Pennisctum trachyplyyllnm Pilger; mit Ausnahme der letzten Art sind diese Gräser schon für den westafrikanischen Tropenwald charakterisiert worden. I'. Whiththllm ist bisher gefunden worden in Usambara und im westlichen Uluguru, in einer Höhe von rooo- $400 \mathrm{~m}$; am Süd-Meru tritt es auch in Blößen des Nebelwaldes noch bei $2000 \mathrm{~m}$ Höhe auf. Auch an den anderen Standorten bevorzugt es die Lichtungen und wird dort, in Gesellschaft von Panicun sulcatum usw., bis $2^{\mathrm{I}} / 2 \mathrm{~m}$ hoch; die Halme sind reich rerzweigt, dic offenen, dünnen, lanzettlichen Blattspreiten sind bis $25 \mathrm{~cm}$ lang und nach der Basis zu bis $2 \mathrm{~cm}$ breit.

Die unteren Gebirgsregenwailder des Secngebietes Zentralafrikas be- 
sonders vom Victoriasee bekannt) beherbergen einige formen von speziell westafrikanischem Anschluß, die weiter nach Osten nicht rorkommen. Teben einigen Panicum-Arten, wie P. Stuhlmamiii K. Schum, und P. platmotum K. Schum., die als Waldgräser ansteigende Halme und offene, ziemlich breite Blattspreiten haben, finden sich nämlich hier noch Leptaspis conichifora Hack. und Urelytrum digitatum $\mathrm{K}$. Schum. Erste Art ist bei der Betrachtung des westafrikanischen Urwaldes schon erwähnt worden: von der Gattung I relytrum sind noch drei Arten bekannt, $T$. agrepprocides Hack. in Angola, I. squarrosum Hack. in Transvaal, Oranje-Freistaat und Betschuanaland, I. sigremteum Pilger im oberen Kongogebiet. I. digitutum hat bis über meterhohe Halme mit kurzen Blättern, die Ährchen sind in sparrige Ähren angeordnet.

\section{Im Nebelwald oder Höhenwald.}

Aus dem Höhenwald Usambaras ist neben Oly're lattefolin. die auch hier wieder auftritt, besonders zu erwähnen Festuca Englori Pilger, die oberhalb Kwai bei $2400-2600 \mathrm{~m}$ gefunden wurde. Die charakteristische Art, die im tropischen Afrika keine näheren Verwandten hat, erimnert in ihrer Tracht sehr an Festuca gigantea Vill,; sie perenniert mit einem kurzen, dicken Rhizom, das mehrere bis $\mathrm{I}_{2} / 2 \mathrm{~m}$ hohe Halme hervorbringt; die bis $40 \mathrm{~cm}$ langen Blattspreiten sind dunkelgrün, linealisch, offen, mit starkem Nittelncrv, die Rispe ist lang, armblütig und trägt lange, abstehende $Z_{\text {weige. }}$

Besser bekannt ist die Gramineenflora des Höhenwaldes am Kilimandscharo. die cine Anzahl sehr bemerkenswerter Typen enthält, unter ihnen Acritochactc Folkensiz Pilger, IEhharta aby'ssinica Hochst., I'sculobronus siliaticus K. Schum., I'or leptoclata Hochst. - Ehrharta abj'ssiniar ist vielleicht nicht spezifisch von der im östlichen Südafrika vorkommenden E. fanicar Sm. verschieden, jedenfalls ihr nahe verwandt. Letztere Art tritt noch in verschiedenen Tropengegenden der alten Wrelt auf, wo sie aber wohl eingeschleppt ist, sonst ist die scharf definierte Phalarideengattung auf Südafrika beschränkt und dort im ganzen Gebiet mit 25 Arten reich entwickelt. In Ostafrika finclet sich $E$. aby'ssinica in Abyssinien auf Bergen bei $2500 \mathrm{~m}$, in Usambara an schattigen Stellen des oberen Buschwaldes bei $1600 \mathrm{~m}$, in Hochwald des Kilimandscharo bei $2700-2800 \mathrm{~m}$ und wächst dort einzeln zwischen anderen Gräsern zerstreut oder bildet größere Gruppen. Die Pflanze hat ein lockeres Gefüge, die diinnen Halme sind in unteren Teil niederliegend oder ansteigend, seltener mehr oder weniger aufrecht, mit kurzen gleichmäßigen Internodien, hier und da aus den Knoten verzweigt; die Blattspreiten sind offen, diinnhäutig und biegsam, schmal, linealisch, bis über $20 \mathrm{~cm}$ lang, kahl und schwach rauh.

Nicht unähnlich ist ihr im Wachstum Acritochacte Volkcnsii, der Vertreter einer endemischen Panicengattung, die bisher nur in Gürtelwalde des Kilimandscharo bei $2100 \mathrm{~m}$ gefunden wurde; die dünnen Halme der Art sind nicderliegend, im unteren Teil mit kurzen Internodien; an den Ǩnoten werden öfters Wurzeln entwickelt und fast aus allen Knoten brechen aufrechte, zarte, blühende Halme hervor, deren kleine Blätter offen, lanzettlich, dünn und bieg- 
sam sind: die Rispe ist aus zwei bis drei küzeren Trauben mit einseitig stehenden Ährchen zusammengesetzt.

Nur ostafrikanisch ist ferner die Gattung Psendobromus K. Schum., von der eine Art, P. siliaticus K. Schum. am Kilimandscharo und in Bergwäldern von Uluguru bei $2100 \mathrm{~m}$ vorkommt, die andere, $P$. africanus Stapf in Transvaal bei Houtbosch; HACKEL wollte die Gattung zu Brachyelytrum (tropischamerikanisch) ziehen, doch liegt ihre Verwandtschaft wohl eher bei Festuce; großen Festuca-Arten wie F. gigantia Vill. gleichen die Formen im Habitus auffallend. Am Kilimandscharo ist I'. siliaticus besonders bei ungefähr $2100 \mathrm{~m}$ Höhe überall im Bergwalde verbreitet und tritt in isolierten Stöcken auf; der Halm ist über meterhoch, die Blätter sind breit und offen, die Rispe locker ausgebreitet und vielblititig.

Von niedrigeren Formen finden sich im Gürtelwald noch Isachne mauritiena Kth., Danthonia ilongata Hochst., sowie an der oberen Waldgrenze in Lichtungen aus der Hochsteppe eingedrungen Tricholaena Tencriffae L. f.) Parl.

Die Gramineenflora der Hochwälder anderer Gebirge Ostafrikas ist sehr wenig bekannt, vom Runssorogebirge wurde der hochwiichsige Bromus mussorensis K. Schum., vom Milanjigebirge Bromus milandjianus Rendle und Festuca milandjiana Rendle beschrieben.

\section{Im Bambuswald der Gebirge.}

In Ostafrika ist vom südlichen Abyssinien an bis zum Kondeland die herrschende Art im Bambusdickicht oberhalb des Regenwaldes Armatinaria alpina K. Schum. (vgl. Fig. r Ioi. Für den Meru liegt die Bambuszone nach UHLIG in einer Höhe von $2200-2800 \mathrm{~m}$; ebenso tritt die Art z. B. massenhaft an den Ulugurubergen beim Übergang des Regenwaldes in Höhenwald, von $2100-2600 \mathrm{~m}$ auf. Sie bildet hier armstarke, bis 8-10 $\mathrm{m}$ hohe Stämme. Nach Norden reicht sie bis zum Gallahochland, wo sie um $2900 \mathrm{~m}$ ausgedehnte Bestände bildet.

Die uibrigen bisher aus dem tropischen Ostafrika bekannt gewordenen Formen, die ich hicr im Zusammenhange erwähnen will, kommen für den Gebirgswald meist nicht in Betracht, sondern stammen aus tieferen Regionen. Bemerkenswert ist zunächst eine in Ostafrika endemische Gattung, Oreobambos Bucharaliz K. Schum.; die Art kommt sowohl im Walde des Handeigebirges in Usambara wie auch bei Amani in einer Höhe von $500 \mathrm{~m}$ vor; ihre Stämme erreichen eine Länge von $20 \mathrm{~m}$. Am weitesten verbreitet ist Oxytenanthera abyssinica (A. Rich.) Benth. (vgl. Fig. I I A, B). Sie bildet in Abyssinien an trocknen Berghängen Bestände; im Ghasalquellengebiet ist sie von ScInWEINFCRTII gesammelt worden; im Nakondeland bildet sie im Unterlande auf lehmigem Boden lichte Haine; zugleich ist sie dic einzige bisher aus Westafrika bekannte wildwachsende höhere Bambusee, wo sie in Togo in felsigen Gegenden bei joo m Höhe rorkommt; in Angola tritt sie nach REx́dLE massenhaft in Flußwäldern auf. Die Höhe der Stämme wird für diese Gegend bis auf $10-13 \mathrm{~m}$ angegeben; in Ostafrika gehört die Form zu den niedrigeren 


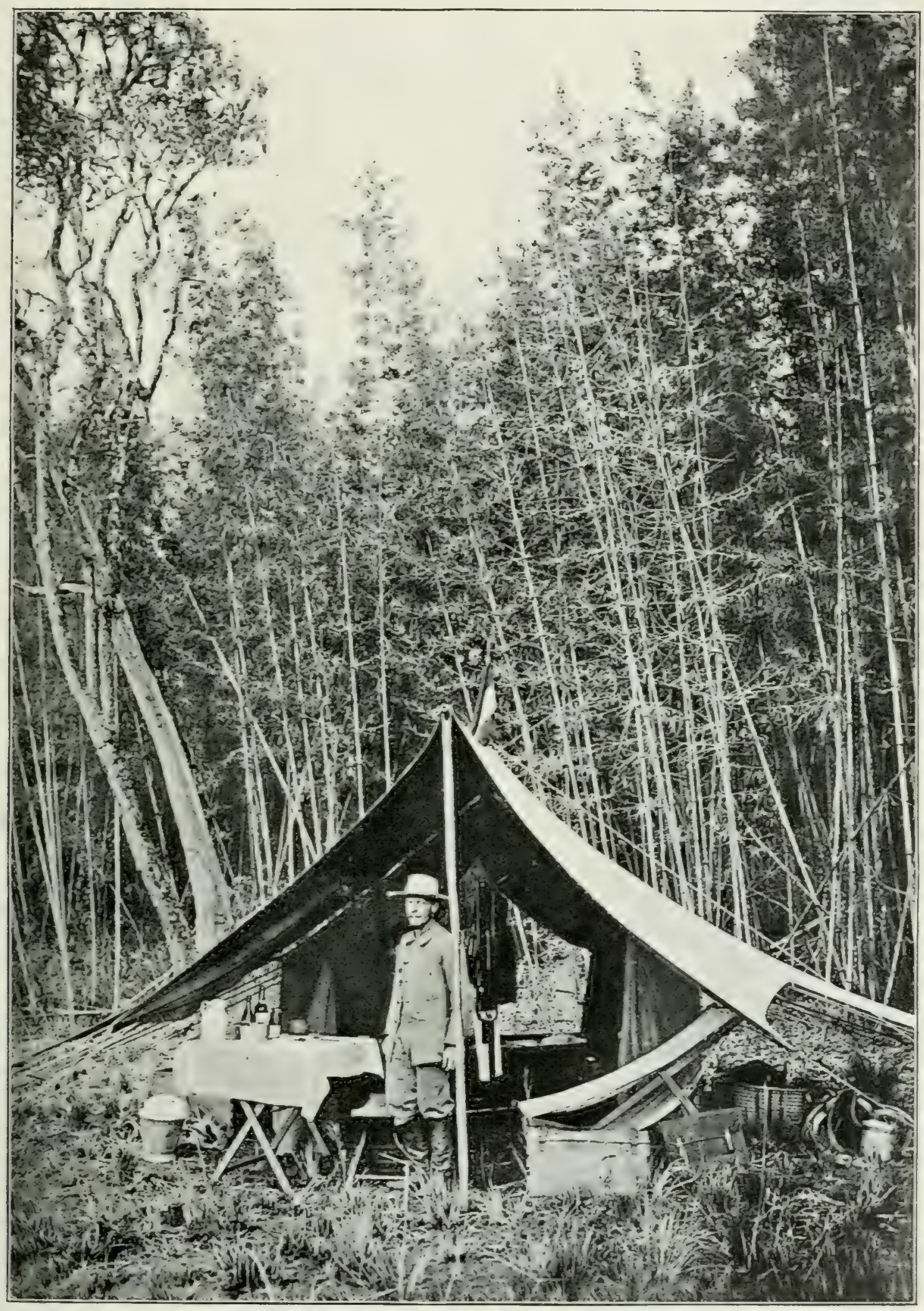

Arundinaria alpina K. Schum. (Bergbambus).

Bambusregion auf dem Hochplateau des Kingagebirges, um $2000 \mathrm{~m}$ ü. d. M. Nach einer Photographie von Walter Goetze (I899). 



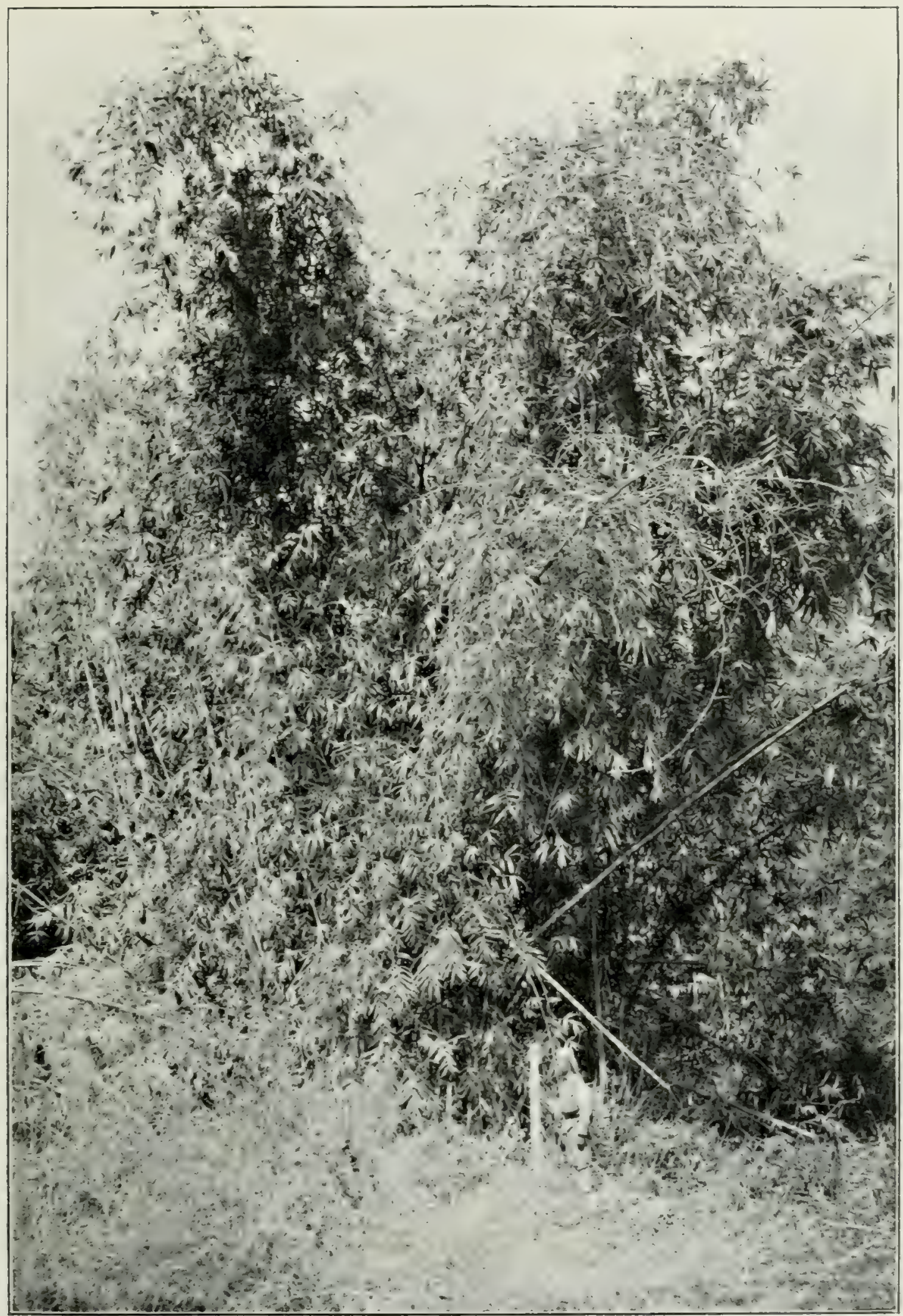

Oxytenanthera abyssinica (Hochst.) Munro.

Bambusbestand im unteren Makondeland.

Nach einer Photographie von Prof. Dr. Fülleborn (I 899 ). 



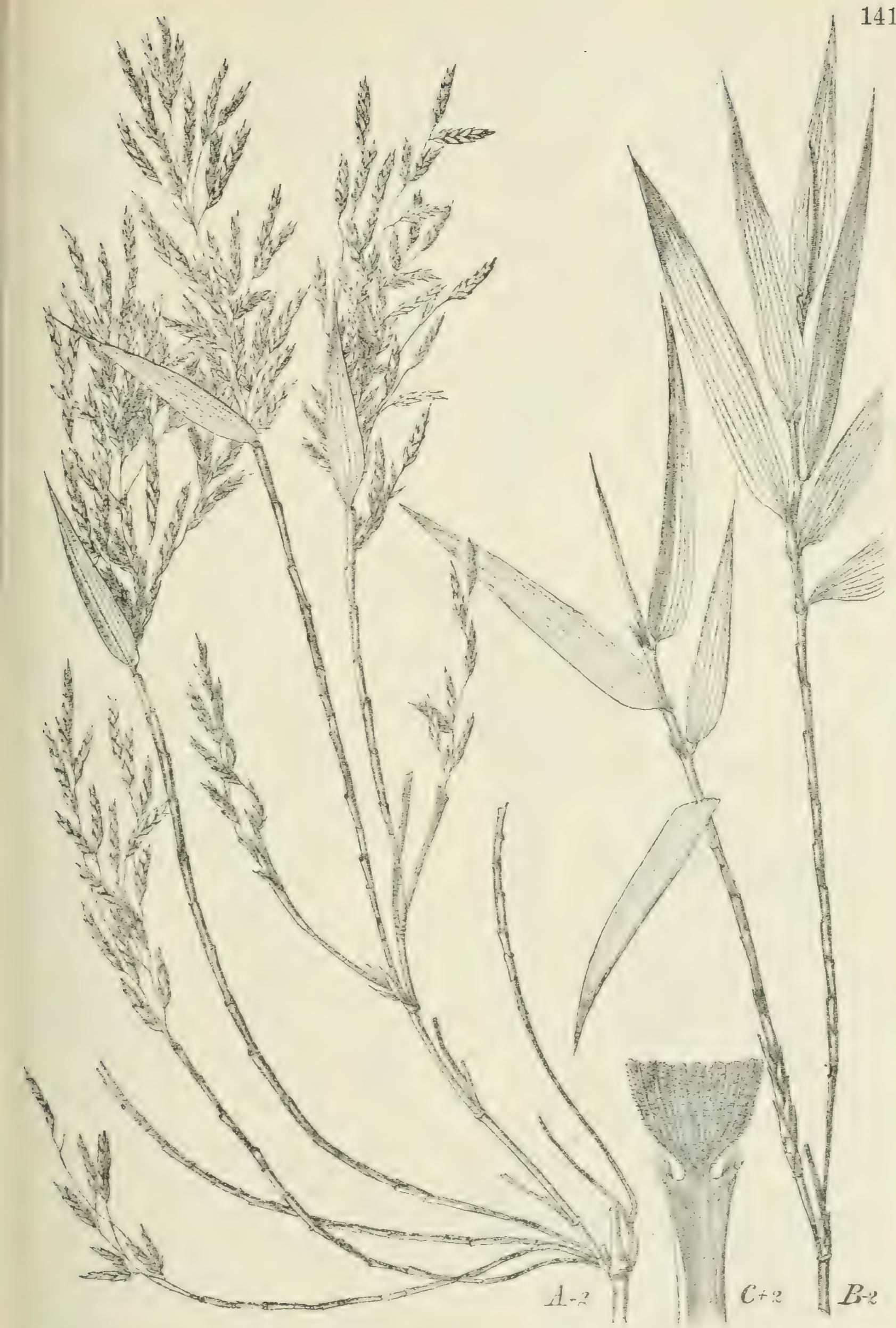

Fig. I1o. Arundinaria alpina K. Schum. $A$ fertiler Zweig; $B$ steriler Zweig; $C$ Spitze der Scheide und Basis der Spreite. 


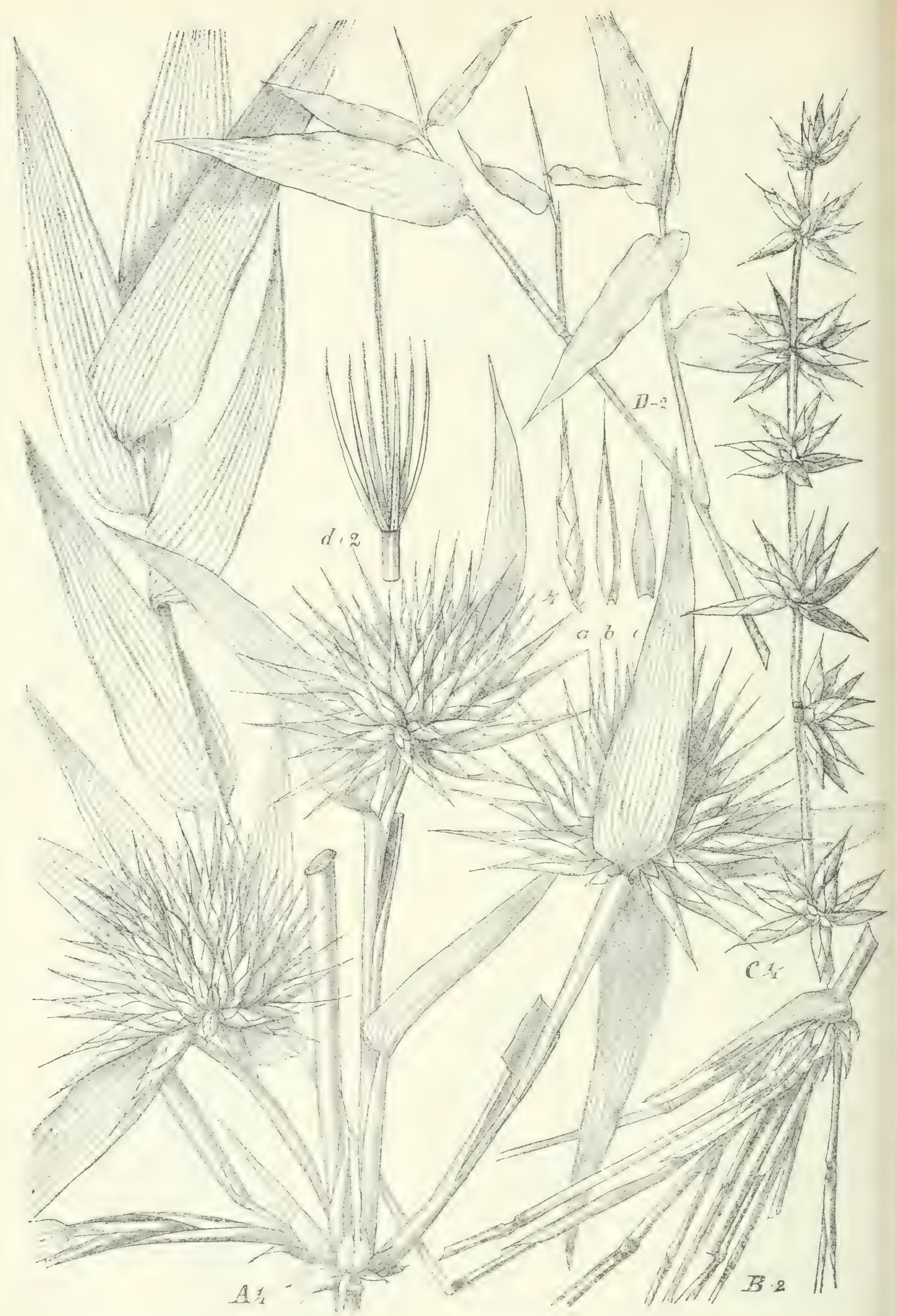

Fig. II I. A, B Oxytenanthera abyssinica (A. Rich.) Benth. $A$ blihhender, $B$ steriler Zweig, $a$ Ährchen, $b, c$ Deck- und Vorspelze der \&\& Blüte. $d$ junge Staubblattröhre und Griffel. $C, D$ O. macrothyrsus $\mathrm{K}$. Schum. $C$ fertiler, $D$ steriler $Z$ weig. 
Bambuseen, deren Höhe 6-8 m nicht übersteigt. Die Gattung besitzt in Ostafrika noch zwei weitere Arten, O. Bramaii Pilger, bisher nur im Irassaland aufgefunden, und (). marothyrsus K. Schum. (rgl. Fig. I I $C, D$. die im Buschland der küstennahen Gegenden in Lsambara und Maknnde Keinere Bestände bildet. Diese Bambuseen werden in Ostafrilia in mannigfacher Weise benutzt. zum Hausbau usw: und werden deshalb durch Stecklinge angebaut. Dic Samen von 0 . aby'ssinica werden gegessen, die Art wird in Makonde von den Eingeborenen als mbunga (Reis' bezcichnet: die hochwiichsigere Art C. mure thyosus (mjanzil findet nur zu Bauten Terwendung. Das Vorkommen von mehreren Orythanthera-Arten weist auf die Verwandtschaft mit der indischen Flora hin: aus Indien und Burma sind noch ungefähr zehn . Irten bekannt. Anmdinaria ist in dieser Beziehung indifferent, da die Gattung mit vielen Arten in den Tropen beider Weltteile auftritt.

\section{Gräser der hydrophilen Formationen.}

I. Im Wald auf Alluvialboden und baumlosem Alluvialland.

Im westlichen tropischen Afrika ist reicher Urwald nicht nur an den Hängen der Gebirge, sondern auch in den Gebieten der gewaltigen Ströme und ihrer Zuflüse entwickelt; die Gramineenflora ist im schattigen Walde selbst nur schwach vertreten, viel reicher in Lichtungen, auf feuchteren Sandbänken. sumpfigen IViesenstrecken und in den Sumpfgeländen, die lange anhaltenden, regelmäßig wiederkehrenden Überschwemmungen ausgesetzt sind.

Eine Reihe der Formen. die im Lferwald an großen Strümen. z. B. am Kongo heimisch sind, finden sich auch im Regenwald Kameruns wieder. besonders die interessanten Zwergbambuseen. deren Betrachtung bei cer Besprechung jener Formation ihren Platz gefunden hat. Weiter nödlich. im Gebiete des Niger, sind diese Bambuseen bisher nicht aufgefunden worden, doch liegt dazu die Möglichkeit ror: die rom Kongo bekannten Arten sind: Micrumlamus barbinotis Franch., India iltiater Franch.. Guduluella marantifolia Franch. und Atractocarpa olyriformis Franch. Ihnen schließen sich von wichtigeren Waldgräsern an Isachne Büllncri Hack., Panicum ovalifolium Poir., P. uncinatum Raddi, Leptochloa uniftura Hochst. Ton Gramineen. die reichlich an baumlosen feuchten Sandstrecken an den Kongoufern auftreten. sind zu erwïhnen Imfirator

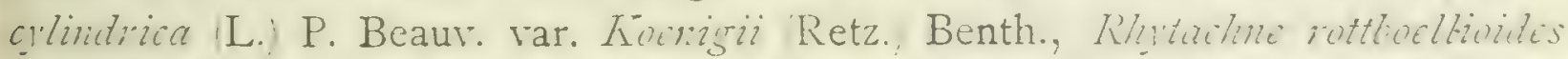
Desv. auch in Angola und am Niger', Nhtirinc congensis Hack., thimpogon Gugamus Kth. in der trpischen Form ron Angola bis Senegambien. - 1.

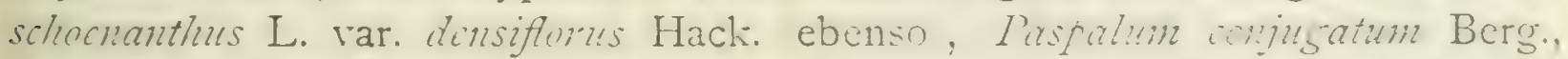

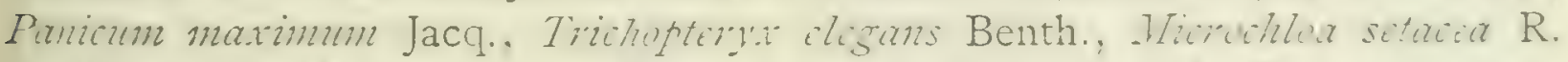
Br. (tropisch). Mehrere dieser Arten gehen auch auf ähnliche Formationen in der Nähe der Fliisse weiter südlich nach Angola iber. Im dichteren Walde der Flußränder finden wir hier Kottbocllic cuatuta L. f., ein kräftiges hochwüchsiges, I-2 $\mathrm{m}$ hohes Gras, das besoncers an den Rändern der ITälder auftritt, Andropogon cailis Hochst. var. slabivs ws Rencle, mit meterhohen Halmen, A. hirtifloms $\mathrm{Kth}$., A. mutans $\mathrm{L}$. var. angolensis Rendle, A. squarrosus L., mit 
$2-2^{\mathrm{T}} l_{2} \mathrm{~m}$ hohen, kräftigen Halmen, Paspalum paniculatun Gärtn., Fanicum orimoides $\mathrm{Sw}$., mit $2-2^{\mathrm{y}} \mathrm{l}_{2} \mathrm{~m}$ hohen kletternden Halmen und Luftwurzeln an den

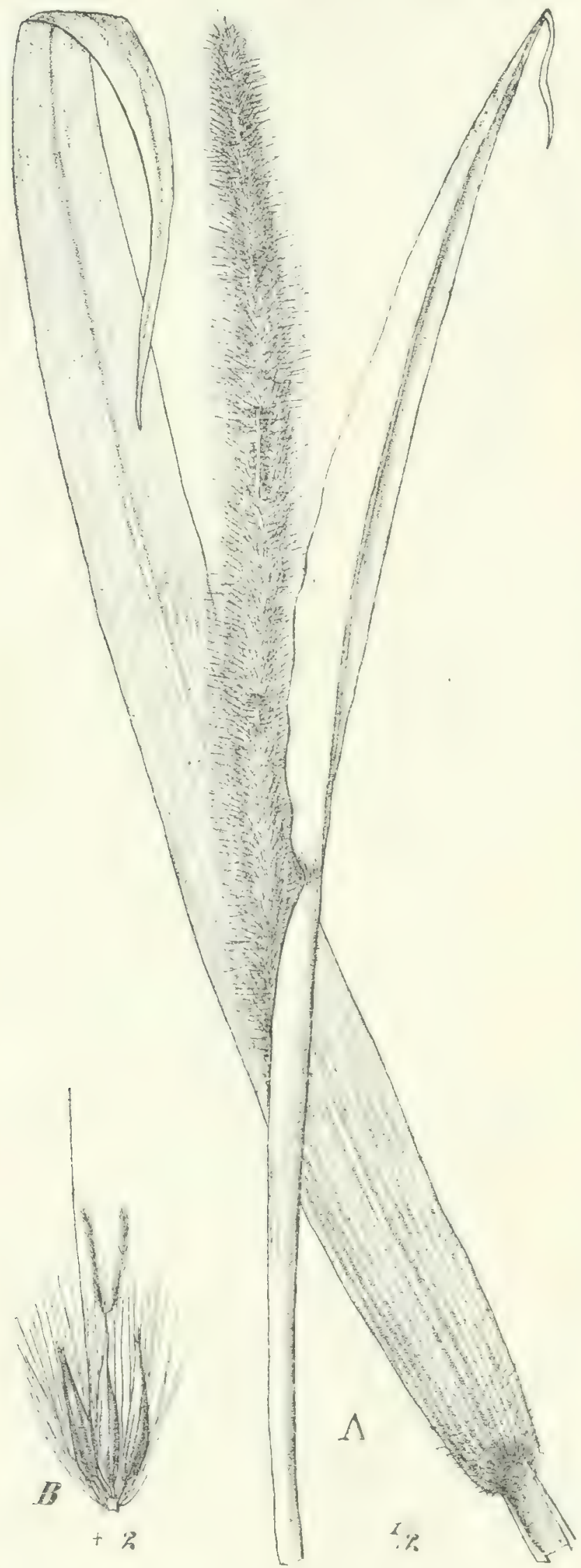

Fig. I12. Pennisetum purpureum Schum, et Thonn. $B$ Gruppe von Ährchen mit Involucrum.
Knoten (zu vergleichen mit Olyra latifolic im feuchteren Urwald), $P a-$ nicum sulcatum Aubl., Leptochloa uniflor $\alpha$ Hochst., ein zartes Gras, das in Uferwäldern in dichten Beständen wächst. In niedrigeren Dickichten, an Waldrändern kommt viel vor Panicum horizontale Mey., eine im tropischen Afrika weit verbreitete Art; infolge ihres Wachstums ist sie mit anderen Gräsern dieser Standorte dicht verflochten; der dünne Halm liegt nämlich nieder und kriecht so am Boden hin, an den Knoten bewurzelt; an den Knoten entspringen aufrechte, bliihende Äste mit zierlichen aus Ähren zusammengesetzten Rispen, die bei ihrem Aufrichten die Blattscheiden, in denen sie entstehen, vom Halme ablösen; die Spreiten sind dünn, offen, von lanzettlicher Form; manchmal sind die Halme auch mehr oder weniger gekniet ansteigend, aus dem Knoten verzweigt; dann bleiben die Seitenäste, die in diesem Falle mehr in der Richtung der Hauptachse liegen, länger in den Scheiden.

Auf offenen sandigen, feuchten Plätzen der Ufernähe kommen in Angola besonders folgende Arten vor: Arthraxon ciliaris P. Beauv., in einer Varietät, die sich der var. geminus Hack. annähert, wächst in dichten Beständen, die aus den niederliegenden, an den Knoten bewurzelten Halmen gebildet werden; die blïhenden Halme sind aufsteigend; die Art ist in den Tropen der alten Welt weitverbreitet. Ferner Andropogon halepensis (L.) Brot. var. effusus Hack., A. mufus Kth., an sonnigen, 
trockneren Stellen der Uferbänke, Eriochloa polystachy Kth., Panicum cruspaionis Nees, mit meterhohen Halmen, P. maximum Jacq., ein im tropischen Afrika in $\operatorname{rerschiedenen~Formationen~weitverbreitetes~Gras~mit~} \mathrm{I}-2 \mathrm{~m}$ hohen Halmen, I'munisetum purpurcum Schum. et Thonn. (P. Benthani Steud.), Perotis indica (L.) K. Schum., Ctenium elcgans Kth., Chloris barbata Sw., Dinebra arabica Jacq., Pappophorum benguellonse (Rendle', Schmidtia quinqueseta Benth., Eragrostis Chapellicri Nees, E. interrupta P. Beauv. var. namaquensis (Nees).

Wie ersichtlich, treten besonders an diesen Standorten schon Formen von sonst südlicherer Verbreitung auf, worauf noch später zuriickzukommen sein wird.

Von besonderer Bedeutung für das westliche tropische Afrika ist Pennisetum purpircum Schum. et Thonn. (vgl. Fig. 112), das als Elefantengras bekannt ist. In Westafrika ist die Art von der Goldkuiste bis Loanda verbreitet, in Ostafrika in Sansibar. Usambara, Nyassaland und Mossambique.

Das riesige Gras wird an feuchten Plätzen bis $6 \mathrm{~m}$ hoch, mit bis meterlangen unteren Blättern: an trockneren Stellen, in der Savanne, in Lichtungen usw., bleibt es niedriger, mit ungefähr $2 \mathrm{~m}$ hohen Halmen.

In Ostafrika kommt es im baumlosen Alluvialland der größeren Flüsse in tieferen Lagen vor. in Mossambique auf sandigen W'iesen, doch auch in Graslichtungen des Gebirgsbusches und in Lichtungen des Urwaldes bei $1000 \mathrm{~m}$.

In Togo ist Pennisetum purpureum sehr verbreitet und bildet in den Niederungen bis $6 \mathrm{~m}$ hohe. dichte Bestände: in Kamerun besiedelt das Elefantengras besonders Urwaldlichtungen, wo ganze Flächen mit ihm bestanden sind. und reicht so bis zur Waldgrenze: in der Ebene ist es seltener: am oberen und unteren Kongo kommt es auf Alluvialland, in verlassenen Kulturen usw, vor, auch mehr vereinzelt in lichten Palmenhainen an der Kongomündung; nach Süden dringt es bis Loanda vor, wo es reichlich im Gebiete des Urwaldes, in sekundären Dickichten Capinaes), auf tiefgelegenen ITiesen und an Uferbänken auftritt. Es ist eines der besten Futtergräser.

2. Auf sumpigen Wiesen der unteren Regionen, besonders in der Nähe der Flüsse.

In Ostafrika ist in sumpfigen Niederungen in Usambara, U'segua, Usaramo besonders häufig Antropogon halepensis (L.) Brot. var. effusus Hack. Von A. halcpcnsis sind aus dem tropischen Afrika noch einige Formen bekannt, doch ist die var. effusus die wichtigste und verbreitetste, die nach den Angaben der Sammler auch auf recht verschiedenen Standorten vorkommt. Der starke, bis 2-3 $\mathrm{m}$ hohe, dicht mit breiten Blättern bekleidete und mit einer großen ausgebreiteten Rispe abschließende Halm gibt der Pflanze den Habitus eines Schilfgrases: sie nähert sich in der Form einigen Kulturrassen der Durrh beträchtlich. Die Varietät reicht in Ostafrika rom Ghasalquellengebiet bis zum östlichen und südlichen Kapgebiet. Sie findet sich außer in Sumpfniederungen auch viel in vernachlässigten Pflanzungen, ist überhaupt eines der wichtigsten Gräser der Niederungen der fruchtbaren Vorlandsteppe. In Westafrika reicht 


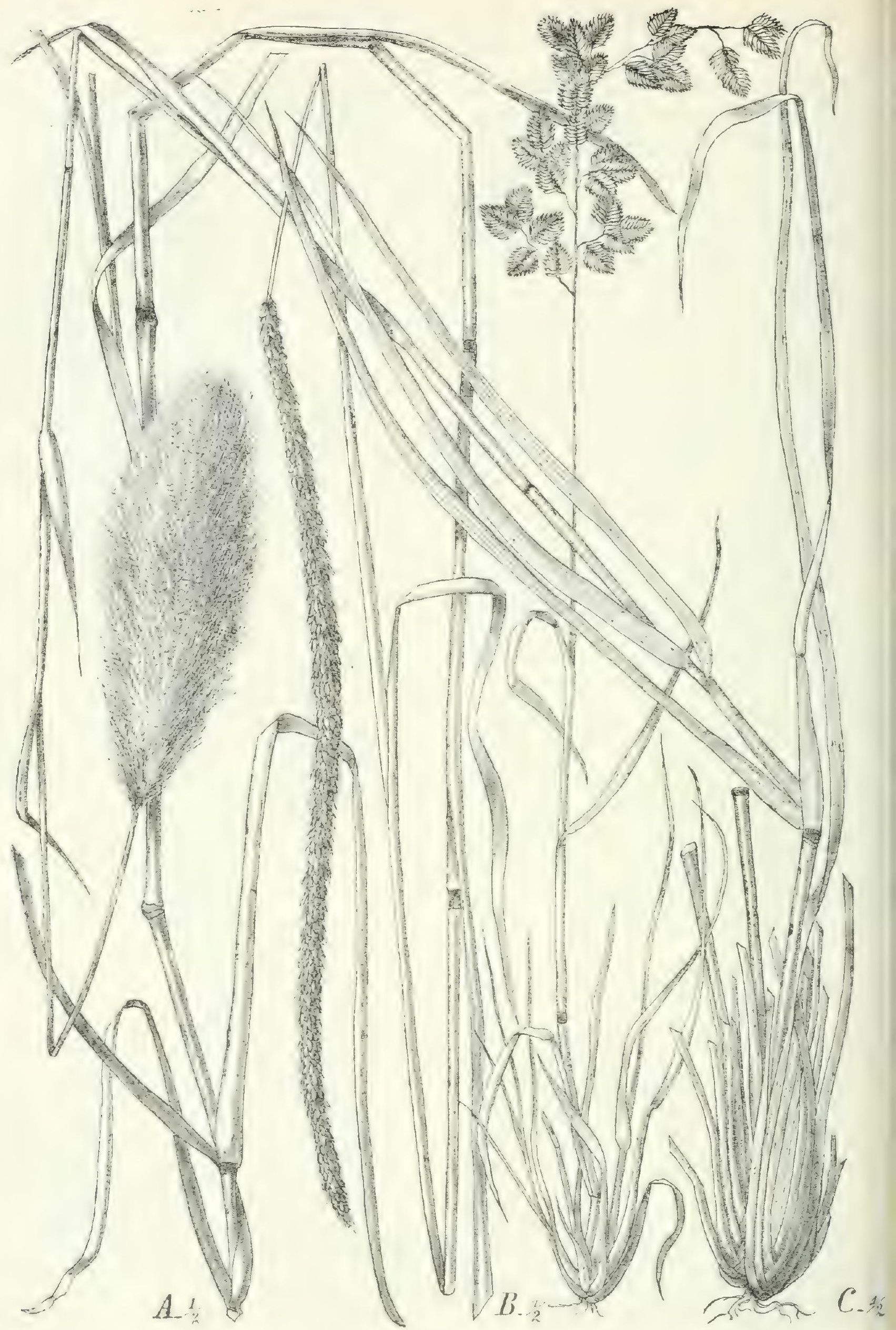

Fis. II3. A Setaria aurea Hochst. Gras feuchter Wiesen und Steppen. $B$ Eragrostis superba Wawra et Peyr. C Chloris myriostachya Hochst. Hüufige Steppengräser. 
ihre Verbreitung von Oberguinea bis zum westlichen Kapland; so findet sie sich auf Kulturland in Togo, ebenso in Kamerun, ferner in Gabun und im Kongogebiet in der Nähe der Flüsse an freien Stellen. I.cersia hexandra Sw., die auch als eigentliches Wassergras erwähnenswert ist, geht auch auf feuchte Wiesen über, so häufig in Usambara, Kamerun und in Angola, ebenso Panicum equitans. In Ostafrika tritt ferner häufig auf Sumpfwiesen der Niederung Paspalum scrobiculatum L. und Imperate cylindricar (L.) P. Beauv. auf; ferner Evagrostis unioloides (Retz.) Nees, eine im tropischen Asien weitverbreitete Art; in Abyssinien findet sie sich nach SCHINIPER auf feuchten Brachäckern bei $2100 \mathrm{~m}$, in Usambara ferner auch an niedrigen Hügeln und im gelichteten Walde bei 1;00 m: das perennierende Gras hat gewöhnlich zahlreiche extravaginale Neusprosse, die aber nicht kriechen, sondern alle aufrecht sind; es entstehen so ziemlich dichte und große Rasen: die Halme haben im unteren Teil gewöhnlich mehrere kurze Internodien, an denen auch häufig Zweige gebildet werden, dann ein bis zwei stark verlängerte Internodien; die mehr oder weniger hervorragende Rispe ist klein, locker, mit olivgrünen, dichtblütigen Ährchen.

Ferner ist als Bewohner feuchterer Standorte Setaria aurca Hochst. (vgl. Fig. II 3 A) zu erwähnen; die Art geht in Ostafrika von Abyssinien bis Natal und Pondoland, in Westafrika von Senegambien bis zum oberen Kongogebiet; sie tritt z. B. um $1500 \mathrm{~m}$ auf feuchten Wiesen am Urwald in Usambara auf, in Togo auf Schlickboden in einzelnen Büschen, auf Sandinseln im Pool am Kongo usiv, doch geht sie auch auf trockncre Standorte, lichte Gebüsche usw. iiber. Bei Exemplaren feuchterer Standorte bildet die Pflanze einen mit dichter Ähre abschließenden, bis $\mathrm{I}^{\mathrm{y}} / 2 \mathrm{~m}$ hohen Halm, der am Grunde von langen (bis $30 \mathrm{~cm})$ Scheiden umgeben ist, die breit, dicht distich angeordnet, übereinanderfallen und scharf in der Mitte gefaltet sind, ein geröhnlicher Typus von Gräsern feuchter, sumpfiger Standorte: in die langen Scheiden sind lange intravaginale Neusprosse eingeschlossen: die Blattspreiten sind aufrecht, kräftig, linealisch bis breitlinealisch, mehr oder weniger offen oder in der Mitte gefaltet. Exemplare, die von trockneren Standorten stammen, haben diese regelmäßige Anordnung der Scheiden am Halmgrunde nicht; die Internodien am Halmgrunde sind häufig nicht ganz gestaucht, sondern kurz entwickelt, so daß dadurch die Basis mit den Scheiden, die dann auch meist viel kürzer sind, mehr verlängert wird; es kommen auch gelegentlich kurze extravaginale Neusprosse vor, die an der Basis hervorbrechen: die Länge und Breite der Blattspreiten wechselt stark. Mit diesem Gras zusammen findet man auch Eragrostis superba Wawra et Peyr. und Chloris myriostachya Hochst. (Fig. I 3 BC).

Für sumpfige Stellen in Unyamwesi bei $1000 \mathrm{~m}$ Höhe wird erwähnt Eragrostis congesta Oliv. Die Art treibt mehrere $50-60 \mathrm{~cm}$ hohe Halme mit wenigen extravaginalen Neusprossen; der untere Teil, der mehr oder weniger gekniet und an den Knoten verzweigt ist, hat mehrere kurze Internodien, öfter ist er auch niederliegend und dann mit aufrechten Asten versehen; die Blattspreiten sind linealisch, offen, kurz, die Rispe ist mehr oder weniger aus der 
obersten Scheide herausgehoben und besteht aus einigen getrennten, sitzenden dichten Büscheln von Ährchen.

In Togo sind folgende Formen für feuchte Senkungen in der Savanne, sumpfige und feuchte Wiesen in der Nähe der Gewässer bemerkenswert: Trichoptcry'x ambicns $\mathrm{K}$. Schum. tritt auf an zeitweilig iiberschwemmten Wiesen am Otifluß bei $200 \mathrm{~m}$, wo sie auf große Strecken die vorherrschende Grasart ist, dann an feuchten Senken der Savanne bei Sokode in großen zusammenhängenden Beständen, auf Wiesen und flachen Terrainwellen; sie scheint auch auf etwas trocknere Standorte überzugehen. Das bis $2 \mathrm{~m}$ hohe, prächtige Gras hat starke, aufrechte Halme, die am Grunde von derben, langen, übereinanderfallenden Scheiden umgeben sind: die Halme haben mehrere lange Internodien, die von den Scheiden nur teilweise bedeckt werden: in den langen Scheiden am Grunde entwickeln sich einzelne lange, intravaginale Neusprosse: die Blattspreiten sind lang, sehr derb, bis I $\mathrm{cm}$ breit, selten ganz offen, meist etwas von beiden Rändern her eingerollt, manchmal bis zur Berührung der Ränder: die Wurzeln sind kräftig, durchbrechen am Halmgrunde die Scheiden und tragen dichtstehende dünne Nebenwurzeln.

Ferner bildet Trichoptery'x elegans (Hochst.) Hack. (sonst von Abyssinien bekannt) in nassen Teilen der Savanne zusammenhängende Bestände. Sie unterscheidet sich von der vorigen durch niedrigere, I $\mathrm{m}$ hohe, mehr zierliche Halme; das Rhizom ist dick und wollig behaart und bringt eine Anzahl Halme und kurze intravaginale, sowie extravaginale Neusprosse hervor, die alle gleichmäßig aufwärts gerichtet sind; die alten Scheiden am Halm lösen sich in Fasern auf; die Halme haben nur ein bis zwei Knoten, also sehr stark verlängerte Internodien, die zum größeren Teil nicht von Scheiden bedeckt sind: dic Blattspreiten sind meist nicht länger als $20 \mathrm{~cm}$, derb, linealisch, offen, das Blatt unter der Rispe ist stark verkiirzt; Spreiten und Scheiden sind mit derben, kurzen, auf kleinen Warzen stehenden Borsten bedeckt. Eine dritte Art ist T. hordciformis Stapf, die in Togo auf zeitweilig überschwemmten Wiesen am Otiufer vorlzommt. Die Rispe ist bei ihr sehr dicht und gedrungen: sie bildet keine Rasen und hat nur vereinzelte intravaginale Neusprosse.

Den drei Trichoptery $x$-Arten schließt sich Eragrostis blepharostachya K. Schum. an, die in Togo bei $200 \mathrm{~m}$ an nassen Stellen nahe dem Überschwemmungsgebiet vorkommt. Die Halme sind ${ }_{1} / 2-1 \mathrm{~m}$ hoch: aus intraraginalen Neusprossen wird ein dichter Rasen erzeugt: die Blattspreiten sind linealisch-lanzettlich: im Habitus ähnelt die Art E. supcrba, bei der aber extravaginale Sprosse gebildet werden. Anscheinend sind alle vier erwähnten Arten nach ihren Merkmalen nicht als typische Sumpfgräser zu bezeichnen, sondern werden auch befähigt sein, an ihren Standorten eine trocknere Periode zu überstehen bzw. auf trocknere Standorte überzugehen. Auch von Andropogon ceresizformis Nees, der auf nassen Wiesen auftritt, werden trocknere Standorte, wie Felsspalten des Agomegebirges erwähnt. Die Art ist sonst noch im Kalaharigebict und im östlichen Kapland, im tropischen Westafrika bis Huilla und im Ghasalquellengebiet verbreitet, wobei mehrerc unerhebliche Varietäten 


\section{.}




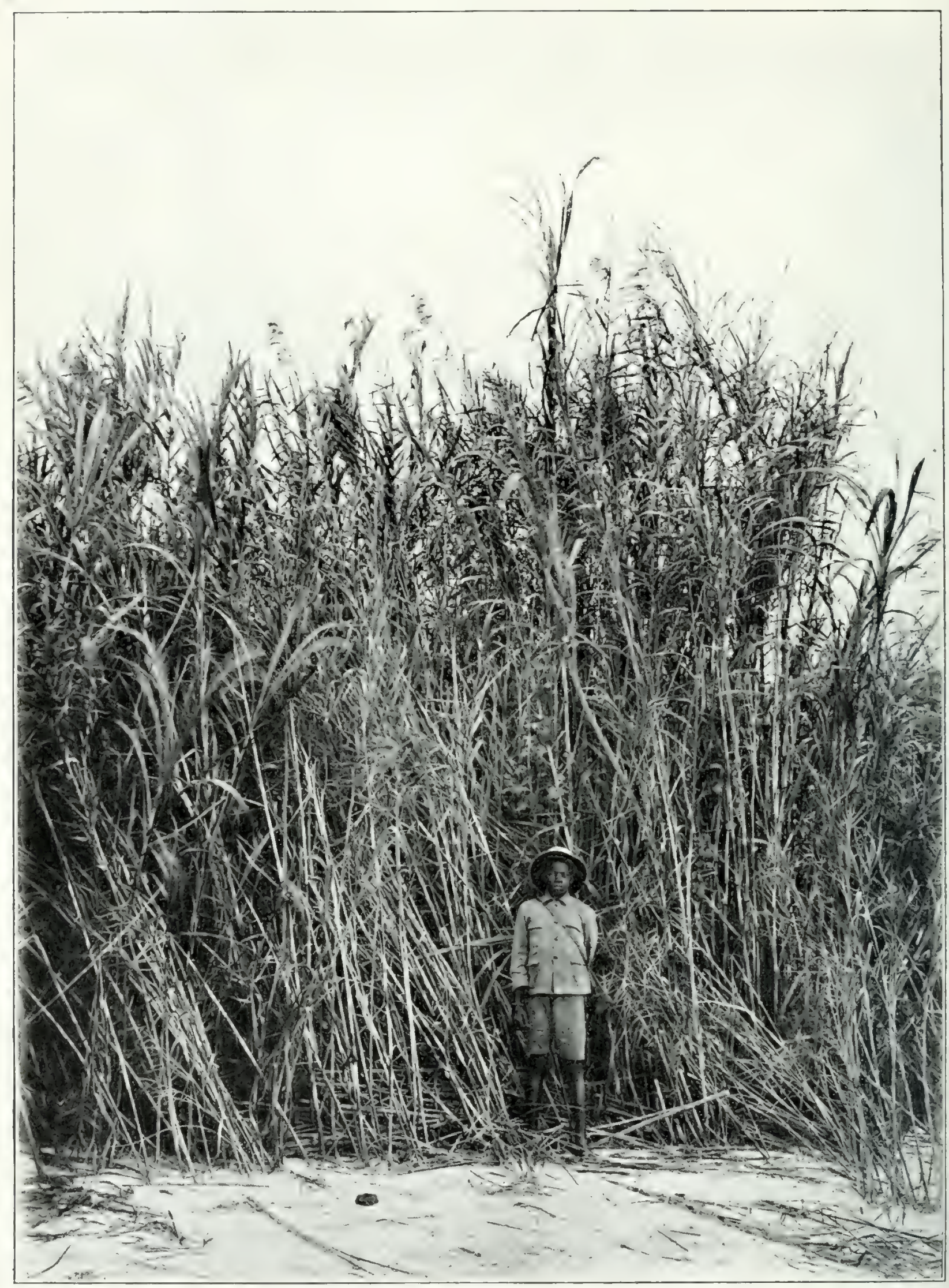

Phragmites communis (Lam.) Crép.

Schilfdickicht am Victoria Nyansa.

Nach einer Photographie von Exzellenz Prof. Dr. Robert Koch (1907). 
unterschieden werden. Soweit sich aus den Angaben ersehen läßt, bevorzugt die Art sumpfige oder feuchte Standorte. Sie hat kurze extravaginale Neusprosse, meterhohe Halme mit kurzen, offenen Blättern: die Halme sind nach oben zu verzweigt und bilden so eine Rispe aus kurzen, von Spathen eingehüllten Trauben.

Ferner ist für Togo noch ein prachtrolles Gras zu erwähnen, eine RhytachuiArt, die vielleicht ron $R$. congocnsis sich nicht spezifisch abtrennen läßt, aber doch in einigen Merkmalen abweicht. Die Halme erreichen $2^{\mathrm{I}}{ }_{2}-3 \mathrm{~m}$ Höhe und liefern gutes, nicht hohles Rohr, das zu Pfeilschäften. Hürden, als Flechtmaterial usw. verwandt wird. Die Art wird deshalb auf feuchten Niederungen, am Rande von Lagunen angepflanzt und durch Teilung der Wurzelstöcke vermehrt.

Für Angola sind auf sumpfigen Standorten der Niederungen folgende Arten bemerkenswert: Sucharum .Ifunroanum Hack. (Huilla. sonst ron Transvaal und Natal bekannt, rasig. Halme jo cm hoch, Andropogon halepinsis (L.) Brot. var. iffusus Hack., A. squarrosus L. f. var. nigritamus Benth.) Hack. Pungo Andongo. sonst im Nigergebiet, Senegal und Ghasalquellengebiet: Halme bis $2 \mathrm{~m}$ hoch, dicht von Scheiden bedeckt, Rispe groß, mit ungeteilten Ästen', Eiragrostis caniftora Rendle einjährige Pflanze mit fußhohen Halmen, deren Grund von übereinanderfallenden Scheiden bedeclit ist: Huilla). Auf feuchteren Wiesen treten auf Paricum horicontale Hey., Anaropogon fastigiatus Sw. Pungo Andongo, ferner Abyssinien, Sennaar. Togo, sonst im tropischen Amerika weitrerbreitet: ein einjähriges oder perennierendes Gras mit $60-0 \mathrm{~cm}$ hohen Halmen und nickenden Trauben, Andropogon sichrensis Hochst., A. bractiatus Willd. (ein schönes, hochwüchsiges Gras mit reicher Rispe. sonst nur aus dem tropischen Amerika bekannt. Paspalum scrobiculatum L., I'aniann brianthum Hochst. I'. maximum Jacq., Tricholacha rosea Nees. Trichuftory simplex (Nees) Benth. Pungo Andongo, Transraal. östliches Kapland, Ctcnium elegans Kth. (Senegambien bis Pungo Andongo).

\section{In Schilfdickichten.}

Pluragmitcs communis (Lam.) Crép. ist über das ganze tropische Afrika verbreitet und bildet an Lfern von Flüssen und Bächen oft ausgedehnte Dickichte. Teilweise treten hohe Formen auf, die dem I'h. karka Trin. nahe stehen, doch sind beide Arten, wie schon HOOKER in der Flora of British India bemerkt. nach Herbarmaterial nicht sicher zu trennen. Wie in anderen Ländern perenniert Phragmites mit extravaginalen Neusprossen und bildet weithin kriechende Rhizome aus, durch die das Gras ganze Strecken für sich allein okkupiert. In Abyssinien findet sich die Art an Bachrändern überall $\wp n$ 2ICO $\mathrm{m}$ abwärts. geht durch ganz Ostafrika bis nach dem Kapland: in Testafrika ist sie gleichfalls rom Senegal südlich bis ins Kapland verbreitet, iiberall in Angola und im Kunenegebiet begleiten ihre bis $4 \mathrm{~m}$ hohen Dickichte die Flußläufe. IThrgg mitis bevorzugt überall befeuchteten Sandboden, wie er an flachen Lffern ron Seen und Flüssen auftritt: so nehmen z. B. auch am Tanganyika hohe Schilfdickichte Strecken flachen Sandstrandes ein. 
Dic Form rom Tanganyika wird übrigens von HACKEL als eigene Art, Ph. pungens, beschrieben, ist aber noch zweifelhaft.

An einigen Standorten scheint der 2-3 $\mathrm{m}$ hohe Andropogon halepensis (L.) Brot. var. cffusus Hack. sich mit Phragmites zu vergesellschaften oder ähnliche Bestände zu bilden. Im allgemeinen liebt die Form aber trocknere Plätze.

4. Wasserbewohnende Gräser des Überschwemmungsgebietes großer Ströme und stehender Gewässer.

$\mathrm{Zu}$ den Gräsern, die an das Leben in regelmäßig überschwemmten Gebieten angepaßt sind und sich besonders während des höheren Wasserstandes entwickeln, gehören I'ossia procera Wall., Sacchamm spontancum L., Odontilytrum aby'ssinicum Hack. (Cenchrus abyssinicus), Panicum Burgu Chevalier. Letztere Art, die wohl nur eine Form von P. stagninum Retz (aus der Crusgalli-Gruppe) darstellt, ist besonders im westlichen Sudan am mittleren Niger verbreitet. Die Halme entwickeln sich zum Beginn der Überschwemmungszeit und dauern bis zum Beginn der trockneren Zeit aus; sie bedecken häufig als gewaltige im Wasser ausgebildete Dickichte meilenweite Strecken ohne jede Unterbrechung. An den Stellen, wo die Feuchtigkeit sich das ganze Jahr erhält, perennieren die im Sumpfe kriechenden Rhizome, die neue Sprosse hervorbringen; an ausgetrockneten Stellen treiben die jungen Pflanzen aus Samen aus. Die Schnelligkeit des Wachstums übertrifft zu Anfang das Steigen des Wassers und die jungen Halme wachsen iber das Niveau ständig empor; die Blätter, die bei weitcrem Anstcigen rom Wasser bedeckt werden, faulen und aus den Knoten brechen dichte Büschel von Wurzeln hervor. Einzelne Seitensprosse, die entwickelt werden, bleiben in den Blattscheiden längere Zeit eingeschlossen und erhöhen die Dichtigkeit des Dickichts. Die Halme werden bis $2 \mathrm{~m}$ lang und überragen die Wasserfläche um ungefähr $50-80 \mathrm{~cm}$.

Am oberen Nil tritt Sacchamm spontanemm L. an die Stelle von Panicum Burgu. Die Art reicht in Ostafrika von Ägypten bis zum nördlichen MassaiSteppengebiet, wo sie von UILIG aufgefunden wurde, und kommt nach HACKEL auch am unteren Niger vor. In Agypten ist sie häufig im Schlammboden des Niles bis zu + m Höhe cntwickelt und treibt, wenn der Nil anschwillt, Wurzeln aus den unteren Halmknoten: nach dem Fallen des Wassers umgeben die trocknen Wurzeln bis zu Meterhöhe den unteren Teil des aufrechten Halmes; in Abyssinien begleitet sie in einer Höhe von rooo- $1200 \mathrm{~m}$ den Tacazelauf und seine Nebenflüsse.

Sacchamm spontanemm, das auch in Nordafrika und selbst Sizilien vorkommt, bildet ein Beispiel für die V'erwandtschaft der Flora mit dem tropischen Asien, wo die Art weit rerbreitet ist; wie riele andere Arten erreicht sie durch Zentralafrika noch das nördliche Westafrika. T'ossia cuspidata (Roxb.) K. Schum. ( $T$. procere Wall. et Griff.) ist von ähnlicher Verbreitung: Ostindien, von Kordofan (nicht in Abyssinien und Igypten) in Ostafrika bis zum nördlichen Seengebiet (Unjoro, Usinja), Senegal, südlich bis zum Kongo (nach 
Chevalier). Die Halme dieser schönen Andropogonee sind im unteren Teile untergetaucht oder flutend, an den Knoten bewurzelt und ragen bis Neterhöhe über das Wasser empor. Am weißen Nil, z. B. an der Mündung des Bahr el Arab, bilden sie große Vegetationsbarren, die die Schiffahrt behindern.

Als Wassergras, dessen untere Halmteile beständig untergetaucht oder im Schlamm leben und sich an den Knoten bewurzeln, kommt fiur das nördliche tropische Afrika auch Oryza satiza L. in Betracht; der Reis ist sicher an vielen Standorten wild anzutreffen: so erwähnt ihn SCHIMI'ER für die Buchten des Zanasees in Abyssinien, auch in größeren Morästen daselbst: die Früchte werden nur im Falle der Not als Getreide benutzt; ebenfalls ist wilder Reis in Sümpfen am Senegal gefunden worden, sowie im Überschwemmungsgebiet des Kongo.

In Wassertiumpeln der Hochebene Abyssiniens bei $2700 \mathrm{~m}$ Höhe kommt eine eigentimliche Panicee vor, auf die HACKeL die Gattung Odontclytrum gründete. $O$. abj'ssinicum Hack. ist ein wahrscheinlich flutendes Wassergras mit bewurzelten Halmen und ziemlich stark erweiterten unteren Scheiden und flachen Blättern; der ährenförmige Bliitenstand erhebt sich nur wenig über die Wasserfläche.

Neben diesen wichtigsten wasserbewohnenden Gramineen können noch erwähnt werden Lecrsia aby'ssinica Hochst., Panicum cquitans Hochst., Panicum intirruptum Willd. (ron Abyssinien bis Natal, Indien und Nalesien), $P$. pjramidalc Lam. im tropischen Afrika weitverbreitet, im Kapland an der Südküste und im Osten, P. ciliocinctum Pilger im Ghasalquellengebiet. Bei Panicum intermptum sind die im Wasser liegenden unteren Teile der Halme nackt, stark ausgehöhlt, an einzelnen Knoten noch mit verfaulten Scheidenresten versehen, mit dichten Büscheln von langen, fein verzweigten Wurzeln aus den Knoten; der obere, aufgerichtete Teil des Halmes zeigt lange Internodien, die mit lockeren breiten Scheiden großenteils bedeckt sind: die Blattspreiten sind bis $30 \mathrm{~cm}$ lang, der Blütenstand ist dicht und schmal.

\section{Gräser der subxerophilen Formationen.}

I. Offene Grassteppe.

Für die Grassteppe Ostafrikas kommen in erster Linie Andropogoneen in Betracht, unter ihnen besonders A. vicurdus L. subsp. margiriatus (Steud.) Hack., A. cymbarius L., A. mufus Kth. 'J. fulitumus Hochst.) Hack., A. livitus L., A. intermedius R. Br. $\delta$. punctatus Roxb. Hack., ferner Themeda triandra Forsk. Th. Forskalii Hack. ('. i'ulgaris Hack., 1. punctatı Hack.). Letztere wichtigste Art kann als Typus der ostafrikanischen Steppengräser bezeichnet werden. Die sehr formenreiche Art ist durch alle tropischen und subtropischen Gebiete rerbreitet, so auch im tropischen und südlichen Afrika. Sie tritt in der Steppe untermischt mit anderen Arten auf, an anderen Stellen ist sie fast allein herrschend und bildet ein stundenweites dichtes Grasmeer. Die Pflanze erzeugt dichte Rasen mit intravaginalen Neusprossen, die Halmbasis ist dicht mit übereinanderfallenden Scheiden bedeckt; die aufrechten oder gekniet ansteigenden Halme werden 
bis 2-3 $\mathrm{m}$ hoch: im Verhältnis zu ihrer Höhe sind sie ziemlich dün, sie sind unterwärts verzweigt, häufig mit intravaginal entstehenden, die Scheiden durch-

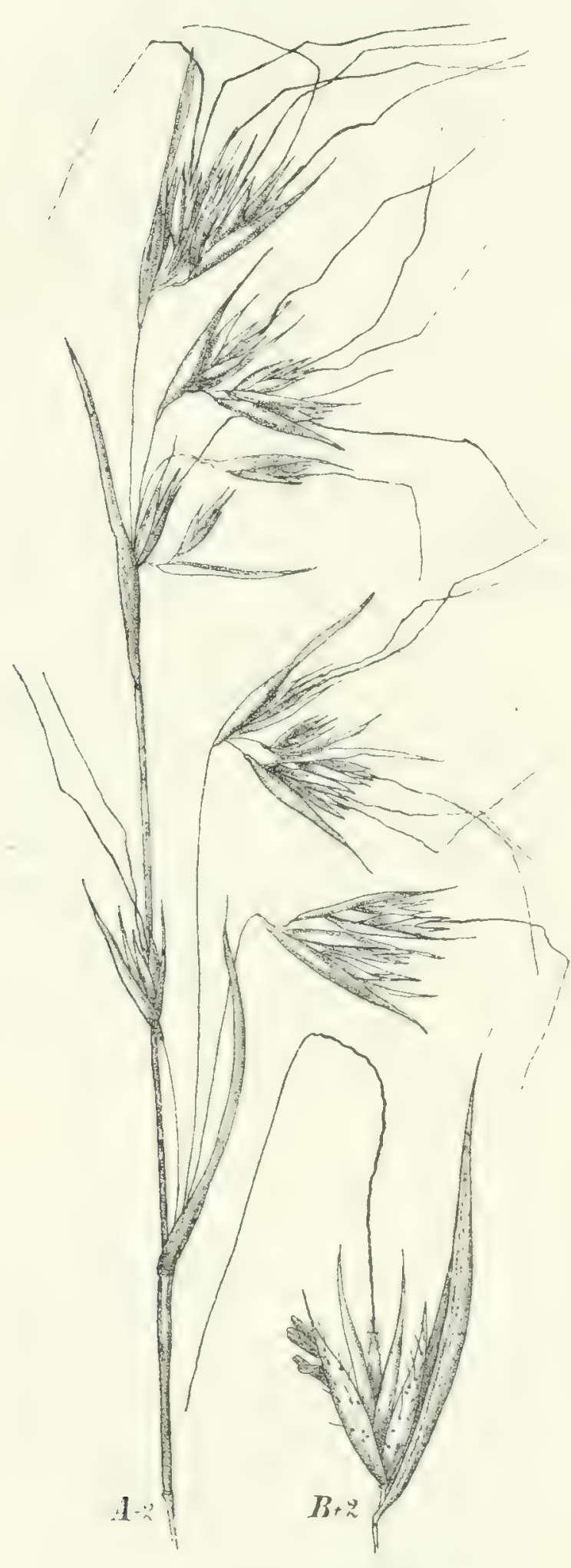

Fig. I14. 'Themeda triandra Forsk.; $B$ Äbrchengruppe. brechenden Zweigbüscheln, und tragen eine von Blättern unterbrochene Rispe; die Blattspreiten sind schmal und derb; die Ährchen sind an der Spitze zierlicher Zweige kopfig gedrängt, je eine Gruppe von ihnen von einer kahnförmigen Scheide umgeben.

Nächstdem sind von Bedeutung die Andropogon-Arten aus der CymbopogonGruppe, unter ihnen $A$. cymbarins $\mathrm{L}$. (vgl. Fig. I 5 B). Diese Art bildet keine geschlossenen Rasen mit intravaginalen Neusprossen, sondern die basalen Teile der hohen Halme bestehen aus kurzen, nackten oder am Knoten mit Scheidenresten versehenen Internodien. An den Knoten brechen mehr oder weniger starke Wurzeln hervor, deren Abbruchsnarben weiter hinauf sichtbar sind. Die Innovation ist durchaus extravaginal; an den unteren freien Knoten sind Knospen, die dicht mit Schuppen bedeckt sind, anzutreffen oder mehr oder weniger verlängerte Sprosse. Kräftige Halme zeigen in den oberen Scheiden Büschel von Zweigen, die intravaginal entstehen, dann die Scheiden zur Seite drängen, so daß diese schließlich das Internodium ganz frei lassen. Ähnliche Sproßverhältnisse weisen z. B. folgende hochwiichsige Arten auf: bei P'ennisetum purpureum (vgl. S. 145) entstehen an den Knoten der unteren sehr kurzen nackten Internodien des mächtigen Halmes Wurzeln und extravaginale Sprosse, die sich entweder aufrichten oder sich zu kriechenden Ausläufern verlängern; die oberen Zweige entstehen in den Scheiden; bei Andropogon Gayanus (vgl. Fig. 1 20) kann man beobachten, daß in den oberen Internodien die jungen Triebe die Scheide in einem kurzen Spalt durchbrechen und aus diesem hervorwachsen; Andropogon spictabilis treibt sehr zahlreiche starke 
W'urzeln und verlängerte ausläuferartige Triebe: bei A. schocnanthus tritt an einzeInen Exemplaren besonders deutlich die Tatsache hervor, daß die unteren kurzen Internodien viel dünner als die oberen sind: der untere dünne Teil des Halmes mit zahlreichen mit Scheidenresten bekleideten Internodien ist niederliegend und an den Knoten bewurzelt, ganz allmählich werden die Halmstücke dicker, bis die normale Halmstärke erreicht ist. Aus allen diesen Angaben geht hervor, daß hier, im Gegensatz z. B. zu Themeda keine Rasen gebildet werden, sondern die hohen, am Grunde nackten Halme einzeln stehen; es scheint so, als ob die Halme nicht im ganzen nach Verlauf einer Vegetationsperiode absterben, sondern am Grunde perennieren und neue, die Scheiden aus einem Spalt durchbrechende oder sie abdrängende bliihende Sprosse bilden und daß daneben durch ausläuferartig verlängerte Triebe neue Halme gebildet werden, die sich ziemlich entfernt erst aufrichten, da jeder Halm viel Platz zu seiner Entwicklung beansprucht. Die Gräser dieses Typus gehören im allgemeinen weniger der echten Steppe als der Baumsteppe (Savanne und Campine) an, doch sind Formen von A. cymbarius und A. schoinanthus zweifellos Komponenten der ostafrikanischen Hochgrassteppe.

Beide Gräser ähneln sich sehr durch ihre großen reichblütigen Rispen, in denen die Trauben der Ährchen durch rötlich gefärbte kahnförmige Spaten mehr oder weniger eingehïllt werden; die Blattspreiten sind sehr derb, offen, linealisch, lang verschmälert, wie auch bei den nachher zu erwähnenden Arten besonders am Rande sehr stark rauh. A. cymbarins L. wird bis $4 \mathrm{~m}$ hoch. Die Art ist ron Abyssinien bis Natal durch ganz Ostafrika verbreitet und kommt auch auf den Maskarenen vor.

A. schoenanthus L. (vgl. Fig. is A), der sich wegen seines Ölgehaltes durch stark aromatischen Geruch auszeichnet und aus diesem Grunde auch von den Eingeborenen als Suppengewiirz verwandt wird, hat $2 \mathrm{~m}$ hohe Halme. Die Art ist mit einer Reihe von Varietäten durch die Tropen der alten Welt weitverbreitet.

Dem Typus von Themeda dagegen schließt sich aus der CymbopogonGruppe an Andropogon nardus subsp. marginatus. Die Halme dieser Form sind relativ dünn, mit breitem Grund umgreifen zahlreich übereinanderfallend die anliegend behaarten Scheiden ihre Basis, so daß diese knollig verdickt erscheint; die Neusprosse entstehen intravaginal.

Ferner sind aus der Cymbopogon-Gruppe von Bedeutung Andropogon hivtus (vgl. Fig. i 6 . A) und A. mfus; beide mit lockeren, armblütigeren, langen Rispen. 1. hirtus bildet ziemlich niedrige, dichte Rasen; am Grunde der dünnen Halme sind mehrere kurze Scheiden zusammengedrängt; neben intravaginalen Neusprossen entstehen zahlreich extravaginale, die sich bald aufrichten, so daß der Rasen mehrere gleichstarke blühende Äste enthält.

Aus der Amplizlopliz-Gruppe von Andropogon ist zu erwähnen A. intermedius R. Br. var. punctatus Hack., mit extravaginalen Neusprossen und gekniet ansteigenden Halmen; die schmalen starren stark rauhen Blattspreiten sind bis $50 \mathrm{~cm}$ lang, die Rispe ist aus sparrigen Âsten mit mehreren Trauben zu- 


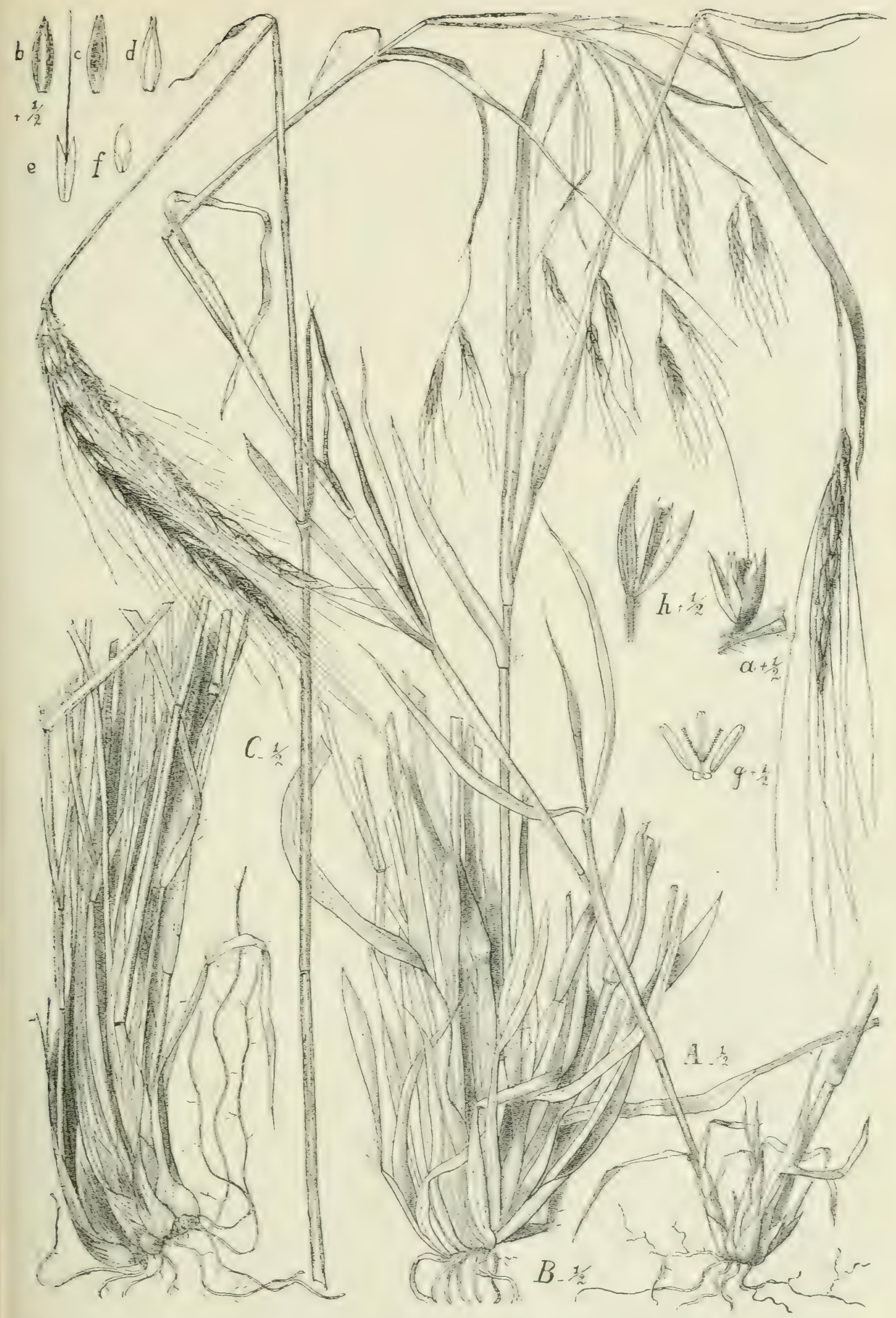

Fig. Ir6. $A$ Andropogon hirtus L.; $B$ Andropogon contortus L.; $C$ Andropogon schirensis Hochst., $a \S$ Ährchen, $b-f$ Spelzen des $\&$ Ährchens, $g$ Blüte, $h$ gestieltes 0 Ährchen. 
sammengesetzt. Dieselbe Form kommt in Südafrika in Transvaal und Natal vor, sonst ist die Art über die Tropen und Subtropen der alten Welt weitverbreitet.

Zur Arthrolophis-Gruppe gehörig ist A. schircnsis Hochst. (vgl. Fig. I16 C, der in der Vorlandsteppe Usambaras viel auftritt; die Art geht sonst von Abyssinien durch Zentralafrika bis ins Nigergebiet und kommt auch in Südafrika im Oranjestaat und Natal vor. Die kurzen aufrechten Neusprosse sind extravaginal: die Halme erheben sich zu Meterhöhe, die schmalen, am Rande stark rauhen Blätter sind bis $30 \mathrm{~cm}$ lang; der schlank aus dem Rasen sich heraushebende Halm schließt mit zwei ungeteilten Trauben $a b$.

Auch Andropogon contortus L. (vgl. Fig. I I6 B), der an vielerlei trocknen Formationen auftritt, fehlt in der offenen Grassteppe nicht. Die Art perenniert mit kurzen, aufrechten, extravaginalen Neusprossen: die Halme sind bis meterhoch und meist nach oben zu buschig mit bliihenden Trieben verzweigt: die offenen Blätter sind kurz und sehr derb, am Rande stark rauh: die Trauben stehen, wie es für die Ititeropogon-Gruppe charakteristisch ist, einzeln an der Spitze der Blütenzweige. A. contortus ist mit mehreren Formen über die wärmeren Länder der ganzen Erde verbreitet.

Aus anderen Gruppen der Gramineen sind folgende Arten für die offene Grassteppe Ostafrikas von Wichtigkeit:

Pennisetum ciliare (L.) Link, sonst verbreitet im Mittelmeergebiet, Abyssinien, Deutsch-Südwestafrika, siidliches Kapland, mehrere Varietäten von beschränkterer Verbreitung: ferner Pemisetum . Therkeri Leeke (nur Deutsch-Ostafrika); Panicum brizanthum Hochst., im tropischen Afrika und Natal.

Setaria aurea Hochst. fa. minor Mez, die in Ostafrika von Usambara bis zum Nyassaland auf viclen trockneren Formationen eine bedeutende Rolle spielt, ist in ihrem ganzen Wuchse ausgeprägter xerophil als der Typus: die Halme sind niedriger, nur 50-60 cm hoch, in größerer Anzahl im Rasen zusammenstehend: die Scheiden der am Grunde zusammengedrängten Blätter, die sich mehr oder weniger zerfasern, sind kurz. die Neusprosse meist intravaginal, seltener extravaginal: die Halme sind zierlich mit verhältnismäßig stark verlängerten Internodien: die Blattspreiten sind schmal, linealisch, mehr oder weniger rauh, dünn, offen oder (trocken, unregelmäßig eingefaltet oder am Rande umgebogen: es kommt vor, daß mehrere untere, sonst gestauchte Internodien sich verlängern, dann hört der dichte rasenförmige Wuchs auf und die unteren Internodien sind stark verzweigt.

Dieser Art gleicht im Wachstum Tetrapogon bidentatus Pilger, der von der Steppe des Kilimandscharogebietes um $800 \mathrm{~m}$ bekannt ist, durch sein kriechendes Rhizom, den dichten Rasen mit zahlreichen intravaginalen Neusprossen, aus dem sich die $50 \mathrm{~cm}$ hohen, an der Basis verzweigten Halme herausheben. Die verwandte Art dieser Chloridee, T. iillosus Desf,, kommt von den Kanaren durch Nordafrika bis Vorderindien vor.

Von anderen Chlorideen sind einige Arten von Chloris von Bedeutung, unter ihnen besonders Chloris myriostachy a Hochst. vgl. Fig. I $13 C_{\text {, }}$, die in 
Abyssinien und in den Steppen Ostafrikas weitverbreitet ist, auch auf Sandboden der Insel Tanga und im Küstenland vorkommt (nach RENDLE auch in Loanda); die Art ist durch ihre ovale, reichblütige, außerordentlich dichte zusammengezogene Rispe leicht kenntlich. Die Halme sind kräftig, bis I m hoch, aufrecht oder an den Knoten etwas gekniet, am Grunde mit zahlreichen, übereinanderfallenden, bis $10 \mathrm{~cm}$ langen Scheiden bekleidet, und bringen kräftige intravaginale Neusprosse hervor: die Blattspreiten sind trocken, linealisch, rauh, selten über $20 \mathrm{~cm}$ lang, die letzte unter der Rispe stark verkürzt: die meisten Exemplare zeigen starke Verzweigung aus den Halmknoten und zwar manchmal ganze Büschel von Sprossen, die das Aussehen von Gruppen von intravaginalen Neusprossen haben; einzelne Äste verlängern sich kräftig und können sich selbst wieder an den Knoten verzweigen: die Internodien sind dann von Scheiden frei, da diese von den Zweigbiischeln zur Seite gedrüclit werden und vergehen, doch war an den Exemplaren niemals Niederliegen der Halme und Bewurzelung der Knoten zu beobachten. Ähnliche Verzweigung, nur mehr nach der Basis zusammengeriickt, zeigt Chloris petraca Thunb., die gleichfalls zahlreiche intravaginale Neusprosse erzeugt: die Internodien des Halmes sind hier länger, die oberen Spreiten mehr verkiirzt; in der Form der Rispe ist die Art von Ch. myriostachy stark unterschieden: die Rispe ist braun, doldenähnlich mit zahlreichen Ästen und vielen kleinen, ganz kurz begrannten Ährchen. Ch. petraca ist im südlichen und östlichen Kapland verbreitet und geht durch Ostafrika bis Abyssinien.

Interessant ist das Auftreten von zwei Cynocim-Arten in der Steppe Ostafrikas. Cynodon dactylon (L.) Pers. ist eine kosmopolitische Graminee, die auch in Afrika als Strandgras, auf Sandplätzen, Brachäckern usw. große Verbreitung hat; in den Steppen am Kilimandscharo bei $900 \mathrm{~m}$ und an freien Flächen innerhalb des Steppenbusches in Usambara bei $800 \mathrm{~m}$ und höher tritt eine hohe Form auf mit bis meterlangen Halmen, die aber nicht sicher vom Typus abzutrennen ist. Es sind sehr kräftige Pflanzen, deren Bestockung an den vorhandenen Exemplaren nicht kenntlich ist; die Halme sind zum Teil am unteren Ende niederliegend mit aufrechten Ästen aus den Knoten, oder die Halme sind mehr oder weniger aufrecht, aus den Knoten büschelig verzweigt; die Blattspreiten sind bis $15 \mathrm{~cm}$ lang und bis $7 \mathrm{~mm}$ breit. Nicht unähnlich diesen kräftigen Formen von $C$. dactylon ist Cynodon plactostachy'nn (K. Schum. Pilger, das im MIassaigebiet in trockner Buschsteppe und offener Steppe häufig ist, am Pangani stellenweis allein herrscht. Der derbe IVurzelstock bringt bis meterlange, teilweis ron Scheiden freie Halme hervor; die Neusprosse sind extravaginal und mehr oder weniger verlängert: der Halm ist häufig niederliegend. mit extravaginalen aus den Scheiden hervorbrechenden Sprossen oder er ist aufgerichtet und mehr oder weniger verzweigt; auch bei den aufgerichteten Halmen, an denen die Scheiden erhalten sind, durchbrechen noch extravaginale Sprosse den Scheidengrund, daneben kommen dann Zweige vor, die in den Scheiden entstehen und nur oben aus ihnen heraustreten; diese Zweige entstehen manchmal in ganzen Büscheln, die die Scheiden zur Seite 
drücken; die offenen Blattspreiten sind hart, lang linealisch-lanzettlich, bis $25 \mathrm{~cm}$

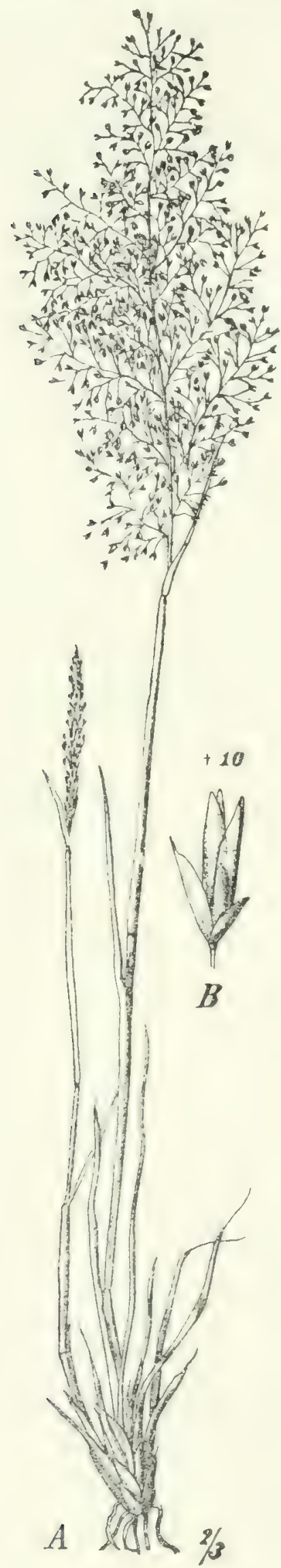

Fig. I17. Sporobolus festivus Hochst. $A$ Habitus; $B$ Ährchen. lang und sehr stark rauh.

Aus der Gattung Eragrostis ist das wichtigste Gras der Steppen und verwandter trockner Formationen Eragrostis superba Wawra et Peyr. (vgl. Fig. I 1 3 ). Die Art kommt vor in Ostafrika von Uganda bis nach Natal, in Westafrika von Loanda bis Namaland. Sie hat ein kräftiges Rhizom; die Neusprosse entstehen fast durchaus extravaginal, doch richten sich die Sprosse sofort auf, so daß die Halme dicht beieinander stehen; die derben Halme sind $\mathrm{I}_{2}$ - I $\mathrm{m}$ hoch, meist mehr oder weniger stark gekniet; in diesem Falle sind eine Anzahl ziemlich gleichmäßiger Internodien vorhanden, die länger als die Scheiden sind; oder aber die Halme sind aufrecht, mit nur ein bis zwei Knoten und weit herausgehobener Rispe; häufig bildet der Halm blühende Seitensprosse aus; die Blattspreiten sind lang linealisch, lang verschmälert, derb, rauh, flach, sehr unregelmäßig von den Rändern her eingerollt; die Rispe ist groß und locker, mit abstehenden, kurz verzweigten Ästen und großen flachen Ährchen.

In ihrer vegetativen Entwicklung stehen zwei niedrigere Arten im geraden Gegensatze zu den Cynodon-Arten, Eragrostis bifaria (Vahl) Wight und Sporobolus festivus Hochst. Eragrostis bifaria kommt in Ostindien und in Steppengebieten Ostafrikas vor, wo sie stellenweise häufig oder herrschend auftritt. Die Halme sind nur $30-35 \mathrm{~cm}$ hoch, aufrecht oder nur am untersten Knoten gekniet; sie sind am Grunde dicht mit derben Fasern zerfallener Scheiden bedeckt und von einigen niedrigen intravaginalen Neusprossen umgeben; der dünne Halm hat nur einen Knoten, der zweite untere ist im kurzen Rasen versteckt; die Scheide ist viel kürzer als das Internodium; der Blütenstand ist ährenförmig, aus zweireihig angeordneten Ährchen zusammengesetzt; die Blattspreiten sind kurz, an den Halmblättern nur $3-5 \mathrm{~cm}$ lang, linealisch, stumpflich, am Mittelnerven eingefaltet und von den Rändern 
her eingebogen, so daß sich diese fast berühren. Dieser Art gleicht im Wachstumsmodus Sporobolus festiz'lls Hochst. (vgl. Fig. I I 7), der im tropischen Afrika weitverbreitet ist und auch im östlichen Kapland vorkommt; die intravaginalen Neusprosse sind sehr zahlreich, die Blätter schmal, fadenförmig zusammengerollt; die Rispe ist von ovalem Umfang, mit sehr zahlreichen, sehr kleinen Ährchen: die alten Scheiden werden im kurzen Büschel zum Teil in Fasern aufgelöst, was besonders bei der var. stuppeus Stapf der Fall ist, wo dann diese Fasern in dichten Mengen den Grund des Rasens umgeben.

Überblicken wir die vorstehenden Angaben über den Aufbau der wichtigsten Formen der ostafrikanischen Steppengräser, so fallen eine Anzahl gemeinsamer Züge ins Auge, die den Standortsbedingungen dieser weiten unter langer Trockenzeit stehenden Grasfluren entsprechen. Solche sind die Bildung von dichten Büscheln mit zahlreichen Innovationen, aus denen sich die jährigen Halme meist hoch herausheben, während das kräftige Rhizom und die zusammengedrängten Neusprosse die Trockenzeit überdauern. Bei fast allen Formen finden wir, daß die Blattspreiten schmal und lang verschmälert, derb und trocken und besonders stark rauh, an den Rändern häufig kurz, rauhzähnelig sind: vielfach sind die oberen Spreiten stark verkürzt; die Hochgräser bilden meist zahireiche blühende Zweige aus, besonders die Andropogoneen, so daß reiche von Blättern unterbrochene Rispen entstehen. Da die Gramineenflora der Steppe aus vielen Gattungen zusammengesetzt ist, so geht die Anpassung auch entsprechend den Typen der Gattungen und Artgruppen recht verschiedene Wege: so sind z. B. die Arten mit intravaginalen Neusprossen, wie sie ja vorzugsweise bei xerophilen Gräsern auftreten und zur Bildung eines dichten Büschels beitragen, nicht häufiger als solche mit extravaginalen: doch bedingen letztere bei den meisten Steppengräsern durchaus kein lockeres Gefuige, sondern sie bleiben im Jahre ihrer Entstehung kurz und kruimmen sich sofort bei ihrem Wachstum aufwärts, so daß sie die Halmbasen dicht umgeben. Interessant ist in dieser Beziehung die Annäherung der Cymodon-Formen an ein dichtes büscheliges Wachstum.

Unter den Steppengräsern finden sich viele auffallend weit in Afrika oder überhaupt in den Tropen verbreitete Arten, wie Thomede triandre, die in zahlreiche Formen gespalten sind: vergleichen wir aber die Gattungen, die in der ostafrikanischen Steppe eine Rolle spiclen, so sehen wir zwei fuir andere Steppengegenden, besonders des tropischen Amerika, hervorragend wichtige Gattungen ganz zurücktreten, nämlich - Aristicke und Stiper. Stiper kommt iiberhaupt nicht ror, von Aristida ebenfalls keine Arten, die als Gräser der subxerophilen Steppe zu bezeichnen sind, denn A. allowsis Hochst. bewohnt in Usambara trockne Grasfluren höherer Regionen.

In Westafrika treten weite offene Grassteppen besonders in Togo auf; ihre Zusammensetzung weicht in einer Reihe von Komponenten von der ostafrikanischen Steppe erheblich ab. Folgende Arten sind für die offenen Grasflächen von besonderer Bedeutung: Andropogen cxilis Hochst. var. Pititianus (Rich.) Hack., A. nodulosus Hack., A. semilerbis Kth., A. fastigiatus Sw., 


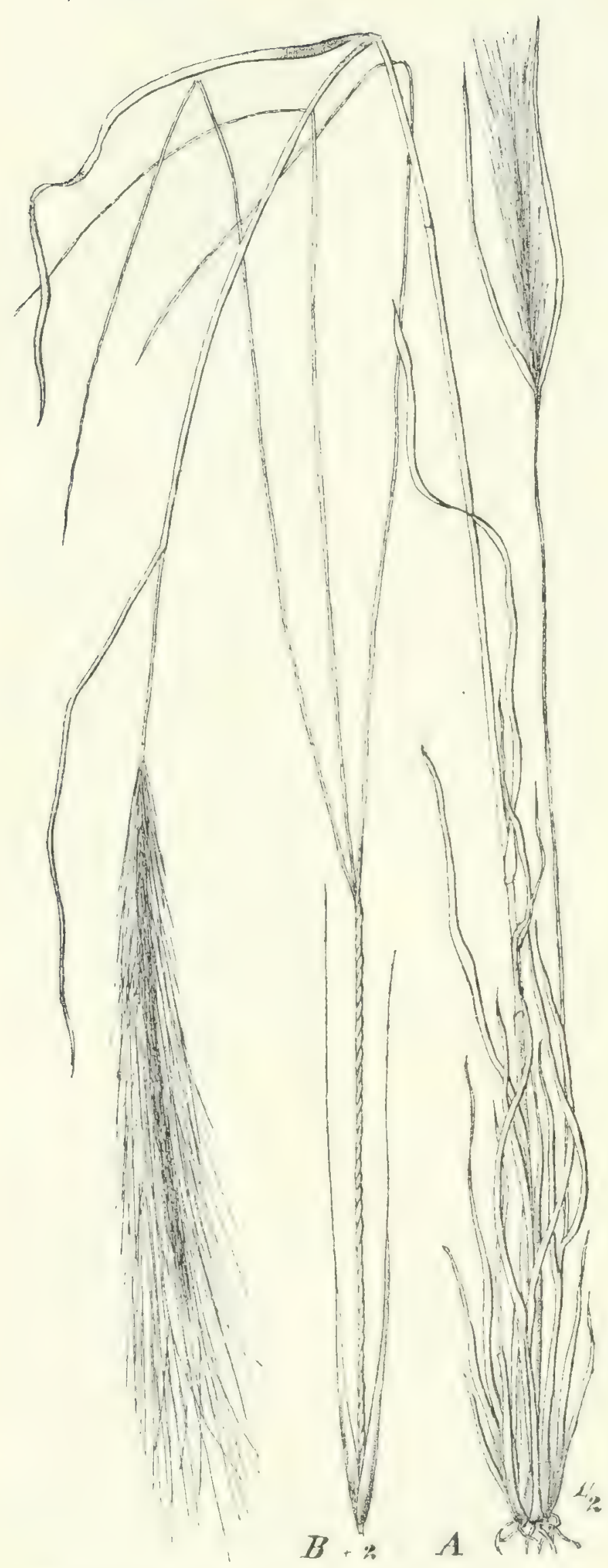

Fig. 118. Aristida Kerstingii Pilger. $A$ Habitus; $B$ Ährchen.
A. Gayamis Kth., A. apricus Trin., A. contortus L., A. schoenanthus L., A. rufus Kth., A. Barteri Hack., Thelepogon elegans Roth, Rottboellia caudata Hack., Panicum Gayanum Kth., P. debile Desf., P. leptorrhachis Pilger, P. maximum Jacq., Setaria aurea Hochst., Pennisetum setosum (Sw.) Rich., Aristida longiflora Schum. et Thonn., A. Kerstingii Pilger, Trichopteryx Kerstingii Pilger.

Einige Andropogon-Arten, die auch in Ostafrika eine wichtige Rolle spielen, kehren hier wieder; A. contortus ist in der Steppe zerstreut, nach Angabe der Sammler auch auf allen möglichen Bodenarten anzutreffen; von $A$. schocnanthus L. herrscht die Unterart densiftorus Hack. mit sehr kompakter Rispe; Andropogon mufus tritt sowohl in der typischen Form wie in der var. meficomus (Hochst.) Hack. auf; die Art ist im tropischen Afrika weitverbreitet, im Westen bis zum Kunene-Zambesigebiet nach Süden, sonst im tropischen Brasilien. Größer ist die Zahl der Arten, die entweder nur im westlichen Afrika eine mehr oder weniger weite Verbreitung haben oder bis nach dem nördlichen Ostafrika herübergeben; in Togo endemisch sind z. B. Aristida Kerstingii (vgl. Fig. I I8) und Trichopteryx Kerstingii, in Togo und im Nigergebiet kommen vor Andropogon Barteri und A.nodulosus, in Senegambien und Togo Panicum leptorrhachis Pilger; Rottboellic caudata kommt vor von Togo bis Angola, Aristida longiflore bis Amboland; Andropogon 
exilis Hochst. geht von Abyssinien bis zum Ghasalquellengebiet und dann nach Togo über: A.firstigiatus hat in Afrika eine ähnliche Verbreitung. knmmt aber dann noch im tropischen Amerika und Ostindien ror: A. afrius ist nit der typischen Form weit im tropischen Amerika verbreitet, in Togo und in Nigergebiet tritt die var. afizanus Hack. und in Ostindien die var. indicus Hack. auf. $\mathrm{Zu}$ den niedrigeren Formen, die besonders in höher gelegenen Steppengeländen um $300 \mathrm{~m}$ auftreten, gehört Andropogon cxilis var. Petiticri:us aus der Schizuchym-Gruppe, mit einzelnen Trauben: die zierlichen Halme sind stark verzweigt, die kurzen Blätter offen: von ähnlichem Wachstum ist A. nulullosus aus derselben Gruppe. Bis I m hoch wird A. apricus, der mit kurzen extravaginalen Sprossen perenniert und aus den oberen Knoten der zierlichen Halme viel verzeigt ist: die Trauben stchen zu zweit an der Spitze der Zweige, am Grunde mit einer spathaförmigen Scheide des obersten Blattes. A. fustigiatus, der einzige Vertreter der Diectomis-Gruppe, mit einzelnen Trauben mit dunkelgefärbten zahlreichen Grannen, hat halbmeterhohe, zierliche Halme und sehr schmale, lang haarförmig gegen die Spitze verschmälerte Blätter. Alle diese Formen bilden nur lockere Büschel aus, die sterilen Neusprosse sind wenig zahlreich. Ihnen schließt sich an Sitaria grlanca P. Beaur. var. abjusinitia R. Br., eine in den Tropen weitrerbreitete zartere einjährige Form mit mehreren blühenden Halmen und kurzen dünnen Blättern: die Kleine Blïtenähre ist an dem dünnen Halmende meist lang aus der obersten Scheide herausragend, ferner Panicum debile Desf.

$\mathrm{Zu}$ den mittelhohen Formen gehört Aristila longiflere Schum. et Thonn. (A. leiverlycina Trin. et Rupr., die in manchen Gegenden den Hauptbestandteil der Steppe bildet, ein ausdauerndes. graugrünes Gras mit $\mathrm{I}_{-} \mathrm{I}^{\mathrm{I}}{ }_{+} \mathrm{m}$ hohen Halmen, die kräftig und aufrecht sind, mit mehreren zienlich gleichmäßigen Internodien: die Pflanze bildet keine dichten Rasen, da nur wenige intravaginale Neusprosse rorhanden sind: hier und da wird auch ein extravaginaler Sproß gebildet; die Halme sind häufig aus den Knoten verzweigt und die Scheiden von den Knoten abgedrüngt; die Blattspreiten sind sehr schmal, bei den Halmblättern bis $30 \mathrm{~cm}$ lang, starr und mehr oder weniger aufrecht, ron beiden Ründern her eingerollt: die Rispe ist schmal, die Ẍhrchen haben drei laäftige, gleichlange, stark rauhe Gramnen. Durch außerordentlich lange Grannen ist die schmale Rispe ron A. Kerstingii ausgezeichnet, einer einjährigen. Irt mit langen, sehr schmal fadenförmig zusammengerollten Blättern, die bei einer Höhe von $250 \mathrm{~m}$ wächst: ähnlich kommt I'aniamn Gergamm Kith. und P. Fanmannii K. Schum. vor. Gleichfalls einjährig ist Thelipegon clegrens Roth, eine Andropogonee, die in Ostindien, Abyssinien und durch Zentralafrilia nach Togo verbreitet ist, auch im ostafrikanischen Seengebiet auftritt: in cier Steppe ron Togo bildet sie größere Gruppen ohne Beimischung anderer Arten; die ziemlich kräftigen Halme sind bis meterhoch, aufrecht oder ansteigend: die Blattspreiten sind aus stengelumfassender Basis lanzettlich oder mehr linealisch. groß. offen. 


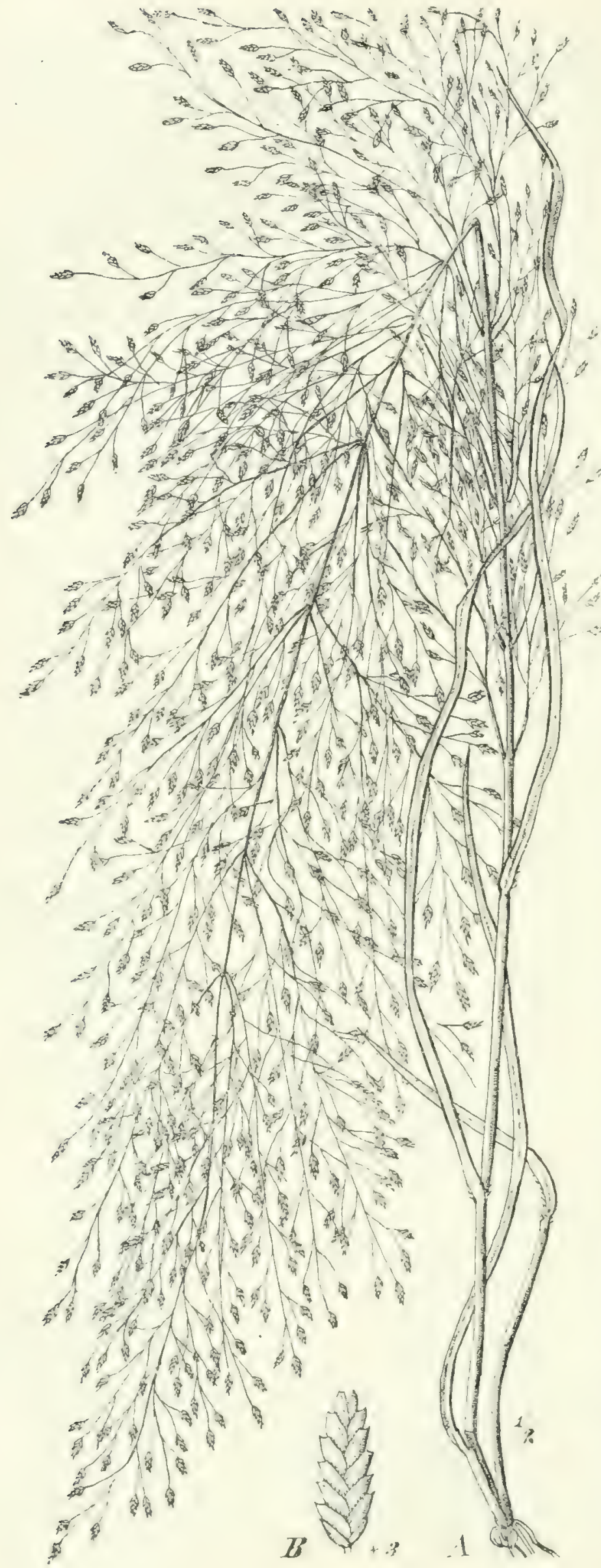

Fig. I19. Eragrostis aspera (Jacq.) Nees. A Habitus; $B$ Ährchen.
Aus der Gattung Eragrostis findet sich bei $300 \mathrm{~m}$ Höhe $E$. aspcra (Jacq.) Nees (vgl. Fig. I I 9), eine Art der Cataclastos-Gruppe, die im tropischen Afrika eine weite Verbreitung hat und auf mehrerlei trocknen Formationen vorkommt; sie reicht in Ostafrika von Abyssinien bis nach Natal, in Westafrika bis Huilla, kommt ferner im südlichen Kapland und im siidlichen Ostindien vor; die einjährige Pflanze treibt mehrere aufrechte oder etwas gekniete, niedrige Halme, die mit einer ausgebreiteten Rispe mit zierlichen, stark rauhen Zweigen abschließen; die Blattspreiten sind schmal, bis $20-30 \mathrm{~cm}$ lang, offen.

Endlich ist noch die Gattung Trichoptery'x zu erwähnen; so

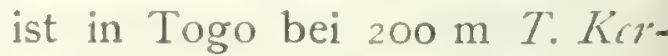
stingii Pilger auf weite Strecken die herrschende Grasart: die einjährige Pflanze bildet zierliche, bis $70 \mathrm{~cm}$ hohe Halme mit. sehr schmalen, zusammengerollten Blättern; ebenso ist die einjährige 1.hordeiformis Stapf in derGrasflur bei $300 \mathrm{~m}$ Höhe anzutreffen. Die nahe verwandten Gattungen Tristachye und Trichoptery't spielen in den trocknen Formationen des tropischen und südlichen extratropischen Afrika eine große Rolle; Trichopteryx flammida ist Brasilien und dem westlichen Afrika gemeinsam, sie erreicht durch das Kongogebiet das ostafrikanische Seengebiet; von den übrigen 20 Trichoptery $x$ Arten sind die meisten in Westafrika entwickelt und häufig von 
beschränkter Verbreitung; T. gigantea Stapf geht von Huilla und dem Kongogebiet bis Senegambien und zum Ghasalquellengebiet; im ostafrikanischen Seengebiet treten auf Th. spirathera K. Schum. und $T$. kagerensis K. Schum., in Ukamba 7 : grisea K. Schum., in Somaliland T. somalensis (Franch.) Engl., in Madagaskar $T$. brevifolia Hack.; T. simplex (Nees) Benth. kommt vor in Pungo Andongo, in Transvaal, im östlichen Kapland und im tropischen Ostafrika, T. Dregcana Nees in Transvaal, Natal und in den östlichen Shirihochländern. Trichoptery $x$ ist eine von den Gattungen, die mit einer oder wenigen Arten Brasilien und das tropische Afrika gemeinsam bewohnen und dann in Afrika reicher entwickelt sind; das gleiche ist der Fall für Melinis, auch Tristachya schließt sich hier an; mit einer Art, 1. barbata, ist die Gattung durch Arabien bis Beludschistan verbreitet.

$\mathrm{Zu}$ den hochwüchsigen Grasarten, die besonders in niedriger gelegenen Teilen vorkommen, gehört Andropogon Gayanus Kth. (vgl. Fig. I 20) und var. cordofanus (Hochst.) Hack., eine Art, die häufig bei $200 \mathrm{~m}$ größere Strecken vorherrschend bedeckt; sie ist in Ostafrika von Abyssinien bis zum Sambesi-

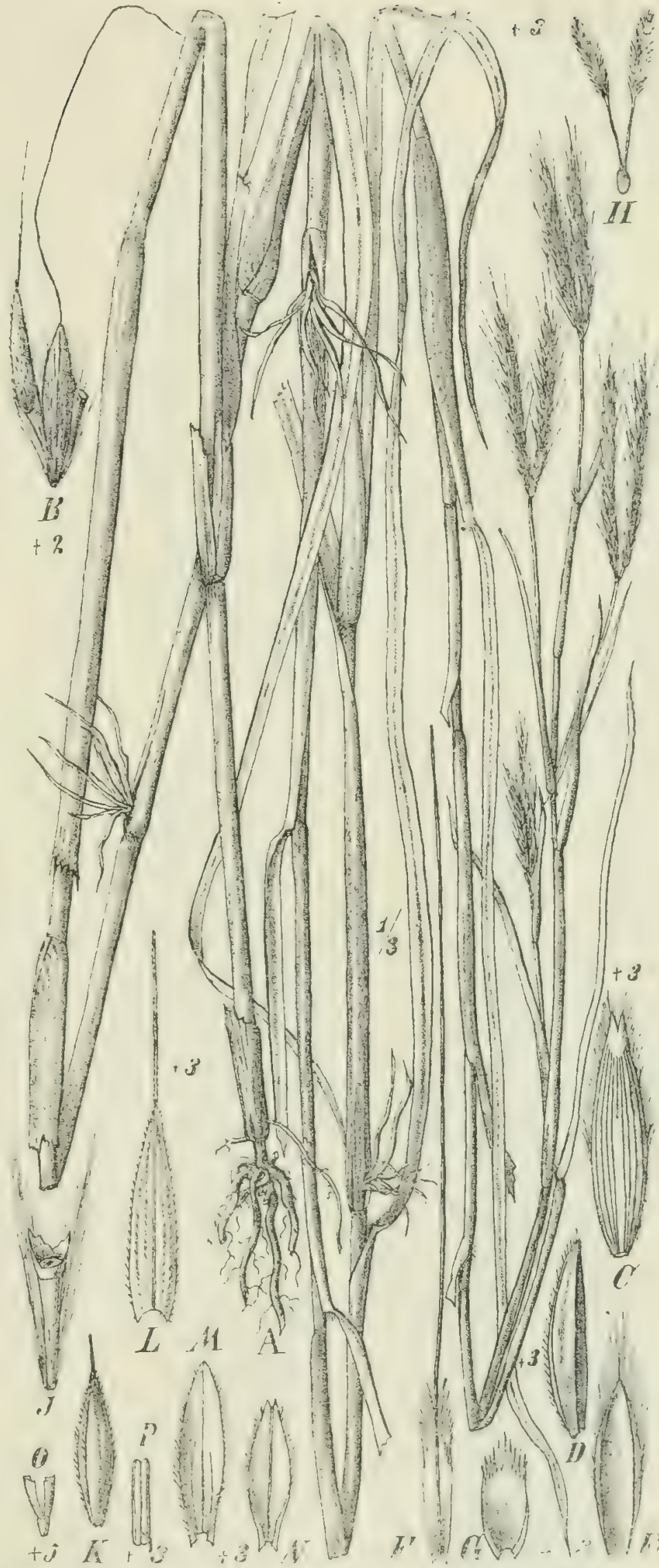

Fig. 120. Andropogon Gayanus Kth. A Habitus; $B$ Achsenglied, sitzendes und gestieltes Ährchen; $C, D, E, F, G$ Spelzen des $\$$ Ährchens; $H$ Fruchtknoten; $\mathcal{F}$ Stiel des $\widehat{O}$ Ährchens; $K, L, 1, \Lambda$ Spelzen des 3 İhrehens; $O$ Lodiculae; $P$ Staubblatt. 
gebiet, in Westafrika von Senegambien bis Amboland ausgedehnt; die Pflanze perenniert mit extravaginalen und intravaginalen Neusprossen und produziert

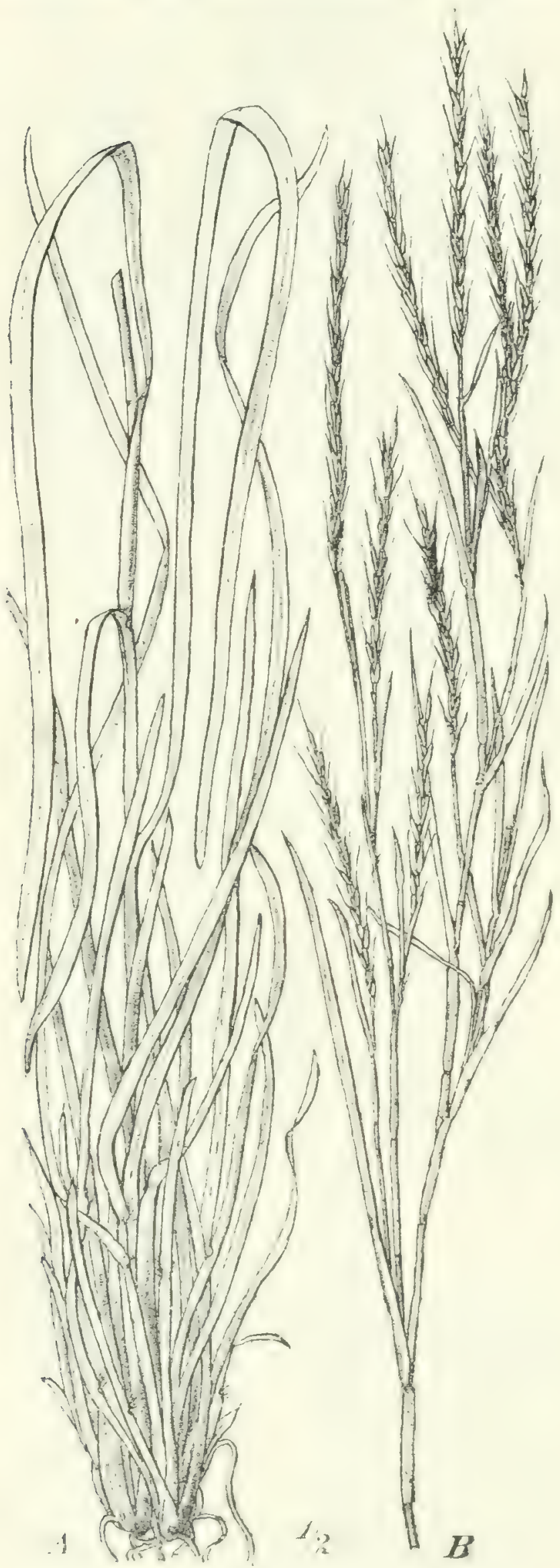

Fig. 121. Andropogon semiberbis Kth. hohe starke Halme; die Blattspreiten sind $20-40 \mathrm{~cm}$ lang, offen, derb, an den Rändern stark rauh; der Halm bringt nach oben zu zahlreiche blühende Zweige hervor, die je zwei Blütentrauben tragen, die am Grunde wie ihr gemeinsamer Stiel von Spathen umhüllt sind. Einen ähnlichen Bau hat Andropogon semiberbis Kth. (vgl. Fig. I 2 I), der mit der typischen Form im tropischen Amerika, mit der var. leptostachy'us (Benth.) Hack. im Nigergebiet und in Togo vorkommt; hier erreicht das Gras eine Höhe von $2 \mathrm{~m}$ und ist strichweise sehr verbreitet und vorherrschend. Ferner sind zu erwähnen A. schocnanthus L., A. rufus Kth. und A. Barteri Hack.; letztere Art, jedenfalls einjährig, ist sonst noch im Nigergebiet vorkommend; sie gehört zur Cymbopogon-Gruppe und zeichnet sich durch die dichte, reichblütige, dunkelgefärbte Rispe aus. Ferner tritt häufig auf Panicum maximnun Jacq., eine im tropischen und südlichen Afrika sowie im tropischen Amerika sehr weitverbreitete und nach Indien durch Kultur übergegangene Art, die mit intravaginalen Neusprossen perenniert und mächtige, bis $3 \mathrm{~m}$ hohe Halme erzeugt, sodann Pennisetum indicum (Murr.), O. Ktze., eine Art, die im tropischen Amerika und Afrika eine weite Verbreitung zeigt.

Der Charakter der trocknen Grasfluren Togos und der benachbarten Gebiete ist von dem der Steppen Ostafrikas wesentlich verschieden; in oberen Lagen herrscht eine Vegetation von Gräsern, die 
zum größeren Teil niedrig sind und einjährig wachsen oder nur schwache Innovationsbildung zeigen: auch die Grasfluren der unteren Lagen entsprechen anscheinend nicht dem Charakter der Hochgrassteppen Ostafrikas, sondern tragen wohl ein weniger xerophiles Gepräge, worauf auch das massenhafte Vorkommen von P'cunisctum purpurcum in den Niederungen hinweist. Früher wurden eine Anzahl von Arten erwähnt, die an sumpfigen oder feuchteren Stellen der Grasflur auftreten, aber auch wohl auf trocknere Standorte übergehen; gerade die charakteristischen Arten aber perennieren durch kräftige Neusprosse und unterscheiden sich so von ihren verwandten Formen, so daß sie doch wohl einer besonderen Formation angehören und ihre Standorte nicht nur gelegentlich feuchter sind.

Von den für Togo für die offenen Grasformationen erwähnten Arten gehen die meisten auch auf die mit Bäumen und Gebüsch bedeckten, offeneren Gelände über, auf die sogenannte Baum- oder Buschsavanne, Baumgras- oder Parksteppe. So finden sich in der Baumgrassteppe Panicum maximum Jacq., Andropogon rufus Kth., Andropogon diplander Hack., Aristida cocrulescens Desf., A. Inngiftora Schum. et Thonn., in der Buschsteppe Andropogon Gay'anus Kth., Aristida Kerstingii Pilger. Andropogen diplander Hack. kommt vor im Ghasalquellengebiet und in Westafrika südlich bis Huilla; die Art gehört zur Cymbopogon-Gruppe und bildet bis $3 \mathrm{~m}$ hohe, kräftige Halme; die Blattspreiten sind linealisch, bis 40-50 cm lang, am Rande sehr stark rauh; die große Rispe ist locker, stark verzweigt, mit rötlichen, die Trauben umgebenden kahnförmigen Spathen. Aristida cocrulescens Desf. ist mit A. adscensionis L. nahe verwandt und von ihr vielleicht nicht spezifisch zu trennen: die Art tritt im Mittelmeergebiet auf und ist im tropischen Afrika weitverbreitet, mit mehreren wohl unterschiedenen Varietäten. Sie geht auf mehrerlei Formationen iiber, kommt auch viel als Unkraut auf Kulturland vor. Die Halme des einjährigen Grases werden bis $60-80 \mathrm{~cm}$ hoch, die unteren Internodien sind gewöhnlich mehr oder weniger gekniet: die Blattspreiten sind sehr schmal, unregelmäßig mehr oder weniger von den Rändern her eingerollt, von derber Textur; die Rispe ist schmal, ziemlich dicht, mit kurzen Grannen.

In Ostafrika läßt sich gleichfalls beobachten, daß eine Reihe von Arten der offenen Grassteppe auf die Buschgrassteppe und Baumgrassteppe übergeht: so sind z. B. Andropogon schoenanthus L. und Eragrostis bifaria Vahl auf Geländen, die mit Akazien bestanden sind, häufig, ebenso (jmodun plectcstachy'um (K. Schum.) Pilger auf Buschsteppen im Kilimandscharogebiet weithin herrschend.

2. Kampine und niedrige, nicht xerophile Grasflur.

Besonders im westlichen und nördlichen zentralen Afrika sind Fluren von hochwiichsigen Gräsern entwickelt, dic nicht den ausgesprochen xerophilen Charakter der Hochgrassteppen Ostafrikas, der durch den Wechsel der günstigen und unguinstigen Jahreszeit bedingt wird, an sich tragen; für sie findet man in IVestafrika häufig den Ausdruck Kampine angegeben: solche fruchtbaren Gras- 
fluren treten auch noch im Seengebiet auf, wo ihre Zusammensetzung noch wenig bekannt ist. Im Gebiete des Kongo konnten wir z. B. Formationen flutender Gräser unterscheiden, wie sie an den großen Strömen reich entwickelt sind, dann im Anschluß an die Flüsse die Bestände der Gramineen auf mehr oder weniger durchfeuchteten sandigen Uferbänken, ferner auf sumpfigen und feuchten Wiesen. Große Gebiete nehmen nun im Anschluß daran die Hochgrasfluren ein, deren wichtigste Komponenten in Westafrika die folgenden sind: Urilytrun gigantum Pilger, Rhytachne congocnsis Hack., Andropogon squarrosus L. f. $\beta$. nigritanus Hack., Andropogon diplander Hack., A. schoenanthus L. b. densifforus Hack., I'micum maximum Jacq., I'. longepetiolatum Pilger, I'ennisetum Benthami Steud., P. purpureum Schum. et Thonn., P. Schweinfurthii Pilger, Trichoptoryx flammila (Trin.) Benth., T. grigantia Stapf, alles hochwüchsige Arten von teilweis mächtiger Größe. Trichoptery'x gigantca kommt vor im Ghasalquellengebiet, in Senegambien, im Kongogebiet und in Huilla; die aufrechten Halme werden über $3 \mathrm{~m}$ hoch: kurz ausläuferartige extravaginale Sprosse, dic mit starken Schuppen versehen sind, durchbrechen die seidigwollig behaarten Scheiden am Grunde des Halmes: beim Weiterwachsen verdicken sich diese Ausläufer stark rhizomartig und gehen in blühende Halme uiber, deren Grund von übereinanderfallenden, sich deckenden kräftigen Scheiden bedeckt ist; T. flummila, die in Afrika in Gabun, im oberen Kongogebiet und im Seengebiet vorkommt, ist sonst in Brasilien verbreitet.

Urelytrum sigantem, einer Gattung der Andropogoneen angehörend, die mit wenigen Arten auf das mittlere und siidliche Afrika beschränkt ist, kommt im oberen Kongogebiet vor: die mächtigen Halme schließen mit einer halbmeterlangen Rispe ab, deren starre, leicht zerbrechliche Äste wirtelig stehen; die breit lincalischen Blätter sind oberseits und am Rande stark rauh. Panicum longepitiolatum, der I'tychophyllum-Gruppe angehörig, ist auf das Ghasalquellengebict beschränkt: die langen lanzettlichen Blattspreiten gehen in einen bis $20 \mathrm{~cm}$ langen starken Stiel aus: Pchnisctum Schu'cinfurthii, mit I'. pontustachy'um Hochst. verwandt, kommt im Sudan vor in Gallabat, wo die Art größere Bestände bildet; die Blattspreiten des hohen Halmes sind bis $50 \mathrm{~cm}$ lang bei $2,5 \mathrm{~cm}$ Breite, oberseits und an den Rändern stark rauh: der dichte, ährenförmige Blütenstand wird über $20 \mathrm{~cm}$ lang.

Alle die erwähnten Gräser zeichnen sich vor den typischen Steppengrasern durch stark beblätterte Halme aus, deren offene Blattspreiten weicher, größer und breiter sind.

Besonders in Westafrika sind ferner mit niedrigen Gräsern bestandene Fluren verbreitet, deren Charakter gleichfalls nicht als xerophil bezeichnet werden kann: ihre wichtigsten Komponenten sind die folgenden: Andropogon brevifolius Sw., Panicum Hackelii Pilger, Panicum parvulum Trin., Panicum dcbilc Desf., Mclinisminutiflora P. Beaur., Sporobolus indicus L.' R. Br., Eragrostis biformis Kth., Trichopteryx reflexa Pilger. Panicum parvulum Trin., eine in den Tropen weitverbreitete Art der Digitaria-Gruppe, die in bestimmten Formen auch in Togo und im Sudan als Getreidegras kultiviert wird, ist z. B. in Gabun 
ein wichtiger Bestandteil dieser niedrigen Grasflur. Das Gras ist reichverzweigt und weit ausgebreitet; der Halm ist niederliegend, mit sehr kurzen Internodien; in den Scheiden entstehen hier blühende Äste, die zuerst horizontal sind und die Scheiden der kleinen Halmblätter nur wenig loslösen; dann richten sie sich senkrecht auf und werden so $15-25 \mathrm{~cm}$ hoch; die unteren Internodien dieser Äste sind kurz, dann folgen ein bis mehrere längere Internodien und der blühende Ast schließt mit der weit herausgehobenen, zierlichen, fingerförmig geteilten Rispe $a b$; die verzweigten Halmbasen sind die Fortsetzung stolonenartiger, niederliegender Triebe, die häufig ziemlich lang werden, ehe sie aus den Knoten die aufstrebenden Äste produzieren; die Blattspreiten sind klein, breit-lanzettlich, bis I cm lang. Aus diesem Wachstumsmodus folgt, daß das Gras schnell größere Strecken okkupieren kann; die oben erwähnten Arten derselben Formation stimmen im wesentlichen mit diesem Wachstumsmodus iiberein, indem nicht wie bei Steppengräsern Halm und Rasen mit kurzen Beisprossen scharf getrennt sind, oder einjährige Arten einen einzelnen, von den Scheiden zusammengehaltenen Busch bilden. Hier kann man keinen scharfen Unterschied zwischen einem blühenden Halm oder Ast machen; die reichverzweigten, niederliegenden Triebe gehen in bliihende Halme aus und geben seitlich ihnen gleichwertige blühende Äste ab; das ganze lockere Sproßsystem kann mehr oder weniger lange vereint bleiben oder in mehrere Individuen zerfallen; ferner sind die Arten durch kurze, offene Blätter ausgezeichnet.

So überzieht in Gabun in der-

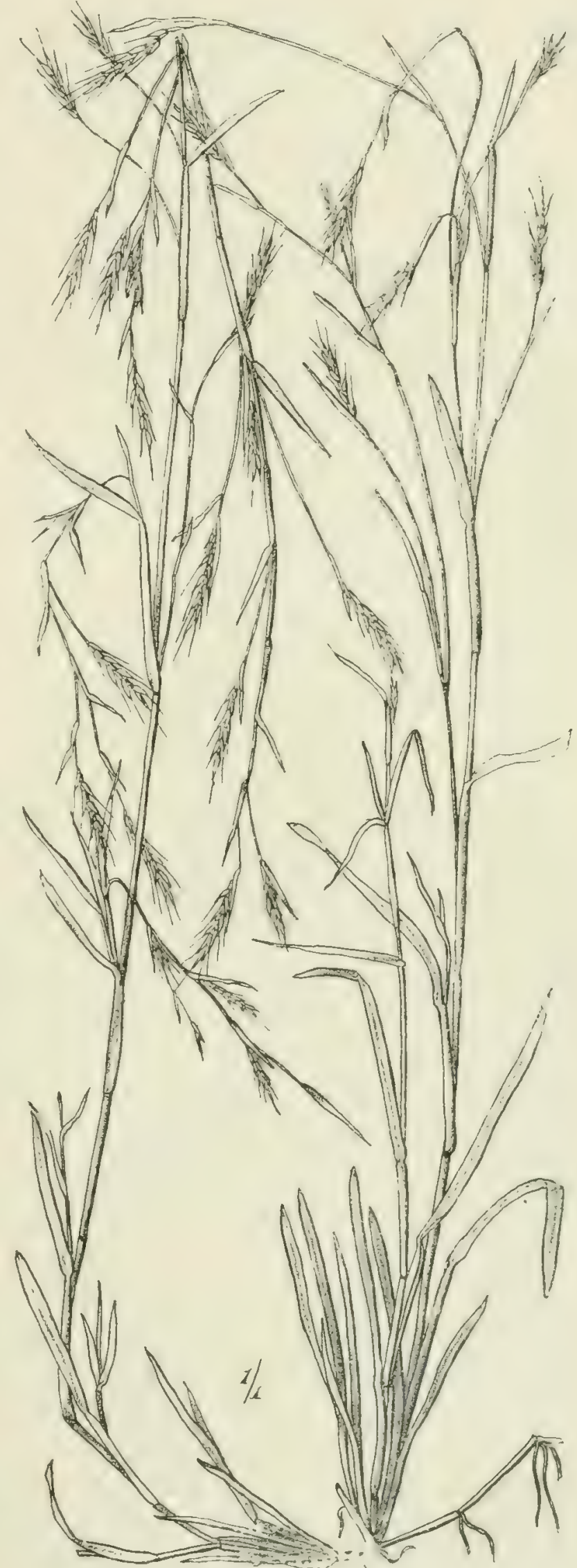

Fig. 122. Andropogon brevifolius Sw. 
selben Formation das endemische I'anicum (Digiturict) Hackclii große Strecken "filzartig", indem auch hier die zierlichen Halme niederliegen und verzweigt sind. Diesen Formen schließen sich Panicum debili, Eragrostis biformis Kth. und der sehr charakteristische Andropngon brciifolius an (vgl. Fig. 122). Letztere Art ist kosmopolitisch und auch in tropischen Afrika weitrerbreitet; sie hat äußerst zierliche, bis meterlange Halme, die fast aus allen Knoten dünne blühende Zweige hervorbringen. so daß die Pflanze wahre Dickichte erzeugen kann; die sehr feinen einzelnen Trauben sind von rötlichen Spathen umgeben. Die Art tritt auch in der niedrigen Grasflur auf, wie sie in Kamerun öfters bei etwa $900 \mathrm{~m}$ den Urwald ablöst. Hier geht auch Oplismenus hirtellus, eine ähnlich wie die oben erwähnten Gräser gebaute Art, vom Lrwald auf die Graslichtungen über, ferner Manisuris granularis L. f.

Ferner bilden einen wichtigen Bestandteil Trichoptery reftixa Pilger und Eragrostis ina'alida Pilger, zwei Arten mit sehr diinnen und zierlichen Halmen: von Eragrostis-Arten zeigen ein ähnliches Wachstum die in clieselbe Formation eintretenden Eragrestis biformis Kth. in Senegambien, Kamerun und Gabun und E. Cambessediana (Kth.) Steud. in Senegambien und Togo.

In Ostafrika finden sich im unteren Buschlande häufig große Strecken von Grasfluren, deren wichtigste Komponenten folgende Arten sind: Andropogon contortus, Panicum maximum, Eleusine indica, Dactyloctenium aegyptiacum, Eragrostis ciliaris, Eragrostis unioloides.

\section{Gräser im Gebirgsbusch Ostafrikas.}

In den Lichtungen des Gebirgsbusches, wie er sich in Ostafrika in Usambara und am Kilimandscharo in weiter Ausdehnung findet, treten zunächst eine Anzahl mehr oder weniger hochwiichsiger Andropogoni-Arten auf: Andropogon exothecus, A. cymbarius, A. hirtus, A. contortus. Die letztere Art kommt in vielerlei Formationen vor, A. cymbarius und A. him sind Steppengräser, A. ixothecus ist besonders in der Hochgebirgstegion verbreitet; die Arten sind perennicrend und xerophil ausgebildet; ihnen schließ3t sich an die dicht buschig wachsende Eragrostis superba und Pemisetum ciliura. Niedriger, aber gleichfalls dichte isolierte Rasen bildend ist Iiragrostis Horpachno, Schimperi, die in Usambara als das Hauptgras des Gebirgsbusches zu bezeichnen ist; ferner kommt in dieser Formation am Kilimandscharo das niedrige. kriechende I'mitcum parvulum Trin. vor.

Diese Formen gehen auch vielfach auf das offencre trocknere Wiesenland uiber. dann findet sich hier noch besonders Setaria aurea Hochst. f. minor Mez. Diese Form ist ausgeprägter xerophil als der Typus, niedriger, $50-60 \mathrm{~cm}$ hoch; eine Anzahl von Halmen bilden ein dichtes Büschel: die Scheiden der an Grunde zusammengedrängten Blätter sind kurz und zerfasern später mehr odur weniger, die Neusprosse sind meist intravaginal; manchmal verlängern sich die unteren Internodien etwas und verzweigen sich aus den Knoten, so daß der rasenförmige Wuchs aufhört: die Blätter sind schmal linealisch, lang, dünn, offen oder unregelmäßig eingefaltet oder am Rande eingebogen. 
Diesem Typus entsprechen auch einige Formen, wie wir sie aus den Sammlungen von Götze aus Ubena und Unyika von Plateaus bei 1600-1800 m kennen: Andropogon exothecus Hack., Anthephora Hochstetteri Nees var: glabra Pilger, Tristachya inamoena K. Schum., Evagrostis (Harpachnc) Schimperi (Hochst.) Benth., Erogrostis trachyphylla Pilger; letztere Art, mit der südafrikanischen E. brizoides Nees nahe verwandt, bildet kleine dichte Rasen mit mehreren Halmen und zahlreichen Neusprossen. Die wichtigsten Arten, die in Ostafrika in die an Gräsern arme Adlerfarnformation eintreten, sind Andropogon halepensis var. effusus und Setaria aurea fa. minor. Von letzterer Art gibt z. B. Buchwald für Usambara an, daß sie »fast das einzige Gras der Adlerfarnformation « ist.

4. Gräser des Buschsteppenvorlandes auf fruchtbarem rotem

Boden und schwarzem Boden.

In dem fruchtbaren Buschsteppenvorland, wie es in Ostafrika besonders als Übergang von der Gebirgsregion zur offenen Steppe vorhanden ist, herrschen wie in der offenen Steppe hochwüchsige Andropogon-Arten, die mehr zerstreut wachsen oder auch geschlossen Lichtungen des Busches besiedeln. Solche Arten sind: A. helopliilus $\mathrm{K}$. Schum., A. pertusus, A. purpureosericeus Hochst., A. hirtus, A. contortus L., A. halepensis var. effusus, A. schoenanthus, A. schirensis Hochst. In Usambara sind die wichtigsten A. helophilus, der häufig große Flächen einnimmt, und $A$. halepensis var. effusus. Ihnen schließen sich noch besonders folgende Arten anderer Gattungen an, die den reichen

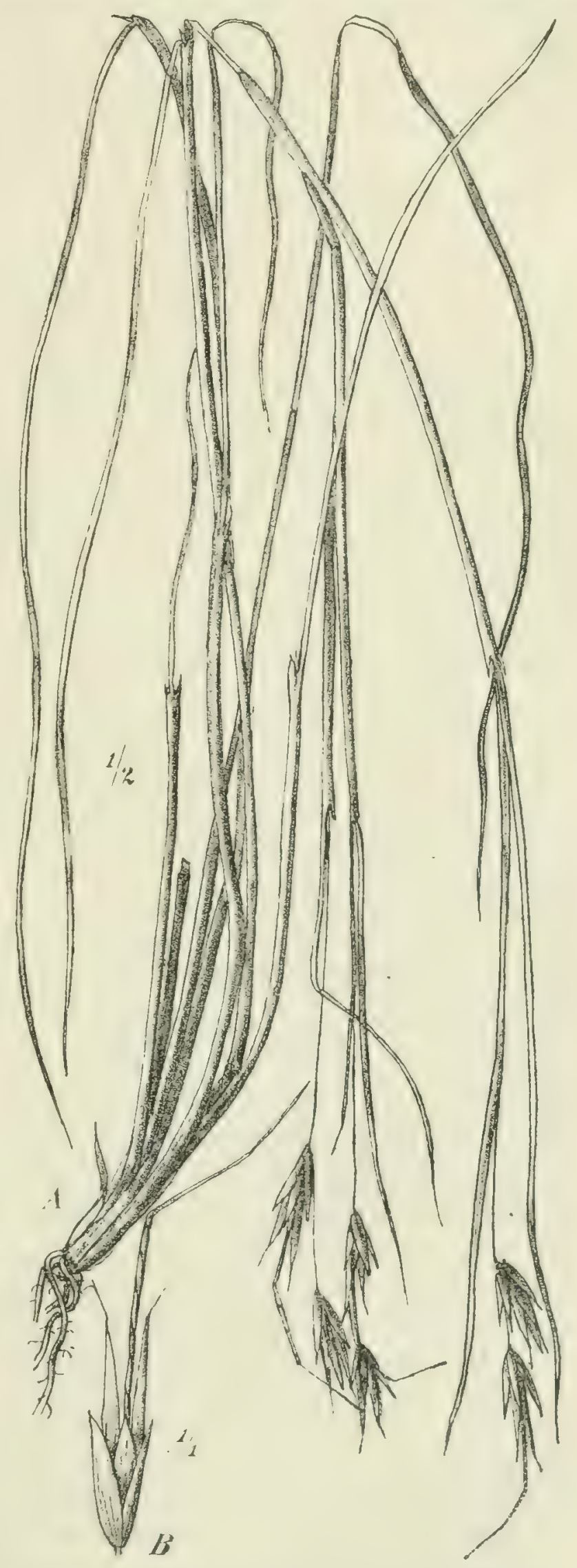

Fig. 123. Andropogon exothecus Hack. A Habitus; $B$ Ährchengruppe. 
Graswuchs dieser Gelände zusammensetzen: Ponicum maximum, Imperata arundinacea, Setaria aurea, Pennisetum ciliare, Pennisetum setosm, Elensine indica, Eragrostis tenuifolia Hochst., Eragrostis chalcantha Trin. var. Holstii K. Schum. Offene Flächen innerhalb des Busches besiedelt auch häufig in großen Massen Cynodon dactylon (L.) Pers., der sich durch seine Ausläufer leicht ausbreitet, ferner Lcptocarydion aulficastrum (De Not.j Stapf, ein bis meterhohes Gras mit dichter, ährenförmiger Rispe, das von Natal bis Usambara vorkommt. Eine zweite Art (L. alopccuroides Hochst.) findet sich in Abyssinien.

5. Gräser der oberen trocknen Bergweiden, felsigen Gipfel und Hänge der Berge.

In der baumlosen Zone oberhalb des Waldgürtels der Hochgebirge treten eine Reihe von Arten auf, die mit denen tieferer Zonen in keiner Beziehung stehen, sondern zu Gattungen gehören, deren eigentliches Verbreitungsgebiet als boreal bezeichnet werden muß. Am Kilimandscharo beginnen die Bergwiesen in einer Höhe von $2500 \mathrm{~m}$. Hier hat den hervorragendsten Anteil an der Bildung der Grasnarbe Eragrostis oliracea K. Schum.: die Pflanze wächst in einzelnen Stöcken, die aber stellenweise fast ausschließlich herrschen, wesentlich in einer Höhe von $2400-2700 \mathrm{~m}$; sie ist $30-40 \mathrm{~cm}$ hoch und bildet dicht geschlossene Büschel, die aus zahireichen zusammengedrängten intravaginalen Neusprossen bestehen: die Scheiden dieser Neusprosse sind kurz, ihre Spreiten dagegen, die starr, steif und sehr schmal, fast fadenförmig rundlich zusammengerollt sind, reichen häufig bis an die Rispe, die schmal und ziemlich dichtblutig ist. Die Art tritt auch in einer Hohe von $2000 \mathrm{~m}$ an trocknen Berghängen bei Kwai in Usambara auf.

Andere Arten, die auf den Bergwiesen des Kilimandscharo vorherrschen, sind folgende: Ancropogon exothecus Hack., A. amethytinus Steud., Agrostis Tolkensii Stapf, Agrostis producta Pilger und besonders Festuca macrophylla Hochst. Überblicken wir die habituellen Züge, die diese Gräser der gleichen Formation gemein haben, so ergibt sich, daß sie alle, wie Eragrostis cliz'acer, dichte geschlossene Büschel bilden mit zahlreichen intravaginalen Neusprossen, deren Blätter starre schmale, mehr oder weniger eingerollte oder gefaltete Spreiten haben; die meist zahlreichen rispentragenden Halme heben sich deutlich aus dem dichten Rasen heraus: bei Agrostis Tolkensiz sind die zierlichen Halme bis $40 \mathrm{~cm}$ hoch und knotenlos oder zeigen nur nahe dem Grunde einen Knoten: eine lange Scheide mit kurzer Spreite umhüllt sie zum größeren Teil, das obere Halmende ist nackt.

Einige von diesen Arten gehen auch auf die steinige Hochebene des Kilimandscharo weiter hinauf, so Aridropogon exothecus Hack. (vgl. Fig. I 23). Dieses Gras, das auch auf den nicdrigeren Gebirgen L'sambaras auftritt, erreicht auf den Bergwiesen am Kilimandscharo bei $2100 \mathrm{~m}$ cine Höhe von über $2 \mathrm{~m}$; von trocknen Bergwiesen am Nawenzi bei $2700 \mathrm{~m}$ stammen Exemplare, deren Höhe nur noch $50-60 \mathrm{~cm}$ beträgt, und schließlich sind im Krater des 
Kifinika, $3200 \mathrm{~m}$ über dem Meer, Exemplare von nur $30-35 \mathrm{~cm}$ Höhe aufgefunden worden.

Typische Hochgebirgsgräser der Lavafelder, Geröllhalden und steinigen Hänge sind Agrostis Volkensii Stapf, Danthonia bonussica K. Schum., Kocleria convoluta Hochst. und Festuca abyssinica Hochst. Agrostis I'olkensiz, die schon an Bergweiden auftritt, ändert an den höher gelegenen Standorten durch noch derbere und starrere Blätter ab, die Rispen erheben sich kaum über den dichten Rasen. Am klarsten zeigt den Typus der Hochgebirgsgräser der trocknen Standorte Danthonia borussica (vgl. Fig. I $2+A$ ); die Halme des Grases, das mit langen, derben Wurzeln ausgeristet ist, sind meist ungefahr $20 \mathrm{~cm}$ hoch, seltener bis $30-35 \mathrm{~cm}$ : sie sind am Grunde umgeben von dichten Rasen von intravaginalen Neusprossen, deren Scheiden alle kurz sind, lange erhalten bleiben und die in ihnen entstehenden weiteren Sprosse dicht zusammenfassen; die Blätter sind kurz und derb und von den Rändern her mehr oder weniger eingerollt; in einzelnen sterilen Sprossen, bei denen gewöhnlich die Scheiden dicht übereinander fallen, wird eines der sonst ganz verkürzten Internodien um $\mathrm{I}-2 \mathrm{~cm}$ verlängert und an der Spitze entsteht ein neues dichtes Sproßbuischel, wodurch der Rasen vergrößert und auseinandergezogen wird: schließlich können, wenn die Sproßbüschel auswachsen und blühende Halme hervorbringen, auch neue selbständige Rasen auf diese Weise entstehen; die blihenden Halme sind nur im unteren Teil von mehreren kurzen, übereinanderfallenden Scheiden umgeben, nach oben zu nackt, die Rispe ist sehr locker und trägt nur zarte, wenigblütige Zweige.

Mit mehreren Varietäten tritt im Hochgebirge des Kilimandscharo Koelcria convoluta auf, in deren verschiedenem Habitus sich deutlich der Einflu? des Standortes erkennen läßt. Der Typus, auch in Abyssinien verbreitet, kommt auf höheren, trockneren Bergwiesen vor; es gehören hierher kräftige, lockerwüchsige Pflanzen bis zu $70 \mathrm{~cm}$ Höhe: der Halm erhebt sich hoch über den Rasen, ist aber fast bis zum Grunde knotenlos und nur im unteren Teil mit übereinanderfallenden Scheiden bedeckt. Die Hochgebirgsform, var. z'olcanica Domin unterscheidet sich in einer Reihe von Merkmalen; sie bildet außerordentlich dichte Büschel mit zahlreichen intravaginalen Neusprossen, deren Blätter bedeutend kürzer sind (kaum je io $\mathrm{cm}$ erreichend), derb, starr, in der Mitte gefaltet und mit gewölbten Seitenhälften, so daß sie sich einer von den Rändern eingerollten Form nähern; der Rasen ist $10-15 \mathrm{~cm}$ hoch, die kurzen Halme ragen nur wenig über ihn hinaus. Die ganze Pflanze ist entweder kahl oder kurz abstehend steifhaarig (subvar. supina Engl... Die var. iolcanica gehört zu den letzten Blütenpflanzen des Hochgebirges, so kommt sie am Fuß des Kibo in einzelnen Büschen zwischen Felsblöcken vor, ferner auf Aschenfeldern am Westabfall der Mawenzispitze bei $4500 \mathrm{~m}$; ihr gleicht in dieser Hinsicht Danthonia borussica, die unter $3000 \mathrm{~m}$ nicht gefunden wird und am Kilimandscharo und Meru bei 3500-4000 $\mathrm{m}$ am häufigsten ist; am Kibo erreicht sie bei $4800 \mathrm{~m}$ die Vegetationsgrenze und am Merugipfel fand sie UhLIG in einer Höhe von $4700 \mathrm{~m}$ im Fclsgeröll. Bis zu gleichen Höhen tritt 


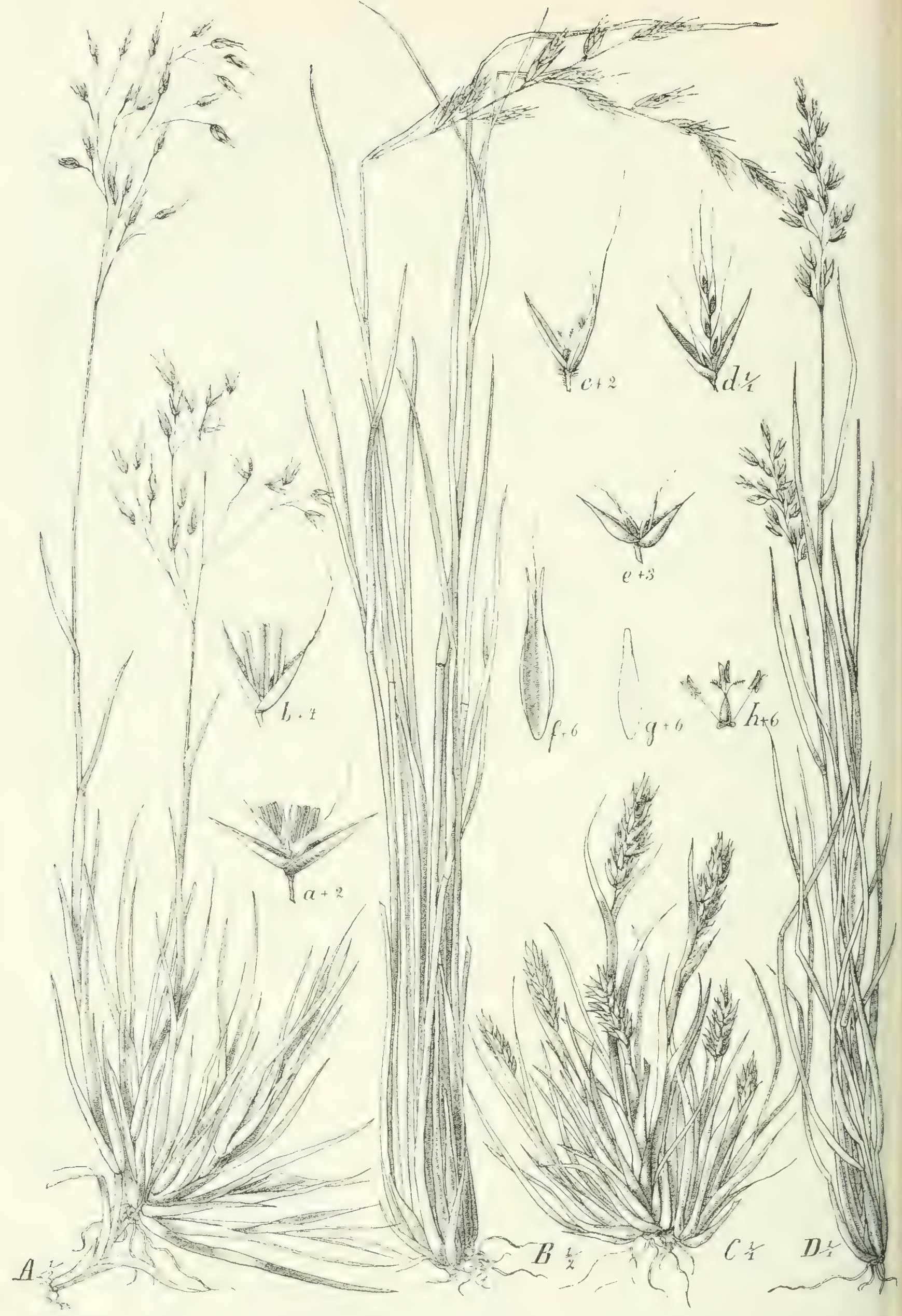

Fig. 124. A Danthonia borussica K. Schum., a Ährchen, $b$ Bluite mit Deckspelze und Vorspelze; $B$ D. subulata A. Rich., $d$ Ährchen, $C$ Blitte mit Deckspelze und Vorspelze; $C$ D. nana Engl.; $D$ D. trisetoides Hochst. var. tenuis Ensl., e Äbrchen, $f$ Deckspelze, $g$ Vorspelze, $h$ Blüte. 
auch Agrostis Iolkensii auf (nach UHLIG am Fuße des Ostkibo bis $4800 \mathrm{~m}$ ), und am gleichen Standorte in feuchteren Stellen der Felsklüfte eine niedrige Varietät mit starren Blättern von Festuca abyssinica.

Von den erwähnten Gräsern des Kilimandscharo-Hochgebirges sind Eragrostis olivacea, Agrostis producta, A. Tolkensii, Danthonia burussica endemisch: die anderen Arten finden sich auch im Hochgebirge Abyssiniens wieder, außerdem aber noch eine Reihe von Arten, die nicht nach dem Kilimandscharo iibergehen. Von wichtigeren Hochgebirgsgräsern trockner Standorte Abyssiniens sind zu erwähnen: Andropogon exothecus Hack., A. pratensis Hochst., Themeda triandre Forsk. var. punctate (Hochst.', Agrostis quinqueseta Hochst., Panicum muticum Forsk., Lira caryoplyyllea L., mehrere Danthonia-Arten, Kocleria convoluta Hochst., Poa pumilio Hochst., Poa simensis Hochst., I. Schimperiana Hochst., Festuca aby'ssinia Hochst., F. macroplyylla Hochst. Die höchsten Standorte erreichen hier z. B. an Gipfel des Bachit bei $4300 \mathrm{~m}$ Poa pumilio, eine ganz niedrige Art, und Danthonia nana Engl. (vgl. Fig. I 24 C), die bis $4500 \mathrm{~m}$ hinaufgeht; letztere Art ist mit $D$. anthoxanthiformis verwandt und stellt vielleicht nur eine sehr niedrige Hochgebirgsform von ihr mit dichten Rasen und intravaginalen Neusprossen dar.

Gleichfalls finden sich einige der erwähnten Arten in der Flora des Kamerungebirges wieder, die aber auch mehrere endemische Arten enthält. $\mathrm{Zu}$ ihnen gehört Trichoptery camenuncnsis Stapf: nach Angaben der Sammler bildet diese Form bei weitem den größten Teil der Grasdecke des Gebirges bei $2000-3000 \mathrm{~m}$. T. camcruncnsis unterscheidet sich von den gewöhnlichen Hochgebirgstypen durch Ausbildung von extraraginalen Neusprossen, die aber nicht kriechen, sondern aufrecht, kurz die Basis der blihhenden Halme umgeben; die Halme sind aufrecht oder aber auch im unteren Teile gekniet und mehr oder weniger ansteigend, mit mehreren Internodien von mehr gleichmäßiger Länge als sonst bei Gräsern der hohen Bergweiden. Wir werden nicht fehlgehen, wenn wir die eben beriihrten Charaktere als solche betrachten, mit denen die Hochgebirgsart mit den verwandten Arten der Gattung aus tieferen Regionen in Verbindung geblieben ist, denn 7 : comcrnmsis ist wie Andropogon cxothcous eine Art, deren Verwandte tropisch afrikanisch sind. Auf Grasflächen des Kamerungebirges kommen ferner vor Andropogon . Manniz Hook. f., A. Smithicmus Hook. f., A. amethystinus Steud., I'anicum pusillum Benth., Agrostis Mannii Hook. f.), Aira caryophyllea L., Streblochacte mutans Hochst., Danthenia clongata Hochst., Festuca aby'ssinica Hochst., Bromns serebridus Hook. f., und zu den größten Höhen des Piks steigen empor Kecleric convoluta Hochst. und Danthonia anthoxanthiformis Hochst.

\section{Feuchte und sumpfige Stellen der Hochgebirge.}

Einen wesentlich anderen Habitus zeigen eine Reihe von Formen der Hochgebirge, die an feuchteren Standorten wachsen, so das am Kilimandscharn endemische Anthoxanthum nivale K. Schum. (vgl. Fig. 125). Es tritt an feuchten Plätzen, wie an Schneequellen bei einer Höhe von $2800-3900 \mathrm{~m}$ auf. 
Die Pflanze perenniert mit extravaginalen Neusprossen, die entweder zusammengedrängt sind oder aber im unteren 'Teile ausläuferartig verlängert; der Grund aller Sprosse ist dicht mit breiten Scheiden besetzt; die Blattspreiten sind offen, ziemlich breit linealisch lanzettlich, gestreift, biegsam; unter der schmalen zusammengezogenen Rispe, die nur wenig herausragt, hüllt eine stark verlängerte Scheide den Halm ein. Ähnliche Be-

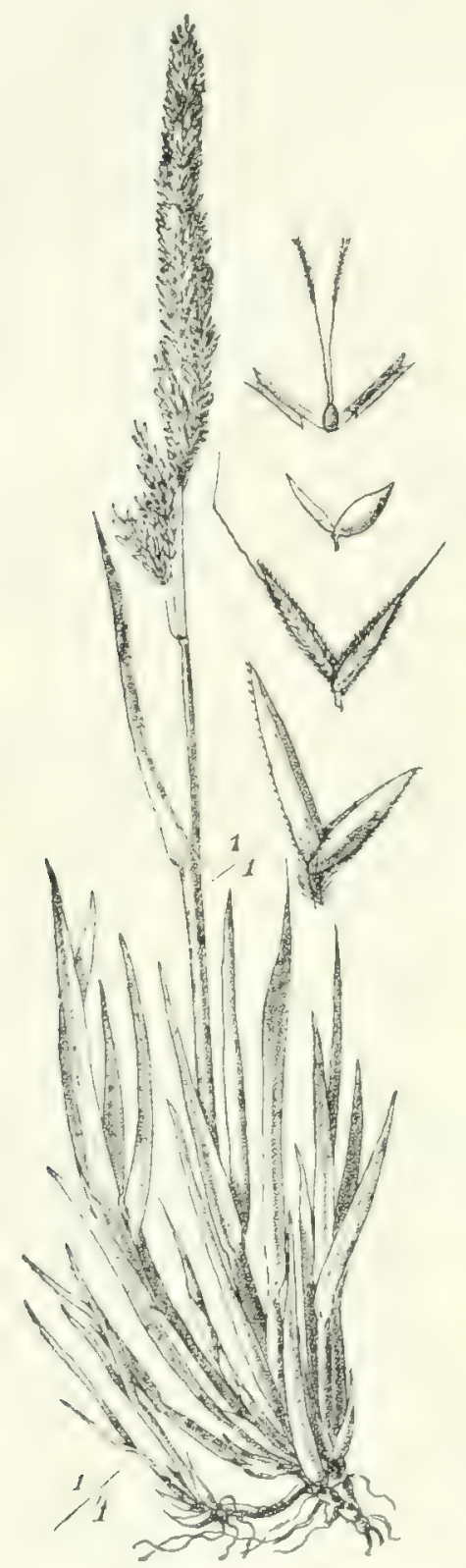

Fig. 125. Anthoxanthum nivale K. Schum. stockungsverhältnisse kehren auch bei Danthonia chrysurus K. Schum. wieder, die an feuchteren Stellen der Bergwiesen und Hänge bei $2700-3300 \mathrm{~m}$ auftritt; es ist dies ein prachtvolles, bis I $\mathrm{I}_{2} \mathrm{~m}$ hohes Gras mit bis $20 \mathrm{~cm}$ langer, reichblitiger goldgelber Rispe; die Halme bilden am Grunde extravaginale Sprosse, die mit derben, kurzen, dicht deckenden Schuppenscheiden besetzt sind und so mehrere Zentimeter wachsen, ehe die Scheiden länger werden und die Halmbildung beginnt; der Halm steht dann senkrecht aufrecht. Durch diese Bestockung werden die Halme einzeln voneinander getrennt; sie sind am Grund von einer Anzahl von übereinanderfallenden, sich deckenden Scheiden umgeben, deren äußere 4-5, deren innere bis $15 \mathrm{~cm}$ lang sind; alle Scheiden sind aufrecht, da sie keine intravaginalen Sprosse bergen; die Spreiten der Sproß- und unteren Halmblätter sind bis $40-50 \mathrm{~cm}$ lang, derb, schmal, von den Rändern her völlig zusammengerollt. Die Art der Scheidenbildung an der Halmbasis und die Art der Ausläufer ist überhaupt füir Gräser feuchterer Wiesen usw. charakteristisch.

$\mathrm{Zu}$ den Bewohnern feuchterer Standorte der Hochgebirge gehören ferner in Abyssinien: Panicum humile Hochst. und Crinipes abyssinicus Hochst., dann Agrostis-Arten, wie A. Schimperiana in Abyssinien und Deutsch-Ostafrika, und $A$. vestita in Abyssinien. Diese Formen von Agrostis zeigen ein lockeres Wachstum, schlanke zierliche Halme mit offenen dünnen Blättern, so daß sie vom Habitus der Formen trocknerer Standorte erheblich abweichen.

Was nun die verwandtschaftlichen Beziehungen der Hochgebirgsgräser anbetrifft, so fallen zunächst einige Gattungen auf, die sonst eine nördlichere Verbreitung zeigen und keine Verwandten in den niedrigeren Regionen haben. Hierher gehört Koeleria; $K$. convoluta ist mit $K$. cristata nahe genug verwandt; sie findet sich sowohl in Abyssinien, wie am Kilimandscharo und im Kamerungebirge: $K$. cristate ist in Sudafrika, zugleich in Nordafrika, Europa und Nordamerika verbreitet: gleichfalls kommt $K$. iristata oder verwandte 
Arten in den Hochgebirgen Asiens und Südamerikas vor. Airc caryoply llea L. findet sich in Abyssinien und auf dem Kamerungebirge; sie geht auf tiefere Regionen nicht über, wie sonst in ihrem Verbreitungsbezirk im Kapland (südliches Kapland), Mittelmeergebiet und Zentraleuropa. Anthoxanthum nirale' ist endemisch am Kilimandscharo, ohne Verwandte in Abyssinien; vier Arten der Gattung treten in Europa auf, eine davon auch in Nordasien und Nordamerika. Agrostis und Festuca sind mit zahlreichen Arten über die ganze Erde verbreitet, besonders aber auf der nördlichen Hemisphäre entwickelt: in Südamerika sind die Festuca-Arten meist Bewohner der Hochanden. Nicht alle Arten sind im tropischen Afrika auf die Hochgebirge beschränkt, doch sind sie vorzugsweise auf ihnen entwickelt und finden sich so besonders in Ostafrika, in Süden auf den Milandjibergen noch $F$. milandjiana Rendle: in Südafrika treten drei endemische Arten auf, F. scabra Vahl, durch ganz Suidafrika verbreitet, $F$. costater Nees und $F$. longifes Stapf im südlichen und östlichen Kapland.

Danthonica ist im Gegensatz dazu eine Gattung; die wesentlich auf der südlichen Hemisphäre ihre Heimat hat; speziell gehört D. borussica $\mathrm{K}$. Schum. zur Pentaschistis-Gruppe, die fast ganz auf Südafrika beschränkt ist, wo zahlreiche Arten in allen Provinzen auftreten; als Hochgebirgsgräser sind Danthonien z. B. auch in Neuseeland und auf den Anden Südamerikas anzutreffen. Von Gebirgsgräsern Afrikas, die zu Gattungen gehören, die auch sonst im tropischen Afrika reichlich entwickelt sind, sind zu nennen: Trichopterytr camerunensis. Andropogon erothecus und A. ancthy'stinus, I'anicum pusillum, Evagrostis olivacea.

\section{E. Gräser rein xerophiler Formationen.}

I. Gräser sandiger Flächen.

Als Länder mit Sandstrecken in größerer Ausdehnung kommen besonders das Kunenegebiet und Damara-Namaland hier in Betracht. Ber Besprechung der Dünengräser waren zwei Eragrostis-Arten, E. cypcroides und E. spinosa erwähnt worden, die aber auch in geeigneten Geländen auf das Binnenland übergehen. Besonders E. spinosa, das Togelstraußgras, mit seinen starren dornigen Rispen ist in den Wüsten des Inlandes verbreitet, wie sie namentlich von der Küste aus sich weit in das Innere erstrecken; die erwähnten Gräser sind an Standorte mit beweglichem Sand gewohnt; ihre Sprosse werden von Sandmassen bedeckt, unter denen sie sich wieder hervorarbeiten; sie erhalten so ihren unregelmäßigen Wachstumstypus mit stark verlängerten kriechenden Sprossen oder dichten Büscheln kurzer bluihender Sprosse. Athnlich ist es im Norden mit den Acluropus-Arten, die Bewohner sandiger Küsten des Mittelmeeres und des Roten Meeres sind, aber z. B. in die Wüsten am Roten Meere übergehen. wo sie kleine Bestände bilden, besonders auf stark salzhaltigem Boden eingetrochneter Tümpel. Im allgemeinen gehören die Eragrostis-Arten nicht zu den Wüstenberohnern und so extrem angepaßte Typen wie E. sfinosa fallen stark aus dem Typus der Gattung heraus. Auf Sandstrecken wüstenähnlichen Charakters kommt im nordwestlichen Afrika ferner vor E. bifinnatı 
(L.) K. Schum. (nach ST.IPF der Vertreter einer eigenen Gattung Desmostachy'a); sic ist verbreitet in Indien, Arabien, Ägypten und durch Kordofan-Sennar bis Deutsch-Ostafrika. Die Art ist durch kriechenden Wurzelstock, lange Ausläufer, sowie durch kräftige Halme mit starren, schmalen Blättern und ährenförmigem Bliitenstand ausgezeichnet; sie bewohnt Meeresküsten, kommt dann aber in Wuisten an salzhaltigen Stellen vor, auf Binnendünen mit beweglichem Sande, so auf Sandbänken des oberen Nilgebietes, wo sie wie andere Dünengräser durch ihre Fähigkeit losen Sand zu binden, von Nutzen ist.

Von gleichem Typus ist Cynodon dactylon, der auch in Südwestafrika auf Sandfächen des Inlandes übergcht, aber kein Wüstengras ist, wohl eins der wichtigsten Futtergräser dieser Gegenden, von dem WEimITSCH sagt für Golungo Alto): the only kind of grass in the district, which can be given without danger to horses: ebenso gefährlich ist aber das Gras als Eindringling in die Kulturen der verschiedensten Art.

Ein zweiter Typus der Gräser wïstenähnlicher Strecken Südwestafrikas, besonders auf Sandboden, der sich dem oben beschriebenen annähert, ist die halbstrauchige Form, wie sie in Damaraland und Namaland z. B. in Ehrharter aphlyllar Schrad., Aristide namaquansis Trin., Aristida fastigiater Hack., Triraplizs romosissima Hack. verkörpert ist. Ehrhervte aflylla ist bis fast meterhoch, reich verzweigt mit nach unten zu holzigen Halmen; die Zweige stehen einzeln oder in Buischeln: die derben Scheiden sind meist ganz blattlos, seltener mit kurzen, sehr schmalen, stacheligen Spreiten versehen. Die Art kommt in Nama-Land bei 1500-1700 $\mathrm{m}$ Höhe vor. Triratlis ramosissima Hack. bildet in den steinigen wiistenähnlichen Geländen, die in Groß-Namaland bei Keetmanshop dem Aub-Rivier folgen. eine fast halbstrauchige Form aus mit mehreren unterwärts holzigen Halmen, die teilweise ron Scheiden entblößt und aufrecht und büschelig verzweigt sind; bei einer Form auf sandigem Boden bei Windhoek in Damaraland sind die Halme nicht holzig und mit Scheiden bedeckt; sie brechen in großer Anzahl aus den sehr starken niederliegenden Rhizom seitlich hervor; alle Neusprosse sind extravaginal.

Ferner ist Aristidu fostigiata I Iack. ron Groß-Namaland cine halbstrauchige Art; der perennierende Teil der Pfanze bildet einen holzigen aufrechten, mit kurzen Trieben reich rerzweigten Busch. der blattlos mit kurzen Schuppen beKleidet ist; alle Neusprosse sind extravaginal; die Blätter sind kurz, starr, zusammengerollt. Die Art gehört zur Selition Stipagrostis, bei der die Grannen zierlich seidig-federig behaart sind, ebenso wie A. namaquensis; letztere hat ein lang kriechendes, ausläufertrcibendes Rhizom; die büschelig gedrängten aufsteigenden oder aufrechten Halme sind unterwärts holzig, mit sehr starren, stechenden Blättern versehen. Die Art kommt in Klein- und Groß-Namaland vor; so ist sie z. B. in außerordentlich starrer und kräftiger Form, mit bis $2 \mathrm{~m}$ hohen, von Scheiden größtenteils entblößten Hahmen auf Sanddünen zwischen Gibeon und Keetmanshop anzutreffen, wo ihre Sprosse weithin den Sand durchdringen. Zwischen dem Typus der Gräser mit langkricchenden Sprossen und den halbstrauchigen Formen existieren natülich Übergänge, wie einen solchen 
schon A. namaquensis darstellt. Gleichfalls gehört hierher Diplaclene paucinereris (Nees; Stapf ( $D$. cincrece Hack.), dic in Damaraland in den Dünen der Walfischbay, in den trocknen Flußbetten bei Swakopmund, sowie im Inlande bei Salem am Swakop und auf salzig-sandigen Flächen an der warmen Quelle bei KleinBarmen um II $50 \mathrm{~m}$ vorkommt; die Pflanze ist graugrün, halbstrauchig, mit niederliegenden mit außerordentlich starren Schuppen bekleideten Sprossen mit ansteigenden büschelig verzweigten Ästen; die Zweige sind dicht mit Blättern bekleidet, deren abstehende Spreiten kurz, sehr derb, offen, linealischdreieckig und stechend sind; die Epidermis trägt Papillen, die austrocknend mit Luft erfüllt die graue Farbe erzeugen.

Zur Sektion Stipagrostis von Aristida gehören eine Reihe der bekanntesten und typischsten Wüstengräser der alten Welt, sowohl im siidwestlichen, wie im nördlichen Afrika und Vorderasien. Sie sind meist von der oben beschriebenen Form durch die Bildung dichter, starrer, niedriger Büschel unterschieden, also mit basaler, zusammengedrängter Verzweigung. Eine solche charakteristische Art ist die in GroßNamaland aufWüistensand vorkommende Aristida obtusa Del. (Fig. 126); sie bildet ein außerordentlich dichtes, kurzes Büschel mit zahlreichen kurzen, zusammengedrängten Neusprossen, aus dem sich scharf abgesetzt eine Anzahl niedriger (bis $30 \mathrm{~cm}$ ), dünner Halme erheben. Diese haben nur einen Knoten, das untere Internodium ist zum größten

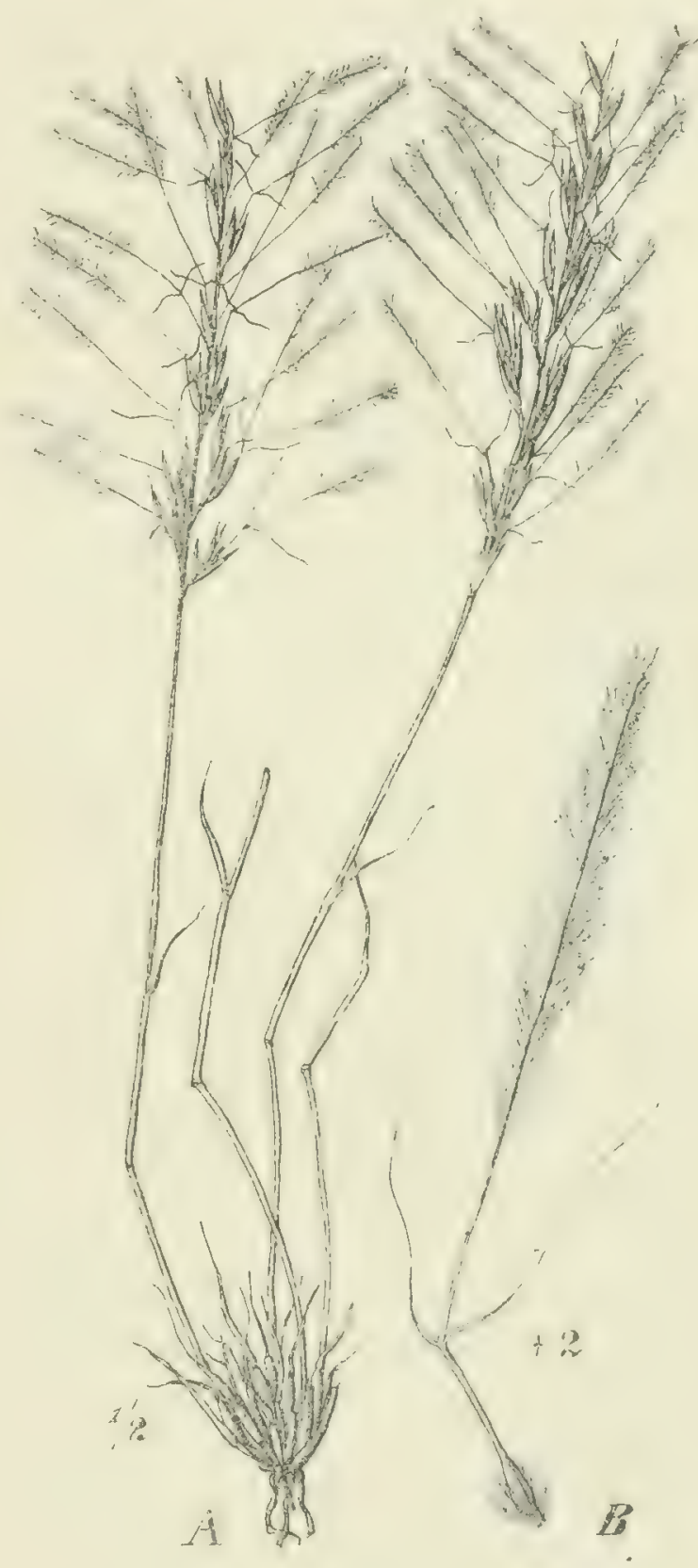

Fig. 126. Aristida obtusa Del. A Habitus; $B$ Ährchen. Teil von der kurzen, im Rasen verborgenen Scheide frei: die Rispe ist schmal und zusammengezogen. Die Blattspreiten sind gerühnlich sehr liurz, starr, gebogen, graugruin, schr schmal, von den Ründern her cingerollt, so daß diese zusammenstoßen; dic Scheidenmündung ist mit cinem Bïschel weißseidiger, spreizender Haare belkeidet. Aus dem Rasen brechen Gruppen von langen, kräftigen Wurzeln hervor, die mit einem dichten Fil\% bel-leidet sind, cler Sand festhält, so daß die Wurzeln mit einem Mantel von Sand umgeben sind. Diese Eigentimlichleit findet sich bei allen, 
auch einjährigen Gräsern, die Sandwüsten bewohnen. Von A. obtusa ist auch eine Form bekannt, bei der die Blattspreiten noch feiner fadenförmig und bis I $5 \mathrm{~cm}$ verlängert sind, ohne daß sonst Unterschiede vorhanden sind; auch existieren zwischen beiden Formen allerhand Übergänge. Zwei ganz ähnliche Typen von Damara-Namaland sind Aristida ciliata Desf. und A. uniplumis Lichtenst. Letztere Art bedeckt in Groß-Namaland auf Sandebenen größere Strecken fast ausschließlich, *wie gesät». Beide Formen, die halbstrauchige und die dicht kurzbüschelige kehren auch in den Wüsten Nordafrikas und Vorderasiens wieder, zu ersterer gehört A. pungins Desf., zu letzterer A. hivtigluma Steud. Diese Art ist auf Sandflächen in Abyssinien bei 1000-1500 m, sowie am oberen Nil verbreitet.

Die halbstrauchige Form, sowie dic Form der Dünengräser bedingt naturgemäß einc ausschließlich oder vorwiegend extravaginale Innovation; daß aber auch bei dieser eine dichtere Rasenbildung erfolgen kann, läßt sich an Exemplaren von Aristida Hoiktettcriana Beck erkennen; die Art ist leicht kenntlich durch ihren einfach traubigen Blütenstand, aus dem die seidigen Grannen hervorsehen; sie kommt in Damaraland sowie in Groß-Namaland vor; die Neusprosse werden extravaginal erzeugt, sie sind aber nur kurz und aufrecht und bilden ein dichtes Büschel, aus dem sich die zierlichen aufrechten Halme herausheben; seltener nur gewinnt der Rasen durch teilweise Verlängerung unterer Internodien ein mehr buschiges Aussehen.

Aus anderen Gattungen entspricht dem Typus von Aristida obtusa z. B. Anthephorar pubescens Nees, die an vielen Stellen in Damara- und Namaland besonders auf Sandboden vorkommt; die Art bildet dichte, kräftige, manchmal vielstöchige Büschel, deren Halme am Grunde öfters von sich zerfasernden Scheiden dicht umhiillt sind, die auch die intravaginalen Neusprosse einschließen; die Halme sind aufrecht, mit lang herausragendem schmal ährenförmigem, zottig behaartem Bluitenstand; die Blattspreiten sind offen, derb, schmal linealisch, lang verschmälert. Wie ersichtlich weicht die Art im Habitus gänzlich vom Typus der Gattung A. elegans Schreb. ab, der in der var. cristata Döll von Gabun bis Loanda auf sandigen Wiesen, in Kulturen usw. vorkommt, sonst im tropischen Amerika verbreitet ist. Diese Art hat niederliegende Halme, die an den Knoten kurz berrurzelt sind und aufrechte, blihende Äste erzeugen. Dagegen ist A. Hoihstittiri Nees im Habitus entsprechend, die in Abyssinien auf steinigen Bergen bei 2000 m vorkommt, dann wieder im Seengebiete auftritt, wo die Art einmal ron Fischer bei Kagehi gesammelt wurde; eine besondere Varietät, var. glabra Pilger, kommt im Nyassaland vor, wo sie. GöTZE auf trocknen Wiesen bei $1750 \mathrm{~m}$ sammelte. Auch Andropogon contortus L., die iffter erwähnte, weitrerbreitete Art, ist häufig in Damaraland auf sandigem Boden. Er ist ebenso wie Schmiltia bulbosa Stapf und Pogennarthria falcata (Hack.) Rendle eine weniger ausgeprägt xerophile Art.

Von perennierenden Paniceen aus Damara-Namaland seien erwähnt Tricholaena arenaria Nees, sowie Pennisetum geniculatum (Thunb.) Leeke und $P$. Fonmerianmn Lecke. Alle drei haben ein kriechendes, kräftiges Rhizom 
mit ansteigenden Halmen und schmalen, derben, meist eingerollten Blättern. Auffallend ist nun die große Anzahl der im Amboland und Damara-Namaland, im Inlande, nicht im Wüstenstreifen der Küste auftretenden einjährigen Gräser; es ist oft nicht leicht zu sagen, ob eine Art wirklich einjährig ist und alle in den Scheiden entstehenden Sprosse noch in derselben Vegetationsperiode zur Bliite kommen läßt: jedenfalls blühen dic Gräser im ersten Jahre und sind durch mangelnde Rhizombildung und Zuriicktreten der bei den perennen Arten so außerordentlich stark markierten xerophilen Charaktere bemerkenswert. Meist werden diese Gräser von den Sammlern als Sandbewohner bezeichnet; eine Einteilung der Standorte nach mehr oder weniger wüstenähnlichem Charakter oder dem einer trocknen Grasflur auf Sandboden vermag ich nach den mangelhaften Angaben der Sammler nicht zu geben: hier wie bei den perennierenden Arten des Inlandes, besonders der Gebirge, wird ein scharfer Unterschied zwischen Sandboden und Steinboden nicht zu machen sein, da das zu Sand zerfallende Gestein mehr oder weniger von der Bedeckung entblößt sein kann oder unter einer tieferen Schicht lockeren Sandes sich verstecken kann. Im folgenden seien eine Reihe der wichtigeren Arten aufgezählt: ihre weiteren oder engeren Verbreitungsbezirke sollen später im Zusammenhang gegeben werden: Panicum (s brachiaria) grloneratum Hack., P. xantholancum Hack., P. brachymm Hack., P. (Eupanicum) Schinaii Hack., Tricholaend breititila Hack., Anthephore Schinsii Hack, A. mululatifolia Hack., Tragus racemosus (L.) Hall., Perotis vaginata Hack., Aristida coemulescens Desf., A. gracilior Pilger, A. subacaulis (Nees) Steud., A. stipiformis Poir., Sporobolus nebulosus Hack., Chloris virgata Sw., Triraphis purpurea Hack., T. Fleckii Hack., Schmidtica quinqueseta Benth., Pappophorum cenchroides Licht., Eragrostis membranacea Hack., E. hereroensis Hack., E. ramosa Hack., E. namaquensis Nees, E. cchinochloided Stapf, E. brismutha Nees, E. porosa Nees, Lasiochloa utriculosa Nees. Die meisten dieser Gräser haben offene, linealische bis lanzettlich-linealische, diinne, häufig schlaffe Blattspreiten; ein typisches Beispiel dafür ist Anthephore undulatifolia Hack. Hiervon sind ausgenommen Sporobolus nebulosus, sowie Aristida gracilior und A. subacaulis, die eingerollte Blattspreiten haben: Übergänge mit schwach eingerollten oder gefalteten Blattspreiten zeigen Panicum brachyurum, Aristida coemulescens, A. stipiformis, Chloris virgata, Eragrostis membranacea, Lasiochloa utriculosa. Was'den Habitus anbetrifft, so haben nur wenige Arten, wie Tragus racemosus, niederliegende Halme mit aufrechten blühenden Ïsten; meist sind die Halme, die zu mehreren bis vielen im Rasen zusammenstehen, aufrecht oder ansteigend und dann mehr oder weniger gekniet; zwischen beiden Formen existieren Übergänge; fast immer aber gehen alle Halme von cinem gemeinsamen Centrum aus. Tragus racemosus ist einjährig (oder vielleicht auch perenn?) mit mehr oder weniger zahlreichen Halmen: diese sind entweder aufrecht oder an den untersten, z. T. von Scheiden ganz freien Internodien niederliegend und häufig sogar an den Knoten bewurzelt; sie bilden im allgemeinen einen deutlich zusammengefaßten Busch, die Pflanze verliert aher diesen Habitus, wenn die 
niederliegenden IJalme sich verzweigen und sekundäre Rasen erzeugen: die Internodien am Halme sind kurz und ziemlich gleichmäßig; die Blattspreiten sind offen. kurz, derb, stark gestreift, am Rande stachelig gewimpert. Ähnlich ist häufig Schmidtia quinquiseto gebaut (vgl. Fig. I 2-j), die aber längere, schlaffere Blätter hat: die Pflanze bedeckt \%. B. bei Otjimbingue Sandflächen so dicht wie ein Getreidefeld: sie ist entweder rasenbildend mit mehr oder weniger aufrechten Halmen oder die Halme kömnen lang niederliegun und sich an den

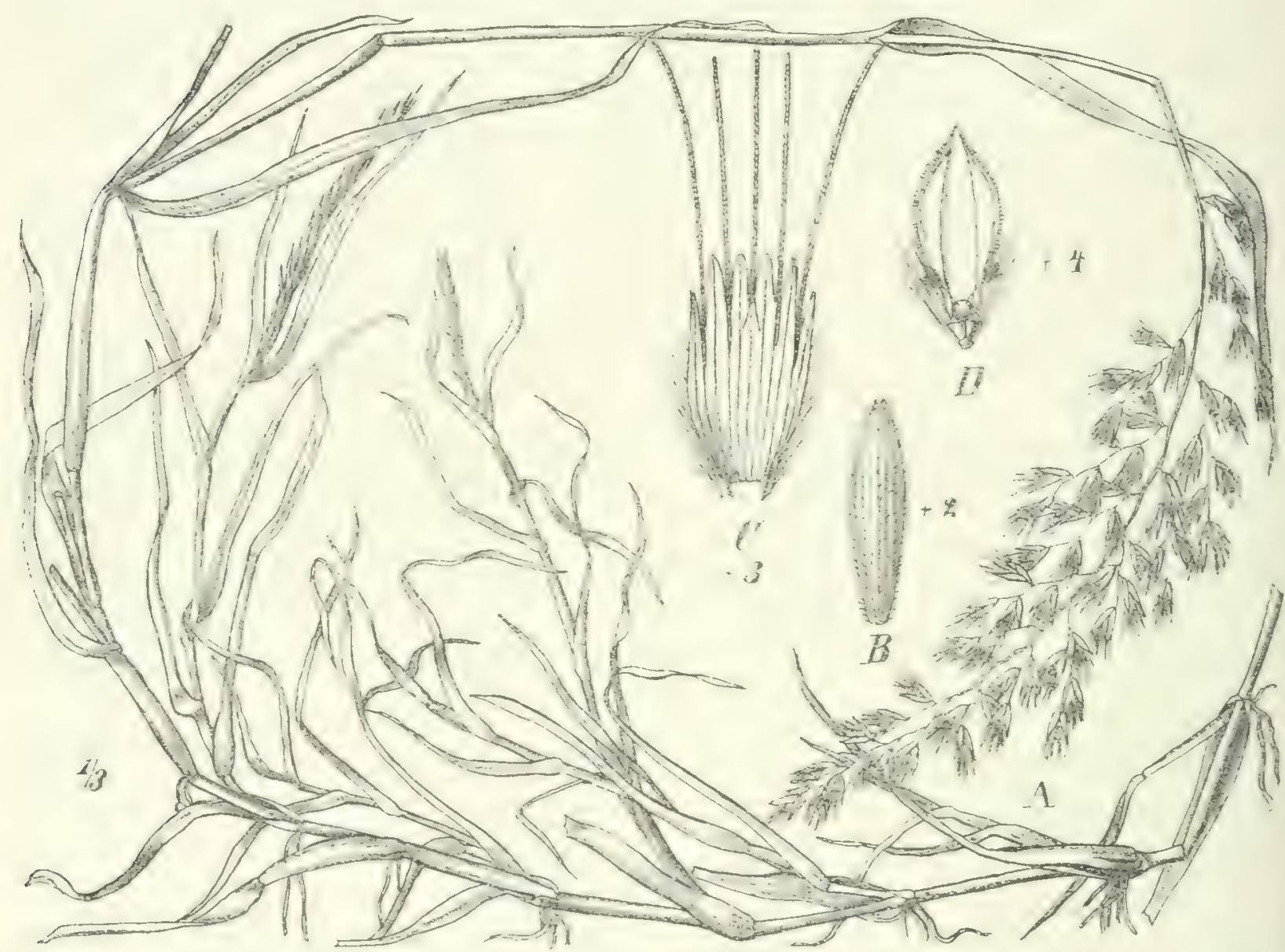

Fig. 127. Schmidtia quinqueseta Benth. A Habitus; $B$ Hüllspelze; $C$ Deckspelze; $D$ Trorspelze mit den beiden Schiippchen und der Blüte.

Knoten bewurzeln. Die verwandte perennierende Art Sch. bulbosa hat kurze dicke, zusanmengedrängte; aufrechte extravaginale Neusprosse: clurch die die Basis der Pflanze knollig angeschwollen erscheint.

Stärker zur geschlossenen Rasenbildung als Sch. quinqueseta neigt Chloris irirgata, die im ersten Jahre blüht, aber auch wohl perenniert (vgl. Fig. I 28). Meist wird ein dichter Busch mit aufrechten Halmen ausgchildet, doch sind auch einzelne Halme am Grunde kurz niederlicgend. scharf gekniet und aus Cen Knoten verzweigt und bewurzelt. Diesem Typus schließen sich an: Trootis vaginata Hack., Panicum glomeratum, Triraphis purpurea, T. Flcckit, Eragrostis ramosa, E. echinochloidea, bei denen einzelne Halme am Grunde mehr oder weniger gelsniet und niederliegend sind, sich aber fast niemals bewurzeln. 
Zahlreiche Arten bilden mehr oder weniger dichte Rasen aus, in denen alle Halme aufrecht sind. $Z u$ den höheren Formen gehört Aristida stipiformis, die wohl auch perenniert. Die kräftigen Halme sind bis über meterhoch, mit meist drei Internodien; am Grunde ist der Halm von einer Anzahl dicht übereinander fallender, sich deckender Scheiden umgeben, die mehr oder weniger auseinanderspreizen; intravaginale Neusprosse werden in geringer Anzahl entwickelt; häufig werden einzelne blühende Seitenzweige aus den Halmknoten entwickelt; die Rispe ist groß und weit, mit den zierlichen Ästen locker ausspreizend; die Grannen sind lang und stark rauh; die Blattspreiten werden bis über $50 \mathrm{~cm}$ lang und sind sehr schmal und von den Rändern her völlig oder teilweise eingerollt; der Rasen bildet starke Wurzelbüschel, die Wurzeln sind dicht behaart und mit einem Mantel von Sand umgeben, wie es bei den meisten Arten der Fall ist. $\mathrm{Zu}$ den hochwüchsigeren Arten, deren Halme bis ungefähr $75 \mathrm{~cm}$ hoch werden, gehören ferner Panicum brachynum, Panicum Schinzii, Eragrostis membranacea, Eragrostis echinochloidea. Eine Anzahl von typisch einjährigen Arten mit kurzer Vegetationszeit, die gewöhnlich dichte kleine Rasen bilden, bleiben dagegen äußerst niedrig; so ist Aristida subacaulis nur ungefähr $3 \mathrm{~cm}$ hoch, Triraphis purpurea 8-12 cm;

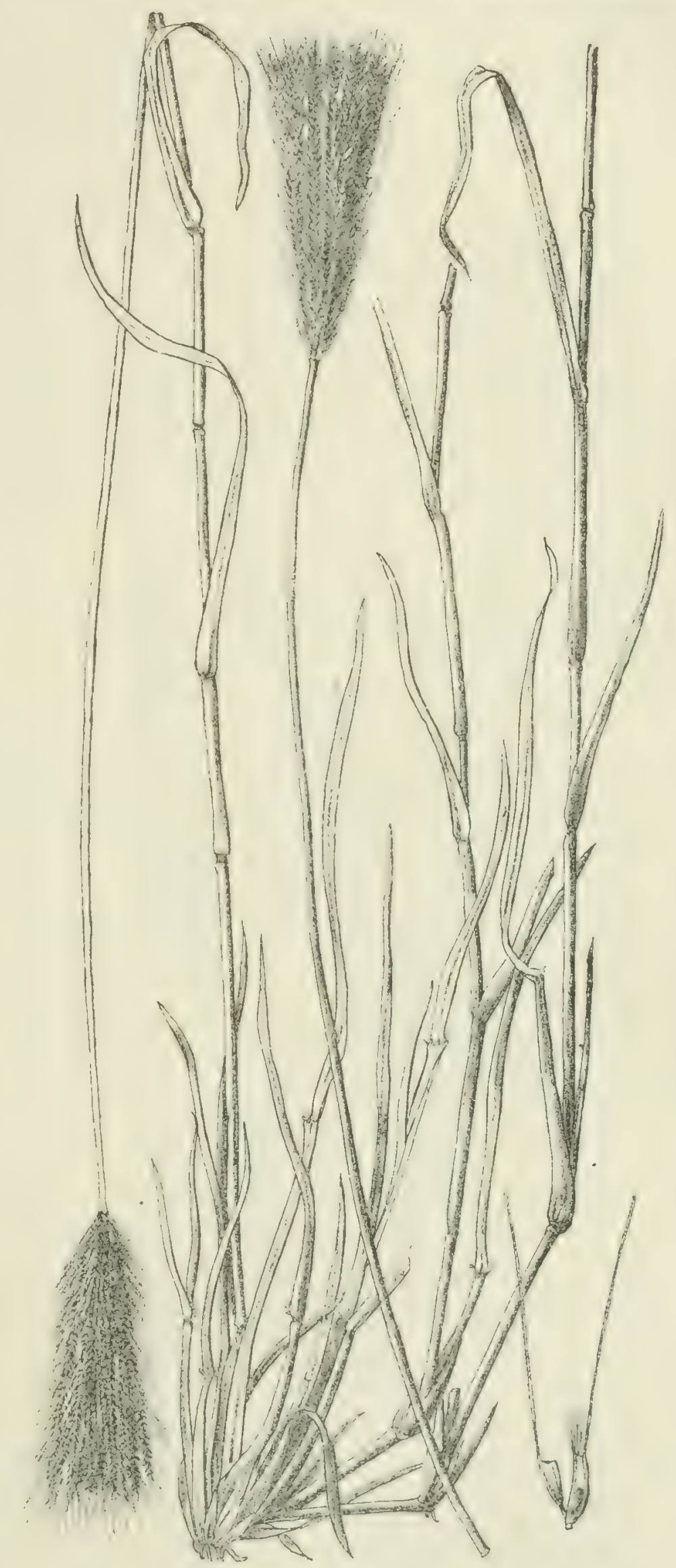

Fig. 128. Chloris virgata Sw. 
bei Eragrostis hereroensis sind die Halme nur $4^{--6} \mathrm{~cm}$ hoch, die sie abschließende lockere Rispe aber ungefahr Io cm; bei der größeren Zahl von Arten liegt die Höhe der ganzen Pflanze zwischen 20 und $40 \mathrm{~cm}$.

Bemerkenswert ist, daß eine Reihe von Arten an den Blattspreiten und Scheiden mit weichen abstehenden Haaren bekleidet ist, die häufig drüsig-klebrig sind, so daß man dann nieder-

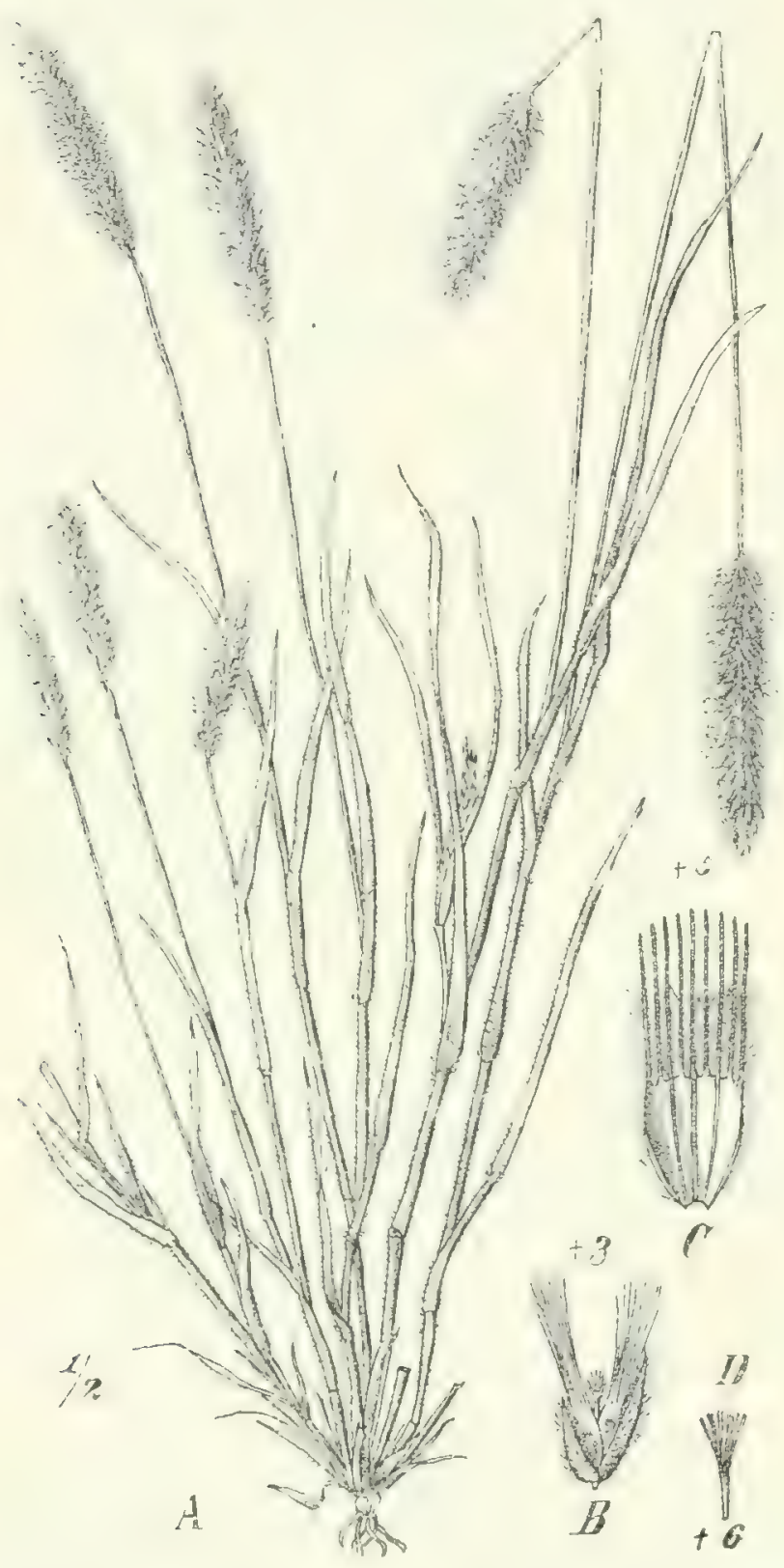

Fig. I29. Pappophorum cenchroides Licht. $A$ Habitus; $B$ Ährchen; $C$ Deckspelze; $D$ Achsenfortsatz. liegende Teile der Pflanze mit zahlreichen Sandkörnern behaftet findet; hierher gehört Schmidtic quinqueseta, Panicum glomeratum und P.xantholeucum, Pappophoram scabrum und $P$. cenchroides (vgl. Fig. I 29); auch sitzende klebrige Drüsen kommen vor, so bei Eragrostis porosa und $E$. anmulata: andere Arten, wie Lasiochloo utriculosa und Triraphis Fleckii sind mit steifen Borstenhaaren bekleidet, die auf kleinen Warzen sitzen.

In den jetzt berührten Gebieten von Amboland bis Klein-Namaland haben die Arten und Gattungen teils Anschlu $B$ an die südafrikanische Flora, teils an die tropisch afrikanische Flora. Die folgende Übersicht zeigt die Verbreitung der einzelnen Arten über weitere oder engere Gebiete. Es treten auf:

I. Nur im Amboland: Panicum xantholeucum, P. brachyurum, P. Schinsii, Anthephore Schinzii, Perotis vaginata, Aristida stipitata, A. alopecuroides, Triraphis Sclinisii, Willkommia samentosa und $W$. amma, Eragrostis membranacca.

2. Nur in Damaraland: Monebytrum Luederitziamum, Sporobolus nebulosus.

3. Nur in Groß-Namaland: Pemisctum Liocmerianum, Tricholacna breitifila, Aristida fastigiata, A. mollissina, Triraphis ramosissima, T. purpurea, Eragrostis leptocalynma, E. chaunantha.

4. Nur in Klein-Namaland: Danthonia (F'nterschistis) lima, D. (Pentaschistis) filiformis, D). (Pentaschistis) bracliyathora (Stapf), D. (Pentaschistis) cuadenia (Stapf), I) anthonia pumila, D. tenclla, D. stanua, Lasinchloa utriculosa, Crochloa 
pusilla, Chactobromas incolucratus, Ch. Drescanus zugleich in dem KarrooGebiet), ebenso Ehrharta pusilla.

5. In Klein- und Groß-Namaland: Eragrestis brisentha, Trichelatna arenaria.

6. In Damara- und Groß-Namaland: Aristida sabulicolar, Anthephorer puthescens (zugleich im Kalahari-Gebiet), ebenso Eragrostis cchinochloidex.

7. Von Damaraland bis Klein-Namaland: Aristida Hochstetteriana, A. lutcscens, Diplaclune pancineri'is, Entoplocamia aristulate (damit verwandt I: benguellensis Rendle in Mossamedes), Pappophorum cenchroides.

Weiter nördlich reichen im westlichen Afrika folgende Arten:

8. Leucophry's 'Panicum,' mesocoma (Nees) Rendle (Groß- und Klein-Namaland, Mossamedes', Ponicum glonncratum (Damara-Namaland, Mossamedes), Anthephere undulatifolia (Groß-Namaland und IIossamedes), Aristida Welitischii Rendle (Huilla, eine Varietät in Klein-Namaland), A. éstitı Südafrika, im Westen bis Huilla), A. subacaulis (Klein- und Groß-Namaland, Damaraland, Mossamedes, Triraphis nana (von Klein-Namaland bis ILossamedes), Irragrostis forosa (Loanda, Damaraland bis Klein-Namaland, Karroo', E. annuluter Mlossamedes, KleinNamaland, Kalahari).

Ferner sind verbreitet:

9. In Klein-Namaland und im südwestlichen Kapland Ehrharte aphyllir, E. melicoides, E. brevifolia.

ı. Vom südwestlichen Kapland bis Damaraland Errygrostis cypcroides und E. spinosa.

I1. Von Damara-Namaland nach Kalahari und Transvaal Aristida uniplunis, Schmiltic bulbosa, Fingerhuthic africand ferner noch im südwestlichen Kapland), eine zweite Art im südlichen und östlichen Kapland, eine dritte in Afghanistan.

I2. In ganz Südafrika und Klein-Namaland Festuca scabrca Vahl.

13. In Damara-Namaland und ganz Suidafrika Pennisctum geniculetum (Thunb.) Leeke, Aristida congesta, A. vestita.

I4. Im tropischen Afrika und in Damara-Namaland Schmidtic quinqueseter z. B. auch in Loanda), Eragrostis ramaquinsis laußerdem im Kalaharigebiet und Natal), Aristider stipiformis (Nubien, Kordofan, Senegambien, Sierra Leone, Kalahari, Betschuanaland).

15. Im tropischen Afrika, in Südwestafrika und Südafrika Andropogon contortus, Tricholaena rosea, Tragus racemosus, Chloris airgata, Cynodon dactylon, Pogonarthria falcata (Deutsch-Ostafrika).

I6. In Südwestafrika, Südafrika und Nordafrika Aristider obtuscr (SüdwestKapland, Karroo, Kalahari, Damara-Namaland, Nordafrika, Arabien', A. ciliuter (zentrales und westliches Kapland, Damara-Namaland, Nordafrika), Fappophorum siabrum (Südwest-Kapland, Karroo, Kalahari, Namaland, Marokko. Algier).

Die im vorstehenden gegebene Liste hat naturgemäß nur einen provisorischen Charakter, da die Gramineenflora der betreffenden Gebiete noch nicht völlig bekannt ist: immerhin lassen sich aus der Zusammenstellung für die Verbreitung der Gräser einige Resultate erkennen: In Damara-Namaland sind 
eine Anzahl endemischer Arten vorhanden, deren Anschluß aber meist bei siidafrikanischen Formen zu suchen ist /die Gattung Tirirephis, die reiche Entwicklung von Aristida); eine endemische Gattung ist Monclytrum, von Entoplocamin kommt noch eine zweite Art in Mossamedes vor; überhaupt ist die Anzahl der Arten nicht gering, die bis mach Mossamedes reichen, während in Benguella diese Typen mit siidafrikanischer Verwandtschaft fast ganz erlöschen. Klein-Namaland wird in den höher gelegenen Teilen von STAPF zur Kapprovinz gerechnet: die hier endemischen Arten gehüren besonders zu der südafrikanischen Selition I'untuschistis der Gattung Dornthoriar; es sind aber auch

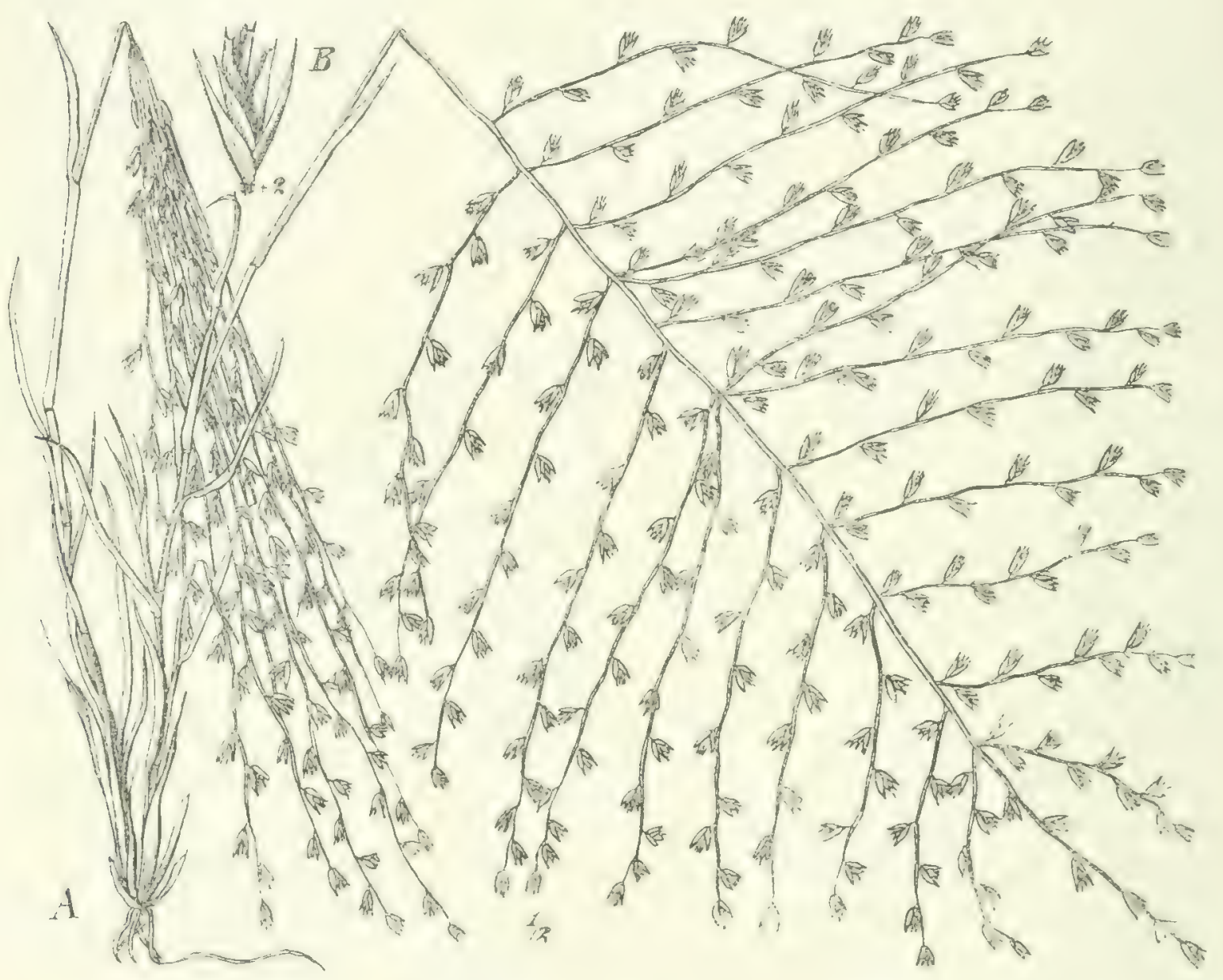

Fig. I30. Crossotropis grandighmis (Nees) Rendle. A Habitus; $B$ Ährchen.

eine Anzahl von Arten vorhanden, die Klein-Namaland nur mit Damara-Namaland gemeinsam hat. Das tropisch-afrikanische Element ist von geringem Einfluß in Damara-Namaland: einige weitverbreitete Formen, die bis nach Süafrika reichen, treten auch hier auf. Auf den Wüstenflächen Südwestafrikas kehren einige Bewohner der nordafrikanischen Wüsten wieder.

Ich möchte an dieser Stelle auf die Verbreitung einiger eigentumlicher Gattungen hinweisen, die besonders fü die Übergangsgebictc von dem tropischen nach dem siidlichen Afrika charakteristisch sind:

I. Elytrophorus. E. articulatus P. Beauv. ist im tropischen Asien und Australien weitverbreitet und tritt im tropischen Afrika in Nubien, Kordofan, 
im Ghasalquellengebiet und in Senegambien auf; eine zweite Art, E. globularis Hack., in Amboland (RAUTANEN) und am Kunene (BAUM).

2. Craspcdorhachis, eine Chlorideengattung, wurde von BENTHAII nach einer Pflanze vom unteren Zambesi beschrieben, C. africana Benth.; eine zweite Art aus derselben Gegend ist C. Meny'harthii Hack.

3. Crossotropis, eine von STAPF beschriebene Chlorideengattung, ist mit der Art C. grandiglumis (Nees) Rendle verbreitet in Natal, Karroo, Kalahari, Betschuanaland, Pungo Andongo und Huilla (Fig. 130).

4. Pogonarthria Stapf ist mit Diplacline verwandt; nur P. falcala (Hack.) Rendle, verbreitet in Damara-Namaland, Loanda, Huilla, Kalahari, Transvaal, Natal, ferner im ostafrikanischen Seengebiet (Fig. I3r).

5. Leptocarydion Hochst. mit Triraphis verwandt; zwei Arten, L. alopecuroides Hochst. in Abyssinien (und nach RENDle in Pungo Andongo), L. vulpiastrum. (De Not.) Stapf von Natal bis Usambara.

6. Phyllorhachis, eine eigentümliche Gattung der Paniceae (oder nach Rendle der Phareae); eine Art P. sagittata Trimen in Pungo Andongo, Angola, ferner im östlichen Kapland, bei Lions Creek (SCHLEChteR).

Xerophile oder subrerophile Gräser sandiger Flächen im tropischen Afrika.

In Ostafrika ist in Usambara, im Gebiet des Kilimandscharo und im Seengebiet viel verbreitet Melinis minutiflora P. Beauv. (vgl. Fig. 132). Nach VolKens überzieht sie sandige Plateaus und $\mathrm{Ab}$ hänge auf große Strecken hin; tritt lichtes Gebüsch auf, so lehnt sie sich

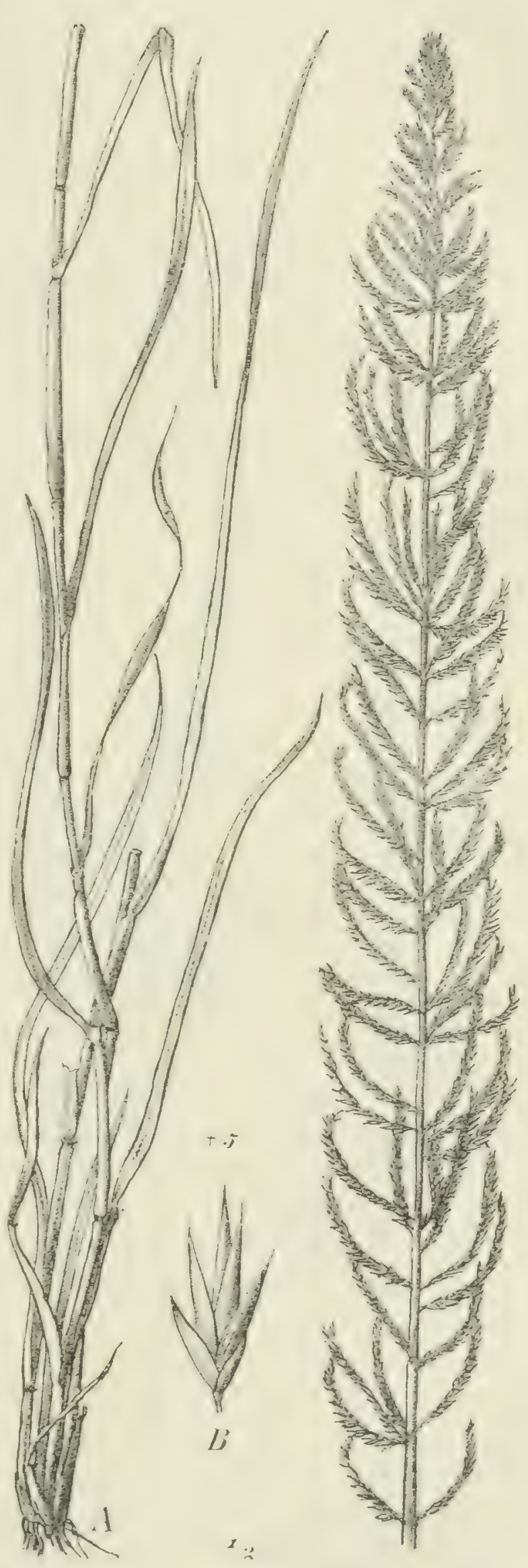

Fig. 131. Pogonarthria falcata (Hack.) Rendle. $A$ Habitus; $B$ Äbrchen. 
an dieses an und kann dann bis zu 2 m Höhe hinaufklimmen. Die Pflanze ist mit abstehenden Haaren bekleidet und stark klebrig, eine Eigenschaft, die sie mit einer Reihe von Sandgrüsern in Südivestafrika teilt; der Halm ist stark verzweigt und niederliegend, im unteren Teil mit kurzen Internodien, aus deren Knoten kuirzere oder längere Äste hervorbrechen; erhebt sich ein Ast zur Rispenbildung, so sind die letzten Internodien mehr verlängert: die Rispe selbst

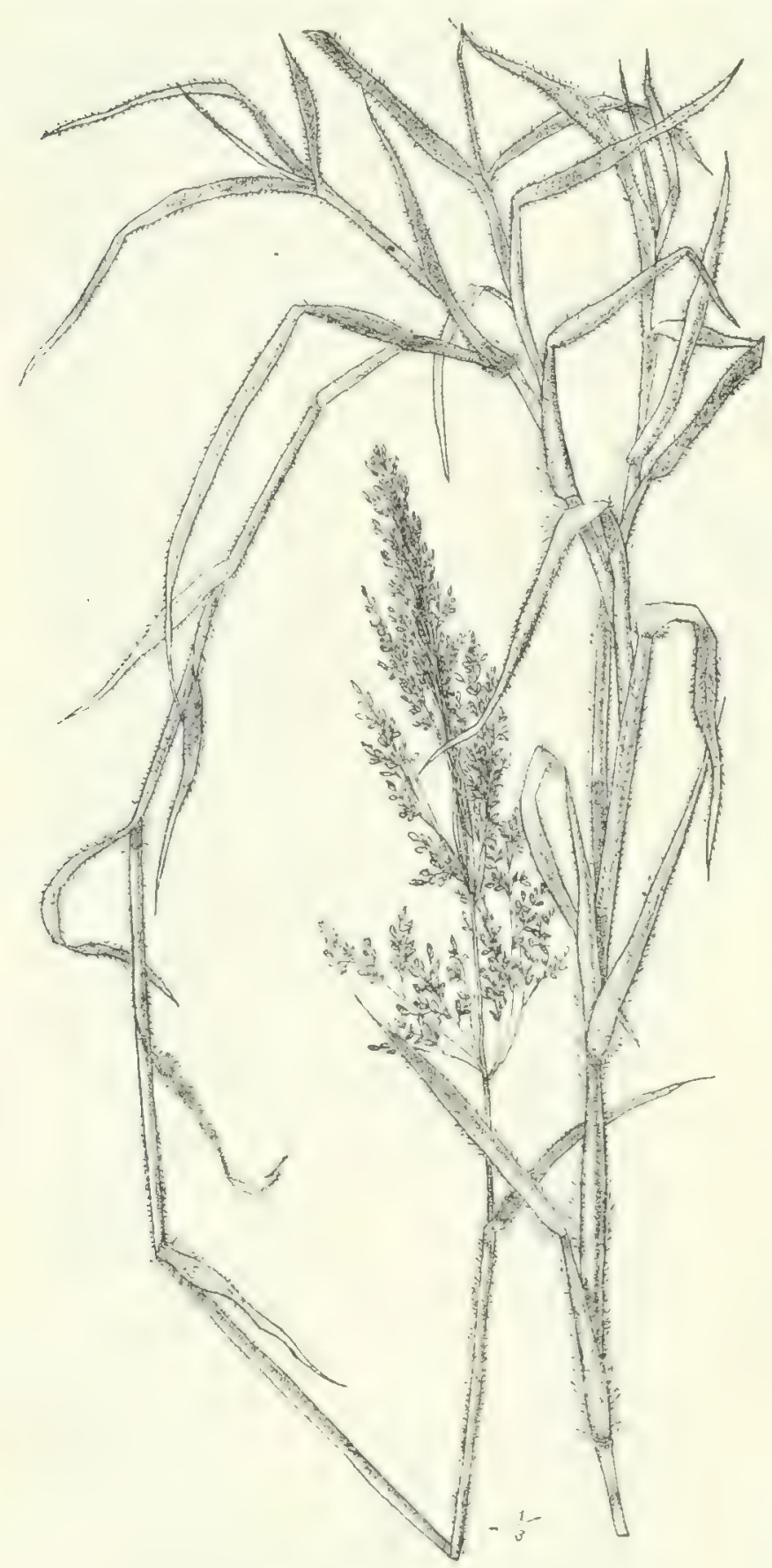

Fig. 132. Melinis minutiflora P. Beauv. ragt nur wenig heraus oder ist an der Basis von der obersten Scheide umschlossen; die Blätter sind offen, linealisch, lanzettlich. Die Art kommt auch in Brasilien und auf Madagaskar sowie in Natal vor; im tropischen Afrika ist sie weitverbreitet, in Ostafrika nördlich bis Usambara, in Westafrika von $\mathrm{Ka}$ merun, wo sie auf sonnigen Grasfeldern bei $900 \mathrm{~m}$ vorkommt, bis Pungo Andongo und Golungo Alto, wo sie nicht nur im Gebüsch auf sandigem Boden, sondern auch auf reicherem, feuchterem Boden auftritt. Während $M$. minutiflora in Brasilien die einzige Art ist, hat die Gattung in Afrika eine größere Entwicklung erfahren; die Art bildet mehrere Varietäten, die besonders in der Begrannung abändern, dann sind von Pungo Andongo drei weitere Arten beschrieben; ferner kommt M. temuissima Stapf in Kamerun und im Kongogebiet vor, dann mit der var. abyssinica in Abyssinien; endlich beschrieb HACKEL aus Abyssinien noch $M$. ambigua, eine Art, die die Gattungen $M$. und Tricholaena verknüpft. HACKEL kommt zu dem Schlusse, daß beide Gattungen zu vereinigen sind. Tricholaence ist eine Gattung der Tropen der alten Welt, speziell Afrikas.

Auf sandigen Flächen des tropischen Ifrika sind ferner verbreitet Tragus raccmosus (L.' Hall, dann Andropogon cymbarius, A. mufus, Eragrostis Chapelicri. So ist z. B. A. cymlarius im Kilimandscharogebiet in der Landschaft Marangu das häufigste Gras auf den sandigen Hügeln, wo es bei $1400-1500 \mathrm{~m}$ ganze 
Flächen überzieht. Endlich sind vier in Afrika weitverbreitete einjährige Arten zu erwähnen, Aristida hordcacea Kith., Dactyloctenium acgyptiacum (L.) Willd., Eragrostis aspera (Jacq.) Nees (vgl. Fig. IIg' und, E. tremula (Lam.) Hochst. Aristida hordeacea gehört der Seltion. Arthratherim an: sie ist in Ostafrika von Abyssinien bis Usambara verbreitet, wo sie z. B. auf Sandboden bei Amani auftritt, in Westafrika von Senegambien bis Huilla: die Halme sind bis $40 \mathrm{~cm}$ hoch: die bliihenden oder noch nicht blühenden Halme schließen sich entweder zu einem dichten Rasen zusammen, oder am Grunde sind die Internodien mehr oder weniger verlängert, teilweise nackt und niederliegend, so daß der Rasen locker auseinandergezogen wird; aus den Knoten brechen dann Ïste hervor, die abstehend die Scheiden zur Seite drängen: die aufrechten Halme oder Äste haben nur einen bis wenige Knoten, so daß die sehr dichte Rispe lang hervortritt; die Blattspreiten sind rauh, derb. gewöhnlich längs des Mittelnervs gefaltet. Dieser Art entspricht habituell Eragrostis aspera, die gewöhnlich zahlreiche blïhende Halme mit großer ausgebreiteter Rispe mit rauhen zierlichen Ästen hat: sie ist verbreitet in Südindien, in Ostafrika von Abyssinien bis Natal, in Westafrika ron Togo bis Huilla; Eragrostis tremula, gleichfalls habituell ähnlich, ist in Ostafrika von Erythrea bis Nyassaland rerbreitet, in Westafrika bis zum Kongogebiet.

\section{F. Gräiser des Kulturlandes, des gerodeten Landes, Ruderalgräser.}

Die Gräser, die in den kultivierten Geländen mit den Kulturpflanzen zusammen als Unkräuter auftreten oder verlassene Kulturen in Besitz nehmen, sind in ihrem Vorkommen allermeist nicht an solche Stellen gebunden, sondern finden sich auch in mancherlei benachbarten Formationen, die durch guten Boden ausgezeichnet und meist kulturfähig sind. Dadurch, daß die Bearbeitung für Kulturzwecke in Angriff genommen wird, finden aber diese Gräser die Möglichkeit größerer Ausbreitung: der schattige Urwald wehrte ihrem Tordringen, nach seiner Rodung finden sie Luft und Licht zu starker Entwicklung; die Anpflanzung der Kulturgewächse schließt viele Konkurrenten aus, die Unkrautgräser aber begleiten sie und siedeln sich an Feldrändern und Wegen überall an; so sind unter ihnen besonders solche Arten vertreten, die eine große Ausbreitungsfähigkeit haben, einjährige Arten, die reichlich Samen erzeugen, oder perennierende Arten mit kriechenden Rhizomen und Ausläufern, die weithin den Boden durchdringen und häufig auch den Kulturpflanzen scharfe Konkurrenz bereiten.

Wenn also die Unkrautgräser auch urspriinglichen Formationen meist entstammen, so bilden sie doch durch ihre Auswahl eine bestimmte Genossenschaft; viele von ihnen sind nicht nur im tropischen Afrika weitverbreitet und treten überall an kultivierten Plätzen auf, sondern sie sind auch kosmopolitisch in den Tropen und Subtropen und gehören zur gewöhnlichsten Unkraut- und Ruderalflora. Sie unterschciden sich naturgemäß nach der Bodenart, auf der die Kulturen angelegt sind, besonders nach dem Grade der Feuchtigkeit, den die Anpflanzungen bedingen. 


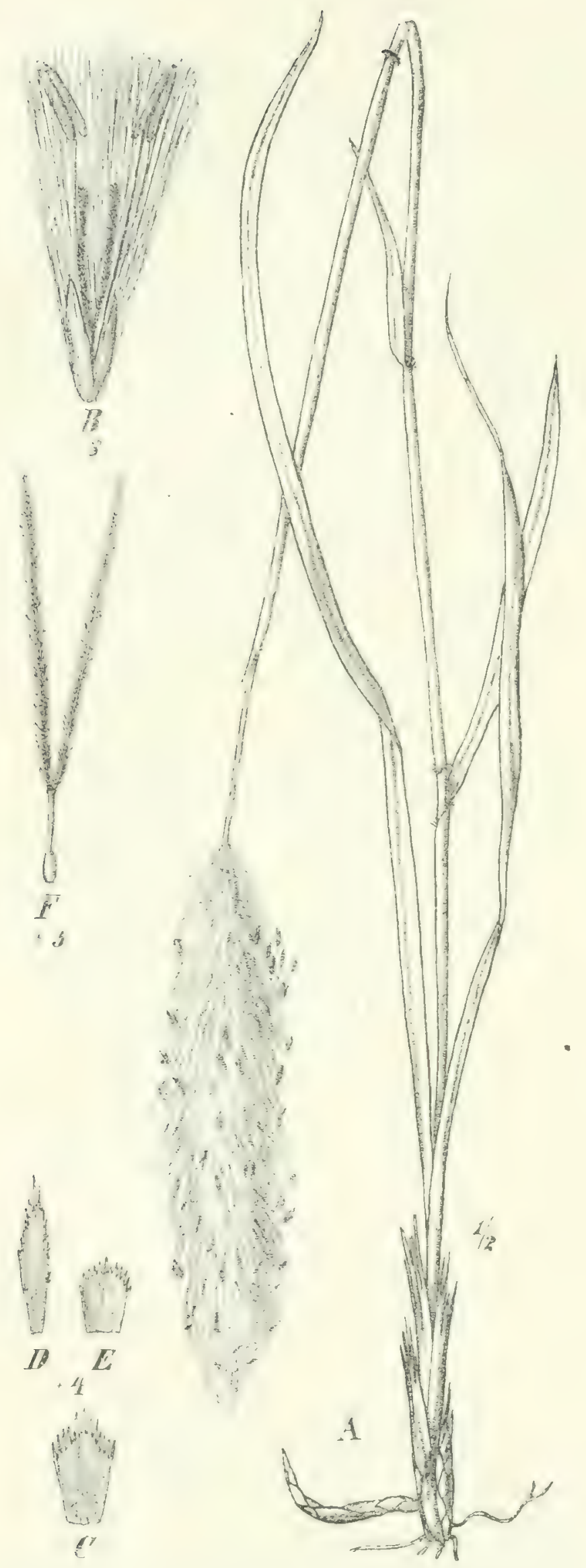

Fig. I 33. Imperata cylindrica (L.) P. Beauv. $A$ Habitus; $B$ Ährchen; $C, D, E$ innere Spelzen; $F$ Fruchtknoten.

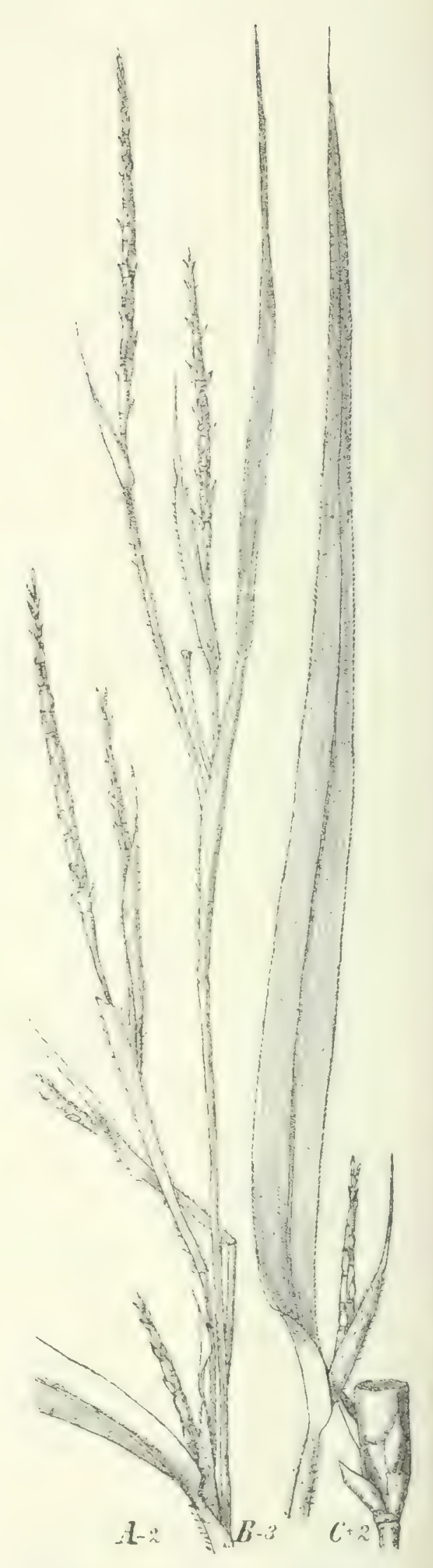

Fig. 134. Rottboellia exaltata L. f. $A, B$ Habitus; $C$ zwei Achsenglieder der Ähre. 
Dann ist aber im allgemeinen auch ein Lnterschied zu machen zwischen solchen Gräsern, die zusammen mit den Kulturen auftreten oder auf abgeernteten Feldern sich besonders entwickeln, und solchen, die ron verlassenen Pflanzungen und Rodungen allmählich Besitz ergreifen. Das bekannteste Beispiel der letzteren Gruppe ist Imperate cylintrica L. P. I3eaur. Fig. 133, die in den Tropen und Subtropen der alten Welt überall verbreitet ist; die Art bewohnt in Afrika feuchtere oder sumpfige Wiesen, fruchtbaren Boden der Buschsteppe, ron Bedeutung wird sie aber erst auf altem Kulturland, wo sie sich durch ihre Ausläufer stark ausbreitet: so kann sie ron großen Strecken allein Besitz ergreifen und ist dann kaum noch wieder auszurotten: ebenso schädigt das Gras in Malesien die Kulturen schwer; es ist dort als Alang-Alang von trauriger Berühmtheit. Ihm schließsen sich in Afrika folgende hochwüchsige perennierende Formen an: Rottbocllia traltuti I. f. KFig. 13t, durch die Tropen der alten Weit rerbreitet, liommt auch (jedenfalls eingeschleppt) in Westindien ror: es bewohnt in Afriki Lichtungen des Lrwaldes, gerodetes Land und Kulturland. Andropogon halepensis (L.) Brot. var. cffusus reicht in Afrika von Usambara bis Natal und von Togo bis Klein-Namaland und besiedelt recht verschiedene Formationen: von der fruchtbaren Vorlandsteppe Deutsch-Ostafrikas z. B. geht die Art auf rernachlässigte Fulturen über. Ebenso verhïlt sich thïroperon mufus Kth. Pennisetum setosum (Sw.) Rich. ist im tropischen Afrika weitverbreitet, in Westafrika südlich bis Golungo alto, außerdem in Madagaskar und im tropischen Afrika; ron Buschsteppe, Steppe und Savanne geht die Art, häufig massenhaft, auf rernachlässigtes Kulturland ïber. Cntotheco muroniala (P. Beaur. Benth. ist verbreitet in Madagaskar, Sansibar, Usambara, Nigergebiet, Kamerun, Kongogebiet; die Art ist rom selben Typus wie C. lafpacer, die als wichtiges Waldgras gew iirdigt wurde; meist ron Rändern des Urwaldes aus geht $C$. mucronata auf Kulturen iiber, die dort angelegt werden, so z. B. in Usambara; im Sachsenwald bei Dar-es-Salam ist C. mucronata viel anzutreffen und wird an schattigen Stellen bis uiber mannshoch. In Togo tritt

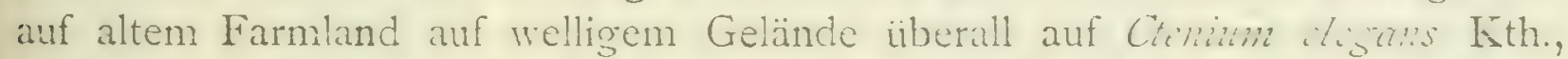
an einzelnen Stellen kleine Flächen rein bedeckend: dic Art reicht ron Senegambien bis Pungo Andongo; sie besiedelt im allgemeinen trockne Gelände, soll aber nach WeLwitic(I) in Pungo Andongo auch auf feuchteren Wiesen vorkommen. Die Exemplare aus Togo sind xerophil ausgebildet, I-I,5 m hoch: sie bilden kleine Büsche mit wenigen intravaginalen Neusprossen mit haarfeinen Blättern: die Halme sind zierlich, aufrecht, mit wenigen langen Internodien: die Blattspreiten sind sehr schr is meist fein fadenfömig zusammengerollt, stark rauh; die cinseitige, mit langen Borsten rersehene thre wird bis $20 \mathrm{~cm}$ lang.

Auf sehr verschiedenen Bodenarten kommt Sporobolus indicus (L.) R. Br. ro: (vgl. Fig. Icu (), ein tropisch-liosmopolitische Art, bei der nach der mehr ausgebreiteten oder ährenförmig zusammengezogenen Rispe, sowie dem Modus der Bestockung und Beblatterung mehrere Formen zu unterscheiden, aber nicht scharf zu trennen sind. So sammelte Schiniper z. B. in Abyssinien bei 
I 200-I $300 \mathrm{~m}$ Exemplare «auf sumpfähnlichen Stellen, deren Grundlage Sand ist . Hier haben die Exemplare mehrere bis über meterhohe Halme, die am Grunde von iibereinander fallenden 5-10 cm langen Scheiden umgeben sind, in denen nur wenige intravaginale Neusprosse entstehen; die Scheiden tragen lange Spreiten, die schmal linealisch, derb, offen oder unregelmäßig gefaltet sind; der Halm hat mehrere lange Internodien und ist meist völlig oder fast ganz bescheidet: die Scheidenbildung am Grunde der Halme entspricht dem öfter erwähnten Typus der Gräser sumpfiger Wiesen. Ähnliche Exemplare liegen vor z. B. von feuchten Wiesen in Usambara und im Vorlande des Meru bei I $500 \mathrm{~m}$; die breiten und zarten Grundscheiden sind zahlreich und fallen iihereinander, nur intravaginale Sprosse werden gebildet; die Rispe ist sehr schmal. Sehr hohe Exemplare sind auch die von LÉCARD in Senegambien gesammelten mit der Bemerkung: terrains riches, bord des fleuves. Exemplare trocknerer Standorte zeigen mannigfache Unterschiede: von trockneren Grasflächen der Niederungen Usambaras liegen Formen ror, deren Grundscheiden kiirzer und sehr starr, deren Blattspreiten stark zusammengerollt sind: Exemplare, die in Togo »an steinigen Wegen " gesammelt sind, sind niedrig, bis $40 \mathrm{~cm}$ hoch, haben sehr kurze Scheiden am Grunde und kurze, sehr schmale, zusammengerollte Blätter. Lberhaupt tritt bei Formen trocknerer Standorte die Scheidenbildung am Halmgrunde zurück; so haben Exemplare von Lateritboden des Seengebietes in Ostafrika nur wenige kurze Scheiden und stark zusammengerollte Spreiten. Noch auffälliger ist das Auftreten von extravaginalen Neusprossen neben intravaginalen: erstere sind aber nur kurz und aufrecht: solche Exemplare, wie ich sie rom Kilimandscharogebiet und von der Goldkuiste sah, haben sehr schmal zusammengerollte Blattspreiten.

Solche Arten, die durch niederliegende, sich bewurzelnde Halme und Ausläufer sich verbreiten, sind Panicum curvatum L., P. parmulum Trin., Cynodon dactylon (L.) Pers. P. curvatum kommt vor in Natal, Deutsch-Ostafrika und außerhalb Afrikas auf den Maskarenen und in Siidindien; es besiedelt besonders feuchtes Kulturland, ferner schattige Plätze, Flußufer und Ränder stehender Gewässer: die Pflanze hat einen kurzgliedrigen, lang kriechenden, diinnen, an den Knoten schwach bewurzelten Halm, der zahlreiche Äste treibt, die die Scheiden ablösen: die Äste sind im unteren Teil kurzgliedrig und häufig wieder verzweigt, dann aufrecht und rispentragend, mit längeren Internodien: die Blattspreiten sind bis herauf zur Rispe gleichlang, lanzettlich, offen, zugespitzt, die Rispe ist klein und flatterig. An ähnlichen Stellen wie P. parinlam findet sich im tropischen Afrika auch $P$. horizontale, das einen entsprechenden Habitus hat.

Die beiden anderen erwähnten Arten sind tropisch und subtropisch kosmopolitisch. Ton P. parulum werden Formen besonders in IVestafrika (Togo, Französischer Sudan) als Getreidegräser kultiviert: das Gras gleicht in der Wuchsform ganz I'. cur'atum: es ist reich verzweigt und weit ausgebreitet; die stolonenartigen niederliegenden Triebe mit den zahlreichen kurzen Internodien und den kleinen abstehenden steifen Blattspreiten werden oft ziemlich 
lang, ehe sie beginnen, aus den Knoten die aufsteigenden Halmsprosse zu treiben.

Cynodon dactylon ist eine Art, die in mancherlei Formationen auftritt, als Strandgras in der Littoralzone, ferner im Steppenbusche, in der offenen Steppe, auf Sandplätzen usw.; in Kulturen und verlassenen Kulturen ist sie vielfach

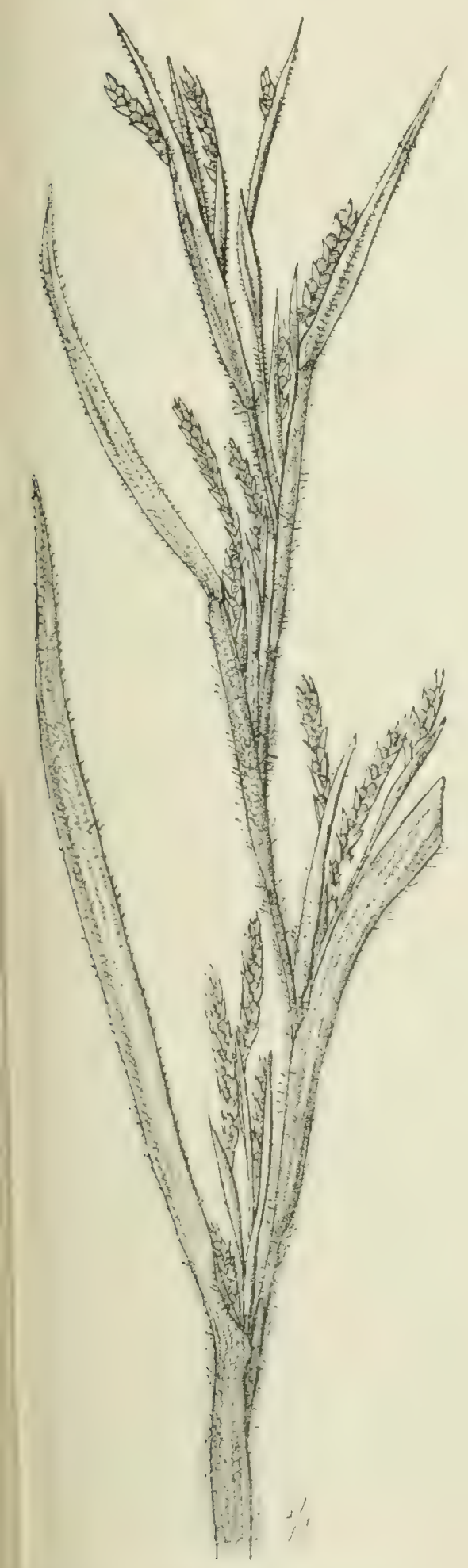

lig. 135. Manisuris granularis L. f.

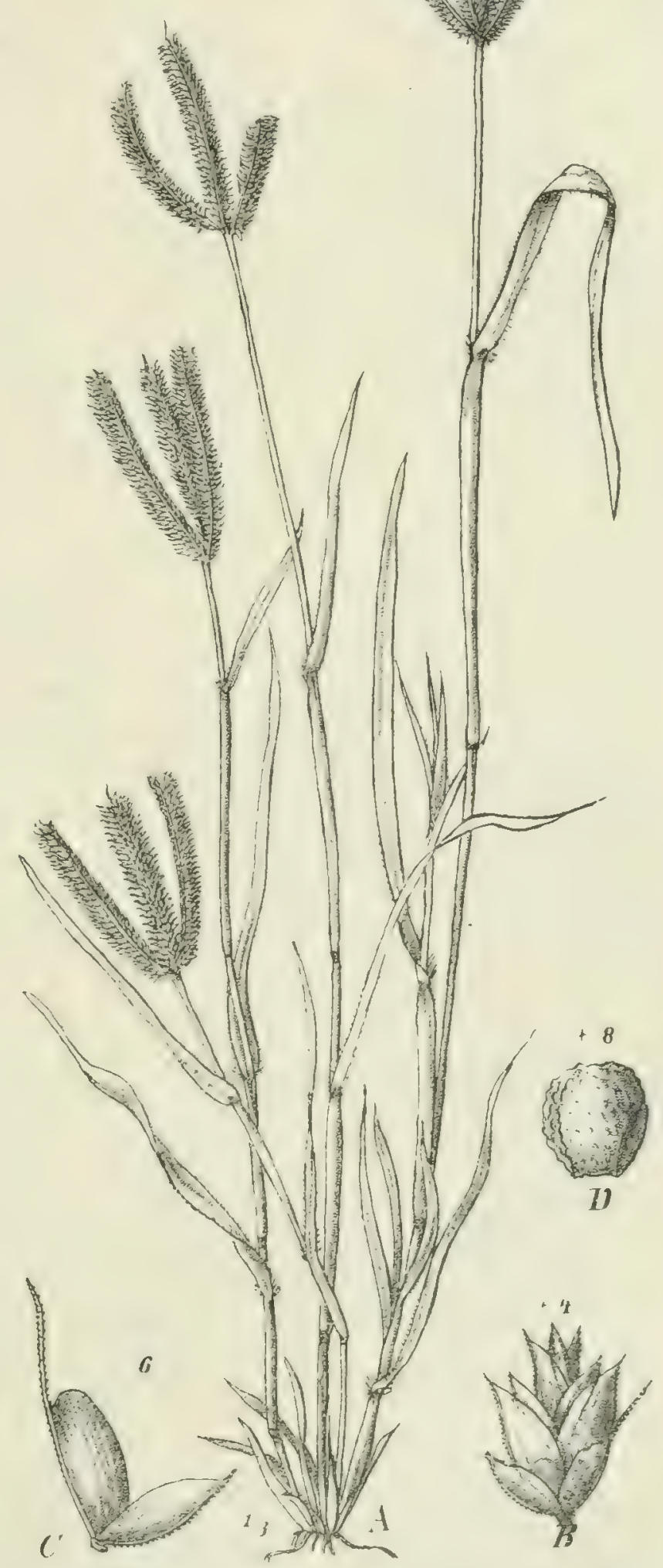

Fig. 136. Dactyloctenium aegyptiacum (L.) Willd. $A$ Habitus; $B$ Ährchen; $C$ Hiilspelzen; $D$ Frucht von der Seite. 
anzutreffen: Cymoion ist ein sehr vielgestaltiges Gras, das nicht nur in der Lainge und Breite der Blätter und in der Höhe, sondern auch im ganzen Habitus wegen der verschiedenen Ausgestaltung der Ausläufer und der am Grunde niederlicgenden Halme stark variiert: häufig sind stolonenartige Ncusprosse vorhanden, die dicht mit kurzen Schuppen besetzt sind; von ihnen aus finden sich alle Übergänge bis zu niederliegenden Halmen mit normalen Scheiden und Spreiten, die im unteren Teil an den Knoten bewurzelt sind und aufrechte Äste produzieren, dann sich selbst aufrichten und Rispen tragen: später vergehen die Scheiden und Spreiten an den niederliegenden Teilen, so daß die Internodien frei werden.

Die größere Anzahl der Gräser, die vorwiegend auf kultiviertem Gelände auftreten, sind einjährig und eine Reihe von ihnen sind in den Tropen als Unkräuter weitverbreitet. Hierher gehören: Manisuris granularis L. f. (vgl. Fig. I 35), Panicum cnus galli L., Setaria glanca (L.) P. Beauv., S. verticillata (L.) Beauv., Aristida coernlescens Desf., Dactylocteninm aegyptiacum (L.) Willd., (vgl. Fig. I36), Chloris virgata Sw., Elensine indica (L.) Gärtn., Eragrostis ciliaris (L) Lk. Weniger weitverbreitet sind Perotis indica (L.) K. Schum. Sansibar--Sambesi, Senegambien-Huilla: Ostindien, I) inctra ritroftexa Tahl Panz. Abyssinien - Massaisteppengebiet, Ghasalquellengebiet, Senegambien, Loanda: Ostindien und Eragroustis asperra 'Jacc.' Nees (Tropisches Afrika; suidliches Ostindien!. Die erwähnten drei Arten kommen sonst in natürlichen Formationen mehr auf trocknem Boden. meist Sandfächeri vor und sind als Kulturunkräuter weniger wichtig. Die einjährigen Gräser bilden neist große Rasen mit vielen Halmen und sind oft stattliche Formen, die viel Platz beanspruchen, zierlicher sind z. B. Eragrostis ciliaris und Setaria glauca. Die wichtigsten und verbreitetsten Arten, die uiberall in den Tropen, wo nur immer Kulturland zu finden ist. mit Sicherheit auftreten, sind Monisuris granlaris, Eleusine indica und Eragrostis ciliaris.

Anhangsweise seien die wichtigsten Kulturgräser des tropischen Afrika erwähnt:

Andropogon sorghum (L.) Brot., Durrha, in zahlreichen Varietäten; die Formen mit lockeren, großen Rispen liefern besonders Getreide, die Formen mit kolbenähnlichen Rispen werden häufiger zur Bereitung alkoholischer Getränke verwandt.

Pennisetzm americanum (L.) K. Schum., Negerhirse; die zahlreichen Varietäten sind zweifellos auf verschiedene wilde Arten von Pennisetum zuriickzufiihren.

Oryza sativa L., Reis, besonders in Ostafrika in Kultur, dort auch wilde Formen (vgl. S. ${ }_{5}$ I). Zea Mays L., aus dem tropischen Amerika, in steigendem Maße in Kultur genommen.

Eleusine coracana (L.) Gärtn., Dagussa, Korakan, besonders in Ostafrika und in Abyssinien kultiviert (dort bis $2400 \mathrm{~m}$ ).

Eragrostis aby'sinica (L.) Lk., Tef, in Abyssinien als Getreide besomders von $2000-2600 \mathrm{~m}$ kultiviert.

Triticum vulgare Vill., Weizen, in Abyssinien besonders $\mathrm{um} 3000 \mathrm{~m}$ in mehreren Varietäten gebaut, ebenso auch Hordeun anlgare L., die Gerste (bis gegen $4000 \mathrm{~m}$ ).

Sacharum officinarum L., Zuckerrohr, in Afrika wie überall in den Tropen in Kultur; in manchen Gegenden. Werden andere Gräser zur Zuckergewinnung benutzt, so Panicun Burgu Chevalier (rgl. S. 150). 


\section{Fam. Cyperaceae.}

Zum größten Teil Hydrophyten, wenige Mesophyten, noch weniger Xerophyten.

Die Cyperaceen enthalten viele Arten, welche gesellig auftreten und für Pflanzenformationen charakteristisch sind; es ist aber schon für den Fachbotaniker oft schwierig, die einzelnen Gattungen beim ersten Anblick zu erkennen, und ebenso schwer, den Habitus derselben mit wenig Worten zu beschreiben: die Bestimmung der Arten aber kann meist ohne großes Vergleichsmaterial nicht vorgenommen werden und muß meistens Spezialisten uberlassen werden. Es kann sich daher hier, wie bei mehreren anderen formenreichen Familien nur darum handeln, eine knappe Übersicht über die Gattungen nebst Hinweisen auf die durch massenhaftes Auftreten besonders charakteristischen Arten zu geben; die Berïcksichtigung der Formation, in welcher die einzelnen Arten vorkommen, gibt häufig Anhaltspunkte für die Bestimmung. Folgende Übersicht dürfte demjenigen, der einige Zeit auf Untersuchung verwenden kann, zur Erkennung der Gattungen verhelfen.

A. Ährchen mit Zwitterbliiten oder nur einzelne Blïten eingeschlechtlich.

Unterfam. Scirpoideae.

a) Zwei Vorblätter oder eins vorhanden. Stengel ohne Knoten in einen Blütenkopf endigend ............. I. Lipocarpheae.

(a) Zwei dünne, kleine Vorblätter vorhanden . . . . . . . Lipocarpha.

3) Zwei große Vorblätter, zu einem löffelförmigen, über das Deckblatt hinausragenden Gebilde vereinigt . . . . . . . . . . . . . . . . . . Ascolepis.

y) Nur ein medianes, zartes Vorblatt. Blüten mit einem Staubblatt. . Hemicarpha.

b) Keine Vorblätter . . . . . . . . . . . . . . . II. Scirpeae.

a) Deckspelzen der Ährchen zweireihig........ I. Cyperinae.

I. Eine aus sechs, auch an der Frucht bleibenden Borsten gebildete Bliitenhiille. Blütenstand rispig .

Carpha.

II. Keine Blütenhülle.

1. Ährchen vielblütig oder selten einblütig, dann aber die unteren Deckspelzen die oberen nicht umschließend und an solchen Arten der Griffel dreischenkelig. Blätter am Grunde des Stengels ............... Cyperus.

* Griffel dreischenkelig.

† Ährchenachse bleibend, Knäuel oder Ähren eine Dolde oder einen. Kopf zusammensetzend, bisweilen einzeln ...... Untergatt. Eucyperus.

$\div$ Ährchenachse in so viele Sticke zerfallend, als Frïchte vorhanden sind, sonst wie Eucyperus . . . . . . . . . . . . Untergatt. Torulinium.

$\div \div$ Ährchenachse in einem Stïck abfallend; sonst wie Eucyperus.

○ Deckspelze am Kiel nicht gefligelt...... Untergatt. Mariscus.

$\odot \odot$ Deckspelze am Kiel geflügelt ....... Untergatt. Courtoisia.

** Griffel zweischenkelig.

$\div$ Nïßchen seitlich zusammengedrïckt, Knäuel oder Ähren in Dolden

Untergatt. Pycreus.

$\because \because$ Nüßchen vom Rücken her zusammengedrückt, Blïtenstand wie bei Eucyperus

Untergatt. Juncellus.

2. Ährchen ein- oder zweiblütig, Griffel zweischenkelig. Drei bis ein sitzende Ähren in einem von drei bis sechs laubigen Bracteen umgebenen Kopf . . Kyllinga. 
ß) Deckspelzen der Ährchen spiralig ......... 2. Scirpinae.

I. Griffel am Grunde nicht oder nur wenig verdickt.

I. Hypogynischer Discus vorhanden, mit der Frucht abfallend. Ährchen in einem Kopf am Ėnde des nicht knotigen Stengels ......... Ficinia.

2. Hypogynischer Discus fehlt.

* Deckspelzen behaart. Stengel dreikantig, bis oben beblättert. Ährchen in scheindoldiger Rispe . . . . . . . . . . . Fuirena.

** Deckspelzen kahl. Verteilung der Blätter am Stengel verschieden. Ährchen in einem Kopf oder in Scheindolden.......... Scirpus.

II. Griffel am Grunde verdickt.

* Borstige Blütenhuille vorhanden. Griffelbasis nicht von der Frucht abfallend. Ährchen einzeln, endständig . . . . . . . Eleocharis.

** Bliitenhiille fehlend.

$\div$ Griffelbasis schmal, mit dem Griffel abfallend. Ährchen in Dolden oder einzeln endständig. . . . . . . . . Fimbristilis.

$\div$ Griffelbasis angeschwollen, nicht von der Frucht abfallend. Ährchen in Dolden oder in einem Kopf oder einzeln endständig ...... Bulbostilis.

B. Ährchen aus männlichen und weiblichen Bliten bestehend, welche an Achsen ungleicher Ordnung stehen ......... Unterfam. Caricoideac. a) Thrchen wenigblitig. Bluten meist zwitterig oder einzelne männlich. Borstenförmige Blütenhülle vorhanden oder fehlend

III. Rhynchosporeae.

(e) Deckspelzen zweizeilig. Früchte ungeschnäbelt. Ährchen in einem Kopf . Schoenug. ß) Deckspelzen spiralig oder nur undeutlich zweizeilig.

I. Griffel dreischenkelig. Keine Borsten in der Blüte. Drei oder weniger Staubblätter. I. Gesamtblütenstand rispig. Große Sumpfpflanze ........ Cladium.

2. Gesamtblittenstand kopfig. Strandpflanze mit langen Rhizomen . . Remirea.

II. Griffel zweichenkeligg. Firüchte seschnähelt . . . . Rhynchospora.

b) Ährchen wenigbliitig. am Grunde mit mehreren Deckspelzen. Endblite männlich, Seitenbliiten zwitterig ........ IV. Gahnicae.

Deckspelzen zweizeilig. Ährchen in Rispen .......... Tetraria.

c) Ährchen mit einer endständigen weiblichen Blüte, am Grunde mit zwei kahnförmigen Deckspelzen, in deren Achsel eine aus einem Staubblatt bestehende männliche Blüte steht ......... V. Hypolytreae. (i) Blütenstand doldig. Zwischen den männlichen Bliten und der weiblichen keine leeren Deckspelzen . . . . . . . . . . . Hypolytrum.

3) Blütenstand koprig. Zwischen den mïnnlichen Blüten und der weiblichen mehrere leerc Deckspelzen .

Mapania.

d) Thrchen eingeschlechtlich oder dancben androgyne. Weibliche mit eincr fruchtharen weiblichen Bliite ohne schlauchförmiges Vorblatt, dariber einige Dockspelzen mit oder ohne männlichen Blïten: männliche Ïhrchen mehr- bis vielblütig. Blätter am Stengel zerstreut.

c) Blüten mit zablreichen Hüllborsten. Ährchen in langer Rispe .... Eriospora.

в) Blïten ohne Hiillborsten.

I. Fruchtbare Ährchen auch mit männlichen Blüten oder nur mit leeren Deckspelzen über der weiblichen. Blütenstand rispig .......... Scleria.

II. Jruchtbare thrchen mit einer pseudoterminalen weiblichen Blite. Ährchen in axillären Köpfen . . . . . . . . . . . . . Diplacrum. 
e) Ährchen zweiblütig zu einer endständigen thre rereint (solche nicht in Afrika) oder Ährchen mit einer grundständigen weiblichen Bliite und zahlreichen männlichen oder durch Abort einblitig. Weibliche Blüte mit schlauchförmigem Vorblatt.

VII. Cariceac.

(c) Ährchen androgyn, mehrblütig, oder durch Abort einblütig . . Schoenoxiphium.

B) Ährchen einblititig (scheinbare Blüte), selten androgyn .

Carex.

Die meisten $C$. sind Bewohner feuchter Standorte \pm Hydrophyten und unter diesen finden sich nicht wenige in den ganzen Tropen oder wenigstens in denen der alten Welt verbreitete Arten, da die kleinen Nüßßchen der C: mit feuchter Erde leicht durch Vögel rerschleppt werden können und außerdem flutendes Wasser zur Verbreitung beiträgt.

Während in den extratropischen Gebieten die Caricoileat besonders reichlich vertreten sind, treffen wir in den Tropen besonders viel Siripuideat, deren Blitenstande in den Ährchen nur oder vorherrschend Zwitterbliten enthalten.

I. Scirpoideae. - Lipocarpheae. Merkmale S. 193.

Lipocarpha R. Br. Habituell erinnern die Arten an Cipcuss. Untergattung; Mariscus: aber man hat nur darauf zu achten, dal bei $L$. die sehr zahlreichen Bracteen dicht spiralig gestellt sind und zwischen ihnen und der Blute noch zwei Torblätter vorhanden sind. Die meisten Arten bilden dichte Polster auf feuchten Wiesen und an Flußufern. Die beiden häufigsten Arten sind L. arśntia R. Br. (mit einwärts gekrümmten Spitzen der Deckspelzen (Fig. I 39 L), ron Senegambien und Abyssinien bis Natal, L. pulikwrima Ridley mit nach außen gehrümmten Spitzen der Deckspelzen, weniger weit nach Norden gehend, als die vorige. Im westlichen tropischen Afrika finden wir ron Senegambien bis zum Kongo L. tricips Lam.! Nees ziemlich häufig, sie hat im Gegensatz zur vorigen Art keinen Griffel. MIit dieser ist auch verwandt die in den Buschsteppen Senegambiens und Togos vorkommende, diinnstengelige L. filifumis Wahl Kth. Ton Angola bis zum Shire Ilochland kommt die durch lang zugespitzte Deckspelzen ausgezeichnete L. albiceps Ridley vor.

Hemicarpha Nees umfaßt zwei kleine Pflanzen. welche neucrdings von C. B. Clarke zu Scirpus gezogen wurden; die eine in Amerika verbreitete H. micrantha (Vahl) Pax (Fig. I37 F) findet sich auch in Angola und im Damaraland, die andere, H. isolefis lees, ist sehr zerstreut ron Indien bis Senegambien und bis zum Kapland. Beide wachsen auf ganz sumprigem Boden.

Ascolepis Nees ist eine sehr charahteristiche Gattung. mit einem 12-zo cm messenden Kopf ron sehr dichtbliihenden Ährchen: zwei miteinander verwachsene ziemlich große Vorblätter schließen die Blite ein. Die Gattung ist auch dadurch interessant, daß ron den sonst auf das tropische Afrika beschränkten Arten die eine. bis $4.5 \mathrm{dm}$ hohe, durch ihre schneeweißen Köpfe auffallende, schon am Niger und oberen Nil vorkommende A. apinsis kith. Ridley an sumpfigen Orten bis nach Kapland rerbreitet ist und in den Gebirgen bis zu $1900 \mathrm{~m}$ aufsteigt, die andere bis ; dm hohe, mit schwach bräunlichen Köpfen versehene A. brasiliunsis C. B. Clarke, in tropischen Westafrika zerstreut, auch in Südamerika häufig und in Madagaskar vorkommt, 
eines der unzähligen Beispiele, welche eine größere Verwandtschaft der afrikanischen Flora mit der amerikanischen illustrieren. Im tropischen Afrika weitverbreitet ist auch .1. proted Welw. mit I-5 dm langen Halmen und weißen bis goldgelben Köpfen, an deren Peripherie die Vorblattschuppen sich bisweilen sehr stark vergrößern, eine höchst veränderliche Art. Die Begrenzung der Arten ist in dieser Gattung höchst unsicher.

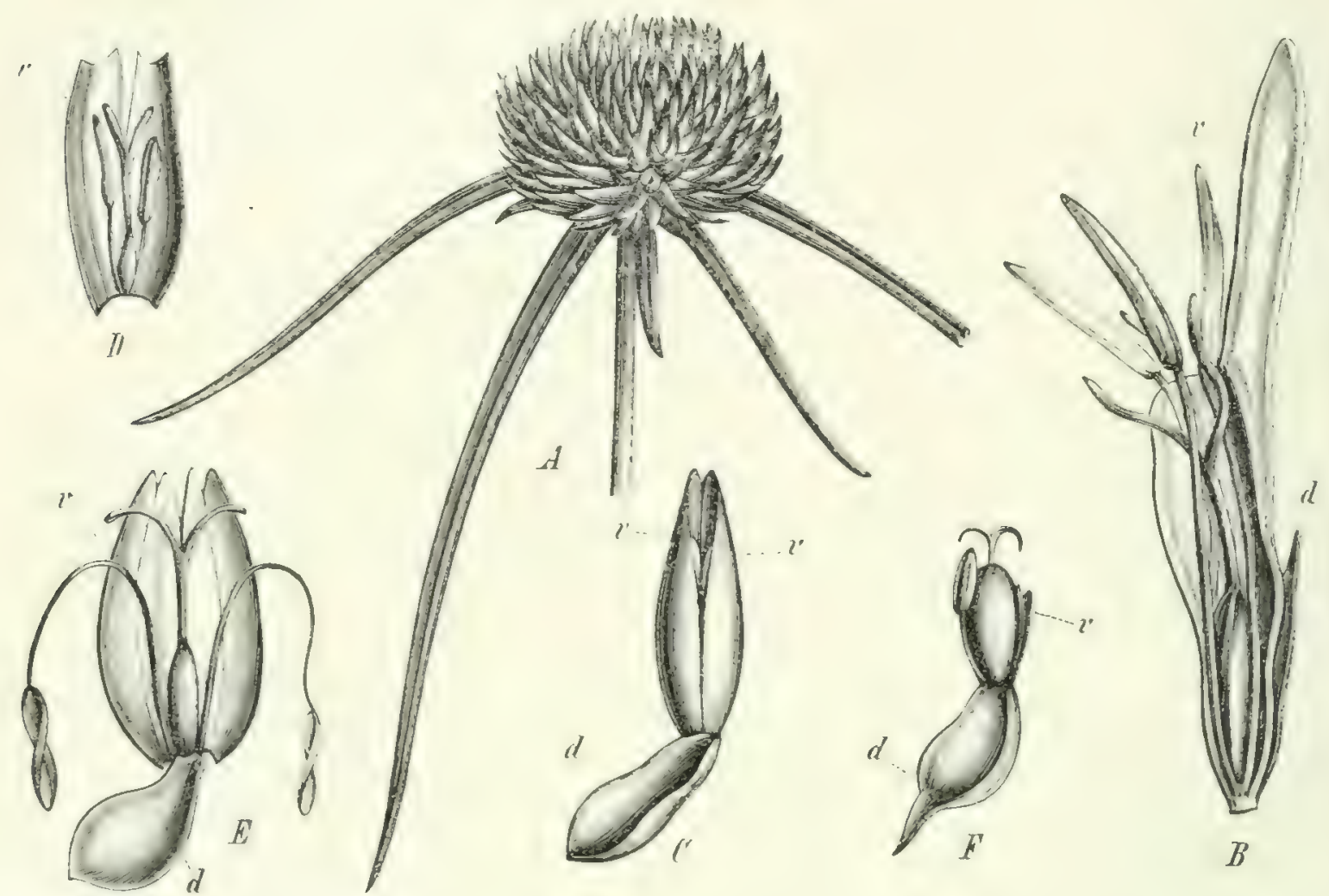

Fig. ${ }^{3}$ 7. $A, B$ Ascolepis speciosa Welw. $A$ Blütenstand; $B$ einzelne Blüte mit zwei transversalen, vorn verwachsenen Vorblättern (v); $C-E$ Ährchen eines Hypolytrum, v zwei kahnförmige Deckspelzen, in deren Achsel eine aus einem Staubblatt bestehende ô Blüte steht, eine $ᄋ$ Blüte endständig; F Hemicarpha micrantha (Vahl) Pax. Monandrische Zwitterblite mit median hinterem Vorblatt. Nach PAX.

II. Scirpoideae. - Scirpeae. Merkmale S. 193.

Carpha R. Br. Diese Gattung ist interessant durch ihre zerstreute Verbreitung auf der siidlichen Hemisphäre/Australien, Neuseeland, Chile, Bourbon, Siidafrika) und ihr vereinzeltes Vorkommen in den tropischen Gebirgen Afrikas. Da die Nüßchenfrichte bei allen an der Spitze mehr oder weniger rauhhaarig sind. so ist wahrscheinlich, daß diese Behaarung zur Verbreitung durch Vögel beitrigt. Von Kapstadt bis zum Pondoland ist die fast $2 \mathrm{~m}$ hohe C. glomerata Thunb. Nees an Flußufern zerstreut, eine auffallige Pflanze mit oft $3 \mathrm{dm}$ langer, aus zahlreichen Köpfen zusammengesetzter Rispe: zwei andere Arten des östlichen Kaplandes sind kleiner und seltener. Die von STLHLMLмx zuerst auf dem Ruwenzori um $3300 \mathrm{~m}$ entdeckte, von mir selbst auch in Vestusambara auf Felsen der Adlerfarnformation bei Mlalo (Hohenfriedeberg, I600 m) aufgefundene C. I:mini K. Schum.) C. B. Cr..1RKl: weicht in ihrem Habitus von den rorigen erheblich ab) und nähert sich mehr der (. Authertii Nees auf Bourbon; 
sie bildet dichte Büschel mit sehr schmalen Blättern und bis $6 \mathrm{dm}$ langen Stengeln, welche in lange Rispen mit mehreren länglichen, braunen Ährchen endigen.

Cyperus L. mit seinen Untergattungen besitzt im tropischen Afrika uiber 200 Arten, welche ganz besonders in den hydrophilen Formationen der unteren Regionen hervortreten, so namentlich in stehenden Gewässern, an den Flußufern und in Lagunen. Hier wachsen die größten Arten mit $1-2 \mathrm{~m}$ hohen Schäften, z. B. C. flabclliformis Rottb. (Fig. I38 C-E), leicht kenntlich an $\&$ bis mehr breiten und langen Hochblättern, welche den zusammengesetzten doldenähnlichen Blïtenstand überragen (häufig auch in Waldsümpfen bis zu I $800 \mathrm{~m}$ ü. MI.). Der im westlichen Kapland häufige, I $\mathrm{m}$ hohe C. textilis Thunb., welcher im Mittelmeergebiet hier und da kultiviert wird, erreicht das tropische Afrika nicht, dagegen geht der ähnliche $C$. sexangularis Nees nordwärts bis zum Sambesi; ferner $C$. articulatus $L$., sehr leicht kenntlich an den langen, später holzig werdenden, beim Verbrennen wohlriechenden, daher von den Hausa als Weihrauch verwendeten Rhizomen und an den durch Bruch des Markes veranlaßten zahlreichen Querringen des Stengels, an dessen Basis keine Laubblätter stehen; C. corymbosus Rottb., mit höchstens I dm langen Grundblättern, in Togo, Angola und Natal gefunden, auch mit wohlriechendem Rhizom und bisweilen angebaut: C. radiatus Vahl, einjährig, bis $6 \mathrm{dm}$ hoch, mit laubigen, den Bliitenstand iiberragenden Bracteen und fingerförmig angeordneten, sitzenden $\overparen{A} h r e n$, von Senegambien und Nubien bis zum unteren Sambesi und Angola; C. exaltatus Retz., bis $1,3 \mathrm{~m}$ hoch und mit gestielten Ähren, von den Cap Verden und Ägypten an bis zum unteren Sambesi; C. immensus C. B. Clarke, eine riesige, bis $3 \mathrm{~m}$ hohe, besonders von der Sansibarküste bis zum Kilimandscharo und im Kongogebiet häufigere Art, deren $4 \mathrm{~cm}$ breite Blätter zum Dachdecken benutzt werden. Dieser Art sehr ähnlich sind C. grandis C. B. Clarke und C. auricomus Sieber, beide im Gegensatz zu der vorigen mit mehr stielrunden Ährchen, letztere noch ausgezeichnet durch den scharf dreikantigen Stengel; C. grandis in Englisch- und Deutsch-Ostafrika, C. auricomus von Ägypten und Senegambien häufig bis zum Sambesi und Benguella. Ferner möge erwähnt werden C. (Tomlininum) ferox L. C. Rich., im tropischen Westafrika. Eine schöne, leicht kenntliche Art ist der 0,3-1,2 $\mathrm{m}$ hohe C. (Mariscus) ligularis $\mathrm{L}$., auffallend durch sehr fein gesägten Blattrand und zylindrische blaß zimtbraune bis dunkelrotbraune zusammengesetzte Ähren, schon auf Madeira, dann von Senegambien bis Loango, auch im tropischen Amerika und auf den Maskarenen. Gelbgrüne, sehr dichte und reichblütige Blütenstände besitzt C. (Mariscus) hemisphacricus Boeck., eine so kräftige Pflanze wie die vorige und verbreitet von BritischOstafrika bis zum südlichen Nyassaland, auch auf Äckern und im Gebirge bis I $900 \mathrm{~m}$ aufsteigend. In Südafrika verbreitet sind der auch im Nediterrangebiet verwilderte C. (Mariscus) congistus Vahl, mehr auf das südliche und westliche Kapland beschränkt C. (Mariscus) riparius (Schrad.). In die Gebirge des Kaplandes steigt auf C. Mariscus! tabularis Schrad. Auch von der Untergattung 


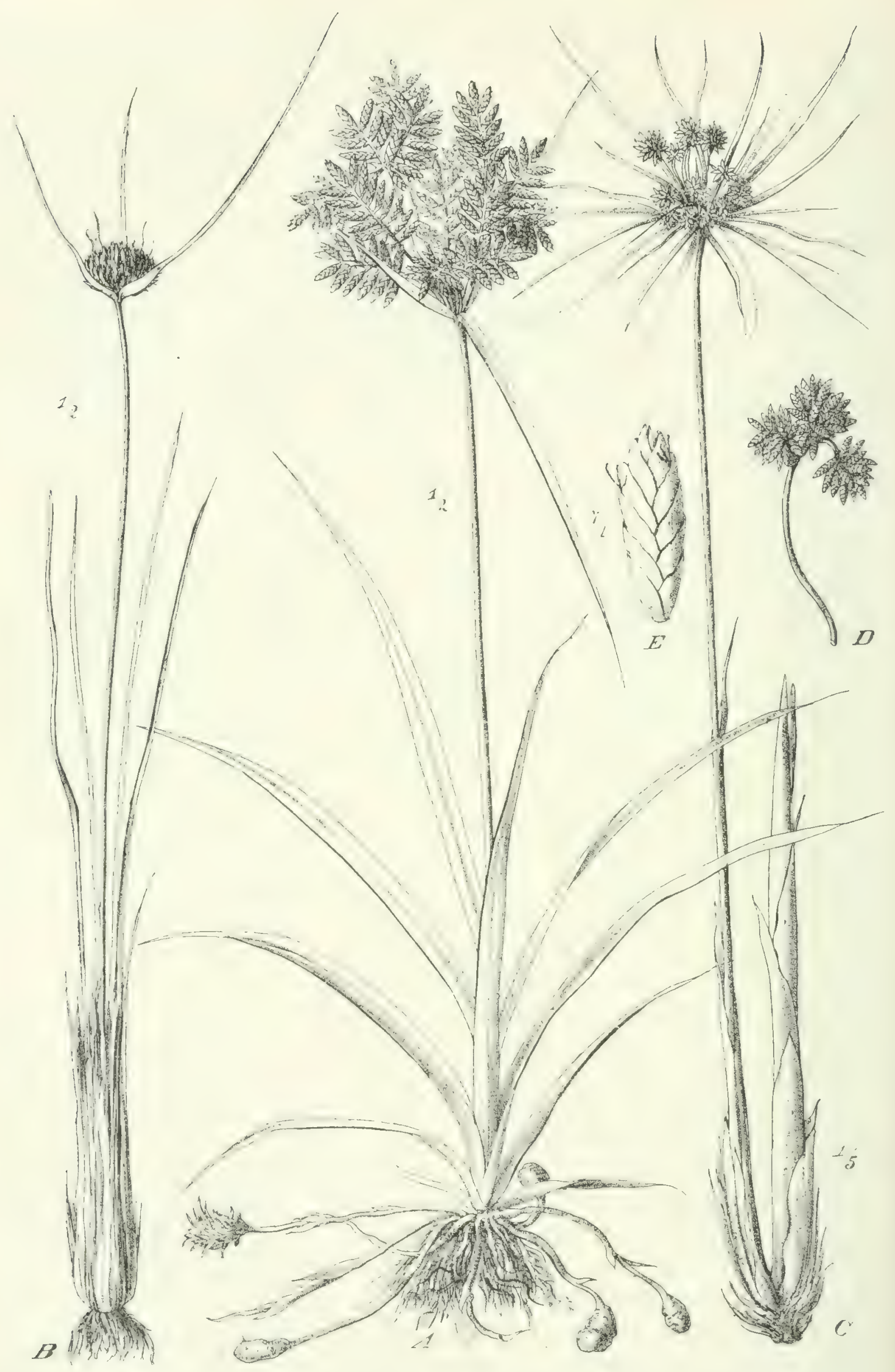

Fig. I38. A Cyperus esculentus L.; $B$ C. kyllingioides Vahl; $C-E$ C. flabelliformis Rottb. 


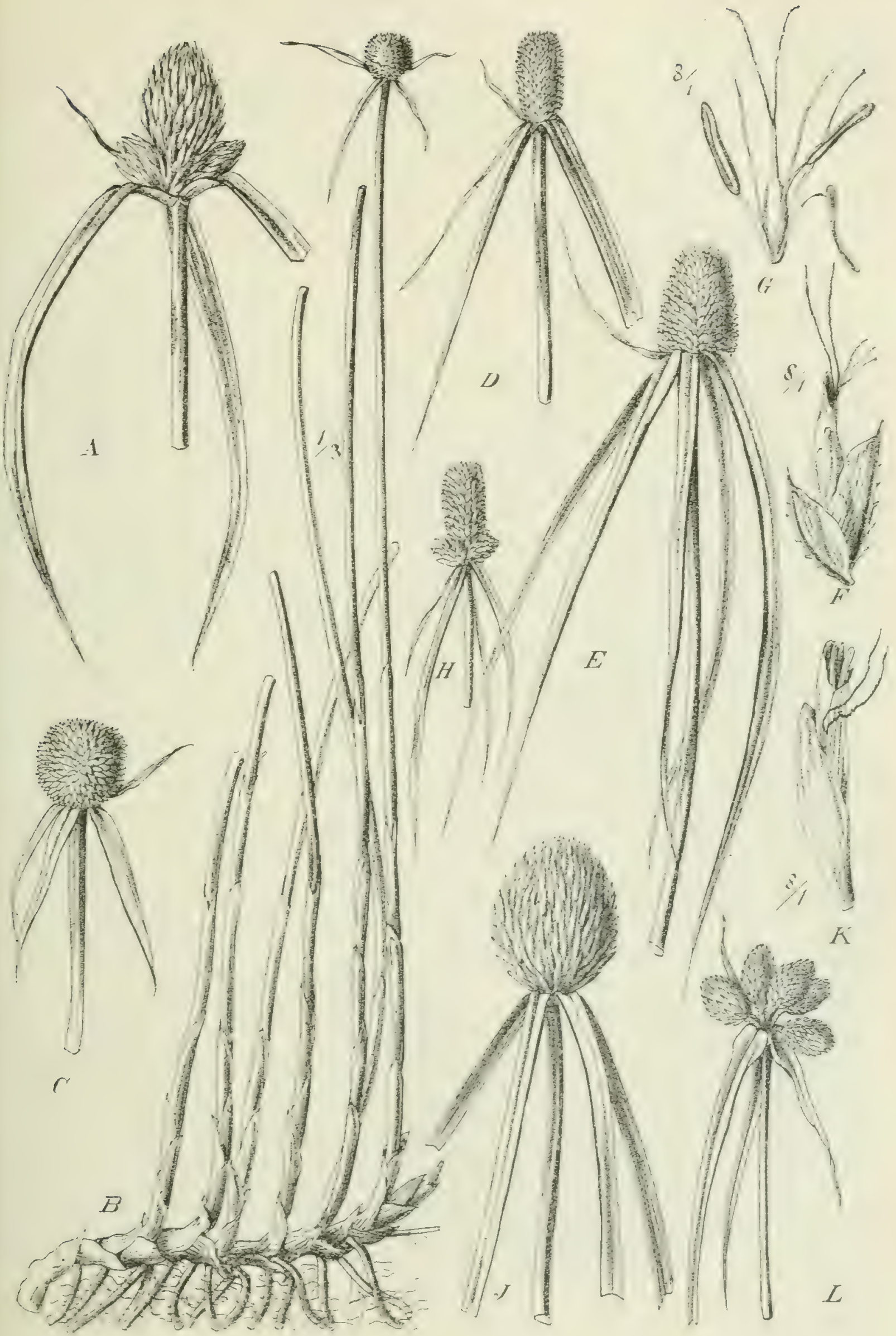

Fig. 139. A Kyllinga triceps Rottb.; $B, C$ K. peruviana Lam.; $D$ K. erecta Schumacher; $E-G$ - K. polyphylla W.; $H$ K. cylindrica Nees: $\mathcal{F}, K^{K}$ K. alba Nees; $L$ Lipocarpha argentea R. Br. 
Pycreus findet sich eine schöne, bis $4,5 \mathrm{dm}$ hohe Art mit langen Blättern und kastanienbraunen $\dddot{h}$ ren in Sümpfen des tropischen und südlichen Afrika, C. lancus Thunb. Die größte in Sümpfen rorkommende Art (bis I $m$ hoch) dieser Untergattung ist C.albomarginatus Steud., von Senegambien und Kordofan bis zum suidlichen Nyassaland. Ferner gehört zu den großen an Seen und Sümpfen wachsenden Arten C. alopecuroilles Rottb., bis 2,5 $\mathrm{m}$ hoch und mit bisweilen I m langen Bracteen am Grunde der Dolde, von einzelnen Autoren wegen der zweischenkeligen Griffel der unnatiurlichen Gattung Funicllus zugerechnet.

Aber auch die höchsten dieser Arten stehen erheblich zurück hinter dem gewaltigen, bis $5 \mathrm{~m}$ hohen, an den Ufern der großen Flüsse und Seen eine eigene Formation bildenden C'. pofj'mus L., der Papyrusstaude, deren Hauptart im V'esten von Lagos bis Angola (Golungo Alto) verbreitet ist und auch im suidlichen Vyassaland (6co-rgoo m i.. M.) vorhommt, während die Unterart antiquormm (V'illd.), ausgezeichnet durch das Abfallen der Ährchen oberhalb der untersten blïtenlosen Deckspelzen, von Ägypten durch Ostafrika bis zu den Ufern des Shire im portugiesischen Ostafrika zu verfolgen ist.

An Flußufern finden wir aber auch zahlreiche kleinere Arten, so z. B. den auch in Europa wachsenden C. flei'escins L., den einjährigen bis $5 \mathrm{dm}$ hohen C. difformis L., die cbenfalls einjährigen C. sphacelatus L. häufig an Lagunen), C. aristatus Rottb. (auch nicht selten in Steppensumpfen), ferner den mehrjährigen, am Grunde des 2- t,5 dm hohen Stengels zwiebelartigen C. maculatus Boeck., den bis $6 \mathrm{dm}$ hohen und durch knollig verdickte Rhizome ausgezeichneten C. rotumdus L., welcher auch nicht selten auf Kulturland, besonders auf Reisfeldern angetroffen wird; C. (Mariscus) kyllingioides Vahl (Fig. I 38 B), verbreitet bis Südafrika; C. caracasanns Boeck. (= Mariscus flabelliformis H. B. Kth.), eine fast tropisch kosmopolitische Pflanze, ist merkwürdigerweise bis jetzt nur im Westen ron Liberia bis zum Kongo, namentlich auch am Seestrand

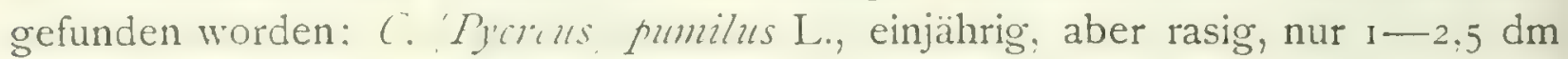
hoch, weitverbreitet in der aiten Welt. An zwei Griffelschenkeln leicht erkennbar sind die ebenfalls einjährigen und nicht sehr hohen Arten der zienlich künstlichen Untergattung Fumcillus, C. pustulatus Vahl, -von Senegambien und dem Ghasalquellengebiet bis zum Kongo, C. fy'gmacus Rottb., nur von Senegambien, Kordofan und Sennar nordwärts. An Ufern wachsen auch die zwei Arten der L'ntergattung Conroisia, schwache bis $3 \mathrm{dm}$ hohe Pflanzen mit doldigen hellbräunlichen Blütenständen, C. cyporoites Nees in Ostafrika und Deutsch-Südwestafrika, sonst auch noch in Indien und Madagaskar, der nur wenig abweichende (C. assimitis Steud. (Fig. I $40 K-L$ ) von Britisch-Ostafrika bis Abysinien und zum Grenzgebiet vom Gallahochland und Boran.

Eine höchst charakteristische, nur in den Sümpfen der unteren Waldregion von Kamerun bis Angola vorkommende Art ist C. fertilis Boeck. mit breitlineal-lanzettlichen Laubblättern am Grunde der wenig-strahligen Dolden. Ebenso ist kaum einer anderen Art ähnlich der mit langen, schmalen Blättern und breiten silbergrauen thren versehene, zur Untergattung Fycrus gehörige C. catarictarmm K. Schum. ron den Stromschnellen des Lokundje in Kamerun. 


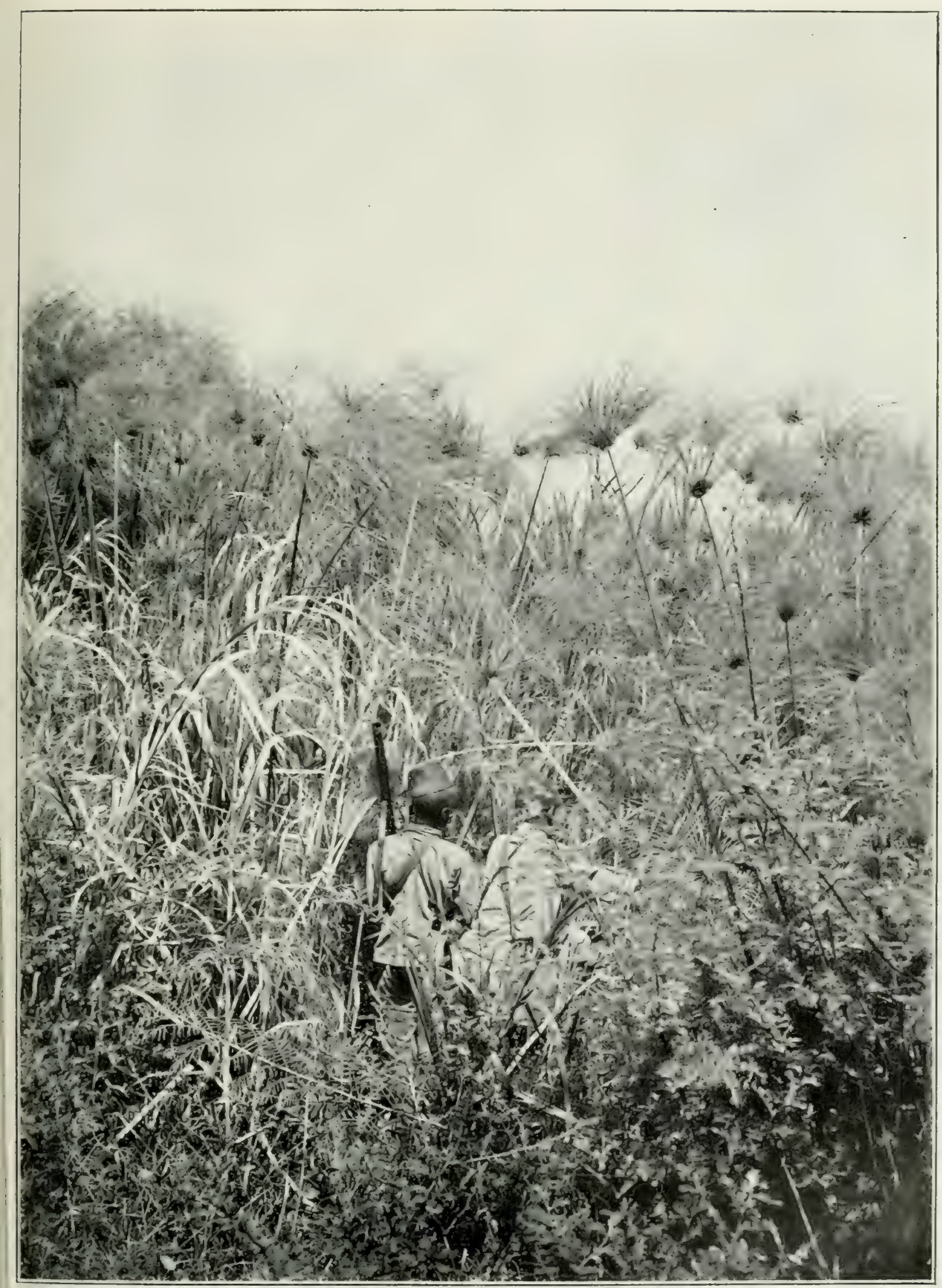

Cyperus papyrus L.

Papyrussumpf am Victoria Nyansa.

Nach einer Photographie von Exzellenz Prof. Dr. Robert Koch (1907). 

Einige Arten treten auch an den Gebirgsbächen der Règenwälder sowie der Höhenwälder auf, ebenso finden wir in den Sümpfen fast aller Regionen

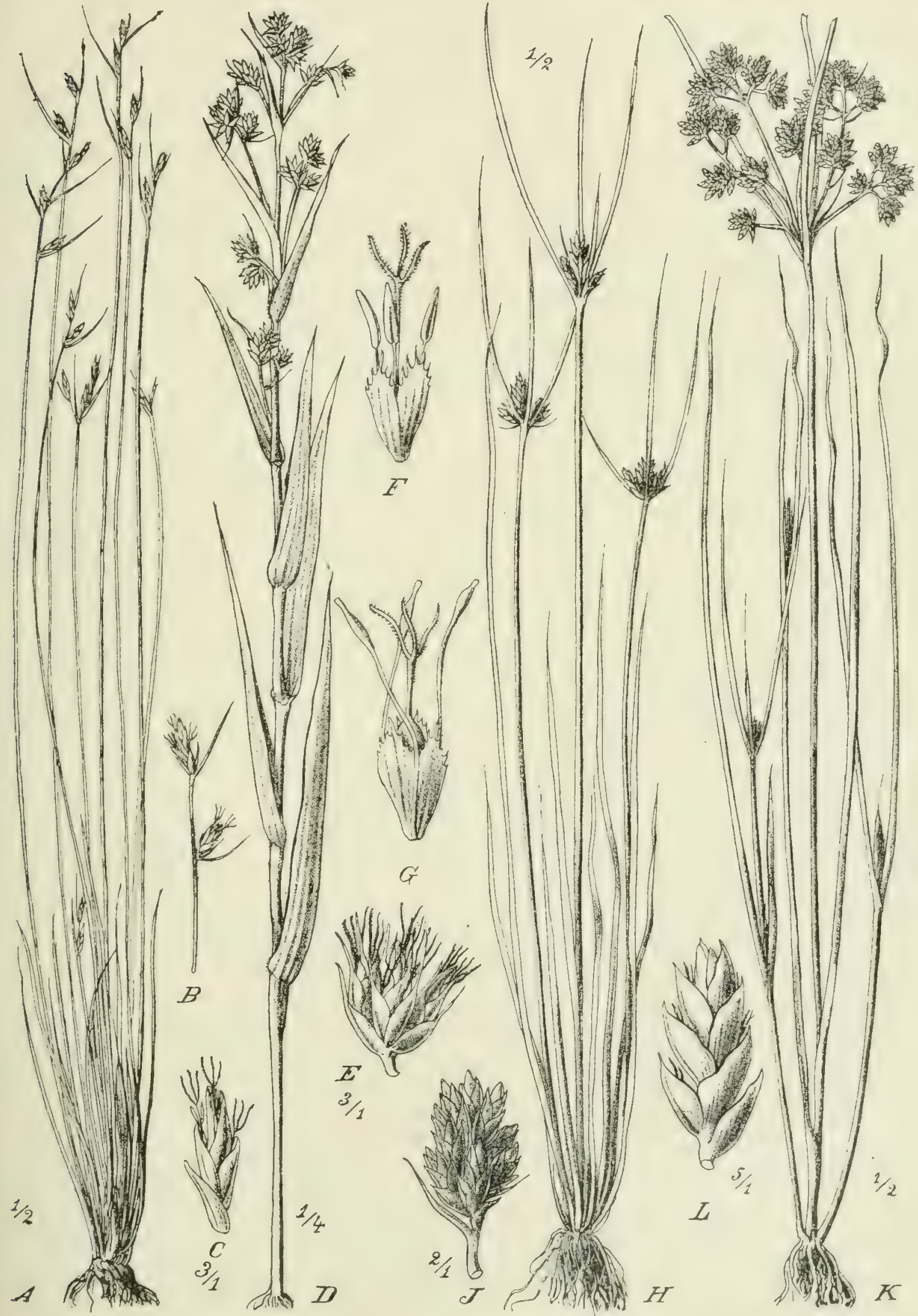

Fig. 140. $A-C$ Fimbristilis exilis Roem. et Schult.; $D-G$ Fuirena umbellata Rottb. $H, \mathcal{F}$ Cyperus atronitens Hochst.; $K, L$ Cyperus (Courtoisia) assimilis Steud. 
einige Cyperus, am meisten in denen der Ebene, aber auch an Waldsümpfen und Quellsümpfen außerhalb des Waldes bis zu $3000 \mathrm{~m}$ Höhe ü. M.

Von solchen in das Hochgebirge aufsteigenden hydrophilen Arten seien erwähnt: C. dichoostrchy'us Hochst. (Abyssinien bis Nyassaland und Benguella, I600-2500 m), mit langen Rhizomen und zusammengesetzten, doldenähnlichen Blütenständen; ferner C. Mannii C. B. Clarke, auf Fernando Po, San Thomé, dem Kamerungebirge, dem Kirunga und in Usambara von I $300-3 c 00 \mathrm{~m}$; C. I)eckenii Boeck. in Westusambara, am Kilimandscharo und im Nyassaland, von I $300-2600 \mathrm{~m}$; C. derreilema Steud. in Abyssinien und am Ruwenzori im Bambuswald bei $3000 \mathrm{~m}$; C. Renschï Boeck., eine riesige, $2 \mathrm{~m}$ hohe Art mit oben dreikantigem Stengel von der Goldküste und dem Ghasalquellengebiet bis Angola, bis $1900 \mathrm{~m}$ ü. M. aufsteigend; C. Schimperiames Steud., in Nubien und Abyssinien (bis I $900 \mathrm{~m}$ ), U'sambara und am Kilimandscharo ( $1600 \mathrm{~m}$ ), auffallend durch kurze Blätter und kastanienbraune Ährchen; C. maranguensis K. Schum. am Kilimandscharo, Ruwenzori (1 I00-I600 m) und Ostusambara, woselbst er zu Flechtereien benutzt wird: (. Mariscus) tomatophllus $\mathrm{K}$. Schum. am Kilimandscharo ron ifoo-3000 m, ebenda (. (.1/ariscus) alpestris K. Schum.: mit den beiden letztgenannten Arten verwandt und größer als diese ist $C$. (M riscus) magmis C. B. Clarke, von Westusambara und dem Mauplateau im Massaihochland, von den Eingeborenen auch wie C. immensus C. B. Clarke zum Dachdecken benutzt.

Neben diesen Arten der Untergattungen Encyperus und Mariscus finden wir in den Hochgebirgen auch einige Arten der Untergattung Pycreus, so C. nigricans Steud. von Abyssinien über den Kilimandscharo bis zum südlichen Nyassaland, C. maranthus Boeck. auf dem Hochland zwischen Rukwasee und Tanganyika und in Angola; ('smgsumolintus Vahl, kleinköpfig, von der Erythrea durch Abyssinien bis Bukoba, näher verwandt mit dem durch lange, kriechende Rhizome ausgezeichneten C. Mundtii Kth., welcher südlich bis Kapstadt verbreitet ist, auch auf den Maskarenen und sogar in Spanien vorkommt. Häufiger im Hochgebirge, als in unteren Regionen stellt sich auf Bachkies und an anderen feuchten Plätzen der 2-5 dm lange $C$. atronitens Hochst. ( $=$ C. elegantulus Hochst.) ein (Fig. I $40 H-\mathcal{F}$ ).

Auf feuchten Wiesen von Liberia und Uganda bis Natal und Benguella kommt der mit kurzem Rhizom versehene $C$. tenax Boeck. vor, aus der Ebene bis zu I600 $\mathrm{m}$ ü. M. aufsteigend. Nicht selten ist C. (Mariscus) coloratus Vahl, und wie in allen Tropenländern so auch im ganzen tropischen Afrika häufig C. (Pycreus) polystachyus $\mathrm{R}$. Br.

Auf feuchten Wiesen und in Sümpfen, namentlich auch in solchen in der Steppe und an der Küste ist vom suidlichen Mittelmeergebiet an bis zum südlichen und südwestlichen Kapland $C$. (Funcellus) laevigatus L. verbreitet, leicht erkennbar an dem horizontal kricchenden Rhizom mit dichtstehenden fleischigen, am Grunde höchstens ein kumes L aubblatt tragenden 3--6 dm hohen Stengeln: im Gebirge steigt er bis I $200 \mathrm{~m}$ auf.

Sehr cigenartig ist der in Sümpfen der Sansibarkuste zerstreut wachsende 
C. prolifer Lam. mit 50-100 strahligen Dolden, in denen häufig bis $30 \mathrm{~cm}$ lange junge Pflanzen entstehen.

Am Seestrand finden sich auch noch andere Arten: so der auch sonst rerbreitete C. compressus L., in Deutsch-Südwestafrika und Benguella der I m hohe, starre C. marginatus Thunb. Auf Dinen Ost- und Westafrikas findet sich mehrfach der großköpfige C. maritimus Poir. Auf nassen Feldern werden die Cypcrus oft ein lästiges Unkraut, so C. haspan L., der ebenso wie der ähnliche, jedoch einjährige C. fluritus Retz. auch an sandigen Fluß- und Bachufern häufig ist. ferner der tropisch-kosmopolitische C. distans L. f. mit langen Bracteen am Grunde der Dolden und sehr dünnen abstehenden, traubig angeordneten Ährchen; C. rotundus L., seltener C. longus L., häufig auch der C. Mariscus Sidirimus Nees' K. Schum., welcher durch die dunkelroten Scheiden der grundständigen Blätter und doldig angcordnete, zusammengesetzte ẗhren auffällt. Thnlich ist der ebenfalls sehr verbreitete C. umbillatus Tahl Boeck., bei welchem die Ährchen kleiner, dichter und starrer sind als bei C. Sieherianus.

Während auf den erwähnten Standorten den Cypcrus während eines größeren Teiles des Jahres, wenn nicht fortdauernd reichlichere Bodenfeuchtigkeit zukommt, ist dieselbe bei den Arten der folgenden Standorte während mehrerer Monate sehr eingeschränkt.

Als Pflanze trocknerer Wiesen ist besonders C. esculentus L. (Fig. I38 A) zu nennen. der in fast allen wärmeren Ländern der alten und neuen Welt verbreitet ist; er besitzt 1,5-6 dm lange, am Ende dreikantige Stengel und Dolden mit braunen, traubig angcordneten Ïhren, sodann dünne Ausläufer, welche an ihrem Ende als Nahrungsmittel dienende Knollen tragen, er kommt sowohl in der Ebene wie in den Gebirgen vor und steigt am Ruwenzori bis zu Igoo m auf; er wird im Damaraland auch kultiviert. Dort und überhaupt rom Amboland an südwärts bis in das Kapland findet sich häufig der höchstens $4 \mathrm{dm}$ hohe, am Ende der Stolonen mit Zwiebeln versehene C. wsitutus Burch. (orojeñ der Hereros). Vom Djurland bis Usambara findet sich zerstreut C. (Mariscus) djurcnsis Boeckl. mit fast kugeligen Köpfchen.

In tiefgründiger Niedcrungssteppe und auch auf ärmerem Boden sehen wir häufig zur Regenzeit die to-to cm hohen Iüuschel des einer Killing ähnlichen, auch in Siidafrika weitverbreiteten (: compuitus Lam., auffallend durm seine weißlichen kopfförmigen Bliitenstände, sowie auch durch die am Grunde fast zwiebelartig erscheinenden Stengel. Sehr ähnlich sind der mit längerem Rhizom versehene C. angolensis Boeck. rom Kongo bis zum lyassaland. aufsteigend bis zu $1900 \mathrm{~m}$ ) und C. margaritaccus Vahl, im Wuchs mit dem C. compactus ühereinstimmend, aber mit weniger und breiterun thren in den Köpfen 'sehr häufig auf sandigen Steppen ron Senegambien und Sansibar bis Südafrika;. Sehr häufig ist auch auf leichtem sandigem Boden zur Regenzeit ron Kordofan und Senegambien bis Südafrika C. amoubilis Tahl, eine $15-20 \mathrm{~cm}$ hohe einjährige Pflanze mit schmalen braunen Ähren, etwas weniger häufig der ähnliche C. uncinatus Poir. 
Besonders in Baumsteppen von Togo und dem Ghasalquellengebiet bis Angola findet sich der schlanke, am Ende des Schaftes rauhe $C$. Schweinfurthianus Boeck. Auch C. Fenstianus Steud. kommt häufig an feuchten sandigen Stellen der Baumsteppen und der parkartigen Buschgehölze von Senegambien und Nubien bis Usambara vor. Die auffallendste Steppenpflanze der Gattung ist C. Karlschmnami C. B. Clarke, mit zusammengerollten Blättern und I $\mathrm{m}$ langem Schaft, welcher $2-4 \mathrm{~cm}$ lange und $8 \mathrm{~mm}$ breite Ähren mit weißgelben strohartigen Bracteen irägt, bisher nur in Togo bei Sokodé gefunden. Eine sehr charakteristische, allerdings bis jetzt erst an wenigen Stellen nachgewiesene Art der Baum- und Buschsteppen von Djur bis zum Nyassasee ist der rasige C. (Mariscus) mollipes $\mathrm{K}$. Schum., nur I $5-30 \mathrm{~cm}$ hoch, auffallend durch die bleibenden und zerfaserten Scheiden der alten grundständigen Blätter, welche die zwiebelig verdickte Basis des Stengels umhüllen. Anderseits findet sich in Djur auch der ganz xerophytische C. (Mariscus) macropus Boeck. Hierher gehört auch der sehr kleine C. Kerstingii Engl., welcher, nur 8-I0 cm hoch, dichte Rasen bildet. Steppenbewohner Transvaals und der benachbarten Gebiete sind C. (Mariscus) capensis (Schrad.) Boeck., C. (Tariscus) Marlothii Boeck. Eine höchst eigentümliche Steppenpflanze ist auch C. (Meriscus:) ochroccphalus (Boeck.) C. B. Clarke, mit langen, dicht beschuppten Rhizomen und $15 \mathrm{~cm}$ hohen, in einen kugeligen Kopf endenden Sprossen von PoGge bei Kimbundu in Lunda entdeckt.

Endlich sind auch einige Arten durch ihr Vorkommen in Felsspalten der Hochgebirge charakterisiert, so der nur $15 \mathrm{~cm}$ hohe C. Tintriffac Poir. in den Gebirgen von Abyssinien bis zum Kilimandscharo, dann auch wieder in den Gebirgen Südafrikas. Hier finden wir auch den, bisweilen $5 \mathrm{dm}$ hohen, mit zahlreichen breiten Hochblättern versehenen C. albostriatus Schrad. In Westusambara fand ich auf trocknen Felsen bei Sakare um $1500 \mathrm{~m}$ häufig C. (Mariscus) Clarkeanus K. Schum. (= Mariscus Taylori C. B. Clarke).

Kyllinga Rottb. Sehr leicht kenntlich an den kopfförmigen, von den Tragblättern der vier bis sieben thren überragten Blütenständen und an den mit zwei Griffelschenkeln versehenen Stempeln. Dic Gattung ist zwar auch in anderen warmen Ländern vertreten, aber in Afrika besonders reichlich. Tiefes oder fließendes IVasser sagt keiner der fast 40 afrikanischen Arten zu, wohl aber gedeiht $K$. triceps Rottb. (Fig. I39 A, ziemlich leicht kenntlich an den aus drei Ähren gebildeten Köpfen an Flußufern, an feuchten Bergwiesen und auf feuchtem Seestrand, $K$. Inlboianlis Boeck. (mit einem von braunen Blattscheiden bedeckten Rhizom und strohgelbem Bliitenkopf auf nassen Feldern in Deutsch-Ostafrika, $K^{2}$. brciffolier Rottb. (mit kriechendem Rhizom und entfernt stehenden, einköpfigen Stengeln; auf Sandinseln mit feuchtem Untergrund an Bächen W'estafrikas, $K$. lewocchlukl Boeck. auf feuchtem Waldboden in Ostafrika, K. crecta Schumacher (Fig. I 3y I), mit kriechendem Rhizom und einem in der Jugend goldgelben Kopf am Ende der kurzen Stengel, vom Ghasalquellengebiet und Sicra Lenne an suidwärts bis Uitenhage und Kapstadt auf nassen Wiesen, aber auch an trocknen Plätzen und bis $1900 \mathrm{~m}$ in den Ge- 
birgen aufsteigend, K. peruitanc Lam. (Fig. 139.B, C, mit kriechendem Rhizom, scheidigen, spreitenlosen Blättern am Grunde der $5-7 \mathrm{dm}$ hohen, einköpfigen und mit kurzen Bracteen versehenen Stengel an nassen Ilätzen des äquatorialen Westafrika und im tropischen Südamerika. Auf mäßig feuchten Wiesen trifft man außer $K$. triceps auch $K$. polyphylla Willd. (mit dickem Rhizom und bis $5 \mathrm{dm}$ hohen, ein- bis dreiköpfigen Stengeln und zahlreichen Bracteen) von Mombas bis Dar-es-Salam, im Kongostaat und Angola, auch auf den Maskarenen. Zahlreiche Arten finden wir auf den Grasfluren der Gebirge und auf Weideland, auch auf Waldwiesen bis zu einer Höhe von $3800 \mathrm{~m}$ ü. M., so ganz besonders $K$. cylindrica Nees (Fig. I $39 H$ ) mit weißlichen Ähren; die auch in Südafrika häufige, durch einen großen, weißen, kugeligen Kopf ausgezeichnete K. alba Nees (Fig. $139 \mathcal{F}, K$ ) steigt nur bis zu etwa $\mathrm{i} 600 \mathrm{~m}$ auf.

Ficinia Schrad. Dies ist eine vorzugsweise suidafrikanische Gattung, von welcher 58 Arten unterschieden werden. Es sind in dichten Rasen wachsende Pflanzen, meist nur $1-3 \mathrm{dm}$ hoch, manchmal auch kleiner, vom Habitus der Scirpus, aber mit sehr schmalen Blättern und dadurch ausgezeichnet, daß der Fruchtknoten auf einem verkehrtpyramidalen Gynophor steht. Einige Arten wachsen am Meeresstrand und an Flußufern, die meisten aher auf den Gebirgen des Kaplandes. Von diesen kommen F. filiformis Schrad. und F. gracilis Schrad. auch am Kilimandscharo in einer Höhe von $3000 \mathrm{~m}$ ï. M., letztere sogar noch bis $3400 \mathrm{~m}$ vor, sowohl an grasigen Hängen, wie an steinigen Halden; F. gracilis auch sehr häufig am Mau Escarpment des Massaihochlandes. F. filiformis Schrad. fand ich auch häufig auf den kahlen, die Adlerfarnformation überragenden Gipfeln IVestusambaras, von I500-I800 m ü. M. Eine Art, F. clandestina (Hochst.) Boeck. findet sich noch in den Hochgebirgen Abyssiniens.

Fuirena Rottb. Dies sind viel kräftigere Pflanzen als die vorigen; sie stehen auch der Gattung Scirpus nahe, unterscheiden sich aber von den afrikanischen Arten der letzteren durch den beblätterten Stengel und die rispige Inflorescenz. Alle Arten wachsen auf feuchten Standorten, mehrere in Sümpfen, oft in großer Zahl, da mehrere weithin kriechende Rhizome besitzen, an denen in kurzen Abständen Stengel entspringen. Die Arten der Untergattung Eu-Fuircna sind dadurch ausgezeichnet, daß sie drei breite häutige hypogyne Schüppchen besitzen. Von ihnen sind besonders folgende zwei zu beachten. Die einjührige F. glonerata Lam., eine $3-4 \mathrm{dm}$ hohe Pflanze, welche im ganzen tropischen Afrika sowohl wie in Madagaskar und dem Monsungebiet auf zeitweise unter Wasser stehendem Schlickboden vorkommt. Viel größer $(0,5-1,5 \mathrm{~m})$ ist die mehrjährige mit holzigem Rhizom versehene $F$. umbellata Rottb. (Fig. I $40 D-G$ ), auch auffallend durch starke Behaarung, lange Blattscheiden und $1,5-2,5 \mathrm{dm}$ lange rispige Bliitenstände; sie ist wie in allen tropischen Gebieten so auch im tropischen Afrika verbreitet von Senegambien und dem Ghasalquellengebiet bis Angola und nach dem suidlichen Nyassaland, fehlt aber in Natal; sie ist besonders häufig an Lagunen und anderen sumpfigen Plätzen, an Gebirgsbächen und Quellsümpfen findet sie sich nur bis zu $1300 \mathrm{~m}$ ü. M.; in Kamerun 
wird auch aus ihr Salz gewonnen. Auch F. cincrasicns Ridley, mit kriechendem Rhizom und etwa $3 \mathrm{dm}$ hohen Stengeln verdient Erwähnung; wir finden sic häufig auf feuchtem Sandboden in Deutsch-Ostafrika und Benguella. Im Kapland sind andere Arten, wie F. hirta Vahl, F. Ecklonii Nees, F. coemulescens Steud., hesonders in der Kustenzone anzutreffen und die beiden letzten Arten finden sich auch in Natal. In der Lntergattung Hemiscirpus zeigen die Bluten der einzelnen Arten entweder keine Borsten oder, wenn solche rorhanden, so sind diese lineal, nicht flach. Die häufigste Art ist F. pubescens Kth., von Südafrika durch das tropische Afrika bis Corsica und Portugal und uiber Abyssinien, wo sie auch bis zu $2,00 \mathrm{~m}$ ü. MI. aufsteigt, bis zum Pendschab. Größere Bliitenähren besitzt die auch durch diches Rhizom ausgezeichnete F. fachymhiza Ridley, welche von Ostafrika bis Natal und Angola zerstreut vorkommt.

Scirpus L. Die im tropischen Afrika verbreiteten 24 Arten sind alle Bewohner nasser Standorte. Darunter sind einige, welche in Europa und auch sonst in der nördlichen gemäßigten Zone verbreitet sind, so Sc. lacustris L. in Sierra Leone, Sc. mucronatus L. in Kamerun, Sc. fluitans L. in Tümpeln und an Flußufern der Hochländer ron Abyssinien, Ostafriki und Angola, bisweilen große Strecken freudig grün färbend, Sc. sctacens L. in Abyssinien und am Kilimandscharo von $2300-3000 \mathrm{~m}$, Sc. supinus L., sehr zerstreut von Senegambien und Darfur bis zum Kapland, Sc. maritimus L. in Ost- und Westafriki, gern auf fuchten Baumwollfeldern, der im Nediterrangebiet, Suidafrika und dem Monsungebiet häufige Sc. littoralis Schrad., Sc. cemmus Vahl, der im siddichen Nittelnecrgebict namentlich in Algerien vorkommt, wurde bis jetzt nur auf den Kapverden und sehr häufig in Südafrika vom Kapland bis Natal und Transvaal gefunden; der in Europa verbreitete Sc. holoschoenus L. ist an den Küsten des Kaplandes durch eine besondere Varietät Thumbergii (Boeck.) C. B. Clarke vertreten. Einige Arten hat das tropische Afrika mit dem tropischen Amerika gemein, so Si. sfollicins Lam., Boeck. (Sierra Leone und Haiti), Sc. cubensis Poepp. et Kth. (in beiden Erdteilen verbreitet), Sc. ky'llingrivics Boeck. Sencgambien, Ostafrika und Westindien. Der in Kapland sehr häufige aber sehr kleine Sc. antarcticus L. ist eine der Pflanzen, welche Silafrika mit Australien, Neu-Seeland und St. Helena in Beziehung bringen; ähnlich verhalten sich die im tropischen Afrika auch fehlenden Sc. nodosus Rottb. (bis I $\mathrm{m}$ hoch) und Sc.prolifer Rottb. (bis $6 \mathrm{~m}$ hoch). Eine größere kräftige Art wie Sc. lacustris, maritimus und littoralis ist nur noch Sc. corymbosus Roth, der bis $3 \mathrm{~m}$ hoch wird und von Ägypten bis Südafrika und Madagaskar, auch bis Indien verbreitet ist und in den Gebirgen bis zu I $900 \mathrm{~m}$ aufsteigt; er ist häufig an Flußufern und seine langen Halme werden in Angola viel zur Herstellung von Matten verwendet.

Eleocharis R. Br. Von dieser Gattung werden I5 tropisch afrikanische Arten aufgezahlt. Außur der in Europa häufigen, auch ron Angola bekannt gewordenen E. palustris L. hat Afrika mit Europa Oberitalien) E. atrofurpura (Retz. Kth. gemein, Welche in Kordofan, Senegambien und am unteren Kongo gefunden wurde. E. mitrata (Griseb.) var. africana C. B. Clarke rom Niger 
weist auf Amerika hin, ebenso E. microcarpa Torrey von Djur. Auch steht die bis I $\mathrm{m}$ hohe $E$. fistulosa Link, welche im tropischen Afrika, sowie in Südafrika und Madagaskar vielfach gefunden wurde, anderseits auch im MIonsungebiet rorkommt, der amerikanischen E. mututa R. Br. nahe. Dic ubrigen Arten Afrikas sind alle an sehr wenig Orten gesammelt worden, so daß es sich nicht empfiehlt, näher auf sie einzugehen. Nur dies sei erwähnt, daß I: marginatula Steud. in Abyssinien und im Nassaihochland um $2600 \mathrm{~m}$ i. MI. vorkommt. Von keiner andern Art ist ein so hohes Vorkommen bekannt.

Fimbristilis Vahl. Von dieser in den Tropenländern, besonders in denen der alten Welt reich entwickelten Gattung kennt man jetzt etwa $2+$ Arten, von denen einige wegen ihres häufigen und bisweilen massenhaften Auftretens wohl zu beachten sind. Drei Arten sind dadurch ausgezeichnet, daß bei ihnen die Ährchen unten zweizeilig, oben spiralig angeordnete Deckspelzen tragen. $\mathrm{Da}$ ist zunächst die überall kurz behaarte bis $50 \mathrm{~cm}$ hohe $F$. africania Dur. et Schinz zu nennen, bei welcher die Stämmchen 3-1o kopfförmig zusammengedrängte braune thrchen tragen: sie wächst meist auf feuchtem Sandboden und Schlick und steigt stellenweise bis $1900 \mathrm{~m}$ ii. M. auf. IF. tristachy (Tahl Thwaites, die höchste Art der Gattung, mit 1-1,25 m hohen Stengeln, welche zwei bis fünf Ährchen von 2,5 cm Länge tragen, findet sich nur an den Küsten West- und Ostafrikas auf Schlickboden an den Lagunen und am Rande der Mangrovenformation; sie kommt auch im südlichen Indien und auf Ceylon vor. F. monostachya (L.) Hassk., welche nur etwa $4 \mathrm{dm}$ hohe Stengel mit meist einem Ïhrchen entwickelt, ist weitverbreitet in allen wärnmeren Teilen der Erde, in Afrika namentlich im Westen, aber auch in Sansibar; sie wächst in der Ebene an feuchten Orten, in der höheren Region bis zu $1000 \mathrm{~m}$ auf Niedergrassteppen. - Bei allen anderen Arten sind auch die unteren Spelzen der Ährchen spiralig angeordnet. Bei mehreren Arten Trikhelestylis, sind die Griffel dreischenkelig. Leicht erkennbar ist von diesen die durch starre, breit linealische, an der Spitze plötzlich verschmälerte Blätter und in zusammengesetzten Dolden zusammengedrängte Ährchen ausgezeichnete F. obtusifolia Kth., welche in den Küstengebieten Mest-Ostafrikas, der Naskarenen und des tropischen Amerika verbrcitet ist; sie wächst in Ostafrika namentlich auf den Korallenkalkinseln. - Zahlreiche andere Arten haben lockere Ährchen: F: complanata (Retz.) Link, eine in den Tropen verbreitete Art mit am Ende stark zusammengedrücktem, bis $6 \mathrm{dm}$ hohem Stengel, an Flußufern in Abyssinien, am Kongo und in Angola: F. miliacea (Thunb.) Vahl, mit zahlreichen, breit elliptischen Ährchen, auch ein Tropenkosmopolit; F. exilis Rocm. et Schult. (Fig. I $40 .-C$ ) eine einjährige, nur etwa $+\mathrm{dm}$ hohe, mit abstehenden Haaren besetzte Pflanze, sehr gemein im ganzen tropischen und südlichen Afrika auf alten Kulturfeldern und sandigen Plätzen der Steppen, bisweilen eine Art Rasen bildend, auch in den oberen Gebirgsregionen, besonders in der Adlerfarnfornation bis zu I760 m; F. cionizna P. Savi, mit zahlreicheren Ahrchen und kleineren Nüßchen, schon länger von den Reisfeldern Italiens bekannt, erstreckt sich vom tropischen Westafrika bis zum Kongo. - Die Gruppe Dichilostilis hat 
zweischenkelige Griffel. Von den hierher gehörigen (einjährigen) Arten ist die in den Tropen weitverbreitete $F$. squarosa (Poir.) Vahl ausgezeichnet durch einen Kranz abstehender Haare am Grunde des Griffels und zwei Staubblätter; es ist eine höchstens $17 \mathrm{~cm}$ hohe, ain Flußufern häufige Pflanze; $F$. dichotonn (L.) Vahl, etwas kräftiger als die vorige und wie die folgende mit achtrippigen Nüßchen, aber mit polygonalen Ïhrchen, ist auf feuchten Wiesen und auf Kulturland in ganz Afrika verbreitet; $F$. diphylla (Retz.) Vahl, wie die vorige, aber mit stielrunden $\dddot{H}$ hrchen, ist auf nassen Wiesen und an Flußufern gemein; F. femginca (L.) Vahl, wie mehrere andere Arten mit glatten Nüßchen, auch ein Kosmopolit der wärmeren Teile der Erde, bis $7 \mathrm{dm}$ hoch, fällt auf durch die rostfarhenen bis kastanienbraunen, bis $4 \mathrm{~mm}$ langen Ährchen und ist sehr häufig an zeitweise unter Wasser stehenden Plätzen, namentlich auch am Seestrand; F. longiculmis Steud., über I $\mathrm{m}$ hoch, sonst der vorigen sehr ähnlich, findet sich an den Küsten von Mombassa und Sansibar; F. nigritana C. B. Clarke, etwa $7 \mathrm{dm}$ hoch, ist eine Steppenpflanze Togos, Nigeriens und Bukobas.

Bulbostilis Kth., der vorigen Gattung sehr wahe stehend und wesentlich nur dadurch unterschieden, daß die verdickte Griffelbasis an dem Nüßchen verbleibt, ist doch eine natürliche Gattung, deren Arten im Gegensatz zu den meist hydrophilen Fimbristilis mehr xerophil sind; sie haben immer äußerst schmale, oft haarige Grundblätter und der Blütenstand ist entweder eine einfache oder zusammengesetzte Dolde, oder ein Köpfchen von Ährchen oder ein einzelnes Ährchen. Viele Arten gehen in den Hochgebirgen sehr hoch hinauf, einige bis zu einer Höhe von $3600 \mathrm{~m}$ ü. M. - Lockeren doldigen Blitenstand mit gestielten Hhrchen finden wir z. B. bei folgenden Arten: b. coleotricha (Hochst.j C. B. Clarke mit etwa $+\mathrm{dm}$ hohem haarigem Stengel, in Steppen, ron Senegambien bis Nyassaland; B. pubmula (Poir.) Kth., der vorigen nahe stehend, von Kamerun bis zum Nyassasee vorkommend, steigt im Kamerungebirge bis zu $3300 \mathrm{~m}$ auf. B. abortia' (Steud.). C. B. Clarke mit etwa 6 $\mathrm{dm}$ hohem, kahlem Stengel, von ähnlicher Verbreitung; B. Burchellii (Ficalho et Hiern C. B. Clarke, mit etwa $5 \mathrm{dm}$ hohem kahlem Stengel, mehr in Steppen des Siidens, rom südlichen Nyassaland und Benguella an südwärts. Die mit viel kleineren Thrchen versehenen $B$. capillaris (L.) Kth. und B. pusilla (A. Rich.) C. B. Clarke steigen aus der unteren Region in den Gebirgen hoch auf, erstere $\mathrm{im}$ Kamerungebiete und am Kilimandscharo bis $\mathrm{zu} 3300 \mathrm{~m}$. - Dolden mit Köpfen von thrchen besitzt $B$. Zeyheri Boeck. C. B. Clarke, welche aus einem Rhizom bis $5 \mathrm{dm}$ hohe Stengel entwickelt, in Siidafrika häufig ist und auch in Ukamba von $1600-1900 \mathrm{~m}$ ü. M. vorkommt. - Bei folgenden auch meist in Steppen und Gebirgen vorkommenden Arten enden dic Stengel in ein aus Thrchen zusammengesetztes Köpfchen: P. harlata (Rottb.) Kth., eine 2,5 dm hohe einjährige Pflanze, ron Senegambien his zum unteren Kongo, Steppenplanze: $R$. cartiocarta (Ridley) C. B. Clarke, bis $5 \mathrm{dm}$ hoch, in Steppen Westafrikas, Rhodesias und Suidafrikas; B. laniceps (K. Schum.) C. B. Clarke mit sehr schmalen Uhrchen kommt nur im WVesten vor. Dagegen ist die mit $2-5 \mathrm{dm}$ hohen, behaarten Stengeln versehene ?. firamcntosa Kth. im ganzen tropischen 
Afrika bis Transvaal zerstreut: B. Schimperiend 'Hochst. C. B. Clarke vom zentralafrikanischen Seengebiet nach Abyssinien $(2700 \mathrm{~m})$ aufsteigend. B. scleropus C. B. Clarke, mit $+\mathrm{dm}$ langen Stengeln und schwarzbraunen harten Blattscheiden, ist von Sïdafrika bis nach dem südlichen Nyassaland ( $\mathrm{I} g \mathrm{~g} \mathrm{O} \mathrm{m}$ ) gelangt. $B$. erratica (Hook. f.) C. B. Clarke mit Rhizom im Kamerungebiet bis $3600 \mathrm{~m}$ und B. atrosanguinea (Boeck.) C. B. Clarke, auf den Gebirgen Ostafrikas und Benguellas, von i $300-3600 \mathrm{~m}$, sind Felsenpflanzen.

\section{Caricoideae. - Rhynchosporeae.}

Schoenus L. Die boreale, auch noch in Nordafrika und dem nordwestlichen Indien vorkommende hygrophile Pflanze Sch. nigricans L. hat auch Abyssinien und das nördliche Somaliland erreicht; sie findet sich dann wieder vom ssïdwestlichen Kapland bis Griqualand West.

Cladium P. Browne. C. jamaicense Crantz $(=$ C. germanicum Schrad. $=$ C. mariscus $\mathrm{R}$. Br.), eine bekannte $2,5 \mathrm{~m}$ hohe Sumpfpflanze, welche wie in Europa auch in anderen gemäßigten und wärmeren Teilen der Erde sich zerstreut auf Sumpfwiesen findet, wurde außer auf den Kapverden auch in Angola bei Malandscha gefunden.

Remirea Aubl. Die einzige Art dieser Gattung, R. maritina Aubl., ist eine am sandigen Strand des atlantischen Ozeans verbreitete Strandpflanze mit oft $6 \mathrm{~m}$ weit kriechenden und sich verzweigenden Rhizomen, an denen in Abständen von $3-6 \mathrm{~cm}$ etwa $12-15 \mathrm{~cm}$ hohe, von unten an verzweigte und dicht mit starren, lineal-lanzettlichen Blättern besetzte Sprosse entspringen, die ebenso wie die aufrechten Äste in einem zwischen den Blättern etwas versteckten. eiförmigen Kopf von sitzenden Höhe und bilden über große Flächen ausgedehnte stachelige Rasen. Die Pflanze findet sich von Sierra Leone bis zur Tagomündung.

Rhynchospora Vahl. Von dieser weitverbreiteten Gattung finden sich 9 Arten im tropischen Afrika: 5 Arten haben einen langen ungeteilten oder kurz zweischenkeligen Griffel. $R$. Wallichiond (Kth.) C. B. Clarke, sehr schmalblätterig und mit $+-5 \mathrm{dm}$ langen in einen Kopf endenden Stengeln, im Monsungebiet zerstreut, ist auch an einigen Küstenpunkten des westlichen und östlichen tropischen Afrika aufgefunden worden, so auch in Sansibar und Inhambane; die ihr nahe stehende $R$. erinacea tRidley' C. B. Clarke an Flußufern in Benguella. Die im tropischen Amerika häufige $R$. cyperoüles (Swartz) Britton, welche an ihren Rhizomen bis $7 \mathrm{dm}$ lange graugruine Stengel mit Dolden blasser kugeliger Köpfe trägt, wurde auch auf moorigem Sumpfboden an der Goldküste, im Amboland und am Kubango, sowie von Pondoland bis Mossambik und auf den Maskarenen gefunden. $R$. aurce Vahl (Fig. I i I $D-F$, ein stattlicher bis $2 \mathrm{~m}$ hoher, hreitblättriger tropischer Kosmopolit mit rispigem Blitenstand, ist an Flußufern des tropischen Afrika weitverbreitet: ihr steht die $R$. spectabilis Hochst. aus Natal nahe. - + Arten haben zweischenkeligen Griffel. $R$. glauca Vahl, weit zerstreut in den Tropen, mit 3-8 dm langen Stengeln, findet sich in Südafrika von Kapstadt bis zum sudlichen Nyassaland, MIt. Zomba, 1300-I900 m), auch auf den MIaskarenen und in Algier. R. candida (Boeck.) Engler, Charakterpflanzen Afrikas. I. 


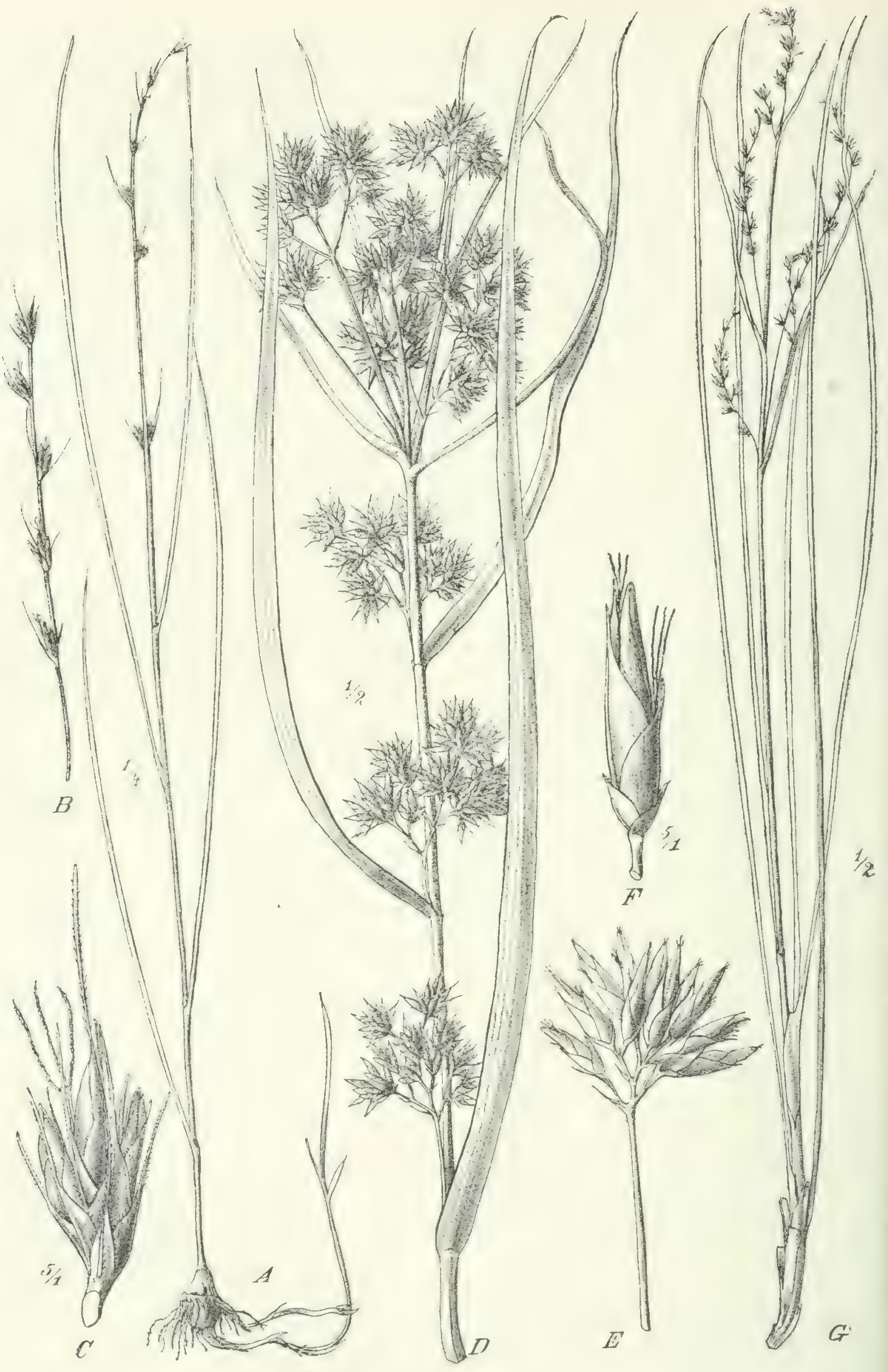

Fig. I4.I. $A-C$ Scleria bulbifera A. Rich.; $D-F$ Rhynchospora aurea Vahl; $G$ Eriospora abyssinica A. Rich. 
C. B. Clarke, eine senr schöne Pflanze, welche aus ihrem Rhizom bis 6 dm hohe Stengel mit lockerer Scheindolde ron weißen Ährchen entwickelt, findet sich mehrfach in Sümpfen ron Ober-Guinea bis Benguella. sodann im Nýassaland bis zu $1900 \mathrm{~m}$ ü. M. und auf Madagaskar, aber auch in Guiana und Brasilien. Beziehungen zu Amerika zeigen auch folgende bisher erst an einzelnen Stellen Afrikas aufgefundene Arten: R. micantha Vahl |Ober-Guinea, Teneriffa, trop. Amer.), R. Barteri C. B. Clarke Nigeria, nahestehend der westindischen R. die'ergens Britton, R. tencrmma L'rban 'Sachsenwald bei Dares-Salam, Westindien, steht auch der vorigen Art nahe).

\section{Caricoideae. - Gahnieae.}

Tetraria P. Beauv. ist eine in der Küstenregion des Kaplandes, besonders im Südwesten, mit 32 Arten vertretene Gattung, deren nächste Verwandte in Australien, Jeu-Seeland und dem extratropischen Südamerika vorkommen: sie ist also meridional oder subantarktisch: doch ist eine Art, $T$. circinalis Schrad. C. B. Clarke, eine rasige Planze mit etwa 2,5 dm hohen Stengeln und zusammengezogenen Rispen brauner länglicher Ährchen. ron HoIsT auch in Usambara gefunden worden.

\section{Caricoideae. - Hypolytreae.}

Hypolytrum A. Rich, ist ausgesprochen hydro-hygrophil: in allen tropischen Ländern finden sich Arten dieser jedenfalls sehr alten Gattung. Fünf Arten finden sich nur im tropischen Mestafrika ron Senegambien bis zum Kongo, nicht in Angola, darunter $H$. africanmm L. ohne Stolonen, mit t-8 dm langen Blättern und Stengeln ohne Knoten. Eine andere häufige Art ist H. nemomin (P. Beauv: Spreng.. deren $+-8 \mathrm{dm}$ hoher Stengel am Grunde Stolonen entwickelt, mit ein bis zwei Knoten versehen ist und linealische, schwanzförmige, bis 7 dm lange Knoten entwickelt. Diese Art hat die Verbreitung der vorigen, findet sich aber außerdem noch im Regenwald von Ostusambara. Bei allen Arten stehen die thrchen in reich zusammengesetzten Rispen.

Mapania Aubl. Ton dieser in hydro-hygrophilen Formationen der Tropen weitverbreiteten Gattung kennen wir sieben Arten, welche alle nur im Kamerunund Gabungebiet in Uferwäldern rorkommen: es sind stattliche mehrjährige PAanzen mit I-I,5 $\mathrm{m}$ langen, dreinervigen, am Rande rauhen Blättern und kïzzeren Stengeln mit einem oft ziemlich großen Kopf ron thrchen, in denen zwischen zwei männlichen Blüten eine weibliche Blite oder zwischen den beiden männlichen Bliiten und der cndständigen weiblichen Bliute mehrere blittenlose Spelzen stehen. Die Hochblätter am Grunde des Kopfes sind bei . I. scabr $\%$ rima (Boeck.) C. B. Clarke. .I. africana Boeck., .I. scians K. Schum. und .I. dotichostacta K. Schum. kurz, bei allen anderen Arten lang und laubig. eines ganz besonders groß, bis I m lang bei der oberhalb Buea in Kamerun um I $200 \mathrm{~m}$ vorkommenden M. Deistelii K. Schum. (Fig. I42 B-L). M. ampliarginatu K. Schum. (Fig. I $\& 2$ A zeigt ein horizontales Rhizom mit tief in den Boden gehenden Wurzeln und lang gestielten, länglichen, stark dreinervigen Blättern. Der Bau der Bliitenstände ist aus unserer Figur und deren Erklärung ersichtlich. 


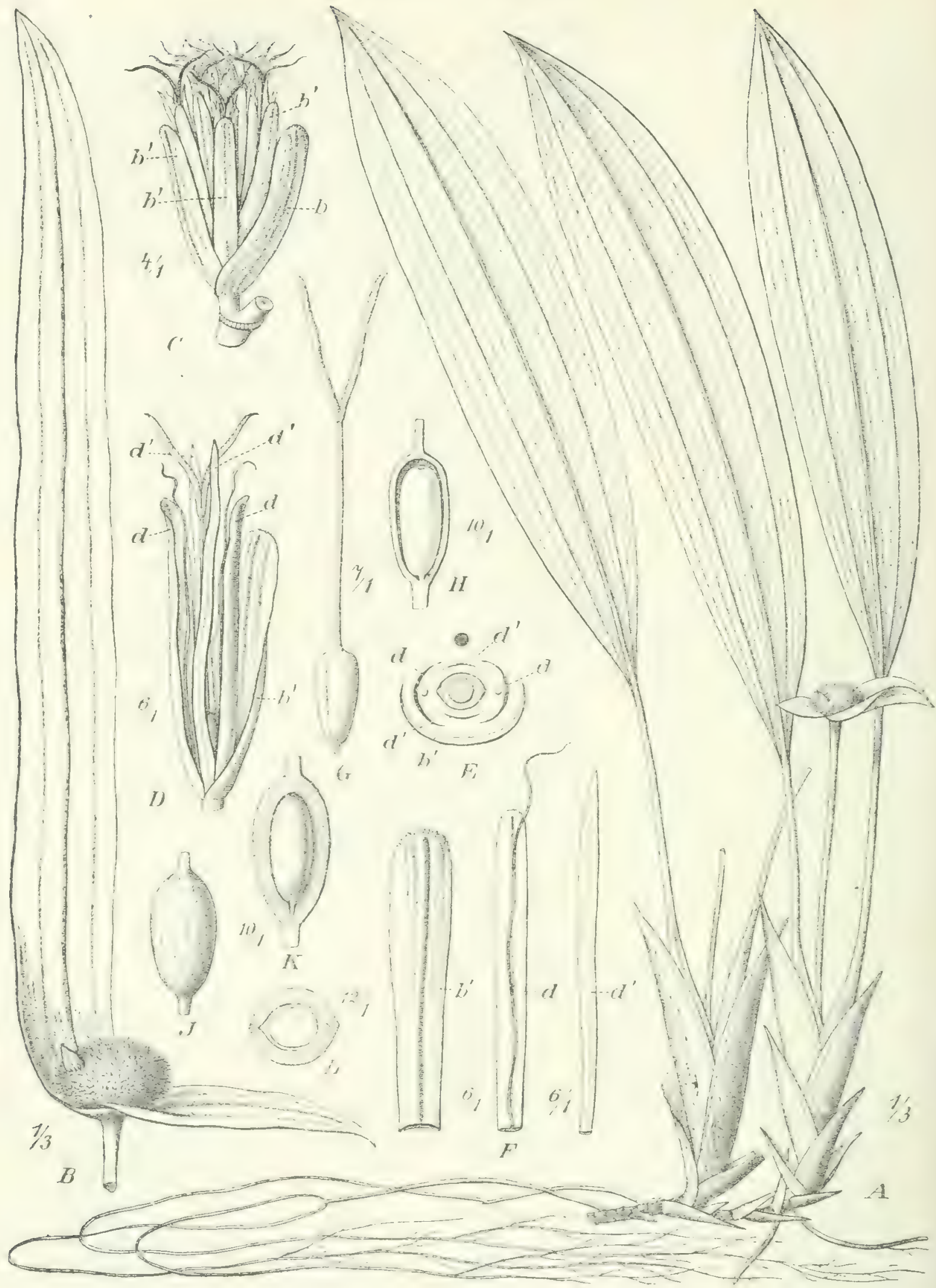

Fig. 142. A Mapania amplivaginata K. Schum. B-L Mapania Deistelii K. Schum. $B$ Blïtenstand mit zwei großen Hochblättern; $C$ eine Ähre vorletzter Ordnung; $D$ eine Ähre letzter Ordnung (Ährchen); $E$ Diagramm derselben; in $C, D$ und $E$ b Tragblatt der Ähre vorletzter Ordnung, 6' Tragblätter der Ähren letzter Ordnung, die Deckblätter der auf ein fadenförmiges Staminodium reduzierten $\tilde{\sigma}$ Blüten, $d^{\prime}$ die beiden die endständige $ᄋ$ Blüte einschließenden Deckblätter; $F$ die (inzelnen Trachliitter und I)eckblätter; $G$ Pistill oder $\subseteq$ IBlite; $H$ Fruchtlinoten mit der Samenanlage; $\mathcal{F}$ Frucht mit Rest des Griffels; $K$ Frucht geöffnet; $L$ Frucht und Same im Querschnitt. - Original. 


\section{Caricoideae. - Selerieae.}

Eriospora A. Rich. Diese eigentumlichen xerophytischen Cyperaceen sind auffallend durch die am Stengel verteilten Blätter mit stengelumfassenden, ticf gespaltenen Scheiden mit einem Haarkranz oder einer Ligula am Grunde der Spreite und lange Rispen mit dïnnen Ährchenstielen. Man kennt sechs Arten im tropischen Afrika und eine in Madagaskar. Eine eiförmige Ligula am Ende dreikantiger Scheiden besitzt die $6 \mathrm{dm}$ hohe $1:$ filosa Benth. in Ober-Guinea, auch in Togo, wo sie (bei Sokodé-Basari um $600 \mathrm{~m}$ ü. M.) an oft senkrechten Felsen graugrüne Rasen von oft mehr als I m Durchmesser bildet. - Bei den anderen Arten sind die Scheiden zusammengedrickt und die Ligula ein kurzer Haarkranz. Eine schon länger bekannte Art ist E. abj'ssinica A. Rich. mit kahlen Stengeln und bis 3,5 dm langen Rispen, in Abyssinien um 2500-2700 m, in Angola um 300-1 $100 \mathrm{~m}$ (Fig: I4 I G). E. Schrueinfurthiana (Boeck.) C. B. Clarke von den Baginse-Bergen im Lande der Niamniam steht ihr sehr nahe. Behaarte Stengel haben die in den Gebirgen des Nyassalandes und DeutschOstafrikas zerstreuten Arten E. Olia'tri (Boeck.) C. B. Clarke und E. sillosula C. B. Clarke. Schwächer behaart und durch dreikantige Scheiden ausgezeichnet ist E. Rehmanniana (Boeck.) C. B. Clarke von Pretoria in Transvaal.

Scleria Berg. Die Stengel sind beblättert und enden in Rispen mit eingeschlechtlichen oder zweigeschlechtlichen đ̈hrchen. Dic Arten der Sekt. Hjpopormm tragen am Grunde der Ährchen eine weibliche, weiter oben eine oder einige männliche Bliiten. Etwa acht einjährige Arten gehören hierher, von denen die bis $6 \mathrm{dm}$ hohe auf zeitweise überschwemmten WTiesen wachsende S. pirgracilis Kunth ron Indien bis Senegambien, Togo und Nigerien zerstrent rorkommt. I7 andere Arten, welche wie die rorigen kleine oder borstige Bracteen besitzen, sind perennierend. Erwähnt sei S. livitill Swartz, welche von Amerika über das tropische und suidliche Afrika hinweg bis Madagaskar verbreitet ist; sie und die in Westafrika, sowie im Nyassaland und Natal an feuchten Abhängen der Gebirgsbuschsteppen wachsende S. catophylla C. B. Clarke fallen auf durch die bei der Fruchtreife hängenden T̈hrchenknäuel. Bei der von Sennar bis Pondoland zerstreut rorkommenden S. Buchanani Boeck. und der von Abyssinien bis Angola in Gebirgssümpfen wachsenden S. bulbifora A. Rich. (Fig. I I A-C finden wir am Grunde zwiebelig verdickte Stengel. Eine besonders häufige Art dieser Gruppe ist die von Ukamba bis zum östlichen Kapland verbreitete S. Dregeana Kunth, welcher noch einige andere von Natal und Transvaal nahe stehen. Zahlreiche andere diinnstengelige Arten wachsen auf Wiesen an Flußufern. Dagegen ist eine kräftige mehrjährige Pflanze mit laubigen Bracteen die bis I $\mathrm{m}$ hohe, in tropischen und subtropischen Gebieten häufige, in Afrika aber auf die Ostriiste ron Mombassa bis 'Tanga beschränkte S. lithosferma Swartz mit ciförmigen, glatten, weißen Nüßchen. - In die Sekt. Eusclcria gehören kräftigere Pflanzen mit meist eingeschlechtlichen Ährchen und deutlichem hypogynischem Discus, zunächst mehrere einander recht nahe stehende einjährige Arten, wic S. folioser A. Rich., S. canaliculato-triquetra Bocck, beide Sumpfbewohner, ferner S. glandiformis 
Boeck., bis I, 5 m hoch, auch auf trocknerem Boden, namentlich aber auf zeitweise überschwemmtem Boden. Unter den mehrjährigen befinden sich einige weitverbreitete Arten, so die bis $6 \mathrm{dm}$ hohe in Sierra Leone und Liberia an Abhängen vorkommende S. spiciformis Benth., ausgezeichnet durch längsstreifige Nüßchen. Dagegen sind die $3 \mathrm{~mm}$ dicken, fast kugeligen Nüßchen glatt bei der bis $2 \mathrm{~m}$ hohen vom Monsungebict bis in das ostafrikanische Küstenland reichenden S. oryzoides Presl. Weiße, an der Spitze oft schwarze Nüßchen auf dunkelrotem Discus kennzeichnen die I $\mathrm{m}$ hohe, von Sierra Leone und dem Ghasalquellengebiet bis zum östlichen Kapland verbreitete S. melanomphald Kunth; dieser ähnlich, aber kleiner ist S. natalensis C. B. Clarke. Eiförmige, schwach dreikantige, glatte, weiße Nüßchen auf verkehrt-pyramidalem Discus besitzt die bis $6 \mathrm{dm}$ hohe, in Westafrika verbreitete S. ovuliger $\alpha$ Nees. Abweichend von allen Cyperaceen ist durch ihre dünn behaarten 5 bis $6 \mathrm{~m}$ hoch klimmenden und verzweigten, bis $4 \mathrm{~cm}$ dicken Stengel S. Barteri Boeck., welche von Sierra Leone bis zum unteren Kongo in den Urwäldern vorkommt, auch bis $900 \mathrm{~m}$ ii. M. aufsteigt; sie ist auch interessant durch weiße oder bunte Nüßchen auf schwärzlich-rotem, gelapptem Discus. - Drei ziemlich stattliche Arten gehören zu der Sekt. Opluyoscloria, bei der alle Ährchen eingeschlechtlich sind und die am Rande gewimperten Lappen des hypogynischen Discus eine Art Becher bilden. Die Nüßchen sind glatt bei der von Senegambien und dem Ghasalquellengebiet bis zum Nyassaland verbreiteten, auch auf den Maskarenen vorkommenden S. raccmosa Poir., desgl. bei der weniger kräftigen, auf das äquatoriale IVestafrika beschränkten S. Togelii C. B. Clarke, hingegen warzig bei S. vermcos $\alpha$ Willd. - Die Sekt. Acrinlus zeichnet sich durch endständige weibliche Bliite der Ährchen aus. Dahin gehören die bis $4 \mathrm{dm}$ hohe S. griegifolia C. B. Clarke von Benguela und die I $m$ hohe $S$. acrinlus C. B. Clarke von Uganda und Madagaskar.

Diplacrum R. Br., von Siltrie durch eingeschlechtliche, weibliche Ährchen mit scheinba: endständiger, weiblicher Blite verschieden, ist in Afrika durch zwei sehr verschiedene Arten vertreten. D. africanum C. B. Clarke ist eine cinjährige nur $0,5-1,2 \mathrm{dm}$ hohe, dicht behlätterte Pflanze, mit kicinen achselständigen Bliitenköpfchen, die sich auf Wiesenland an Flußufern von Sencgambien bis zum Ghasalqucllengebiet findet. D. longifolimn (Griseb.) C. B. Ciarke, mit 6 dm hohen dreikantigen Stengeln und entfernter stehenden Köpfchen, habituell an Sparganium erimnernd, findet sich in Gräben an den tieferen Stellen des sandigen Vorlandes von Liberia und Sierra Leone; die Pflanze ist auch häufig in Trinidad und Brasilicn, also wieder eine der vielen Westafrika mit dem tropischen Amerika in Verbindung bringenden Pflanzen.

\section{Caricoideac.-- Cariceae.}

Schoenoxiphium Nees ist eine Carex nahe stehende Gattung mit knotig geglicdertem Stengel und Thren oder langen Rispen, deren seitliche Öhrehen eine weibliche Blite und ein bis sechs männliche oder nur eine weibliche enthalten. Die Gattung ist mit sechs Arten vorzugsweise in Natal und Kapland bis zum Tafelberge vertieten; das bis $5 \mathrm{dm}$ hohe Sih. mufum Nees (Fig. I $+3 I I$ ) 


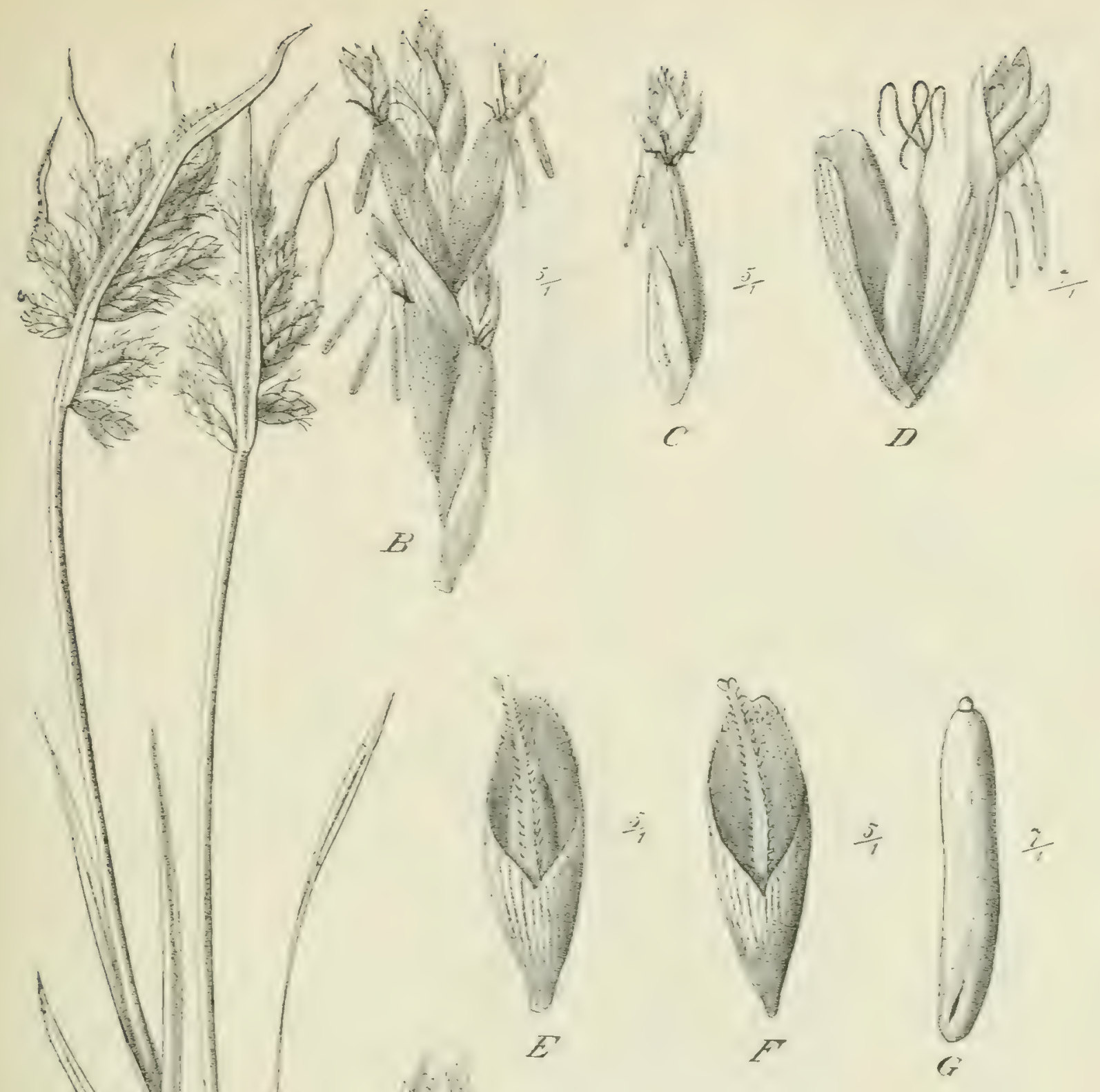

Fig. 143. Schoenoxiphium. $A-D$ Sch. Ecklonii Nees. $A$ Habitus; $B$ Ähre; $C$ Ährchen; $D$ dasselbe ausgebreitet, die $ᄋ$ und die $\sigma \cdot$ Blüten an der breiten Ährchenachse zeigend. $E-G$ Sch. capense Nees. E Ährchen mit Rudimenten der ô Blüten; $F$ dasselbe nach Entfernung des Nüßchens; $G$ Nüßchen. I Sch. rufum Nees, Ährchenachse mit den ö Blüten. F-L Sch. rufum (Wahlenb.) Kuekenth. var. Lehmannianum (Nees). F Androgynes Ährchen; $K$ dasselbe von hinten. $L$ Eingeschlechtliches Ährchen mit der Rhachilla. - Nach KüKentHal. 


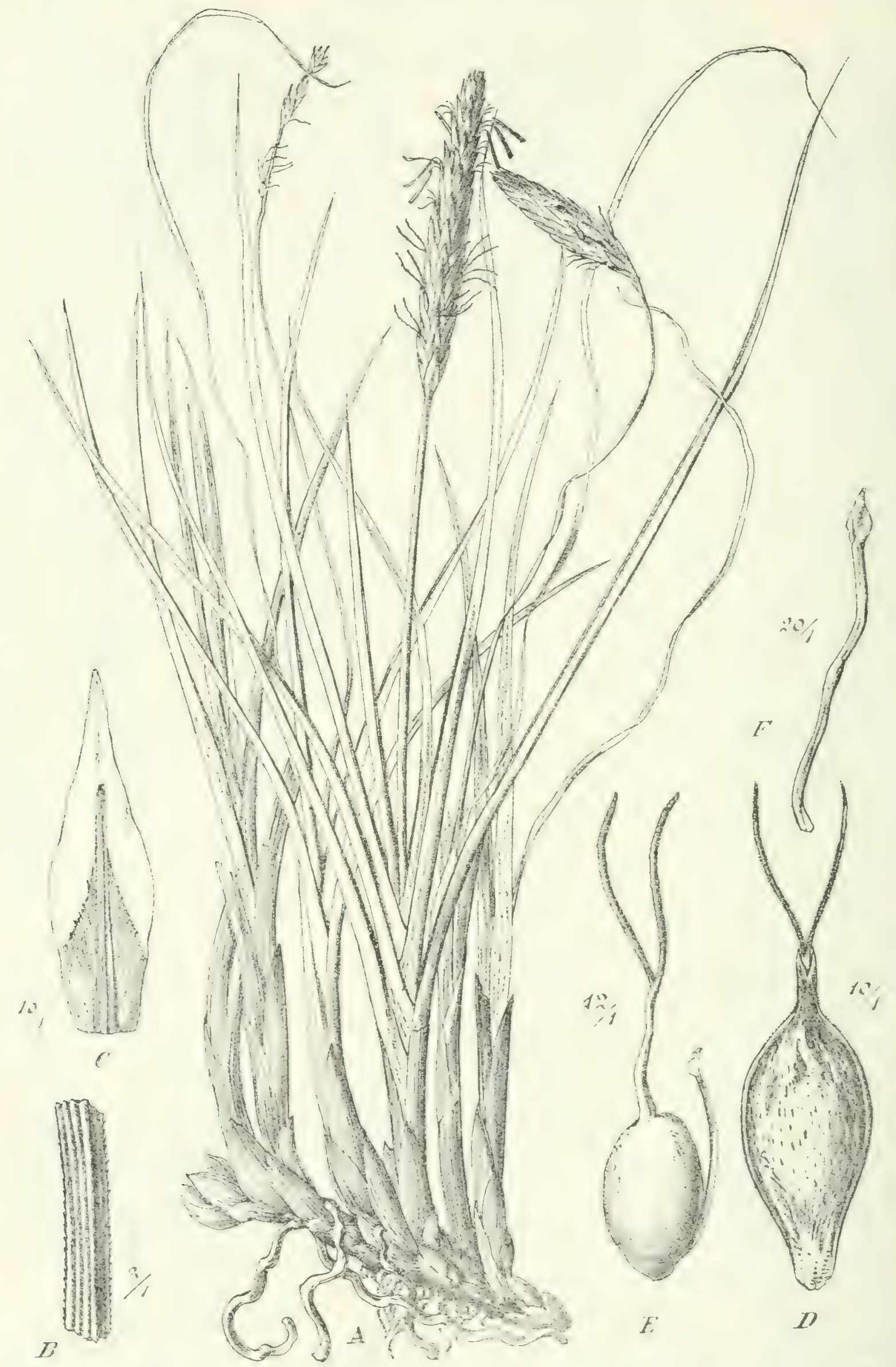

Fig. 144. Carex monostachya A. Rich. var. triquetrifolia (Boeck.) Kuekenth. A ganze Pflanze: $B$ Stück des Halmes; $C$ Tragblatt der weiblichen Blüte; $D$ schlauchförmiges Vorblatt mit weiblicher Blüte; $E$ Nuß mit der Ährchenachse; $F$ letztere stärker vergr. - Nach Kükfnthal. 
geht nach dem Oranjefreistaat hinüber, und Sch. Kunthicmum. Kuckenth. sowic Sch. spartcum (Wahlenb.) Kunth kommen auch in Transvaal vor, eine Varietät des letzteren, var.Schimperiamm (Boeck.) Kuekenth., können wir von Graaf Reinet über Natal zum Runssoro (1900-2600 m) und Debra Tabor in Abyssinien (2800 m) verfolgen, eine andere var. Lelmnannianum (Nees) Kuekenth. Fig. I43 I-L) vom Kapland uiber Natal nach Usambara. Sch. capense Nees (Fig. I +3 E-G), das am Tafelberg bei Kapstadt wächst, wird bis I $m$ hoch, das dort ebenfalls vorkommende Sch. Ecklonii Nees (Fig. I $43 A-D$ ) erreicht höchstens $4,5 \mathrm{dm}$.

Carex L. Wie sehr diese Gattung einem temperierten und kalten Klima angepaßt ist, zeigt sich in der Art ihres Torkommens im tropischen Afrika, wo sie nur auf den Hochgebirgen und in diesen mit. zwei Ausnahmen Care.r. masscnsis, cyrtosaccus) nicht unter I $900 \mathrm{~m}$ ï. II., mehrfach aber über $3000 \mathrm{~m}$ anzutreffen ist. Es sind also alle Arten mesotherm und oligotherm, aber nur ein kleiner Teil der afrikanischen Carex ist borealen Lrsprungs; die Mehrzahl sind endemisch, so ron den 28 Arten des afrikanischen Wald- und Steppengebietes nach Këkexthals neuester Monographie 20. Der kleinere Teil der afrikanischen Carices besitzt zweischenkelige Griffel, und unter diesen sind zwci Arten durch Stengel mit einer endständigen Ähre ausgezeichnet; sic bilden die auf die Gebirge des tropischen Ostafrika beschränkte Gruppe Longespicatcre der Untergatt. Primocarex Kuekenth., nümlich die bis 5,5 dm hohe C. monostaclyy A. Rich. (Fig. I it, welche in der hochalpinen Region Abyssiniens (Berge Silke und Guna um $+500 \mathrm{~m}$ ' und des Kilimandscharo ( $\mathrm{m}+4000 \mathrm{~m}$ ) an trockneren Stellen zwischen Lavablöcken in kleinen Polstern rorkommt, sowie C. runssorensis K. Schum. am Ruwenzori (Runssoro) um $3800 \mathrm{~m}$.

Bei dieser kleinen Gruppe ist die Zahl der Griffel konstant, dagegen ist dies bei anderen nicht der Fall, und es ist Kükexthar.s Einteilung von Corex der Vorzug gegenuiber der in der Flora of trop. Africa durchgeführten zu geben. Zweischenkelige Griffel, aber nicht immer, finden sich auch bei der Untergattung Vignca, die hauptsächlich durch sitzende, stets zweigeschlechtliche Ähren und den Mangel eines adossierten Vorblattes am Grunde der weiblichen thrchen charakterisiert ist. Dreischenkelige Griffel herrschen ror bei den Untergattungen Indocarex und Eucarex, deren Ähren meist gestielt sind, und deren $O$ ẗhrchen stets mit einem schlauchförmigen Vorblatt rersehen sind. Bei Indocare.r mit der Gruppe Indicue ist dieses Vorblatt schlauchförmig und die zweigeschlechtlich, bei Eucarcx hingegen ist dieses Vorblatt tubenförmig und die Ähren sind meist eingeschlechtlich. Zur Untergattung I Fignea gehören nur drei Arten Ostafrikas, die im abyssinischen Hochland un $3000 \mathrm{~m}$ oder dartiber vorkommende C. Koestlini Hochst. Fig. I +5) mit der Varietät irytherrhiza Boeck. und die an Bächen Hochabyssiniens wachsende C. conferter Hochst.; eine Varietät der letzteren, var. leptosaccus (C. B. Clarke, Kuekenth., findet sich am Kilimandscharo um $3300 \mathrm{~m}$. Interessant ist aber, daß in ITestusambara die dritte Art dieser Sippe, C. lycurus K. Schum., vorkommt.

Zu der Untergattung: Indocarex, welche im malagassischen Gebiet mit elf 
Arten vertreten ist, gchören vier kontinentalafrikanische. Bemerkenswert durch ihr Vorhommen auf verschiedenen, voneinander weit entfernten Hochgebirgen Afrikas ist C. echinochloc Kunze, cine kräftige o,6- I m hohe Pflanze, an offenen stcinigen Plätzen Abyssiniens (1900- $=800 \mathrm{~m}$ ), des Ruwenzori und Usambaras, außerdem auch im Kamerungebirge um $2600 \mathrm{~m}$; die Varietät chlorosaccus (C. B. Clarke) Kuekenth. wächst auf Fernando Po um $2300 \mathrm{~m}$ und am Kilimandscharo um $2300 \mathrm{~m}$, eine andere Varietät nyassensis (C. B. Clarke) Kuekenth. in den Gebirgsländern nördlich und südlich des Nyassa. Sodann gehören noch dieser Verwandtschaft an C. leptocladus C. B. Clarke auf dem Gipfel von San Thomé, C. spicato-paniculata C. B. Clarke (Fig. I46) in Deutsch-Ostafrika, in

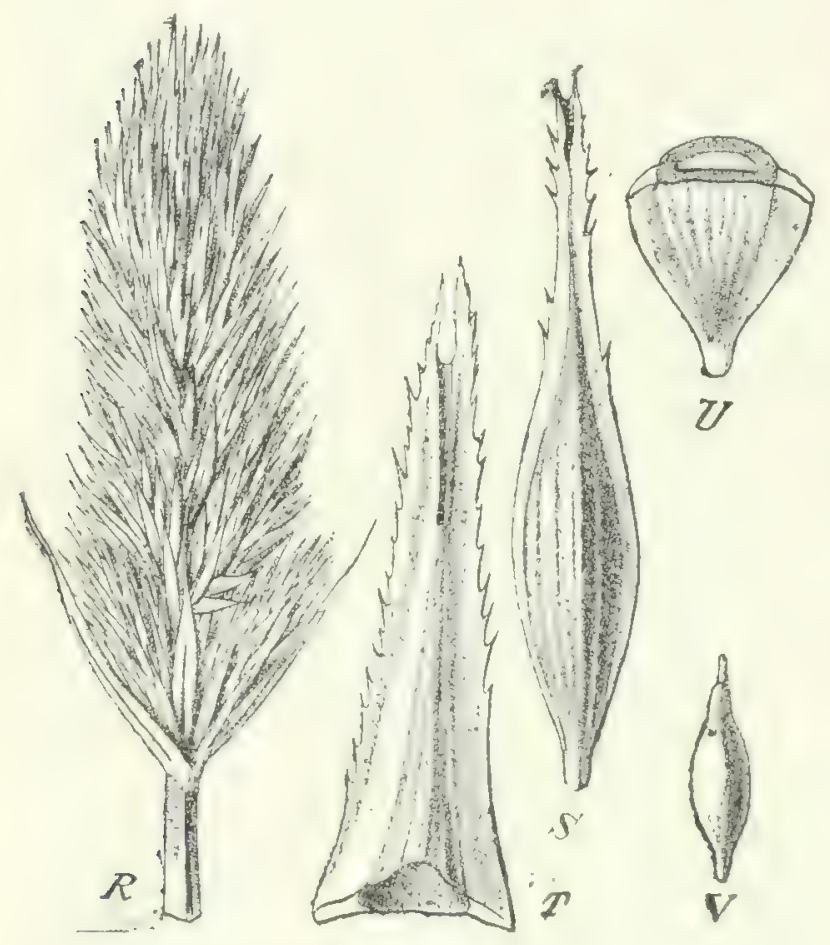

Fig. 145. Carex Koestlini Hochst. - Nach KüKenthal. den Drakensbergen und auf den Maskarenen, C. condensata Nees in Natal und den Drakensbergen, auch im nördlichen Indien. Vom Monsungebiet erreicht Natal und Transvaal C. phacota Spreng.

Eine große Zahl afrikanischer Eucarex (7) gehört zur Selktion Elatae, welche im mitteleuropäischen Gebiet nur mit einer nicht endemischen Art vertreten ist, dagegen vom Mediterrangebiet und Makaronesien aus über das Monsungebiet und Afrika bis nach Australien und den siidatlantischen Inseln reicht. Die I $m$ hohe C. Boryana Schkuhr findet sich zerstreut in den obersten Regionen von Fernando Po, an Bächen des Ruwenzori um $3300 \mathrm{~m}$ und auf den Maskarenen, ihr sehr nahe steht C.cyrtosaccus C. B. Clarke, welche im südlichen Nyassaland um I 300-igoo m vorkommt. Ebenso stattlich ist ( simusis IIochst. (Fig. I +7 ), auch wieder auf den höchsten Gebirgen unseres Gebietes zerstreut, in Abyssinien (um $3800 \mathrm{~m}$ ), am Ruwenzori (1900-2600 m), auf dem Kamerunpik (2300-3300 m). Auf dem Kilimandscharo kommen zwei der vorigen nahe stehende Arten vor, C. vallis-Rosetto K. Schum. unter 3000 m, C. longepedunculata K. Schum. über 3000 m. Eine Art dieser Sektion, C. withioficir Boott, findet sich auch im Kapland ron Kapstadt bis nach Albany, hier in Wäldern bis zu $700 \mathrm{~m}$ aufsteigend. C. Petitiana A. Rich. (Fig. I48) ist eine I $\mathrm{m}$ hohe Art Abyssiniens, deren Verwandte (Sekt. Maximae) sich von Mularonesien durch das Mittelmeergebict nach Ostindien verfolgen lassen; sie ist auch in Südafrika ron Natal bis nach dem siidwestlichen Kapland rerbreitet, sonst ist aber in Afrika diese Gruppe nicht zu weiterer Entwicklung gelangt. Die auf dem Kilimandscharo und Ruwenzori vorkommende, I $m$ hohe $C$. Folmstonii Boeck. gehört einer weit, bis in die neue Welt verbreiteten Sektion 


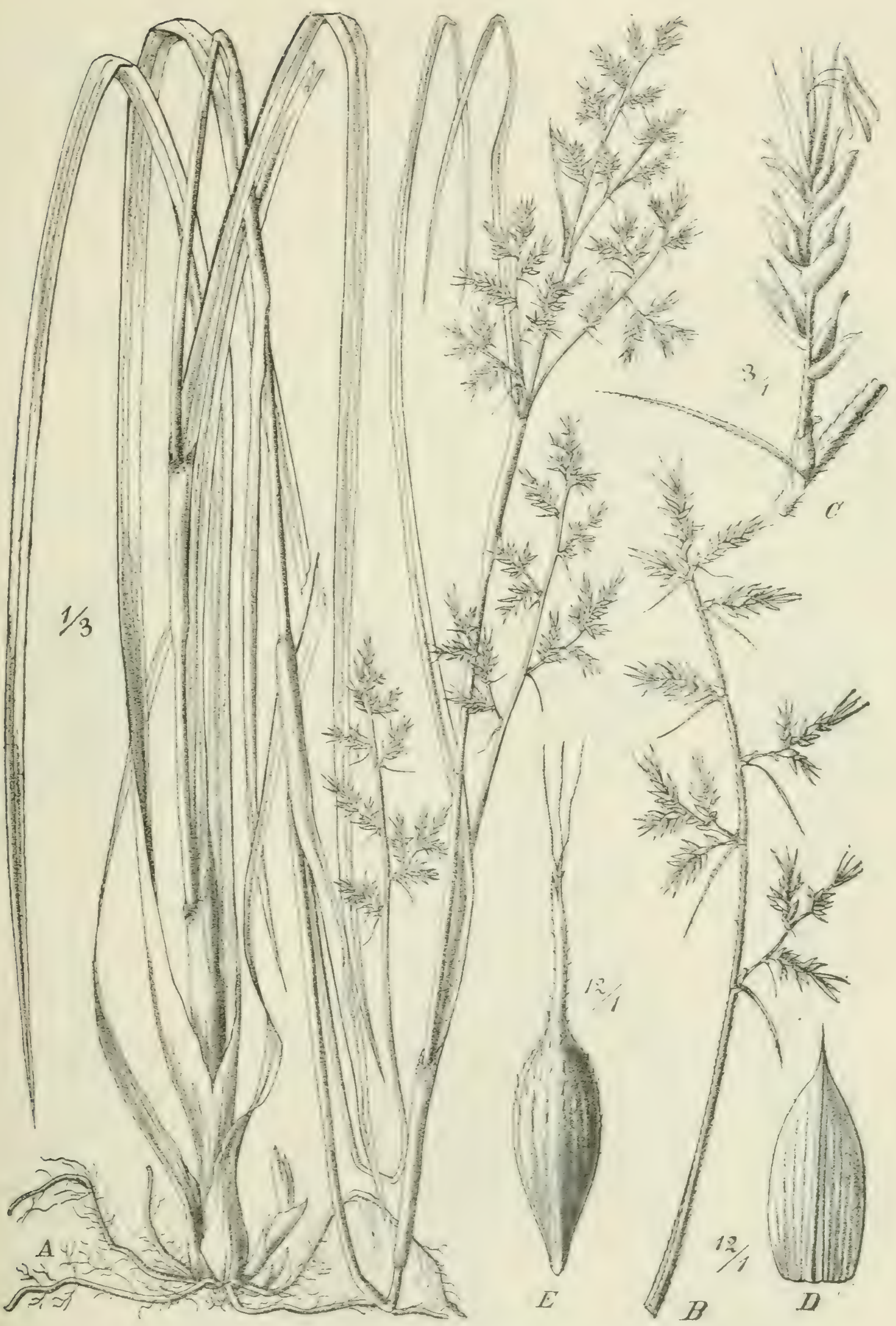

Fig. 146. Carex spicato-paniculata C. B. Clarke. - Nach KürexthaL. 


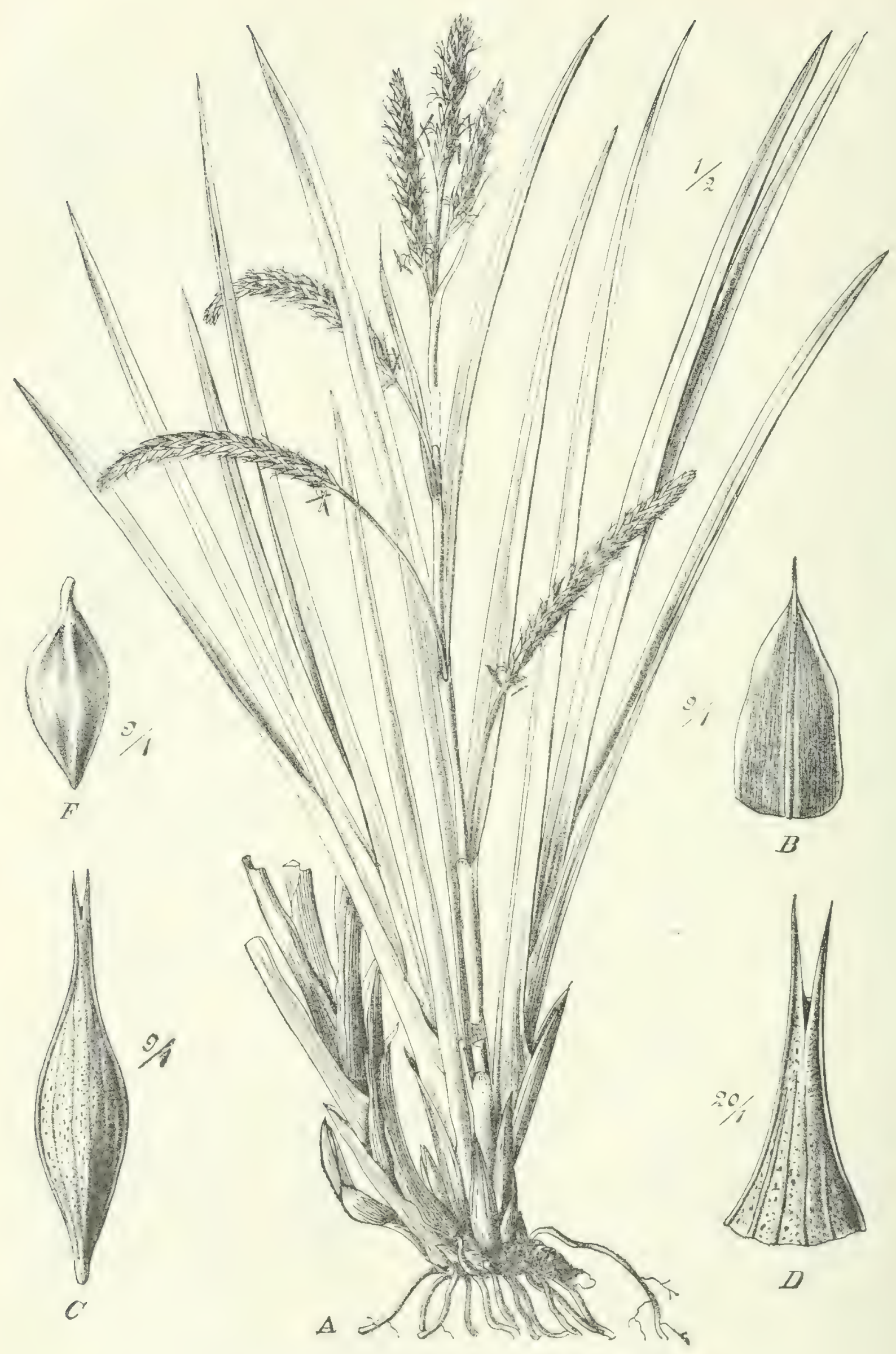

Fig. 147. Carex simensis Hocbst. - Nach Kükenthal. 


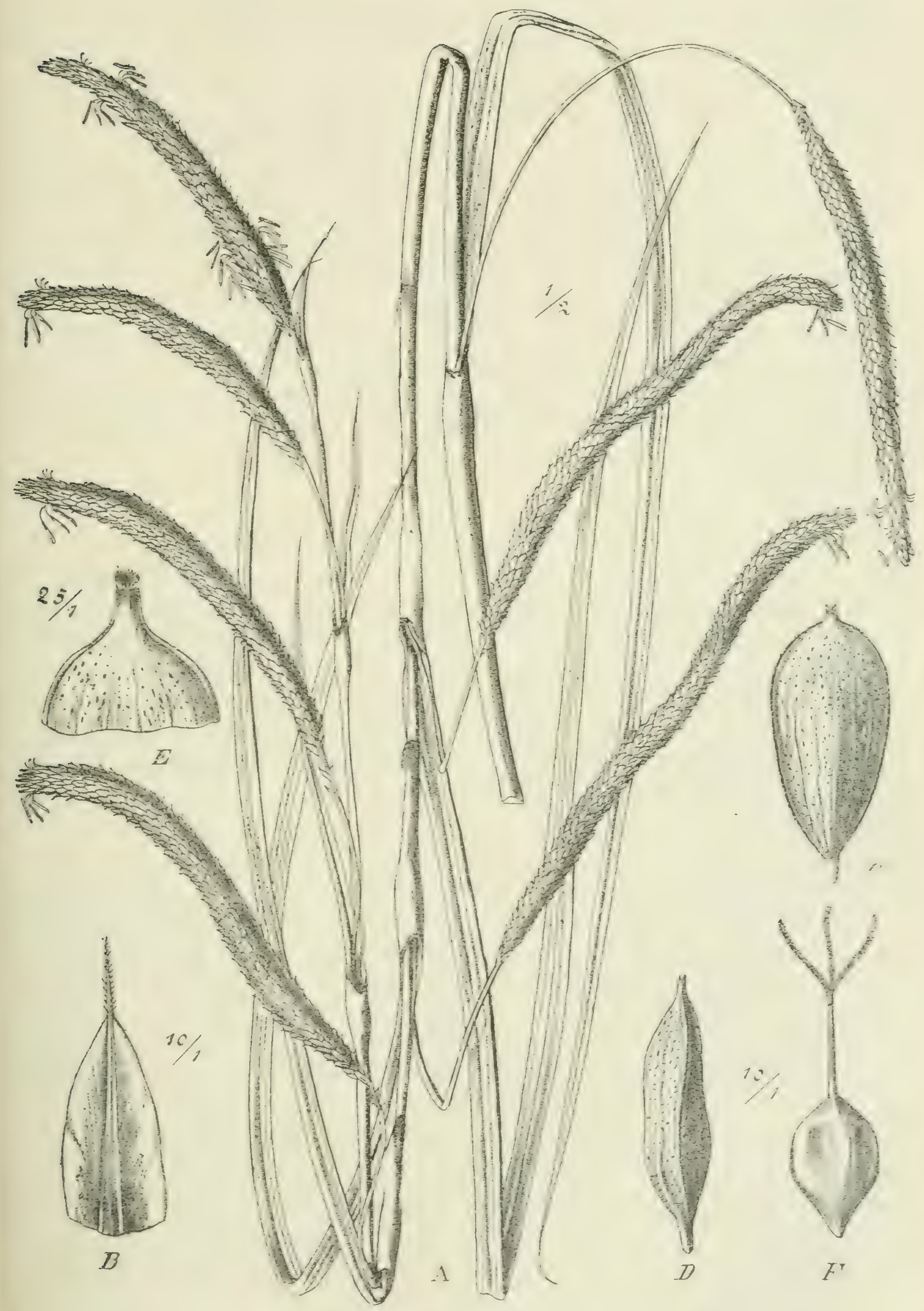

Fig. 148. Carex Petitiana A. Rich. - Nach KüKEnTHaL. 
IYminothlacnd an und steht in Afrika isoliert da. Während im großen und ganzen hervortritt, daß die IVanderung der meisten afrikanischen Carices entlang des großen ostafrikanischen Gebirgssystems und von hier in der äquatorialen Zone westwärts nach den hohen Gebirgen erfolgt ist, finden wir in Südafrika noch einige in der nördlich gemäßigten Zone weitverbreitete Arten, von denen sich keine Spur im tropischen Afrika nachweisen läßt, C. dìiss Huds., welche auch in Makaronesien auftritt, in Klein-Namaland, C. antpina L. im östlichen Kapland, C. acutiformis Ehrh. in Transvaal und dem östlichen Kapland, C. extensa Gooden. von Natal bis Port Elisabeth entlang der Küste, C. flava L. im Basutoland um $3000 \mathrm{~m}$. Außer diesen haben wir noch $C$. cermua Boot. var. austroafricand Kuekenth. in Natal und Transvaal, welche auf Ostindien hinweist. C. clazrata Thunb., vom südwestlichen Kapland bis zum Oranjestaat vorkommend, gehört in die Gruppe der Paludosat, und C. cognata Kunth nebst der var. drokenshergensis (C. B. Clarke) Kuekenth. gehört wie die auf Madagaskar wachsende C. sphatrogy'n Bak. in die Verwandtschaft der C. psezulocyperus L.

\section{Fam. Palmae.}

Die Zahl der afrikanischen Palmen, welche zum großen Teil bis zu gewissem Grade als megatherme und mesotherme Hydrophyten, zum kleineren Teil als Subxcrophyten anzusehen sind und durch ihr Vorkommen das Vorhandensein von Grundwasser anzeigen, ist keine große, wenn man sie mit der des Monsungebietes oder des tropischen Amerika vergleicht; aber die meisten Arten tragen doch durch Häufigkeit ihres Vorkommens sehr zur Charakteristik einzelner Formationen bei. Die I 3 einheimischen und zwei in Kultur vertretenen Gattungen sind alle leicht kenntlich und verteilen sich systematisch folgendermaßen:

A. In den Bliiten drei Carpelle, frei oder locker vereint, jedes zu einer Beere sich entwickelnd ........... Unterfam. Coryphoideae.

a Fiederpalmen mit einer den ganzen Blütenstand umhïllenden Scheide. Blüten eingeschlechtlich

Phoeniceae.

Phoenix.

b Fächerpalmen mit mehreren unvollständigen Scheiden am Grunde der Äste des Blütenstandes. Blïten polygamisch . . . . . . Sabaleae. Hierher nur die mediterrane Gattung . . . . . . . . . Chamaerops.

B. Drei verwachsene Carpelle, ron denen jedes befruchtete eine einsamige Steinfrucht ausbildet. Fächerpalmen ..... Unterfam. Borassoideae.

a) Die männlichen Bliiten zu Wickeln vereint in Gruben der sie tragenden Äste. Niemals verzweigt.

Borassus.

b) Dic männlichen Bliiten einzeln in den Gruben der sie tragenden Äste. Stamm verzweigt oder einfach.

r) Nährgewebe des Samens nicht gefurcht . . . . . . . . . . Hyphaene. H 3) Nährgewebe des Samens durch einspringende Leisten des Steinkerns gefurcht. Medemia. 
C. Drei verwachsene Carpelle sich zu einer cinzigen cinsamigen, mit Schuppenpanzer versehenen Frucht entwickelnd. Alle afrikanischen Gattungen Fiederpalmen

\section{Unterfam. Lepidocaryoideae.}

a) Stamm mit kurzen Internodien aufrecht. Fruchtknoten vollständig dreifächerig

Raphicae.

Raphia.

b) Stamm mit langen Internodien. Rotang

Calameae.

r) Pflanzen mehrmals fruchtend.

I. Spathen vorhanden.

1. Fruchtknoten unvollständig dreifächerig

Calamus.

2. Fruchtknoten vollständig dreifächerig

U. Spathen fehlend

ß) Pfanzen nur einmal fruchtend .

Oncocalamus.

Eremospatha.

Ancistrophyllum.

D. Drei verwachsene Carpelle sich zu einer drei- bis einfächerigen, nicht gepanzerten Frucht entwickelnd. Fiederpalmen ..... Ceroxyloideae.

a) Beerenfrüchte ......................... Areceae.

c) Carpell mit hängenden Samenanlagen. Nährgewebe des Samens homogen.

I. Staubblätter viele

Sclerosperma.

II. Staubblätter sechs .

Podococcus.

B) Carpell mit aufrechter Samenanlage. Nährgewebe zerklüftet. Kulturpflanze . Areca.

b) Steinfrüchte

Cocoeae.

(6) Männliche Blïten in Gruben der Kolben. Pericarp fleischig . . . . . Elaeis.

ß) Männliche Blüten an der Oberfäche der Kolben. Pericarp faserig. Nur kultiviert. Cocos.

Phönix L. Etwa vier Arten dieser durch die Dattelpalme allgemein bekannten Gattung finden sich in Afrika. Auf allen Kanarischen Inseln ist I\%. Fubce Webb et Berth. an Bergabhängen der unteren Region vereinzelt anzutreffen. Obwohl auch sie für eine Stammpflanze der Dattelpalme gehalten worden ist, so ist sie doch durch ihre viel kräftigeren und mehr starren Blätter von $1 /$. dacty'lifira verschieden, auch dadurch, daß der Kelch der weiblichen Bliitenhülle die Blumenkrone fast his zur Spitze einschließt, während cr bei der Dattelpalme nur halb so lang ist. Sodann ist die Frucht eirund-spitz und der Same cbenfalls eirundlich. Die Dattelpalme hat ihr größtes Areal im nördlichen Afrika; aber dieses Areal ist ein künstliches: ein cigentliches Heimatsgehiet der Dattelpalme vermögen wir mit Sicherheit nicht anzugeben; so viel ist aber gewiß, daß es nicht in den feuchteren Gebieten des tropischen Afrika zu suchen ist, ebensowenig in den Steppengebieten. In letzteren wird sie jetzt hier und da angepflanzt, so in der ägyptischen Äquatorialprovinz, im Djurgebiet, in Togo, bei Tabora in.Ostafrika, in Deutsch-Südwestafrika: in den ersteren gedeiht sie schlecht, so auch auf Sansibar. Der Dattelpalme am nächsten kommt die in der Erythrea, im Tal von Aligede (1000-1500 m), im Tal ron Ainsaba, in Hamasen und his Adua in Abyssinien, an der unteren Grenze der Hochsteppenregion der Woina Dega von rgoo-2200 m wildwachsende, eine Höhe von 4,5-Io m erreichonde "Sich", Ph. alyssinica Drude, welche von der Dattelpalme dadurch abweicht, daß der Kelch der weiblichen Bliite mehr als halb so lang als die Corolle ist und der oben nur schwach zugespitzte Same von einem 
harten Endocarp fest umschlossen wird. Diese Pflanze wurde von STEudner als der Dattelpalme nahestehend erkannt, und meiner Meinung, daß in dieser Pflanze die Stammart der Dattelpalme vorliege, hat sich auch Drude (Engl. Bot. Jahrb. XXI [1896] 117) bestimmt angeschlossen. Die häufigste Art in Afrika ist I'/l. reclinata Jacq. (Fig. I 49). Es hat sich durch die Untersuchungen BECCIRIS ${ }^{2}$ ) ergeben, daß die Idee zweier nach Ost und West in Afrika getrennt nebeneinander hergehender Arten aufzugeben sei und sämtliche wilden Phocnix. von Afrika unter $P h$. reclinate Jacq. zusammenzuziehen seien; nach DRUDEs Untersuchungen ${ }^{2}$ ) scheint es aber doch, daß die westafrikanische Ph. spinosa Thonn. einige Unterschiede (an der Spitze callöse, nicht gefranste Blumenblätter, verhältnismäßig etwas längere Staubblätter, breit umfassenden Kelch mit zwar spitzen, aber nicht zugespitzten Lappen) gegenüber der ostafrikanischen Ph. reclinatc Jacq. darbietet, so daß sie vielleicht als Unterart anzusehen ist. Die

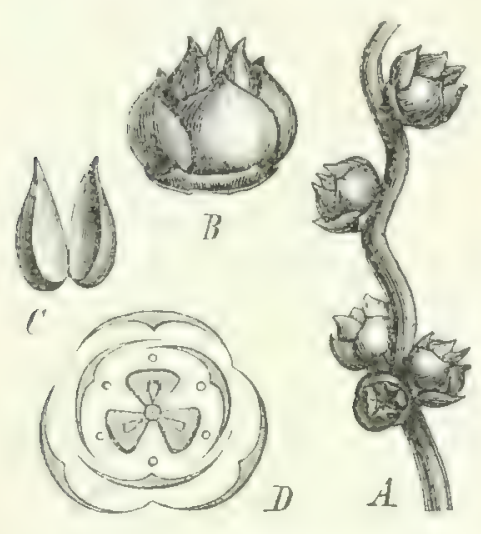

Fis. I 49. Phoenix reclinata Jacq. ㅇ. $A$ Stiick eines Blütenzweiges, nat. Gr.; $B$ einzelne Blüte; $C$ zwei Carpelle daraus;

$D$ Diagramm. ostafrikanische Form beginnt im Djur-Land, findet sich in Uganda, sehr häufig am Victoria Njansa, zwischen Albert- und Albert-Edward-See, bei Mombassa, am Ugalla, häufig in Ost- und West-Usambara (bis zu I $900 \mathrm{~m}$ ü. M.), häufig im Nyassa-Land, auf Pemba und an der Küste von Deutsch-Ostafrika, ferner häufig in Natal und weiter suidwärts bis in die Gegend der Algoa-Bay.

Im Westen können wir sie von Senegambien uiber Sierra Leone und die Goldküste nach dem Nigerdelta verfolgen, sodann finden wir sie im KongoBecken und in Angola, ferner am Kakulovar, am Chitanda, am Kubango, nur vereinzelt am Kuito im südlichen Benguela, endlich auch am Ngami-See. In Ostafrika und auch in Westafrika findet sie sich besonders häufig in der Küistenzone, namentlich an Flußufern; in den Gebirgen Ostafrikas (hier mrala genamnt) meidet sie die regenreicheren Abhänge, welche direkt den Seewinden ausgesetzt sind, und findet sich mehr an den Abhängen, wo zwar noch nicht die Trockenheit der Steppe herrscht, aber doch der Regenfall nicht so stark ist, wie an den direkt dem Osten zugewendeten Abhängen. In der Steppe selbst tritt sie nur vereinzelt an grundwasserreichen Stellen auf.

Borassus L. Die wahrscheinlich im Mündungsgebiet des Indus heimische, im tropischen Asien vielfach kultivierte Palmirapalme, B. flabllifor L., erscheint in Afrika in der durch eine Anschwellung an der Spitze des $15-25 \mathrm{~m}$ hohen Stammes ausgezeichneten Var. acthiopum (Mart.) Warb. (vjoe-tjo in Guinea, m'rumo kisuahcli, Deleb-Palme). Wie die Phocnix sind auch diese Fächerpalmen zweihäusig; die männlichen Bliitenstände sind mit mehreren dick walzenförmigen Ästen versehen, an denen Gruppen von etwa zchn Blüten in kleine

I) Beccari, Malesia III. 345-4I6.

2) Drude, Palmenflora des trop. Afrika, in ENGLegs Bot. Jahrb. XXI (1896) 117. 


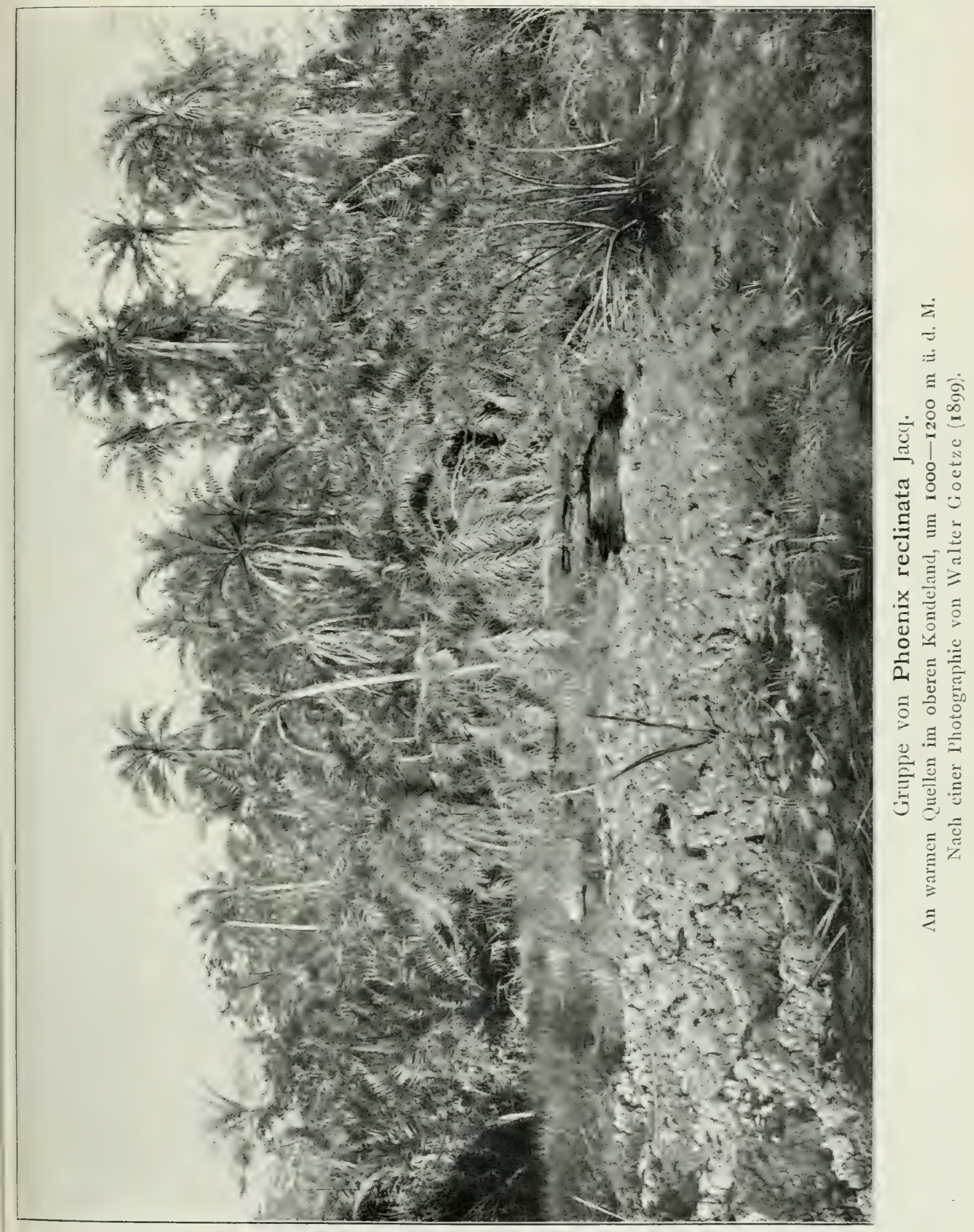





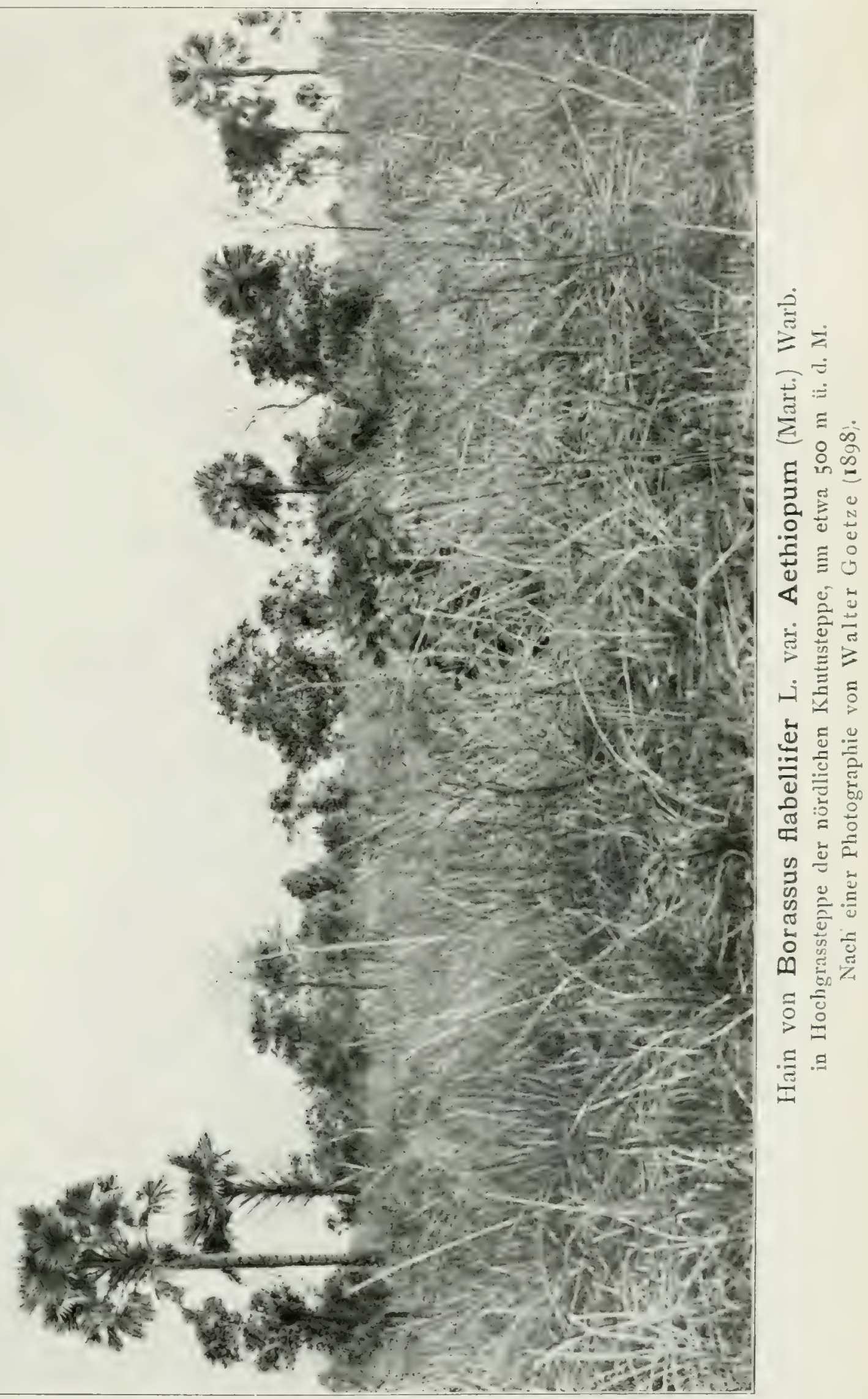



Grübchen eingesenkt sind. Fiģ. I 50.) Die weiblichen Blütenstände sind dick und unverzweigt, mit wenigen sehr großen Stempelblüten (Fig. I 5 I), aus denen bis $20 \mathrm{~cm}$ breite, I $5 \mathrm{~cm}$ lange Steinfrüchte mit drei bis zwei Steinkernen hervorgehen. Diese sowohl einzeln, wie in größeren Beständen einen schönen Anblick gewährende Palme findet sich von Senegambien bis Nigerien in feuchterem Grasland,spärlichin Kamerun, auf San Thomé, am unteren Kongo, sodann am Kasai; sie ist fernerimGhasalquellengebiet, im Djurland, in Zentralafrika am Nil bei Dufile, im Madiund Mabodeland häufig; seltener im Lande der Monbuttu, ferner in der Ebene am Nordwestufer des AlbertEdward-Sees im Grasland des Issangi, seltener in Uganda, häufiger östlich von Busisi im Süden des Victoria Njansa, in Unyamwesi, am Ugalla; am Kwou-Fluß und Manyara-See, sodann in Ukami, in der Küstenzone von Pangani bis Usagara, ferner am Fuß von Ostusambara, in der Kisaki-Steppe nicht fern vom Msoro und Msengere, in der $\mathrm{Ki}$ -

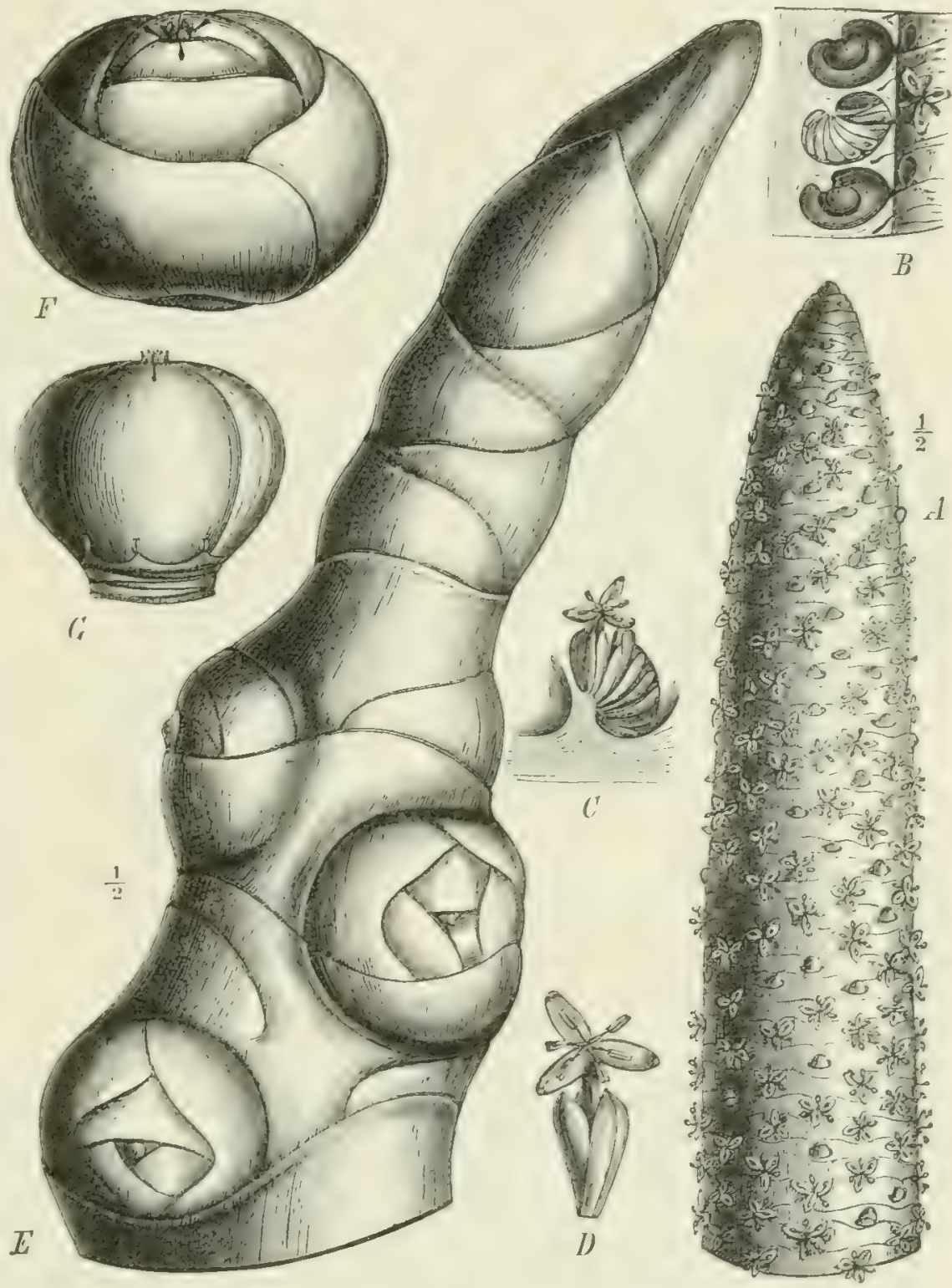

Fig. I 50. Borassus flabellifer L. Teile des Blütenstandes. A Spitze eines of Astes; $B$ Längsschnitt durch denselben, die Stellung der Bliten in den Gruben zeigend; $C$ eine Grube mit einem Wickel von Blüten; $D$ männliche Blüte; $E$ Spitze eines $O$ Kolbens; $F$ weibliche Blüte; $G$ Stempel. - Nach DrUdE in den Nat. Pflanzenfam. saki-Steppe und der Nakuta-Steppe zwischen Khuta und Uhehe, häufig in fruchtbaren Niederungen des welligen Steppenlandes. Dann treten áber auch im NO. des Rukwa-Sees Borassus-Haine auf, ebenso in den Flußtälern der Nachbargebiete, besonders auf schwarzem Schwemmland noch zwischen Iooo und I I oo $\mathrm{m}$.

Hyphaene Gaertn. Die Dumpalmen sind ebenfalls Fächerpalmen mit eingeschlechtlichen zweihäusigen Blitten; ihre Blätter sind steifer als bei der 
Delebpalme und von matterem Grün; nachdem sie abgestorben sind, hängen sie senkrecht rom Baume herunter. Die Früchte sind rundlich oder gelappt, mit faserigem, außen dunkel lederfarbigem und glänzendem Pericarp, mit holzigem Endocarp und hohlem, harten, schneeweißem Nährgewebe. Die Zahl der afrikanischen Arten ist unsicher, da man von vielen nur Früchte kennt; sie sind aber von großer Bedeutung für die Charakteristik vieler Steppengebiete, zumal sie häufig gesellig vorkommen, und es ist notwendig, auf die einzelnen Arten näher einzugehen; zugleich aber seien diese Palmen, namentlich in den inneren Teilen Afrikas, der weiteren Beachtung derjenigen empfohlen, welche bei längerem Aufenthalt in der Nähe ihrer Standorte Gelegenheit haben, reichlicheres NIaterial.zu sammeln. Alle Hyphaenen gedeihen nur in Steppengebieten;
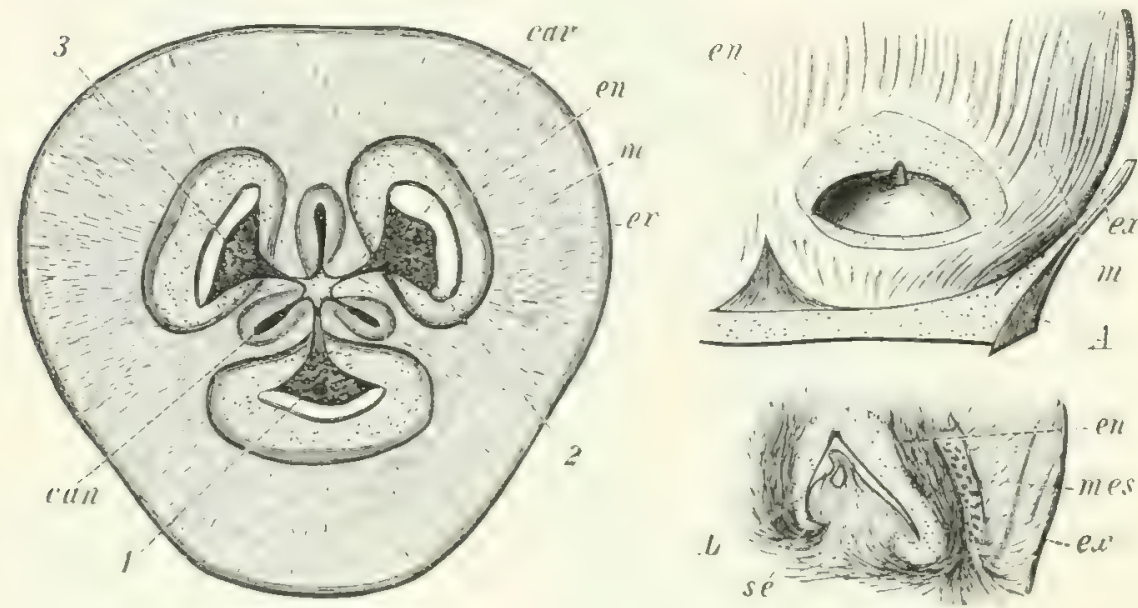

Fig. I51. Borassus flabellifer L. Querschnitt durch einen jungen Fruchtinoten, drei Samenanlagen umgeben von dem jungen Endocarp en, durch eine kleine Höhlung cav von der Samenanlage getrennt; drei Kanäle can wechseln mit den drei Fächern ab und treten auf dem Gipfel des Fruchtknotens (Fig. I50 G) zutage. m Mesocarp, ex Exocarp. Rechts Längsschnitte aus dem Fruchtknoten mit je einer Samenanlage, oben blofjgelegt, unten durchschnitten und den Embryosack si zeigend. A ein Staminodium. Nach Drude. aber sie lieben etwas feuchten Untergrund und zeigen solchen durch ihr Vorkommen an. Ein Teil der Arten ist durch dichotomisch verzweigte Stämme charakterisiert. Hierher gehört die am weitesten nach Norden, nach Ägypten (wild noch in der Großen Oase und bei Deyroût-ech-cherîf im Niltal) und Arabien reichende $H$. thebaica (Del.) Mart. mit schief eiförmigen, undeutlich dreikantigen Fruichten; sie ist durch Nubien, Kordofan, Sennar bis zum Bahr-el-Abrad zu verfolgen, findet sich auch in der Erythrea und im niederen Somaliland, endlich auch noch bei Lamu. Anderseits tritt sie auch an den Ufern des Gambia in Senegambien auf. Siidwärts wird sie abgelöst von H. coriaced Gaertn. Kisuata m kotsche, welche kreiselförmig-birnförmige, seicht gefurchte Früchte besitzt; sie ist besonders häufig in der Küstenregion von IVitu bis zum Sambesi und ziemlich viclgestaltig, auf den Creekwiesen bei Tanga zwergig, buschartig, aber bliihend und fruchtend, in Gebiischen auch niedrig, außerhalb derselben aber bis $15 \mathrm{~m}$ hoch und von der Mitte des Stammes an verzweigt. In der Kuistenregion erscheint sie mehr vereinzelt; aber im Innern trifft man sie in Steppenniederungen, z. B. am Fuß des Paregebirges und in den Oasen Kahe und Taveta, in größeren Beständen an. - Ebenfalls verzweigten Stamm, aber lang birnförmige Früchte besitzt die ron GoETzE in der KisakiSteppe entdeckte $H$. Iromullandii Dammer, deren Höhe auf $20-27 \mathrm{~m}$ angegeben 


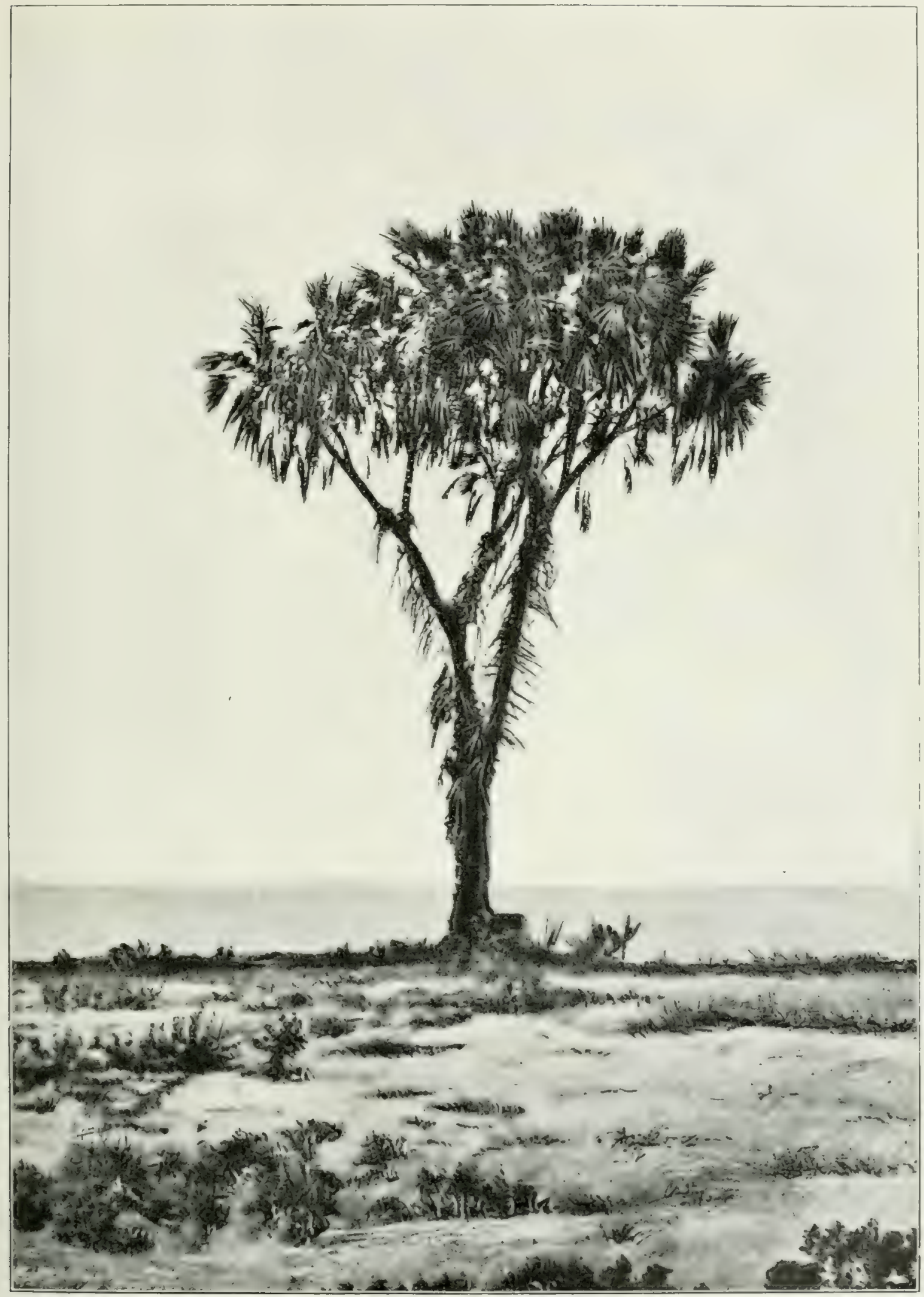

Hyphaene coriacea Gaertn.

in der Küstensteppe bei Dar-es-Salām.

Nach einer Photographie von Walter Goetze (1899). 

wird. - Einen unverzweigten Stamm von nur 6- Io m Höhe besitzt $H$. crinite Gaertn., deren Blätter zwischen den Abschnitten faserig und beiderseits dünn weißfilzig sind und deren längliche oder verkehrt-eiförmige Früchte ein Pericarp mit zahlreichen Fasern enthalten, welche kürzer sind als der Steinkern. Diese Art findet sich auch in Deutsch-Ostafrika am Pangani im Mania-Distrikt, dann am Südende des Nyassa-Sees, am Shire River, am oberen Sambesi in Mlossambik oberhalb Beira und in Natal. H. Goet $\approx$ ei Dammer wird mit einfachem Stamm bis $21 \mathrm{~m}$ hoch und entwickelt schiefe Früchte; sie kommt höher vor als andere Arten, zwischen Khuta und Uhehe am Ostabhang der Vidunda-Berge am Ruaha. - Nördlich vom Nyassa-See bis zum Rukwa-See findet sich ziemlich häufig die durch eiförmige, auf einer Seite leicht gekielte und goldgelbe Früchte ausgezeichnete $H$. anrantiaca Dammer. H. ientricosa Kirk, ausgezeichnet durch in der Nitte etwas angeschwollenen Stamm und mit großen kugeligen Friichten, läßt sich von den Viktoria-Fällen des Sambesi suidwärts bis zum Ngami-See und westwärts bis Ovambo, Nord-Hereroland und Kaoko, ins Kunene-Gebiet zwischen Humba und der Mründung des Chitanda, zur Mündung des Knebe und in das Pfannenfeld zwischen Kubango und Kuito verfolgen. Im nördlichen Hereroland kommt sie nördlich von $20^{\circ} \mathrm{s}$. Br. sowohl im $\mathrm{O}$. wie im $\mathrm{W}$. von Grootfontein vor: auch die in den Wasserläufen des Kaoko bis zum Uniab von Dr. HARTIAari beobachteten buschigen und hochstämmigen Palmen düften hierzu gehören. Wahrscheinlich ist hierzu auch H. bengucllcnsis Welw. von Mossamedes zu rechnen. Schließlich ist als noch einigermaßen bekannte Art H. grinucensis Schumach. et Thonn. zu erwähnen, auch mit einfachem Stamm und kurz kreiselförmigen Früchten, häufig auf trockenen sandigen Huigeln entlang der westafrikanischen Küste von Loango bis Loanda.

Medemia P. W. von Württemberg, mit der vorigen Gattung nahe verwandt, unterscheidet sich besonders durch ihr etwas zerklüftetes Nährgewebe. Die seit längerer Zeit bekannte. M. argun Mart.) P. Wilh. von Württemberg kommt in Nubien und Kordofan zwischen 20 und $21^{\circ} \mathrm{n}$. Br. vor: ferner im Wadi Delah bei Murat in der großen nubischen Wüste, zwischen Korosko und Abu Hammed. Diese Art trägt ellipsoidische dunkelbraune Fruichte. Eine zweite, ungenügend bekannte Art ist $M$. abiadensis Wendl. am weißen Nil.

Raphia B. Beauv. Diese durch enorm große, den Stamm oft an Länge bedeutend uibertreffende Fiederblätter ( +2 I $\mathrm{m}$ ) ausgezeichneten Palmen besitzen große hängende Blïtenstände, welche mehrfach verzweigt dicht zusammengedrängte Ästchen tragen, die von becherförmigen Bracteen dicht besetzt sind: an den Endzweigchen findet sich immer eine männliche Bliite mit 3-i 6 Staubblättern am Grunde und eine weibliche Blite an der Spitze. Die einzelnen Arten sind noch keineswegs vollständig bekannt, und es ist wünschenswert. daß auch von diesen Palmen möglichst vollständiges, immer von einem und demselben Baum stammendes. Iaterial eingesendet werde. Inwieweit die Früchte, nach deren Gestalt die Arten unterschieden werden, in ihrer Form veränderlich sind, wird vielfach noch zu ermitteln sein, ebenso, inwieweit die Zahl der Staubblätter bei den einzelnen Arten konstant ist. Nach der Fruchtreife sterben 
die Bäume ab. Die bekannteste Art ist die auch im tropischen Amerika (Miindungsgebiet des Tocantins und Amazonas) rorkommende $R$. imifere P. Beauv. (Weinpalme, Igi-oguro, eriko, akpako der Yoruba, BambooPalme [Fig: $\mathrm{I}_{52}$ ]); dem etwa $3 \mathrm{~m}$ hohen Stamm entsprießen bis $6 \mathrm{~m}$ lange Blätter und lange hängende Blütenstände, welche Io-männige Blüten und zuletzt cylindrisch-ellipsoidische Friichte mit acht bis neun Reihen von Schuppen tragen. Von Sierra Leone bis Old Calabar findet sich diese Art häufig an Flußufern, dann vom unteren Kongo bis Benguela, wo sie merkwirdigerweise nach WeLwitsch im Morro de Lopollo zwischen i 700 und $1900 \mathrm{~m}$ vorkommt; sie soll nach KIRK und BUCHANAN auch im Süden des Nyassa-Sees wachsen. Dieser Art stehen nahe $R$. longiflore Mann et Wendl. mit von unten an verzweigtem, $5 \mathrm{~m}$ hohem Stamm und I I $\mathrm{m}$ langen Blättern, mit I5-männigen Staubblättern und länglich-ovalen, von zwölf Schuppenreihen bedeckten Früchten,
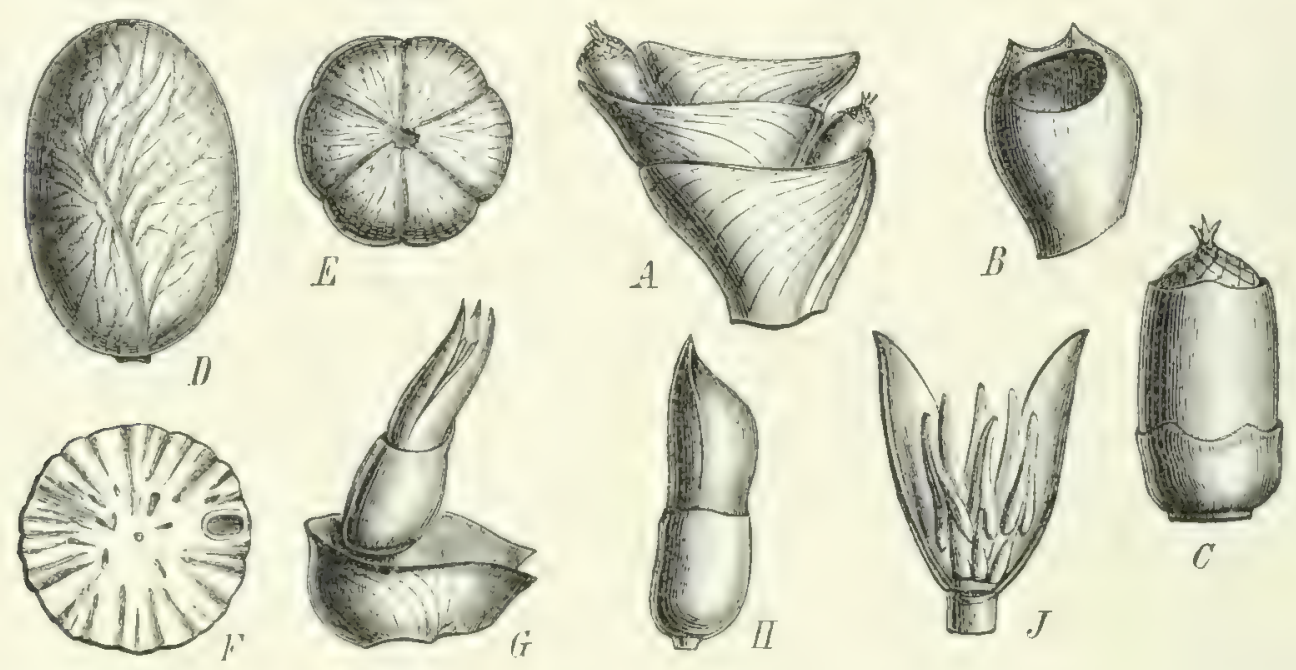

Fig. I52. Raphia vinifera P. Beauv. $A$ Zwei $O$ Blüten; $B$ deren Vorblätter; $C$ einzelne Blüte; $D$ Sane vom Rücken; $E$ derselbe vom Grunde; $F$ derselbe im Durchschnitt mit dem Embryo; $G$ ồ Bliite mit Deck- und Vorblatt; $I /$ dieselbe frei; $\mathcal{F}$ dieselbe geöffnet. - Nach DRUDE.

an der Goldküste und auf der Corisco-Insel in Spanisch Gabun, ferner K. Hookiri Mann et Wendl. mit io $m$ hohem Stamm, i 3 m langen Blättern, I6-männigen Bliiten und oval-ellipsoidischen Früchten, an sumpfigen Plätzen ron Old Calabar, Kamerun und der Corisco-Insel (ukot genannt), endlich auch $R$. sese de Wild. mit $10-15 \mathrm{~m}$ hohem Stamm und etwa $2 \mathrm{~m}$ langen Blättern, sehr verbreitet im ganzen Kongostaat. Es wird dann ferner in Westafrika noch $R$. Gacrtneri Mann et Wendl. unterschieden, von der man nur Bliiten- und Fruchtstände kennt; die männlichen Blüten enthalten bei dieser acht Staubblätter und die Früchte sind oval-ellipsoidisch: sie ist in Sierra Lcone, an der Goldkïste und auf Fernando Po bis zu $160 \mathrm{~m}$ ii. M. gefunden worden. In der Fruchtform schließt sich an die genannten Arten K. Monbuttorm Drude an, bei welcher der Stamm nur I,5 m hoch wird und die männlichen Blïten sechs Staubblätter enthalten; sie findet sich sicher in Zentralafrika, in Djur und im Mombuttuland in den Tälern bei Munza; es ist daher wahrscheinlich, daß auch die nördlich vom Albert-Edward-Njansa, am Albert-Njansa und im Niam-Niam und Dinka- 


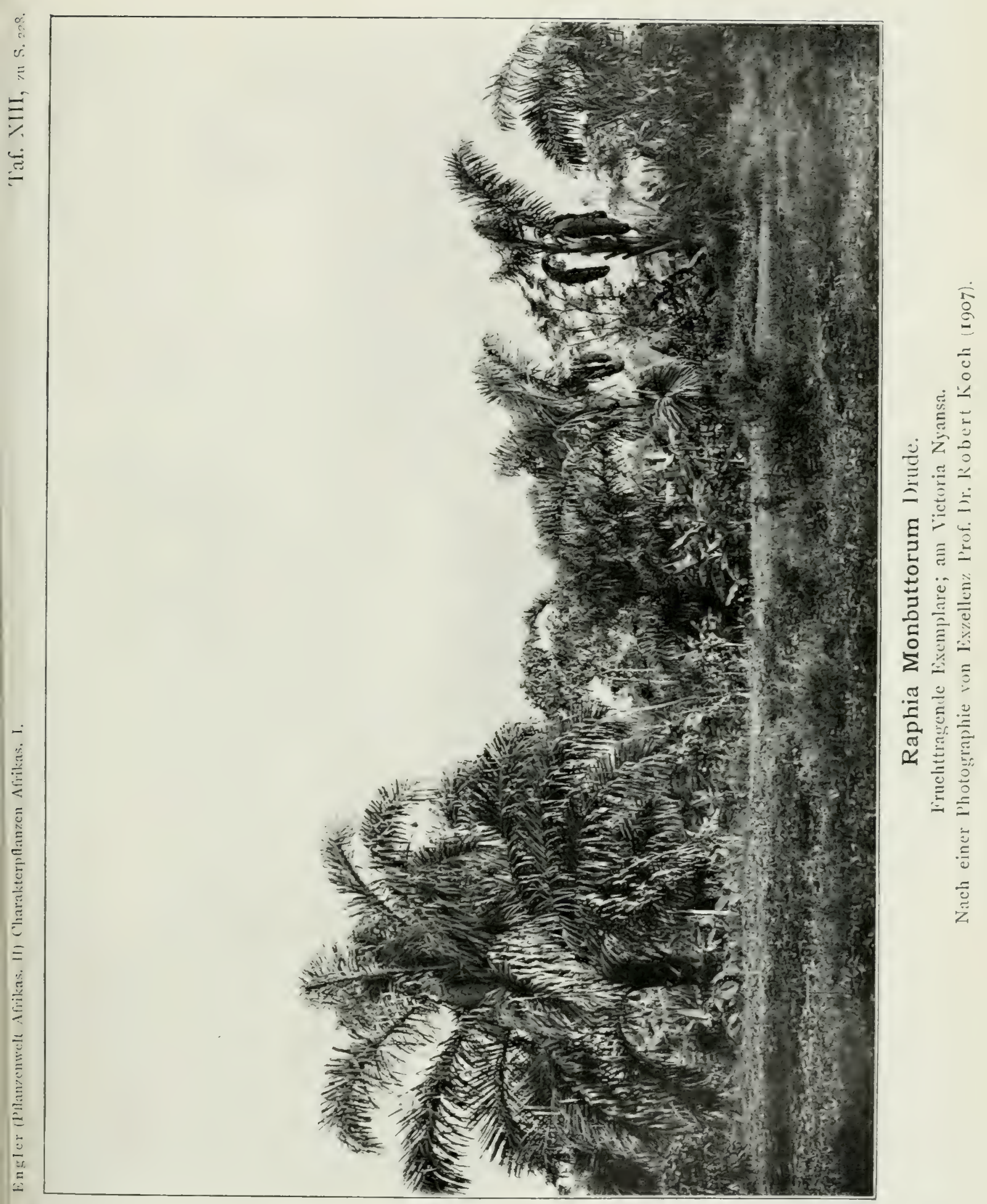



Gebiet beobachteten Weinpalmen zu dieser Art gehören. Durch mehr oder weniger kreiselförmige Früchte ist $R$. textilis Welw. ausgezeichnet, welche in Angola an Bächen von $600-660 \mathrm{~m}$ vorkommt. Mit ihr verwandt zu sein scheinen $R$. Laurentii de Wild. mit $2 \mathrm{~m}$ hohem Stamm und 5- $\mathrm{I} 4 \mathrm{~m}$ langen Blättern, in sumpfigen Teilen des Kongogebietes, sowie R. Gentiliana de Wild. bei Gala am mittleren Kongo. Die größten Blätter von allen besitzt R. muffic (jacq.) Mart. Fig. 153): ihr 2- $8 \mathrm{~m}$ hoher Stamm trägt bis $21 \mathrm{~m}$ lange Blätter und auch kreiselförmige Früchte; sie kommt wie auf Madagaskar auch auf den Inseln Sansibar und Pemba vor und ist zerstreut ron Useguha und WestUsambara bis Usagara, auch am Djipe-See und bei Kahe unweit des Kilimandscharo anzutreffen. Selten findet man größere Bestände von Raplica, sie wachsen meist vereinzelt.

Die Gattungen der Kletterpalmen sind nur in West- und einem Teil von Zentralafrika anzutreffen; die wichtigste ist

Ancistrophyllum Mann et Wendl.; sie ist monocarpisch und durch zweizeilig gestellte Zwitterbliiten charakterisiert; die an den ro-20m langen dünnen Stämmen stehenden Fiederblätter enden in lange Peitschen, welche an Stelle der Fiedern kleine Dornen tragen. Die auffallendste Art ist A. secundiflorum Wendl. (Fig. 154), deren nur $3 \mathrm{~cm}$ dicker Stamm bis $20 \mathrm{~m}$ lang wird; die $4-4,5 \mathrm{~m}$ langen Blätter sind mit 3-4,5 dm langer Scheide und mit langer Ochrea versehen, die Rhachis der Fiederblätter ist zwischen den Fiedern mit Stacheln besetzt, und oberhalb der Fiedern treten bis I 8 zuriick-

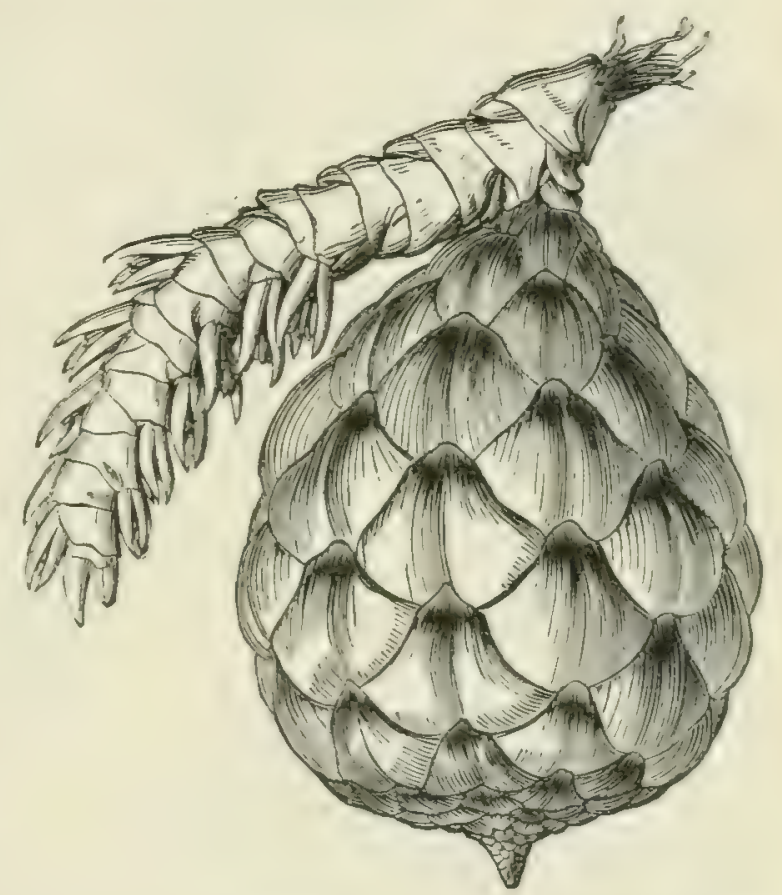

Fig. I53. Zweigchen des Blutenstandes von Raphia ruffia Jacc.l Mart. mit einer gereiften Frucht und abgeblühten $\vec{\jmath}$ Blïten in den oberen Scheidendeckblättern.

Nach MaOuT und Decaisne. gekrümmte, etwa $5 \mathrm{~cm}$ lange Dornen an Stelle der Fiedern auf, welche die Anheftung der Blätter und damit auch das Aufhängen der Stämme ermöglichen. Der Blütenstand wird bis $2 \mathrm{~m}$ lang und die 10-I5 Äste ersten Grades erreichen I m Länge; die scheidigen Bracteen schließen immer zwei Zwitterblüten ein, aus denen $1,2 \mathrm{~cm}$ große, einsamige, orangefarbene Früchte hervorgehen. Diese Art findet sich in den Uferwäldern von Sierra Leone bis Kamerun, sodann vom unteren Kongo bis Angola, im unteren und oberen Kongogebiet und im Lande der Niam-Niam. Zwei andere Arten, welche einen kürzeren Blattstiel und breitere Fiedern, ferner runde, nicht zusammengedrüchte Samen besitzen, sind A. lacie (Mann et Wendl.) Drude in Gabun und A. opacum (Mann et Wendl.) Drude an der Goldkiiste, bei Barombi in Kamerun und auf Fernando Po, hier bis zu $300 \mathrm{~m}$ aufsteigend. 


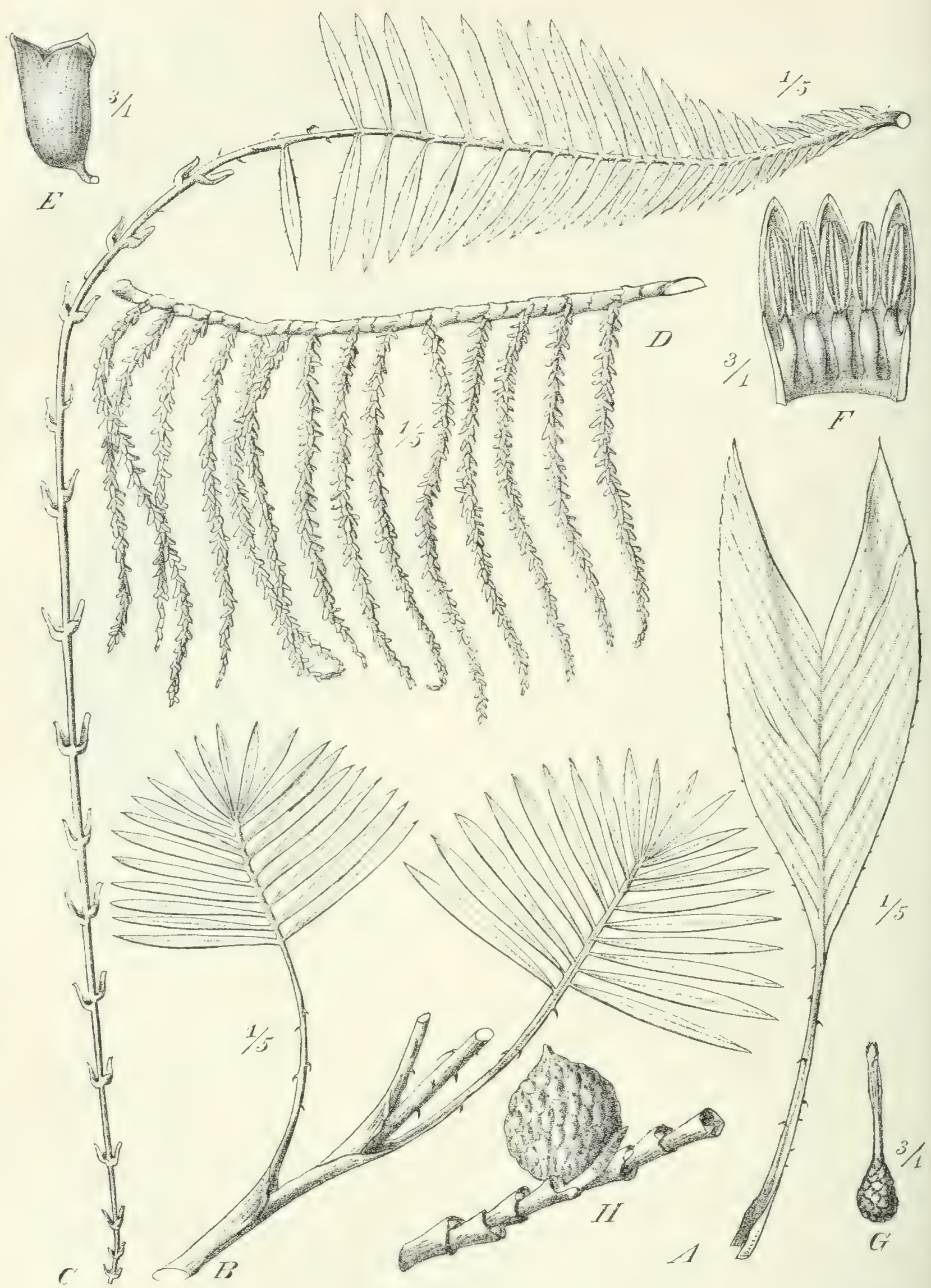

Fig. 154. Ancistrophyllum secundifforum Wendl. $A$ junges Blatt; $B$ Zweig mit älteren Laubblättern; $C$ ein Kletterblatt, alle ${ }^{T} / 5$ nat. Gr.; $D$ Stück des Blittenstandes; $E$ äußere Bliitenhülle oder Kelch; $F$ innere oder Blumenkrone mit den Staubblättern; $G$ Stempel; $H$ Stück des Frucht$z$ weiges. 
von kleinen Dornen besetzte Peitsche endigen, in Lagos und Gabun, in der Sierra del Crystal bis zu $500 \mathrm{~m}$ aufsteigend, $O$. aconthocncmis Drude, mit zweispaltigen oder oberwärts gefiederten Blättern und sehr langen Peitschen, in Gabun und am Kongo.

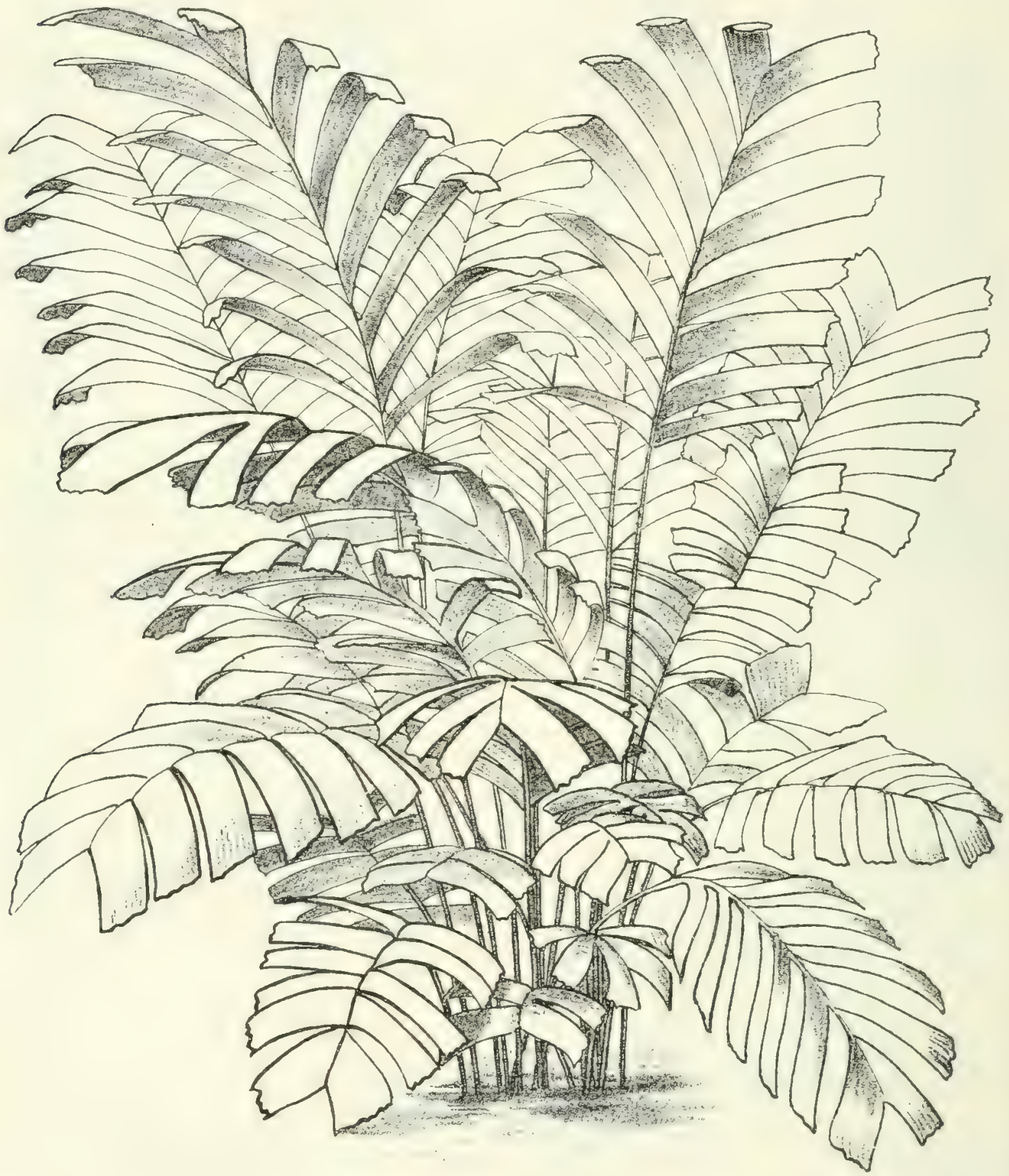

Fig. 156. Sclerosperma Mannii Wendl. Habitus. - Nach Hooker.

Eremospatha Mann et Wendl. besitzt Fiederblätter, deren Peitsche auch mit zurïckgekriimmten verdornten Ficdern versehen ist, wie bei Ancistrophyllum; dagegen finden sich an den Zwitterblüten tragenden Blütenständen keine Scheiden. Die Verbreitung dieser drei Arten zählenden Gattung ist ähnlich wie bei Ancistrophyllum, da eine Art, E. Hookeri Wendl.; mit elliptisch ver- 
kehrt-eiförmigen Blättchen nicht bloß im Nigerdelta und Kamerun. sondern auch im Mombuttuland an Flußufern rorkommt. E. cusfulate (Mann et Wendl.) findet sich in Gabun und bei Kiri im NO. des Leopold-Sces im mittleren Kongogebiet: E. Hankeillarna de Wild. bei Stanlerville und Bassongo: andere sind auf Sierra Leone und Gabun beschränkt.

Areca L. Die im Monsungebiet verbreitete $A$. catechu L. wird bisweilen kultiviert, namentlich auf Sansibar und bei Pangani.

Die beiden folgenden Gattungen gehören zu den Geonominae, deren Verwandte mit Ausnahme der vorderindischen Gattung Bintinckic tropisch amerikanisch sind.
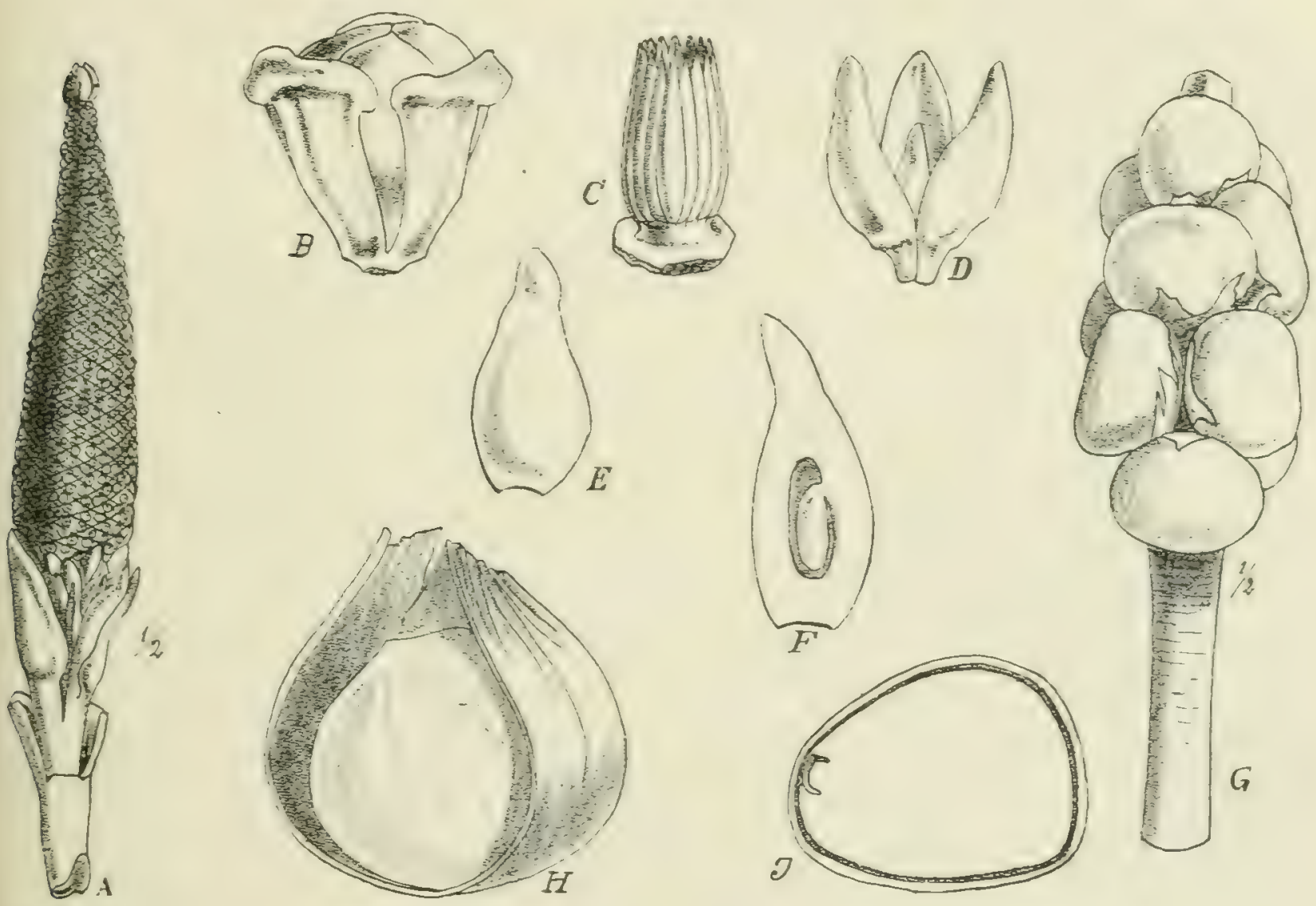

Fig. 157. Sclerosperma Mannii Wendl. A Blütenstand, unten mit weiblichen Bliten zwischen den männlichen, hierauf nur männliche; $B$ đิ Blüte; $C$ Andröceum; $D \subseteq$ Bliite; $E$ Pistill; $F$ dasselbe im Längsschnitt; $G$ Fruchtstand; $H$ Frucht nach Entfernung eines Teils des Pericarps;

F Same im Längsschnitt. - Nach Hooker.

Podococcus Mann et Wendl. Kleine Palnen mit einfachem, höchstens $2 \mathrm{~m}$ hohem Stamm, $2 \mathrm{~m}$ langen fiederschnittigen Blättern und einem lateralen hängenden, einfachen, von vier Scheiden umgebenen Kolben, an welchem die Bliten in Triaden mit einer zentralen Zwitterbliite und zwei seitlichen Blüten stehen. P. Barteri Mann et Wendl. ist die einzige in den unteren Lfer- und Niederungswäldern rom Nigerdelta bis Gabun rorkommende Art (Fig. I55;:

Sclerosperma Mann et Wendl. Am Grunde kurz verzweigte Stämme entwickeln bis $+\mathrm{m}$ lange, länglich-elliptische Fiederblätter mit nach oben sich 
verbreiternden Fiedern und tragen am Grunde bis $2 \mathrm{dm}$ lange bräunliche Kolben, deren unten stehende Triaden eine weibliche Mittelbliite mit einem Carpell tragen. Die männlichen Blïten besitzen zahlreiche Staubblätter. 5. Termii Wendl. findet sich auf sumpingen Plätzen am Gabun-Fluß (Fig. 157).

Elaeis guineensis Jacq., die Ölpalme, bedarf keiner ausführlichen Beschreibung, da jedermann diese ansehnlichen Fiederpalmen, deren säulenförmiger, IO-20, nicht selten $30 \mathrm{~m}$ hoher Stamm von den lange stehen bleibenden und oft zahlreichen Epiphyten zum Ansatz dienenden Stumpfen der Blattstiele besetzt ist, leicht zu erkennen vermag. Die Fiederblätter werden bis $7 \mathrm{~m}$ lang und haben bis I $\mathrm{m}$ lange Fiedern, welche ebenso wie bei Cocos in Gegensatz zu Then zuriickgeschlagen sind. Die Bäume entwickeln bisweilen schon im füften Jahr, meistens später zuerst zahlreiche reich verzweigte männliche Bliitenstände ron I-I,5 dm Länge, im folgenden Jahr unterhalb der männlichen drei bis vier weibliche Blütenstände. An alten kräftigen Exemplaren steigt deren Zahl auf sieben; sie sind viel gedrungener und haben in dornige Spitzen endende Äste, sowie dornige Deckblätter. Nach sechs bis neun Monaten bilden sie Fruchtstände von $3-5 \mathrm{dm}$ Länge und $2,5-4 \mathrm{dm}$ Breite, von 20-50 Kilogramm Gewicht mit Hunderten pflaumengroßer gelber oder rötlicher, veilchenartig riechender Steinfrüchte. Die Ölpalme ist häufig rings um den Golf von Guinca und im unteren Kongogebiet, erstreckt sich aber auch noch weit ostwärts, teils an Bergabhängen (Hinterland von Kamerun), teils in den Galleriewäldern längs der Fliisse, so am Kongo bis zum Oberlauf, auch im Mombuttuland und in IVest-Niam-Niam, in Makraka auf einer kleinen Insel des Jeï $\left(3^{\circ} 40\right.$ n. B.), im Ghasal-Gebiet wahrscheinlich bis ("+2, besonders aber nördlich vom Albert-Edward-Njansa, sowie westlich vom Albert-Njansa; sie wurde ferner an den Ufern des Tanganyika-Sees, sowie am Vestufer des Nyassa-Sees bei Sani Hill, Fort Hill und Songue beobachtet; doch ist sie an mehreren der siidöstlichen Fundorte, sowic in Senegambien und Libcria wohl nur angepflanzt und verwildert. Dagegen scheint sie wild und häufig in den Uferwäldern ron Angola zu sein, wo auch eine kleinfrüchtige Varietät cxistiert, wild auch wohl auf St. Thomas und Fernando Po. Angepflanzt kommt sie aber auch noch in Benguela vor, hier und da im Küstengebiet von Ostafrika, in größerer Menge auf Pemba. Die Ölpalme wird in Guinea tachu-tio, in Angola dihóho genannt: am Kongo heißt die Frucht maba, der Steinkern e mba, der Fruchtstand cachio. Interessant ist, daß die einzige Schwesterart der Ölpalme, IIncis guincunsis L., im äquatorialen Amerika von Costa Rica bis zum Amazonas vorkommt, angepflanzt auch auf Madeira.

Cocos mucifua L., die bekannte Cocospalme, entwickelt meist einen glatten Stamm, da die Blätter vollständig abfallen; bei ihr stehen in demselben Bluitenstand männliche und weibliche Bliiten gemischt. Ob sie ursprünglich in Ostafrika sich ron selbst angesiedelt hat. läßt sich nicht entscheiden, jedenfalls gedeiht sie jetzt, oft in großen Beständen. an der ganzen Küste von DeutschOstafrika und daruber hinaus bis in die Nihe der Sambesi-Mündung: sie gedeiht auch noch in größerer Entfernung von der Küiste, so bei Tabora, $650 \mathrm{~km}$ 
rom Meere entfernt, auf mit Salz gedüngtem Boden. sogar bei Udschidschi am Tanganyika. In Westafrika findet sie sich auch angepflanzt in Senegambien, am unteren Kongo und in Angola, sowie auf St. Thomas.

\section{Fam. Araceae.}

Während diese Familie in den Regenwäldern des tropischen Amerika und des Monsungebietes durch Mannigfaltigkeit der Gattungen und Zahl der Arten sehr viel zur Charakterisierung dieser Formation beiträgt; ist sie in Afrika weniger entwickelt. Doch treten einige Arten bisweilen in großer Zahl ron Individuen auf. Die Gattungen verteilen sich auf rerschiedene Gruppen, weiche meist auch schon ohne Blïten an den Blättern erkennbar sind. Für das genauere Studium dieser Pflanzen empfiehlt es sich, die Blïtenstände in Alkohol zu konservieren. IIanche knollige Arten entwickeln Blätter und Bliitenstände zu rerschiedenen Jahreszeiten; hier ist leicht zu Verwechslungen Veranlassung gegeben und es ist zweckmäßig, Knollen dieser Arten in Kultur zu nehmen oder auch zur Beobachtung nach Europa zu senden. Phrsiologisch sind viele Araceen Hydromegathermen, Hydrohygrophyten, d. h. sie lieben sowohl feuchten Boden wie feuchte Luft; sie kommen daher teils in Sumpfen, teils an Bachufern, teils in den unteren Regenwäldern vor; in den oberen Regenwäldern aber werden sie schon seltener und in den Nebelwäldern fehlen sie fast ganz. Vollkommene Hydrophyten sind Fistiu. Zarituleschice. Typhonodormm, Cyrtosferma und Anbius, letztere zwei aber zugleich auch hygrophytisch, da sie auch feuchte Luft beanspruchen. Die kletternden Culiasia, Rhcktoflyllum, Corcestis, Aficraphidephora sind alle Hydrohygrophyten. Als Hygrophyt kann Callopsis angesehen werden; sie geht aber nicht iiber I000 m ü. MI. hinaus. Die Gattungen Sanicmatum und frisatma enthalten die am höchsten rorkommenden Hygrophyten. Die Gattungen Gonatopus, Anchomanes, I'scudohydrosme, Ziganthera sind zumeist subxerophytisch oder tropophytisch, d. h. nur während eines Teiles des Jahres regetieren sie lebhaft, dann aber tritt eine Ruheperiode ein. Während ihrer Tegetationstätigkeit lieben aber die meisten Beschattung und nähern sich dadurch den Hygrophyten, große Bodenfeuchtigheit beanspruchen sie nicht, lieben aber etwas lockeren Waldboden, wie auch einige Stylochiton. Dagegen sind andere Stylochiton und Zamioculcas Xerophyten, namentlich einige Arten der ersteren Gattung.

Übersicht der tropischen afrikanischen Gattungen.

A. Nicht schwimmende Pflanzen.

a) Stengel, Blattstiele und Wurzeln ohne Milchsaftschläuche und ohne Spicularzellen. Seitennerven zweiten und dritten Grades netzförmig verbunden, sehr selten fast parallel ..... Unterfam. Pothoideae. (t) S. mit Nährgewebe. Blüten $\Im^{\top}$ Q , ohne Blitenhülle. - Kletternde Sträucher mit spiraligen Blättern .

Culcasieae. Culcasia. 
ß) Bluiten $\sigma^{\top} Q$, aber mit Rudimenten des anderen Geschlechtes. Knollengewächse mit gefiederten oder dreifach gefiederten Laubblättern

Zamioculcaseae.

I. Blätter einfach gefiedert . . . . . . . . . Zamioculcas.

II. Blätter dreifach gefiedert . . . . . . . . . . . Gonatopus.

b) Ohne Nilchsaftschläuche; aber das Grundgewebe, wenigstens der Stengel und Blätter, manchmal auch das der Wurzeln, mit Spicularzellen. Seitennerven dritten oder vierten Grades oder zweiten, dritten und vierten Grades netzförmig verbunden. Blüten $\$$, meist nackt. Samenanlagen umgewendet oder amphitrop . . . Unterfam. Monsteroideae. Kletterpflanzen Westafrikas. Einzige Gattung . . Afroraphidophora.

c) Land- und Sumpfpflanzen mit Knolle oder Rhizom. Leitbündel der Blattstiele und Stengel mit geraden Milchsaftschläuchen. Blüten $₫$ oder $\sigma^{\top}$ Q. Samenanlagen umgewendet. Nährgewebe meist o. - Blätter im Umriß pfeilförmig, oft vielfach getcilt, netznervig Unterfam. Lasioideae. ( ) Bliiten \& mit Bliitenhiille. Sumpfstauden . . . . . . Lasieae. Einzige Gattung ............ Cyrtosperma.

3) Bluiten meist $\jmath^{r} \bigcirc$, ohne Blïtenhülle. Häufig Kolbenanhang mit rudimentären Blütenanlagen, welche meist in eine nur gefurchte oder auch glatte, anatomisch aber differenzierte Schicht vereinigt sind. Nährgewebe der Samen o. - Knollenpflanzen. Amorphophalleae. I. Kolben bis zur Spitze mit Blüten oder wenigstens mit deutlichen Blütenrudimenten. 1. Spatha kahnförmig. Fruchtknoten einfächerig. - Häufig . Anchomanes. 2. Spathazusammengerollt. Fruchtknoten zweifächerig. - Selten. Pseudohydrosme. II. Kolben am Ende mit Staminodien. Antheren der ô Bliten panrweise verwachsen. - Selten.

Zyganthera.

III. Kolben mit einem aus rudimentären Blittenanlagen gebildeten Anhang. - Häufig.

Hydrosme.

y) $\sigma^{7}$ und $Q$ Bliiten ohne Blütenhülle. Nährgewebe o. - Stauden oder Kletterpflanzen mit pfeilförmigen Blättern. Blütenstand ohne Anhang

I. Stamm kletternd.

Nephthytideae.

1. Oे Blütenstand von dem 0 durch einen mit rndimentären Blütenanlagen besetzten Raum getrennt. Blätter nicht durchlöchert . . . . . . Cercestis.

2. ô Blïtenstand an den $ᄋ$ sich anschließend. Blätter im Umriß pfeilförmig oder herzförmig, die größeren durchlöchert . . . . . . Rhektophyllum.

II. Stamm kriechend. Blätter pfeilförmig. . . . . . . . . Nephthytis.

d) Land- oder Sumpfpflanzen. Leitbündel mit geraden Milchsaftschläuchen. Blüten $\sigma^{7}$,, nackt. Nährgewebe meist + . Blätter fast stets mit parallelen Seitennerven ...... Unterfam. Philodendroideae. (x) Kriechende Staubblätter der $\sigma^{\top}$ Bliiten vereint. . Anubiadeae. Einzige Gattung . . . . . . . . . . . . . . Anubias. 3) Stamm unterirdisch. Sumpfpflanzen mit pfeilförmigen Blättern

Zantedeschieae.

I. Staubblätter der ô Blïten frei。 - Südafrika ...... Zantedeschia.

II. Staubblätter der ơ Blüten in ein Synandrium vereint. - Sansibar. Typhonodorum. Letztere Gattung zeigt im Blütenbau viel Übereinstimmung mit den Colocasioideae. 
e Land- oder Sumpfpflanzen. Leitbündel oft mit verzweigten Milchsaftschläuchen, selten mit geraden Milchröhren. Blïten $\jmath^{\top} \subseteq$, ohne Blütenhiille; die Staubblätter zu Synandrien vereint. Blïtter netznervig, die Seitennerven zweiten Grades einen zwischen den Seitennerven ersten Grades verlaufenden Kollektivnerven bildend. Blïtenstand bisweilen mit Kolbenanhang . . . . . . . Unterfam. Colocasioideae. Nur eingeführte Kulturpflanzen der Gattungen Alocasia, Colocasia, Xinthosoma, Caladizum.

f Land-oder Sumpfpflanzen. Leitbüindel mit geraden Milchsaftschläuchen. Blüten $\sigma^{\top} \underline{O}$, sehr selten mit Bliitenhülle. Staubblätter frei oder vereint. Samenanlagen geradläufig oder umgewendet. Nährgewebe +. - Meist Knollengewächse mit netznervigen Blättern . Unterfam. Aroideae. (i) Blïten mit Bliitenhiille. Staubblätter fadenförmig Stylochitoneae. Einzige Gattung Stylochiton.

B) Blüten ohne Blütenhülle. Pistill einfächerig.

I. Samenanlagen geradläufig .

Areae.

r. Blätter und Blütenstände gleichzeitig. Ränder der Spatha frei A Arisaema.

2. Blätter und Blütenstände nicht gleichzeitig. Ränder der Spatha unten verwachsen. Blätter fußförmig

Sauromatum. Außerdem im mediterranen Nordafrika die Gattungen Arum, Biarum, Arisarum, Antrosinia, in Makaronesien Dracunculus.

II. Samenanlage umgewendet

Zomicarpeae.

Einzige afrikanische Gattung

Callopsis.

B. Schwimmende Wasserpflanzen. - J Bluten mit zwci zu einem Synandrium vereinigten Staubblättern, in cinem einzigen Quirl. C Blüten nur eine mit $\infty$ geradläufigen Samenanlagen. - Bliihende Sprosse mit einem Niederblatt, einem Laubblatt und kleinem Blïtenstand. Beisprosse in Stoloneis auswachsend

Unterfam. Pistioideae. Einzige liattung

Pistia.

Culcasia Pal. Beauv. ist auf das tropische Afrika und die nächst benachbarten Inseln beschränkt und bewohnt die Regen- und Nebelwälder. Nur wenige Arten haben ein aufrechtes freistehendes Sympodium, die meisten vielmehr lange sympodiale nach Art des Epheus kletternde Stämmchen, welche oft viele Meter hoch an Bäumen aufsteigen. Im übrigen sind die Merkmale der Gattung hinreichend durch die Abbildungen erläutert. Die meisten Arten finden sich im tropischen IVestafrika ron Liberia bis Angola. Aufrechte Stämmchen von $0,5 \mathrm{~m}$, höchstens I $\mathrm{m}$ Höhe besitzen: C. gracilis N. E. Brown in Uferwäldern von Sierra Lcone, C. strinlata Engl. Fig. I $5 S-1-H)$ in lichten IVäldern, C. Dinklagci Engl. (Fig. Ij\& F-L) und C. Mcrmii |Hook. f.) Engl. in tief schattigen Wäldern Kameruns.

Unter den kletternden Arten kann man unterscheiden zwischen denjenigen, bei welchen der Kolben von der Spatha eingeschlossen ist, und den anderen, bei welchen er darüber hinwegragt. Sehr zierliche, kleinblättrige Arten sind C. lancelata Engl. (Fig. I 58.7 ) und C. pariftora N. E. Brown (Fig. I59-1-G), in schattigen Wäldern Kameruns, die letztere Art auch auf Fernando Po und am Stanley-Pool. Von den großblättrigen Arten ist besonders hervorzuheben 


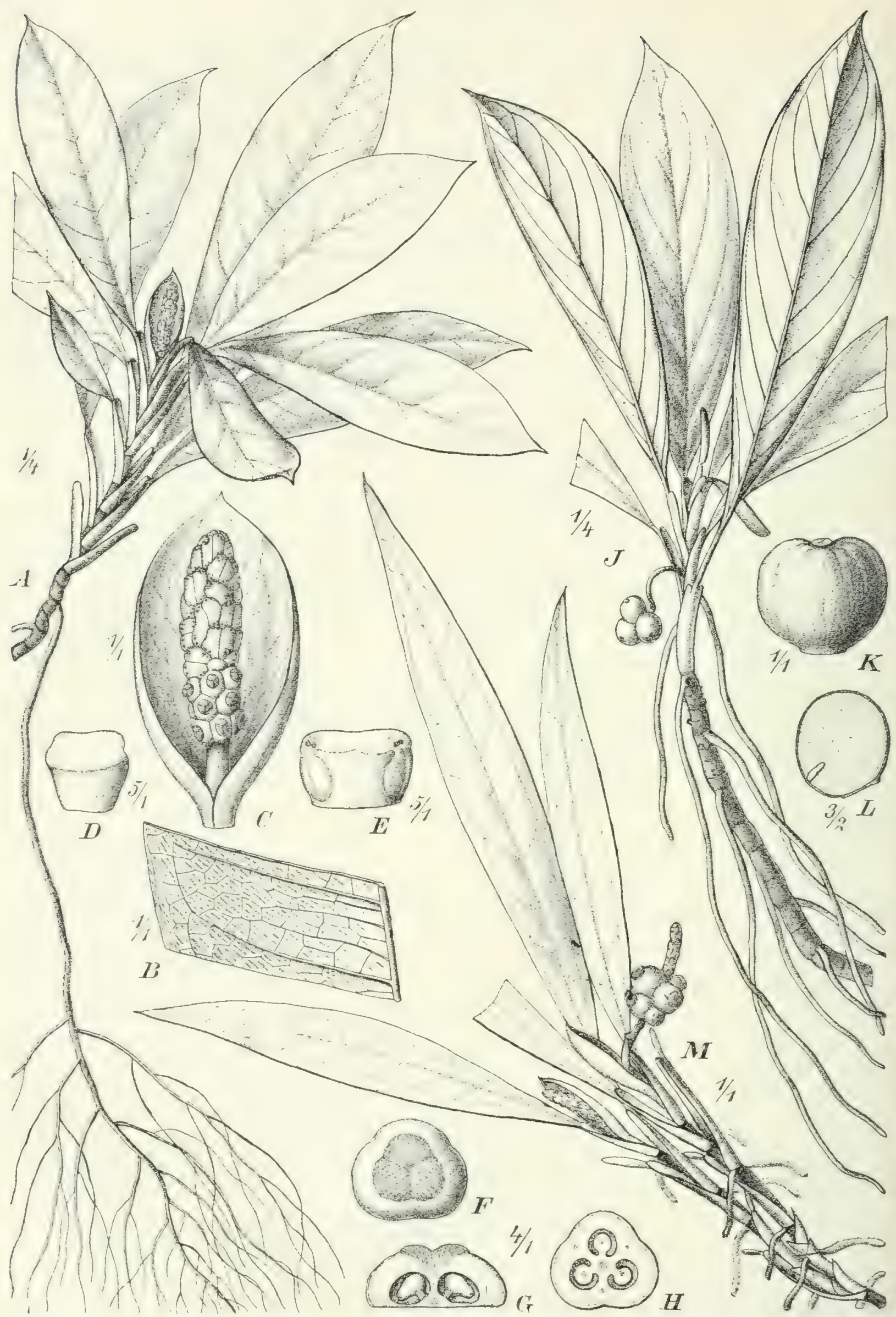

Fig. 158. Culcasia. $A-H$ C. striolata Engl. $A$ ganze Pflanze; $B$ Teil des Blattes, von oben; $C$ Spatha und Kolben; $D$ Staubblatt von vorn; $E$ dasselbe von hinten; $F$ Pistill von oben; $G$ Pistill im Längsschnitt; $H$ Fruchtknoten im Querschnitt. $\mathcal{F}-L$ C. Dinklagei Engl. F Habitus; $K$ Beere; $L$ Samen. $M$ C. lanceolata Engl. Habitus. - Original aus Pfanzenreich. 



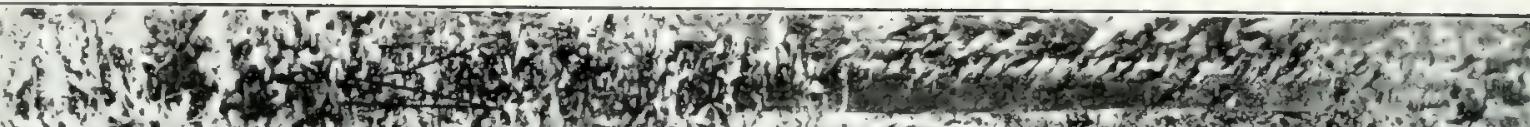

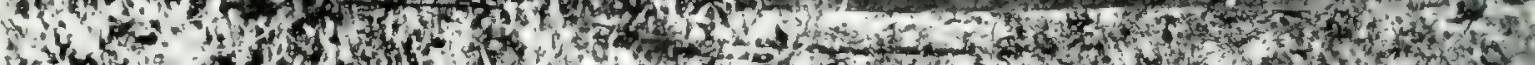

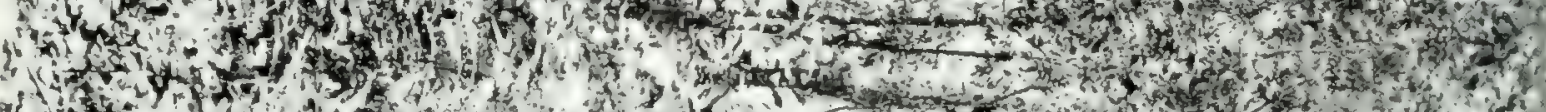

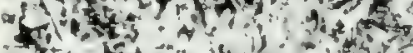

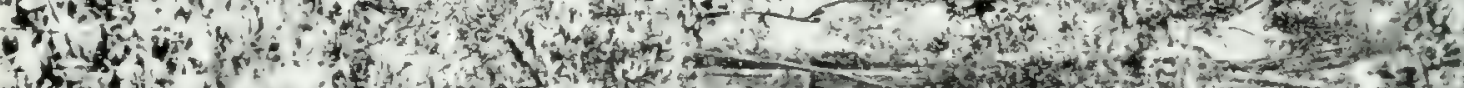

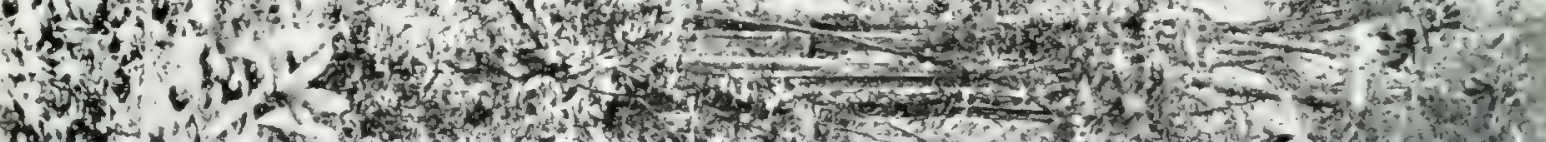

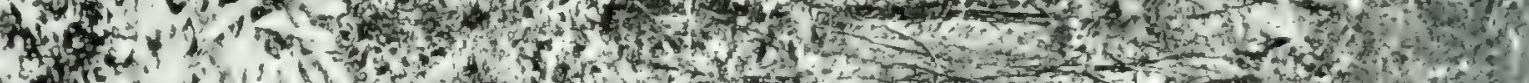

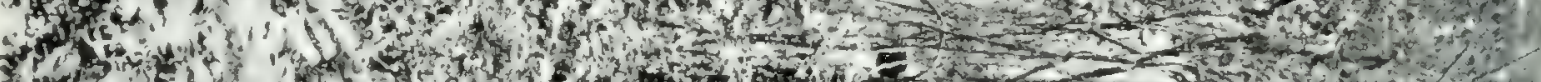

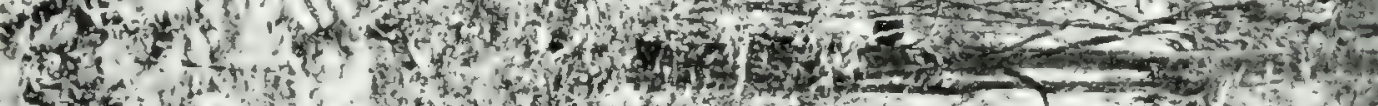
S. 3. s.t.

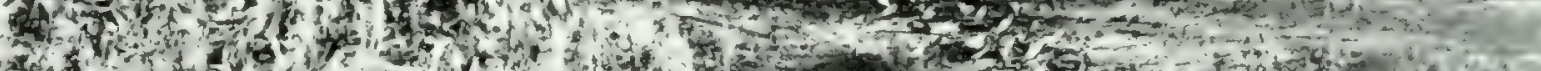
In

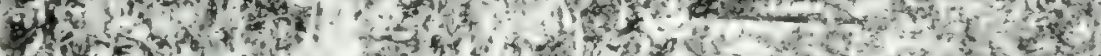

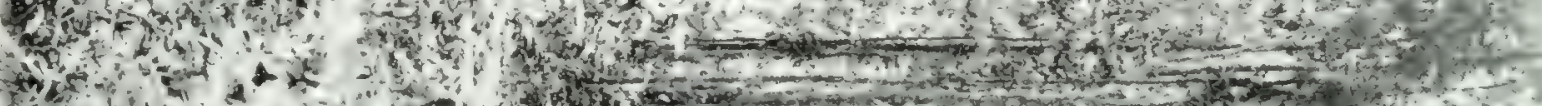

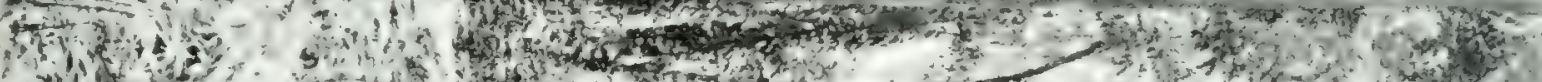

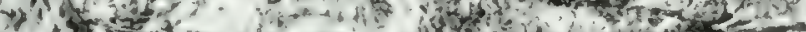

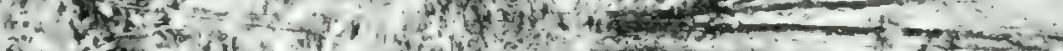

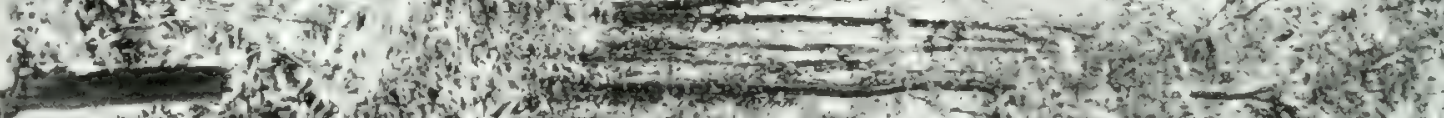

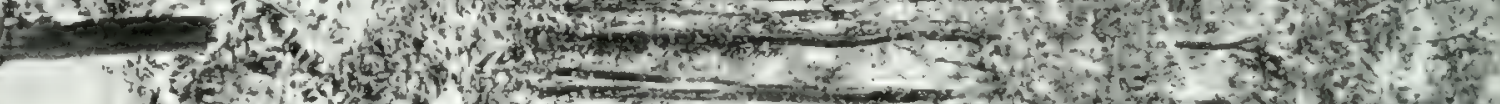
"if

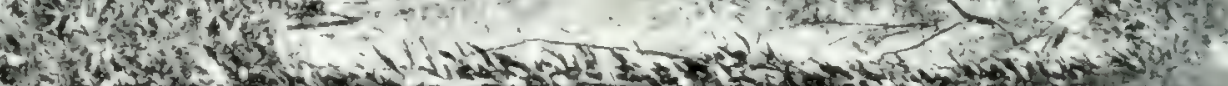

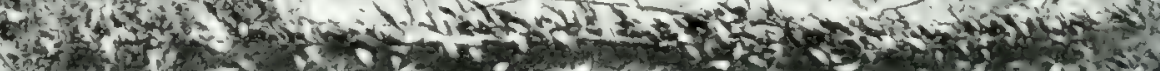

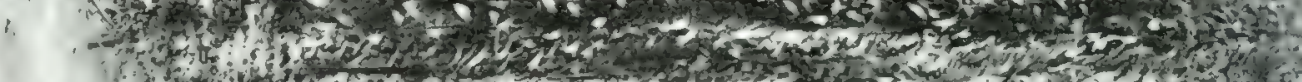

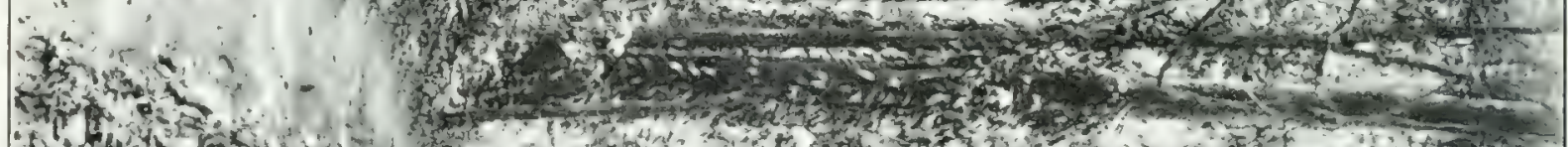
Af

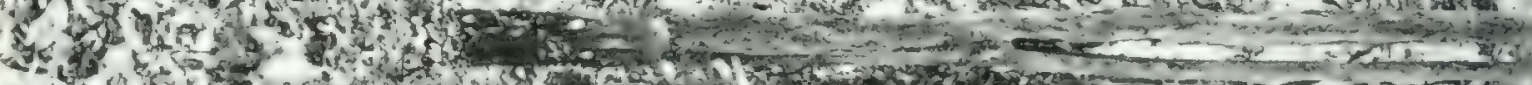

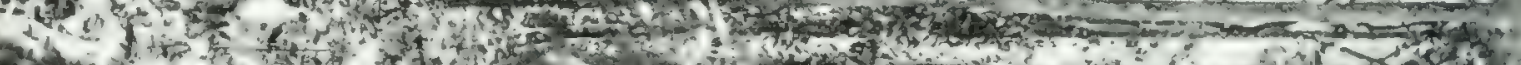

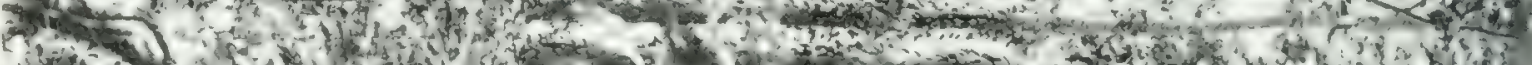

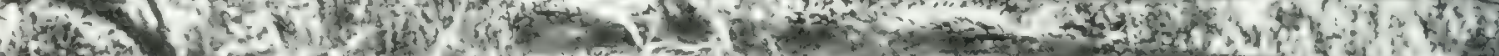

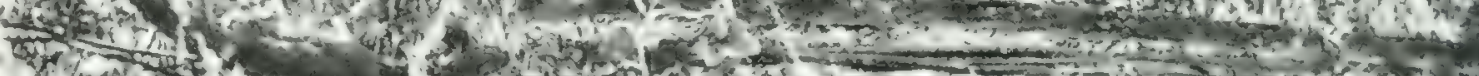

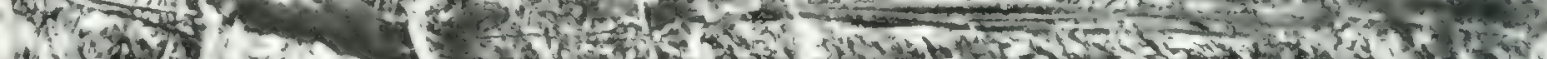

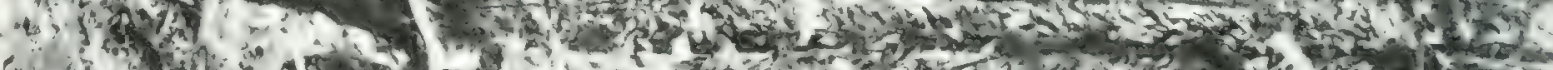

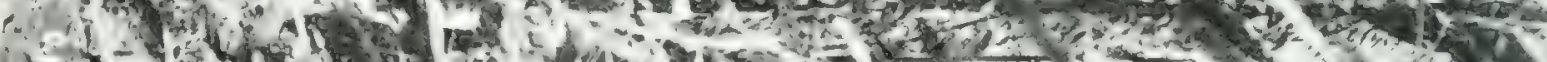

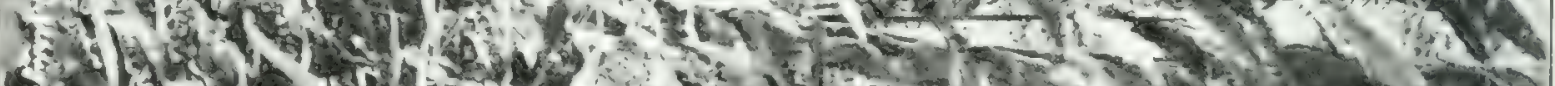

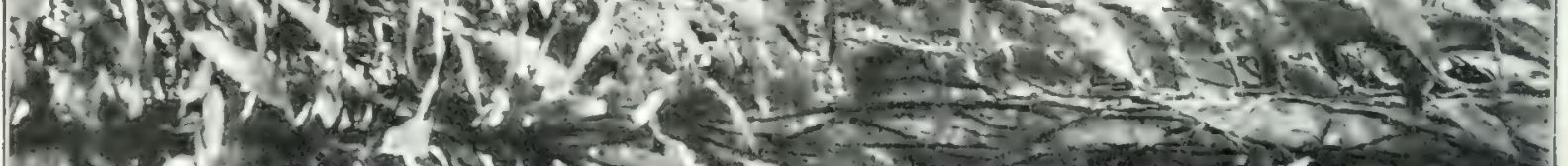

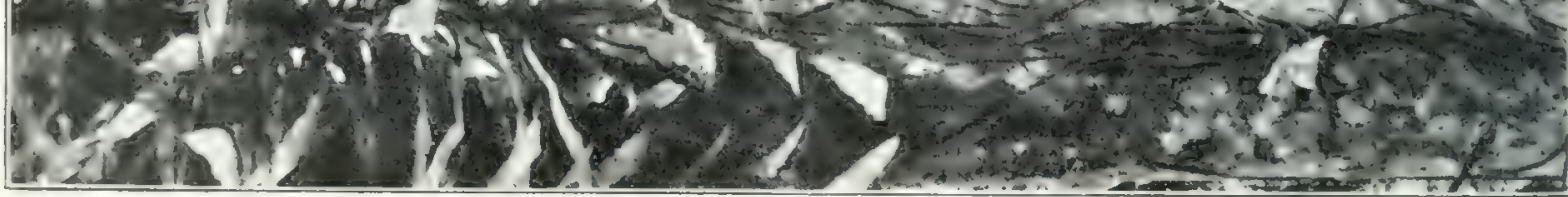


C. angolensis Welw., deren längliche Spreiten 2,5-3 dm lang sind; sie hlettert in den Ufer- und Regenwäldern bis hoch in die Bäume hinauf und ist von Sierra Leone bis Angola und zum oberen Kongo verbreitet und steigt aus der Ebene bis zu I $400 \mathrm{~m}$ ü. MI. auf. Mehrere nahestehende Arten Westafrikas sind von geringer allgemeiner Bedeutung; erwähnenswert ist aber C. folcifolic
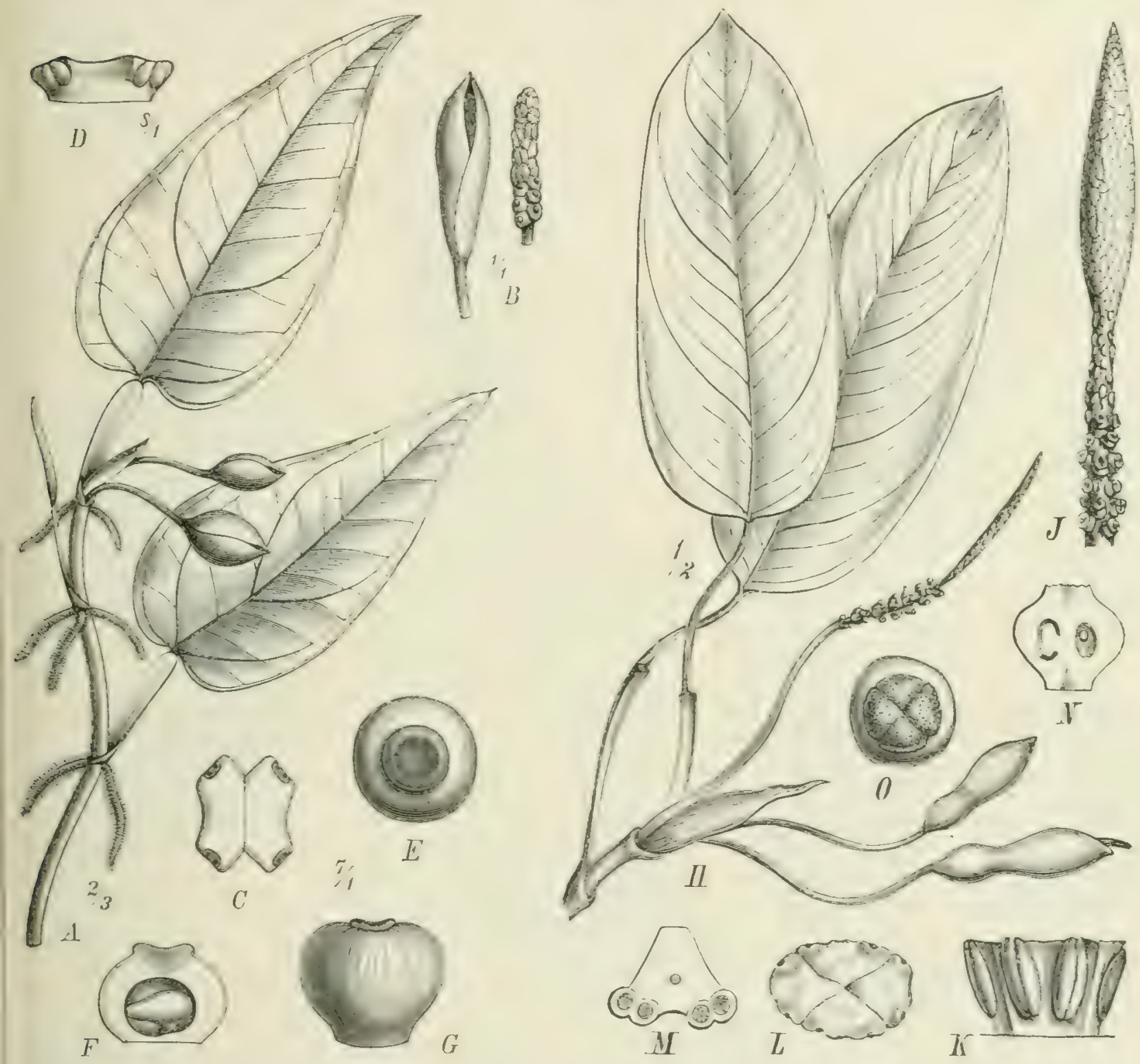

Fig. 159. $A-G$ Culcasia parviflora N. E. Brown. $A$ Habitus; $B$ Spatha und Kolben; " $C$ zwei Staubblätter im Querschnitt; $D$ Staubblatt; $E$ Pistill von oben; $F$ dasselbe im Längsschnitt; $G$ Frucht. $H-O$ C. scandens (Willd.) P. Beauv. $H$ blühender Zweig, von welchem eine Spatha entfernt ist; $\mathcal{F}$ Kolben; $K$ Andröceum; $L$ dasselbe von oben; $I I$ Staubblatt im Querschnitt; $N$ Pistill im Längsschnitt; $O$ Narbe.

Engl., eine ziemlich stattliche Art des Ulugurugebirges, daselbst im Regenwald bei $1600 \mathrm{~m}$ ü. M. Weiter verbreitet als alle anderen ist C. scandens (Willd.) Pal. Beauv. (Fig. I59 II-O; sie findet sich zunächst in demselben Areal wie C. angolensis, ist aber durch Togo und Kamerun bis zum Scharigebiet, sodann durch das Kongowaldgebiet bis zum Ghasalquellengebiet und bis Kukoba zu verfolgen, tritt ferner in Usambara bis zu $1000 \mathrm{~m}$ ii. MI. massenhaft auf und 
wird auch noch in Uferwäldern in der Nähe der Sansibarkuiste angetroffen. Diese Art sieht man häufig in tiefschattigen Wäldern alle Baumstämme bekleiden; auch fallen die hängenden roten Fruchtstände, welche oft massenhaft vorhanden sind, ziemlich stark auf.

Zamioculcas Schott, welche ich wegen ihrer Anatomie auch zu den Pothoideae stelle, ist, wie die Abbildung zeigt, eine sehr eigenartige Pflanze,

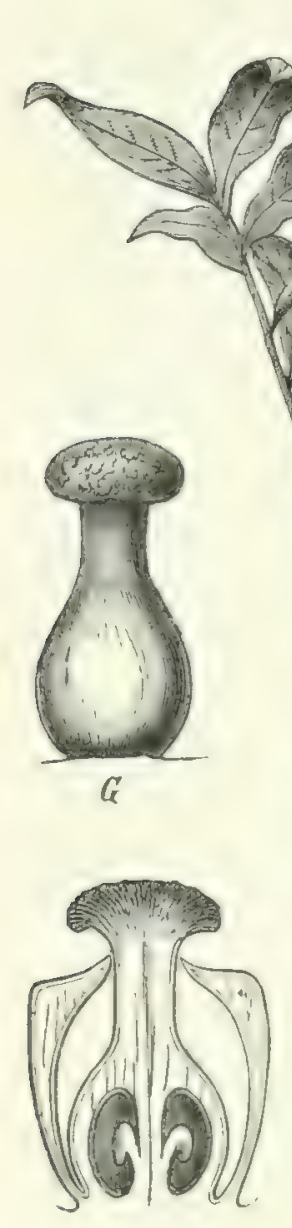

$\vec{E}$
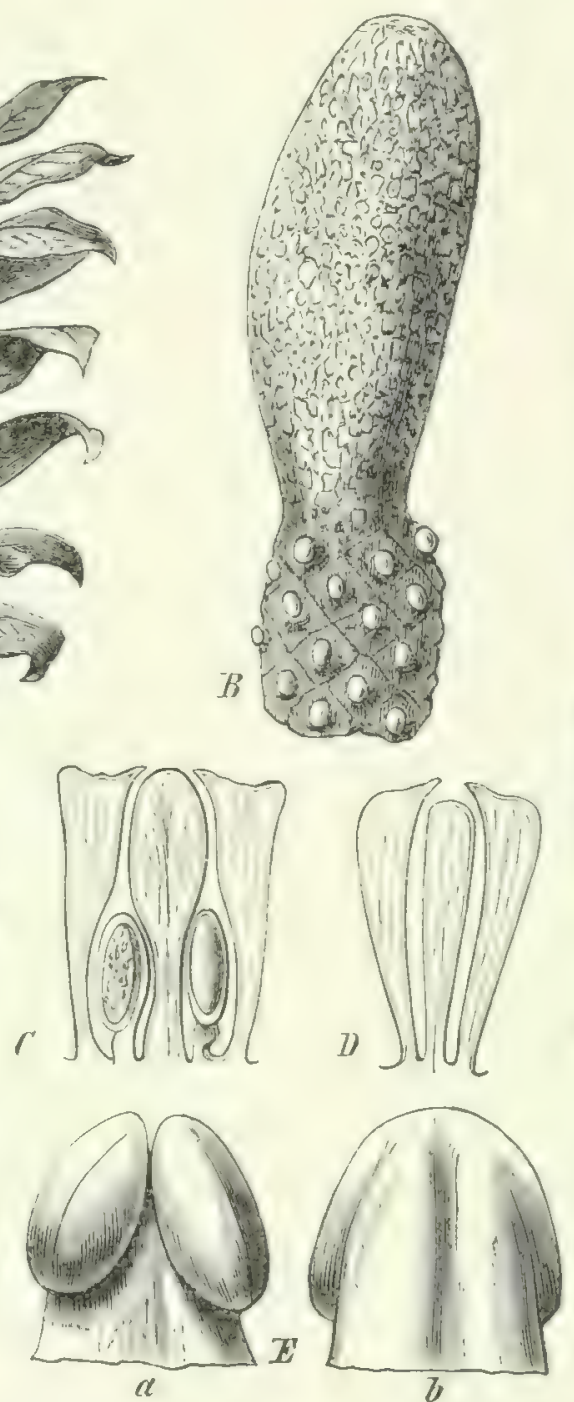

Fig. I60. Zamioculcas zamiifolia (Lodd.) Engl. $A$ Habitus, ${ }^{1} / 5$ n. Gr.; $B$ Inflorescenz in n. Gr.; $C$ ơ Blüte im Längsschnitt mit dem verkiimmerten Gynöceum; $D$ Längsschnitt durch eine ganz sterile Blüte; $E$ Staubblatt von hinten $(a)$ und von vorn $(b) ; F \bigcirc$ Blite im Längsschnitt; $G$ Gynöceum; $H$ Blattfieder, deren Basaiteil eine sproßerzengende Knolle entwickelt hat.

die nur mit der folgenden einigermaßen verwandt ist. Bei der einzigen Art Z. admïfolia (Lodd.; Engl. entspringen einer starken Knolle dicke dunkelgrüne bis $5 \mathrm{dm}$ lange gefiederte Blätter, deren Fiedern nach dem Abfallen an ihrem unteren Ende Knollen und an diesen neue Sprosse entrickeln (Fig. I60). Die kurzgestielten weißen Blütenstände erinnern einigermaßen an diejenigen der einer anderen Unterfamilie angehörigen Stcudncra oder Rcmusatia. Die Pflanze wurde zuerst von Sansibar angegeben, ist aber mit Sicherheit nur von den Gebirgen des Sansibarkiistengebietes bekannt, von den Rabai-Hills bei 
MIombassa, von Ostusambara, wo ich sie an steinigen Bachufern unterhalh Amani um etwa $100 \mathrm{~m}$ ü. M. sammelte, und von Westusambara, wo ich sie am Nordabfall des Gebirges an ausgetrockneten Bachufern der Gebirgssteinsteppe um etwa I000 m ü. M. zwischen Steinen mit succulenten Euphorbien und Dorstenien fand.

Gonatopus Hook. f., mit der vorigen Gattung nahe verwandt, aber durch dreifach gefiederte, meist nur einzeln auftretende Laubblätter und einen langgestielten Bliitenstand verschieden, enthält zwei einander nahestehende Arten. G. Boirinii (Decne.) Hook. f. (Fig. I6I) mit fast I m langen Blättern findet sich in tiefgründigem Waldboden bis zu einer Höhe ron $700 \mathrm{~m}$ ii. M. von Nombas bis Westusambara und auch im südlichen Nyassaland. Der nahestehende G. angustus N. E. Brown mit viel schmaleren Blattabschnitten kommt am Sambesi bei Boruma vor.

Afroraphidophora Engl. steht in der Mitte zwischen der im Monsungebiet sehr reich entwickelten Gattung Raflizilophore und der tropisch-amerikanischen Stenospematizm. Die Arten klettern wie ein Teil der Culcasien und besitzen sehr zahlreiche parallel verlaufende Nerven. Die dicke weiße Spatha fällt gleich nach der Entfaltung ab. Die Pistille sind wie bei Raphiziophora nicht vollkommen gefächert, und die Samenanlagen sind wie bei Stcnuspcrmatium an langen Funiculis am Grunde befestigt. Während 1 . pusilli (N. E. Br.) Engl. bis jetzt nur in Gabun gefunden wurde, kommt die größere A. africana (N. E. Br.) Engl. in Sierra Leone, Togo (Misahöhe), Karnerun und auf Fernando Po vor. Sie klettern ähnlich wie die Culcasic.

Cyrtosperma Griff. ist eine dem ältesten Typus der Lasiovilice entsprechende Gattung, von welcher einige Arten im Monsungebiet, zwei im tropischen Amerika vorkommen, eine im tropischen ITestafrika. Alle sind Sumpfgewächse mit knolligem Rhizom, an den Blattstielen und Stengeln mehr oder weniger stachelig und haben pfeilförmige, netznerrige Spreiten. Das afrikanische C. senegalense (Schott) Engl. wird bis $3 \mathrm{~m}$ hoch; die Spatha wird bis $4 \mathrm{dm}$ lang, gelbgrün mit dunkelrotbraunen Streifen; der Kolben trägt Zwitterblüten mit dunkelviolettem Perigon und ist etwa $1,7 \mathrm{dm}$ lang. Die Pflanze wächst massenhaft an Flußufern und in Sümpfen von Senegambien bis zum Kongo, an welchem sie aufwärts bis Stanley-Pool gefunden wurde.

Anchomanes Schott zeigt im Gegensatz zu der vorigen Gattung nackte und geschlechtlich differenzierte Blïten, oben männliche, unten weibliche, ferner nur ein Laubblatt, dessen drei Abschnitte dichotomisch und fiederig geteilt sind. Eine sehr weitverbreitete Art ist A. difformis (Blume) Engl., mit I $-2 \mathrm{~m}$ hohem, stacheligem Blattstiel und Stengel, vorzugsweise in trockeneren Hängewäldern, dort aber gern in der Nähe von Bächen. Sie ist von Sierra Leone bis Angola (Pungo Andongo) verbreitet, auch auf Fernando Po; sie ist ferner im Djurland in Zentralafrika beobachtet worden, häufig in den Bergwäldern Ostusambaras und auch auf dem Muëra-Plateau. Nur wenig verschieden ist von dieser Art A. Welzuitschii Rendle von Angola, viel mehr der fast $3 \mathrm{~m}$ hohe A. giganteus Engl. von der Umangi-Insel im oberen Kongo, sehr auf- 


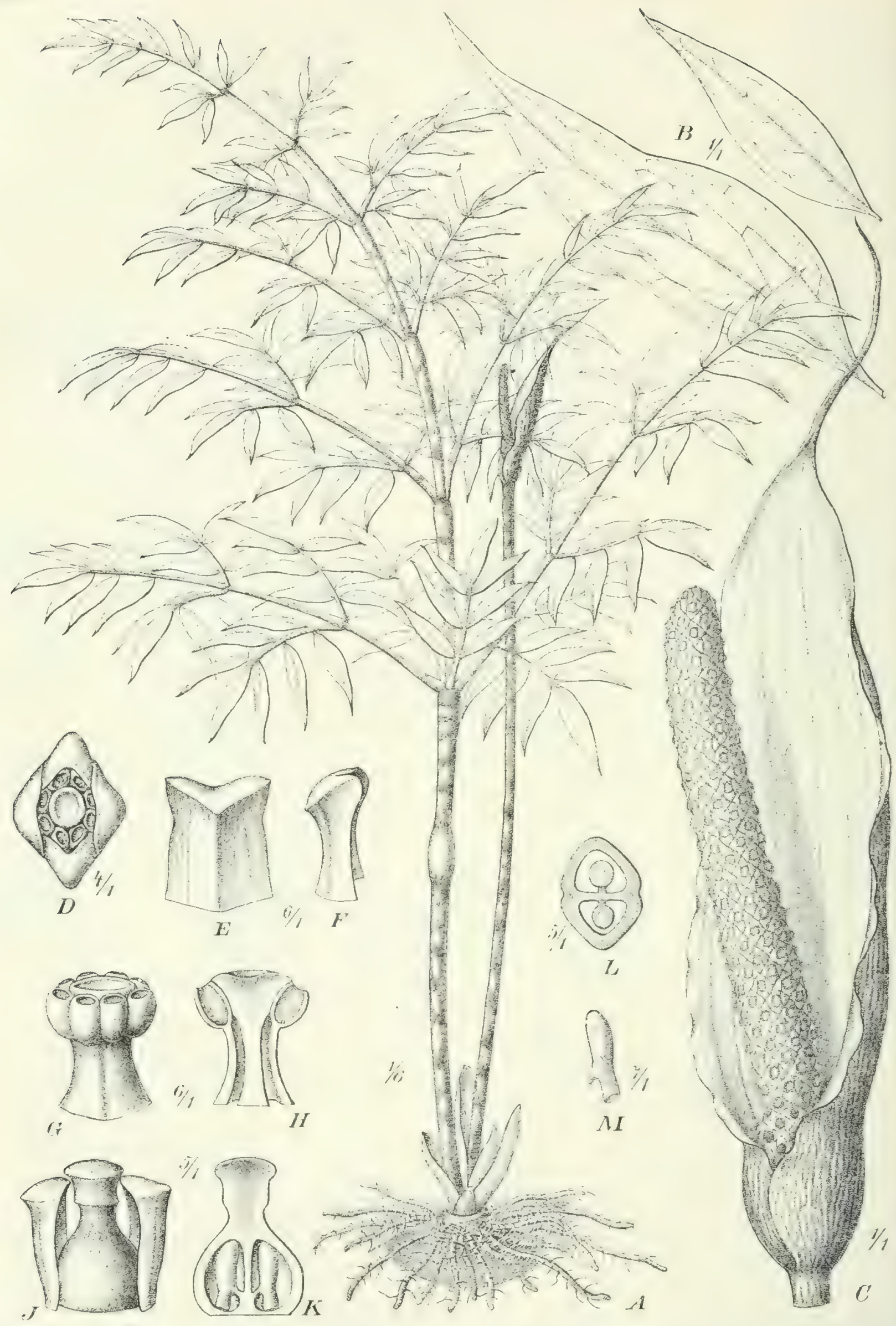

Fig. I6I. Gonatopus Boivinii (Decne.) Hook. f. A Habitus; $B$ Blättchen; $C$ Blütenstand; $D$ Bluite; $E$ Perigonblatt vom Rücken; $F$ dasselbe von der Seite; $G$ Andröceum mit dem rudimentären Pistill; $H$ dasselbe im Längsschnitt; F Perigonblätter und Pistill der \& Blüte; $K$ Pistill im Längsschnitt; $L$ dasselbe im Querschnitt; $M$ Samenanlage. 
fallend durch eine fast $1 \mathrm{~m}$ lange Spatha. Dagegen ist eine sehr kleine Art A. Bochmii Engl. in Uniamwesi im Bezirk Ugunda.

Pseudohydrosme Engl. Von dieser und der folgenden Gattung kennt man noch nicht die Blätter. Die einzige Art, P. gabuncnsis Engl., entwickelt auf einem kurzen Stiel eine etwa $4 \mathrm{dm}$ lange. einen Trichter bildende Spatha, welche einen kurzen Kolben überragt, der in seinem unteren Drittel weiblich, in dem darüber befindlichen Teil männlich ist. Die Pflanze wurde nur einmal an Flußufern bei Munda in Gabun gefunden und verdient weitere Beachtung.

Zyganthera N. E. Brown. Die einzige Art, Z. Büttncri Engl. N. E. Brown, besitzt eine etwa $7 \mathrm{dm}$ lange Spatha. Ihre Inflorescenz ist der der vorigen Gattung ähnlich, aber verschieden durch Verwachsung der zwei Staubblätter der männlichen Blïten und durch das Torhandensein einer Formation steriler Bliiten oberhalb der fruchtbaren. Auch diese Pflanze bedarf dringend weiterer Beobachtung.

Hydrosme Schott steht Amorfluflurlus sehr nahe und besitzt einen aus verschmolzenen Blütenrudimenten bestehenden Kolbenanhang, welcher bei den meisten Arten iiber die Spatha hinwegragt. Ton Amorphophlus unterscheidet sich die Gattung durch die an sehr kurzen Funiculis stehenden dicken Samenanlagen. Alle Arten entwickeln, wie auch die Vertreter der beiden vorigen Gattungen, ihre Bliitenstände in der Trockenzeit, ihr einziges großes, schirmförmiges Laubblatt 's. die Abbildung zu Beginn der Regenzeit. Von den etwa 30 Arten findet sich der größere Teil im Westen von Senegambien bis Angola, der kieinere Teil rom Gallahochland bis zum Sambesi. Ton vielen Arten existiert iiberhaupt nur ein Exemplar in Berlin, Kew oder Brüssel, zumeist kennt man nur die in Kultur genommenen Arten einigermaßen vollständig. Einige Arten haben besonders auffallende Merkmale. So ist H. Elliotii N. E. Br.j Engl., welche zwischen niedrigem Gras in Sierra Leone wächst, ausgezeichnet durch eine kleine mit ihren unteren Rändern verwachsene Spatha und eine sehr kurze Inflorescenz. Bei H. lionthsis Lem.' Lingl. 'Fig. I62 ist die Inflorescenz mit dem Kolben fast so lang wie die Spatha und der Kolbenanhang kurz eiformig, fast liugelig; die Blätter zeichnen sich durch schmale linealische Segmente aus; die Art ist nicht selten in Sierra Leone und Togo. Interessant ist $H$. dracontioid's Engl. dadurch, daß die den kurzen Kolben bedeckende. 3,5 dm lange Spatha ron oben nur eine kleine Öffnung zeigt; sie findet sich in der trockensten Steppe des inneren Togo und auch mehr gegen die Küiste, an der Goldküste und im Nigergebiet, auch an Flußufern.

Sehr auffallend ist $H$. Teuszii Engl. von der Bismarchinsel im Kurango in Angola mit dreilappiger Spatha. Ebenso wie bei dieser. Art ist dic Inflorescenz auch kürzer als die Spatha bei H. Sin'tinfurthii Engl. Fig. I6j', welche rom Ghasalquellengebiet bis zum Tschadsee sehr rerbreitet zu sein scheint, bei der vom unteren Sambesi bis ins Nyassaland verbreiteten H. mossambicensis Klotzsch, H. Goitzci Engl. in den Vidundabergen zwischen Khutu und Thehe und einigen anderen, welche alle einen kurzen Spathasticl besitzen. Dagegen ist der Stiel $4-5$ mal länger als die Spatha bei der an Flußufern Kameruns 


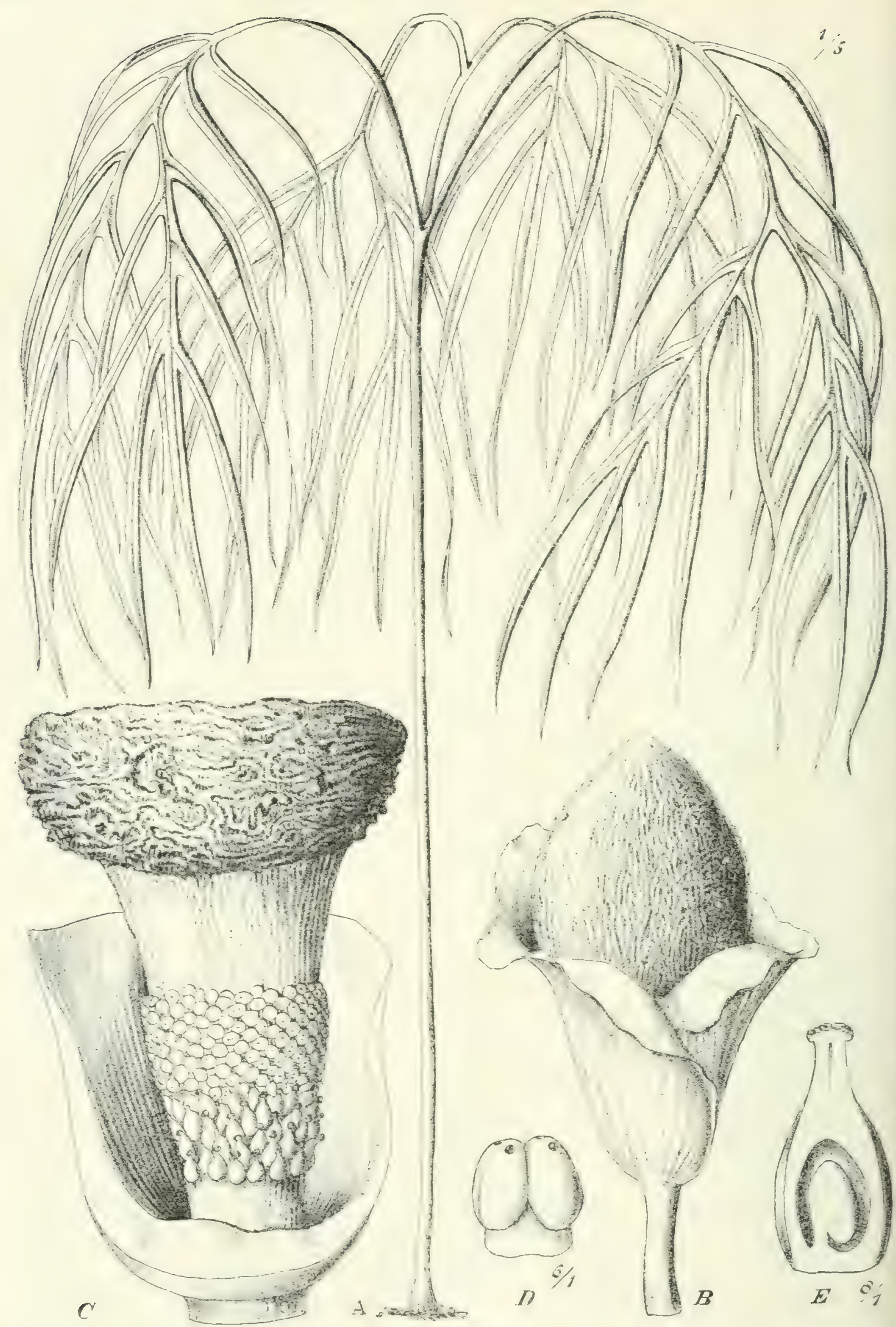

Fig. 162. Hydrosme leonensis (Lem.) Engl. $A$ Blatt, ${ }^{1} / 5$ n. Gr.; $B$ Inflorescenz, $3 / 2$ n. Gr.; $C$ unterer Teil der Inflorescenz nach Entfernung der Spatha; $D$ Staubblatt; $E$ Pistill im Längsschnitt. - Original. 


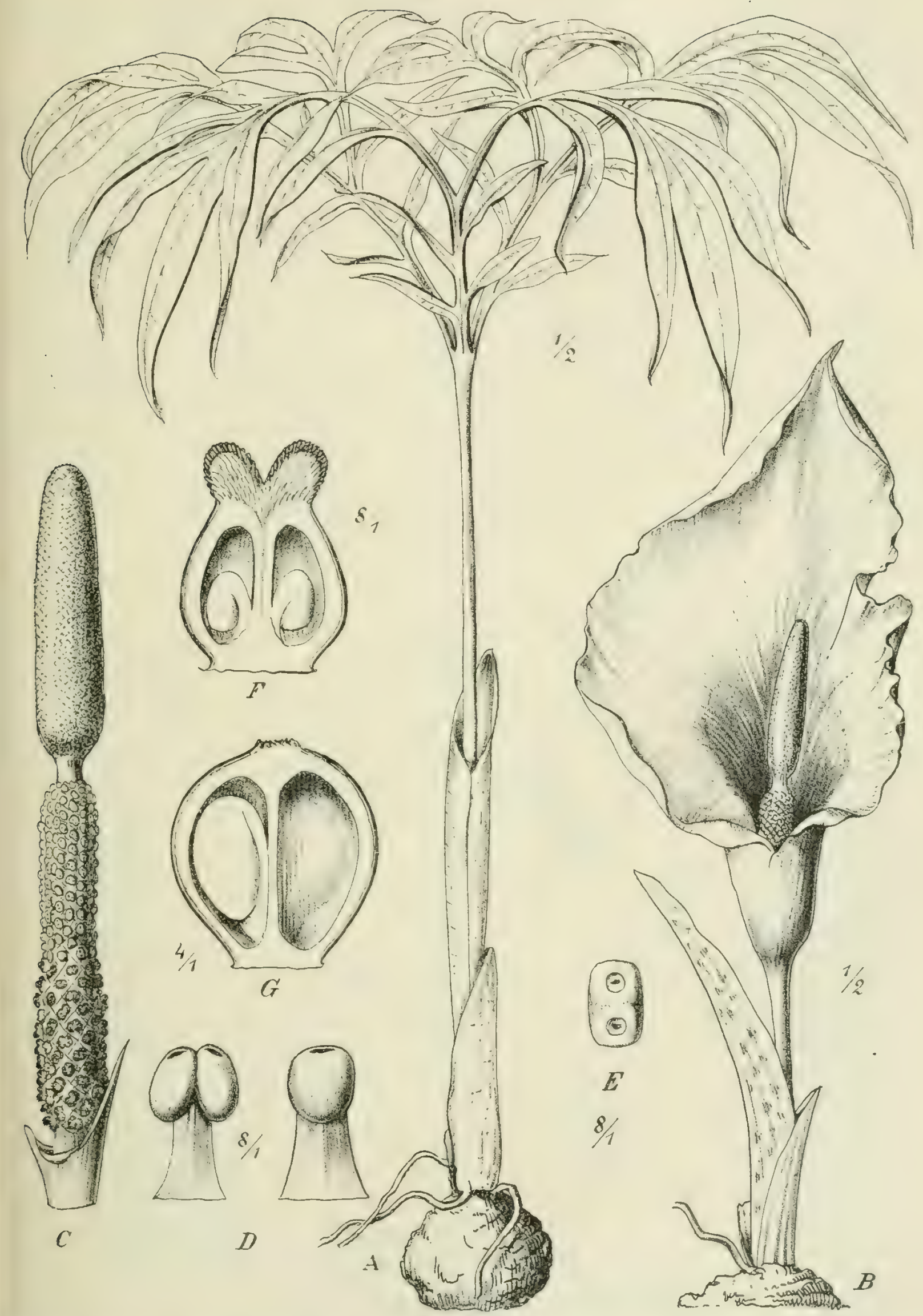

Fig. 163. Hydrosme Schweinfurthii Engl. $A$ nicht blihende Pflanze; $B$ Blitenstand, beide $1 / 2$ n. Gr.; $C$ Inflorescenz mit dem Kolbenanhang; $D$ Staubblätter; $E$ Anthere von oben; $F$ Pistill in Längsschnitt; $G$ Frucht im Längsschnitt. - Original. 


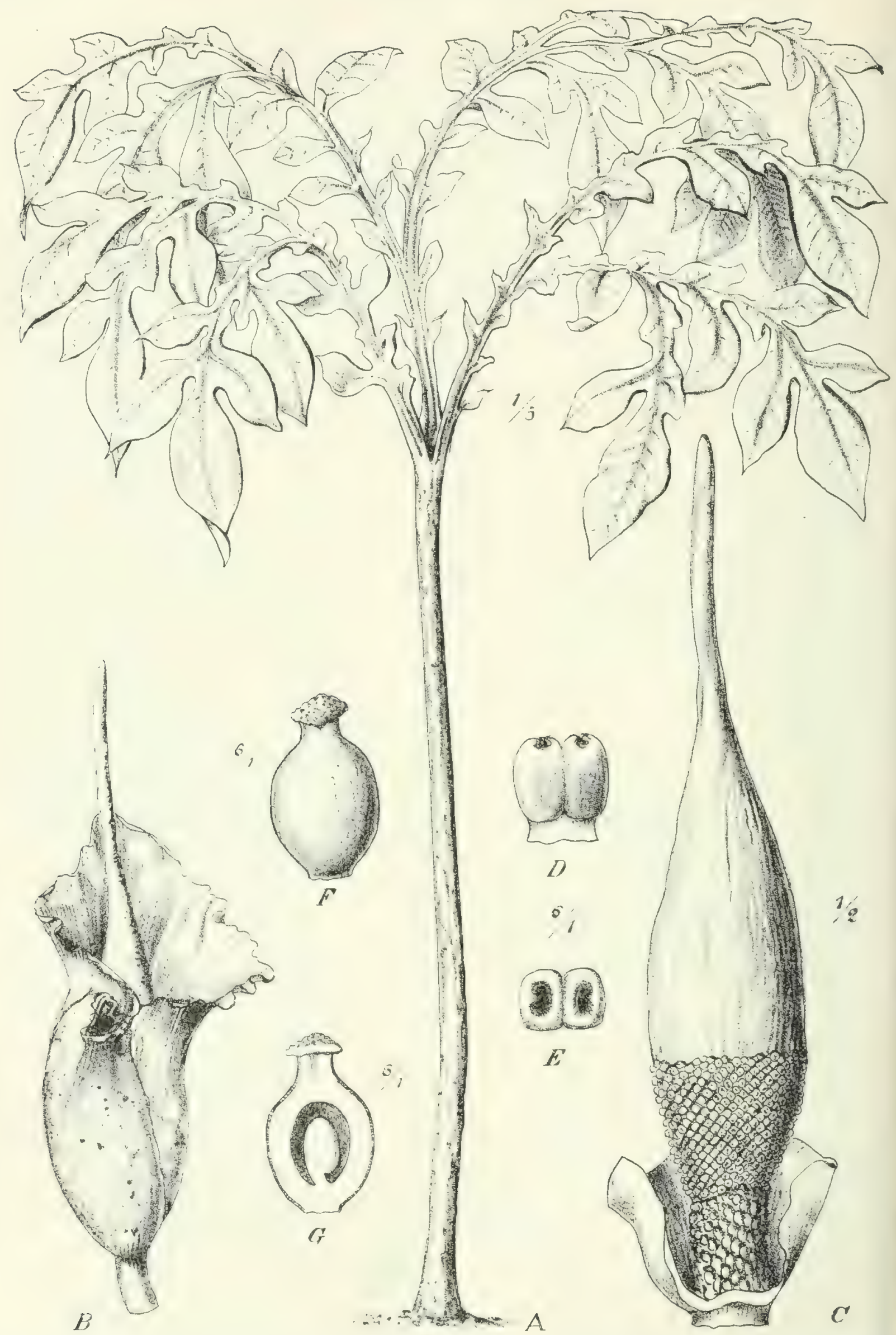

Fig. 164. Hydrosme maxima Engl. (Mombassa). A nicht blïhende Pflanze, ${ }^{1 / 5} \mathrm{n}$. Gr.; $D$ Spatha und Inflorescenz, ${ }^{\mathrm{Y}} / 5 \mathrm{n}$. Gr.: $C$ Inflorescenz fiur sich, ${ }^{\mathrm{I}}{ }_{2} \mathrm{n}$. Gr.: $D$ Staubblatt; $E$ dasselbe von oben: $F$ Pistill; $G$ dasselbe im Längsschnitt. - Original. 
wachsenden H. Preussii Engl. Bei einer viel größeren Zahl von Arten, deren Blïtter alle, wie auch die zuletzt genannten, längliche, \pm zugespitzte Segmente besitzen, ragt der spitz zulaufende Kolbenanhang iber die Spatha oft erheblich hinaus, so bei $H$. Eichleri Engl., welche mit der vorher erwähnten H. Tcusaii zusammen auf der Bismarckinsel im Kwango gefunden wurde, und bei H. Stcudtii Engl. von Kamerun. Von den übrigen Arten will ich nur erwähnen $H$. maxima Engl. (Fig. I64) mit 2,5 dm langer Spatha auf 7,5 dm langem Stiel und $5 \mathrm{dm}$ langem Kolben, bei Mombassa, und die von mir bei meinem ersten Besuch des Sigitals in Ostusambara in Begleitung von Dr. StuHLianN aufgefundene H. Stuhlmannii Engl. (Fig. I65), mit $5 \mathrm{dm}$ langer Spatha und $7 \mathrm{dm}$ langem Kolben, bis $3 \mathrm{~m}$ hohem Blattstiel und einer Spreite von fast $2 \mathrm{~m}$ Durchmesser; es ist die riesigste Art Ostafrikas.

Cercestis Schott ist eine Gattung kriechender oder kletternder Pflanzen mit herzförmigen, pfeil-oder spießförmigen oder dreilappigen Blättern, mit unten zusammengerollter, oben konkaver und abfälliger Spatha, welche einen Kolben mit nackten, weiblichen und männlichen Blüten umschließt; wir kennen fünf Arten aus den unteren Regenwäldern Westafrikas von Sierra Leone bis zum Kongo und von Fernando Po.

Rhektophyllum N. E. Brown, eine höchst interessante monotypische Gattung mit $R$. mirabile N. E. Brown Fig. I66), einer Pflanze, welche wie die vorigen teils am Boden kriecht, teils an Bäumen bis über $10 \mathrm{~m}$ hoch hinaufklettert und dabei einen 3-9 cm dicken Stamm entwickelt, mit herzpfeilförmigen oder breit pfeilförmigen Blättern, von denen die unteren ungeteilt und weiß punktiert, die oberen (mit dem Blattstiel bisweilen I m langen) zwischen den Nerven von schmalen Löchern durchbrochen sind, so daß sie den Blättern von Ifonstora dcliciose etwas ähnlich wcrden. Diese Art findet sich schon im Nigergebiet, sie ist ganz besonders häufig in den unteren Regenwäldern Kameruns und auf Fernando Po, ferner auch im Lande der Mombuttu, im zentralafrikanischen Seengebiet und in den Wäldern westlich vom Victoria Njansa.

Nephthytis Schott. Diese Gattung ist mit Cercestis näher verwandt; aber alle Arten haben kurze kriechende Rhizome und pfeilförmige oder spießförmige Blätter, ferner langgestielte Inflorescenzen mit offener grüner Spatha, welche den kurzen, von nackiten weiblichen und männlichen Blïten besetzten Kolben überragt. Vier Arten verteilen sich auf die IValdgebiete von Liberia bis Gabun nebst Fernando Po. (Fig. I67.)

Anubias Schott. Zu dieser Gattung gehören krautige Pflanzen mit kriechenden Rhizomen, welche häufig auf Steinen an Bächen frei liegen und mit ihren aufrechten, lang gestielten, fiedernervigen, lanzettlichen bis pfeilförmigen Blättern sowie ihren in den Blattachseln stehenden Bliitenschäften oft dichte Rasen bilden; sie wachsen auch am Rande von Sümpfen. Bis jetzt kennen wir aus IVestafrika ron Sierra Leone bis Angola neun bis zehn Arten, ron denen einige einander sehr nahe stehen, einzelne, wie die auf Fernando Po und in Kamerun sehr häufige A. Bartori Schott, desgleichen A. hetcrophylla. 

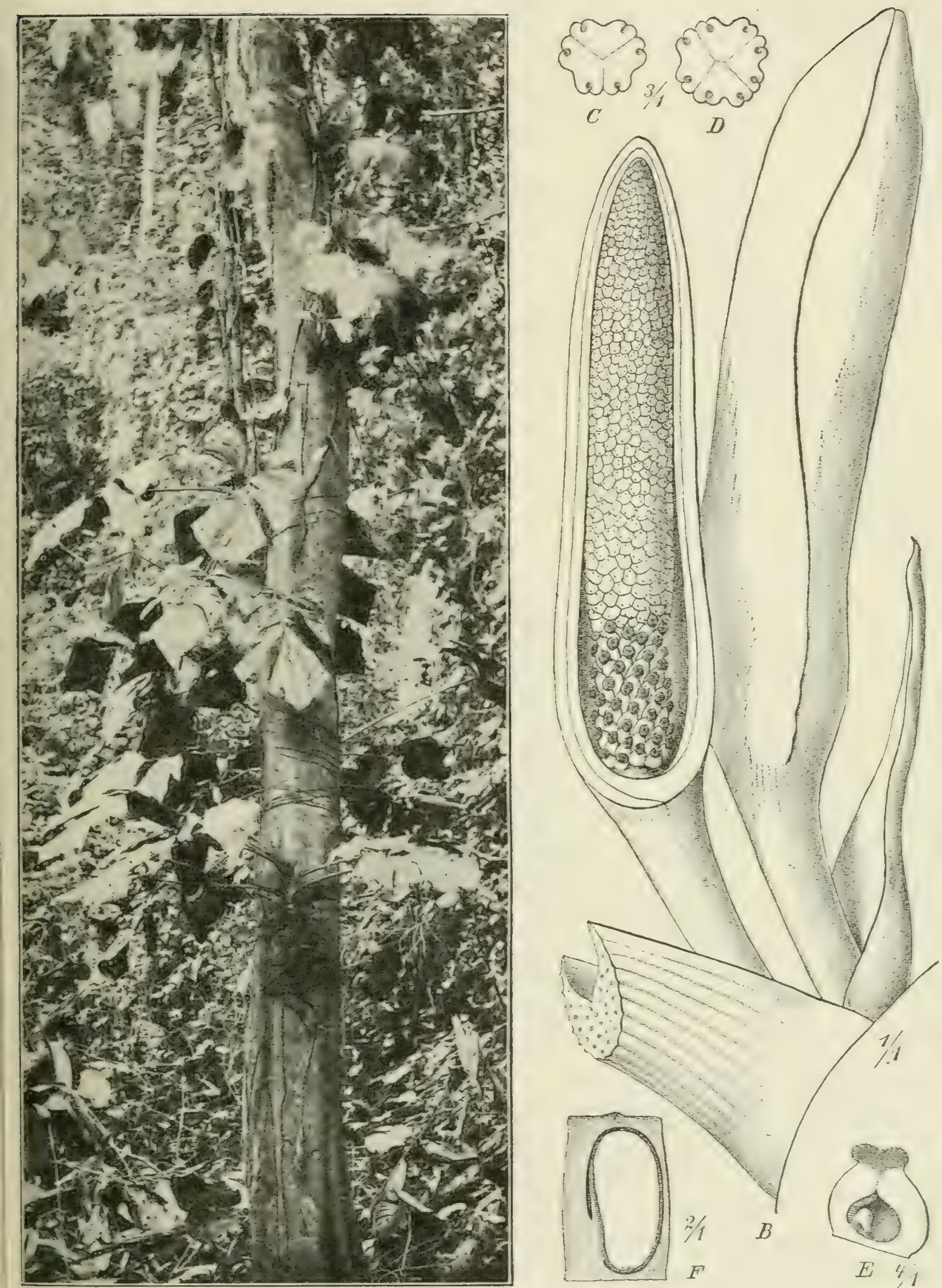

$A$

Fig. I66. Rhektophyllum mirabile N. E. Brown. $A$ ganze Pflanze an einem Stamm kletternd im Regenwald von Victoria, Kamerun, nach einer Photographie von Dr. Bücher. $B$ zwei Blütenstände; $C, D$ männliche Blüten; $E$ weibliche Bluite; $F$ Beere im Längsschnitt. - Original. 
von Angola, recht verschieden gestaltete Blätter entwickeln, so daß die Unterscheidung der Arten oft schwierig ist. Wie es scheint, ist keine der Arten erheblich gegen Osten vorgedrungen; auch scheinen sie nicht über $800 \mathrm{~m}$ aufzusteigen (Fig. I68).

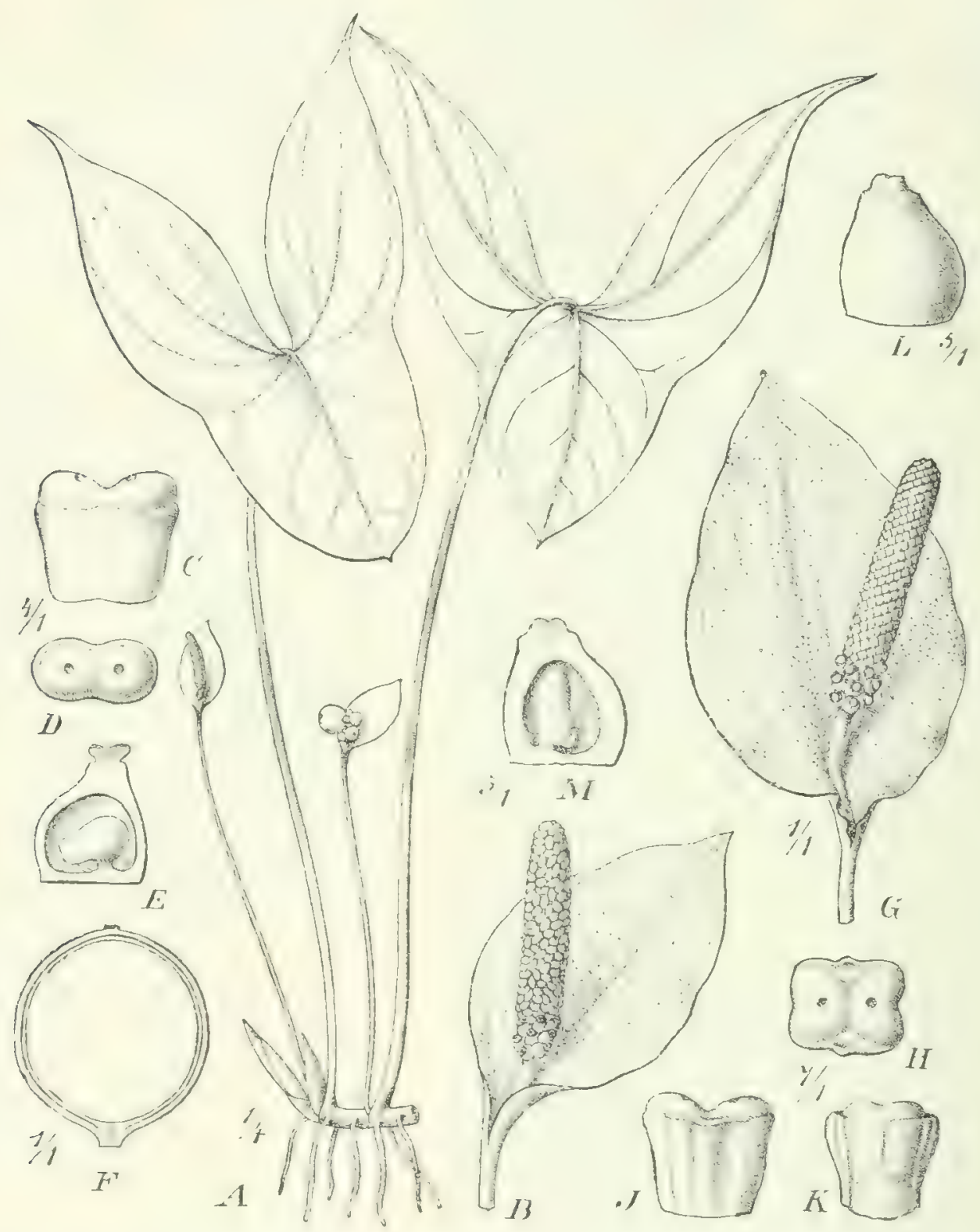

Fig. 167. Nephthytis. $A-F$ N. Gravenreuthii Engl. $A$ ganze Pflanze; $B$ Inflorescenz mit braun punktierter Spatha; $C$ Staubblatt von der Seite; $D$ dasselbe von oben; $E$ Pistill oder 우 Blüte; $F$ Frucht im Längsschnitt. $G-M N$. Poissoni Engl. (Kamerun); $G$ Inflorescenz; $H-K$ Staubblatt; L, $M$ Pistill. - Original.

Zantedeschia Spreng. (Kicharlia Funth), ist wohlbekannt durch die häufig als Zimmerpflanze kultivierte Z. acthiopica (L.) Spreng., eine der schönsten Zierden auf feuchten Wiesen um Kapstadt und überhaupt im südwestlichen Kapland. Lange Zeit kannte man nur diesc Art; allmählich aber sind andere Arten, auch aus dem tropischen Afrika, bekannt geworden, von denen aber kaum cine der erstgenannten an Schönheit gleichkommt, so Z. alsomaculata 
(Hook. f.) Engl. von den Wittebergen nordwärts bis Tembuland, bis zu einer Höhe von I $500 \mathrm{~m}, 2$. melanolenca (Hook. f.) Engl. mit gelber, innen am

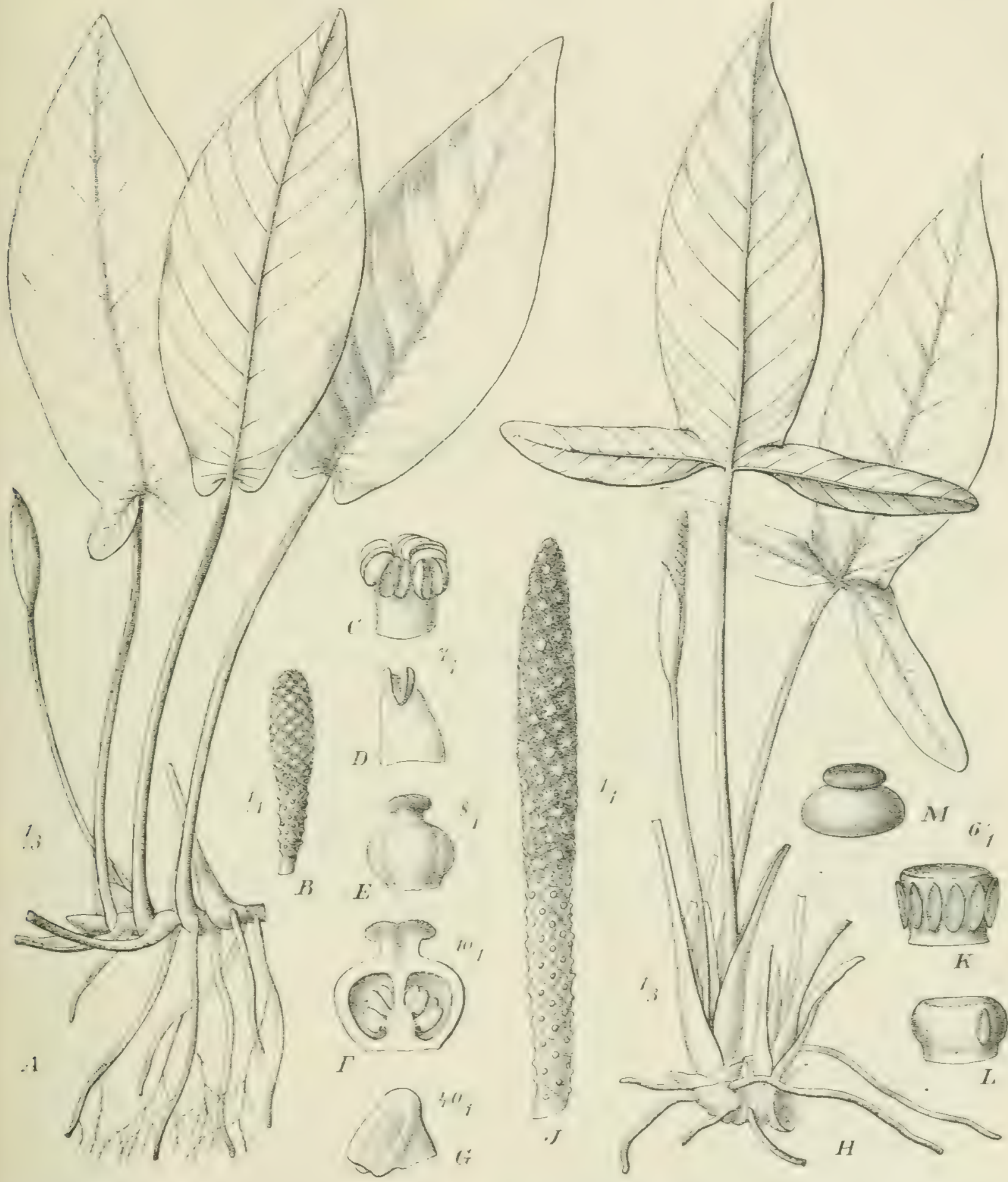

Fig. 168. Anubias. $A-G$ A. auriculata Engl. aus Kamerun, Bipinde. $A$ Rhizom mit Blättern und einem Blütenstand, ${ }^{1} / 3 \mathrm{n}$. Gr.; $B$ die Inflorescenz; $C$ of Blüte; $D$ ein Staubblatt; $E$ Pistill; $F$ dasselbe im Längsschnitt; $G$ Samenanlage. $H-M$ A. hastifolia Engl. von Kamerun, Batanga; auch am Kongo. $H$ ganze Pflanze; $\mathcal{F}$ Inflorescenz; $K$ Andröceum; $L$ ein Synandrium mit nur einer fertilen Theka; $M$ Pistill. - Original.

Grunde dunkel karminfarbener Spatha, in Natal, Maschonaland und dem suidlichen Nyassaland; Z. Relunamii Engl., mit schmalen lanzettlichen Blättern, auf steinigen Hiigeln in Natal von I $300-1600 \mathrm{~m}$, Z. hastatcr Hook. f.l im 
Basutoland, in Transvaal und Natal, auch eine nur 3-5 dm hohe Art mit spießförmigen am Grunde weichhaarigen Blättern; Z. angristiloba (Schott) Engl., größer als vorige, mit kahlen Blättern, in Sümpfen und an Flußufern von Benguela, Angola und Transvaal (Lydenburg).

Typhonodorum Schott, mit der einzigen Art T. Lindleyanum Schott (Fig. I69, I 70), ist in der Beschaffenheit der Blätter einer riesigen Zantedesclica zu vergleichen, zeigt aber in den Blüten mehr Übereinstimmung mit Alocasia. Die im tiefen Wasser von Bächen und Sümpfen wachsende Pflanze besitzt ein dickes Rhizom und wird $3-+\mathrm{m}$ hoch, indem die bis $9 \mathrm{dm}$ langen Blattstiele bis $\mathrm{I}, 3 \mathrm{~m}$ lange pfeilförmige Spreiten tragen. Die bis $8 \mathrm{dm}$ lange Spatha

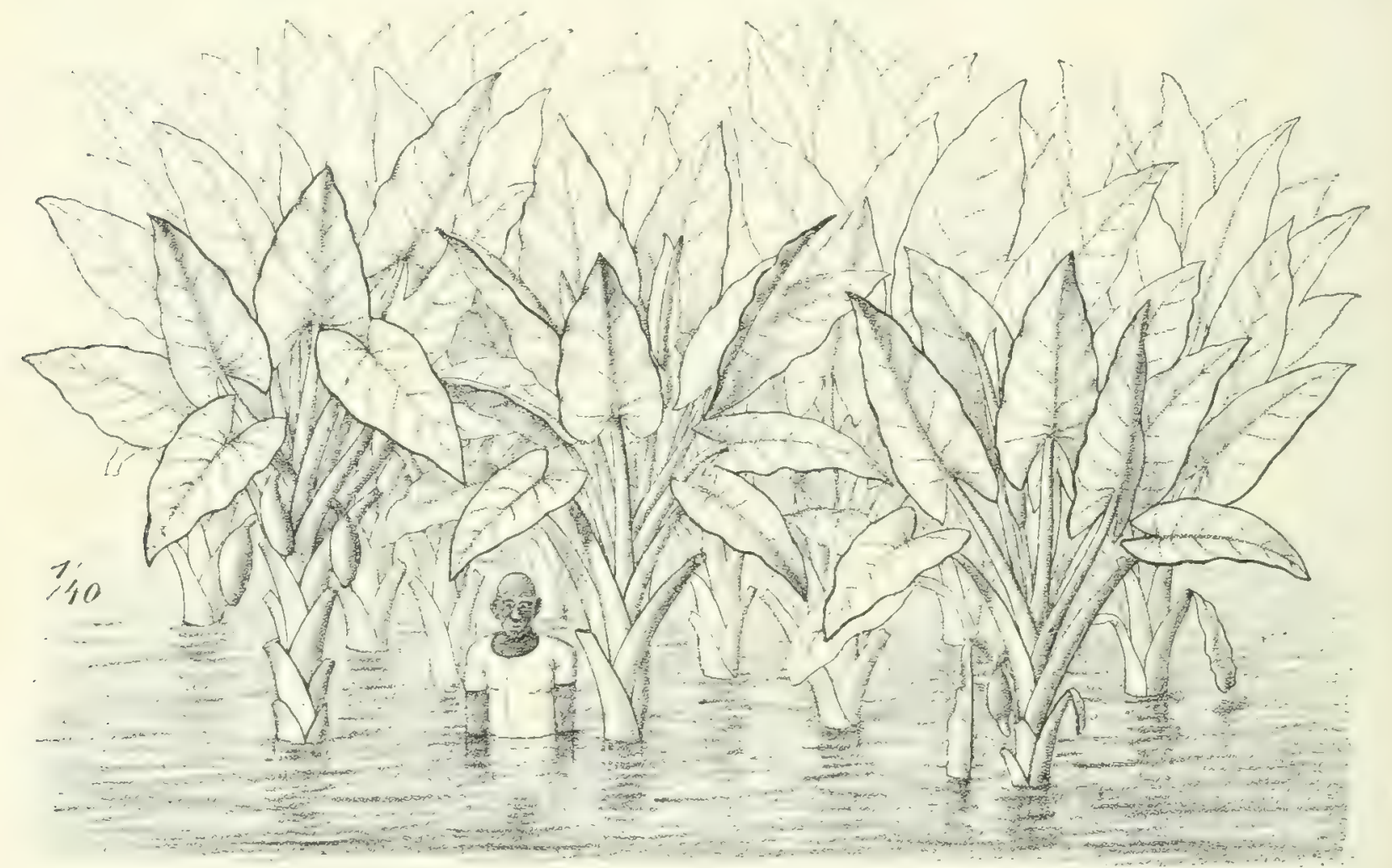

Fig. 169. Sumpfformation am Mwera-Pond auf Sansibar mit Bestand von Typhonodorum Lindleyanum Schott. Im Vordergrund links und rechts ein fruchttragendes Exemplar, in der Mitte ein blühendes. - Original.

schließt einen bis 5,5 dm langen Kolben ein, an welchem oberhalb der fertilen männlichen Inflorescenz noch ein langer kegelförmiger Teil Synandrodien trägt. Die Gattung ist besonders noch charakterisiert durch große verkehrt-eiförmige Becren, welche einen verkehrt-eiförmigen Samen einschließen, dessen Embryo vermittelst eines fast kugeligen Saugers das Endosperm vor dem Austreten aus der diinnen Fruchtwand aufehrt und schon in der Frucht mehrere Niederblätter zu einer Länge von $\mathrm{I}-2 \mathrm{~cm}$ ausbildet. Die Beeren schwimmen lange auf dem Wasser, bis der Embryo seine Blätter entwickelt hat. Die Pflanze ist auf dem afrikanischen Festland bis jetzt nicht beobachtet worden, sondern nur auf Sansibar, den Comoren, Mauritius und Madagashar. (Vergl. ENGL. Bot. Jahrb. XXXVI (1905) 235-237.) 


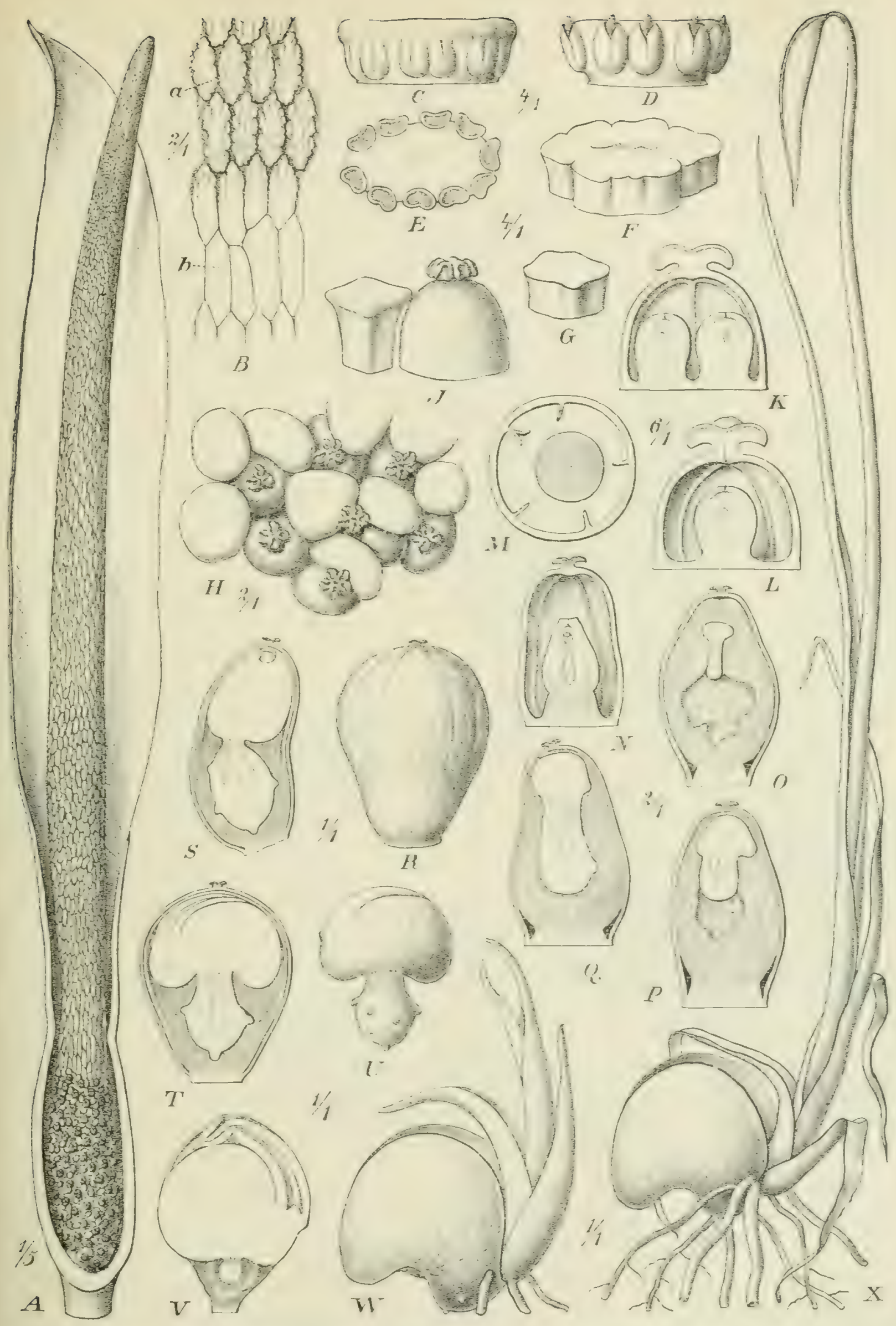

Fig. I7o. Typhonodorum Lindleyanum Schott. A Blütenstand nach Entfernung der halben Spatha, I/5 n. Gr.; $E$ Stückehen der Inflorescenz, a fruchtbarc Srnandrien, ob die darunter stehenden Symandodien: $C$, $D$ Syrandrium von der Seite, $E$ ein solches im Querschnitt: F Synandrodium: G Synandrodium aus dem oberen Teil der InHorescenz; $H$ Stück der weiblichen Inforescenz mit Staminodien; F Pistill und Staminodium: $K$, $L$ Längsschnitte durch die Pistille; $1 /$ Querschnitt durch ein solches mit einer Samenanlage; $N$ Pistill mit befruchteter Samenanlage; $O, P$ weitere Entwicklung des Embryo, darunter noch Embryosack mit Endosperm; $Q$ weiter vorgeschrittener Embryo, welcher das Enclosperm aufrezehrt hat: $I$ beere mit stark entwickelten Enbryo: $S$ dievelle in zwei aufuinanacr senkrecht stehenden Längsschnitten. Das (organische) obere Ende des Kotyledon hat sich zu einem Sauger ausgebildet, welcher in das Nucellargewebe vordringende Ausstülpungen treibt. $U$ ein solcher Embryo freigelegt; $V$ Durchschnitt durch einen Embryo mit schwächer entwickeltem Sauger, der noch von Endosperm umgeben ist; $W, X$ Embryonen mit weiterer Entwicklung der ersten Blattanlagea. - Original. 
Alocasia Schott, Colocasia Schott, Xanthosoma Schott, Caladium Vent. sind im tropischen Afrika nur kultiviert oder verwildert auftretende Colocasioideac. Die in Monsungebiet heimischen Alocasia macrorrhiza Schott und Colocasia antiquorm Schott sowie das aus Westindien stammende Tanthosoma irolacemm Schott werden in den Tropen allgemein als Knollen- und Blattgemüsepflanzen kultiviert, in Afrika ganz allgemein $C$. antiquomm. Diese findet
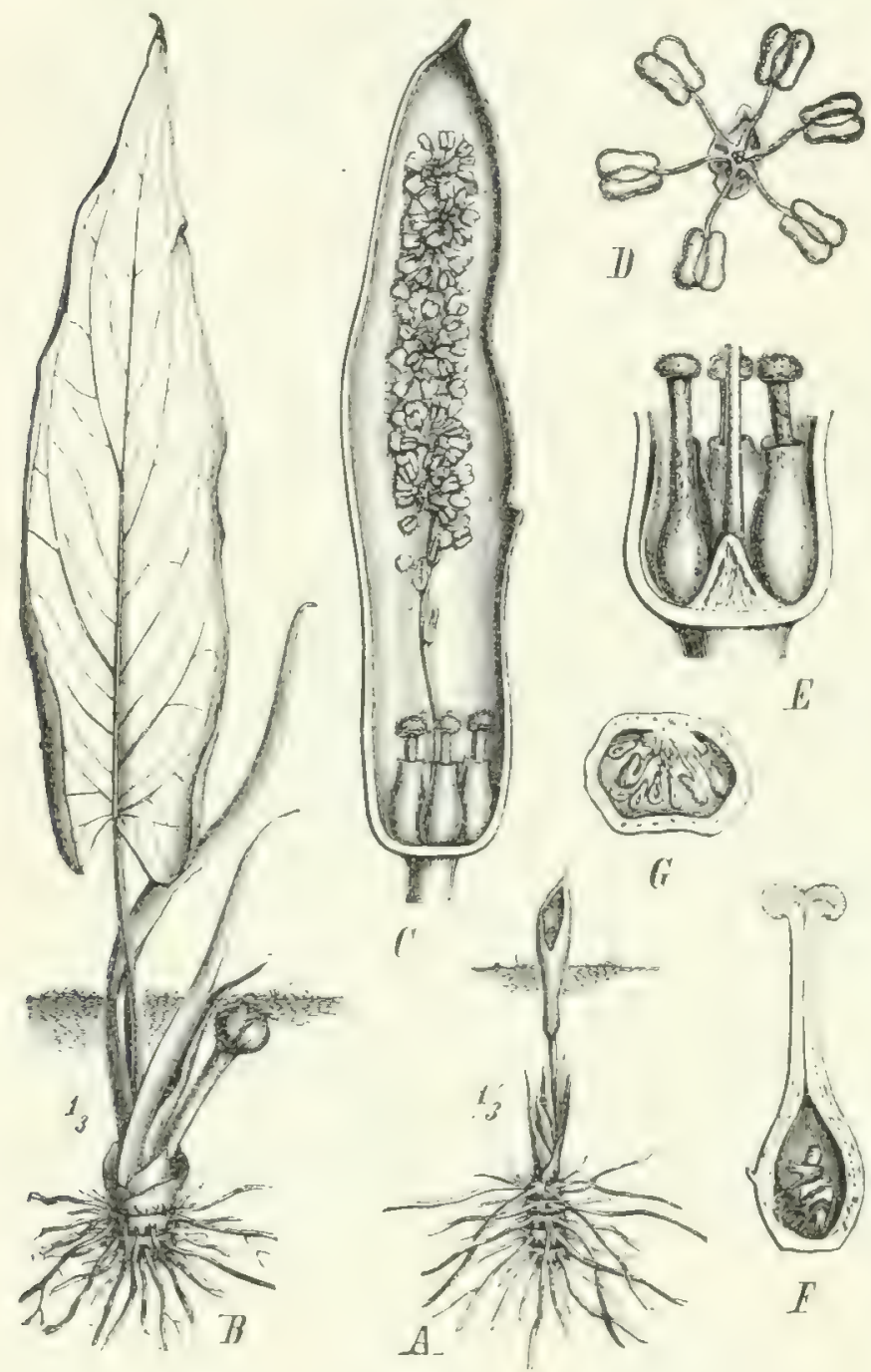

Fig. I71. Stylochiton lancifolius Kotschy et Peyr. aus dem Ghasalquellengebiet. $A$ blühende Pflanze, größtenteils unterirdisch; $B$ Pflanze mit Blättern und Fruchtstand, beide I 3 n. Gr.: ('Blitenstand nach Entfernung der halben Spatha; $D$ ơ Blüte; $E$ ein Teil der 9 Inflorescenz; $\%$ Pistill im Lïngsschnitt; $G$ dasselbe im Querschnitt. - Nach Kotschy und PEYRITSCH.

ist es wahrscheinlich, daß einzelne Arten an verschiedenen Standorten beide Typen der Entwicklung zeigen. Tiele Arten sind noch sehr unvollkommen bekannt; Beobachtungen über Entwicklung der Pflanzen wären von Interesse. Von den Arten, welche in der Regel gleichzeitig Blätter und Inflorescenzen entwickeln, nenne ich S. maximus Engl. im tiefen Schatten der 
Strandwaldungen von Usaramo in Deutsch-Ostafrika und der Delagoa-Bay; S. natulensis Schott in Natal; S. Zcnkcri Engl. (incl. S. grabonicus N. E. Brown), an feuchten schattigen Waldplätzen auf Fernando Po, in Kamerun und Gabun. Bei den beiden ersten Arten stehen die weiblichen Blüten quirlig (Sekt. Spirogyne Engl.), bei der letztgenannten in einem Quirl (Sekt. Cyclogyne Engl.). Andere Arten entwickeln an ihren Sprossen abwechselnd Niederblätter und Laubblätter und schließen diese mit Niederblättern und einer wenig über die Erde tretenden Inflorescenz ab; dann kommt in der Achsel eines Niederblattes ein neuer Sproß zur Entwicklung, welcher zur Regenzeit Laubblätter trägt. So verhält sich S.lancifolius Kotschy et Peyr. (Fig. I 7 I), welcher im Ghasalquellengebiet häufig vorkommt und in seinen sonstigen Merkmalen dem $S$. Zenkeri sehr ähnlich ist, so auch S. kerentsis N. E. Brown in der Erythrea, der sehr viel Übereinstimmungmit S. hypogacus Le-

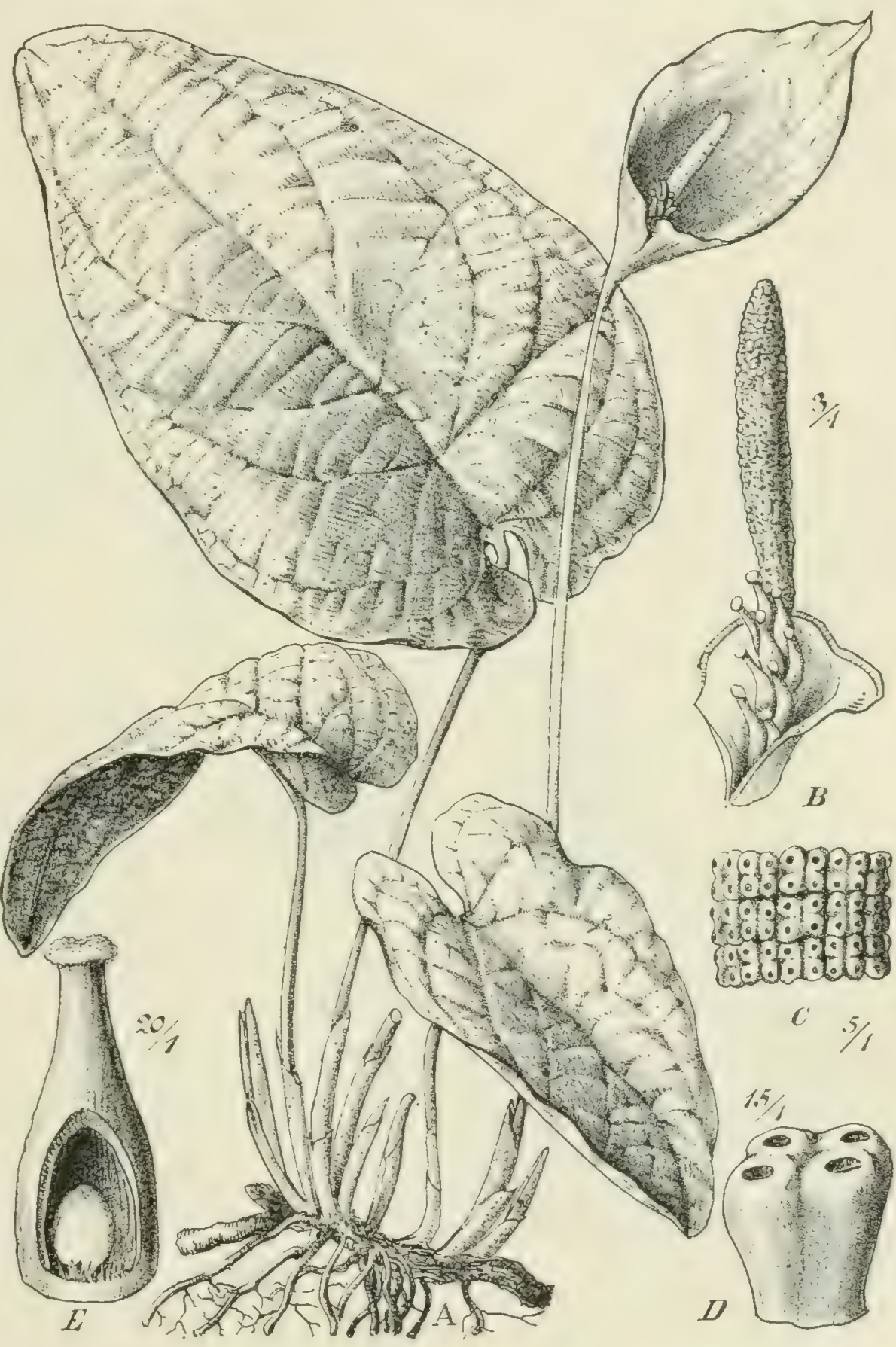

Fig. 172. Callopsis Volkensii Engl. (Ostusambara). A ganze Pflanze, n. Gr.; $B$ Inflorescenz, nach Entfernung eines Teils der Spatha; $C$ Stiick der männlichen Inflorescenz; $D$ ein Staubblatt; $E$ weibliche Blüte oder Pistill geöffnet. - Original. prieur zeigt, welcher in Senegambien gefunden wurde und seine Inflorescenzen gleichzeitig mit den Blättern hervorbringt.

Callopsis Engl. Eine endemische monotypische Gattung mit C. Tolkcnsii Engl. (Fig. I72), aus deren kriechendem Rhizom gestielte, herzeiförmige Blätter mit $8-\mathrm{I} 2 \mathrm{~cm}$ langen Spreiten und Inflorescenzen mit schneeweißer 
eiförmiger Spatha entspringen. Der kleine kurze Kolben ist mit seinem weiblichen Teil der Spatha angewachsen. Diese zierliche Pflanze tritt oft massenhaft in der unteren Regenwaldregion Ostusambaras von 600-goo m auf. Von Prof. Precss wurde die Pflanze auch lebend aus Kamerun eingesendet; aber Herbarexemplare habe ich von dort nicht gesehen.

Sauromatum Schott. Von dieser durch fußförmige Blätter, -eine unten geschlossene, nach oben lang verschmälerte Spatha und langen dünnen cylindrischen Kolbenanhang, sowie durch lange keulenförmige Pistillodien

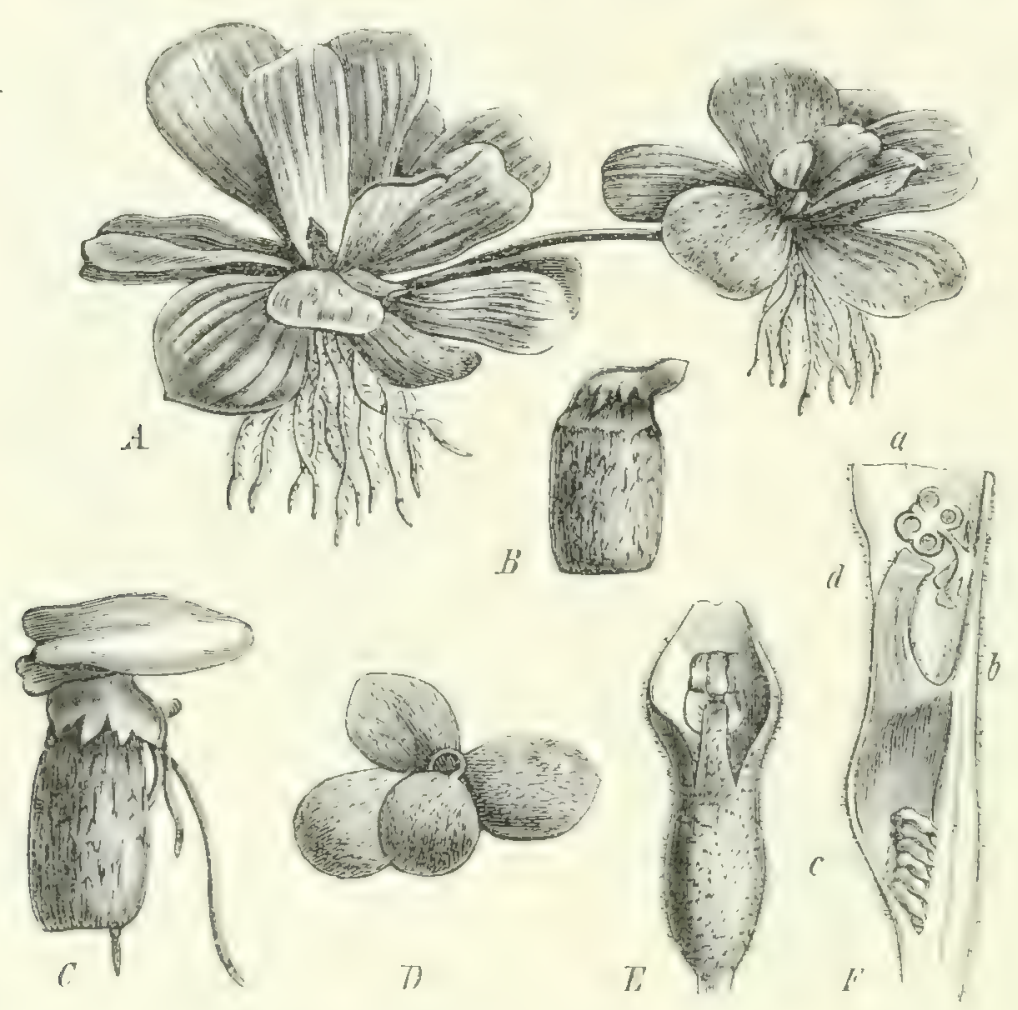

Fig. I73. Pistia stratiotes L. $A$ ansgewachsene Pfanze, ${ }^{\top} / 3 \mathrm{n}$. Gr., links blühend, mit einem Ausläufer; $B$ Same mit dem austretenden Keimling; $C$ Keimpflanze mit zwei Laubblättern und den ersten Wurzeln, stark vergr.; $D$ junge Pflanze in nat. Gr.; $E$ Spatha von vorn, zweimal vergr.; $F$ Spatha und Kolben im Längsschnitt, $a$ Quirl der ô Blüten, deren Antheren sich mit zwei an ihrem Scheitel befindlichen, der Kolbenachse parallelen Spalten öffnen, $b$ Manschette oder Ring von sterilen Blütenanlagen gebildet, $c$ Placenta der 우 Blüte mit zahlreichen Samenanlagen, $d$ Griffelkanal und Narbe. - Original aus den Nat. Pflanzenfamilien.

zwischen weiblicher und männlicher Inflorescenz ausgezeichneten Gattung; welche im westlichen und mittleren Himalaya, sowie in Sumatra durch je eine Art vertreten ist, kennen wir auch eine Art aus den afrikanischen Gebirgen; S. mulicum Schott, mit keulenförmigen Pistillodien, fundet sich insbesondere in der Erythrea und in Ober-Sennar von 500-rooo m, ferner am Kilimandscharo, bei Marangu um $1500 \mathrm{~m}$ und im südlichen Nyassaland; etwas abweichend nit fadenförmigen Pistillodien in Angola bei Ambaca in Felsspalten um $1000 \mathrm{~m}$ ï. $\mathrm{M}$.

Arisaema Mart. Diese Gattung ist im tropischen, subtropischen und temperierten Asien besonders formenreich; in Afrika findet sie sich nur nördlich des Äquators mit zwei bis drei Arten. A. enncaphyllnnn Hochst., mit fünf bis 
ncun radiär angeordneten lanzettlichen Blattsegmenten, knmmt in der abyssinischen Provinz Semen bei Enschedeap vor; das ihr sehr ähnliche, durch scharf gezïhnte Blättchen ausgezeichnete 4 . Schimperimm Schott findet sich ebenda und steigt bis $2700 \mathrm{~m}$ auf. A.mitnarimm N. E. Brown rom Rumenzori aus einer Höhe von $2300-2600 \mathrm{~m}$ ist noch unsicher. Eine Art wurde neuerdings auch von Dr. Mndbril: in den Hochwäldern am Kiw-See gefunden.

Pistia stratiotes L. (Fig. I73, die bekannte schwimmende Aracee, welche sich nach Art eincr Stratiotes und Flubocharis massenhaft durch Ausläufer und auch durch Samen rermehrt, ist wie in allen tropischen Ländern so auch im ganzen tropischen Afrika von Senegambien und Sennar südwärts bis zum Sambesi und Kasai in stehenden Gewässern und auch an Flußufern verhreitet, oft große Flächen mit ihrem graugrünen Laub bedeckend.

\section{Lemnaceae (Wasserlinsen).}

Die bekannten Wasserlinsen, über deren morphologische und hiologische Verhïltnisse, welche hier nicht behandelt werden sollen, man Ausfuhrliches in den Nat. Pflanzenfam. II. 3. S. I $5+$ - IC + findet, sind in stehenden Gewässern ron ganz Afrika verbreitet, tragen aber wegen ihrer geringen Dimensionen kaum etwas zur Physiognomik der Gewässer bei, da sie in diesen meist zwischen anderen Tasserpflanzen rorkommen, nicht wie in kleineren Tümpeln der gemäßigten Zone oft allein herrschend. Jedoch ist Thilffur cylimiracer Hegelmaier in Angola in felsigen, reines Trinkwasser enthaltenden Becken ohne Begleitpflanzen gefunden worden. Auch sind sie ron nur wenigen Sammlern beachtet, und was gesammelt wurde, harrt noch grindlicher Durcharbeitung. Sicher dürte aber ein erneutes Studium dieser Pfänzchen in Afrika noch manches Neue ergeben. Alle in Europa rorkommenden Limncr, sowie Sfrirdela polymhizi Schleid. sind auch in den Nilländern konstatiert worden. Ferner ist Lcmma fancicostater Hegelmaier ron der Erythrea bis Quelimane und Angola verbreitet, L. acquinoctialis Welw. im Ghasalquellengebiet, in Uganda und Loanda nachgeriesen. Außer der in Deutsch-Ostafrika, Angola und Benguela aufgefundenen $\|_{0}$ lffur artiza (L.) Wimm. kennt man noch vier Arten dieser Gattung aus dem tropischen Afrika, ron denen II: Hïliztsiliz Hegelmaier auch im tropischen Amerika vorkommt.

\section{Fam. Flagellariaceae.}

Von dieser kleinen Familie findet sich nur eine Art, welche durch beistehende Abbildung charakterisiert ist, in Afrika. Es ist dies Flagchlaria ination L. var. glinccusis (Schumach.) Engl. (Fig. I 7 t, wie dic im tropischen Asien verbreitete $F$. indica L. eine hochkletternde Pflanze mit duinnen İsten und Rankenbläıtern. Die afrikanische Varietät unterscheidet sich von der Monsunpflanze durch gespaltene Blattscheiden und dünne, zickzackartig gebogene $̈$ stchen der Inflorescenz. Die kleinen Bliiten sind äußerlich denen eines Fumus ähnlich und stehen in großen Rispen. Die kugeligen Steinfriichte enthalten meist 
cinen, selten zwei Samen mit kleinem, linsenförmigem Embryo. Diese Art finclet sich ganz besonders häufig in den Küstengebüschen, in Westafrika von der Goldküste bis Ambriz in Angola, in Ostafrika von Mombassa bis zum Pondoland. Im inneren Afrika wurde sie bis jetzt nur wenig beobachtet.

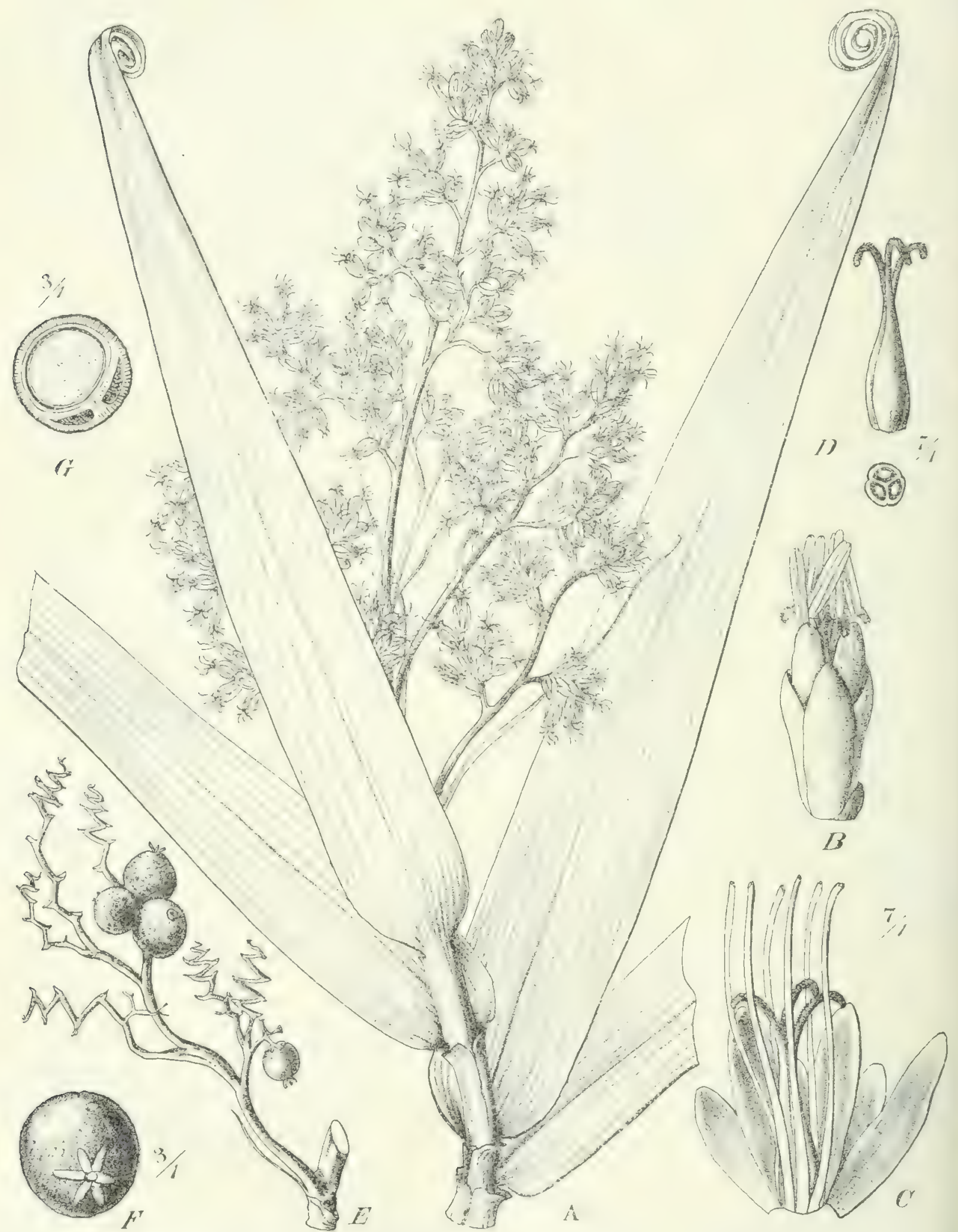

Fig. I74. Flagellaria indica L. var. guineensis (Schumach.) Engl. $A$ blühender Zweig, n. Gr.; I) Hlite; (' dieselbe geüfnet, mit Weglassung der Intheren: I) I'istill; I: Zweig des Fruchtstandes; $F$ Frucht, vergr.; $G$ Querschnitt durch dieselbe. 


\section{Fam. Restionaceae.}

Diese Familie ist der südlichen Hemisphäre eigentimlich und wie noch einige andere derartige besonders reich im südwestlichen und siidlichen Kapland entwickelt. Es sind morphologisch und systematisch sehr interessante Pflanzen vom Habitus der Gräser und Cyperaceen. Aber so wenig eine besonders enge Verwandtschaft zwischen den beiden genannten großen Familien besteht, ist eine solche zwischen den Restionaceen und einer der genannten vorhanden. Sie haben nur das mit den genannten Familien gemein, daß ihre auf Windbestäubung cingerichteten Bliten in den Achseln dichtstehender Decliblätter stehend Ährchen bilden, welche in mannigfacher Weise zu zusammengesctzten Blütenstünden rereinigt sind; auch kommen sie gesellig wie die Gräser und Cyperaceen vor und nehmen im südkaplïndischen Vegetationsbild oft die Stelle der Gräser ein. Ihre Bliiten sind aber mit Bliitenhüllen versehen, meist diöcisch, und die weiblichen enthalten in dem ein- bis dreifïcherigen Fruchtknoten cine geradläufige, hängende Samenanlage, in der sich später cin linsenfürmiger, dem mehligen Endosperm anliegender Embryo entwickelt. Man muß also über vieles oberflächlich hinwegsehen, wenn man von den Restionaceen, einem ausgesprochen australen Typus, die Gramineen ableiten will. Wie mehrere der australen Familien, so sind cie Restionaceen außer in Südafrika auch in Australien und Neu-Seeland und im südlichen Chile (hier freilich nur spärlich/ vertreten und weisen damit auf einen siidpolaren Ursprung: hin. Wir kennen gegenwärtig ungefähr 250-260 Arten, von denen 190 in ${ }_{13}$ Gattungen im südlichen und namentlich südwestlichen Kapland vorkommen. vielfach als wesentliche Bestandteile offener Formationen, aber auch in Gebüschen, bisweilen über $2 \mathrm{~m}$ hoch, vielfach auch interessant durch die große Verschiedenheit der männlichen und weiblichen Pflanzen. In Suidwestafrika haben einige Arten die Kamier-Berge fast unter $3 \mathrm{C}^{11} \mathrm{~s}$. B. erreicht; im Südosten ist der in südlichen Kapland häufige Lifteimpus foniculatus Rottb. Mast. nach Natal gelangt, wo er in einem felsigen Tal nahe bei den BeraanFällen vorkommt. Andere Arten sind unsicher für Natal. Noch interessanter ist aber, daß im südlichen Nyassaland, auf dem NIt. Zomba, eine bisher noch nicht bekannte Art, Hypolacha . Whanii X. E. Brown, aufgefunden wurde. Dieses verhältnismäßig weit gegen den Iquator vorgeschobene Vorkommen unter $15^{\circ} \mathrm{s}$. Br.j findet sein Analogon in dem Vorlommen eines Liptecartus in Cochinchina. Es ist uibrigens zu beachten, daß gerade die Gattungen Hyolumen und Liftocurpus, welche in Ostafrika vorgedrungen sind, die auch außerhalb Afrikas am weitesten verbreiteten Gattungen der Familie sind. Hyfolacrid findet sich auch in Australien, Tasmanien und Neu-Seeland. Leftocurfus ebenfalls in Australien, Tasmanien und Neu-Seeland und auch in Chile.

\section{Fam. Mayacaceae.}

Eine kleine interessante Familie von Wasserpflanzen, welche bis vor einigen Jahren uns nur aus Amerika bekannt war, enthält auch eine Art, Mayaca 
Frnmii Gürke Fig. I 75), welche in Benguela vorkommt. Wie die Abbildung zeigt, trägt dieser Hydrophyt an dünnem, wenig verzweigtem Stengel dünne linealische Blätter und in einzelnen Blattachseln eine bis drei langgestielte Bliiten,

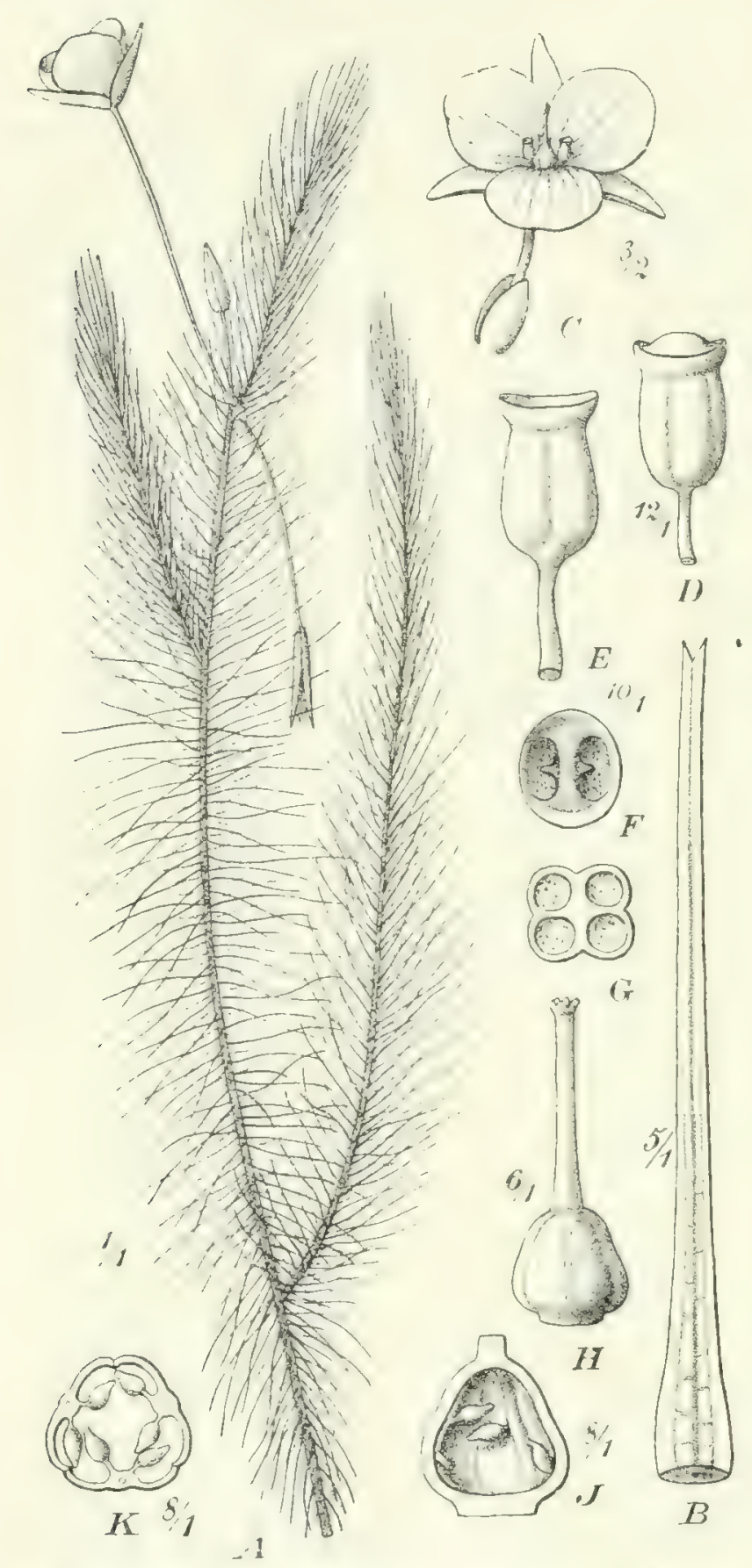

lig. I75. Mayaca Irammii Gürke (Benguela). A oberes Stuick der Pflanze; $B$ Blatt; $C$ Blitte mit zwei Vorblättern am Grunde; $D$ Staubblatt jung; $E$ dasselbe älter; $F$ Scheitel der Anthere; $G$ Querschnitt derselben; I/ Pistill; 7 Iängaschnitt durch den Fruchtknoten; $K$ Querschnitt. - Original. welche so wie die der folgenden Familie Kelch und Blumenkrone besitzen, doch sind die zarten weißen Blumenblätter getrennt. Nur die drei vor den Kelchblättern stehenden Staubblätter sind entwickelt und öffnen sich durch eine Pore am Scheitel. Der Fruchtknoten enthält an drei wandständigen Placenten je eine Samenanlage. Die Frucht ist wie bei der folgenden Familie eine dreiklappige Kapsel. Die interessante Pflanze findet sich an ruhigen Stellen des Flusses Quiriri bei Sakkemecho um I $200 \mathrm{~m}$ ü. M., woselbst sie im Jahre Igoo von Herrn Baum, dem Botaniker der Kunene-Sambesi-Expedition, entdeckt wurde. Sie steht der brasilianischen $M$. longipes Mart. am nächsten.

\section{Fam. Xyridaceae.}

Eine kleine, in den wärmeren Ländern der Erde verbreitete Familie von Hydrophyten. Mehrjährige Kräuter mit langen, linealischen oder lineal-lanzettlichen Blättern, mit achselständigem Blütenschaft und endständiger Ähre, deren dachziegelig sich deckende, oft braun gefärbte Hochblätter in ihren Achseln eine dreigliedrige heterochlamydeische Blüte tragen. Der Kelch derselben besteht aus zwci kleineren seitlichen und einem größeren Blatt; die weiße, gelbe oder blaue Blumenkrone ist verwachsenblättrig; mit einer Röhre, welcher drei vor den Blumenblättern stehende fertile Staubblätter angewachsen sind, während dic drei äußeren Staubblätter zu Staminodien umgewandelt sind oder fehlen. Der Fruchtknoten ist einfïicherig 
Farinosae. - Xyridaceae.

und besitzt drei wandständige oder von unten frei aufsteigende Placenten mit zahlreichen kleinen geradläufigen Samenanlagen; er entwickelt sich zu einer Kapsel mit drei Klappen, welche auf ihrer Mittellinie die Samen tragen.

Wir kennen etwa 33 Arten, welche in Afrika an feuchten Plätzen sehr zerstreut sind und häufig mit Eriocculon zusammen vorkommen. Die verbreitetste Art ist $X$. capensis Thunb. (Fig. I $76 A_{\curvearrowleft}-\mathcal{F}$ ), welche schon in Abyssinien vorkommt, auch in DeutschOstafrika und Benguela gefunden wurde und über die Sambesi-Fälle, die Magalisberge und Tembuland bis Tulbagh und Wynberg im Kapland verfolgt werden kann. Meistens findet sie sich in größerer Höhe oberhalb II00 $\mathrm{m}$. Eine andere, größere und durch zusammengedrückten Stengel ausgezeichnete Art, mit gelben Blüten, $X$. anceps Lam. (Fig. $176 \mathrm{~L}$ ), ist von Sierra Leone bis zum Kongo und von Sansibar bis Natal beobachtet worden. Eine sehr kräftige Art mit $6-7 \mathrm{dm}$ langen Blütenschäften ist $X$. decipiens N. E. Brown von Sierra Leone und Angola. Auch X. batokana N. E. Brown von Nord-Rhodesia wird fast ebenso hoch, desgleichen $X$. Hildebrandtii

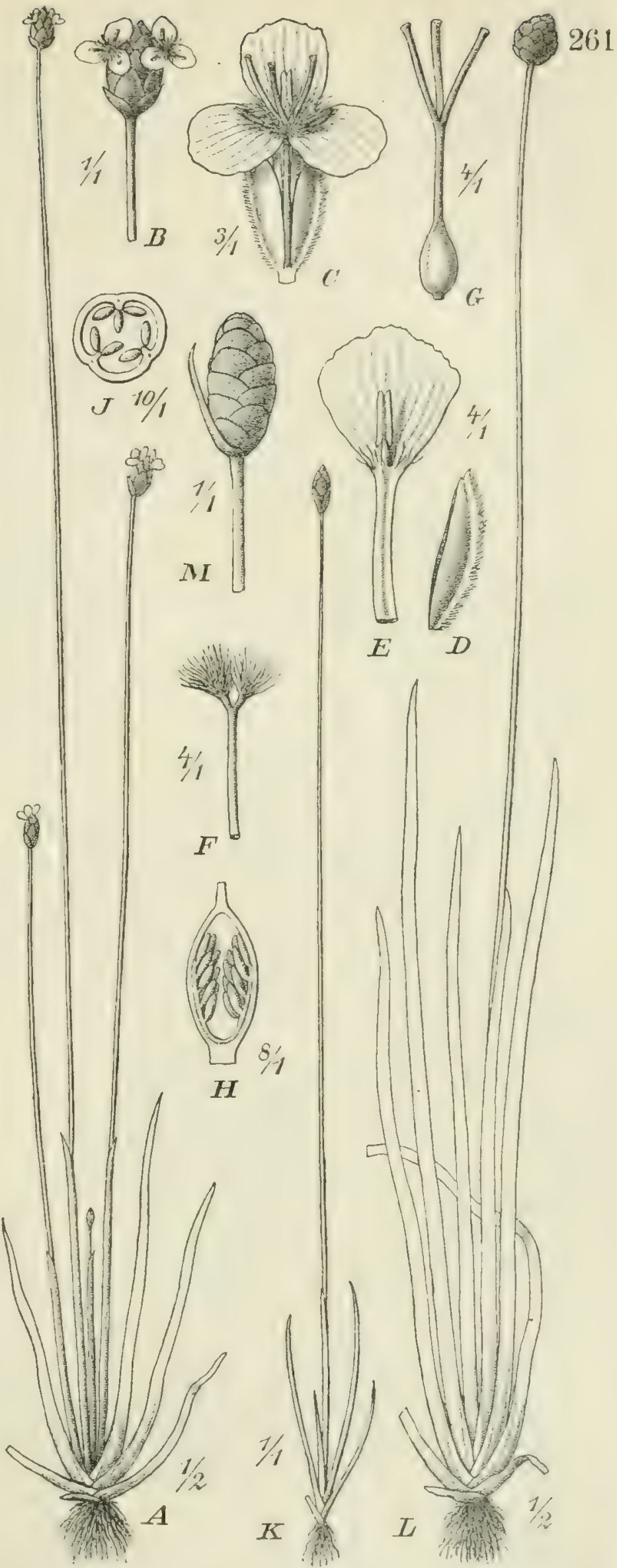

Fig. 176. Xyris. A- $\mathcal{Z} \mathrm{X}$. capensis Thunb. (Bukoba, Ostafrika). $A$ ganze Pflanze; $B$ Blütenkopf; $C$ Blïte; $D$ Kelchblatt; $E$ Blumenblatt; $F$ Staminodium; $G$ Pistill; $H$ Längsschnitt durch den Fruchtknoten; $\mathcal{F}$ Querschnitt. $K \mathrm{X}$. filiformis Lam. (Sierra Leone). $L \mathrm{X}$. anceps Lam. (Pondoland). $M \mathrm{X}$. Hildebrandtii Nilss. (Südl. Nyassaland), Blütenstand. 
Nilss. (Fig. I $-6 M$ ), welche von Madagaskar iiber das nördliche und südliche Nyassaland bis Angola und Benguela verbreitet ist. Von den übrigen 28 Arten kommen die meisten auf den Westen und zwar allein neun Arten auf die hier und da buschigen Hochplateau-Sümpfe Benguelas, drei andere auf Angola, zwei auf das Kongogebiet, eine auf das Kamerungebiet, fünf auf das Nigergebiet und Sierra Leone. Bei der großen Artenzahl von Benguela kommen nicht bloß die für Xyris günstigen Standortsverhältnisse in Betracht, sondern auch der Umstand, daß IVELITSSCI mehr als andere Botaniker auch kleine, unscheinbare Pflanzen beobachtete. Vom Nyassaland kennen wir etwa fünf, vom Maschonaland eine und von Sansibar eine Art, . I. Inmilis Kunth, welche auch auf Mauritius und Madagaskar vorkommt. Es ist also die Gattung bis jetzt besonders reichlich im westlichen Afrika entwickelt.

\section{Fam. Eriocaulaceae.}

Diese interessante, in den meisten wärmeren Ländern der Erde vertretene Familic enthält meist auf feuchtem, sandigem Boden oder in Sümpfen gesellig wachsende Pflanzen, von denen manche im tropischen Amerika vorkommende über I $\mathrm{m}$ Höhe erreichen, während andere, darunter auch einige afrikanische, nur einige Zentimeter hohe Zwergpflänzchen sind. Habituell erinnern sie an Cyperaceen, fallen aber immer durch ihre nit einem Hüllkelch versehenen, am linde von Schïften stchenden Blütenliöpfchen auf, welche denen der Compositen durchaus analog sind. Die Blïtenhüllen sondern sich in Kelch und eine meist verwachsenblättrige und trockenhäutige, bisweilen fehlende Blumenkrone. Von den sechs Staubblättern der männlichen Bliiten fehlen meist die äußeren. Der Fruchthnoten cker weiblichen Bliiten ist zwei- bis dreifächerig, in jedem Fach mit ciner geradläufigen, hineinhängenden Samenanlage; der Griffel besitzt meist drei einfache oder gespaltene Schenkel. Bisweilen sind die randständigen Blüten zygomorph. Die Blütenköpfchen machen, wie es scheint, immer erst einen männlichen und dann weiblichen Zustand durch, d. h. die Staubblätter stäuben aus, bevor die Narben empfängnisfihing sind. Die Früchtchen sind fachspaltige Kapseln, die Samen klein, mit linsenförmigem Keimling am Mikropylende. Zu beachten ist, daß an der Schale der kleinen Samen die langgestreckten, dünnwandigen Zellen der äußeren Schicht zum Teil zerstört werden und Haaren ähnliche Reste von verdickten Wandpartien bisweilen zurückbleiben und die Samen behaart erscheinen lassen. Diese falschen Haare diurften vielleicht auch etwas zu' Verbreitung der Samen beitragen, obwohl im allgemeinen anzunehmen ist, dal3 dieselben vorzugsweise mit Erde den Füilen der Wasservögel anhaftend ron diesen verschleppt werden. Die in Amerika besonders stark entwickelte Familic ist in Ifrika nur mit drei Gattungen vertreten, wclche sich folgendermaßen sondern:

A. Staubblätter doppelt soviel als Blumenblatter: diese innen an der Spitze mit einer Driise.

a) Blumenblätter aller Bliiten frei

Eriocaulon. 
b) Blumenblätter der $\circlearrowleft \widehat{~ B l i ̈ t e n ~ i n ~ e i n e ~ t r i c h t e r f o ̈ r m i g r e ~ R o ̈ h r e ~ v e r e i n i g t, ~ d i e ~ d e r ~} O$ Blüten unten frei, im übrigen mit den Rändern verwachsen . . . . . . . . Mesanthemum.

B. Staubblätter ebensoviel wie Blumenblätter; diese ohne Drüsen. Die Blumenblätter am Grunde und an der Spitze frei, in der Mitte verwachsen

Syngonanthus.
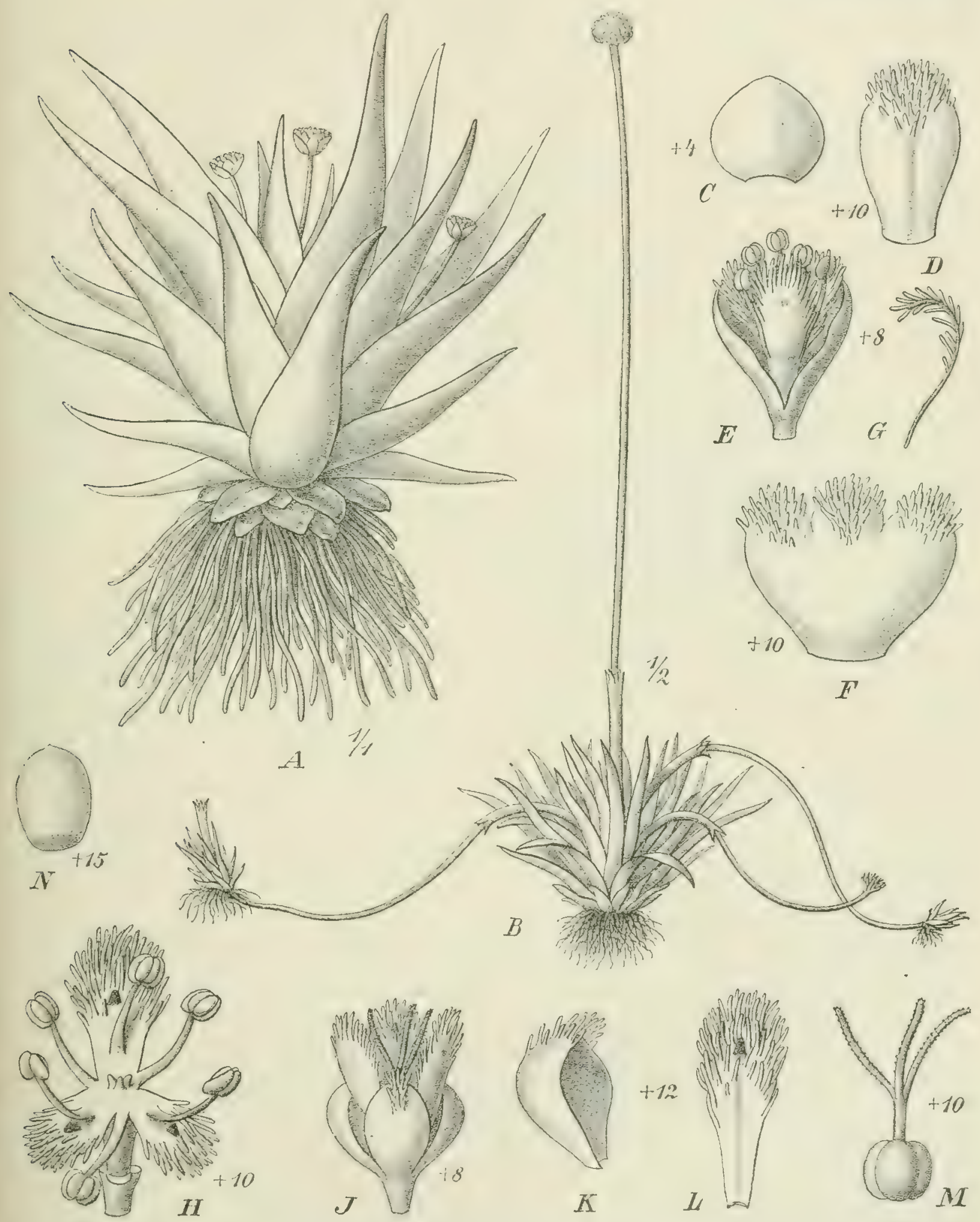

Fig. 177. A Eriocanlon Volkensii Engl, vom Kilimandscharo. $B-N$ E. Woodii N. E. Brown. $B$ Habitus; $C$ Hüllblatt; $D$ Deckblatt; $E$ ơ Blïte; $F$ Kelch der ô Blïte; $G$ Längsschnitt durch denselben; $H$ of Bluite nach Entfernung des Kelches; $\mathcal{F}$ 우 Blite; $K$ Kelchblatt derselben 2. Blumenblatt derselben; $M$ Pistill; $N$ Same. - Nach RuHLAND. 
Eriocaulon L. Wir kennen aus Afrika 44 Arten, von denen die nördlichsten in Senegambien (drei) und Abyssinien (zwei) vorkommen; von diesen ist das etwa I dm hohe $E$. abyssinicum Hochst. der Hochebenen von Tigre und Shire auch im Somerset-Distrikt des südöstlichen Kaplandes zugleich die suidlichste Art. In Südwestafrika ist den hydrophilen Eriocanlon, welchen in dem moorigen Hochland von Benguela noch eine besonders rciche Entwicliung gestattet ist, durch die meist herrschende Trockenheit des Bodens eine Schrarke gesetzt; wir finden da das in Natal und Griqualand vorkommende I: africamm Hochst. noch am Watersberg im nördlichen Hereroland. Die Eriocanlon treten zwar nur in hydrophilen Formationen auf; aber sic herrschen in denselben nicht allein, sondern wachsen gemeinsam mit anderen kleinen hydrophilen Pflanzen

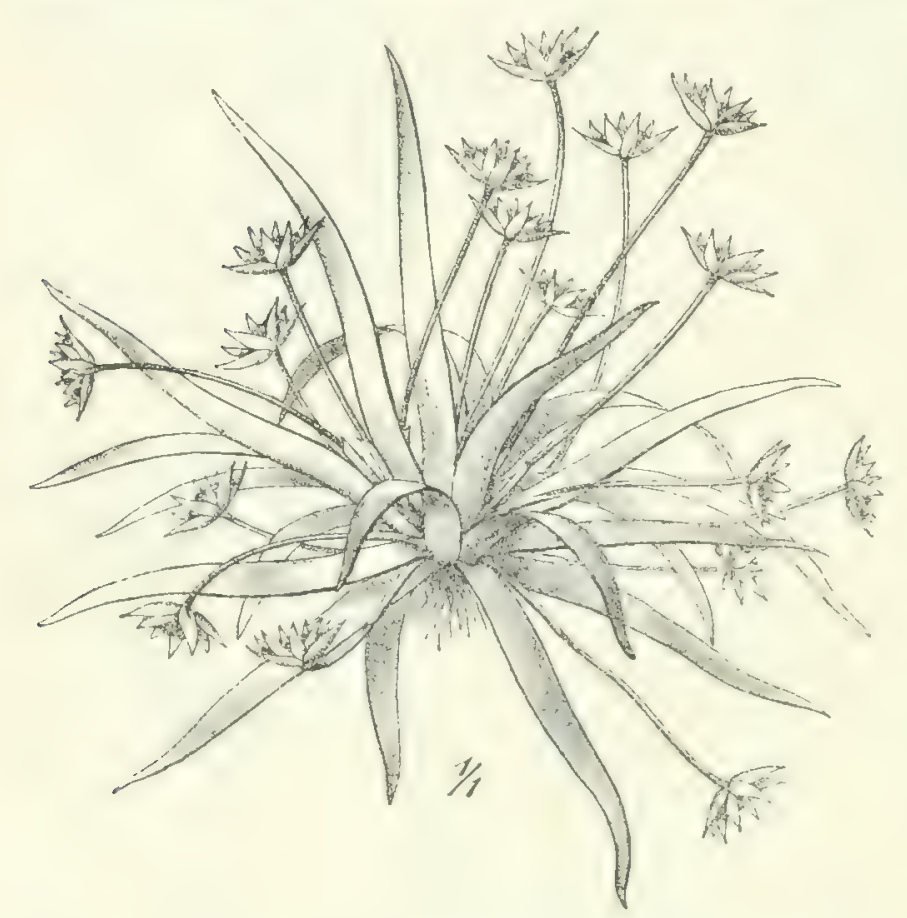

Fig. I78. Eriocaulon xeranthemoides van Heurck et Miill. Arg. — Nach Ruhland.

an den ihnen zusagenden Standorten. Es liegt dies daran, daß nur wenig Arten, wie $E$. Woodii N. E. Brown (Fig. I $77 B-N^{\top}$ ) und E. stolonifem Welw. (in kalten Gebirgsbächen Benguelas), Ausläufer oder überhaupt Sprosse mit etwas längeren Seitenachsen bilden. Einige Arten wachsen untergetaucht im Wasser; diese haben einen mehr gestreckten Stengel mit abstehenden linealischen fadenförmigen Blättern und dünnen, langen Stielen der Blütenköpfchen, so namentlich $E$. submersm Welw. in Benguela, von welchem sogar behauptet wird, daß es unter dem Wasser blühe. Ähnlich verhält sich E. bifistulosum van I Icurck et Müll. Arg., im Nigergebict und im Ghasalquellengebiet. Eine große Zahl bildet dichte Büschel von sehr rerschiedener Größe. Einige sind ganz winzige Pfänzchen, wie die in Fig. I79 abgebildeten E. pumilum Afzel. (Fig. I $79 E-N$ ) in Sierra Leone, E. longipetalum Rendle (Fig. I79 B, C) in

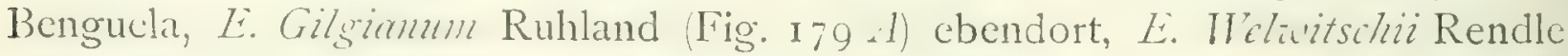
in Angola, E. xeranthemoides van Heurck et Müll. Arg. (Fig. I78) in Sierra Leone und E. subulatum N. E. Brown an den Viktoria-Fällen des Sambesi. Diese kleinen Arten wachsen meist auf sandigen, zeitweise überschwemmten Plätzen, gern auch in flachen Mulden der Felsen, in welchen das zeitweise iiberflutende Wasser etwas Grus angesammelt hat. Auf sumpfigen Wiesen kommen größere Arten vor, von denen E. lactum Rendle mit $6 \mathrm{dm}$ langen Blütenschäften wohl die stattlichste Art ist; sie wächst auf den Plateaus von Benguela, im Mashonaland und im Norden des Nyassa-Sees. Durch breite linealische Blätter zeichnen sich aus E. latifolim Smith in Sierra Leone, E. Sclimpori 
Koern. am Djan Meda in Abyssinien um $2800 \mathrm{~m}$ und $E$. mesanthenoides Ruhl. auf dem Lukwangule-Plateau in Uluguru. Diesc Art bildet auch große Polster von ${ }^{\mathrm{I}}={ }_{\mathrm{m}}$ Durchmesser, und die Bliitenschäfte werden auch 5 dm lang. Am höchsten steigt auf $E$. Thlkwsii Engl. (Fig. I-7. I am Kilimandecharo um 3000-3200 m, in feuchten Senkung 11 geschlossene rasige Masson bildend, mit lanzettlichen, nur 3-6 dm langen, am Grunde aber $1, \$ \mathrm{~cm}$ breiten und nach ohen sich verschmälernden Blättern und $3-5 \mathrm{~cm}$ langen Bliitenschäften.
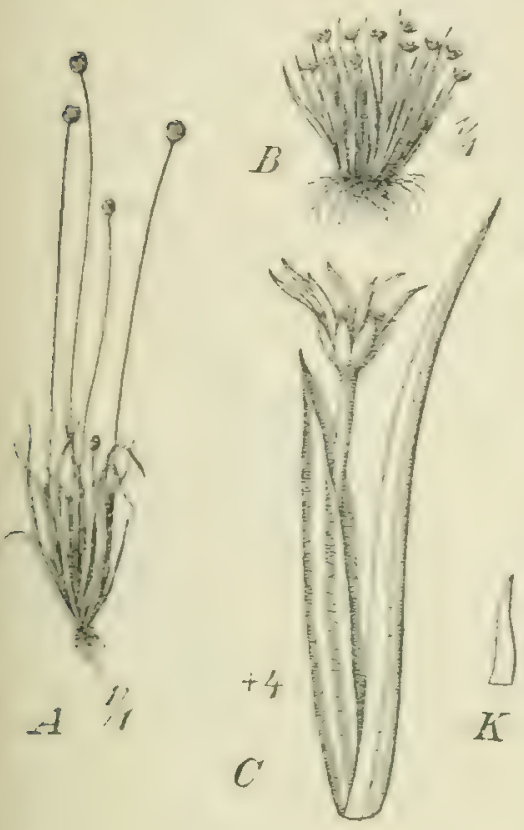

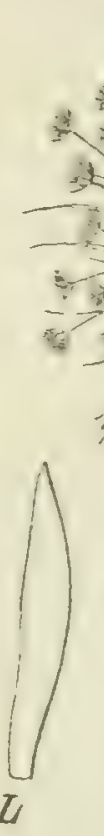

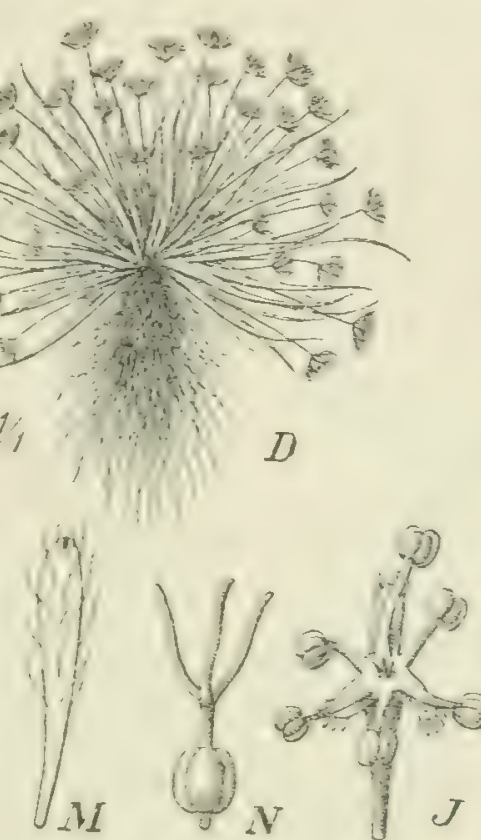

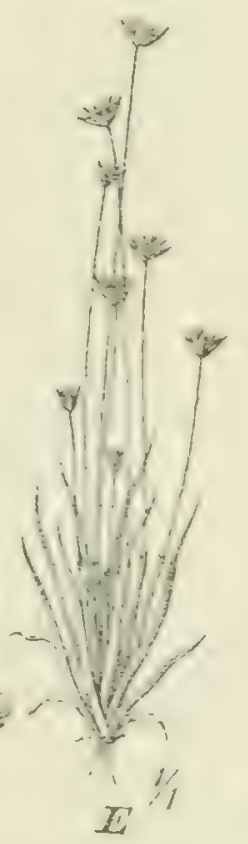

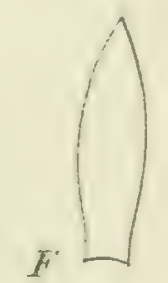
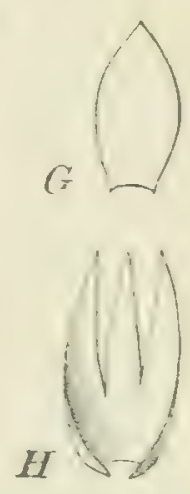

Fig. I79. $A$ Eriocaulon Gilgianum Ruhland. $B, C$ E. longipetalum Rendle. $B$ ganze Pflanze; $C$ Blütenschaft, viermal vergr. $D E$. Welwitschii Rendle. $E-N$ E. pumilum Afzel. $E$ Habitus; $F$ Hüllblatt; $G$ Deckblatt; $H$ Kelch der ơ Blüte; $f$ ơ Blüte nach Entfernung des Kelches; $K$ hinteres Kelchblatt der $O$ Bliite; $L$ seitliches Kelchblatt derselben; $I /$ Blumenblatt; $N$ Pistill.

Mesanthemum Koern. Von dieser Gattung finden sich zwei Arten in Madagaskar und zwei auf dem afrikanischen Kontinent. Sie sind habituell den breitblättrigen, zuletzt erwahnten Arten der vorigen Gattung ähnlich. II. Prescottionum Bong.) Koern. in Sierra Leone zeichnet sich durch kahle Tragblïtter der Bliiten aus, während das auch in Sierra Leone vorkommende M. radicans Koern. von dichten, weißen Haaren besetzte Tragblätter besitzt. Letztere Art ist zunächst im tropischen Westafrika in dem sandigen Torland an feuchten Stellen sowie im Waldland an Sumpfrändern und Flußufern ron Senegambien bis Loango verbreitet; sodanin wurde sie im mittlerun Kongogebiet und in Benguela, oberhalb MIossamedes, am Laringua unweit des Longa, um II80 $\mathrm{m}$ ii. M. gefunden. Wichtig ist aber, dals sie auch bei Bukoba am Victoria Njansa vorkommt.

Syngonanthus Ruhl. ist eine im tropischen Suidamerika mit etwa io Arten auftretende Gattung; wir kennen aber auch aus Wrest- und Südafrika im ganzen vier Arten. Sie kommen alle südlich rom İquator, ziemlich zerstreut, ror: S. Wahlbergrii (Vikstr.) Ruhl., ein bis I,2 dm hohes Pfänzchen an Südabhängen 
der Magalisberge und nördlich derselben in Sümpfen am Nylstrom, S. Wclaritschii (Rendle) Ruhl. in Benguela bei Huilla auf früher bebauten Feldern, S. Schlechteri Ruhl. in der Nähe des Stanley-Pool und S. Poggeamus Ruhl. bei Kimbundo unter $10^{\circ} \mathrm{s}$. Br. Letztere Art, welche $3 \mathrm{dm}$ lange Blïtenstengel besitzt, kommt brasilianischen Arten am nächsten, während die anderen, viel kleineren Arten mit keiner südamerikanischen näher verwandt sind. Sowohl die geringe Verwandtschaft dieser Formen mit südamerikanischen, wie auch das zerstreute Vorkommen der Arten im Innern ron Südafrika spricht durchaus gegen die Annahme einer "Einwanderung in jüngerer Zeit. Andererseits ist keincrlei engere Verwandtschaft mit den in der alten Welt rertrutenen Gattungen aufzufinden. So bleibt also nur die Annahme ehemaliger Verbindungswege zwischen Südamerika und Südafrika.

\section{Fam. Rapateaceac.}

Von dieser den Bromeliaceen nahestehenden Familie kannte man lange Zcit nur etwa 20 Vertreter im äquatorialen Amerika, in der Hylaea. Durch DinistaGe wurde aber eine neue Gattung bei Gran Bassa in Liberia entdeckt. Die Rapateaceen sind alle Sumpfpflanzen mit kurzem Stamm und langen, am Grunde scheidigen Blättern, deren Mittelnerv sich von der Spreite in eine der zusammengelegten Scheidenhälften fortsetzt. Während die amerikanischen Gattungen meist lange Blütenschäfte besitzen, hat die afrikanische Gattung Maschalocephahus Gilg et K. Schum. (Fig. I80) kurz gestielte Blütenstände in den Achseln der Blätter. Der Blütenstand ist mit zahlreichen Bracteen versehen und die Blüten besitzen eine lange, dünne Röhre von 3,5-4 cm Länge mit I $2 \mathrm{~mm}$ langen Abschnitten, sechs Staubblätter sind der Röhre angewachsen. Der dreifächerige Fruchtknoten enthält in jedem Fach eine aufrechte Samenanlage. Die Samen sind ellipsoidisch, mit weißer glatter Schale. Die einzige, bis jetzt bekannte Art, M. Dinklagci Gilg et K. Schum., wächst an sumpfigen, tiefschattigen Stellen der Urwaldreste des sandigen Vorlandes von Liberia.

\section{Fam. Commelinaceae.}

Diese in den Tropenländern reich entwickelte Familie umfaßt nur krautige Gewächse, von denen einzelne (Palisota) einen kräftigen, die meisten schwächere Stengel besitzen. Dieselben sind immer knotig, mit mehreren, meist saftigen, am Grunde scheidigen, parallelnervigen, häufiger kahlen, scitener behaarten Blättern besetzt. Hieran und an der in Kelch und Blumenkrone mit schr zarten, ungemein leicht welkenden Blumenblïttern gesonderten Blütenhülle sind diese Pflanzen leicht zu crkennen. Dagegen ist die Unterscheidung der Gattungen weniger leicht. Man achte vor allem auf die Staubblätter und das Verhalten der Frucht. Die Familie hat sich zunächst nach zwei Richtungen entwickelt, zur Gruppe der Iollicac mit nicht aufspringenden Pericarp und zu zwvei anderen Gruppen, bei denen die Kapsel mit zwei bis drei Klappen 


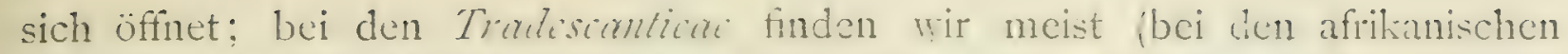
inmer sechs Staubblätter, bei dẹn Commilinia nur dẹe his zwei fruchtbare

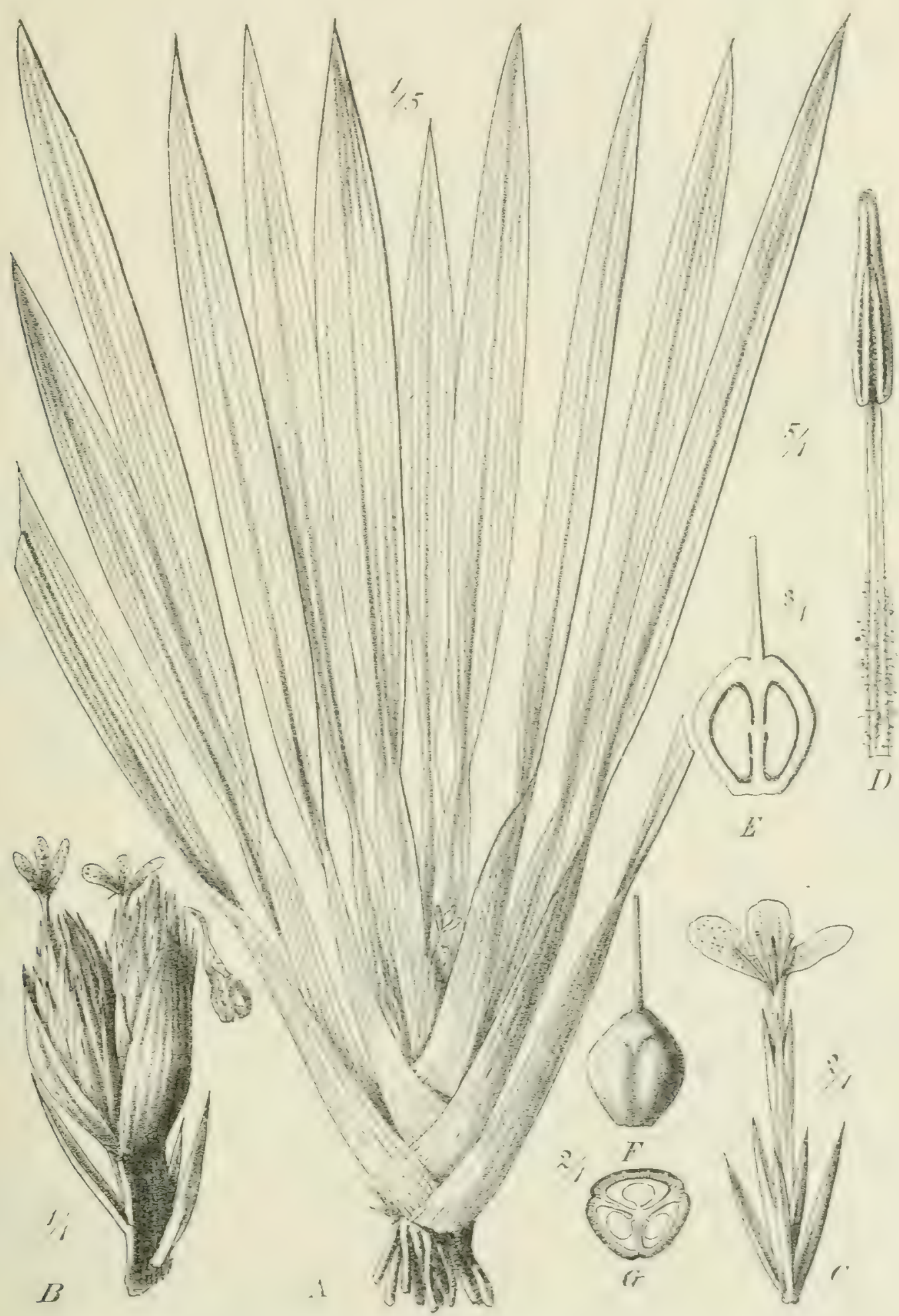

Fig. 180. Maschalocephalus Dinklagei Gilg et K. Schum. A ganze Pflanze, ${ }^{1} / 5$ n. Gr.; $B$ Blütenstand, n. Gr.; $C$ Bliite mit Bracteen; $D$ Staubblatt; $E-G$ Pistill. - Original.

Staubblätter, außerdem noch o- + Staminodien; doch ist zu beachten, daß bei den Pollieae auch nur drei fruchtbare Staubblätter vorkommen. 


\section{Übersicht der Gattungen.}

1. Frucht nicht aufspringend. Meist nur drei Staubblätter fruchtbar Pollieac. a) Blattränder unbehaart oder mit kurzen, krausen Haaren besetzt. Pericarp krustig, zerbrechlich

Pollia.

b) Blattränder mit Seidenhaaren besetzt. Pericarp saftig

Palisota.

B. Frucht eine zwei- bis dreiklappige Kapsel.

a) Sechs fruchtbare Staubblätter, selten fünf

Tradescanticac.

ic) Fruchtknoten dreifïcherig.

I. Samen 4-ro in jedem Fach. Lockere Rispe.

Buforrestia.

II. Samen 2-I in jedem Fach. Oft dichte Trugdolden.

I. Stiel des Blïtenstandes die Blattscheide durchbrechend. . . . Forrestia.

2. Stiel des Blïtenstandes die Plattscheide nicht durchbrechend.

* Staubblätter hypogyn

Cyanotis.

** Staubblätter mit der Röhre der Blumenkrone verwachsen. Coleotrype.

B) Fruchtknoten zweifàcherig; eine Samenanlage in jedem Fach . . . . Floscopa.

b) $3-2$ fruchtbare Staubblätter, $0-4$ Staminodien .... Commelineac.

(6) Blittenstände in der Achsel scheidenartiger Deckblätter.

I. Unfruchtbare Staubblitter mit kreuzfümigen Antheren. Fruchtknoten meist dreifücherig. . . . . . . . . . . . . . . Commelima.

II. Unfruchtbare Staubblätter mit linealischen, nur am Grunde verbundenen Thecis. Fruchtknoten zweifächerig.

Polyspatha.

B) Bliitenstände ohne scheidenartige Deckblätter.

I. Kelchblätter klein, stumpf.

Aneilema.

II. Kelchblätter groß, lanzettlich, spitz

Anthericopsis.

Man hat für die Ërkennung der Gattungen auch einigen Anhalt an der Art des Vorkommens, worauf in folgendem aufmerksam gemacht wird.

\section{Pollieae.}

Alle sind Pflanzen der Regenwälder, Hygrophyten.

Palisota Reichb., eine ausschlieBlich afrikanische Gattung mit Blättern, weiche am Rand rostfarbene, seidige Behaarung tragen, mit einer aus Trugdolden zusammengesetzten Rispe ziemlich kleiner, weißlicher oder schwach rosafarbiger oder bläulicher Blüten (Fig. I8I). Etwa elf Arten finden sich im tropischen IVestafrika, dic meisten nur im Kamerungebict (ink1. Fernando Po und St. Thomas), einige daruber hinaus; sie wachsen immer im Schatten auf humusreichem Boden; eine bis I $\mathrm{m}$ hohe Art, $P$. orientalis $\mathrm{K}$. Schum. findet sich in den Kegenwildern von Ostusambara. Von den westafrikanischen ist besonders zu beachten P. livrsuta (Thunb.) K. Schum. (Fig. I82) (= P. thyrsiflora Benth.), welche $\mathrm{I}-5 \mathrm{~m}$ hoch wird und die oberen, bis $3,7 \mathrm{dm}$ langen, I dm breiten Blätter fast quirlig zusammengedrängt zeigt; sic wurde zuerst von THunberG als Dracaena beschrieben; sie ist eine von Senegambien bis zum unteren Kongo verbreitete Urwaldpflanze, welche sich besonders noch durch zweireihig gestellte Samen von den anderen unterscheidet. Wie bei dieser Art sind die Blitenstiele am Grunde gegliedert auch bei der nur 3-6 dm hohen P. ambigua C. B. Clarke, auch im Westen von Lagos bis zum Kongo zerstreut. Bei cinigen anderen Arten mit beblätertem Stengel sind die Bluitenstiele nicht gegliedert, so auch bei $P$. Schwcinfurthii C. B. Clarke, welche von 


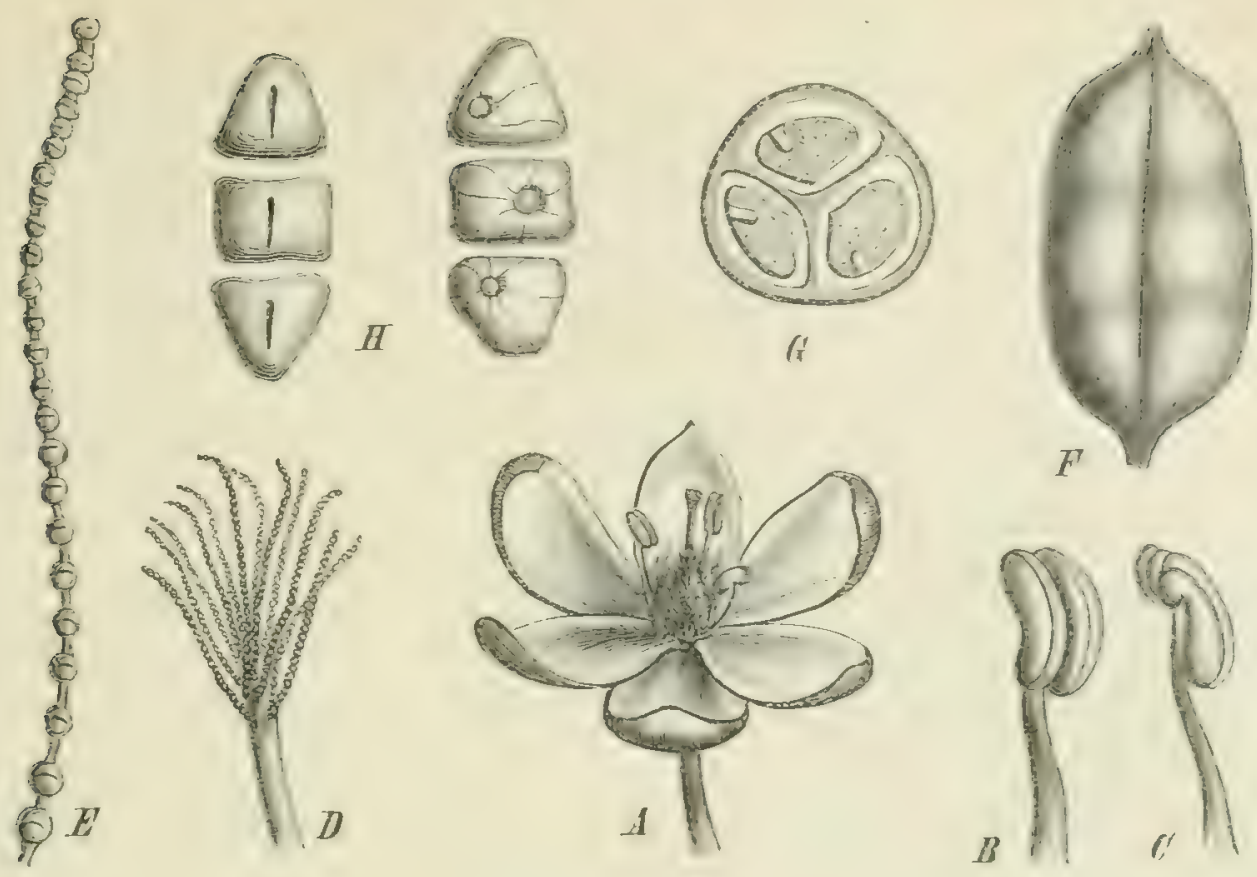

Fig. ISr. Palisota Barteri Hook. f. (Kamerun). A Blüte; $B, C$ Staubblatt; $D$ Staminodien vor den Kelchblättern; E Haar eines Staminodiums; F Frucht von P. ambigua (P. Benuv.) C. B. Clarke (Gabun); $G$ Querschnitt derselben; $H$ Same eines Faches von vorn und hinten.

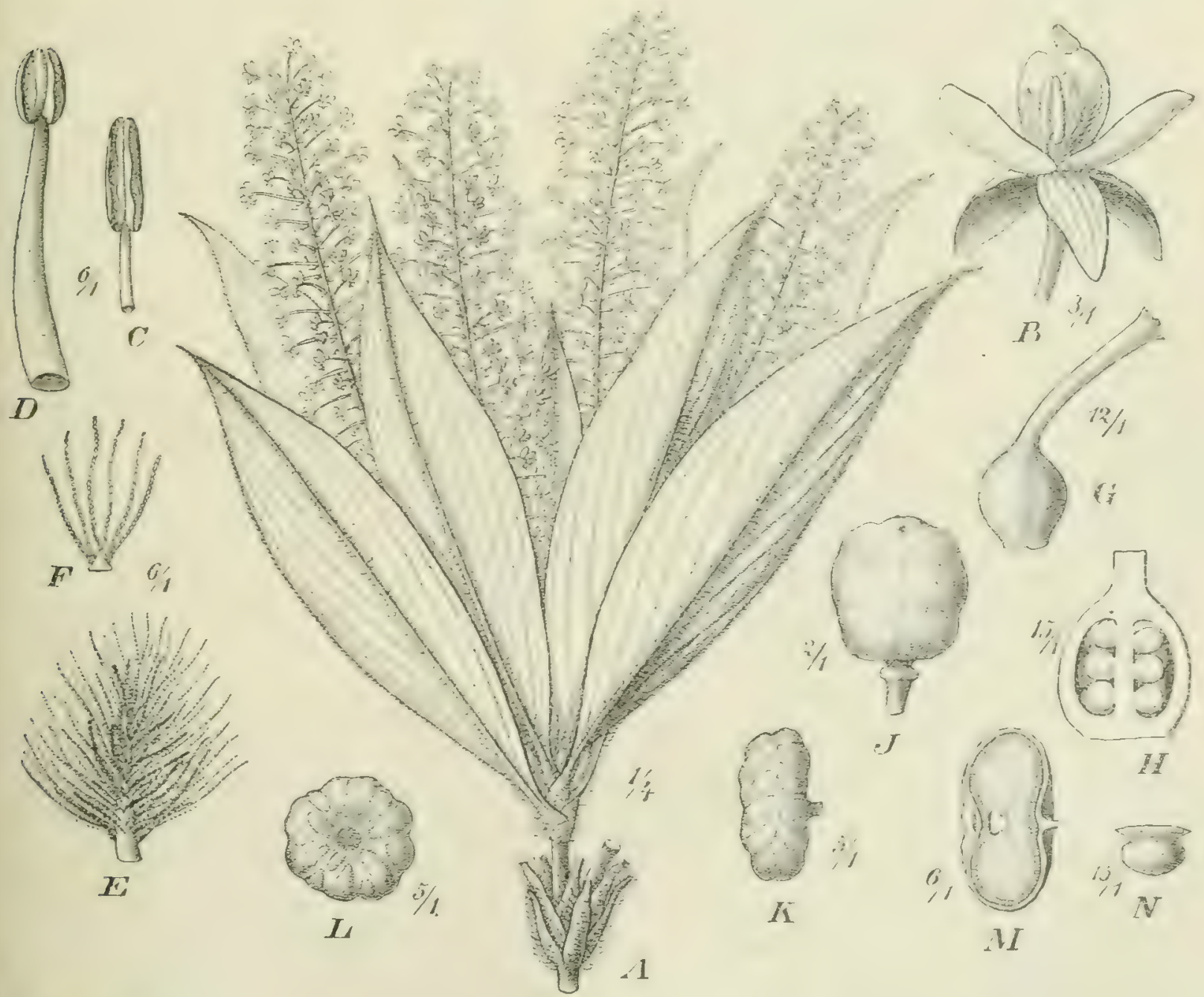

Fig. IS2. Palisota hirsuta (Thunb.) K. Schum. $A$ blühender Zweig; $B$ Blitte; $C, D$ Staubblätter; $E, F$ Staminodien; $G, H$ Pistill; 7 Kapsel; $K^{2}-M$ Same; $N$ Embryo. 
Gabuin bis Angola und uiber das obere Kongogebiet hinaus bis zum Ghasalquellengebict und Uganda angetroffen wird; sie wird $\mathrm{I}-2 \mathrm{~m}$ hoch. Drei andere Arten haben nur am Grunde große Blätter, weiter oben kleine, so I. bracteosa C. B. Clarke von Liberia bis Kamerun und St. Thomas (rooo bis $1500 \mathrm{~m}$ ) und P. Mamii C. B. Clarke auf dem Kamerunberge und Fernando Po (600-1000 m). Beide erreichen nicht 3 dm Höhe.

Pollia Thunb., auch außerhalb Afrikas vertreten, zählt hier nur vier Arten. Dic bis $2 \mathrm{~m}$ hohe I'. cuntinsente C. B. Clarke fundet sich ron Sierra Leone bis Angola und auch in Uganda, die kleinere $(6 \mathrm{dm}) P$. Manmii C. B. Clarke ist auf Kamerun und St. Thomas beschränkt. Zu diesen beiden längere Zeit bekannten Arten Westafrikas kommen noch hinzu P. brectenta K. Schum: und P. cyanocarpe K. Schum. von Uluguru, letztere auch in Ostusambara.

\section{Tradescanticac.}

Die Arten von Buforrestia und Forrestia sind Hygrophyten, die von Floscopa meist Hydrophyten, die Cyanotis zum Teil Xerophyten.

Buforrestia C. B. Clarke, erkennbar an der lockeren Blitenrispe und an den 4-10-samigen Fächern der Kapsel, ist eine der vielen auf Guiana (eine Art) und Afrika (zwei Arten) beschränkten Gattungen. B. Manini C. B. Clarke mit kahlen Kelchblättern wächst nur auf Fernando Po; $B$. imporforata C. B. Clarke mit klebrigen Kelchblättern, eine $5 \mathrm{dm}$ hohe Pflanze, ebenda, auf den Princes Inseln, von Sicrra Leone zerstreut bis zum Kongo und auch in Ostusambara.

Forrestia A. Rich., eine Gattung des Monsungebietes, ist von voriger durch gedränste Bliitenstände, welche die Blattscheiden am Grunde durchbrechen, und I--2samige Kapselfächer unterschieden; man kennt aber noch nicht die Früchte der beiden afrikanischen Arten, welche in Gabun und Kamerun selten sind; es ist daher auch nicht absolut sicher, daß sie wirklich zu dieser Gattung gehören.

Cyanotis D. Don, eine formenreiche, paläotropische Gattung, fällt auf durch dic schr gedrängten trugdoldigen Bliitenstände, an welchen die sichelförmigen Bracteen häufig zweireihig stchen. Viele sind Felsenpflanzen und steigen hoch in die Gebirge auf; sie sind auch reichlicher in Ostafrika, als in Westafrikil vertreten. Nicht wenige haben sich zu ausgesprochenen Jerophyten cntwickeln künnen, geschuitzt durch dichte Iaarbekleidung und durch Entwicklung unterirdischer Zwiebeln.

Vier Arten sind mit einer unterirdischen Zwiebel versehen, insbesondere C. hirsuta (Hochst.) Fisch. et Mey., eine bis $3 \mathrm{dm}$ hohe Pflanze mit lanzettlichen Blïttern und uber die Blattscheiden hervortretenden Inflorescenzen, von der Erythrea durch Abyssinicn und das Massathochland bis zum Kilimandscharo und zum südlichen Nyassaland, hier wie auch mehrere andere Hochgebirgspflanzen in geringerer Höhe $(800-1900 \mathrm{~m}$ ) als in Abyssinien (800-2600 $\mathrm{m}$ ) und am Kilimandscharo $(2900 \mathrm{~m})$. Mehr versteckt sind die Inflorescenzen bei der von Arabien und der Erythrea bis zum Natabeleland zerstreut rorkommenden C. foecunda (Hochst.) Hassk. Eine westafrikanische Art mit Zwiebel ist 
die schmalblättrige $C$. angusta C. B. Clarke, welche auf Felsen in Nigerien und am unteren Kongo gefunden wurde. - Sehr verbreitet ist die einjährige, wollig behaarte, am Grunde stark verzweigte C. lanata Benth. (Fig. 183); sie kommt auf Felsen und auch auf Ackerland vor. - Die übrigen (8) Arten zeigen einen mehr rasigen Wuchs mit blühenden Seitenzweigen. Von ihnen wächst $C$. Mrnnii C. B. Clarke an Bächen des Kamerungebirges und des Clarence Peak auf Fernando Po von $2300-3000 \mathrm{~m}$ ii. M., in viel geringerer Höhe in Angola (800 bis I $260 \mathrm{~m}$ ). Beblätterte Stengel mit 2-3 Blütenknäueln entwickelt die von der Erythrea bis Südafrika in den Gebirgen (bis zu I $500 \mathrm{~m}$ ) wachsende C.nodiflora Kunth (Fig. I 84 $A$ ); Stengel mit scheidigen Bracteen am Grunde der Bliitenknäuel besitzen C. caespitosa Kotschy et Peyr. (vom Ghasalquellcngebiet bis Nigerien) und C. longifolia Benth. (vom Massaihochland und Ungoro durch Uniamwesi bis Angola in Gebirgen zerstreut vorkonmend.

Coleotrype C. B. Clarke, eine Cyanotis nahestehende Gattung, mit dünner Röhre der verwachsenen Blumen-

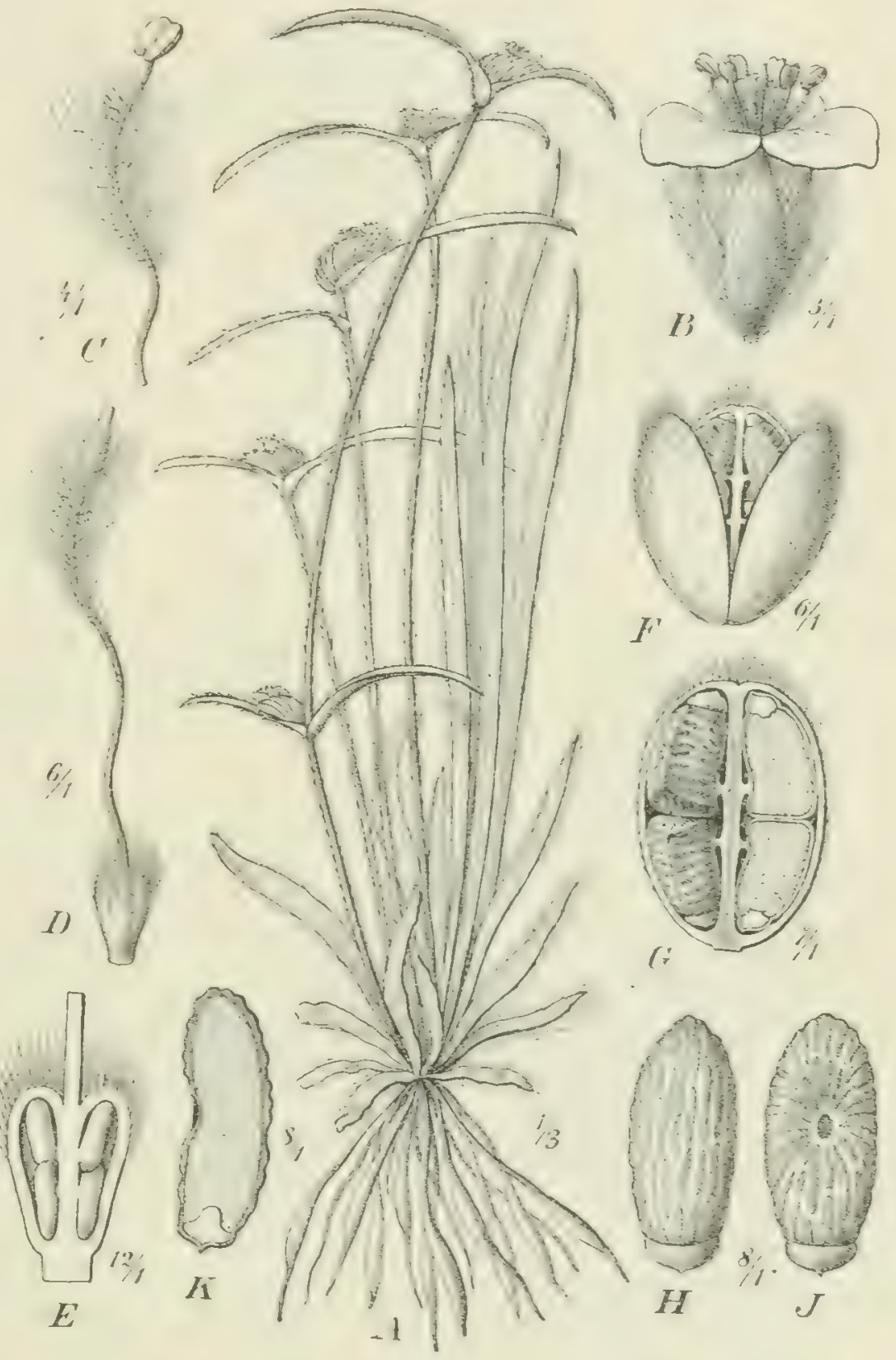

Fig. IS 3 . Cyanotis lanata Benth. A ganze Pflanze, I/3 n. Gr. $B$ Blïte; $C$ Staubblatt; $D$ Pistill; $E$ Längsschnitt durch den Fruchtknoten; $F$ Kapsel aufspringend; $G$ eine Klappe derselben mit vier Samen; $H$ Same von hinten; $\mathcal{F}$ derselbe von vorn, mit dem Nabel. blätter, ist hauptsächlich in Madagaskar vertreten; aber eine Art mit niederliegenden Zweigen. C. nutulensis C. B. Clarke (Fig. I $8+B$ ), findet sich auch in Natal und eine andere, C. Laurentii K. Schum., in Uferwäldern des Kassai und anderer Zufliisse des Kongo, sowie bei Batanga in Kamerun. Die Blitien stehen in dichten Kiniuehn. 
Floscopa Lour. Zum Teil einjährige Kräuter mit dünnen, beblätterten Stenseln und endständigen Rispen, deren letzte Zweige zwei Reihen kurz gestielter Bluiten mit meist rosa gefärbten Blumenkronen tragen. Etwa zehn Arten kommen im tropischen Afrika vor und zwar meistens an Fluß- und Bachufern, häufig mit am Grunde niederliegenden Zweigen. Die lanzettlichen
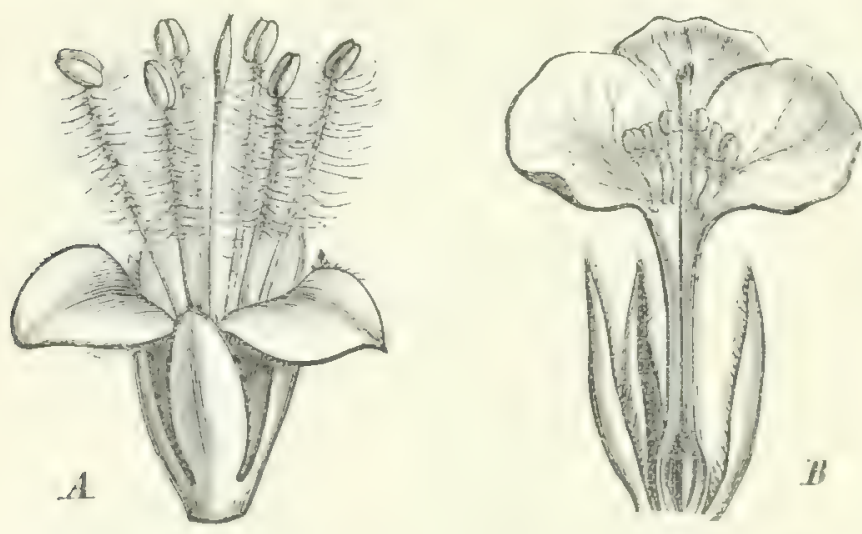

Fig. 184. A Blite von Cyanotis nodiflora $\mathrm{K}$ th. $B$ Blite von Coleotrype natalensis C. B. Clarke. Blätter sind am Grunde stielartig verschmälert bei F.africana (Beauv.) C. B. Clarke, die von Sierra Leone bis zum Kongo verbreitet ist. Sitzende Blattspreiten hat dagegen die namentlich im Osten von Abyssinien bis zum südlichen Nyassaland häufige $F$. rivulcris (A. Rich.) C. B. Clarke, welche auch bis zu $2600 \mathrm{~m}$ i.. M. aufsteigt. Von Angola bis zu den Viktoria-Fällen des Sambesi und bis Natal kommt F. glomerata (Kunth) Hassk. vor. Schlicklich ist auch noch auf $F$. flatile C. B. Clarke hinzurcisen, welche an 2,5 dm langen Stengeln schmal lanzettliche Blätter und Rispen gelber Bliiten trägt; sie kommt in Nigerien, dem Ghasalquellengebict und im nördlichen Nyassaland vor.

\section{Commelineae.}

Die meisten von ihnen sind Mesohydrophyten, die nach Regen sich sehr rasch entwickeln, mchrere wachsen auch an längere Zcit feuchten Plätzen und einige, namentlich Polyspatha und Aneilena, sind Hygrophyten.

Commelina L. Diese Gattung fällt leicht auf durch zusammengefaltete Bracteen, welche zwei Cymen einschließen, von denen die untere oft nur männliche Bliiten enthïlt und bald abstirbt oder auch sanz fchlt, während dic andere Zwitterbliiten am Grunde und männliche am Ende trägt. Die nahezu ;o afrikanischen Arten verteilen sich auf zwei Untergattungen, Didymoon mit zwei Samenanlagen in jedem ventralen Fach des Ovariums und I oder o in dem dorsalen, ferner Monom mit einer Samenanlage in jedem ventralen Fach. Die Selitionen innerhalb dieser Untergattungen können erst nach dem Reifen der Friichte erkannt werden; es hat daher wenig Wert, ausfiihrlicher auf die zahlreichen Arten einzugehen, welche man zumeist doch nur mit Hilfe umfangreichen Herbarmaterials bestimmen kann. Im Vegetationsbild der Fluß-, Teich- und Bachufer, lichter Gebiische, aber auch des Kulturlandes fallen sie oft durch häufiges Vorkommen auf, zumal in den Morgenstunden, wo sie ihre dann rasch welkenden Blüten cntfalten. Einzclne besonders häufige Arten will ich aber hervorheben. Mehrere gehören zu der Sekt. Eucommelina, bei welcher die dorsale Klappe der Kapsel mit dem eingeschlossenen Samen sich ablöst und schließlich aufspringt; so: C. mdiftora L., ein Tropenunliraut mit unterwärts niederliegenden, bis $6 \mathrm{dm}$ langen, beblïtterten Zweigen, blauen 
Blüten und schwarzen, genetzten Samen, an Bachufern und auf feuchten Äckern vom Weißen Nil bis zum unteren Sambesi; C. scondcns IVelw. mit bis $3 \mathrm{~m}$ langen Stengeln, linealischen Blättern und cylindrisch-ellipsoidischen Samen, am Cuansa in Angola, am Tanganyika-See und auf Madagaskar; C. subulata Roth, eine nur 3-t $\mathrm{dm}$ hohe, cinjährige Pflanze mit linealischen Blättern und kleinen blauen Blüten, zerstreut in West-, Ost- und Südafrika, aber von Gabun bis Senegambien noch nicht bekannt; $C$. benghalensis L. (Fig. 185), einjährig, mit am Grunde niederliegenden und wurzelnden $Z$ weigen von $3-8 \mathrm{dm}$ Länge und häufig mit unterirdischen Zweigen, welche kleistogame Blüten und große Früchte bilden; sie kommt von den Kapverden und dem Soturbagebirge bis zum Südende Afrikas (Uitenhage und Knysna) vor, auf feuchten Plätzen und auch an schattigen Felsen. - Bei den Arten derSekt. Heterocarpus springt die mit dem eingeschlossenen Samen sich ablösende dorsale Klappe nicht auf. Hierher gehört C. Forskalci Vahl, eine von unten reich verzweigte Pflanze mit länglich stumpfen Blättern und am Grunde verwachsenen Rändern der Spatha und kleinen blauen Bliiten, von den Kapverden, Arabien und Nubien bis zum unteren Sambesi und dem Matabeleland, auch auf den Maskarenen, wie die vorige an Flußund Bachufern und auf Kulturland; C. africana $\mathrm{L}$. mit bisweilen $\mathrm{I} \mathrm{m}$

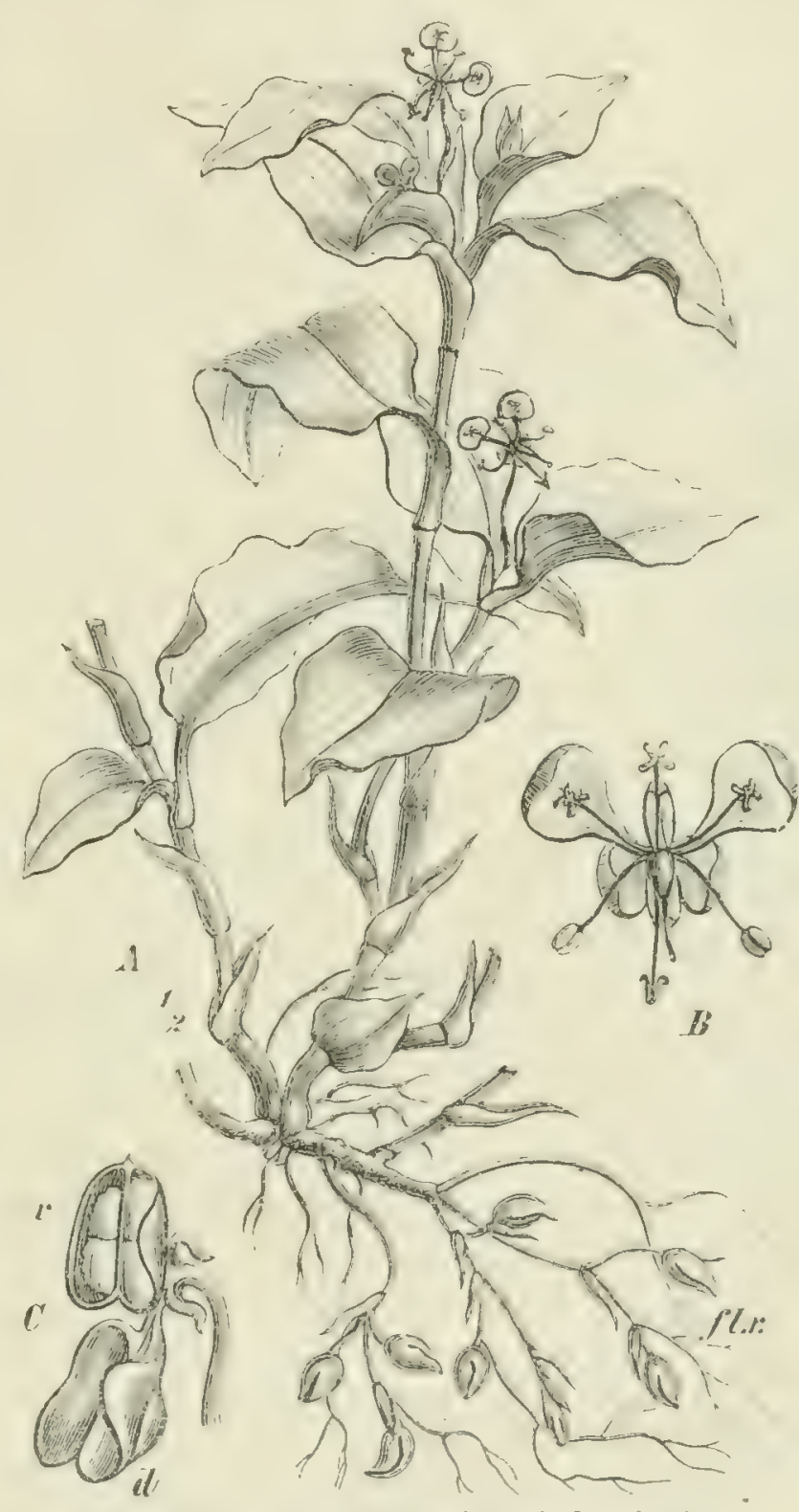

Fig. 185. Commelina benghalensis I. Nach Wight. langem, reich verzweigtem Stengel, mit länglichen, kahlen Blättern, his $5 \mathrm{~cm}$ langen, zugespitzten Bracteen und gelben Blüten, findet sich im Gras und in Gebüschen von Sierra Leone und der Erythrea suidlich bis Kapstadt, aufwärts bis zu $1900 \mathrm{~m}$ ü. M. Die der vorigen Art nahestehende C. edulis A. Rich., welche kleinere, mit kurzer Spitze versehene Spathen besitzt, findet sich in der Erythrea und Abyssinien (bei $3000 \mathrm{~m}$ ) und hat ihren lateinischen Namen (Zada Maschill in Tigre) davon, daß die Blätter wie Spinat genossen werden. Das gilt aber auch von den Blättern anderer Arten. Auch C. Krebsianc Kunth mit behaarten, lanzettlichen Blättern ist weit verbreitet.

Engler, Charakterpflanzen Afrikas. I. 
Die Arten der Sekt. Dissciocarpus enthalten meist im dorsalen Fach gar keinen Samen, und ihre Kapsel ist zwischen den Samen der vorderen Fächer eingeschnürt. Ton den i 8 Arten dieser Selition seien folgende hervorgehoben: $C$. imbcrbis Hassk., mit 3-6 dm langen, mitunter spreizklimmenden, lanzettlichen Blättern und länglich-riereckigen Samen, ist von der Erythrea bis zum südlichen Nyassaland und Angola in Buschgehölzen, auch in der Steppe häufig. Mehr kubische Kapseln besitzt C. latifolia A. Rich., die von Kordofan bis Tanga und auch am unteren Kongo vorkommt. Lineal-lanzettliche Blätter und kleinere Spathen finden wir bei C. madagascarica C. B. Clarke, welche außer in Madagaskar auch in der Erythrea und am Ruwenzori, von mir selbst auch bei Mombo in Usambara gefunden wurde. Durch zusammengedrängte Spathen zeichnet sich C. capitata Benth. aus, eine bis I $\mathrm{m}$ hohe Pflanze des westafrikanischen Regenwaldes von Senegambien bis Angola, aber auch an dem Ostufer des Albert Edward-Sees. Recht eigentiimlich sieht C. longicapsa C. B. Clarke aus, kriechend mit lanzettlich-verkehrteiförmigen, in einen Stiel verschmälerten Blättern, im unteren Regenwald von Gabun und Batanga in Kamerun. Innerhalb der Untergattung . Tonom besitzt die Sektion Trithyrocarpus Kapseln mit drei einsamigen Fächern. Hierher gehören die schmalblättrige C. mmbllater Thonn., in Nigerien, Togo und Uniamwesi, die mit elliptischen Blättern versehene C. bracteosa Hassk., welche in den Steppengehölzen und Trockenwäldern, auch in den Grassteppen Ostafrikas bis zum Sambesidelta rorkommt. Endlich ist in Mestafrika, namentich ron Senegambien bis Togo, von der Küste bis zum Gebirge, sowie in Angola weit verbreitet C. Togelii C. B. Clarke. Zu der durch nicht aufspringendes, dorsales Fach charakterisierten Selition Hiteropjxis gehört C. Baincsii C. B. Clarke, mit schmal lanzettlichen Blättern und gestielten Inflorescenzen mit einzelnen Spathen von Deutsch-Ostafrika bis zum suidlichen Nyassaland und Angola. Mehrere, am Ende der Zweige zusammengedrängte Spathen finden wir bei der graugrünen C. albcsitus Hassk., welche auf den Kaprerden, in Dahomey und dann rom nordöstlichen tropischen Afrika durch Arabien bis Scinde häufig ist. - Zweifächerige Ovarien und zweisamige Kapseln zeichnen die Sektion Spathodithyrsos aus, als deren Repräsentanten C. Zenkeri C. B. Clarke von Kamerun und C. pyrrhoblepharis Hassk. von Abyssinien genannt sein mögen.

Polyspatha Benth., eine endemische, monotypische Gattung, zeichnet sich dadurch aus, daß der his 7.5 dm lange, mit breit elliptischen Blättern besetzte Stengel in einen langen, biswcilen mit ein bis zwei g-leich entwichelten Seitenästen versehenen I3litenstand endigt. der eine größere Anzahl kleiner Spathen trägt. $P$. pamioulata Benth. ist an Bachufern und auf feuchtem IValdboden in den Regenwäldern Westafrikas ron Sierra Leone bis Kamerun verbreitet.

Aneilema R. Br. zeigt im Blitenstand nicht die zusammengefalteten, scheidenartigen Bracteen, wclche wir hei den beiden vorigen Gattungen gefunden haben. Man kennt etwa 24 Arten aus dem tropischen Afrika, von denen einzelne auch im tropischen Asien, drei auch im östlichen Kapland vorkommen. $\mathrm{Zu}$ der Untergattung Tricarpellaria, welche durch eine gleichmäBig drei- 
fächerige Kapsel charakterisiert ist, gehört 4 . sinicun Lindl., eine bis I $\mathrm{m}$ hohe Pflanze mit entfernt stehenden, schmal linealischen Blättern und dichotomischen Inflorescenzen, von Sierra Leone bis Damaraland und vom Ghasalquellengebiet bis Zululand auf Uferwiesen und an Sumpfrändern, aufsteigend bis $1900 \mathrm{~m}$. - Alle übrigen Arten gehören zu der durch zweifächerige Kapseln charakterisierten Untergattung Dicarpellaria. Innerhalb dieser entfallen

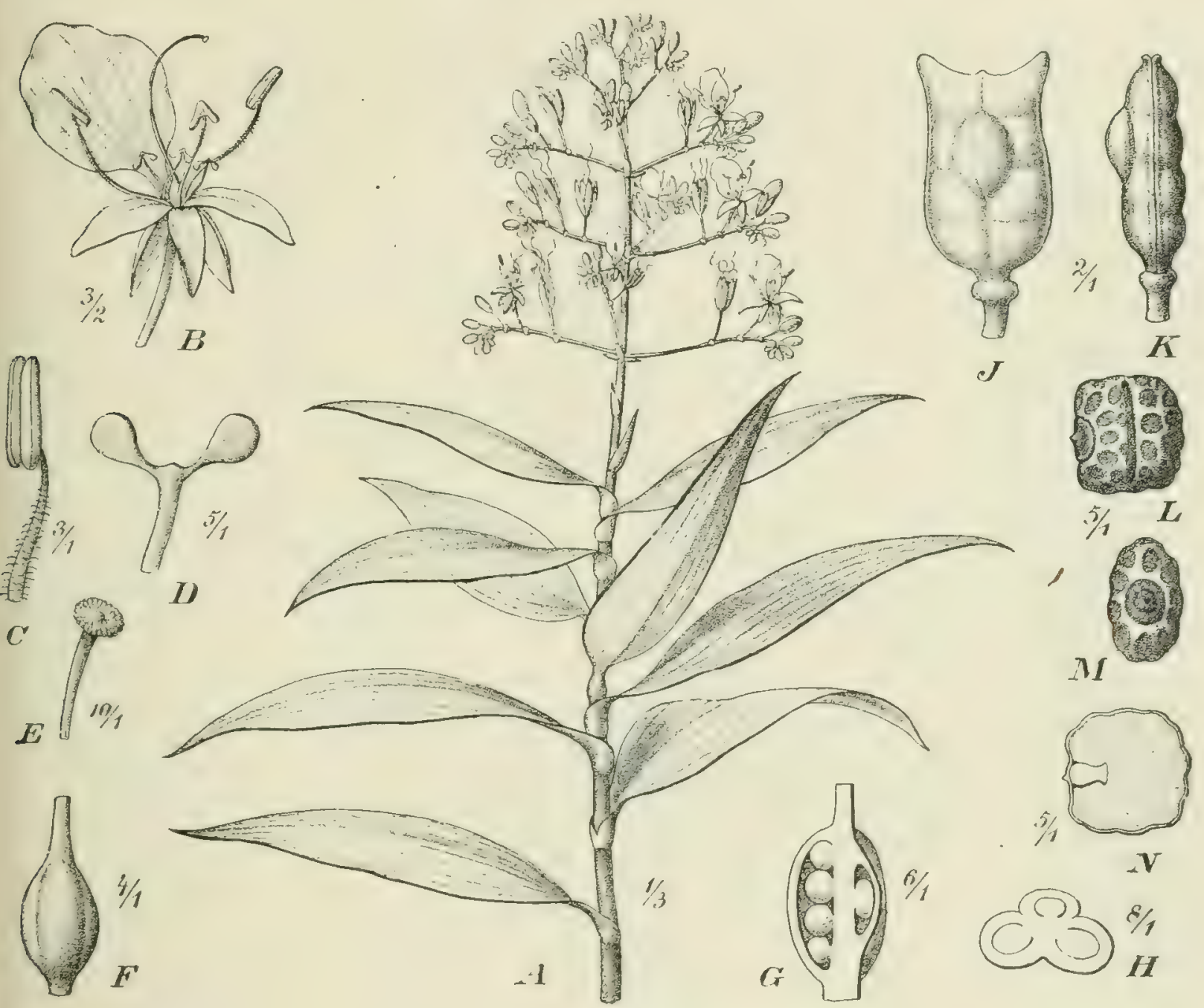

Fig. 186. Aneilema aequinoctiale (Beauv.) Kth. $A$ oberer Teil eines Stengels, I/3 n. Gr. $B$ Blüte nach Entfernung von zwei Blumenblättern; $C$ Staubblatt; $D$ Staminodinm; $E$ Griffel mit Narbe; $F$ Fruchtknoten; $G$ Längsschnitt durch denselben; $H$ Querschnitt durch denselben; $\mathcal{F}, K$ Kapsel; $L, M$ Same; $N$ Querschnitt desselben, mit dem Embryo. - Original.

drei afrikanische Arten auf die Sektion Amelina, bei welcher die abgesetzte Kapsel mit zwei Hörnchen versehen ist; von diesen ist A. acquincetiale (Beauv.) Kunth (Fig. 186), eine bis 2,5 $\mathrm{m}$ hohe Pflanze mit elliptischen oder lanzettlichen Blättern und lilafarbenen Bliiten, in feuchten Ufergebiischen von Arabien und Uganda bis Transvaal und Pondoland, in den Gebirgen aufsteigend bis 1900 und $2300 \mathrm{~m}$. Das viel schwächere $A$. tacazzeanum Hochst. findet sich nicht bloß in der Erythrea und Abyssinien, sondern auch im Bezirk Lindi (BussE) und auf Mossambik. - Die artenreichste Sektion ist Lamproilithyros mit ellipsoidischen Kapseln. Schwach lanzettliche Blätter und gelbe Bliiten 
besitzt A. Folnnstonii $\mathrm{K}$. Schum., welches vom Kilimandscharo bis zum südlichen Nyassaland in den Gebirgen bis zu $1000 \mathrm{~m}$ ü. M. vorkommt. Die anderen Arten haben blaue oder weiße Bliiten. Häufig von Liberia bis Angola, im Ghasalquellengebiet, am Ruwenzori und im südlichen Nyassaland ist A. bcminicusc Kunth, eine bis $6 \mathrm{dm}$ hohe Pflanze mit länglichen, zugespitzten Blättern, an Bachufern auf humusreichem Boden. Habitucll ähnlich, aber durch
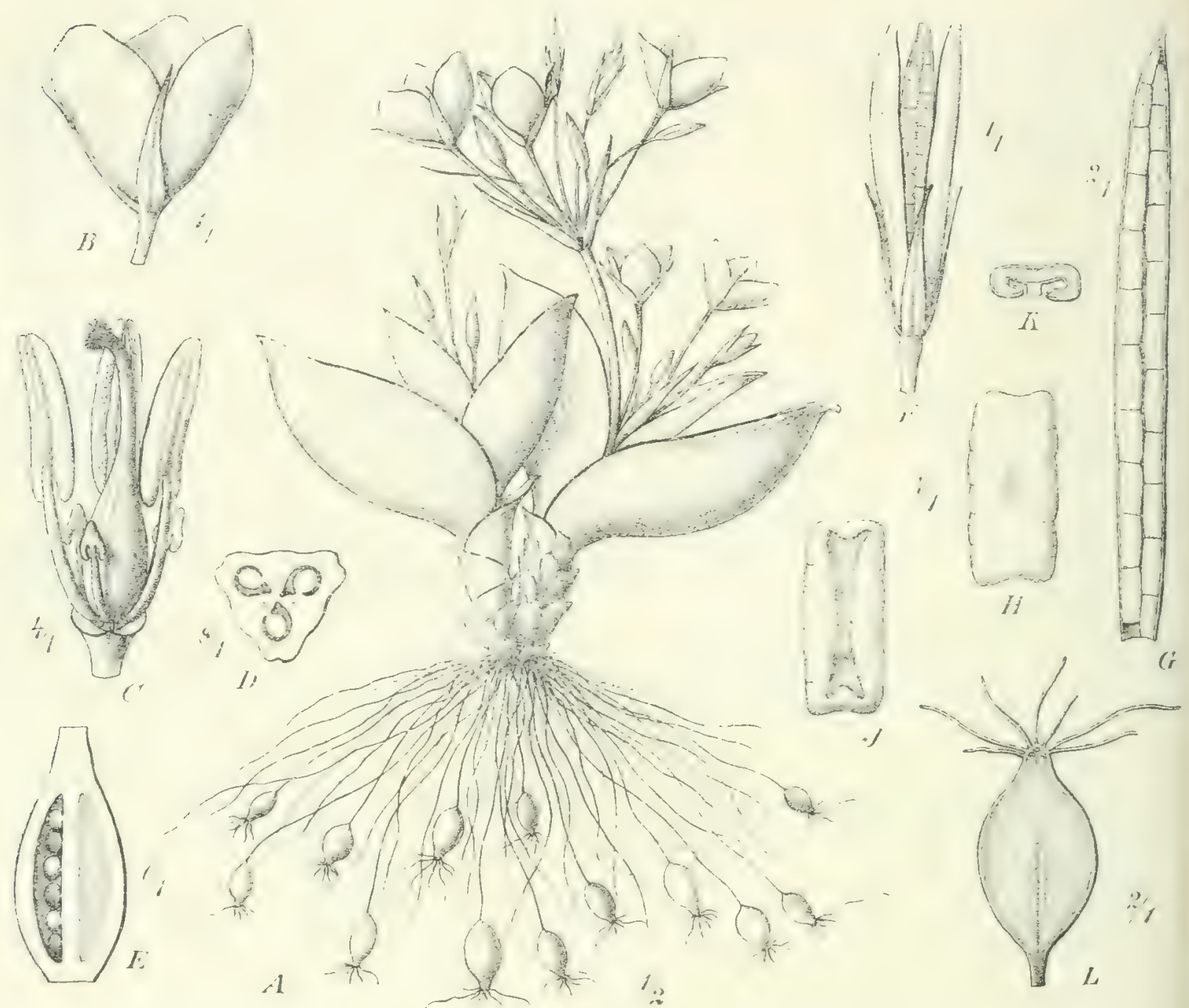

Fig. I87. Anthericopsis sepalosa (Rendle) Engl. $A$ ganze Pflanze, ${ }^{\mathrm{T}} / 2 \mathrm{n}$. Gr.; $B$ Blïte; $C$ dieselbe nach Entfernung der Blittenhülle; $D$ Querschnitt durch den Fruchtknoten; $E$ Längsschnitt durch denselben; $F$ aufspringende Kapsel; $G$ eine Klappe derselben; $H$ Same von der Rückseite; F derselbe mit dem Nabel; $K$ Querschnitt des Samens; $L$ Längsschnitt durch eine Wurzelknolle. - Original.

mehr voneinander abstehende Seitenäste der Rispen und weniger Samenanlagen (zwei bis eine in jedem Fach) verschieden ist A. orato-oblong gum Beaur., welches nur im Westen von Sierra Leone bis zum Kongo und im tropischen Amerika vorkommt. Dieser Art entspricht in Ostafrika A. P'ctersii (Hassk.) C. B. Clarke, welches mehr lanzettliche Blätter besitzt, in Gebirgsland aber auch breitblättriger vorkommt; es ist häufig auf Kulturland und in feuchten Gebiischen vom Sansibarküstengebiet bis zum Sambesidelta. Im Ghasalquellen- 
gebiet und dem der zentralafrikanischen Seen fincet sich - S. Silicinfurthii C. B. Clarke, mit dichten Rispen und lineal-länglichen Blättern. Sehr schmallanzettlich sind die Blätter bei A. lancoclatum Benth., das von Lagos durch Togo und Nigerien bis Kamerun zerstreut ist, aber auch aus Kordofan vorliegt. - Endlich ist noch eine Sektion I'scudoaxillar's zu erwähnen, bei welcher auch entfernt stehende Seitenzweige in Blütenrispen endigen; hierzu gehört A. pedunculosum C. B. Clarke, welches von Uganda bis Nyassaland in den Gebirgsregenwäldern von I300-3000 m im Waldesschatten zwischen Gras und Farnen, insbesondere an Bächen sich ausbreitet, aber auch in geringurer Höhe im Bezirk Lindi vorkommt.

Anthericopsis Engl. ist eine Gattung, welche in mancher Beziehung zwar Ancilena nahekommt, aber in mehreren Merkmalen sich doch recht auffallend nicht bloß von dieser Gattung, sondern auch von den übrigen Commelinaceen unterscheidet. Die Kelchblätter sind länger als die weißen Blumenblätter, die vor den Kelchblättern stehenden Staubblätter haben kurze Staubfäden und lange Antheren, während sonst bei den Commelinaceen das Lmgekehrte der Fall ist: die vor den Blumenblättern stehenden Staubblätter sind zu sehr kleinen Staminodien reduziert. Auffallend sind auch die langen, cylindrischen Kapseln mit zweireihig gestellten Samen, die scheindoldige Anordnung der Bliiten und die zahlreichen, dünn fadenförmigen, in eine eiförmige Knolle endigenden ITurzeln. Die einzige Art dieser Gattung, A. sipalose (Rendle) Engl. (Fig. I 8;), ist eine bis $2 \mathrm{dm}$ hohe, zu Beginn der Regenzeit oft massenhaft auftretende Pflanze der Niederungssteppen, schon im Somaliland, dann in Englisch- und Deutsch-Ostafrika, namentlich am Fuß des Paregebirges, auch in Unyika im nördlichen Nyassaland bei I $300 \mathrm{~m}$. Die grundständigen Blätter variieren zwischen eilanzettlich und lineal-lanzettlich, die Blüten sind weiß bis rosa.

\section{Fam. Cyanastraceae.}

Cyanastrum Oliv, die einzige Gattung dieser von mir (Bot. Jahrb. XXVIII. S. 357) aufgestellten Familie enthält Kräuter mit einem Rhizom, das aus uibereinanderliegenden, knollig angeschwollenen Gliedern besteht, mit länglichen bis herzförmigen Blättern, die jederseits einige stärkere und ebensoviel schwächere, von Grund aus bogig aufsteigende Nerven besitzen, zwischen welchen zahlreiche, dünne Queradern verlaufen. Der unterwärts mit einigen stengelumfassencen Niederblättern und mit ebensolchen Hochblättern versehene, in eine lockere Rispe endigende Schaft trägt hellblaue bis dunkelblaue Bliten, deren Antheren sich mit zwei Poren öfnen. Der Fruchthnoten sitzt einer halbkugeligen, ron der Basis der Blütenhülle umschlossenen Erweiterung der Blütenachse auf, ist schwach dreilappig und in jeden Fach mit zwei umgewendeten Samenanlagen versehen. Die Frucht ist tief dreiteilig und ein Teil schließt einen Samen ein, in welchem dem kleinen Embryo ein stärkeführendes Perisperm anliegt. - Lange Zeit war nur C. cordifolimn Oliv. (Fig. I 88 f-. $/$ ); bekannt, mit herzeiförmigen Blättern, an lichten Waldplïtzen in Kamerun und 
Gabun, auch im Inneren von Yoruba. Dann wurden noch einige Arten der Gattung im Osten gefunden, C. Goctscamm Engl. (Fig. I $88 G, H$ ), ebenfalls mit herzförmigen Blattspreiten, aber hellen Blüten, im Ufergehölz am Lofio

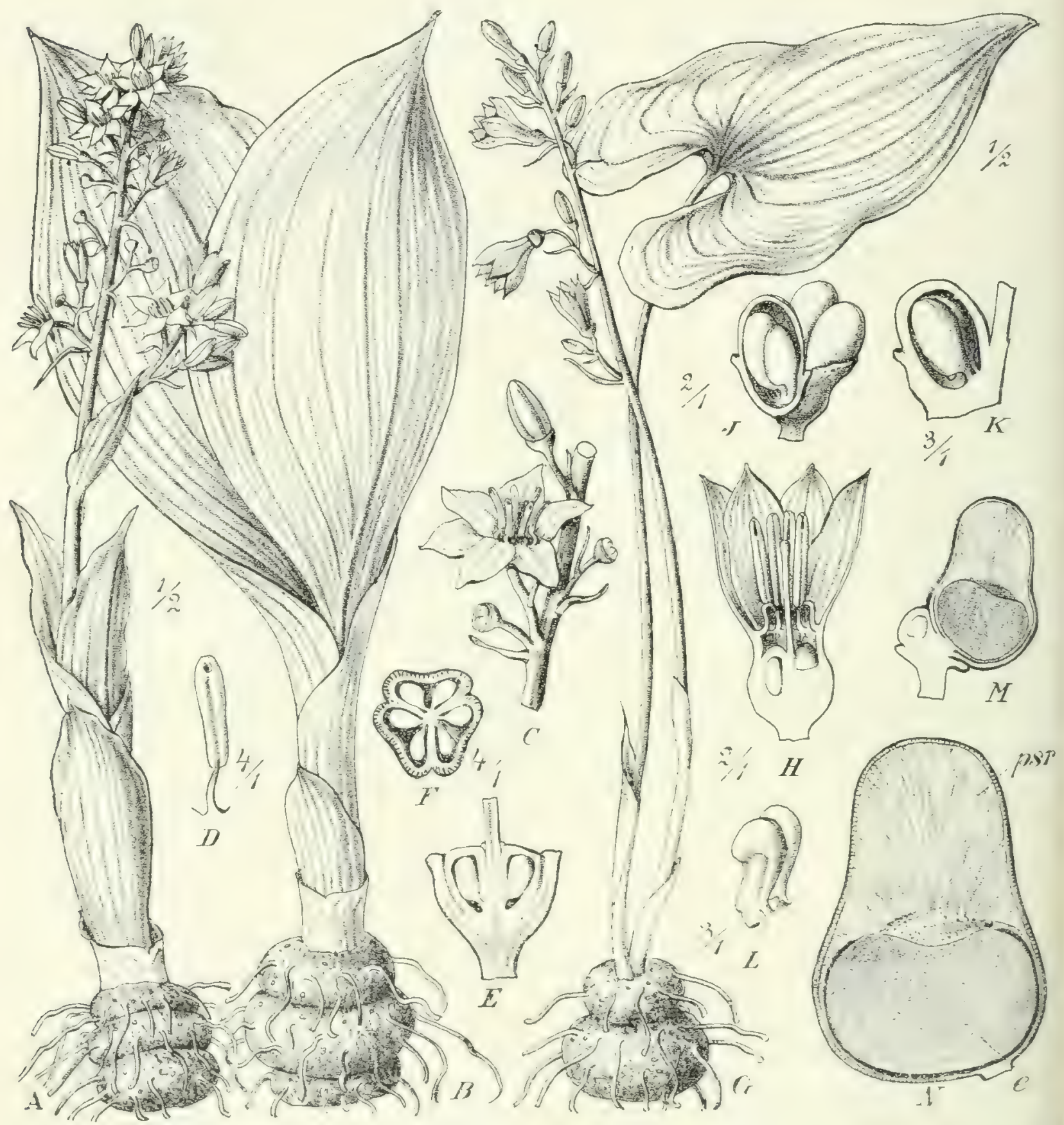

Fig. 188. A-F Cyanastrum hostifolium Engl. (Ostafrika). A blithende Pflanze vor Entwicklung der Blätter; $B$ PHanze mit entwickelten Blättern; $C$ Ästchen des Blütenstandes; $D$ Staubblatt; $E$, F Fruchtknoten. $G, H$ C. Goetzeanum Engl. (Uhehe). $G$ bliihende Pflanze; $H$ Blüte. $\mathcal{F}-M$ C. cordifolium Oliv. $\mathcal{F}, K$ Fruchthnoten bei beginnender Reife; $L$ die Samenanlagen mit beginnender Entwicklung zum Samen; $M /$ Fruchtknoten mit einem Jeifen Samen; $\lambda$ Same vergr., psy das Perisperm, $\varepsilon$ der Embryo. - Original.

in Uhehe, um $600 \mathrm{~m}$ ü. M., C. hostifoliun Engl. (Fig. 188 A-F), mit eiförmigen Blattspreiten, in lichter, hügeliger Baumsteppe am Ruhembe zwischen Khutu und Uhehe, um $500 \mathrm{~m}$ ii. M., C. Bussei Engl., mit lanzettlichen Blättern 
bei Seliman-1Iamba im Bezirk Lindi. Unvollkommen bekannte Arten sind C. Fohnstonii Bak. zwischen Tanganyika- und Nyassa-See, C. Terdickii de Wild. von Lukafu in Katanga, im südöstlichen Teil des Kongostaates, ungefähr unter derselben Breite wie C. Bussei. Zu Zeiten der Hungersnot dienen die knolligen Rhizome des letzteren als Nahrungsmittel.

\section{Fam. Pontederiaceae.}

Diese Familie von Hydrophyten enthält nur fuinf im tropischen Afrika rorkommende Arten, ron denen einzelne ziemlich verbreitet sind. Es sind W'asserpflanzen von ziemlich verschiedenem Habitus, mit sympodialem Stengel, häufig zweizeiligen Blättern und meist ährenförmigem Bliitenstand. Die einzelnen Bliiten sind corollinisch, meist vereintblättrig und mit langer Röhre rersehen, welcher innen sechs oder weniger Staubblätter angewachsen sind. Nicht selten sind einzelne Blüten kleistogam. Der oberständige Fruchtknoten entwickelt sich zu einer Kapsel oder Schließfrucht. Die Samen sind mit mehligem Nährgewebe versehen. Die drei in Afrika vorkommenden Gattungen unterscheiden sich folgendermaßen:

A. Blüten mit sechs Staubblättern.

a) Blätter der Blütenhülle bis zum Grunde frei

Monochoria.

b) Blätter der Blütenhülle unten in eine Röhre vereinigt .

B. Blïten mit drei Staubblättern

Eichhornia.

Monochoria Presl, mit der einzigen Art .M. africana N. E. Brown, ist eine t-6 dm hohe Pflanze mit langgestielten eiförmigen, etwas herzförmigen Blättern und violetten, etwa $5 \mathrm{~mm}$ langen Blüten. Sie wurde nur im Ghasalquellengebiet im Lande Djur gefunden: vier andere Arten kommen im tropischen Asien vor.

Eichhornia Kunth. Fünf Arten dieser Gattung finden sich im tropischen Amerika und nur E. mutans (Beauv.) Solms in Afrika, von Senegambien und dem Nigergebiet bis nach dem Ghasalquellengebiet, in Sumpfen. Der rerzweigte, kriechende und im Schlamm wurzelnde Stamm trägt sitzende, lineale, untergetauchte Blätter und über das Wasser tretende, langgestielte Luftblätter mit breiteiförmiger Spreite. Die blauen Bliiten besitzen eiṇe bis $2,5 \mathrm{~cm}$ lange Röhre und sechs kleine Lappen.

Heteranthera Ruiz et Pav. Auch diese Gattung ist in Amerika stärker vertreten, nämlich mit sechs Arten, während in Afrika drei rorkommen. Von der vorigen Gattung ist sie hauptsächlich durch das Vorkommen ron kileistogamen Blüten, durch das Vorhandensein von nur drei Staubblättern und durch unvollkommen oder gar nicht gefächerten Fruchtknoten unterschieden, auch sind die Blüten nur halb so groß wie dort; zwei Arten kennen wir nur aus Senegambien, $H$. callaefolia Reichb. und $H$. potanogeton Solms, aber $H$. Kotschyean Fenzl ist bis jetzt schon in Kordofan, im zentralafrikanischen Seengebiet, am Sambesi, in Transvaal und Angola nachgewiesen, sicher noch weiter verbreitet. 
Es ergibt sich hiermit, daß die Familie der Pontederiaceen viel stärkere verwandtschaftliche Beziehungen zur Flora des tropischen Amerika, als zu der des tropischen Asien aufweist.

\section{Fam. Juncaceae.}

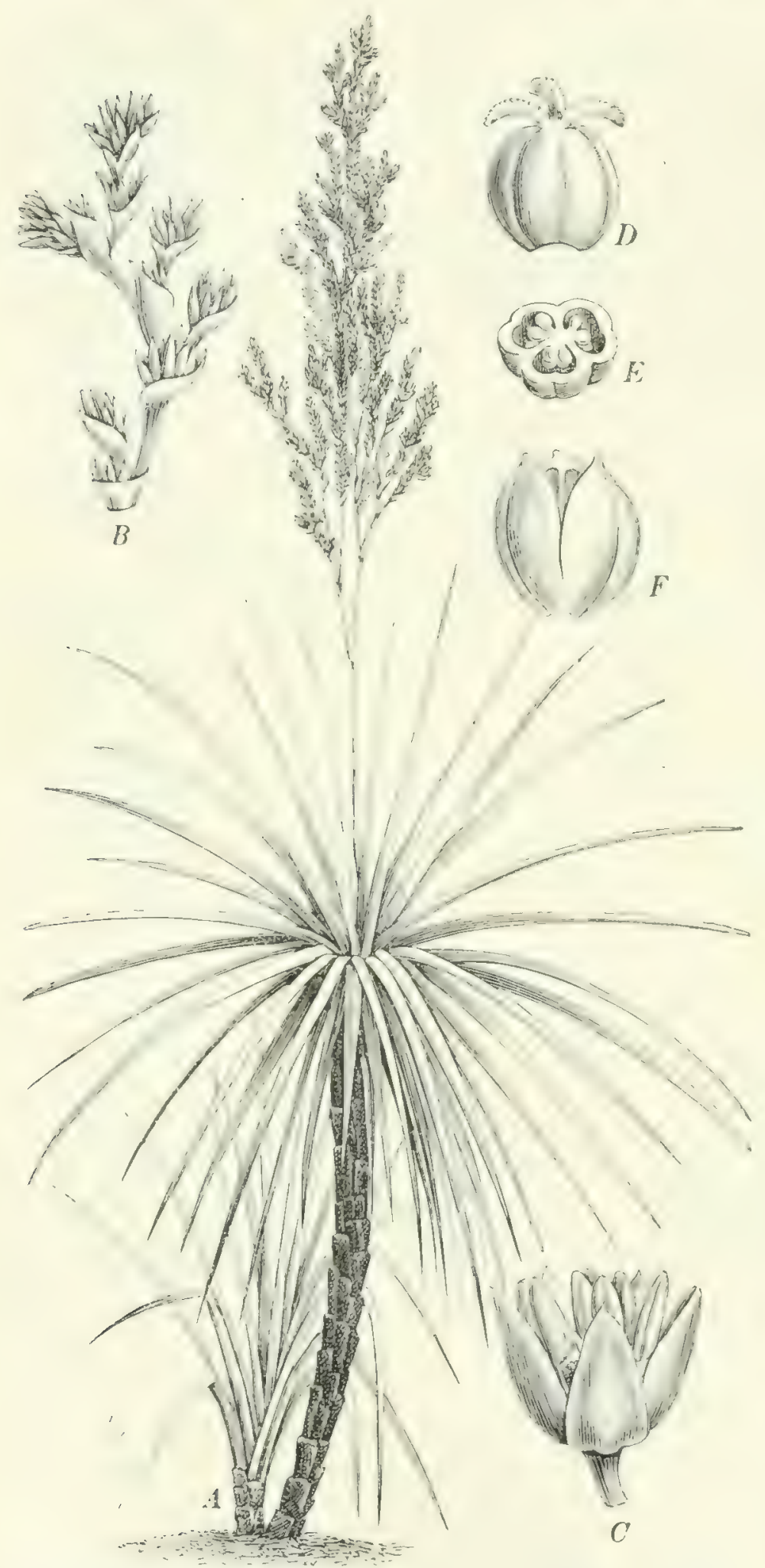

Fig. I89. Prionium serratum (L.f.) Drège. $A$ ältere blithende Pflanze und junger Sproß; $B$ Stück des Blitenstandes; $C-E$ Blïte; $F$ Kapsel.
Diese Familie ist im tropischen Afrika von geringer Bedeutung, während sie im Kapland eine nicht unwichtige Rolle spielt. Dort findet sich

Prionium E. Mey., eine vor allen anderen Juncaceen durch armdicke Stämme von I- I, 5 Länge, scharf gesägte Blätter und riesige Rispen ausgezeichnete Gattung mit der einzigen Art $P$. serratum (L. f.) E. Mey., dem Palmiet, welches im südlichen Kapland an Flußufern dichte Bestände bildet, auch bis zu I $300 \mathrm{~m}$ ii. M. aufsteigt.

Juncus L. Drei auch im Mediterrangebiet vertretene und überhaupt in der nördlich gemäßigten Zone stark entwickelte Gruppen sind mit einigen sich leichtansiedelnden Arten auch nach Suidafrika und einzelnen Punkten des tropischen Afrika gelangt. Der zu den Poiophylli gehörige F. bufonius L. ist im ganzen Kapland zerstreut und findet sich in Abyssinien von 2300 bis $3900 \mathrm{~m}$. F. capitatus Weig., der in Mitteleuropa und dem Mittelmeergebiet verbreitet ist, hat seinen Weg sowohl nach demKamerungebirge (2300 m), wie nach Abyssinien (3400 m) gefunden. Von den Gemini ist . effusus L. nur an ein- 
zelnen Stellen der östlichen Kapkolonic und Natals, sowie im Nassaihochland $1900-2700 \mathrm{~m})$ gefunden worden und wohl durch Zugvriggcl eingeschleppt; F. glaucus Ehrh. ist aber im östlichen Kapland und im Oranje-Freistaat mit einer endemischen Varietät acutissimus Buchenau vertreten, was auf ältere Einwanderung hindeutet. - Von den Thalussii hat $\dddot{J}$. maritimus L. vom Kapland bis Natal sich stark ausgebreitet, stellenweise bis zu einer Höhe von I $600 \mathrm{~m}$, außerdem findet er sich an der Küiste von Benguela, in Senegambien und bei Meid im Somaliland. F. acutus L. ist im Kapland mit einer häufig vorkommenden, endemischen Varietät Lcopoldii Buchenau vertretcn. Die durch Querfächerung der Laubblätter ausgezeichneten Sifiati sind namentlich im südlichen und östlichen Kapland mit fünf Arten entwickelt, von denen $\mathscr{F}$. punctorius L. f. in der Küstenkette des Somalilandes, Abyssiniens und der Erythrea wiederkchrt, F. oxycarpus E. MIey. auch in Benguela häufig ist und rereinzeit auch in Usambara, dem Somaliland und der Erythrea rorkommt. Zu dieser Sektion gehört auch der im Mittelmeergebict nicht seltene $\mathcal{F}$. Fontancsii J. Gay (F. articulatus Desf., der von der Erythrea durch Abyssinien auch nach dem Kenia gelangt ist und namentlich oberhalb der Waldregion angetroffen wird. Von den im Kapland, namentlich im sïdlichen Teil und im Westen bis KleinNamaqualand recht zahlreichen Granlinifoliz trifit man im tropischen Afrika nur den schönen, breitblättrigen F. lomatoplyyllus Spreng. in Natal und in Transvaal. Mit diesem ist dann wieder nahe verwandt $\mathscr{F}$. Bachiti Hochst., welcher in hoch gelegenen Sümpfen Usambaras, des Kilimandscharo 2500 m: und Semens in Abyssinien (3500-3700 m) vorkommt. Als eine Zwischenform zwischen den beiden letztgenannten Arten wird $\mathscr{F}$. Engrleri Buchenau von ITestusambara ( 1 - $-1600 \mathrm{~m}$ ) angesehen. Die weite Verbreitung mehrerer Funcus-Arten erklärt sich durch die Beschaffenheit ihrer Samenhaut, deren äußere Zcllschicht eine starke Neigung zur Verschleimung besitzt und daher Tieren leicht anhaftet.

Luzula DC. Alle in Afrika vorkommenden Arten stehen borealen oder europäischen nahe und sind als Ablömmlinge derselben anzuschen. Die einzige suidafrikanische Art, L. africana Drìge, welche auf feuchten Grasplätzen des Katberges im Kapland und auf dem Nont aux Sources in Basutoland um $3100 \mathrm{~m}$ rorkommt, bezeichnet BLCHEX.1. ${ }^{\mathrm{I}}$, als direkten Abkümmling ron L. compestris DC, wie auch schon früher KUNTH getan hatte. An diesen Formenkreis schließt sich auch L. compestris DC. rar. Menmii Buchenau an, welche auf dem Clarence Peak von Fernando Po um 2600 m, auf dem Kamerungebirge von $2600-4500 \mathrm{~m}$, von den Grasmatten bis in das Lavageröll vorkommt. L. abyssinica Parl., über welche ich mich früher ${ }^{2}$ ausführlich ausgesprochen habe, ist mit L. spicata DC. mehr als mit jeder anderen Art verwandt und auf den ostafrikanischen Hochgebirgen in verschiedenen Varictäten entwickelt; die in der abyssinischen Provinz Semen um $3900 \mathrm{~m}$ vorkommende und auch in der Bambuszone des Kenia um $1900 \mathrm{~m}$ angetroffene Pflanze mag als die

3) BUCheNaU in Abhandl. d. naturwiss. Ver. zu Bremen, IV. 4. S. 4 I4.

2) ENGLER, Über das Verhalten einiger polymorpher Pflanzentypen der nördlich gemäßigten Zone bei ihrem Übergang in die afrikanischen Hochgebirge, Festschr. f. P. Ascherson, S. 553 ff. 
typische gelten; sic wird durch kräftigeren Wuchs ubertroffen von der Varietät Filimandscharia Engl., welche am Kilimandscharo auf Waldwiesen um I 900 m beginnend in der Grasregion häufig ist und auch noch in der Ericinella-Region um $3000 \mathrm{~m}$ angetrofien wird, um dann zwischen den Lavablöcken des Mawensi in die niedrige, mehr beharte und gedrängtbliitige Tarietät Tolk'nsii (Buchenau) Engl. überzugehen. Die im Gürtelwald des Kilimandscharo von $2500-2900 \mathrm{~m}$ rorkommende $L$. Fohnstonii Buchenau ist verwandt mit der auch auf Teneriffa und in Südeuropa wachsenden L. Forsteri DC. Die auf den Kanarischen Inseln vorkommenden Arten gehören einer anderen Sippe an, der in Europa weitverbreiteten, und riele Terwandte besitzenden L. nomorosa (Poll., E. Mey. L. canariensis Poir. in den Lorbeerwäldern von Gran Canaria und Teneriffa ist eine prächtige Art, welche unter den nächststehenden Arten wohl nur von der andinen L. gigantea Desv. an Größe übertroffen wird. Dagegen ist die auch in unteren Regionen außerhalb der ITälder vorkommende L. purpura Link) Masson cine einjahrige, in der Größe wechselnde Art: ihre Samenhaut ist durch besonders starke Quellungsfähigkeit ausgezeichnet.

\section{Fam. Liliaceae.}

Die Liliacece gehören in ganz Afrika vom Mediterrangebiet an bis zum Kapland zu den wichtigeren Bestandteilen der einzelnen Formationen, zumal sie in denselben oft gesellig mit grolser Zahl von Individuen auftreten, so namentlich in steppenartigen Formationen aller Art und auf den Bergwiesen, auch im Gebirgsbusch, weniger im Alluvial- oder Regenwald. Mehrere der in Afrika durch großen Formenreichtum ausgezeichneten Gattungen treten uns auch noch im Mittelmecrgebiet mit einzelnen Arten entgegen, wie Smilar und Trginca, und andere derartige, wie Asperagus und Anthorimm, gehen mit einer Art bis nach dem suidlichen Skandinavien.

Bei der großen Zahl der in Afrika auftretenden Gruppen der Liliaceen empfichlt es sich, hier cine systematische Lbersicht derselben mit Anfuihrung der dazu gehörigen Gattungen zu geben.

A. Khizom oder Zwiebelknolle mit endständigem Blütenstand. Antheren extrors und Kapsel scheidewandspaltig; oder Antheren intrors und Kapsel scheidewandspaltig, oder Antheren extrors und Kapsel fachspaltig, nur selten Antheren intrors und Kapsel fachspaltig. Frucht niemals eine Beere

Unterfam. Melanthioideae.

a) Rhizom. Samen fast kugelig oder kreisförmig oder flach Uvularieae. a) Blätter meist mit rankender Blattspitze.

I. Blitenhiille abstehend, ansehnlich Gloriosa.

II. Blïtenhiille glockig, aber getrenntblättrig ............. Littonia.

III. Blïtenhülle glockig, vereintblättrig . . . . . . . . . . . Sandersonia.

3) Blätter ohne Ranke ................... . Walieria.

b) Zwiebelknolle oder kurzes Rhizom. Same fast kugelig.

a) Stengel beblättert. Antheren extrors

Anguillarieae. 
I. Kapsel scheidewandspaltig.

I. Blütenhülle getrenntblättrig.

* Blüten in einer Dolde. Zwiebelknollen

Androcymbium.

** Blüten in Ähren oder einzeln. Zwiebel. Kapland.

$\div$ Fruchtknoten dreikantig......... Bacometra.

$\because$ Fruchtknoten dreilappig . . . . . . . . Dipidax.

2. Blütenhülle vereintblättrig mit kurzer Röhre. Ähre ..... Wurmbea.

II. Kapsel fachspaltig.

I. Staubfäden fadenförmig. Blïten langgestielt. Kapland . Ornithoglossum.

2. Staubfäden flach. Blïten langgestielt ......... Iphigenia.

ß) Schaft verkürzt, unterirdisch, mit $\mathrm{I}-3$ grundständigen Blättern. Kapsel

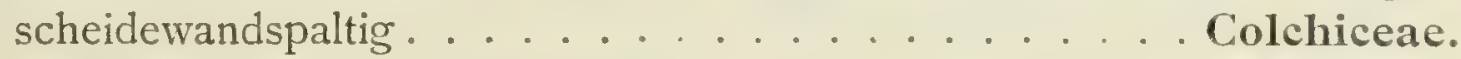

Mediterrane Gruppe; reicht bis Abyssinien .......... Merendera.

13. Rhizom mit grundständigen Blättern oder Stamm mit Schopf oder beblätterter oder verzweigter Stengel, noch seltener Knolle oder Zwiebel. Bliitenstand meist terminal. Antheren intrors, bisweilen am Scheitel sich öffnend. Kapsel fachspaltig, sehr selten Beere oder Nüßchen

\section{Unterfam. Asphodeloideae.}

a) Bliitenstand racemös oder rispig. Blütenhüillblätter getrennt oder vereint

Asphodeleae.

a) Rhizom. Blittenhillle trichterförmig. Mediterrane Gattung, bis Nubien Asphodelus.

B) Rhizom. Blütenhülle radförmig.

I. Antheren ohne Grübchen auf der Rïckseite.

I. Staubfäden kahl. Fächer der Fruchtknoten mit zwei Samenanlagen Bulbinella.

2. Staubfäden lang gebärtet. Fächer der Fruchtknoten mit vier bis mehr Samen-

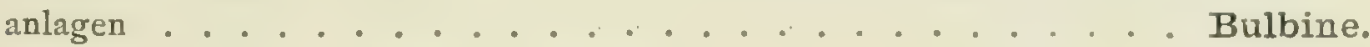

II. Antheren in einem am Grunde befindlichen Grübchen den Staubfaden aufnehmend.

I. Bluitenbuille nach dem Verbliihen nicht gedreht.

* Blüten höchstens $1,5 \mathrm{~cm}$ lang.

† Kapsel stumpfkantig, nicht gelappt ........ Anthericum.

tr Kapsel tief dreilappig oder scharfkantig.

Bliiten locker tranbig .

OO Blïten in dichter Ähre.

X Hohe Pflanzen mit schmalen Blättern ..... Dasystachys.

$X \times$ Niedrige Pflanze mit eiförmigen Blättern ..... Verdickia.

** Blüten 2,5 cm lang .............. Acrospira.

2. Bliutenhülle nach dem Verbliihen gedreht.

* Blütenstand mehrblütig. Kapland . . . . . . . . Caesia.

** Blütenstand mit I-3 kurzgestielten Blüten. Kapland ..... Nanolirion.

v) Zwiebel oder Knolle. Stengel am Grunde mit einigen frühzeitig absterbenden Blättern oder zur Blütezeit ohne solche. Blïtenschaft einfach oder verzweigt, mit langen Blütenstielen. Antheren am Grunde angeheftet, ohne Grübchen.

I. Blïten in windendem, einfachem oder reich verzweigtem oder geradem, gespreizt verzweigtem Blütenstand. Samen glatt. Zwiebel.

I. Blütenstand überall Blüten tragend. ......... Schizobasis.

2. Blitenstand reich rerzweigt. die unteren Zweige ohne Bliiten. Nur Kapland Bowiea.

II. Blüten in einfacher gerader Trambe. Samen wollig. Knolle.. Eriospermum.

b) Blätter der Blïtenhülle zum größten Teil untereinander vereint, bisweilen etwas zygomorph. Staubblätter gar nicht oder nur am Grunde mit der Bliitenhülle vereint ............... Aloinea. 
ic) Bliitenstand deutlich endständig, dichtährig.

I. Blittenhitlle röhrig. Bliten meist hångend, seltener aufrecht. . . . Kniphofia.

II. Blütenhïlle glockig. Bluiten abstehend oder anfrecht. . . . . Notosceptrum.

B) Blittenstand scheinbar axillär, meist lockerblitig, traubig oder rispig. Nicht selten oberirdischer, einfacher oder verzweigter Stamm mit Dickenwachstum.

I. Frucht trocken.

I. Blüten klein, aufrecht, weißlich. Kleine Pflanzen.

* Blütenhiiliblätter frei, aufrecht oder etwas zurückgebogen.

$\therefore$ Deckblätter breit. Staubfäden flach. Blätter langgrannig und warzig

Aloë Untergatt. Aloinella.

+† Deckblätter klein, dreieckig. Staubfäden fädlich . . . Chamaealoë.

** Blütenhiillbïatter verwachsen oder zusammenneigend.

if Fruchtknoten und Kapsel zugespitzt. Blätter wenig fleischig. Chortolirion.

$\div \div$ Fruchtknoten und Kapsel rundlich. Blätter fleischig.

Blitenhüllblätter an der Spitze sternförmig abstehend

Apicra.

$\bigcirc \bigcirc$ Blütenhüllblätter zweilippig abstehend......... Haworthia.

2. Blititen ziemlich groß, hängend oder abstehend, lebhaft gefärbt.

* Blitenhülle um den Fruchtknoten herum bauchig angeschwollen. Gasteria.

** Bliitenhiulle unten nicht angeschwollen............... Aloë.

II. Frucht fleischig, beerenartig. . . . . . . . . . Lomatophyllum.

C. Zwicbel oder liurzes Rhizom. Schraubeldolde, von zwei breiten, bisweilen vercinigten Huliblättern umschlossen, seltener von zwei schmalen Hochhlätterin gestuitzt oder auf einzelne Blüten reduziert Unterfam. Allioideae. a) Rhizom. Blïtenhiille vereintblättrig ......... Agapantheae.

(t) Blütenhïille trichterförmig, ohne Nebenkronenlappen. Kapland . . Agapanthus.

3) Blïtenhïlle mit krugförmiger oder cylindrischer Köhre, am Schlund mit drei Nebenkronenlappen ................. Tulbaghia.

b) Zwiebel oder am Grunde verdickter Stengel. Blitenhille getrennt- oder vereintblättrig ....................... Allieae.

Allium.

D. Zwiebel. Blitenstand endständig, traubig. Bliitenhuille getrenntblättrig oder vereintblïtrig. Antheren stets intrors. Kapsel loculicid Lnterfam. Lilioideae. Im tropischen und südlichen Afrika nur die Gruppe der ... Scilleae.

a) Samen zusammengedriickt oder kantig.

๙ Blitenbülle getrenntblättrig.

I. Bliitenhülle bleibend

Albuca.

II. Blütenhülle abfällig.

Urginea.

3) Blütenhiille vereintblättrig.

I. Röhre breit und kurz, Abschnitte abstehend. Bliiten groß . . . . Galtonia.

II. Röhre glockig.

I. Abschnitte abstehend.

Drimia.

2. Abschnitte aufrecht, zusammenneigend ......... Rhadamanthus.

III. Röhre cylindrisch.

I. Äußere Abschnitte abstehend, innere aufrecht. . . . . . . . Dipcadi.

2. Abschnitte sehr kurz. - Nur Kapland . . . . . . . . . . Litanthus.

b) Samen kugelig oder verkehrt-eiförmig.

๔) Blütenhülle getrenntblättrig oder nur ganz am Grunde syntepal.

I. Abschnitte abstehend oder glockig zusammenneigend. Staubfäden fadenförmig oder nahe am Grunde verbreitert . . . . . . . . . . . . . Scilla.

II. Abschnitte abstehend. Staubblätter am Grunde verbreitert. Blütenstand anit einem Schopf von Hochblättern über den Blïten ........... Eucomis. 
III. Abschnitte abstehend oder zusammenneigend. Staubblätter flach.

I. Bliten in Traube oder Dolde, langgestielt

Ornithogalum.

2. Bliten klein, in Ähren sitzend.

- Drimiopeis.

3) Blütenhülle vereintblättrig.

I. Mehrere Grundblätter.

I. Blütenhülle trichterförmig, gerade, am Grunde nicht zusammengezogen Hyacinthus.

2. Blütenhülle trichterförmig, gekrümmt. Samen unbekannt, daher Stellung zweifelhaft

Pseudogaltonia.

3. Blïtenhülle cylindrisch. - Nur Kípland . . . . . . . . Veltheimia.

II. Nur zwei bis fünf Grundblätter.

I. Auch die untersten Hochblätter in ihren Achseln Bliten tragend.

* Staubblätter frei, mit fadenförmigen Staubfäden.

† Änbere Blätter der Blütenhülle kürzer als die inneren. Zwei bis fünf Laubblätter am Grunde. - Nur Kapland . . . . . . . . Lachenalia.

$\div$ Äußere Blätter der Blütenhülle ebenso lang wie die inneren. Zwei Laubblätter an Grunde. - Jur Kapland . . . . . . . . . . Polyzena.

** Staubblätter am Grunde in einen Ring rereinigt . . . . W Whiteheadia.

2. Die unteren Hochblätter ohne Blüten, dachziegelig. Blüten in Dolden.

* Staubblätter frei. Abschnitte der Blütenhülle ungleich. - Nur Kapland Massonia.

** Staubblätter am Grunde in einen Ring vereint. Abschnitte der Blütenhülle fast gleich. - Nur Kapland .............. Daubenya.

E. Stamm nicht selten mit Dichenwachstum durch ein peripher angelegtes Folgemeristem, aufrecht, bisweilen kurz, mit beblättertem Schopf, oder Rhizom mit grundständigen Blättern. niemals Zwiebul. Blätter nie fleischig;, aber bisweilen lederartig. Blätter der Blütonhülle getrennt oder am Grunde vereint. Antheren intrors. Beere ..... Unterfam. Dracaenoideae.

a) Frucht kugelig, beerenartig, mit dickem Pericarp ........ Dracaena.

b) Frucht mit dünnem, bald zerstörtem Pericarp ........ Sansevieria.

F. Rhizom unterirdisch, in oberirdische blihence Zweige cndigend und sich unter der Erde weiter verzweigend oder unten fortwachsend und seitliche Blütenzweige entwickelnd. Beere...... Unterfam. Asparagoideae. Rhizomzweige in oberirdische. beblätterte Stengel encigend. Stengulblätter klein, schuppenförmig, in ihren Achseln schmale oder breite. blattartige Zweige (Phyllokladien) tragend ......... Asparageae.

a) Staubblätter frei. Blüten einzeln oder zu mehreren am Grunde der meist schmalen blatt-

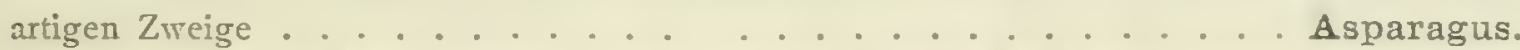

b Staubblätter in ein krugförmiges icbilue vertinigt. Blïten an breiten blatiartigen Zweigen stehend. - Nur Kanaren . . . . . . . . . . Semele.

G. Sträucher oder Halbsträucher mit aufrechten oder kletternden Zweigen. Blitenzweige am Grunde mit cinigen schuppigen Hochblättern. Bliten homoiochlam oder heterochlam. Beere mit kugeligen Samen

Unterfam. Luzuriagoideae.

Einzige Gattung im östlichen Südafrika. ........ Behnia.

H. Sträucher und Halbsträucher mit kletternden Zweigen und circi- bis fünfnervigen, netzadrigen Blättern. Blüten klein in achselständigen Dolden oder Trauben oder endständigen Rispen. Fächer des Fruchtknotens mit ein bis zwei geradläufigen oder halbumgewendeten Samenanlagen

Unterfam. Smilacoideae.

Smilax. 
Unter dieser großen Zahl von Gattungen befinden sich nur wenige, welche als Hydrophyten bezeichnet werden können; es sind dies namentlich viele Kniphofir und Agapanthus, sowie auch einige Scilla. Etwas größer ist die Zahl der Hygrophyten; es sind dies Smilax, Belmia, Semele, Chlorophytum, Dracaena und Asparagns, letztere drei aber nur zum Teil, da einige Arten auch subxerophytisch oder ausgesprochen rerophytisch sind. Nesophyten, auf mäßige Wasserzufuhr vom Boden angewiesen, sind einzelne Gloriosa, andere subxerophytisch: Littonia und Sandersonia, die Anguillaricae, Androcymbium, Humber, Bacometra, Dipidax, Nerendera, mehrere Chlorophytum, einige Scilla. Bei weitem die große Mehrzahl der afrikanischen Liliaceen sind Subxerophyten, welche nach längerer Ruhe in der Trockenzeit oder auch noch während der kälteren Regenzeit Südwest-Kapland bei Beginn der wärmeren Regenzeit ihre bliihenden Stengel entwickeln und dann oft durch große Zahl der Individuen das Aussehen einzelner Formationen, namentlich offener, bestimmen. Ausgesprochene Xerophyten, welche mit zeitweiser geringer Bewässerung auskommen, sind die meisten Aloineac, mit Ausnahme der obenerwähnten Fniphofic und einiger Hlö-Arten, ferner die Sanse-icria, einige wenige Dracacna und Asparagus.

Bei der Besprechung der einzelnen Gruppen und Gattungen will ich mit den beerenfrüchtigen beginnen, bei welchen eine weitere Verbreitung durch Tiere möglich ist.

\section{Asparagoideae.}

Asparagus L. Eine Gattung, welche von der Küste an bis in die Bergwälder, auf dem trockensten Kalkfels, auf sandigem oder lehmigem Boden, bisweilen aber auch auf humösem Waldboden angetroffen wird. Mehrere Arten erinnern an unseren $A$. officinalis, wie \%. B. der von Nubien bis Transvaal verbreitete, auf grasigen Plätzen und im Nald vorkommende, $\mathrm{I}-2 \mathrm{~m}$ hohe A. asiaticus L.; aber schon bei kurzem Aufenthalt in Afrika lernt man abweichendere Gestalten dieser Gattung kennen. Im trockenen Korallenkalk der Inseln von Dar-es-Salam sehen wir den nur $20-30 \mathrm{~cm}$ hohen Asparrous humilis Engl., und auf denselben Inseln klimmt im dichten Gebüsch von KandelaberEuphorbien und hartlaubigen Sträuchern bis zu einer Höhe von $2 \mathrm{~m}$ und dariber A. falcatus L. (Fig. I90) mit breit linealischen und starren Cladodien; diese auch in Ostindien rorkommende Art ist an vielen Stellen, meist in xerophytischen Formationen konstatiert worden rom Somaliland bis zum Sambesi, sodann westwärts bis zum Victoria Njansa, auch in Yoruba und am Kilimandscharo bis zu einer Höhe von $1600 \mathrm{~m}$ ii. M. Eine ebenfalls auffallende, durch weniger hreite Cladodien ausgezeichnete Art ist der in Natal heimische, jetzt als Zimmerpflanze sehr verbreitete 4 . Sfrengri Regel. Während bei den meisten Arten dic Kleinen schuppenartigen Blätter, in deren Achseln die Cladodien entstchen, mit einem zurückgebogenen, sporenartigen Dorn versehen sind, fehlt ein solcher bei dem im Nyassaland, nord- und südwärts vom Nyassa-See bis zu einer Itühe ron I $800 \mathrm{~m}$, sowie auch im Kapland rorkommenden, bis $2 \mathrm{~m}$ hohen 1. rirgatus Bak., welcher etwas an unseren Besenginster erinnert. Dagegen 
besitzt der bis $2 \mathrm{~m}$ hohe $A$. africanus Lam. (Fig. I I $A-D$ ), welcher vorzugsweise in Steppengehölzen verbreitet ist, an seinen Blättern stachelspitze Dornen, sowie auch lange pfriemenförmige Cladodien und in Scheindolden stehende Bliiten, deren feiner, an Naiglöckchen erinnernder Duft im Beginn der Regenzeit sich weithin bemerkbar macht; diese Art scheint im ganzen tropischen und subtropischen Afrika von der Erythrea bis Senegambien, sowie bis Südafrika verbreitet zu sein; sie fehlt auch nicht auf Socotra und in Arabien. Der vorigen nahestehend, aber kletternd und mit küirzeren Cladodien versehen ist . $t$. asiaticus $\mathrm{L}$.

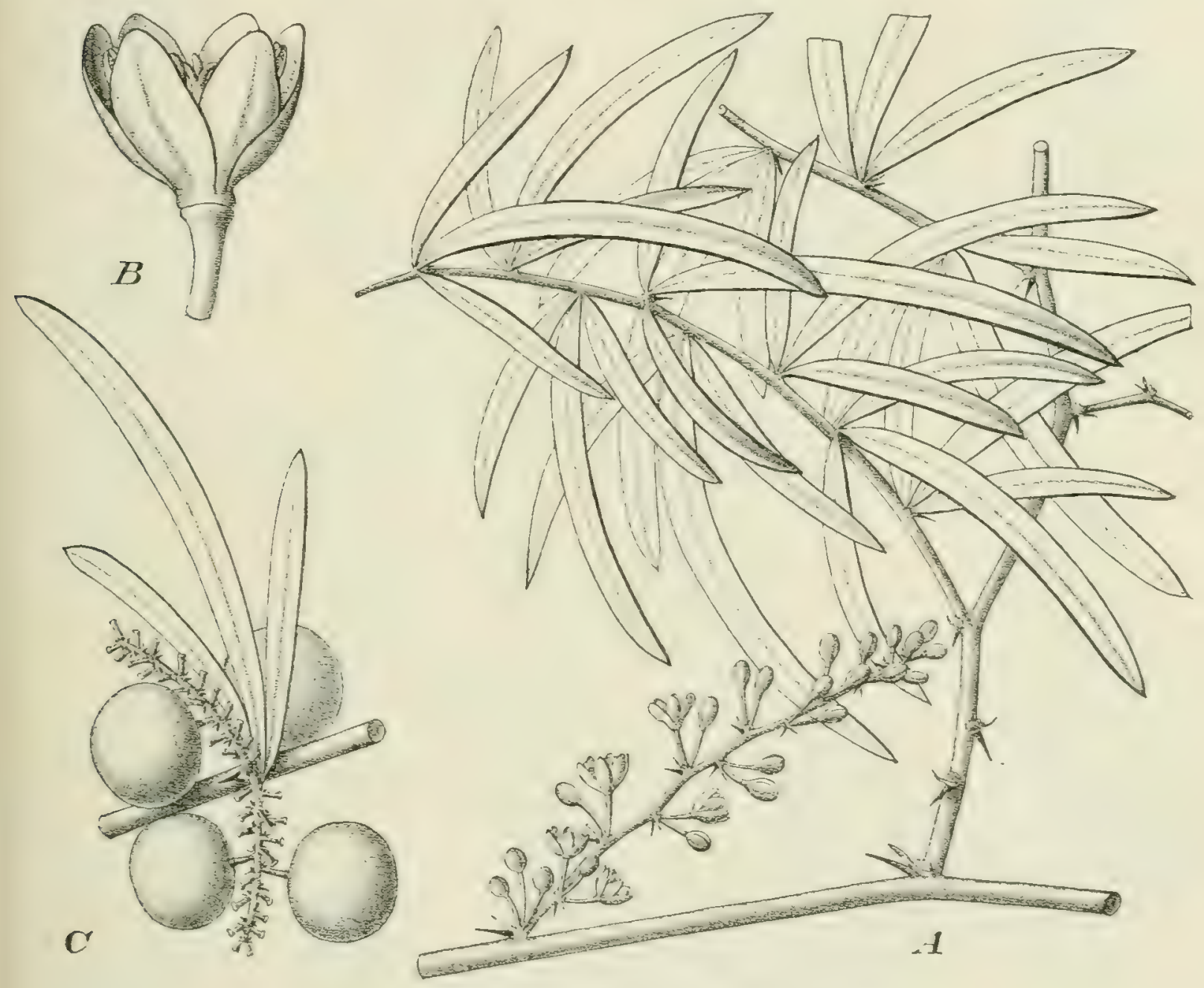

Fig. 190. Asparagus falcatus L. - Original.

(Fig. Igr $E, F$ ), welcher sich aus dem tropischen Asien über Arabien nach Nubien und von hier durch Ostafrika bis zur Delagoa-Bay und zum Oranjefluß verfolgen läßt.

Sehr auffallend ist A. racemosus Willd. (Fig. 192), ein bis $6 \mathrm{~m}$ hoch im Gesträuch hinaufklimmender Strauch, dessen Stämmchen bis I cm dick wird und bisweilen 2-3 cm lange, ungemein kräftige Blattdornen trägt, auch bisweilen über das Geäst der Bäume herunterhingt und lange, linealische Cladodien besitzt, die aber in ihrer Breite je nach den Standorten Strandbusch, Steppengehölz, Gebirgsivald) sehr variieren; bei ihm stehen die Blüten in $2-5 \mathrm{~cm}$ langen, traubenähnlichen Blïtenständen. Auch diese Art wird im ganzen tropischen 
Afrika bis nach Amboland angetroffen und wird auch rom Kapland angegeben. Iit dieser Art etwas verwandt ist der $2-3 \mathrm{~m}$ hoch kletternde $A$. drepanophyllns Wilw, bisweilen mit $3 \mathrm{~mm}$ breiten, 2-5 $\mathrm{cm}$ langen, schwach sichelförmigen Cladodien, eine ausgezeichnete Art. die im oberen Kongogebiet und Angola an Fluß-

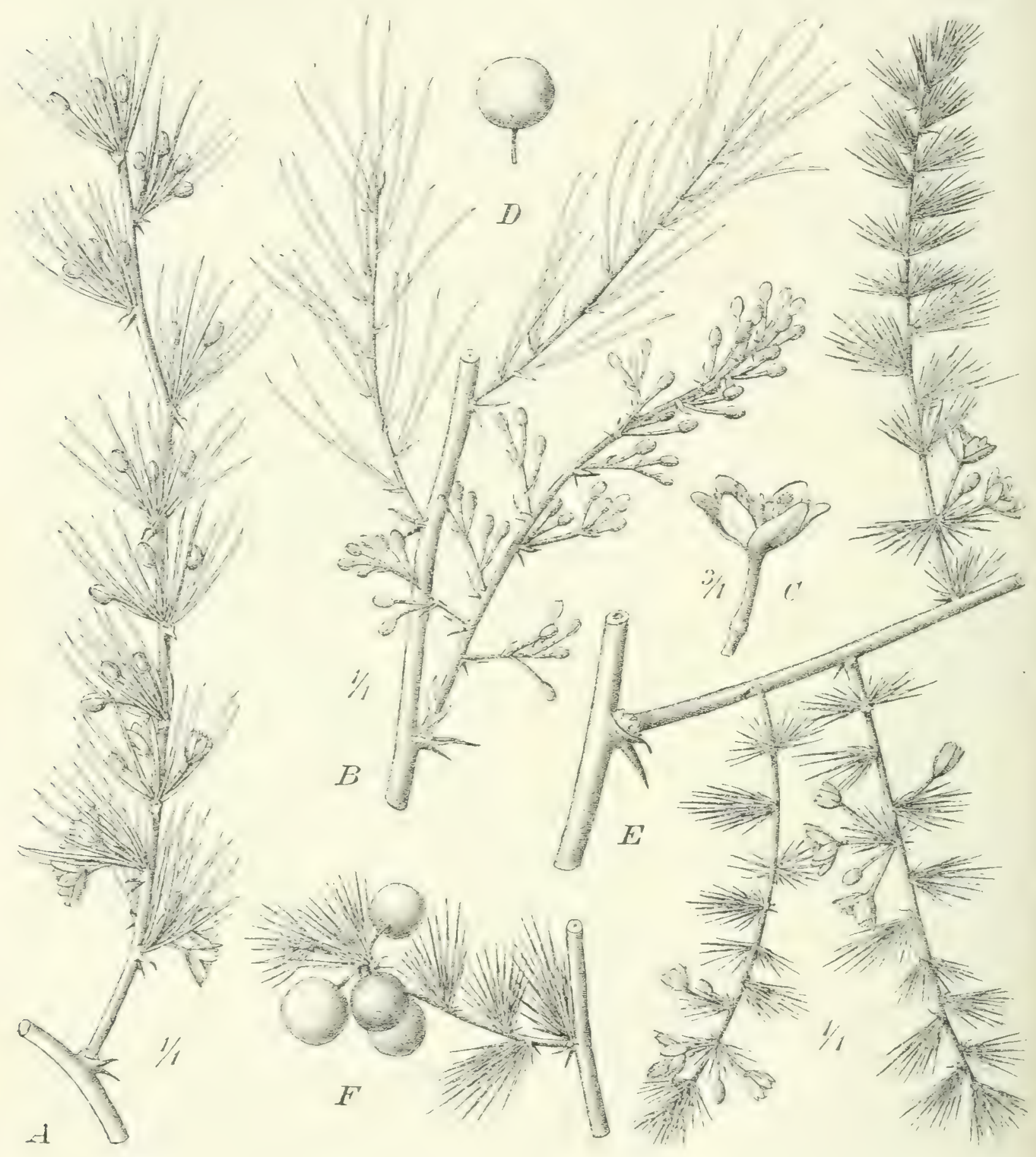

Fig. 19I. $A-D$ Asparagus africanus Lam. $E-F$ A. asiaticus L. - Original.

ufern, sowic in dichten Bergwäldern vorkommt. In die nähere Verwandtschaft ion 4. racmosus gehört auch der in siidlichen Nittelmeergebiet und auf den Kanarischen Inseln vorkommende A. alturs L., welcher auch lange Blattdornen entwickelt, dic ihn zu einem Hakenkletterer machen. Endlich wollen wir von den etwa to bekannten afrikanischen Asparagus noch A. plumosus Bak. und 
A. medcoloides Thunb. hervorheben, zwei Arten, die seit einigen Jahren ganz besonders zu Tafeldekorationen verwendet werden und bei Blumenausstellungen nicht selten eine hervorragende Rolle spielen. Der durch seine diunnen, zarten

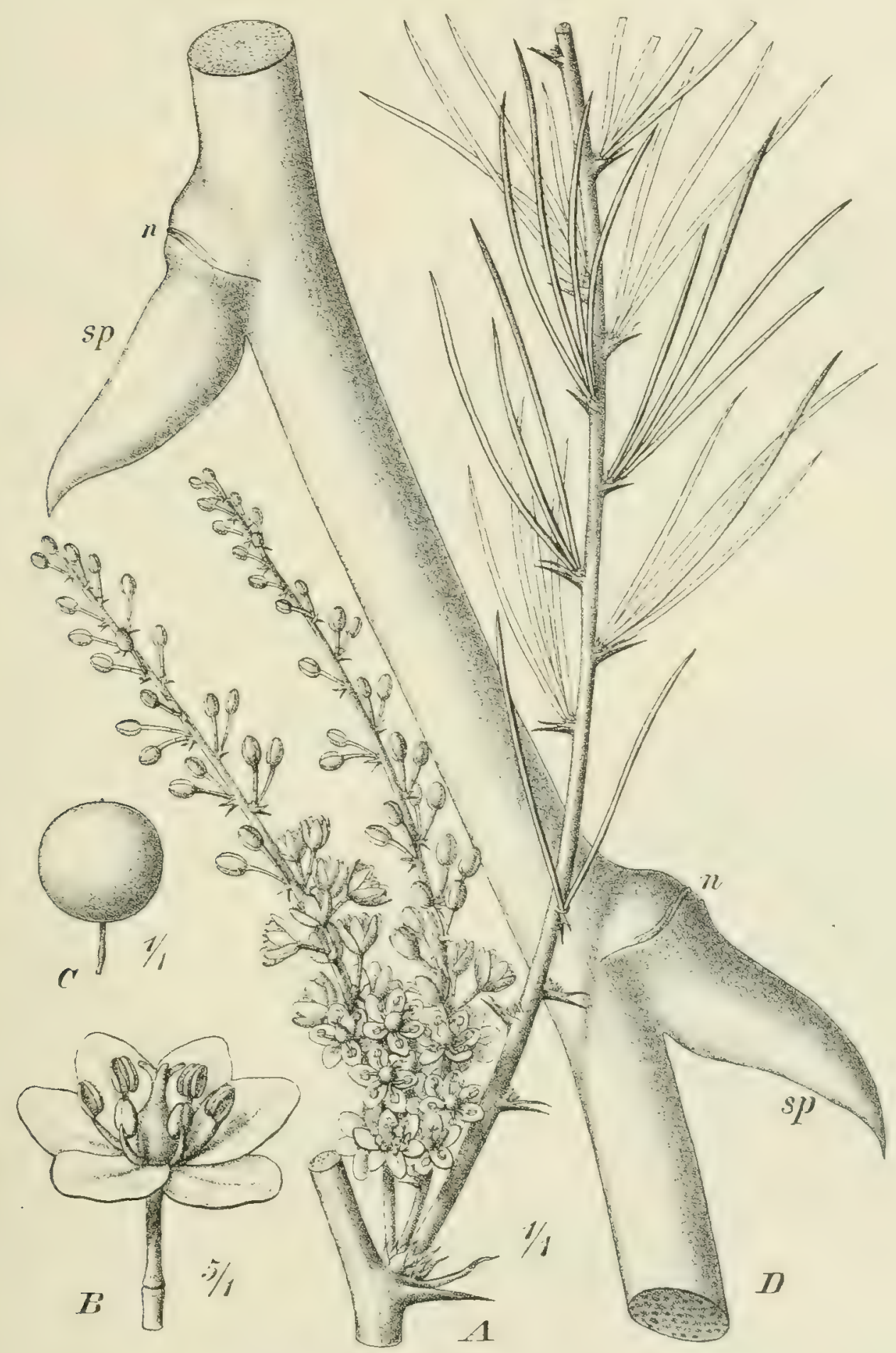

Fig. 192. Asparagus racemosus Willd. $D$ ein älterer Zweig mit verholztem Sporn $(s p)$ der Schuppenblätter, von denen bei $n$ die Ansatzstelle (Narbe) sichtbar ist.

Cladodien, kleine Blattdornen und langen aufsteigenden, hin und her gebogenen Stengel ausgezeichnete 4 . plunnosus ist in waldartigen Beständen der Ebene und der Gebirge von Englisch-Ostafrika bis Pondoland verbreitet. A. medeoloides Thunb., welcher breite, eiförmige Cladodien besitzt, welche denen von Ruscus 
ähnlich, jedoch viel biegsamer sind, findet sich im östlichen tropischen Afrika nur im Gebirgsbusch in einer Höhe von etwa $1300 \mathrm{~m}$ und darüber; er ist bis jetzt konstatiert vom Gallahochland, von Kikuju und Uluguru. Dann tritt er in Transvaal, in Namaland, sowie im westlichen und östlichen Kapland auf.

Semele Kunth mit S. androgyna (L.) Kunth ist ein höchst auffallender, bisweilen mehrere Meter hoch kletternder Strauch der oberen immergriinen Nebelwälder der Kanarischen Inseln; man findet ihn noch besonders schön in dem Wald oberhalb Taganana auf Teneriffa.

\section{Smilacoideae.}

Smilax L. Während im tropischen Asien und Amerika diese Gattung sich zu großer Mannigfaltigkeit entwickelt hat, kennen wir im tropischen Afrika nur zwei Arten, von denen die eine, Sm. Kraussiana Meissn., sich in Buschund Waldformationen, aber meist an lichteren Stellen, sowic auch in der so häufig an Stelle vernichteten Waldes auftretenden Adlerfarnformation findet, vom Ghasalquellengebiet an bis Natal und von Senegambien bis zum unteren Kongogebiet. Wir finden Sm. Franssiana von der Ebene bis zu einer Höhe von $2000 \mathrm{~m}$ ï. M.: aber im Gallahochland und Nyassaland, vielleicht auch in anderen ostafrikanischen Hochgebirgen finden wir die eigentuimliche Sur. Goctacana Engl., welche eiförmige, am Grunde stumpfe oder herzförmige Blätter und Blütenzweige mit drei bis vier Blitendolden besitzt.

\section{Dracaenoideac.}

Dracaena L. Während Smilax im tropischen Asien reichlicher auftritt als im tropischen Afrika, ist umgekehrt die Gattung Dracacna in Afrika reicher entwickelt als im tropischen Asien, auch zeigt sie eine große Mannigfaltigkeit in der Sproßentwicklung und Stammbildung. Am reichsten treten dic Dracacna im tropischen Regenwald auf und hier finden sich ebenso niedrige, halbstrauchige oder staudenartige Formen, wie mächtig entwickelte Bäume; die letzteren sehen wir auch in Waldlichtungen und in der an Stelle von Wald getretenen Adlerfarnformation, einzelne auch in Gebirgssteppen. Es dürften mindestens 60 Arten in Afrika zu unterscheiden sein; auch noch über Natal hinaus bis Uitenhage kommt eine $0,6-3 \mathrm{~m}$ hohe Art, D. Hookeriana $\mathrm{K}$. Koch, vor. Von hohen baumartigen Dracaenen möchte ich zuerst die am weitesten verbreitete nennen: D. fragrans (L.) Gawl. (Fig. 193), in unseren botanischen Gärten als Aletris fragrans kultiviert, tritt schon in Abyssinien auf und ist dann durch das zentralafrikanische Seengebict bis in das siidliche Nyassaland zu verfolgen; wir finden sie aber auch im Westen von Sierra Leone bis Angola zerstreut, vielfach kultiviert. Die höchsten für diese Art mir bekannt gewordenen Maßangaben sind $10-12 \mathrm{~m}$. Der vorigen Art steht D. deremensis Engl. von Ostusambara nahe, welche jedoch durch länger gestielte und um die Hälfte längere Bliiten unterschieden ist, auch nicht ïber $5 \mathrm{~m}$ hoch wird. If $\mathrm{m}$ erreicht die von Ober-Guinea bis Angola in lichten Wäldern und vereinzelt in dichten Buschgehölzen vorkommende D. arborca (Willd.) Link; an letzteren Standorten ragt sic oft mit zahlreichen, dünnen Ästen über das übrige Laubwerk hinaus. Ein sehr stattlicher Baum, vielleicht der höchste von allen, ist die auf Usambara 
und Usagara beschränkte Dracaina fafuhu Engl., ron der ich selbst I5-I $8 \mathrm{~m}$ hohe Exemplare mit I m langen Bliitenständen gesehen habe, während andere Beobachter auch $25 \mathrm{~m}$ Höhe angegeben haben; sie ist kaum unter $800 \mathrm{~m}$ Höhe ü. M. anzutreffen. steigt in den Waldlichtungen bis zu $1500 \mathrm{~m}$ auf und findet sich auch in der Adlerfarnformation des ostafrikanischen Gebirgslandes. Alle diese Arten haben dicke Stämme wie die Drachenbäume von Teneriffa.

Kleinere Bäume des Regenwaldes sind die bis ro $\mathrm{m}$ hohen D. Mamnii Bak. und D. Deistcliana Engl. von Kamerun, die + $\mathrm{m}$ hohe D. Perottetii Bak. von Senegambien, die I2 $\mathrm{m}$ erreichende $D$. parviftora Bak., die 4 bis $5 \mathrm{~m}$ hohe, großblütige D. Prenssii Engl. in Kamerun. Strauchund baumartig entwickelt sind D. reflexa Lam. var. nittens Bak. und D. usambarensis Engl., an deren Zweigen die linealischen Blätter locker stehen und nicht $\mathrm{zu}$ einem Schopf zusammengedrängt sind. Beide finden sich als Unterholz im Walde und an sonnigen Waldrändern, erstere (bis $3 \mathrm{~m}$ hoch) in Angola, letztere (von mir bis $6 \mathrm{~m}$ hoch gesehen, nach anderen bis

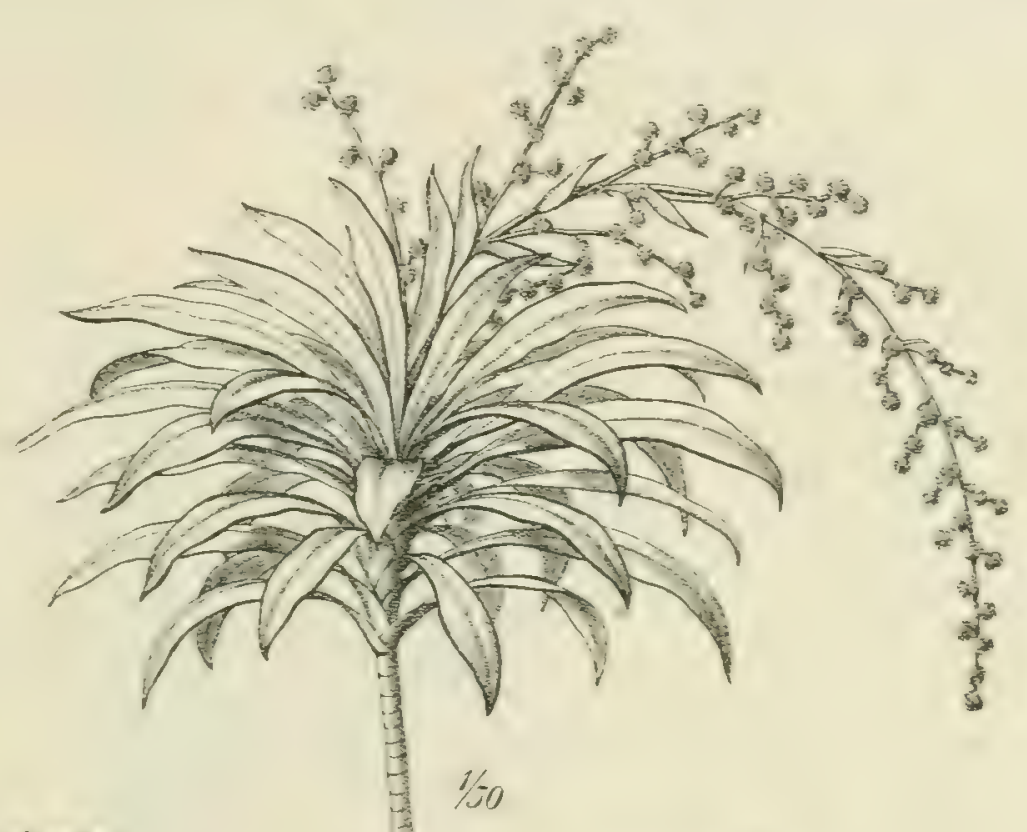
I $2 \mathrm{~m}$ hoch) von Usambara bis zum Rungwe in den Gebirgswäldern, auch am Kilimandscharo. Einen anderen Typus stellen dar mehrere reich verzweigte Sträucher, an deren Zweigen die Blätter stellenweise genähert, dann aber wieder durch größere Internodien getrennt sind; es sind alles Formen des Regenwaldes, in dem sie an der Bildung 
des Unterholzes teilnehmen. Hierher gehören namentlich die ron Sierra Leone bis Gabun verbreiteten D. camcrooniana Bak. und J). surculosa Lindl. (Fig. 194), sowie die im französischen Kongogebiet vorkommende D. cerasifora Hua mit sitzenden Blättern, ferner die gestieltb!ättrigen Arten D. laxissima Engl. ron Kamerun und D. clliptica Thunb. et Dalm., welche in Ostafrika vom Seengebiet bis zum Nyassaland verbreitet ist und auch in Ostindien vorkommt. In Westafrika finden sich noch einige andere Arten dieser Gruppe. Außerdem sind aber aus den IVäldern Westafrikas noch mehr als ein Dutzend niedrige Arten

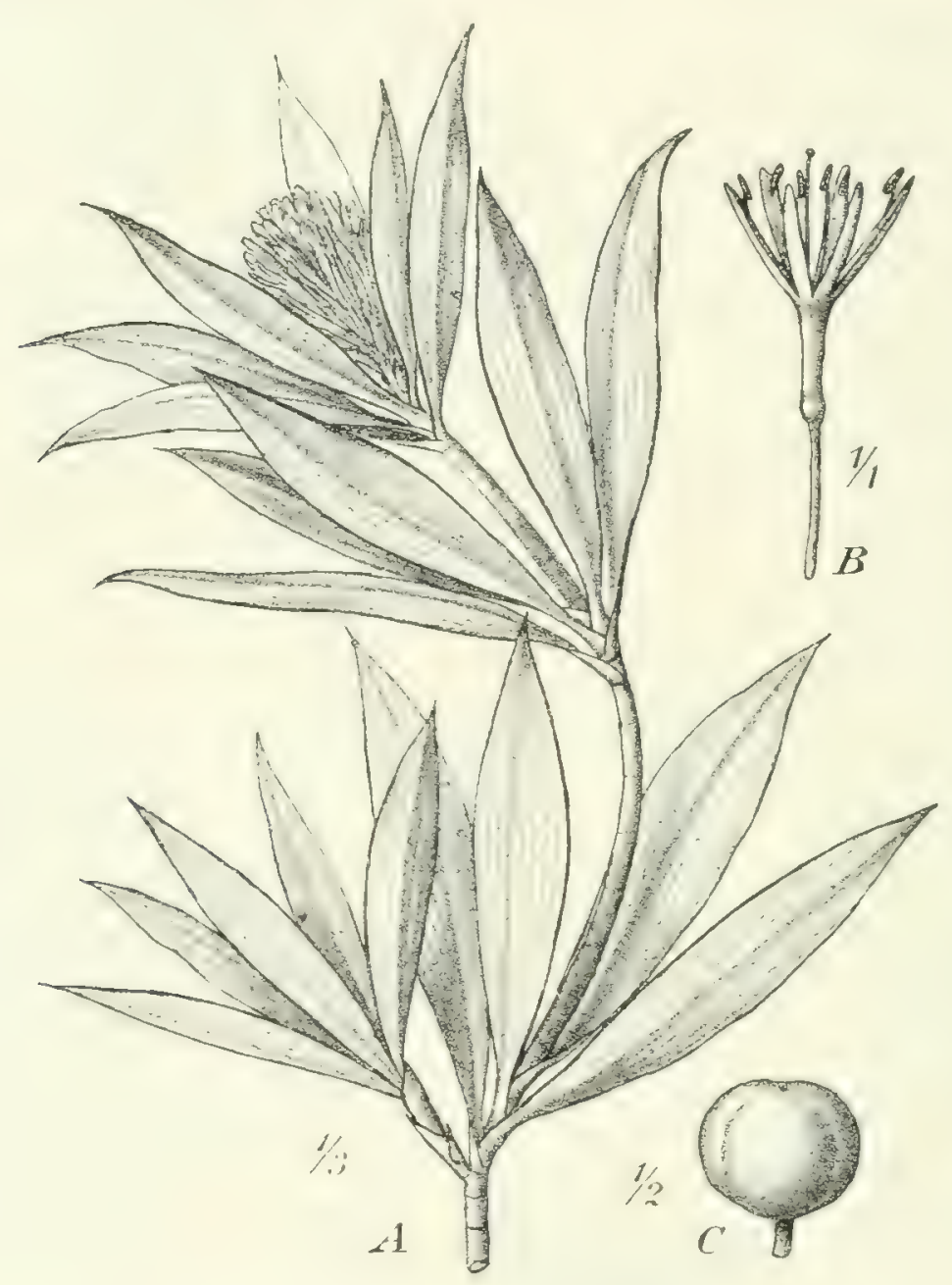

Fig. 194. Dracaena surculosa Lindl. (Kamertn). - Original.

mit gestielten, lanzettlichen oder eiförmigen Blättern bekannt geworden; unter diesen hat die durch eiförmige, quer grün und silbergrau gestreifte Blätter ausgezeichnete I)raiacna Golizicana Bull aus Ober-Guinea als Zierpflanze für Warmhäuser eine gewisse Bedeutung. Auch gehört hierher D. Poggci Engl. (Fig. I95) rom Lomami im Kongogebiet. In Kamerun wächst auch die eigenartige, bis $4 \mathrm{~m}$ hohe $D$. cylindrica Hook. fo, deren ganzer Stamm von dicht stehenden, lanzettlichen Blättern besetzt ist und mit einer kugeligen Inflorescenz dicht gedrängter Bliiten abschließt. Thhnlich verhält sich die $5 \mathrm{~m}$ hohe $D$. bicolor Hook. ron Fernando Po, doch stehen bei ihr die Blätter weniger dicht. Sehr eigenartig ist die im gebirgigen Angola vorkommende I). acaulis Bak., deren 
0,3- I m lange, lanzettliche Blätter eine grundständige Rosette bilden, welche von einer $\mathrm{I}-1,5 \mathrm{~m}$ hohen Blütenrispe überragt wird. Xerophytische Dracaenen sind nur wenige zu nennen, nämlich D. orabit Kotschy et Peyr., die im östlichen Afrika am weitesten nördlich (von der Erythrea bis Suakin) vorkommende Art, mit $2-2,5 \mathrm{~m}$ hohem, gabelig verzweigtem Stamm und $0,4-0,6 \mathrm{~m}$ langen, starren, schwertförmigen Blättern, die ihr sehr ähnliche I). Henningtonii Bak. von Uniamwesi, die mit großen lanzettlichen Blättern

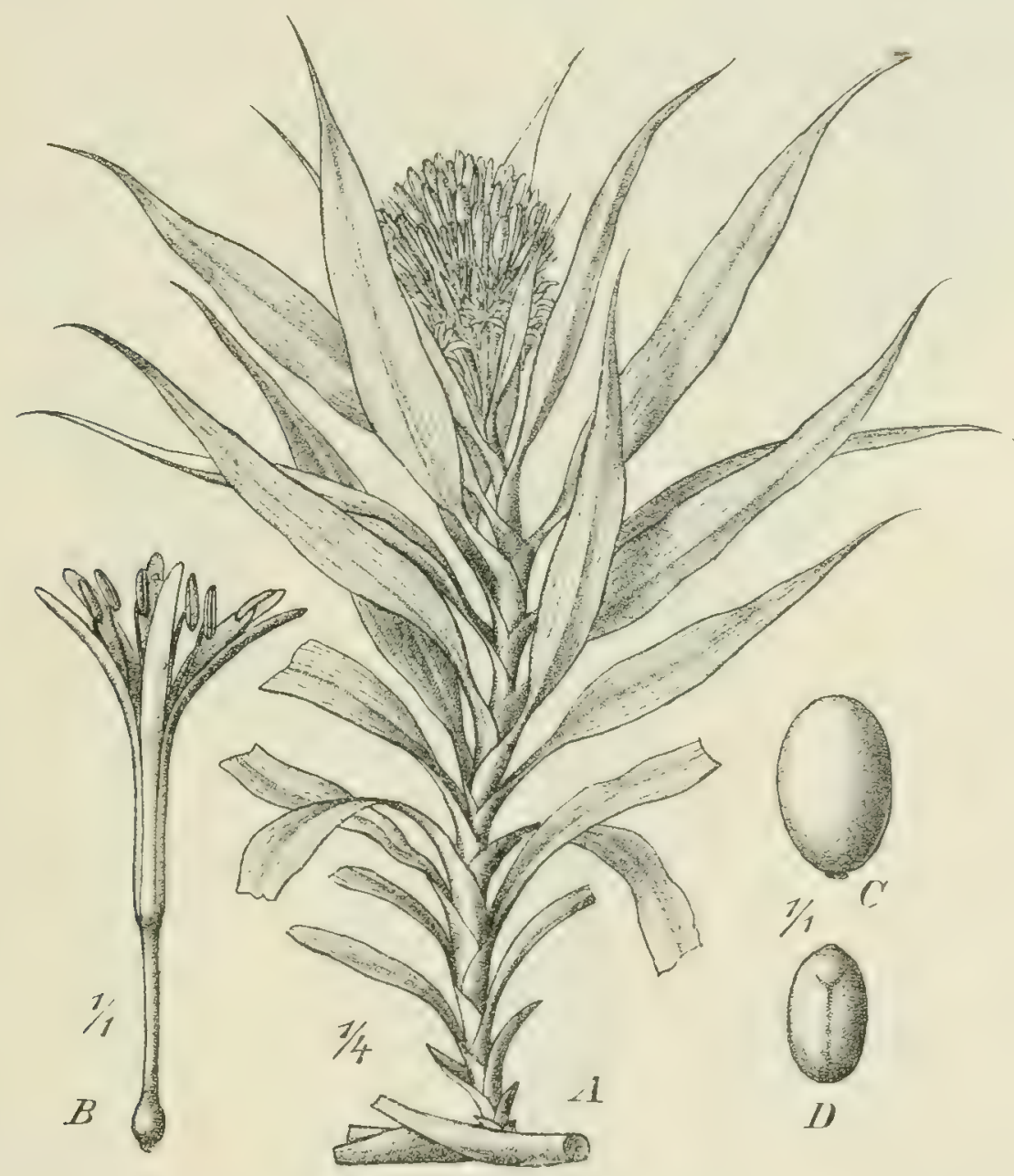

Fig. 195. Dracaena Poggei Engl. (Kongostaat). - Original.

versehene D. Stcudncri Engl. aus dem abyssinischen Hochland, I). Ellenbiticund Engl. vom Gallahochland, zwischen Luku und Sheik-Hussein, um I $500 \mathrm{~m}$, die bis $10 \mathrm{~m}$ hohe, gabelig verzweigte $D$. schizantha Bak. vom nordöstlichen Somaliland und die stattliche $D$. cimnabari Balf. f. von der Insel Socotra. Den letztgenannten Arten steht auch die am weitesten nach Norden vorgeschobene Art, die bekannte $D$. draco L. von Teneriffa nahe, deren stattlichstes, von AL. vos Huxbold bewundertes Exemplar (Fig. I 96) zwar jetzt verschwunden ist, von der aber immer noch gewaltige Exemplare angetroffen werden, welche mit denen von $D$. papahu und $D$. arborea verglichen werden können.

Sansevieria Thunb. Mit den Dracaenen scheint mir einigermaßen verwandt diese durch dünnwandige Frïchte ausgezeichnete Gattung, deren Arten namentlich 


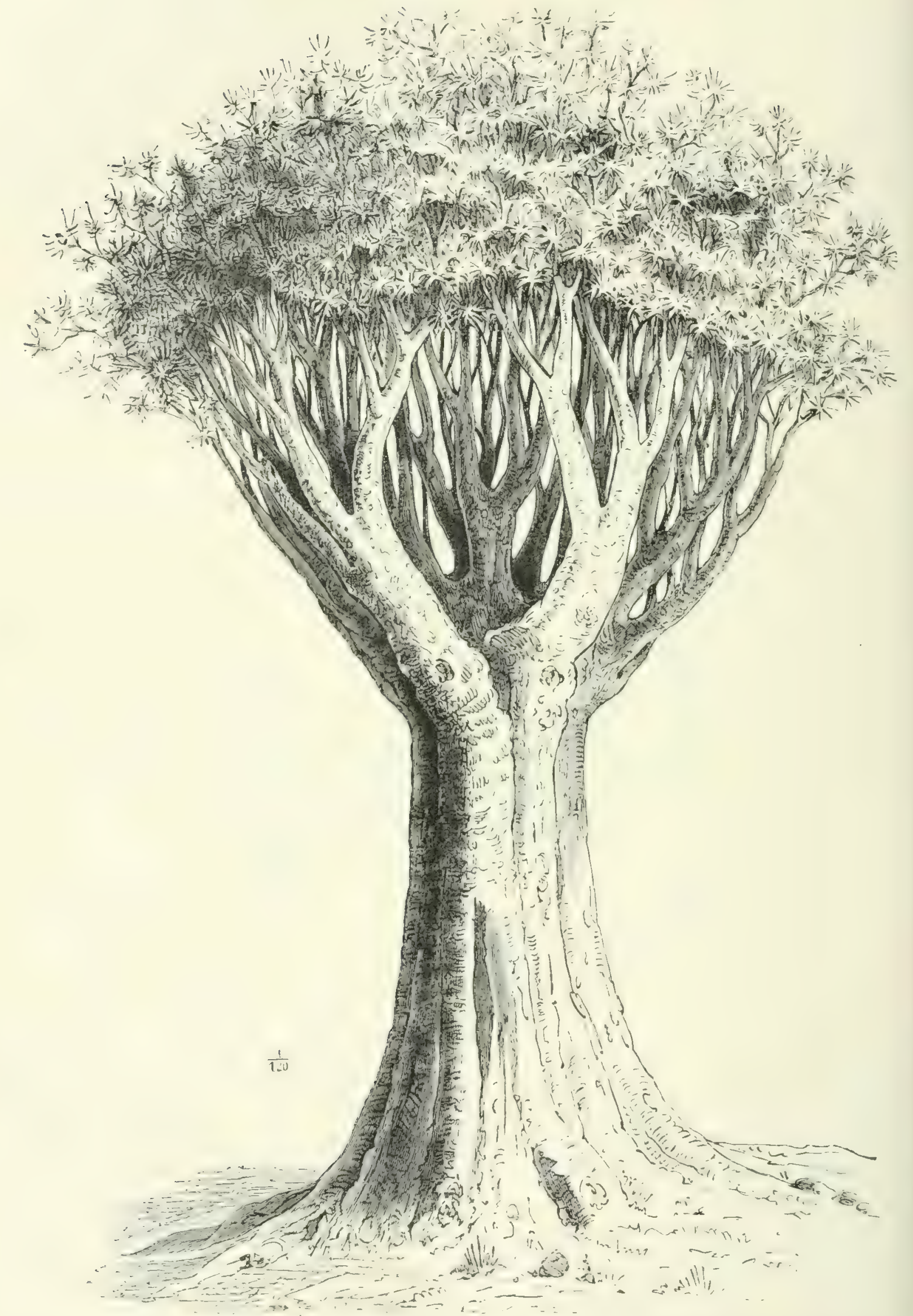

Fig. 196. Dracaena draco L. Das im Jahre I\$6S durch einen Orkan zerstörte Exemplar von Orotava auf Teneriffa. 
in den Steppenformationen des tropischen Afrika eine hervorragende Rolle spielen. Sie besitzen alle kräftige, sich reichlich verzweigende Rhizome, deren Sprosse flache oder zusammengefaltete oder endlich stielrunde, ungemein starre, ron mächtigen, einen recht brauchbaren Faserstoff abgebenden Bastbündeln durchzogene Blätter tragen. Die am weitesten verbreitete Art ist S. guincensis Willd. (Fig. I97 A-C), mit flachen, lanzettlichen, bisweilen I m langen Blättern: sie
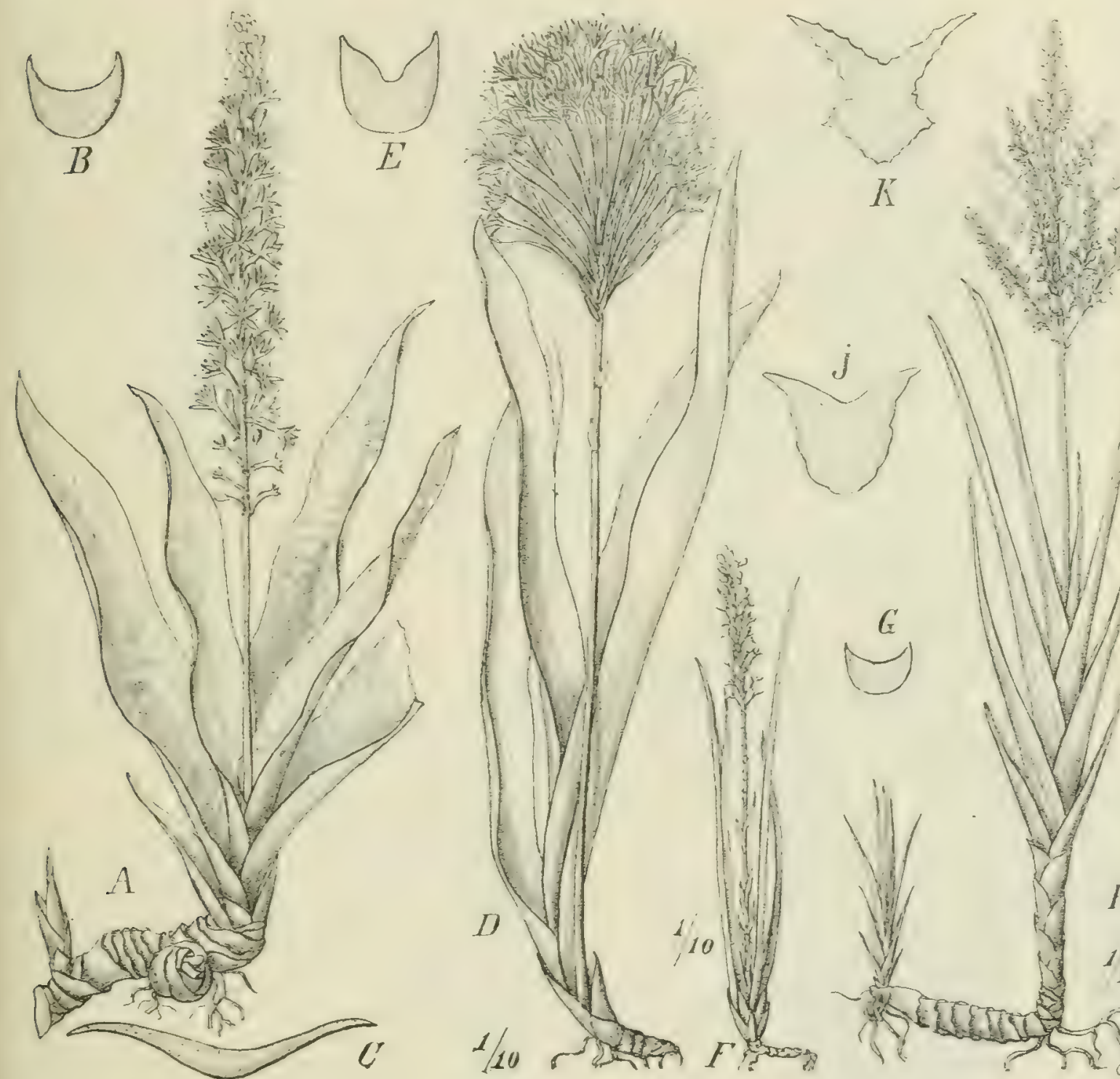

Fig. 197. $A-C$ Sansevieria guineensis Willd. $B$ Querschnitt des Blattes am Grunde; $C$ ein solcher von oben. $D, E \mathrm{~S}$. longiflora Sims. (Ostusambara). $E$ Querschnitt des Blattes unten. $F, G$ S. Volkensii Gürke. $G$ Querschnitt des Blattes in der Mitte. H S. Ehrenbergii Schweinftb. $\mathcal{F}$ Querschnitt des Blattes unten; $K$ ein solcher aus der Mitte. $-D-G$ Original, das iibrige nach GÜRKEE.

findet sich vielfach an trockenen Abhängen der Steppenbäche und in den Steppenbuschgehölzen, vom nördlichen Abyssinien und der Erythrea an bis zum unteren Sambesi, im zentrakafrikanischen Seengebiet und ron Sierra Leone bis zum unteren Kongo, auch auf Fernando Po. Etwas weniger verbreitet ist die langblütige S. longiflor $\alpha$ Bak. (Fig. I97 D, E), doch ist sie nachgewiesen in Westafrika, im Lande der Niam-Niam und Usambara. An diese Arten schließen sich 
einige andere auf hleinere Bezirke beschränkte Arten an, wie S. scncrambica Bak. in Senegambien, S. Kirkii Bak. im suddichen Nyassaland, auch die mit $2 \mathrm{~m}$ langen lanzettlichen Blättern versehene S. nilotica Bak. vom Ghasalquellengebiet. Oben rinnige, an der Rückseite abgerundete

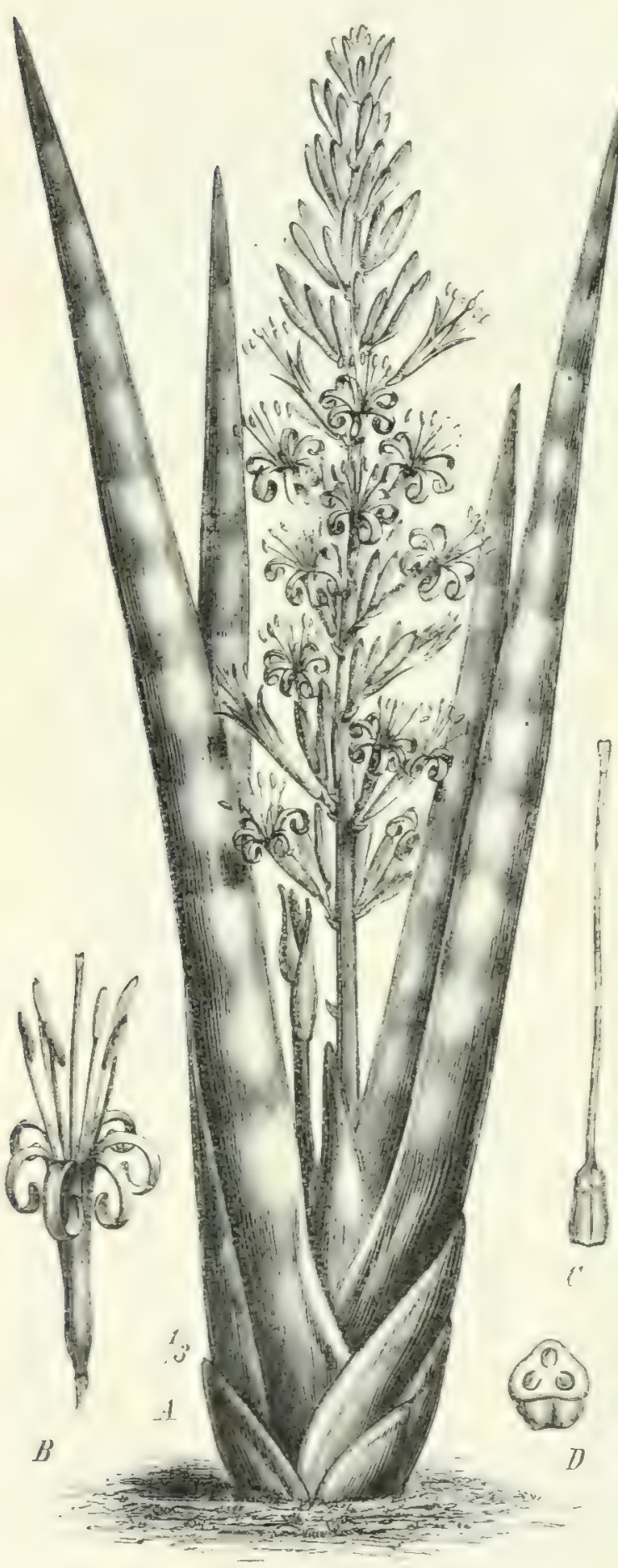

Fig. I9\$. Sansevieria cylindrica Boj. Blätter besitzen S. Volkensii Gürke (Fig. I $97 F, G$ ) mit nur $5 \mathrm{dm}$ langen Blättern und S. Ehrenbergii Schweinfth. (Fig. I $97 H-K$ ), deren aufrechte Sprosse zahlreiche, zweireihig gestellte, bis $2 \mathrm{~m}$ lange, oben stark pfriemenförmige Blätter und eine große, im Umriß dreieckige Blitenrispe tragen. Beide Arten sind Bewohner der Dornbuschsteppen, die erstere vorzugsweise im Kilimandscharogebiet, die letztere von den Küstenländern des Roten Meeres bis in die Steppen von Deutsch-Ostafrika, oft in großer Häufigkeit auftretend. Weniger zahlreiche, aber auch bis $2 \mathrm{~m}$ lange, nur am Grunde scheidige, dann stielrunde und lang zugespitzte Blätter trägt S. cylinzdrica Boj. (Fig. I98), welche von der Erythrea bis zum Matabeleland verbreitet ist und auch im unteren Kongogebiet, in Angola und dem Amboland beobachtet wurde.

\section{Luzuriagoideae.}

Behnia Didrichs. Eine sehr isoliert stehende Gattung, stark verzweigt, spreizklimmend, mit sitzenden eiförmigen Blättern, welche jederseits von fünf bis sieben starken Längsnerven und zahlreichen, sehr deutlichen Quernerven durchzogen sind; die Blüten stehen in axillären. Trugdolden und besitzen ein trichterförmiges, verwachsenblättriges Perigon. Die einzige Art, B. reticulata (Thunb.) Didrichs., ist in Wäldern von Natal und Transvaal bis Uitenhage verbreitet.

TVenden wir uns nun den kapselfriichtigen Liliaceen zu, und zwar zunächst den Melanthioideae.

Gloriosa L. Die fünf afrikanischen Arten dieser Gattung besitzen so wie die ihrer weniger ansehnlichen Terwandten eine unterirdische Knolle, der cin 
Stengel mit zahlreichen, meist an der Spitze rankenden Blättern und großen, prächtig gefärbten, sternförmig ausgebreiteten Blüten entspringt. In den Regenwäldern der Gebirge, im Westen auch in der Ebene, finden wir die auch im tropischen Asien vorkommende G. supcrba L. mit oft $3 \mathrm{~m}$ langem Stengel und orangefarbenen Blïten. Oft ebenso kräftig entwickelt ist die im ganzen

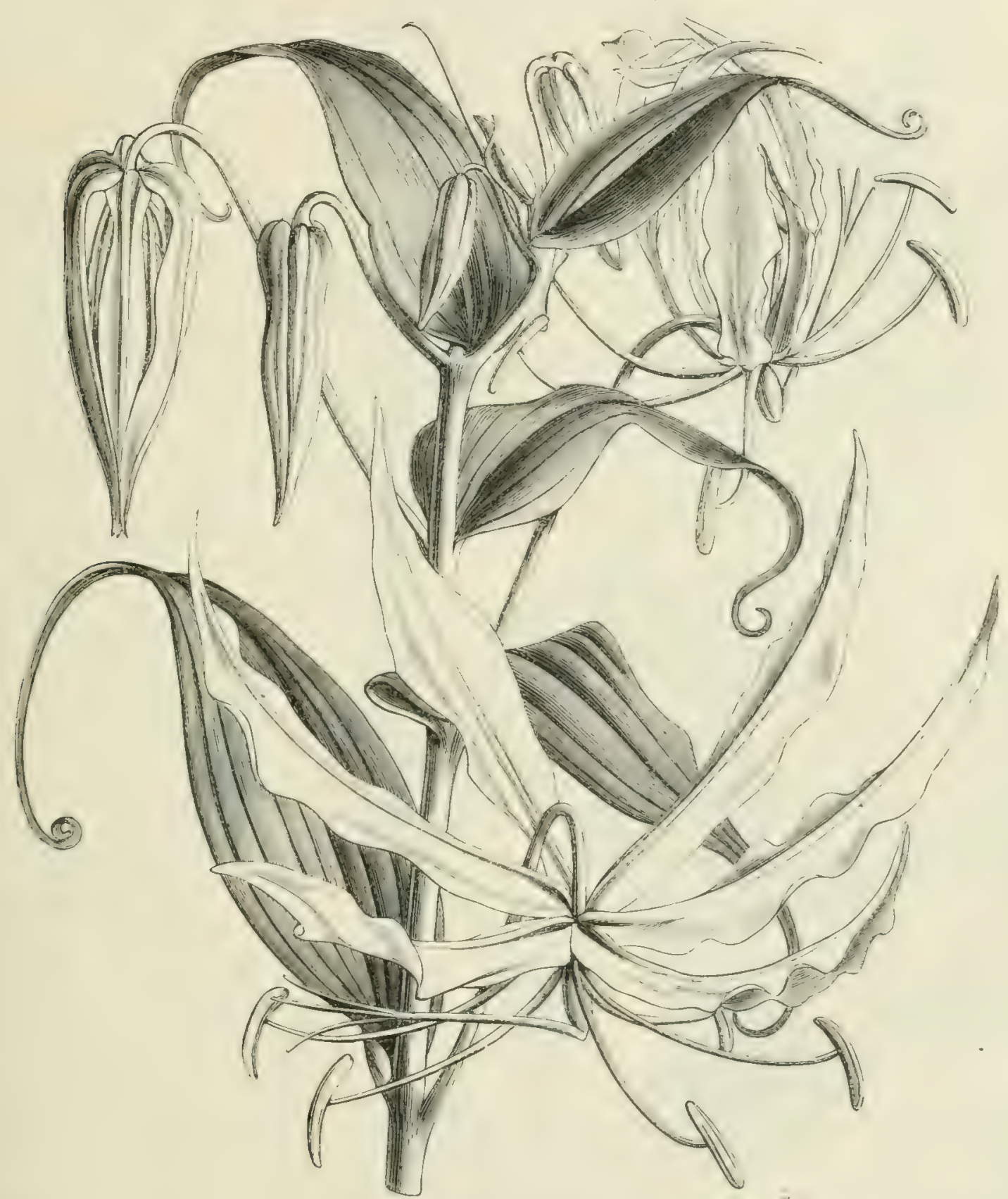

Fig. 199. Gloriosa virescens Lindl, var. grandiflora (Hook.) Bak. - Nach Bot. Magaz.

tropischen Afrika verbreitete G. airescens Lindl. mit roten, gelben oder grüngelben Bluiten (Fig. I99); je nachdem sie auf Dünensand, Marschboden, an feuchten schattigen Plätzen, in der Obstgartensteppe oder auf humusreichem Waldboden wächst, variiert sie in der Distanz und Breite der Blätter, der Größe und Farbe der Blüten; sie scheint nicht über $1+50 \mathrm{~m}$ Höhe ü. M. aufzusteigen. Einen kürzeren, aufrechten Stengel haben die beiden folgenden Arten: G. speciosa 
(Hochst.) Eng-1. ( $=$ G. aly'ssinica A. Rich.' mit prachtvollen, roten, breitblättrigen Bliiten ist nur in der Erythrea, Abyssinien, dem Galla- und Somaliland auf feuchten Grasplätzen, in einer Höhe von I300-2000 $\mathrm{m}$ ii. M. anzutreffen. Dagegen entspricht dieser Art auf den Gebirgen des Nyassalandes im Norden.

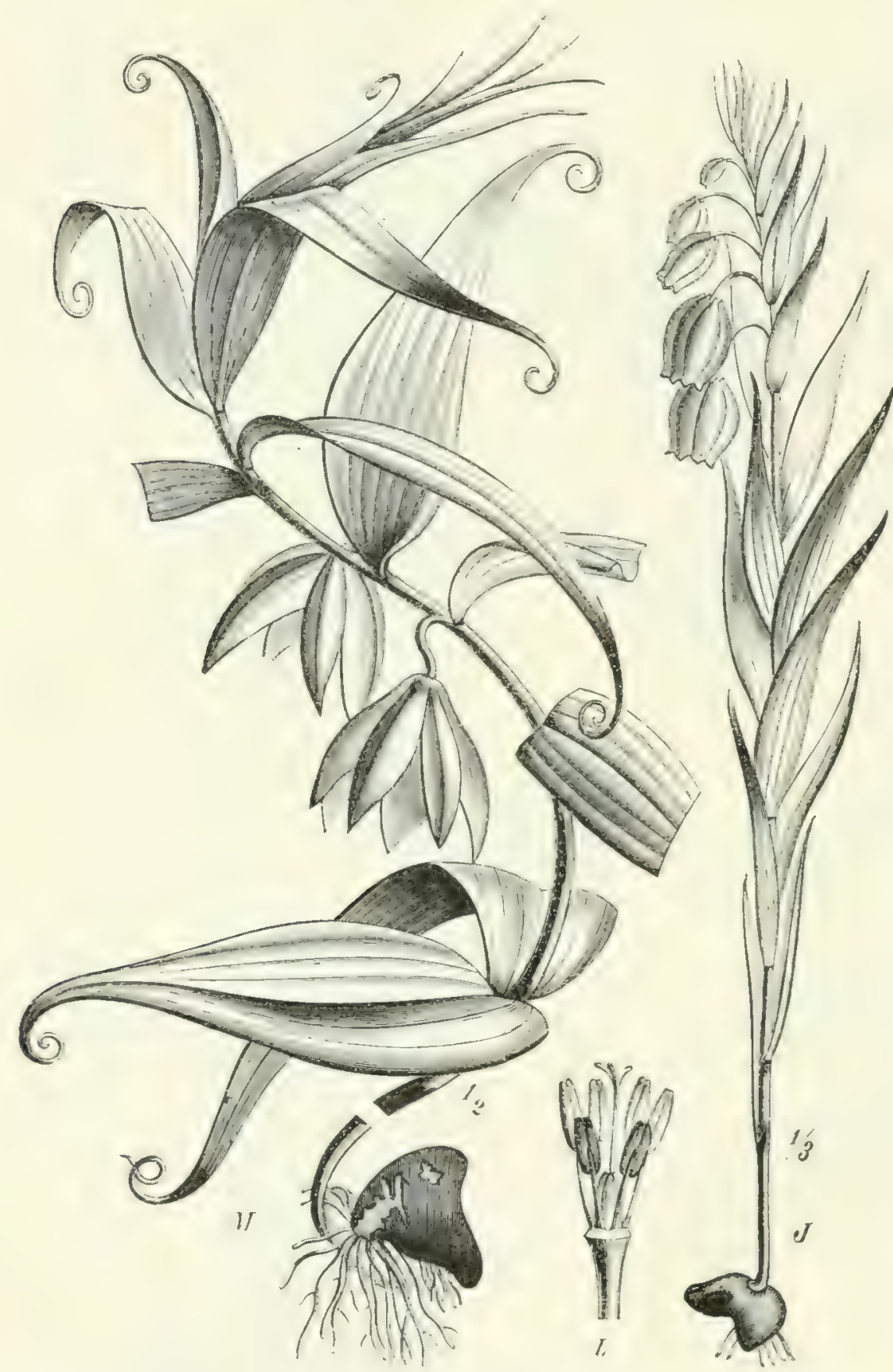

Fig. 200. $\mathcal{F}, L$ Sandersonia aurantiaca Hook. fo (Natal) II Littonia modesta Hook. (Transvaal, Natal). - Nach Bot. Magaz.
IVesten und Süden des Sees die mit rankenlosen Blättern und nickenden, roten, gelbgefleckten Blüten versehene $G$. Carsoni Bak.

Littonia Hook. f. ist mit Gloriosa nahe verwandt, aber in allen Teilen kleiner und mit glockig zusammenneigenden Blütenhüllen versehen; ihre Arten finden sich vorzugsweise in Buschsteppen des Somalilandes und Harars, eine auch am Tanganyika - und Muera-See, eine in Wäldern von Angola, L. modesta Hook. in Natal und Transvaal (Fig. $200 M$ ).

Sandersonia Hook. f., durch verwachsenblättrige Blütenhüllen ausgezeichnet, ist mit $S$. aurantiaca Hook. f. (Fig. $200 \mathcal{F}, L$ ) von Natal durch Griqualand bis Pondoland auf Grasland und an Waldrändern verbreitet.

Walleria Bak. zeichnet sich dadurch aus, daß das Perigon mit der

Basis des Fruchtknotens verwachsen ist; der beblätterte Stengel trägt in zahlrcichen Blattachseln blaue Blüten; zwei Arten sind auf steinigem Gebirgsland von Uhehe und vom mittleren Tanganyika bis zum suidlichen Nyassaland rerbreitet, II: Nackonaii Kirk auch in Benguela und $I$ : matans Kirk auch in Transvaal. 
Iphigenia Kunth Fig. 201, D, E), Zwiebelgewächse mit schmalen Stengelblättern, flachen Staubblättern und fachspaltiger Kapsel. Von dieser auch im Monsungebiet vertretenen Gattung wachsen auf steinigen und sandigen Plätzen

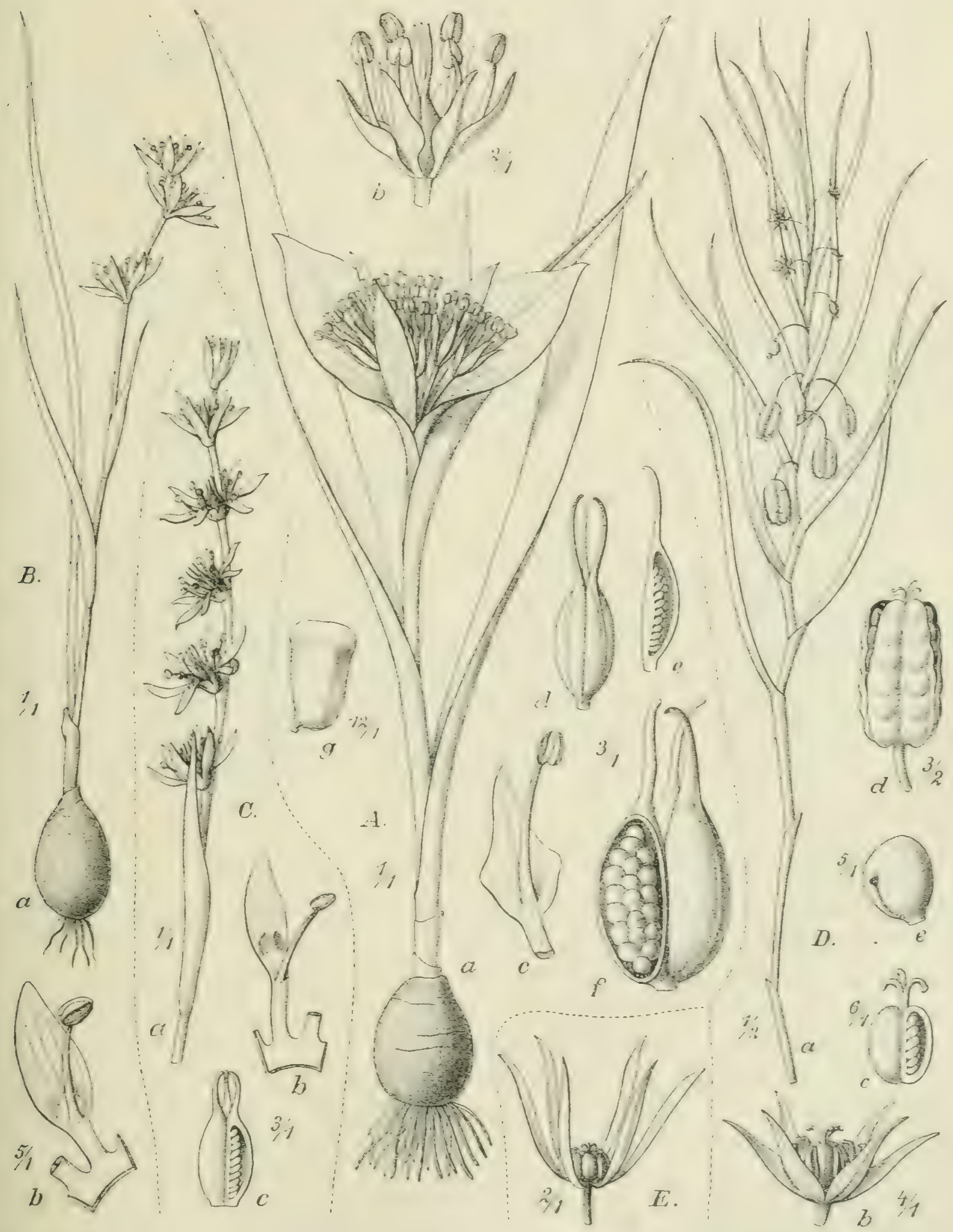

Fig. 201. A Androcymbium striatum Hochst. (Abyssinien). $B$ Wurmbea tenuis (Hook. f.) Bak. (Kamerungebirge, um $3000 \mathrm{~m}$ ü. MI.). C W. Goetzei Engl. (Uhehe). $D$ Iphigenia Oliveri Engl. (Taveta). E I. somaliensis Bak. (Brit. Somaliland). - Original. 
der. Steppen bei Delagoa-Bay etwa sechs Arten, von denen keine besonders häufig aufzutreten scheint. I. Cliuri Engl. Fig. 20I $D$ kommt bei Taveta vor.

Ornithoglossum Salisb., von voriger Gattung durch fadenförmige Staubblätter unterschieden, geht rom sïdlichen Nyassaland und Amboland südwärts bis Kapstadt. Die einzige Art ist O. glaucum Salisb.

Wurmbea Thunb. und die folgenden Gattungen haben scheidewandspaltige Früchte. Die Bliten dieser Gattung aher sind in Gegensatz zu den übrigen vereintblättrig. So wie von Ifluginum gibt es auch von dieser Gattung einige Arten in Australien; die afrilianischen, höchstens 3 dm langen Pflanzen mit ährig stehenden Blüten sind sehr zerstreut: die sehr veränderliche $\pi^{*}$ : capcnsis Thunh. findet sich von Kapstadt bis Griqualand East und steigt in den WitteBergen bis $2600 \mathrm{~m}$ auf, ihr nahe steht die auch in Natal vorkommende $W$. Kroutssii Bak. Sodann finden sich cinzelne Arten auf feuchten Hochgebirgswiesen, WV. Goetzei Engl. in Uhehe (Fig. 201 C) und W. tenuis Bak. (Fig. 201 B) auf dem Kamerungebirge und Fernando Po.

Bacometra Salisb. mit einer Art und Dipidax Salisb. mit zwei Arten sind auf das siidliche Kapland beschränkte Gattungen kleiner Zwiebelgewächse.

Androcymbium Willd. Vorzugsweise in den afrikanischen Gebirgen auftretende Gattung, von welcher auch Arten im Mittelmeergebiet und in Südafrika vorkommen. Es sind dies Zwiebelgewächse mit tief in der Erde steckendem Stengel, dessen schmale oder lanzettliche Blätter cinen loopförmigen oder doldigen Blïtenstand nit mehreren Bliiten einschließen, deren schmal genagelte, konkave Bliitenahschnitte zusammenneigend eine Bliite rom Habitus der Colchicum-Blüte ergeben. Dem in Natal, Transvaal und der Kalahari verbreiteten $A$. mclanthioides Willd. steht ziemlich nahe das mit ansehnlichen, weißlichen, dur Lïnge nach grün gestreiften Bliiten rersehene A. striatum Hochst. (Fig. 201 A); dasselbe findet sich oft herdenweise auf Hochgebirgswiesen von Ahyssinien bis nach dem Nyassaland, z. B. Uhehe', sowie auch in Benguela. In dem letzteren und im Hereroland kommt auch das schöne A. roscum Engl. vor.

Merendera Ram. Im Mittelmeergebiet ron Spanien bis Afghanistan rerbreitet, besitzt diese Gattung im tropischen Afrika nur eine auch in Yemen rorkommende Art in Abysinicn und dem Gallahochland. .Terendera abyssinica A. Rich., welche mit ihren ansehnlichen, roten, auch nur wenig uiber die Erde tretenden Bluten um $2000-2000 \mathrm{~m}$ i. .I. die trockenen Bergwiesen schmuickt.

\section{Lilioideae. - Scilleae.}

Während wir bei den zuletzt besprochenen Pflanzen meistens Zwiebelknollen finden, sind die im tropischen Afrika sehr zahlreichen Scilleae mit einer tunicaten Zwiebel versehen, wie sie hei den Hyacinthen vorkommt. Über I50 Arten sind uns bekannt, von denen viele herdenweise in den Steppen und auf Gebirgswicsen, nur wenige in Buschgehölzen und Wäldern auftreten. Die ziemlich schwachen Gattungsmerkmale treten zum Teil in Fig. 205 hervor: die Lnterscheidung der Arten stößt selhst bei sehr eingehendem Studium auf große Schwierigkeiten, welche erst gehoben sein werden, wenn die 
Sammler sich entschließen, reichlicheres Material und zugleich farbige Skizzen der frischen Pflanzen zu liefern.

Eucomis l'Hér. Diese durch einen endständigen Schopf steriler Hochblätter ausgezeichnete Gattung (ro Arten) reicht vom östlichen Kapland bis Natal (hier fünf Arten bis zu $2300 \mathrm{~m}$ ii. M.) und dem suidlichen Nyassaland, wo E. zambesiaca Bak. bis zu $1900 \mathrm{~m}$ ü. M. aufsteigt. Auch die von Uitenhage bis Transvaal verbreitete E. undulata (Thunb.) Ait. steigt bis I600 m auf (Fig. 203).

Albuca L., Urginea Steinh., Ornithogalum L. sind drei Gattungen mit freien, meist weißlichen Blütenhüllblättern, welche häufig verwechselt werden.

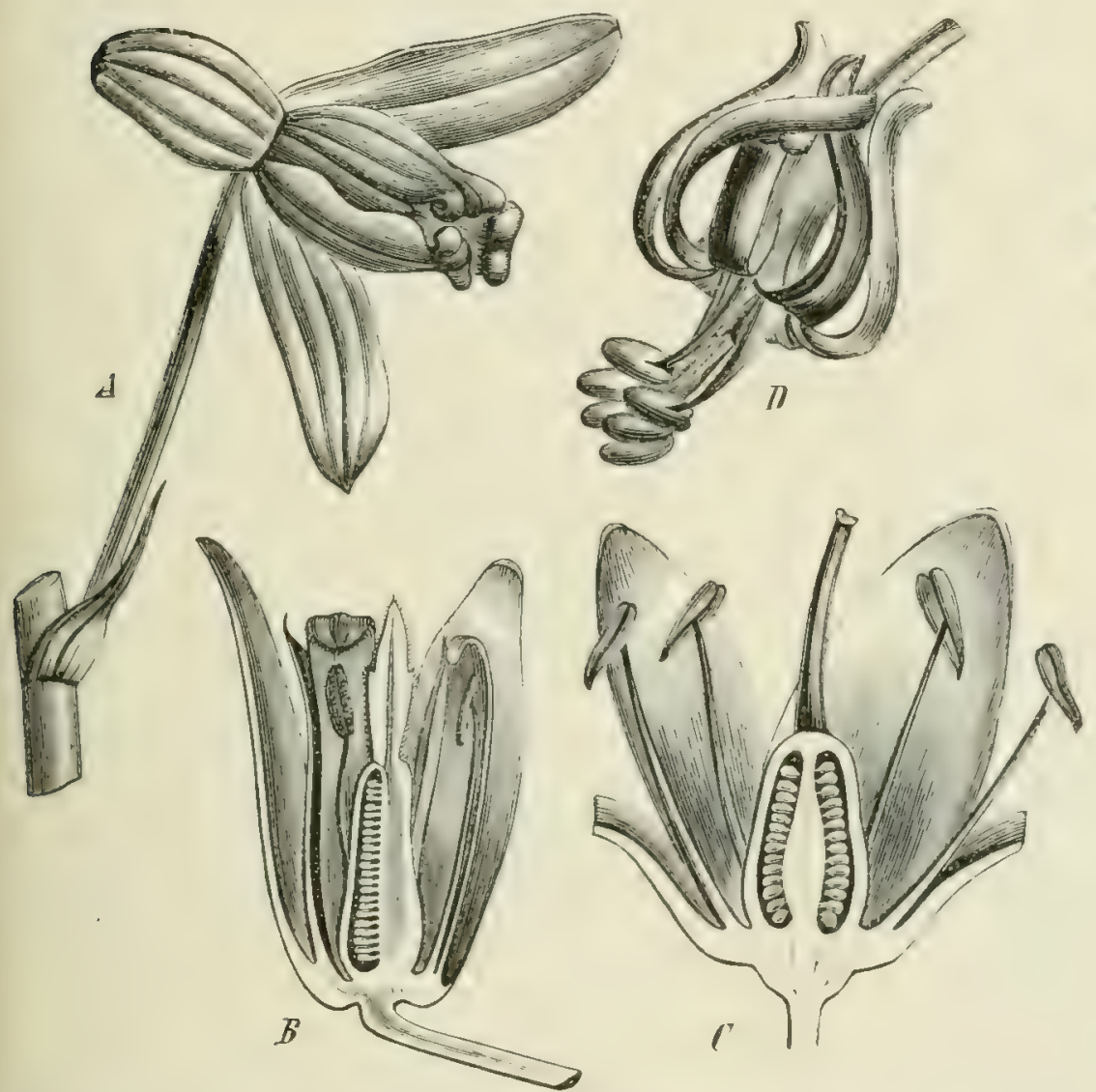

Fig. 202. $A, B$ Albuca juncifolia Bak. (Siidl. Kapland). $C$ Urginea scilla Steinheil. (Mediterrangebiet). $D$ U. altissima (L.) Bak. (West- und Südafrika).

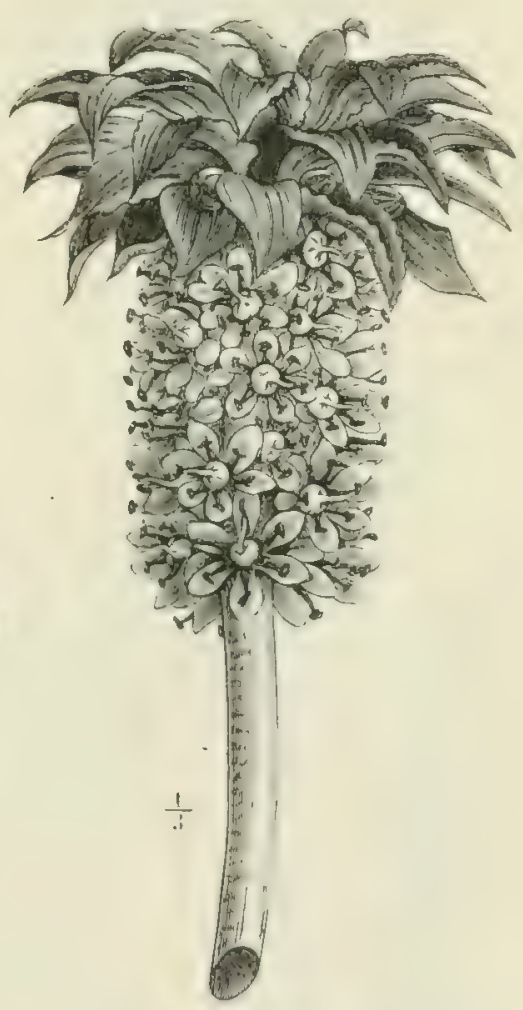

Fig. 203. Eucomis undulata (Thunb.) Ait. (Kapland bis Transvaal).

Albuca erkennt man an den mit breitem, grünem oder bräunlichgrunem Kielund Mittelstreifen versehenen Tepalen; sie wachsen gern in Felsritzen und an trockneren Abhängen der Gebirge; sie sind namentlich zahlreich in Ostafrika bis zum südlichen Nyassaland, in Angola, Benguela und Hereroland, sodann weiter südlich bis zur Kaphalbinsel. Etwa 60 Arten, bei deren Unterscheidung es auf die Zahl der Bliiten, die Beschaffenheit der Staubblïtter und Griffel ankommt, duirften zu unterscheiden sein. Nur die abyssinische -1. abysininica Dryand. steigt zu den oberen Bergwiesen bis zu $3300 \mathrm{~m}$ Höhe auf. Die in Fig. $20+$ abgebildete 4 . pachy'chlamy's Bak. fällt auf durch die über die Erde 
hervortretenden Zwiebelschuppen: ich sammelte sie bei Ottoshop in Transvaal in der Dolomitsteppe. Eine besonders große Pflanze ist A. Schucinfurthii

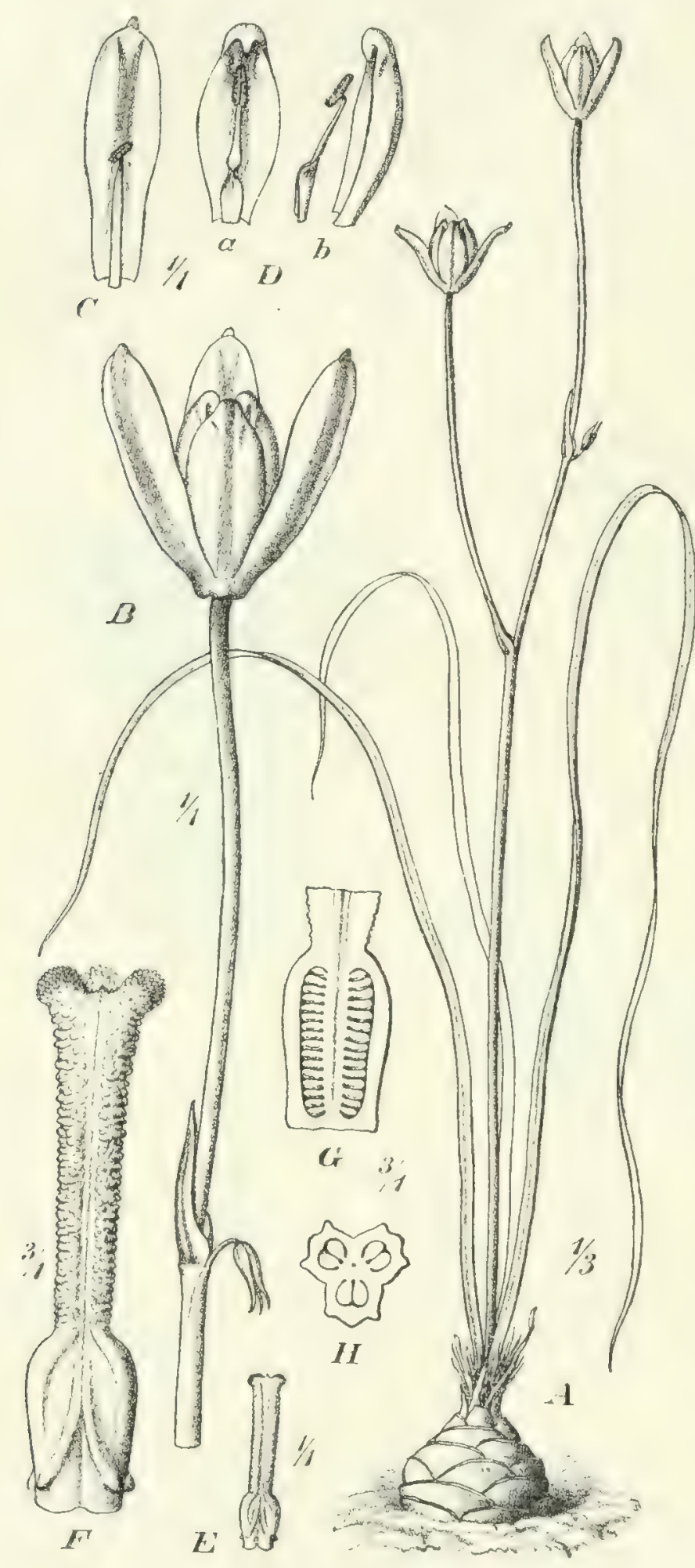

Fig. 204. Albuca pachychlamys Bak. (Transvaal). Original.
Engl. aus dem Lande der NiamNiam (Fig. $205 A$ ).

Urginea Steinh. Die etwa 48 afrikanischen Arten dieser Gattung haben gespornte Bracteen und sehr flache Samen; häufig treten die Inflorescenzen erst hervor, wenn die Blätter abgestorben sind. Nur wenige Arten steigen in größere Höhen hinauf, so die in Grassteppen von Senegambien bis zur Erythrea verbreitete $U$. micrantha (Rich.) Solms (Fig. 205 B) in Abyssinien bis zu $1900 \mathrm{~m}$ ü. M. Wie diese Art, so besitzt auch U. altissima Bak. eine bis $6 \mathrm{dm}$ lange Inflorescenz; sie ist verbreitet von Sierra Leone bis Loango und durch das Nyassaland bis Siidafrika. Durch sehr lockere Trauben an sehr langen ( $\mathrm{I}, 5 \mathrm{~m}$ erreichenden) Stengein fällt auf $U$. indica (Roxb.) Kunth (Fig. 205 C), welche wir zerstreut von Senegambien und dem Nigergebiet durch das Ghasalquellengebiet bis zur Erythrea und darüber hinaus bis Ostindien verfolgen können.

Bei der nahestehenden Gattung Ornithogalum sind die Kapseln weniger tief gelappt, als bei $U_{r}$ ginea, und die Samen nicht flach; eine auffallende Art ist $O$. caudatum Ait. mit 5-6 dm langen, 2,5 bis $3,7 \mathrm{~cm}$ breiten Blättern und bis $3 \mathrm{dm}$ langen Trauben an $\mathrm{I} \mathrm{m}$ langem Stiel; sie ist vom Somaliland bis Südafrika etappenweise anzutreffen. Ebenso stattlich ist

0. Iongibractcatum Jacq. (Fig. 206 D) in Ukamba und dem Amboland. Durch breite Blätter und doldentraubigen Bliitenstand fällt auf O. c.tcclsum Diels (Fig. 206 C). 
Liliiflorne. - Liliacene.

303

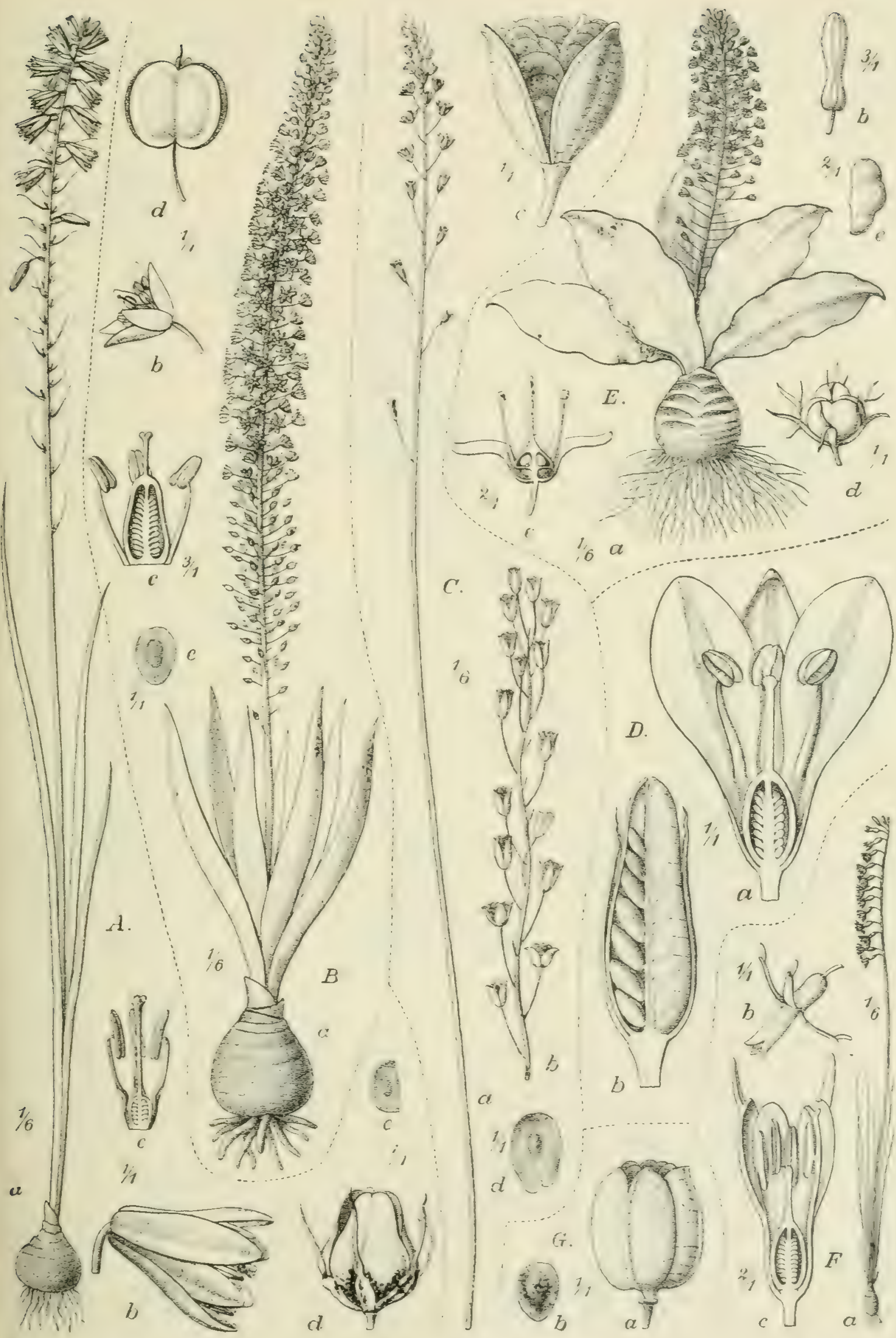

Fig. 205. A Albuca Schweinfurthii Engl. Niam-Niam?' $B$ Trginea micrantba Rich. Solms Abysinien. C C . inclica Koxb. Kth. Senerambien'. D Galtonia candicans Decne. Drakensberge). E Drimia brevifolia Bak. (Somaliland) F Dipcadi Wentzelianum Engl. (Uhehe). $G$ D. sansibaricum Engl. (Sansibar). - Original. 
Scilla L. ist durch Trauben mit blauen oder lilafarbenen, getrenntblättrigen Bliiten und durch schwach gelappte Fruchtknoten ausgezeichnet. Man unterscheidet über go Arten im tropischen und südlichen Afrika; aber für deren

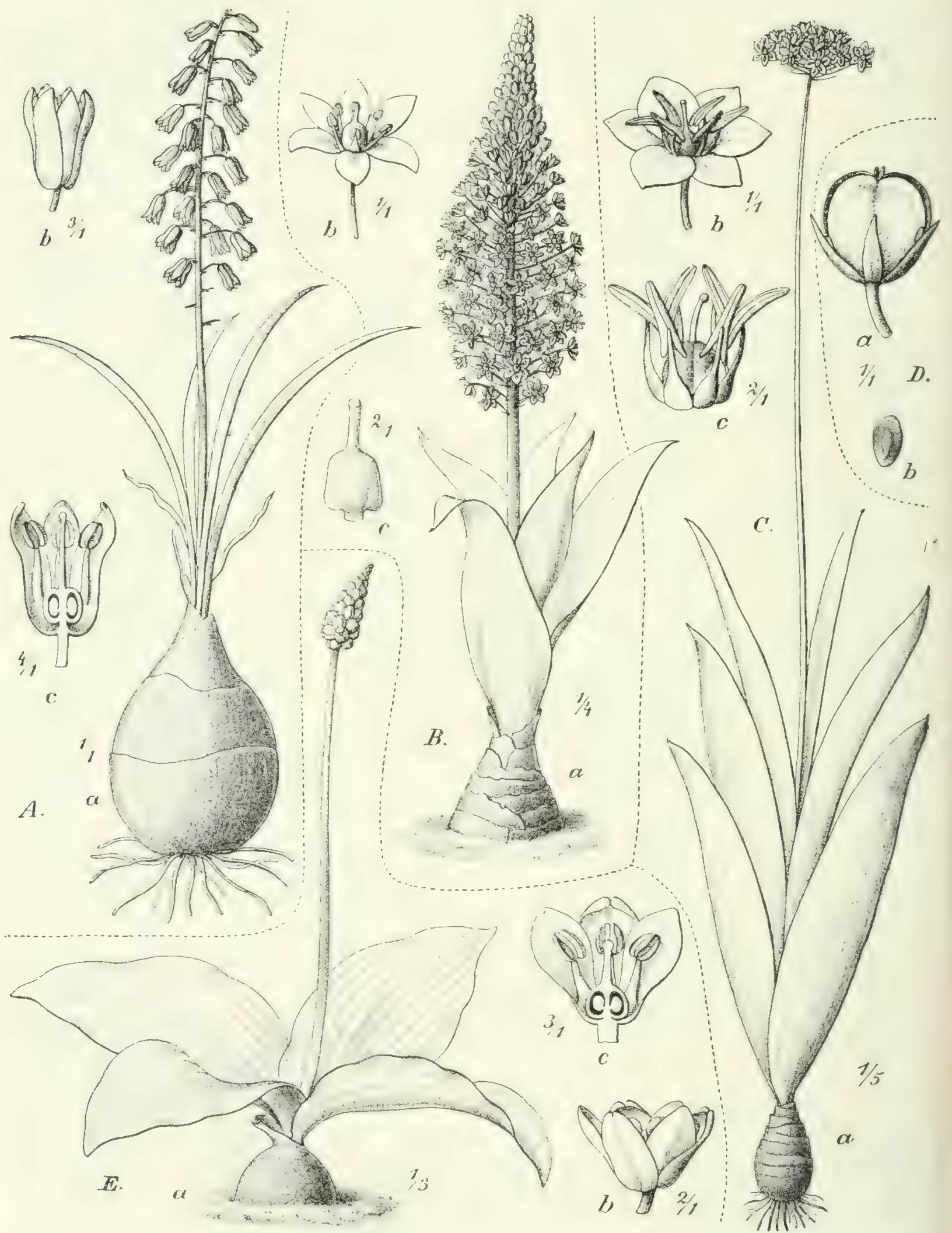

Fig. 206. A Scilla edulis Engl. (Djur, Zentralafrika). $B$ Sc. natalensis Planch. (Natal, Transvaal). $C$ Ornithogalum excelsum Diels (Lydenburg in Transvaal). $D$ O. longibracteatum Jacq. (Ukamba, Ostafrika). E Drimiopsis Holstii -Engl. (Usambara, Gebirgsland). - Original. 
genauere Kenntnis und für die Ermittlung ihrer Verbreitung ist noch unendlich viel zu tun. Mehrere Arten finden wir an sandigen Flußufern und auf Sandbänken, so z. B. Sc. cameroonizana Bak., andere auf feuchten Grasplätzen, z. 13. Sc. cdulis Engl. in Zentralafrika (Fig. 200 -1), Si. Lecticnii Lingl. |Fig. 207| am Kongo, Sc. indica Bak. in Kamerun, noch andere in lichten Gebüschen. meistens herdenweise. Einige Arten fallen auf durch etwas graugrüne, dunkelpurpurn oder braun gefleckte Blätter, wie Se. simmanm Bak. in Angola und dem französischen Kongogebiet, Sc. metester Bak. in Ostafrika, Si. Ledicnii Engl. (Fig. 20\%) am unteren Kongo. Letztere ist außerdem auffallend dadurch, daß die Blätter an der Spitze Adventivwurzeln bilden. Von höher in die Gebirge aufsteigenden Arten nenne ich Si. rigidifolic Kunth, welche lederartige

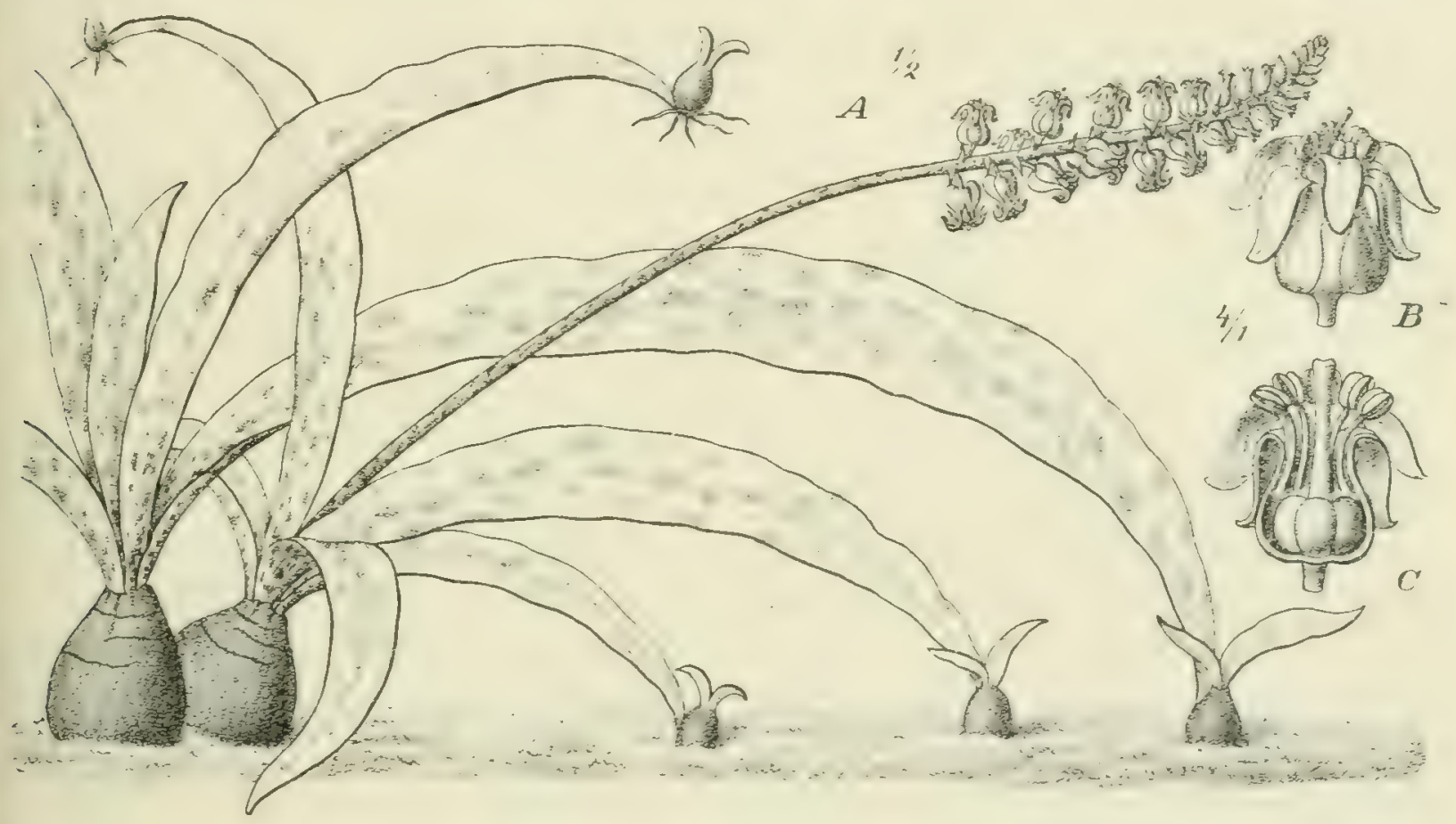

Fig. 207. Scilla Ledienii Engl. (Unterer Kongo.

lanzettliche Blätter besitzt, übrigens auch durch ihre schon am Grunde abstehenden Tepalen von den anderen Arten verschieden ist, bei denen die Tepalen erst oberhalb der Basis abstehen. Von den $5^{6}$ suidafrikanischen Arten findet sich die große Mehrzahl ron Natal suidwärts durch den östlichen Teil der Kapkolonie.

Drimiopsis Lindl., mit Silla nahe verwandt, ausgezeichnet durch glnckenförmig zusammenneigende Tepalen und kleine, abortierende Blïten an Ende der weißen Traube, umfaßt etwa I 2 Arten; von diesen findet sich D. Barteri Bak. an felsigen Plätzen im Nigergebiet, 6 Arten sind aus Ostafrika bekannt geworden, wo sie auf Steppen und Bergwiesen bis zu I $300 \mathrm{~m}$ ü. M. vorkommen, wie D. Holstii Engl. in Usambara (Fig. 206 E).

Bei den übrigen Scilleae sind die Tepalen am Grunde vereint.

Drimia Jacq. besitzt grïnliche oder rötliche, glockenförmige Bliiten mit schmalen, zuriickgebogenen Abschnitten, tiefgelappte Kapseln und flache Samen. 
Die Arten wachsen gern an Abhängen, teils zwischen Steinen, teils im Grasland, manche auch auf etwas feuchten Senkungen in Tälern. Die bis jetzt beliannten 30 Arten sind meist auf Ostafrika, vom Somaliland an, bis zum Kapland verteilt (Fig. $205 \mathrm{E}$ ).

Rhadamanthus Salish, von voriger Gattung durch aufrechte oder abstehende Abschnitte des Perigons verschieden, kommt nur mit zwei Arten im östlichen Kapland vor.

Hyacinthus L., mit länglicher Perigonröhre und länglichen Abschnitten derselben, ferner mit geschwollenen, nicht zusammengedrängten Samen, spielt nur eine unbedeutende Rolle: eine Art, H. ledebourioides Bak., scheint vom südlichen Nyassaland bis zum unteren Sambesi häufig'er vorzukommen, und H. corymbosus L. findet sich mehrfach im siidlichen Kapland. Von einer dritten aus Suidafrika stammenden, kultivierten Art kennt man, wie von so vielen anderen Zwiebelgewächsen, nicht die engere Heimat.

Veltheimia Gleditsch, von voriger Gattung durch kurze Perigonabschnitte unterschicden, ist mit drei Arten in der Kapkolonie zu Haus und kommt auch in Klein-Namaqualand vor.

Galtonia Dcne., mit lïnglicher Kronenröhre und zahlreichen, kantigen Samen, cnthïlt drei sehr stattliche Zwiebelgewächse des östlichen Kaplandes; die weißen großen Bliiten stehen in langen Trauben. G. candicans Decne. (Fig. $205 D)$ steigt in den Drakensbergen und den Wittebergen bis zu $2600 \mathrm{~m}$ auf.

Pseudogaltonia Pechuelii O. Ktze. ist eine stattliche, im Hereroland vorkommende Pflanze mit lanzettlichen, lederartigen Blättern und zahlreichen (bis Ioo, grünlichweißen, etwas gekrümmten Blüten in dichter Traube.

Dipcadi Medic, eine Gattung von mehr als 40 Arten, mit vereinten Tepalen (Fig. $205 \mathrm{~F}, G$, welche am Ende schwanzförmig zugespitzt sind, ist leicht zu erkennen. Dic größte Artenzahl dieser auch im Kapland vertretenen Gattung finden wir rom üstlichen Kapland bis Abyssinien und von Damaraland bis Angola, einzelne im Nigergebiet und Ghasalquellengebiet (z. B. D. sansibarianm Engl., Fig. $205 G$, von der Meeresküste bis in die Hochgebirge. Auch diese Gattung hat wie Crgince und Silla noch ihre Vertreter im Mittelmeergebiet. Daß diese und noch so viele andere Liliaceengattungen im Mittelmeergebiet, im tropischen Afrika und im Kapland vorkommen, erklärt sich leicht dadurch, daß sie einen großen Teil des Jahres nur unter der Erde leben und während ihres kurzen, obcrirdischen Lebens die Lebensbedingungen in den genannten Gebieten nicht sehr verschieden sind.

Litanthus fusillus Harv., mit länglichem Perigon und kurzen Abschnitten ist cin kleines ron Uitenhage bis Swaziland vorkommendes Zwiebelgewächs mit sehr schmalen Blättern und nickenden Blüten.

Whiteheadia Harv. mit einer Art in Klein-Namaqualand,

Polyxena Kunth mit ro Arten und

Lachenalia Jacq. mit 42 Arten haben alle angeschwollene locker stehonde Samen in den Kapseln und finden sich nur in der Kapkolonie, vorzugsweise im Süden und Westen. 
Massonia Thunb. mit 33 Arten und

Daubenya Lindl. mit drei Arten haben sitzende, doldige Bliitenstände und zwei breite, gegenständige, dem Boden anliegende Laubblätter. Dic vereintblättrigen Perigone sind bei der ersten Gattung aktinomorph, bei der zweiten zygomorph. Die Verbreitung ist ähnlich, wie bei vorigen; auch sie crreichen nicht Natal.

\section{Asphodeloideae.}

Anthericum L. Eine der formenreichsten und schwierigsten Gattungen in Afrika, mit etwa I 20 Arten, davon etwa mehr als ein Drittel südlich ron Transvaal und Natal. Etwa $3 / 4$ der tropischen Arten wachsen auf den Steppen bis zu $1800 \mathrm{~m}$ Höhe, großenteils in Ostafrika und Angola, seltener im nordöstlichen Afrika, einige auch an sandigen Flußufern, manche auf felsigem Grunde, einige in Gebuischen. Auffallend große Formen sind A. coulcsichs Bak. $(6 \mathrm{dm}$ hoch am unteren Niger und 4 . superpositum Bak. $8 \mathrm{dm}$ hochi im Ghasalquellengebiet. Einige Arten Angolas gedeihen auch auf feuchtem, sumpfigem Boden, ebenso A. Grantii Bak. in Uniamwesi.

Chlorophytum Ker ist mit Anthericum sehr nahe verwandt und durch tiefer gelappte Kapseln und flache Samen unterschieden. Die Arten dieser Gattung kommen unter viel mannigfacheren Vegetationsbedingungen vor, als die der vorigen; nahezu 80 Arten sind aus Afrika bekannt und nur etwa fünf finden sich südlicher als Natal. An ihrem Rhizom finden wir immer sehr zahlreiche, oft $2-3 \mathrm{~mm}$ dicke, saftreiche, entweder cylindrische oder spindelförmige oder mit einer spindelförmigen, bisweilen auch eiförmigen Anschwellung versehene Wurzeln. Die meisten Arten sind Bewohner der Regenwälder und wachsen teils im Schatten, teils in Lichtungen. Daher sind sie auch besonders zahlreich rom IVesten bis zum Ghasalquellengebiet und zeigen eine größere Mannigfaltigkeit in der Gestaltung der Blattspreite als die Anthorica. Eine der häufigsten Arten ist Chl. macrophlyllum (Rich.) Aschs. (Fig. 208 C, D)), das von Togo bis zum Kongo und von Abyssinien bis zum Nyassaland in den Regenwäldern und auch in den Uferwäldern an den Steppenfliissen häufig vorkommt: es besitzt breit lanzettliche Blätter, eine reich bluihende, zusammengezogene Rispe und zahlreiche, dicke Wurzeln mit faserigen Nebenwurzeln, welche den reich humösen Boden durchsetzen. Eine sehr schöne, etwas ähnliche Art ist Chl. amanicuse Engl. (Fig. 208, E-G) von den Bergwäldern Ostusambaras. Eine weiter verbreitete Art ist auch Chl. gallabatinse Schwf, das his 6 dm hoch wird, einen reich verzweigten Blütenstand und an diinnen Wurzeln seitlich stehende Knollen trägt; es ist ron Abyssinien und dem Gallaland bis nach dem Ghasalquellengebiet verbreitet. Als besonders auffallende Arten der Waldregion nenne ich noch folgende: Chl. Holstii Engl. in Usambara, auch mit eiförmigen Knollen an den Nebenwurzeln, Chl. alismifolinm Bak. richtiger alismatifolium, Fig. 208 A, B) mit zeitweise vom Wasser überschwemmten Blättern, von Togo bis Kamerun, Chl. cordatunn Engl. mit herzförmigen Blattspreiten in Kamerun, Chl. pusillum Schwfth., mit breiten, dem Boden anliegenden Blättern und langen, am Ende keuligen Wurzeln, unter Buschwerk im 


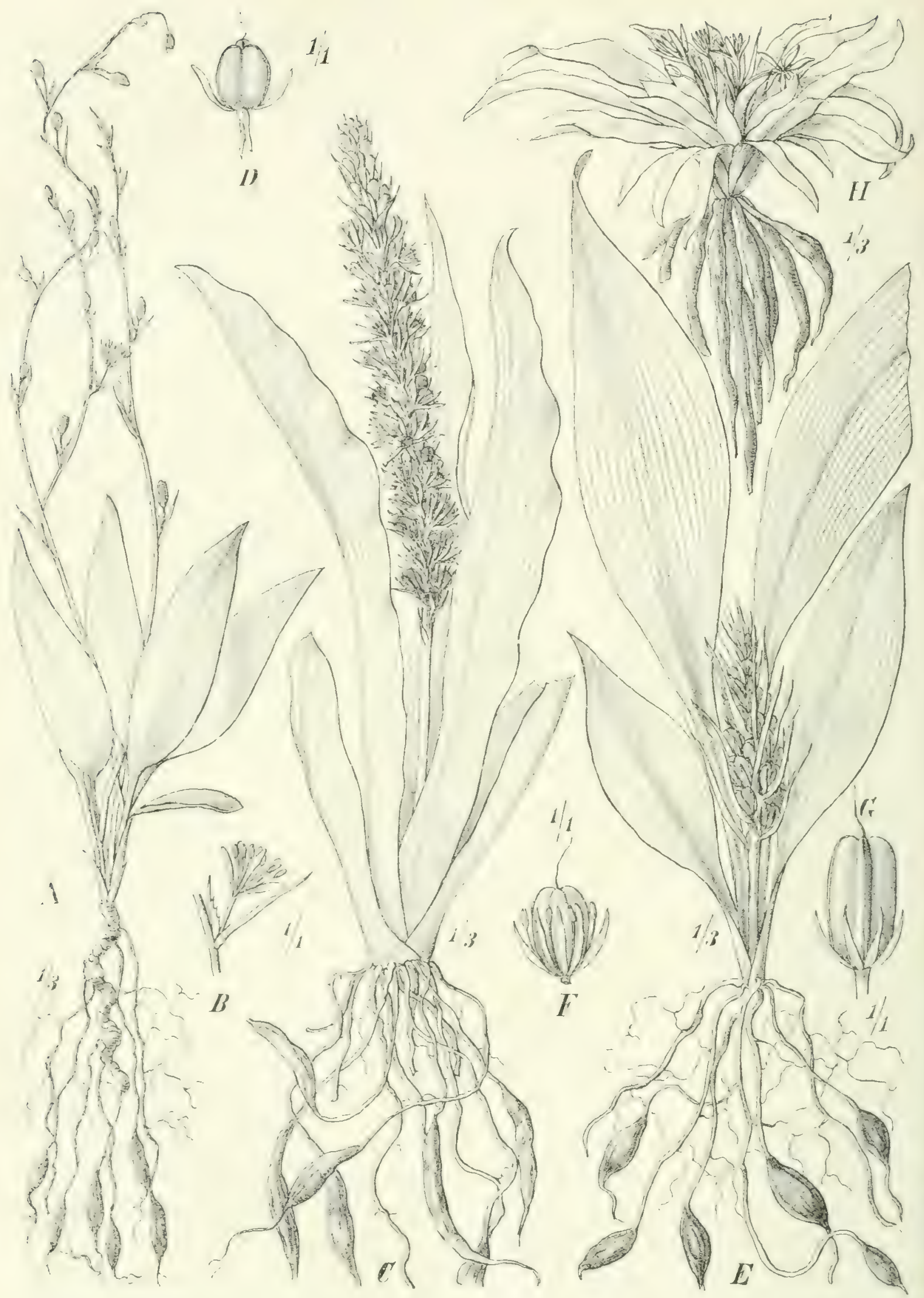

Fig. 208. $A, B$ Chlorophytum alismifolium Bak. (Kamerun). $C, D$ Cbl. macrophyllum (Rich.) Aschers. (Kilimandscharo, Kulturregion.) E-G Chl. amaniense Engl. II Chl. Schimperi Engl. (Abyssinien.) - Original. 
tiefen Schatten der Wälder des Ghasalquellengebietes. Nur wenige Arten werden in gewisser Höhe angetroffen, wie die im Gebuisch zwischen Steinen wachsenden, mit langen Wurzeln versehenen Chl. tetraplyyllum (L. f.) Bak. und Chl. Schimperi Engl., ersteres im mittleren Abyssinien um $2000 \mathrm{~m}$, letzteres (Fig. $208 H$ ) ebenda um $2600-3000 \mathrm{~m}$ ii. M. Endlich finden sich in der Steppe Ost- und Zentralafrikas einige Arten zerstreut; aber vorzugsweise in Niederungssteppen. Eine von Nubien, Kordofan und Abyssinien bis zum Kilimandscharo unter I $600 \mathrm{~m}$ ii. $\mathrm{M}$. sehr verbreitete Art ist Chl. tubcrosum (Roxb.) Bak. (Fig. 209); ich sah sie beim Eintritt der Regenzeit herdenweise die Niederungssteppen am Fuß des Parcgebirges mit ihren ziemlich dicht über dem Boden beginnenden milchweißen Blïtenrispen schmücken. Das Rhizom und ein großer Teil des Stengels stecken sehr tief in dem Boden und zahlreiche dünne Wurzeln sind mit dicken Endknollen versehen.

Dasystachys Bak. sind Stauden mit dicht zusammengedrängten, fast sitzenden Blüten, sonst wie vorige. Die ${ }_{5} 5$ bekannten Arten sind fast alle Bewohner der Steppen von Ostafrika bis Benguela bis zu einer Höhe von I $900 \mathrm{~m}$ ii. M.

Verdickia de Wild, ist eine monotypische Gattung mit einer nur I dm hohen Pflanze, $V$. Katangensis de Wild., welche breitgestielte eiförmige Grundblätter und eine dichte Ähre weißer Blüten besitzt, in denen die das Perigon überragenden Staubblätter am Grunde angeheftete Antheren tragen. Die Pflanze wächst

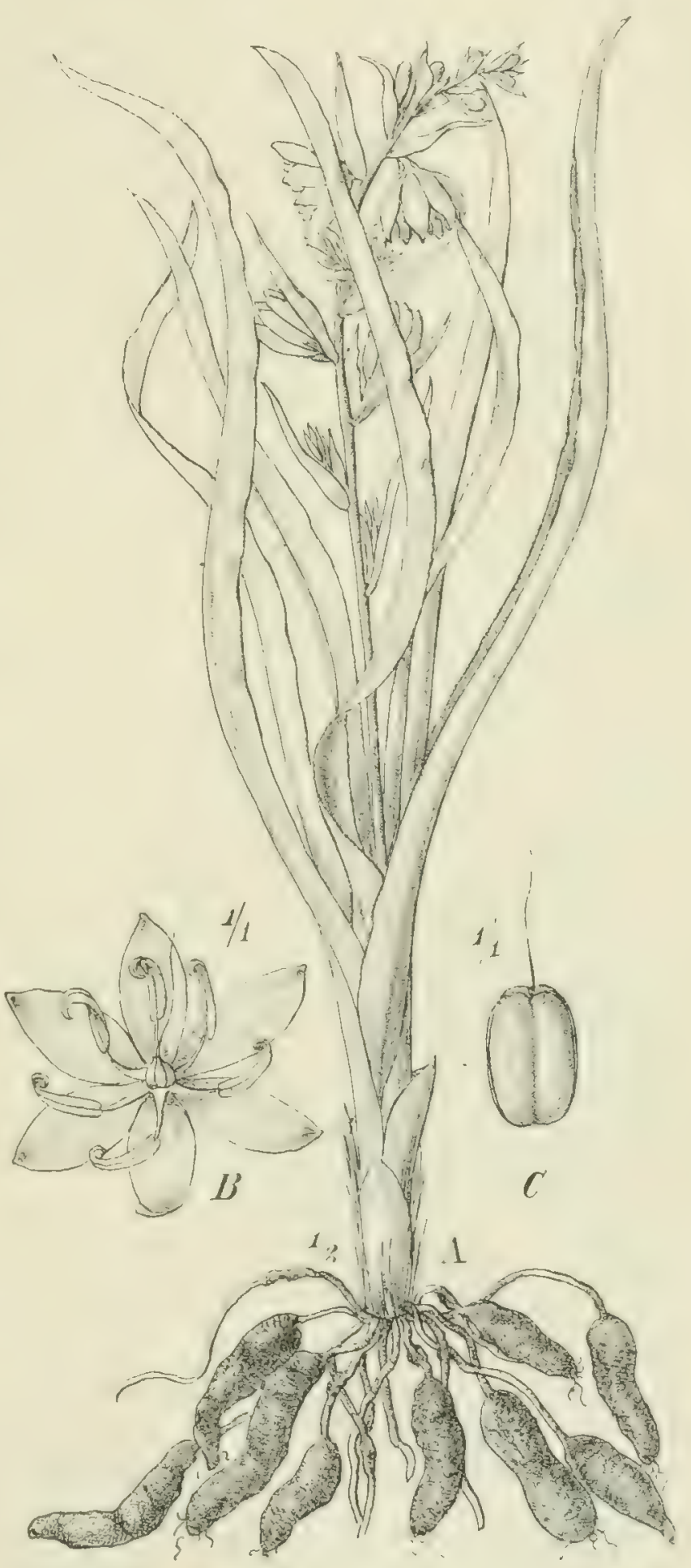

Fig. 209. Chlorophytum tuberosum (Roxb.) Bak. $A$ ganze Pflanze; $B$ Bliite; C Kapsel. - Original. am Lukafu in Katanga auf lehmigem Boden.

Acrospira asphodeloides Welw., eine hohe Pflanze mit schwertförmigen, bis I $\mathrm{m}$ langen Blättern und einer bis $5 \mathrm{dm}$ langen Traube von $2,5 \mathrm{~cm}$ langen Bliiten, kommt in Angola auf felsigem Boden bei Pungo Andongo vor. 
Caesia R. Br. mit drei Arten und Nanolirion Benth. mit einer Art im suidlichen Kapland zeichnen sich von den vorigen Gattungen, mit denen sie den Bau der Staubblätter gemeinsam haben, dadurch aus, daß ihr Perigon nach dem Verblïhen sich zusammendreht; einige verwandte Formen dieser Gattungen, sowie auch der beiden folgenden finden sich in Australien und Neu-Seeland.

Bulbine $\mathrm{L}$. ist von allen besprochenen Gattungen der Asphodelcac verschieden durch gebärtete Filamente und mit dem Rücken, nicht an der Basis dem Filament aufsitzende Antheren; man kennt etwa 26 Arten aus Afrika, von denen etwa 23 nur südlich von Natal vorkommen. Unter diesen ist besonders interessant B. coulcscons L. mit einem bisweilen $3 \mathrm{dm}$ langen Stämmchen; sie findet sich mehrfach auf Sandhügeln entlang der Küste von Uitenhage bis King IVilliams 'Town und auch an der Grenze der Karroo bis zu einer Höhe ron $1000 \mathrm{~m}$. Im östlichen Natal, Transvaal und weiter siidwärts findet sich zerstreut F. narcissifolia Salm Dyck mit linealen graugrünen Blättern. Sodann sind sehr viele Arten bis jetzt erst von einzelnen Stellen Südafrikas bekannt geworden.

Bulbinella Kunth ist von voriger Gattung durch kahle Staubfäden und weniger Samenanlagen zwei in jedem Fach verschieden. Sechs Arten kommen siidlich ron Natal und Transvaal vor, $B$. cornoser Bak. mit 4,5 dm langem Schaft auf feuchten Felsen in Natal, $B$. Burkiti Bak. mit I m langem Schaft am Aapis River in Transvaal.

Diesen in beschränkteren Gebieten auftretenden Arten steht als eine sehr weitverbreitete und auf feuchten Wiesen, in offenen Gehölzen mit sandigem Boden oft dichte Rasen bildende Pflanze Bulbine asploulcloides (L.) Spreng. gegenüber; zahlreiche linealische Blätter stehen am Grunde eines mit zahlreichen kleinen, leuchtend gelben Bliten rersehenen Stengels. Diese Pflanze ist verbreitet von Abyssinien bis Kapstadt und steigt am Kilimandscharo mit L"berspringung des Gürtelwaldes bis zu $3000 \mathrm{~m}$ ü. M. auf. Die ähnliche B. aloiles L.) Willd. findet sich nur im Nyassaland und in Südwestafrika bis Kapstadt. Als besonders auffallende, wenn auch nicht sehr verbreitete Pflanze möge $B$. platyplyylla Bak. erwähnt werden, deren $5 \mathrm{~cm}$ breite, bis I, $5 \mathrm{dm}$ lange Blätter am Grunde eines I m langen Bliitenschaftes stehen; sie wächst in Uniamwesi in sandigem Buschgehölz.

Eriospermum Jacq. (Fig. 210). Sehr eigenartige, in Südafrika zahlreich, im tropischen Afrika seltener vorkommende Gewächse. Einer kräftigen Knolle entsprießen ein bis drei ziemlich dicke, bisweilen eiförmige Laubblätter und ein Blütenschaft mit kleinen Blïten an langen Sticlen, später mit kugeligen Kapseln, welche dicht wollig behaarte Samen einschließen. Die meisten Arten bewohnen sandigen trockenen oder feuchten Boden der Steppengebiete in Ostafrika, Angola, Benguela und Hereroland, wo man besonders auf diese Gattung achten möge.

Schizobasis Bak. Bei dieser ist der Stengel dünn, mit langen, rutenförmigen oder abstehenden und windenden oder reich verästelten und ver- 
schlungenen Zweigen versehen, welche kleine Blïten in Trauben tragen. Diese eigentümlichen Pflanzen finden sich meist auf sehr trockenen Steinsteppen, S. Alagclliformis Bak. mit einfacher Traube am Aapis River in Transvaal, S. Macowani Bak. mit Rispe in der Gegend von Somerset East, S. angolensis Bak. mit scheindoldiger Rispe auf Felsen bei Pungo Andongo in Angola um $800-\mathrm{I} 200 \mathrm{~m}$, S. intricata Bak. mit scheindoldiger Rispe, von Somerset bis Barberton in Transvaal, S. cuscutoides (Burch.) Benth. mit windendem Stengel im Oranje-Freistaat.

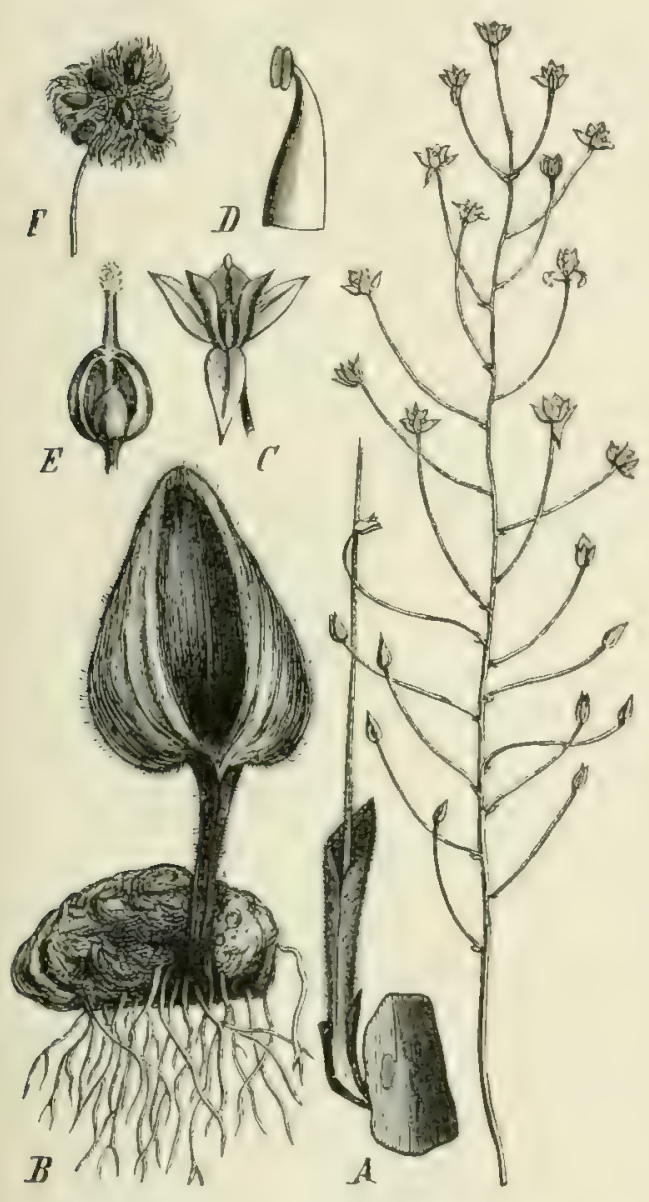

Fig. 2 10, Eriospermum lanuginosum Jacq. $A$ Blütenstand; $B$ Knolle mit Blatt; $C$ Blüte; $D$ Staubblatt; $E$ Pistill. Nach JACQUiN.

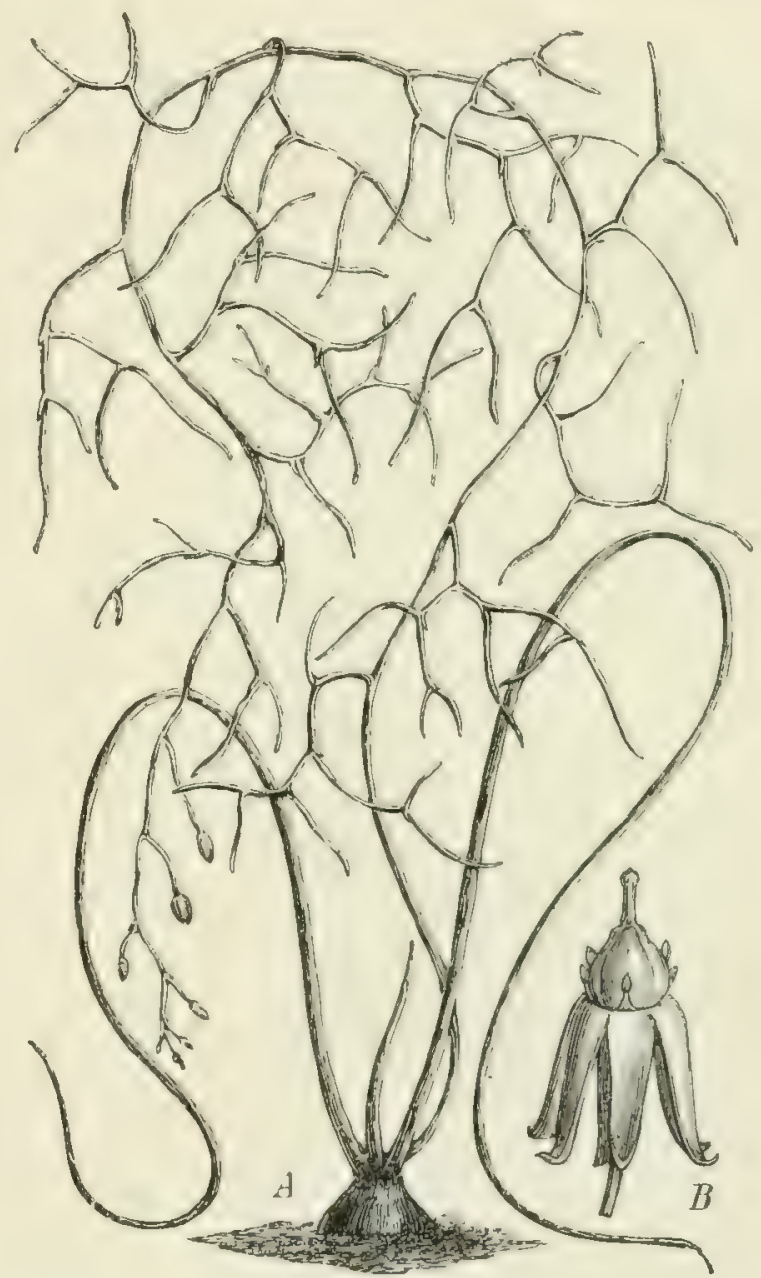

Fig. 21 r. Bowiea volubilis Harvey. $A$ ganze Pflanze, $1 / 3$ n. Gr.; $B$ einzelne Blüte. - Nach Engler in Nat. Pflanzenfam.

Bowiea z'olubilis Harv. steht der letzten Art voriger Gattung am nächsten; die Stengel werden bis $3 \mathrm{~m}$ lang, verzweigen sich stark und winden, aber ein großer Teil der Stiele trägt keine Bliten; die eigenartige reiche Entwicklung des Stengels geht auf Kosten der ein bis zwei kleinen, stielrundlichen, sehr bald absterbenden Blätter und der Blüten vor sich.

\section{Asphodeloideae - Aloineae.}

Diese Gruppe ist für die Vegetationsformationen Afrilias von der größten Bedeutung; es sind echt afrikanische Charakterpflanzen, von denen die meisten Kniphofic mehr oder weniger Feuchtigkeit lieben, während Notosceptrum, Aloc und die übrigen Gattungen mehr oder weniger xerophil sind. 
Kniphofia Moench. (Fig. 2 I 2-2 I5) sind stattliche Pflanzen, deren Habitus und Merkmale aus den beigefuigten Abbildungen ersichtlich sind. Alle haben die Tracht der bei uns häufig kultivierten K. w'aria (L.) Hook, doch sind sie häufg kleiner und armbliitiger. Immer wachsen sie in größerer Zahl beisammen und bisweilen bedccken sie ganze Wiesen odcr Hänge mit ibren zwischen langen, schmalen Blättern stehenden Blïtenschäften, welche oft Hunderte orangefarbener, gelber oder weißer röhriger Blüten tragen. Nach der neuesten Bearbeitung der Gattung von A. BERGER werden 67 Arten unterschieden. Es ist nun auffallend, daß die Hauptmasse dieser Arten auf Ostafrika von der Erythrea bis zum südöstlichen Kapland verteilt ist und daß, obwohl die Gattung auch in Jemen mit einer Art, in Madagaskar mit zwei Arten vertreten ist, sic in Angola und Benguela, auch in Damaraland, in denen doch sonst viele der in Ostafrika entwickelten Liliifloren-Gattungen sich ebenfalls wohl fühlen, nicht anzutreffen ist. Zwar kommen zwei Arten, $K$. mpalcnsis Engl. und $K$. dubia de Wild., westlich rom Tanganyika-See vor; aber in Angola und dem übrigen IVesten fehlen sie bis jetzt. Im südwestlichen Kapland finden sich nur zwei Arten, K. acidintalus Berger hei Simonstown und am Zwarteberg und K. Bachmamniz Bak. im Malmesbury-Distrikt, in der Umgebung ron Hopefield. Diese Arten und noch cinige andere, rom l'ondoland his Natal vorkommende wachsen in den untersten Regionen; aber die meisten und namentlich die näher am İquator vorkommenden sowie auch die abysinischen finden sich nur an hochgelegenen Berglehnen und auf feuchen Bergwiesen. Ton den 10 Gruppen, welche BERrek unterschcidet, sind nur dic auf Arabicn und Madagaskar beschränkten im südüstichen Afrika nicht anzutreffen. Ganz besonders reich ist Natal an endemischen Arten. Hier kommen auch die kleinblütigen Arten vor, deren Perigon nicht iiber I $8 \mathrm{~mm}$ lang wird; so finden wir bei Durban auf Wiesen $K$. panciflora Bak. ( $\$$ Pauciflorac), auf grasigen Hügeln um 550-650 m ü. M. K. modcsta Bak. (\$ Modestac), im Pondoland von 330-650 m, in Natal bei I $300-1650 \mathrm{~m}$ $K$. parviflora Kunth (\$ Parviflorae, Fig. 2 I2 F, $K$ ), bei 1000-I $300 \mathrm{~m} \mathrm{~K}$. Buchmanii Bak. (Fig. $212 A-E$ ), und in den Drakensbergen bei $1650-2300 \mathrm{~m}$ K. breviflore Bak. (Fig. $212 F-H$ ) aus derselben Gruppe. In diesem Gebirge begegnen wir auch $K$. multiflora Wood et Evans bei $2000 \mathrm{~m}$. In den

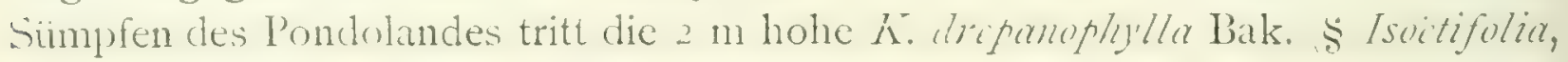
Fig. 2 I3 $C, D)$ auf, deren Blüten sowie die der folgenden länger als i $8 \mathrm{~mm}$ sind. Ebenda findet sich auch $K$. laxiflora Kunth ( $\$$ Laxiflorae) in dem benachbarten Natal auch in geringer Höhe ii. M., die derselben Gruppe angehörige $K$. natalcnsis Bak. und im westlichen Natal in Gebirgssümpfen bei $1330 \mathrm{~m}$ die K. ichopensis Schinz (Fig. 214, E). Außer diesen kommen in Pondoland und Natal noch sieben Arten aus der Gruppe der Uvariae vor, bei denen das Perigon keulig-cylindrisch und zuletzt oberhalh des () variums zusammengezogen, auch meist über $25 \mathrm{~mm}$ lang ist. Die schon seit I 707 in Kultur befindliche K. M(r)ia (L.) Mnch. ist cine Gebirgspflanze des üstlichen Kaplandes; sic wächst auf den Snecur Bergen im Distrikt Graaf Reinet ron I $350-2000 \mathrm{~m}$ ï. M., auch im Somcrset-Distrilit und Basutoland: in Oranje-lireistaat kommt eine Varietat 


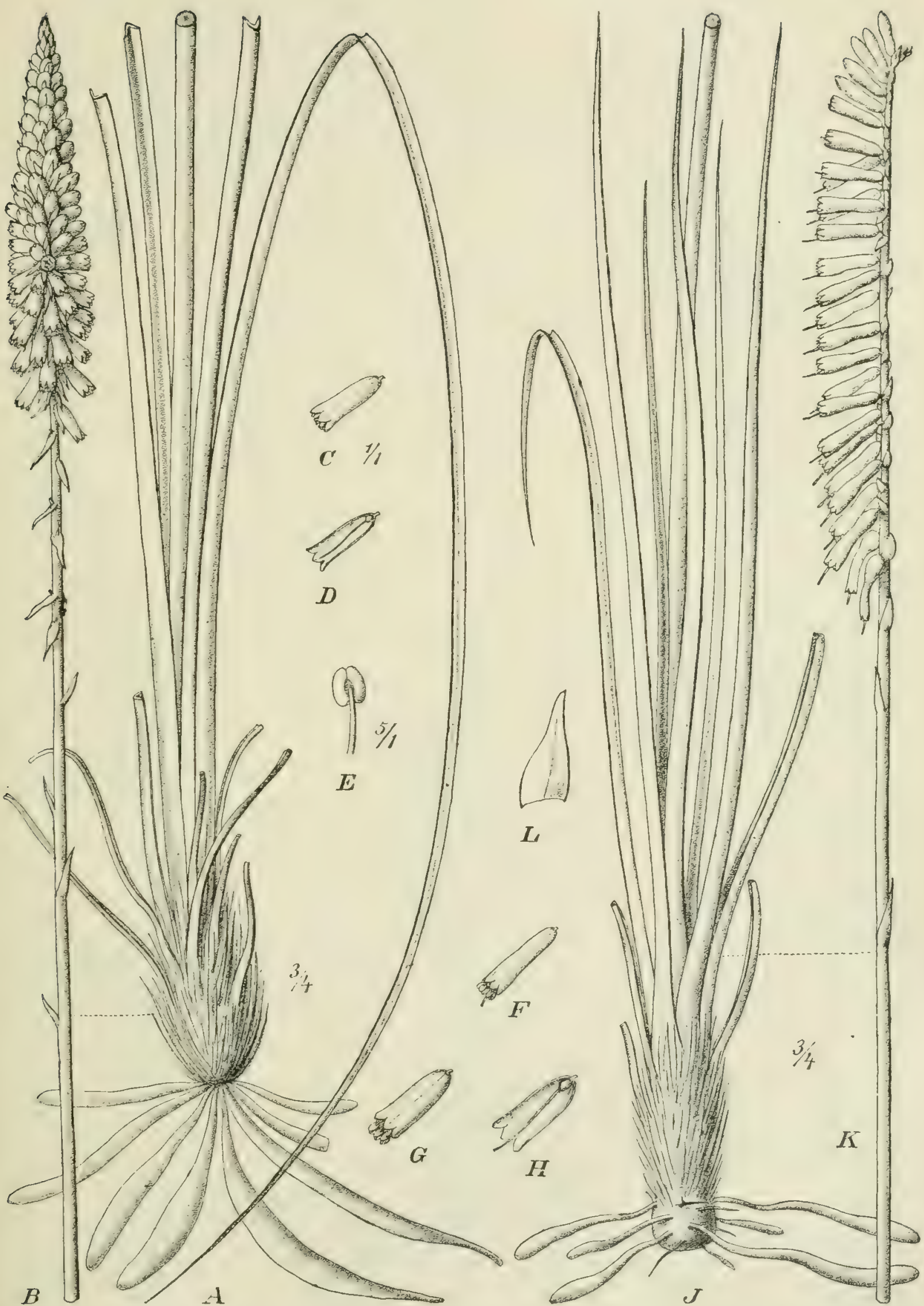

Fig. 212. Kniphofia. $A-E \mathrm{~K}$. Buchananii Bak. (Natal, um $1000-1300 \mathrm{~m}$ ), $F-H$ K. breviflora Bak. (Gebirgsland von Natal, Van Reenens Paß, $1650-23 c 0$ m ii. M.) $\mathcal{F}_{2} K \mathrm{~K}$. parviflora Kth. (Pondoland, 330-650 $\mathrm{m}$ ü. M., und Ost-Griqualand, $2000 \mathrm{~m}$ ii. M.) - Nach Berger. 


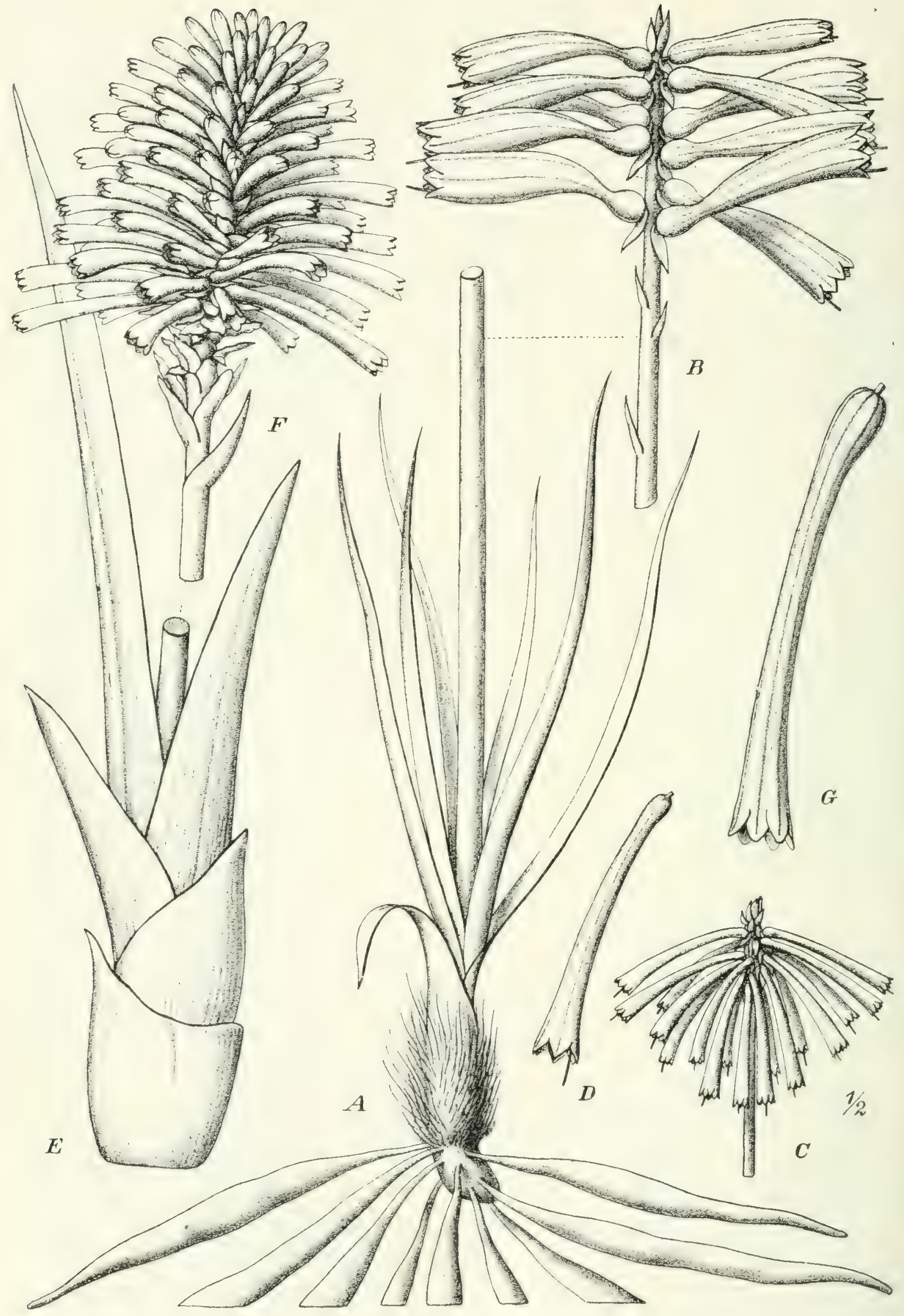

Fig. 213. Kniphofia. $A, B \mathrm{~K}$. isoëtifolia Hochst. (Bergwiesen im Hochland von Abyssinien.) $C, D \mathrm{~K}$. drepanophylla Bak. (Pondoland, in Sümpfen mit Zantedeschia aethiopica zusammen vorkommend.) $E-G \mathrm{~K}$. dubia De Wild. (Katanga im Kongostaat, auf der Westseite des suidlichen Tanganyika.) - Nach BERGER. 
Liliiflorae. - Liliaceae.

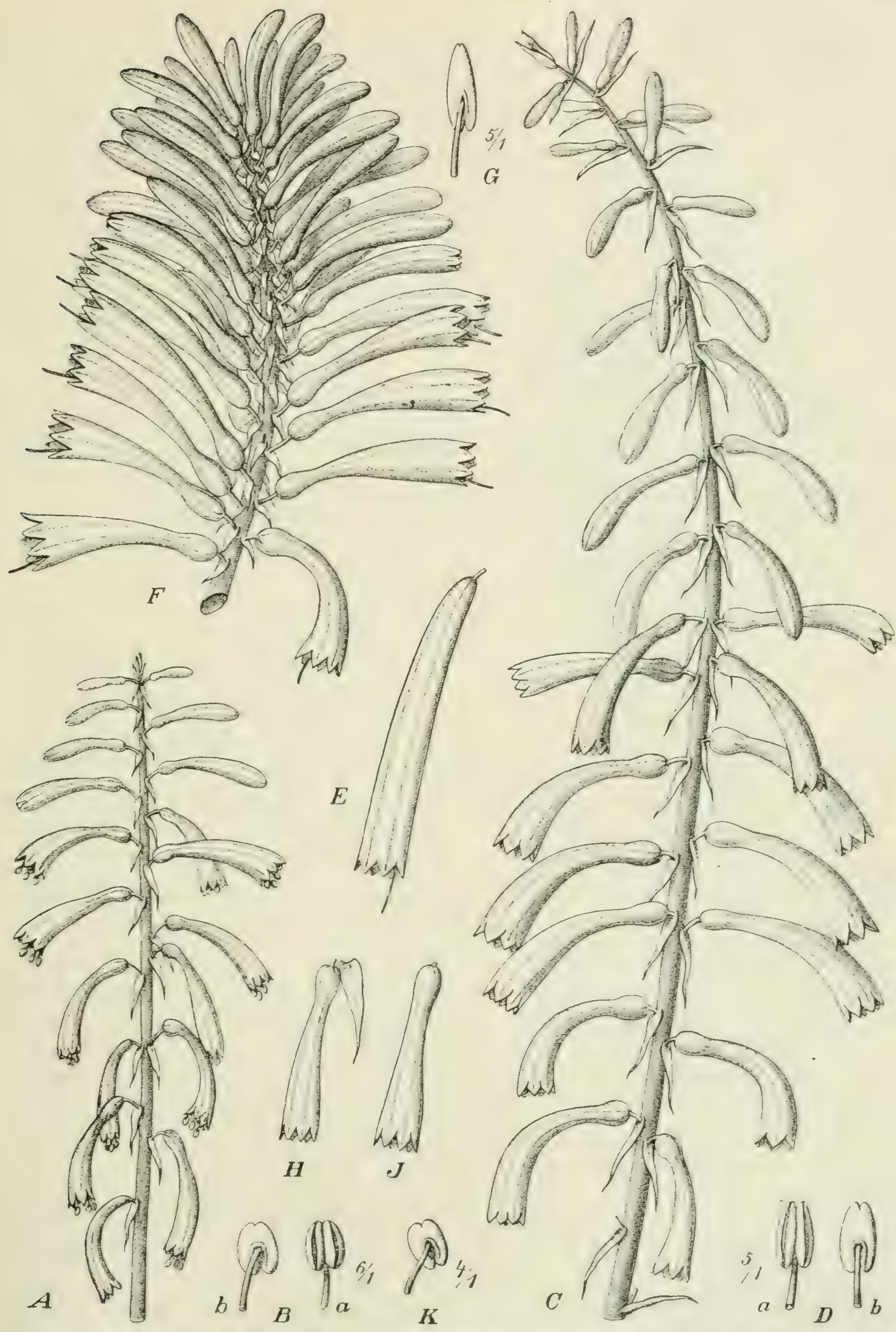

Fig. 2I4. Kniphofia. $A, B$ K. Ellenbeckiana Engl. Gallahochland.) (; $D$ K. Schimperi Bak. (Abyssinien, bei Debra Tabor, um $2700 \mathrm{~m}$ ï. MI.) E K. ichopensis Schinz (Natal, Ixopo, um rooo-1330 m i. M.) F, G K. Goetzei Engl. (Nördl. Nyassaland, Porotoberg, um $2400 \mathrm{~m}$ ii. MI. $H-K$ K. Thomsonii Bak. (Kilimandscharo, 2600-3600 m ii. M.) - Nach Berger. 


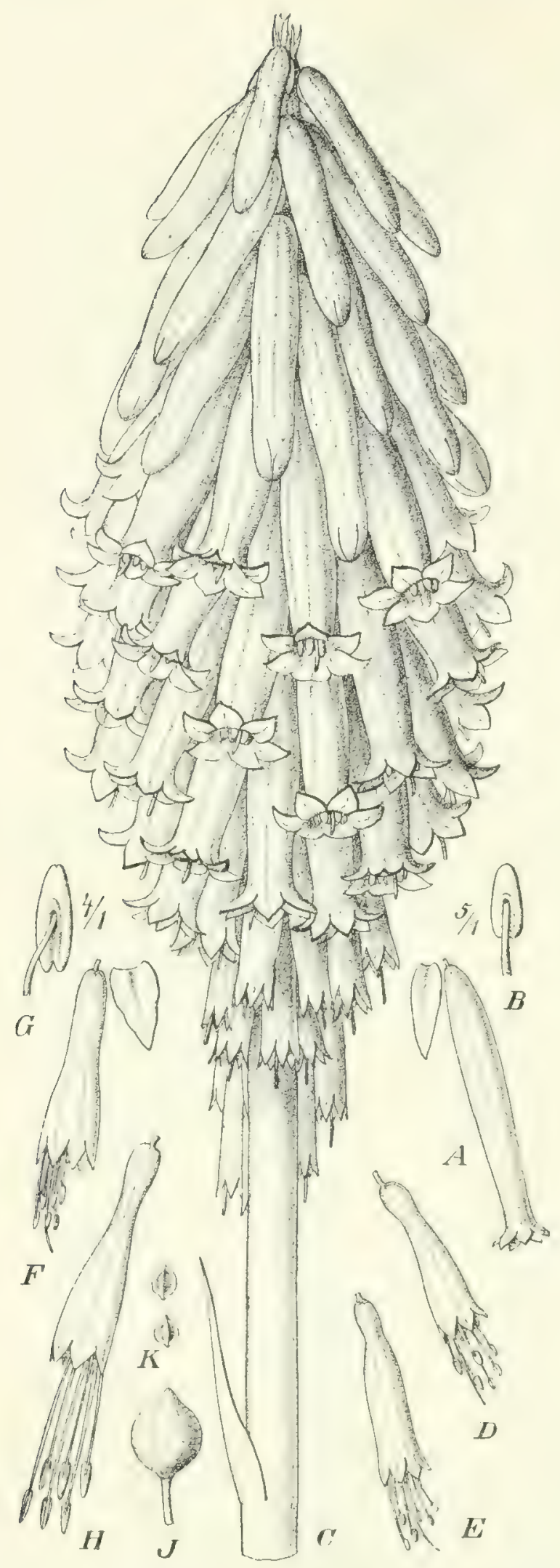

Fig. 215. Kniphofia. $A, B \cdot K$. obtusiloba Diels (Spitzkopp bei Lydenburg in Transvaal). C K. Macowanii Bak. (Südöstliches Kapland, Boschberg im Somersetdistrikt, I500-I600 m ii. M.) $D, E K$. rivularis Berger ('Transvaal, Modderfontein bei Pretoria). $F-K$ K. densiHora Engl. (Abyssinien, Urahut, um 2700 bis 3600 m ii. M.) - Nach BERGER. mit $2 \mathrm{~m}$ hohem Stengel vor. Die nahestehende, durch kleinere graugrüne Blätter ausgezeichnete $K$. samentosa Kunth ist in Transvaal heimisch. Es sei dann noch darauf hingewiesen, daß noch einige andere Arten in Transvaal, im südlichen und nördlichen Nyassaland auftreten, immer in bedeutenderer Höhe ü. d. M., je mehr wir uns dem Äquator nähern, K. Thomsonii Bak. (Fig. 2I $4, H-K$ ) auf den Bergwiesen des Kilimandscharo von 2600-3660 $\mathrm{m}$ und mehrere (7) Arten im Gallahochland und Abyssinien bis zur Erythrea. Von morphologischem Interesse ist, da $B$ in Südafrika zwei Arten mit uiber die Erde tretendem Stamm vorkommen, K. coulesccns Bak. in den Stormbergen der östlichen Kapkolonie und K. Northice Bak. in den Wittebergen von $2500-3200 \mathrm{~m}$ ii. M.

Notosceptrum Benth. steht der vorigen Gattung sehr nahe und unterscheidet sich von derselben nur durch kurze, glockige, tief geteilte Perigone; die Blätter sind sehr schmal, gekielt und am Rande etwas knorpelig. Die Arten finden sich in den regenärmeren Gebirgsländern, aber auf feuchten Standorten. In dem Küstengebiet von Natal kommen sie nicht vor, wohl aber die beiden kleinsten Arten, N. natalense Bak. und N. brachy'stachy'm A. Zahlbr., im östlichen Natal in einer Höhe von 1000 bis $1330 \mathrm{~m}$ ï. M., erstere Art auch in Transvaal, letztere auch in Ost-Griqualand. Ferner wächst in Transvaal im Distrikt von Lydenburg $N$. aloides Benth., bei welcher die Perigonabschnitte ganz frei sind. Eine riesige Pflanze ist $N$. andongense Bak. in Pungo Andongo mit $5 \mathrm{dm}$ langem kräftigem Grundstock, 3-5 cm langen Faserwurzeln und bis $3 \mathrm{~m}$ langen linealischen Blättern, welche einen kräftigen oft über $3 \mathrm{~m}$ hohen Stengel mit 
$3 \mathrm{dm}$ langem Bluitenstand umgeben: sie kommt in hochgrasigen Dichichten oft massenhaft vor. 1 . binsucllense Bak, nur etwa hall so groß, findet sich auf feuchten Plätzen bei Huilla in Benguela.

Chortolirion A. Berg. ist cine kleine Gattung, welche den Übergang von den beiden vorigen zu Hai'(r)thir bildet: die schmalen, am Rande knorpeligen und klein gezähnten Blätter gehen am Grunde in breite Schcicen über; welche eine kugelige oder eiförmige Zwiebel bilden. Zwei Arten kommen in Transvaal vor, eine in dem benachbarten Betschuanaland und eine in Benguela.

Haworthia Duval (Fig. 216), kleine succulente Pflanzen mit spiralig angeordneten, oft warzigen Blättern, mit diunnom Stiel und ziemlich kleinen, in Trauben stehenden Blüten, umfaßt etwa 6 I Arten, von denen eine große Zahl sich in Kultur befinden; aber nur von etwa I 3 kennt man die Fundorte, welche fast alle den Gebirgen des östlichen Kaplandes angehören und Kaum mehr als $400 \mathrm{~m}$ ü. M., zum Teil niedriger gelegen sind. Nur eine Art, H. g:cuca Bak., soll aus dem Oranje-Freistaat stammen; vier Arten wurden in der Gegend ron Graaf Reinet nachgewiesen. Es ist wohl zicmlich sicher anzunehmen, daß alle ührigen aus der Kapkolonie in die Gärten eingeführten Arten auch dem südlichen Gebirgsland angehören und nur in den Grenzgebieten der Karroo vorkommen.

Apicra Willd., kleine succulente Sträucher mit dicht stehenden, kurzen triangulären fleischigen Blättern und kurzen, schlanken Bliitenstengeln, enthält \& Arten, ron denen wir auch nur teilweise die im südlichen Kapland gelegenen Fundorte genauer kennen.

Chamaealoe A. Berg. ist eine monotypische, Hoc nahestehende Gattung; welche durch lange fadenförmige Staubfäden in kleinen Bliten ausgezeichnet ist; man kennt aber die Pflanze, welche jedenfalls aus dem Kapland stammt, nur in Kultur.

Gasteria Duval (Fig. 2i7). Diese Succulenten mit zweireihig gestellten und spiralig gedrehten, fleischigen, meist zungenförmigen Blättern haben in der Regel einen langen, hüufig etwas verzweigten Blütenstand mit etwas hängenden, gekrümmten, vereintblättrigen Perigonen. Etwa +2 Arten sind bekannt, aber auch nur von wenigen wissen wir mehr, als daß sie aus dem südlichen Kapland stammen, einzelne aus dem Gebiet der Algoa-Bay, eine Art, G. candicans Haw., von Worcester im südwestlichen Kapland.

Aloe L. Wenn wir auch jetzt schon nahezu 170 Arten aus dem tropischen Afrika kennen, so ist damit die Zahl der existicrenden doch noch lange nicht erschöpft. Die Aloe gehören zu den Pflanzen, welche nur wenig oder ungenügend von den botanischen Reisenden gesammelt werden, und ein großer Teil der in den Herbarien befindlichen Exemplare ist unbestimmbar; nur Prof. Dr. SchweINretri, der im verständnisvollen Sammeln afrikanischer Pflanzenobjekte aller Ast noch immer unerreicht dastcht, hat auch fuir diese Gattung vorziigliches Studienmaterial zusammengebracht.

Die Aloc-Arten wachsen teils in grasigen Steppen, teils auf trockenem, kiesigem oder lehmigem Boden, teils in Felsritzen. Einc monotypische Unter- 


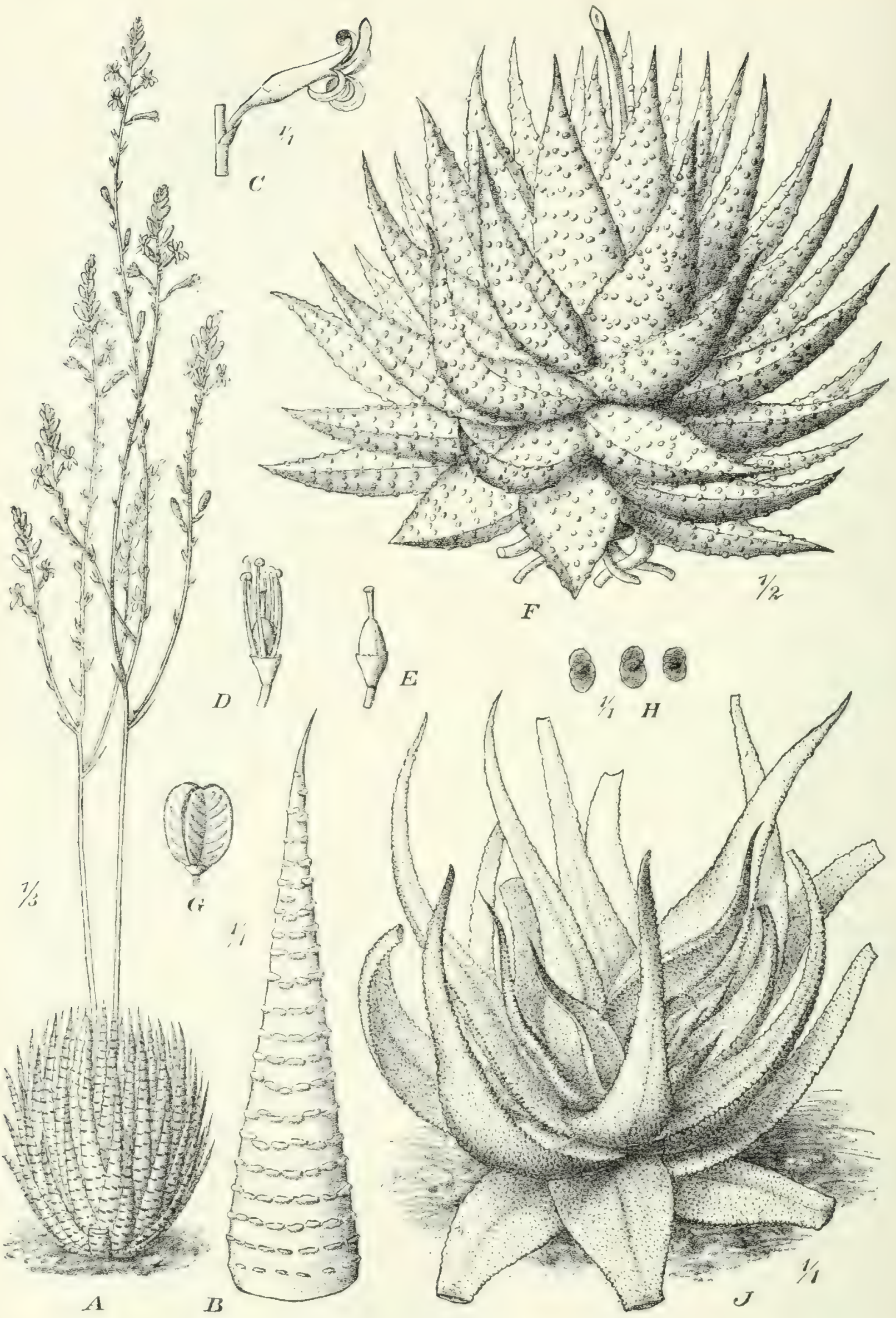

Fig. 216. A-E Haworthia fasciata Haw. $F-H$ Haw. margaritifera Haw. F Haw. radula Haw. (Alle im südlichen Kapland.) 
gattung Aloinella ist auf Zentral-Madagaskar beschränkt. Eine zweite Untergattung Leptoaloe umfaßt etwa i7 Arten mit \pm linealischen, kleingezähnten,

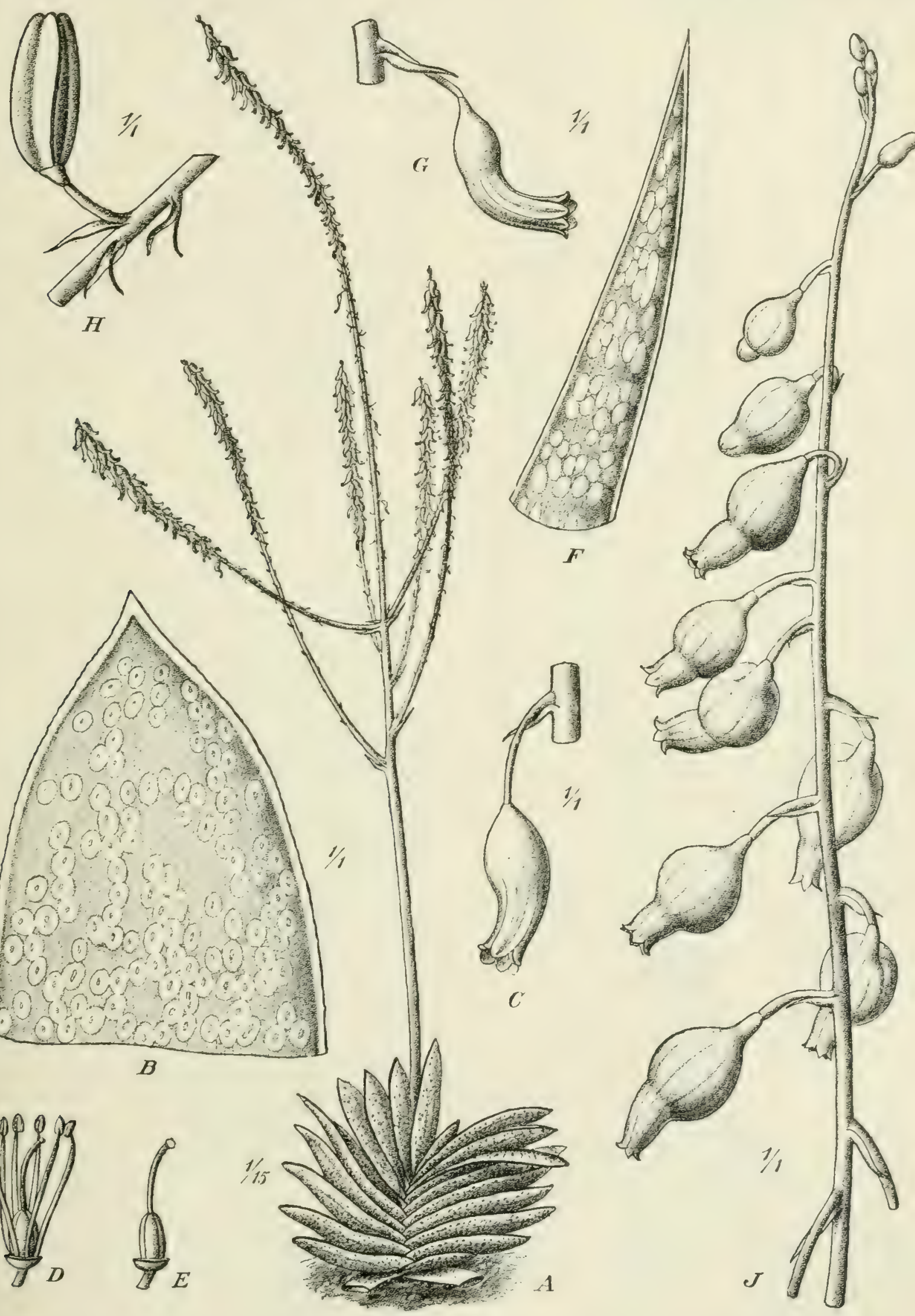

Fig. 217. A-E Gasteria maculata Haw. $F-H$ G. pulchra Haw. $\mathcal{F}$ G. planifolia Bak. (Alle im stidlichen Kapland.) $-C-G$ nach SALM, $\mathcal{F}$ nach BaKer, das übrige nach BERGER. 


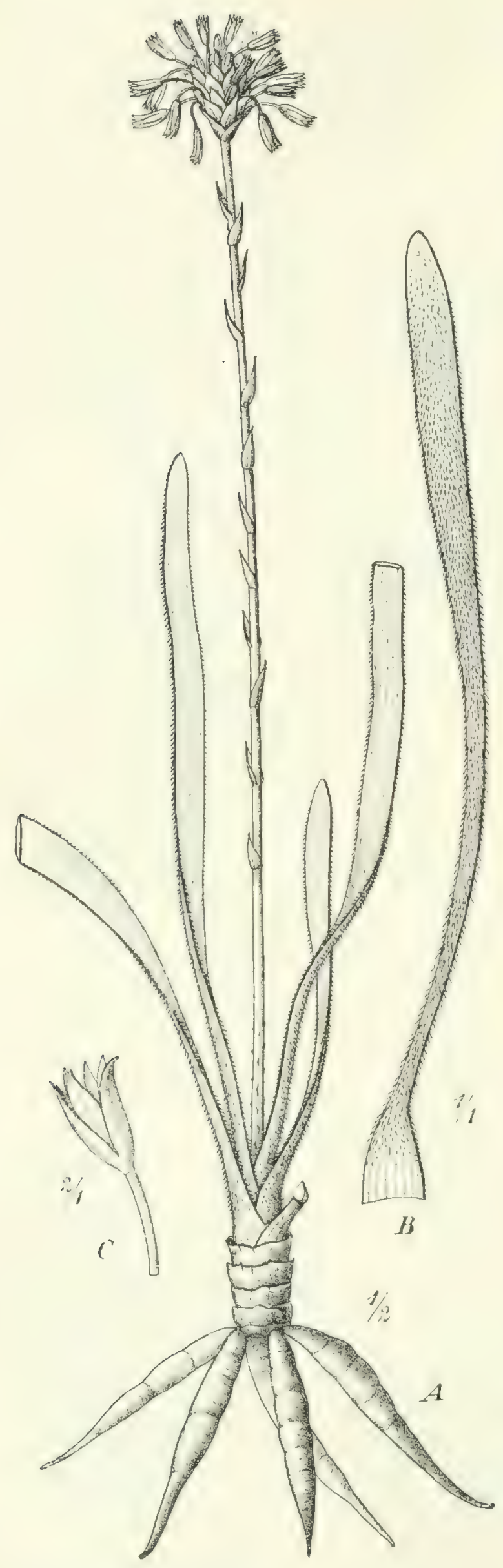

Fig. 218. Aloe parviflora 13ak. (Natal, bei Pinetown, um $1000 \mathrm{~m}$ ï. M.) - Nach BERglk. oft nur wenig succulenten Blättern, welche von Uitenhage und Port Elisabeth bis zum Kilimandscharo aufWiesen, auf steinigen Triften, auf Sandboden, an Flußufern angetroffen werden, die meisten südlich vom Nyassa-See in geringerer Höhe i. d. M., so $A$. parviflora Bak. in Natal (Fig. 2 I8), A. Nuttii Bak. aber auch auf dem Plateau von Ubena um $1750 \mathrm{~m}$ und $A$. Folnustonii Bak. am Kilimandscharo von $2900-3000 \mathrm{~m}, A$. graminifolia Berger auf steriler Grassteppe zwischen Kilimandscharo und Meru um $1000 \mathrm{~m}$ ü. M. Die verbreitetste Art ist A. Cooperi Bak., welche in dem siidöstlichen Teile der Kapkolonie nicht selten, auch in Natal und Transvaal bei Pretoria, Johannisburg und Lydenburg angetroffen wird. Diese Arten erinnern durch ihre schmalen Blätter ziemlich stark an die Kniphofia. Die große Mehrzahl der Arten (140) gehört zur Untergattung Eualoe, in der der neueste Monograph dieser Pflanzengruppe (A.BERGER) 26 Sektionen unterscheidet, die vielfach schon an dem Habitus kenntlich sind.

$\mathrm{Zu}$ den kleineren Arten gehören A. longistyla Bak. (Fig. 2 I9 $A-D$ ) im südöstlichen Kapland und der Karroo sowie die in Transvaal an Felsen von Pretoria bis Rustenburg vorkommende A. Peglorie Schoenland (Fig. 2 I $9 E$ ), zahlreiche Arten des südöstlichen Kaplandes, wie A. hmmilis Mill. (Fig. 220) und die in der Karroo überall verbreitete A. variegata L. mit dicht dachig, dreireihig gestellten, lanzettlich-dreieckigen, weißgefleckten Blättern und einer lockeren Traube leicht gekrümmter Bliten. Etwas größer als die vorigen sind die Arten der Saponarine und Asperifolice. In der erstgenannten, artenreichen Sektion zeigen die glatten Blätter zahlreiche helle Flecken und Striche, und der 
häufig dichotome Bliitenschaft trägt Bliiten mit am Grunde abgerundetem Perigon; sie sind vom südwestlichen Kapland durch Süd- und Ostafrika verbreitet bis zur Erythrea und mehrere oft recht charakteristisch. A. safonaria Haw. Fig. 221) ist in Natal häufig und die ihr nahestehende A. latifolia Haw. von Albany bis in

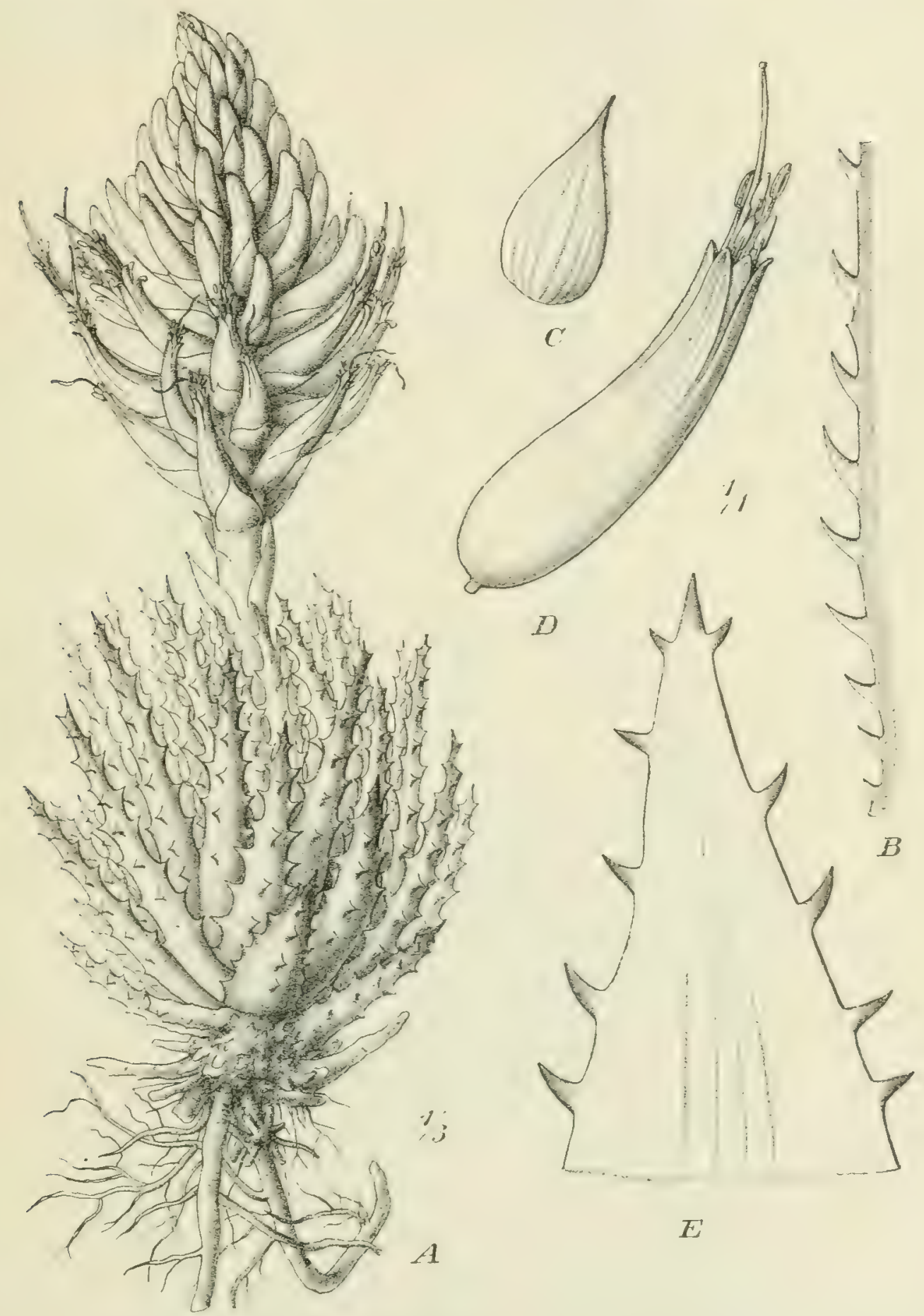

Fig. 219. $A-D$ Aloe longistila Bak. (Südwestliche und zentrale Kapkolonie). E A. Peglerae Schoenland (Transvaal, IVonderboomport bei Pretoria).

die Karroo verbreitet. Vom Betschuanaland durch die Kalahari, einen Teil von Transvaal und durch Deutsch-Südwestafrika bis Loanda kommt A. zebrina Bak. (Fig. 222) vor. A. striate Haw. (Fig. 223) ist im südöstlichen Kapland verbreitet und kommt auch in Groß-Namaland bei Gubub in einer halbschattigen 
Schlucht vor. Im Hereroland und überhaupt in Deutsch-Siidwestafrika ist A. horcroensis Engl. (Fig. 224) häufig. Eine Charakterpflanze für die Baumund Buschsteppen im Norden der Magalisberge, namentlich fuir die lichteren Teile derselben von Pretoria bis Seerust und Ottoshoop, ist A. transualcnsis O. Ktze. Im östlichen Sambesigebiet kommen zwei Arten dieser Gruppe vor, in Usambara bei einer Höhe von rooo $\mathrm{m}$ ii. M. und am Kilimandscharo von

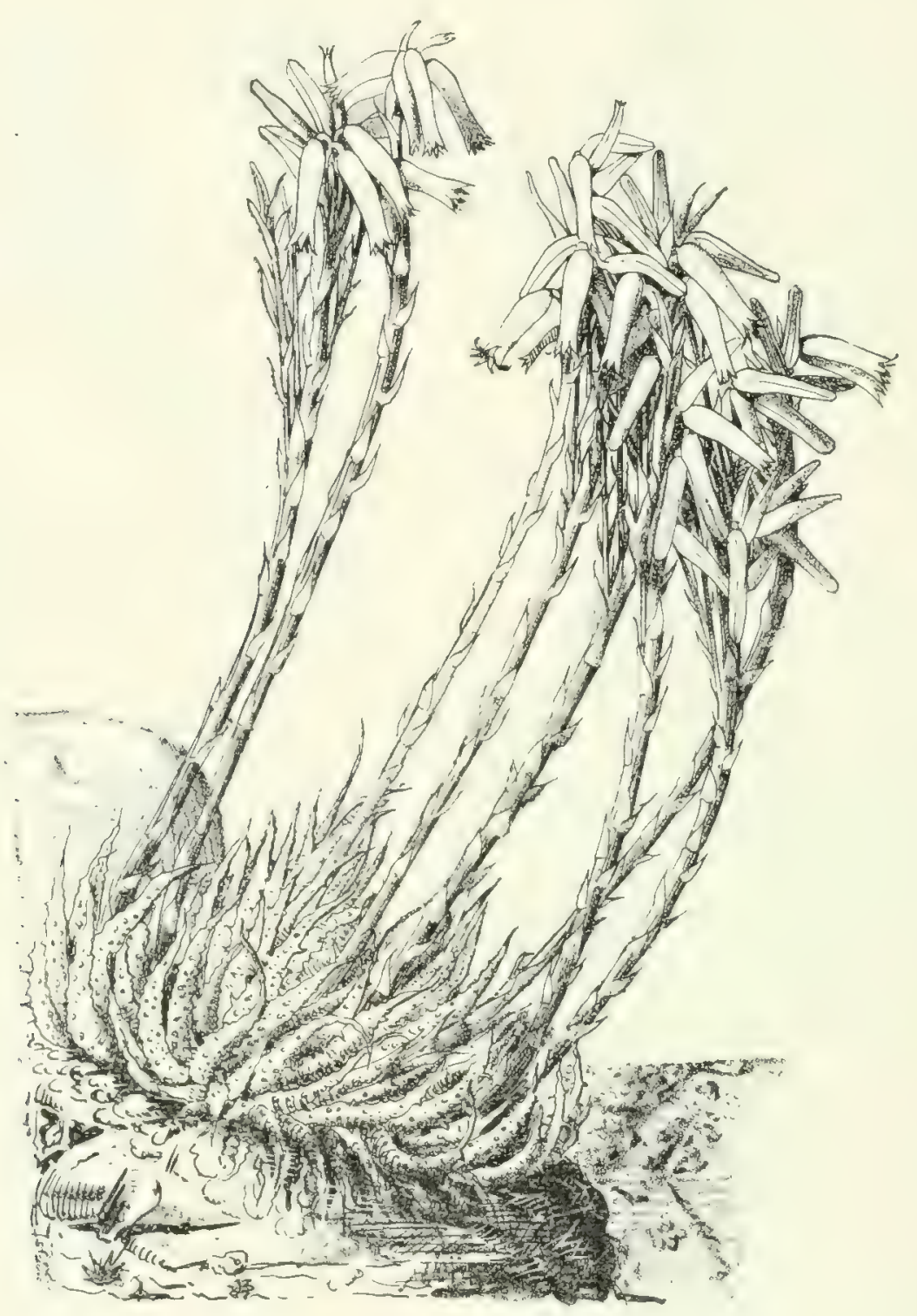

Fig. 220. Aloe humilis Mill. var. echinata Willd. (Östliches Kapland, Somerset East).

I 300--r $900 \mathrm{~m}$ A. lateritia Engl. (Fig. $225 A--D$ ), östlich vom Tanganyika die nahestehende A. Bochmii Engl, im südlichen Somaliland A. Lillonbcckii Berger, im mittleren Abyssinien und in der Erythrea von I600-2200 $\mathrm{m}$ ü. M. A. macrocarper Todaro. - Eine kleinere Gruppe, die Asporifoline mit papillös-rauher Epidermis der graugriinen, nicht gefleckten Blätter und mit am Grunde zusammengezogenem Perigon, enthält cinige im Westen und in der Mitte der Kapkolonic vorkommende Arten. - Vicle Arten aber entwickeln sich kräftiger als die vorigen, sei es, daß der Stamm kurz bleibt oder baumartig wird; diese 
haben auch große, meist schwertfürmige Blätter und einen verzweigten Blütenstand, ferner ein am Grunde meist zusammengezogenes Perigon. Ziemlich iso-

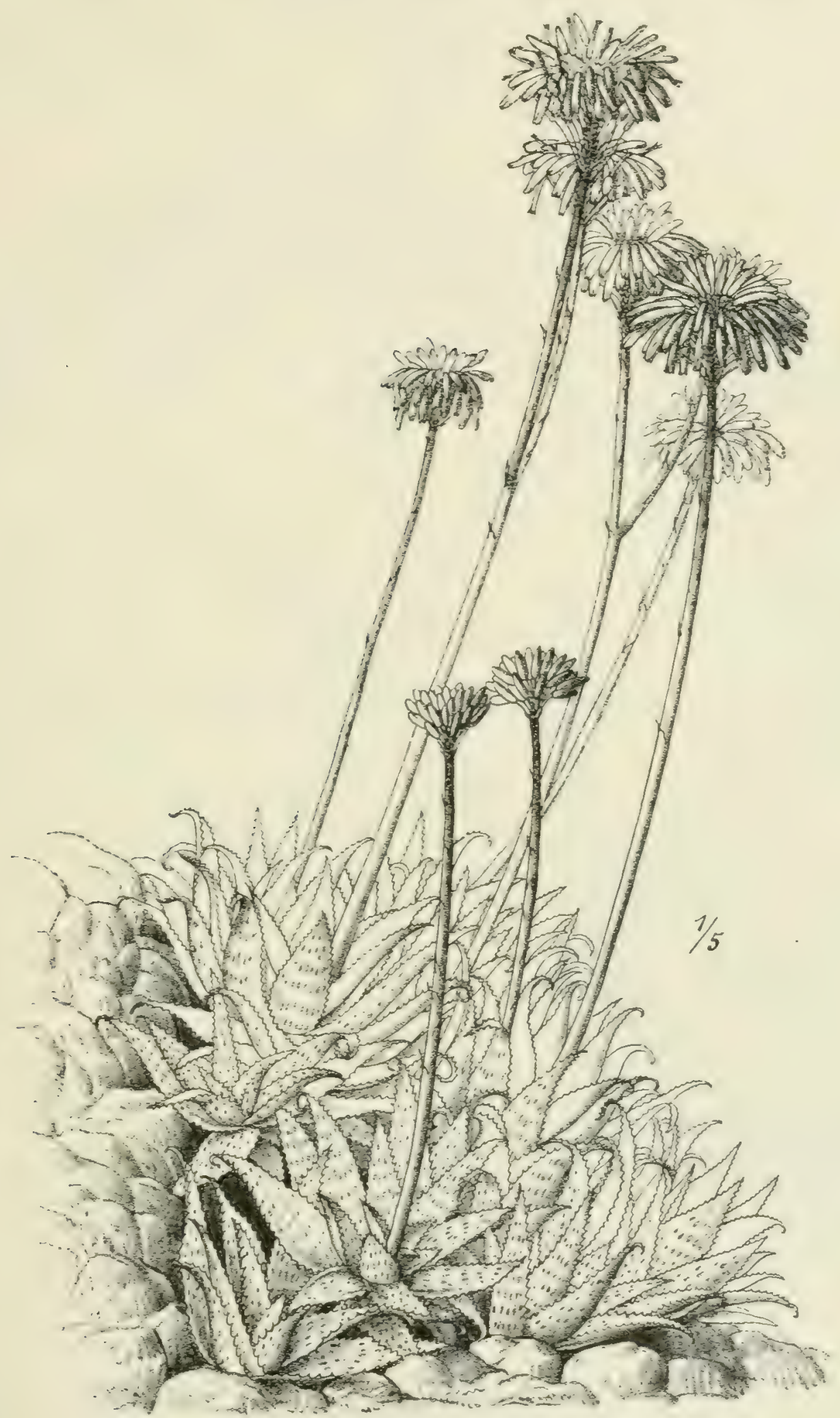

Fig. 221. Aloe saponaria Haw. (Natal.) - Nach BERGER.

liert steht die grundstämmige, durch dreieckig-lanzettliche Blätter ausgezeichnete, mit lockeren Blütentrauben und am Grunde stumpfen Perigonen versehene 1. fercrassa Todaro (-1. Schimperi Schweinfth., Fig. 226), welche namentlich 
in der Erythrea in Spalten und Rissen steiler Gehänge von i $900-2600 \mathrm{~m}$ häufig ist, aber auch in Tigre vorkommt. - Artenreicher sind mehrere Gruppen, bei denen das Perigon am Grunde zusammengezogen ist. Mehrere bemerkenswerte Arten bilden die Gruppe der l'erae, deren lange Blütentrauben breite, zuletzt zurückgeschlagene Bracteen tragen; die in der Massaisteppe am Fuß des Paregebirges vorkommende, bis $2 \mathrm{~m}$ hohe A. deserti Berger; ferner A. rutro-

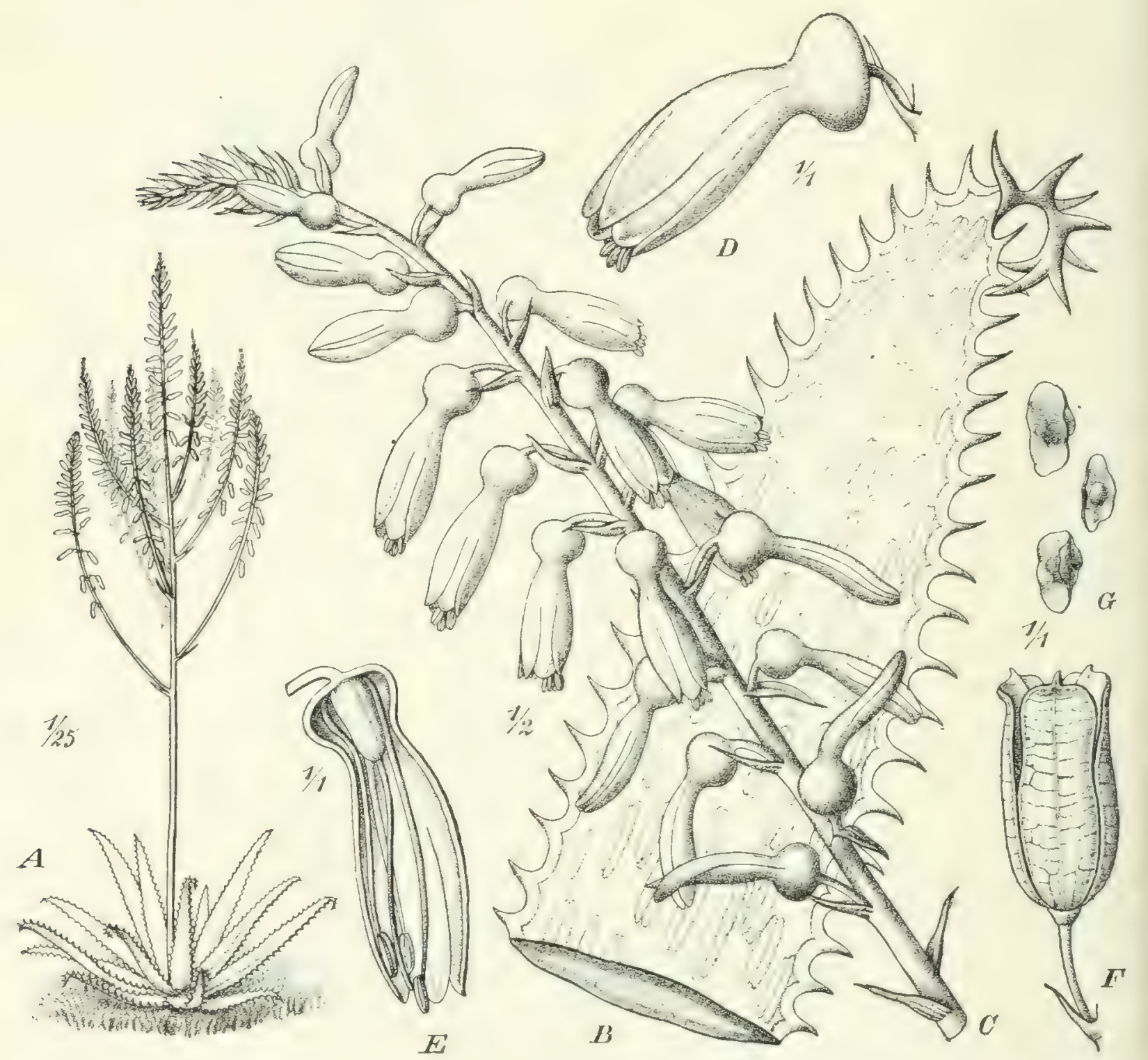

Fig. 222. Aloe zebrina Bak. (Angola, Detatsch-Südwestafrika, Transvaal.) $A$ Habitus; $B$ Blatt; $C$ Traube; $D$ Perigon; $E$ Blite; $F$ Kapsel; $G$ Samen. $-B-C$ nach Bot. Magaz., das übrige nach BERGER.

Inted Schinz Fig. 227) mit 2,5-4,5 $\mathrm{m}$ hohem, cinfachem Stamm, 5-6 dm langen, graugrünen Blättern und $3 \mathrm{~cm}$ langen, gelbroten Blüten, häufig im Amboland an der Etosapfanne auf Grassteppen, ferner im Hereroland an Abhängen felsiger Hügel, auch in Groß-Namaqualand und in der Kalahari: A. litoralis Bak. in der ganzen Küstenregion von Loanda; ferner die im Mittelmeergebiet und anderen wärmeren Ländern häufig angepflanzte und verwilderte, aber doch wohl 


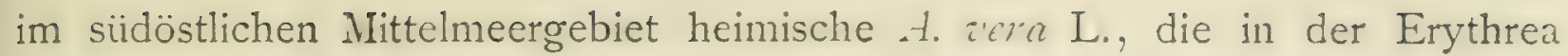
von 1000-1700 $\mathrm{m}$ häufige A. trichosantha Berg., nebst der in Yemen vorkommenden Varietät menachensis Schweinfth.; A. tomentosa Defl. in Yemen. Den vorigen ähnlich, aber durch aufrechte Bracteen verschieden sind die auf Sansibar vorkommenden Arten -1. bracky'stachy's Bak. und 1. Lastii Bak., sowie

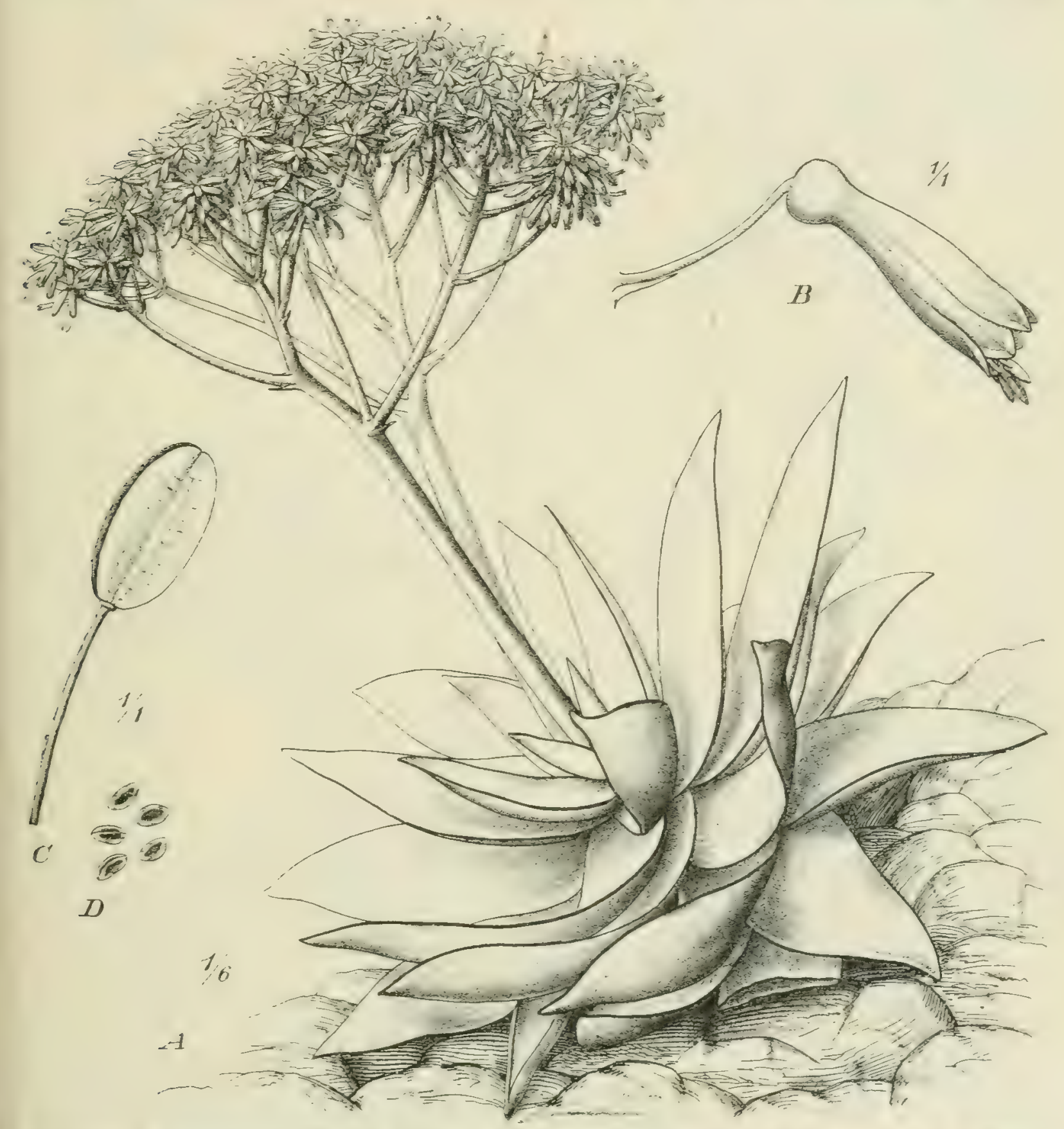

Fig. 223. Aloe striata Haw. A Habitus: I Perigon; C Kapsel; D Same. - Nach Brncer.

A. crptopoula Bak. im östlichen Sambesigebict. - Schmälere Bracteen, welche wenig kürzer oder nur halb so lang sind als die Blïtenstiele, kommen der Gruppe der Acthiopicai $z u$, ron denen mehrere Arten im tropischen Afrika eine Rolle spielen, A. wnonosa Engl. im Baschilangegebiet, einige Arten in Angola, A. Biuttneri Berger in Togo, A. somulicnsis Wright im Somaliland (Fig. 228, A. aethiopica (Schweinfth.) Berger (Fig. 230) in Abyssinien (Tigre und A. aby's- 
sinica Lam. (Fig. 229) in Abyssinien und der Erythrea, von $1600-2700 \mathrm{~m}$ in der Hochgrassteppe und im offenen Buschgehölz. - Bei der nahestehenden Gruppe der Tropicales sind die Bracteen viel kürzer, als die Blütenstiele. Hierher gehört wiederum eine Art der Erythrea, welche durch ihr häufiges Vorkommen auf den Plateaus und in den Tälern von $1400-2700 \mathrm{~m}$ sehr

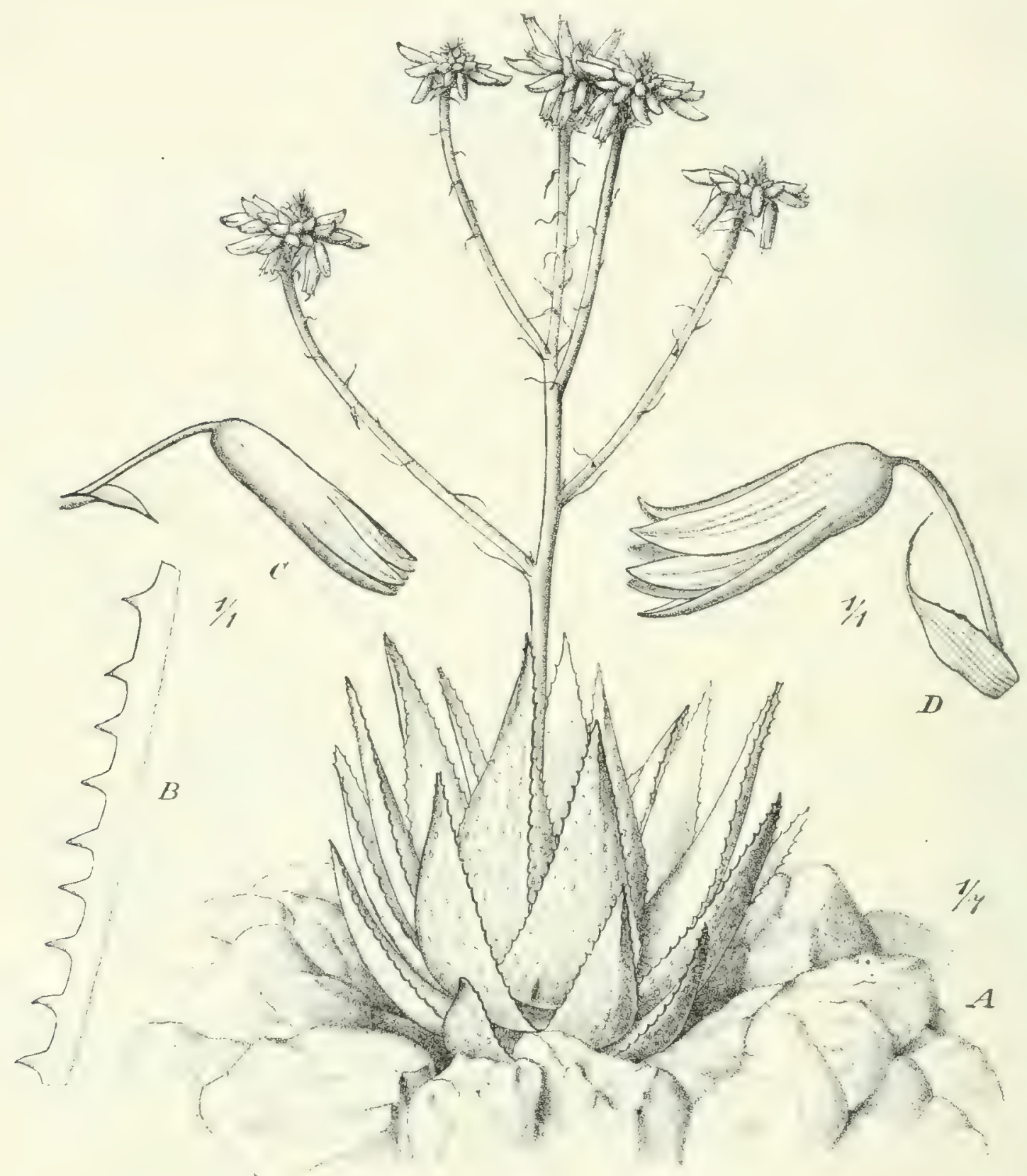

Fig. 224. Aloe hereroensis Engl. var. orpeniae Berger. A Habitus. - A hereroensis Engl. $B$. Blattrand; $C$ jüngere Blüte; $D$ ältere Blüte. (Deutsch-Südwestafrika, Glimmerschieferhiig el, Karibib bis Kubus.) - A nach Schönland, das übrige nach Berger.

charakteristisch ist, A. em Berger, mit 4-5 cm langem, von Grund aus verzweigtem Stamm, bis $6 \mathrm{dm}$ langen und bis $7 \mathrm{~cm}$ breiten Blättern, auch in Nubien, zwischen Atbara und dem Roten Meer, sowie zwischen Berbera und Suakin. Ferner gehört hierher A. Pcrryi Bak, von Socotra, welche die berühmte Socotra-Aloe, den Tâjef, liefert, mit einfachem, etwa $3 \mathrm{dm}$ hohem 


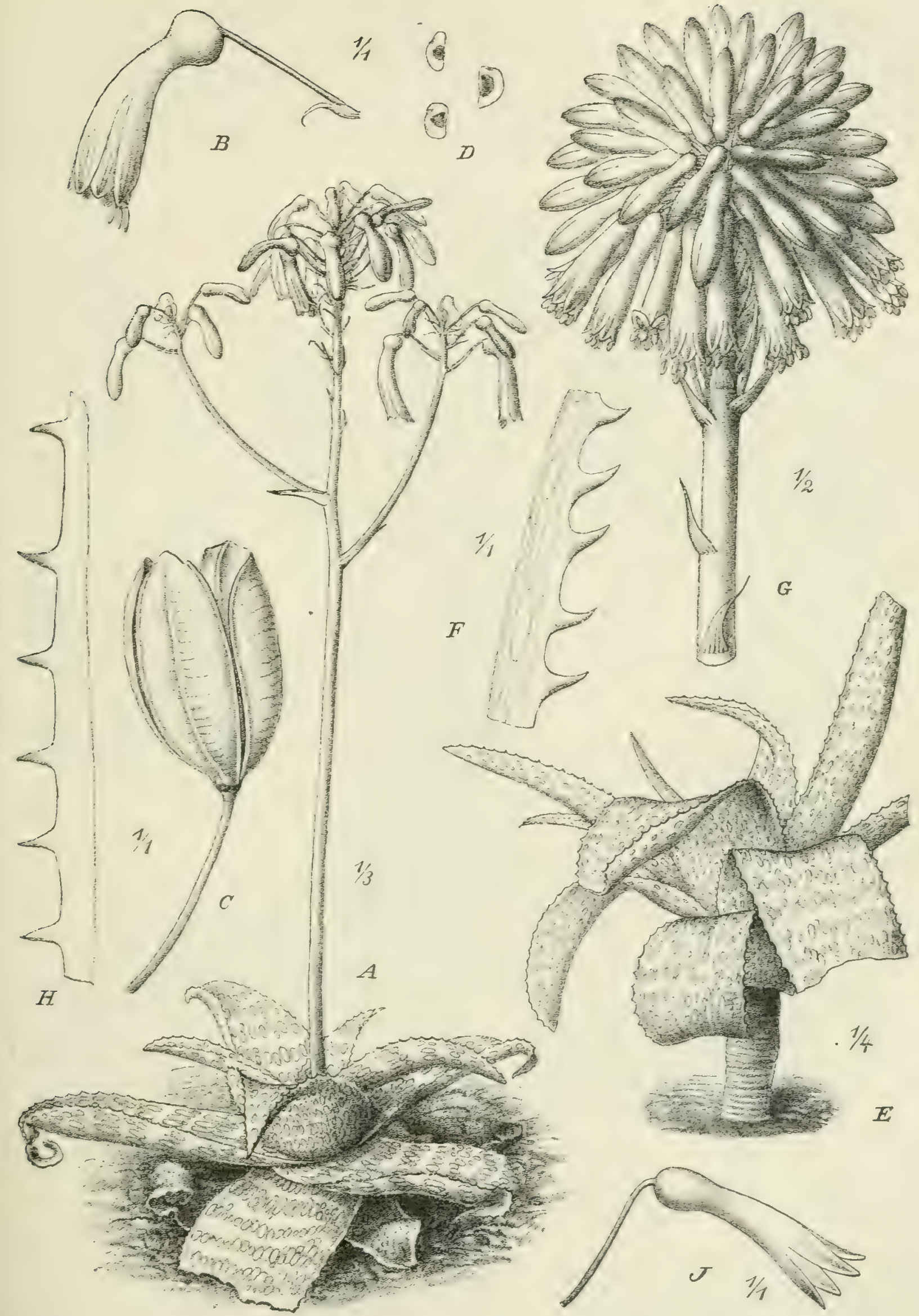

Fig. 225. $A-D$ Aloe lateritia Engl. (Usambara). $E-G$ A. leptophylla N. E. Brown (Südwestliches Kapland, Worcester). H, F A. Böhmii Engl. (Zentralafrikanisches Seengebiet, Gonda), - G nach Bot. Magaz., das ïbrige nach BERger. 
Stamm (Fig. 23 I A-G). Einen höheren Stamm besitzt A. Schucinfurthii Bak., auf Granithügeln im Niam-Niam-Land. Etwa $1,8 \mathrm{~m}$ hoch wird der Stamm bei der in Uganda, namentlich in Entebbe von $1250-1650 \mathrm{~m}$ weitverbreiteten A. Dawci Berger, über $\mathrm{I} m$ hoch bei der in Benguela wachsenden 4 . palmiformis Bak. Einen niedrigeren Stamm besitzt A. Engliri Berger (Fig. 232),

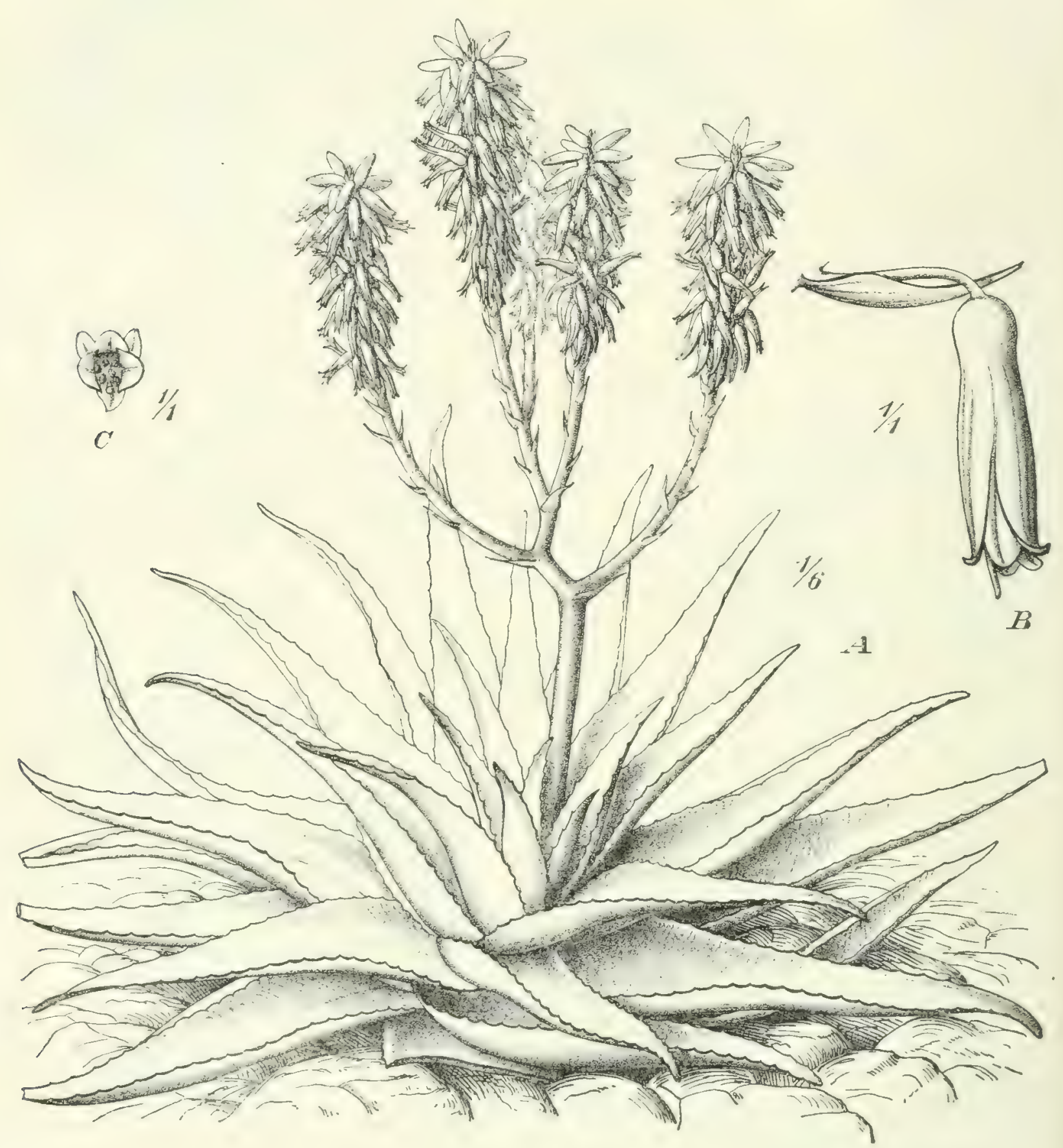

Fig. 226. Aloe percrassa Todaro var. saganeitiana Berger. (Erythrea.) - Nach BERger.

welche ich schr häufig in lichten Baumsteppen zwischen Taveta und den Burabergen antraf und die mit ihren prachtvoll roten Blitenrispen weithin leuchtet; ihr ähnlich ist $A$. Rivae Bak. (Fig. 23I $H-L$ ) im nordwestlichen Boran im Somaliland, ferner H. rabaicnsis Rendle in den Rabai-Hills unweit Nombas. Mehrere andere Gruppen, welche als Prolongratic zusammengefaßt werden, 
haben entweder einen dünnen Stengel oder sind strauchig mit oft niederliegenden, locker beblätterten Stengeln. Hierher z. B. 1. commixtı Berger im Kapland (Fig. 233). Mehrere dünmblättrige Arten des südöstlichen und des suidwestlichen Kaplandes nebst einer Art ron Madagashar bilden dic Gruppe der Merrifolidi.

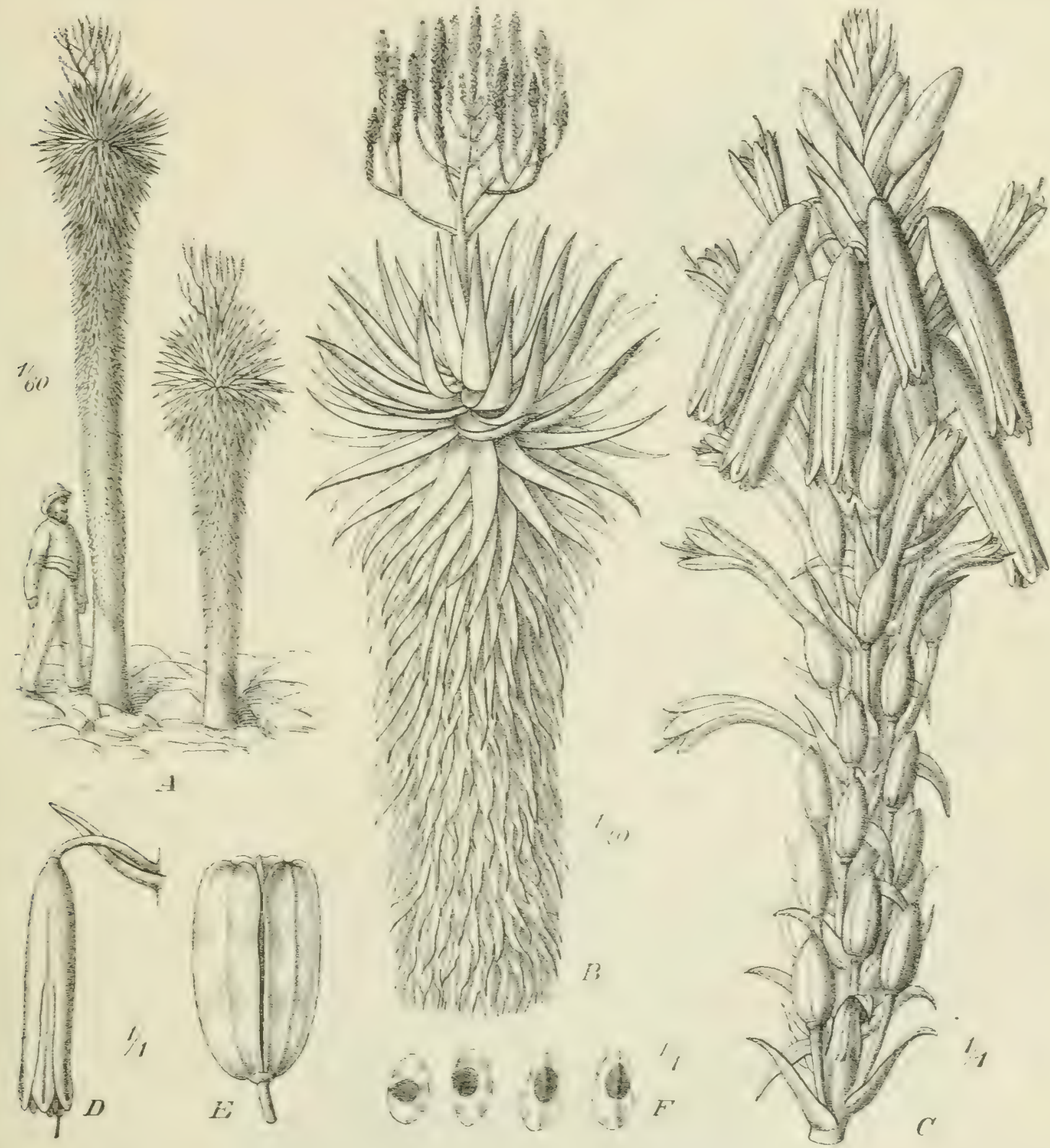

Fig. 227. Aloe rubro-lutea Schinz. (Kalahari, Olifants Kloof.) $A$ Habitus, ${ }^{\mathrm{I}} / 60 \mathrm{n}$. Gr.; $B$ oberer Teil, I/2o n. Gr.; $C$ Traube; $D$ Perigon; $E$ Kapsel; $F$ Samen. - Nach Berger.

Fleischiger sind die Blätter bei den Monostachyte, welche auch durch einfachen Blitenschaft charahterisiert sind. Hierzu gehören -1. squmms Bak. von Socotra, A. a'itucnsis Bak. von IVitu Fig. 23+F-H), -1. Montcirri Bak. von DelagoaBay, eine Art von Madagaskar, A. Camowniz Hemsl. von L'ganda Fig. $23+$ - $-D-D)$ und A. Princiae Berger 'Fig. $23+E$ ) von den Ltschungwebergen im Nyassa- 
lande. - Rispige Inflorescenzen haben die den vorigen ähnlichen Plourostachyac, von denen einige Beachtung verdienen, A. Pirottae Berger und A. Ruspoliana Bak. im Somaliland, A. inermis Forsk. in Südarabien in der Nähe der Stadt

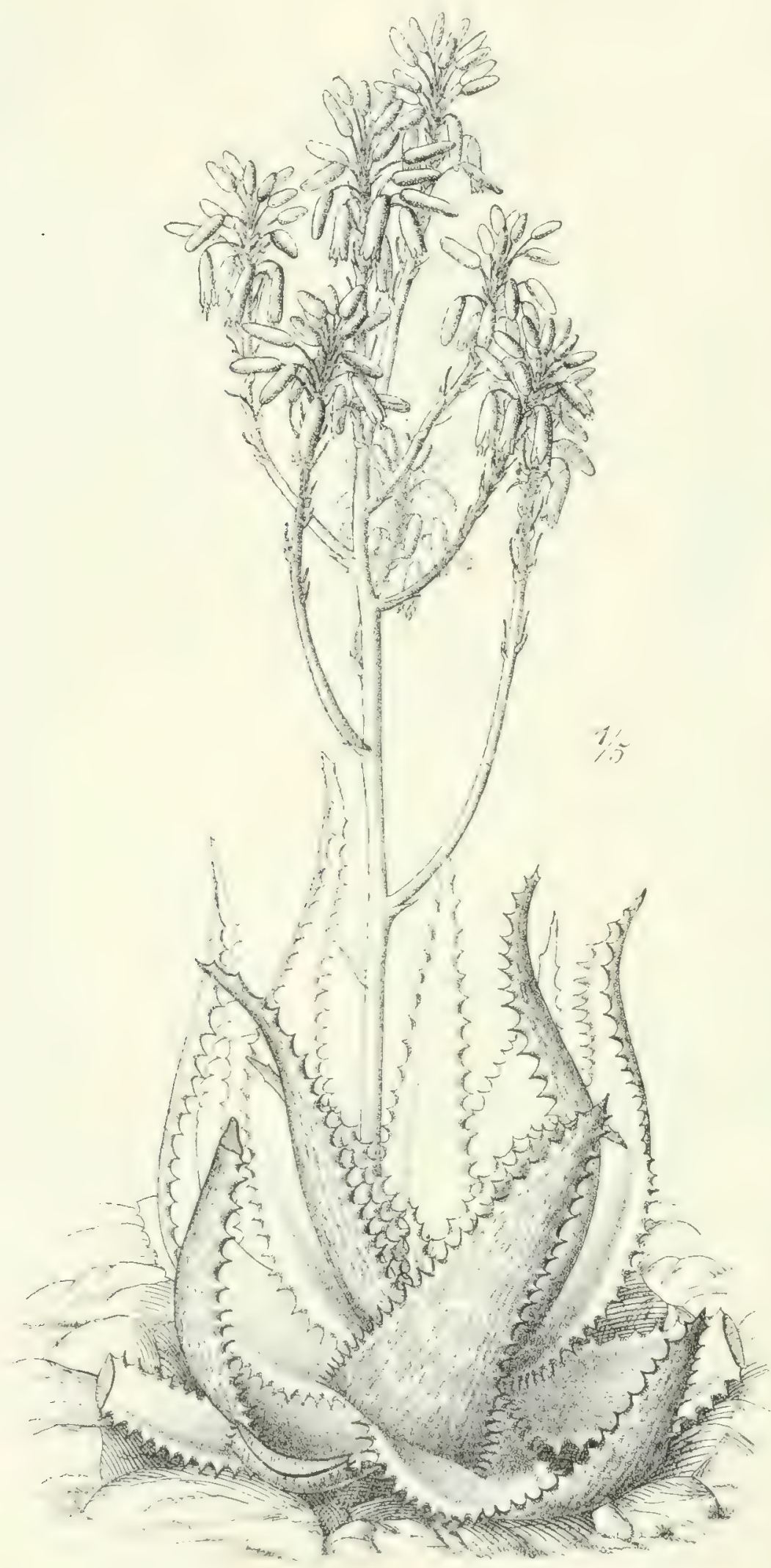

Fig. 228. Aloe somaliensis Wright. Habitus. (Wahrscheinlich nördliches Somaliland.) Nach BERGEr. 
Taëz, A. lencantha Berger Fig. 235 E. im Gallahochland. H. sccundiffera Eng]. in der immergrünen Dornbuschsteppe des Kilimandscharogebietes, H. Hillebrandtii Bak. Fig. $235 .-1-D$, wahrscheinlich in Usagara. - Die nahestehenden Fruticosae sind nur durch grüßere Bracteen verschieden. Wichtig ist 1. findins

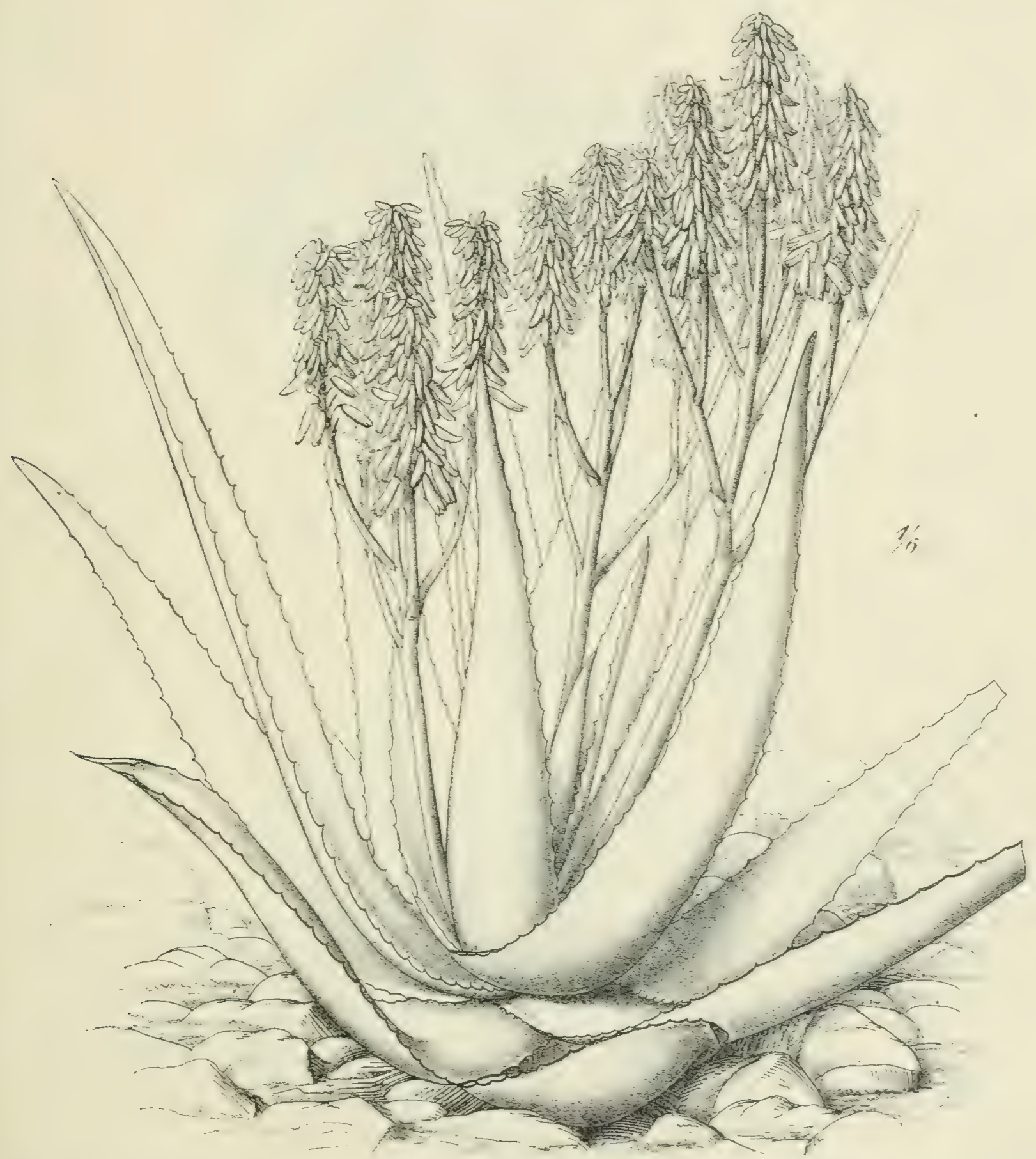

Fig. 229. Aloe abyssinica Lam. Habitus. (Kohaito-Plateau in der Erythrea, um 2600-2700 m, auch sonst häufig in Beständen von 1600-2400 m.) - Nach BERGER.

Forsk. (Fig. $236 A-C$ ), welche in Yemen oft in großen Massen von steilen Felswänden herabhängt; ihr ähnlich sind . . confusı Engl. an felsigen . Abgriunden des Dschalla-Sees (rooo m) am Kilimandscharo, A. Bussici Berger an Felsabhängen des westlichen Usagara I $100 \mathrm{~m}$, 1. cimnaburina Diels Fig. $236 \mathrm{D}$. E 
bei Lydenburg in Transvaal. - Sechs zum Teil sehr formenreiche Arten bilden die Gruppe der Mitriformes, mit dicken fleischigen Blättern und cylindrischem Perigon; sie sind alle im Kapland heimisch. - Eine Anzahl Arten

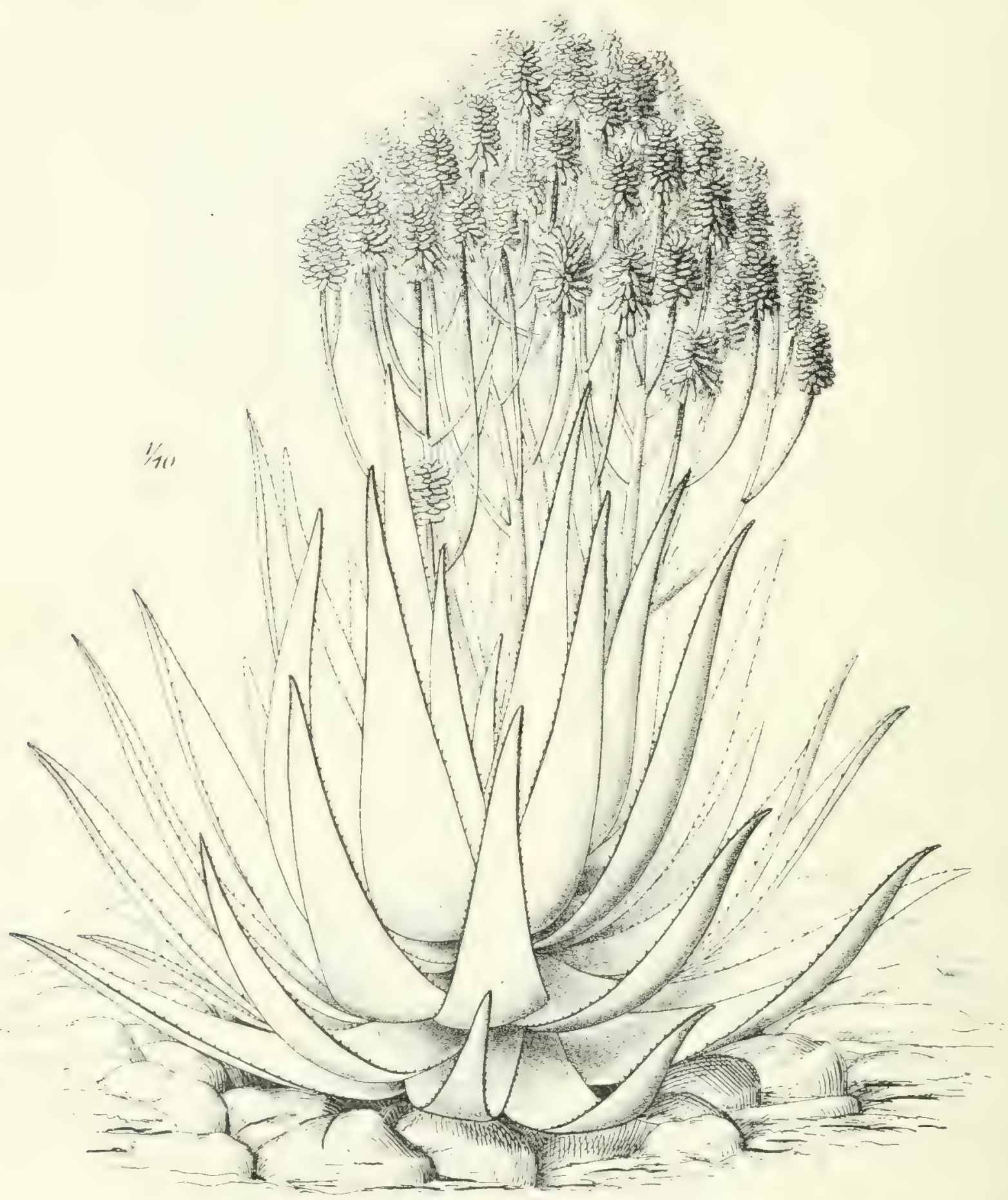

Fig. 230. Aloe aethiopica (Schweinf.) Berger. Habitus. (Abyssinien, Tigre, bei Abba Gerima, um 2000-2620 m.) - Nach Berger.

wird strauchig oder baumartig und entwickelt nach einem Schopf ron Blättern eine kräftige Inflorescenz mit großen Bracteen und cylindrischen, am Grunde abgerundeten Blïtenhiullen mit meist freien Bliitenhiillblättern. Hierzu gehören einige auf das Kapland beschrïnkte Gruppen, wie die der Purpurascentes mit 
cylindrischem Perigon und freien Perigonblättern: ihre wichtigste Art ist die am Tafelberg bei Kapstadt um tco $m$ ü. M. wachsende A. succotrincr Lam. (Fig. 237). Nächst dieser die Gruppe der Arboriscentis mit der ungemein

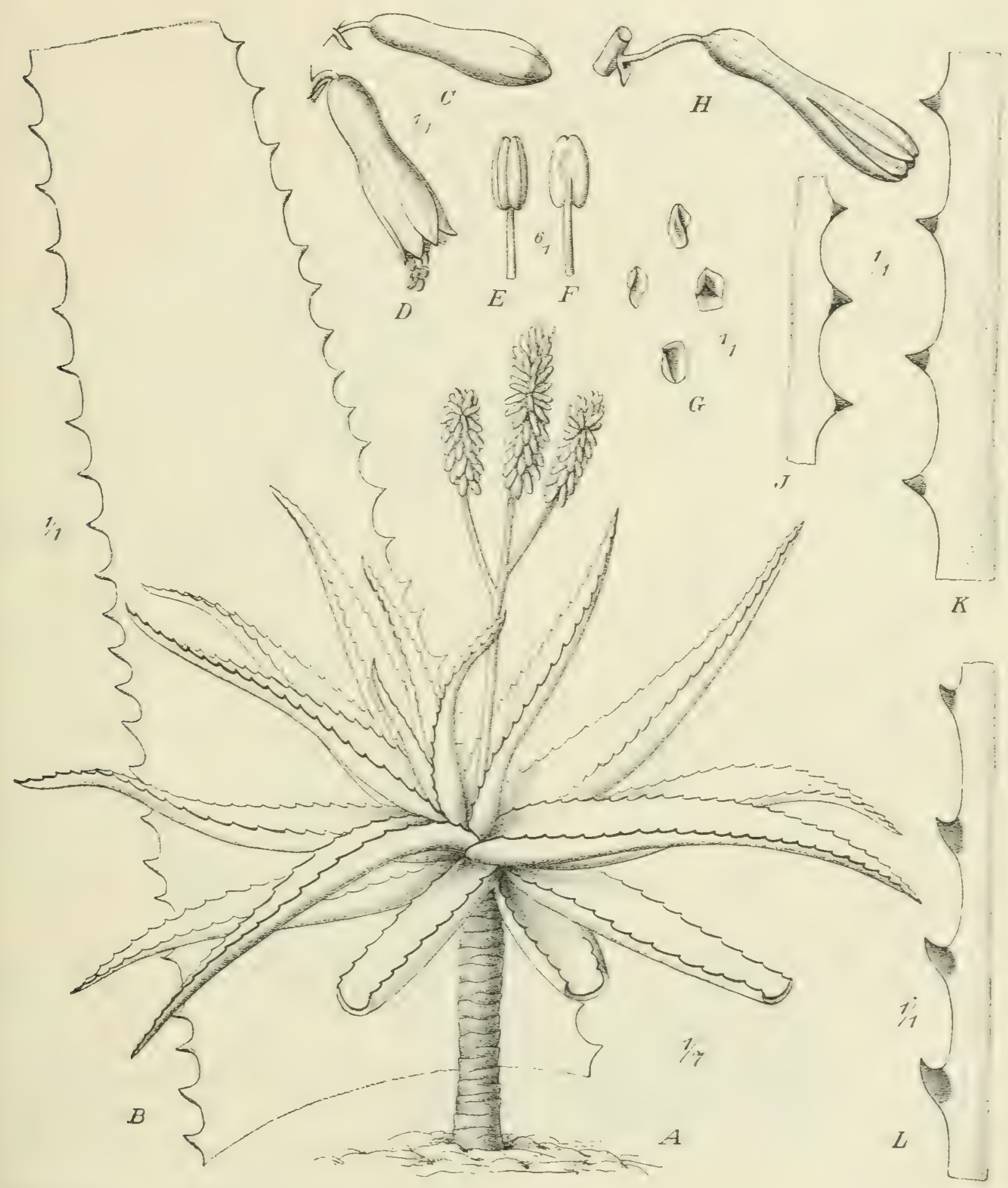

Fig. 23r. $A-G$ Aloe Perryi Bak. auf Socotra. $G$ Samen. $-H-L$ A. Rivae Bak. (Somaliland, Gobbo Duaya und Coromma im nordwestlichen Boran.)

formenreichen $A$. arborescens Mill. (Fig. 238), zu welcher auch die aus dem Kapland bis nach Natal verbreitete var. natalensis (Wood et Evans) Berger gehört, eine bis $2 \mathrm{~m}$ hohe, oft vom Grund an verzweigte Pflanze: ferner schließt 
sich hier die im östlichen Kapland bis zu $1000 \mathrm{~m}$ Höhe vorkommende $A$. pluridens Haw. an. - Von der Gruppe der Arborescentes mit kurzen Staubfäden unterscheidet sich die der Principalis durch lang hervortretende Staubfäden.

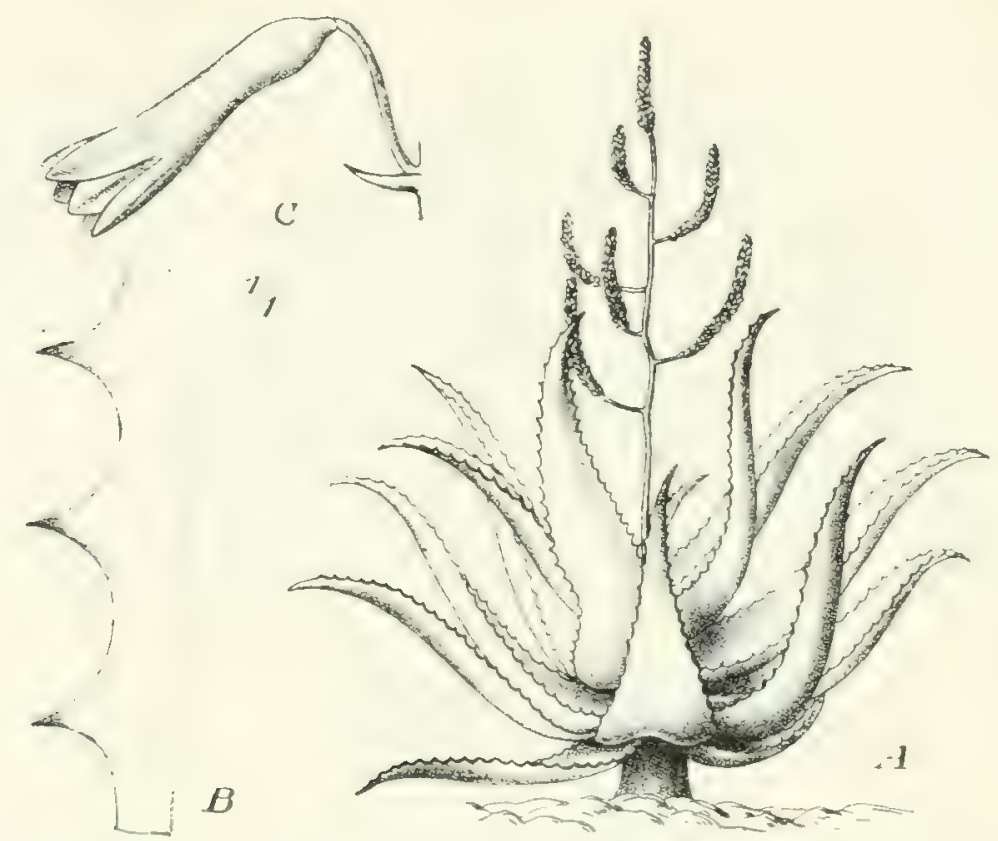

Fig. 232. Aloe Engleri Berger. $A$ etwa ${ }^{\mathrm{I}} / 30 \mathrm{n}$. Gr.; $B$ Blattrand; $C$ Perigon. (Kilimandscharogebiet, zwischen Tareta und den Burabergen.) - Nach BERGER.

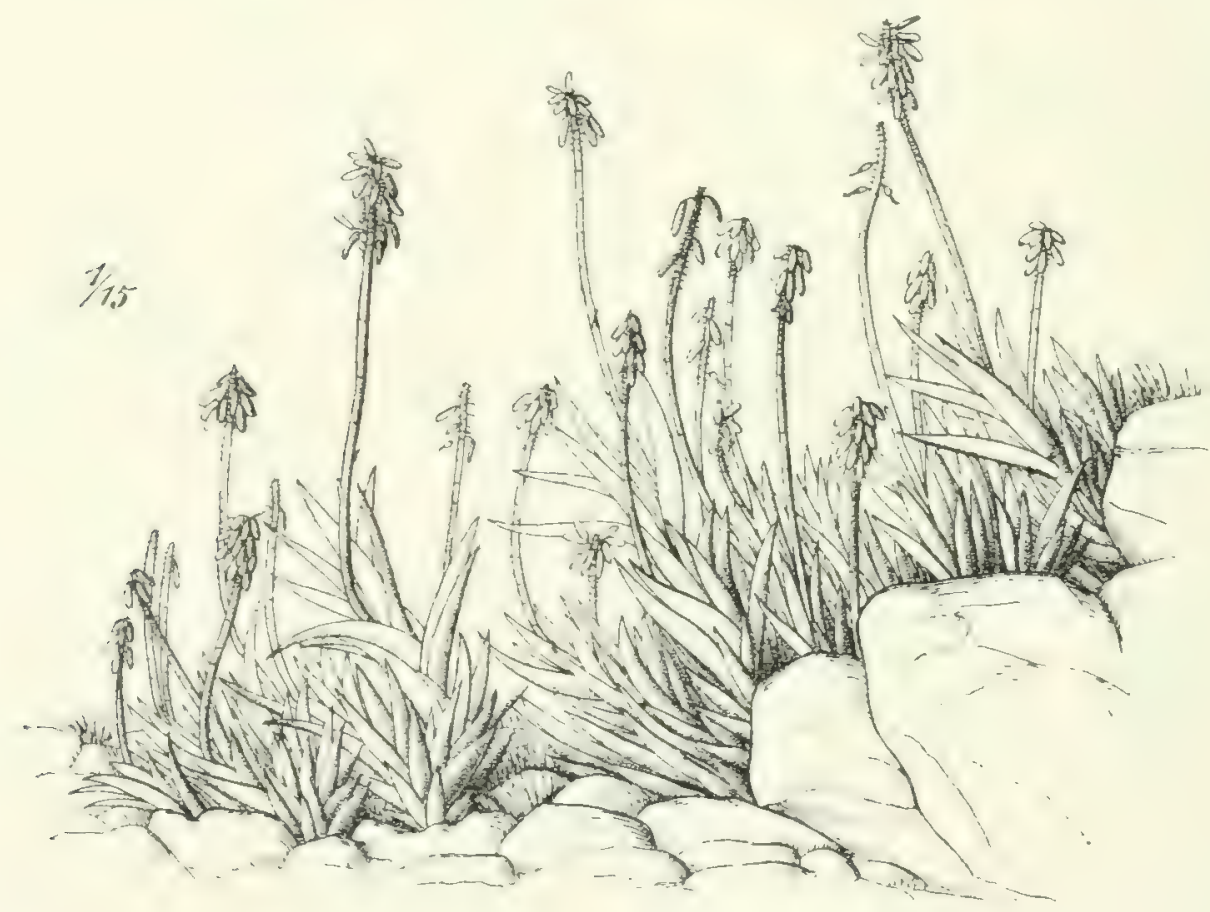

Fig. 233. Aloe commixta Berger. (Simonstown im südwestlichen Kapland.) - Nach Berger.

A. mubroviolacea Schwfth. (Fig. 239), mit etwa I m langem Stamm und fast $4 \mathrm{~cm}$ langen Blüten, vertritt diese Gruppe in Yemen $(2900 \mathrm{~m}) ; A$. Schoelleri Schwfth. findet sich auf Felsen in der Erythrea. Eine sehr stattliche Pflanze von $-\$ \mathrm{~m}$ Höhe ist die im östlichen Kapland vorkommende A. spiciosa Bak. 
Auch die große A. macroclade Bak. von Madagaskar und mehrere andere kapländische schließen sich hier an.

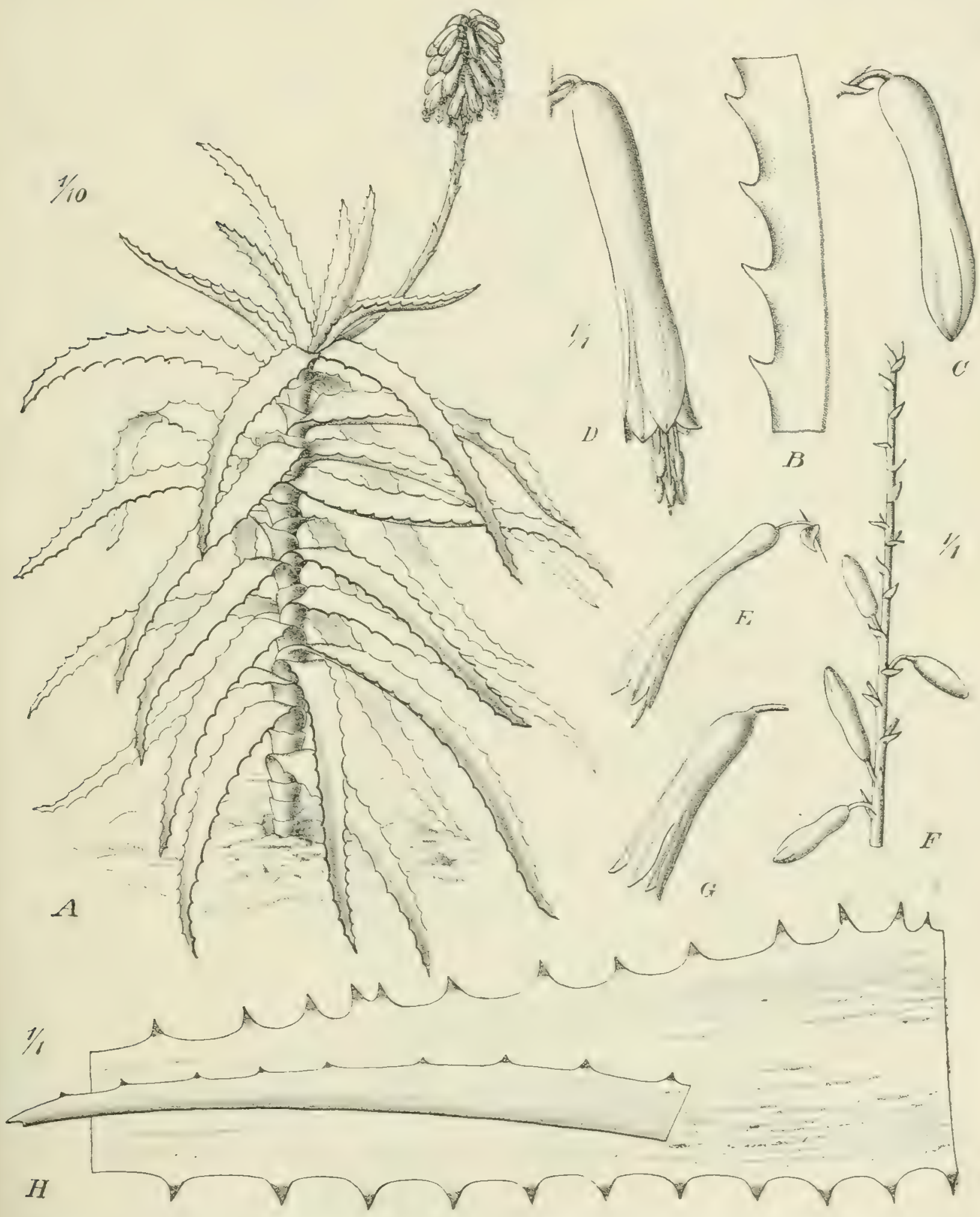

Fig. 234. $A-D$ Aloe Cameronii Hemsl. $E$ A. Princeae Berger. $F-H$ A. vituensis Bak. $A-D$ nach Bot. Magaz., das übrige nach BERGER.

Dic Sektion Pruchylcndron enthält hochstämmige Arten mit derb lederigen, stark stachelig gezähnten Blättern, mit dichten Blïtenständen und kleinen Bracteen: von den im Kapland verbreiteten Arten reicht die $\mathrm{I}-3 \mathrm{~m}$ hohe 
A. ferox Mill. (Fig. 240), welche im suidöstlichen Afrika oft ganze Strecken bedeckt und ebcnso wie A. succotrina Lam. des Kaplandes Aloeharz liefert,

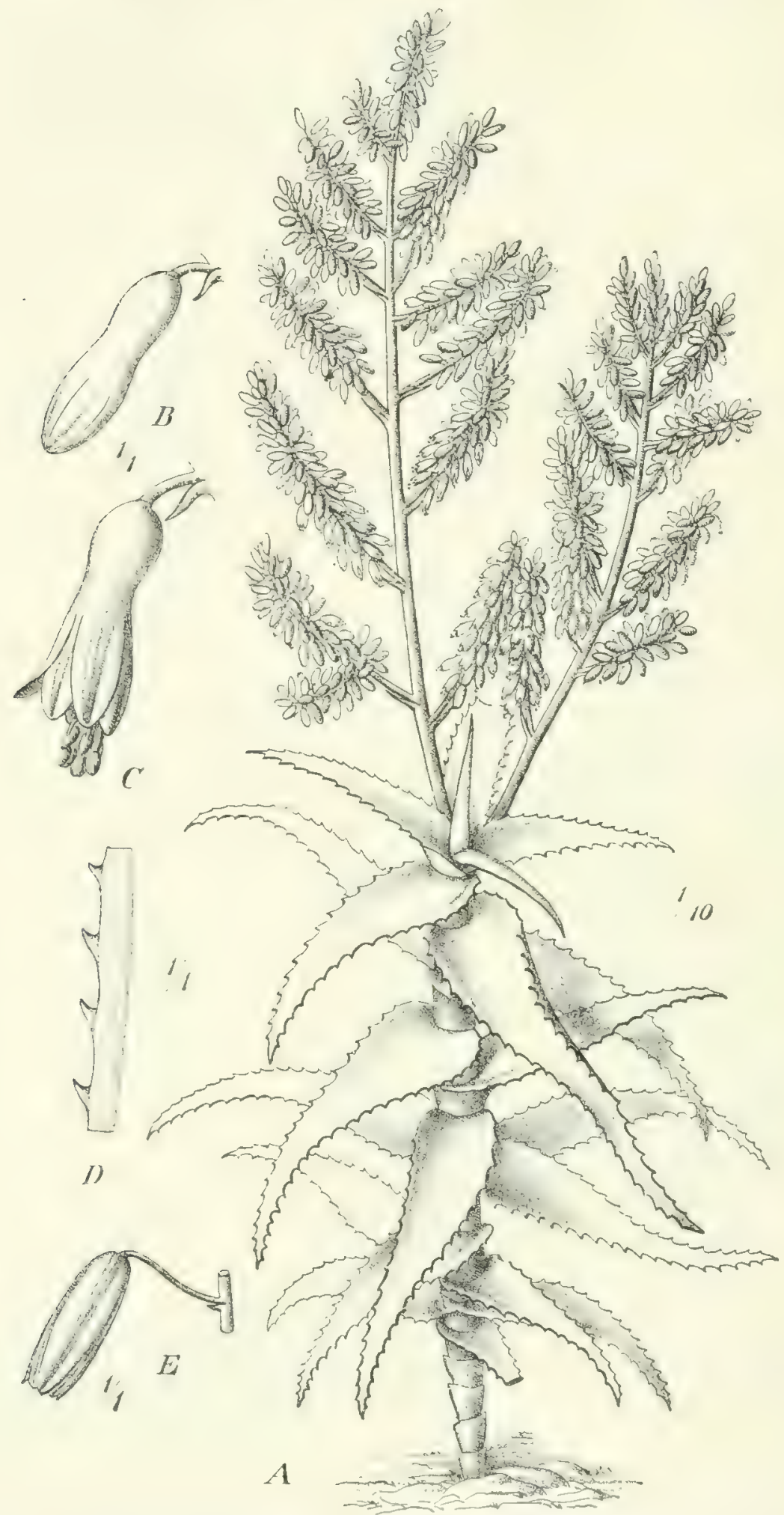

Fig. 235. $A-D$ Aloe Hildebrandtii Bak, kommt vor im Euphorbien-Dornbusch bei Kidete in Westusagara. E A. leucantha Berger. - $A-D$ nach Bot. Magaz., $E$ nach BERGER.

bis Delagon-Bay. Dieser Art steht nahe A. Marlothii Berger (Fig. 2+1) von Betschuanaland und den Klippriversbergen bei Johannisburg, die letzteren fast ausschließlich bedeckend. Einen $5 \mathrm{~m}$ hohen Stamm besitzt die bei Bula- 
wayo in Rhodesia vorkommende A. excelsa Berger. Größer als alle diese Arten wird die bei Grahamstown im östlichen Kapland häufige A. africanic Mill.; sie erreicht schließlich eine Höhe von $7 \mathrm{~m}$. Auch A. mpestris Bak.

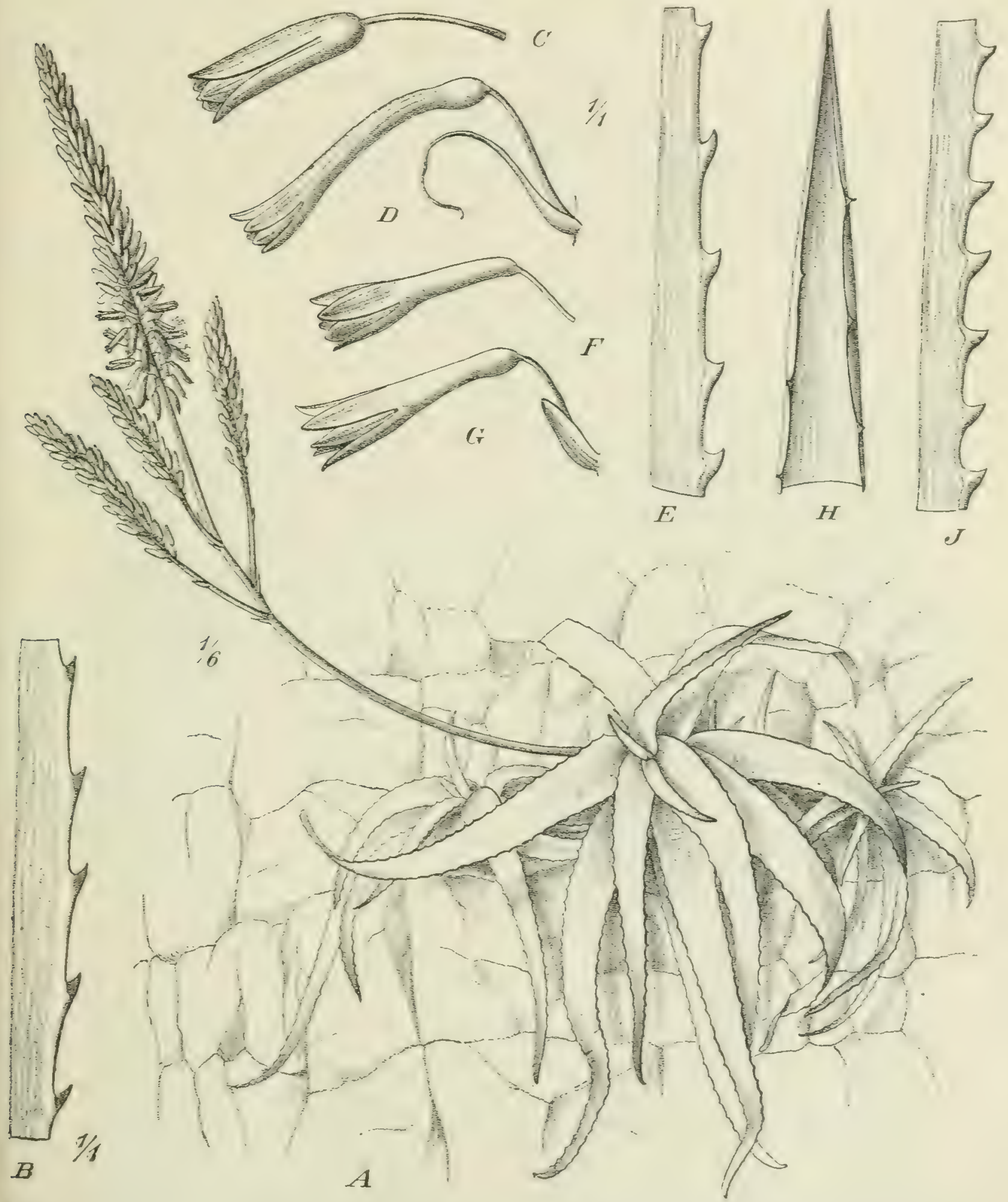

Fig. 236. $A-C$ Aloe pendens Forsk. (an steilen Felswänden in Yemen), $D-E$ A. cinnabarina Diels (Speckboom-River bei Lydenburg in Transraal). F- F A. leptosiphon Berger.

von Klein-Namaqualand gehört hierher. Nun sind noch einige riesige, baumartige, systematisch isoliert dastehende Formen zu erwähnen, welche auf die Grenzgebiete des tropischen Afrika beschränkt sind. - Die Sehtion Aloicicuirm: 
enthält nur die A. Bainesii Dyer (Fig. 242), I 2-20 m hohe Bäume mit einem Stammdurchmesser von $\mathrm{I}, 2-\mathrm{I}, 5 \mathrm{~m}$ und lederigen, tief rinnigen, bis $\mathrm{I} \mathrm{m}$ langen Blättern, gelblichroten Bliiten und weit hervortretenden Staubblättern, in Kaffraria und Natal; eine Varietät Barberac Dyer findet sich in Ost-Griqualand. $\mathrm{Zu}$ nur halb so hohen (8-io m) Bäumen, aber ebenso dickem Stamm entwickelt sich die zur Sekt. Dracaealoe gehörige A. dichotoma Lf., welche von Clanwilliam und Klein-Namaqualand bis Hereroland verbreitet ist; sie besitzt kleine, fleischige, fast halbsticlrunde Blätter und erzeugt im ausgewachsenen Zustand kräftige, verzweigte Blütenstände mit gelben. $3-3,5 \mathrm{~cm}$ langen

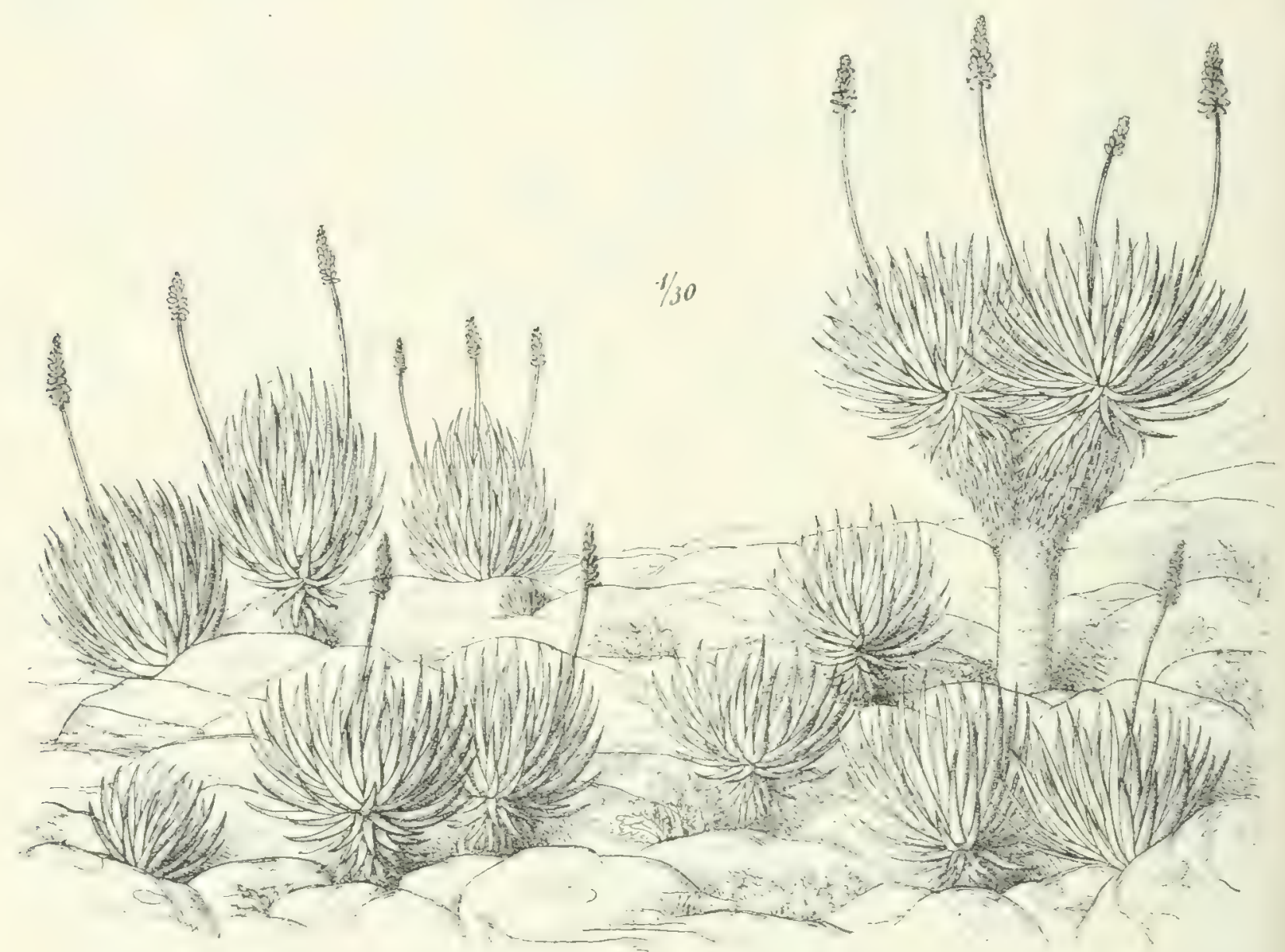

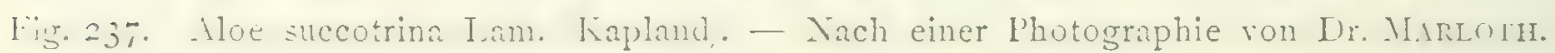

Blüten. - Diesen beiden Arten entspricht in Yemen A. sabaea Schwfth., welche von $600-1800 \mathrm{~m}$ im Buschgehölz oft ganze Bestände bildet; sie wird bis $9 \mathrm{~m}$ hoch, ist reich verästelt und trägt $0,6-1 \mathrm{~m}$ lange, bis $\mathrm{I} \mathrm{m}$ breite Blätter in dichten Rosetten. - Weit vom tropischen Afrika entfernt in der Gegend ron Tuibagh und Worcester des siidwestlichen Kaplandes findet sich die baumartige ( $1-3 \mathrm{~m}$ hohe), reich verzweigte, durch zusammengedrängte, zweireihige, zungenförmige Blätter ausgezeichnete .1. plicatilis Mill., welche die Sektion Kumara bildet.

Lomatophyllum Willd. Wir sahen, daß einzelne Sektionen von Aloc auch mit wenigen Arten in Madagaskar vertreten sind. Es ist interessant, daß die so natürliche und für Afrika nebst Südwestarabien so bezeichnende 


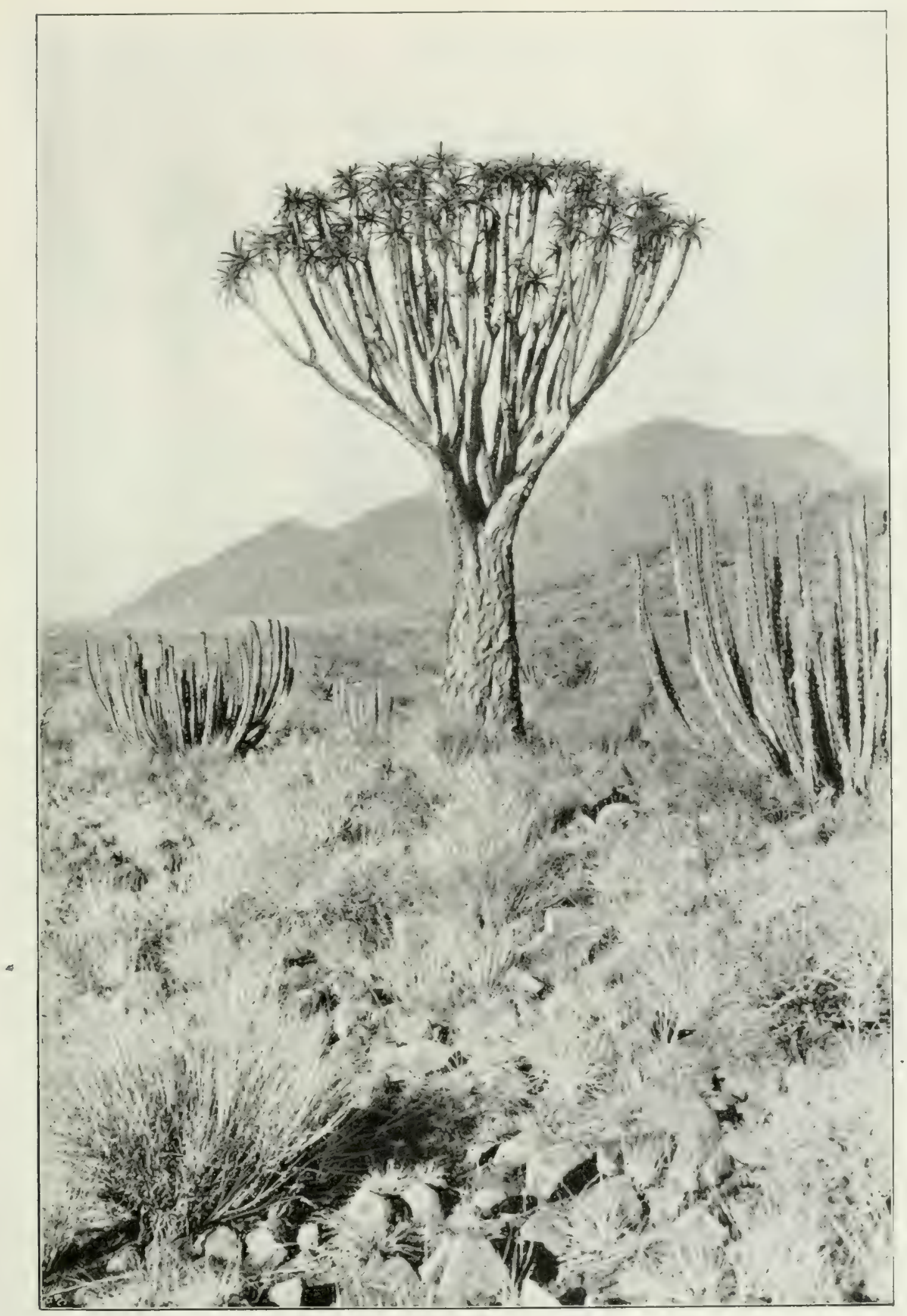

Aloe dichotoma L. f。

am Westabhang des Groß-Nama-Landes in D. S. W.-Afrika mit Euphorbia (virosa Willd.?) - Nach Robrbach. 

Gruppe der Aloincae auch noch auf den Maskarenen mit einer endemischen Gattung vertreten ist, welche sich hauptsächlich durch fast beerenartige Früchte unterscheidet. L. purpureum (Lam.) Th. Dur. et Schinz, L. rufocinctum Salm und L. macrum Salm finden sich alle auf Mauritius, an trockenen Berglehnen

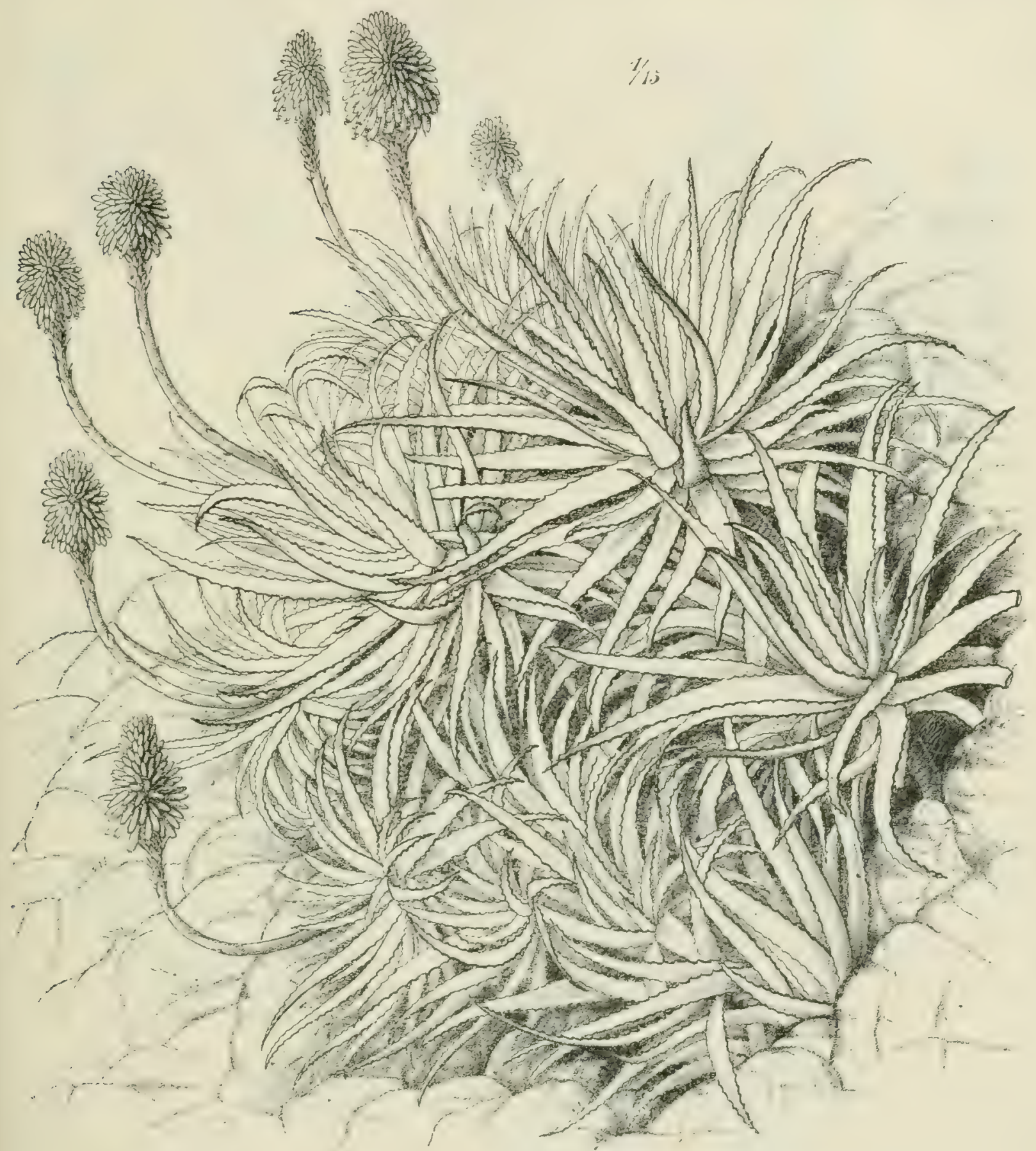

Fig. 238. Aloe arborescens Mill. var. pachythyrsa Berger. - Nach Berger.

von 2-300 m. Ob die erstere Art, welche von ABBot auf den AldabraInseln gefunden wurde, auch dort heimisch ist, ist noch genauer festzustellen.

\section{Allioideae.}

Agapanthus l'Hér. enthält nur eine, allerdings schr veränderliche Art, den vielfach kultivierten .t. unbullatus l'Hér. mit kurzem, knolligem Grundstock, 
fleischigen, linealischen, bis $6 \mathrm{dm}$ langen Blättern und einer auf etwa I $\mathrm{m}$ langem Stiel stehender Dolde blauer trichterförmiger Blüten, ist verbreitet vom Tafelberge bei Kapstadt bis Uitenhage und läßt sich über die Gebirge von Somerset $(1300 \mathrm{~m})$ und den Oranje-Freistaat bis Transvaal und nach dem östlichen Natal verfolgen.

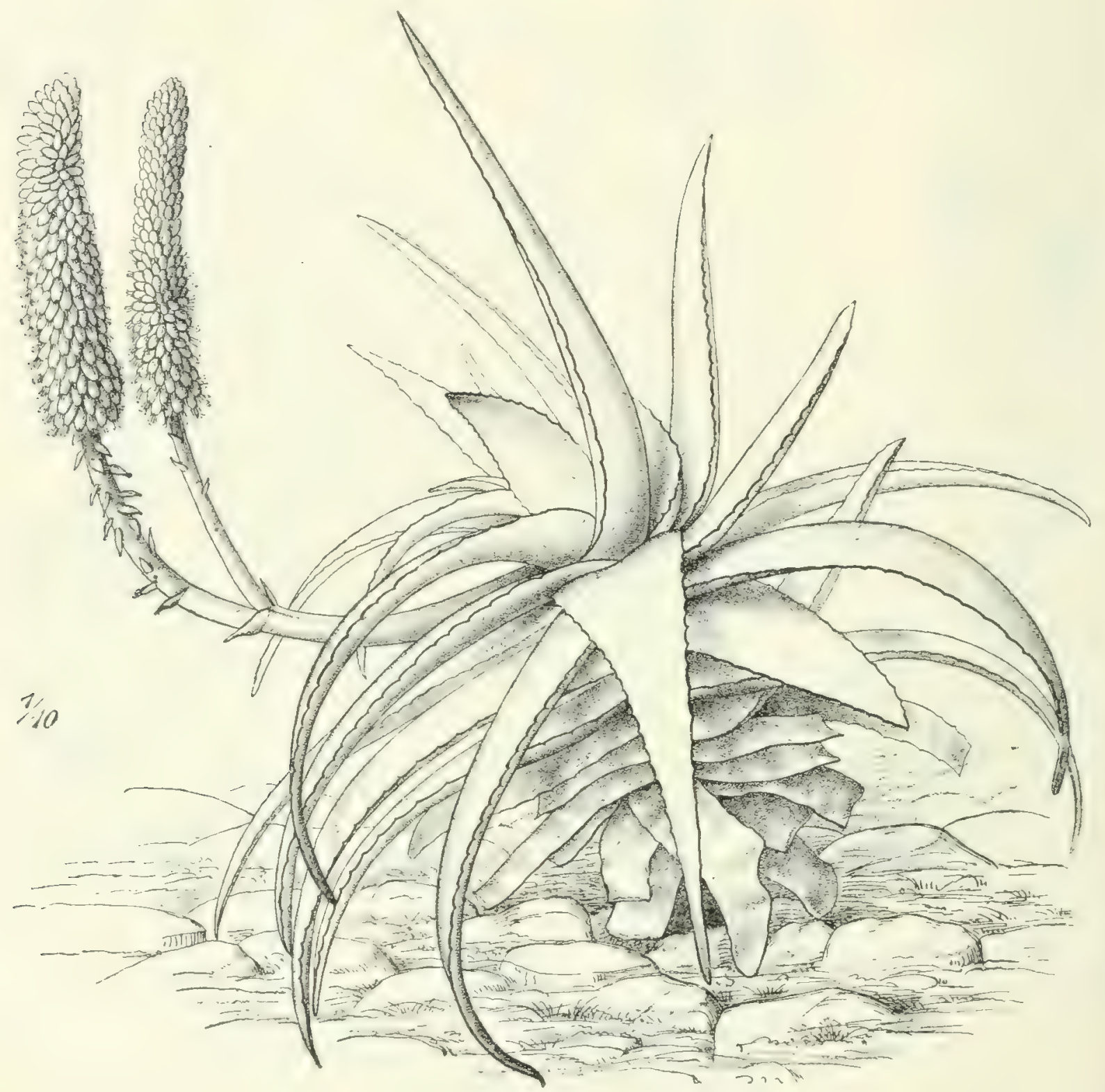

Fig. 239. Aloe rubroviolacea Schweinf. (in Yemen, an der Spitze des Berges Schibam oberhalb Menacha, um $2900 \mathrm{~m}$ ü. M.). - Nach BERGER.

Tulbaghia L., ausgezeichnet durch drei fleischige Nebenkronenlappen vor den inneren Abschnitten der krugförmigen oder cylindrischen Perigonröhre, mit linealischen oder zungenförmigen Blättern, erimnert durch den Geruch der ganzen Pflanzen an Allium. Sechs Arten kommen nur im südlichen Kapland vor; T. acutiloba Harv. erstreckt sich von dort bis Natal, T. alliacea L. f. läßt sich vom südlichen Kapland bis nach dem südlichen Nyassaland verfolgen, unci T. lomentha Bak. findet sich von Griqualand East bis Natal und Trans- 


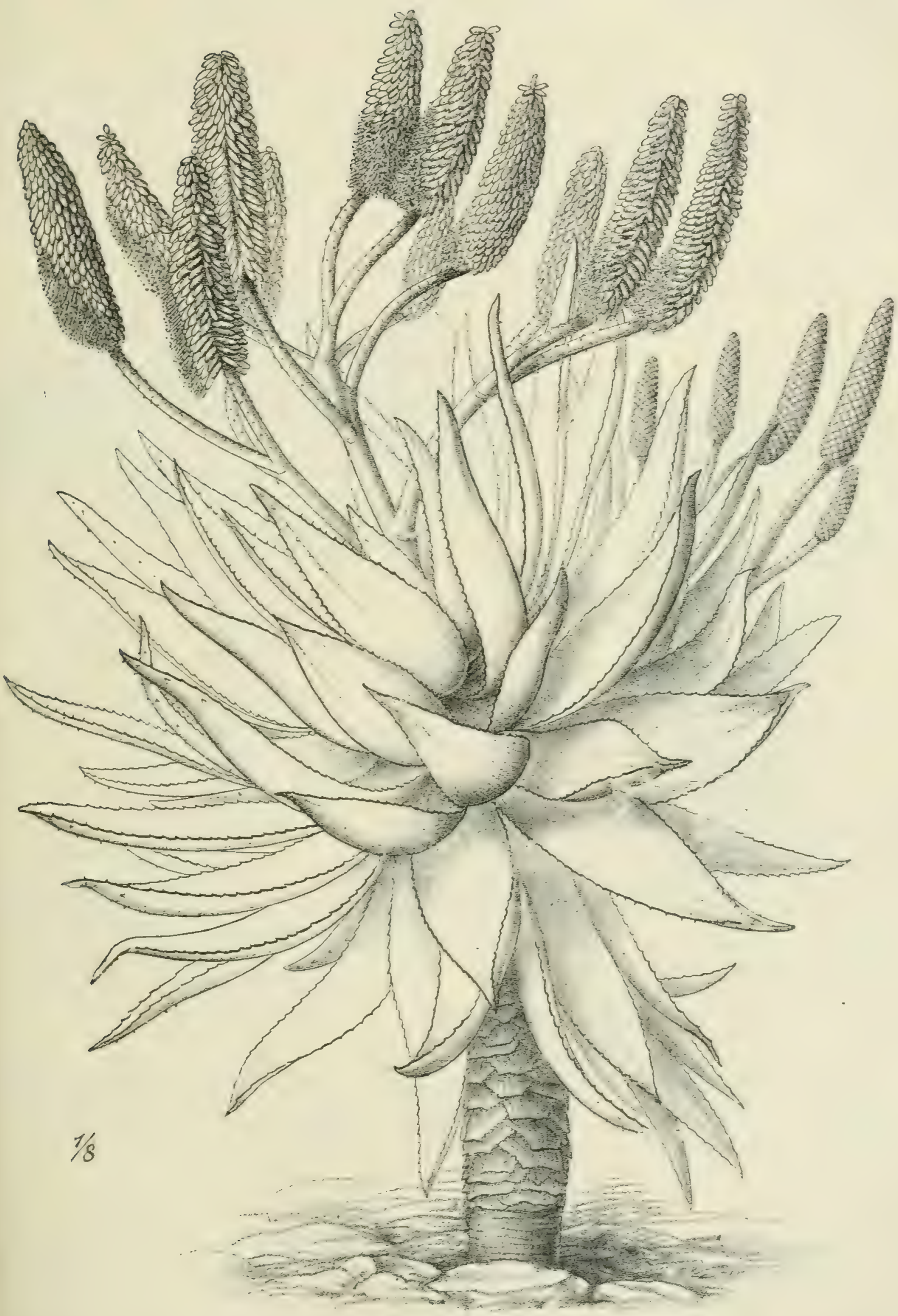

Fig. 240. Aloe ferox Mill. Habitus. (Ladysmith und östliche Kapkolonie,; - Nach Berger. 
vaal. Sodann kemnen wir noch eine Art von Angola, eine von PortugiesischOstafrika, eine (T. Cameroni Bak. rom nördlichen Nyassaland und dem suidlichen Gebiet des Tanganyika.

Allium L. Daß von dieser der nördlich gemäßigten Zone angehörigen, im Mittelmeergebiet und den asiatischen Steppengebieten besonders reich entwickelten Gattung auch zwei Arten, das dem A. subhirsutum L. nahestehende A. spathaceum Steud. und A. alibile A. Rich., in dem abyssinischen Hochland vorkommen, ist nicht $\mathrm{zu}$ verwundern. Dagegen ist sehr bemerkenswert und

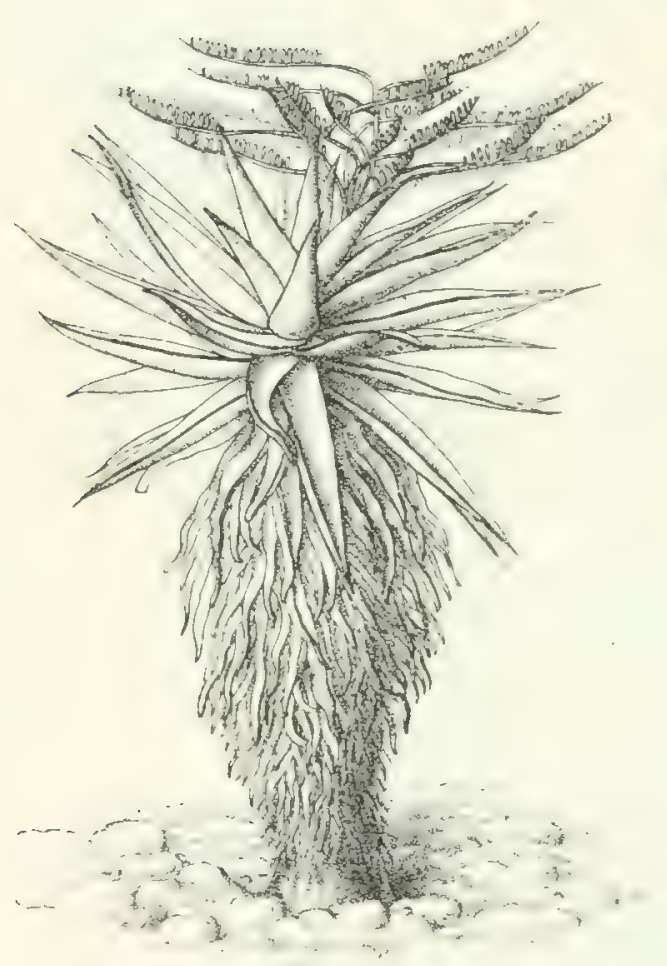

Fig. 24r. Aloe Marlothii Berger (Klippriviersberge bei Johannesburg). - Nach photograph. Aufnahme von Dr. Marloth.

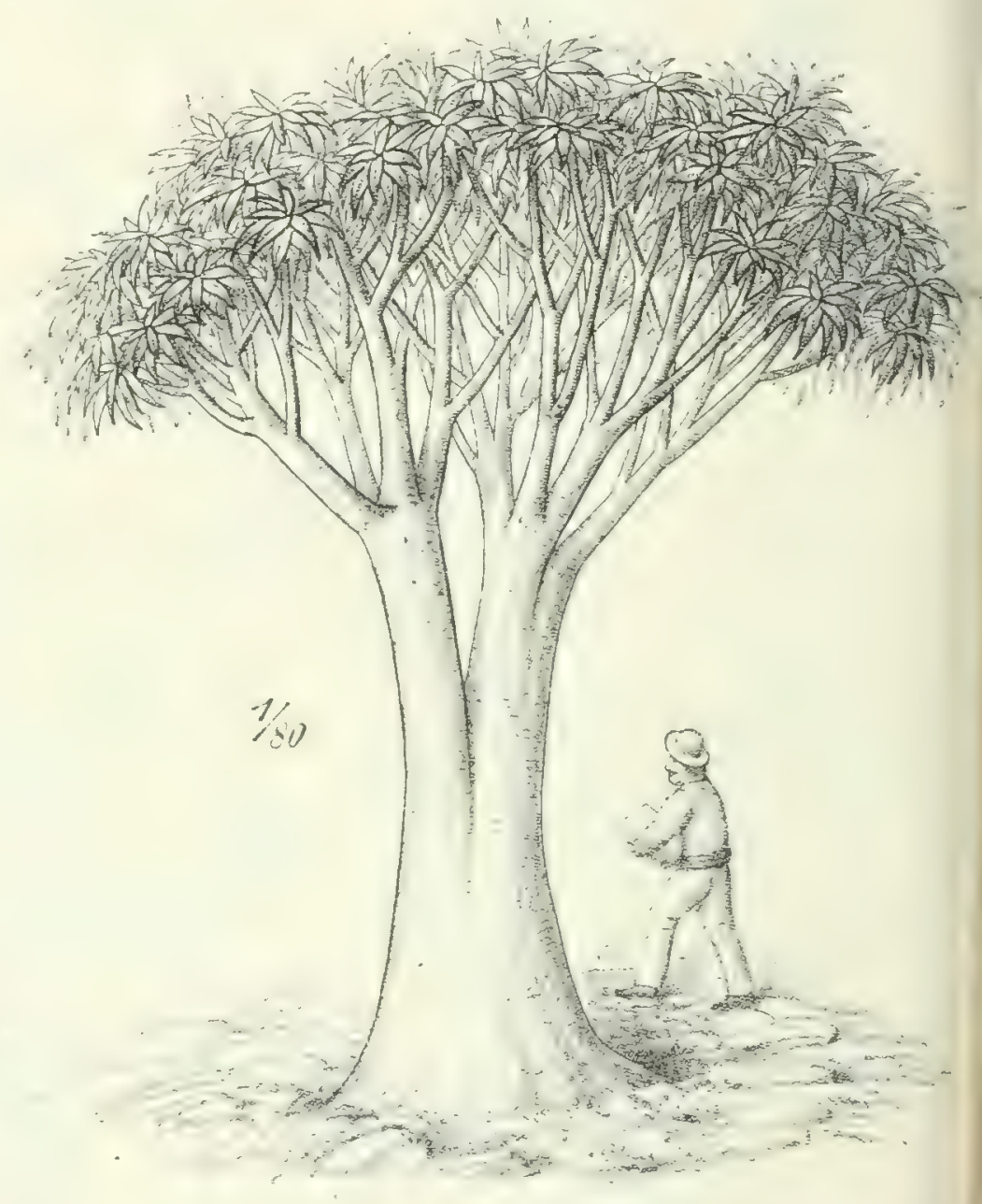

Fig. 242. Aloe Bainesii Dyer (Natal). Nach Sir THIS. DYER.

weiter zu beachten das Vorkommen von $A$. angolcnse Bak. auf grasigen Triften von Golungo Alto in Angola, ebenso das Vorkommen von A. Dregeamun Kunth an mehreren Stellen des Kaplandes.

\section{Fam. Haemodoraceae.}

Diese der südlichen Hemisphäre angehörige und vielleicht nicht ganz na\{üliche Familic umfaßt nach der Lmgrenzung ron PAX nur krautige Pflanzen mit kurzem Rhizom, mit schmalen, längsfaltigen, reitenden, am Grunde des Stengels zusammengedrängten, oben zerstreuten Blättern und reichblitiger In- 
florescenz. Die Blüten sind hauptsächlich dadurch charakterisiert, daß nur die drei inneren Staubblätter entwickelt sind. Der ober- oder unterständige Fruchtknoten enthält in jedem der drei Fächer nur wenige Samenanlagen, und die Narbe ist kopfförmig.

Drei Gattungen, Wachondorfic L., Dilatris Berg., Lanaric Ait. zusammen mit fünf Arten, sind auf das südwestliche und südliche Kapland beschränkt; sie sind Mesohydrophyten, Bewohner feuchter Krautfuren. Eine sehr stattliche Pflanze ist die bisweilen I $\mathrm{m}$ hohe Hachenturfor thyrsiffora $\mathrm{L}$. mit einer bis $3 \mathrm{dm}$ langen, dichten Rispe leuchtend gelber Blüten. In östlichen Kapland und auch in Natal findet sich auf feuchten schattigen Plätzen die nur $3 \mathrm{dm}$ hohe Barlictet arred Hars. mit einer dichten Traube gelber Bliiten.

\section{Fam. Amaryllidaceae.}

Von dieser Schwesterfamilie der Liliaceae kommen im tropischen Afrika nur mit unterirdischem Rhizom oder mit einer Zwiebel verschene I'flanzen vor. Die meisten Arten treten wie auch die mit unterirdischem Grundstock versehenen Liliaceen und Iridaceen an ihren Standorten in größerer '/ahl der Individuen auf.

Ferner sehen wir einen grolsen Teil der im tropischen Afrika rorkommenden Amaryllidaccen-Gattungen sich bis nach Südafrika erstrecken, während zwei Gattungen, Crimum und Hypoxis, uherhaupt in wärmeren Ländern einc größere Verbreitung besitzen.

Bei mehreren der mit Zwiebeln versehenen Amaryllidaceen (Crimum, Hacmanthus, Nerine') schließst der Sprol.3 mit einer doldenartigen ron Hochblïttern umhüllten Inflorescenz ab, während sich in der Achsel des rorletzten Blattes ein neuer Laubblätter tragender Sproß entwickelt.

Für Afrika kommen nur die in folgender lbersicht enthaltenen Gattungen in Betracht; auf die nur im Kapland vorkommenden Gattungen ist weiterhin nicht eingegangen, ebenso auch nicht auf die kultivierten Agavoideen.

A. Zwiebel. Schaft blattlos, mit einem von Involukralblättern umhiillten doldenartigen Bliitenstand oder einer Einzelbliite . Unterfam. Amaryllidoideae.

a) Blüten ohne Nebenkrone.

Amaryllideae.

(ধ) Fächer des Fruchtknotens mit wenigen Samenanlagen.

I. Antheren am Grutnde angeheftet. Nur im Kapland

Hessea.

II. Antheren in der Mitte angeheftet.

I. Samenanlagen in jedem Fach des Fruchtknotens nie mehr als zwei.

* Frucht eine Beere.

Haemanthus.

** Frucht eine Kapsel

..Buphane.

2. Samenanlagen in jedem Fach mehr als zwei, bis sechs.

* Frucht eine Beere. . . . . . . . . . . . Clivia.

** Frucht eine Kapsel. Nur im Kapland . . . . . . . . Strumaria.

ß) Fächer des Fruchtknotens mit vielen Samenanlagen.

I. Blüten ohne Röhre oder mit kurzer, in reichen Scheindolden.

I. Staubfäden am Grunde angeschwollen, meist miteinander vereint . . Nerine:

2. Staubfäden frei, fadenförmig.

* Samen stark zusammengedriickt. Blüten wenig zygomorph. 
+ Antheren in der Mitte der Rückseite eingefuigt. Nur im Kapland Vallota.

tt Antheren am Grunde angeheftet........... Anoiganthus.

** Samen rundlich. Blüten stark zygomorph.

t Kapsel kreiselförmig, dreikantig. Samenanlagen in das Gewebe der Placenta eingesenkt

Amaryllis.

t+ Kapsel dreischneidig. Samenanlagen nicht eingesenkt . . Brunswigia.

II. Blüten mit langer Röhre.

I. Bliiten einzeln. Staubfäden sehr kurz.

* Staubblätter in einem Kreis. Blütenhülle präsentiertellerförmig. Nur im Kapland

Gethyllis.

** Staubblätter in zwei Kreisen. Blütenhülle trichterförmig. Kapland Apodolirion.

2. Bliiten in reichen Scheindolden.

* Samenanlagen in das Gewebe der Placenta eingesenkt.

† Bliten kurz gestielt oder sitzend........... Crinum.

计 Blïten lang gestielt. Nur im Kapland.......... Ammocharis.

** Samenanlagen in die Placenta nicht eingesenkt.

† Blütenhülle mit langer Röhre und ktrrem Saum .... Cyrtanthus.

$\div$ Abschnitte der Blïtenhülle so lang als die Röhre.... Stenolirion.

$\div+$ Abschnitte der Blütenhülle länger als die Röhre . . . . Hippeastrum.

h Bliten mit Nehenkrone, bisweilen nur einzelne Schuppen oder ein Ring

Narcisseae.

I. Staubfäden innerhalb der aus zwölf Schuppen bestehenden Nebenkrone der Röhre der Blütenhülle eingefügt. Frucht eine Beere ......... Cryptostephanus.

II. Staubfälen aus dem Rande der becherfürmigen Vebenlrone frei werdend. Röhre der Blïtenhülle trichterförmig ........... Pancratium.

III. Stanbfäden frei. Rühre der Blittenhiille trichterfürmig; am Grunde mit schuppenförmigen Bildungen oder mit schmalem Ring. Wahrscheinlich in Afrika nur yerwildert

Hippeastrum.

B. Stamm mit sekundärem Dickenwachstum wie bei den Dracaenoideae, mit dichter Rosette von fleischigen, großen Blättern. Blütenstand traubig oder rispig. . . . . . . . . . . . . . Unterfam. Agavoideac.

a) Staubfäden länger als die Blütenhülle. Heimat Amerika. In Afrika kultiviert . Agave.

b Staubfäden kürzer als die Ijlitenhülle. Wie turige . . . . . Fourcroya.

C. Rhizom. Stengel mit gew öhnlichen Laubblattern. Unterfam. Hypoxidoideae. a) Sechs Staubblätter.

(c) Frucht eine Kapsel.

Hypoxis.

3) Frucht eine Beere . . . . . . . . . . . . Curculigo.

b) Nur drei Staubblätter. Kapland............. Pauridia.

Sie sind meistens Mesohydrophyten oder Subxerophyten, doch sind auch nicht wenige Hydrophyten und einige Xerophyten.

\section{Amaryllidoideae.}

Hessea Herb. Neun Arten kommen in der Kapkolonie auf Diinen und Wiesen vor, aber keine geht bis Natal.

Haemanthus L. Von dieser Gattung kommen etwa 50 Arten in Afrika, caron 3 I in Sudafrika ror: sie fehlen auch nicht in Arabien. Ihre dichtdoldigen Ijicitenstände sind ron zahlreichen Bracteen umgeben und sind entweder weil3 ad.r prangen in den verschiedensten Nuancen von purpurrot bis scharlachrot. Die meisten (I y Arten des tropischen Afrika gehören der Untergattung Virissa 
Salisb. an, bei welcher die Blätter dinn sind und sowohl die Bracteen wie die Abschnitte der Bliitenhülle sich ausbreiten. Die suidlichste Art ist H. Katharinae Bak., mit zu gleicher Zeit auftretenden Blättern und Bliitenständen, in Natal und Transvaal auf steinigen Hügeln (Fig. 243). Die hüufigste Art ist der mit grünen Bracteen und bläulich-roten Blüten versehene H. multifurus Martyn, der in Wäldern und Waldlichtungen von Kordofan und der Erythrea bis zur DelagoaBay sowie von Sierra Leone bis Kamerun vorkommt. Einige Arten Ost- und Westafrikas stehen dieser nahe. Während bei dieser Art und einigen anderen der Blattbuischel seitlich vom Blütenschaft steht, erscheint derselbe von Blättern umgeben bei H. cinnabarinuls Decne. und H. longipes Engl. (Fig. 244), welche nebst mehreren anderen nahestehenden Arten auf die Wälder des tropischen Westafrika beschränkt sind.

Eine in bedeutenderHöhe, auf Bergwiesen vorkommende Art ist der im Kingagebirge des nörd-

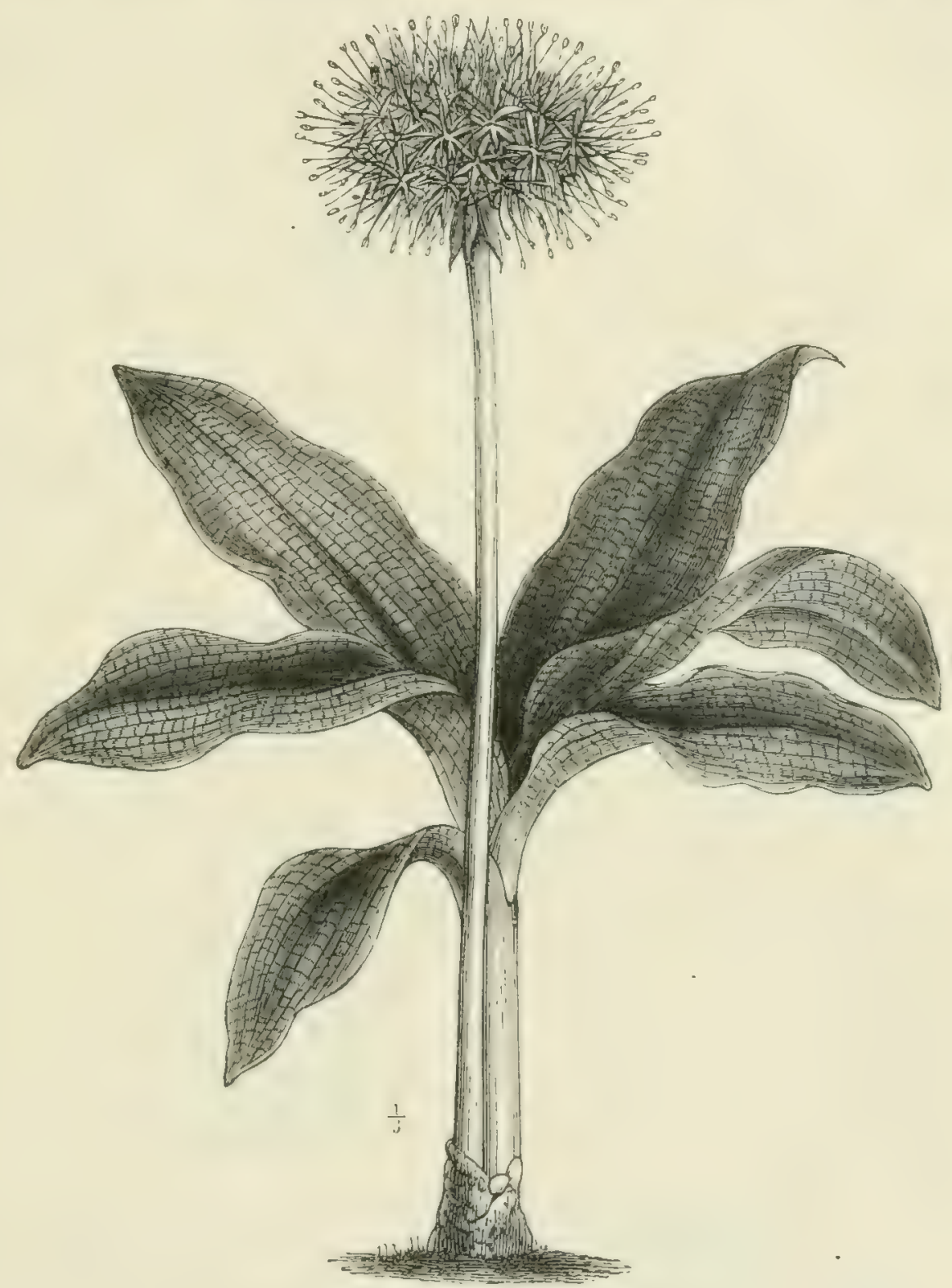

Fig. 243. Haemanthus Katharinae Bak. - Nach Bot. Magaz.

lichen Nyassalandes um $2400 \mathrm{~m}$ ü. M. auftretende $H$. Goetzei Harms mit zinnoberroten Blüten. Ebenfalls dünne krautige Blätter besitzen die Arten der Untergattung Gyaxis Salisb., bei welcher aber die Bracteen und die Perigonabschnitte immer aufrecht sind. Hierher gehören H. lirachugandrus Bak., mit weißen Blüten, in Sierra Leone bei Kundixa im TWasser vorkommend, H. biraliris G. Beck auf dem Dschebel Haquin in Harar und H. somuticnsis Bak. auf dem Golis Range in Somaliland, ferner H. magnificus I Ierb. von der Delagoa- Bay bis Natal, ausgezeichnet durch einen über die Erde hervortretenden Stamm, leuchtend grüne Bracteen und scharlachrote Bliiten, H. natalcnsis Poppe mit 
am Ende rotbraunen Niederblättern, rotbraunen Inrolukralblättern und grinen Bliiten, an feuchten Plätzen in Natal und Griqualand, H. prnicuss L., mit kurzem Stamm und deutlich gestielten ilättern, mit grïnen Bracteen und blaßroten Bliten, von Natal und Tembuland südwärts bis in die Gegend von Port Elisabeth; diese letzteren Arten sind alle seit längerer Zeit in Kultur. Von der Untergattung Mclicho Salisb. mit dicken, zweircihig stehenden Zwiebelblättern und zwei dicken fleischigen Laubblättern und ausgebreiteten liracteen finden sich H. montanus Bak. und H. candidus Bull. im oberen Natal. Die im Kapland

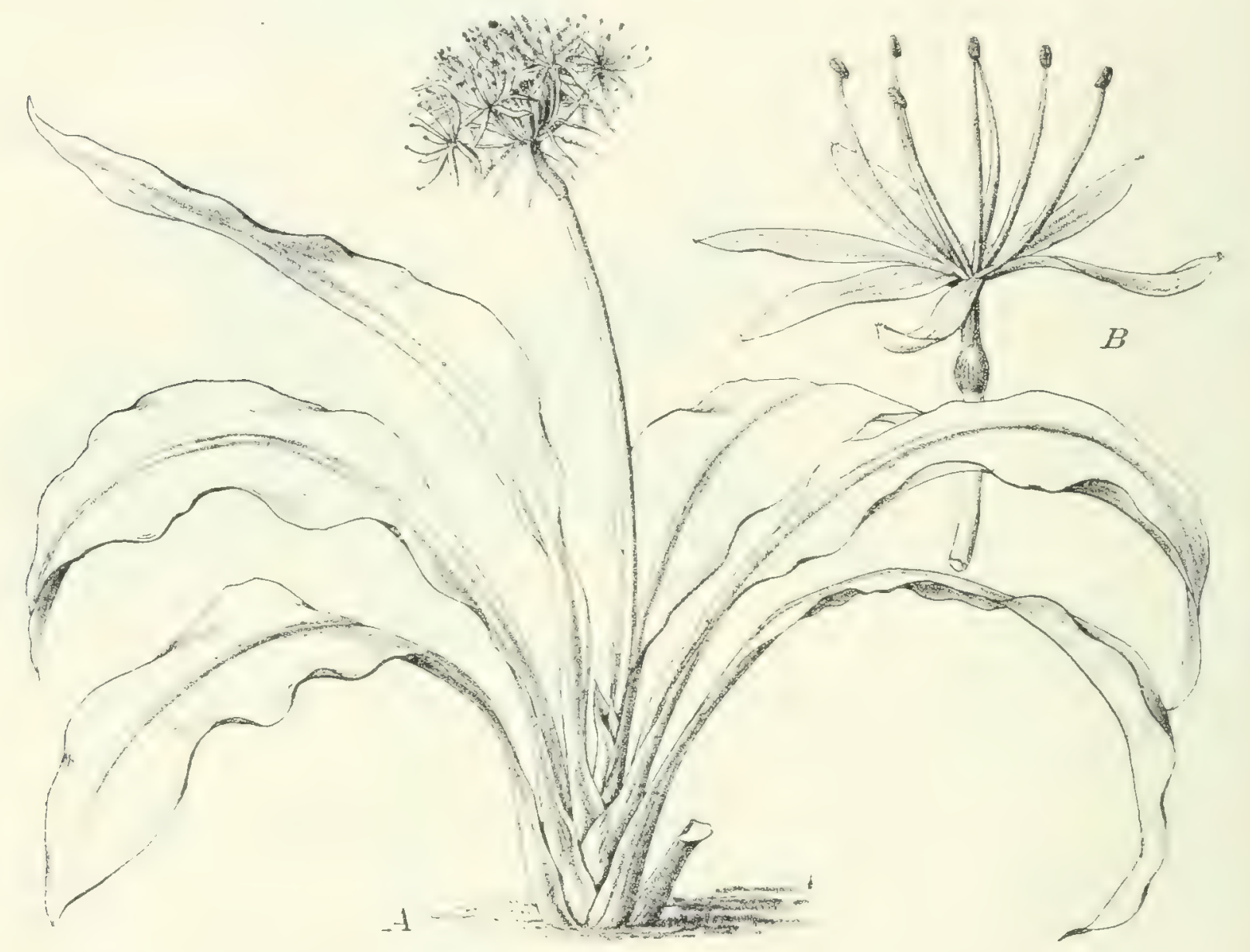

Fig. 244. Hremanthus longipes Engl. $A$ Habitus, ${ }^{I} / 4$ n. Gr.; $B$ Blüte. - Original.

reichlich entwickelte Untergattung Diailes Salisb., mit abstehenden Bracteen und P'rigonalswchnitten, kommt auch noch in Natal ror: sehr auffallende Pflanzen sind $H$. deformis Hook. f., bei welcher vier kreisförmige, behaarte Laubblätter die weiße Inflorescenz nur wenig hervortreten lassen, ferner H. hirsutus Bak. mit zwei länglich-runden behaarten Blättern, kurzem Bliitenstand und leuchtend roten Bracteen, welche einen roten Blïtenstand einschließen, in Natal und bei Barberton in Transvaal.

Buphane Herb. Nächtige Zwichelgewächse, von der vorigen becrenfrüichtigen Gattung durch lireiselfirmige Kapselfrüchte verschieden. - Von den drei Arten ist besonders zu beachten: $B$. disticha (L. f.) Herb. mit oft $2 \mathrm{dm}$ im Durchmesser haltender Zwiehel, mit zweireihig gestellten, lederartigen. schwert- 
förmigen, welligen, 3-5 dm langen Blättern und einer grulien Scheindolde ron nur etra $3.5 \mathrm{~cm}$ langen roten Bliiten. Diese in Sudafrika häufige und schon lange als Pfeilgift liefernd bekannte, auch in unseren Gewächshäusern kuitivierte Art findet sich ebenso in Natal und. Angola, wie in den Plateaulandschaften des siidlichen und nördlichen Yyassalandes, auf Grassteppen und in Buschgrassteppen. Außser dieser kommt eine kleinere Art, B. longifedicellate Pax, in Griqualand-West und B. cilirris L., Herb. mit starren, gewimperten Blättern im Suiden und Westen der Kapkolonie vor.

Clivia L. Die Zwicbel besteht bei dieser Gattung nur aus den verbreiterten Scheiden der zahlreichen, zweireihig stehenden Blätter: der Stiel der doldigen Inflorescenz ist zusammengedrüickt, die Bracteen sind grün, die trichterförmigen Bluiten rotgelb, die Frucht eine Beere. Drei Arten finden sich in Natal, C. (Imatoplyllmmi) minate Hook.) Regel mit gerader Blïtenhülle kommt in der Gegend von Pietermaritzburg um $900 \mathrm{~m}$ ï. M. vor; C. nobilis Lindl. und C. Gardeni Hook., beide mit gekrummter Blitenhülle I:ucliaia), gehen ron Natal nach Transvaal hiniiber.

Strumaria Jacq., wie vorige Gattung mit mehr als zwei Samenanlagen in jedem Fach des Fruchtknotens, mit zwei Bracteen, glockenförmigen Bliiten und Kapselfrüchten, ist mit fünf Arten auf die westliche Kapholonic beschränkt.

Nerine Herb., ausgezeichnet durch an Grunde angeschwollene miteinander vereinigte Staubfäden, sind Zwiebelgewächse mit schmalen Blättern und Scheindolden. welche von zwei lanzettlichen Bracteen gestiitzt sind, und mit $\doteq$ karminroten Blüten. I 5 Arten finden sich in dem Gebiet rom südlichen und östlichen Kapland bis zum inneren Natal und Transvaal. Nur im inneren Natal i zco bis I $900 \mathrm{~m}$ ) kommt .1. pancratioilies Bak. vor: I. angustifolin Bak. geht von Natal durch Transvaal bis nach dem Somerset-Distrikt.

Brunswigia Heister. Große Zwiebelgewächse mit nach der Blütezeit hervortretenden, schwanz- oder zungenförmigen Blättern, starken Stielen der scheindoldigen, von zwei Bracteen gestuitzten Inflorescenz und leuchtend roten Bliiten mit kurzer Röhre. Frucht eine dreikantige Kapsel mit rundlichen Samen. Die oft

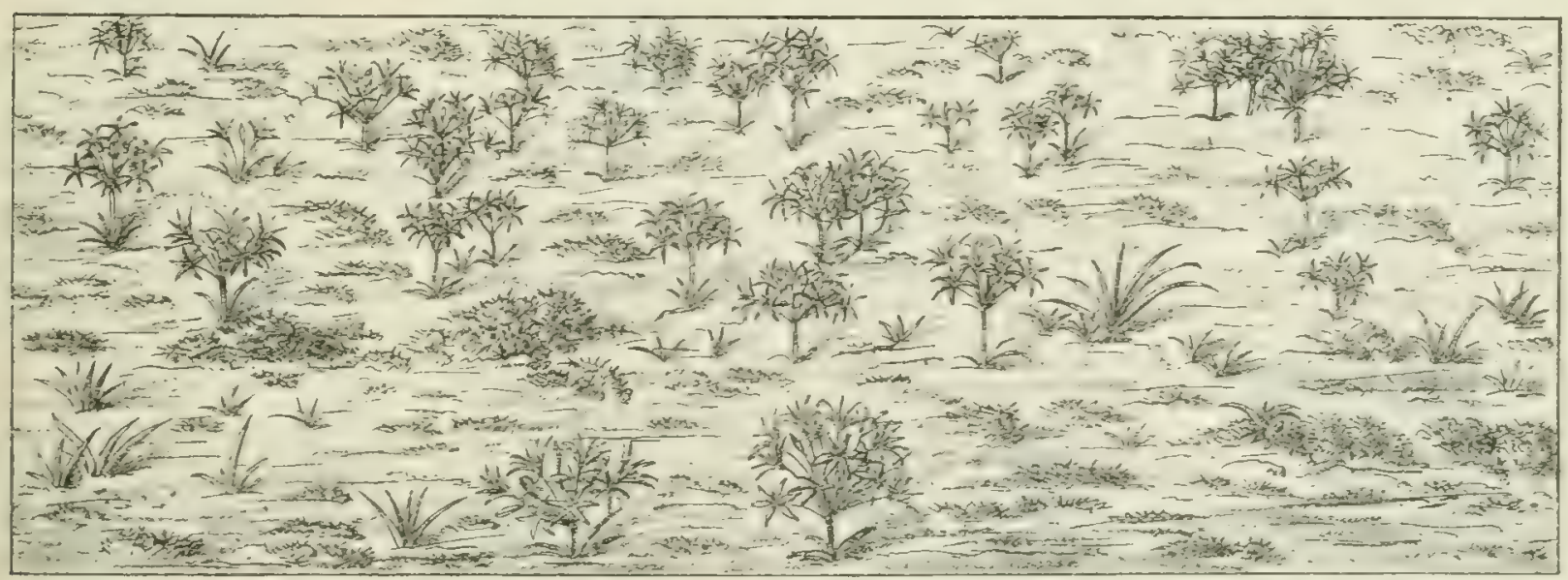

Fig. 245. Skizze einer Formation von Brunswigia in der Pfanne Bonche der Kalahari, ca. $24^{\circ} \mathrm{s} . \mathrm{Br}$. $22^{\circ}$ ö. L., nach einer Photographie von Prof. Dr. L. Schulicze. Soweit das Auge sieht, ist die Pfanne im Dezember von vielen Tausenden der Brunswigia bedeckt. - Original. 
gesellig im Grasland auftretenden Arten dieser Gattung machen sich sowohl in der Bluitezeit durch ihre großen Blütenstände, wie nach dem Verblühen durch die großen kugeligen Fruchtstände bemerkbar, welche meistens im ganzen abbrechen und über die Steppen rom IVind hingetrieben werden. Ton den elf südlichen Arten haben vier schwanzformige Blätter, darunter die von Uitenhage bis Natal rerbreitete $B$. Foscphinac (Red.) Gawl. mit o,6- I dm langen und einem $4-5 \mathrm{dm}$ langen Bliitenstengel. Sieben andere Arten haben zungenförmige Blätter, so auch dic im südlichen Kapland, namentlich auch auf den Sanddünen bei Kapstadt häufige B. giganter Heist. und dic in Natal um $1600 \mathrm{~m}$ in der IVeenen County rorkommende $B$. natalensis Bak. Ungenigend behannt sind die im Hereroland und Amboland vorkommende Art, sowie auch die in Usagara und zwischen Nyassa- und Tanganyika-See von I300-I600 $\mathrm{m}$ vorkommende B. Kirkii Bak.

Amaryllis L., welche auch wie die rorige Gattung kugelige Samen besitzt, aber durch viel größere Blüten und in das Placentargewebe eingesenkte Samen ausgezeichnet ist, ist mit ihrer prächtigen, in der Bliitenfärbung stark variierenden Art, A. billaionna L., auf die Kaphalbinsel, besonders auf die Flats in der Lmgebung von Kapstadt beschränkt.

Vallota Herb., mit großen, roten, langröhrigen Blizten und stark zusammengedrïchten Samen. enthält auch nur eine im siidlichen Kapland vorkommende Art, $V$. purpurea Herb.

Anoiganthus Bak. mit kleinen, trichterformigen, milchweißen oder gelblichen Blïten, welche zu zwei bis zehn in einer Scheindolde stehen, auch mit zusammengedrückten Samen. enthält eine im östlichen Kapland und Natal, meist im Bergland bis zu $1600 \mathrm{~m}$ ii. M. vorkommende Art, A. breviflom (Harv.) Bak. Dieser ähnlich, aber durch längeres Perigon verschieden, ist A. gracilis Harms, an rasigen Ahhängen des Kingagebirges im nördlichen Nyassaland, bis $2400 \mathrm{~m}$ ii. .1.

Crinum L. Von dieser in allen wärmeren Ländern verbreiteten Gattung kennen wir jetzt schon etwa 43 Arten aus dem tropischen Afrika bis Natal, cine derselben auch noch suidlich ron Natal rorkommend und füf nur im Kapland wachsend. Sie finden sich vorzugsweise auf feuchtem sumpfigem Boden, auch in Niederungen der Steppe, von Sierra Leone und Kordofan an südwärts. Bisweilen wird man auf Reisen durch Steppenniederungen beim Beginn der Regenzeit stundenlang durch dic zahlreichen uber fahlgelbe Grasreste oder direkt iiber len Boden sich erhebenden stattlichen Blütenstände einer Crimm-Art erfreut; sie fehlen auch nicht in Deutsch-Siidwestafrika, wo das prächtige C. leucophlllum Bak. Fig. 246; in Damaraland und Amboland, C. Belkimmm Schinz im Hereroland heimisch sind.

Unter (len Arten mit gerader cylindrischer Röhre (Sekt. Stcnustir) fällt vor allen auf das in Sierra Leone und Fernando Po im Wasser wachsende und zahlreiche, I $m$ lange, schwanzförmige Blätter tragende C.natans Bak.; auch im Niger-Delta kommt es unmittelbar in der Nähe der Mündungen vor. Eine ancere in Fliissen unter Wasserschnellen wachsende Pflanze, die aber eine gekrimmte I'erigonröhre besitzt Sekt. Codonorimum) ist (C. lonsifolium Thunb. 
var. farinianum Bak. in der Kalahari. Eine riesige Pflanze ist das im unteren Kongogebiet heimische C. massaianum (Linden et Rodig) N. E. Brown mit mehr als $1 \mathrm{~m}$ langen Blättern. So wie die beiden letzten Arten haben auch noch folgende auffallendere Arten gekrümmte Perigonröhren: C. Sasderiamum Bak., sehr häufig auf feuchten Plätzen in Sierra Leone mit nur $6 \mathrm{dm}$ langen Blättern und wenigblütig, C. scabrunn Herb., häufig von der Erythrea bis zum Ghasal-

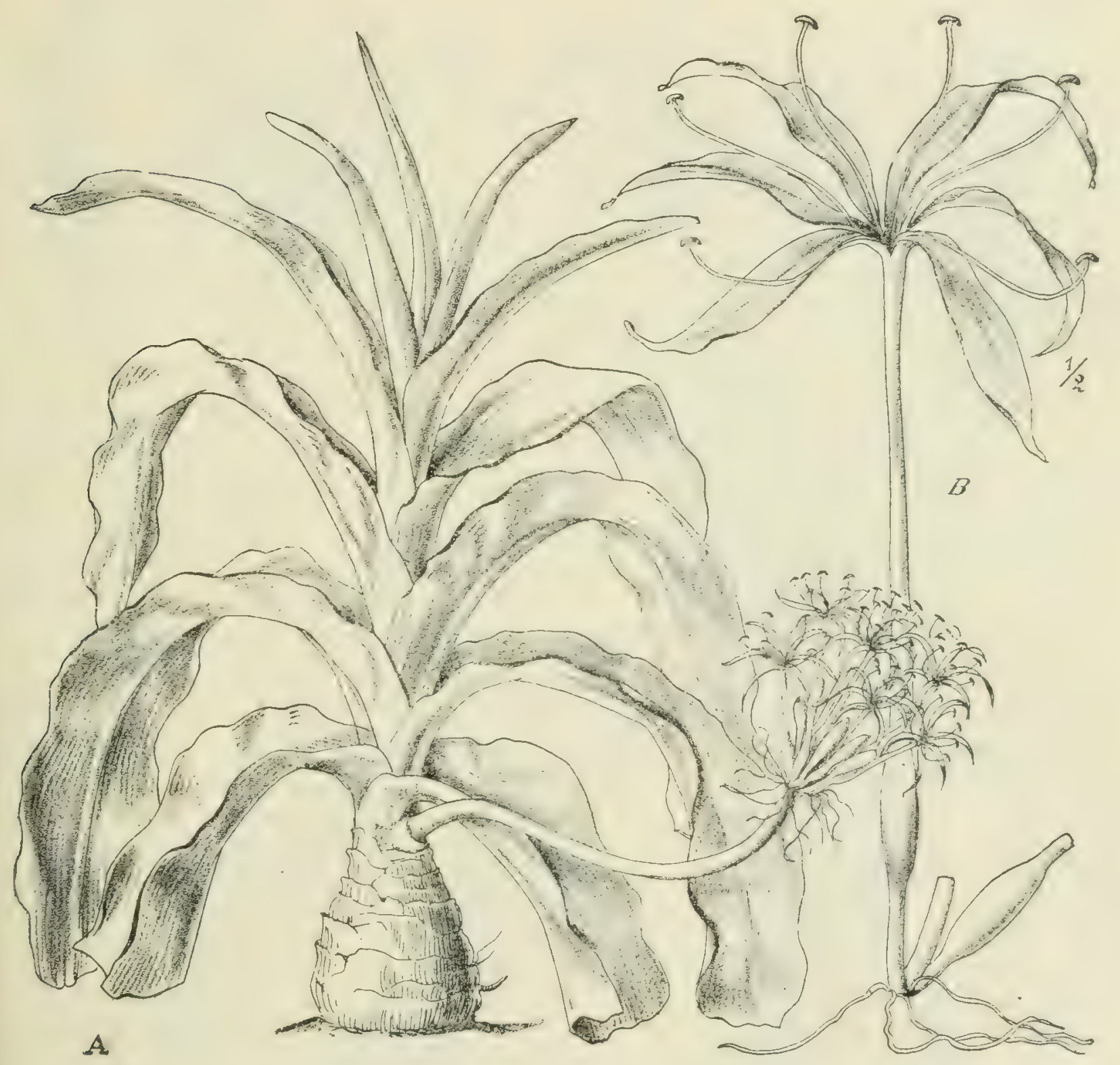

Fig. 246. Crinum leucophyllum Bak. A ganze Pflanze, I/ro n. Gr.; $B$ Blüte, I/2 n. Gr. Nach Bot. Magaz.

quellengebiet, C. fimbriatulum Bak. auf Sumpfwiesen an der Küste von Loanda, bisweilen mit I,5 m langen Blättern, C. seylanicum L. auf den Sandbänken des Sambesi-Deltas, C. Kirkii Bak. (Fig. 247) mit riesiger Zwiebel, bis I,3 m langen Blättern und prächtigen, grünlichen, rotgestreiften Blüten, in Deutsch-Ostafrika, in der Nähe des Kilimandscharo, endlich das weitverbreitete weißblühende C. giganteum Andr., es kommt von Sierra Leone bis Angola und vom Ghasalquellengebiet bis zum südlichen Nyassaland vor. Auch die südlicheren 
Arten gehören zu derselben Sektion Colonocrinum, C. ITacou'ani Bak., vom inneren Natal südwärts bis Transvaal, C. Forbesianım Herb. an der Delagoa-Bay, C. Hourci Hook. f. in Natal und das häufig kultivierte, prächtige C. longifoliun Thunb., welches vom inneren Natal bis Kapstadt, besonders an Flußufern verbreitet ist.

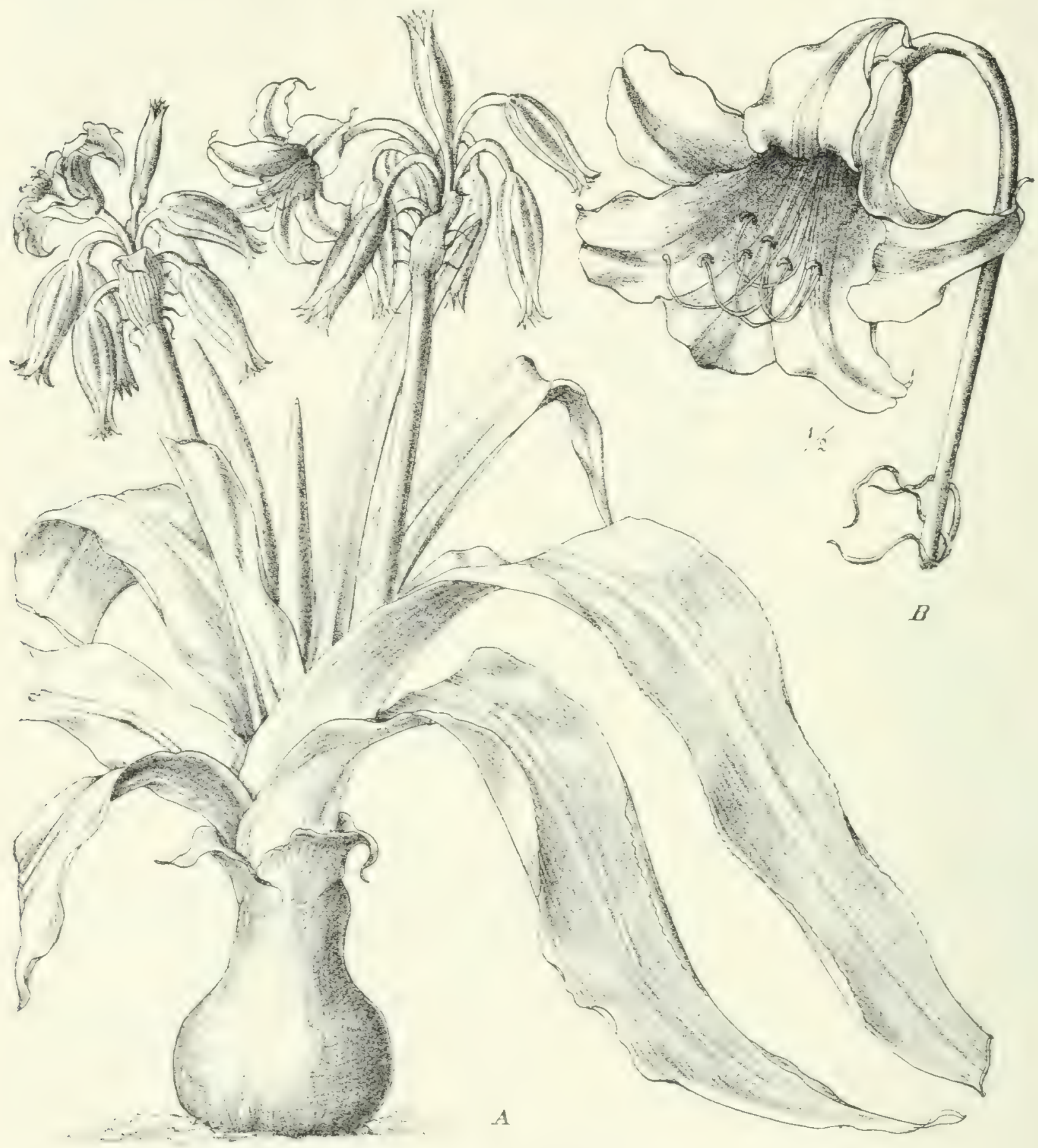

Fig. 247. Crinum Kirkii Bak. A Ganze Pflanze, I/6 n. Gr.; B Blite, I/2 n. Gr. Nach Bot. Magaz.

Ammocharis Tirtiblin Schinz. durch langgesticlte Bliiten won Crimm verschieden, wie bei einzelnen Nerine und Brmswigia zur Blitezeit ohne Laubblatter uber der Erde. mit zahlreichen Bjliten in kugeliger Scheindolde, ist auf Hercoland und Groß-Jamaqualand beschränkt: A. cocinca l'ax findet sich in 
der Nähe von Kimberley; und A. falcata (l'Hér.) Herb. Lommt vom inneren Natal (Pietermaritzburg) auf sandigem Boden bis Kapstadt vor.

Cyrtanthus Ait. ist vorzugsweise südafrikanisch (2+Arten), doch kommt C. Irchitschii Hiern. noch am Kunene und bei Huilla in Benguela um r 200 bis $1800 \mathrm{~m}$ ü. M. vor, findet sich auch in den Gebirgen im Süden des Nyassa-Sees, während C. sanguineus Hook. Fig. 24 ') in Natal und bei Mombassa in Wäldern gefunden wird.

Stenolirion Bak. Die auf kurzem Stiel in einer Scheindolde stehenden, wenigen Blïten haben eine cylindrische Röhre und gleich lange, linealische Abschnitte, ferner Beerenfriichte. Nur eine Art, St. Elliotii Bak., findet sich an Abhängen bei Urundi in Deutsch-Ostafrika von $1300-1600 \mathrm{~m}$.

Hippeastrum Herb. Von dieser den Amaryllis ähnlichen, im tropischen Amerika reich entwickelten, aber durch schuppenförmige Bildungen oder einen häutigen Ring am unteren Teil der Röhre ausgezeichneten Gattung kommt das stattliche, rot blühende, im tropischen Mexiko heimische H. reginae Herb. sehr häufig in den Regenwäldern der Prince-Inseln vor; es wird vermutet, daß die Pflanze dort verwildert ist.

Pancratium L. Die die Staubblätter verbindende Nebenkrone zeigt zwischen denselben je zwei Zähne. Die Gattung reicht vom tropischen Asien bis Afrika und zum Mittelmeergebiet. Schon in Ägypten und Arabien finden wir $P$. tortuosum

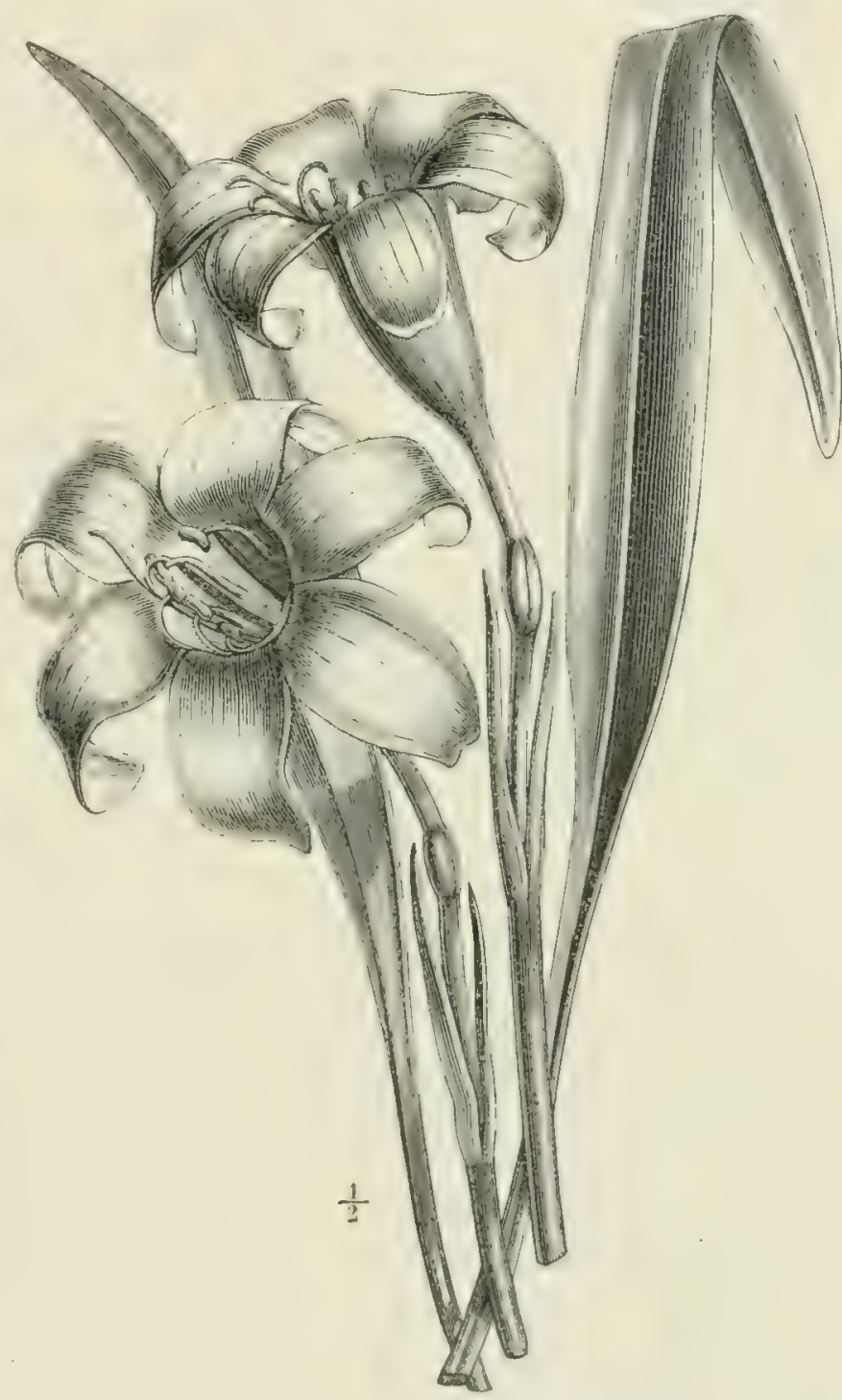

Fig. 248. Cyrtanthus sanguineus Hook. f. Bot. Magaz. Herb., dessen $3 \mathrm{dm}$ lange Blätter spiralig gedreht sind und dessen I, 2-1,5 dm lange Bliiten auf kurzem Sticle stehen. Bisher nur bei Suakin gefunden wurde P. maximun Forsk. mit einblütigen Stielen. Dagegen ist eine fast im ganzen tropischen Afrika in Buschgehölzen vorkommende Art I'. triunthum Herb. mit fast 2 dm langen Bliiten; die Pflanze findet sich auch noch im Hercroland und am Ngami-See.

Cryptostephanus W'elw. et Bak., vom Habitus der Cyrtunthus, aber mit einer aus zwölf linealischen, fleischigen Schuppen bestchenden Nebenkrone am Schlunde der Perigonröhre und mit Beerenfriichten, ist mit C. hucmenthoudis Pax in Taita, 
dem von Buschsteppen bedeckten Hügelland im Südosten des Kilimandscharo, und mit C. densiftorns Welw. in Benguela, von $1300-1600 \mathrm{~m}$, vertreten. Es wird zu prüfen sein, ob die Gattung näher mit Cy'rtenthus oder Narcissus verwandt ist und ob überhaupt die Nebenkronenbildung in erster Linie als erstes .Icrkmal für die Einteilung der Anaryllidaceac zu verwenden ist. Beide Arten haben sehr zahlreiche Blüten, die erste bis Ioo, die zweite 20-30.

Hymenocallis Salisb. ist eine vorzugsweise amerikanische Gattung, von der nur eine Art, H. senegrambica Kunth et Bouché, am Strand von Sierra Leone und Angola vorkommt und sich vielleicht noch als mit irgend einer amerikanischen Art identisch erweisen dürte.

\section{Hypoxidoideae.}

Die durch ein unterirdisches Rhizom, längsfaltige Blätter und gelbe Blüten charakterisierte, in Afrika allein vertretene Gruppe der Hypoxideac umfaßt drei Gattungen, welche ihre Hauptentwicklung in Südafrika haben.

Hypoxis L. Bei dieser leicht zu erkennenden Gattung sind die Abschnitte des Perigons frei, bei Sonnenschein ausgebreitet und meist leuchtend gelb; die Kapsel öffnet sich entweder durch einen Ringspalt oder klappig. Die Blüten stehen entweder einzeln oder in Trauben oder Scheindolden. Die dem knolligen Grundstock entspringenden Blätter sind ausdauernd, linealisch oder lanzettlich. Jetzt unterscheidet man schon 54 Arten in Afrika, von denen 38 nur in Suidafrika, 13 nur aus dem tropischen Afrika (exklus. Natal) bekannt sind. Die Gruppe Fonthic enthäit neun völlig kahie Arten, von denen einige namentlich in den Flats der Kaphalbinsel, aber auch in Klein-Namaqualand durch ihr häufigeres Auftreten charakteristisch sind. Viel zahlreicher sind die Fuhlypoxis mit behaarten Blättern und Blüten. Sehr verbreitet sind die kleinblütige H. angustifolia Lam. und die großblutige $H$. villosa L. f. Die erstere ist von Somaliland durch Ostafrika bis Südafrika, auch auf Madagaskar und den Maskarenen anzutreffen, ferner von Gabun bis Angola und von der Meeresküste bis zu $2600 \mathrm{~m}$ Höhe ü. M. Dagegen findet sich die zweite Art vorzugsweise in Hochgebirgen. Auch H. obtusa Burch., welche von Natal und Transvaal siidwärts bis in den Oranje-Freistaat hinein vorkommt, geht durch das Nyassaland und Usaramo bis nach den Yandi-Hills in Englisch-Ostafrika. Außer diesen drei Arten kommen noch 14 andere in Natal vor, fünf davon nur dort, sechs auch in Transiaal und südwärts, drei nur südwärts. Von den weiter verbreiteten ist eine schöne auffallende Art die dicht silberhaarige $H$. argentca Harv. mit nur ein bis zwei, meist zwciblitigen Blütenstielen. Ferner verdient Frwähnung II. rigidula Bak., mit fün bis sechs linealischen, starren Blättern und drei bis acht in Trauben stehenden Blïten, ron Natal südlich bis zu den Zuurbergen und westlich bis in das westliche Transvaal verbreitet. Bis $6 \mathrm{dm}$ lange Blätter und bis $3 \mathrm{dm}$ lange Stengel mit vier bis zehn scheintraubig stehenden Blüten hesitzt H. Roopcrii Moore, die ron der Delagoa-Bay bis Albany und bis in das westliche Transvaal zerstreut vorkommt. Die meisten Arten sind Bewohner von Grassteppen, im Hochgebirge von Bergwiesen. Außer den bereits erwähnten, auch in Suidafrika vorkommenden Arten finden sich auf Bergwiesen in 
Benguela vier Arten, darunter die vielblütigen H. polystachya Welw: und H. subspicata Pax, in Angola zwei, im südlichen Nyassaland zwei, im Massaihochland drei, in Abyssinien eine. In Lichtungen des Gebirgsbusches finden sich die rielblütige, durch große Knollen ausgezeichnete $H$. Gectaci Harms in Unyika um I $300^{\circ} \mathrm{m}$ nördliches Nyassaland und H. kilimanjariar Bak. am Krilimandscharo um $1600 \mathrm{~m}$.

Curculigo Gärtn. Bei dieser Gattung sind die Blätter des Perigons in eine den Fruchtknoten einschließende Röhre vereint und die Frucht ist beerenartig. C. pilosa (Schum. et Thonn.) Engl. mit länglicher Knolle, linealischen, bis $6 \mathrm{dm}$ langen Blättern und einzeln stehenden, fast röhrigen Bliiten ist vom Westfuß des abyssinischen Hochlandes und rom Somaliland bis Togo und zur Goldküste, südwärts bis zum südlichen Nyassaland und Angola rerbreitet; sie wächst vorzugsweise an Flußufern. Im Süden tritt an Stelle dieser Art C: flicata I. f.) Engl., welche vom Klip River in Tatal (I Ico-I500 m bis Kapstadt an schattigen Plätzen zerstreut ist; sie hat linealische, nur bis 2.5 dm lange Blätter. Nur ein größeres lanzettliches Blatt und $5 \rightarrow 7 \mathrm{~cm}$ lange Bliitenstiele besitzt $C$. namaquensis Bak. in. Klein-Namaqualand.

Pauridia Harv. ist eine nur im südwestlichen Kapland vertretene Gattung, deren einzige Art, $P$. hypoxidoides Harr, ein kleines Knollenpflänzchen mit 2,5-5 cm langen Blättern und mehreren einblütigen Blütenstielen, wegen des Vorhandenseins ron nur drei inneren Staubblättern eine Ausnahmestellung bei den Amaryllidaceen einnimmt, aber doch naturgemäß nur hierher gestellt werden kann.

\section{Fam. Velloziaceae.}

Xerophytische Felsenpflanzen.

Die Tellosiaciae sind eine durchaus eigenartige Familie der Liliiforen, deren Vertreter auch dem Laien auffallen, zumal sie an trockenen. felsigen Abhängen zwischen Steinen oder in den Ritzen kahler Granitberge oft herdenweise auftreten. Die Familie ist merkwürdigerweise auf Südamerika, Afrika und Madagaskar beschränkt und wie die Erivoculacene in Brasilien besonders reich entwickelt. Dort kommen in den trockenen Campos sowohl viele Tillozic wie auch Barbacenic vor; in Afrika und Nadagaskar treffen wir nur Arten der auch in Brasilien vertretenen Sekt. Jirophyta. Alle entwickeln zahlreiche kleine Samen.

Barbacenia Vandelli. Im nördlichen Teil Somaliland und Abyssinien sowie im südlichen Magalisberge) ihres afrikanischen Areals finden sich einige Arten mit rasigem Wuchs, z. B. Barbaccnia Schnitzleiniana (Bak.' Pax vgl. Fig. 249: die große MIehrzahl der ron Natal bis zur Massaisteppe, sowie rom Hereroland bis Angola verbreiteten Arten (I \&) bildet mehr oder weniger verzweigte, schwärzliche; ron netzfaserigen Blattscheiden dicht bedechte Stämme bis zu $15 \mathrm{~cm}$ Dicke, die an ihren Zweigenden einen Schopf linealischer, spitzer, starrer, bisweilen dicht und kurz behaarter Blätter tragen, aus deren Achseln die dünn gestielten, ansehnlichen, weißen, blaß-oder dunkelblauen Bliiten hervor- 
treten; letztere erreichen bei der am Malosa im siidlichen Nyassaland vorkommenden $B$. splindens Harms eine Iünge von $6 \mathrm{~cm}$ und bei der $B$. IT hutacliana Harms fast ebensoviel. Wohl die kräftigste Art ist B. Goetzci Harms hiseja), welche am Ruaha an der Nordgrenze von thehe in einer Höhe von $600 \mathrm{~m}$ vorkommt. In trockenen steinigen Abhängen Westusambaras findet

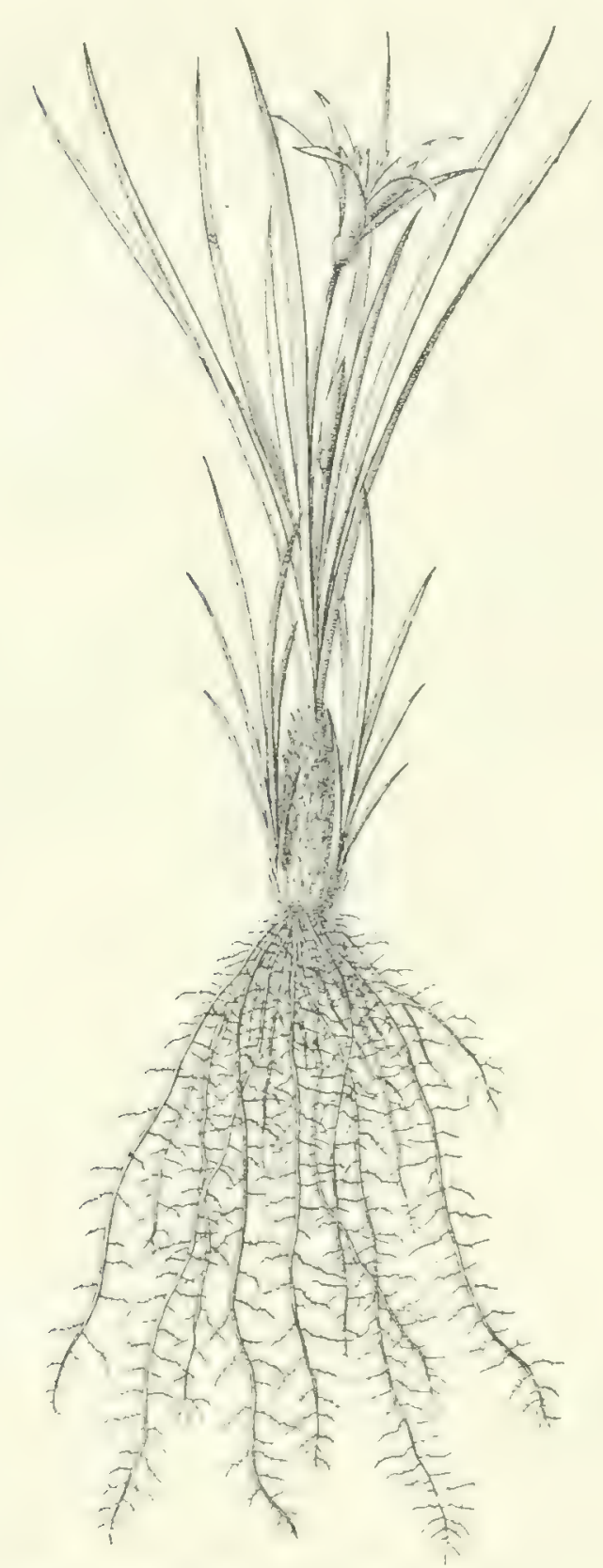

Fig. 249. Barbacenia Schnitzleiniana (Bak.) Pax, $1 / 3$ n. Gro - Original.

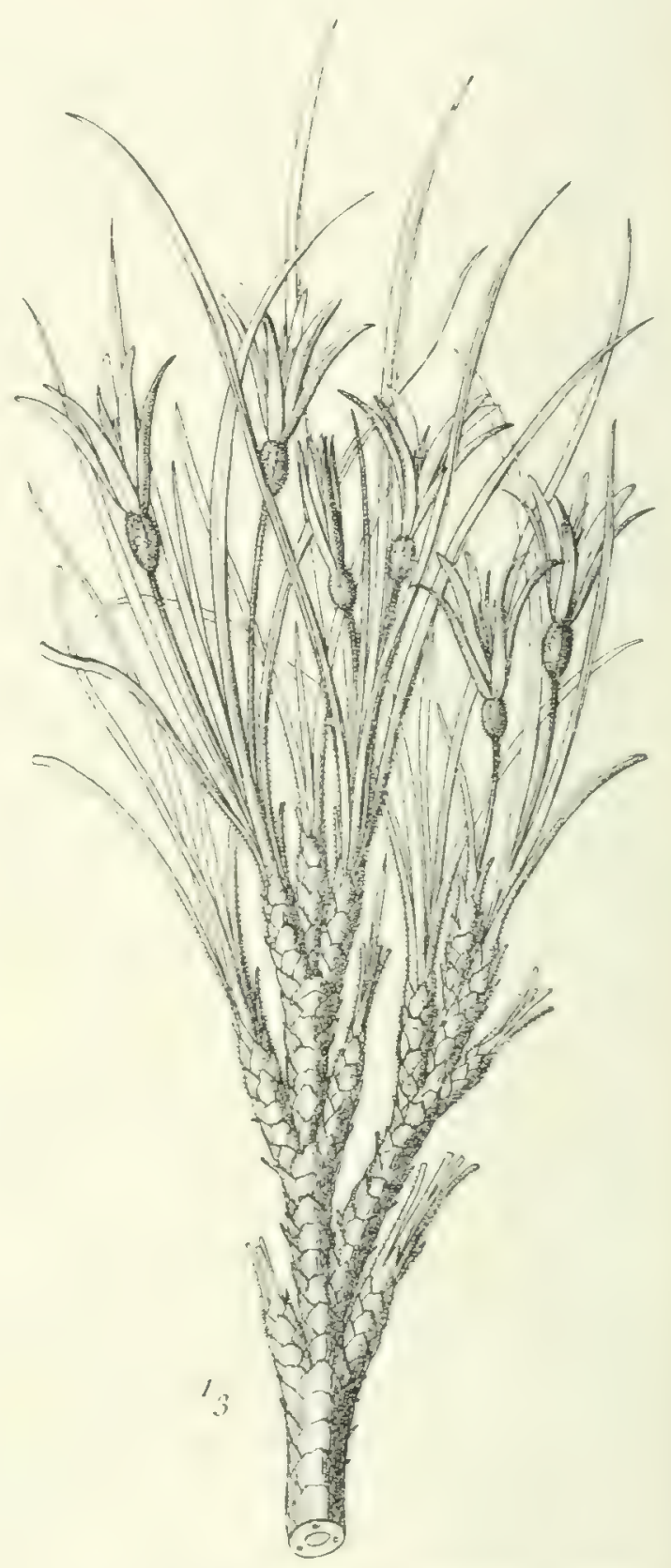

Fig. 250. Barbacenia nequatorialis Harms. Zweigstiick, ${ }^{\mathrm{I}} / 3 \mathrm{n}$. Gr. - Original.

sich nicht selten B. acquatorialis I Jarms, deren liliten hellbläulich bis weiß

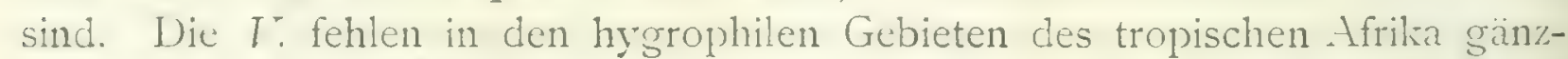
lich, im tropischen Afrika kommen sie imner nur in den regenarmen Gehieten und an Standorten vor, an denen das Wasser abfließt und an denen ihnen Konkurrenten nicht den P'latz streitig machen, in engen Felsspaiten, innerhalh deren sie ein reiches, ticf gehendes Wurzelsystem entwickein, sie finden sich 
auch in den trockenen Gebieten Madagaskars, und eine Art kommt auch im suidlichen Arabien vor. Höchst beachtenswert ist die Tatsache, dals in Ostindien, wo die Granitberge des südlichen Vorderindiens geeignete Standorte darbieten, die $T$. fehlen, daß sie aber mit ciner großen Zahl von Arten und auch mit einer anderen Gattung in Brasilien auftreten. Für die Erklärung der Verbreitung in Afrika geniigt die Kleinheit der Samen, welche durch die W'inde leicht weithin fortgefuhrt werden können; dagegen bedarf die Beschränkung der Verbreitung auf Brasilien und Afrika anderer Voraussetzungen.

\section{Fam. Taccaceae.}

Diese nur etwas über ro Arten umfassende Familie hat ihre stärkste Entwicklung im IIonsungebiet, in Afrika finden wir nur die hier abgebildete (Fig. 251, 252), auch im tropischen Asien wild und kultiviert verbreitete Art
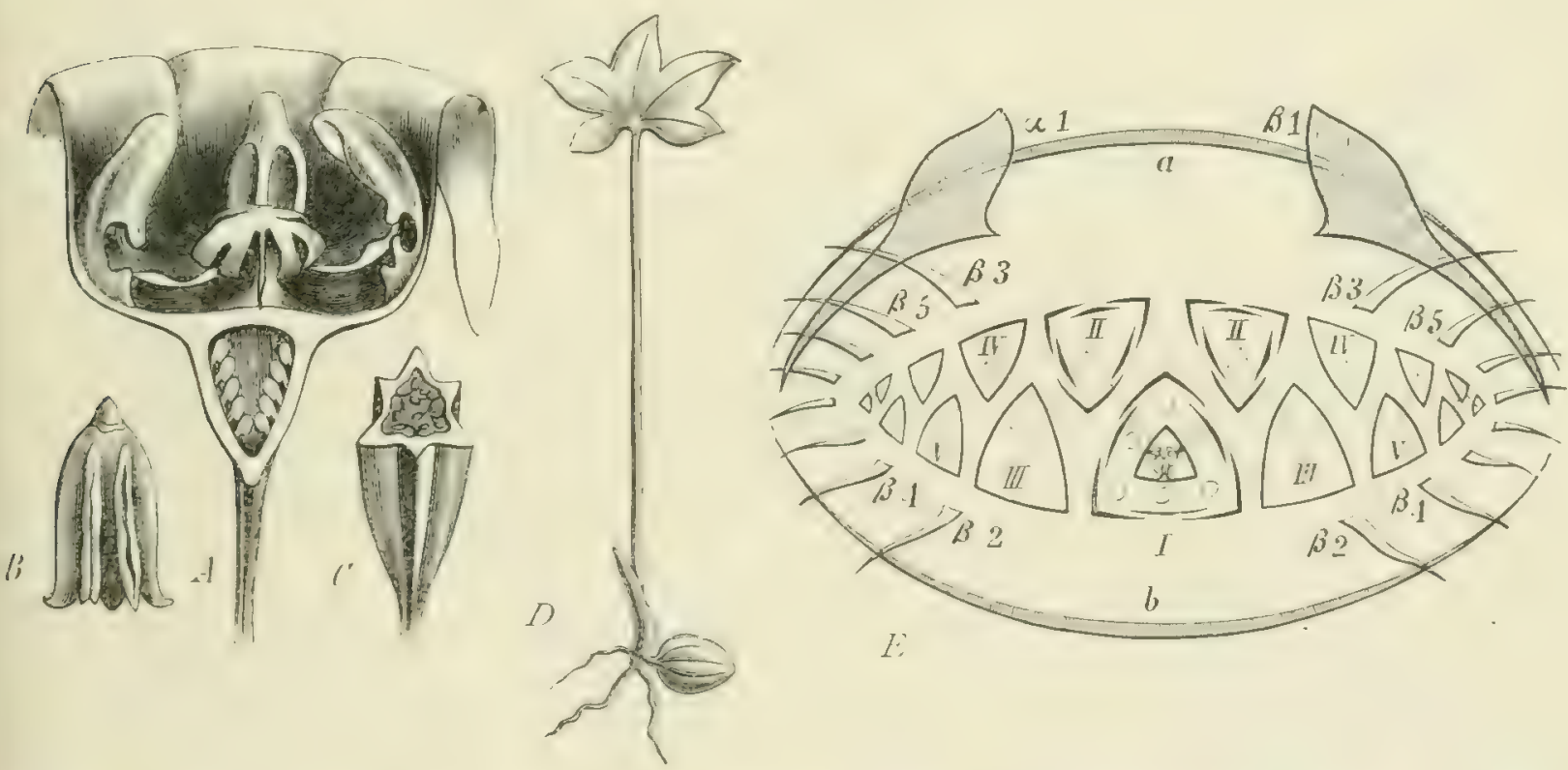

Fig. 25I. A-C Tacca integrifolia Gawl. (Monsungebiet). A Längsschnitt durch die Blüte; b Anthere; C Querschnitt durch den Fruchtknoten. $D$ T. pinnatifida Forst. Keimpflanze. $E$ T. cristata Jack. (Monsungebiet). $a, b$ die beiden großen Hochblätter; $I$ Endbliite, der die beiden Vorblätter " und $\beta$ vorangehen. In den Achseln dieser entstehen die Bliiten II, mit den Vorblättern $\beta_{2}$, aus deren Achsel wieder die Blüten III hervorgehen usf. Ähnlich sind die Verhältnisse bei $T$. pinnatifida.

Tacca pimnatifuda Forst., deren Blätter etwas an diejenigen der Araccen-Gattungen Hydrosme und Amorphophallus erinnern. Besonders eigenartig ist der Bliitenstand, und die Blüten fallen besonders auf durch die breiten, in zwei Lappen gespaltenen Griffelschenkel. Diese Art findet sich besonders häufig auf Schlickund Sandboden in den Gehölzen des Küstenlandes und an Flußufern. sowohl im Osten wie im Westen des tropischen Afrika, aber auch im zentralen Afrika vom nordwestlichen Abyssinien bis nach dem südlichen Nyassaland. Die stärkereichen Knollen, welche als Nahrungsmittel dienen, erreichen bisweilen $3 \mathrm{dm}$ Durchmesser, und der Blattsticl sowie der Blütenstiel werden bisweilen I m lang. 


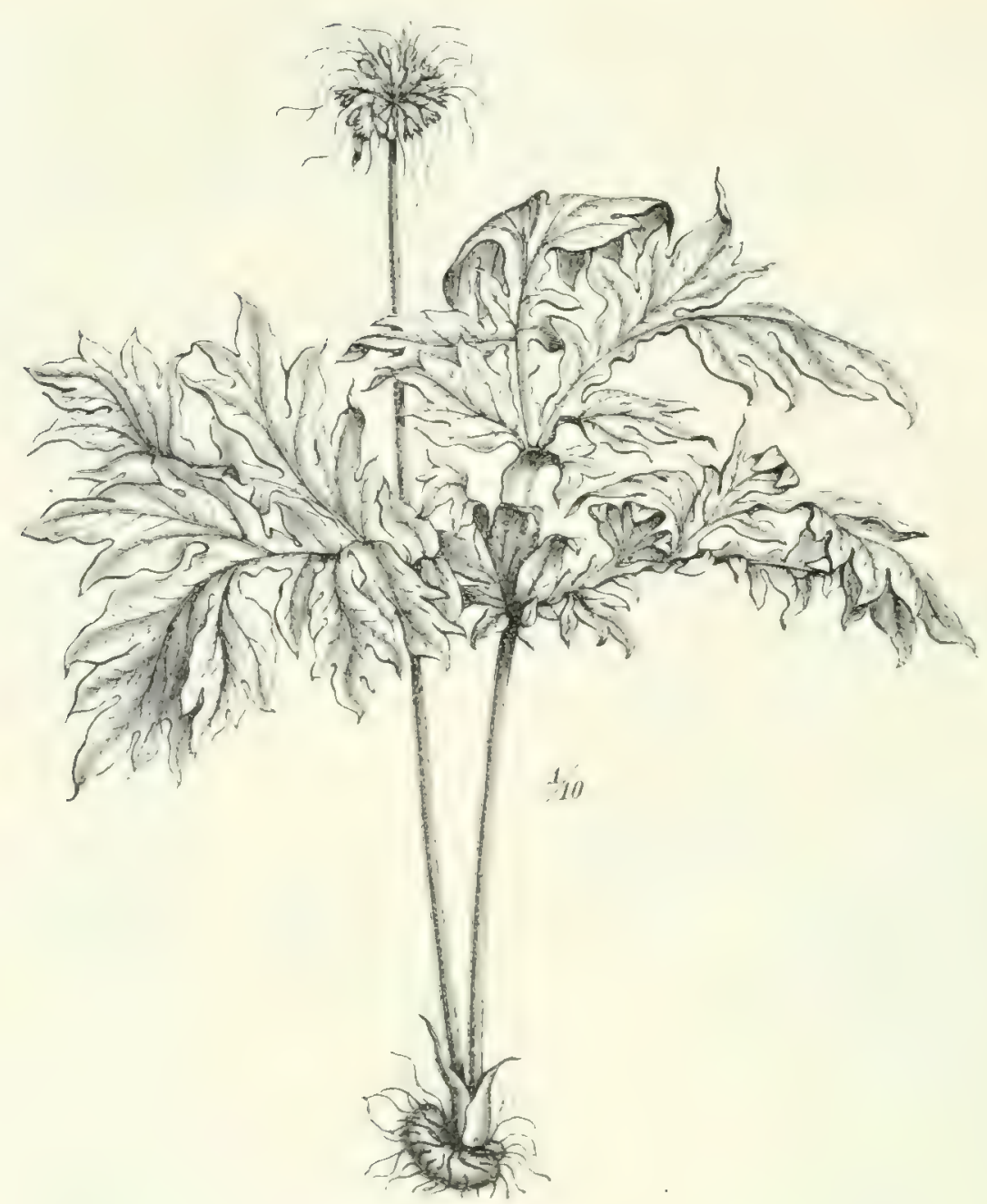

Fig. 252. Tacca pinnatifida Forst. I/I0 n. Gro - Original.

\section{Fam. Dioscoreaceae.}

Megatherme und mesotherme Hygrophyten, aber auch Subxerophyten und einzelne sogar Xerophyten.

Die Dioscorcaceen sind zwar sehr formenreich in allen wärmeren Ländern, namentlich in deren Waldformationen, aber die große Mehrzahl der Arten gehört nur einer Gattung, Dioscorea L., an. Sie umfaßt alle tropisch-afrikanischen Arten, auch die südafrikanischen, von denen man früher einzelne als Testudinuria abzutrennen liebte. Nit Ausnahme der letzteren besitzen alle afrikanischen Dioscoreen unterirdische Knollen. welche oft ganz beträchtliche Länge (bis $5 \mathrm{dm}$, und Dicke bis $1,5 \mathrm{dm}$ erreichen; diesen entspringen windende, bisweilen auch stachelige Stengel mit wechselständigen, seltener gegenständigen, langgestielten, rundlichen oder eiförmigen, seltener drei- fünf-siebenteiligen Blättern, in deren Achseln sich häufig wiederum Knollen bilden, welche faustgroß werden können. Die Bliten sind oft sehr klein, immer zweihäusig und in axillären Athren oder Trauben vereint. In den männlichen Blüten finden wir eine einfache Blütenhülle und sechs Staubblätter oder nur drei fruchtbare und drei Staminodien. Der unterständige Fruchtknoten der weiblichen Bliiten entwickelt sich bei Dioscorec zu einer tief dreilappigen Kapsel, welche bei einem 


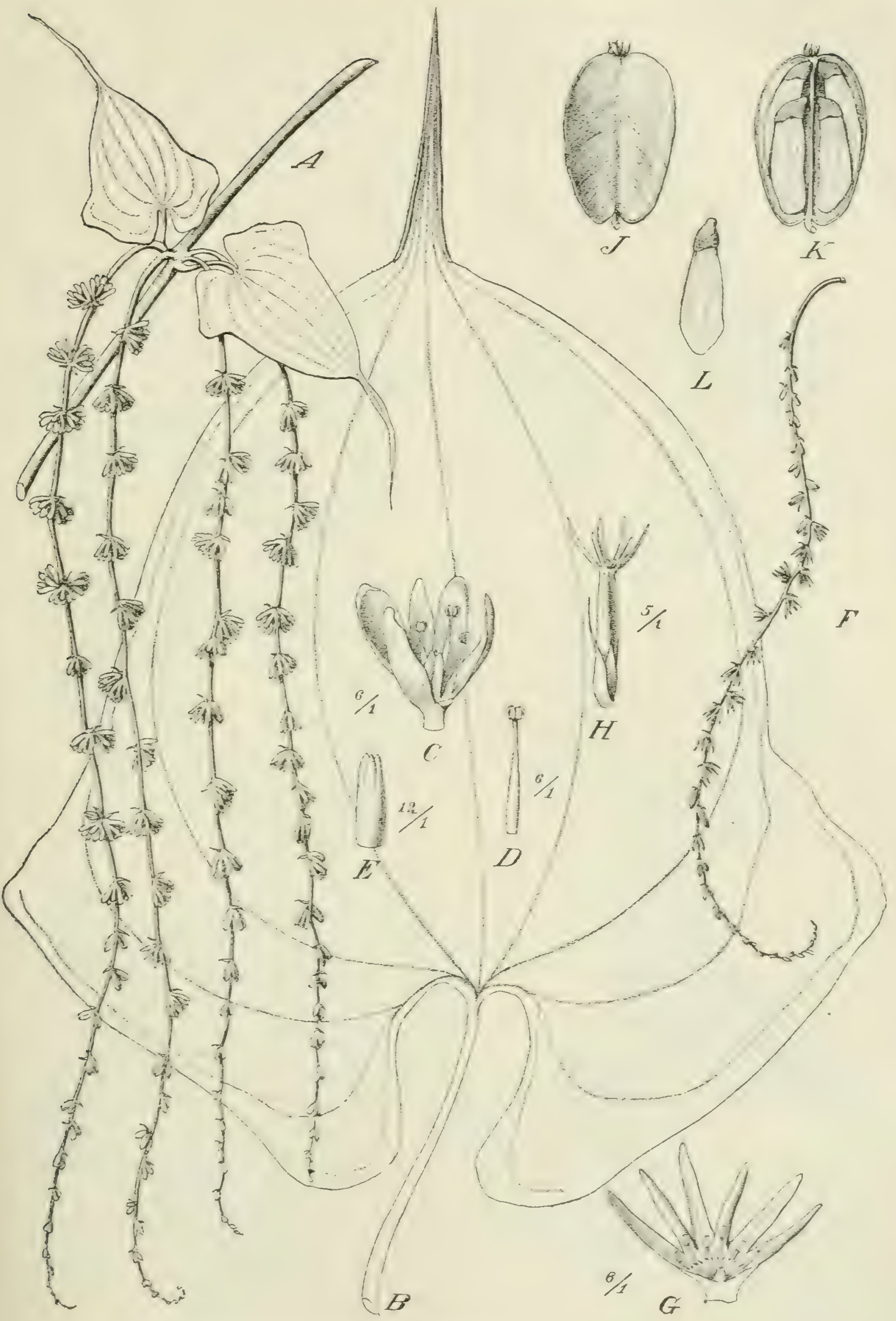

Fig. :53. $A-E$ Dioscorea macroura Harms. $F-L$ D. sativa L. - Original. 


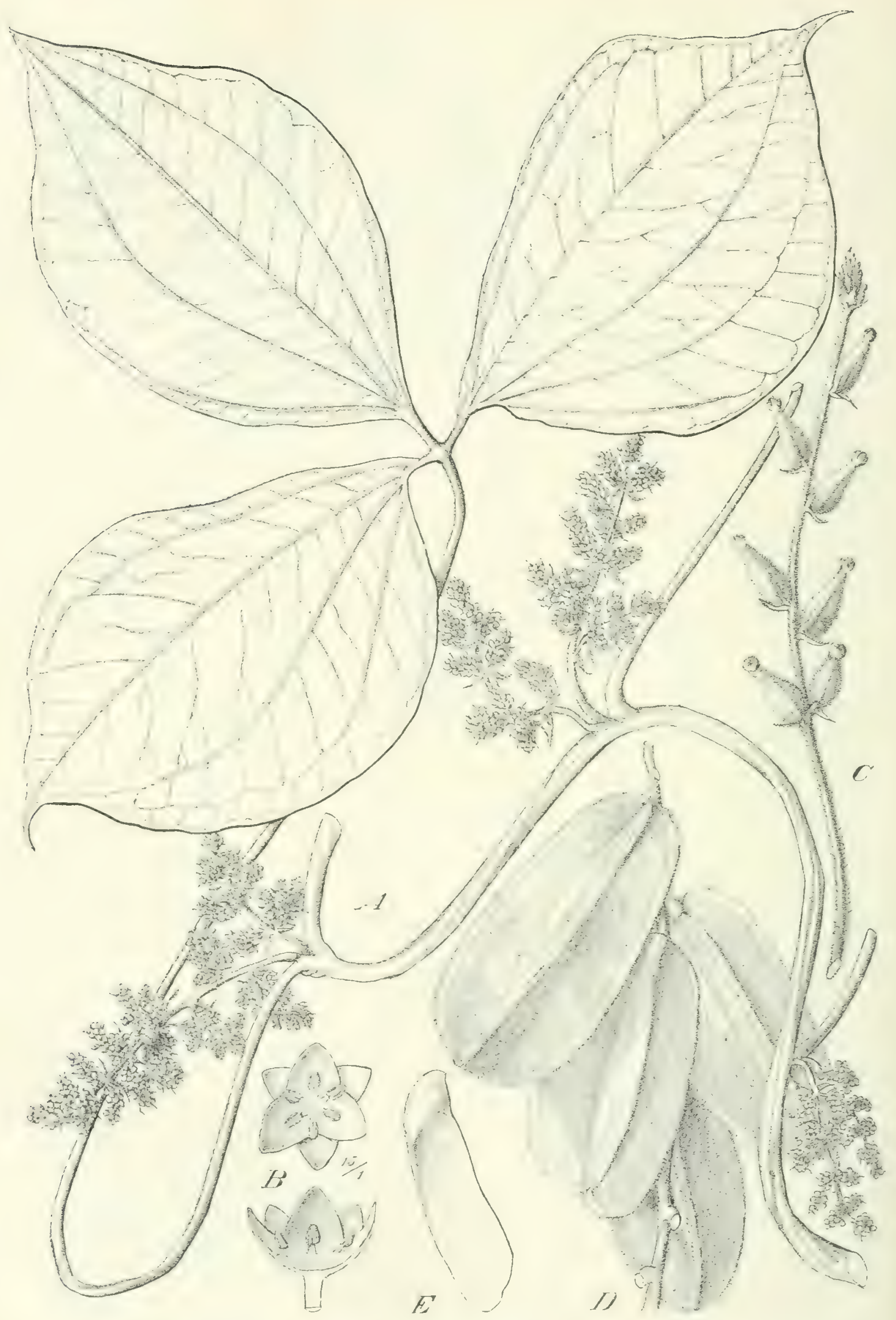

Fig. 254. Dioscorea dumetorum (Kunth) Pax. - Original. 
Teil der Arten ringsum geflügelte Samen einschließst, während eine kleincre Zahl Untergattung Hclmia längliche Kapseln und nur am unteren Ende geflügelte Samen besitzt. Nur fünf bis sechs der etwa 25 tropisch-afrikanischen Arten sind weiter verbreitet. Wohl in allen Waldgebieten des tropischen Afrika und auch außerhalb derselben findet sich als Kulturpflanze die zur Gruppe Opsoplyyton Uline gehörige D. sativa L. (Fig. $253 F-L$ ) mit kahlen, herzförmigen, oft $3 \mathrm{dm}$ langen und breiten Blättern, oft mit Knollen in den Achseln der Blätter und elliptischen Kapseln. In ihre Verwandtschaft gehören auch

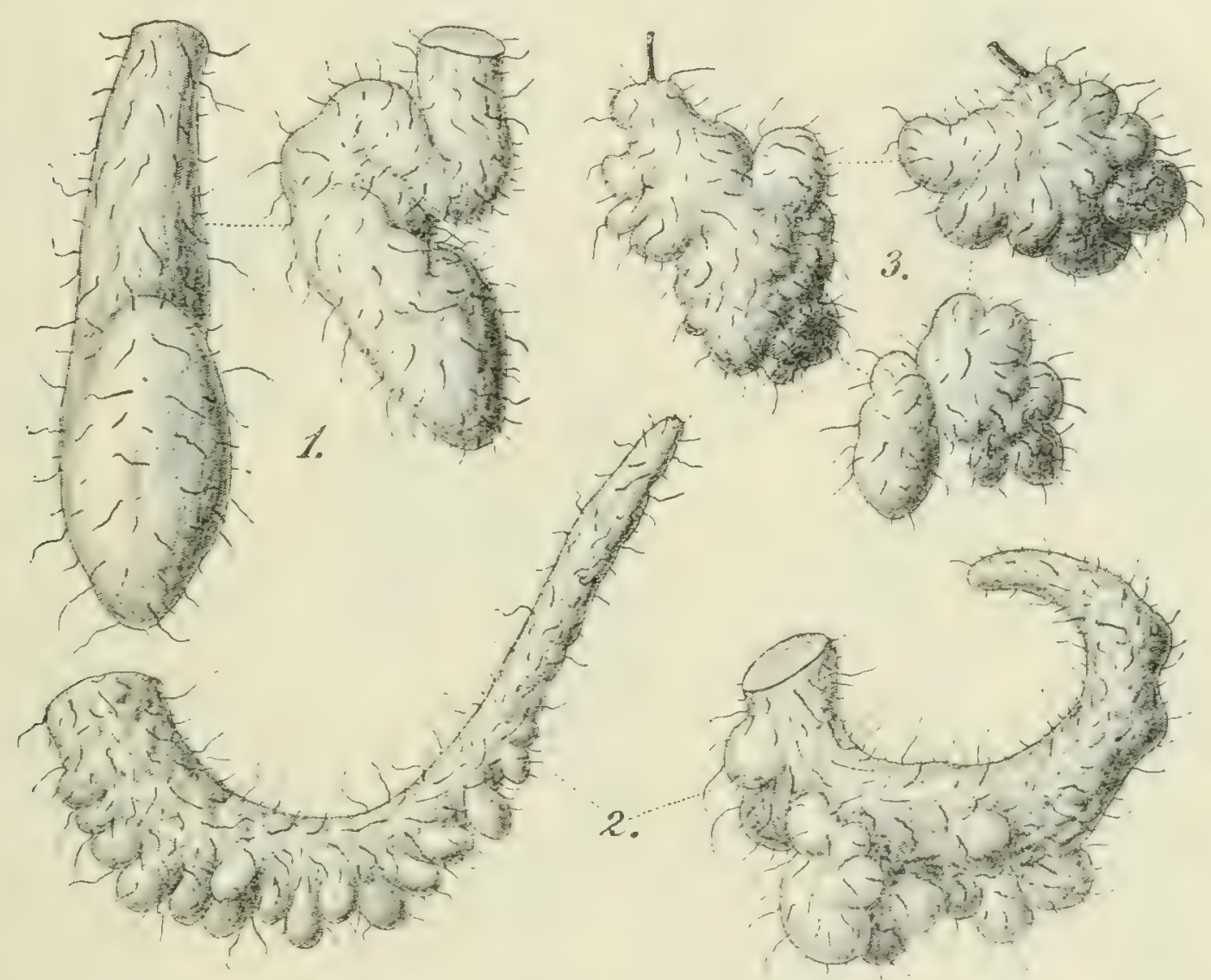

Fig. 255. Dioscorea dumetorum (Kunth) Pax. $x$ moyo ya ngombe (Ochsenherz), 2 netesa (langes bis armlanges Rhizom mit knolligen Auswüchsen), 3 ubika hehi (selten angebaut, Knollen nur I dm lang und breit).

D. sonsibarcusis I'ax, von Bagamoyo bis zum Kilimandscharo verbreitet, und die in Fig. $253 A-E$ abgebildete D. macroura Harms, welche von Togo bis zum Kongo rorkommt. Ebenso ist als Kulturpflanze beliebt die zur Gruppe Lasiophlyton Lline gehörige D. dumctomm (Kunth: Pax Fig. 25ł mit rundem, stacheligem Stengel und gedreiten, unterseits weichhaarigen Blättern, bisweilen mit stacheligen, axillären Knollen, oft hoch in die Bäume kletternd; sie ist verbreitet von Lagos bis Angola, von der Erythrea bis zum Sambesi. Von dieser häufig kultivierten Art gibt es riele Varietäten, von denen die beifolgend (Fig. 255, 256) abgebildeten allein in Usambara kultiviert werden.

Auch die von Transvaal bis in das siidliche Kapland verbreitete D. cotinifolia Kunth (D. malifolin Bak.) und dic in der Knysna wachsende D. ITundii 
Bak. duirften in die Gruppe Opsophyton Uline gehören. Zu einer anderen durch drei unfruchtbare und drei fruchtbare Staubblätter charakterisierten Gruppe (Botryosicyos) gehörig ist D. Quartiniana A. Rich. (Fig. 257), verbreitet in ganz Ostafrika von Abyssinien bis zum Nyassaland, auch auf den Comoren und in Westafrika von Senegambien bis Angola. Hieran schließen sich noch

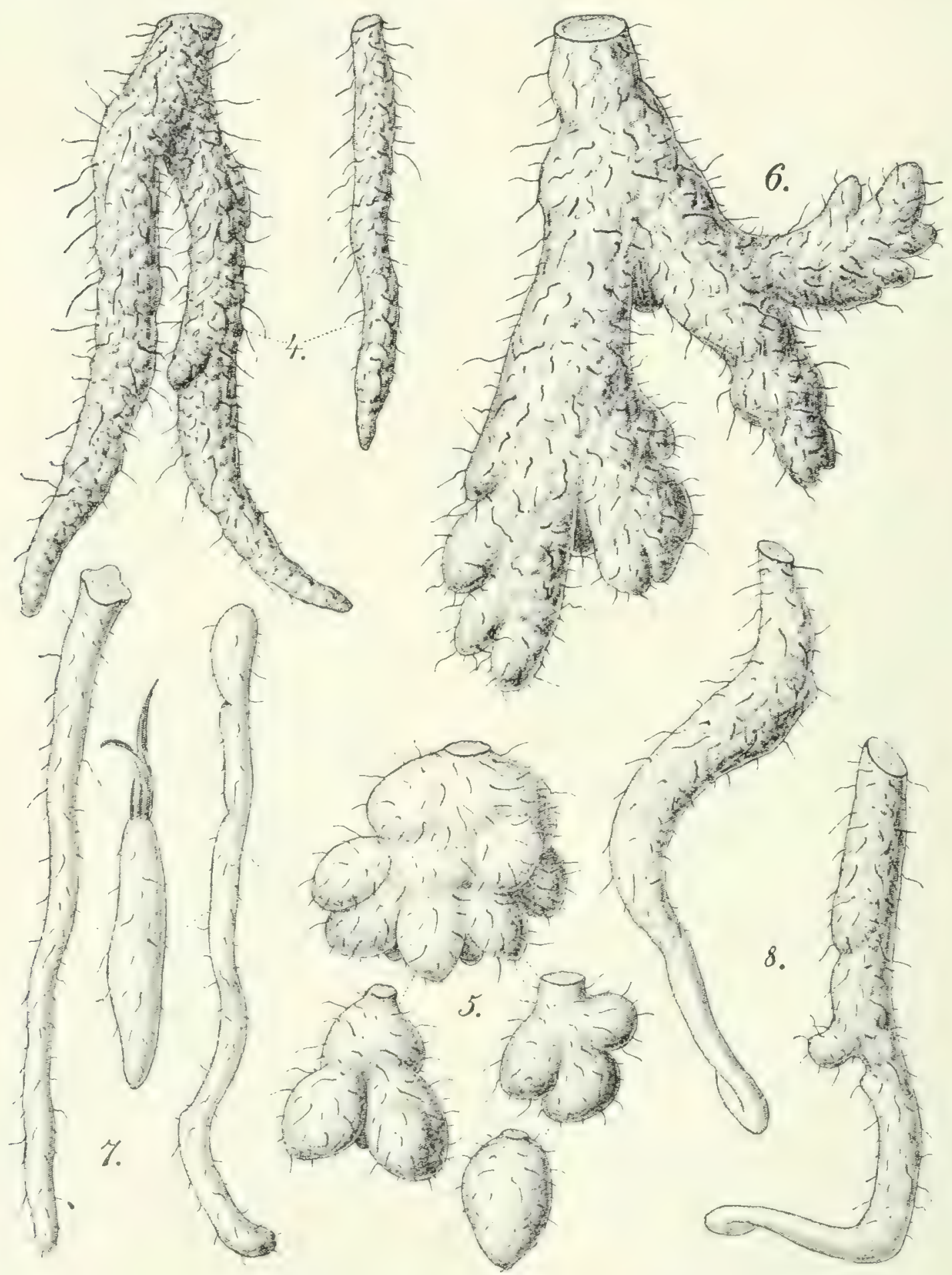

Fig. 256. Dioscorea dumetorum (Kunth) Pax. $4 \mathrm{Kila}$ y a mamba (Krokodilschwanz, bis $3 \mathrm{dm}$ lang und 3-4 cm dick, mit schuppiger Rinde), $5 \mathrm{Kunguni}$ (wächst von allen Sorten am kräftigsten), 6 pome ya quitscho (Quitschoblut, Knolle 3-5 dm lang und armstark mit schleimigem, unter der Oberfläche kirschrotem Fleisch), 7 luzi (Faden-Wasserkartoffel, bis I m lang), 8 angwa (bis $4 \mathrm{dm}$ lang; wenig kultiviert). 


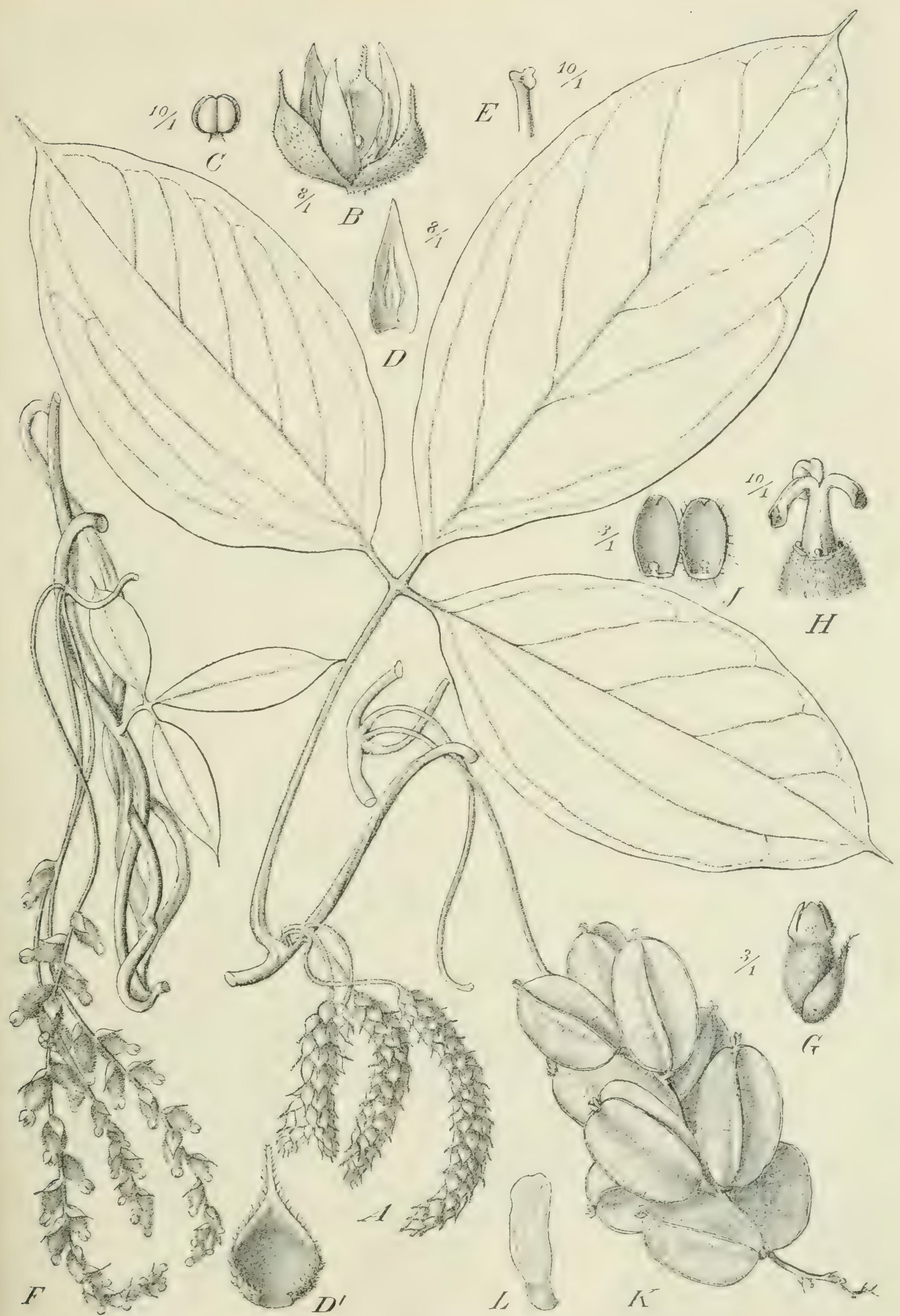

Fig. 257. Dioscorea Quartiniana A. Rich. -- Original. 
einige andere an: $D$. Alichiatasi Harms, auch mit gedreiten Blättern in Angola, und vier mit fünffingerigen Blättern, D. Schacinfurtizanc Pax im Djurland, mit stumpfen, verkehrt-eiförmigen lilättchen, I). Stuhlmanmii Harms in Usaramo, mit schmalen Blättchen, D). Holstii I Iarms im Gebirgsregenwald von Usambara, mit langgestielten Blättchen. Auch die bei Durban in Natal vorkommende D. crinita Hook. f. gehört dieser Gruppe an.

Folgende gehören zur Untergattung Eudioscorea. Durch sehr große, herzförmige, lang zugespitzte Blätter und große Früichte fällt auf I). hylophila Harms (Fig. 258); sie wurde im Regenwald ron Nguclo in Ostusambara gefunden; ihr verwandt ist I). Irenssii I Iarms im Ghasalquellengehiet, in Togo und Kamerun. Diese beiden Arten bilden die Sektion oder Gruppe Macrocarpaea Uline. Drei andere Gruppen tropisch-afrilianischer Eudioscorea besitzen meist gegenständige Blïtter und Kapseln, deren Querdurchmesser größer ist als die Länge. Durch Sternhaare und gleich große Perianthblätter ist die Gruppe Astcrotrichar Uline ausgezeichnet. Sehr verbreitet in Ostafrika von Abyssinien bis zum n irdlichen Nyassaland und vielleicht noch weiter ist D. Schimpiriand Hochst. Ihr steht nahe die in Kamerun wachsende I). Duscuii Uline. Ungleiche Perianthblätter und nicht mit Sternharen verschene Blätter kommen der Gruppe Iinantiophyllum Liline zu. Hierher gehört $D$. aly'ssinica Hochst., welche wir schon im nördlichen Abyssinien finden und welche auch in Togo häufig ist; ihre Blätter sind eiförmig und am Grunde tief herzförmig. Dagegen sind dieselben fast kreisförmig und schwach herzförmig bei 1). prohonsilis Benth.; sie ist sehr verbreitet in den Regenwaildern des ganzen westlichen Afrika von Sierra Lcone bis Angola, fehlt aber auch nicht im zentralen Afrika und kommt auch in Usaramo vor. Auch D. alata L., welche an dem vierfligeligen Stengel und tief herzfürmigen Blïttern zu crkcnnen ist, gehürt hierher; sic besitzt große Knollen, wegen deren sie kultiviert wird. Ob sie im tropischen Afrika, wo sie rom Ghasalquellengebiet bis zum Niger, auf San Thome und in Angola beobachtet wurde, wild ist, duirfte noch zu entscheiden sein. Die Gruppe Syntefalcia Lline ist durch sternhaarige Bekleidung, ungleiche P'erianthblätter und Lmbilung von drei Staubblättern zu Staminodien charakterisiert: dazu gehören D. Iypotricha Uline und D. semperflorens Uline des Kongogebietes. So wie zur Untergattung Helmia gehören auch zu Endioscorea einige in Natal und dem südlichen Kapland vorkommende Arten, von denen besonders die mit gelappten Blättern versehenen D. mpicola Kunth, D. multiloba Kunth und $n$. dièrsifolid Griseb. hervorgehoben sein mögen, die beiden letzteren in Natal und Pondoland. Ton mehreren kapländischen Formen kennen wir noch keine Friichte und haben Schwierigkeit, deren systematische Stellung zu bestimmen.

Die dritte Untergattung Testudinaria (Salisb.) Uline ist von geringerem Umfang und enthält die Gruppe Eutestudinaria, welche durch oberirdische Knollen mit mehr oder weniger mächtiger, in polygonale Stücke zerrissener Korkschicht ausgezeichnet ist. Die Samen sind hier unterhalb der Vitte an der I'lacenta befestigt und nach oben gefliigclt. Hicrher gehört die sehr bekannte D. clephantipes (1'Hérit.), eine xerophytische Felsenpflanze mit oft 


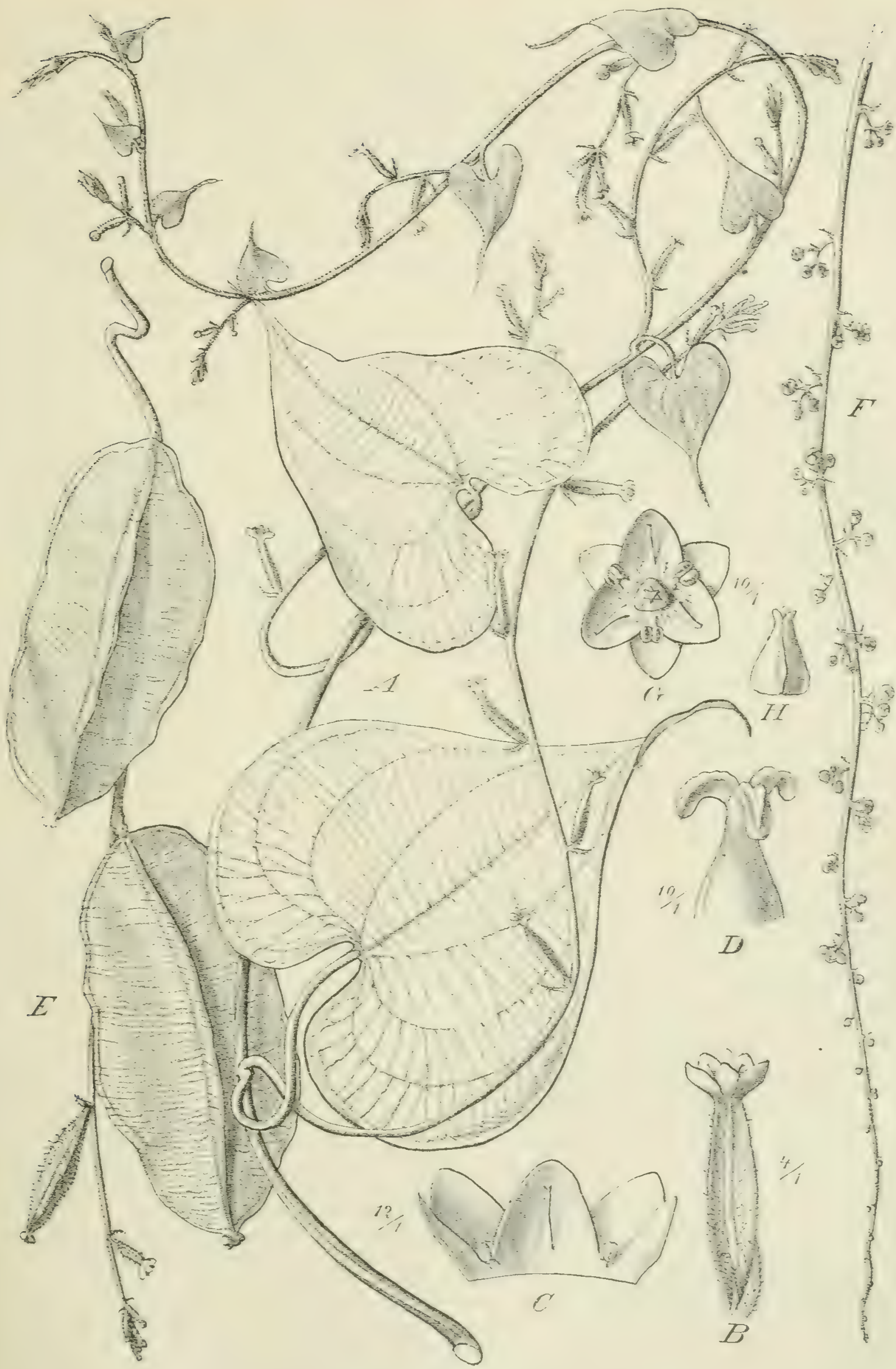

Fig. 25S. Dioscorea hylophila Harms. - Origiual. 
0,7 - I $m$ dickem und hohem Stamm, welchem düne windende Zweige mit fast rundlichen, schwach herzförmigen Blättern entspringen. Die Kapseln sind im Umriß verkehrt-eiförmig, scharf dreiflügelig. Vom Uitenhage-Distrikt im südlichen Kapland an können wir die Pfanze iber die Zuurberge, die Boschberge nach den Gebirgen von Graaff-Reinet verfolgen. wo sie in einer Höhe von I000-I300 $\mathrm{m}$ vorkommt; ebenso findet sich diese interessante Pflanze, deren stärkereiche Knollen in Suidafrika als Nahrungsmittel (Hottentot bread) dienen, auch im Oranje-Freistaat. Eine zweite Art, D. situatica Ecklon, der vorigen ähnlich, aber mit tiefer herzformigen und oft schwach dreilappigen Blättern, hat ziemlich dieselbe Verbreitung, erstreckt sich aber weiter nordwärts bis nach Natal, wo sie auch am Fuß der Drakensberge bis $1800 \mathrm{~m}$ ü. M. vorkommt, und bis in den Distrikt von Lydenburg in Transvaal. Die Gattung I)ioscorea geht uber die Region des Gebirgsbusches in Afrika nicht hinaus: es wird keine Art oberhalb Ig0o $\mathrm{m}$ ü. M. angetroffen; an der Grenze von Asien und Europa kommt nur D. cancasica Lipshy in Felsspalten des abscharischen Kalkgebirges um 250-300 $\mathrm{m}$ vor; sie ist mit der tropisch-asiatischen D. dittoidea Wall. verwandt. Auch die in den Pyrenäen in der alpinen Region wachsende Bordcrea fyrenaica (Bub. et Bordère) Miégeville hat nichts mit den afrikanischen Arten zu schaffen; es sind die Reste einer ehemals stärkeren Entwicklung der Dioscoreaceen in Europa, welches heute noch im Süden in IVäldern ziemlich häufig den beerenfrüchtigen Tamus commmis L. aufweist. Diese Pflanze erscheint zwar im kontinentalen Europa isolicrt; aber in Makaronesien finden wir zwei Verwandte, Tamus edulis Lowe im Laurel von Teneriffa, Palma und Madera, sowie auch in den Barrancos von Gran Canaria, T. parvifloms Kunth auf Madera und Teneriffa.

\section{Fam. Iridaceae.}

Wie die Zwiebelgewächse aus den Familien der Liliacece und Amaryllidaccac treten auch die afrikanischen Irilaceae gesellig auf; ferner finden wir wie bei den Amaryllidaceen, ja in noch viel höherem Grade, eine stark hervortretende Verwandtschaft der im tropischen Afrika rorkommenden Iridaceen mit denen des subtropischen und temperierten Südafrika; es gibt überhaupt außer der wahrscheinlich aus dem tropischen Amerilia stammenden Marica der westafrikanischen Inseln keine Gattung dieser Familie im tropischen Afrika, welche nicht auch in Suidafrika auftritt, und zwar daselbst in noch größerer Artenmannigfaltigkeit; zwei Gattungen jedoch, Romulca und Gladiolus, sind auch noch im Nittelmeergebiet, die letztere bekanntlich auch in Mitteleuropa, anzutreffen. Da wir ferner im tropischen Afrika die Iridaceen durchweg nur in Gebirgsländern, in diesen aber wieder vorzugsweise auf Grasfluren der höheren Regionen entwickelt sehen, so steht es außer Zweifel, daß das urspriingliche Entwicklungsgebiet der afrikanischen und eines Teils der suideuropäischen Iridaceen Siidafrilia ist. Die meisten der afrikanischen Iridaceen sind zwar durch schöne Blütenfärbung auffallende, aber im übrigen nicht sehr stattliche Gewächse: nur die Gattung Glabiolus enthält cinige, bis ein Meter 
hoch werdende Arten. Fast alle sind Subxerophyten, viele MIoraca, mehrere Aristea und Lapeyronsia mesotherme Hydrophyten.

Folgende L'bersicht der in Afrika südlich rom Uittelmeergebiet vorkommenden Gattungen (nach PAx) reicht zur Bestimmung der Gattungen aus, sofern man über Blïten verfiigt. Einige der auf das Kapland beschränkten Gattungen sind nur in dieser Übersicht berücksichtigt.

Übersicht der in Afrika vertretenen Gattungen der Iridaceae.

A. Blüten einzeln oder mehrere achselständige um eine terminale Endblüte stehend. Pflanzen niedrig, oft mit unterirdischem Blütenstiel. Blätter nicht reitend . . . . . . . . . . . Unterfam. Crocoideae. a) Oberirdischer Stengel fehlend. Rühre der Blütenhüle sehr lang. Hierher Crocus L. im Mediterrangebiet; im Kapland ........... Syringodea.

b) Oberirdischer Stengel kurz. Röhre der Blütenhülle kurz oder mäßig lang.

c) Staubblätter frei. Griffeläste nicht blumenblattartig verbreitert . . . . Romulea.

B) Staubfäden in eine Röhre vereint. Griffeläste oben blumenblattartig. - Nur im Kapland

Galaxia.

B. Blüten mehrere, von Spathen (Tragblättern) umschlossen, zu zusammengesetzten Blütenständen am Ende eines deutlich entwiclielten Stengels vereint. Blätter zweizeilig, reitend.

a) $\mathrm{Zu}$ einer Spatha mehrere Blüten gehörig. Bliiten meist regelmäßig

Unterfam. Iridoideac.

a) Röhre der Blütenhülle kurz oder fehlend. Kapsel nicht von der Spatha eingeschlossen.

I. Griffeläste verbreitert oder mehrfach geteilt, über dieStaubblätter fallend.

I. Narben auf der Unterseite der Griffeläste ....... Moraeeae.

* Griffeläste breit, blumenblattartig . . . . . . . . Moraea.

** Griffeläste in drei Abschnitte geteilt. Auf den westafrikanischen Inseln, aus Amerika stammend

Marica.

2. Narben an der Spitze der Griffeläste ...... Tigridieae.

* Griffeläste ungeteilt Kapland . . . . . . . . Homeria.

** Griffeläste geteilt, vorn pinselförmig getwimpert. Kapland . . . Ferraria.

II. Griffeläste ungeteilt, nicht verbreitert . . . . . Sisyrinchieae. Nur im Kapland . . . . . . . . . . Bobartia.

(3) Röhre der Blütenhülle \pm entwickelt. Kapsel von der. Spatha umhüllt . . . . . . . . . . . . . Aristeae.

I. Sämtliche Blütenhiillblätter gleich oder fast gleich.

I. Abschnitte der Blütenhülle kürzer als die Röhre. Kapland. . . Witsenia.

2. Abschnitte der Blütenhülle länger als die Röhre.

* Abschnitte nicht geregelt. . . . . . . . . Aristea.

** Abschnitte der Blütenhülle geregelt. Kapland .........Klattia.

II. Innere Blütenhuillblätter 2-3 mal länger als die äußeren. Kapland . . Cleanthe.

b) Zu einer Spatha nur eine Blüte gehörig; diese meist zygomorph

Unterfam. Ixioideae.

(i) Griffeläste ungeteilt

Ixieae.

I. Blüten nicht oder wenig zygomorph.

I. Griffeläste pfriemenförmig.

* Rhizom. Staubfäden länger als die Antheren.

Schizostylis. 
** Zwiebel. Staubfäden liurz.

† Griffel verlängert. Nur im Kapland . . . . . . . . Geissorrhiza.

t† Griffel kurz................ Hesperantha.

2. Griffeläste blattartig verbreitert.

* Griffeläste linealisch . . . . . . . . . . . . . . . . Ixia.

** Griffeläste keilförmig.

$\div$ Narben rorn ganzrandig.

it Narben vorn ausgerandet.

- Dierama.

Streptanthera.

II. Blüten stark zygomorph, oft gekriimmt

Gladioleae.

I. Blütenhülle gerade, aufrecht.

* Blätter flach, kahl.

† Röhre der Blïtenhülle kürzer als die Abschnitte.

Abschnitte haarförmig zugespitzt. Kapland ..... Melasphaerula.

$\bigcirc \bigcirc$ Abschnitte stumpf oder kurz stachelspitzig.

$\triangle$ Röhre der Blütenhülle oberwärts nicht verbreitert . . . Tritonia.

$\triangle \triangle$ Röhre der Blitenhülle oberwärts trichterförmig. Kapland . Sparaxis. t+ Röhre der Blütenhüille verlängert.

○ Abschnitte der Bliitenhiille ziemlich gleich...... Acidanthera.

$\bigcirc \bigcirc$ Abschnitte der Bliutenhille sehr verschieden ....... Synnotia.

** Blätter längsfaltig, behaart . . . . . . . . . Babiana.

2. Blütenhiille gekrimmt.

* Abschnitte derselben so lang oder kürzer als die Röhre . . . Gladiolus.

** Abschnitte derselben kürzer als die Röhre . . . . . Antholyza.

ß) Griffeläste zweiteilig . . . . . . . . . . . . Watsonieae.

I. Röhre der Blütenhiille kurz. Blïten klein. Kapland. . . . . Micranthus.

II. Röhre der Blütenhülle verlängert. Blüten ansehnlich.

I. Staubfäden kurz. Röhre der Blittenhülle gerade oder wenig gelarümmt

Lapeyrousia.

2. Staubfäden verlängert. Röhre der Blïtenhülle gekrümmt.

* Spatha länglich, lanzettlich . . . . . . . . . . . . . Watsonia.

** Spatba kurz, glockenförmig................. Freesia.

\section{Crocoideae.}

Romulea Naratti ist nahe verwandt mit Crous, habituell derselben ähnlich, aber durcl eine kiurzere Röhre des Perianths ausgezeichnet. Die Gattung ist ebenso wie Crocus im mediterranen Gebict nicht selten und zählt daselbst nach BÉGUINET I 4 Arten; von diesen ist die von Griechenland bis Kleinasien verbreitete R. Linaresii Parl. (Fig. $260 A$ ) in einer Subspecies ( $R$. abyssinica Bég.) in Abyssinien gefunden worden, wo sie in der oberen Grasregion vorkommt, wihrend die Hauptart im Nittelmeergebict nur in geringer Höhe über dem Meere (höchstens $1000 \mathrm{~m}$ ) anzutreffen ist. Ziemlich wenig sind von ihr verschieden die auf dem Kamerungebirge ( $R$. camerooniana Bak.) und dem Kilimandscharo ( $R$. campanuloides Harms, Fig. $260 B)$ in der oberen Grasregion wachsenden Arten, etwas mehr die im Kikuju-Gebirge wachsende R. Fischri Pax. Aus dem übrigen Gebirgsland des tropischen Afrika kennen wir bis jetzt keine Art, doch halte ich es nicht für ausseschlossen, daß später noch solche gefunden werden und die Verbindung zwischen den mediterranen und so zahlrcichen kapländischen herstellen. Es ist fraglich, ob Kommlic aus dem Kapland ïber dic tropisch-afrikanischen Gebirgsländer nach dem Mittel- 
meergebiet gelangt und dort als Seitenast Croins entwichelt hat oder ob beide Gattungen mediterranen Ursprunges sind. Da die in Südeuropa und Asien reich entwickelte Gattung Iris mit Hirmodectylus einem von den Crocidece durchaus verschiedenen Stamm der Iridaceen angehört und die beiden noch bekannten Gattungen der Crocoildat, Syringodea (acht Arten und Galaria zwei

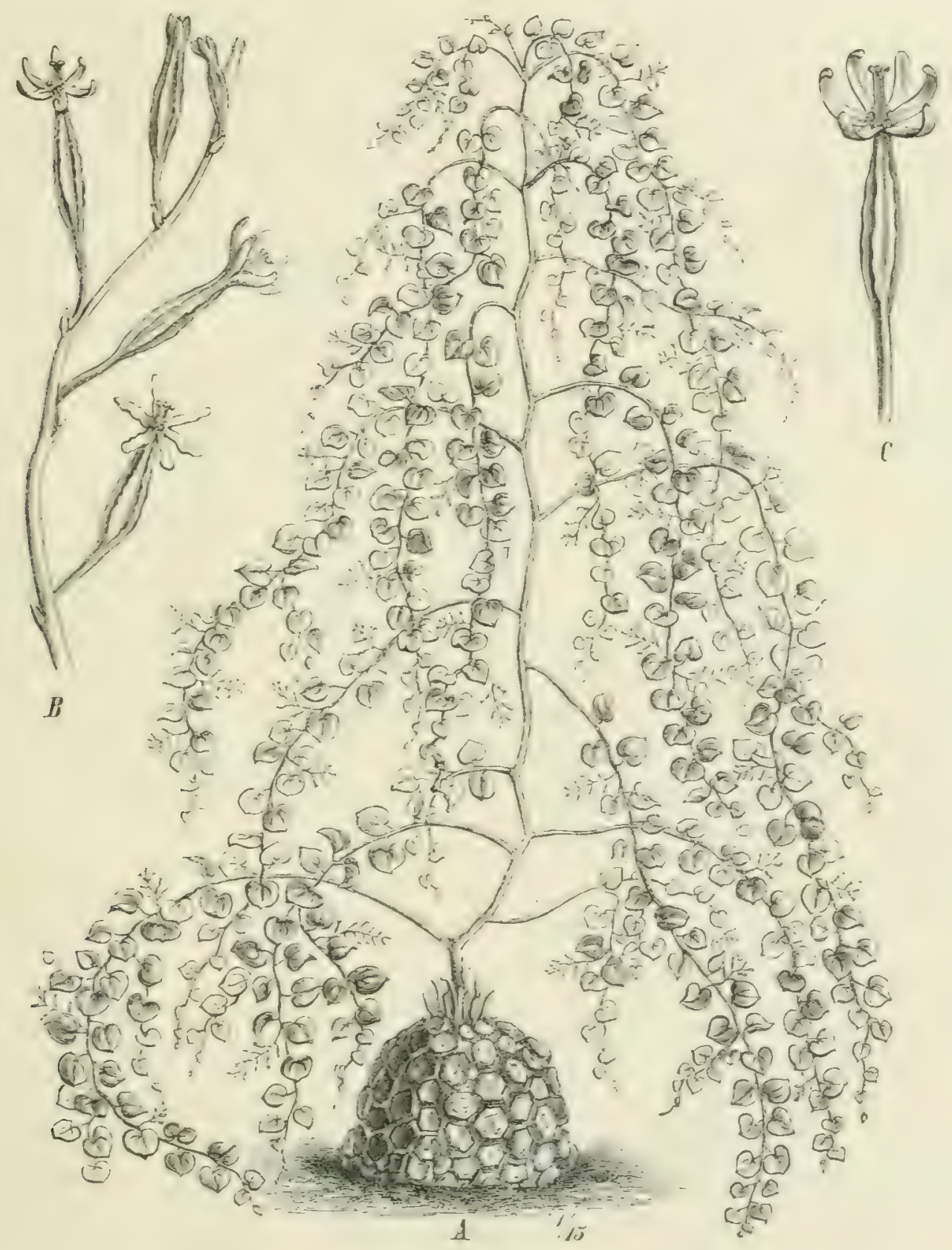

Fig. 259. Dioscorea elephantipes (1'Hérit.) (D. elephantopus Spreng).

Arten, nur im Kapland vorkommen, so entscheide ich mich für die erste, oben angedeutete Hypothese.

\section{Iridoideae.}

Von dieser Unterfamilie sind die curch freie Kapseln und sehr kurze oder fehlende P'erigonröhre charakterisierten. Iforicaci im tropischen und sïdlichen Afrika nur durch. Thorace und IFarica vertreten, dic den vorigen nahestehenden Tigriliteac durch drei Gattungen, die Aristcuc, bei welchen die Lapsel ron 
der Spatha eingeschlossen wird und eine Perigonröhre vorhanden ist, durch einige Gattungen.

\section{Moraeeae.}

Moraea L. Wie der genetische Zusammenhang der im südlichen und tropischen Afrika, auf den Maskarenen und auch in Australien vorkommenden Gattung IIoraca mit der sicher nahe verwandten Gattung Iris zu erklären ist, muß vorläufig dahingestellt bleiben. Jedenfalls sind die auf den Gebirgen von Bengucla und Angola sowie des Nyassalandes vorkommenden Moraca nahe verwandt mit den siidafrikanischen: . M. angustu (Thunb.) Ker ist sogar beim Übergang ron Siidafrika nach dem Tanganyika-Plateau im Nordwesten des Nyassa-Sees unverändert geblieben, desgleichen die bis zum Umba in DeutschOstufrika gelangte. . iritioiles L. Dagegen ist die auf hochgelegenen Bergwiesen von Semen in Abyssinien vorkommende II. dièr rsifolia Bak. am nächsten mit den in Benguela und Angola vorkommenden Arten verwandt. Da mehrere Aluraca auf sumpfigem Boden wachsen, so ist wohl möglich, daß die kugeligen Samen an den Füßen von Wasservögeln verschleppt werden. In Natal (N)

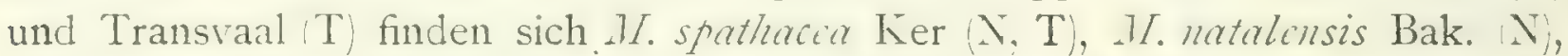
M. simulans Bak. (T), M. Elliotii Bak. $(\mathrm{T})$, M. temuis $\operatorname{Ker}(\mathrm{T})$, M. iridioides L. $\mathrm{A}, \mathrm{T}$; dagegen kommen in der Kapkolonie selbst 37 Arten vor. In Benguela und Angola finden sich zehn Arten, davon .T. zambesiara Bak. auch im Nyassaland; im Nyassaland kommen außer den beiden oben genannten M. angusta und $M$. iridioides noch vier Arten vor.

Marica Ker ist cine tropisch-amerikanische Gattung; die I m hohe, blaublühende 1I. Sabini Lindl. auf Femando Po, der Princes-Insel und in Angola nähert sich sehr der brasilianischen $M$. coemulea Ker und ist wahrscheinlich eingeführt.

\section{Tigridieae.}

Nur kapländisch sind Homeria Tent. und Hexaglottis Tent., dagegen kommt auch im tropischen Afrika vor:

Ferraria L. mit schmalen linealischen Blättern, großen cylindrischen Spathen und großen, nur am MIorgen sich üfnenden Bliten. deren Perigonahschnitte am Rande kraus sind, sowie mit gefransten Griffelschenkeln. Fünf Arten durften im siidwestlichen Kapland heimisch sein, doch ist ron einzelnen ein ursprünglicher Fundort nicht bekannt, $F$. atrata Lodd. mit dunkelpurpurroten Blüten kommt in Victoria-West, F. bechuanica Bak. im Ngamiland, $F$. Welivitschii Bak. mit leuchtend gelben Blüten in Angola vor.

\section{Sisyrinchieae.}

Bobartia Ker (s. oben S. 365). Acht Arten im südlichen Kapland.

Aristeae:

Cleanthe Salisb. (eine Art), Witsenia Thunb. (eine Art, Klattia Bak. eine Art) kommen nur im siidlichen Kapland ror: dagegen ist folgende Gattung auch im tropischen Afrika anzutreffen.

Aristea Ait. Ziemlich auffällig sind auf den Bergwiesen der tropischafrikanischen Gebirgsländer die Arten dieser Gattung durch ihre zwar nicht 


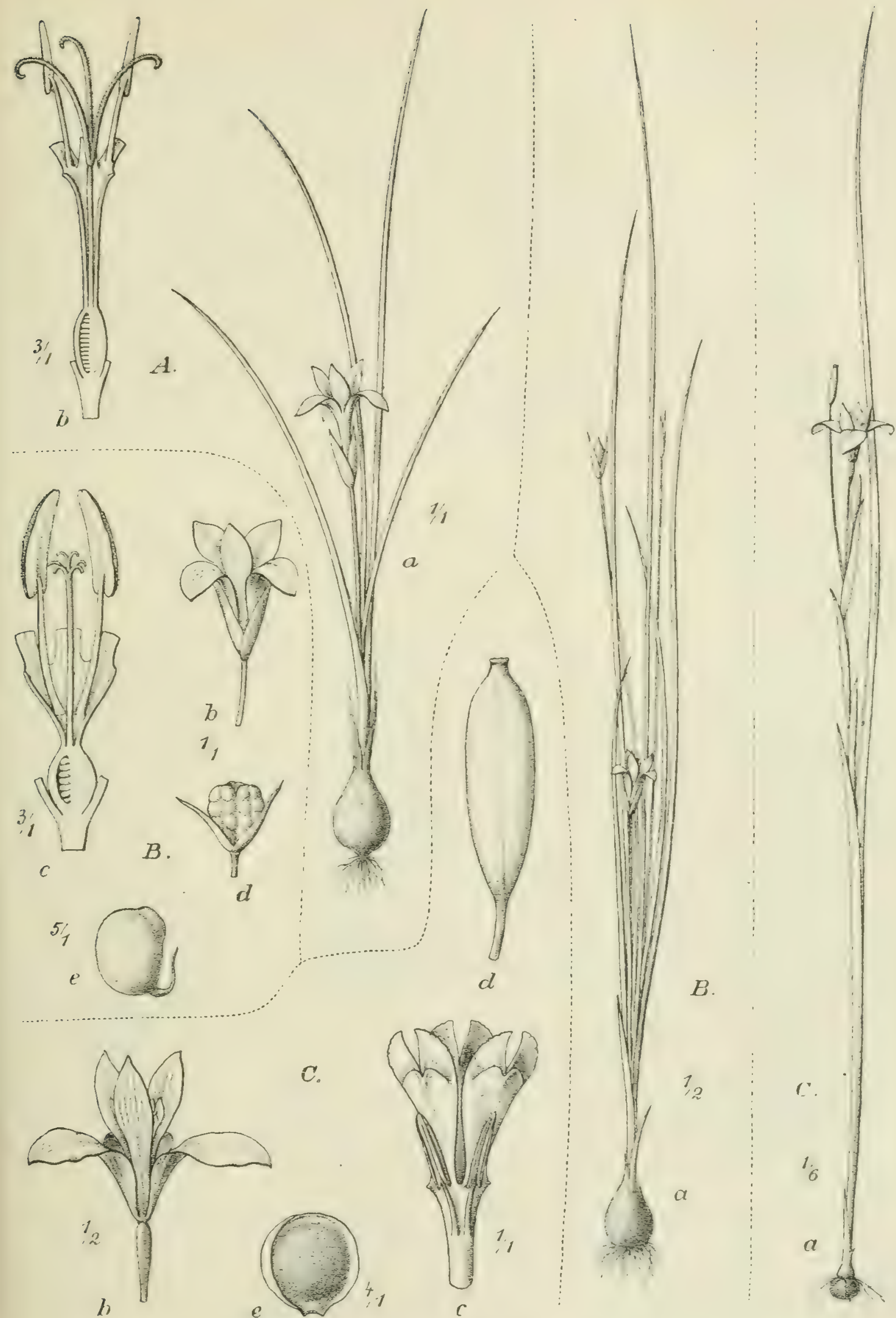

Fig. 260. A Romulea Linaresii Parl. subsp. abyssinica Bég. a Habitus, $b$ Andröceum und Gynäceum im Längsschnitt. $B$ Rom. campanuloides Harms. $a$ Habitus, $b$ Blite, $c$ Andröceum and Gynäceum im Längsschnitt, $d$ Frucht, $e$ Same. C Moraea bella Harms. a ganze Pflanze, $b$ Blüte, $c$ Griffel mit den Staubblättern, $d$ Frucht, e Same. - Original.

Engler Charakterpflanzen Afrikas. I. 
großen, aher leuchtend blauen, selten weißlichen Blüten; die Verbreitungsfähigkeit ihrer kugeligen oder scheibenförmigen Samen ergibt sich daraus, daß einzelne Arten auch in Madagaskar und auf den Maskarenen vorkommen. Eine der verbreitetsten Arten ist die durch flachen Stengel ausgezeichnete A. alata Bak. (Fig 261 A), welche in Usambara nicht selten, am Kilimandscharo bis $3300 \mathrm{~m}$ aufsteigt und auch im Nassaihochland sowie in Abyssinien angetroffen wird. Nach dem Kamerungebirge ist diese Gattung nicht gelangt, wie auch manche andere, welche von Angola über das Tanganyika-Plateau oder von dem südlichen Nyassaland über das Livingstonegebirge und Uhehe (A. uhihensis Harms, Fig. 261 b nach dem nördlichen Ostafrika und Abyssinien gewandert sind. Sechs andere Arten finden sich im Nyassaland und Benguela, neun in Natal, meist auch weiter suidwärts, zwölf nur in der Kapkolonie. Von diesen zeichnen sich A. fruticosa (Thunb.) Pers. und A. corymbosa (Ker) Benth. durch halbstrauchigen oder strauchigen Wuchs aus.

\section{Ixioideae.}

Von dieser Unterfamilie kennen wir aus dem tropischen und südlichen Afrika zusammen 16 Gattungen mit etwa 200 Arten, ron denen die Hauptmasse wie bei den anderen Unterfamilien im Kapland vorkommt.

\section{Ixieae.}

Schizostylis Backh. et Harv. Die beiden Arten dieser Gattung entwickeln am Rhizom wenige grasähnliche Blätter und einen 3-6 dm langen Stengel mit lockerer Blütenähre; die Bliiten haben eine cylindrische Röhre und glockigen Saum und sind bei der von Natal und Transvaal in den Gebirgssteppen um I000- I600 $\mathrm{m}$ bis Stockenstrom im östlichen Kapland vorkommenden S. coccinca Backh. et Harv. dunkclkarminrot, bei der in Natal, Transvaal und dem OranjeFreistaat vorkommenden S. panciflora Klatt blaurot.

Hesperantha Ker. Zwiebelgewächse mit zweireihig gestellten, schmalen Blättern und meist weißen oder rötlich gefleckten, sternförmig abstehenden Abschnitten der Bliitenhülle, in größerer Zahl gesellig auftretend, zahlreich auf den Triften und Grasfluren des siidwestlichen Kaplandes (12). Eine der verbreitetsten Arten, von Kapstadt bis Klein-Namaqualand und Natal, ist H. rodiato Ker; fünf Arten finden sich im zentralen Kapland, acht bis neun in Natal und Transval oder weiter südwärts. Den kapländischen ziemlich nahestehende Arten finden sich auf den höchsten Bergwiesen des Kamerungebirges H. alpinur Benth. et Hook., 2600-3300 m, Fig. $202 \mathrm{~B}$, des Kilimandscharo (H. Tolkensii Harms, 2900-3300 m, Fig. 262 A) und Abyssiniens (H. Petitiana Bak., 1900 bis $3600 \mathrm{~m}$ ).

Geissorrhiza Ker scheint über das südliche Kapland, wo 28 Arten vorkommen, wenig hinauszugehen; nur eine Art kommt etwas weiter nördlich in Klein-Namaqualand vor.

Ixia L. mit 23 Arten ist auch auf das südliche Kapland beschränkt.

Streptanthera Sweet, mit nur zwei Arten, verhält sich wie vorige.

Dierama K. Koch ist in Südafrika durch drei Arten vertreten, von denen D. ponduld (Thunb.) Bak., Fig. 262 C, ausgezeichnet durch einen aus ïhren 
rosafarbener Blüten zusammengesetzten, rispigen Bliitenstand, aus Südafrika über das Nyassaland bis zum Kilimandscharo gelangt ist, wo ich sie in der Grasregion $(2600-3300 \mathrm{~m})$ recht häufig auftreten sah.

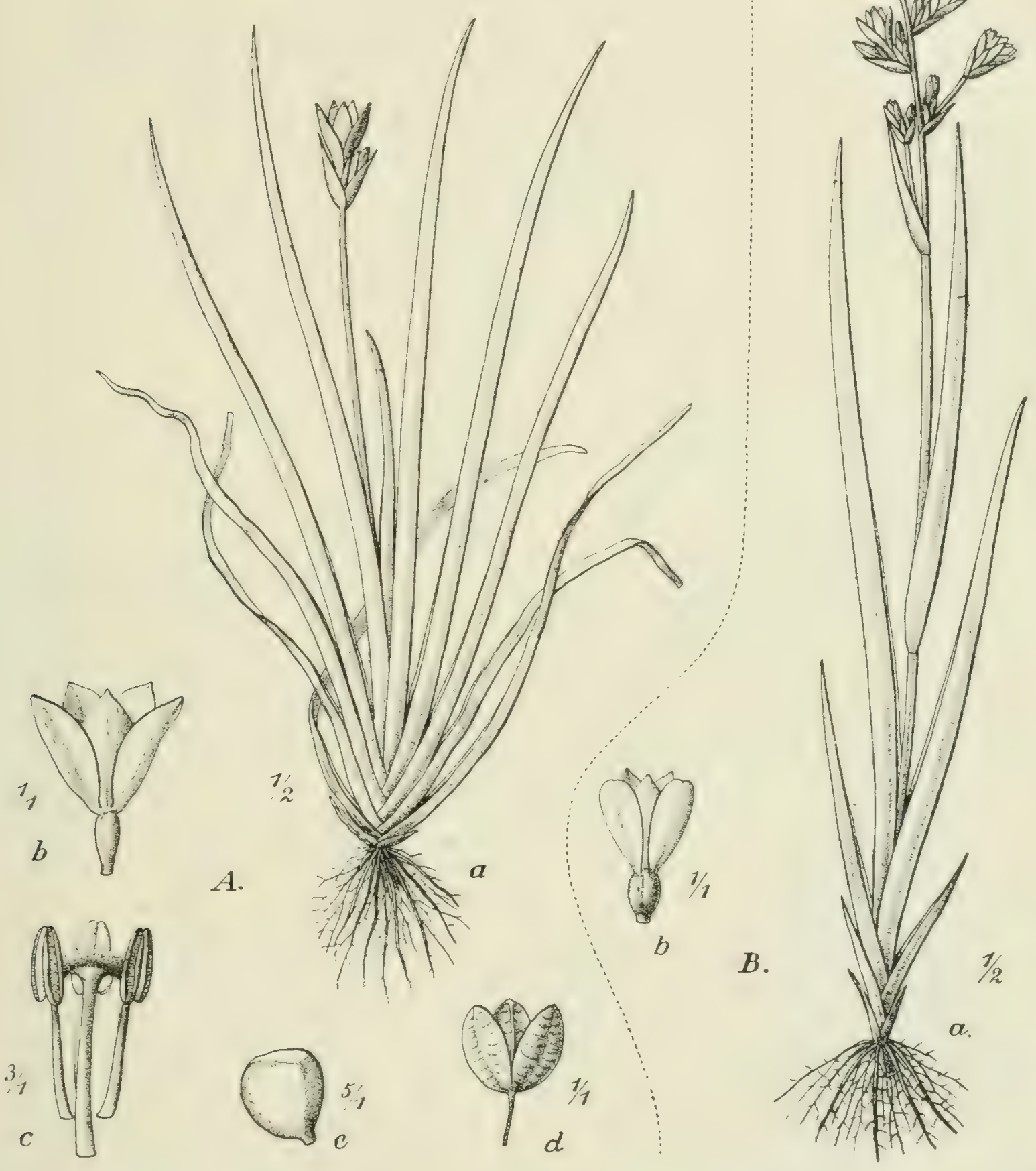

Fig. 261. A Aristea alata Bak. $a$ Habitus, $b$ Blüte, $c$ Griffel und Stanbblatt, $d$ Frucht, $e$ Same. $B$ Aristea uhehensis Harms. - Original.

\section{Gladioleae.}

Diese im tropischen und extratropischen Südafrika besonders reich entwickelte, auch die Maskarenen und Socotra erreichende, nordwärts bis in das Nittelmeergebiet und Nitteleuropa sich erstreckende Gruppe zählt in Afrika acht Gattungen, von denen sechs gerade, aufrechte Perigone haben. Unter 
diesen gehen Babiana Ker (gegen 30 Arten), Ifclaspharmla Ker eine Art), Sfaraxis Ker (drei Arten) und Symotia (zwei Arten) über das siidliche Kapland nicht hinaus. - Gekrümmte Blïtenhïllen besitzen Gladlolus und Antholywa.

Tritonia Ker. Ungefähr 37 Arten sind von dieser Gattung bekannt: daron entfallen auf das siidliche Kapland etwa 17 , auf Klein-Namaqualand zwei, auf das zentrale Kapland eine, auf das östliche Kapland südlich ron Natal fünf, ron denen zwei auch Natal erreichen: sieben andere sind in Natal und Transvaal heimisch und von diesen ist die durch prächtige, große, orangegelbe Blüten auffallende T. aurea Pappe (Crocosmica aurca Thunb., verbreitet bis Ugogo und Westusambara, wo sie in Gebirgsbuschstepjen vorkommt; auch die durch schön rote, aber kleinere Blüten charakterisierte T. laxifolid Benth. ist vom Kapland bis Deutsch-Ostafrika zerstreut. Ferner kommt auf dem östlichen Livingstonegebirge in Ubena T. arrilobe Harms vor Fig. 263 F. Im Osten Afrikas finden wir weiter nordwärts noch die der rorigen nahestehende $T$. bongcnsis Pax im Bongo-Land des Ghasalquellengebietes und 7: monscnsis Schweinf. in der Erythrea bei Geleb um $2300 \mathrm{~m}$ ii. M.

Acidanthera Hochst. ist von voriger Gattung durch die etwas längere Röhre der Bluitenhuille ausgezeichnet. Die wenigen, in lockerer Ähre stehenden Bliten sind weiß mit dunkelpurpurroten Flecken am Schlund bei A. bicolor Hochst. und A. arininocticrlis Bak. (Fig. $263-1$ ). Erstere findet sich einmal südlich rom Nyassa-See im Shire-Hochland, dann wieder in Abyssinien, dem Somaliland und der Erythrea von $1300-2400 \mathrm{~m}$, letztere merkwürdigerweise in Sierra Leone, während sonst keine andere Art in Westafrika gefunden wurde. Den beiden genannten stehen noch sieben Arten mit rein weißen Bliten gegenüber, von denen A. gracilis Pax bei Nombassa und in Ukamba in geringer Höhe ïber dem Neere vorkommt, $A$. Goitaci Harms, an grasigen Abhängen des Hochlandes Lnyika im nördlichen Nyassaland um $2000 \mathrm{~m}$, A. micolor Hochst. in Gehölzen am Takaze in Abrssinien, -1. lariffora 13ak. in der Kulturregion des Kilimandscharo und in Taita. Etwa zehn Arten wachsen im südlichen Kapland, im östlichen und in Natal drei bis vier.

Gladiolus L. Wie bei voriger Gattung, so stehen auch bei Gladiolus die tropisch-afrikanischen Arten (53) den sidafrikanischen an Zahl nicht besonders nach; es scheint, daß sie von $600 \mathrm{~m}$ ii. M. an bis zu $3300 \mathrm{~m}$ auf Grasfluren nicht selten sind. Bis jetzt sah ich keine Art rom Kamerungebirge, während bei Nupe im Nigergebiet, bei Bismarcksburg in Togo und in Sierra Leone einzelne Arten vorkommen. Eine besonders große Zahl ron Species findet sich in dem gebirgigen Nyassaland, darunter auch der südwestlich bis Benguela, nordwärts bis Abyssinien verbreitete G. Quartinianus A. Rich., fast I $\mathrm{m}$ hoch und mit locker stehenden, blaßgelben bis blutroten Bliiten. Noch größer ist der am Kilimandscharo bis $3300 \mathrm{~m}$ aufsteigende G. splendidus Rendle, dessen leuchtend karminrote Blüten $10 \mathrm{~cm}$ lang werden: dagegen ist der ebenda an der Schneegrenze wachsende G. Teziii Bak. nur $5 \mathrm{dm}$ hoch und trägt gelbe, bis $7,5 \mathrm{~cm}$ große Bliiten. Tiele andere Arten sind nicht stattlicher als die siideuropäischen. 
Antholyza L. Bei dieser Gattung ist die Röhre des Perigons nicht trichterförmig wie bei voriger Gattung, sondern unten fadenförmig, in der oberen Hälfte cylindrisch, mit länglichen oder lanzettlichen Abschnitten, von denen der oberste der längste ist. Während die Gladiolus-Arten vorzugsweise auf offenen

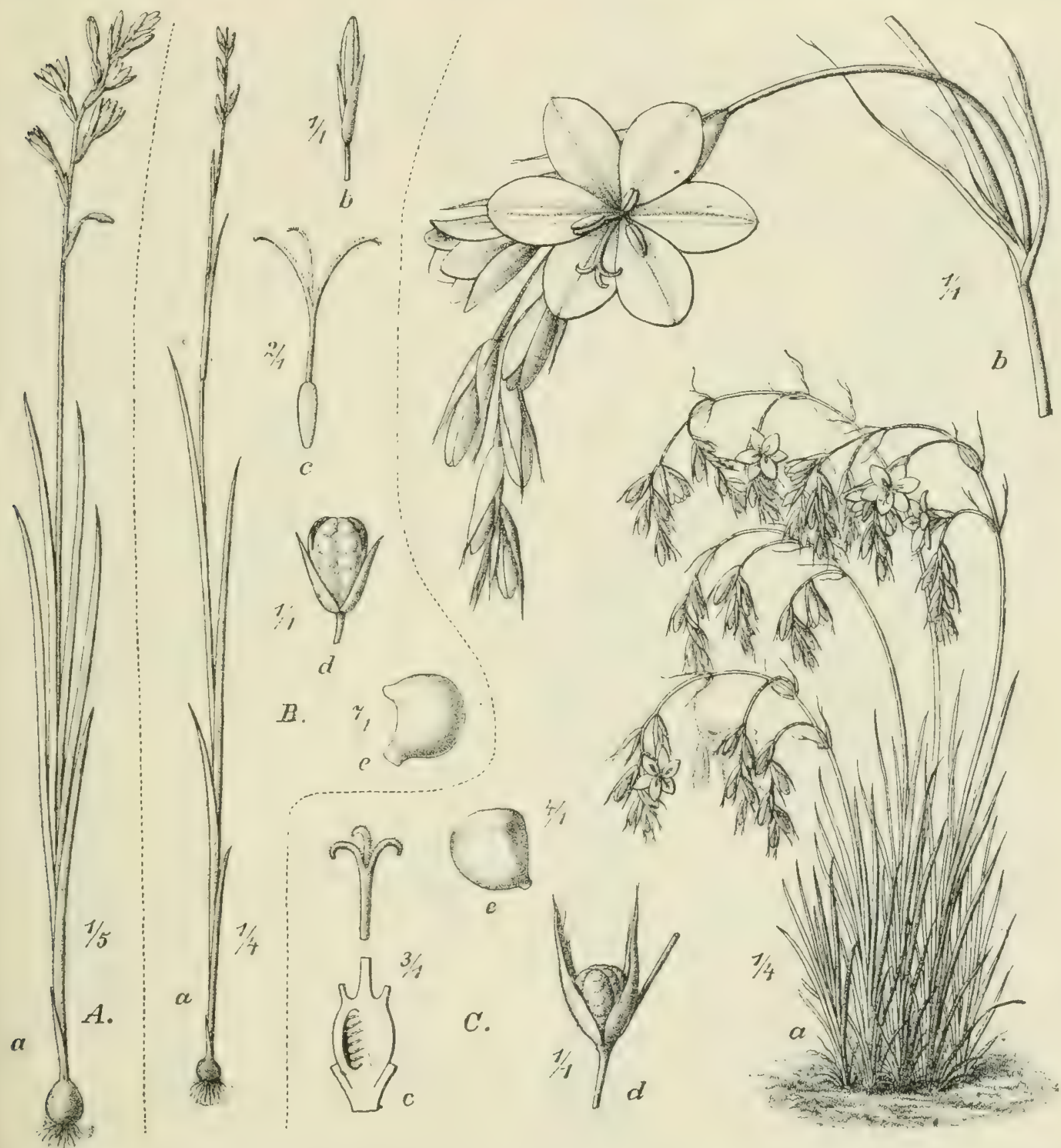

Fig. 262. A Hesperantha Volkensii Harms, $B$ Hesperantha alpina (Hook。 f.) Benth. a Habitus, $b$ geschlossene Blüte, $c$ Stempel, $d$ Frucht, $e$ Same. C Dierama pendula Baker. a Habitus, verkl., $b$ Stïck eines blühenden Stengels in n. Gr. nach Bot. Magaz. r36o, $c$ Narbe und Fruchtknoten im Längsschnitt, $d$ Frucht, $e$ Same. - Original.

Grasfluren vorkommen, finden wir die Arten der nahestehenden Gattung Antholyza vorzugsweise am Rande von Buschgehölzen, auffallend durch leuchtend rot gefärbte Bliiten; sie sind bei weitem nicht so zahlreich im tropischen Afrika wie die Gladiolus. In Benguela und Rhodesia, merkwürdigerweise auch 
in Togo, findet sich je einc Art in nicht bedeutender Höhe über dem Meere, dagegen sind vier andere in den oberen Regionen der Erythrea und Abyssiniens sowie des Kilimandscharo heimisch, A. Schuccinfurthii Bak. (Fig. $263 C$ ) in der Erythrea von $1000-2100 \mathrm{~m}$ ü. M., A. abyssinica Brong. bis $2900 \mathrm{~m}, A$. gracilis

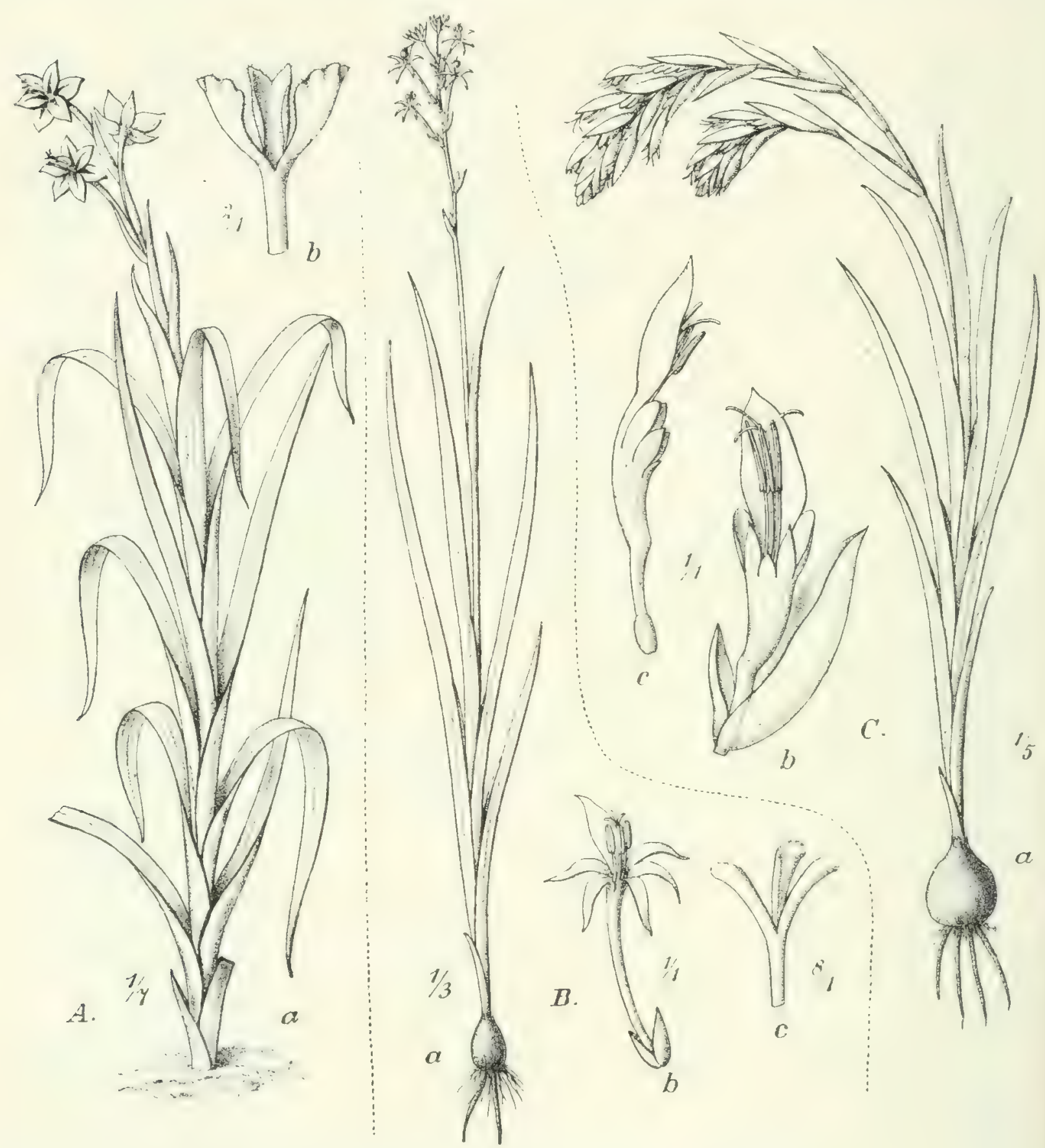

Fig. 263. A Acidanthera nequinoctialis Baker (Sierra Leone) n. Bot. Magaz. 7393. a Habitus, stark verkl., $b$ Narbe, vergr. $B$ Tritonia acriloba Harms (Livingstonegebirge). $a$ Habitus, $b$ Bliite, c Griffel. $C$ Antbolyza Schweinfurthii Baker, a ganze Pflanze, stark verkl., $b$ Blïte von vorn, $c$ dieselbe von der Seite gesehen und ohne Bracteen.

Pax am Kilimandscharo von $2600-4200 \mathrm{~m}$, letztere wahrscheinlich nur eine Varietät der ebenda von $2800-3600 \mathrm{~m}$ vorkommenden $A$. watsonioides Bak. In Transvaal und Natal kommen drei Arten vor, im südlichen Kapland etwa zehn. 


\section{Watsonicae.}

Micranthus Pers. zwei Arten und Freesia Klatt mit einer sehr veränderlichen Art) sind auf das südliche Kapland beschränkt.

Watsonia Miller. Zwiebelgewächse mit starren, schwertförmigen Blättern und meist ansehnlichen, meist leuchtend roten, in einfachen oder verzweigten

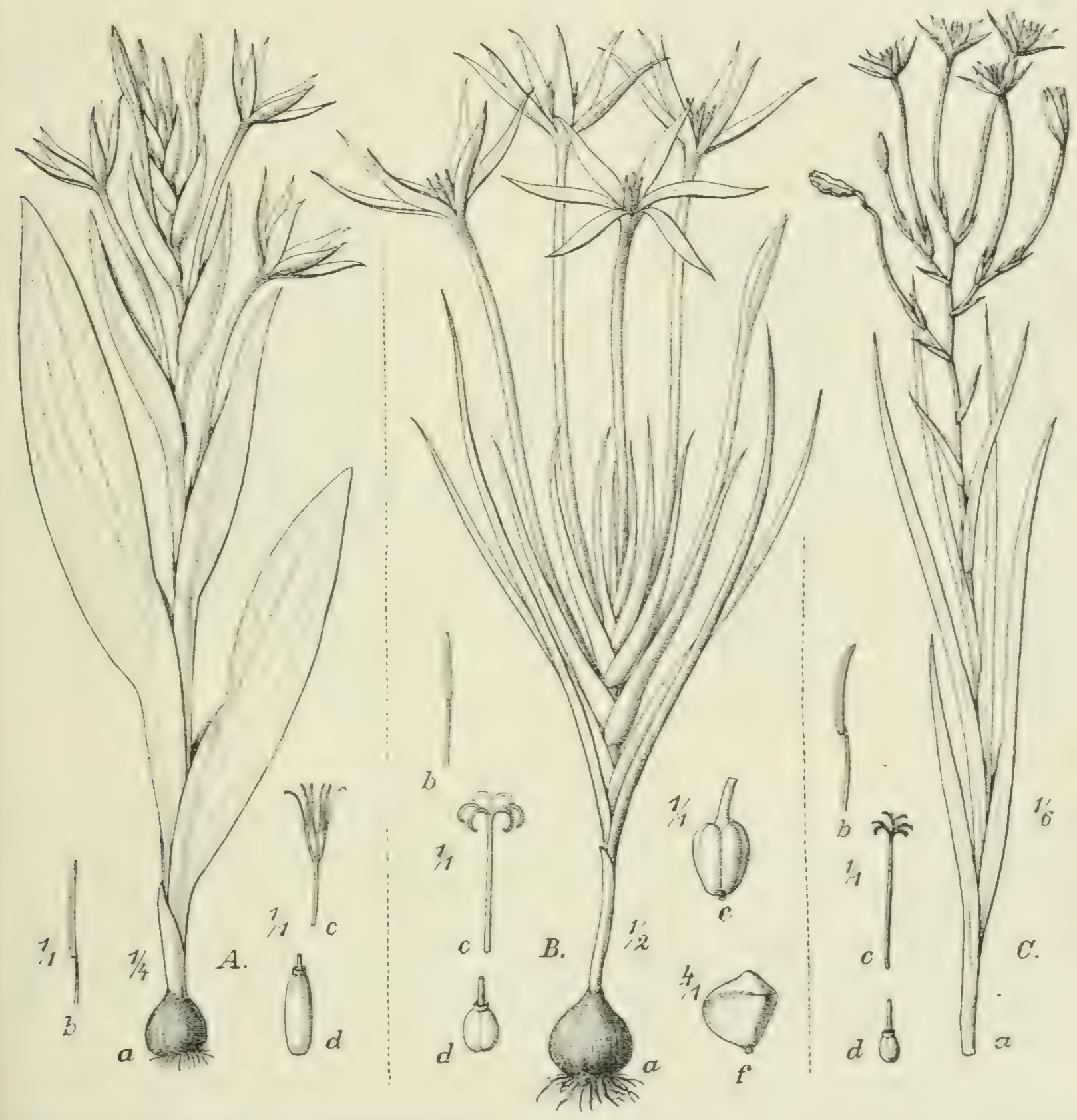

Fig. 264. A Lapeyrousia euryphylla Harms (Iringa, in Uhehe, um I500 m ï. 1I.). B L. odoratissima Bak. (Benguela und Uhehe). C L. cyanescens Bak. (Benguela). - Original.

Ähren stehenden Blüten. Bis Transsaal dringt ror: H. rosen Ker mit fast $2 \mathrm{~m}$ langem Stengel und bis I $\mathrm{m}$ langen Blättern: ferner II. ITcrianu L.) Mill. mit etwa I $\mathrm{m}$ langem Stengel und rosafarbenen Blüten, deren Röhre länger ist als bei der vorigen; sie kommt auch im westlichen Natal um 1500 m vor. Sodann ist $W^{*}$. dinsiffore Bak. in Natal. Transvaal und dem Oranje-Freistaat 
anzutreffen, eine bis I $m$ hohe Art, mit $40-50$ in dichter Ähre stehenden Blüten. Zwölf andere finden sich mehr im südlichen Kapland.

Lapeyrousia Porr. hat im Gegensatz zu den vorigen Gattungen eine gerade Perigonröhre und kurze Staubblätter. Von den etwa 40 Arten dieser Gattung wächst etwa die Hälfte in der Kapkolonic teils auf sandigem, teils auf steinigem, teils auf sumpfigem Boden. In Transvaal finden sich vier Arten, von denen $L$. Sandersonii Bak. über Rhodesia bis zum Hereroland und siidlichen Nyassaland reicht. Beide werden nicht üher $6 \mathrm{dm}$ hoch. Eine der $L$. IVclicitschii Bak. von Angola nahestehende Art, L. sctifolia Harms, wurde auch von GoETzE im östlichen Livingstone-Gebirge, um $2100 \mathrm{~m}$ i.. M. gefunden. Derselben Art nähert sich auch L. abyssinica Bak. in Kalabat im westlichen und mittleren Abyssinien. Auch L. cocrulea Schinz von Otjitambe im Hereroland gehört in diesen Formenkreis. Durch eine längere Rühre der Bliitenhülle $(3-4 \mathrm{~cm})$ sind ausgezeichnet L. Bainesii Bak., welche sich vom Kapland bis in das Gebiet des Nyassa-Sees erstreckt, L. caudata Schinz in dem benachbarten Amboland und L. curyphylley Harms (Fig. 26+A) auf dem Hochland von Uhehe. Hier wächst auch um I $800 \mathrm{~m}$ die schmalblättrige L. Gracbncriand Harms. In dem Gebirgsland von Benguela sowie in dem benachbarten Ovamboland finden sich noch einige Arten mit 6-I5 cm langer Perigonröhre, wie L. odoratissima Bak. (Fig. 264 B) und L. cyanescens Bak. (Fig. 264 C). Im Gegensatz zu den vorigen Arten besitzen einige andere lange, grundständige Blätter und einen Blütenschaft, so namcntlich die von Südafrika bis Usagara zerstreute L. cruente (Lindl.) Bak. mit sechs bis zwölf blauroten, in einseitswendiger Ähre stchenden Blüten, und L. grandiffera Bak., welche von der Delagoa-Bay bis zum südlichen Nyassaland vorkommt.

\section{Fam. Musaceae.}

Die Familie der Bananengewächse ist für das tropische und das südöstliche Afrika höchst charakteristisch; ihre stattlichen Formen sind nicht bloß in den unteren hydrophilen Wäldern der regenreichen Gebiete, sondern auch im hygrophilen Gebirgsregenwald anzutreffen, während dic Bananenkultur weit über clas natïrliche Areal der Gattung Mhtsi hinaus auf den Kanaren, in Algier und Ägypten sowie im südlichen Natal $\left(30^{\circ} \mathrm{s} . \mathrm{Br}\right.$. $)$ mit Erfolg betrieben wird.

Für Afrika und Madagaskar kommen drei zu zwei verschiedenen Unterfamilien gehörende Gattungen in Betracht, die sich folgendermaßen unterscheiden:

A. Blätter spiralig. Bliiten meist dillinisch, reihenweise in den Achseln breiter Hochblätter. Bliitenhiülle homoiochlamydeisch, fünf Bliitenhiillblätter vereint, das sechste hintere frei. Beere. Samen ohne Arillus Unterfam. Musoideae. Einzige Gattung. . . . . . . . . . . . . . Musa.

3. Blätter zweireihig. Bliiten in Wickeln in der Achsel einer konkaven Bractee. Kelchblätter frei . . . . . . . . . Unterfam. Strelitzioideae. 
a) Von den drei inneren Blütenhuillblättern sind zwei erheblich größer und bilden, sich gegenseitig umfassend, ein pfeilförmiges Gebilde, das dritte unpaare ist viel kleiner und konkav

b) Von den drei inneren Blütenhüllblättern sind zwei nur wenig größer als das dritte Ravenala.

Musa L. Die großen Bananen besitzen ein Rhizom, vermüge dessen sie ausdauern, die oberirdischen mächtigen Sprosse aber sterben nach dern Verbliihen $a b ;$ in dem Bliitenstand sind die unteren Bliten weiblich, die mittleren häufig zwitterig, die oberen männlich. Ton den Blïtenhuillblättern sind fuinf in eine an der Rückseite offene Röhre verwachsen, und das sechste Perigonblatt ist frei. Fünf Staubblätter sind immer fruchtbar. das sechste nur bisweilen.
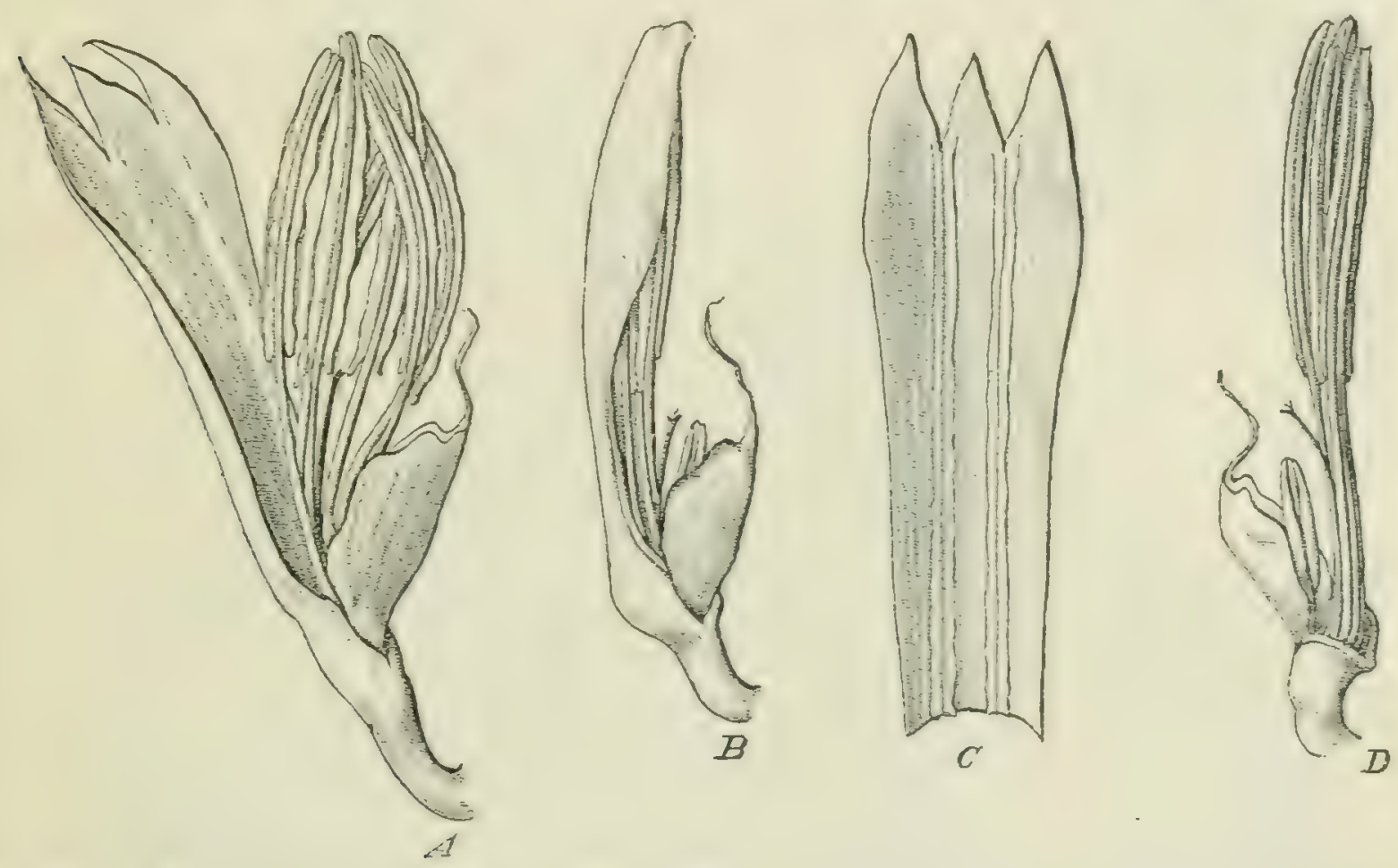

Fig. 265. Musa ensete I. F. Gmel. A Blüte geöffnet; $B$ dieselbe geschlossen, das eine Perigonblatt nur halb so lang als die fünf anderen rerwachsenen der Unterlippe; $C$ die Unterlippe; $D$ Blüte nach Entfernung der Unterlippe. - Nach K. Schumanx.

Die bekannte, langgestreckte Beerenfrucht, welche bei den kultirierten Formen meistens, aber keineswegs immer samenlos ist, enthält bei den wildwachsenden Arten kugelige oder kantige, bisweilen große Samen mit harter Schale und ohne Arillus.

Eine Untergattung Physocaulis besitzt am Grunde stark rerdickte Scheinstämme, welche nach der Entwicklung des Bliitenstandes und der Friichte absterben, sich also so verhalten wie manche Agaven und Corypluc, seltener auch der Vermehrung dienende Seitensprosse, immer in der Achsel jeder Bractee zwei Reihen von Blüten. Hierher gehören die afrikanischen Arten, M. clefhantorum $\mathrm{K}$. Schum. et Warb. mit $7,7 \mathrm{~m}$ hohem Krautstamm und bis $3 \mathrm{~m}$ langen Blattspreiten, an grasigen Abhängen ron launde in Kamerun. M. ichtricosct Welw: mit am Grunde stark angeschwollenem Krautstamm, an felsigen Orten in der Nähe ron Wasserläufen bei Pungo Andongo in Angola, Mr. Sckivini- 
furthii $K$. Schum. et Warb., im Lande der Niam Niam, am Gipfel des Baginse. Aus Ostafrika ist schon lange bekannt M. ensete Gmel. (Fig. 265, 267 F, G), eine riesige, bis $\mathrm{I} 3 \mathrm{~m}$ hohe Pflanze, deren mit rotem Mittelnerv versehene Spreiten bei $6 \mathrm{~m}$ Länge I $\mathrm{m}$ Breite erreichen; im abyssinischen Hochland in lichten Waldungen. In Usambara, besonders in Westusambara, findet sich an Abhängen und in Bachschluchten, bei Sakare noch von $\mathrm{r} 200-\mathrm{I} 300 \mathrm{~m}$, die stattliche M. Holstii K. Schum. (Fig. 266, 267 A-E), welche bei 5-6 $\mathrm{m}$ Höhe einen verhältnismäßig kurzen aber dicken Scheinstamm mit fast $5 \mathrm{~m}$ langen

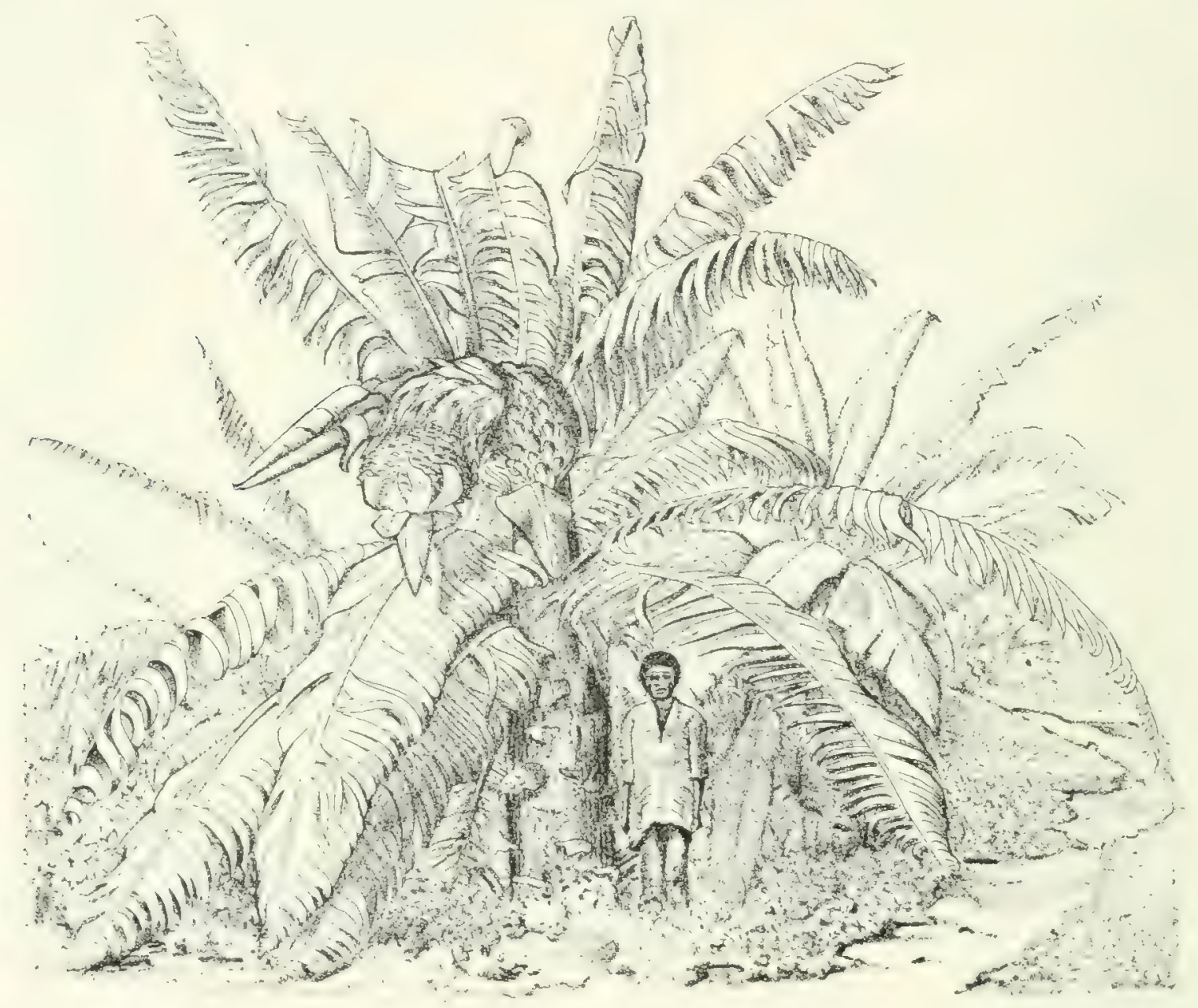

Fig. 266. Minsa Holstii K. Schum. (Westusambara). - Nach einer Photographie ron Prof. Uhlig.

Blattspreiten entrrickelt, die einen ganz feinen Wachsuberzug ausscheiden. Der Blütenstand wird I m lang. Die Friichte sind große birnfürmige Beeren mit glatten Samen, während die der M. cnsete gerippt und am Scheitel mit einer Grube versehen sind. Die Art bedeckt bei Sakare bisweilen da, wo der Wald gefällt ist, größere Flächen und vermehrt sich durch Ausläufer. Südlich ron Usambara in Ukami kommt $M$. proboscidec Oliv. vor, und aus Uluguru wurde M. ulugurensis Warb. et Moritz beschrieben, welche der $M$. Holstii jedenfalls sehr nahe steht, obwohl sie einen schlankeren Stamm besitzt.

Von M. Livingstoniana Kirk, welche einen dicken, kegelförmigen Krautstamm und kantige, warzige Samen besitzt, weiß man nur, dal sie im Nyassaland zwischen 12 und 19 ? S. B. vorkommt. Wilde Musa kommen auch in 
Ruanda ror, und es werden auch solche noch aus anderen Teilen Afrikas von Reisenden erwähnt; alle diese Angaben haben aber nicht den geringsten Wert, sofern nicht genaue Aufnahmen und Beschreibungen gemacht oder die einzelnen

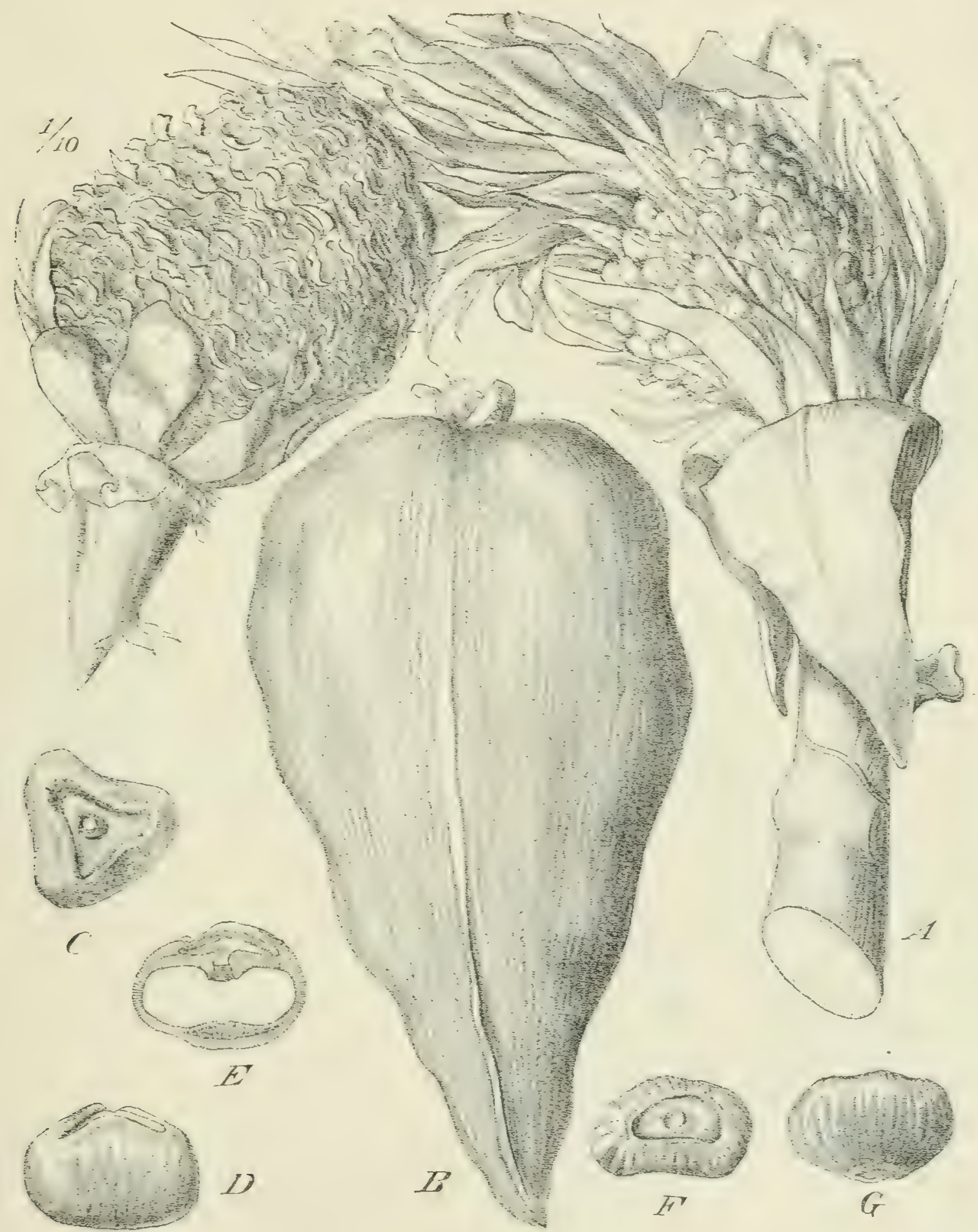

Fig. 267. Musa Holstii K. Schum. $A$ Blütenstand; $B$ Frucht; $C$ Same von unten; $D$ derselbe von der Seite; $E$ derselbe im Längsschnitt; $F, G$ Same ron Mrusa ensete. - Nach K. Schumaxx.

Teile, besonders die Bliten und Samen, zu weiterem Vergleich gesammelt werden. Daß den wilden . In $u$ s -Arten Afrikas auch von seiten der Kolonisten mehr Aufmerksamkeit geschenkt werde, empfiehlt sich wegen ihrer Bastfasern: es ist wohl anzunehmen, daß, wie sich bei M. ulugurensis eine Verwendbarkeit 
der Bastfascrn zur Herstellung ron Tauen ergeben hat, eine solche auch bei anderen Arten sich herausstellen wird.

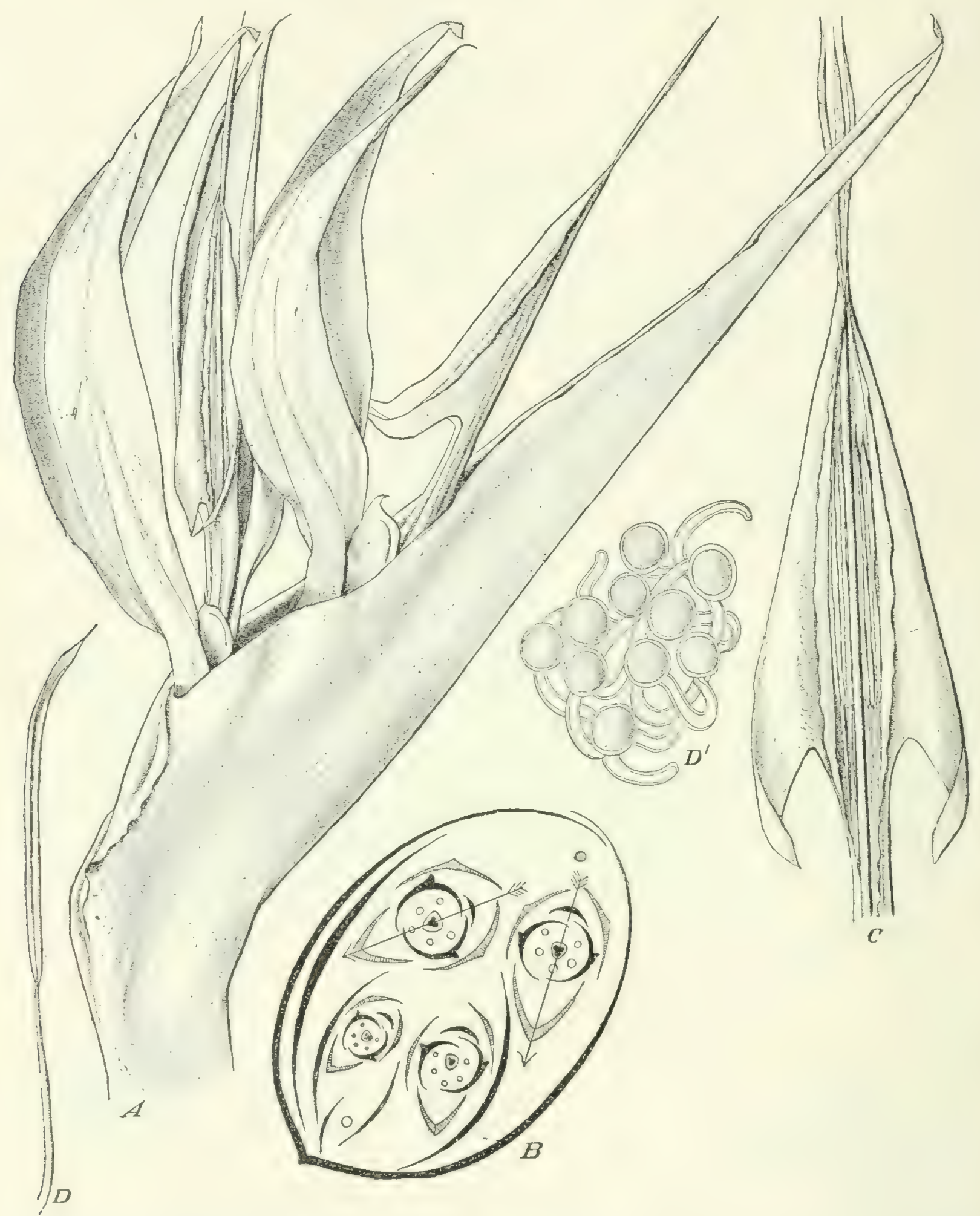

Fig. 268. Strelitzia angusta Thunb. $A$ Blütenstand; $B$ Diagramm desselben; $C$ die beiden inneren großen Perigonblätter, die Staubblätter und der Griffel mit den drei Narben; $D$ Staubblatt; $D^{\prime}$ Pollen. - Nach K. SciuUmann.

Strelitzia I3anks. Die in ihrer Größe sehr verschiedenen Arten stimmen außer in der Zweizeiligkeit der Blattstellung noch darin uiberein, daß ihre Blüten 


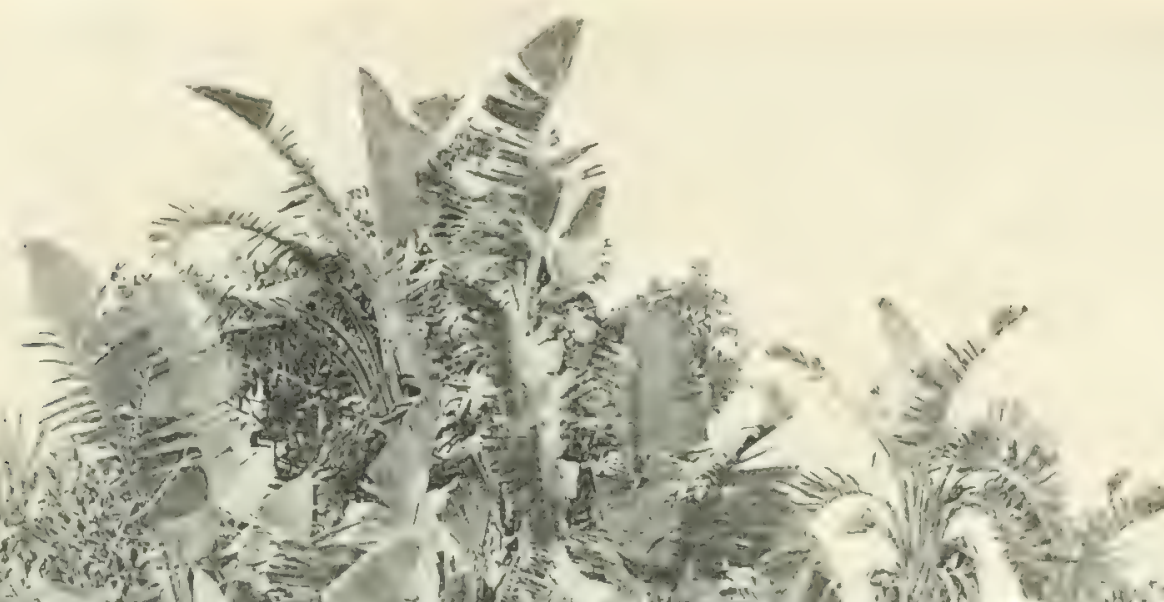

Ter

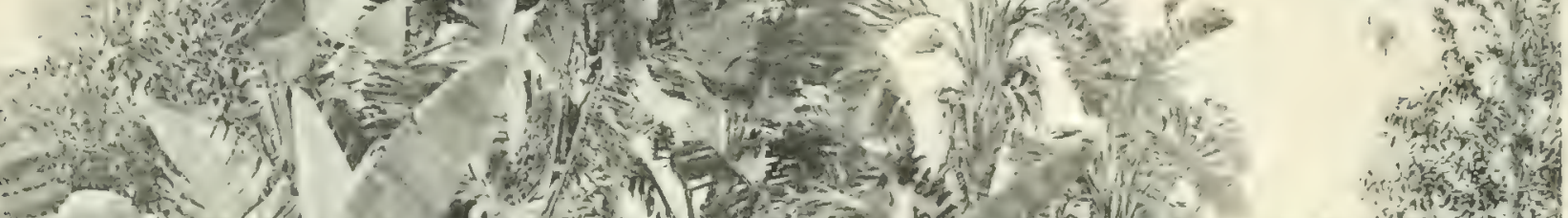

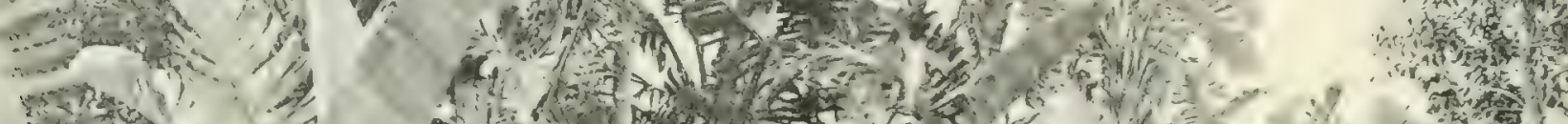

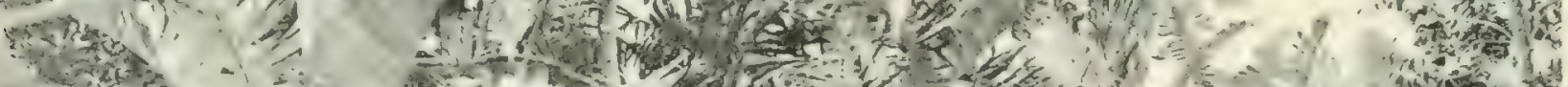

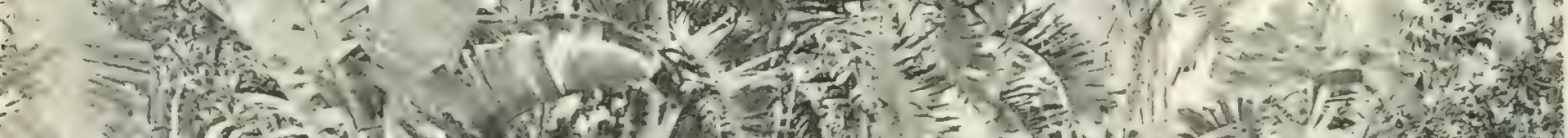

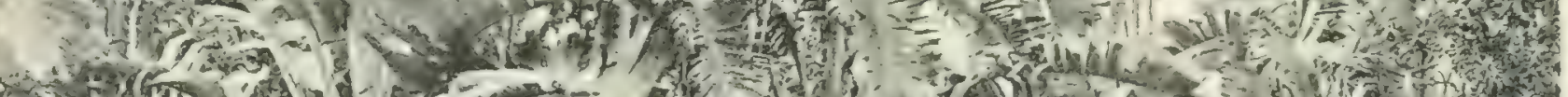

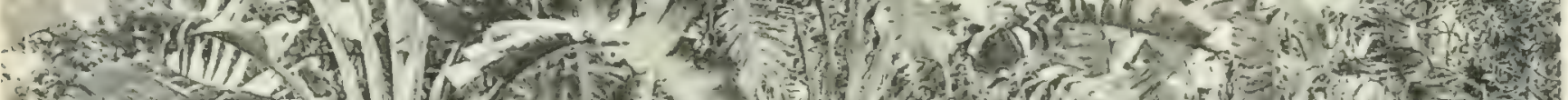

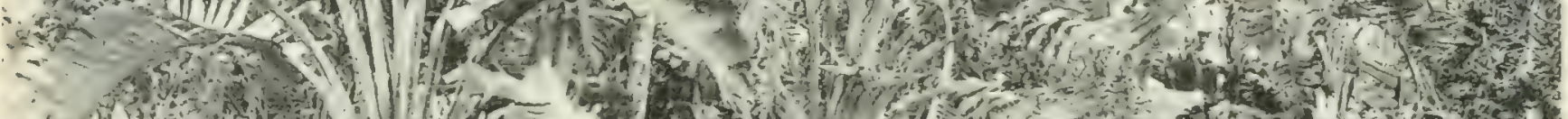
3.t.

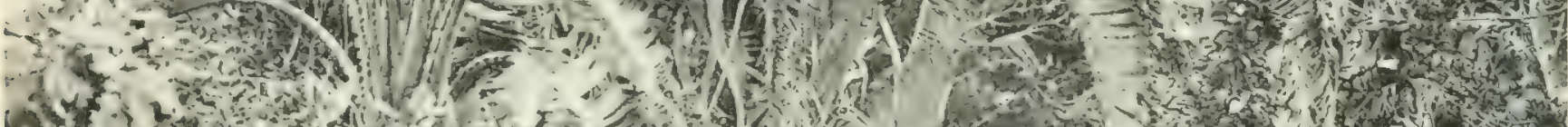

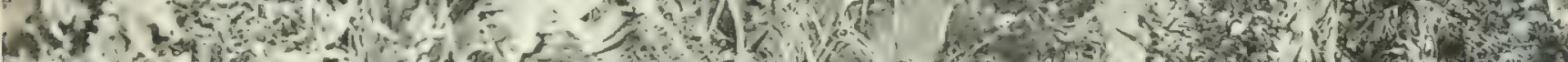

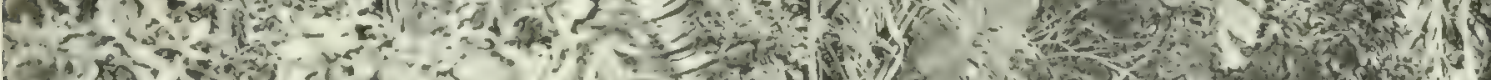

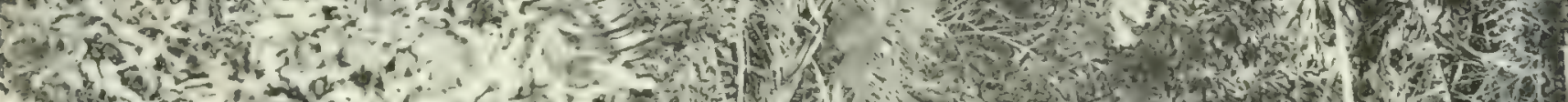

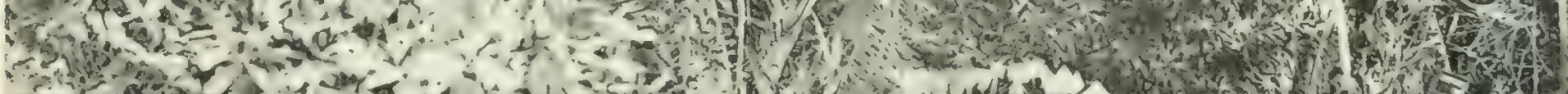

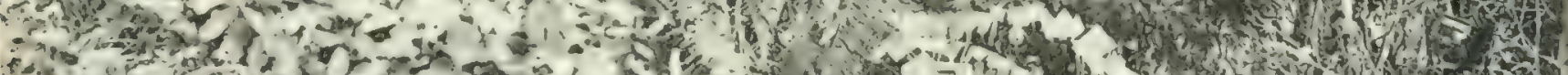
1.

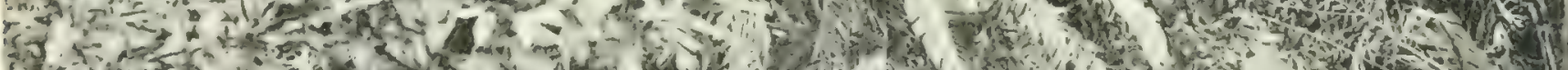
P.

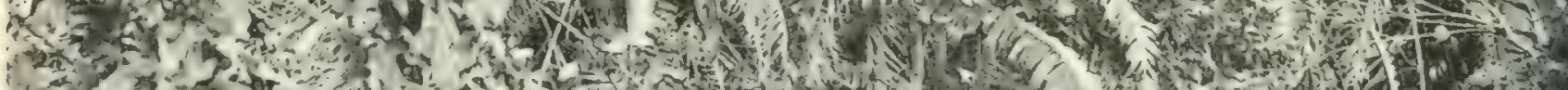

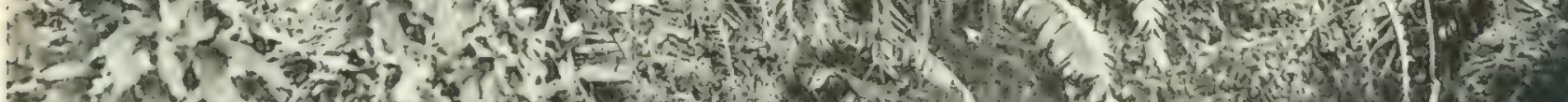

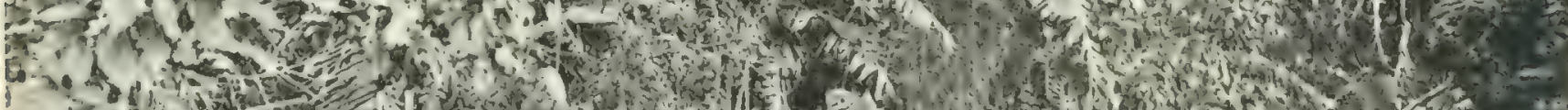

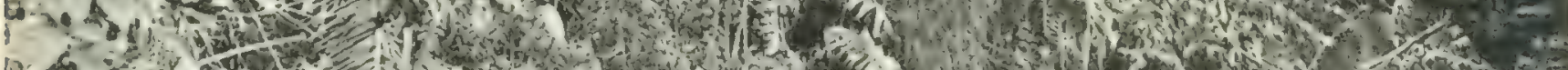

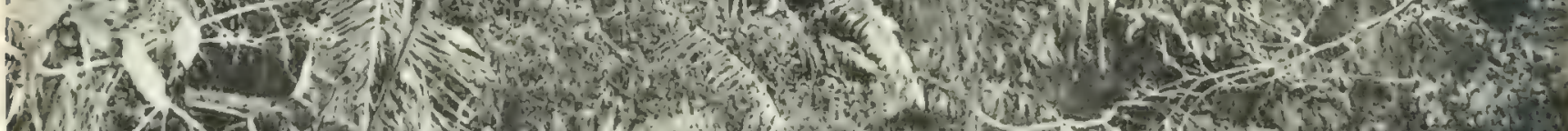

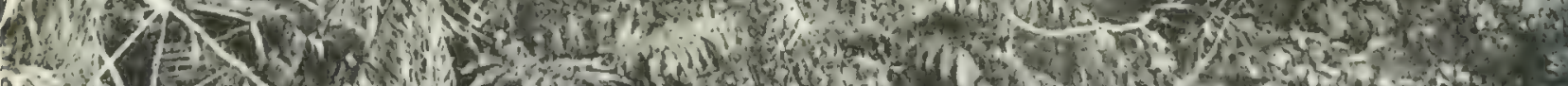

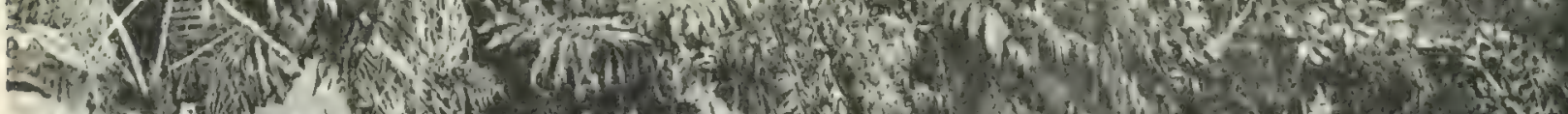

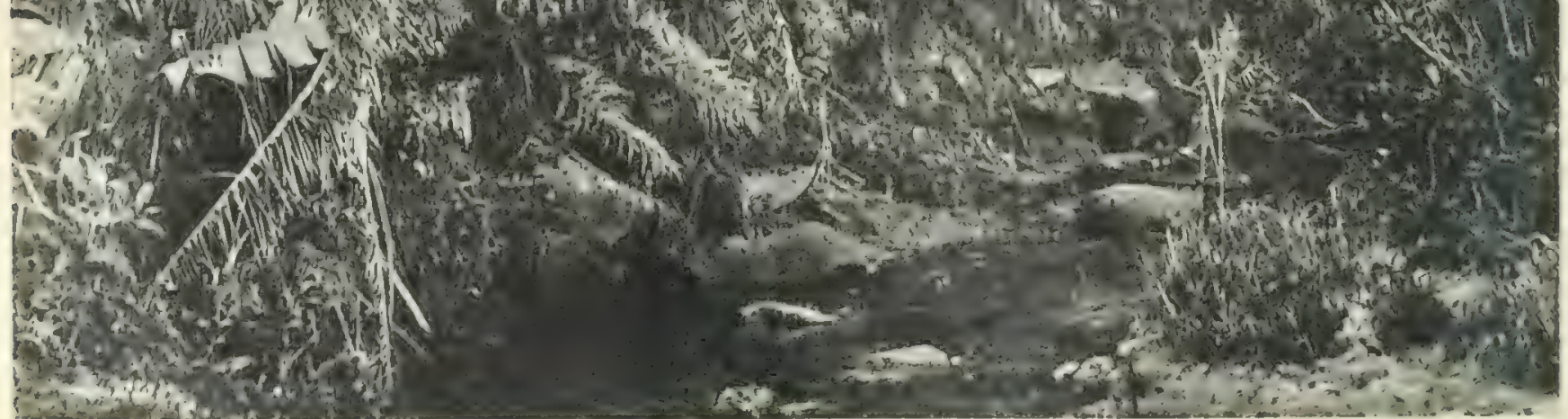

Strelitzia augusta Thunb. 
in Wickeln stehen, welche von einer großen, gefürbten Bractee gestiitzt sind und entweder einzeln stehen oder zu mehreren eine dichte ithre bilden (Fig. 268).

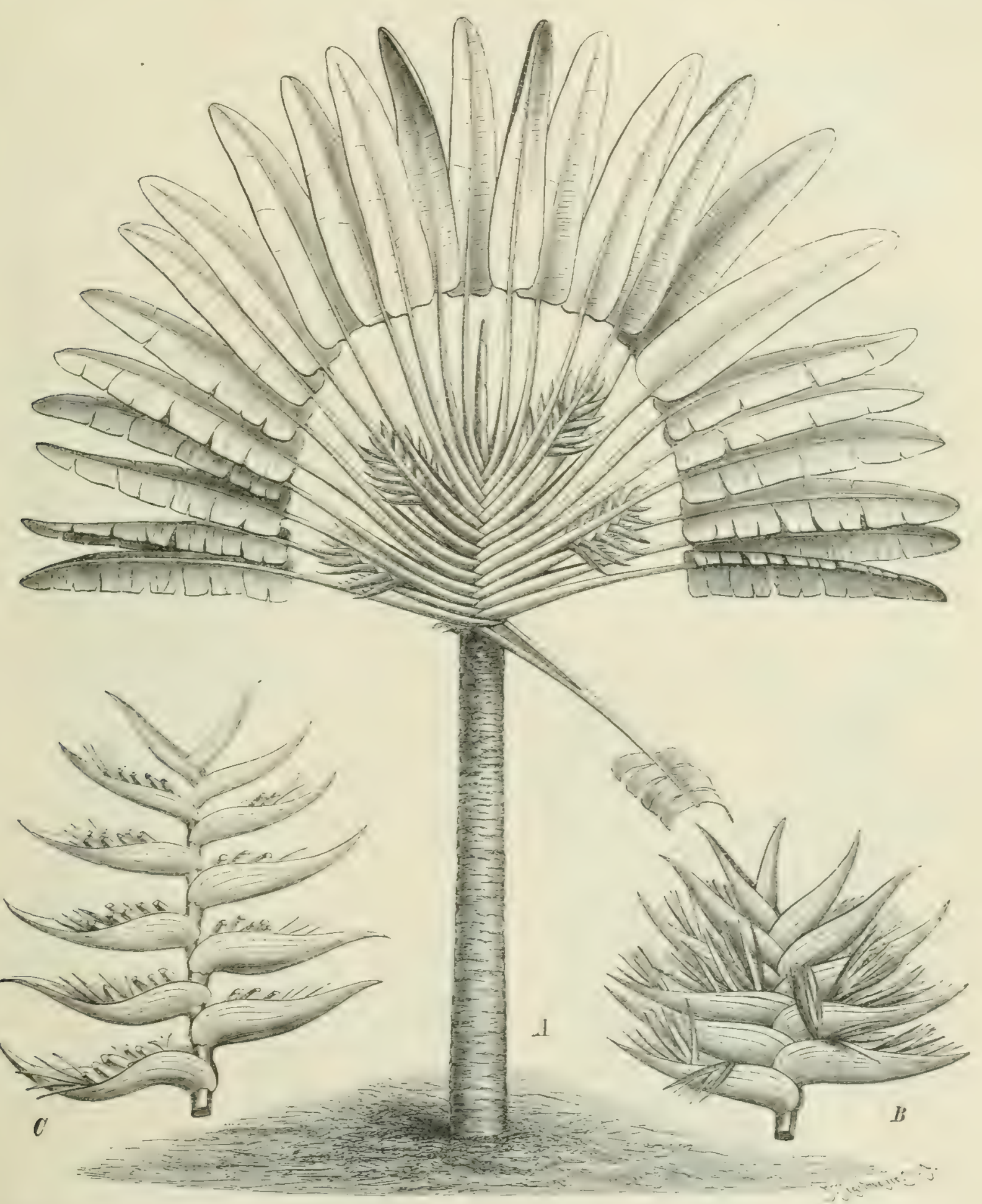

Fig. 269. Ravenala madagascariensis Sonn. $A$ Habitus; $B$ Inflorescenz; $C$ Fruchtstand. Nach L. C. RICHARD.

Die vier bekannten Arten gehören dem südlichen und üstlichen Kapland an. Eine besonders stattliche Art ist St. angusta Thunb. Fig. 208', welche in den Küistenwäldern Natals, namentlich zwischen Durban und Umkomas, sehr häufig ist und oft die $+-5 \mathrm{~m}$ hohen Gehölze dieser VTaldformation uiber- 
ragt: auch in den höher gelegenen Wäldern habe ich sie bis zu einer Höhe von $300 \mathrm{~m}$ ii. $\mathrm{MI}$. gesehen. Die oft $5 \mathrm{~cm}$ großen Blïtenstände mit den großen roten Bracteen und weißen Bliiten sind prachtvoll und sehr auffallend, zudem

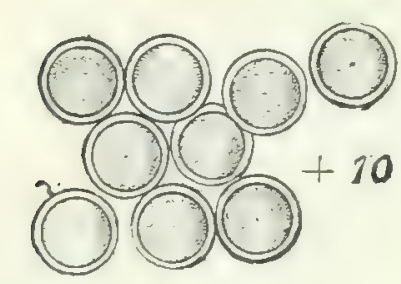

B
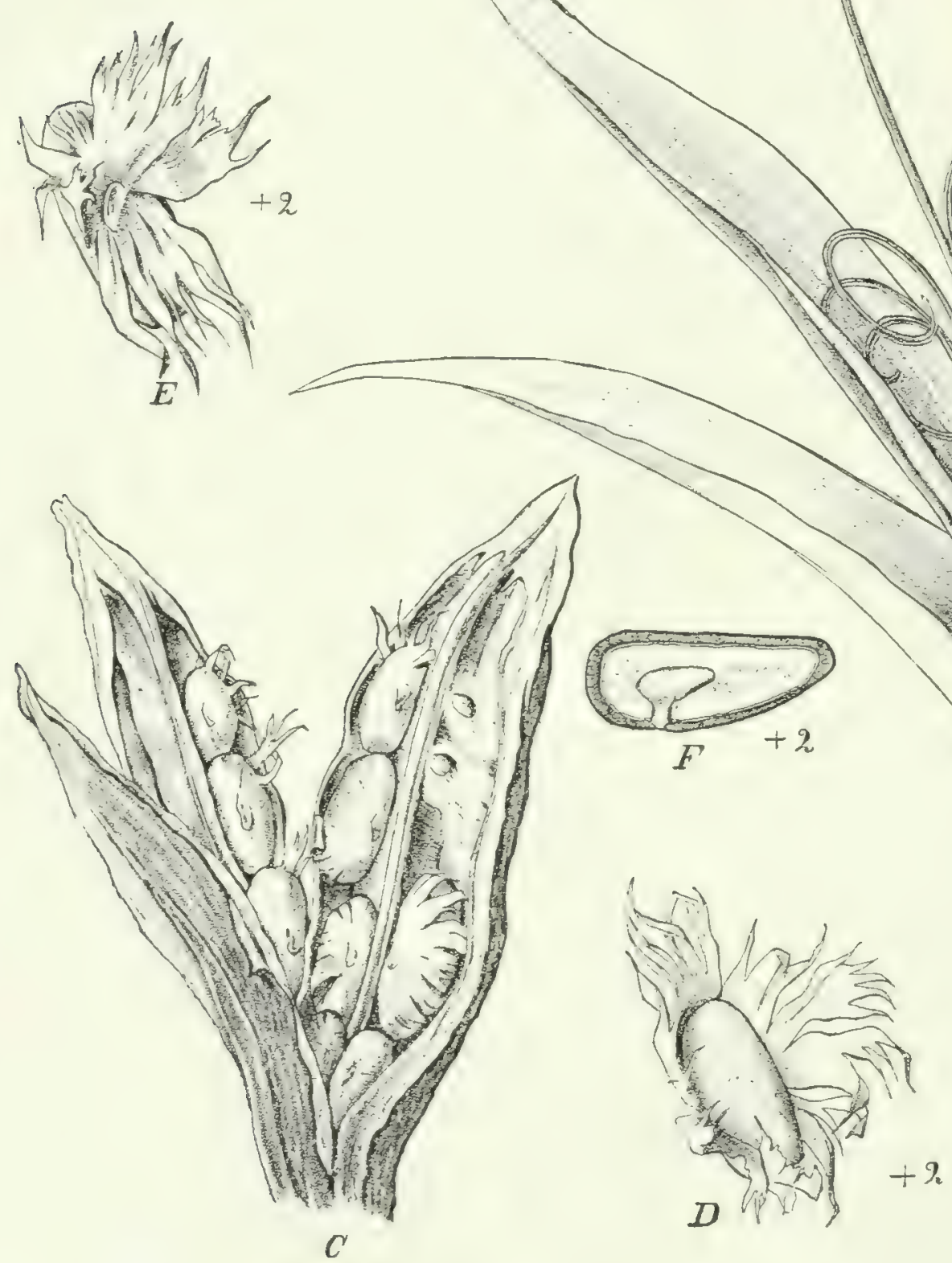

Fig. 270. Ravenala madagascariensis Sonn. $A$ Blüte; $B$ Pollen; $C$ Kapsel; $D$ Same; $E$ Arillus; $F$ Same im Längsschnitt mit dem Embryo. - Nach K. Schumann.

sehr reich an Honig, der, wie auch bei. Musa, am oberen Teil des Fruchtlnnotens abgeschieden wird. Cynniridenvïgel, welche auch bei Mnsa als Befruchter beobachtet worden sind, iibernehmen auch hier die Befruchtung und 
beriihren, indem sie sich auf die beiden großen I3lumenblätter (Fig. 268 C) setzen und dieselben herunterdrïcken, mit ihrem Bauch die ausstäubenden Antheren. Der St. augusta ziemlich ähnlich ist St. Vicolai Regel et Koern. mit am Grunde stumpfen Spreiten, rotbraunen Bracteen und blassen, scitlichen Blumenblättern. Nur einen kurzen Stamm und mit dem Stiel nur etwa I $m$ lange Blätter besitzt St. reginae Banks, welche im siidöstlichen Kapland bei Albany und Uitenhage an felsigen Abhängen wächst. Noch mehr xerophytisch ist St. parífolia Dryand, im südöstlichen Kapland bei Port Elisabeth wachsend, mit schmal lanzettlichen Spreiten; bei ihrer Varietät juncca Bot. Reg. geht auch diese verloren, und der spreitenlose Stiel erinnert an die Blätter von Sansericria cylindrica. Diese Arten haben seitliche blaue und im übrigen gelbe Blumenblätter.

Ravenala Adans. Interessant ist, daß mit Strelitaic die bis $30 \mathrm{~m}$ Höhe erreichende Raicnala madagascaricnsis Sonn. verwandt ist, daß aber die in der Hylaea, in Para und Guiana vorkommende kleinere $R$. guicuncusis (L.C. Rich.) Benth. den suidafrikanischen Strelitzien noch etwas näher steht. $R$. madagascaricnsis, welche in Parkanlagen der Tropen als riesige Zierpflanze häufig angepflanzt wird, bedeckt in Madagaskar von der Küste bis $600 \mathrm{~m}$ ï. M. oft ganze Abhänge und kommt noch bis $1600 \mathrm{~m}$ in den Bergwäldern vereinzelt vor. Sie fällt namentlich auch zur Fruchtreife durch die großen, hellblauen Arilli der Samen auf; bei den Strcliticia ist der Arillus gelb, bei Husa fehlt ein solcher ganz. Pflanzengeschichtlich ist es von der größten Bedeutung, da $\beta$ die so eigenartige Unterfamilie der Strclitsioidcae in Guiana, im südöstlichsten Afrika und in Madagaskar vertreten ist.

\section{Fam. Zingiberaceae.}

Meist megatherme Hydrophyten und Hygrophyten, einige Subxerophyten.

Die Vertreter dieser Familie sind zwar im tropischen Afrika nicht so zahlreich wie im Monsungebiet, aber sie sind doch in den unteren Waldformationen, namentlich an etwas feuchten Plätzen, bisweilen tonangebend und kommen auch noch in Gebirgsregenwäldern vor; sie wachsen nicht selten gesellig.

Bezüglich des Blütenbaues sei fiur den Laien bemerkt, daß auf drei Kelchblätter drei Blumenblätter folgen und da $\beta$ von den Staubblättern nur eins fruchtbar ist, während die anderen entweder fehlen oder in blumenblattartige Staminodien umgewandelt sind. Namentlich ist zu beachten, daß das in der Bliite sehr auffallende lippenfürmige Gebilde, das sogenannte Labellum, aus zwei vereinten Staminodien gebildet ist.

Die afrikanischen Gattungen verteilen sich folgendermaßen auf die Gruppen der Familie:

A. Blätter zweireihig. Seitenstaminodien verschieden oder fehlend. Nektardriisen vorhanden und polymorph. Pflanzen aromatisch

Unterfam. Zingiberoideae. 
a) Fruchtknoten dreifächerig. Seitenstaminodien petaloid, ron der Beschaffenheit des Labellums . . . . . . . . . . . . . . Hedychieae. Einzige afrikanische Gattung. . . . . . . . . Kaempferia.

b Fruchtknoten dreifächerig. Seitenstaminodien klein oder fehlend

Zingibereae.

( $)$ Labellum oft dreilappig. Anhängsel des einzigen fruchtbaren Staubblattes sehr groß, zusammengerollt und den Griffel einschließend. Oft in Afrika kultiviert, im Monsungebiet heimisch. . . . . . Zingiber officinale Roscoe (Ingwer).

3. Labellum niemals dreilappig. Anhängsel der Anthere nicht zusammengerollt oder fehlend.

I. Blithende Sprosse and Laubsprosse gesondert.

I. Ähren dichtblütig, mit großen, lederigen, dachig angeordneten Bracteen

Aframomum.

2. Ähren lockerblütig. In Afrika kultiviert, im Monsungebiet heimisch

Elettaria cardamomum Maton (Kardamome).

II. Laubsprosse mit Blütenstand endigend

Renealmia.

B. Blätter spiralig. Seitenstaminodien meist ganz fehlend. Nektardrüsen fehlend. Oherirdische Teile der Pflanzen nircht aromatisch . L'nterfam. Costoideae. Einzige Gattung

Costus.

\section{Hedychieae.}

Kaempferia L., im Nonsungebiet reich vertreten, auch in Vorderindien nicht fehlend, zählt in Afrika elf Arten, welche alle der endemischen Untergattung (Zicnkou'skiz angehören. Beistehende Abbildung (Fig. 2jI gibt eine Vorstellung von den blühenden Pflanzen. Auf den ersten Blick'wird es befremdlich erscheinen, dals die in der Abbildung Fig. 2 - I $A, D$ und $E$ hervortretenden. grol3en. kironenartigen Gebilde nicht die eigentliche Blumenkrone, sondern blumenblattartige Staminodien darstelien, welche unten verwachsen sind. (Näheres bei K. Schumann in Englers Pflanzenreich IV. 46 (20. Heft) S. 18); die Blumenkrone repräsentieren die unter der Rühre stehenden drei lanzettlichen Abschnitte und den Kelch das abgestutzte, unterste Blattgebilde. Die einzelnen Arten ron Krempfiriu wachsen unter ziemlich rerschiedenen Verhältnissen, teils in Buschgehölzen steppenartiger Gebiete, teils auf feuchtem Boden. Drei Arten entwickeln ihre lïnglichen Blätter gleichzeitig mit den Bliitensprossen, darunter $A$. rosed Schweinf., wclche rom Ghasalquellengehiet his Beira in Grassteppen oft massenhaft vorkommt, ferner K. Kirkii Hook. f. K. Schum., welche an der Sansibarkuiste vorkommt. Unter den Arten, deren Blätter nach der Bliitezeit sich entwickeln, fällt $K$. pleiantha $K$. Schum. durch $1-2$ dm lange, fuinf- his sechsblitige 13litenzweige auf: sie findet sich auf sumpfigen Wiesen am Kongo und seinen Nebenflüssen. Bei den anderen Arten sind die Blütenstiinde verkiirzt: eine prächtige, grolıbliitige Art mit purpurfarbenen Blïten, aher bis zur Mitte gelbem Labellum und mit $3,5-5,5 \mathrm{~cm}$ langem Anhang des Connectirs ist $K^{-}$. aethicofica Solms l Benth., die rerbreitetste Art, ron Sennaar ( $15^{\prime \prime} \mathrm{n}$. Br.) und Kalabat suidwärts verbreitet bis zu den Morambalabergen bei Mossambik, vielfach im Gebirgsbusch his zu $1000 \mathrm{~m}$ ü. MI., dann über den Tschadsee his Senegambien und Ober-Guinea. auch bei Malandsche in Angola. 
Sehr ährilich ist $K$. Detricurci de Wild. et. Dur. am Marioe im Kongogebiet, ferner $K$. Ethclae I. M. Wood im IIaschonaland und dem angrenzenden Massikessi (Port. Ostafrika). Kleincre violette Blüten und sehr kleinen Connectivfortsatz haben $K$. brachystemon $\mathrm{K}$. Schum, in den unteren Uferwäldern Usambaras, sowie $K^{-}$macrosiphon Bak. in der Steppe bei Mombas. Sehr auffallend und noch weiterer Beachtung wert ist dic bei Inanda in Natal vorkommende $K$. natalensis Schlechter et K. Schum. (Fig. 27 I E, F), deren Blüten diöcisch sind und bei welcher in den weiblichen Bliten außer dem Labellum und zwei seitlichen Staminodien von einer durch diese Staminodien gebildeten Röhre noch zwei lange genagelte Staminodialbildungen ausgehen, welche dem bei den zwitterbliitigen Kümpferien vorhandenen, fercilen Staubhlatt entsprechen.

Aframomum K. Schum, von der im Monsungebiet reich vertretenen Gattung Amomum hauptsächlich dadurch verschieden, daß die beiden seitlichen Abschnitte des dreilappigen Connectiv-Anhängsels dreieckig sind und spreizen oder pfriemenförmig und oft gekrümmt sind, die Frucht aber eine große, eifürmige Beere, nicht eine trockene, dreiklappige Kapsel darstellt. Die to Arten sind alle hydrophil und wachsen immer in großen Mengen gesellig, da sie in Waldsümpfen und an Bachufern sich durch die unterirdischen Rhizome reichlich vermehren. Ihre Laubsprosse erreichen oft eine ganz bedeutende Länge, so bei dem im Kongogehiet in der Nähe ron Chimbete rorkommenden A. Laurentii (de Wild. et Dur.) K. Schum. $4 \mathrm{~m}$ Höhe und bei dem in Gabun wachsenden $A$. gigantenn (Oliv, et Hanbury) K. Schum. mehr als $6 \mathrm{~m}$; bei den meisten Arten werden die Stengel bis $2 \mathrm{~m}$ lang. Die Hauptmasse der Arten findet sich von Sierra Leone bis Gabun. Von diesen sind besonders wichtig A. mclegueta (Roscoe) K. Schum. (Fig. $273 M-P$ ), die Stammpflanze der aromati:chen, früher als Gewürz geschätzten »Grana paradisi", welche von Sierra Leone bis Angola vorkommt, und das von Sierra Leone bis zum Niger verbreitete A. grannm paradisi (Hook.) K. Schum. (Fig. 273 G, H), welches irrtiimlich für die Stammpflanze dieses Gewïrzes gehalten wurde. In Togo wurde bis jetzt nur eine Art aufgefunden, im Kongogebiet und in Angola auch nur einige. Wir kennen ferner drei Arten aus dem Ghasalquellengebiet und als südöstlichste $A$. ambesiacmn (Bak.) K. Schum. vom MIt. Zomba im Süden des Nyassa-Sees aus einer Höhe von $1400 \mathrm{~m}$ ii. M. Auch in Deutsch-Ostafrika finden sich einige Arten in Gebirgsregenwäldern, nämlich $A$. Zimmemannii K. Schum. in Irangi, A. msala K. Schum. und A. crassilabizm K. Schum. in Usambara. Am Himo unterhall des Kilimancscharo gegen Taweita und wahrscheinlich auch in Uluguru findet sich A. angustifolium (Sonn.) K. Schum. (Fig. $273 A-C$ ), eine bis $4 \mathrm{~m}$ hohe Art, die auch auf der Insel Sansibar (wahrscheinlich rerwildert), auf Mauritus angepflanzt. den Serchellen und Madagaskar in Sümpfen rorliommt. Dieser Art steht auch cas im Ghasalquellengebiet in Gallericwäldern von Niam-Niam sehr häufige und $5 \mathrm{~m}$ hohe A. sanguintum $\mathrm{K}$. Schum. nahe. Außer dieser kommen dort noch zwei andere Arten vor. Nur die Früchte und Samen kennt man ron ciner im Somalihochland bei Tumhe unter 9? n. Br. vorkommenden Art, A. korarima Pereira. 


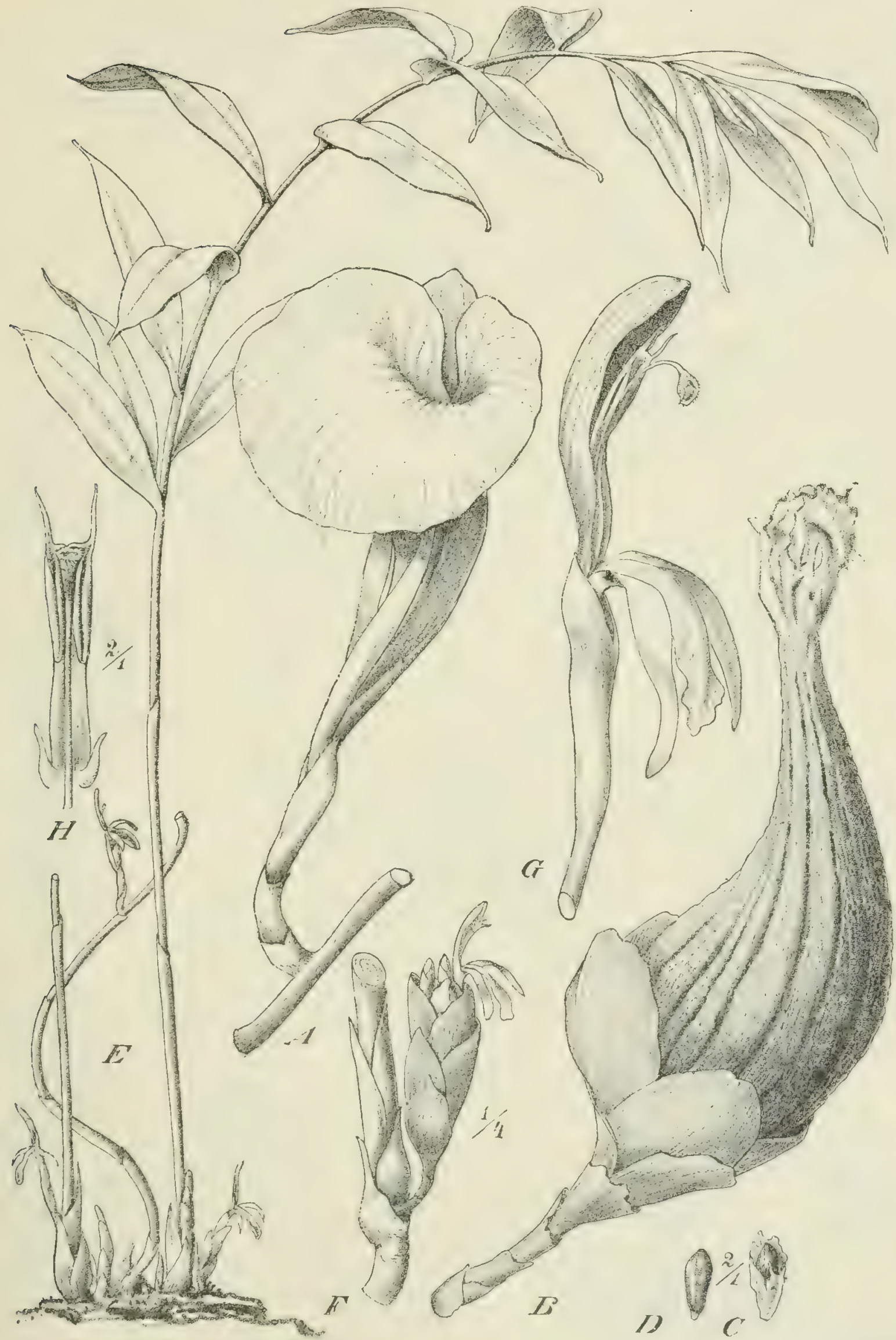

Fig. 272. Aframomum sulcatum (Oliv, et Hanbury) K. Schum. (Liberia). $A$ Blütenstand; $B$ Beere; $C$ Same mit Arillus; $D$ Some ohne solchen. E A. Hanburyi K. Schum. (Kamerun, Fernando Po). $F-H$ A. Baumannii K. Schum. (Togoland, Misahöhe). $F$ Blütenstand; $G$ Blüte; $H$ Staubblatt. Nach K. Schiumann. 


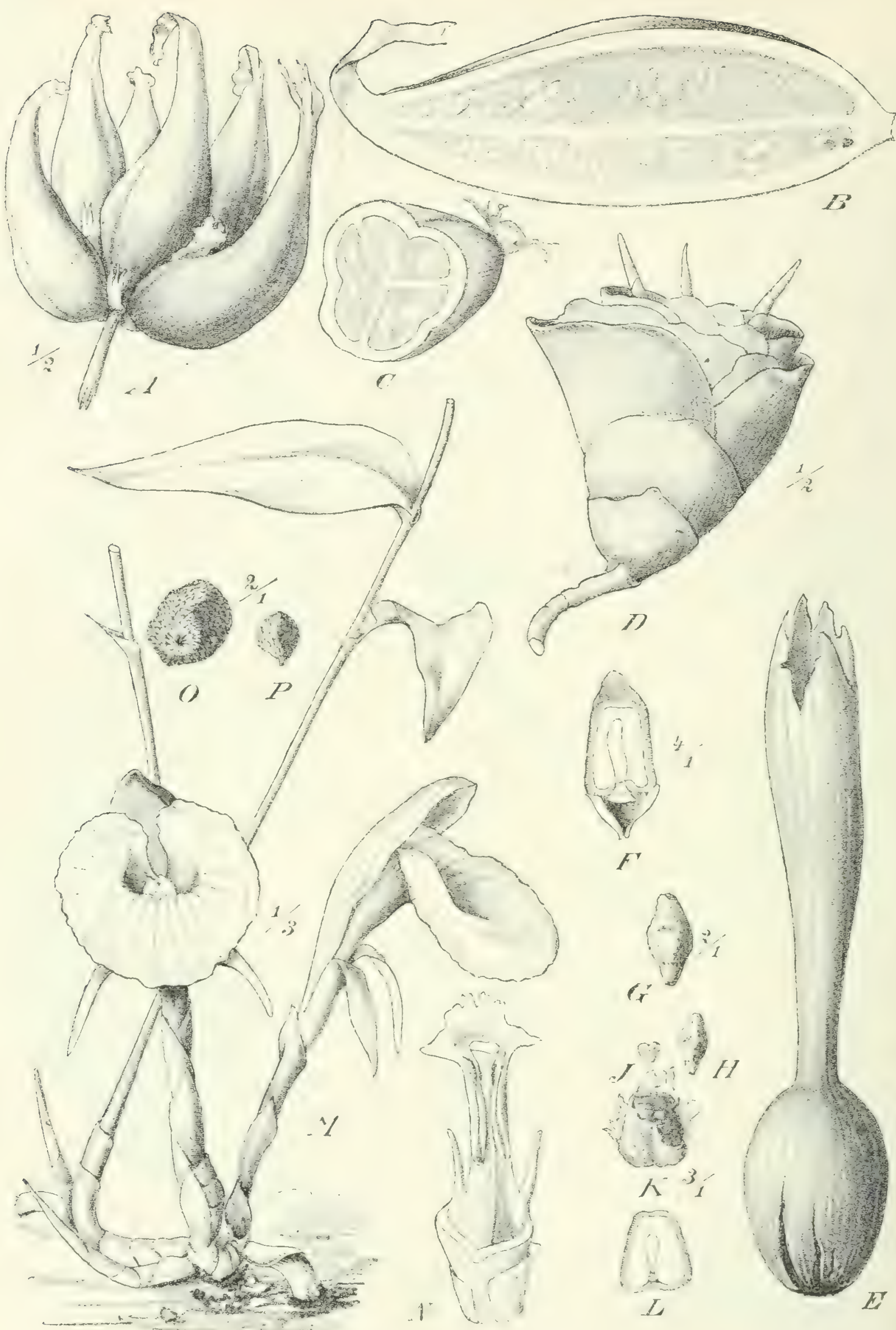

Fig. 273. $A-C$ Aframomum angustifolium (Sonn.) K. Schum. $A$ Beeren; $B$ eine solche im Längsschnitt; $C$ dieselbe im Querschnitt. $D-F$ A. citratum (Pereira) K. Schum. (Kamerun). $D$ Inflorescenz; $E$ Beere; $F$ Same im Längsschnitt. $G, H$ A. granum paradisi (Hook.) K. Schum. F-L A. meleguetella K. Schum. (Sierra Leone). Same. M-P A. melegueta (Roscoe) I. Schum. $A$ Habitus; $N$ Andröceum; $O$ Same vergr.; $P$ derselbe in nat. Gr. - Nach K. Schumanv. 


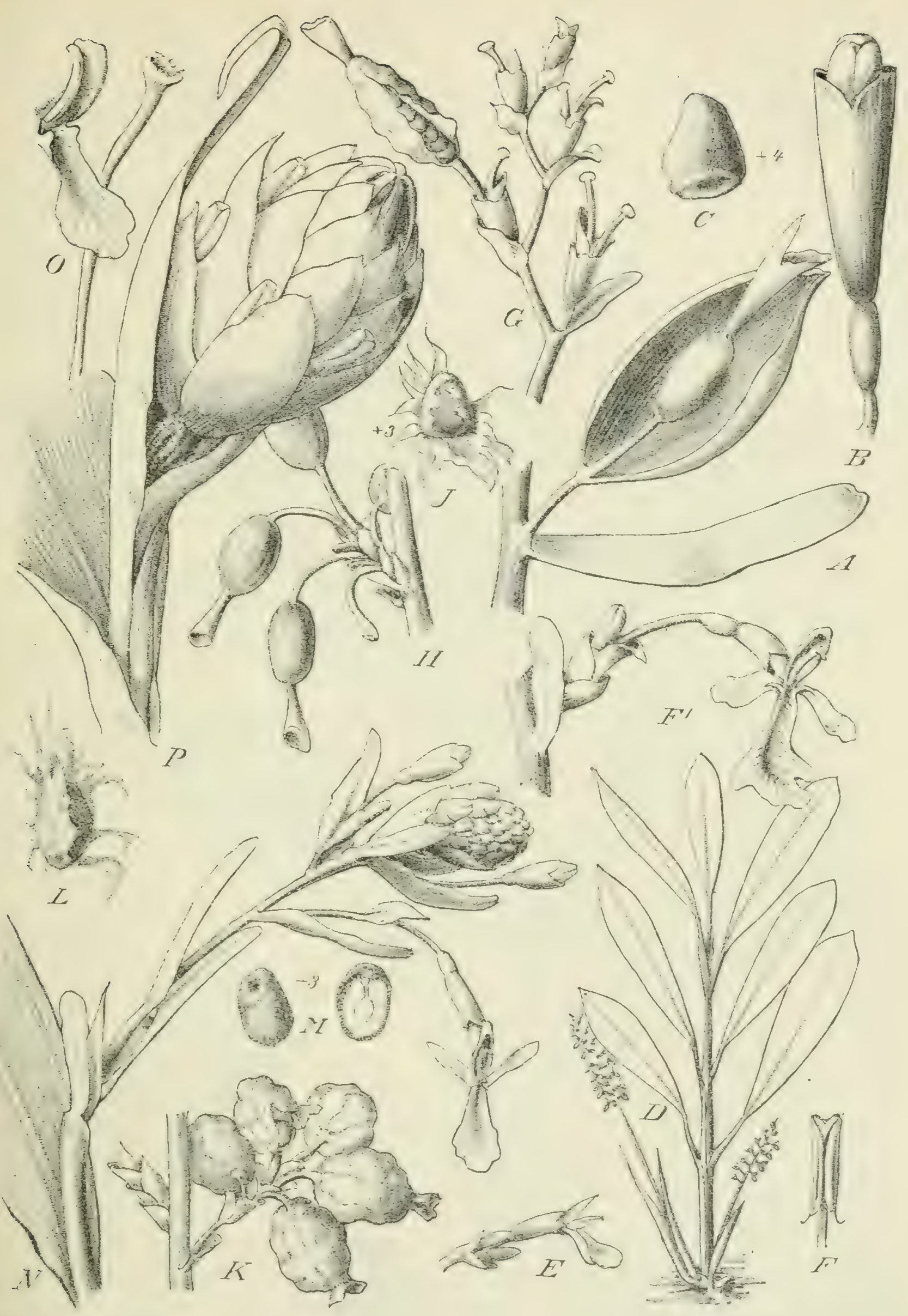

Fig. 274. Renealmia. $A-C$ R. brasiliensis K. Schum. (Rio de Janeiro, Minas Geraes). $A$ Blüte mit Vor- und Tragblatt; $B$ Knospe; $C$ Same. $D-F$ R. macrocolea K. Schum. $D$ Habitus, verkleinert; $E$ Blite; $F$ Staubblatt. $F, G$ R. cincinnata (K. Schum.) Bak. (Kamerun, Gabun). $H, \mathcal{F}$. Dewewrei Dur. et de Wild. Lukolela im Kongogebiet. $H$ Frucht; 7 Same. $K-M$ R. occidentalis (Swartz) Sweet (WVestindien, Brit. Guiana, Columbien). Frucht und Same. $N, O$ K. racemosa (L.) A. Rich. (Antillen) $N$ Inflorescenz; $O$ Staubblatt mit Labellum. $P$. R. strobilifera Poepp. et End1. (Columbien, Costa Rica, Venezuela). - Nach K. Schumaxw. 
Renealmia L. wird von voriger Gattung leicht dadurch unterschieden, daß bei einigen Arten die Inflorescenzen am Ende von Laubsprossen stehen, bei allen aber die flache Anthere ron lieinem Anhängsel des Connectivs oder von nur einem sehr kurzen ïberragt wird. Ton besonderem pflanzengeographischem Interesse ist, daß eine größere Zahl von Arten im tropischen Amerika vorkommt. Endständige Inflorescenzen treffen wir bei $R$. Battcnlorgiana Cummins im Lande der Aschanti und $R$. longifolia K. Schum in Liberia. Dagegen hahen viel mehr Arten besondere Bliitenschäfte, und zwar sind die afrikanischen von den sich ebenso verhaltenden amerikanischen durch ein stark hervortretendes Labellum unterschieden. Die Zahl der im Kamerungebiet (einschließlich St. Thomas und Fernando Po) vorkommenden Arten beträgt acht; im unteren Kongogebiet finden sich drei und in Togo bei Nisahöhe eine Art, R. macrocolea K. Schum. (Fig. 274D-F). Sehr interessant ist aber, daß auch in Ostusambara im Gebirgsregenwald zwei Arten vorkommen, von denen hauptsächlich R. Engleri K. Schum. um Amani bei $950 \mathrm{~m}$ häufig ist.

\section{Costoideae.}

Costus L. Diese teils niedrigeren, teils sehr hohen, krautigen Gewächse besitzen nicht selten spiraling gedrehte Stengel mit in gekrimmter Linie dicht stehenden Blättern, deren \pm ciförmige Spreite kurz zugespitzt ist. Die gclb, rot, orangefarben gefärbten oder weißen Blïten stehon in dichter Ähre, welche entweder am Laubsproß cndständig ist oder einem Niederblattsproß angehört. Die Bliten fallen besonders auf durch das sehr große, meist ungeteilte Labellum, welches das verbreiterte Staubblatt mit der in der Mitte der Spreite ansitzenden Anthere umgibt. Die Arten dieser besonders in Amerika und Afrika reichlich rertretenen Gattung lieben besonders feuchte Standorte in der Nähe ron Bächen der wärmeren Teile Afrikas; in den Gebirgen scheinen sie nicht über $1000 \mathrm{~m}$ aufzusteigen; wie die Afrommmum bilden auch sie bisweilen Bestände. Der Untergattung Fiucosłus gehören hohe, lrräftige Formen an, bei denen die Blätter oft spiralig leiterfurmig nach der Divergenz ${ }^{\mathrm{H}}{ }^{\prime}{ }^{\mathrm{B}}$, angeordnet sind. Hierher gehören etwa ró Arten des tropischen Westafrilia von Senegambien bis Angola: besonders große Formen sind (: I)ezitu'tri de Wild. bei Chinganga am Kongo, $3 \mathrm{~m}$ hoch, der von Kamerun bis zum Kongo vorkommende C. Lucanusianus K. Schum. (Fig. 275), oft ïber $2 \mathrm{~m}$ hoch, der $2-3 \mathrm{~m}$ hohe, von Senegambien bis Sierra Leone verbreitete C. afer Ker, der $2,5 \mathrm{~m}$ hohe C. anomocaly. K. Schum. bei Misahöhe in Togo. Die größte Art von allen ist C. gigantcus Welw, auf den Inseln St. Thomas und Principe, an den Fluissen ron 600-900 m iiber $;$ m hohe Bestände bildend, auch ausgezeichnet durch einen ellipsoidischen, If $\mathrm{cm}$ langen und $9 \mathrm{~cm}$ dicken Bluitenstand mit blutroten Bracteen und gelbem, gefranstem Labellum. Es scheint, daß diese Art auch in Kamerun vorkommt, doch wird noch weiter Material zu sammeln sein. Zwei Arten finden sich auch im Lande der Niam-Niam, ferner C. samentosus Boj. an Bächen in Sansibar, C. subbiflorus K. Schum. in Lichtungen und an Bachufern Ost- und Westusambaras recht häufig bis zu $1000 \mathrm{~m}$ ii. MI., C. ulugurensis K. Schum. im Ulugurugebirge. Die Untergattung Hitucistus, welche sich durch cine 
am Laubstengel entstehende, hängende Inflorescenz auszeichnet, enthält nur zwei Arten von Gabun und dem unteren Kongo. Zur Untergattung Epi-

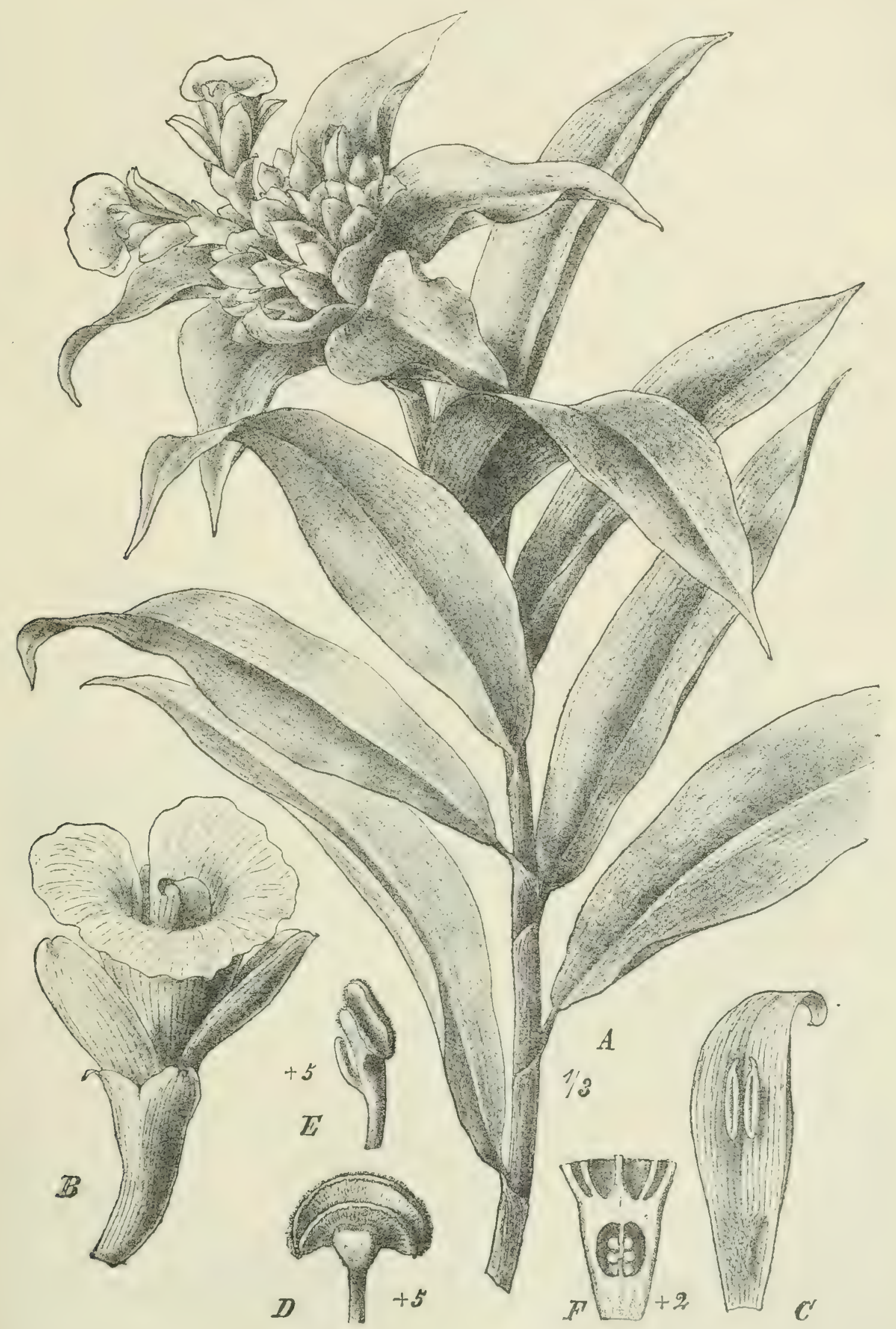

Fig. 275. Costus Lucanusianus K. Schum. $A$ Pflanze, ${ }^{\mathrm{T}} / 3$ n. Gr.; $B$ Blüte; $C$ Staubblatt; $D$ Griffelspitze; $E$ dieselbe von der Seite; $F$ Längsschnitt durch den Fruchtknoten. - Nach Schlechter. 
costus gehören außer einer in Guiana vorkommenden Art vier von Kamerun und drei von Gabun; es sind zum größeren Teil (mit Ausnahme des terrestrischen C. Tappenheckiamus, epiphytische Pflanzen, deren Laubstengel meist nur $0,5 \mathrm{~m}$ hoch wird, während der Bliitenstengel eine kurze Ähre mit wenigen, bläulich ođer rötlich gefärbten Bliten trägt; sie wachsen meist in sumpfigen Waldlichtungen der regenreichsten Gebiete; C. bicolor J. Braun et K. Schum. kommt auch auf Berggipfelin der Bangwa-Station von I foo- $1500 \mathrm{~m}$ vor. - Zur Untergattung Cadalacna gehören drei afrikanische und mehrere brasilianische Arten, dic an einem meist kurzen oder gestauchten Stengel mit

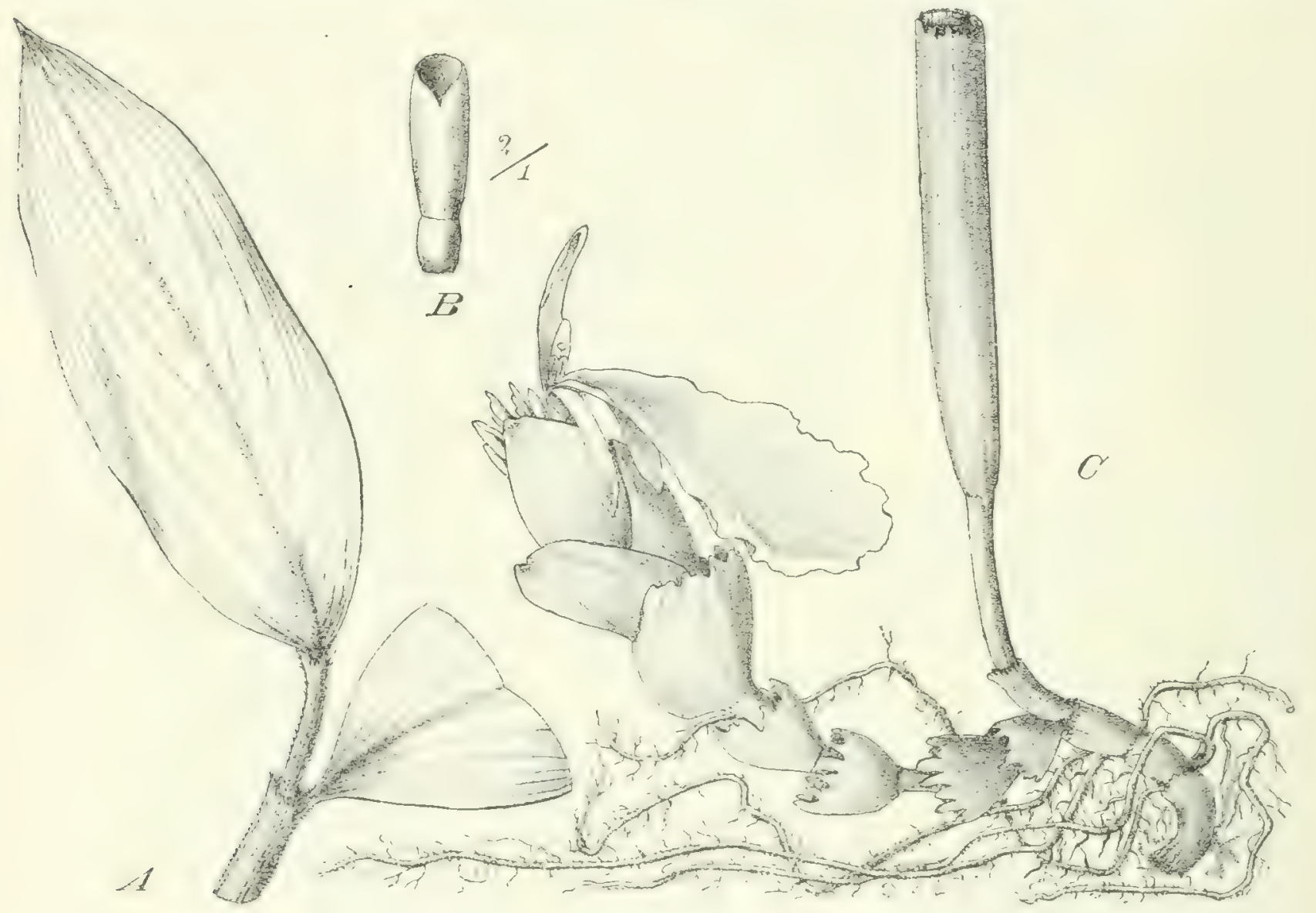

Fig. 276. C. nemotrichus K. Schum. (Kamerm, Groß-Batanga). - Nach K. Schumann.

einer sehr kurzen, kopfähnlichen Ähre gelber Blïten abschließen, die von den Laubblättern umhïllt ist. Außer C. pistiifolius (Gagnepain) K. Schum. bei Malandsche in Angola gehören zu dieser L'ntergattung noch C. spuctalilis : Fenzl; K. Schum., der von Fazogl in Kordofan-Sennaar an Flußufern bis zum Djurland, dann im unteren Usambara, ferner in Senegambien, auf St. Thomas und am Kongo vorkommt, also eine der weitest verbreiteten Arten, und C.macranthus K. Schum. (Fig. 277 A, im nördlichen Nyassaland und den Noramballagehirge, von $600-950 \mathrm{~m}$. Endlich ist noch eine kleine Untergattung Paracostzis zu nennen, mit kriechenden Stengeln, welche nur ein bis wenige Laubblätter und einen kurzen Bliitenstand tragen; hierher gehört C. Englcrianus K. Schum. $($ Fig. $277 B)$ von Sierra Leone und Kamerun, merkwuirdigerweise einer Art Borneos nahestehend. 


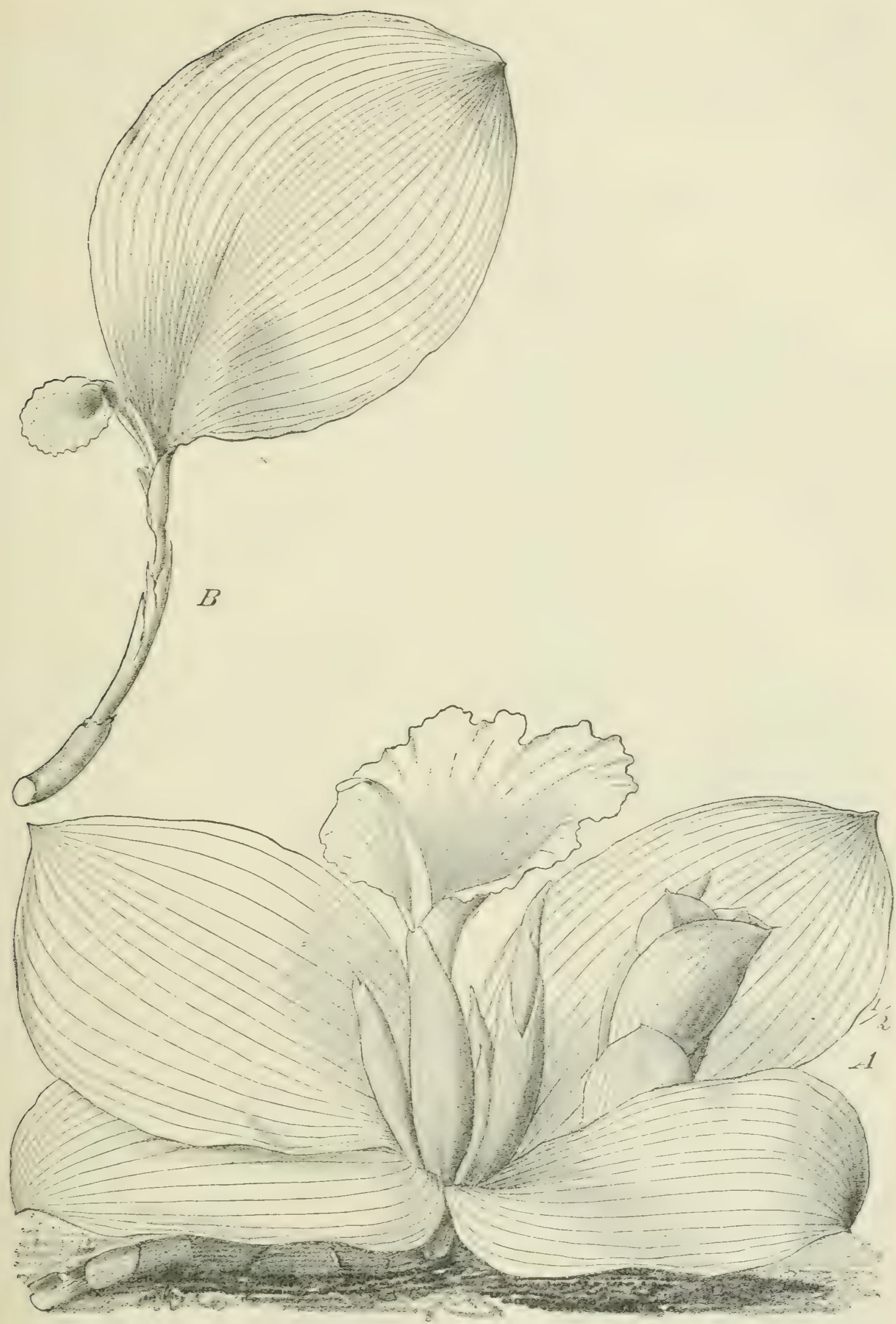

Fig. 277. A Costus macranthus K. Schum.; B; C Englerianus K. Schum. - Nach K. Sunumiv. 


\section{Fam. Cannaceae.}

Ton Camna, der im tropischen Amerika mit vielen Arten vertretenen, einzigen Gattung der Familie, hat eine Art, C. indica L. mit der Subspecies C. orientalis Roscoe, im ganzen Monsungebict und an feuchten Standorten des tropischen Afrika von Senegambien bis Angola und ron Mombassa bis Natal cine weite Verbreitung gewonnen. Da sie eine außerordentlich beliebte und leicht zu kultivierende Zierpflanze ist, so ist wohl anzunehmen, daß sie mit Hilfe des Menschen verbreitet wurde.

\section{Fam. Marantaceae.}

Alle Hydrophyten.

Diese Familie ist für die hydrophilen Formationen des tropischen Westafrika von noch größerer Bedeutung als die Zingibcraceac, wenigstens ist die Zahl der in Betracht kommenden Gattungen noch größer, als bei der Schwesterfamilic; auch giht es keine einzige Art, welche nicht hydrophil wäre, und endlich ist bis jetzt noch keine Art auBerhall des westafrikanischen Waldgebietes und des Ghasalpuellengebietes nachgewiesen worden. Die rerwandtschaftlichen Bezichungen zu der Marantaceenflura des tropischen Asien sind schwächer, als zu der des tropischen Amerika; vor allem aber macht sich ein starker Gattungsendemismus geltend.

\section{Übersicht der in Afrika vorkommenden Gattungen.}

A. Fruchtknoten deutlich dreifächeriç; aber dic Samenanlage in zwei Füchern abortierend

a) Blïtenpaare mit kleinen, verdickten, fast drüsigen Vorblättern versehen; die Bracteen abfällig.

(i) Blätter homodrom. Frucht glatt.

I. Blütenstand endständig, rispig. Frucht nicht gefligelt. . . . . Sarcophrynium.

II. Blütenstand am Rhizom, kurzährig. Frucht dreifügelig . . . Thaumatococcus.

3) Blätter antidrom. Frucht spitz warzig.

I. Kapsel aufspringend, Samen mit lamellösem Arillus. . . . . Hybophrynium.

II. Kapsel nicht aufspringend. Samen ohne Arillus . . . . . Trachyphrynium.

b) Bliitenpare ohne Vorblätter.

r) Blitenpaare einzelu; Blütenstand ährenförmig. Bracteen ausdauernd. Frucht eine Caryopis .

Halopegia.

B) Blïtenpare zwei oder mehr.

I. Calloses Staminodium sehr groß und so lang wie die äußeren oder länger. Ährige Inflorescenz aus dem Rhizom hervortretend . . . . . . . Afrocalathea.

II. Calloses Staminodium kitrzer als die äußeren. Inflorescenz in der Mitte des Laubsprosses oder am Ende solcher.

I. Blïtenstand kopfförmig. Deckblätter bleibend. . . . . . . . Phrynium.

2. Blitenstand traubig oder rispig. Deckblätter abfallend...... Clinogyne.

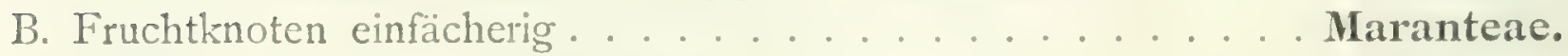

a) Zwei Staminodien. In Afrika kultiviert. . . . . . . . . . . . . Maranta.

b) Nur ein Staminodium. Deckblätter abfällig. . . . . . . . . . . . Thalia.

\section{Phrynieae.}

Sarcophrynium K. Schum. sind am Grunde beblätterte Kräuter mit endständiger Rispe und ungefligelten Friichten, meist $1{ }^{1} / 2-2 m$, selten $+\mathrm{m}$ hoch. 
Die elf Arten dieser Gattung finden sich von Liberia an bis zum unteren Kongo sehr häufig in Waldsümpfen und an Bächen, an denen S. brachy'stachy'un (Koernicke) K. Schum. bisweilen allein die Vegetation zusammensetzt. 3-4 m hohe Dickichte bilden S. oxy'carpum K. Schum. und S. adcnocarpum K. Schum. in Kamerun.

Thaumatococcus Benth., von voriger Gattung durch ährigen Blïtenstand am Ende eines Grundsprosses verschieden, ist mit einer Art, T. Daniellii (Benn.) Benth. (Fig. 278), in Sierra Leone, dem unteren Nigergebiet und auf den Kamerun vorliegenden Inseln vertreten.

Hybophrynium K. Schum. Während bei den erstgenannten Gattungen die Blätter am Stengel alle homotrop sind, sind sie bei dieser und der folgenden antitrop; auch zeigen beide ein warziges Ovarium und ebensolche Frucht. H. Brannianum K. Schum. (Fig. 279A-F), eine zuletzt halbstrauchige, spreizklimmende Pflanze mit weißen Blumenkronen, bildet in den unteren Wäldern von Sierra Leone bis Angola und bis zum Ghasalquellengebiet oft ein dichtes Unterholz.

Trachyphrynium Benth., von voriger Gattung durch nicht aufspringende Kapsel und das Fehlen eines Arillus unterschieden, zerfällt in zwei Untergattungen, von denen Lasiodelplyys durch behaarten Fruchtknoten und bleibende Bracteen gekenntzeichnet ist. Dahin gehören $T$. Danckelmannianum Joh. Braun etK.Schum. (Fig. $279 L, M$ ) in Kamerun und Gabun und T. Liebrechtsiamem De Wild. et Dur. im Kongogebiet. Bei der zweiten Untergattung sind die Fruchtknoten zwar warzig, aber glatt und die Bracteen abfällig.

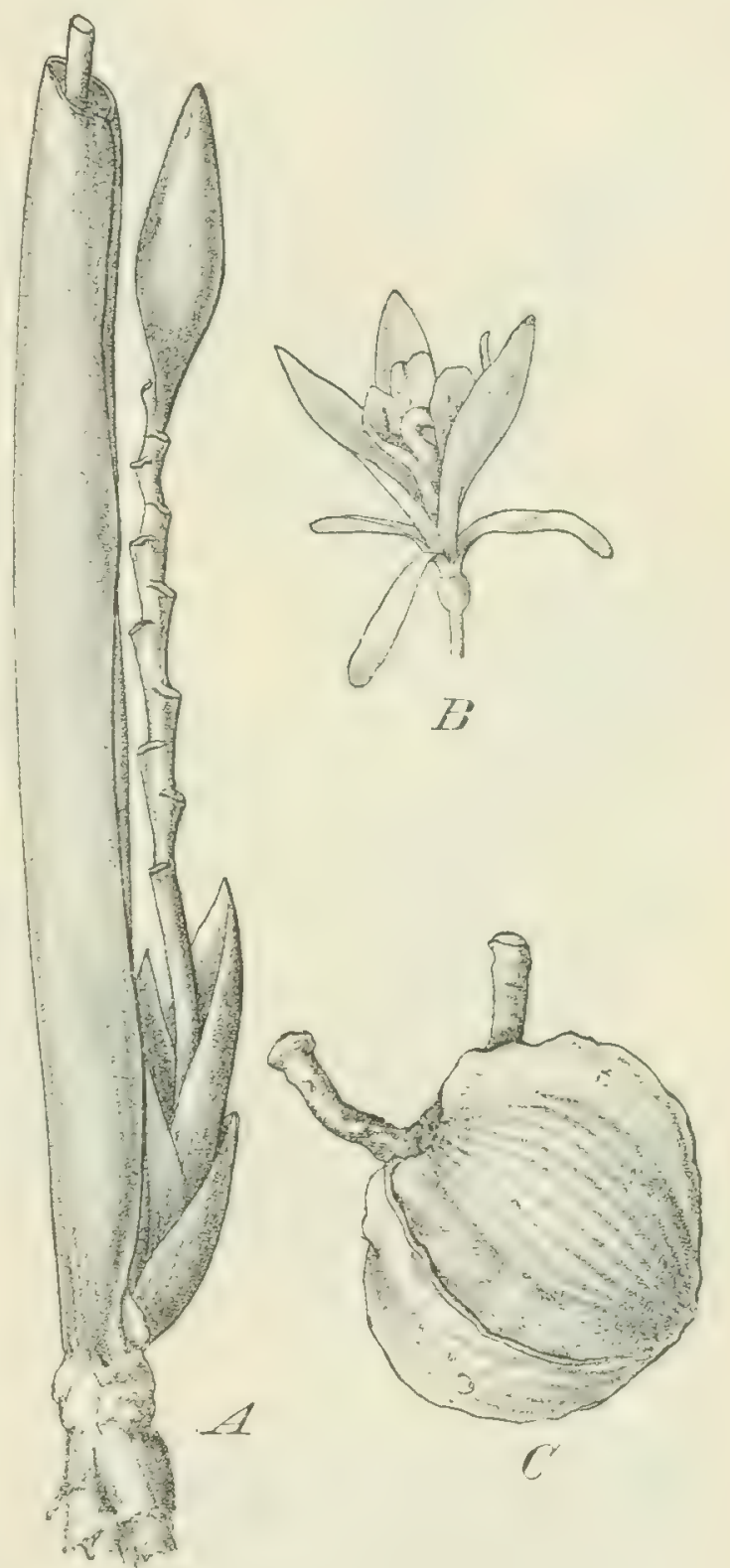

Fig. 278. Thaumatococcus Daniellii (Benn.) Benth. $A$ Bliitenstand; $B$ Blite ; $C$ Frucht. Nach K. Schumann.

T. Zcnkerianm in Kamerun, T. violacenn Ridley (Fig. $279 N$ ) von Kamerun bis Angola, T. Pogrecontum K. Schum. (Fig. $279 G-K$ ) im Baschilangegebict sind die hierher gehörigen Arten, welche sich beziiglich ihres Vorkommens so wie Hybophryninum verhalten. T. Zcnkcrianum K. Schum. klettert $10 \mathrm{~m}$ hoch.

Halopegia K. Schum. und die folgenden drei Gattungen zeichnen sich vor den besprochenen dadurch aus, daß die Blütenpaare keine Vorblätter besitzen. Zudem stehen bci dieser Gattung die Blütenpaare einzeln in der Achsel jeder 


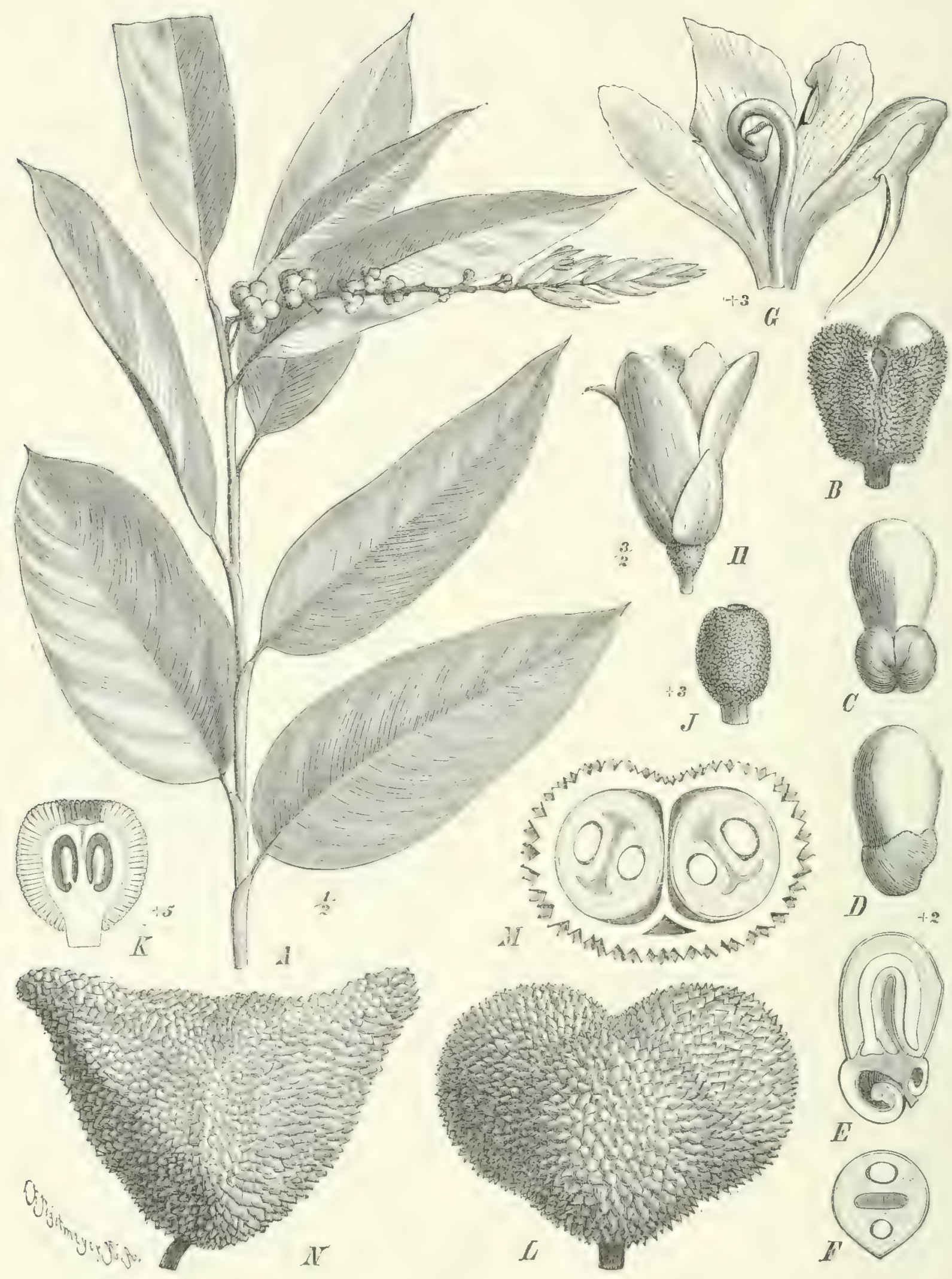

Fig. 279. A-F Hybophrynium Braunianum K. Schum. A Habitus; $B$ Kapsel; $C$, $D$ Same vom Riicken und von der Seite; $E, F$ derselbe im Längs- und Querschnitt. $G-K$ Trachyphrynium Poggeanum K. Schum. $G$ Andröceum aufgeschnitten und ausgebreitet; $H$ Blìte; F Fruchtknoten; $K$ derselbe im Långsschnitt. $L, M T$. Danckelmannianum $K$. Schum. $L$ Kapsel; $M$ eine zufälligerweise zweilappige Kapsel im Querschnitt. $N$ T. violaceum Ridley, Kapsel. - Nach K. Schumann. 
Bractee und die Frucht ist eine Caryopsis. Sie sind schilfähnliche Sumpfgewächse. Merkwürdig ist, daß die in Sümpfen Westafrikas und des NiamNiamlandes rorkommende $H$. a zurea K. Schum. (Fig. 28 I $P-R$ ) drei Verwandte in Java, auf den Andamanen und in Hinterindien besitzt.

Afrocalathea rhizantha K. Schum. (Fig. 280) ist ein Kraut mit kriechendem Rhizom und mit Stengeln, die nur ein langgestieltes Laubblatt mit eilanzettlicher Spreite tragen und mit besonderen Blütensprossen. Die Pflanze wächst in schattigen Wäldern Südkameruns und Gabuns.

Phrynium Willd. Die zwei afrikanischen Arten sind abgesehen ron Bliitenunterschieden gegenüber der vorigen Gattung dadurch charakterisiert, daß der kopfige Blütenstand am Laubstengel steht. P. confertum (Benth.) K. Schum. mit blauen Blüten und P. Mannii (Benth.) K. Schum. mit weißen Bliiten finden sich im Kamerungebiet, erstere auch noch in Angola, an humusreichen, schattigen Waldplätzen und bis $1000 \mathrm{~m}$ ü. M. aufsteigend, letztere eine 2,6 $\mathrm{m}$ hohe Pflanze an sumpfigen Bachrändern auf Fernando Po.

Clinogyne Benth. Reichverzweigte Halbsträucher mit gestielten Blättern und mit traubiger oder rispiger Inflorescenz, deren Bracteen nicht wie bei Phryninm ausdauern, sondern abfallen. I 8 Arten sind bereits in den Sümpfen und an den Bachufern der westafrikanischen Urwälder von Sierra Leone bis zum Kongo nachgewiesen worden; von diesen kommt die bis $4 \mathrm{~m}$ hohe C. Schweinfurthiana K. Schum, nicht bloß von Sierra Leone bis Kamerun, sondern auch im Ghasalquellengebiet, im Lande der Djur und Niam-Niam vor; außer dieser nach Osten vorgedrungenen Art verdient noch C. ugandcnsis K. Schum. genannt zu werden, welche in Uganda westlich vom Victoria Njansa häufig ist. Eine $+\mathrm{m}$ hohe Art ist auch die in Togo und Kamerun häufige C. lencantha K. Schum. (Fig. 28 I $E-M T$ ). Die übrigen Arten sind nur $\mathrm{I}-2 \mathrm{~m}$ hoch oder niedriger; aber alle sind gesellig.

Maranta L. ist tropisch amerikanisch; aber $M$. anmdinacea L. (Fig. 28I $B-D, 282$, welche wegen ihrer stärkereichen Rhizome in allen tropischen Ländern kultiviert wird, rerwildert auch häufig in Afrika; ich fand sie auch in einem Waldsumpf von Ostusambara unweit Kwamkoro.

Thalia L. Diese Gattung enthält sieben Arten, meist hohe Sumpfgerrächse mit grauem Wachsreif, gestielten, aus breiterer Basis nach oben stark verschmälerten Blättern und lockerer, reichblütiger Rispe, die alle in Amerika heimisch sind, von denen aber die weitrerbreitete Th. grcuiculata L. auch im ganzen westlichen Afrika häufig und ïber das Kongogebiet auch bis in das 

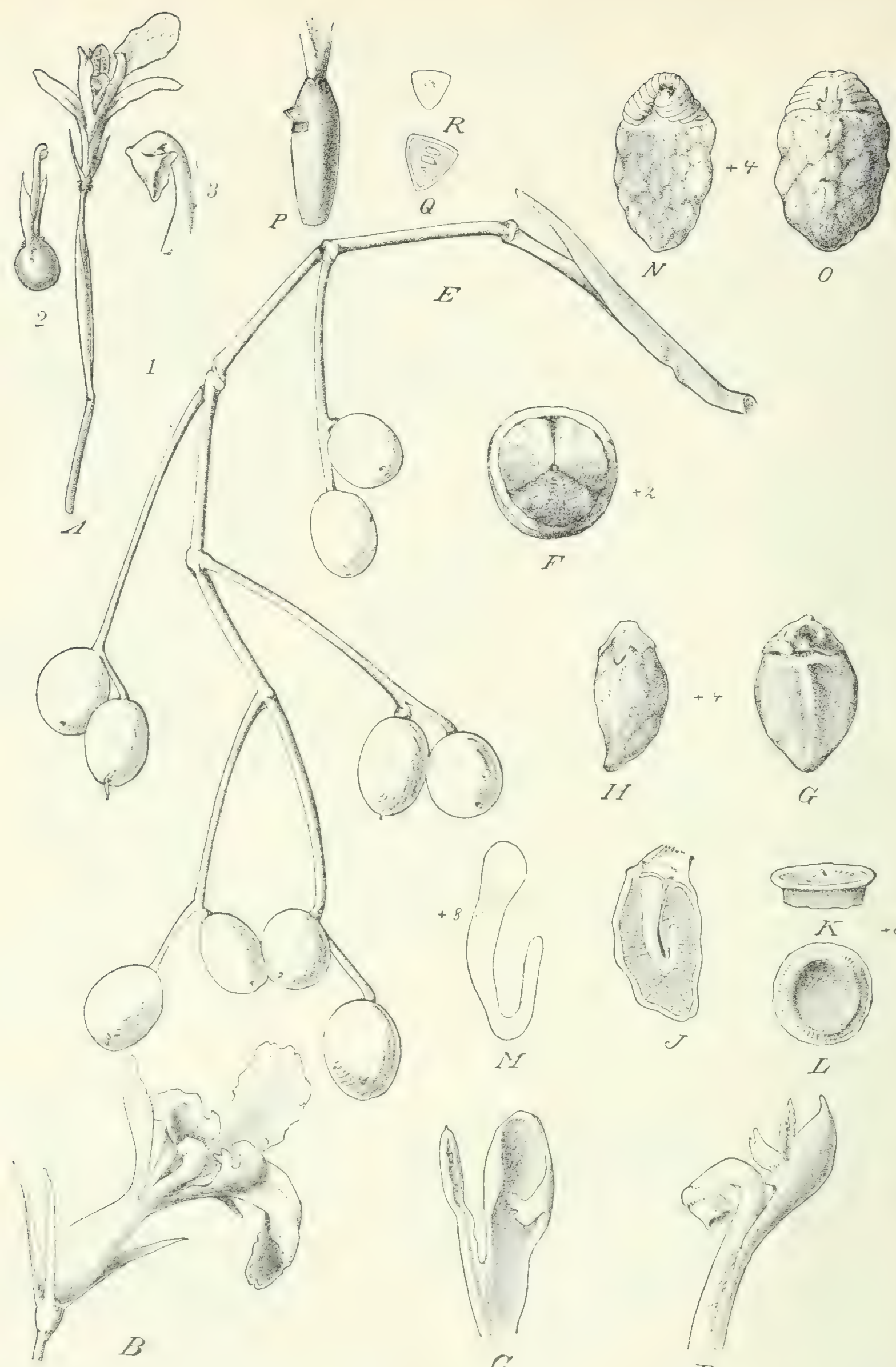

0
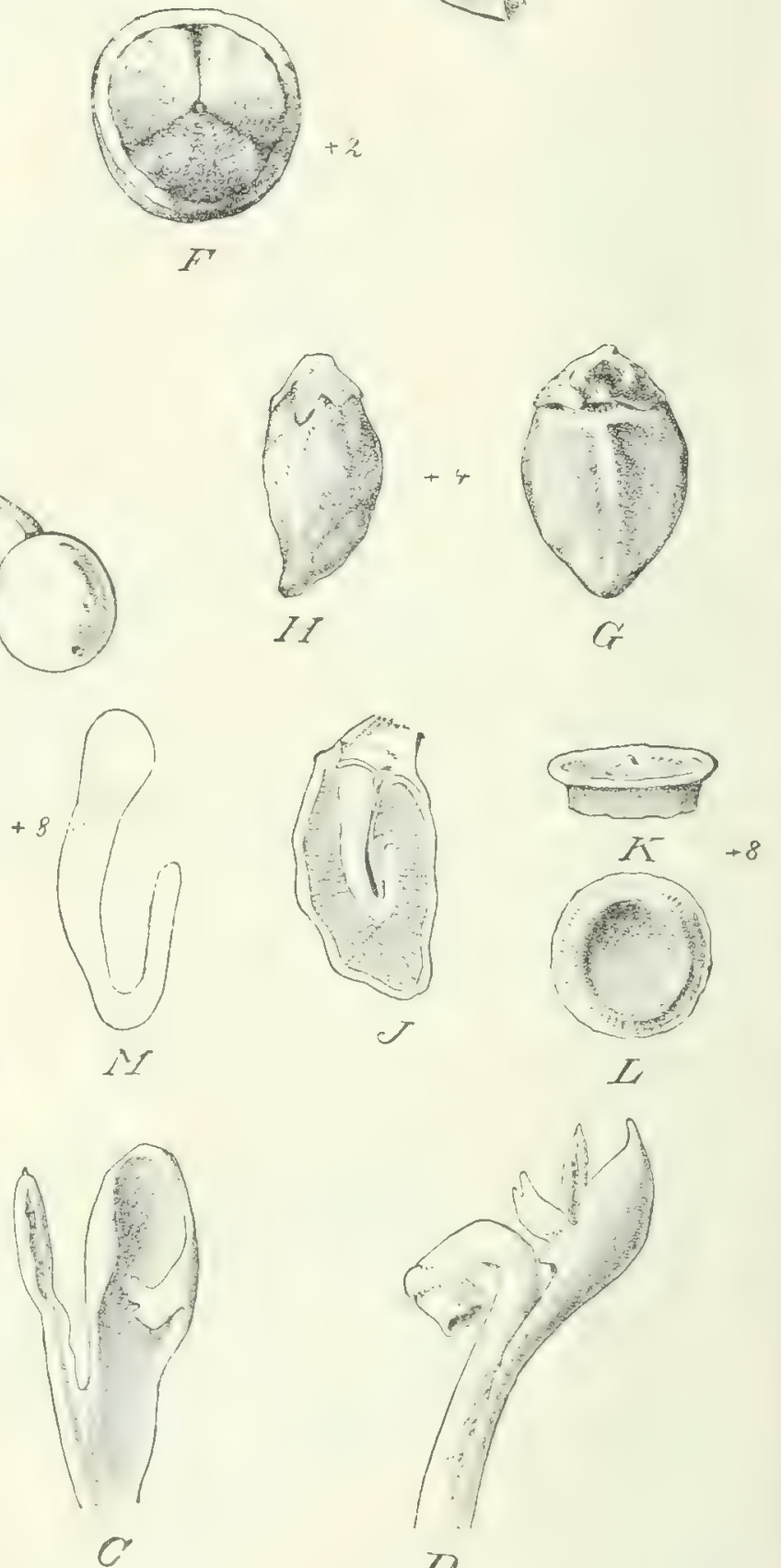

$D$

Fig. 28r. A I-3 Clinogyne monophylla K. Schum. (Gabun). 1 Blite; 2 Kapsel; 3 Narbe. $B-D$ Maranta arundinacea L. $B$ Blïte; $C$ Staubblatt und kapuzenförmiges Staminodium; $D$ dieselben mit dem Griffel. E- $M$ Clinogyne leucantha $K$. Schum. E Fruchtstand; $F$ Same in der quer durchschnittenen Kapsel; $G$ Same von der Banchseite; $H$ derselbe seitlich gesehen; 7 derselbe im Längsschnitt; $K, L$ Samendecliel; $M I$ Embryo. $N, O$ Clinogyne arillata K. Schum. (Kamerun, Eden-Fälle). $N$ Same von der Rückenseite; $O$ derselbe von der Bauchseite. $P-K$ Halopegia azurea K. Schum. P Caryopsis; $Q$ dieselbe im Querschnitt; $R$ Querschnitt des Samens. - Original. 


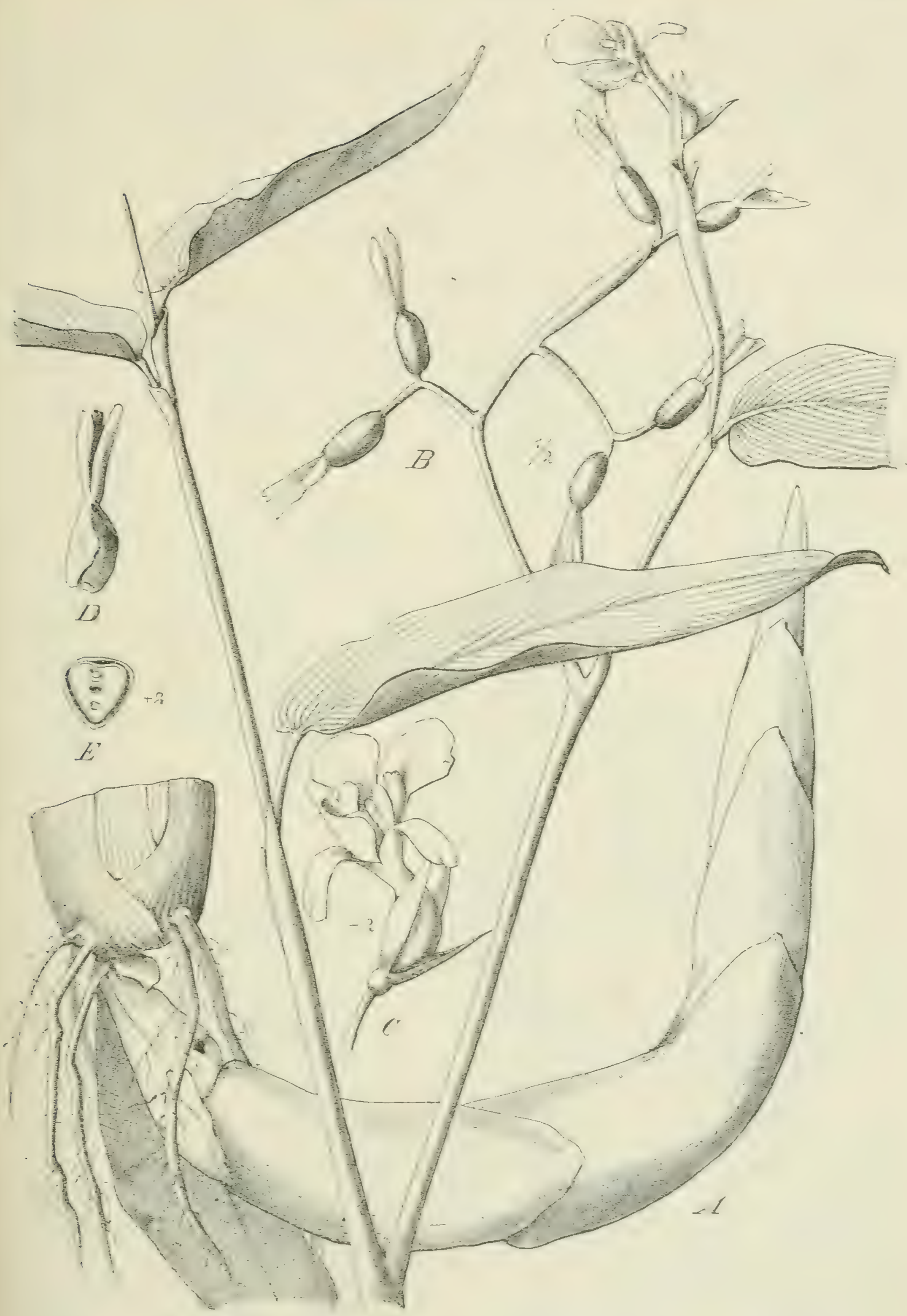

Fig. 282. Maranta arundinacea L. $A$ Rhizom; $B$ Blütenstand; $C$ Blüte; $D$ Kapsel; $E$ Same im Querschnitt. - Nach K. SchuMarn. 
Ghasalquellengebiet gelangt ist; sie findet sich ïberall an Flußläufen und in Sümpfen. Th. cocmlea Ridley und Th. It'cleitschii Ridley in Angola dürften als Varietät zu der genannten Art zu stellen sein. Die Früchte sind $\mathrm{I} \mathrm{cm}$ große, kugelige Nüsse mit einem kugeligen Samen, dessen Transport über große Meeresstrecken hinweg schwerlich anzunehmen ist.

\section{Fam. Burmanniaceae.}

Meist saprophytische Hygrophyten.

Von dieser Familie, deren Arten zumeist in Regenwäldern an dicht beschatteten, lockir humïsen Stellen wachsen, kannte man lange Zeit nur wenige Arten. Es sind aber in neuester Zeit niehr, namentlich aus Kamerun bekannt geworden, und es ist anzunehmen, daß bei eingehenderer Erforschung der Regenwälder noch mehr aufgefunden werden. Die Pflanzen sind leicht kennt-

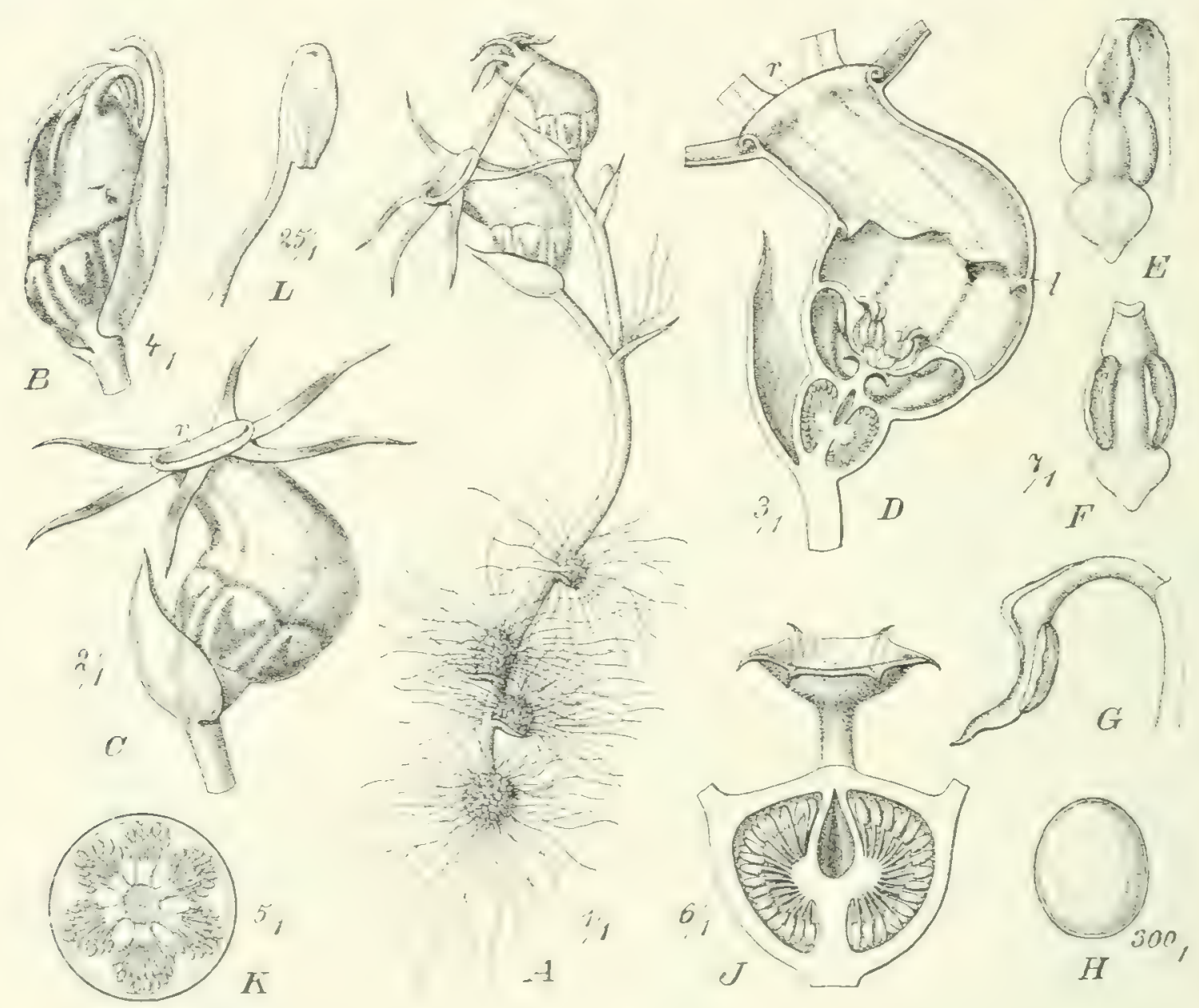

Fig. 283. Thismia Winkleri Engl. A Ganze Pflanze in natïrlicher Größe mit vier Gruppen von geschwänzten Bulbillen; $B$ Knospe in der Achsel einer Bractee, mit ineinander greifenden Abschnitten des Saumes; $C$ Blïte, an welcher die unteren dunklen Flecken weinrot, die oberen dunkel chromgelb gefärbt sind; $\%$ der Ring an der Mündung. $D$ Blïte im Längsschnitt, zeigt den oberen Ring und die in der Mitte befindliche gelappte Lamelle $l$, ferner die Insertion der Staubblätter, sowie deren Stellung zur Narbe; im untersten Kessel der Blüte fanden sich kleine Insekten; $E$ Staubblatt von der Rückseite; $F$ Anthere von der Vorderseite; $G$ Staubblatt, seitlich gesehen; $H$ Pollen; 7 Längsschnitt durch den Fruchtknoten, darïber Griffel und Narbe; $K^{\prime}$ Querschnitt durch den Fruchtknoten; $L$ eine Samenanlage mit Funiculus. - Nach ENgler in Bot. Jahrb. XXXV. 
lich; sie sind klein, $0,5-\mathrm{I}, 5 \mathrm{dm}$ hoch, nur selten mit einigen chlorophyllhaltigen Blättern am Grunde versehen, meist blaßgelblich, mit kleinen, schuppenförmigen Blättern. Ihr eigentümlicher Bau der Blïten und Früchte ergibt sich aus unseren Abbildungen und deren Erklärungen. Die außerordentlich kleinen, feilspanartigen, mit Flügeln versehenen und in jeder Kapsel in großer Menge produzierten Samen erleichtern die Verbreitung der Arten; aber wie bei allen Urwaldpflanzen, welche am Boden wachsen, kann dieselbe doch nur auf kleinere
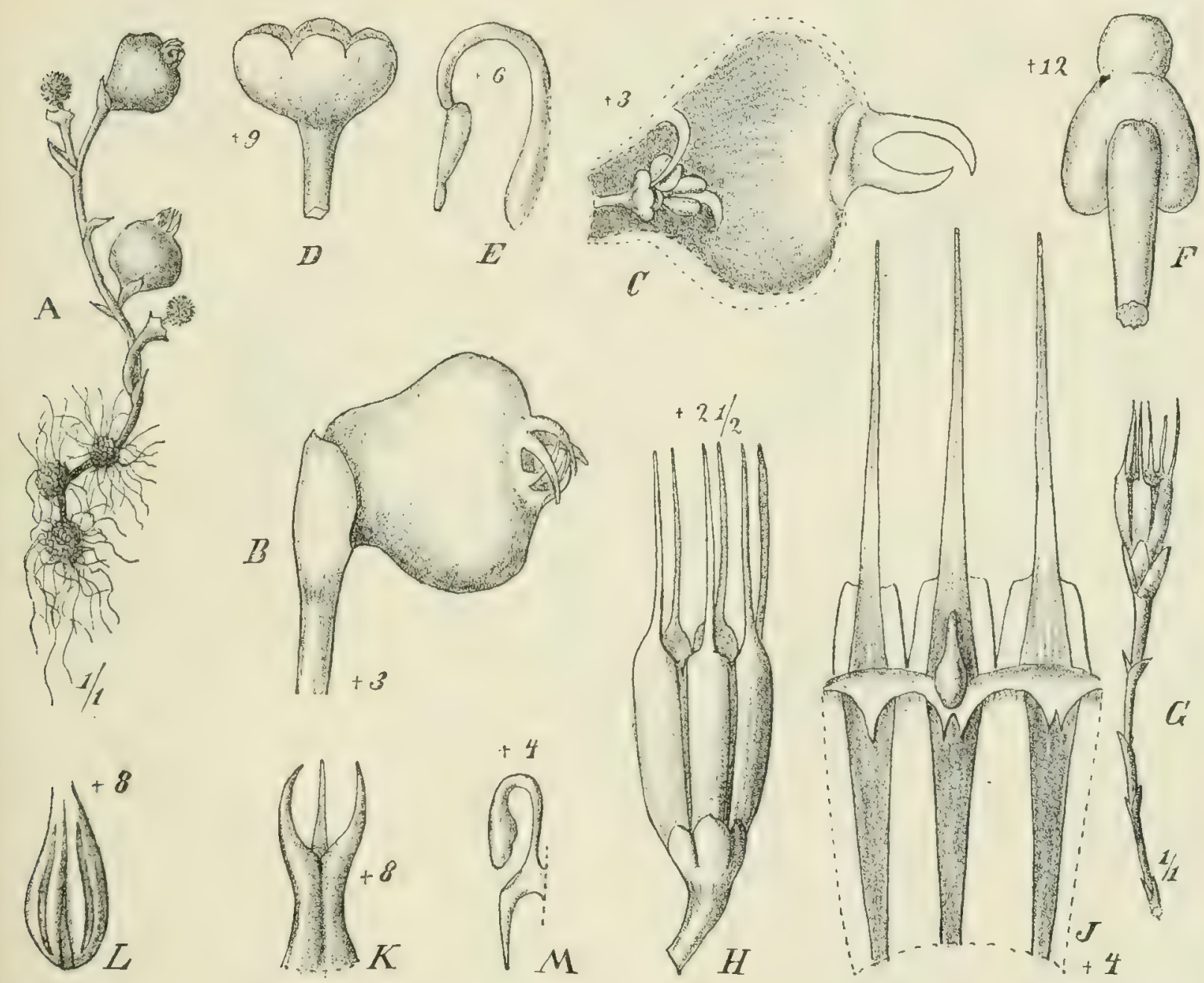

Fig. 284. $A-F$ Thismia pachyantha (Schlecht.) Engl. $A$ Habitus; $B$ Bliite; $C$ Längsschnitt durch dieselbe; $D$ Griffel; $E, F$ Staubblätter, $G-M$ Oxygyne triandra Schltr. $G$ Habitus; $H$ Blïte; $K$ Griffel; $L-M$ Staubblätter. - Nach Schilechter in Engl. Bot. Jahrb. XXXVIII.

Entfernungen hin erfolgen. Wenn nun drei hier besprochene Gattungen außer in Afrika auch im tropischen Amerika und Asien vertreten sind, so läßt dies auf ein sehr hohes Alter der Familie schließen.

Die vier in Afrika vertretenen Gattungen unterscheiden sich folgendermaßen:

A. Perigon breit glockig. Griffel kurz.

a) Blüte mit sechs nach innen gebogenen Staubblättern

Thismia.

b) Bliite mit drei Staubblättern .

Oxygyne.

Engler, Charakterpflanzen Afrikas. I. 


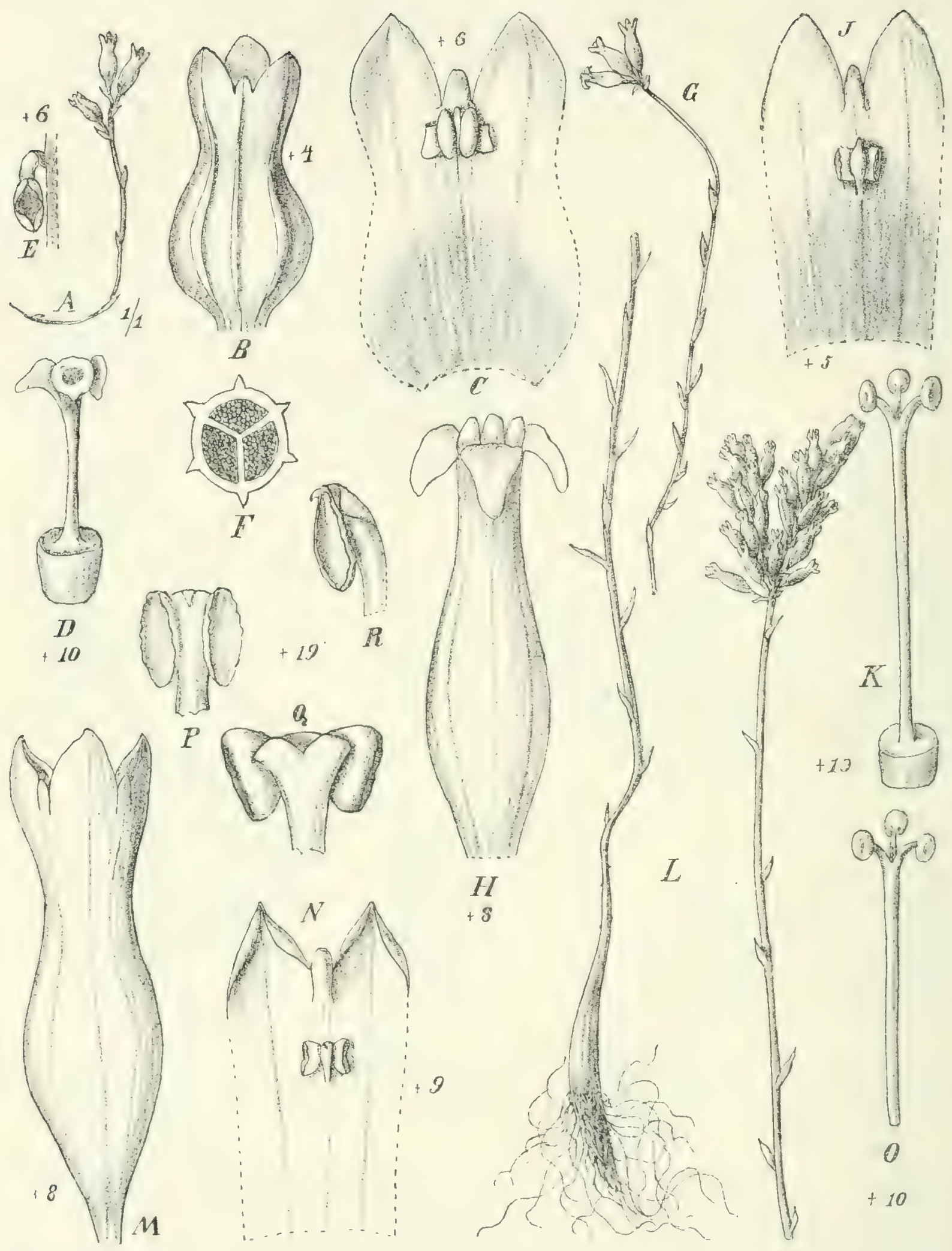

Fig. 285. Burmannia. $A-F$ B. hexaptera Schltr. $A$ Habitus; $B$ Blïte; $C$ Teil des Perigons mit Röhre; $D$ Griffel mit Fruchtknoten; $E$ Staubblatt; $F$ Durchschnitt durch den Fruchtknoten. $G-K$ B. aptera Schltr. $G$ Habitus; $H$ Blüte; $\mathcal{F}$ Teil des Perigons mit Anthere; $K$ Griffel. $L-R$ B. densiflora Schltr. $L$ Habitus; $M$ Blüte; $N$ Teil des Perigons mit Anthere; $O$ Griffel; $P-R$ Staubblätter. - Nach Schlechter in Engl. Bot. Jahrb. XXXVII. 
B. Perigon schmalglockig oder krugförmig. Drei Staubblätter mit aufrechten Antheren.

a) Fruchtknoten dreifächerig .

Burmannia.

b) Fruchtknoten einfächerig mit drei wandständigen Placenten Gymnosiphon.

Thismia Griff. ist mit drei Arten in Kamerun vertreten, welche einer eigenen Sektion Afrothismia Engl. angehören. Dieselbe ist charakterisiert durch etwas gekrïmmte Röhre, in welcher die Staubblätter unterhalb der Nitte frei werden, und durch eine zentrale Säule im Fruchtknoten, von welcher in der Mitte die Placenten abgehen. Interessant ist auch, da $\beta$ an dem unteren, etwa I mm dicken, kugeligen Ende des Rhizoms sehr zahlreiche Brutknöllchen entwickelt werden, welche in $1-1,5 \mathrm{~cm}$ lange, dünne Schwänzchen übergehen. Die Brutknöllchen haben ziemlich große, peripherische Zellen, welche mit endotropher Mykorrhiza erfüllt sind; im Innern der Knöllchen finden sich zahlreiche größere Zellen, welche Bündel von Raphiden enthalten. Außer der von mir zuerst beschriebenen Thismia Hinklcri Fig. 283', welche Dr. Hub. Winkler bei NeuTegel unweit Buea entdeckte und Herr G. Zeniser bei Bipindi, Dr. Schlechter bei Moliwe auffand, hat letzterer auch noch eine andere Art bei Moliwe gefunden, die er als Afrothismia pachyantha (Fig. $28+A-F$ ) bezeichnete. Mir scheint die Abtrennung dieser Formen als Sektion innerhalb der Gattung Thismia ausreichend fiur die Unterscheidung.

Oxygyne Schlechter. Die bis jetzt allein bekannte Art dieser Gattung, O. triandra Schltr. (Fig. $28+G-M$ ), kommt mit den beiden vorher erwähnten Arten von Thismia zusammen bei Moliwe in Kamerun vor.

Burmannia L. Seit längerer Zeit kennt man B. bicolor Mart. var. africanic Ridley von Huilla in Benguela und den Wäldern im Norden des Nyassa-Sees, ausgezeichnet durch violett und gelb gefärbte Bliiten. Hierzu kommen aber noch drei neue, von Dr. Schlechter in Kamerun aufgefundene Arten: $B$. aptera Schltr. (Fig. $285 G-K$ ), B. densiftora Schltr. (Fig. $285 L-R$ ) und $B$. hexaptera Schltr. (Fig, $285 A-F$ ).

Gymnosiphon Blume. Die Arten dieser Gattung haben meist Tracht und Größe der $B$. densiflora, aber das Perigon ist weiß und drei Perigonzipfel sind breit verkehrt-eiförmig. Zwei Arten kommen vom Nigergebiet bis Gabun vor; eine dritte, G. usambaricus Engl., tritt in Ostusambara herdenweise- in den Wäldern zwischen Amani und Kwamkoro auf.

\section{Fam. Orchidaceae.}

Diese Familie ist ebenso wie die der Palmen und Araceen in Afrika bei weitem nicht in so zahlreichen ansehnlichen Formen vertreten, wie im Monsungebiet und im tropischen Amerika. Zwar lernen wir täglich neue Arten aus Afrika kennen, aber fast immer gehören sie zu den bereits bekannten Gattungen dieses Erdteils, und epiphytische Arten mit ansehnlichen Bliiten treten uns nur selten entgegen. Kleinblutige Epiphyten, namentlich aus der Gattung Angraccunn, gehen im östlichen Afrika bis Abyssinien nordwärts und siidwärts bis zum 
siidlichen Kapland, wo auch noch die nahestehende Gattung . My'stacidinn mit einigen Arten auftritt. Dagegen ist die Zahl der Erdorchideen eine recht bedeutende, besonders in den Gebirgsländern von den Grasfluren der oberen Buschregion an bis zu den obersten Bergwiesen; gegen Süden treten entsprechende Formen in niederen Regionen bis in die Nähe des Meeres auf; so finden sich auf den "Flats " der Kaphalbinsel und unter $160 \mathrm{~m}$ ü. M. etwa 20 Arten; dagegen kommen oberhalb $160 \mathrm{~m}$ auf der Kaphalbinsel nach BoLUs etwa 59 Arten vor, während noch 23 Arten sowohl unterhalb, wie oberhalb $160 \mathrm{~m}$ wachsen. Auch in den Steppen fehlen die Orchideen nicht ganz; es kommen in denselben sogar Epiphyten (Angracum) vor. Nicht wenige der Erdorchideen entwickeln ansehnliche Inflorescenzen, und hesonders dic Arten ron Hexbmaria zeigen mitunter sehr eigenartig gestaltete Bliiten. Blaligruine, weiße und gelbe Blüten sind sowohl bei den Epiphyten wie bei den Erdorchideen entschieden vorherrschend; rote und violette Blïten sind seltener.

Folgende kurze Übersicht (im wesentlichen nach PFITzER) gibt über die systematische Stellung der afrikanischen Orchideen Aufklärung.

Die beiden seitlichen oder alle Staubblätter des inneren Kreises fehlend oder Staminodien, selten fruchthar, das unpaare des äußeren Kreises regelmäßig fertil. Nur die seitlichen Narbenlappen empfängnisfähig, der unpaare Narbenlappen rudimentär oder zum Rostellum umgehildet . Unterfam. Monandrae.

A. Pollinien nach der Basis hin Anhängsel (Caudiculae entwickelnd, welche mit den Klebmassen des Rostellums in Verbindung treten. Antheren niemals abfallend .

Basitonae. Einzige Gruppe. - Erdorchideen mit Wurzelknollen, an deren Spitze eine Knospe sitzt

Ophrydeae.

a) Säule äußerst kurz oder fehlend, Labellum an deren Grunde eingefügt. Anthere aufrecht. Spiegelnarben .

Gymnadeniinae.

ce) Klebmassen ganz nackt.

I. Blumenblätter nicht genagelt.

1. Labellum mit ausgebreiteten Seitenlappen. Rostellum breit und niedrig.

* Klebflächen nach dem zwei- oder dreilappigen Labellum zugewandt, wagerecht. t Labellum ohne Sporn. Nur im Kapland........ Stenoglottis. It Labellum mit Sporn............. Holothrix. ** Klebfächen senkrecht gestellt, mit den Caudiculae einen rechten Winkel bildend

Platanthera.

2. Labellum viellappig. Petalen zwei- bis fünfspaltig. Im Kapland . Scopularia. II. Blumenblätter genagelt, mit stark konkaver Platte. Kapland . . Huttonaea.

B) Klebmassen durch Umschlagung der Ränder der Antherenfächer von diesen umschlossen.

I. Labellum in viele schmale Fransen zerschnitten. Kapland. . . . Bartholina.

II. Labellum dreilappig . . . . . . . . . . Deroemeria.

b) Wie vorige; aber die Narben als besondere lange Fortsätze hervortretend . Habenariinat.

() Narbe ganz, nicht zweiteilig.

I. Narbe breit, kurz und dick. Labellum der Säule etwas angewachsen.

I. Blitte resupiniert. Labellum nach unten ........ Cynosorchis.

2. Bliite nicht resupiniert. Labellum nach oben.

Amphorchis. 
II. Narbe schlank oder cylindrisch. Labellum frei.

r. Sporn lang und dïn. Rostellum ganz kurz oder haubenartig . Habenaria.

2. Sporn verlängert. Rostellum dreilappig mit längerem Mittellappen. Narbe lappig

Barlaea.

B) Narbe gegabelt . . . . . . . . . . . . . . . Roeperocharis.

c) Labellum an Grunde der Sïule eingefuigt. Die Anthere mit letzterer einen Winkel bildend

a) Medianes Sepalum und Labellum nicht gespornt.

I. Narbe mit zwei aufrechten, linealen Armen. Im Kapland . . . . . . Pachites.

II. Narbe polsterartig oder grubig.

I. Petalen knieartig gebogen, Labellum klein, fleischig. . . . . . Forficaria.

2. Petalen gerade. Labellum mit breitem Nagel und breiter, dreizähniger Platte

Brachycorythis.

ß) Labellum aufwärts gewandt, mit zwei absteigenden Spornen oder Höckern. Narbe an der Spitze der verlångerten Sånle. . . . . . . . . . . . . Satyrium.

y) Labellum mit absteigendem Sporn.

I. Medianes Sepalum den seitlichen ziemlich gleich. Nur Kapland. Schizochilus.

II. Medianes Sepalum breiter als die seitlichen. Lippe linear . . . Platycoryne.

d) Labellum nicht gespornt, eben. Mittleres Sepalum helmartig.

I. Labellum aus breitem, konkavem oder sackartigem Nagel und einer ungeteilten Platte gebildet. Nur Kapland . . . . . . . . . . . . . . Schizodium.

II. Labellum aus basalem Sack und winziger schmaler aufrechter Platte gebildet

III. Labellum eben.

Brownleea.

1. Zwei getrennte Klebmassen. Seitenlappen des Rostellums länger als der Mittellappen. Narbe ungeteilt . . . . . . . . . . . . . . . Disa,

2. Eine gemeinsame Klebmasse. Lappen des Rostellums ziemlich gleỉch lanģ? schmal. Narbe zweiteilig. . . . . . . . . . . . . Herschelia.

3. Eine gemeinsame Klebmasse. Narbe ungeteilt. Kapland. . . . Monadenia.

d) Labellum auf der Såule selbst eingefügt, meistens mit Anhängseln. . . . . Coryciinate.

( ) Seitliche Sepalen am Ruicken gespornt oder sackartig. . . . . . . . . Disperis.

ß) Seitliche Sepalen flach.

I. Platte der Lippe der Säule unmittelbar ansitzend. Kapland . . Pterygodium.

II. Platte der Lippe mit einem deutlichen Nagel der Säule ansitzend. Nur Kapland

Ceratandra.

y) Seitliche Sepalen bis zur Spitze verwachsen.

Corycium.

13. Pollinien ohne Anhängsel oder solche nach der Spitze hin entwickelnd. Staubfäden meist dünn und zart, die Antheren leicht abfallend Acrotonae. a) Blütenstïnde an der Spitze der ein Sympodium bildenden Sprosse terminal. (i) Blätter in der Knospenlage zusammengerollt; die Blattfläche und Blattscheide nicht voneinander abgegliedert; Pollen meist weich, körnig, die Antheren an ihrem Platz welkend. .

Neotticae.

I. Anthere das Rostellum weit überragend............ Pogonininae.

I. Labellum von den übrigen Blïtenhüllblättern rerschieden, der Säule angedrückt oder dieselbe umfassend, ohne Hypochil. Antheren übergeneigt bis hängend

Terrectolea.

* Ein dem einblütigen Stengel in mittlerer Höhe ansitzendes Laubblatt Pogonia.

** Ein grundständiges Laubblatt ................. Nervilia.

2. Labellum von den übrigen Blütenhüllblättern verschieden, aber ohne Hypochil, die Säule umhiillend. Antheren das Rostellum iiberragend, ïbergeneigt bis aufrecht

Vanillinae.

Kiletternd .

Vanilla. 
3. Labellum mit deutlichem, oft gesporntem Hypochil. Anthere aufrecht

Cephalanterinae.

* Blittenschaft mit Laubblättern. Lippe ohne eigentlichen Sporn . Epipactis.

** Blütenschaft schuppig, ohne Laubblätter. Labellum gespornt . Epipogon.

4. Kelchblätter und Blumenblätter verwachsen. Anthere ïbergeneigt. Saprophytisch Gastrodiunae.

* Kelch und Blumenblätter nur am Grunde vereint. Labellum kahl Auxopus.

** Kelch und Blumenblätter zu einer abwärts gespaltenen Röhre vereint Gastrodia. II. Anthere in der Regel ebenso lang wie das Rostellum und demselben dicht anliegend.

I. Blätter weich, netzaderig, nicht längsgefaltet. Pollinien wachsartig oder pulverig, nicht in viele bestimmte Massen abgeteilt ......... Cranichidinac.

Manniella.

2. Blätter wie bei den vorigen. Pollinien in viele bestimmte Massen abgeteilt. Labellum spornlos oder mit kurzem Sack.......... Physurinae.

* Mit dentlichem, länglichem Stipes zwischen den Pollinien und der Klebmasse des Rostellums.

t Sepalen frei................... Zeuxine.

+f Sepalen bis zur Mitte röhrig verwachsen. Säule mit zwei aufrechten, schmalen

Armen . . . . . . . . . . Cheirostylis.

** Caudiculae der Pollinien unmittelbar der Klebmasse des Rostellums aufgesetzt. t Säule kurz, gerade. Blïte symmetrisch geöffnet. Labellum aufrecht, bauchig

Hetaeria.

tf Säule verlängert, schlank ............ Platylepis. *** Caudiculae der Pollinien unmittelloar der Klebnasse des Rostellums angeheftet.

Labellum schmal, flach oder konkav, den Blumenblättern ähnlich Gymnochilus.

3. Blätter längsfaltig, derb. Pollinien pulverig, einem schlanken vom Rostellum sich ablösenden Stipes angefügt, mit schildförmiger Klebmasse .... Tropidiinae.

Corymbis.

ß) Blätter in der Knnospenlage gefaltet. Äußerer Kreis der Blütenhülle dem inneren höchstens gleich entwickelt; in der Regel der letztere, namentlich das Labellum, am meisten in die Augen fallend.

I. Blätter meist ungegliedert. Vier wachsartige Pollinien ohne Anhang

I. Blätter ungegliedert. Spreite nicht abfallend.

Liparideae.

* Anthere aufrecht.

Orestias.

** Anthere übergeneigt, abfallend

Liparis.

2. Blätter gegliedert. Spreite abfallend.

Oberonia.

II. Blätter meist gegliedert. Säule mit deutlichem Fuß. Zwei oder vier wachsartige Pollinien mit sehr kurzem Stipes sich der Klebmasse anheftend. Epiphyten

Polystachyeae.

I. Säule kurz, Kinn sehr stark. Labellum dreilappig

- Polystachya.

2. Säule kurz. Kinn schwach. Labellum ungeteilt

Neobenthamia.

3. Säule verlängert. Kinn schwach. Labellum dreilappig ..... Ansellia.

b) Blïtenstände auf besonderen Seitensprossen.

a) Blätter in der Knospenlage zusammengerollt.

I. Stammglieder schlank oder gleichmäßig angeschwollen. Vier oder acht wachsartige Pollinien mit Caudicula, ohne Stipes . . Phajeae. 1. Laubblätter nicht gegliedert.

* Labellum frei, die Säule umfassend ............ Phajus.

** Labellum der Säule angewachsen, mit abstehender Platte. . . Calanthe.

2. Laubblätter gegliedert . . . . . . . . Ancistrochilus. 
II. Wie vorige; aber zwei oder vier Pollinien ohne Caudicula, mit kurzem Stipes

Cyrtonodieae.

I. Labellum gespornt oder am Grunde sackartig.

* Sepalen schmäler oder weniger gefärbt als die Petalen.

** Sepalen und Petalen ziemlich gleich .

Lissochilus.

2. Labellum nicht gespornt, auch nicht sackartig .

Eulophia.

Pteroglossaspis.

(i) Blätter in der Knospenlage zusammengefaltet.

I. Laubtriebe mit begrenztem Spitzenwachstum. Sympodium.

I. Stamm heteroblastisch. Blütenstände unter der Luftknolle entspringend. Pollinien anhangslos, sehr selten mit schmalem, linealem Anhängsel

Bolbophylleae.

* Seitliche Sepalen oben getrennt, unten mit ihren Außenrändern verklebt. Blüten in doldenartiger Traube

Cirrhopetalum.

** Seitliche Sepalen frei oder mit den in der Knospe benachbarten Rändern etwas verklebt. Antheren ohne Connectivfortsatz. Pollinien normal

Bolbophyllum (inkl.. Megaelinium!.

2. Blütenstände tiefer entspringend als der Laubsproß. Meist mit Luftknollen. Pollinien mit Stipes

Maxillarieae. Einzige Gattung in Afrika

.Eulophidium.

II. Laubtriebe mit unbegrenztem Wachstum. Laubblätter gegliedert. Blütenstand meist vielblütig. Lippe meist gegliedert oder gespornt

Sarcantheae.

I. Rostellum ohne gebärtete Anhängsel.

* Sporn sackartig, in der Regel kürzer als die Kelch-und Blumenblätter. Seitliche Lappen der Lippe getrennt und breit abgerundet

Saccolabium.

** Sporn oft sehr lang. Seitliche Lappen der Lippe gewöhnlich undeutlich

Angraecum.

2. Rostellum mit gebärteten Anhängseln

Mystacidium.

Entsprechend der Tendenz unserer Darstellung bespreche ich die afrikanischen Orchideen mit Rücksicht auf ihre biologischen Terhältnisse.

a) Kletternde Orchidaceen.

Vanilla Sw, welche in den Väldern fast aller Tropengebiete vorkommt, ist in Afrika mit zehn Arten rertreten, ron denen neun beblätterte Stengel haben und im tropischen Westafrika ron Sierra Leone bis in das mittlere Kongogebiet nicht selten sind. Alle haben recht ansehnliche Bliiten. Bei einigen ist die durch Vereinigung der Lippe und Säule gebildete Röhre ebenso breit wie lang; $V$. cucullata Krzl., bei welcher die oberen $2 / 3$ der Säule frei ron der Lippe sind, scheint nicht bloß in Kamerun, sondern auch im Sachsenwald bei Dar-es-Salam rorzukommen. Hier finden wir auch die höchst eigentuimliche, blattlose $T$. Rochiri Rchb. f, welche vielblitige weiße Blütentrauben trägt. Diese Art findet sich auch in der Nähe ron NIombas und in der Succulentensteppe am Nordfuße des Lsambaragebirges und am Fuße des Paregebirges; ihre Kapseln erreichen eine Länge ron $1,5 \mathrm{dm}$, und die Bliten haben einen Durchmesser von $;-8 \mathrm{~cm}$. I . imperialis Krzl., welche bei launde in Kamerun bis zu goo m ii. XI. vorkommt, besitzt bis $1,5 \mathrm{dm}$ lange, $7-8 \mathrm{~cm}$ breite Blätter und wachsgelbe Blüten von $\mathrm{I}, 2 \mathrm{dm}$ Durchmesser. 
b) Epiphytische Orchidaceen.

Solche fehlen in keiner Formation. Zwar sind sie besonders reichlich in den Kronen der Regenwaldbäume und auf den Bäumen und Sträuchern der Nebelwälder: aber sie kommen auch in Trockenwäldern und selbst in Busch-

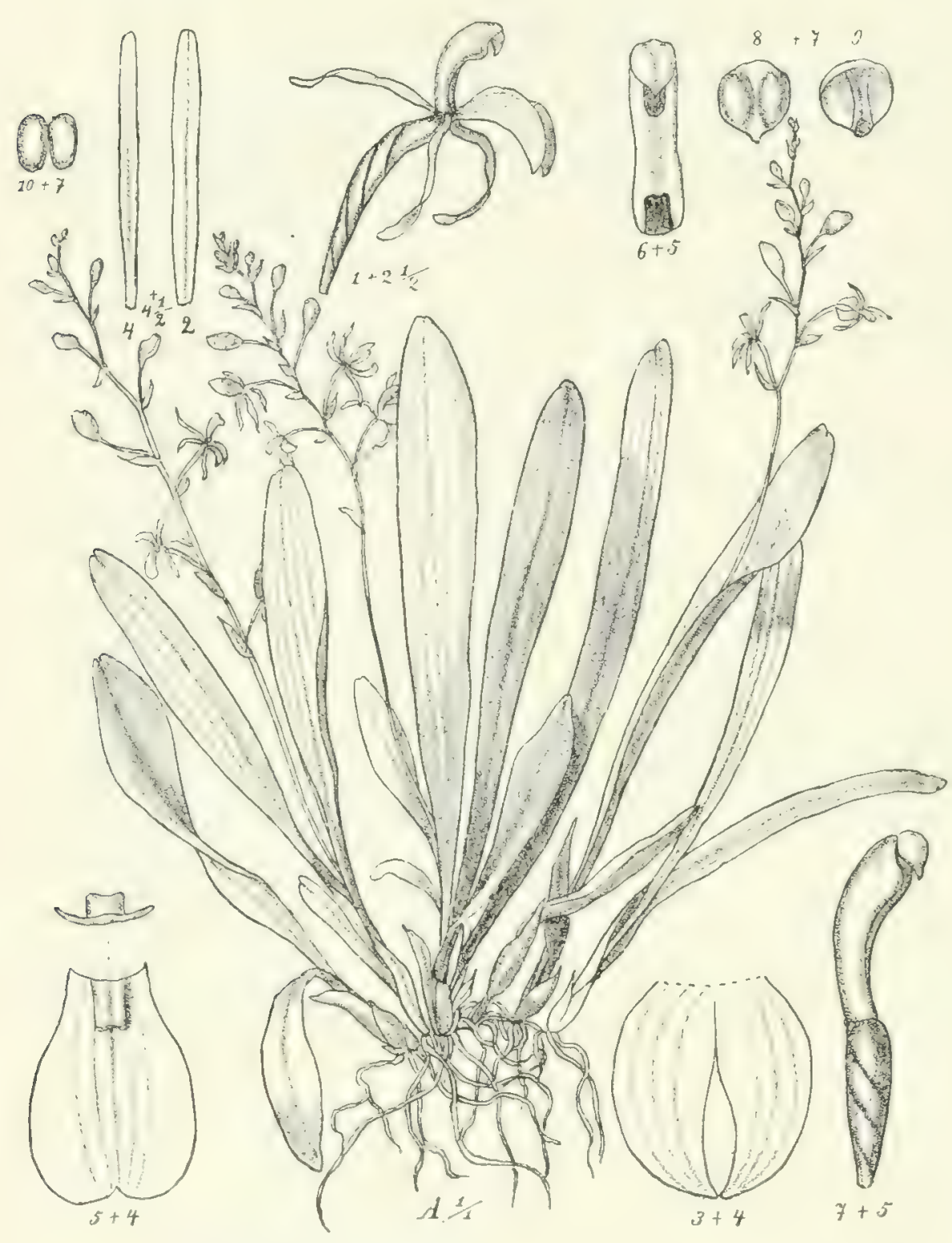

Fig. 286. Liparis epiphytica Schltr. A Ganze Pflanze in n. Gr.; $I$ Blüte; 2 mittleres Kelchblatt; 3 seitliche Kelchblätter; 4 Blumenblatt; 5 Labellum; 6 Säulchen von yorn; 7 dasselbe von der Seite; 8-9 Anthere von vorn und hinten; IO Pollinien. - Nach Scillechter. gehölzen der Steppe vereinzelt vor. Auch auf den Affenbrotbäumen findet man nicht selten ganze Klumpen epiphytischer Orchidaceen, insbesondere Ansellia africana. $\mathrm{Zu}$ den einzelnen Gattungen ist folgendes zu bemerken:

Liparis Rich. Die meisten Arten dieser in Malagassien und Indien reicher als in Afrika vertretenen Gattung sind terrestrisch; aber L. tridens Krzl. aus dem Regenwald von Lolodorf in Kamerun und die hier abgebildete L.epiphytica Schltr. (Fig. 286) vom Sanga-Fluß bei Nkundi in Kamerun wachsen mit Polystachya, Angraecum und Farnen epiphytisch.

Oberonia brevifolia Lindl. ist ein kleines, einige $\mathrm{cm}$ hohes Pflänzchen mit zweireihig gestellten, schwertfömigen Blättern und einer Ähre sehr kleiner gelblichgrüner Bliten. Es finctet sich ziemlich häufig auf Baumfarnen im Regenwald ron Ostusambara, auf den Comoren und auf den Maskarenen sowie im Monsungebiet. Eine ähnliche Pflanze kommt auf St. Thomas vor.

Polystachya Hook. Von dieser zwar auch im tropischen Amerika nicht ganz fchlenden, vorzugsweise aber paläotropischen Gattung sind schon etwa 
I 00 Arten aus dem tropischen Afrika bekannt, wo sie aus. der Küstenregion, von der Mangrovenformation bis zur obersten Baumgrenze anzutreffen sind. Sie wachsen nicht bloß epiphytisch, sondern bisweilen auf Felsblöcken zwischen Moos; einige Arten wachsen auch auf sandigem Boden, wie I'. sabulosa Schltr., P. Tayloriana Benth. und P. Neobonthamia Schltr. (- Veobcnthania gracilis Rolfe).

Sie entwickeln dünne Wurzeln, kurze, bisweilen zu Luftknollen verdickte Stengel mit schmalen oder länglichen, mehrnervigen Blättern, die am Grunde in umfassende Scheiden zusammengezogen sind, und meist kleinen, häufig weißen, gelblichen oder bräunlichen, in Ähren oder Trauben und Rispen stehenden Blüten. Die größte Zahl der Arten findet sich in Westafrika von Sierra Leone bis Angola, doch kennen wir auch eine große Zahl ostafrikanischer Arten von Abyssinien bis zum Kapland. Bei den meisten Arten sind die Stengel oder die Luftknollen dicht zusammengedrängt. Unter diesen nimmt eine Sonderstellung ein $P$. clastica Lindl., eine nur $1,5 \mathrm{dm}$ hohe Pflanze mit flachen Haftwurzeln, mit wenigen Bliiten, deren dreilappiges, I, $25 \mathrm{~cm}$ langes Labellum S-förmig gekrümmt ist. Zwei Arten von St. Thomas ( $P$. disticha Rolfe) und von Kamerun ( $P$. caloglossa Rchb.) zeichnen sich durch zickzackförmige Spindel des Blütenstandes aus. - Einige in der obersten Buschregion der Hochgebirge vorkommende Arten zeichnen sich durch einen großen, fleischigen, vier- bis sechslappigen Kamm des Labellums aus, nämlich $P$. Prenssii Krzl., 0,7-I,5 dm hoch, mit kurzer Blitentraube, auf den Sträuchern des obersten Gebirgsbusches im Kamerungebirge, von 2200-27co m ii. M., $P$. alpina Lindl., ein nur $5 \mathrm{~cm}$ hohes Pflänzchen mit einbliitigem Schaft, $P$. Heckmamiana Krzl., eine zwischen Moos und Sticta versteckte kleine rasige Pflanze mit elliptischen, zweilappigen Blättern und einem I-r,5 cm hohen einbliitigen Schaft, der vorigen Art ziemlich nahestchend, im Gebirgsregenwald von Uluguru auf den höchsten Bäumen; $P$. conocherris Krzl., eine ebenfalls rasige Art mit I cm langen Luftknollen, 2-4 cm langen, zweilappigen Blättern und weißen, am Rande schwach violetten Bliiten, deren Kelchblätter I, $6 \mathrm{~cm}$ lang sind, während die seitlichen Blumenblätter $\mathrm{I}, 3 \mathrm{~cm}$ und das Labellum $\mathrm{I}, 5 \mathrm{~cm}$ lang werden, nach Prof. KRÄnzLIN eine der wenigen, wirklich schönen Arten Ostafrikas. Kurze Blütenstände mit einer bis zwei ziemlich großen Blïten besitzen die hier abgebildete $P$. Supfiana Schltr. (Fig. 287) von Bibundi in Kamerun und P. reflexa Lindl. sowie $P$. grandiflore Lindl. in Sierra Leone. Die übrigen Arten haben erheblich kleinere Blüten, auch die Rasen bildende und mit etwa I dm hohen, einblütigen Stengeln versehene I'. cacspitifica Krzl. an alten Baumstämmen in Ostusambara. - Eine crheblich größere Zahl (iiber 50) von $P$. ist kräftiger und weist Unterschiede teils in der Größe der Blätter, teils in der Entwicklung der Blütenstände (Rispen oder Trauben), teils in der Gestalt der Blüten auf. Von diesen Arten seien hervorgehoben als etwas weiter verbreitete: $P$. cultriformis (Thou.) Spreng., mit länglichen Luftknollen, länglichen Blättern und in Rispen stehenden Bliten, im Kamerungebirge oberhalb Buea, am Kilimandscharo bis zur Baumgrenze und in Usambara, ferner auf 
den Maskarenen und Madagaskar; P. laxiflore Lindl., bis $5 \mathrm{dm}$ hoch, von Sierra Leone bis Gabun, $P$. tessellata Lindl. im Nigerdelta, auf St. Thomas und in Angola, die mit ihr verwandte $P$. latifolic de Wild. am unteren Kami im Kongogebiet, I'. poly'llecte Kr\%l. im Kamerungebirge und in Bukoba, I'. golun-

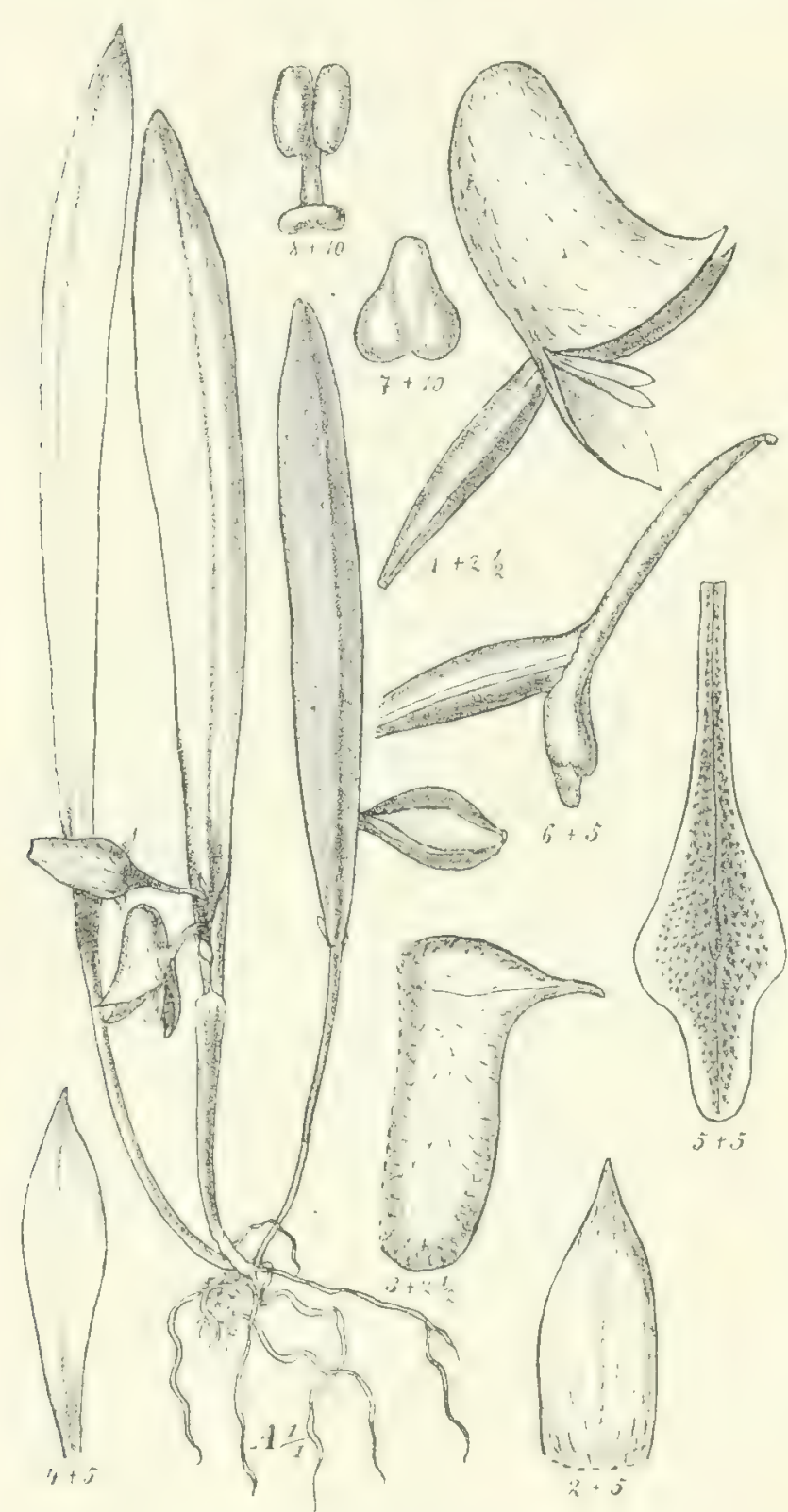

Fig. 287. Polystachya Supfiana Schltr. $A$ Pflanze in n. Fr. I Plite; I mittleres Kelchblatt; 3 seitliches Kelchblatt; 4 Blumenblatt; 5 Labellum; 6 Säulchen mit Fruchtknoten; 7 Anthere; 8 Pollinien. - Nach SCHLECHTER. gensis Rchb. fo mit nur schwach angeschwollenem Stengel im Mombuttuland und Angola, sehr häufig auf alten Affenbrotbäumen. Letztere sind uberhaupt oft stark besetzt mit Arten dieser Gattung; außer der vorigen findet man auf ihnen in Angola noch $P$. nitidula Rchb. f. und P. Adansoniae Rchb. f. - Einige Arten zeichnen sich dadurch aus, daß die Luftknollen übereinander sich entwickeln und $2,5-5 \mathrm{~cm}$ lang werden, so die in Usambara, auf den Maskarenen, Seychellen und Madagaskar vorkommende $P$. fusiformis Lindl., mit kleinen Rispen. Bei drei einander sehr nahestehenden, in der Heideregion des Ruwenzori 2700 bis $3000 \mathrm{~m}$ ü. M.) wachsenden Arten sind die aufeinanderfolgenden Stengelglieder nur schwach verdickt; es sind dies $P$. spatella Kral., P. Elliotii Rendle und P.ruzucnzoriensis Rendle. Einblättrige Luftknollen, welche sich übereinander auftürmen, mit sitzenden, ziemlich großen, I cm langen, hellbraunen Kelchblättern und noch etwas längerem Labellum besitzt 1’. crassifolia Schltr., welche auf Waldbäumen bei Moliwe in Kamerun vorkommt. - Endlich sind noch zwei Arten zu erwähnen, welche an einem kricchenden Rhizom voneinander entfernt Luftknollen entwickeln: es sind dies I'. bulboplylloiles Rolfe, auf Ölpalmen im Nigerdelta und in Sierra Leone, sodann P. micropetala Rolfe auf Fernando Po.

Schließlich sei noch darauf hingewiesen, daß sowohl dic amerikanischen Arten wie auch die indischen alle mit der oben erwähnten $P$. tesselata Lindl. nahe verwandt sind. 
Ansellia Lindl. Dies sind stattliche und ziemlich häufige Eppiphyten mit $3 \mathrm{dm}$ - I m langem, mehr oder weniger in der Mitte oder uiber derselben verdicktem Stamm und langen, zweireihig gestellten. lanzettlichen, längsfaltigen Blättern, mit großen Bliitenrispen und recht anschnlichen Bliiten von etwa $+\mathrm{cm}$ Durchmesser, mit gelbem, drcilappigem Labellum und dunkelbraun gefleckten Tepalen. Die häufigste und in nur wenig verschiedenen Formon auftrctende Art ist A.africana Lindl.; sie findet sich von Sierra Leone bis Benguela, auch auf Fernando Po, nur in den unteren Regionen, z. B. auf Ölpalmen; sie ist ferner nicht selten im Sansibarküstengebiet von Tanga bis Dar-es-Salam und auch von mir in der Massaisteppe am Fuße des Paregebirges auf Adansonien beobachtet worden. Auf Affenbrotbäumen kommt auch am unteren Sambesi die etwas kleinere A. humitis Bull vor. A. congonsis Rodigas am Kongo besitzt kleinere Blüten als die vorigen.

Eulophia R. Br., zu der vorzugsweise Erdorchideen gehören, enthält auch einige epiphytische Arten. z. B. E. luria Lindl. mit länglichen, bis $5 \mathrm{~cm}$ langen Luftknollen, lanzettlichen Blätter nund 3-6 dm langem, rispigem Stengel, welcher rötlichgrüne Blüten trägt; sie kommt von Sierra Leone bis Gabun vor; ferner E. flexuosa Krzl. vom Kilimandscharo, mit genäherten Luftknollen, linealen Blättern und kurzen Trauben weißer Blüten an ziemlich langem Schaft, und E. Tayloriand Rolfe, mit axillären Büscheln ron Blüten, in Deutsch-Ostafrika zwischen der Küste und Uyui, sowie auf den Manganja-Hügeln von EnglischOstafrika.

Cirrhopetalum Thourrsii Lindl. ist von mir in Usambara bei Amani auf Stämmen von Cyatheen aufgefunden worden, nachdem sie vorher von Madagaskar und den Maskarenen bekannt war: dic Pflanze ist in Afrika der einzige Vertreter einer im Monsungehiet reich entwickelten Gattung. Dem Rhizom entspringen voneinander entfernt kleine Luftknollen und die Blätter überragende, doldenähnliche Bliitenstände mit bräunlichen Blüten, deren seitliche, äußere Tepalen am Grunde frei, sonst aber mit ihren Rändern verklebt sind.

Genyorchis Schltr. ist eine interessante Gattung, welche mit der folgenden verwandt, aber dadurch charakterisiert ist, daß die größeren scitlichen Kelchblätter mit dem Fuß der Säule ein helmförmiges Gebilde darstellen und die Pollinien mit einem gemeinsamen Stipes einer querverlaufenden Drüse aufsitzen. G. pumila (Lindl.) Schltr. (Fig. 288), G. micropetala (Lindl.) Schltr. und G. platybulbon Schitr. sind die Arten dieser Gattung, erstere von Sierra Leone bis zum Nigerdelta, letztere auf Fernando P'o, die dritte bei Moliwe in Kamerun.

Bolbophyllum Thou. (inkl. Megaclinim Lindl. ist eine vorzugsweise paläotropische Gattung, von der etwa 80 Arten im tropischen Afrika vorkommen. Die Sproßverhältnisse sind dieselben wie bei voriger Gattung, die Bliiten stehen seltener in Dolden, häufiger in Ähren oder Trauben, bisweilen einzcln an den Sticlen, die aus der Achsel eines der grundständigen Niederblätter entspringen. Bisweilen ist die Spindel des Bliitenstandes verdickt, bei der Sektion Megaclinium ist die Spindel des Blütenstandes rerbreitert. Die äußeren Huillblätter der Blite sind frei. Bei der Bestimmung der Arten hat man haupt- 
sächlich auf den Bliitenstand und die Beschaffenheit des Labellums, sowie darauf zu achten, ob an den Luftknollen ein oder zwei Blätter stehen. Die meisten Arten kommen in Westafrika von Sierra Leone bis Angola vor, und zwar von der Mangrovenregion (z. B. B. Rhizophorat Lindl. in Nigergebiet) bis zu einer Höhe von etwa $2000 \mathrm{~m}$; sie gehen nicht so hoch hinauf wie die

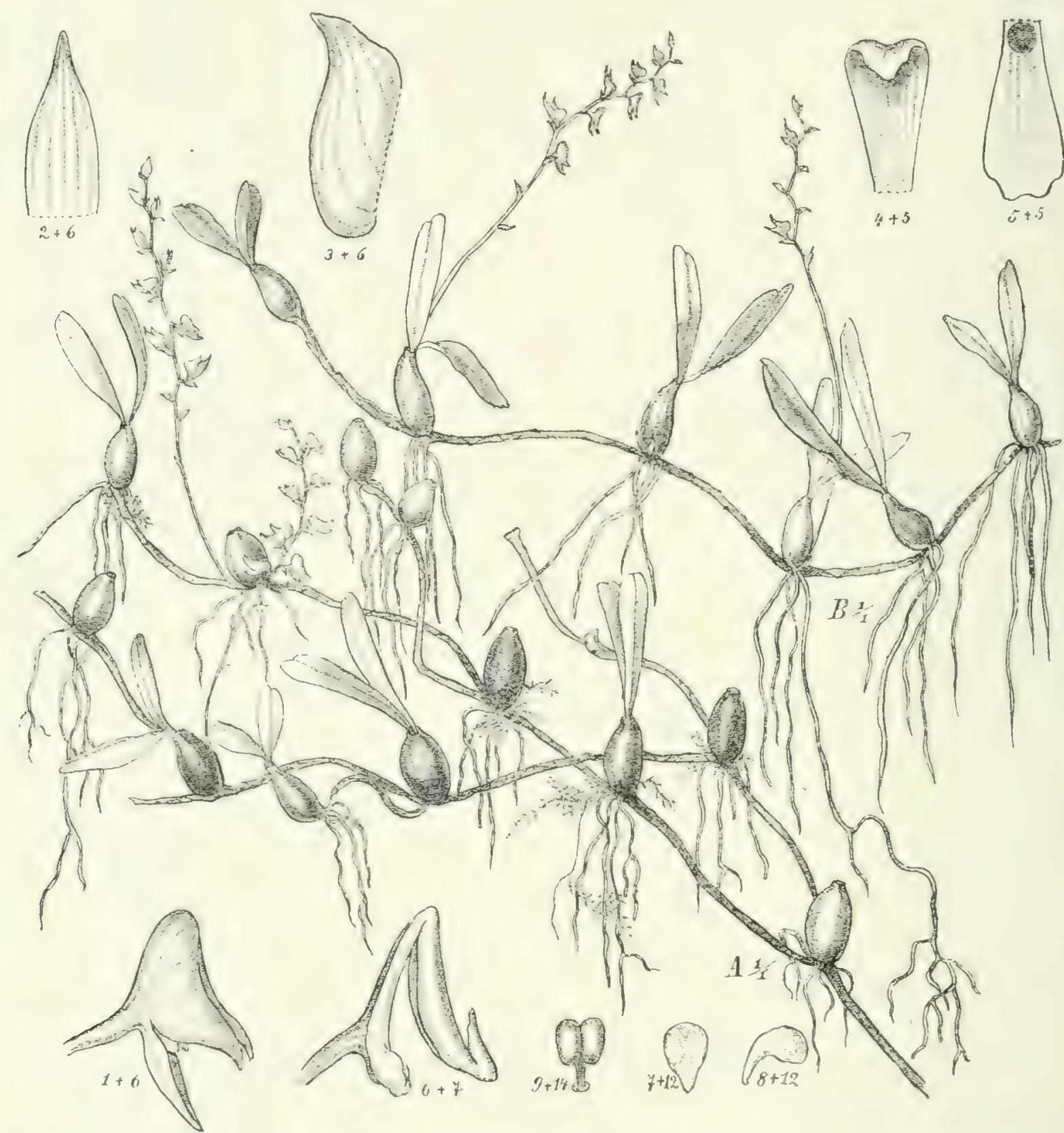

Fig. 288. Genyorchis pumila Schltr. A Habitus; I Blïte; 2 mittleres Kelchblatt; 3 seitliches Kelchblatt; 4 Labellum von unten; 5 dasselbe von oben; 6 Säulchen mit Labellum und Petalen; 7 Anthere von oben; 8 dieselbe von der Seite; 9 Pollinien. - Nach Schlechter.

Polystachyen: in Ostafrika sind bis jetzt erst drei Arten aufgefunden worden, nämlich $B$. T'scmbarac Krzl. von mir selbst im Gebirgsbuschgehölz oberhalb Sakare um i 600 m ii. M. auf Agauria, zusammen mit Polystachya-Arten, $B$. Gilgianm Krzl. im Utschungwegebirge von Uhehe um $1800 \mathrm{~m}$ ii. M.. B. oxy'ptcrum Rchb. f. (Fig. 28y: auf Felsblöcken zwischen Moos im Kondeland um 
I000 $\mathrm{m}$ ii. M. Als Beispiele für die verschiedenartigen Typen der Gattung nenne ich folgende: B. filiforme Krzl. mit zwei lanzettlichen Blättern oberhalb der Luftknollen und $6 \mathrm{dm}$ langen lockeren Ähren kleiner völlig kahler Blüten,

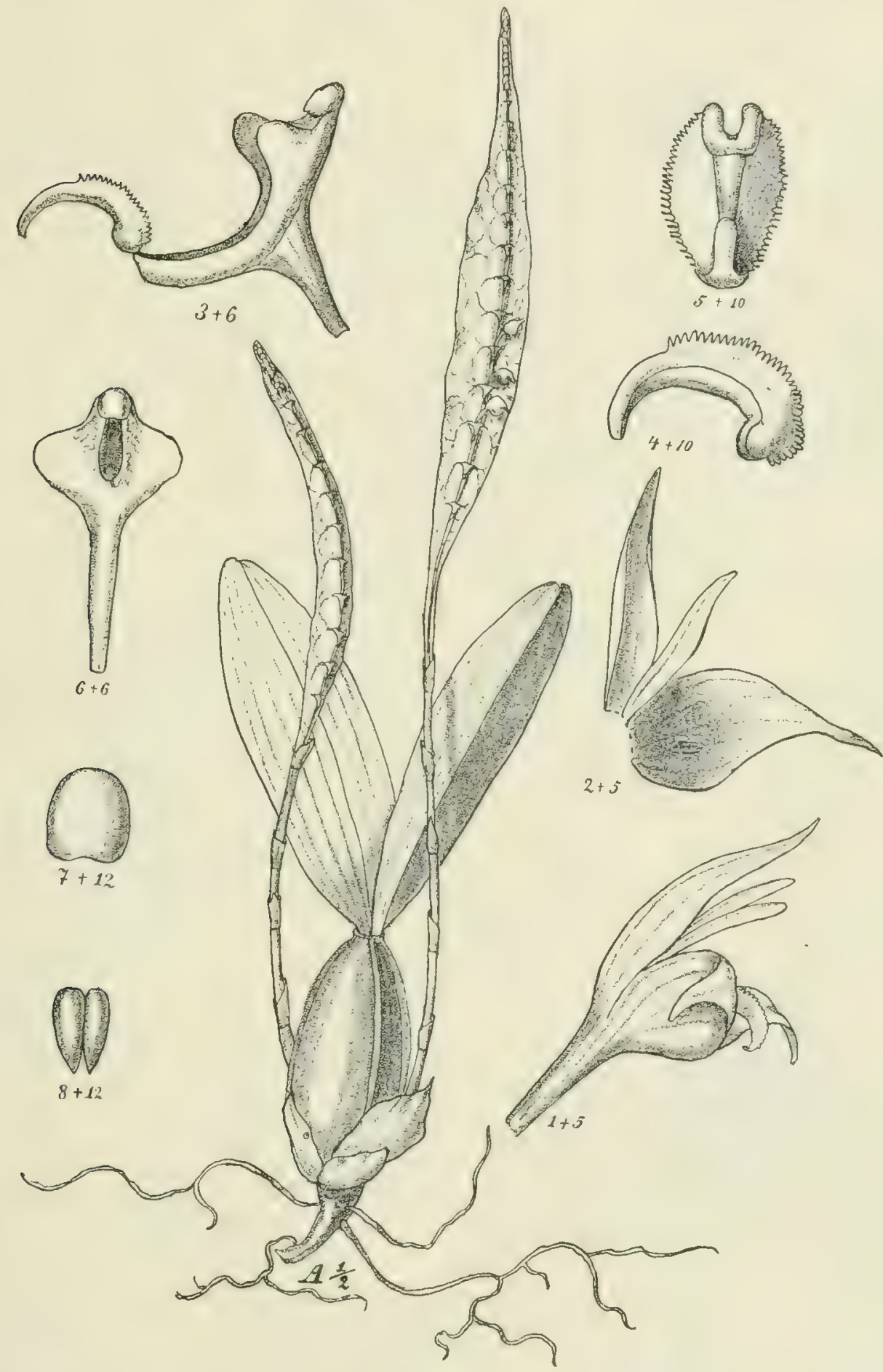

Fig. 289. Bolbophyllum oxypterum Rchb. f. $A$ ganze Pflanze; $I$ Blitte; 2 mittleres und ein seitliches Kelchblatt nebst einem Blumenblatt; 3 Säulchen mit Labellum; 4 Labellum von der Seite; 5 dasselbe von unten; 6 Säulchen; 7 Anthere; 8 Pollinien. - Nach Schlechter.

in Kamerun bei Viktoria; B. creonastes Rchb. f. mit zwei länglichen Blättern, etwa I dm langem Blütenschaft und $5 \mathrm{~cm}$ langer Ähre, im Kamerungebirge um $1600 \mathrm{~m}$ ii. M. Diese Arten haben höchstens $+\mathrm{mm}$ lange Bracteen. 0,7-1,2 cm 
lange Bracteen finden sich bei B. bifarizm Lindl., mit zwei schmal-länglichen Bliittern und zweireihig stehenden Blüten, im Kamerungebirge und Angola bis zu $1600 \mathrm{~m}$, ferner bei $B$. Mannii Hook. f. mit $4-7 \mathrm{dm}$ langem Schaft und I dm langer thre zweireihig gestellter Blüten, im Kamerungebirge um i6oo m

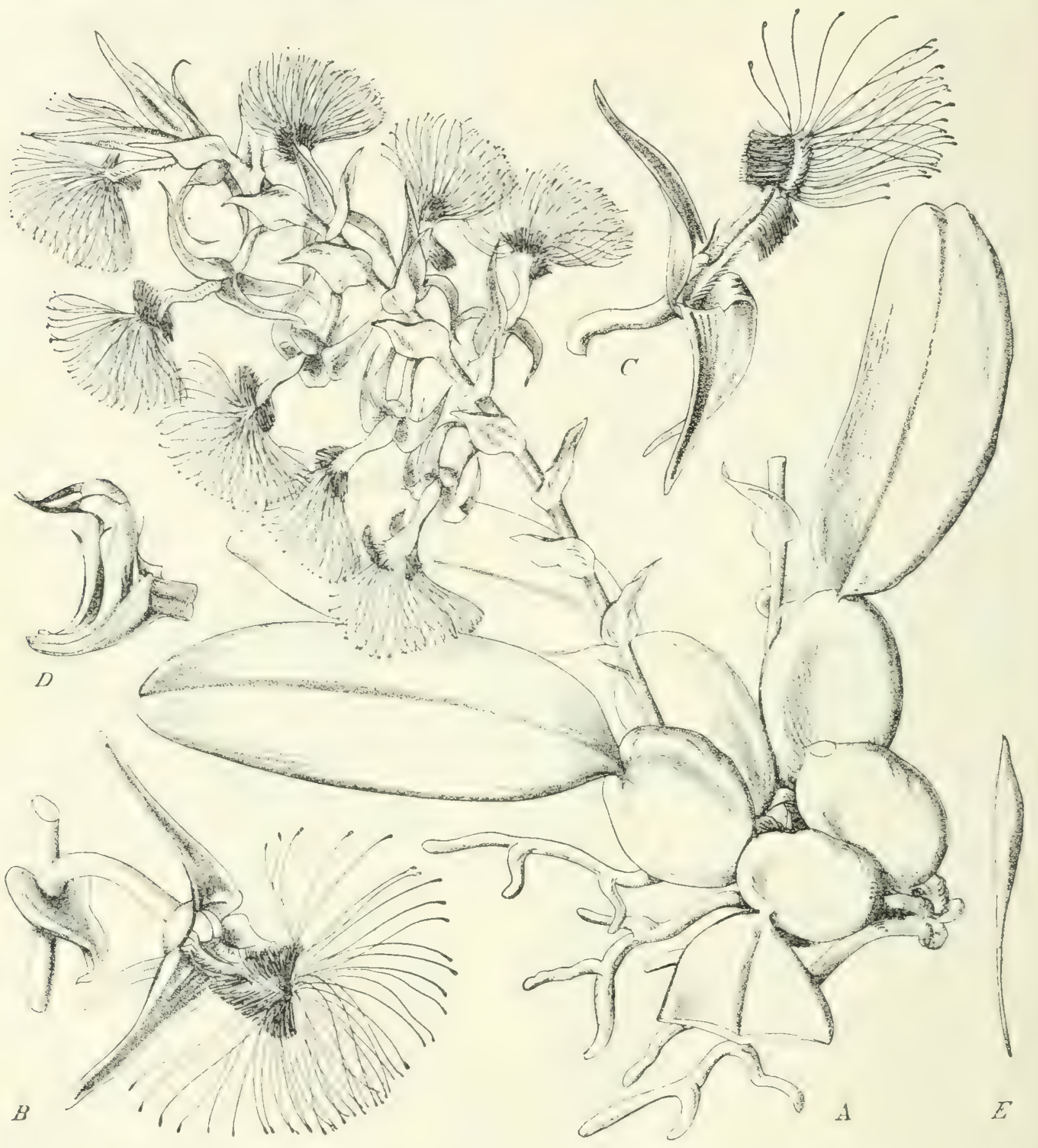

Fig. 290. Bolbophyllum barbigerum Lindl. (Sierra Leone, Lagos). $A$ Ganze Pflanze; $B, C$ Blüte; $D$ Säulchen mit Anthere; E Pollinium. - Nach Bot. Magaz.

ü. M. Die Bracteen sind $\mathrm{r}, 5-2 \mathrm{~cm}$ lang bei $B$. lupulinum Lindl. mit dreikantigen Luftknollen, länglichen Blättern, $3 \mathrm{dm}$ langen Blitenstengeln und I, $5 \mathrm{dm}$ langer Ähre, in Sierra Leone und Kamerun in der Küstenregion. Ein bis zwei spatelig-rerkehrtlanzettliche Blätter oberhalb der fast kugeligen I.uftknolle und nur $2,5 \mathrm{~cm}$ lange Schäfte mit ciner grünlich-weißen Bliite finden wir bei B. elacidum Lindl, auf Ölpalmen im Nigerdelta. 


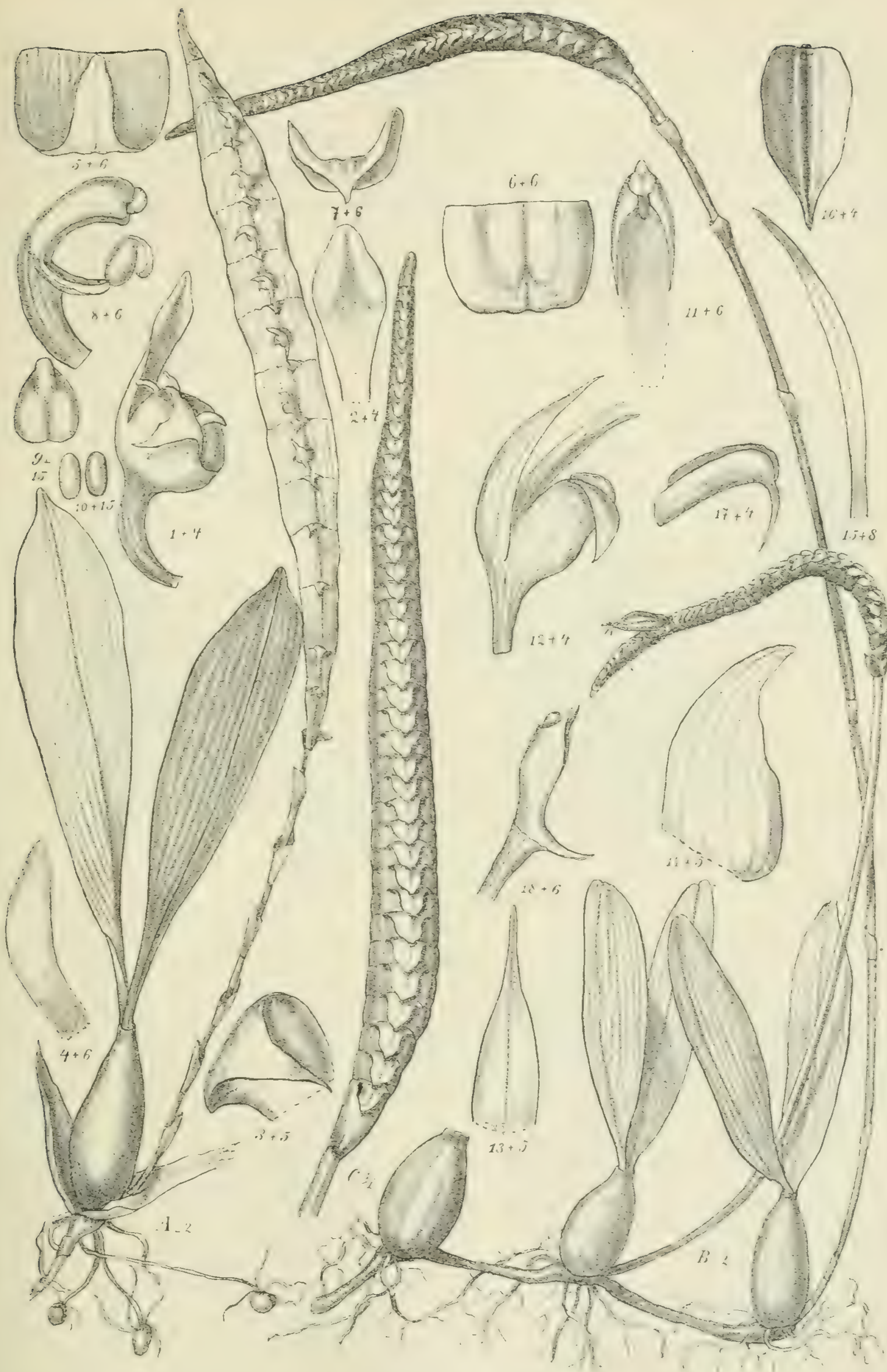

Fig. 29r. A Bolbophyllum Bakossorum Schltr. I Blite; 2 mittleres Kelchblatt; 3 seitliches Kelchblatt; 4 Blumenblatt; 5 Labellum von unten; 6 dasselbe von oben; 7 dasselbe von vorn; 8 Säulchen mit Labellum; 9 Anthere; IO Pollinien; II Såulchen von vorn. $B, C$ B. kamerurense Schltr. I2 Blüte; I3 mittleres Kelchblatt; I4 seitliches Kelchblatt; I5 Blumenblatt; 16 Labellum von oben; 17 dasstlbe von der Seite; 18 Säulchen. - Nach Sculecriter. 
Zahlreiche Arten haben Knollen mit einem Blatt und in Trauben stehende Bliiten, z. B. B. flaridlum Lindl. mit länglich-lanzettlichen Blättern, $7-12 \mathrm{~cm}$ langen Blïtenschäften und gelblich-grünen Bliiten, in Sierra Leone, das schöne 73. anrantiacum Krzl. mit goldgelben Bliitentrauben im Kamerungebirge um I $900 \mathrm{~m}$ ii. M., B. cocoinum Batem. Mit vierkantigen Knollen, einem lanzettlichen Blatt und einem bis $2,5 \mathrm{dm}$ langen, vielbliitigen Schaft, die Bliiten mit gewimpertem Labellum; $B$. comatum Lindl. mit lanzettlichem Blatt, I,2 dm langem Schaft, wollig behaarten Kelchblättern und gewimperten Blumenblättern, auf Fernando P'o; B. calamarium Lindl, mit einem bis $1,8 \mathrm{dm}$ langen, lederartigen Blatt, fast $6 \mathrm{dm}$ langem Schaft und $\mathrm{I}-\mathrm{I}, 5 \mathrm{dm}$ langer Traube gelber Bliten,

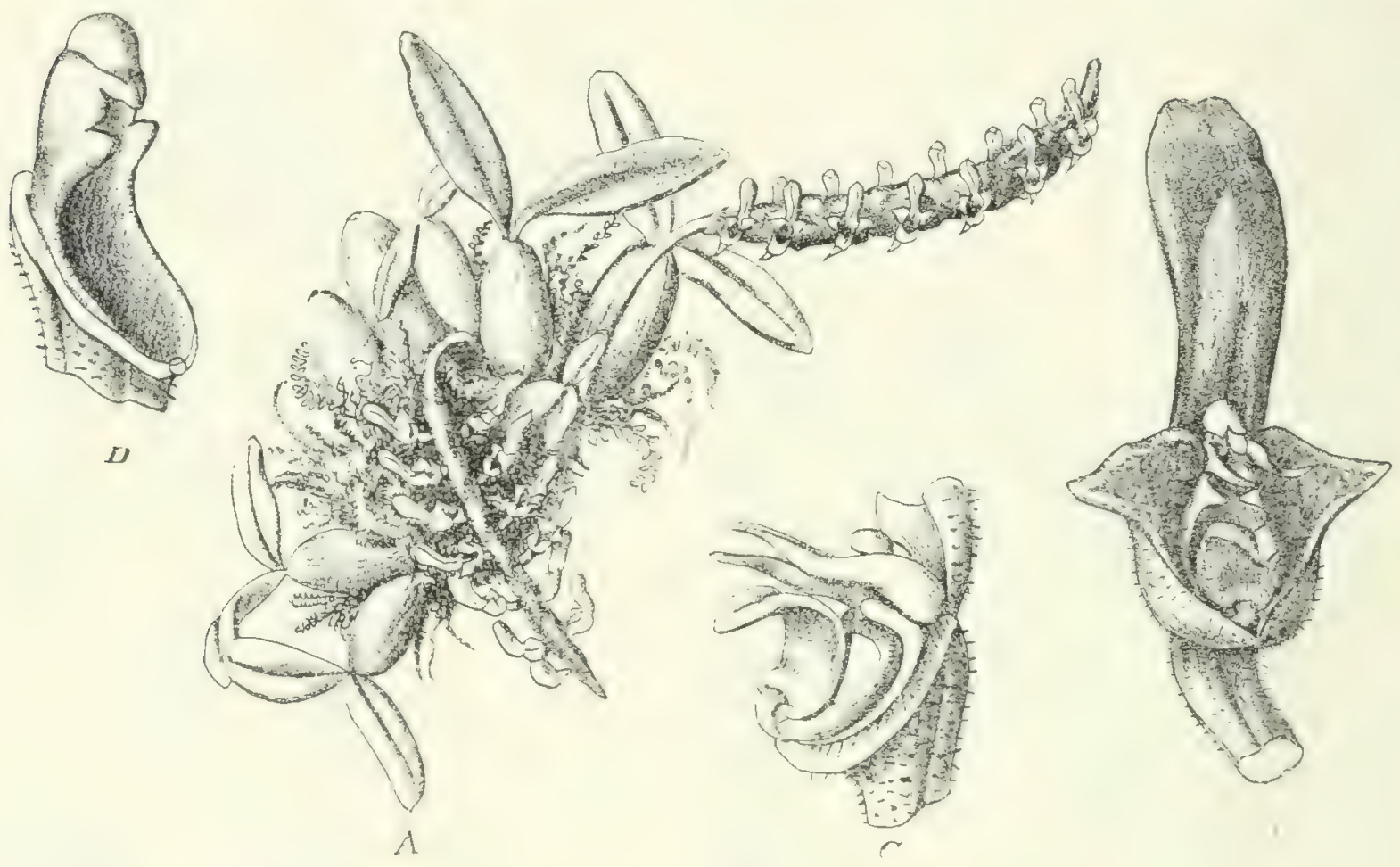

Fig. 292. Bolbophyllum minutum (Rolfe) (Sierra Leone). $A$ Ganze Pflanze; $B$ Blitie; $C$ Säulchen und Labellum; $D$ Säulchen mit Anthere. - Nach Bot. Magaz.

deren karminrotes Labellum zungenförmig und am vorderen Ende lang gewimpert ist, von Sierra Leone bis Kamerun. Ebenfalls gebärtetes Labellum findet sich bei $B$. saltatorim Lindl. in Sierra Leone und bei $B$. barbigernm Lindl. (Fig. 290), welche wohl auch noch anderweitig gefunden werden dirften, desgleichen bei IF. Findtianum de Wild. am Loliva im Kongogebiet. Ein dreilappiges Labellum kommt in den sehr kleinen Bluiten des B. horminiostachy's Rchb. f. von Sierra Leone vor.

In der Sektion Megaclinium haben wir zunächst einige Arten, bei denen die Rhachis der Blitenähre dick und fleischig ist und stumpfe Ränder besitzt, so bei B. strobilifernm Krzl. mit länglich-lanzettlichen 1,5 dm langen Blättern und $3 \mathrm{dm}$ langem, nach oben in eine spindelförmig verdickte Rhachis iibergehendem 13liitenschaft. Ähnlich verhält sich B. leucorrhachis Rolfe, cine schöne Art von Lagos, ferner B. Kermenunchse Schltr. von Bibundi (Fig. 29 I B, C). Die uibrigen 
Arten haben eine dün gefligelte Rhachis, wie das in Fig. 2y I I abgebildete B. Bakossomm Schltr. aus dem Nyassossogebiet. Wir kennen von diesem Typus etwa 20 Arten aus dem tropischen Westafrika, darunter auch B. Arnoldiannm de Wild. im Kongogebiet und B. Sangae Schltr. von Gabun, letztere mit fast krcisformigen, rosenkranzartig aneinandergereihten Luftknollen. Die kleinste Art ist B. mimutum (Rolfe) (Fig. 292) mit länglichen, $2,5-3 \mathrm{~cm}$ langen Blättern und $5 \mathrm{~cm}$ langen, karminroten Blütenschäften, von denen sich karminrot und goldgelb gefärbte Bliiten abheben; es kommt auf dem Sugastoaf in Sierra Leone bis $1000 \mathrm{~m}$ ii. M. vor. In Ostafrika fehlen auch die Arten dieser Sektion nicht gänzlich; so haben wir B. Melleri (Hook. f.) im Sambesigebiet auf dem Chiradzulu bei Namalowe, um $600-800 \mathrm{~m}$, B. Sandersoni Oliv. in Natal.

Ancistrochilus Rolfe aus der Gruppe der Phajeae ist eine monotypische Gattung. A. Thomsonianus (Rchb. f.) Rolfe, deren Eigentiimlichkeiten durch beistehende Figuren (Fig. 293, 294) erläutert werden, ist eine der schönsten afrikanischen Orchidaceen; sie kommt in geringer Höhe ii. M., unfern der Küste auf den Gebirgen von Old Calabar vor.

Angraecum Thou. ist die artenreichste Gattung

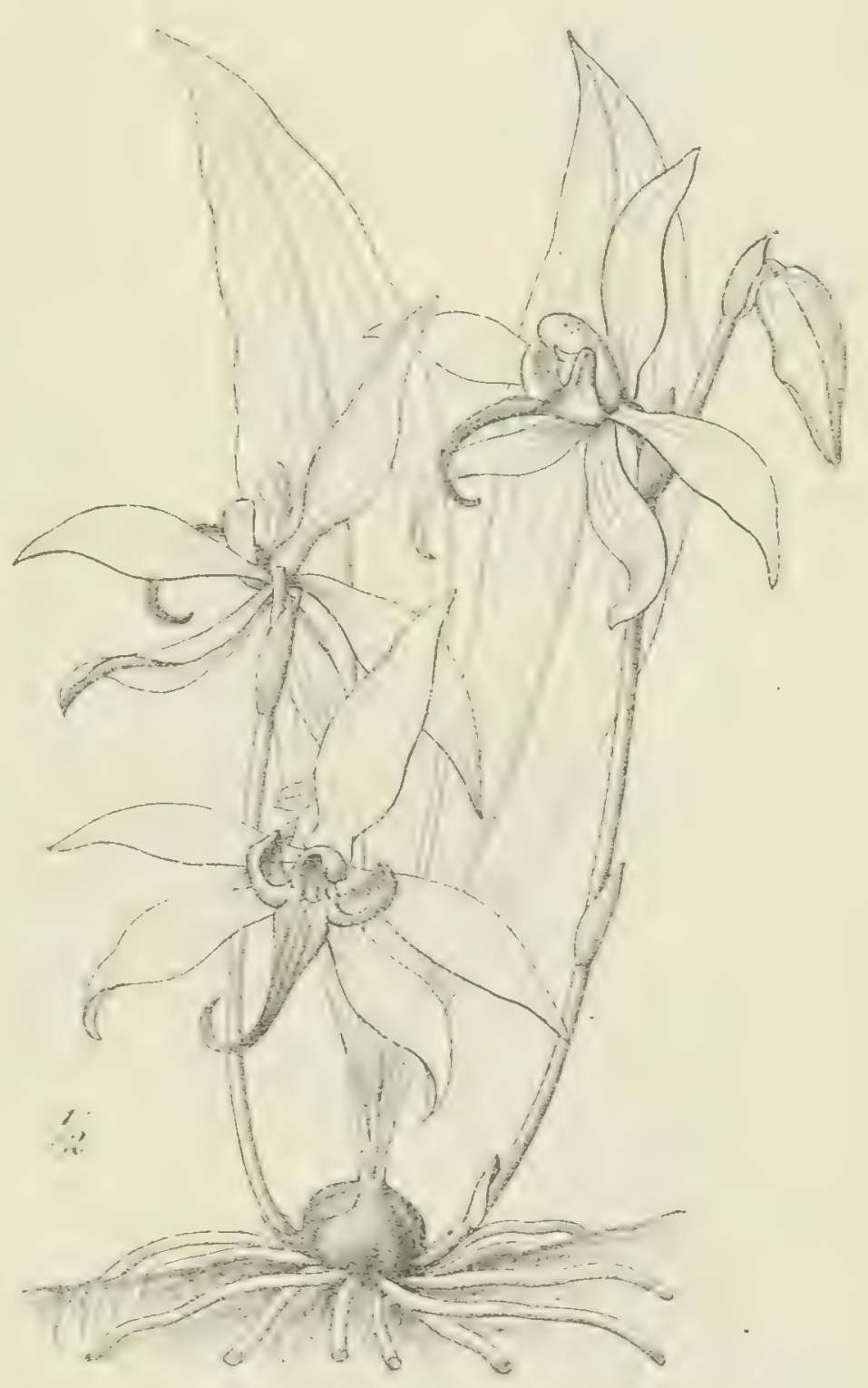

Fig. 293. Ancistrochilus Thomsonianus (Rchb. f.) Rolfe. Nach Bot. Magaz. untêr den epiphytischen afrikanischen Orchidaceengattungen, wenn man, wie es die Verwandtschaftsverhältnisse erfordern, Listrestrith's nicht davon abtrennt und Ifystaikizm auf die kapliandischen Arten heschränli. 13ei derartiger. Ungrenzung können wir etwa I30 Arten für das tropische Afrika annehmen. Sie sind besonders zahlreich in den Kegenwäldern des westlichen Kiistenlandes. fehlen aber auch nicht in \%entral- und ()stafrika, auch nicht in trockenen Steppengebieten und in den oberen Buschregionen der Hochgebirge. 
Für unsere Zwecke der allgemeinen Orientierung empfiehit es sich, das hahituclle l'erhalten voranzustellen und zuerst diejenigen Grupjen zu besprechen, bei welchen die zweiseitig beblätterten Stämmchen entweder frei aufrecht wachsen oder sich anklammernd klettern oder auch kurz bleiben. Hieran schließen sich ganz wenige Formen, bei welchen die diinnen Stengel von den Baumästen herunterhängen:

r. Arten, bei denen jedes der beiden kugeligen Pollinien mit einem Stielchen versehen ist, welches einer eigenen Drüse aufsitzt; diese Arten, zum Teil auch' als Acronthus beschrieben, werden von RoLFE zu Mystacidim gezogen, welche Gattung ich im Anschluß an BoLus und SCHLECHTER auf die kapensischen Arten beschränke. - Durch reitende, ein-

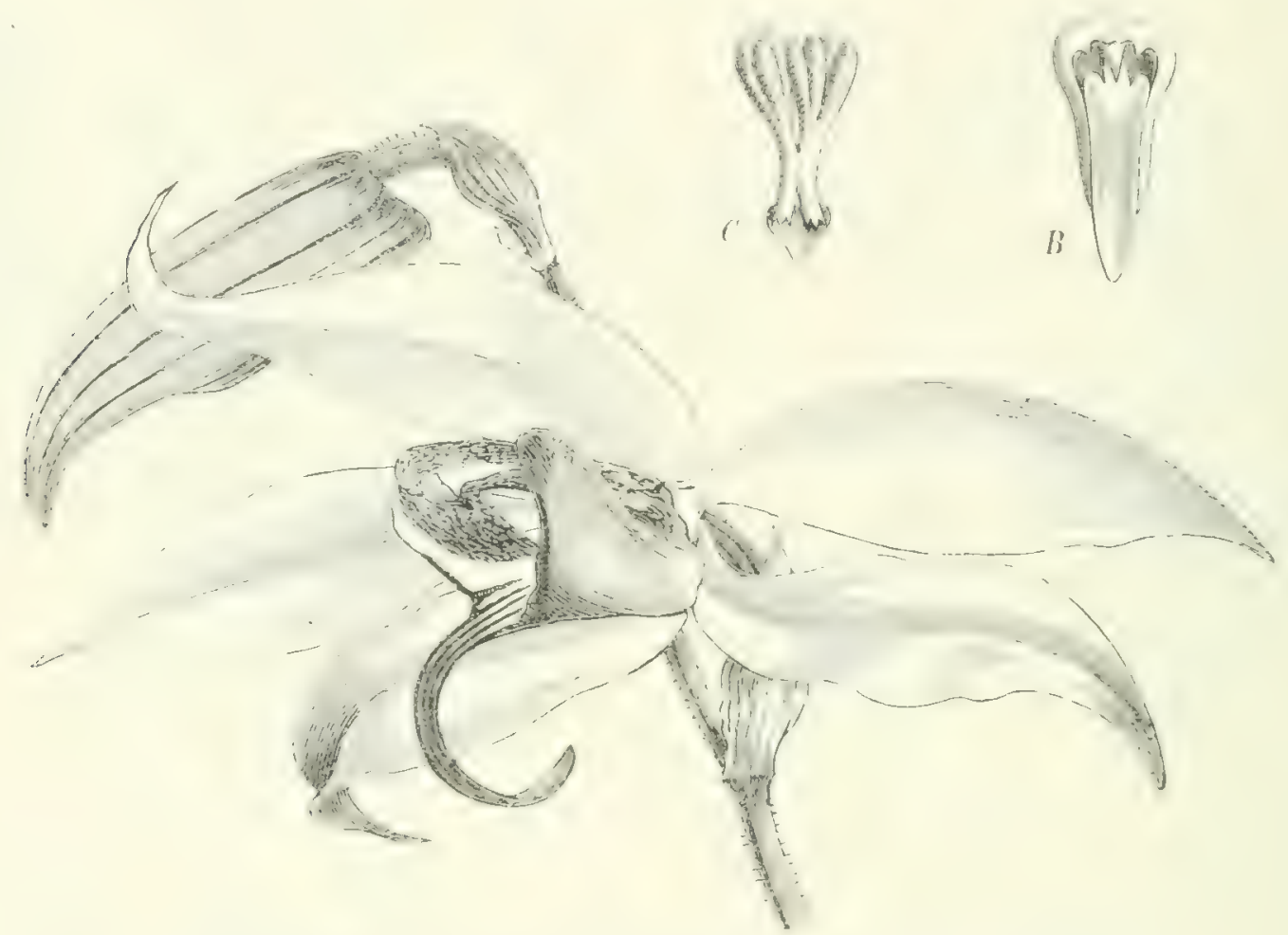

Fig. 294. Ancistrochilus Thomsonianus (Rchb. f.) Rolfe. A Blüte, in $\mathrm{n}$. Gr. (nach Gard. Chron.); $B$ Anthere; $C$ Polliwien.

ander dicht genihterte, sichelfümig zurückgehogene Blätter ist ron allen verschieden A. distichm Lindl. (Fig. 295) mit kleinen weißen Blüten, sehr verbreiteter, his 2 dm langer und verzweigter Epiphyt, ron Sierra Leone bis Gabun. - Die übrigen Arten haben flache Blätter. Eine schöne, stattliche Art mit $2,5-3 \mathrm{~cm}$ langen Internodien und $1,2-1,5 \mathrm{dm}$ langen Blättern, welche wie auch die vieler folgender Arten am Ende ungleich zweilappig sind, mit einzeln stehenden, großen, weißen Blüten, deren Kelch und Blumenblätter $5-6 \mathrm{~cm}$ und deren Sporn $\mathrm{I}-\mathrm{I}, 2 \mathrm{dm}$ lang wird, ist $A$. infundibulare Lindl. auf der I'rinces-Insel. Daran schließen sich die mit endständiger. zwci- bis dreiblitiger Traube und nur wenig kleineren Bliten versehenen A. astroarche Ridl. von St. Thomas und A. longicandatum (Rolfe) von Lagos. Viel mehr Arten haben erheblich kleinere Bliten in Trauben. Wir finden lange axilläre hängende 
Trauben an langem Stengel z. B. bei .1. romthopollinimu (Rchb. f., in Angola,

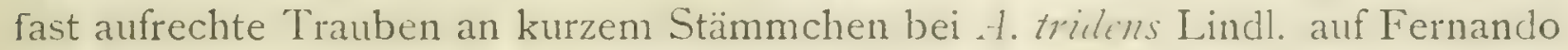
Po und bei $A$. dolabriforme (Rolfe) auf St. Thomas.

Venighliitige Trauben an kuirzerem oder längerem Stamm zeigen einige Arten West- und Ostafrikas. Hier können wir auch A. sesquipedale Thou. anführen, welches PFiTzER nebst einigen anderen Arten der Maskarenen und

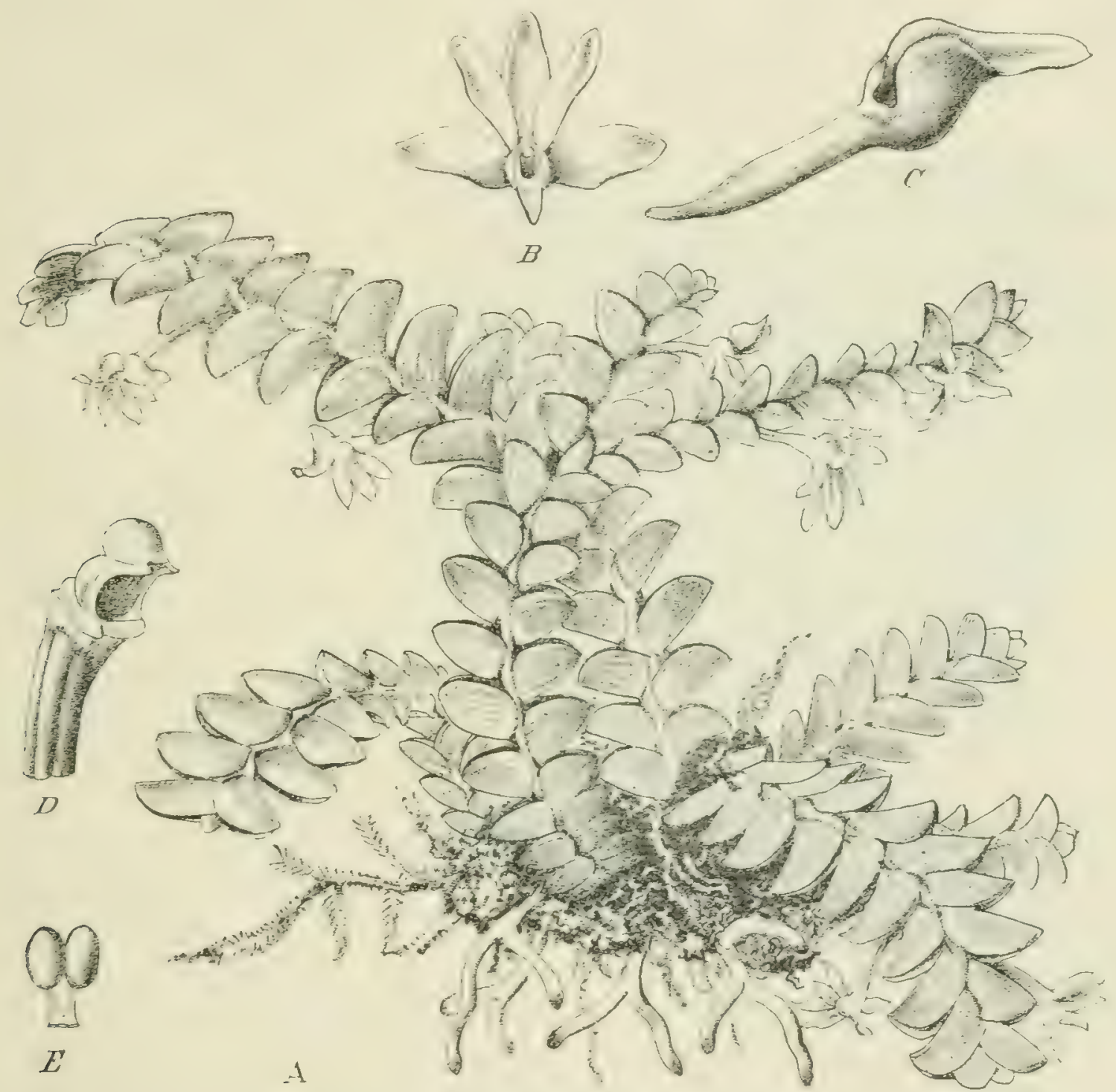

Fig. 295. Angraecum distichum Lindl. $A$ ganze Pfanze; $B$ Blüte; $C$ Labellum; $D$ Säulchen mit Anthere; $E$ Pollinien. - Nach Bot. Magaz.

Madagaskars als Gattung Macroplectrum abtrcunte. Indes scheint mir der Lnterschied, daß hier die Stielchen der Pollinien zwei getrennten, breiten Membranen aufsitzen, zu geringfügig, um die Aufstellung dieser Gattung zu rechtfertigen. A. sesquipedale Thou., von dessen Wachstum Fig. 24,6 eine Vorstellung gibt, übertrifft an Größe der Bliiten und Länge des Sporns $5 \mathrm{dm}$ ) alle anderen Arten; die Pflanze soll nicht bloß auf Madagaskar, sondern auch auf Sansibar vorkommen.

2. Jedes Pollinium ist gestielt, aber beide Stielchen treffen in einer Drüse zusammen bei Listrostuchy's. Die Zahl der mit längerem Stamm rersehenen 
Arten ist geringer, als die der kurzstämmigen. Einige Arten fallen auf durch besonders große Bliiten mit langem Sporn. Es muß aufmerksam gemacht werden auf $A$. caudatum Lindl. in Sierra Leone und dem Nigerdelta, mit lineallänglichen, $3 \mathrm{dm}$ langen und $4-5 \mathrm{~cm}$ breiten Blättern und 2,5-3 dm langen Trauben, deren Bliiten $+-5 \mathrm{~cm}$ lange, lincal-lanzettliche, srüne Kelch- und Blumenblätter und ein weißes, mit abgesetzter Spitze versehenes Labellum und einen bis 2,5 dm langen Sporn besitzen. Diese prächtige Pflanze wurde auch im Kongogebiet am Tumba-See unter I!"s. Br. gefunden. Nur wenig kleiner sind die weißen Blüten des von Lagos bis Kamerun vorkommenden .1. Chailhumum

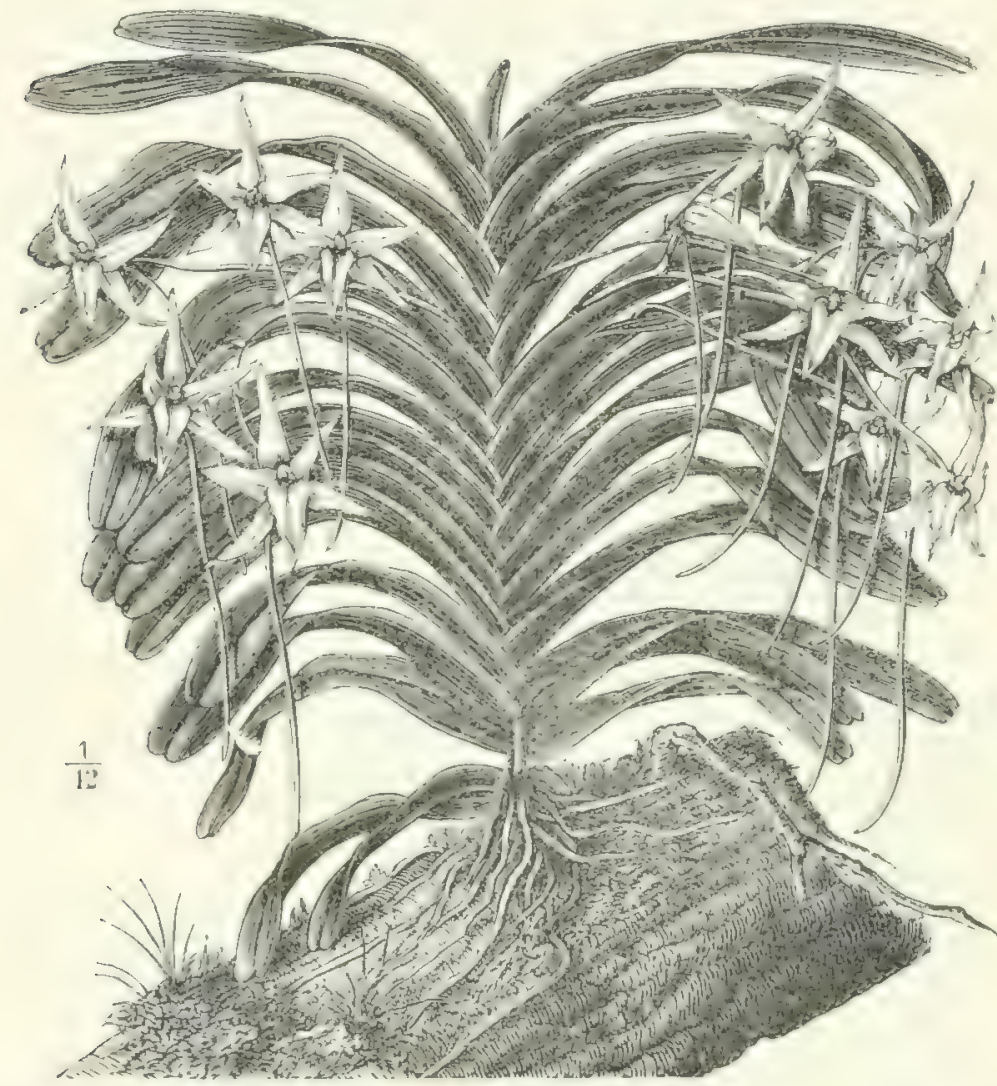

Fig. 296. Angraecum sesquipedale Thou. 1/12 n. Gr. Nach Nat. Pflzfam. Hook., bei welchem der grüne, zugespitzte Sporn 8- io cm lang wird. Von den im Westen vorkommenden, kletternden Arten mit kleineren Bliiten nenne ich noch 1 . bidens (Afzel.), mit $0,7-\mathrm{I}, 5 \mathrm{dm}$ langen Trauben weißer Bliiten, an denen die Sepalen $5 \mathrm{~mm}$, der keulenförmige Sporn nur $6-7 \mathrm{~mm}$ lang wird. Unter den kurzstämmigen Arten ist weitverbreitet von Sierra Leone bis Kamerun A. pellnicidum Lindl. $(=A$. Althoffii Krzl.), auffallend durch $3-6$ dm lange, hängende Trauben mit vielen, abwechselnd stehenden, durchscheinenden weißen Blüten. Bei A. vericatum Lindl., welches von der Goldkiiste his Kamerun rerbreitet ist, sind die Bractecn und Bliten gegenstindig; der gekrummte Sporn verkehrt-cifömis und angeschwollen. A. frergrentisimmin (Rchb. f.) ist ähnlich, hat aber einen kürzeren Sporn; es findet sich häufig in Angola um i Ioo $\mathrm{m}$ ü. M. auf Felsen, welche von Moosen und Flechten bedeckt sind, zusammen mit Rlipsalis und Sarcostemme. Drei ostafrikanische Arten, 1. mostaclinum Krzl.) in Usambara, .1. srominifolinm Krzl.) in IVestusambara, um I $900 \mathrm{~m}$ ï. M., mit schmal-linealischen Blättern, A. virgula Krzl. am Ruwenzori um $2700 \mathrm{~m}$ haben in Quirlen stehende Bliten. In Westafrika kommen vier Arten mit kopfigen Inflorescenzen vor, darunter A. Brannii (Durand et Schinz). - Einige andere westafrikanische Arten haben schwertförmige Blätter; es sind dies meist sehr kleine Arten, nämlich A. forsipatum (Krzl.) mit I dm langen Blättern und viel kuirzeren Trauben, um Buea in Kamerun bei I $400 \mathrm{~m}$ ï. M., 
- Z. Znkeri (Krzl.), mit t-5 cm langen Blättern und aufrechten, etwas längeren Trauben, bei Yaunde in Kamerun, A. Batesii (Rolfe) mit 2,5-6 cm langen Blättern und cinseitswendigen, vichbliitigen Trauben. - - Endiich gehurt noch zur Lntergattung I.istrustuhls eine dumnstengelige. hängunde, bisweilen uber 2 .m lange Art mit stielrunden. Blättern und wenigen, einzeln oder in Büscheln stehenden, weißen Blüten, A. subulatum Lindl,g auf alten Bäumen in der Mangrove von Sierra Leone bis zum Nigerdelta und auf Fernando Po. Ähnliches Wachstum zeigt A. filifornte (Krzl.) in Mpororo, um $2000 \mathrm{~m}$.

3. Die beiden Pollinien stehen auf gemeinsamem Stiel, der mit einer einzigen Drüse verbunden ist. Dies sind die Angraecum im engeren Sinne, zu denen auch etwa - Arten mit längerem, bisweilen kletterndem Stamm gehören: sie sind voneinander meist durch die Beschaffenheit des Labellums und des Sporns verschieden, und einige sind recht stattliche Pflanzen, so A. Ellisii Rchb. f. var. occilentale Krzl. im Regenwalde von Buea in Kamerun mit länglichen Blattern und ;-o (im langen Biitenstinden nit vielen, 5 -o cm im I)urch-

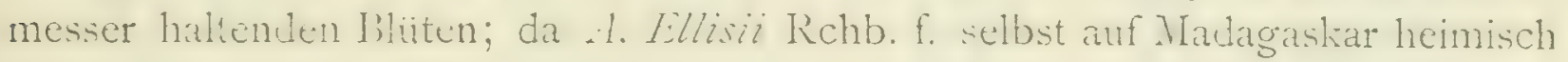
ist, so wird dieser Pflanze noch weitere Aufmerksamkeit zu schenken sein, ebenso wie dem A. Thomsoni Rolfe von Leikipia im Massaihochland (I goo bis

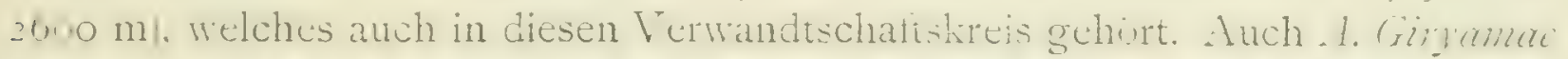
Rendle, mit is dm langen Trauben groluer rejlier I'iiten, das bui Mombis, auf Sansibar, in Ostusambara und am Kilimandicharo aufofunden wurde, ist mit

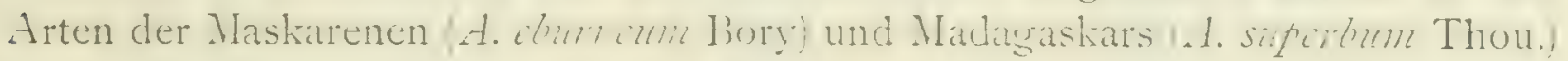
verwandt. Dagegen haben das in Kamerun und am Loango in Lunda vorkommende A. Eichlerianum Krzl. sowie das in der Erythrea bei Tilfil um $800 \mathrm{~m}$ von Prof. Schweinfurtil entdeckte A. Schocllerianm Krzl. wenigblitige Trauben. Das von Sierra Leone bis Kamerun verbreitete A. inbricatmm Lindl. hat, wie noch mehrere andere kletternde Arten West- und Ostafrikas, dreimal kleinere Blüten als die vorigen. - Vinc schr eigentumliche kletternde Art ist das hier abgebildete A. scandens Schltr. (Fig. 297) vom Ngoko in Südostlamerun, welches seine horizontal abstehenden Adventivwurzeln zum Spreizklimmen zwischen Gestriuch benutzt. Unter den kurzstimmigen Arten ist eine ganz besonders aufallende, .1. Holdlifolim (Rchb. f.) Rolfe, mit verkehrt-eiförmigen, zweilappigen Blittern, bis 3 dm langen Trauben und über $2 \mathrm{dm}$ langem Sporn, in Angola. Thnliche Blätter, ahur viel kleincre Inflorescenzen und Bliiten besitzt das abyssinische A. brachycarpum Rchb. f. Als weiter verbreitete Arten ()stafrikits seien noch genannt -1. Kirki Rchb. Rolfe mit schmal heilförmigen Blättern, aufrechten odur abstehenden, zwei- bis funfblitigen Trauben und bis $3.5 \mathrm{~cm}$ langen Kelchilattern. non . Lombas bis L'sambara und am Kilimandscharo, 1. Kutsklumm Rchb. f. Fisg. 21,5 mit länglichen Blättern, langen, hängenden Trauben und ehenfalls bis $3,5 \mathrm{~cm}$ langen Kelchblättern, von Obersennar zerstreut bis zum siidlichen Nyassaland, A. dives Rolte mit lineal-länglichen Blättern, zahlrcichen, vielblitigen Trauben und nur ; mm langen Kelch- und Blumenblittern, bei Momhas und am Kilimandscharo. Von kleinblitigen westafrikanischen Arten möge noch - t. gracillmum Krzl. 
erwähnt werden, mit länglich verkehrt-eiförmigen Blättern und $3-+$ dm langen, wenigblütigen Trauben.

Interessant ist, daß bei dieser Gattung wie bei einigen anderen epiphytischen Orchidaceen sich auch Arten herausgebildet haben, deren Stengel wie bei Polymhiza und Taeniophyllum keine Laubblätter, sondern nur Niederblätter

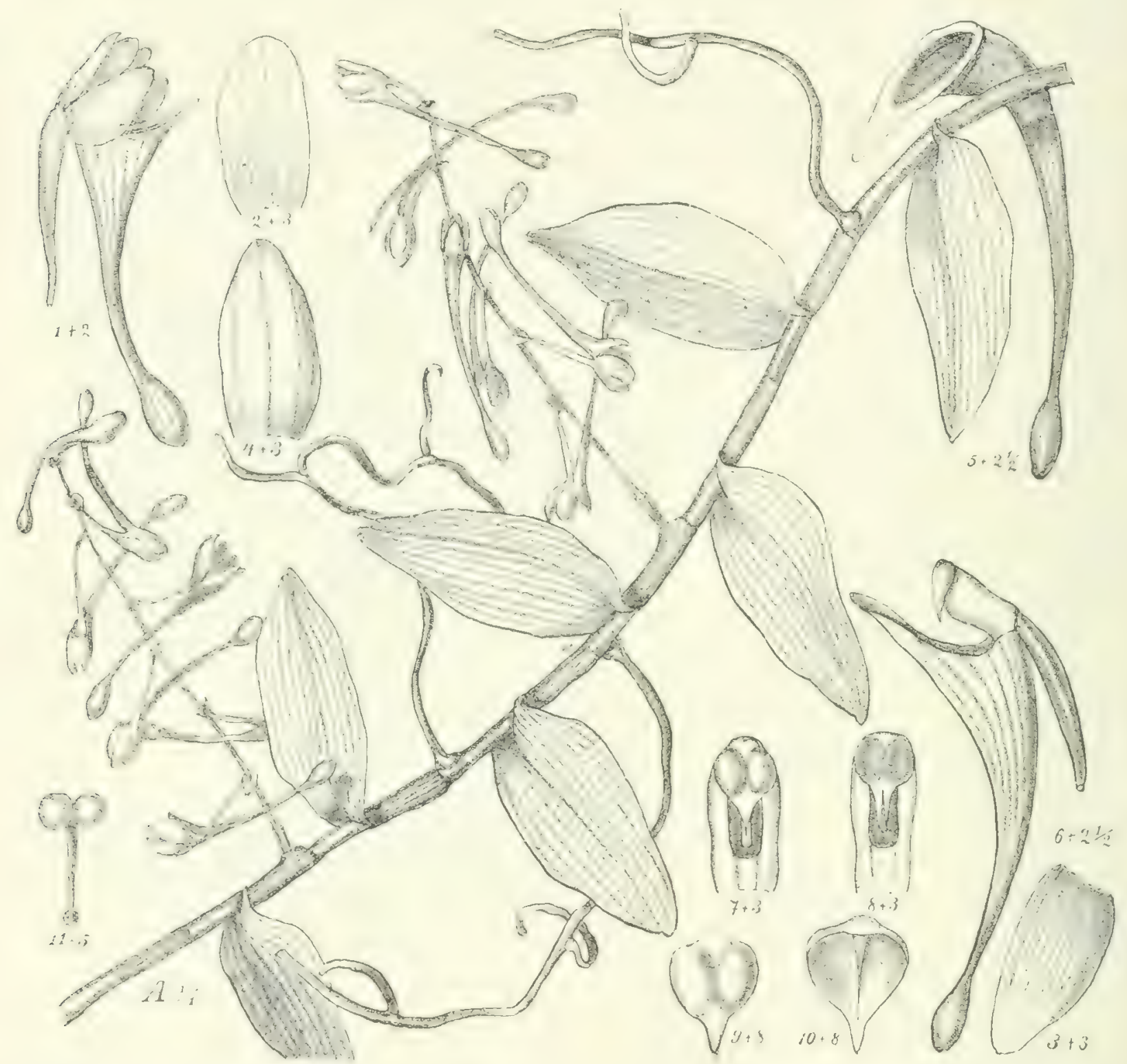

Fig. 297. Angraecum scandens Schltr. A Stiick der Pflanze; I Blüte; 2 mittleres Kelchblatt; 3 seitliches Kelchblatt; 4 Blumenblatt; 5 Labellum; 6 dasselbe mit dem Säulchen von der Seite; 7 Säulchen von vorn; 8 dasselbe nach Entfernung der Anthere; 9, IO Anthere von vorn und hinten; II Pollinien. - Nach Schlechter.

entwickeln. Alle diese Arten haben dafür sehr lange Haftwurzeln, vermöge deren sie auch assimilieren. Dies ist zunächst bei 1. aplullum Thou. der Fall, welches einen kletternden stengel besitzt, an welchem zahlreiche, bis $2,5 \mathrm{~cm}$ lange Blütentrauben mit zicmlich lang gespornten, kleinen Blüten sitzen; diese interessante Pflanze ist unweit Mombas anzutreffen und findet sich auch auf Mauritius und Madagaskar. Einige andere laubblattlose Arten haben ganz kurze Stämmehen, 


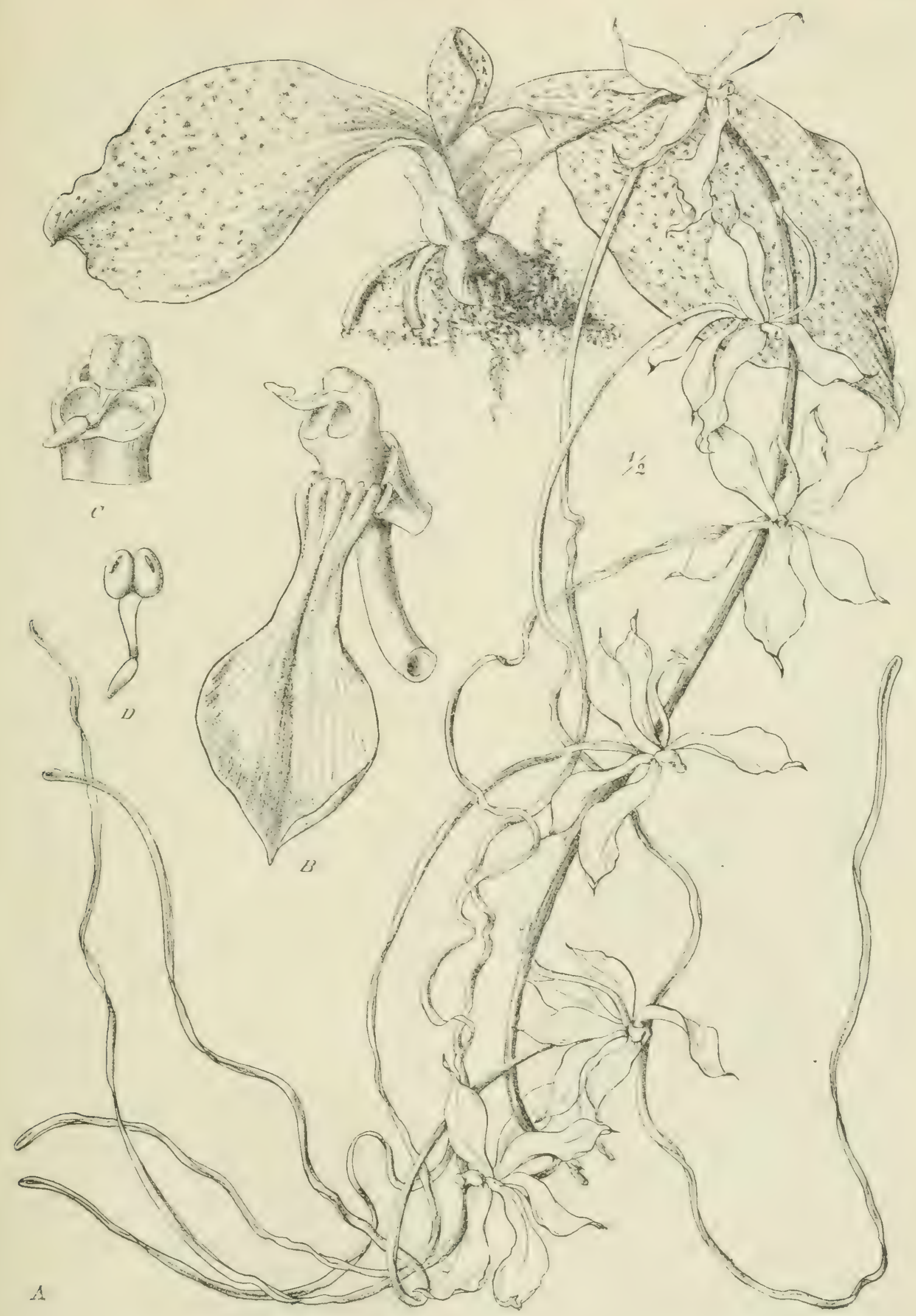

Fig. 298. Angraecum Kotschyanum Rchb. f. $A$ Ganze Pflanze; $B$ Säule und Platte des Labellums mit einem Stïckchen des Sporns; $C$ Anthere geöffnet, die Pollinien zeigend; $D$ Stielchen mit den Pollinien. - Nach Bot. Magaz. 
S() 1. (jugnnimmm Rehb, f., dessen zahlreiche Trauben Bliten mit $5 \mathrm{~mm}$ langem Sporn tragen, verbreitet von der Erythrea bis Taita und in Angola; ferner A.chilochisterc Rchb.f., dessen

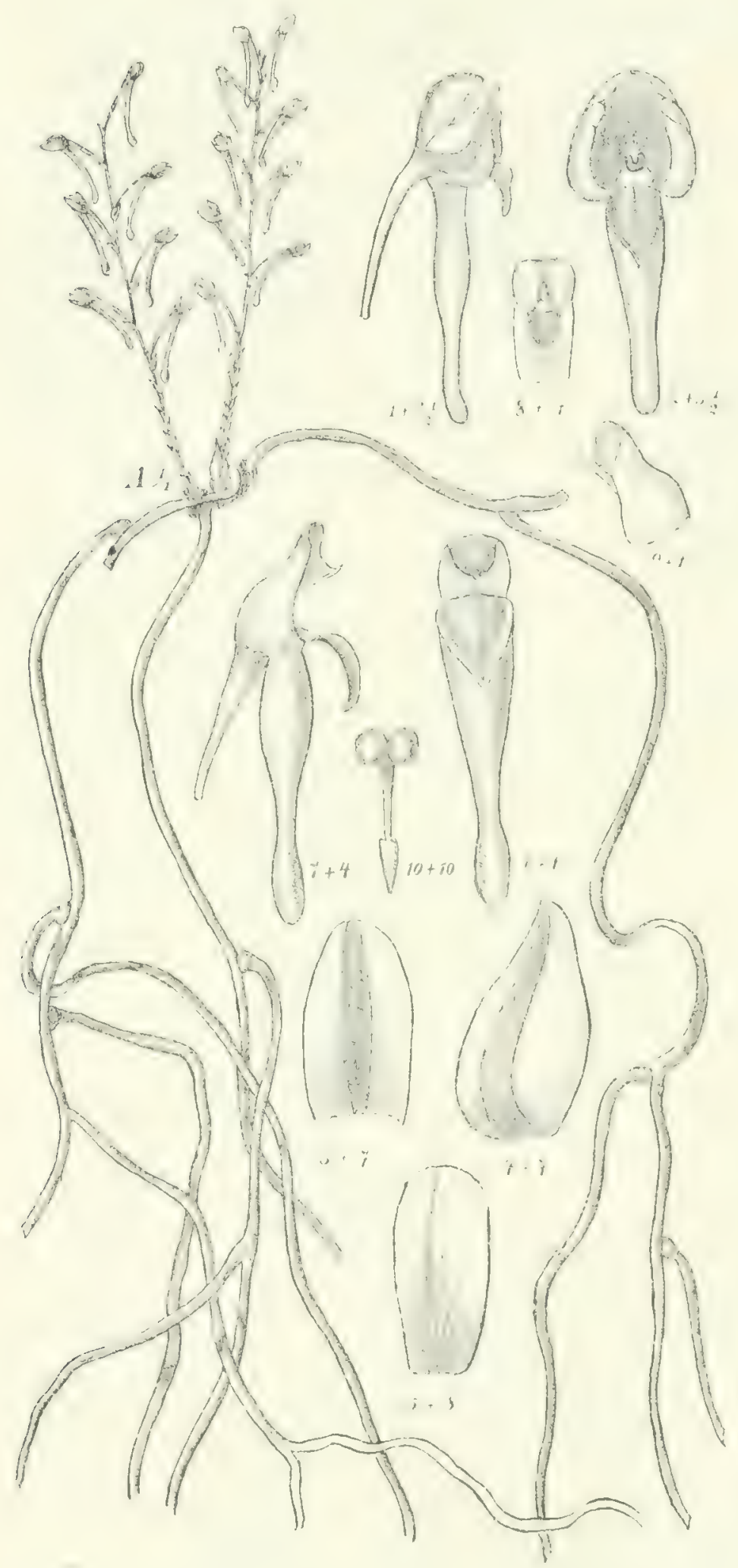

Fig. 299. Angraecum micropetalnm Schltr. A ganze Pflanze; $I$ Blitte; 2 dieselbe von vorn; 3 mittleres Kelchblatt; 4 seitliches Kelchblatt; 5 Blumenblatt; 6 Labellum mit Säulchen von vorn; 7 dieselben von der Seite; 8 Säulchen von vorn; 9 dasselbe von der Seite; ro Pollinien. - Nach Schlechter.
Bliiten nur halb so groß sind als bei der vorigen Art und einen kurzen, breit sackförmigen Sporn besitzen; es ist von Mombassa durch die ostafrikanischen Steppengebiete bis Natal verbreitet und auch auf Madagaskar anzutreffen. Aus Westafrika ist das hier abgebildete, in Kamerun heimische A.micropetalum Schltr. zu erwähnen; durch besonders reichliche Wurzelbildung zeichnet sich A. crinale de Wild. aus, das bis jetzt bei Kiri im Kongogebiet gefunden wurde. Schließlich sei auch noch das ebenfalls mit den Wurzeln assimilierende, aber mit $1,2-2 \mathrm{dm}$ langen Blütentrauben versehene A. konduense de Wild. von Kondue im Kongogebiet erwähnt.

Saccolabium Blume steht der vorigen Gattung sehr nahe und ist hauptsächlich durch ganz kurzen Sporn und deutlich dreilappiges Labellum charakterisiert. Wir kennen bis jetzt nur zwei Arten von Mombas, welche der durch fleischiges Labellum charakterisierten Sektion Acampe angehören, S.pachyglossum Rolfe und S. mombersense Rolfe, beide mit etwa 2 dm langen, zungenförmigen Blättern und in Trauben oder Rispen stehenden Bluiten. 
c) Erdorchideen.

Die zahlreichen Erdorchideen Afrikas können wir in ombrophile, mesohydrophile und xerophile cinteilen: aber wenigstens die beiden letzten Typen finden sich häufig in derselben Gattung vertreten.

a) Vorherrschend ombrophile Gattungen, die zugleich auch hydrophil oder hygrophil sind.

Disperis Sw. Von dieser auffälligen, auch im Monsungebiet verbreiteten, durch zwei gespornte Kelchblätter ausgezeichneten Gattung gibt es teils subxerophile Arten, welche in großer Zahl im Kapland, in geringerer auf den afrikanischen Hochgebirgen auftreten, teils ombrophile Arten, welche in den Schluchten- und Regenwäldern des tropischen Afrika wachsen. Die waldbewohnenden Arten haben meist zwei bis drei breite, einander genäherte oder gegenständige Blätter, so D. Reichnoachiona IVelw. bei Pungo Andongo in Angola, D. Folnnstonii Rchb. f. und D. Kerstenii Rchb. f. im Gürtelwald des Kilimandscharo, D. ncmorosa Rendle im Bergwald des Ruwenzori, D. togoensis Schltr. (Fig. 30o) auf den Agomebergen bei Aschantikpoeta, D. mozambicensis Schitr. in feuchten Gebüschen bei Beira an der Mündung des Pungwe, D. virrginalis Schltr. und D. anthoceros Rchb. f. in Bergwäldern am Houtboschberg Transvaals (bei $2200 \mathrm{~m}$ ), D. comorensis Schltr. auf den Comoren.

Pogonia Juss., zu den NeottieacPogoninae gehörig, sind Kräuter mit knolligem Rhizom und nur ein bis drei nach dem Blïhen auftretenden Blättern: der schaft trïgt entweder Einzelbliiten oder eine Traube. Traubenblütige Arten sind P. Kotschyi Rchb. f. in Obersennar,

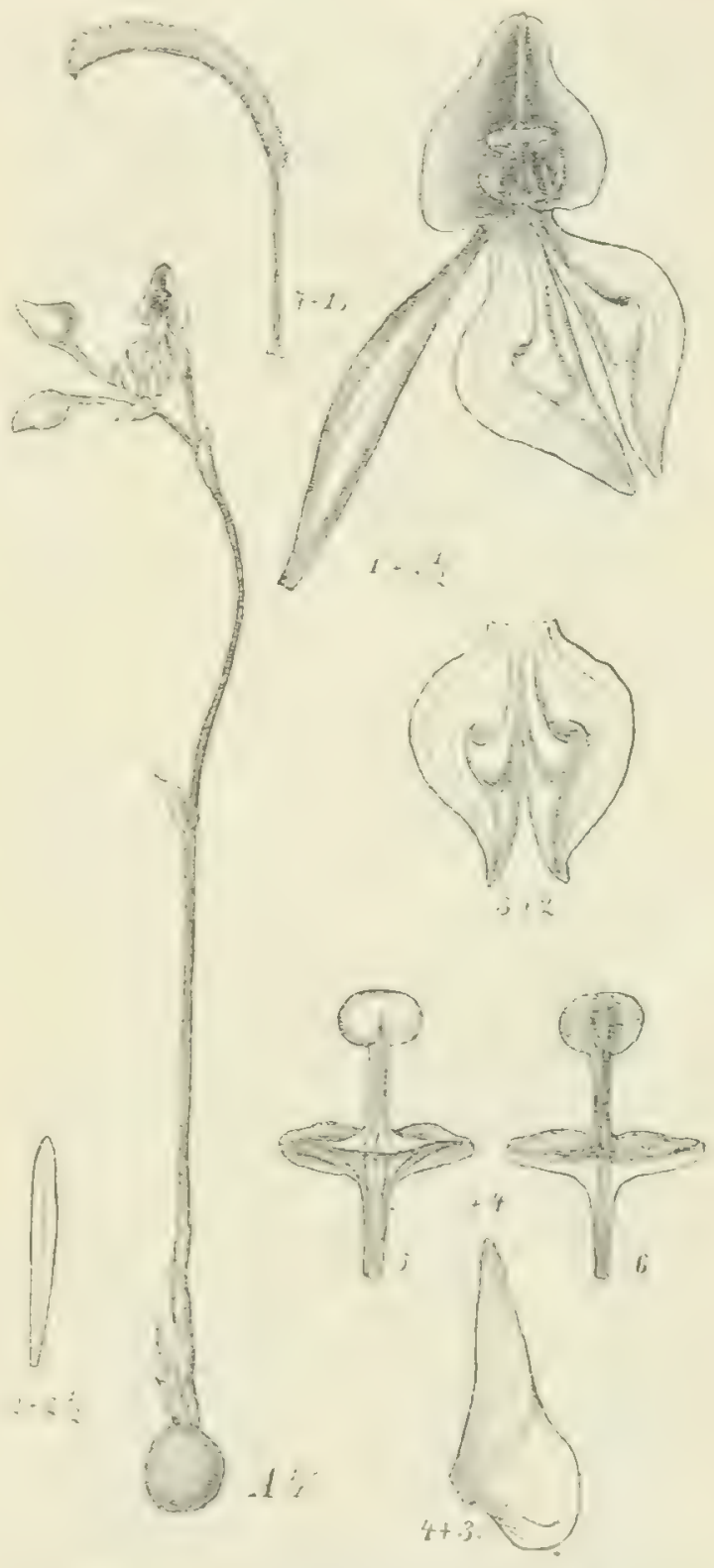

Fig. 300. Disperis togoensis Schltr. A Pflanze in nat. (ir.; I likite; : mittleres Kelchblat: 3 seitliche liclehiblitter: + Shlumenblatt: 5I abellum won vern; o dasselloc ron hinten: 7 Pollinium. - Nach Schlechter. P. umbrosa Rchb. f. mit 4-7 dm hohem Schaft und einem ei-nierenförmigen Blatt auf den westafrikanischen Inseln und ron Sierra Leone bis Angola an

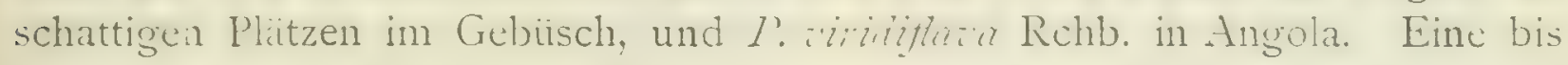
zwei große Bliiten finden wir bei $P$. shirensis Rolfe und $P$. Buchananii Rolfe (Fig. 30I) im südlichen und nördlichen Nyassaland, nur eine Blïte an dem $5-7 \mathrm{~cm}$ hohen Schaft der P. Thouarsii Blume (?) in Sierra Leone. 


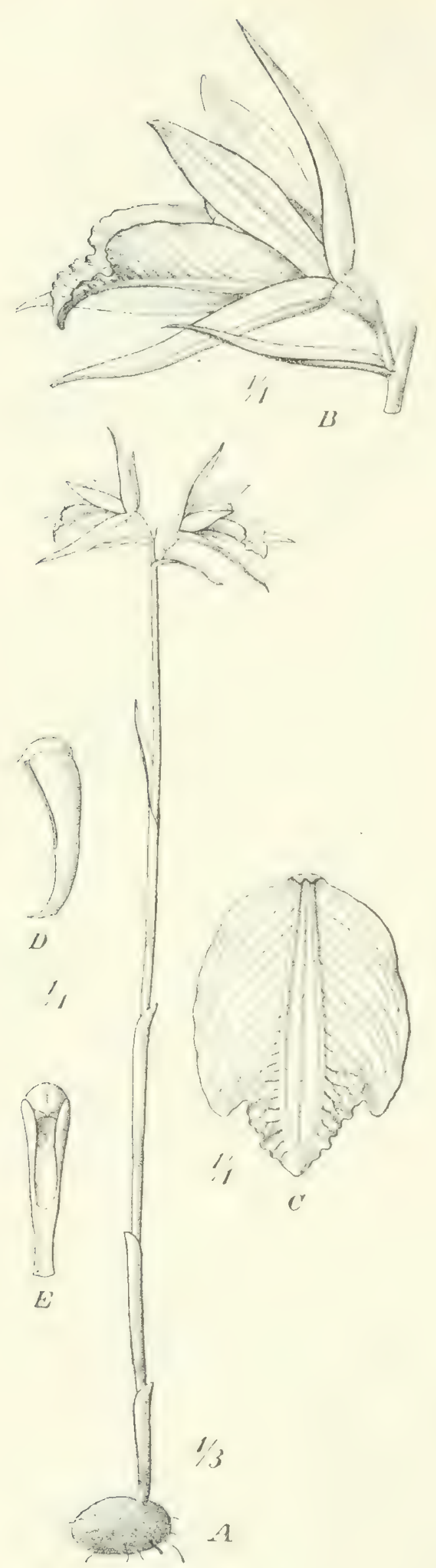

Fig. 30r. Pogonia Buchananii Rolfe (Unyika im nördlichen Nyassaland), - Original.
Epipactis L. C. Rich. aus der Gruppe der Neottieac-Cephalantherinae, bekanntlich in Europa durch einige weitverbreitete Arten vertreten, ist neuerdings auch in Afrika nachgewiesen worden. E. abyssinica Pax in Abyssinien, im östlichen Schoa, ist eine $4 \mathrm{dm}$ hohe Pflanze, welche vorzugsweise an Bachufern vorkommt und der orientalischen E.veratrifolia Boiss. nahesteht. E. somaliensis Rolfe ist eine $3-6 \mathrm{dm}$ hohe braunbehaarte Pflanze, welche im Küstengebirge des Somalilandes sowie des Gallahochlandes in Bachbetten der Waldregion vorkommt, und die nahestehende E. africana Rendle, eine viel kräftigere, bis $2 \mathrm{~m}$ hohe Pflanze mit $6 \mathrm{dm}$ langer Bliitentraube kommt auch im Gallahochland im Gebiet Sidamo an Waldbächen vor, ferner am Ruwenzori in der Heideregion um 2600-3300 $\mathrm{m}$.

Nervilia Gaud. Bei dieser mit der vorigen verwandten Gattung ist ein einziges rundliches Laubblatt vorhanden, und die durch verlängertes Säulchen ausgezeichneten Blüten stehen an einem laubblattlosen Schaft. Es wurde von Prof. Volkens bei Marangu am Kilimandscharo eine nicht blühende Pflanze gesammelt, welche mit Nervilia vom Himalaya Ähnlichkeit hat.' Es sei hier nur darauf aufmerksam gemacht, damit eventuell konstatiert werden kann, ob die Planze zu Pogonia oder Nervilia gehört.

Zeuxine Lind1. und die folgenden Gattungen der Neotticae-Physurinae lieben etwas Feuchtigkeit an halbschattigen Plätzen. Es sind kleine, höchstens $4 \mathrm{dm}$ erreichende Pflanzen mit kriechendem Rhizom, sitzenden Blättern und kleinen, in $̈$ hren stehenden Bluiten mit freien Kelchblättern. Sechs Arten finden sich von Sierra Leone bis Angola, meist an Bachufern der Regenwälder. Im eigent- 
lichen Ostafrika ist die Gattung noch nicht nachgewiesen: aher wir kennen Z. cochlearis Schltr. aus Natal, wo sie auf feuchten sandigen Plätzen im Mundungsgebiet des Umgeni-Rirer bei Durban vorkommt. Andere Arten finden sich im Monsungebiet.

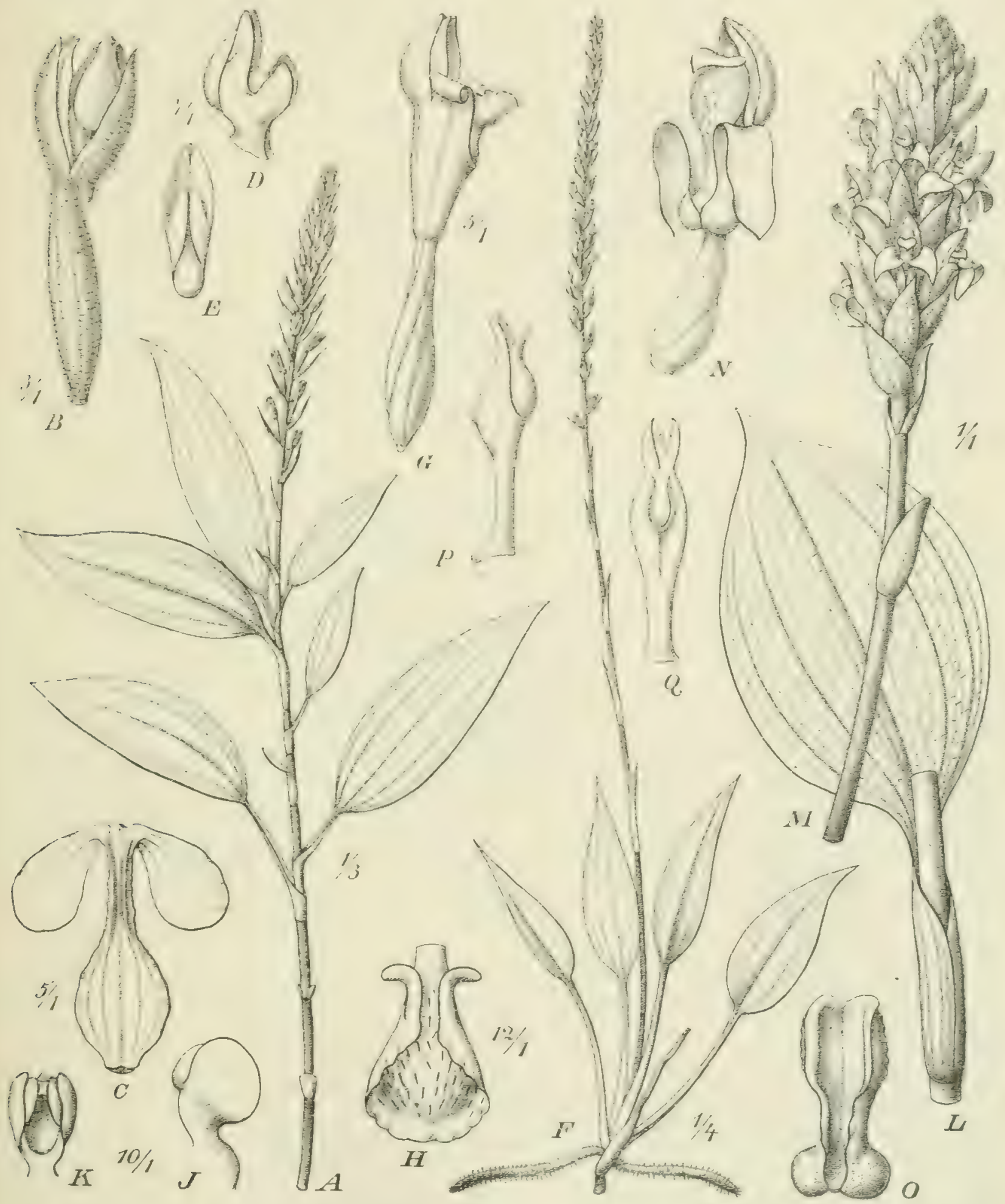

Fig. 302. $A-E$ Hetaeria Mannii (Rchb. f.) Benth. $A$ Habitus; $B$ Einzelblite; $C$ Labellum; $D$ Gynostemium von der Seite gesehen; $E$ dasselbe von vorn; $F-K$ Platylepis Engleriana $K$ rzl.; $F$ Ganze Pflanze; $G$ Einzelblüte; $H$ Labellum; $\mathcal{F}$ Gynostemium von der Seite gesehen; $K$ dasselbe von vorn; $L-Q$ Platylepis glandulosa (Lindl.) Rchb. f.; $L$ Blatt; $M$ Hlititenstand; $V$ Einzelblüte; O Labellum; $P, Q$ Gynostemium. - Nach Bolus. 
Cheirostylis Blume, von voriger Gattung durch bis zur Mitte verwachsene Kelchblätter verschieden und mit aufrechten, schmalen Armen an der Säule, ist mit zwei Arten auf den Gebirgen von Sierra Lcone, auf der Insel St. Thomas und dem Kamerungebirge von goo- $1000 \mathrm{~m}$ vertreten; sie haben zahlreiche kurz gesticlte blitter mit hreit ciformiger Spreite und kurze vielbliitige Trauben.

Hetaeria Blume. Während bei den beiden vorigen Gattungen die Pollinien in einen länglichen Stipes übergehen, sitzen bei dieser Gattung die Schwänzchen der Pollinien der Klebmasse des Rostellum unmittelbar auf. $H$. Mannii (Rchb. f.) Benth. (Fig. $302 A-E$ ), etwa $5 \mathrm{dm}$ hoch, mit elliptisch-lanzettlichen Spreiten und rielblütger Traube, ist clic einzige Art, welche am Kamerunfluß vorkommt. Alle iibrigen Arten sind in Vorderindien und dem Monsungebiet heimisch.

Platylepis A. Rich. ist von voriger Gattung durch eine lange schlanke Säule unterschieden. Die einzige kontinental afrikanische Art, P. glandulosa (Lindl.) Rchb. f. (Fig. $302 L-Q$ ), kommt auf Fernando Po um $600 \mathrm{~m}$, auf der Princes-Insel und in Angola vor, ferner auch in Natal. Drei andere Arten wachsen auf den Maskarenen.

Manniella Rchb. f. unterscheidet sich von beiden vorangehenden Gattungen dadurch, daß die Kelchblätter unter der Mitte eine Röhre bilden. $M$. Gustavi Rchb. f. ist eine $6--7 \mathrm{dm}$ hohe Pflanze mit einigen breit-eiförmigen Grundblättern und $\mathrm{I}, 5-3 \mathrm{dm}$ langer Traube; sie wächst auf St. Thomas von IOO-I IOO m, auch auf dem Kamerungebirge und in einer Varietät picto de Wild. auch bei Kondue am oberen Kasai.

Microstylis Nutt. Von dieser in den Tropen verbreiteten und auch in Europa vertretenen Gattung kommt .1. frurefins Krzl. auf dem Sugarloaflurg in Sierra Leone an feuchten Felsen im Walde vor, während MI. stclidostachj' Rchb. f., ein auch nur 5-8 cm hohes, sehr kleines Pflänzchen, sich auf der Princes-Insel findet. Mit der letzten Art nahe verwandt ist M. katochilos Schltr. in Bambusbeständen bei der 25-Miles-Station oberhalb Beira, um $70 \mathrm{~m}$ ü. M. Die Gattung besitzt so wie Oberonia ein nach oben gekehrtes Labellum.

Orestias Ridl., so wie Liparis mit nach unten gekehrtem Labellum, ist besonders charakterisicrt durch seitlich stehende, weit divergierende Theken der Anthere. O. clegans Ridl. ist ein bis jetzt nur von St. Thomas bekannt sewrordenes. is cm hohes Plänzchen mit eifümigen oder lanzettlich-eiformigen Blättern.

Liparis Rich., von voriger Gattung durch parallel verlaufende Theken unterschieden. enthalt aulser ciner epiphytischen und einigen in Nooren wachsenden Arten einzelne, welche in Regenwäldern am Boden wachsen, so die stattliche L. Bowokeri Harv. in beschatteten Felsspalten Kaffrariens, Natals, des Nyassalandes und des Kilimandscharo, ferner L. hemitilioides Schltr., I,5-2 dm hoch, mit ciformiger Kinolle, cinem grundstindigen, dem lioken anliegenden, herzeiförmigen Blatt und drei bis fünf kleinen Blättern, in den Urwäldern der 25-Miles-Station westlich von Beira. Außer diesen kennen wir L. Gerrardi 
Rchb. f. von Natal und L. crpensis Lindl., sowohl an Abhiingen des Tafelberges bis zu $750 \mathrm{~m}$, wie auf den sandigen Flats bei Kapstadt.

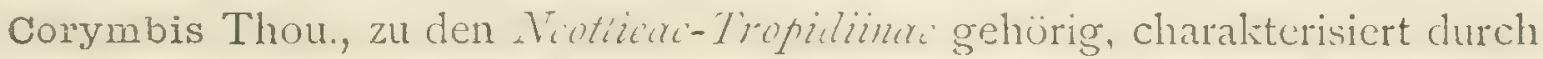
aufrechte Anthere und langes Rostellum der Bliite, umfaß3t große Frauter mit vielen Faserwurzeln, mit elliptisch-lanzettlichen lïngsfaltigen Blättern und ziemlich großen weißen Bliten in axillären oder endstindigen Rispen oder Trauben.

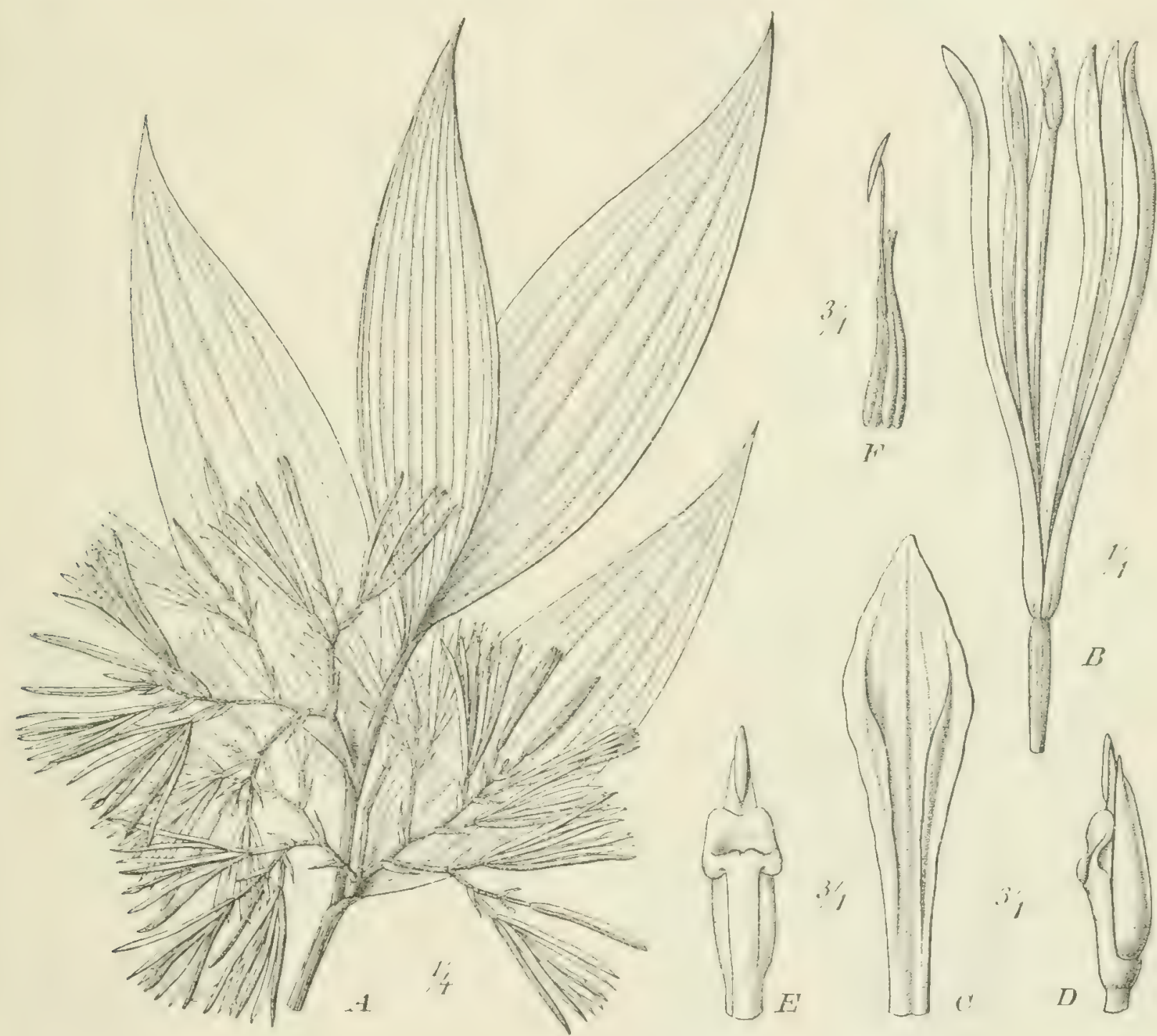

Fig. 3०3. Corymbis corymbosa Thou. $A$ Habitus; $B$ Einzelblïte; $C$ Labellum; $D$ Gynostemium von der Seite gesehen; $E$ dasselbe von vorn; $F$ Pollinien. - Original.

C. Michitsthii Rchh. f. ist cine $\mathrm{I}-2 \mathrm{~m}$ hohe Maldpflanze des tropischen Mestafrika (Sierra Leone bis Angola, Fernando Po, St. Thomas); C. corymbosa Thou. (Fig. 3o3), nur hally so grol3, kommt in den Wäldern Usagaras, im zentralafrikanischen Seengebiet und in Madagaskar vor.

Calanthe R. Br., zu den Phajeae gehörig, sind Erdorchideen mit gewöhnlich sehr verkuirtem, seltener verlängertem Stamm mit grolien linglich-lanzettlichen vielnervigen Laubblïttern, in deren Achsch aufrechte, meist vielhlitige Trauben stehen: die Blïten sind anschnlich und hesitzon cin der Süule angewachsenes Labellum mit flacher oder zurïkgebogener und drei- oder vier- 
lapplyer Spreite. Die Galtung ist pantropisch, am reichsten im Monsungebiet: C. corymbosa Lindl. entwickelt einen $4 \mathrm{dm}$ langen Schaft mit vielen Blüten von

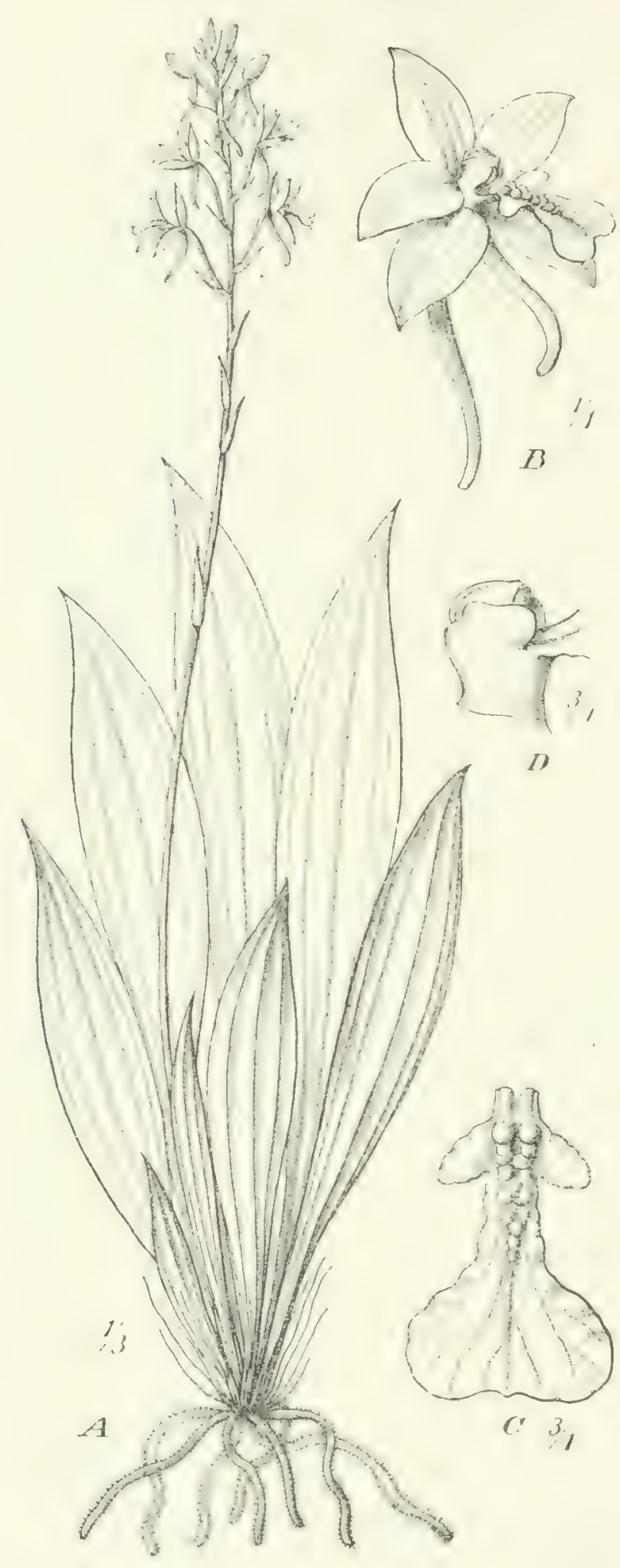

Fig. 304. Calanthe natalensis Rchb. f. A Ganze Pflanze; $B$ Blite; $C$ Labellum; $D$ Gynostemium von der Seite gesehen. - Original. Maxillariene zugerechnet, aber von den übrigen Gattungen derselben durch ein gesporntes Labellum unterschieden, ist im tropischen Amerika und in beim Welken blau werden; sie ist häufig im Regenwald von St. Thomas, Fernando Po und des Kamerungebirges, um I $600 \mathrm{~m}$ ï. $\mathrm{M}$. Nur wenig verschieden ist C.dclphimioides Krzl., ebenfalls auf dem Kamerunberge, bei I $200 \mathrm{~m}$ ii. M. C. Volkensii Rolfe, welche am Kilimandscharo im Regenwald um $2100 \mathrm{~m}$ vorkommt, und C. natalensis Rchb. f. (Fig. 304) im Nyassaland, an den Victoriafällen des Sambesi und in Natal zeichnen sich durch lineal-längliche Seitenlappen des Labellums aus; sie dürften wohl nur als Varietäten der von Madagaskar bekannten C. siluatica Lindl. anzusehen sein.

Phajus Lour. Aus einem kräftigen Rhizom entspringen Blätter mit etwa 2 dm langem Stiel und $3 \mathrm{dm}$ langer, länglich-lanzettlicher Spreite und ein die Blätter bisweilen etwas überragender Schaft mit sechs bis acht ansehnlichen Bliiten, deren Labellum am Grunde die Säule umfaßt bei Ph. Mamii Rchb. f., der auf der Sierra del Crystal in Gabun vorkommt. Auf den Maskarenen finden sich noch vier Arten dieser Gattung und 15 andere im Monsungebiet.

Eulophia-R. Br. und Lissochilus R. Br., zwei der artenreichsten Gattungen, enthalten auch mehrere Schattenpflanzen (vgl. S. 4II).

Eulophidium Pfitzer, von PFitzer wegen der am Grunde zusammengefalteten Blätter den etwa $4 \mathrm{~cm}$ Durchmesser, welche 
Westafrika zu Hausc. E. Lcdicnii (Stein) am unteren Kongo, in Angola und auf St. Thomas, ist cine l'flanze mit gefurchten Iuftknollen, welche cin längliches, mit grauen unregelmäßigen Qucrhinden versehenes Blatt und cinen hellbräunlichen, lockeren Bliitenstand tragen. Fine andere, auch sehr seltene Art ist das an Lagunen in Togo vorkommende E. Fameckcamm Kral.

b) Gattungen, deren Arten vorherrschend an offenen Standorten, teils auf feuchtem Boden, teils in trockenen Grasfluren, teils auch auf nacktem Boden vorkommen. Hydrophile, mesohydrophile und xerophile Formen.

Stenoglottis Lindl, ron den folgenden Gattunģen durch das Fehlen eines Sporns an clem drei- bis fünfspaltigen Labellum ausgezcichnet, mit fleischigen und knollig rerdickten IVurzeln, grundständigen Blittern und einseitswendigen Trauben kleiner Blüten, zählt drei Arten, davon S. fimbriata Lindl. im Kapland, die schöne, ansehnliche S. longifolia Hook. f. in Natal und S. zambesiacn Rolfe im südlichen Nyassaland, mit 3,7 dm langem Schaft.

Holothrix Rich. ist cine artenreiche Gattung mit nur ein oder zwei grundständigen, dem Boden anliegenden. ciförmigen oder kreisfürmigen Blattern, welche cin mehr oder wenger reiches IV assergewebe enthalten, dessen Inhalt bei der Entwicklung des Blütenstandes verbraucht wird; der dünne, meist haarige Schaft trigt kleine Bliiten in einseitswendiger ithre. Zahlreiche Irten kommen in Südafrika vor, eine auf den Comcren, zwei auf Madagaskar und gegen $20 \mathrm{im}$ tropischen Afrika, letztere meist auf trockenen Grasfluren der Gebirge ()stafrikas von der Erythea bis Natal und Transval, einige in Angola und zwei auf lem Kamerungebirge. Die stattlichste Art ist //. lonsifforer Rolfe mit zwei herzformigen Grundbliattern und stark gefranstem, üher $3,5 \mathrm{~cm}$ langem Labellum, in Benguela. Ähnliche, aber nur halb so große Bliiten besitzt //. grandiflora Rchb. f. (Fig. $305 E-H$ ), welche in Siidafrika vorkommt und von mir noch in Grassteppen bei Umtali gefunden wurde. H. Lestii Rolfe im südlichen Nyassaland und H. medusa Krzl. in Benguela haben tief zerschlitzte Tepalen und ebenso ein Labellum mit weiten linealen Abschnitten. Bei den übrigen Arten ist das Labellum weniger tief geteilt oder gar nicht, am meisten noch bei 1 . scopularia Rchb. f. (= pleistodactyla Krzl., (Fig. $305 A-D$ ), auf den Bergwiesen des Kilimandscharo von 2;00 -30co m. Dic auf dem Kiamerungebirge oberhalb $2400 \mathrm{~m}$ vorkommenden H. tridcntata (Hook. f.) Krzl. und $H$. platydectyler Krzl. haben siebenlappiges I abellum, ebenso II. I I'assar Rolfe in ïstlichen Nyassaland. Die ibrigen Arten Ostafrikas, von denen /I. Tirthimar Rchb. f. am weitesten, in Arabien, im Somaliland und der Erythrea von $2100-$ $2700 \mathrm{~m}$ ü. M. verbreitet ist, haben ungeteiltes oder weniglappiges Labellum. Einige Arten sind habitucll durch cinige längliche, am Grunde des Stengels stehende Blätter ausgezeichnet, so H. Usambarae Krzl. in Usambara und $H$. Schmidtii Krzl. auf den Comoren.

Huttonaea Iarv, eine kieine durch genagelte und gefranste Blumenblitter ausgezcichncte Gattung, ist schon länger mit zwei Arten aus dem Kapland 


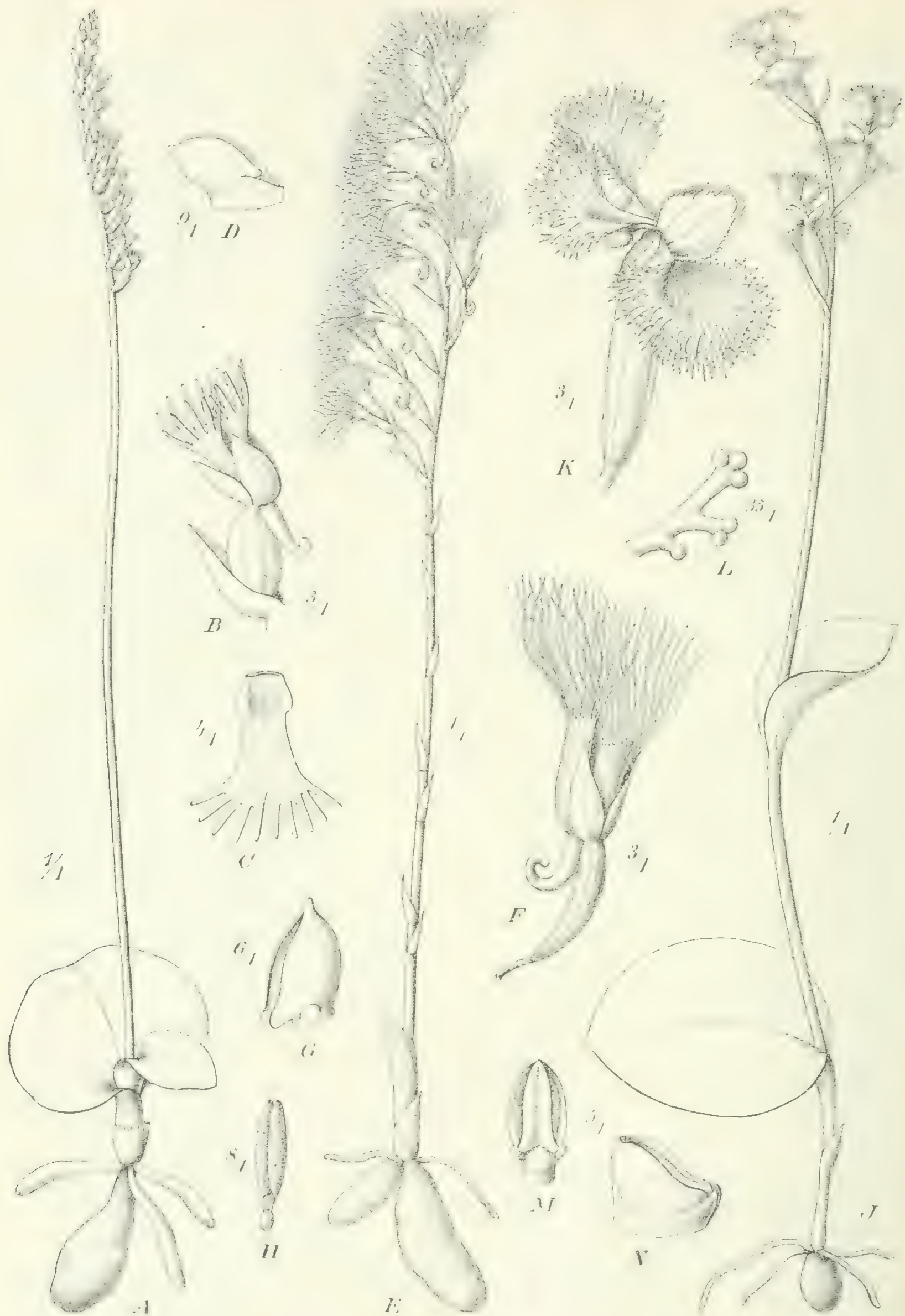

Fig. 305. A-D Holothrix scopularia Rchb. f. A Ganze Pflanze; $B$ Blite; C Blumenblatt; $D$ Gynostemium von der Seite gesehen; $E-H$ Holothrix grandiflora Rchb. f.; E Ganze Pflanze; $F$ Blite; $G$ Gynostemium von der Seite gesehen; $H$ Pollinium; $\mathcal{F}-\lambda^{\top}$ Huttonaca oreophila Schltr.; $I$ Ganze Pfanze; $K$ Blüte; $I$ Stiick des ausgefransten Randes eines Blumenblattes; $M$ Gynostemium von vorn gesehen; $N^{\top}$ dasselbe von der Seite. - Original. 
bekannt; aber eine Art, H. oreophila Schltr. (Fig. 305 F-N), wurde von SCHLECHTER am Van Reenen's Paß im oberen Natal um $2300 \mathrm{~m}$ gefunden.

Platanthera Rich. Da die Gymnadeniznae von den Habenarizinae nur dadurch verschieden sind, daß3 bei letzteren die Narbenfortsïtze frei ausgebildet sind und dieses Merkmal ctwas kiinstlich zu sein scheint, so ist die Begrenzung einzelner Gattungen der Habenariinae schwankend; es scheint aber, daß die vier von ROLFE zu Platanthera gestellten tropisch-afrikanischen Arten besser zu Habenaria oder Brachycorythis gestellt werden, wie dies KRÄNZLIN und andere getan haben. Dagegen folge ich KRÄNZLIN, indem ich die in der Flora of tropical Africa zu Peristylus gestellten Arten als Platantheren ansehe. Es sind alles Arten der hochgelegenen Bergwiesen, und zwar sind vier Arten, darunter P. Petitiana (A. Rich.) Engl., bis jetzt nur aus Abyssinien bekannt, $P$. Volkensiana Krzl., eine fast I $m$ hohe Pflanze mit 2,5 dm langer Ähre, vom Kilimandscharo um $3100 \mathrm{~m}$, P.Preussii Krzl. vom Kamerungebirge.

Deroemeria Rchb. f. ist offenbar verwandt mit Holothrix; die Pflanzen zeigen zur Blütezeit keine Blätter oder nur ein breites, kreisförmiges Grundblatt. Die Bluitenschäfte tragen zahlreiche kleine Bliten in einer Ähre; das geöhrte Labellum ist enger mit der Säule verbunden. Alle Arten (sieben) finden sich in Ostafrika auf den Hochgebirgssteppen oder trockenen Bergwiesen, sechs davon in Abyssinien von rgoo-3100 $\mathrm{m} ;$ D. triloba Rolfe im nördlichen Nyassaland wird

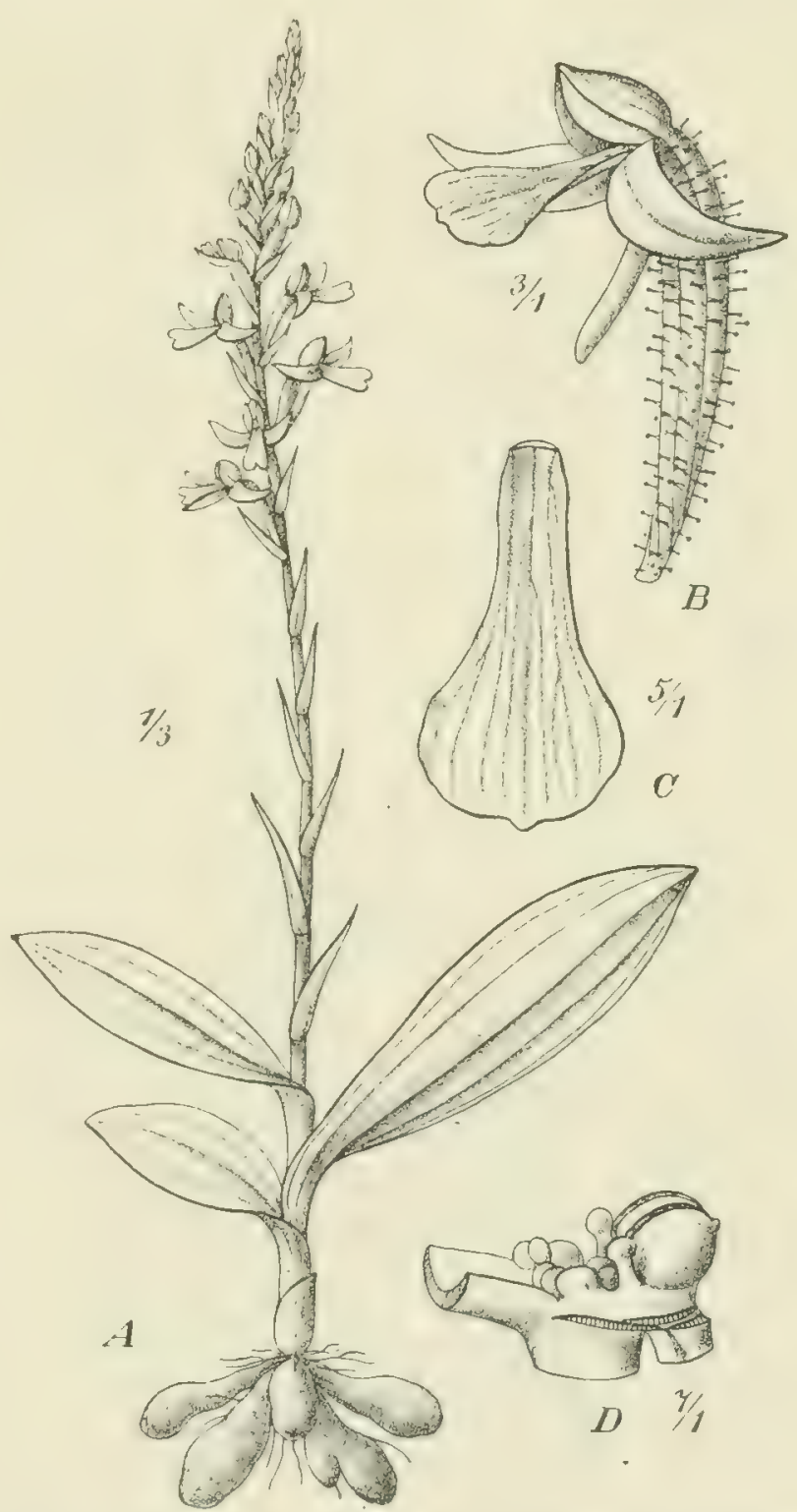

Fig. 3o6. Cynosorchis Buchwaldiana Krzl. Á Cianze Pflanze; $B$ Blüte; $C$ Labellum; $D$ Gynostemium von der Seite gesehen. - Original. vielleicht besser zu Holothrix gestellt.

Cynosorchis (Cynorchis; Thou. ist cine vorzugsweise auf den Maskarenen vertretene Gattung der Habenariinac, deren Hauptmerkmal die kurzen und dicken, nicht wie bei Habcnaria schlanken Narben sind. Elf Arten sind jetzt von den Gebirgen Ostafrikas bekannt; die nördlichste ist C. macamptoides Krzl. mit kurzen rötlichen Trauben und $3 \mathrm{~mm}$ langen Bluten, in der Heideregion des Ruwenzori, von 2700-330u $\mathrm{m}$, die südlichste Art ist C. Kirkii Rolfe in 
den Norambalagebirgen. Auch an den steinigen Abhängen Westusambaras, in einer Höhe von $2200 \mathrm{~m}$, kommt zwischen Erica- und Berberis-Sträuchern eine rotblühende, 2-3 dm hohe Art vor, C. Buchualdiana Krzl.; sie wird wie alle Erdorchideen Kimmgu genannt (Fig. 306). Eine schöne Pflanze ist $C$. pleistadonia (Rchb. f.) Engl. (=C. Volkcnsii Krzl.) auf den Bergwiesen des Kilimandscharo von $2600-3300 \mathrm{~m}$ : sie besitzt ein bis zwei länglich-eifömige Grundblätter, an fast $3 \mathrm{dm}$ langem Schaft bis I dm lange Trauben ansehnlicher violetter Blïten.

Amphorchis Thou, von der vorigen Gattung hauptsächlich durch nach oben gekehrtes Labellum unterschieden, ist auf den Maskarenen mit drei Arten, in Westafrika im Nigergebiet bei Nupe durch 4. acidintulis Lindl. vertreten; es scheint cine hỵrophile P'flanze zu scin, deren cifömige gewimperte Grundblätter wie bei Anoectochilus argentens stellenweise chlorophylllos sind.

Habenaria Willd. Lies ist die wichtigste Gattung der afrikanischen Erdorchideen, von der wir mehr als 150 Arten aus dem tropischen Afrika kennen.

Die Untergattung Podandria Rolfe, ausgezeichnet durch sehr stark verlïngerte, 5 mm lange Antheren an der Spitze cines fast $2 \mathrm{~cm}$ langen Stipes und bis $3,7 \mathrm{~cm}$ lange Kelchblätter, enthält nur zwei Arten, H. macrandra Lindl, eine $5 \mathrm{dm}$ hohe Schattenpflanze in L'ferwildern des Nigergebietes, Kameruns und Angolas, ferner H. stenorhynchus Krzl. in Uluguru.

Die echten Habenaria lassen sich zunächst sondern in solche mit ungeteilten und in solche mit gelappten oder geteilten Blumenblätern; sodann hat man auf die Entwicklung der Spreite des Labellums und seines Sporns zu achten. Es können hier natiorlich nur einge ganz besonders auffallende oder durch ihr Vorkommen charakteristische Arten erwähnt werden.

11. calcarat:r Kchb.f.) Benth. mit ungetcilten Blumenblättern und einem Lahellum ron nur $3 \mathrm{~mm}$ Länge: früher als Gattung Firrlacer unterschieden, ist cine Sumpfpflanze Benguelas und der Utschungweberge im nördlichen Nyassaland. Eine großse Anzahl ron Arten haben beblatterte Stengel und dreilappiges oder dreiteiliges Labellum: es sind zum größeren Teil Arten der hochgelegenen Bergwiesen, von denen einige auch weiter verbreitet sind, so H. bracteosa Hochst. in Ahyssinicn, am Kilimandscharo und auf dem Kifinika-Vulkan, /I. tridactyla A. Rich. auch in Abyssinien und am Kilimandscharo.

Ziemlich isoliert steht H. montolizerę Krzl., in den Bergwiesen Abyssiniens, ausgezeichnet durch kurzgespornte Blüten, deren breit-längliches Rostellum am Grunde sehr kleine Narbenlappen besitzt. Eine besonders auffallende Art ist H. Engleriana Krzl. von Bismarcksburg in Togo, eine $6 \mathrm{dm}$ hohe, dichtbeblätterte Pflanze mit Trauben von oft acht Bliiten, die, wie Fig. $309 D$ zeigt, eincn über $1,5 \mathrm{dm}$ langen Sporn besitzen. Ferner sei auf $/ 1$. macrantha Hochst. von Alyssinien und auf $/ 1$. splemlins Rendle vom Kilimandscharo (rgoo bis $3300 \mathrm{mj}$ und die vom Ruwenzori uber Vestusambara und das nördliche Nyassaland (Ubena) bis zum siidlichen Nyassaland (Shire, Blantyre) verbreitete $I$. prestms Rendle (Fig. 307) aufmerksam gemacht. Bei diesen, vielleicht nur 


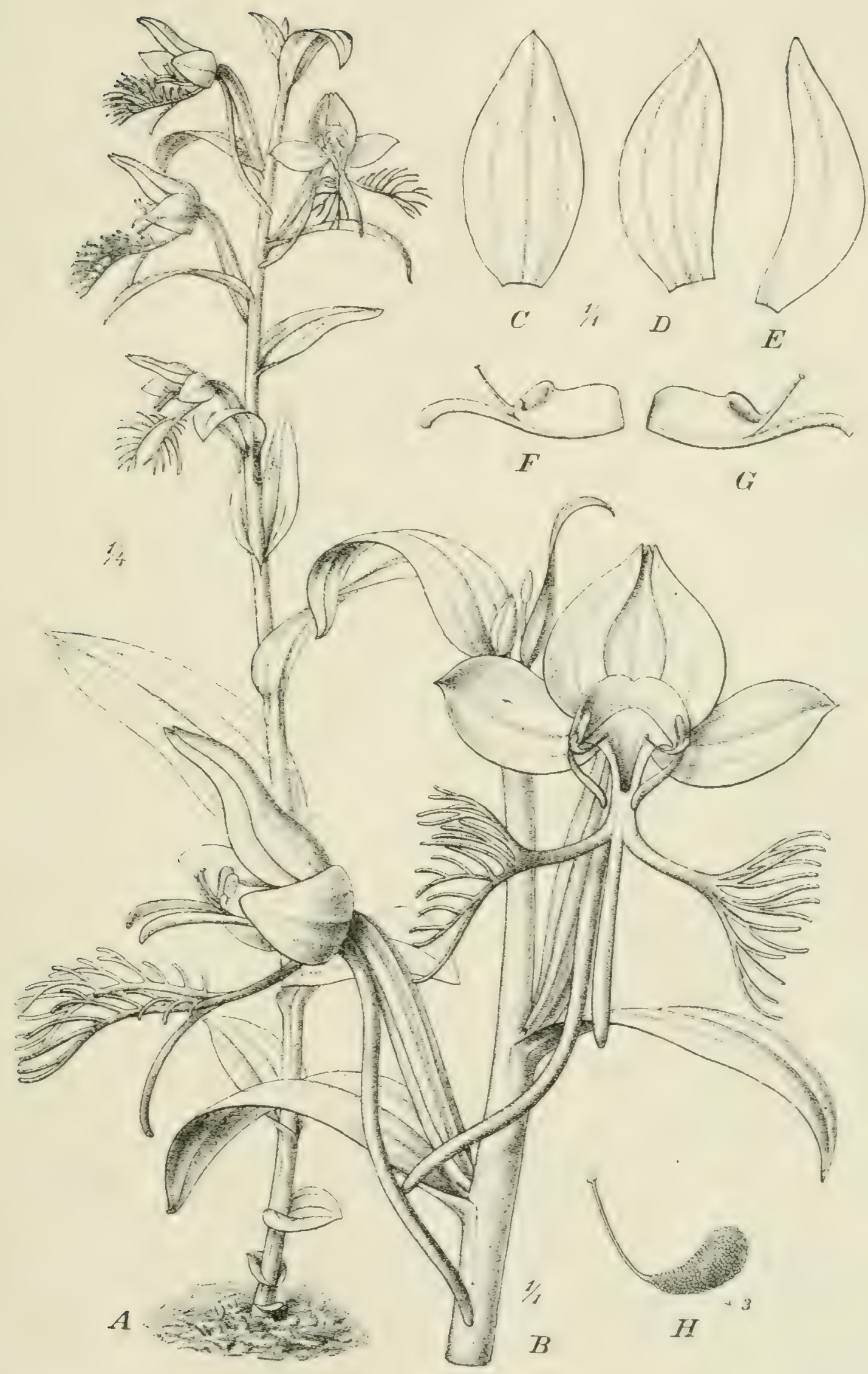

Fig. 307. Habenaria praestans Rendle. A ganze Pllanze, I/2 n. Gr.; $B$ Teil des Blitenstandes, n. Gr.; $C$ hinteres Kelchblatt; $D$ seitliches; $E$ Blumenblatt; $F, G$ Rostellum; $H$ Pollinium. Original nach einem Exemplar des bot. Gartens in Dahlem. 
Varictäten einer Art darstellenden Formen ist das dreiteilige Labellum ziemlich lang genagelt, und die seitlichen Lappen desselben sind fein zerschlitzt. Unter den Arten mit zweilappigen oder zweiteiligen Blumenblättern befinden sich eine Anzahl mit zwei grundständigen kreisförmigen Blättern oder nur eincm. Diese Arten wachsen nur von der Erythrea bis Nyassaland und in Angola in Buschgehölzen der Steppe. Offenbar dienen auch hier wie bei Holothrix die dem Boden anliegenden Blätter als Wasscrreservoir für die in die trockene Zeit fallende Entwicklung der Blitenstände. In der Frythrea und in Abyssinien von $200-\mathrm{I} 600 \mathrm{~m}$, also in der Steppenregion, kommt H. armatissima Rchb. f. vor, mit zwei Blättern am Grunde des $3 \mathrm{dm}$ langen Schaftes und sehr eigentümlichen Bliiten, in welchen das Labellum zwei seitliche, linealfadenförmige, bis $5 \mathrm{~cm}$ lange Abschnitte besitzt und der Sporn I dm lang wird. Ebenso lang wird der Sporn bei H. macrura Krzl. von Malandsche (Malange) in Angola (Fig. $30 \& A-C$ ). If. stylites Rchb. f. ct S. Moore mit $5 \mathrm{~cm}$ langem Sporn des tief dreiteiligen Labellums wächst in der Massaisteppe zwischen Duruma bei Mombas und dem Kilimandscharo. If. cortír Rolfe in Benguela, mit keulenförmigem, I,25 cm langem Sporn, schließt sich an die kapländische H. Dregeana Lindl. an. Schöne große Blüten besitzt II. narissiffore Krzl. von Langenburg am NyassaSee (Fig. $308 D-G)$. Sehr kleinblitig ist die mit einem Grundblatt versehene H. holothrix Schltr. (Fig. $308 / I-M /$ ), welche von BALXI in der Niederung des Longa unterhalb Napalanka im Kunenegebiet um i I50 m gefunden wurde. Über 50 Arten mit zweilappigen oder zweiteiligen Blumenblättern haben länglichlanzettliche oder schmal-lanzettliche bis lineale Stengelblätter; ihre Unterscheidung griundet sich wesentlich auf die Gestalt der einzelnen Bliitenteile. Als besonders große, über I $\mathrm{m}$ hohe Art wäre H. robusta Welw. von Angola zu nennen, desgl. H. Kinkirumer Krzl. in Sümpfen von Jaunde in Kamerun. Auch H. polyantha Krzl. im Westen des Albert Nyanza erreicht I m Höhe. Sodann möchte ich noch darauf hinweisen, daß /I. Wieluitschii Rchb. f., H. anaphy'semen Rchb. f. und H. occultans Welw. in Benguela, H. Soyaursii Krzl. in Gabun, Sumpfpflanzen sind. Sicher ist die Zahl der westafrikanischen Arten viel seringer als die der ostafrikanischen, welche meist in den Hochgebirgen auf Bergwiesen auftreten; am höchsten kommt vor $H$. altior Rendle am Kilimandscharo um $3300 \mathrm{~m}$.

Dic Untergattung Bimatic (Willd.) umfaßt mehrere tropisch-afrikanische Arten, bei welchen die beiden seitlichen Kelchblitter am Grunde vereint sind und der mittlere Lappen des Rostellums kapuzenfirmig ist. Alle sind ostafrikanisch, vom Somaliland und Abyssinien bis. Usambara und zum Kilimandscharo. Eine riesige, bis $1,5 \mathrm{~m}$ hohe Art ist //. Stcudneri Rehb. f. mit länglichen Blättern und zoblitigen Trauben, in deren Bliiten die seitlichen Kelchblätter $3,5 \mathrm{~cm}$ lang sind. Auch /\%. Tolkensimna Krzl., von sandigen grasigen Plätzen am Kilimandscharo um $1000-1600 \mathrm{~m}$, ist stattlich, bis $7 \mathrm{dm}$ hoch mit langen Trauben weißer Blüten, deren ziemlich dicker cylindrischer Sporn $3,7 \mathrm{~cm}$ lang ist, wïhrend die linealen Seitenabschnitte des Labellums 2,5 $\mathrm{cm}$ messen. Üher den Bliitcnlaau von II. Imini Kryl. aus dem zentralafrikanischen Seengebiet giht die 
Abbildung in Fig. 309 - A-C Aufschlul3. Eine der prächtigsten Arten mit besonders interessantem Blütenbau ist die in Fig. 30. I:-Fingebildete H. Kinswi Krzl. von Usambara.

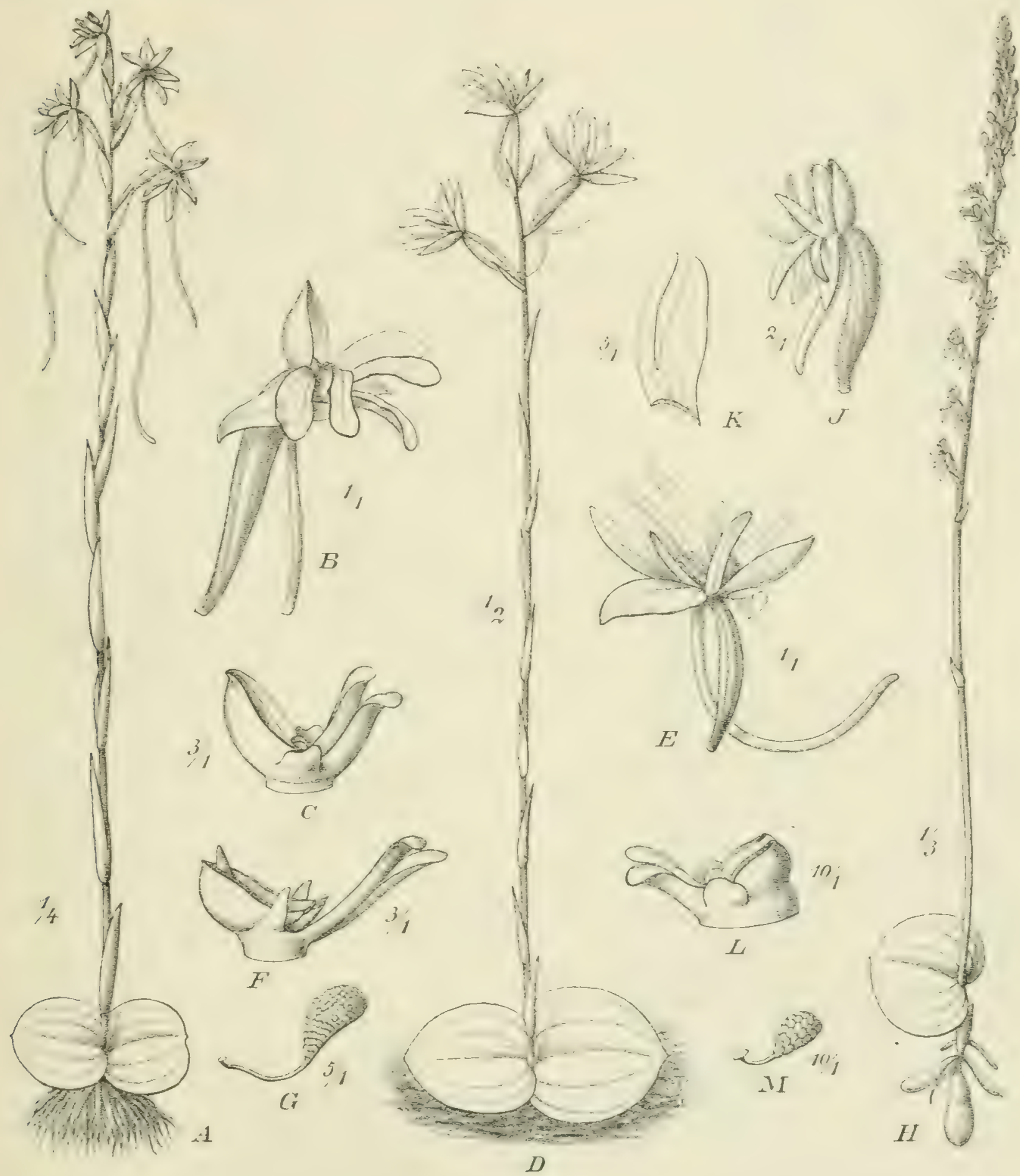

Fig. 308. A-C Habenaria macrura Krzl. A Ganze Pflanze; $B$ Blite; $C$ Gynostemium von der Seite gesehen; $D-G$ Habenaria narcissiflora Krzl. $D$ Ganze Pflanze; $E$ Blite; $F$ Gynostemium von der Seite gesehen; $G$ Pollinium; $H$ - M Habenaria holothrix Schltr. H Ganze Pflanze;

$\mathcal{F}$ Blüte; $K$ Blumenblatt; $L$ Gynostemium von der Seite gesehen; $1 /$ Pollinium. - Original.

Die Arten der Untergattung I'latrichlye zeigen meist nur liurze Narbenfortsätze, welche dem Labellum nicht angewachsen sind: wir haben hier auch Arten mit ungeteilten und mit zweilappigen Blumenblättern: sic scheinen alle 
feuchte Standorte zu lieben. H. aurea Krzl., eine etwa $3 \mathrm{dm}$ hohe Pflanze mit länglich-lanzettlichen Stengelblättern und wenigbliitiger Traube kurzgespornter, goldgelber Blüten, wächst auf Reisfeldern im oberen Senegambien. H. paludescr

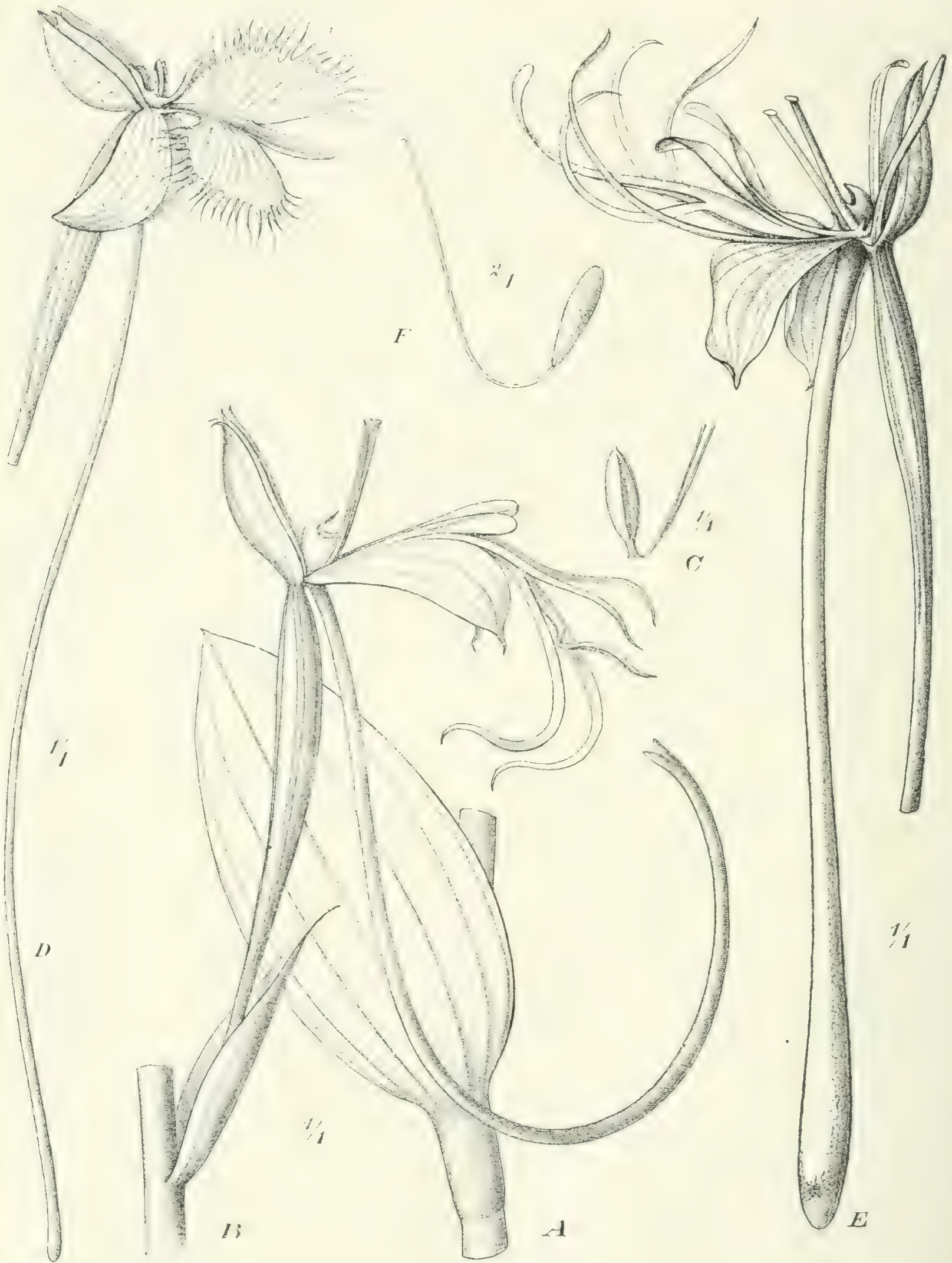

Fig. 309. $A-C$ Habenaria Emini Krzl. $A$ Blatt; $B$ Blüte; $C$ Anthere; $D$ Habenaria Engleriana Krzl. Blüte. $E-F$ Habenaria Kayseri Krzl. E Blüte; $F$ Pollinium. - Original. 
Lindl., mit etwas längerem Sporn, kommt im Nigergebiet vor, H. Wïlfordii Ridley, mit $1,5 \mathrm{~cm}$ lang gespornten gelben Blüten, in Sierra Leone. Durch das Nyassaland bis Uniamwesi finden wir verbreitet $H$. Buchananiana Krzl., ebenfalls mit gelben Blüten und ungeteiltem, länger gesporntem Labellum. H. Protcarum Rchb. f., auf sandigen schattigen Plätzen der Proteaceengehölze, kommt auch in Benguela vor. Angola und dem Luluagebiet gehören $H$. Guingangae Rchb. f. und H. Poggeana Krzl. an, welche zweispaltige Blumenblätter besitzen.

Roeperocharis Rchb. fo ist von Habcnaria hauptsächlich durch eine breite Säule des Gynostemiums mit entfernt stehenden Theken der Anthere und sehr kurz gestielte Pollinien verschieden. Das Labellum ist einfach und mit einem an der Spitze zurückgekrummten Sporn versehen bei $R$. alcicornis Krzl., einer $3 \mathrm{dm}$ hohen Pflanze Abyssiniens mit lineal-lanzettlichen Blättern und gelben Bliiten. Ihr steht ziemlich nahe die durch ein dreilappiges Labellum ausgezeichnete $R$. occidentalis Krzl. (Fig. $3 \mathrm{Io}$ ) in der Grasregion des Kamerungebirges um $2500-2700 \mathrm{~m}$. Außer dieser kommen noch drei Arten in Abyssinien auf Bergwiesen vor; doch wurde $R$. Bennettiana Rchb. f. auch auf dem Kingagebirge im Norden des Nyassasees gefunden und daselbst auch von GOETZE $R$. Wentzeliana Krzl. entdeckt.

Brachycorythis Lindl. Dies sind Erdorchideen mit länglichen ungeteilten Knollen, beblätterten Stengeln und dichtblütigen Ähren oder Trauben. Sie gehören wie die folgenden zu den Satyriinae und sind hauptsächlich noch dadurch charakterisiert, daß das

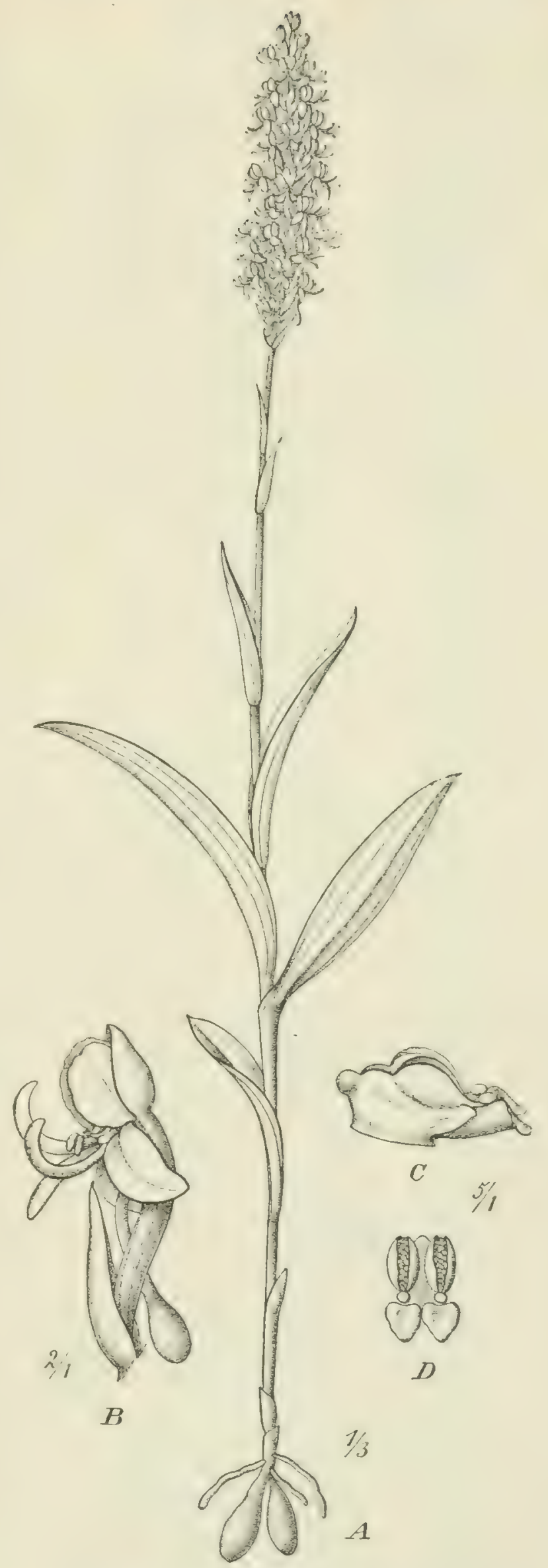

Fig. 310. Roeperocharis occidentalis Krzl. $A$ Ganze Pflanze; $B$ Blitte; $C$ Gynostemium von der Seite; $D$ dasselbe von vorn. - Original. 


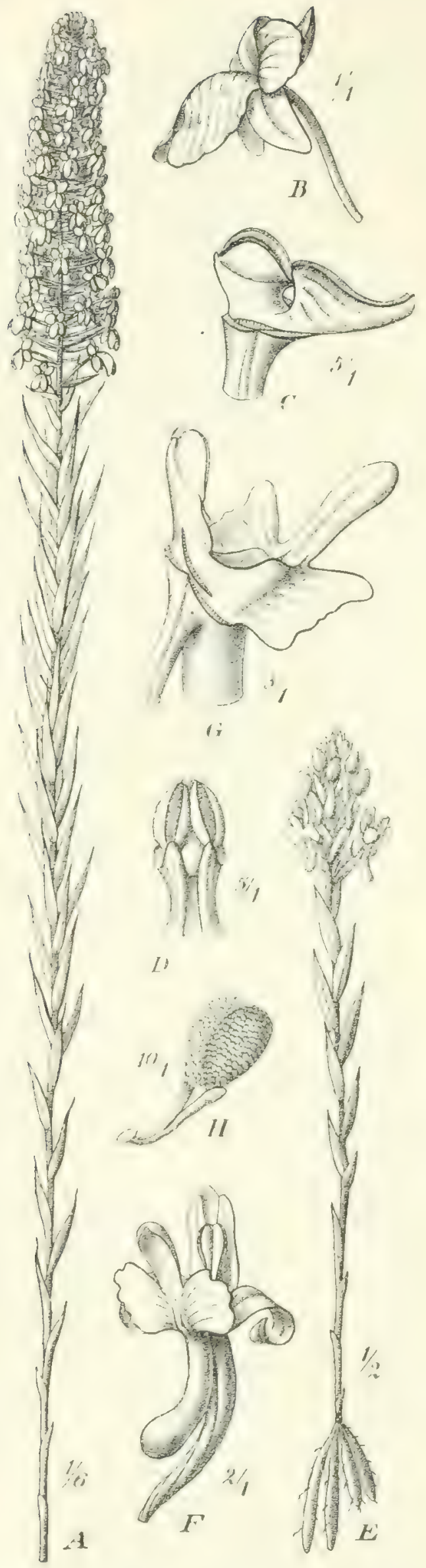

Fig. 319. $A-D$ Brachycorythis pleistophylla Rchb. f. $A$ Habitus; $B$ Bliute; $C$ Gynostemium von der Seite gesehen; $D$ dasselbe von vorn. $E-H$ Brachycorythis tenuior (Schltr.). E Ganze Pflan'e; Fr Blite; $G$ Gynostemium; $H$ Pollinien. - Original.
Labellum mit einem fleischigen, konkaven, an der Spitze verdünnten Nagel und breiter dreizähniger Platte versehen ist. Die meisten Arten lieben etwas feuchte Standorte, so auch die weitverbreitete, bis $6 \mathrm{dm}$ hohe, dicht beblätterte und weichhaarige B. pubescens Harv, welche im Massaihochland und vom Nyassaland bis Natal sowie in Angola vorkommt. Sowohl im Nyassaland wie in Angola und Benguela treten noch einige andere Arten auf. Eine kahle, bis I $m$ hohe, dichtbeblätterte Art ist B. pleistoplyylla Rchb. (Fig. 3 I I $A-D$ ), ziemlich verbreitet im südlichen Nyassaland und bei Kinehassa in Westafrika. Dagegen ist B.temior (Schltr.) (Fig. 3 I I $E-H$ ), von BAUM am Rande der Quirisumpfe im Kunenegebiet um $1300 \mathrm{~m}$ ü. M. gefunden, höchstens $3 \mathrm{dm}$ hoch. $B$. Kalbreyeri Rchb. f. mit 2,5 cm langem Labellum wächst im Kamerungebirge auf Lava, von $1500-2100 \mathrm{~m}$ ü. M.

Satyrium Sw. fällt schon dadurch auf, daß Kelch- und Blumenblätter nach abwärts gerichtet sind, dagegen das zweispornige oder mit zwei kurzen Säcken versehene Labellum nach oben. Die meisten Arten sind hydrophil und wachsen in Sümpfen, an Bachufern, auf feuchten Wiesen; wir kennen jetzt schon weit über 50 Arten, aber noch keine einzige aus dem tropischen Westafrika; sie sind häufig von Abyssinien bis Kapstadt, in Abyssinien und den übrigen tropischafrikanischen Gebirgen meist oberhalb der Waldgrenze, bei Kapstadt in der Ebene; sie sind besonders reichlich vom Nyassaland südwärts und auch in Benguela. Die meisten Arten haben zwei deutliche Sporne; nur S. Mechowii Rchb. f. hat gar keinen Sporn, und vier andere Arten in Benguela und dem Nyassaland besitzen zwei kurze Säckchen am La- 
bellum. Ein einziges Grundblatt kommt bei S. monoplyyllum Krzl. (Fig. 3 I $2 F-\mathcal{F}$ ) in Ubene im nördlichen Nyassaland vor. Zwei kreisförmige Grundblätter finden wir bei dem in Abyssinien und auch in Uhehe vorkommenden S. bifolinn A. Rich. (Fig. 3 I $2 A-E$ ) sowie bei einigen Arten des Nyassalandes. Die zahlreichen anderen Arten haben einige bis viele Stengelblätter und häufig wachsgelbe Bliiten; die größte Art scheint das 6-9 dm hohe S.crassicaule Rendle zu sein, welches auf dem Ruwenzori von 2000-3300 m vorkommt. Auch S. Volkensii Schltr. am Kilimandscharo um $1600 \mathrm{~m}$ ist eine kräftige, $6-7 \mathrm{dm}$ hohe Pflanze.

Brownleea Harv. ist mit der folgenden Gattung Disa nahe verwandt, jedoch unterschieden dadurch, daß die Petalen mit dem dorsalen gespornten Kelchblatt zusammenhängen. Das kleine, nicht gespornte Labellum besitzt nur eine winzige aufrechte Platte. Während mehrere Arten im Kapland und eine in Madagaskar vorkommen, findet sich B. apetala (Krzl.) N. E. Brown auf Bergwiesen des Kilimandscharo um I $900 \mathrm{~m}$ ü. M., B. alpina (Hook. f.) N. E. Brown, eine bis $6 \mathrm{dm}$ hohe Pflanze, auf dem Kamerungebirge von I $900-2600 \mathrm{~m}$.

Disa Berg. Bei dieser im Kapland besonders reich entwickelten, auch in Madagaskar nicht fehlenden und nordwärts bis Abyssinien sich erstreckenden Gattung ist das mittlere Kelchblatt helmartig und das Labellum nicht

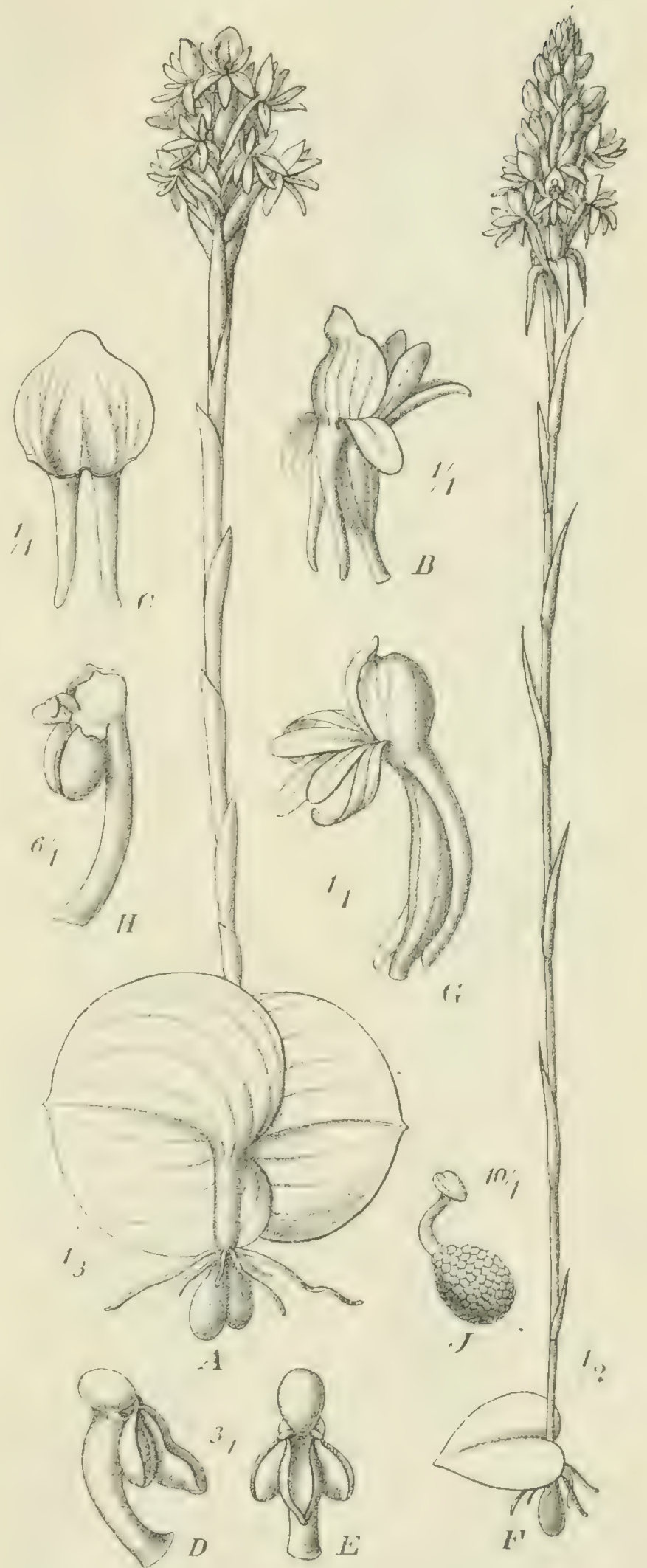

Fig. 312. $A-E$ Satyrium bifolium A. Rich. A Ganze Pflanze; $B$ Blite; $C$ Labellum; $D$ Gynostemium von der Seite geseben; $E$ dasselbe von vorn. $F-\mathcal{F} \mathrm{Sa}$ tyrium monophyllum Krzl. $F$ Ganze Pflanze; $G$ Blüte; $H$ Gynostemium von der Seite gesehen; 7 Pollinium.Original. 


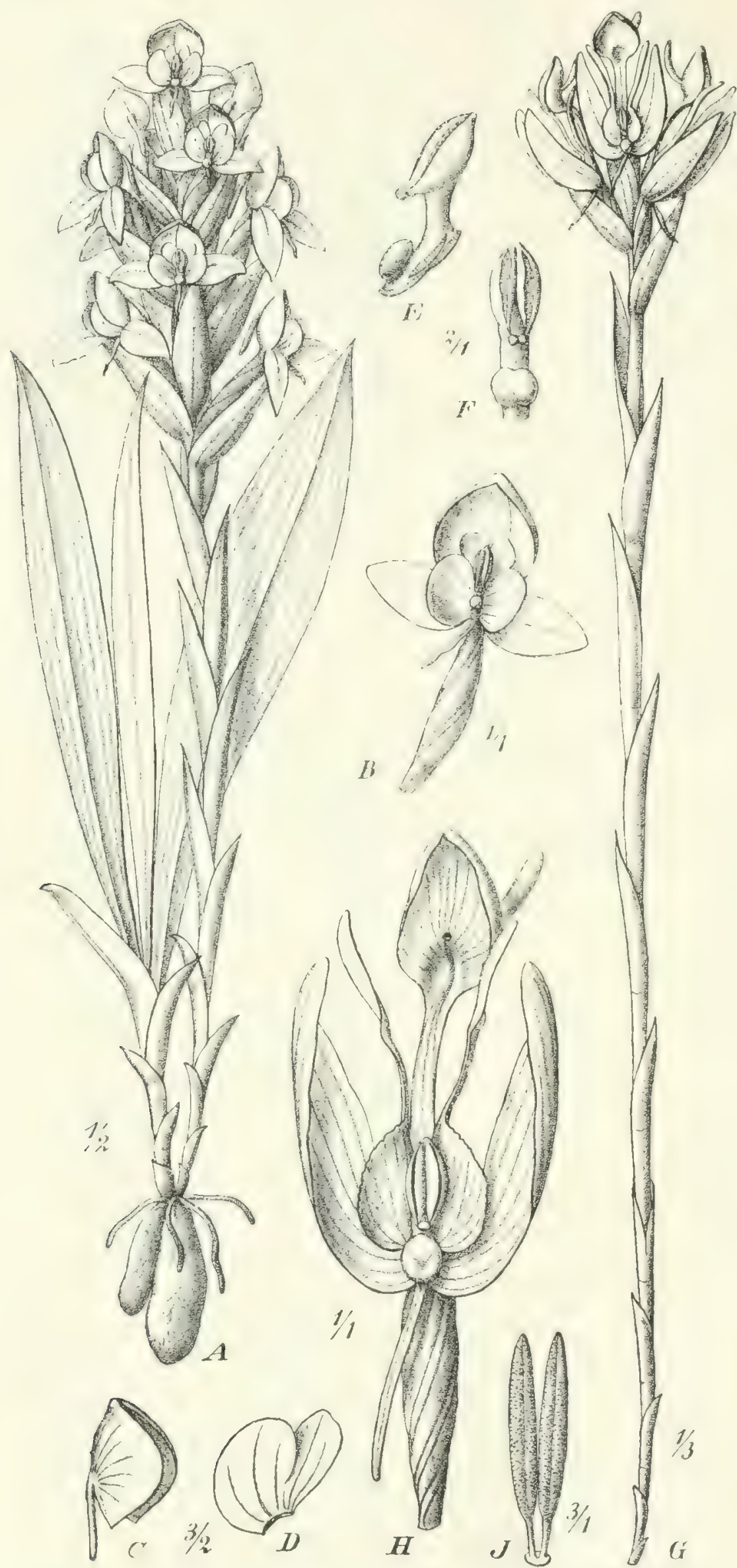

Fig. 313. $A-F$ Disa Engleriana Krzl. $A$ Ganze Pflanze; $B$ Blite; $C$ Labellum; $D$ Blumenblatt; $E$ Gynostemium von der Seite gesehen; $F$ dasselbe von vorn. $G-\mathcal{F}$ Disa Carsoni N. E. Brown. $G$ Habitus; $H$ Blite; $\mathcal{F}$ Pollinien, - Original. gespornt. Bisweilen sind besondere Laubsprosse mit größeren Laubblättern vorhanden und besondere Blütensprosse mit kleineren Blättern. Etwa zo Artenkommen nördlich von Natal vor, die meisten als Bewohner von Mooren und Sümpfen im Hochgebirge. Bei einigen Arten ist das dorsale Kelchblatt spatelförmig, mit einem deutlichen, mit Kanal versehenen Nagel. $D$. Carsoni N. E. Brown (Fig. 3 I $3 G--\mathcal{F}$ ) von Fwambo im Süden des Tanganyika-Sees und auch in Hochmooren der Utschungweberge, ist eine besonders schöne Pflanze, bei welcher der Stengel bis zur Spitze mit graugrünen, etwas rötlichen Scheidenblättern besetzt ist und die $15 \mathrm{~cm}$ lange Ähre bis zwölf große Blüten trägt, letztere mit $2,5-3 \mathrm{~cm}$ langem Nagel und etwa $2 \mathrm{~cm}$ langer Platte des mittleren Kelchblattes und mit $3,7 \mathrm{~cm}$ langen seitlichen Kelchblättern. Eine ebenfalls sehr schöne Art ist $D$. erubescens Rendle, bis $5 \mathrm{dm}$ hoch, mit großen dunkelroten Bliiten, auch bei Fwambo vor- 
kommend, ferner im südlichen Nyassaland, auf dem Zomba-Plateau um I000 m und am Ruwenzori um 1900-2300 m. - Bei den meisten Arten ist aber das dorsale Sepalum nicht spatelformig und nicht genagelt. Ton diesen nenne ich als Arten mit aufrechter Anthere die beiden abyssinischen D. scutellifor a A. Rich. und I. Sihimperi N. F. Brown, D. Wilatisthii Rehb. f. in Benguela, sowie im nördlichen und südlichen Nyassaland, mit ziemlich kleinen, purpur-

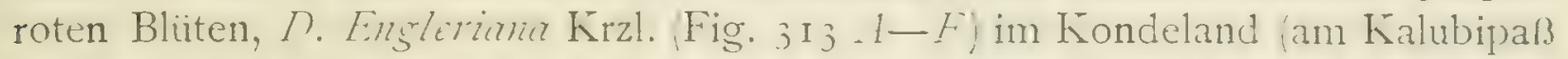
bei Ssoko), D. Mcikinii Rchb. f. mit nur $5 \mathrm{~cm}$ langer thre kleiner karminroter Blïten, am Kilimandscharo von $1900-3300 \mathrm{~m}$. Sowohl am Kilimandscharn wie am Kenia und am Ruwenzori findet sich in einer Höhe von $3300 \mathrm{~m}$ die $6 \mathrm{dm}$ hohe D. Stairsii Krzl., bei welcher die Anthere horizontal steht und das dorsale Sepalum mit einem $2 \mathrm{~cm}$ langen Sporn versehen ist. So wie an Arten der Gattung Satyrinm und Habenaria ist Uhehe auch sehr reich an Disa-Arten: doch finden wir außer der schon vorher genannten, prachtvollen D. Carsoni N. E. Brown auch die zuerst aus dem südlichen Nyassaland bekannt gewordene I). IGalleri Rchb. f. mit krapproten, innen weils und dunkelrot gefleckten Blüten, D. Goetseana Krzl., D. satyriopsis Krzl., D. Princeac Krzl. Im Livingstone- und Kingagebirge wurden auch drei Arten aufgefunden: $D$. uligimusa Krzl. an quelligen Felsen, $D$. liucostuchys Krzl, an trockenen Halden und die durch tief gefranstes Labellum ausgezeichnete $D$. hamatofitalar Rendle, welche im nördlichen und südlichen Jyassaland von $; 00-2000 \mathrm{~m}$ recht verbreitet zu sein scheint.

Herschelia Lindl. $\mathrm{Zu}$ dieser bisher nur aus dem Kapland bekannten Gattung, welche sich ron Disi durch gemeinsame Klebmasse für die Pollinien und durch deutlich zweiteilige Narbe unterscheidet, zieht Prof. KR.NzLN cine ron IV. GuTZE im Kingagebirge auf feuchten Wiesen um $2200 \mathrm{~m}$ ü. M. aufgefundene Pflanze, H. Gortuerna Krzl, von $5 \mathrm{dm}$ Höhe, mit fünfblitiger ïhre. halblugeligem, ungesporntem, unpaarem Kelchblatt und einem $2 \mathrm{~cm}$ langen, faserigen Labellum.

Die im Kapland vorkommenden Gattungen der Sutrriinat, L'achite's Lindl.,

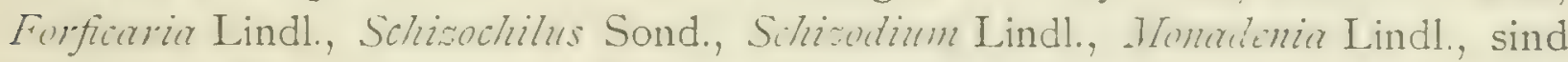
bis jetzt nicht im tropischen Afrika aufgefunden worden.

Erdorchideen aus der Gruppe der Cy'rtopodieae sind zwar nicht. so zahlreich, wie die aus der Gruppe der Ophrytcat; aber doch auch recht formenreich, und fortwährend werden neue Arten von Lissochilus und Finlopluic bekannt, obwohl jetzt schon von jeder dieser beiden Gattungen fast Ioo Arten aus dem tropischen Afrika bekannt sein mögen. Die beiden Gattungen sind nicht ganz scharf gesondert, und nur die Mehrzahl der Lissochilus unterscheidet sich durch die kleinen, abstehenden oder zurückgebogenen Kelchblätter und die großen, oft verschieden gefärbten Blumenblätter. Beide Gattungen enthalten ombrophile, hydrophile und xerophile Arten, und innerhalb der Gattung Eirleplizi haben sich auch Saprophyten und Epiphyten entwickelt; auch kommen bei beiden Gattungen Arten mit unterirdischem Rhizom und mit oberirdischen Luftknollen vor. Diese Gattung ist auch die weiter in den Tropen 
verbreitete, während Lissochilus auf Afrika, die Maskarenen und Arabien beschränkt ist.

Eine ausgesprochene Schattenpflanze ist E. guinecusis Lindl., welche von allen anderen Arten durch einen dïnnen, bis 2,5 cm langen Sporn ausgezeichnet ist, zugleich die verbreitetste Art der Gattung, da sie von Sierra Leone his Angola, im mittleren Kongogebict, im Ghasalquellengebiet, in Abyssinicn und der Erythrea (950-1000 $\mathrm{m}$ ü. M.) vorkommt.

Ombrophil und hydrophil sind aus der Gattung Eulophic E. monile Rchb. f., welche an moorigen schattigen Uferplätzen Angolas in einer Iöhe von I $600 \mathrm{~m}$ vorkommt, ferner $E$. Woodfordii Rolfe, fast $\mathrm{I} \mathrm{m}$ hoch, in Angola und an der Goldlitiste, zugleich aber auch in Westindien und anderen Teilen des tropischen Amerika, su daß es wahrscheinlich ist, daß die Pflanze von dort eingeschleppt ist: eine große, uiber a $\mathrm{m}$ hohe, hydrophile Art ist auch E. cuglossa Rchb. f. mit 2 dm langen oberirdischen Knollen; sic findet sich in Sicra Leone, im Nigerdelta und in Angola an Flußufern: mit Ausnahme des weinsen I abellums sind die Blütenteile griin. An ähnlichen Standorten findet sich in Angola Lissochilus dilectus Rchb. f. mit kräftigem Rhizom, I m hohem Stamm und ziemlich gleich langen Kelch- und Blumenbliittern, in Benguela L. Mikititichiz Rchb. f. mit fast I m langen Blättern, $2 \mathrm{~m}$ langen Blütenschäften und großen Blüten, in denen die Kelchblätter nur drei Viertel von der Länge der Blumenblätter hahen: von Sierra I.cone bis Kamerun, auch in Mangrovesumpfen, I. resens Lindl. mit kräftigem Rhizom, I ni langen lanzettlichen Blättern und $2 \mathrm{~m}$ hohem Stengel, dessen 2-3 dm lange Trauben Bliuten mit rotbraunen Kelchblättern und rusafarbenen Blumenblättern tragen; an Old Calabar-Fluß, in Gabun und am unteren Kongo L. Horsfollii Batem. mit I m hohem Schaft, 3-4 dm langer Traube, purpurroten Kelchblättern und blaß-rosafarbenen Blumenblättern. Im inneren Afrika kommt an zwei ähnlichen Standorten vor 1. porphrriglessus Rchb. f. in I ande der Nian-niam und Mombuttu. - Mehrere Arten wachsen auch in offenen Sümpfen, so Eulophiza dichroma Rolfe, mit dunkelpurpurroten Scitenlappen des Labellums und im übrigen gelben großsen Blüten, an überschwemmten Plätzen in Benguela, F. Stolacana Krzl. im Kondeland um $500 \mathrm{~m}$ ï. M., E. Wameckenn Krzl. im Schlick von Flüssen in Togo, ferner Lissochilus angolensis Rchb. f. in Benguela, L. Sandersonii Rchb. f. im Shirehochland und in Uhehe, L. gigantcus Welw. in Angola. Letztere ist wohl überhaupt die größste bekannte Lidorchidec, da die Blätter über I m lang werden und die Blütenschäfte 2-5 merreichen, nit 3-5 dm langen Trauben von 20-30 hellpurpurfarbenen Bliiten mit $3,7 \mathrm{~cm}$ langen Blumenblittern und griulichen Kelchblittern: zusammen mit Typhr in Sümpfen am (Juango sehr häufig von $300-800 \mathrm{~m}$ ü. M., auch am unteren Kongo.

An Bachufern kommt auch L. Bussicenu Kral. in Ungoni im südöstlichen Deutsch-Ostafrika vor.

Viel größer ist die Zahl der Arten, welche auf mehr oder weniger trockenen Grasfluren vorkommen oder auch in trockenen Buschgehölzen wachsen. Solche finden sich besonders reichlich in Zentral- und Ostafrika, sowie in Benguela. 
Als besonders xerophile Arten dürften zu nennen sein die schr schmalblättrige, nur 2,5 dm hohe, gelbbliihende I: proterum Rchb. f. und die ebenfalls schmalblättrige, $+\mathrm{dm}$ hohe E. Ilikilitschii Rolfe in sandigen Proteaceengehölzen Benguelas, die mit unten knollig verdicktem, I- r,5 m hohem Stamm, leder-

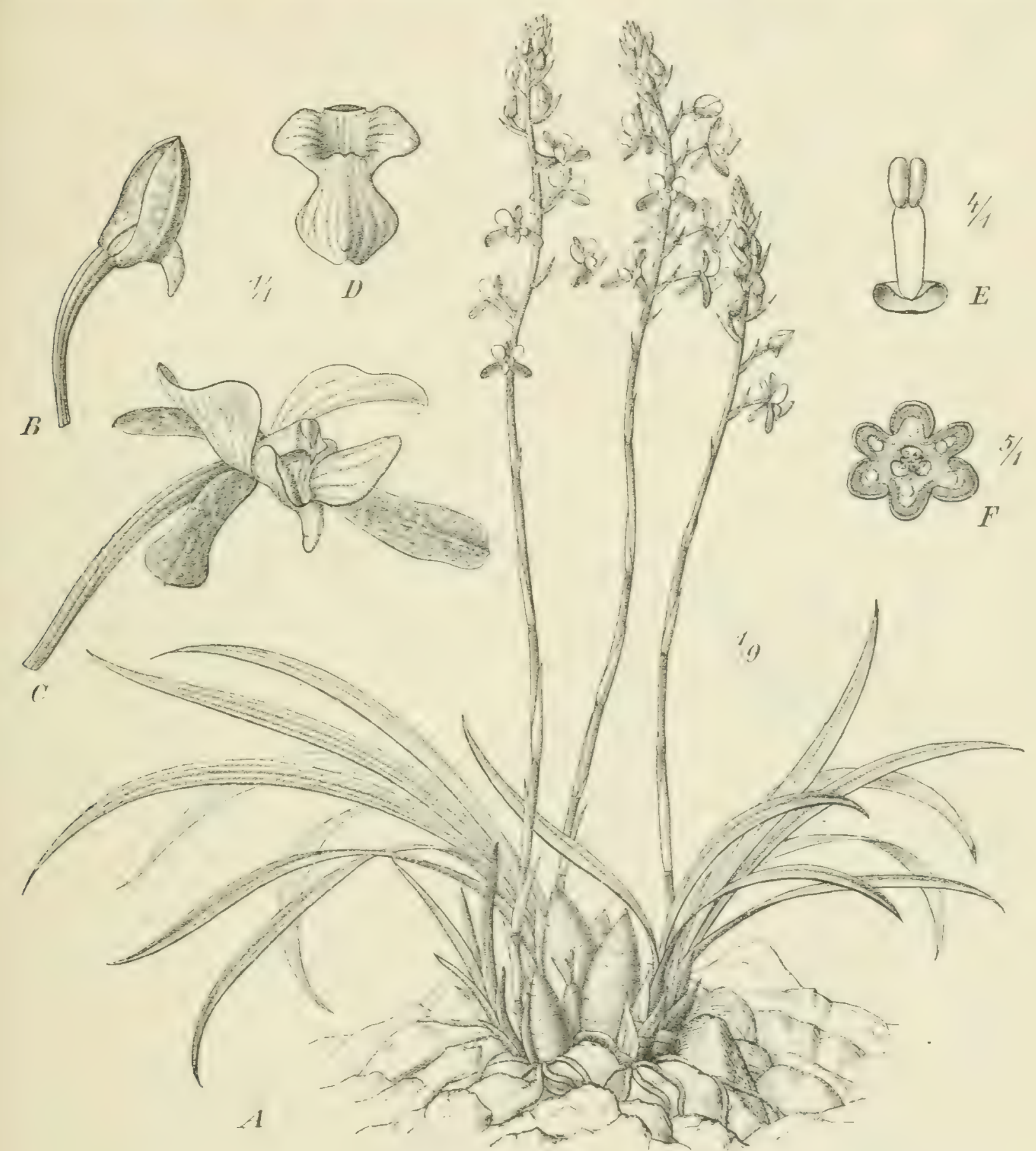

Fig. 314. Lissochilus Krebsii Rchb. f. $A$ ganze Pfanze; $B$ linospe; $C$ Bliite geöfinet; $D$ Labellum; $E$ Pollinien mit Stipes; $F$ Querschnitt des Fruchtknotens. - B-F nach Bot. Magaz., $A$ Original.

artigen, sichelförmigen Blättern und großcn, bis $3 \mathrm{~cm}$ langen Kelchblättern versehene E. Fetcrsii Rchb. f. von Arabien und Abyssinien his Usagara, E. herror cisis Schltr. mit wenigen, schmallinealischen, erst nach dem Verbliihen des 5 dm langen Stengels hervortretenden Blittern, bei Harris in Hereroland: Lissochilus faramlus Rendle, nur $3 \mathrm{dm}$ hoch, auf Laterit in Englisch-Ostafrika, 
L. microccras Rchb. f. auf kurzgrasigen Hügeln im südlichen Nyassaland, $L$. fulchillus Rendle in Karagwe, L. srocitior Rendle im zentralafrikanischen Seen-

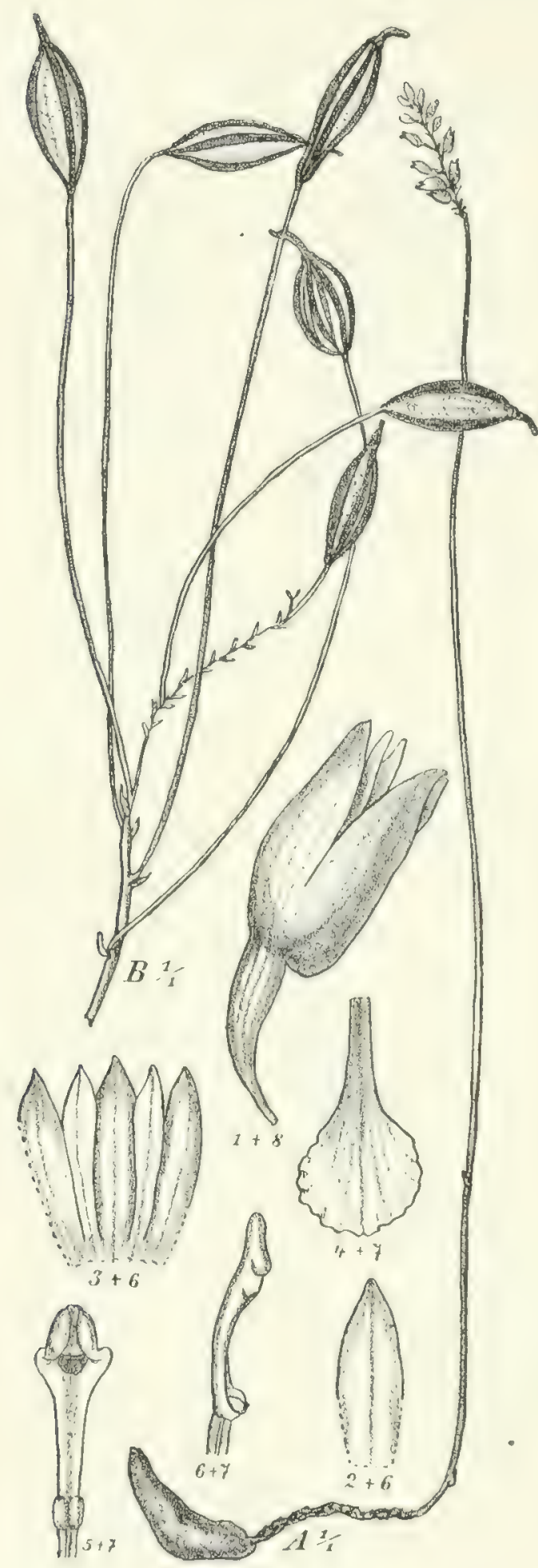

Fig. 315. Auxopus kamerunensis Schltr. $A$ Blihende Pflanze; $B$ Früchte nach Verlängerung der Fruchtstiele, n. Gr.; I Blite; 2 mittleres Kelchblatt; 3 Kelchblätter und Blumenblätter ausgebreitet; 4 Labellum; 5 Säulchen von vorn; 6 dasselbe von der Seite. - Nach Schlechter. gebiet, alles kleinere Arten von nur 3-5 dm Höhe. Eine größere xerophile Art ist L. arabicus Lindl., die ich in Westusambara in sehr trockener Gebirgsbuschsteppe bei Schashua (I $400-\mathrm{I} 500 \mathrm{~m})$ zusammen mit Synadeninm-Büschen fand, während sie vorher aus Arabien von Moschajam Djygâb bekannt war. Prof. KRÄnzlin, der diese Pflanze wie die meisten anderen aus Afrika nach unserem Museum gelangten bestimmte, sagt über dieselbe: "Denkt man den Blütenstand fort, so hat man ein Gewächs, welches weit mehr an eine Sansevieria oder eine Liliiflore aus der Dracaena-Verwandtschaft erinnert als an eine Orchidee. "Die Pflanze besitzt gefaltete, lineal-lanzettliche, bis $6 \mathrm{dm}$ lange Blätter mit sehr stark hervortretenden blassen Längsnerven und einen etwa I $\mathrm{m}$ langen Schaft mit vielen, locker stehenden, gelben Bliiten, deren Blumenblätter von den beiden seitlichen Kelchblättern überragt werden. Auch L. Krebsii Rchb. f. (Fig. 3 I 4), welcher im siidlichen Nyassaland um $2300 \mathrm{~m}$, in den Morambalabergen und weiter suidlich sich findet, gehört hierher; in verschiedenen Formen tritt im ostafrikanischen Steppengebiet von Mombas bis zum unteren Sambesi, zum Betschuanaland und Nyassasee L. Wakefieldii Rchb. f. auf, bei welchem die Kelchblätter nur halb so lang sind wie die Blumenblätter.

Pteroglossaspis Rchb. f. ist eine Euloplica nahestehende Gattung von Steppen bewohnenden Erdorchideen, welche hauptsächlich durch ein sitzendes, ungesporntes Labellum und ein sehr kurzes Gynostemium charakterisiert ist. Die vier Arten der Gattung gehören den ostafrikanischen Hochgebirgen an. Am längsten bekannt ist $P$. eustaclyya Rchb. f. von Abyssinien. Sodann wurde P. Engleriana Krzl. beschrieben, deren lanzettliche Blätter $5 \mathrm{dm}$ lang 
sind und ron den in köpfchenähnliche Trauben endenden Blütenschäften uiberragt werden; die Bliiten sind weiß, mit einem rotbraunen Streifen an den

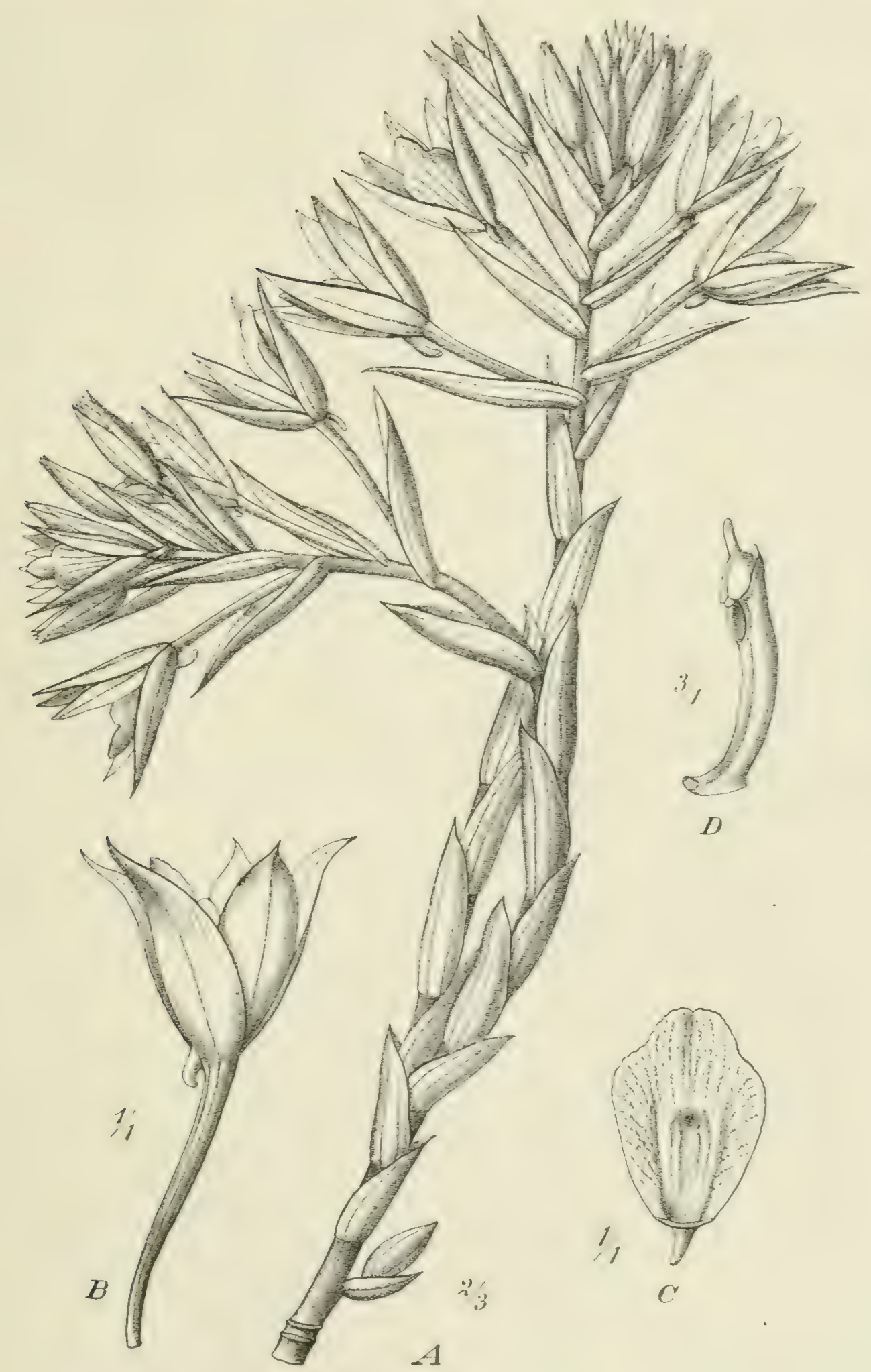

Fig. 316. Eulophia galeoloides Krzl. $A$ Habitus; $B$ Blüte; $C$ Labellum; $D$ Gyuostemium ron der Seite gesehen, - Original.

Seitenlappen des Labellums und etwa $1,25 \mathrm{~cm}$ lang: die P'flanze wächst in den Grassteppen des Kilimandscharo um $\mathrm{r}_{5} \mathrm{co} \mathrm{m}$ ii. .I. Wie heiden anderen nahe- 
stehenden Arten sind $P$. mwenzorensis Rolfe vom Ruwenzori (2300 $\mathrm{m}$ ) und $P$. Carsoni Rolfe von Fwambo am Tanganyika um i $700 \mathrm{~m}$.

d) Saprophyten.

Epipogon Gmel., dessen eine in Europa und dem gemäßigten Asien verbreitete Art ziemlich allgemein bekannt ist, enthält noch eine zweite Art, $E$. mutans (Blume) Rchb. f., welche im ganzen Monsungebiet verbreitet ist und auch in den Urwäldern der Ambashay gefunden wurde. Aus einem knolligen Rhizom entspringt ein $1,5-2,5 \mathrm{dm}$ langer Schaft mit zahlreichen lockeren Scheidenblïttern und wenigen weißen, purpurn gefleckten Bliten in lockerer Traube.

Auxopus Schltr. Die bis jetzt allein bekannte Art dieser Gattung, A. kamernumsis Schltr., ist ganz besonders dadurch interessant, daß bei der Reife der Friichte sich 5-7 cm lange Fruchtstiele ausbilden, während die Blütenstiele nur etwa $\mathrm{I}-\mathrm{I}, 5 \mathrm{~mm}$ lang sind (Fig. 315). Die Pflanze findet sich in Kamerun in dichten Wäldern am Nyolic und Mundame, um etwa $200 \mathrm{~m}$ ziemlich häufig.

Gastrodia R. Br. Diese Gattung und die ihr nahestehende Lencorchis Bl. ist im Monsungebiet verbreitet; aber eine Art, G. africana Krzl., wurde in einem dürftigen Exemplar von Duskx in Kamerun zwischen Love und N"diva gefunden; sie besitzt ein etwa $2,5 \mathrm{~cm}$ langes Rhizom.

Eulophia R. Br. Von dieser Gattung gedeihen die Arten unter den verschiedensten V'crhältnissen, so einige auch im Humus der Urwälder als Saprophyten oder wenigstens als Halbsaprophyten. E. antcmata Schltr. ist eine 3-6 dm hohe P'flanze mit unterirdischer schiefer Knolle, in Büscheln stehenden Stengeln und blassen, aufrecht abstchenden Bliiten von I,7 cm Länge; sie findet sich in Mossambik im Gebiet der Delagoabay in Uferwäldern und in der Gegend von Inhambane im Küstenwald. I: gerstrodioniles Schltr. besitzt cin unterirdisches, längliches, gegliedertes khizon und 2-3 dm lange Stengel mit einer Traube von fünf bis zehn blassen Blïten, die nur $7 \mathrm{~mm}$ lang sind; sie findet sich in den an Orchidecn so reichen Regenwäldern der 25-Miles-Station westlich von Beira. Mit dieser Art ist verwandt E. galcoloides Krzl, aus deren langem unterirdischem Rhizom einige fleischige, rötliche, später bräunliche Bliitenstengel mit blassen Schuppenblättern und blaßgellon anschnlichen I3liiten hervortreten (Fig. 3I6). Die Pflanze wïchst in Ostusambara bei Nderema und Amani um $800 \mathrm{~m}$ an freien Stellen des immergrïnen Regenwaldes auf feuchtem Lehmboden. So bietet die Gattung Eulophic die interessante Erscheinung, dats sie nehen zahlreichen, vollkommen autophytischen Pflanzen auch saprophytische Arten enthält. 


\title{
Register
}

\section{der wissenschaftlichen Pflanzennamen in Band I der Charakterpflanzen Afrikas}

\author{
(II. Band der Pflanzenmelt Afrikas).
}

Beriicksichtigt sind die Familien, Unterfamilien, Gruppen, Gattungen und die abgebildeten Arten. Die fett gedruckten Ziffern geben die Seite an, auf welcher die zitierte Gattung ausführlicher behandelt ist.

Ein Register wichtiger Pfanzenbezeichnungen der Eingeborenen wird dem ILI. Band der Charakterpflanzen beigegeben werden.

Acidanthera Hochst. 366, 372.

- aequinoctialis Baker 374 , Fig. 263.

Acritochaete Pilger II9, 120.

Acrospira Welw. 283, 309.

Acrosticheae 9, 58 .

Acrostichinae 58 .

Acrostichum L. 58.

- aureum L. 57, Fig. 56.

Acrotonae 405 .

Actiniopteris Link 36,45 .

- radiata (Koenig) Link 42, Fig. 37.

Adenogramme Link $3+36$.

Adiantellum (sect.) $4 \%$.

Adiantinae 36,42 .

Adiantum I. 36,42 .

- lunulatum Burm. 4r, Fig. 35.

- tetraphyllum Humb. Bonpl. IVilld. 42, Fig. 36.

Aeluropus Trin. 127, I28.

Aframomum K. Schum. 384, 386

- angustifolium (Sonn.) K. Schum. 3.. Fig. 273 .

- Baumannii K. Schum. 387, Fig. 2,2.

-- citratum (Percira) K. Schum. इi.. Fig. 273 .

- granum paradisi (Hook.) K. Schum. 388 , Fig. 273 .

- Hanburyi K. Schum. 387, Fig. 252.

-. melegueta (Roscoe) K. Schum. 3os, Fig. 273.

- meleguetella K. Schum. 388 , Fig. 273.

- sulcatum (Oliv. et Hanbury) K. Schum. 387 , Fig. 272.

Afrocalathea IK. Schum. 394, 397.

- rhizantha K. Schum. 397.

Afroraphidophora Engl. 236, 241.

Agave 344.

Agavoideae 344 .

Agapantheae 284.

Agapanthus L'Hérit. 284, 339.

Agrostideae I I $5,122$.

Agrostis L. I23.

Aira L. I24.

Engler, Charakterpflanzen Afrikas. I:
Albuca L. $2 S_{4}, 30 \mathrm{I}$.

-_ juncifolia Bak. 3OI, Fig. 202.

-- pachychlamys Bak. 302, Fig. 204.

-. Schweinfurthii Engl. 303, Fig. 205.

Alisma L. I02.

Alismataceae $\mathrm{IO}_{2}$.

Allieae 284.

Allioideac 2S4, 339.

Allium L. $2 S_{4}, 342$.

Alocasia Schott 237, 254.

Aloe L. 284,317 .

- abyssinica Lam. 331, Fig. 229.

- aethiopica (Schweinf.) Berger 332, Fig. 230 .

- arborescens Mill. var. pachythyrsa Berger 339, Fig. 238 .

- Bainesii Drer 3łz, Fig. $2+2$.

- Böhmii Engl. 327, Fig. 225.

-Cameronii Hemsl. 335, Fig. 234. cinnabarina Diels 337 , Fig. 236.

- commixta Berger 334, Fig. 233.

- Engleri Berger 334, Fig. 232.

- ferox Mill. 34 I, Fig. 240.

-- hereroensis Engl. 326, Fig. 224. hereroensis Engl. var. orpeniae Berger 326, Fig. 224 .

Hildebrandtii Bak. 336, Fis. 235.

- humilis Mill. var. echinata Milld. 322, Fig. 220.

- lateritia Engl. 327, Fig. 225.

- leptophylla N. E. Brown 327, Fig. 225.

-- leptosiphon Berger 337, Fig. 236.

- leucantha Berger 336, Fig. 235.

- longistila Bak. 32I, Fig. 2 I9.

- Marlothii Berger 3+2, Fig. 24 I.

- parviflora Bak. 320, Fig. 2 I8.

- Peglerae Schoenland 321, Fig. 2 I9.

- pendens Forsk. 337, Fig. 236.

-- percrassa Todaro var. saganeitiana Berger 328, Fig. 226.

- Perryi Bak. 333, Fig. 23 I.

-. Princeac Berger 335, Fig. 234.

- Rivae Bak. 333, Fig: 23 I. 
Aloe rubro-lutea Schinz 329, Fig. 227.

- rubro-violacea Schweinf. 340, Fig. 239.

- saponaria Haw. 323, Fig. 22 I.

- somaliensis Wright 330, Fig. 228.

-. striata Haw. 325, Fig. 223.

- succotrina Lam. 338, Fig. 237.

-- vituensis Bak. 335, Fig. 234.

- zebrina Bak. 324, Fig. 222.

Aloineae 283.

Aloinclla (subg.) 284 .

Alsophila R. Br. 7, 8.

- aethiopica Welw. 6, Fig. 3.

Amaryllidaceae 343.

Amaryllideae 343.

Amaryllidoideae 343, 344.

Amaryllis L. 344,348 .

Ambrosinia 237.

Ammocharis 344,350 .

Amorphophalleae 236.

Amphorchis Thou. 404, 434.

Anchomanes Schott 236, 24 I.

Ancistrochilus Rolfe 406, 4I7.

- Thomsonianus (Rchb. f.) Rolfe 4I7, Fig. 293, 4I8, Fig. 294.

Ancistrophyllum Mann et Wendl. 223, 229.

- secundiflorum Wendl. 230, Fig. I 54.

Androcymbium Willd. $283,300$.

- striatum Hochst. 299, Fig. 201.

Andropogon L. II7, II 8 .

- brevifolius Sw. I67, Fig. I22.

- contortus L. I55, Fig. I 16.

-- cymbarius L. I53, Fig. I I5.

- exothecus Hack. I69, Fig. I23.

- Gayanus Kth. I63, Fig. I20.

- hirtus L. I55, Fig. II6.

- schirensis Hochst. I55, Fig. I 6 .

- schoenanthus L. I53, Fig. II 5 .

- semiberbis Kth. I64, Fig. I2I.

Andropogoneae II5, II6.

Aneilema R. Br. 268, 274 .

- aequinoctiale (Beaur.) Kth.275, Fig. 86.

Aneimia Sw. 64.

Aneimieae 62, 64 .

Aingraecum Thou. 407, 417.

- distichum Lindl. 419, Fig. 295.

- Kotschyanum Rchb. f. 423, Fig. 298.

- micropetalum Schltr. 424, Fig. 299.

-- scandens Schltr. 422, Fig. 297.

- sesquipedale Thou. 420, Fig. 296.

Anguillarieae 282.

Anoiganthus Bak. 344, 348.

Ansellia Lindl. 406, 4 II.

Anthephora Schreb. I2I.

Anthericopsis Engl. 268, 277.

- sepalosa (Rendle) Engl. 276, Fig. I87.

Anthericum L. $283,307$.

Antholyza L. 366, 373 .
Antholyza Schweinfurthii Baker 374 , Fig. 263 .

Anthoxanthum L. I 22.

- nivale K. Schum. I74, Fig. 125.

Antrophyinae 49.

Antrophyum Kaulf. 49.

- Mannianum Hook. 48, Fig. 44.

Anubiadeae 236.

Anubias Schott 236, 248, 25 I, Fig. I68.

- auriculata Engl. 25I, Fig. I68.

- hastifolia Engl. 25I, Fig. I68.

Apicra Willd. 284, 3 I7.

Apodolirion 344.

Aponogetonaceae 98.

Aponogeton crispus Thunb. 99, Fig. 88.

- Dinteri Engl. et Krause I00, Fig.90.

- distachyus L. fil. 99, Fig. 88.

- fenestralis (Poir.) Hook. f. 99, Fig. 89.

- gracilis Schinz IOI, Fig.9I.

- natans (L.) Engl. et Krause 99, Fig. 88.

- Stuhlmannii Engl. ror, Fig.9I. vallisnerioides Bak. IOI, Fig.9I.

Araceae 235.

Areae 237.

Arecil 1.. 223. 233.

Areceae 223.

Arisaema Mart. 237, 256.

Arisarum 237.

Aristea Ait. $365,368$.

- alata Bak. 37I, Fig. 26I.

- uhehensis Harms 37I, Fig. 26I.

Aristeae $365,368$.

Aristida L. I22, I23.

- Kerstingii Pilger I60, Fig. II8.

- obtusa Del. 177, Fig. I26.

Aroideae 237.

Arthraxon Beauv. II7, II8.

Arthropteris J. Sm. I7, I8.

- obliterata (R. Br.) J. Sm. I7, Fig. I3.

Arum 237.

Arundinaria Mich. I29.

- alpina K. Schum. I4I, Fig. I IO.

Arundineae I 6 , I 24.

Arundinelleae II6, I24.

Ascolcpis Nees I93, I95.

- speciosa Welw. I96, Fig. I37.

Asparageae 285.

Asparagoideac 285, 286.

Asparagus L. 285, 286.

-- africanus Lam. 288, Fig. I9I.

- asiaticus L. 288, Fig. I9I.

- falcatus L. 287, Fig. I90.

- racemosus Willd. 289, Fig. 192.

Asphodeleae 283.

Asphodeloideae 283, 307 .

Asphodeloideae-Aloineae 3II.

Asphodelus 283. 
Aspidieae 9, Io.

Aspidium Sw. IO, I4.

Asplenieae 9, 22.

Aspleniinae 22, 23.

Asplenium L. 23, 25, 31, Fig. 27.

- abyssinicum. Fée 30, Fig. 26.

- auriculatum (Thbg.) Kuhn 31, Fig. 27.

- caudatum Forst. 28, Fig. 24.

- dimidiatun Sw. 28, Fig. 24.

- dimidiatum Sw. genuinum 28, Fig. 24.

- dimidiatum Sw. var. longicaudatum Hieron. 28, Fig. 24.

- dimidiatum Sw. typicum 28, Fig. 24.

- dimidiatum var. Zenkeri Hieron. 28 , Fig. 24.

- formosum Willd. 27, Fig. 23.

-- Laurentii Bomm. 29, Fig. 25.

- Linkii Kuhn 30, Fig. 26.

- longicauda Hook. 25, Fig. 21.

- loxoscaphoides Bak. 3I, Fig. 27.

- praemorsum Sw. 30, Fig. 26.

- praemorsum Sw. var. tripinnatum Bak 3o, Fig. 26.

- protensum Schrad. 26, Fig. 22.

- pulchellum Raddi 27, Fig. 23.

- resectum J. Sm. 27, Fig. 23

- rutifolium (Berg.) Kze. 3I, Fig. 27.

- variabile Hook. 25, Fig. 2i.

- theciferum (Kunth) Mett. 3I, Fig. 27.

- Volkensii Hieron. 30, Fig. 26.

Athyrium Roth 22, 23.

Atractocarpa I29.

Auxopus Schltr. 406, 448.

- kamerunensis Schltr. 446, Fig. 315 .

Aveneae II6, I24.

Azolla Lam. 67.

Babiana 366.

Bacometra Salisb. $283,300$.

Balantium Kaulf. 8.

Bambuseae II6, I29.

Barbacenia Vandelli 353.

- aequatorialis Harms 354, Fig. 250.

- Schnizleiniana (Bak.) Pax 354, Fig.249.

Barlaea 405.

Bartholina 404.

Basitonae 404.

Beckera Fres. I22.

Behnia Didrichs. 285, 296.

Biarum 237.

Blechninae 23, 32.

Blechnum L. 23, 32.

Blyxa Noronha I05, 107.

- octandra (Roxb.) Planch. I09, Fig. 99.

Bobartia Ker 365, 368.

Bolbophylleae 407 .

Bolbophyllum Thou. 407, 4II.
Bolbophyllum Bakossorum Schltr. 4I5, Fig. 29I.

- barbigerum Lindl. 4I4, Fig. 290.

-- kamerunense Schltr. 4I5, Fig. 29I.

- minutum Rolfe 4I6, Fig. 292.

- oxypterum Rchb. f. 4I3, Fig. 289.

Boottia Wall. I05, I09.

- Aschersoniana Gürke III, Fig IOI.

Borassoideae 222.

Borassus L. 222, 224.

— flabellifer L. 225, Fig. I 50, 226, Fig. I 5 I.

Botrychium Sw. 70.

Bowiea 283.

- volubilis Harvey $3 \mathrm{II}$, Fig. $21 \mathrm{I}$.

Brachycorythis Lindl. 405, 439.

- pleistophylla Rchb. f. 440, Fig. 3 II.

- tenuior Schltr. 440, Fig. 3II.

Brachypodium Beallv. I28, I29.

Bromus L. I 28, I 29.

Brownleea Harv. 405, 441.

Brunswigia Heister 344, 347, Fig. 245.

Buforrestia C. B. Clarke 268, 270.

Bulbine L. 283, 3 I 0 .

Bulbinella Kth. 283 , 3 Iо.

Bulbostilis Kth. 194, 208.

Buphane Herb. $343,346$.

Burmannia L. 402, Fig. 285, 403.

- aptera Schltr. 402, Fig. 285.

- densiflora Schltr. 402, Fig. 285.

- hexaptera Schltr. 402, Fig. 285.

Burmanniaceae 400.

Burnatia Micheli I04.

Butomaceae I05:

Caesia R. Br。283, 3 Iо.

Caladium Vent. 237, 254.

Calameae 223.

Calamus L. 223, 23 I.

Calanthe R. Br. 406, 429.

- natalensis Rchb. f. 430, Fig. $30 \%$

Caldesia Parl. I02.

Callitris Vent. 88.

- Schwarzii Marloth 88, Fig..83.

Callopsis Engl. 237, 255.

- Volkensii Engl. 255, Fig. I72.

Campyloneuron Presl (sect.) 5 I.

Cannaceae 394.

Carex L. I95, 2 I 7.

- Koestlini Hochst. 2I8, Fig. I45.

- monostachya A. Rich. var. triquetrifolia (Boeck.) Kuekenth. 2I6, Fig. ${ }^{1} 44$.

- Petitiana A. Rich. 22I, Fig. I48.

- simensis Hochst. 220, Fig. I47.

- spicato-paniculata C. B. Clarke 219 , Fig. 146.

Cariceae 195, 214.

Caricoideae I94, 209, 2 I I, 2 I 3, 2 I 4 (subfam.) 
Carpha R. Br. I93, r96.

Cenchrus L. II9, I20.

Centotheca Desv. I27, I28.

- lappacea Desv. I36, Fig. I08.

Cephalantherinae 406.

Ceratandra 405 .

Ceratopteris Brongn. 60.

- thalictroides (L.) Brongn. 60, Fig. 58.

Cercestis Schott $236,248$.

Cernua Bak. (sect.) 75 .

Ceropteris Link 35, 37 .

Ceroxyloideae 223.

Ceterach Willd. 23, 32.

Chamaealoe Berger 284, 317.

Chamaerops 222.

Cheilanthes Sw. 35, 40.

- farinosa (Forsk.) Kaulf. 39, Fig. 33.

- fragrans (L.) Webb 39, Fig. 33.

Cheilanthinae 35,38 .

Cheirostylis Blume 406, 428.

Chlorideae II 5 , I25.

Chloridion I I9.

Chloris Sw. I25, I26.

- myriostachya Hochst. I46, Fig. I I3.

- virgata Sw. I8I, Fig. I28.

Chlorophytum Ker $283,307$.

- alismifolium Bak. 308, Fig. 208.

- amaniense Engl. 308, Fig. 208.

- macrophyllum (Rich.) Aschers. 308, Fig. 208.

- Schimperi Engl. 308, Fig. 208.

- tuberosum (Roxb.) Bak. 309, Fig. 209.

Chortolirion Berger 284, 317.

Cirrhopetalum Lindl. 407, 4II.

Cladium P. Browne I94, 209.

Clavata Bak. (sect.) 75 .

Cleanthe Salisb. $365,368$.

Cleistachne Benth. II7, II8.

Clinogyne Benth. 394, 397.

- arillata K. Schum. 398, Fig. 28 I.

- leucantha K. Schum. 398, Fig. 281.

- monophylla K. Schum. 398, Fig. 28 I.

Clivia L. 343,347 .

Cocoeae 223.

Cocos L. 223, 234.

Colchiceae 283.

Coleotrype C. B. Clarke 268, 27 I.

Colocasia Schott 237, 254 .

Colocasioideae 237.

Commelina I. 268, 272.

- benghalensis L. 273, Fig. I85.

Commelinaceac 266.

Commelineae 268, 272.

Coniogramme Fée $35,37$.

- fraxinea (Don) Diels 36, Fig. 30.

Corycinae 405.

Corycium 405 .
Corymbis Thou. 406, 429.

- corymbosa Thou. 429, Fig. 303.

Coryphoideae 222.

Costoideae 384, 390.

Costus L. 384, 390.

- Englerianus K. Schum. 393, Fig. 277.

- Lucanusianus K. Schum. 39I, Fig. 275.

- macranthus K. Schum. 393, Fig. 277.

- nemotrichus IK. Schum. 392, Fig. 276.

Courtoisia (subg.) I93.

- assimilis 20I, Fig. I4O.

Cranichidinae 406.

Craspedorrhachis Benth. 125, I85.

Crinum L. 344, 348.

- Kirkii Balr. 350, Fig. 247.

- leucophyllum Bak. 349, Fig. 246.

Crocoideae $365,366$.

Crossotropis Stapf I25, I27, I85.

- grandiglumis (Nees) Rendle I 84, Fig. I 30.

Cryptogramme R. Br. 35, 42.

Cryptostephanus Welw. et Bak. 344, 35 I.

Ctenium Panz. I25, I26.

Culcasia Pal. Beauv. 235, 237, 238, Fig. I 58.

- Dinklagei Engl. 238, Fig. I58.

- lanceolata Engl. 238, Fig. I58.

- parviflora N. E. Brown 239, Fig. I59.

- scandens(Willd.) P. Beauv.239, Fig. I 59.

- striolata Engl. 238, Fig. I58.

Culcasieae 235.

Curculigo Gärtn. 344, 353.

Cyanastraceae 277.

Cyanastrum Oliv. 277.

- cordifolium Oliv. 278, Fig. I88.

- Goetzeanum Engl. 278, Fig. I88.

- hostifolium Engl. 278, Fig. I 88.

Cyanotis D. Don 268, 270.

- lanata Benth. 271, Fig. I83.

- nodiflora Kth. 272, Fig. I84.

Cyathea Sm. 7 .

- camerooniana Hook. fil. 6, Fig. 3.

- Deckenii Kuhn 6, Fig. 3.

- usambarensis Hieron. 6, Fig. 3.

Cyatheaceac 5 .

Cycadaceac 82.

Cycas 82.

Cymodocea Koenig 95.

- antarctica End1. 97, Fig. 87.

- ciliata (Koenig) Ehrenb. 97, Fig. 87.

- nodosa (Ucria) Aschers. 96, Fig. 86.

Cynodon Pers. I25, I26.

Cynosorchis Thou. 404, 433.

- Buchwaldiana Krzl. 433, Fig. 306.

Cyperaceae 193.

Cyperinac I93.

Cyperus 1.. Iy3, I97.

- assimilis Steud. 20I, Fig. I4O.

- atronitens Hochst. 20I, Fig. I4O. 
Cyperus esculentus I. I98, Fig. I 38.

- flabelliformis Rottb. 198, Fig. I 38.

- kyllingioides $\mathrm{Tahl}$ I9S, Fig. I38.

Cyrtanthus Ait. $34+, 35$ I.

- sanguineus Hook. f. $35 \mathrm{I}, \mathrm{Fig} .248$.

Cyrtopodicae 407.

Cyrtosperma Griff. 236, 24 I.

Dactyloctenium Tilld. I 25, I26.

- aegyptiacum (L.) Willd. I9I, Fig. I36.

Danthonia DC. I72.

- borussica K. Schum. I72, Fig. I24.

- nana Engl. I72, Fig. I24.

- subulata A. Rich. I72, Fig. I 24.

- trisetoides Hochst. var. tenuis Engl. 172 , Fig. I24.

Darea Juss. (sect.) 32.

Dasystachys Bak. $283,309$.

Daubenya Lindl. $285,307$.

Davallia Sm. Is, 20.

- denticulata (Burm.) Iett. var. intermedia Mett. 2r, Fig. I7.

Davallieac 9, I7.

Deroemeria Rchb. f. 404, 433.

Didymochlaena Desv. IO, I4.

- Iunulata Desv. I3, Fig.9.

Dierama Is. Koch 366, 370.

- pendula Baker 373, Fig. 262.

Dilatris Berg. 343 .

Dinebra Jacq. I 25 , I26.

Dioscorca dumetorum (Kunth) Pax 35. Fig. 254,359 , Fig. 255,360 , Fig. 25k. - angwa 360, Fig. 256.

- - Iila ya mamba 360, Fig. 256.

- - IKunguni 360, Fig. 256.

- luzi 360, Fig. 256.

- moyo ya ngombe (Ochsenherz) 359, Fig. 255.

— netesa 359, Fig. 255.

- pome ya quitscho 360, Fig. 256.

- - ubika hehi 359 , Fig. 255.

- elephantipes (1'Hérit.) 367, Fig. 259.

- elephantopus Spreng. 367, Fig. 259.

- hylophila Harms 363, Fig. 258.

- macroura Harms 357, Fig. 253.

- Quartiniana A. Rich. 36r, Fig. 257.

Dioscoreaceae 356.

Dipcadi Medic. $284,306$.

- sansibaricum Engl. 303, Fig. 205.

- Ventzelianum Engl. 303, Fig. 205.

Dipidax Salisb. $283,300$.

Diplachne Beauv. I25, I27.

Diplacrum R. Br. I9t, 2 I4.

Diplanthera Thou. 95, 98.

Diplazium Sw. 23.

— proliferum (Lam.) Thou. 24, Fig. 20.

- silvaticum (Bory) Sw. 24, Fig. 20.
Disa Berg. 405, 441.

- Carsoni N. E. Brown 442, Fig. 3I3.

- Engleriana Krzl. 442, Fig. 3I3.

Disperis Sw: $405,425$.

- togoensis Schltr. 425, Fig. 300.

Doodia 23.

Doryopteris J. Sm. 35, 39.

- concolor (Langsdorf et Fisch.) Kuhn 38 , Fig. 32.

Dracaena L. 285, 290.

- draco L. 294, Fig. I96.

- fragrans (L.) Gawl. 291, Fig. I93.

- Poggei Engl. 293, Fig. 195.

- surculosa Lindl. 292, Fig. I94.

Dracaenoideae 285, 290.

Dracunculus 237.

Drimia Jacq. 28 4, 305 .

- brevifolia Bal. 303, Fig. 205.

Drimiopsis Lindl. $285,305$.

- Holstii Engl. 304, Fig. 206.

Drynaria Bory 49, 55.

- Laurentii (Christ) Hieron. 56, Fig. 54.

Echinodorus Buchenau I04.

Ehrharta Thunb. I22.

Eichhornia Kunth 279.

Elaeis Jacq. 223, 234.

Elaphoglossum Schott 58.

- conforme (Sw.) Schott 57, Fig. 55.

Eleocharis R. Br. I94, 206.

Elettaria $3 S_{4}$.

Eleusine Gärtn. I25, I26.

Elionurus Humb: et Bonpl. II7, II8.

Elytrophorus P. Beauv. I27, I28, I 4 .

Enalus L. C. Rich. I06, II3.

Encephalartos Lehm. 82.

- Hildebrandtii A. Br. et Bché. 83, Fig.79.

Enteropogon Niees 125, I26.

Ephedra L: 90.

Epipactis L. C. Rich. 406, 426.

Epipogon Gmel. 406, 448.

Equisetaceae 70.

Equisetum L. 70.

Eragrostis Beauv. I27, I28.

- aspera (Jacq.) Nees I62, Fig. II9.

- ciliaris (L.) Lk. I3I, Fig. Io6.

- superba Wawra et Peyr. I46, Fig. I I3.

Eremospatha Mann ct Wendl. 223, 232.

Erianthus Nichx. I I6, II7.

Eriocaulaceae 262.

Eriocaulon L. 262, 264.

- Gilgianum Ruhland 265, Fig. I79.

- longipetalum Rendle 265, Fig. I79.

- pumilum Afzel. 265, Fig. I79.

- Volkensii Engl. 263, Fig. I77.

- Welwitschii Rendle 265, Fig. I79.

- Woodii 5. E. Brown 263, Fig. I77. 
Eriocaulon xeranthemoides van Heurck et Müll. Arg. 264, Fig. I78.

Eriochloa I I9.

Eriospermum Jacq. 283, 3 I0.

- lanuginosum Jacq. 3II, Fig. 2 IO.

Eriospora A. Rich. I94, 2 I3.

- abyssinica A. Rich. 2 IO, Fig. I4I.

Euadiantum Kuhn (sect.) 42.

Euasplenium (sect.) 26.

Eublechnum Diels (sect.) 34.

Eucheilanthes Hook. (sect.) 40.

Eucomis 1'Hérit. 284, 30I.

- undulata (Thunb.) Ait. 301, Fig. 203.

Eucyperus (subg.) I93.

Eugleichenia Diels (subg.) 62.

Eulophia R. Br. 407, 4II, 430, 448.

- galeoloides Krzl. 447, Fig. 316.

Eulophidium Pfitzer 407, 430.

Eupodocarpus Endl. (sect.) 86.

Tupolypodium Dicls (sect.) 50.

Eupteris Diels (sect.) 45.

Euvittaria Hook. (sect.) 48.

Forraria L. $365,368$.

Festuca I. I28, I29.

Fiestuceae II6, I27.

Ficinia Schrad. 194, 205.

Fimbristilis Vahl I94, 207.

- cxilis Roem. et Schult. 20I, Fig. I40.

Fingerhuthia Nees I27, I28.

Wlagellariaccae 257 .

Flagellaria indica L. var. guineensis (Schu mach.) Engl. 258, Fig. 174.

Flexuosa Prantl (sect.) 64.

Floscopa Lour. 268, 272.

Forficaria 405 .

Forrestia A. Rich. 268, 270.

Fourcroya 344 .

Freesia Klatt 366, 375 .

Fuirena Rottb. I94, 205.

- umbellata Rottb. 20I, Fig. I40.

Gahnieae I94, 2 I I.

Galaxia 365.

Galtonia Dcne. 284, 306.

- candicans Dcne. 303, Fig. 205.

Gasteria Duval 284, 317.

- maculata Haw. 3I9, Fig. 2 I7.

- planifolia Bak. 319, Fig. 217.

- pulchra Haw. 3I9, Fig. 2 I7.

Gastridium Beauv. 123, I24.

Gastrodia R. Br. 406, 448.

Gastrodiinae 406.

Geissorrhiza Ker 366, 370.

Genyorchis Schltr. 4II.

- pumila Schlt1. 4I2, Fig. 288.

Gethyllis 344 .

Gladioleae 366, 37 I.
Gladiolus L。 $366,372$.

Gleichenia Sm.6r.

- polypodioides (L.) Sm. 6I, Fig. 59.

Gleicheniaceae 6r.

Gloriosa L. 282, 296.

- virescens Lindl. var. grandiflora (Hook.) Bak. 297, Fig. I99.

Gnetaceae 90.

Gnetum L. 90.

- africanum Welw. 9I, Fig. 84.

- Buchholzianum Engl. 91, Fig. 84.

Gonatopus Hook. f. 236, 24 I.

- Boivinii (Decne.) Hook. f. 242, Fig. I6I.

Goniophlebium Bl. (sect.) $5 \mathrm{I}$.

Gramineae II4.

Guaduella Franch. I29, I30.

Gymnadeniinae 404.

Gymnochilus 406.

Gymnogramme Desv. 34, 36.

- argentea (Bory) Mett. var. aurea (Bory) IIett. 35 .

Gymnogramminae 34,36 .

Gymnopteris Bernh. IO, I5. auriculata (Lam.) I 5 , Fig. I I.

- gabunensis (Hook.) J. Sm. I 5 , Fig. IO.

Gymnosiphon Blume 403.

Gymnospermae 8z.

Habenaria Willd. $405,434$.

- Emini Krzl. 438, Fig. 309.

- Engleriana Krzl. 438, Fig. 309.

- holothrix Schltr. 437, Fig. 308.

- Kayseri Krzl. 438, Fig. 309.

- macrura Krzl. 437, Fig. 308.

- narcissiflora Krzl. 437, Fig. 308.

- praestans Rendle 435, Fig. 307 .

Habenariinae 404.

Haemanthus L. 343, 344.

- Katherinae Bak. 345, Fig. 243.

- longipes Engl. 346, Fig. 244.

Hacmodoraceae 342 .

Halopegia K. Schum. 394, 395.

- azurga K. Schum. 398, Fig. 28 I.

Halophila Du Pet. Thouars I05, II2.

- ovalis (R. Br.) J. D. Hook. I I , Fig. IO2.

— stipulacea (Forsk.) Aschers. I I2, Fig. IO3.

Halophiloideae I05.

Harpechloa Ktl. I25, I26.

Haworthia Duval $2 \$_{4}$, 3 I7.

- fasciata Haw. 3IS, Fig. 2 I6.

- margaritifera Haw. 3I8, Fig. 2 I6.

- radula Haw. 318, Fig. 216.

Hedychieae 384.

Hemicarpha Nees I93, I95.

- micrantha (Vahl) Pax 196, Fig. I37.

Hemitelia R. Br. 7 .

- capensis (L.) R. Br. 8, Fig. 4. 
Herschelia Lindl. $405,443$.

Hesperantha Ker 366, 370.

- alpina (Hook. f.) Benth. 373. Fin. 262.

- Volkensii Harms 373, Fig. 262.

Hessea Herb. 343, 344.

Hetaeria Blume 406, 428.

- Mannii (Rchb. f.) Benth. 427, Fig. 302.

Heteranthera Ruiz et Pav. 279.

Heterophyllum Spring. (subg.) 76 .

Hippeastrum Herb. 344, 35I.

Histiopteris Agardh 36, 47.

- incisa (Thunb.) J. Sm. 45, Fig. 4I.

Holothrix Rich. 404, 43I.

- grandiflora Rchb. f. 432, Fig. 305.

- scopularia Rchb. f. 432, Fig. 305.

Homeria 365.

Homoeophyllum Spring. (subg.) 76.

Hordeeae II6, I29.

Humata Cav. I7, 20.

- repens (L.f.) Diels 20, Fig. I6.

Huttonaea Harv. 404, 43I.

- oreophila Schltr. 423, Fig. 305.

Hyacinthus L. 285, 306.

Hydrilla L. C. Rich. I05, 106.

- verticillata (L.f.) Royle I06, Fig. 96.

Hydrocharitaceae 105.

Hydrosme Schott 236, 243.

- leonensis (Lem.) Engl. 244, Fig. I62.

- maxima Engl. 246, Fig. I64.

- Schweinfurthii Engl. 245, Fig. I63.

- Stuhlmannii Engl. 247, Fig. 165.

Hyloophrynium K. Schum. 394, 395.

- Braunianum K. Schum. 396, Fig. 279.

Hymenocallis Salisb. 352.

Hymenolepis 49.

- spicata (L. f.) Presl 49, Fig. 45.

Hymenophyllaceae $\mathrm{I}$.

Hymenophyllum L. 5.

- ciliatum Sw. 4, Fig. 2.

- Meyeri Kuhn 4, Fig. 2.

- polyanthos Sw. 4, Fig. 2.

- sibthorpioides (Bory) Mlett. 4, Fig. 2.

Hyphaene Gaertn. 222, 225.

Hypolepis Bernh. 35, 4I.

- Schimperi (Kze.) Hook. 40, Fig. 34.

Hypolytreae I94, 2 I I.

Hypolytrum A. Rich. I94, 2 II.

Hypoxidoideae 344,352 .

Hypoxis L. 344, 352 .

Imperata Cyr. II6, II7.

- cylindrica (L.) P. Beauv. I88, Fig. I33.

Inundata Bak. (sect.) 74.

Iphigenia Kunth 283, 299.

- Oliveri Engl. 299, Fig. 201.

- somaliensis Bak. 299, Fig. 20I.

Iridaceae $36_{4}$.
Iridoidcae 365,367 .

Isachne R. Br. IIO, I20.

Ischaemum L. II7, II8.

Isoetaceae So.

Juncacere 280.

Juncellus (subg.) 193.

Juncus L. 280.

Juniperus L. 89 .

Ixia L. 366,370 .

Ixieae 365,370 .

Ixioideae 365,370 .

Kaempferia L. 384 .

- acthiopica (Solms) Benth. 38 5. Fin. 2- т .

- brachystemon K. Schum. 385 , Fig. 271 .

- natalensis Schlechter et $\mathrm{K}$. Schum. 3. Fig. 2, I.

Klattia Bak. 365,368 .

Kniphofia Moench. 284, 3 I2, 3 I 3, Fig. 2 I 2, 3I4, Fig.2I3, 3I 5, Fig. 214, 316, Fig. 2 I.

- breviflora Bak. 313, Fig. 212.

- Buchanani Bak. 3I3, Fig. 2 I2.

- densiflora Engl. 3I6, Fig. 2 I5.

- drepanophylla Bak. 3I4, Fig. 213.

- dubia de Wild. 3I4, Fig. 2I3.

- Ellenbeckiana Engl. 3I5, Fig. 2I4.

- Goetzei Engl. 315, Fig. 214.

- ichopensis Schinz 3I5, Fig. 2I 4.

- isoëtifolia Hochst. 3I4, Fig. 2 I 3.

- Macowanii Bak. 3I6, Fig. 215.

- obtusiloba Diels 316, Fig. 21.5.

- parviflora Kunth 3I3, Fig. 212.

- rivularis Berger 316, Fig. 215 .

- Schimperi Bak. 315, Fig. 2I4.

- Thomsonii Bak. 315, Fig. 2I4.

Koeleria Pers. I27, I 28.

Kyllinga Rottb. 193, 204.

- alba Nees I99, Fig. I39.

- cylindrica Nees I99, Fig. I 39.

— erecta Schumacher I99, Fig. I39.

- peruviana Lam. I99, Fig. I39.

- polyphylla W. r99, Fig. I39.

- triceps Rottb. I99, Fig. I39.

Lachenalia Jacq. $285,306$.

Lagarosiphon Harv. I05, I06, I07, Fig. 97.

- muscoides Harv. I07, Fig. 97.

— Steudneri Casp. 107, Fig. 97.

Lanaria Ait. 343.

Lapeyrousia Porr. 366, 376.

- cyanescens Bak. 375, Fig. 264.

- euryphylla Harms 375, Fig. 264.

- odoratissima Bak. 375, Fig. 264.

Lasieae 236.

Lasioideae 236.

Latipes Kunth I21, I22.

Leersia Sw. I22.

Lemnaceae 257. 
Lepicystis J. Sm. 49, 55 .

- polypodioides (L.) Hitchc, var. Ecklonii Kze. 5.t, Fig. $5 \mathrm{I}$.

Lepidocaryoideac 223.

Leptaspis R. Br. I I9, I2I.

Leptocarydium Hochst. I25, I27, I 85.

Leptochloa Beauv. I25, I27.

Liliaceae 282.

Lilioideac 284, 300.

Limnophyton Miq. I02.

- obtusifolium (L.) Miq. 103, Fig. 93.

Iiparideac 406.

Liparis Rich. 406, 408, 428.

- epiphytica Schitr. 408, Fig. 286.

Lipocarpha R. Br. I93, I95.

- argentea R. Br. I99, Tig. I39.

Lipocarpheac I93, 195.

Lissochilus R. Br. 407, 430.

— Krebsii Rchb. f. 445, Fig. 3 I4.

Litanthus Harv. 284, 306.

Litobrachia (Presl) (sect.) 46.

Littonia Hook. f. 282, 298.

- modesta Hook. 298, Fig. 200.

Lolium I 29.

Lomaria (Willd.) (sect.) 34.

Lomatophyllum (Villd.) $284,338$.

Lonchitis L. 36, 47 .

- Currori (Hook.) Mett. 46, Fig. 42.

Lophotocarpus Smith I04.

- guyanensis (H. B. I.) Smith I03, Fig. 94.

- var. echinocarpus Buchenau IO3, Fig. 94.

- - var. lappula Buchenau 103, Fig. 94.

_- var. madagascaricnsis Buchenau Io3, Fig. 94.

Loxoscaphe Moore (sect.) 32.

Luzula DC. 28 I.

Iuzuriagoideac $285,296$.

Lygodieac 62.

Lygodium Sw. 62.

- Smithianum Presl 63, Fig. 60.

Lycopodiaceae 70.

Lycopodium L. 70.

- carolinianum L. 73, Fig. 73.

- cernuum L. var. Eichleri Glaz. 74, Fig. 74 .

Holstii Hicron. 7I, Fig. 60.

phlegmaria L. 73, Fig. 72.

saururus Lam. 7I, Fig. 68.

- strictum Bak. 72, Fig. 7I.

- verticillatum L. 72, Fig. 70 .

Manisuris Sw. II 7, II 8 .

- granularis L. f. I9x, Fig. 135.

Manniella Rchb. f. 406, 428.

Iapania Aubl. I94, 2 II.

Mapania Aubl. I94, 2II. Musoideae 376.
Mapania Deistelii K. Schum. 212, Fig. I42.

Maranta L. 394, 397.

- arundinacea L. 398, Fig. 28 I, 399, Fig. 282 .

Marantaceae 394.

Maranteae 394.

Marattia Sm. 68.

- fraxinea Sm. 68, Fig. 66.

Narattiaceae 68.

Marcia Ker 365, 368.

Mariscus (subg.) I93.

Marsilia Fischeri Hieron. 65, Fig. 62.

- muscoides Lepr. 66, Fig. 64.

- trichopoda Lepr. 66, Fig. 63.

Marsiliaceae 65 .

Naschalocephalus Gilg et K. Schum. 266.

- Dinklagei Gilg et IK. Schum. 267, Fig. I 80 .

Massonia Thunb. $285,307$.

Maxillarieae 407.

Nayaca Baumii Gürke 260, Fig. I75.

Nayacaceae 259.

Maydeae II 5 .

Nedemia P. W. von Württemberg 222, 227.

Negaclinium Lindl. 407, 4I I.

Melanocenchris Nees 125, I26.

Melanthioideae 282, 296.

Melasphacrula 366 .

Melinis P. Beauv. I I), I2I.

- minutiflora P. Beauv. IS6, Fig. I32.

Merendera Ram. 283, 300.

Mertensia (Willd.) (subg.) 6 II.

Mesanthemum Koern. 263, 265.

Micranthus Pers. 366,375 .

Nicrocalamus Franch. I29.

Microchloa R. Br. I25.

Nicrolepia Presl I8, 2I.

- speluncae (L.) Noore 22, Fig. IS.

Microstylis Nutt. 428.

Mohria Sw. 64.

- caffrorum (L.) Desv. 63, Fig. 61.

Monadenia 405 .

Monandrae 404 .

Monelytrum I2I.

Monochoria Presl 279.

Monsteroideae 236.

Moraea L. $365,368$.

— bella Harms 369, Fig. 260.

Moraceae $365,363$.

NLusa L. $376,377$.

— ensete J. F. Gmel. 377, Fig. 265, 379, Fig. 267.

- Holstii K. Schum. 378, Fig. 266, 379, Fig. 267.

Musaceae 376 . 
Najadaceae 98.

Najas L. 98.

Nanolirion 283 .

Narcisseae 344 .

Neobenthamia 406.

Neottieae 405 .

Neottopteris (J. Sm.) (sect.) 25.

Nephrodium Rich. Io.

- proliferum (Retz) Keys. I2, Fig. 8.

- propinquum R. Br. II, Fig. 5.

- subquinquefidum (P. Beauv.) Hook. var. tripinnatum Hook. II, Fig. 6.

- totta (Willd.) Diels I2, Fig. 7 .

Nephrolepis Schott I7, I8.

- acuta (Schk.) Presl I9, Fig. I5.

- biserrata (Sw.) Schott I9, Fig. I5.

- cordifolia (L.) Presl I8, Fig. I4.

- davallioides (Sw.) Kze. I8, Fig. I4.

Nephthytideae 236.

Nephthyt is Schott 236, 248, 250, Fig. 167 .

- Gravenreuthii Engl. 250, Fig. I67.

- Poissoni Engl. 250, Fig. 167.

Nerine Herb. 343, 347.

Nervilia Gaud. 405, 426.

Niphobolus Kaulf. 49, 55.

- spissus (Bory) Desv. var. continentalis Hieron. 55, Fig. 53.

Notochlaena R. Br. 35, 40.

Notosceptrum Benth. 284, 316.

Oberonia Lindl. 406, 408.

Oleandra Cav. I7.

- neriiformis (Sw.) Pr. I6, Fig. I2.

- Whitmeei Bak. I6, Fig. I2.

Oleandreae 9, I7.

Oligomacrosporangiatae (sect.) So.

Olyra L. II9, I2I.

- latifolia L. I37, Fig. I09.

Oncocalamus Mann et Wendl. 223, $23 \mathrm{I}$.

Ophioglossaceae 68.

Ophioglossum L. 68.

- Bergianum Schldl. 69, Fig. 67.

- capense Sw. emend. 69, Fig.67.

- Gromezianum Welw. 69, Fig. 67.

- gramineum Willd. 69, Fig. 67.

- lusoafricanum Welw. 69, Fig. 67.

Ophrydeae 404.

Oplismenus Beauv, II9, I20.

Orchidaceae 403.

Oreobambos K. Schum. I29, I30.

Orestias Ridl. 406, 428.

Ornithogalum L. 285,301 .

- excelsum Diels 304, Fig. 206.

- longibracteatum Jacq. 304, Fig. 206.

Ornithoglossum Salisb. 283, 300.

Oropetium I29.

Oryza L. I22.
Oryzeae II 122.

Oryzopsis 123.

Osmunda L. 64.

Osmundaceae 64.

Ottelia Pers. I05, I08.

- alismoides (L.) Pers. IIO, Fig. I00.

Oxygyne Schitr. 40r, 403.

-- triandra Schltr. 40I, Fig. 284.

Oxytenanthera Munro I29, I30.

- abyssinica (A. Rich.) Benth. I42, Fig. I I I.

- macrothyrsus K. Schum. I42, Fig. III.

Pachites 405.

Palisota Reichb. 268.

- ambigua (P. Beauv.) C. B. Clarke 269, Fig. I 8 I.

- Barteri Hook. f. 269, Fig. I 8 I.

- hirsuta(Thunb.) K. Schum.269, Fig. I82.

Palmae 222.

Pancratium L. 344, 35 I.

Pandanaceae 93.

Pandanus L. 93.

Paniceae II 5 , II9.

Panicum L. II8, I20.

Pappophorum Schreb. I27, I28.

— cenchroides Licht. I82, Fig. I29.

Paraneura Prantl (subsect.) 68.

Parkeriaceae 59.

Paspalum L. Ir9.

Pauridia Harv. 344, 353.

Pellaea Link $35,38$.

- adiantoides (Desv.) Prantl 37, Fig. 3 I.

- hastata (Thunb.) Prantl 37, Fig. 3I.

- viridis (Forsk.) Prantl 37, Fig. 3 I.

Pennisetum Rich. I I9,. I20.

- purpureum Schum. et Thonn. I4t, Fig. II2.

Perotis Ait. I2I, I22.

- indica.(L.) IK. Schum. I3I, Fig. I06.

Phajeae 406.

Phajus Lour. 406, 430.

I'halarideae II 5 , I 22 .

Phalaris L. I22.

Philodendroideae 236.

Phlegmaria Bak. (sect.) 74.

Phoeniceae 222.

Phoenix L. 222, 223.

- reclinata Jacq. 224, Fig. I49.

Phragmites Trin. I24.

Phrynieae 394.

Phrynium Willd. 394, 397.

Phyllorrhachis Trim. I2I, I85.

Physapteris (sect.) $4 \mathrm{I}$.

Physurinae 406.

Pinaceae 88.

Pistia L. 237, 257.

— stratiotes L. 256, Fig. 173. 
Pistioideae 237.

Platanthera 404.

Platyceriinae 58.

Platycerium Desv. 58.

- stemmaria (Beauv.) Desv. 59, Fig. 57.

Platycoryne 405.

Platylepis A. Rich. 406, 428.

- Engleriana Krzl. 427, Fig. 302.

- glandulosa (Lindl.) Rchb. 427, Fig.302.

Pleiomacrosporangiatae Hieron. (sect.) 76.

Plcopeltis Humb. et Bonpl。 (sect.) 52.

Poa I.. I $2 \& .129$.

Podocarpus 1'Hérit. 84.

- gracilior Pilger 86, Fig. 81.

- latifolius (Thunb.) R. Br. 87, Fig. 82.

- Mannii Hook. f. 85, Fig. 80.

Podococcus Mann et Wendl. 223, 233.

- Barteri Mann et Wendl. 23I, Fig. I55.

Pogonarthria Stapf 125, I27, I85.

- falcata (Hack.) Rendle I85, Fig. I3I.

Pogonia Juss. 405, 425.

- Buchananii Rolfe 426, Fig. 30r.

Pogoniinae 405.

Pollia Thunb. 268, 270.

Pollieae 268.

Pollinia Trin. I If;, I I7.

Polypodiaceae 8.

Polypodieae 9, 49.

Polypodiinae 49, 50.

Polypodium L. 49, 50.

- excavatum Bory 52, Fig. 47.

- loxogramme MIett. 53, Fig. 49.

- lycopodioides L. 52, Fig. 48 .

- Molleri Bak. 50, Fig. 46.

- phymatodes L. 53, Fig. 50.

- rigescens Bory 50, Fig. 46.

- serrulatum (Sw.) Mictt. 50 , Fig. 46.

- simplex Sw. 52, Fig. 47.

- trichomanoides Sw. 50, Fig. 46.

Polypogon Desf. I23, I24.

Polyspatha Benth. 268, 274.

Polystachya Hook. 406, 408.

- Supfiana Schltr. 410, Fig. 287.

Polystachyeae 406.

Polystichum Roth IO, I4.

Polyxena Kunth 285, 306.

Pontederiaceae 259.

Potamogeton L. 95.

Potamogetonaceae 94.

Pothoideae 235.

Prionium E. Mey. 280.

- serratum (L. f.) Drège 280, Fig. I89.

Pseudobromus IK. Schum. I27, I29.

Pseudogaltonia O. Ktze. 285, 306.

Pseudohydrosme Engl. 236, 243.

Psilotaceae 75.

Psilotum L. 76.
Psilotum nudum (L.) Griseb. 75, Fig. 75.

Pterideae 9, 34.

Pteridella Kuhn (sect.) 38.

Pteridellastrum Prantl (sect.) 39.

Pteridinae $36,45$.

Pteridium Gled. 36, 47.

Pteris L. $36,45$.

- arguta Ait. var. flabellata (Thunb.) Mett. 43, Fig. 38 .

- nitida Mett. 44, Fig. 39.

- quadriaurita Retz 43, Fig. 38 .

- tripartita Sw. 45, Fig. 40.

Pteroglossaspis Rchb. f. 407, 446.

Pterogodium 405.

Ptiloneura Prantl (subsect.) 70.

Puelia Franch. I29, I30.

-- Schumanniana Pilger I34, Fig. 107.

Pycreus (subg.) I93.

Rapateaceae 266.

Raphia P. Beauv. 223, 227.

- ruffia (Jacq.) Mart. 229, Fig. I 53.

- vinifera P. Beauv. 228, Fig. 152.

Raphieae 223.

Rautanenia Buchenau ro4.

Ravenala Adans. 377,383 .

- madagascariensis Sonn. $38 \mathrm{I}$, Fig. 269, 382, Fig. 270.

Remirea Aubl. I94, 209.

Renealmia L. 384, 389, Fig. 274, 390.

- brasiliensis K. Schum. 389, Fig. 274.

- circinnata (K. Schum.) Bak. 389, Fig. 274.

- Dewewrei Dur. et de Wild. 389, Fig. 274.

- macrocolea K. Schum. 389, Fig. 274.

- occidentalis (Swartz) Sweet 389, Fig. 274.

- racemosa (L.) A. Rich. 389, Fig. 274.

- strobilifera Poepp. et End1. 389, Fig.274.

Restionaceac 259.

Rhadamanthus Salisb. 284, 306.

Rhelstophyllum N. E. Brown 236, 248.

- mirabile N. E. Brown 249, Fig. I66.

Rhopalostachya (subg.) 74.

Rhynchospora Vahl I94, 209.

- aurea Vahl 210, Fig. I4I.

Rhynchosporeae 194, 209.

Rhytachne Desv. II7.

Roeperocharis Rchb. f. 405, 439.

- occidentalis Krzl. 439, Fig. 3 IO.

Romulea Maratti 365,366 .

- campanuloides Harms 369 Fig. 260.

- Linaresii Parl. subsp. abyssinica Bég. 369, Fig. 260.

Rottboellia L. f. II7, II8.

- exaltata L. f. II 8, Fig. I34.

Ruppia L. 95. 
Sabaleae 222.

Saccharum II 6 .

Saccolabium Blume 407, 424 .

Salvinia L. 67.

Salviniaceae 67.

Sandersonia Hook. f. 282, 298.

- aurantiaca Hook. f. 298, Fig. 200.

Sansevicria Thunb. 285, 293.

- cylindrica Boj. 296, Fig. I98.

- Ehrenbergii Schweinf. 295, Fig. 197.

- guineensis Willd. 295, Fig. 197.

- longiflora Sims 295, Fig. I97.

- Volkensii Gürke 295, Fig. I97.

Sarcantheae 407.

Sarcophrynium K. Schum. 394.

Satyriinae 405 .

Satyrium Siv. 405, 440.

- bifolium A. Rich. 44I, Fig. 3I2.

- monophyllum Krzl. 44I, Fig. 3 I2.

Sauromatum Schott 237, 256.

Scheuchzeriaceae 102.

Schizaea Sm. 62.

Schizaeaceae 62 .

Schizaeeae 62.

Schizobasis Bak. 283, 3 Io.

Schizochilus 405.

Schizodium 405.

Schizoloma Gaud. I8, 2 I.

- ensifolium (Sw.) J. Sm. 23, Fig. I9.

Schizostylis Backh. et Harv. $365,370$.

Schmidtia Steud. I27, I28.

- quinqueseta Benth. I80, Fig. I27.

Schoenefeldia Kth. I25, I26.

Schocnoxiphium Nees I95, 2 I 4, 2 I 5, Fig. I 43

- capense Nees 2I5, Fig. I43.

- Ecklonii Nees 2I5, Fig. I43.

- rufum Nees 215, Fig. 143 .

- rufum (Wahlenb.) Kuekenth. var. Lehmannianum Nees 215, Fig. I43.

Schoenus L. I94, 209.

Scilla L. 284, 304.

- edulis Engl. 304, Fig: 206.

- Ledienii Engl. 305, Fig. 207.

- natalensis Planch. 304, Fig. 206.

Scilleae 284, 300.

Scirpeae 193, I96.

Scirpinae I94.

Scirpoideae I93, I95, I96.

Scirpus L. I94, 206.

Scleria Berg. 194, 213.

- bulbifera A. Rich. 210, Fig. I4I.

Sclerieae I94, 2 13.

Sclerosperma Mann et Wendl. 223, 233. - Mannii Wendl. 232, Fig. I 56, 233,
Fig. I 57.

Scolopendrium L. 23, 25.

Scopularia 404.
Selaginellaceae 76 .

Selaginella imbricata (Forsk.) Spring. 78, Fig. 77 .

- scandens (P. B.) Spring. 79, Fig. 78.

- yemensis (Sw.) Spring. 77, Fig. 76.

Selago Dillen. (sect.) 7 I.

Semele Kunth 285, 290.

Setaria Beauv. I I9, I20,

- aurea Hochst. I46, Fig. I 3 .

Sisyrinchieae 365,368 .

Smilacoideae $285,290$.

Smilax L. 285, 290.

Sparaxis 366.

Spirogyne Engl. (sect.) 255.

Sporobolus R. Br. I23.

- festivus Hochst. I 58, Fig. II7

- indicus (L.) R. Br. I3 I, Fig. I06.

- virginicus Kth. I30, Fig. I05.

Stachycarpus Endl. (sect.) 86.

Stangeria Th. Moore 82.

Stenochlaena J. Sm. 23, 34 .

- guineensis (Kuhn)Underwood 33, Fig. 28.

Stenoglottis Lindl. 404, 43r.

Stenolirion Bak. 344, 351.

Stenotaphrum Trin. I2I.

Stipa L. I23.

Stratiotoideae 105, I07.

Strelitzia Banks 377, 380 .

- augusta Thunb. 380, Fig. 268.

Strelitzioideae 376.

Streptanthera Sweet 366, 370.

Streptogyne Beauv. I27, I28.

— crinita Link I36, Fig. Io8.

Strumaria Jacq. 343, 347.

Stylochiton Leprieur 237, 254.

- lancifolius Kotschy et Peyr. 254, Fig. I7 I.

Stylochitoneae 237.

Syngonanthus Ruhl. 263, 265.

Synnotia 366.

Syringodea 365 .

Taccaceae 355 .

Tacca cristata Jacq. 355, Fig. $25 \mathrm{I}$.

- integrifolia Gawl 355, Fig. $25 \mathrm{I}$.

-- pinnatifida Forst. 355, Fig. 25 I, 356, Fig. 252

Taeniopsis J. Sm. (sect.) 49.

Taenitidinae 49 .

Taxaccae 84 .

Tenagocharis Buchenau 105.

- latifolia (D. Don) Buchenau I04, Fig.95.

Terrectorea 4.05.

Tetrachaete I2I.

Tetragonostachyae Hieron. (sect.) 76,

Tetrapogon Desf. I25, 126.

Tetraria P. Beauv. I94, 2 II. 
Thalassia Sol. I06, II3.

- Hemprichii (Ehrenb.) Aschers. II3.

Thalassioideae I 06.

Thalia L. 394, 397.

Thaumatococcus Benth. 394, 395.

- Daniellii (Benn.) Benth. 395, Fig. 278.

Thelepogon Roth II7, II8.

Themeda Forsk. II7, II9.

- triandra Forsk. I 52, Fig. I I4.

Thismia Griff. 40I, 403.

- pachyantha (Schlecht.) Engl. 40r, Fig. 284 .

- Winkleri Engl. 400, Fig. 283.

Tigridieae 365,368 .

Todea Willd. 64.

Torulinium (subg.) I93.

Trachyphrynium Benth. 394, 395.

- Danckelmannianum K. Schum. 396, Fig. 279.

- Poggeanum K. Schum. 396, Fig. 279.

- violaceum Ridley 396, Fig. 279.

Trachypogon Nees II7, II8.

Tradescantieae 268, 270.

Tragus L. I2I, I22.

Trichomanes Sm. 3 .

- cuspidatum Willd. 2, Fig. I.

- erosum Willd. 2, Fig. I.

- Hoolieri Presl 2, Fig. I.

- Mannii Hook. 2, Fig. I.

- melanotrichum Schlecht. 2, Fig. I.

- Motleyi v. d. Bosch 2, Fig. I.

- rigidum Sw. var. pectinatum Mett. Fig. I.

- subsessile Mett. 2, Fig. I.

Trichopteryx Nees I24.

Triglochin L. I02.

- elongata Buchenau I02, Fig. 92.

Tripogon Roth I25, I26.

Triraphis R. 13r. I 25.126.

Trisetum Pers. I24.

Tristachya Nees I24.

Triticum I20.

Tritonia $\operatorname{Ker} 366,372$.

- acriloba Harms 374, Fig. 263.

Tropidiinac 406.

Tulbaghia L. 284,340 .

Tumboa Welw. 90.

Typhaceae 93.

Typhonodorum Schott 236, 252.

- Lindleyanum Schott 252, Fig. 169, 253 , Fig. I70.

Urelytrum Hack. II 7 .

Urginea Steinh. 284, 301, 302.

- altissima (L.) Bak. 301, Fig. 202.

- indica (Roxb.) Kth. 303, Fig. 205.
Urginea micrantha (Rich.) Solms ,303 Fig. 205.

- scilla Steinheil 30I, Fig. 202.

Urostachya (subg.) 7 I.

Uvularieae' 282 .

Vallisneria L. I05, 106.

Vallisnerioideae I05, I06.

Vallota Herb. 344, 348.

Vanilla Sw. 405, 407.

Vanillinae 405 .

Velloziaceae 353.

Veltheimia Gleditsch 285, 306.

Verdickia de Wild. 283, 309.

Vittaria Sm. 48.

- elongata Sw. 47, Fig. 43.

Vittarieae 9, 47.

Vittariinae 47.

Volubilia Prantl (sect.) 62.

Vossia Wall, et Griff. I 6 , I 7 .

Wachendorfia L. 343 .

Walleria Bak. 282, 298.

Vatsonia Miller 366, 375 .

Watsonieae 366, 375 .

Whiteheadia Harv. 285, 306.

Wiesneria Hook. f. I05.

Willkommia I 25.

Witsenia Thunb. 365,368 .

Woodsicae 9 .

Woodwardia Sm. 23, 34.

Wurmbea Thunb. 283, 300.

- Goetzei Engl. 299, Fig. 201.

- tenuis (Hook. f.) Bak. 299, Fig. 20 I

Xanthosoma Schott 237, 254.

Xyridaceae 260.

Xyris 261, Fig. I76.

- anceps Lam. 26I, Fig. I76.

- capensis Thunb. 26I, Fig. 176.

- filiformis Lam. 26I, Fig. I 6.

- Hildebrandtii Nilss. 26I, Fig. I76.

Zamioculcas Schott 236, 240.

- zamiifolia (Lodd.) Engl. 240, Fig. I60.

Zamioculcascae 236

Zannichellia L. 95.

Zantedeschia Spreng. 236, 250.

Zantedeschicae 236 .

Zeuxine Lindl. 406, 426.

Zingiber' 384 .

Zingiberaceae 383 .

Zingibereae 384 .

Zingiberoideae 383 .

Zomicarpeae 237.

Zostera L. 95.

Zoysieae II 5, I2I.

Zyganthera N. E. Brown 236, 243. 




PLEASE DO NOT REMOVE CARDS OR SLIPS FROM THIS POCKET

\section{UNIVERSITY OF TORONTO LIBRARY}

QK

381

565

$\mathrm{Bd} .2$

Biological

a Medical

Engler, Adolf

Die Pflanzenwelt Afrikas 
(1) 